

\author{
Heitor Silvério Lopes \\ Luiz Carlos de Abreu Rodrigues \\ Maria Teresinha Arns Steiner \\ (Editores)
}

\title{
Meta-Heurísticas em \\ Pesquisa Operacional
}

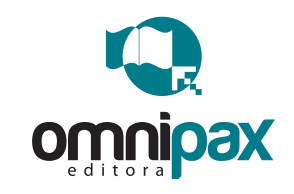

2013 
Copyright (C)2013 Omnipax Editora Ltda

Caixa Postal 16532 - 81520-980 Curitiba, PR

A editora disponibiliza por acesso livre a versão eletrônica deste livro no site: http://www.omnipax.com.br, sob uma licença Creative Commons 3.0 AtribuiçãoNão Comercial-Sem Derivados (CC BY-NC-ND 3.0 BR).

Digital Object Identifier (DOI): 10.7436/2013.mhpo.0

\author{
Capa: \\ Sérgio Alexandre Prokofiev \\ Projeto gráfico e editoração: \\ Omnipax Editora Ltda \\ Ficha catalográfica: \\ Adriano Lopes (CRB9/1429)
}

Dados Internacionais de Catalogação na Publicação

\begin{tabular}{|l}
\hline M587 Meta-heurísticas em pesquisa operacional / editores: \\
Heitor Silvério Lopes, Luiz Carlos de Abreu Rodri- \\
gues, Maria Teresinha Arns Steiner. — Curitiba, PR: \\
Omnipax, 2013 \\
472 p. : il.; $30 \mathrm{~cm}$ \\
Vários autores \\
Inclui bibliografias \\
ISBN: 978-85-64619-10-4 \\
eISBN: 978-85-64619-11-1 \\
1. Pesquisa operacional. 2. Algoritmos computa- \\
cionais. 3. Algoritmos heurísticos. I. Lopes, Heitor \\
Silvério II. Rodrigues, Luiz Carlos de Abreu III. Stei- \\
ner, Maria Teresinha Arns IV. Título. \\
CDD (22. ed.) 003
\end{tabular}


Para todos aqueles que, com seu esforço direto, colaboração, ou apenas paciência, foram imprescindíveis para a conclusão deste trabalho, em especial, Gisele e Maria Clara H.S.L.

À minha esposa, Regina, aos meus filhos, Sarah e Gabriel, e aos meus pais, Delmo e Teresinha, fontes de apoio e incentivo!

L.C.A.R.

Ao meu marido, Pedro; aos meus filhos, Alexandre e Patrícia; à minha nora e ao meu genro, Danielle e Davi; ao meu netinho, João Guilherme e in memorian aos meus pais, Osvaldo e Therezinha Arns, com todo o meu amor!

M.T.A.S. 

A Pesquisa Operacional é uma área do conhecimento fortemente interdisciplinar voltada ao desenvolvimento de modelos matemáticos e algorítmicos para a resolução de problemas reais complexos. Métodos de Pesquisa Operacional têm sido utilizados com sucesso para a obtenção de soluções otimizadas nos mais variados contextos de problemas reais. Os problemas tratados pela Pesquisa Operacional requerem, em geral, grande esforço computacional, sendo, muitas vezes, de complexidade não-polinomial. Como alternativa às modelagens puramente matemáticas, têm surgido, ao longo das últimas décadas, soluções através de procedimentos heurísticos e meta-heurísticos. Considerando-se o grande desenvolvimento de métodos computacionais na área, surge a necessidade de disseminação do conhecimento científico sobre o assunto. Desta forma, o objetivo deste livro foi agrupar trabalhos de pesquisa, com foco multidisciplinar, em dois grupos: os que destacam métodos utilizados em problemas de otimização/aplicação e os que destacam aplicações que podem ser abordadas através de métodos de otimização. A coletânea de capítulos possui caráter didático e mostra, também, um panorama atual da pesquisa no Brasil, de maneira a suprir a falta de material de referência em língua portuguesa sobre o assunto. O livro é composto por 29 capítulos, dos quais 11 foram enquadrados como "métodos" e 18 como "aplicações". Na parte de métodos, as meta-heurísticas utilizadas, em um total de 18, foram (listados em ordem decrescente de aparecimento no texto): Algoritmos Genéticos - AG (abordado em 11 capítulos), Iterated Local Search - ILS (em 5 capítulos), Ant Colony Optimization - ACO (4), Greedy Randomized Adaptative Search Procedure - GRASP (3), Simulated Annealing - SA (3), Busca Tabu - BT (3), Particle Swarm Optimization - PSO (3), Método de Pesquisa em Vizinhança Variável - VNS (2), Algoritmos Transgenéticos - AT (2), Programação Genética - PG, Dinâmica de Sistemas - DS, Beam Search - BS, Sistemas Imunológicos Artificiais - SIA, Reconexão de Caminhos - RC, Very Fast Local Search - VFLS, Evolução Diferencial - ED, Colônia Artificial de Abelhas - CAA, e Algoritmo do Morcego - AM. Na parte de aplicações, em um total de 13, foram tratados (listados em ordem decrescente de aparecimento no texto): Problemas de Roteamento de Veículos - PRV (2), Planejamento Florestal (2), Fundos de Investimentos, Programação de Tarefas, Carregamento e Descarregamento 3D em Navios, Planejamento de Operações de Sistemas Hidrelétricos, Planejamento de Redes de Telecomunicações, Alocação de Registradores, Cadeias de Suprimentos Sustentável, Coleta Seletiva, Alocação de Salas de Aulas, Sequenciamento de Linhas de Montagem Automotivas, Alocação de Células de Telefonia Celular. Estes capítulos foram contribuições de 81 pesquisadores de 37 instituições diferentes.

Heitor Silvério Lopes - UTFPR

Luiz Carlos de Abreu Rodrigues - UTFPR

Maria Teresinha Arns Steiner - PUCPR 



\section{Parte 1: Métodos}

1 GRASP: Procedimentos de Busca Gulosos, Aleatórios e Adaptativos............. 1 Mauricio Guilherme de Carvalho Resende e Ricardo Martins de Abreu Silva

2 Algoritmos Genéticos: Fundamentos e Aplicações........................... 21 Alexandre Ferreira de Pinho, José Arnaldo Barra Montevechi,

Fernando Augusto Silva Marins e Rafael de Carvalho Miranda

3 Uma Introdução à Busca Tabu .................................. 33

Vinícius Amaral Armentano e Rodrigo Moretti Branchini

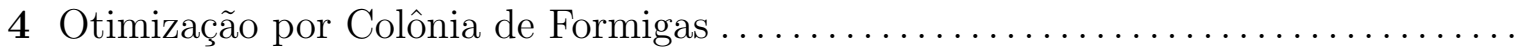
Mauro Henrique Mulati, Ademir Aparecido Constantino e Anderson Faustino da Silva

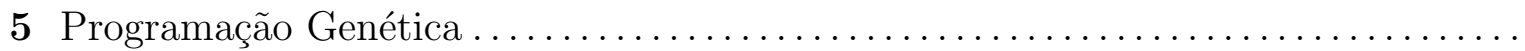
Douglas Adriano Augusto, Heder Soares Bernardino e Helio José Corrêa Barbosa

6 Comparação de Métodos de Computação Evolucionária para o Problema da Mochila Multidimensional .......................................... Jonas Krause, Jelson André Cordeiro e Heitor Silvério Lopes

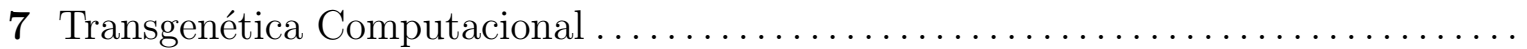
Marco César Goldbarg e Elizabeth Ferreira Gouvêa Goldbarg

8 Introdução aos Sistemas Imunológicos Artificiais Grazziela Patrocinio Figueredo, Heder Soares Bernardino e Helio José Corrêa Barbosa

9 Times Assíncronos.

Jesmmer da Silveira Alves e Humberto José Longo

10 Métodos Penalizados e Não-penalizados para o Problema do Caixeiro Viajante com Grupamento

Mário Mestria

11 Um Algoritmo Heurístico Baseado em Iterated Local Search para Problemas de Roteamento de Veículos Anand Subramanian, Puca Huachi Vaz Penna, Luiz Satoru Ochi e Marcone Jamilson Freitas Souza 


\section{Parte 2: Aplicações}

12 Problema de Roteamento de Veículos Multiobjetivo com Coleta Seletiva ......... 181 Luciana Pereira de Assis, André Luiz Maravilha Silva, Felipe Campelo Franca Pinto, Alessandro Vivas Andrade e Jaime Arturo Ramírez

13 Metodologia para o PRV: um Estudo de Caso para a Distribuição de Água Mineral ............................................... 203 Sheila Margot Gonçalves, Maria Teresinha Arns Steiner e Luzia Vidal de Souza

14 Roteamento de Veículos Utilizando Otimização por Colônia de Formigas e Algoritmo Genético Silvely Salomão Néia, Almir Olivette Artero, Luiza Amalia Pinto Cantão e Cláudio Barbieri da Cunha

15 Modelagem Matemática para Coleta Seletiva no Município de Passo Fundo-RS ... Fábio Roberto Barão, Moacir Kripka e Rosana Maria Luvezute Kripka

16 Resolução de um Problema de Projeto de Cadeia de Suprimentos de Remanufatura Usando Algoritmos Evolutivos.

Ernesto Del Rosario Santibañez Gonzalez, Henrique Pacca Loureiro Luna e Geraldo Robson Mateus

17 Comparação de Heurísticas para a Solução do Problema de Carregamento e Descarregamento 3D de Navios via Representação por Regras

Anibal Tavares de Azevedo, Cassilda Maria Ribeiro, Galeno José de Sena, Antônio Augusto Chaves, Luiz Leduino de Salles Neto e Antônio Carlos Moretti

18 Heurísticas para Otimização do Sequenciamento de Linhas de Montagem Automotivas.

Daniel Brasil, Thiago Ferreira de Noronha e Caroline Rocha

19 Algoritmo Genético e Evolução Diferencial para a Resolução do Problema de Planejamento Hidrelétrico

Priscila Cristina Berbert Rampazzo, Akebo Yamakami e Fabrício Olivetti de França

20 Simulated Annealing Aplicado ao Problema de Alocação de Salas com Deslocamentos Mínimos

Rosana Maria Luvezute Kripka e Moacir Kripka

21 Solução de Problemas de Planejamento Florestal com Variáveis Inteiras com o Emprego de Meta-heurísticas Gilson Fernandes da Silva, Antonio Almeida de Barros Junior, Gustavo Willam Pereira e Adriano Ribeiro de Mendonça 
22 Meta-heurística Otimização por Enxame de Partículas Aplicada ao Planejamento Florestal . . . . . . . . . . . . . . . . . . . . . . . . . . . .

Flávio Augusto Ferreira do Nascimento, Julio Eduardo Arce, Andrea Nogueira Dias,

Afonso Figueiredo Filho, Gabriel de Magalhães Miranda e Celso Carnieri

23 Busca Tabu: Implementação de Estratégias de Memórias de Curto

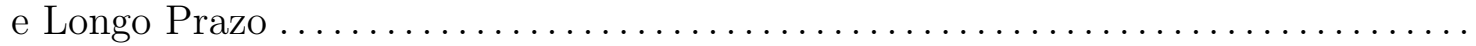

Vinícius Amaral Armentano, Débora Pretti Ronconi, Cintia Rigão Scrich e André Luís Shiguemoto

24 Um Estudo Comparativo de Algoritmos Genéticos e Beam Search para o Problema de Alocação de Células de Telefonia Celular ...

Anibal Tavares de Azevedo e Cassilda Maria Ribeiro

25 Sistema de Apoio à Decisão MILP-Fuzzy para o Planejamento Estratégico de Redes de Acesso em Telecomunicações.

Marcos Antônio de Sousa, Flávio Henrique Teles Vieira, Carlos Magnus Carlson Filho,

Bruno Henrique Pereira Gonçalves e Victor Hugo Teles Costa

26 Algoritmo Transgenético para o Passeio do Pistoneio Periódico com Realimentação Contínua nos Poços.

Marco César Goldbarg, Elizabeth Ferreira Gouvêa Goldbarg e Herbert de Mélo Duarte

27 Problema de Formação de Células de Manufatura com Roteiros Alternativos

e Considerações de Capacidade. .

Luiz Carlos de Abreu Rodrigues, Adriano Pereira Balau e Tiago Rodrigues Weller

28 Uma Solução para o Problema de Alocação de Registradores

Baseada em Meta-heurísticas

Carla Négri Lintzmayer, Mauro Henrique Mulati e Anderson Faustino da Silva

29 Meta-heurísticas Aplicadas ao Desenvolvimento de Novos Fundos

de Investimento

Eder Oliveira Abensur 



\title{
GRASP: Procedimentos de Busca Gulosos, Aleatórios e Adaptativos
}

\author{
Mauricio Guilherme de Carvalho Resende e Ricardo Martins de Abreu Silva*
}

\begin{abstract}
Resumo: Procedimento de busca gulosos, aleatórios e adaptativos (do inglês Greedy Randomized Adaptive Search Procedure - GRASP) é uma meta-heurística multi-partida para otimização combinatória que aplica o método de busca local repetidamente a partir de soluções construídas por um algoritmo guloso aleatório. Este capítulo apresenta os componentes da meta-heurística GRASP, hibridizações com o método de religamento de caminhos e a versão do GRASP paralela. Por fim, exemplos de aplicações da metaheurística GRASP em problemas de lógica e atribuição oriundas da literatura são apresentadas.

Palavras-chave: GRASP, Meta-heurística, Heurísticas híbridas, Religamento de caminhos, Busca local.

Abstract: GRASP (Greedy Randomized Adaptive Search Procedures) is a multi-start metaheuristic for combinatorial optimization that repeatedly applies local search from solutions generated with a randomized greedy algorithm. This chapter presents the building blocks of GRASP, its hybridization with path-relinking, and its parallel implementation. The chapter concludes with examples, found in the literature, of the application of GRASP to logic and assignment problems.
\end{abstract}

Keywords: GRASP, Metaheuristics, Hybrid heuristics, Path relinking, Local search.

\section{Introdução}

Um problema de otimização combinatória pode ser definido por um conjunto finito $E=\{1, \ldots, n\}$, um conjunto de soluções viáveis $F \subseteq 2^{E}$ e uma função objetivo $f: 2^{E} \rightarrow \mathbb{R}$, todos definidos para cada problema específico. Neste capítulo, será considerada a versão de minimização do problema, na qual o objetivo consiste em encontrar uma solução ótima $S^{*} \in F$ tal que $f\left(S^{*}\right) \leq f(S), \forall S \in F$. Dentre os diversos problemas reais práticos de otimização combinatória pode-se citar as mais distintas aplicações, tais como, roteamento, escalonamento, planejamento da produção e inventário, localização de instalações, biologia computacional, entre outras.

Embora muito progresso venha sendo alcançado na tarefa de encontrar comprovadas soluções ótimas em problemas de otimização combinatória, empregando técnicas tais como branch and bound, planos de corte e programação dinâmica, assim como soluções aproximadas via algoritmos aproximativos, entretanto muitos problemas de otimização combinatória que ocorrem na prática se beneficiam de métodos heurísticos que rapidamente produzem soluções de boa qualidade sem necessariamente garantir a otimalidade. Neste sentido, muitas heurísticas modernas para otimização combinatória são baseadas nos guidelines de meta-heurísticas, tais como: algoritmos genéticos, simulated annealing, busca tabu, variable neighborhood search, scatter search, religamento de caminhos, iterated local search, ant colony optimization, swarm optimization e procedimento de busca guloso, aleatório e adaptativo (GRASP).

Este capítulo tem por objetivo apresentar os componentes estruturais básicos do GRASP, incluindo diversos esquemas construtivos, métodos de busca local e hibridizações com religamento de caminhos. Os esquemas de busca local são apresentados na Seção 2. Em seguida, a meta-heurística GRASP é revista na Seção 3. Na Seção 4, oito variantes do método construtivo guloso aleatório são descritas. As hibridizações de GRASP com religamento de caminhos são explanadas na Seção 5, enquanto o GRASP paralelo na Seção 6 . Por fim, exemplos de aplicações da meta-heurística GRASP nas áreas de lógica e atribuição são apresentadas na Seção 7, seguidas pelas conclusões na Seção 8.

*Autor para contato: rmas@cin.ufpe.br 


\section{Esquemas de Busca Local}

Considere o grafo $\mathcal{X}(S, M)$ correspondente ao espaço de soluções vizinhas, onde o conjunto de vértices $S$ representa todas as soluções viáveis de um problema de otimização combinatória e o conjunto de arestas $M$, os movimentos conectando soluções vizinhas. Uma solução $s \in S$ pertence à vizinhança $N(t)$ de uma solução $t \in S$ se $s$ pode ser obtida a partir de $t$ através de pequenas alterações pré-definidas empregadas em $t$. Se a solução $s \in N(t)$, então $t \in N(s),(s, t) \in M$ e $(t, s) \in M$. Por último, diferentes estruturas de vizinhança podem ser definidas para cada problema de otimização combinatória.

Os esquemas de busca local partem de uma solução inicial, por sua vez tida como sendo a solução corrente, a procura de uma solução melhor na vizinhança da solução corrente. Se esta solução existir, automaticamente tornar-se-á a nova solução corrente e a busca local recursivamente será aplicada sobre esta solução. O procedimento termina quando nenhuma solução melhor do que a corrente existir na vizinhança desta última. Tal esquema de busca local exige que o tamanho da vizinhança seja tal que sua exploração possa ser feita eficientemente.

O Algoritmo 1 mostra o pseudo-código para o algoritmo de busca local padrão. A busca local começa em algum vértice $s_{0} \in S$ tornando-o a solução atual $t$, ou seja, $t=s_{0}$. A cada iteração, o algoritmo procura uma solução vizinha que possua um valor da função objetivo melhor do que o valor correspondente à solução corrente, ou seja, uma solução $s \in N(t)$ tal que $f(s)<f(t)$. Se tal solução existir, tornar-se-á a solução corrente, ou seja, $t=s$. Estas iterações são repetidas até não existir nenhuma solução melhor do que a solução corrente $t$ na vizinhança $N(t)$. Neste caso, a solução $t$ é denominada como um ótimo local.

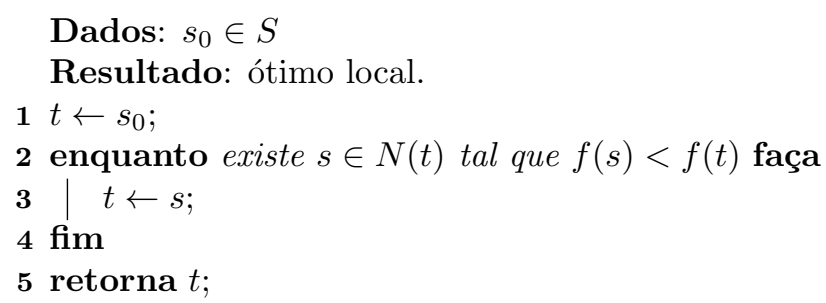

Algoritmo 1: Busca local padrão

A busca local pode ser vista como partindo de um vértice $s \in S$ e examinado os nós adjacentes no grafo $\mathcal{X}$ em busca de uma solução de melhoria. Na variante first-improving, a busca local se move para a primeira solução de melhoria encontrada na vizinhança, enquanto na variante best-improving todas as soluções da vizinhança são avaliadas de modo que a busca local se direcione para a melhor solução encontrada. Pode-se considerar esta fase da busca como sendo a de intensificação, uma vez que apenas uma pequena parte do espaço de soluções está sendo considerada.

Vários enfoques foram propostos para estender a busca local acima citada, tais como, variable neighborhood descent (Andrade \& Resende, 2006; Hansen \& Mladenović, 1998; Martins et al., 1999; Ribeiro \& Souza, 2002; Ribeiro et al., 2002; Ribeiro \& Vianna, 2005), variable neighborhood search (Beltrán et al., 2004; Canuto et al., 2001; Drummond et al., 2002; Festa et al., 2002; Hansen \& Mladenović, 1998; Ochi et al., 2001), busca tabu de memória curta (Abdinnour-Helm \& Hadley, 2000; de Souza et al., 2003; Delmaire et al., 1999; Glover, 1989, 1990; Laguna \& González-Velarde, 1991; Li et al., 2004; Lim \& Wang, 2004; Moura \& Oliveira, 2005; Pu et al., 2006; Serra \& Colomé, 2001; Souza et al., 2001), simulated annealing (de la Peña, 2004; Kirkpatrick et al., 1983; Liu et al., 2000), iterated local search (Baum, 1986, 1987; Baxter, 1981; Johnson, 1990; Martin \& Otto, 1996; Martin et al., 1991; Ribeiro \& Urrutia, 2007), e very-large scale neighborhood search (Ahuja et al., 2001, 2002; Geng et al., 2005), os quais admitem, além da exploração da vizinhança da solução corrente, desde movimentos para soluções de custo maior do que a solução corrente, passando pelo cenário de múltiplas vizinhanças, até a exploração de vizinhanças bem maiores.

\section{Procedimentos de Busca Gulosos, Aleatórios e Adaptativos}

Um método de busca eficaz precisa viabilizar sua diversificação. Portanto, uma boa estratégia para a busca local não deve se ater a uma região particular do espaço de soluções, como por exemplo, em torno de uma solução construída por um algoritmo guloso. Uma alternativa consiste em iniciar uma busca local a partir de várias soluções geradas aleatoriamente, com a expectativa de que haja um caminho de melhoria de custo partindo de uma destas soluções até uma solução ótima ou próxima do ótimo.

Um procedimentos de busca guloso, aleatório e adaptativo repetidamente aplica a busca local a partir de soluções construídas com um algoritmo guloso aleatório. O melhor ótimo local dentre todas as buscas 
locais é retornado como solução da heurística. O Algoritmo 2 apresenta o pseudo-código de um GRASP genérico. Ao fim da fase de construção gulosa aleatória, a solução obtida é viável para diversas instâncias da heurística. Entretanto, para alguns problemas, a solução pode ser inviável, logo requerendo a aplicação de um procedimento de reparo que restaure sua viabilidade. Exemplos de implementações GRASP munidas de procedimentos de reparos para restaurar a viabilidade de soluções podem ser encontrados em Duarte et al. (2007a), Duarte et al. (2007b), Nascimento et al. (2010) e Mateus et al. (2011).

Uma característica especialmente atraente da meta-heurística GRASP é a facilidade com que pode ser implementada. Dado que poucos parâmetros precisam ser inicializados e ajustados, logo o desenvolvimento pode se ater à implementação dos algoritmos e estruturas de dados que garantam a eficiência do projeto. Como será visto a seguir, as implementações básicas do GRASP repousam exclusivamente em dois parâmetros. O primeiro controla o número de iterações dos métodos construtivo e de busca local a serem aplicados. O segundo controla a mistura dos enfoques aleatório e guloso do método construtivo. A despeito de sua simplicidade e facilidade de implementação, GRASP é uma meta-heurística muito eficaz e produz as melhores soluções conhecidas para muito problemas.

GRASP foi introduzido pela primeira vez por Feo \& Resende (1989). Ver Feo \& Resende (1995), Pitsoulis \& Resende (2002), Resende \& Ribeiro (2003), Resende et al. (2010b) e Resende (2008) para um revisão da meta-heurística GRASP e Festa \& Resende (2002, 2009a,b) para uma bibliografia anotada do assunto.

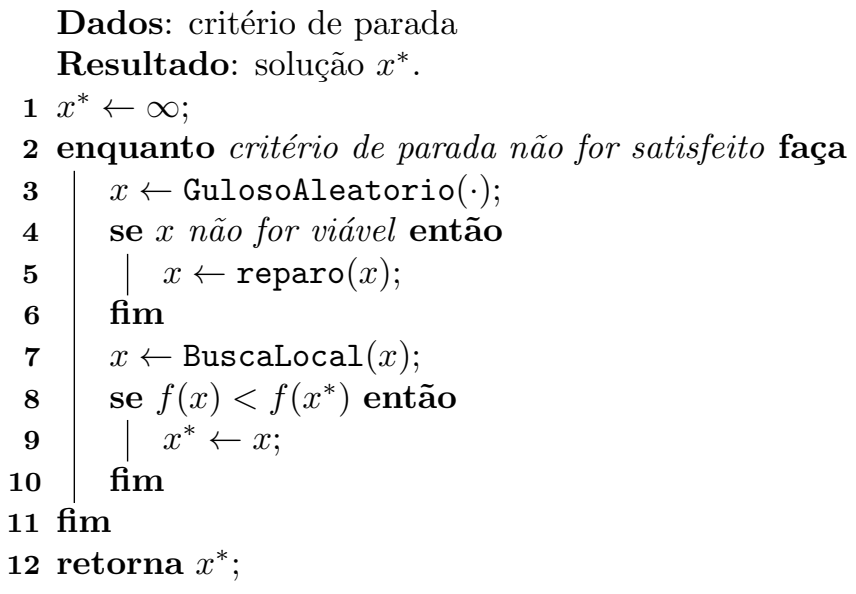

Algoritmo 2: Pseudo-código de um GRASP básico.

\section{Método de Construção Guloso Aleatório}

Os métodos de construção gulosos aleatórios do GRASP visam produzir um conjunto diversificado de soluções inicias de boa qualidade para a busca local. Este propósito é alcançado pela adição de aleatoriedade ao algoritmo guloso. Neste capítulo são ilustradas oito formas de realizar tal tarefa, nas quais as soluções são construídas pela adição de elementos a uma solução parcial.

\subsection{Construção semi-gulosa}

O Algoritmo 3 mostra o pseudo-código para este método de construção. A cada iteração do primeiro esquema de construção, denominado algoritmo semi-guloso por Hart \& Shogan (1987), seja $C$ o conjunto de todos os elementos que podem ser adicionados à solução parcial e seja $L R C(C)$ a lista restrita de candidatos composta por elementos candidatos de alta-qualidade.

A qualidade de um elemento candidato é determinada por sua contribuição, naquele ponto, para o custo da solução sendo construída. A função gulosa $g(c)$ mede esta contribuição para cada candidato $c \in C$. Membros do conjunto $L R C(C)$ podem ser determinados pelo rank ou pela qualidade relativa aos outros candidatos. Membros segundo o rank, também denominados baseados na cardinalidade, são obtidos se o candidato é um dos $q$ candidatos com o menor valor da função gulosa, onde $q$ é um parâmetro de entrada que determina quão gulosa ou aleatória será a construção. Membros baseados na qualidade relativa a outros candidatos determinam um valor de corte para a função gulosa e somente consideram candidatos com uma valor guloso que não seja maior do que este valor de corte. Neste caso, a implementação utiliza um parâmetro real $\alpha \in[0,1]$. Seja $\dot{g}=\max \{g(c) \mid c \in C\}$ e $\grave{g}=\min \{g(c) \mid c \in C\}$. Um candidato $c \in C$ é posto na $L R C$ se e somente se $\grave{g} \leq g(c) \leq \grave{g}+\alpha \cdot(\grave{g}-\grave{g})$. O parâmetro de entrada $\alpha$ determina quão guloso ou aleatório será a construção. Um dentre os candidatos em $\operatorname{LRC}(C)$ é selecionado aleatoriamente e inserido na solução parcial. A construção é repetida até não haver mais candidatos. 
Dados: $E=\{$ conjunto discreto finito $\}$.

Resultado: solução $S$.

$1 S \leftarrow \emptyset ; C \leftarrow E$;

2 enquanto $|C|>0$ faça

3 Para todo $c \in C$ computar o valor da função gulosa $g(c)$;

Definir $L R C(C) \leftarrow\{c \in C \mid g(c)$ tam um valor reduzido $\}$;

Selecionar aleatoriamente $c^{*} \in L R C(C)$;

Adicionar $c^{*}$ à solução parcial: $S \leftarrow S \cup\left\{c^{*}\right\}$;

Seja $C$ o conjunto de elementos que

podem ser adicionados à $S$;

9 fim

10 retorna $S$;

Algoritmo 3: Método construtivo da meta-heurística GRASP: aleatorização do algoritmo guloso ou semi-guloso.

\subsection{Construção por amostragem gulosa}

Neste segundo esquema de construção, denominado construção por amostragem gulosa por Resende \& Werneck (2004), um algoritmo guloso é aplicado a cada amostragem aleatória de candidatos, ao invés da aleatorização do algoritmo guloso. O Algoritmo 4 mostra o pseudo-código para este procedimento construtivo. A cada passo um subconjunto de tamanho fixo de candidatos em $C$ é amostrada e a contribuição incremental ao custo da solução parcial é computada para cada elemento amostrado. Um elemento com a melhor contribuição incremental é selecionado e adicionado à solução parcial. Este processo é repetido até quando não existir nenhum candidato.

Dados: $p, E=\{$ conjunto discreto finito $\}$.

Resultado: solução $S$.

$1 S \leftarrow \emptyset ; C \leftarrow E$;

2 enquanto $|C|>0$ faça

$3 \quad$ Amostrar aleatoriamente $\min \{p,|C|\}$ elementos

4 a partir de $C$ e inserí-los em $L R C(C)$;

$5 \quad$ Selecionar $c^{*}=\operatorname{argmin}\{g(c) \mid c \in L R C(C)\}$;

6 Adicionar $c^{*}$ à solução parcial: $S \leftarrow S \cup\left\{c^{*}\right\}$;

$7 \quad$ Seja $C$ o conjunto de elementos

8 que podem ser adicionados à $S$;

9 fim

10 retorna $S$;

Algoritmo 4: Construção gulosa aleatória da meta-heurística GRASP: amostragem gulosa

\subsection{Construção aleatória-gulosa}

Uma possível restrição da construção gulosa aleatória baseada em uma lista restrita de candidatos é sua complexidade. A cada passo do método construtivo, cada elemento candidato ainda não selecionado tem que ser avaliado pela função gulosa. Nos casos onde a diferença entre o número de elementos do conjunto $E$ e o número de elementos que compõem uma solução do problema é alto, o método construtivo pode não ser muito eficiente. Como ocorre no caso do esquema de construção por amostragem gulosa, este terceiro esquema introduzido por Resende \& Werneck (2004), denominado construção aleatório guloso, também atende esta restrição.

Neste esquema, uma parte da solução é construída pela escolha aleatória de $p$ elementos candidatos e o restante da solução é completado de forma gulosa. A solução resultante é gulosa e aleatória. O valor de $p$ determina quão guloso ou aleatório é o método construtivo. Valores reduzidos de $p$ levam à soluções mais gulosas, enquanto valores maiores levam à soluções mais aleatórios. A amostragem aleatória foi apresentada na Seção 4.2 . 


\subsection{Construção gulosa proporcional}

A cada iteração deste quarto esquema de construção, denominado guloso proporcional e introduzido pela primeira vez por Resende \& Werneck (2004), a função gulosa $g(c)$ para todo elemento candidato $c \in C$ é computada e em seguida um candidato é selecionado aleatoriamente, porém de um modo viciado: a probabilidade de um dado candidato $c^{\prime} \in C$ ser selecionado é inversamente proporcional a $g\left(c^{\prime}\right)-\min \{g(c) \mid c \in$ $C\}$.

\subsection{Construção GRASP reativa}

O quinto esquema construtivo é denominado GRASP reativo. Nos procedimentos de construção guloso aleatório, o projetista deve decidir como balancear os enfoques guloso e aleatório. Uma simples alternativa seria balanceá-los aleatoriamente. Por exemplo, na construção semi-gulosa, com membros em $L R C$ segundo a qualidade relativa aos outros candidatos, o parâmetro $\alpha$ pode ser selecionado de modo uniformemente aleatório a partir do intervalo $[0,1]$, de modo que cada iteração GRASP use um valor diferente de $\alpha$, resultando em um balanceamento diferente entre os enfoques guloso e aleatório.

Prais \& Ribeiro (2000) mostraram que usando um valor fixo para o parâmetro $\alpha$ no esquema semiguloso baseado na qualidade frequentemente retarda o encontro de soluções de alta qualidade, as quais eventualmente seriam encontradas caso outro valor para $\alpha$ fosse utilizado. Sendo assim, eles propuseram uma extensão do procedimento GRASP básico, denominado GRASP reativo, na qual o parâmetro $\alpha$ é selecionado aleatoriamente a cada iteração a partir de um conjunto discreto de possíveis valores. Cabe ressaltar que valores das soluções encontrados ao longo das iterações anteriores servem de guia para o processo de seleção.

Prais \& Ribeiro (2000) definem $\Psi=\left\{\alpha_{1}, \ldots, \alpha_{m}\right\}$ como o conjunto de valores possíveis para $\alpha$. As probabilidades associadas com a escolha de cada valor são inicialmente iguais a $p_{i}=1 / m, i=1, \ldots, m$. Além disto, seja $z^{*}$ a solução titular (a melhor solução encontrada até aquele ponto) e $A_{i}$ o valor médio de todas soluções encontradas usando $\alpha=\alpha_{i}, i=1, \ldots, m$. As probabilidades de seleção são periodicamente reavaliadas tomando $p_{i}=q_{i} / \sum_{j=1}^{m} q_{j}, \operatorname{com} q_{i}=z^{*} / A_{i}$ para $i=1, \ldots, m$. O valor de $q_{i}$ será maior para os valores de $\alpha=\alpha_{i}$ associados às melhores soluções em média. Logo, valores maiores de $q_{i}$ correspondem a valores mais adequados para o parâmetro $\alpha$. As probabilidades mais apropriadas a estes valores irão então aumentar quando forem reavaliadas. Cabe observar, que esta estratégia reativa não é limitada aos procedimentos semi-gulosos com membros em $L R C$ baseados na qualidade relativa. Ou seja, ela pode ser estendida a outros esquemas de construção gulosos aleatório, todos os quais necessitam balancear o aspecto guloso com o aspecto aleatório.

\subsection{Construção com memória de longo prazo}

O sexto esquema de construção, denominado construção com memória de longo prazo, introduz uma estrutura de memória de longo prazo. Embora o GRASP reativo também utilize memória de longo prazo (informações coletadas em iterações anteriores) para ajustar o balanceamento entre os aspectos gulosos e aleatórios, Fleurent \& Glover (1999) observaram que isto não acontecia no GRASP básico. Sendo assim, eles propuseram um esquema de longo-prazo para atender esta questão em heurísticas multi-partida. Memória de longo prazo é um dos fundamentos nos quais se apoia por exemplo a busca tabu (Glover, 1989, 1990). A idéia básica consiste em manter um conjunto de soluções elite a ser usado na fase de construção. Mais detalhes a respeito deste enfoque serão fornecidos no decorrer deste capítulo. Por enquanto, tudo o que é necessário saber consiste em como uma solução tornar-se uma solução elite: esta deve ser melhor do que o melhor membro do conjunto elite ou melhor do que seu pior membro, contanto que seja suficientemente diferente das outras soluções do conjunto.

Fleurent \& Glover (1999) definem uma variável fortemente determinada como sendo aquela que não pode ser alterada sem comprometer o objetivo ou mudar significantemente outras variáveis; e uma variável consistente como a que recebe o mesmo valor em grande parte do conjunto elite. Seja $I(e)$ uma medida das características consistentes e fortemenete determinadas do elemento $e$ da solução a partir do conjunto $E$. Como $I(e)$ torna-se maior na medida em que $e$ aparece mais frequentemente no conjunto de soluções elite, ele é usado na fase de construção da seguinte maneira. Seja $g(e)$ o valor da função gulosa para o candidato $e \in C$, ou seja o custo incremental associado com a incorporação do elemento $e \in C$ na solução em construção. Seja $K(e)=F(g(e), I(e))$ uma função associada aos aspectos gulosos e de intensificação, como por exemplo, $K(e)=\lambda g(e)+I(e)$. O esquema de intensificação que favoresse a seleção dos elementos $e \in C$ com um alto valor para $K(e)$ devem atualizar a probabilidade de seleção para o seguinte valor: $p(e)=K(e) / \sum_{s \in \mathrm{LRC}} K(s)$. Cabe observar que a função $K(e)$ pode variar com o tempo pela mudança dos valores $\lambda$, por exemplo, inicialmente $\lambda$ pode ser inicializado para um valor alto que decresce a medida que a diversifição é chamada. 


\subsection{Construção por amostragem viciada}

O sétimo esquema de construção foi introduzido por Bresina (1996) e denominado de construção por amostragem viciada. Consiste em outra forma de partir de uma seleção uniforme de elementos candidatos na construção de uma solução gulosa aleatória. Ao invés de escolher de modo uniformemente aleatório o próximo elemento candidato a ser adicionado à solução parcial, a construção por amostragem viciada sugere que qualquer distribuição de probabilidade possa ser usada para favorecer alguns tipos de candidatos em particular.

No mecanismo de construção proposto por Bresina (1996), uma família de distribuições de probabilidade é introduzida. Elas são baseadas na colocação $(\operatorname{rank}) r[\sigma]$ atribuída a cada elemento candidato $\sigma$, de acordo com os valores de suas funções gulosas. O elemento com o menor valor da função gulosa tem rank 1 , o segundo menor tem rank 2, e assim por diante. Várias funções viciadas $b(\cdot)$ foram introduzidas por Bresina, tais como, vício aleatório onde $b(r)=1$, vício linear onde $b(r)=1 / r$, vício logarítmico onde $b(r)=\log ^{-1}(r+1)$, vício exponencial onde $b(r)=e^{-r}$ e vício polinomial de ordem $n$ onde $b(r)=r^{-n}$. Após todos os elementos em $L R C$ receberem seus respectivoso ranks, a probabilidade $\pi(\sigma)$ para selecionar o elemento $\sigma \in L R C$ pode ser computada da seguinte forma: $\pi(\sigma)=b(r[\sigma]) /\left(\sum_{\sigma^{\prime} \in L R C} b\left(r\left[\sigma^{\prime}\right]\right)\right)$. Cabe observar que de acordo com este esquema, candidatos podem ser selecionados a partir do conjunto mathitLRC ou a partir do conjunto completo de candidatos, ou seja, $L R C=C$.

\subsection{Construção com pertubação de custos}

No oitavo esquema de construção, denominado construção com pertubação de custos, pertubações aleatórias são introduzidas no problema original como uma forma de obter aleatoriedade. A idéia de introduzir ruído no custo original com o intuito de aleatorizar o processo construtivo é similar ao noising method de Charon \& Hudry (1993, 2002).

Em circunstâncias onde os algoritmos construtivos são insensíveis às estratégias aleatórias padrão, tal como selecionar um elemento aleatoriamente a partir de uma lista restrita de candidatos, a construção com pertubação de custo pode ser mais eficaz do que a estratégia gulosa aleatória do GRASP básico. Ribeiro et al. (2002) mostram que este caso ocorre na heurística de caminho mínimo de Takahashi \& Matsuyama (1980), usado como um dos principais componentes da fase construtiva de um GRASP híbrido proposto para um problema de Steiner em grafos.

Outra situação onde esta estratégia de pertubação dos custos pode ser eficiente ocorre quando não há um algoritmo guloso a ser aleatorizado, como foi o caso do GRASP híbrido desenvolvido por Canuto et al. (2001) para o problem de Steiner com prêmios (prize-collecting Steiner tree problem), o qual fez uso de um algoritmo de aproximação primal-dual de Goemans \& Williamson (1996) para construir soluções iniciais usando custos pertubados.

\section{Hibridizações com Religamento de Caminhos}

A heurítica de religamento de caminhos foi originalmente proposta por Glover (1996) como uma estratégia de intensificação para explorar trajetórias conectando soluções elite obtidas pela busca tabu ou scatter search (Glover, 2000; Glover \& Laguna, 1997; Glover et al., 2000). Partindo de uma ou mais soluções elite na busca por melhores soluções, caminhos que levam a outras soluções elite são gerados e explorados no grafo do espaço de soluções. Para gerar estes caminhos, movimentos são selecionados para introduzir atributos presentes na solução destino na solução corrente. O pseudo-código do Algoritmo 5 ilustra o religamento de caminhos misto sobre o par de soluções $x_{s}$ e $x_{t}$.

O religamento de caminhos misto (Ribeiro \& Rosseti, 2002) alterna os papéis de solução origem e destino a cada movimento. O religamento de caminhos misto começa computando as diferenças simétricas $\Delta\left(x_{s}, x_{t}\right)$ entre a solução origem $x_{s}$ e a destino $x_{t}$. Ou seja, o conjunto de movimentos necessários para alcançar $x_{t}$ a partir de $x_{s}$, e vice-versa. Portanto, dois caminhos de soluções são gerados, um partindo de $x_{s}$ e outro de $x_{t}$. Estes caminhos crescem até se encontrarem para formar um único caminho entre $x_{t}$ e $x_{s}$. A busca local é aplicada na melhor solução $x^{*}$ neste caminho e o mínimo local é retornado pelo algoritmo. Inicialmente, $x$ e $y$ são inicializados como $x_{s}$ e $x_{t}$, respectivamente. A cada passo, o procedimento examina todos os movimentos $m \in \Delta(x, y)$ partindo da solução corrente $x$ em direção às soluções que contêm um atributo adicional de $y$ e seleciona aquele que minimiza $f(x \oplus m)$, com $x \oplus m$ sendo a solução resultante da aplicação do movimento $m$ sobre a solução $x$. Em seguida, o melhor movimento $m^{*}$ é realizado produzindo a solução $x \oplus m^{*}$. Depois, se necessário, a melhor solução $x^{*}$ é atualizada. Por fim, os conjuntos de movimentos disponíveis são atualizados e os papéis de $x$ e $y$ invertidos. O procedimento termina quando $|\Delta(x, y)|=1$.

Religamento de caminhos consiste em um grande avanço no procedimento GRASP padrão, levando a melhorias significantes de desempenho e qualidade das soluções. A hibridização entre religamento de caminhos e GRASP foi primeiro proposta por Laguna \& Martí (1999) e posteriormente seguida por várias extensões, 
Dados: $x_{s} \in S, x_{t} \in S$.

Resultado: solução $x^{*}$.

1 Calcule as diferenças simétricas $\Delta\left(x_{s}, x_{t}\right)$ e $\Delta\left(x_{t}, x_{s}\right)$;

$2 f^{*} \leftarrow \min \left\{f\left(x_{s}\right), f\left(x_{t}\right)\right\}$;

$3 x^{*} \leftarrow \operatorname{argmin}\left\{f\left(x_{s}\right), f\left(x_{t}\right)\right\}$;

$4 x \leftarrow x_{s} ; y \leftarrow x_{t}$;

5 enquanto $|\Delta(x, y)|>1$ faça

$6 \quad m^{*} \leftarrow \operatorname{argmin}\{f(x \oplus m): m \in \Delta(x, y)\}$;

$7 \quad x \leftarrow x \oplus m^{*}$;

$8 \quad$ Atualize $\Delta(x, y)$ e $\Delta(y, x)$;

$9 \quad$ se $f(x)<f^{*}$ então

$10 \quad f^{*} \leftarrow f(x)$;

$11 \quad x^{*} \leftarrow x$

12 fim

$13 \quad t \leftarrow y ; y \leftarrow x ; x \leftarrow t$;

14 fim

$15 x^{*} \leftarrow \operatorname{BuscaLocal}\left(x^{*}\right)$;

16 retorna $x^{*}$;

Algoritmo 5: Religamento de caminhos misto entre as soluções $x_{s}$ e $x_{t}$.

melhorias e aplicações de sucesso (Mateus et al., 2011; Aiex et al., 2005; Canuto et al., 2001; Festa et al., 2007; Oliveira et al., 2004a; Resende et al., 2010a; Resende \& Ribeiro, 2003; Resende \& Werneck, 2004, 2006; Ribeiro et al., 2002). Um resumo de GRASP com religamento de caminhos é apresentado em Resende \& Ribeiro (2005a). Duas estratégias básicas são usadas. Na primeira, o religamento de caminhos é aplicada a todos os pares de soluções elite, seja periodicamente durante as iterações GRASP ou como uma estapa de pós-otimização, após todas as iterações GRASP terem sido realizadas. Na segunda, o religamento de caminhos é aplicado como uma estratégia de intensificação a cada ótimo local obtido após a busca local.

Aplicar religamento de caminhos como uma estratégia de intensificação sobre cada ótimo local geralmente é mais eficaz do que simplesmente usá-lo como uma etapa de pós-otimização. Em geral, combinar intensificação com pós-otimização resulta em uma melhor estratégia. No contexto de intensificação, religamento de caminhos é aplicado em pares $(x, y)$ de soluções, onde $x$ é uma solução ótima local produzida a cada iteração GRASP, após a aplicação da busca local, e y é uma das soluções elite aleatoriamente escolhidas a partir de um conjunto elite com um número máximo Max_Elite de elementos obtidos no decorrer da busca. A seleção aleatória uniforme é uma simples estratégia a ser implementada. Desde que a diferença simétrica é uma medida do tamanho do caminho a ser explorado durante o religamento, uma estratégia viciada que privilegia as soluções $y$ do conjunto elite com alta diferença simétrica em relação a $x$ é usualmente melhor do que aquela usando a seleção uniformemente aleatória (Resende \& Werneck, 2004).

O conjunto elite inicialmente é vazio. Uma vez que se deseja manter este conjunto com soluções diversificadas de alta qualidade, cada ótimo local obtido pela busca local é considerado como um candidato a ser inserido no conjunto elite, caso seja suficientemente diferente de todas as outras soluções atualmente contidas no mesmo. Se o conjunto já possui Max_Elite soluções e o candidato é melhor do que o pior entre eles, então uma simples estratégia consiste em substituir a segunda pela primeira. Outra estratégia, a qual tende a aumentar a diversidade do conjunto elite, consiste em substituir o elemento mais similar à solução candidata dentre todos os elementos do conjunto elite com custo pior do que o custo da solução candidata. Caso o conjunto elite não esteja cheio, o candidato é simplesmente adicionado ao mesmo.

A pós-otimização é realizada sobre uma série de conjuntos. O conjunto inicial $P_{0}$ consiste no conjunto $P$ obtido ao final das iterações GRASP. O valor da melhor solução de $P_{0}$ é atribuída a $f_{0}^{*}$ e um contador de iterações $k$ é inicializado para 0 . Na $k$-ésima iteração, todos os pares de elementos do conjunto $P_{k}$ são combinados através do religamento de caminhos. Cada resultado do religamento de caminhos é testado para inclusão no conjunto $P_{k+1}$ seguindo os mesmos critérios usados nas iterações GRASP. Se uma nova melhor solução é produzida, ou seja, $f_{k+1}^{*}<f_{k}^{*}$, então $k \leftarrow k+1$ e uma nova iteração da pós-otimização é realizada. Caso contrário, a pós-otimização é encerrada com $x^{*} \in \operatorname{argmin}\left\{f(x) \mid x \in P_{k+1}\right\}$ como resultado.

O pseudo-código do Algoritmo 6 ilustra este procedimento. Agora, cada iteração GRASP possui três passos principais. Na fase de construção, um procedimento de busca gulosa e aleatória é usado para construir uma solução viável. Na fase de busca local a solução construída na primeira fase é progressivamente melhorada por uma estratégia de busca na vizinhança, até que um mínimo local seja encontrado. Na fase de religamento de caminhos o algoritmo de religamento de caminhos é aplicado sobre a solução obtida pela busca local e uma 
solução aleatoriamente selecionada a partir do conjunto elite. A melhor solução encontrada ao longo desta trajetória é também considerada como uma candidata a inserção no conjunto elite. Ao final das iterações GRASP, a fase de pós-otimização combina as soluções do conjunto elite na busca por melhores soluções. Mateus et al. (2011) propõem uma nova versão de GRASP com religamento de caminhos, motivado pelo fato de que em alguns problemas um movimento guiado pela solução destino não garante a viabilidade da nova solução construída.

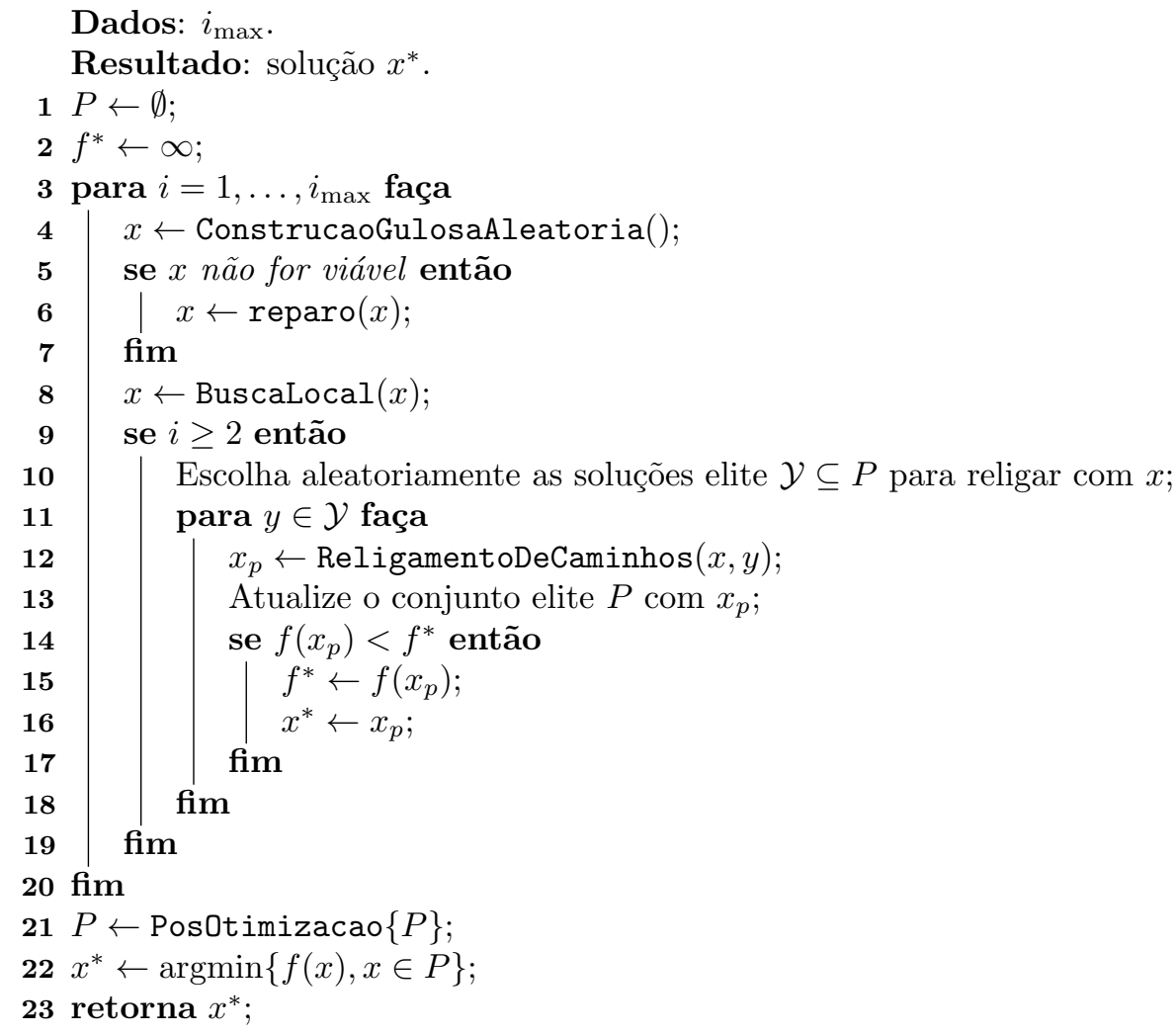

Algoritmo 6: Uma heurística GRASP-PR básica para minimização.

\section{GRASP Paralelo}

Assim como qualquer heurística multi-partida (multi-start) para otimização combinatória, um GRASP pode ser implementado em paralelo dividindo-se $k$ iterações independentes entre $\rho$ processadores. Outro enfoque consiste em dar um valor alvo $\tau$ da função objetivo a cada processador e executar o algoritmo até que o primeiro processador encontre uma solução com valor pelo menos tão bom quanto $\tau$, altura em que o restante dos processadores finalizão suas execuções. Cabe ressaltar que é necessário garantir que nenhuma iteração em paralelo inicie seu processamento com a mesma semente do gerador de números aleatórios (Pardalos et al., 1996). Estes são exemplos do paralelismo do caminho independente múltiplo (multiple independent walk) (Verhoeven \& Aarts, 1995).

Diversas implementações paralelas de GRASP usando as estratégias acima têm sido relatadas na literatura, por exemplo (Martins et al., 2000, 1998; Murphey et al., 1998; Pardalos et al., 1995, 1996). Na maioria destes artigos, uma observação comum foi realizada. A aceleração nos tempos de respostas medidos eram proporcionais ao número de processadores. Um típico exemplo pode ser visto em Pardalos et al. (1996) onde, para uma implementação baseada em PVM de um GRASP paralelo para o problema do MAX-SAT, foi medida uma aceleração média quase idêntica ao número de processadores (ver Tabela 1).

Esta observação pode ser explicada se a variável aleatória solution time to target é exponencialmente distribuída, como indicada pela seguinte proposição (Verhoeven \& Aarts, 1995).

Proposição 1 : Seja $P_{\rho}(t)$ a probabilidade de uma dada solução alvo não ser encontrada em $t$ unidades de tempo com $\rho$ processos independentes. Se $P_{1}(t)=e^{-t / \lambda}$ com $\lambda \in \mathbb{R}^{+}$, i.e. $P_{1}$ corresponde a uma distribuição exponencial, então $P_{\rho}(t)=e^{-\rho t / \lambda}$. 
Tabela 1. Tempo de CPU (em segundos) e aceleração sobre problemas MAX-SAT. Aceleração média é mostrada para 5,10 , e 15 processadores.

\begin{tabular}{|c|c|c|c|c|c|c|c|}
\hline \multirow[t]{2}{*}{ problema } & \multirow{2}{*}{$\frac{1 \text { processador }}{\text { tempo }}$} & \multicolumn{2}{|c|}{5 processadores } & \multicolumn{2}{|c|}{10 processadores } & \multicolumn{2}{|c|}{15 processadores } \\
\hline & & tempo & aceleração & tempo & aceleração & tempo & aceleração \\
\hline jnh201 & 310,4 & 62,8 & 4,9 & 30,5 & 10,2 & 22,2 & 14,0 \\
\hline jnh202 & 312,2 & 59,8 & 5,2 & 31,2 & 10,0 & 23,4 & 13,3 \\
\hline jnh203 & 351,2 & 72,3 & 4,9 & 35,2 & 10,0 & 23,2 & 15,1 \\
\hline jnh205 & 327,8 & 63,4 & 5,2 & 32,1 & 10,2 & 22,5 & 14,6 \\
\hline jnh207 & 304,7 & 56,7 & 5,4 & 29,6 & 10,3 & 19,8 & 15,4 \\
\hline jnh208 & 355,2 & 65,6 & 5,4 & 33,2 & 10,7 & 21,0 & 16,9 \\
\hline jnh209 & 339,0 & 60,5 & 5,6 & 33,6 & 10,1 & 21,6 & 15,7 \\
\hline jnh210 & 318,5 & 57,6 & 5,5 & 32,5 & 9,8 & 20,8 & 15,3 \\
\hline jnh301 & 414,5 & 85,3 & 4,9 & 45,2 & 9,2 & 28,3 & 14,6 \\
\hline jnh302 & 398,7 & 88,6 & 4,5 & 48,2 & 8,3 & 27,0 & 14,7 \\
\hline \multicolumn{2}{|c|}{ aceleração média: } & & 5,2 & & 9,9 & & 15,0 \\
\hline
\end{tabular}

A proposição 1 é oriunda da própria definição de distribuição exponencial. Isto implica que a probabilidade de uma solução com um dado valor ser encontrada em tempo $\rho t$ com um processo sequencial é igual a probabilidade de encontrar uma solução ao menos tão boa quanto o valor dado em tempo $t$ com $\rho$ processos paralelos independentes. Sendo assim, em tempo linear de aceleração é possível alcançar a solução alvo via múltiplos processos independentes.

Uma proposição análoga mediante uma distribuição exponencial bi-paramétrica deslocada (shifted).

Proposição 2 : Seja $P_{\rho}(t)$ a probabilidade de uma dada solução alvo não ser encontrada em $t$ unidades de tempo com $\rho$ processos independentes. Se $P_{1}(t)=e^{-(t-\mu) / \lambda}$ com $\lambda \in \mathbb{R}^{+}$e $\mu \in \mathbb{R}$, i.e. $P_{1}$ corresponde a uma distribuição exponencial bi-paramétrica, então $P_{\rho}(t)=e^{-\rho(t-\mu) / \lambda}$.

Analogamente, a proposição 2 é oriunda da própria definição de distribuição exponencial bi-paramétrica. Isto implica que a probabilidade de uma solução com um dado valor ser encontrada em tempo $\rho t$ com um processo sequencial é igual a $1-e^{-(\rho t-\mu) / \lambda}$, enquanto a probabilidade de encontrar uma solução ao menos tã boa quanto o valor dado em tempo $t \operatorname{com} \rho$ processos paralelos independentes é $1-e^{-\rho(t-\mu) / \lambda}$. Note que se $\mu=0$, então ambas probabilidades são iguais e correspondem a distribuição exponencial não deslocada (non-shifted). Além disto, se $\rho \mu \ll \lambda$, então as duas probabilidades são aproximadamente iguais. Sendo assim, em tempo linear de aceleração é possível alcançar a solução alvo via múltiplos processos independentes.

Aiex et al. (2002) estudaram as distribuições de probabilidade empíricas da variável aleatória tempo-parasolução-alvo (time to target solution) em cinco implementações GRASP. Eles mostraram que, dado um valor da solução alvo, o tempo que o GRASP leva para encontrar uma solução ao menos tão boa quanto a alvo se encaixa em uma distribuição exponencial biparamétrica. Por exemplo, a Figura 1 mostra um gráfico com distribuições teóricas empíricas e estimadas para a heurística GRASP aplicada a uma instância particular de um problema. Este gráfico foi gerado mediante 200 execuções independentes do GRASP, cuja metodologia encontra-se descrita em Aiex et al. (2002).

\section{Aplicações GRASP}

Desde 1980 a heurística GRASP tem sido aplicada a uma grande variedade de problemas de otimização industrial e de pesquisa operacional. Isto inclui problemas em escalonamento, roteamento, lógica, particionamento, localização e layout, teoria dos grafos, atribuição, manufatura, transporte, telecomunicações, desenho automático, sistema de potência elétrico, projeto VLSI, entre outros. Festa \& Resende (2001, 2009a,b) apresentaram uma extensiva bibliografia anotada da literatura sobre GRASP. Nesta Seção será apresentada uma pequena parte destas aplicações, limitando-se a problemas de lógica e de atribuição.

\subsection{Lógica: máxima satisfatibilidade ponderada (Festa et al., 2007).}

A fórmula proposicional $\Phi$ sobre um conjunto de $n$ variáveis booleanas $V=\left\{x_{1}, \ldots, x_{n}\right\}$ na forma normal conjuntiva (conjunctive normal form - CNF) é uma conjunção sobre um conjunto de $m$ cláusulas 


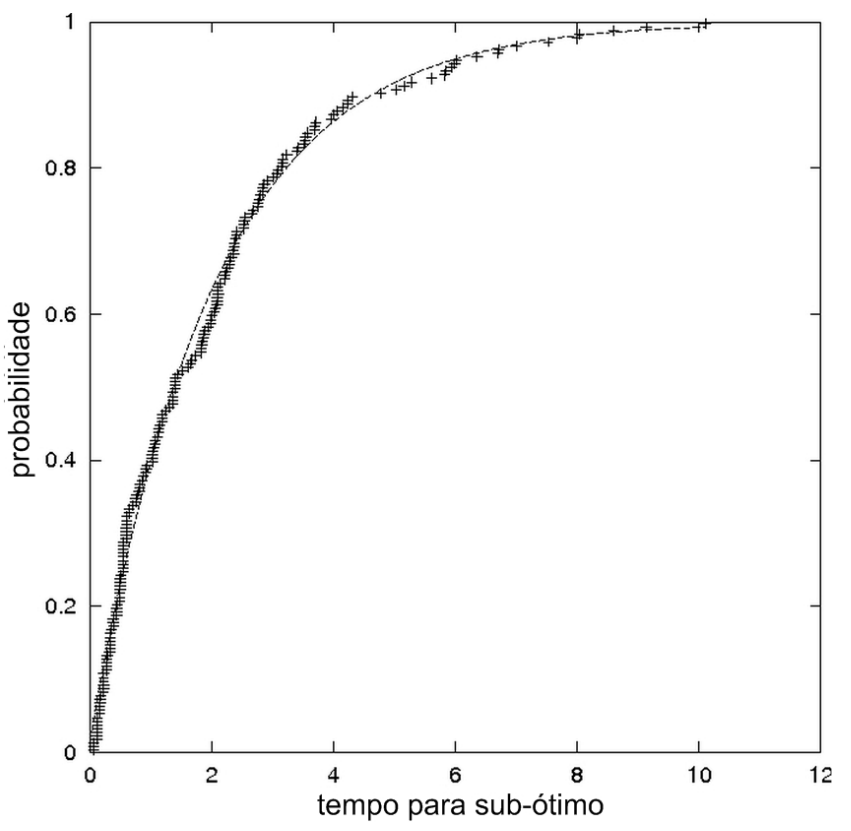

Figura 1. Distribuições teórica e empírica superpostas.

$\mathbb{C}=\left\{C_{1}, \ldots, C_{m}\right\}$. Cada cláusula $C_{i}$ é uma disjunção de $\left|C_{i}\right|$ literais, onde cada literal $l_{i j}$ é uma variável $x_{j}$ ou sua negação $\neg x_{j}$. Formalmente, escreve-se

$$
\Phi=\bigwedge_{i=1}^{m} C_{i}=\bigwedge_{i=1}^{m}\left(\bigvee_{j=1}^{\left|C_{i}\right|} l_{i j}\right)
$$

Uma cláusula é satisfeita se ao menos um dos seus literais é igual a 1 (verdadeiro). O que significa que alguma variável Booleana não negada é igual a 1 (um), ou alguma negada é igual a 0 (zero). A fórmula proposicional é dita estar satisfeita se todas as suas cláusulas são satisfeitas. No problema de satistafibilidade (satisfiability problem - SAT), deve-se decidir se existe uma atribuição de valores-verdade às variáveis tal que uma dada fórmula proposicional é satisfeita. SAT foi o primeiro problema a ser provado como NP-completo (Cook, 1971). O problema da máxima satisfatibilidade (maximum Satisfiability problem - MAX-SAT) é uma generalização do problema SAT onde, dada uma fórmula proposicional, deseja-se encontrar uma atribuição de valoresverdade às variáveis de modo a maximizar o número de cláusulas satisfeitas. Generalizando ainda mais, se for introduzido um peso positivo $w_{i}$ a cada cláusula $C_{i}$, então o problema MAX-SAT ponderado consiste em encontrar uma atribuição de valores-verdade às variáveis tal que a soma de pesos das cáusulas satisfeitas seja maximizada. O problema MAX-SAT tem diversas aplicações práticas e teóricas em áreas tais como teoria da complexidade, otimização combinatória e inteligência artificial (Battiti \& Protasi, 1998). É um problema intratável no sentido de que não existe um algoritmo que resolva o problema em tempo polinomial a menos que P $=$ NP (Garey \& Johnson, 1979).

\subsubsection{GRASP: fase construtiva}

$\mathrm{Na}$ fase de construção do algoritmo, descrita no Algoritmo 7, uma lista restrita de candidatos (LRC) é mantida contendo elementos correspondentes às atribuições de valores 1 (verdadeiro) ou 0 (falso) para variáveis ainda não atribuídas. Escolher um elemento a ser adicionado a uma solução parcial a partir da lista LRC corresponde a atualizar o respectivo valor verdade de uma dada variável. Dada uma solução parcial, a qual corresponde a um conjunto de cláusulas satisfeitas, deseja-se que o próximo elemento a ser adicionado a solução maximize o peso total das cláusulas não satisfeitas que passam a ser satisfeitas após a atribuição. Seja $N=\{1,2, \ldots, n\}$ e $M=\{1,2, \ldots, m\}$ os conjuntos de índices associados aos conjuntos de variáveis e cláusulas, respectivamente. Além disto, para $i \in N$, seja $\Gamma_{i}^{+}$o conjunto de cláusulas não satisfeitas que se tornariam satisfeitas se a variável $x_{i}$ fosse atualizada para verdadeiro, e $\Gamma_{i}^{-}$o conjunto de cláusulas não satisfeitas que se tornariam satisfeitas se a variável $x_{i}$ fosse atualizada para falso. Considere $\gamma_{j}^{+}$e $\gamma_{j}^{-}$o ganho no valor da função objetivo, se for atualizado o valor da variável não atribuída $x_{j}$ para 1 e 0 , respectivamente. Especificamente

$$
\gamma_{i}^{+}=\sum_{j \in \Gamma_{i}^{+}} w_{j} \text { e } \gamma_{i}^{-}=\sum_{j \in \Gamma_{i}^{-}} w_{j}
$$


Se $X \subseteq V$ é o conjunto das variáveis já atribuídas, computa-se o melhor ganho

$$
\gamma^{*}:=\max \left\{\gamma_{j}^{+}, \gamma_{j}^{-}: j \text { tal que } x_{j} \in V \backslash X\right\}
$$

e mantém-se no LRC apenas aquelas atribuições com $\gamma_{j}^{+}$e $\gamma_{j}^{-}$maiores ou iguais a $\alpha \cdot \gamma^{*}$ onde $0 \leq \alpha \leq 1$ é um parâmetro. Uma escolha aleatória a partir de LRC corresponde a uma nova atribuição $x_{s}=1\left(x_{s}=0\right)$, a qual é adicionada a solução parcial $X=X \cup\left\{x_{s}\right\}$. Após cada uma destas adições à solução parcial, os conjuntos $\Gamma_{i}^{+}, \Gamma_{i}^{-}$, assim como os ganhos $\gamma_{j}^{+}$e $\gamma_{j}^{-}$são atualizados, processo o qual é ilustrado no Algoritmo 7 , onde $s$ é o índice da variável já adicionada à solução e $L_{q}$ o conjunto dos índices das variáveis ainda não atribuídas pertencentes à cláusula $C_{q}$. Pode-se reconhecer dois casos possíveis. Se a variável já adicionada foi atualizada para verdadeiro então $\Gamma^{+}, \Gamma^{-}, \gamma^{+}$e $\gamma^{-}$são atualizadas nas linhas $5,8,12$, e 13, enquanto se a variável já atribuída foi atualizada para falso então $\Gamma^{+}, \Gamma^{-}, \gamma^{+}$e $\gamma^{-}$são atualizada nas linhas 19, 22, 26 e 27. O processo é repetido até $|X|=n$. Por fim, o parâmetro $\alpha$ reflete a razão de aleatoriedade versus gulosidade no processo de construção, onde $\alpha=1$ corresponde a pura seleção gulosa e $\alpha=0$ a uma pura seleção aleatória.

Dados: índice $s$.

Resultado: solução para MAX-SAT ponderado.

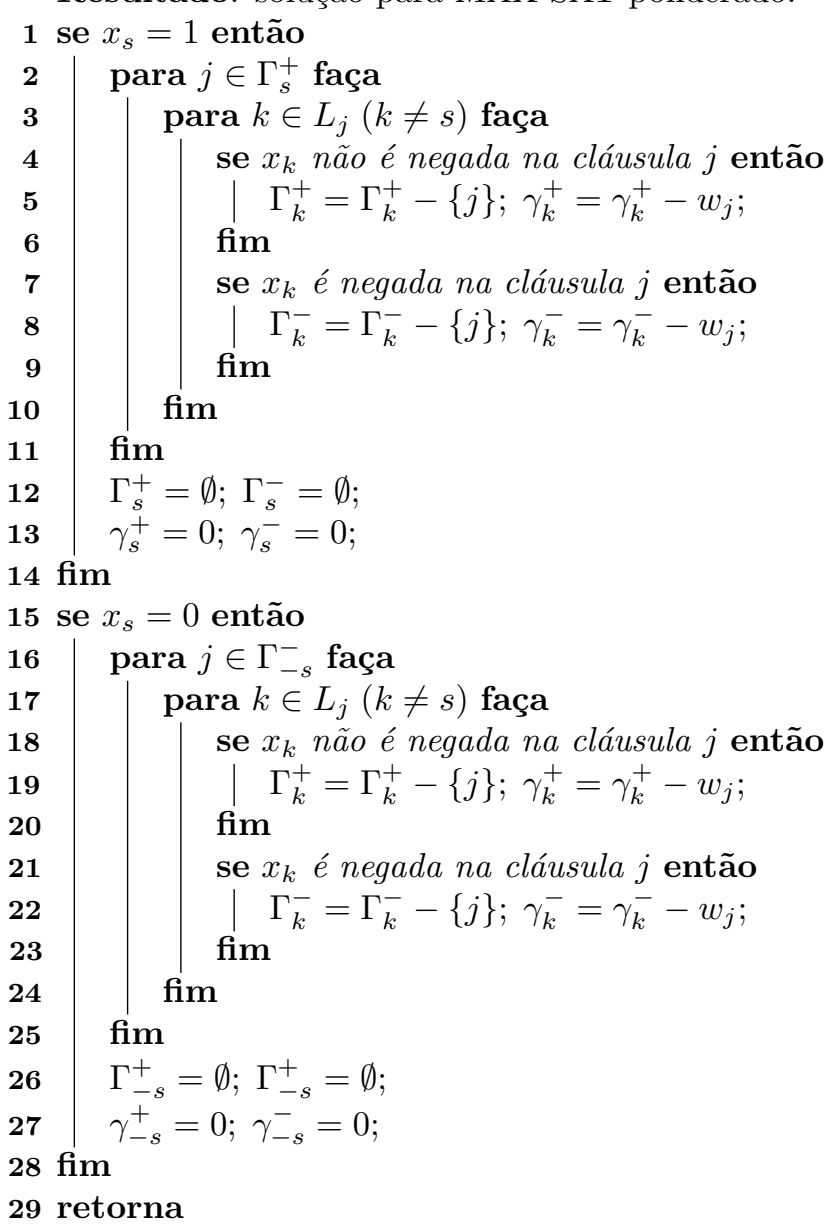

Algoritmo 7: Pseudo-código da função gulosa da fase construtiva do GRASP-PR aplicada ao problema MAX-SAT ponderado.

\subsubsection{GRASP: busca Local}

A vizinhança 1-flip é usada na busca-local, a qual é definida como segue:

$$
N_{1}(\mathbf{x}):=\left\{\mathbf{y} \in\{0,1\}^{n}: d(\mathbf{x}, \mathbf{y})=1\right\} .
$$

onde $\mathbf{x}$ é um máximo local se e somente se $c(\mathbf{x}) \geq c(\mathbf{y})$ para todo $\mathbf{y} \in N_{1}(\mathbf{x})$. Uma implementação direta do procedimento da busca local requereria $\left|N_{1}\right|=n$ avaliações de função para encontrar a melhor solução em 
uma dada vizinhança, onde cada avaliação computaria a soma dos pesos das cláusulas satisfeitas. Se deseja-se encontrar um máximo local, pode-se precisar de um número exponencial de passos computacionais (Johnson et al., 1988; Krentel, 1988). Entretanto, pode-se explorar a estrutura da vizinhança para reduzir o esforço computacional.

Dada uma solução inicial x defina $G_{i}$ como o ganho em peso total resultante da variável $x_{i}$ em $\mathbf{x}$, para todo $i$. Seja $k$ tal que $G_{k}=\max \left\{G_{i} \mid i \in N\right\}$. Se $G_{k}=0$ então x é o máximo local e a busca local termina. Caso contrário, a atribuição verdade resultante de $x_{k}$ em x é um máximo local e, portanto, é preciso apenas atualizar os valores $G_{i}$ tal que a variável $x_{i}$ ocorra na cáusula na qual $x_{k}$ ocorra, pois os valores restantes $G_{i}$ não mudam na nova atribuição verdade.

Após a atualização dos valores $G_{i}$, repete-se o mesmo processo até $G_{k}=0$ onde o procedimento da busca local é terminado. O procedimento é descrito no pseudo-código do Algoritmo 8. Dada uma atribuição verdade x e um índice $k$ correspondente a variável $x_{k}$, o procedimento GerarGanhos é usado para atualizar os valores $G_{i}$ retornados em um array $G$. Note que na linha $2, k=0$ é passado à procedure desde que inicialmente todos os valores de $G_{i}$ sejam gerados (por convenção a variável $x_{0}$ ocorre em todas as cláusulas). Nas linhas 4 até 8, o procedimento encontra um máximo local, cujo valor é salvo na linha 9.

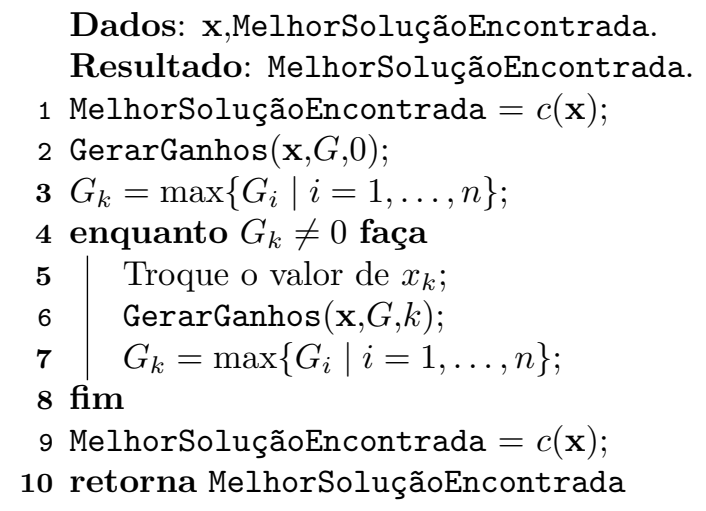

Algoritmo 8: Pseudo-código do procedimento da Busca Local do GRASP-PR aplicado ao problema MAX-SAT ponderado

\subsubsection{Religamento de caminhos}

Seja $\mathbf{x}$ uma solução inicial, y a solução alvo, $\mathcal{E}$ o conjunto elite cujo tamanho não exceda MaxElite. Denota-se o conjunto de soluções gerado pelos elementos comuns de $\mathbf{x}$ e $\mathbf{y}$ como:

$$
S(\mathbf{x}, \mathbf{y}):=\left\{\mathbf{w} \in\{0,1\}^{n}: w_{i}=x_{i}=y_{i}, i \notin \Delta(\mathbf{x}, \mathbf{y})\right\} \backslash\{\mathbf{x}, \mathbf{y}\}
$$

onde é evidente que $|S(\mathbf{x}, \mathbf{y})|=2^{d(\mathbf{x}, \mathbf{y})}-2$. Levando-se em consideração que o tamanho deste espaço é exponencialmente grande, empregar-se-à uma busca gulosa onde o caminho de soluções

$$
\mathbf{x}=\mathbf{w}_{0}, \mathbf{w}_{1}, \ldots, \mathbf{w}_{d(\mathbf{x}, \mathbf{y})}, \mathbf{w}_{d(\mathbf{x}, \mathbf{y})+1}=\mathbf{y}
$$

é construído, tal que $d\left(\mathbf{w}_{i}, \mathbf{w}_{i+1}\right)=1, \quad i=0, \ldots, d(\mathbf{x}, \mathbf{y})$, e a melhor solução oriunda deste caminho é escolhida. Desde que ambas $\mathbf{x}, \mathbf{y}$ são máximos locais em alguma vizinhança $N_{1}$ oriundos da fase construtiva, com o intuito de $S(\mathbf{x}, \mathbf{y})$ possuir soluções não contidas nas vizinhanças de $\mathbf{x}$ ou $\mathbf{y}$ nós deve-se ter $d(\mathbf{x}, \mathbf{y})>3$. Portanto, não é preciso aplicar o religamento de caminhos entre duas soluções que não sejam suficientemente distantes entre si, desde que uma nova solução melhor que ambas x e y não será encontrada.

O pseudo-código do religamentos dos caminhos para o problema da máxima satisfatibilidade ponderada é mostrado no Algoritmo 9. Considerando-se que a solução inicial sempre será uma solução do conjunto elite, enquanto a alvo é oriunda da iteração GRASP, então uma maior liberdade na busca sobre a vizinhança ao redor da solução elite. Na linha 1, uma solução inicial x é selecionada aleatoriamente dentre os elementos do conjunto elite, a qual suficientemente difere da solução alvo y. Na linha 2, a solução inicial é atualizada como $\mathbf{w}_{0}$, e na linha $3 \mathrm{x}$ é salva como a melhor solução. O loop da linha 4 a 17 computa um caminho de soluções $\mathbf{w}_{1}, \mathbf{w}_{2}, \ldots, \mathbf{w}_{d(\mathbf{x}, \mathbf{y})-2}$, e a solução com o melhor valor da função objetivo é retornado na linha 18 . Isto é obtido avançando uma solução por vez de modo guloso, como ilustrado da linha 6 a 12, enquanto a operação $\operatorname{flip}\left(\mathbf{w}_{k}, i\right)$ tem o efeito de negar a variável $w_{i}$ na solução $\mathbf{w}_{k}$. Cabe observar que o caminho nunca entra na vizinhança de $\mathbf{y}$. 
Dados: $p, \mathcal{E}=\{$ conjunto discreto finito $\}$.

Resultado: máximo local $\mathbf{w}^{*}$.

1 Aleatoriamente selecione uma solução $\mathbf{x} \in\{\mathbf{z} \in \mathcal{E}: d(\mathbf{y}, \mathbf{z})>4\}$;

$\mathbf{2} \mathbf{w}_{0}:=\mathbf{x}$

$3 \mathrm{w}^{*}:=\mathrm{x}$

4 para $k=0, \ldots, d(\mathbf{x}, \mathbf{y})-2$ faça

$5 \mid \max :=0$

$6 \quad$ para $i \in \Delta\left(\mathbf{w}_{k}, \mathbf{y}\right)$ faça

$7 \quad \mathbf{w}:=\mathrm{flip}\left(\mathbf{w}_{k}, i\right)$

$8 \quad$ se $c(\mathbf{w})>\max$ então

9
10
11 $\quad \quad \begin{aligned} & i^{*}:=i ; \\ & \max :=c(\mathbf{w})\end{aligned}$

12 fim

$13 \quad \mathbf{w}_{k+1}:=\mathrm{f} \operatorname{lip}\left(\mathbf{w}_{k}, i^{*}\right)$;

$14 \quad$ se $c\left(\mathbf{w}_{k+1}\right)>c\left(\mathbf{w}^{*}\right)$ então

$15 \quad \mathbf{w}^{*}:=\mathbf{w}_{k+1}$;

16 fim

17 fim

18 retorna $\mathrm{w}^{*}$

Algoritmo 9: Pseudo-código do religamento de caminhos do GRASP-PR aplicado ao problema MAXSAT ponderado.

Na integração do procedimento de religamento de caminhos com GRASP, o conjunto elite de soluções é inicializado vazio e até ele alcançar sua capacidade máxima nenhum religamento de caminhos é realizado. Após uma solução y ser encontrada pelo GRASP, ela é passada para o procedimento do religamento de caminhos para gerar outra solução. Cabe observar que a mesma solução y pode ser obtida após o religamento de caminhos. Uma solução y é adicionada ao conjunto elite se alguma das seguintes condições for satisfeita:

1. $c(\mathbf{y})>\max \{c(\mathbf{w}): \mathbf{w} \in \mathcal{E}\}$,

2. $c(\mathbf{y})>\min \{c(\mathbf{w}): \mathbf{w} \in \mathcal{E}\}$ e $d(\mathbf{y}, \mathbf{w})>\beta n, \forall \mathbf{w} \in \mathcal{E}$, onde $\beta$ é um parâmetro entre 0 e 1 , com $n$ sendo o número de variáveis.

Se $\mathbf{y}$ satisfaz uma das condições acima, ela então repõe uma solução elite $\mathbf{z}$ de peso não maior que $c(\mathbf{y})$ e mais similar a $\mathbf{y}$, i.e. $\mathbf{z}=\operatorname{argmin}\{d(\mathbf{y}, \mathbf{w}): \mathbf{w} \in \mathcal{E}$ such that $c(\mathbf{w}) \leq c(\mathbf{y})\}$.

\subsection{Problemas de atribuição: atribuição quadrática generalizada (Mateus et al., 2011).}

O problema da atribuição quadrática generalizada (generalized quadratic assignment problem - GQAP) (Savelsbergh, 1997; Ross \& Soland, 1975; Elloumi et al., 2003; Lee \& Ma, 2005; Cordeau et al., 2006; Hahn et al., 2008) é uma generalização do problema NP-Difícil da atribuição quadrática (quadratic assignment problem - QAP) (Oliveira et al., 2004b; Pardalos et al., 1994; Li et al., 1994) em que múltiplas instalações (facilities) podem ser atribuídas a uma mesma localidade, na medida em que a capacidade destas localidades permitam.

Seja $N=\{1, \ldots, n\}$ um conjunto de instalações (facilities) e $M=\{1, \ldots, m\}$ um conjunto de localidades. Além disto, denote por:

- $A_{n \times n}=\left(a_{i i^{\prime}}\right)$, o fluxo entre as instalações $i \in N$ e $i^{\prime} \in N$, tal que $a_{i i^{\prime}} \in \Re^{+}$, se $i \neq i^{\prime}$, e $a_{i i^{\prime}}=0$, em caso contrário;

- $B_{m \times m}=\left(b_{j j^{\prime}}\right)$, a distância entre as localidades $j \in M$ e $j^{\prime} \in M$, tal que $b_{j j^{\prime}} \in \Re^{+}$, se $j \neq j^{\prime}$, e $b_{j j^{\prime}}=0$, em caso contrário;

- $C_{n \times m}=\left(c_{i j}\right)$, o custo de atribuir a instalação $i \in N$ à localidade $j \in M$, tal que $c_{i j} \in \Re^{+}$;

- $z \in \Re^{+}$, um fator de escala denominado custo por unidade de tráfego;

- $q_{i} \in \Re^{+}$, a capacidade demandada pela instalação $i \in N$ e

- $Q_{j} \in \Re^{+}$, a capacidade da localização $j \in M$. 
O problema da atribuição quadrática generalizada (Savelsbergh, 1997; Ross \& Soland, 1975; Elloumi et al., 2003; Lee \& Ma, 2005; Cordeau et al., 2006; Hahn et al., 2008) consiste em encontrar $X_{n \times m}=\left(x_{i j}\right)$, com $x_{i j}=\{0,1\}$, onde a instalação $i \in N$ é atribuída a localidade $j \in M$ se e somente se $x_{i j}=1$, de modo que as restrições

$$
\begin{gathered}
\sum_{j \in M} x_{i j}=1, \forall i \in N, \\
\sum_{i \in N} q_{i} x_{i j} \leq Q_{j}, \forall j \in M, \\
x_{i j} \in\{0,1\}, \forall i \in N, \forall j \in M
\end{gathered}
$$

sejam satisfeitas e a função objetivo

$$
\sum_{i \in N} \sum_{j \in M} c_{i j} x_{i j}+z \sum_{i \in N} \sum_{j \in M} \sum_{i^{\prime} \in N, i^{\prime} \neq i} \sum_{j^{\prime} \in M} a_{i i^{\prime}} b_{j j^{\prime}} x_{i j} x_{i^{\prime} j^{\prime}}
$$

minimizada. A restrição (3) garante que cada instalação seja atribuída a exatamente uma localidade, enquanto a restrição (4) garante que a capacidade das localidades não sejam violadas.

\subsubsection{GRASP: fase construtiva}

Suponha uma solução parcial do problema da atribuição quadrática generalizada, ou seja, que um número de atribuições já tenham sido realizadas. Para realizar a próxima atribuição, o procedimento precisa selecionar uma nova instalação e uma localidade. Localidades são disponibilizadas uma de cada vez. O procedimento aleatoriamente determina se é para usar uma nova localidade ou uma localidade previamente escolhida, favorecendo a nova localidade quanto mais as previamente selecionadas tenham capacidades disponíveis praticamente insuficientes. Se o procedimento determina que uma localidade previamente selecionada deva ser escolhida, então selecionam-se as instalações que podem ser atribuídas a localidade de máxima capacidade disponível, para em seguida escolher aleatoriamente uma instalação dentre estas. Das localidades que podem acomodar esta instalação, uma é selecionada aleatoriamente e a atribuição é realizada. Por outro lado, se não existem localidades, dentre as já selecionadas, com capacidade suficiente para acomodar uma instalação, uma nova localidade é selecionada aleatoriamente a partir do conjunto das localidades ainda não selecionadas. Como o todo o procedimento acima descrito não garante a produção de uma solução viável, o mesmo é repetido um número máximo de vezes até terminar com uma atribuição válida, ou com uma solução inviável.

A Figura 2 ilustra este procedimento. Na figura, o conjunto $N$ de instalações é particionado entre o conjunto $C F$ de instalações atribuídas e o conjunto $F$ das instalações não atribuídas. Da mesma forma, o conjunto $M$ das localidades é particionado entre o conjunto $C L$ das localidades previamente selecionadas e o conjunto $L$ das localidades não selecionadas. As instalações em $C F$ devem ser atribuídas as localidades em $C L$. O subconjunto de instalações $T$ consiste de todas as instalações não atribuídas com demanda menor ou igual à máxima capacidade disponível dentre as localidades em $C L$. Após uma instalação a partir de $T$ ser aleatoriamente selecionada, o conjunto $R$ consiste de todas as localidades previamente selecionadas capazes de acomodá-lo. Em seguida, uma localidade aleatoriamente selecionada a partir de $R$ recebe esta instalação.

\subsubsection{GRASP: busca local aproximada}

O procedimento construtivo da Seção 7.2.1 produz uma solução viável $p$ que não é garantida ser localmente ótima. Um procedimento de busca local é aplicado de início a $p$ com o intuito de encontrar um mínimo local aproximado. O procedimento de busca local faz uso de duas estruturas de vizinhança denominadas 1-move e 2move. Uma solução na vizinhança 1-move de $p$ é obtida pela mudança de uma atribuição instalação-localidade em $p$. De modo semelhante, uma solução pertencente à vizinhança 2-move de $p$ se dá pela mudança simultânea de duas atribuições instalação-localidade em $p$.

Uma maneira de realizar uma busca local nestas vizinhanças consiste em avaliar movimentos na vizinhança 1-move até encontrar o primeiro movimento que melhore a solução atual. Caso não exista nenhum movimento de melhoria na vizinhança 1-move, soluções pertencentes à vizinhança 2-move são avaliadas até também encontrar o primeiro movimento que melhore a solução atual, caso exista. Outra maneira de realizar uma busca local é avaliar todas as soluções na vizinhança 1-move e 2-move a fim de se mover para a melhor solução de melhoria, caso exista. Em ambas variantes, a busca é repetida até que nenhuma solução de melhoria na vizinhança exista. Neste trabalho, um enfoque intermediário para busca local foi proposto.

Ao invés de avaliar todas as soluções presentes nas vizinhanças 1-move e 2-move, estas são amostradas a fim de povoar uma lista de candidatos com soluções de melhoria. A seguir, uma solução desta lista é selecionada aleatoriamente e um movimento é realizado para aquela solução. A busca é repetida até que não 


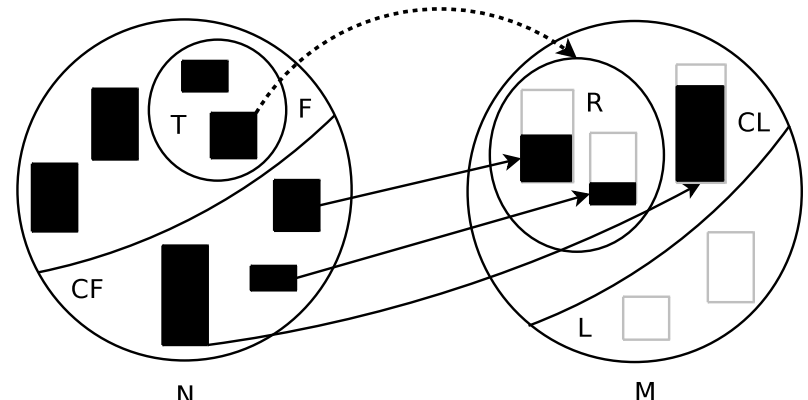

Figura 2. Ilustração de uma etapa da fase construtiva do método GRASP para o problema da atribuição quadrática generalizada.

exista nenhuma solução de melhoria amostrada. Dado que as soluções são amostradas, nem todos os vizinhos podem ser avaliados. Consequentemente, a melhor solução encontrada pode não ser um mínimo local. Por este motivo esta solução é denominada de mínimo local aproximado.

O pseudo-código para a busca local aproximada é descrito no Algoritmo 10. O procedimento toma como entrada a solução inicial $\pi$ e dois parâmetros, MaxCLS e MaxItr, responsáveis por controlar o processo de amostragem.

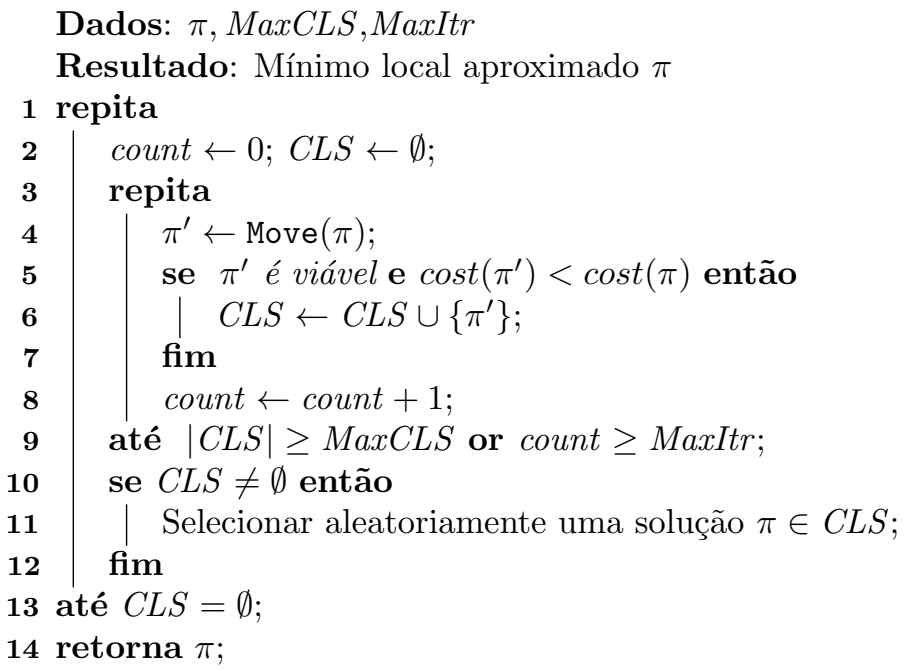

Algoritmo 10: Pseudo-código da busca local aproximada do GRASP para o problema da atribuição quadrática generalizada.

O loop entre as linhas 1 e 13 é repetido até um mínimo local aproximado ser produzido. Na linha 2, o contador da amostragem count e a lista de candidatos $C L S$ são inicializadas. A cada iteração do loop interno situado entre as linhas 3 e 9, as vizinhanças 1-move e 2-move de $\pi$ são amostradas sem reposição pelo procedimento $\operatorname{Move}(\pi)$ da linha 4 . Se este vizinho é uma solução viável de melhoria, ele é inserido em $C L S$ como descrito na linha 6. Este procedimento é repetido até que a lista de candidatos esteja cheia, ou até que um número máximo de vizinhos tenha sido amostrado. Entre as linhas 10 e 12, se a lista de candidato não estiver vazia, uma atribuição $\pi \in C L S$ é aleatoriamente escolhida. Se o conjunto $C L S$ estiver vazio após o processo de amostragem, então o procedimento termina retornando $\pi$ como um mínimo local aproximado (ver linha 14). Caso contrário, o procedimento se move para outra solução em $C L S$, repetindo o loop mais externo.

\subsubsection{Religamento de caminhos}

Motivado pelo fato de que um simples movimento de uma solução $x$ na direção da solução alvo $x_{t}$ não garante a viabilidade da nova solução construída, uma nova variante de religamento de caminhos foi proposta por Mateus et al. (2011).

Suponha que dentre as diferenças entre $x$ e $x_{t}$ encontra-se a localidade atribuída à instalação $f$. Em outras palavras, enquanto a localidade atribuída a $f$ em $x_{t}$ é $l$, a localidade atribuída a $f$ em $x$ é $u, \operatorname{com} l \neq u$. Neste 
caso, não é necessariamente viável realizar um movimento em $x$ que atribua $f$ a $l$. Se a capacidade $Q_{l}$ não é violada, então a nova solução é viável. Caso contrário, um procedimento de reparo deve ser aplicado para tentar tornar a solução viável, como descrito na Figura 3.

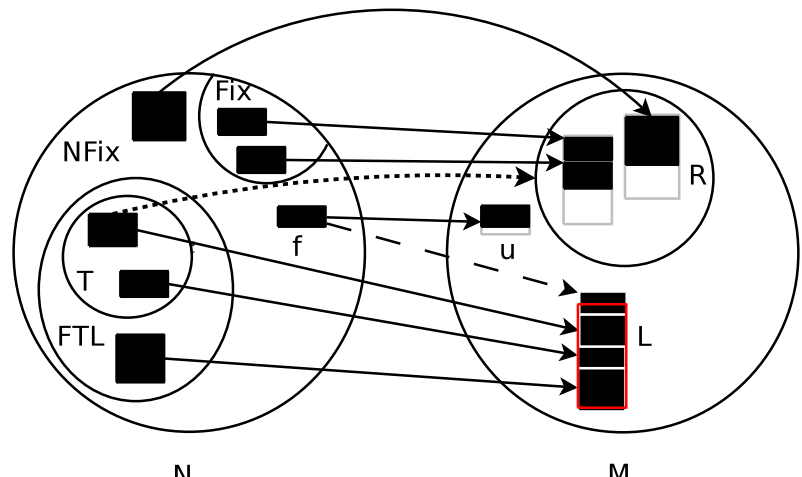

Figura 3. Reparo no religamento de caminhos do GRASP para o problema da atribuição quadrática generalizada.

Neste procedimento de reparo, um conjunto $F T L$ de instalações é criado com todas as instalações ainda não fixadas atribuídas a localidade $l$ cuja capacidade foi violada. Em seguida, o conjunto $T \subseteq F T L$ é construído com todas as instalações em FTL cujas demandas são menores ou iguais a capacidade máxima disponível dentre as localidades em $M$. Após uma instalação de $T$ ser aleatoriamente selecionada, o conjunto $R$ consiste das localidades em $M$ capazes de acomodar esta instalação. Depois uma localidade é selecionada a partir do conjunto $R$ e a instalação é atribuída a ela. Este processo é repetido até que a capacidade da localidade $l$ tenha uma folga não negativa.

Seja $\pi$ uma solução intermediária obtida durante o religamento de caminhos de $\pi_{s}$ a $\pi_{t}$, como ilustrado na Figura 3. O conjunto de instalações $N$ é particionado em dois conjuntos, Fix com as instalações fixadas e nonFix com as instalações restantes. Seja $f \in$ nonFix uma instalação cuja localidade em $\pi_{t}$ é $l$ e em $\pi$ é $u \neq l$, onde $l, u \in M$.

De acordo com a Figura 3, realizar um movimento em $\pi$ que atribui a instalação $f$ na localidade $l$ é inviável, desde que a capacidade $Q_{l}$ da localidade $l$ é insuficiente para acomodar esta instalação. Neste caso, o conjunto de instalações $F T L \subseteq$ nonFix é criado com todas as instalações não fixadas atribuídas a $l$ em $\pi$. Em seguida, o conjunto $T \subseteq F T L$ é construído com todas as instalações em $F T L$ com demandas no máximo igual à máxima capacidade disponível entre as localidades em $M$. Seja $i$ a instalação aleatoriamente selecionada a partir de $T$ e $R$ o conjunto com as localidades de $M$ capazes de acomodar a instalação $i$. Depois, uma localidade $j$ é selecionada aleatoriamente a partir do conjunto $R$ e a instalação $i$ é atribuída a ela. Este processo é repetido até que a capacidade da localidade $l$ tenha uma folga não negativa.

Sabe-se que o processo de religamento de caminhos é uma sequência de passos de $x_{s}$ para $x_{t}$. A cada passo, um movimento é realizado da solução atual $x$ com ou sem reparo. Depois, uma instalação $i$ é selecionada aleatoriamente a partir do conjunto composto de todas as instalações ainda não fixadas corrigidas no passo. Uma instalação é dita corrigida quando a localidade a qual foi atribuída torna-se a mesma atribuída a ela na solução alvo $x_{t}$. Após a instalação $i$ ser fixada, o próximo passo é iniciado. Este processo continua até a solução alvo $x_{t}$ ser alcançada ou quando nenhuma solução viável é obtida de $x$.

Este religamento de caminhos é diferente da variante pardão porque dado as soluções $x_{s}$ e $x_{t}$, seus elementos comuns não são mantidos fixos a priori, de modo a uma pequena porção do espaço de soluções gerado pelos elementos restantes ser explorada. Nesta nova variante, uma instalação é fixada por vez a cada passo do religamento de caminhos.

\section{Conclusões}

Este capítulo considerou os componentes estruturais básicos necessários para projetar heurísticas baseadas nos princípios que regem a meta-heurística GRASP. Estes componentes incluem esquemas de construção aleatórios, procedimentos de busca local e a introdução de estruturas de memória através do religamento de caminhos. Um tópico importante abordado neste capítulo é o GRASP paralelo, além de exemplos de aplicações da meta-heurística GRASP nas áreas de lógica e atribuição. O leitor interessado é direcionado ao artigo de Resende \& Ribeiro (2005b). 


\section{Agradecimentos}

A pesquisa de Ricardo M.A Silva foi parcialmente realizada durante seu pós-doutoramento na AT\&T Labs Research em Florham Park, New Jersey, EUA; e parcialmente financiada pelo Conselho Nacional de Desenvolvimento Científico e Tecnológico $(\mathrm{CNPq})$, pela Fundação de Amparo à Pesquisa do Estado de Minas Gerais (FAPEMIG), pela Coordenação de Aperfeiçoamento de Pessoal de Nível Superior (CAPES), e pela Pró-reitoria de Pesquisa da Universidade Federal de Pernambuco (PROPESQ).

\section{Referências}

Abdinnour-Helm, S. \& Hadley, S., Tabu search based heuristics for multi-floor facility layout. International Journal of Production Research, 38:365-383, 2000.

Ahuja, R.K.; Ergun, O.; Orlin, J.B. \& Punnen, A.P., A survey of very large-scale neighborhood search techniques. Discrete and Applied Mathematics, 123:75-102, 2002.

Ahuja, R.K.; Orlin, J.B. \& Sharma, D., Multi-exchange neighborhood structures for the capacitated minimum spanning tree problem. Mathematical Programming, Ser A, 91:71-97, 2001.

Aiex, R.; Pardalos, P.; Resende, M. \& Toraldo, G., GRASP with path-relinking for three-index assignment. INFORMS Journal on Computing, 17:224-247, 2005.

Aiex, R.M.; Resende, M.G.C. \& Ribeiro, C.C., Probability distribution of solution time in GRASP: An experimental investigation. Journal of Heuristics, 8:343-373, 2002.

Andrade, D. \& Resende, M., A GRASP for PBX telephone migration scheduling. In: Proceedings of The Eighth INFORMS Telecommunications Conference. 2006.

Battiti, R. \& Protasi, M., Approximate algorithms and heuristics for the MAX-SAT. In: Du, D. \& Pardalos, P. (Eds.), Handbook of Combinatorial Optimization. Boston, USA: Kluwer Academic Publishers, v. 1, p. 77-148, 1998.

Baum, E.B., Iterated descent: A better algorithm for local search in combinatorial optimization problems. Technical Report, California Institute of Technology, Pasadena, USA, 1986.

Baum, E.B., Towards practical 'neural' computation for combinatorial optimization problems. In: AIP Conference Proceedings 151 on Neural Networks for Computing. Woodbury, USA: American Institute of Physics Inc., p. 53-58, 1987.

Baxter, J., Local optima avoidance in depot location. Journal of the Operational Research Society, 32:815-819, 1981.

Beltrán, J.D.; Calderón, J.E.; Cabrera, R.J.; Pérez, J.A.M. \& Moreno-Vega, J.M., GRASP/VNS hybrid for the strip packing problem. In: Proceedings of Hybrid Metaheuristics. p. 79-90, 2004.

Bresina, J.L., Heuristic-biased stochastic sampling. In: Proceedings of the AAAI-96. p. 271-278, 1996.

Canuto, S.; Resende, M. \& Ribeiro, C., Local search with perturbations for the prize-collecting Steiner tree problem in graphs. Networks, 38:50-58, 2001.

Charon, I. \& Hudry, O., The noising method: A new method for combinatorial optimization. Operations Research Letters, 14:133-137, 1993.

Charon, I. \& Hudry, O., The noising methods: A survey. In: Ribeiro, C.C. \& Hansen, P. (Eds.), Essays and Surveys in Metaheuristics. Boston, USA: Kluwer Academic Publishers, p. 245-261, 2002.

Cook, S.A., The complexity of theorem-proving procedures. In: Proceedings of the Third annual ACM Symposium on Theory of Computing. p. 151-158, 1971.

Cordeau, J.F.; Gaudioso, M.; Laporte, G. \& Moccia, L., A memetic heuristic for the generalized quadratic assignment problem. INFORMS Journal on Computing, 18:433-443, 2006.

de la Peña, M.G.B., Heuristics and metaheuristics approaches used to solve the rural postman problem: A comparative case study. In: Proceedings of the Fourth International ICSC Symposium on Engineering of Intelligent Systems. 2004.

Delmaire, H.; Díaz, J.A.; Fernández, E. \& Ortega, M., Reactive GRASP and Tabu Search based heuristics for the single source capacitated plant location problem. INFOR, 37(3):194-225, 1999.

Drummond, L.; Vianna, L.S.; Silva, M.B. \& Ochi, L.S., Distributed parallel metaheuristics based on GRASP and VNS for Solving the traveling purchaser problem. In: Proceedings of the Ninth International Conference on Parallel and Distributed Systems. p. 257-266, 2002.

Duarte, A.; Ribeiro, C.C. \& Urrutia, S., A hybrid ILS heuristic to the referee assignment problem with an embedded MIP strategy. In: Bartz-Bielstein, T.; Aguilera, M.J.B.; Blum, C.; Naujoks, B.; Role, A.; Rudolph, G. \& Sampels, M. (Eds.), Hybrid Metaheuristics. v. 4771 de LNCS, p. 82-95, 2007a.

Duarte, A.R.; Ribeiro, C.C.; Urrutia, S. \& Haeusler, E.H., Referee assignment in sports leagues. In: Burke, E.K. \& Rudova, H. (Eds.), Proceedings of the 6th International Conference on Practice and Theory of Automated Timetabling. v. 3867 de LNCS, p. 158-173, 2007b.

Elloumi, S.; Roupin, F. \& Soutif, E., Comparison of Different Lower Bounds for the Constrained Module Allocation Problem. Technical Report CEDRIC-03-473, CNAM, CEDRIC Laboratory, Paris, France, 2003.

Feo, T.A. \& Resende, M.G.C., A probabilistic heuristic for a computationally difficult set covering problem. Operations Research Letters, 8:67-71, 1989. 
Feo, T.A. \& Resende, M.G.C., Greedy randomized adaptive search procedures. Journal of Global Optimization, 6:109133, 1995.

Festa, P.; Pardalos, P.; Resende, M. \& Ribeiro, C., Randomized heuristics for the MAX-CUT problem. Optimization Methods and Software, 7:1033-1058, 2002.

Festa, P.; Pardalos, P.M.; Pitsoulis, L.S. \& Resende, M.G.C., GRASP with path-relinking for the weighted MAXSAT problem. Journal of Experimental Algorithmics, 11, 2007Article 2.4: 1-16.

Festa, P. \& Resende, M., GRASP: An annotated bibliography. In: Ribeiro, C. \& Hansen, P. (Eds.), Essays and Surveys in Metaheuristics. Kluwer Academic Publishers, p. 325-367, 2002.

Festa, P. \& Resende, M., An annotated bibliography of GRASP, Part I: Algorithms. International Transactions in Operational Research, 16:1-24, 2009a.

Festa, P. \& Resende, M., An annotated bibliography of GRASP, Part II: Applications. International Transactions in Operational Research, 16:131-172, 2009b.

Festa, P. \& Resende, M.G.C., GRASP: An annotated bibliography. In: Hansen, P. \& Ribeiro, C.C. (Eds.), Essays and Surveys on Metaheuristics. Boston, USA: Kluwer Academic Publishers, 2001.

Fleurent, C. \& Glover, F., Improved constructive multistart strategies for the quadratic assignment problem using adaptive memory. INFORMS Journal on Computing, 11:198-204, 1999.

Garey, M.R. \& Johnson, D.S., Computers and intractability: A guide to the theory of NP-completeness. New York, USA: W.H. Freeman and Company, 1979

Geng, Y.; Li, Y. \& Lim, A., A very large-scale neighborhood search approach to capacitated warehouse routing problem. In: 17th IEEE International Conference on Tools with Artificial Intelligence. IEEE Computer Society, p. 8, 2005.

Glover, F., Tabu search - Part I. ORSA Journal on Computing, 1:190-206, 1989.

Glover, F., Tabu search - Part II. ORSA Journal on Computing, 2:4-32, 1990.

Glover, F., Tabu search and adaptive memory programing - Advances, applications and challenges. In: Barr, R.S.; Helgason, R.V. \& Kennington, J.L. (Eds.), Interfaces in Computer Science and Operations Research. Kluwer Academic, p. 1-75, 1996.

Glover, F., Multi-start and strategic oscillation methods - Principles to exploit adaptive memory. In: Laguna, M. \& Gonzáles-Velarde, J.L. (Eds.), Computing Tools for Modeling, Optimization and Simulation: Interfaces in Computer Science and Operations Research. Kluwer Academic, p. 1-24, 2000.

Glover, F. \& Laguna, M., Tabu Search. Kluwer Academic, 1997.

Glover, F.; Laguna, M. \& Martí, R., Fundamentals of scatter search and path relinking. Control and Cybernetics, 29(3):653-684, 2000.

Goemans, M.X. \& Williamson, D.P., The primal dual method for approximation algorithms and its application to network design problems. In: Hochbaum, D. (Ed.), Approximation algorithms for NP-hard problems. Boston, USA: PWS Publishing Co., p. 144-191, 1996.

Hahn, P.M.; Kim, B.J.; Guignard, M.; MacGregor Smith, J. \& Zhu, Y.R., An algorithm for the generalized quadratic assignment problem. Computational Optimization and Applications, 40(3):351-372, 2008.

Hansen, P. \& Mladenović, N., An introduction to variable neighborhood search. In: Voss, S.; Martello, S.; Osman, I.H. \& Roucairol, C. (Eds.), Meta-heuristics, Advances and trends in local search paradigms for optimization. Dordrecht, The Netherlands: Kluwer Academic Publishers, p. 433-458, 1998.

Hart, J.P. \& Shogan, A.W., Semi-greedy heuristics: An empirical study. Operations Research Letters, 6:107-114, 1987.

Johnson, D.S., Local optimization and the traveling salesman problem. In: Proceedings of the 17th Colloquium on Automata. Berlin, Germany: Springer-Verlag, v. 443 de LNCS, p. 446-461, 1990.

Johnson, D.S.; Papadimitriou, C.H. \& Yannakakis, M., How easy is local search? Journal of Computer and System Sciences, 37:79-100, 1988.

Kirkpatrick, S.; Gelatt, Jr., C. \& Vecchi, M., Optimization by simulated annealing. Science, 220(4598):671-680, 1983.

Krentel, M., The complexity of optimization problems. Journal of Computer and System Sciences, 36, 1988.

Laguna, M. \& González-Velarde, J.L., A search heuristic for just-in-time scheduling in parallel machines. Journal of Intelligent Manufacturing, 2:253-260, 1991.

Laguna, M. \& Martí, R., GRASP and path relinking for 2-layer straight line crossing minimization. INFORMS Journal on Computing, 11:44-52, 1999.

Lee, C.G. \& Ma, Z., The generalized quadratic assignment problem. Technical Report MIEOR TR2005-01, Department of Mechanical and Industrial Engineering at the University of Toronto, 2005.

Li, Y.; Pardalos, P. \& Resende, M., A greedy randomized adaptive search procedure for the quadratic assignment problem. In: Pardalos, P. \& Wolkowicz, H. (Eds.), Quadratic assignment and related problems. New Providence, USA: American Mathemaical Society, v. 16 de DIMACS Series in Discrete Matehematics and Theoretical Computer Science, p. 237-261, 1994. 
Li, Z.; Guo, S.; Wang, F. \& Lim, A., Improved GRASP with tabu search for vehicle routing with both time window and limited number of vehicles. In: Orchard, B.; Yang, C. \& Ali, M. (Eds.), Innovations in Applied Artificial Intelligence - Proceedings of the 17th International Conference on Industrial and Engineering Applications of Artificial Intelligence and Expert Systems. Heidelberg, Germany: Springer-Verlag, v. 3029 de LNCS, p. 552-561, 2004.

Lim, A. \& Wang, F., A smoothed dynamic tabu search embedded GRASP for m-VRPTW. In: Proceedings of the 16th IEEE International Conference on Tools with Artificial Intelligence. Boca Raton, USA, p. 704-708, 2004.

Liu, X.; Pardalos, P.; Rajasekaran, S. \& Resende, M., A GRASP for frequency assignment in mobile radio networks. In: Badrinath, B.; Hsu, F.; Pardalos, P. \& Rajasejaran, S. (Eds.), Mobile Networks and Computing. American Mathematical Society, v. 52 de DIMACS Series on Discrete Mathematics and Theoretical Computer Science, p. 195-201, 2000.

Martin, O. \& Otto, S., Combining simulated annealing with local search heuristics. Annals of Operations Research, 63:57-75, 1996.

Martin, O.; Otto, S. \& Felten, E., Large-step Markov chains for the traveling salesman problem. Complex Systems, 5:299-326, 1991.

Martins, S.; Resende, M.; Ribeiro, C. \& Pardalos, P., A parallel GRASP for the Steiner tree problem in graphs using a hybrid local search strategy. Journal of Global Optimization, 17:267-283, 2000.

Martins, S.L.; Pardalos, P.M.; Resende, M.G.C. \& Ribeiro, C.C., Greedy randomized adaptive search procedures for the steiner problem in graphs. In: Pardalos, P.M.; Rajasejaran, S. \& Rolim, J. (Eds.), Randomization Methods in Algorithmic Design. American Mathematical Society, v. 43 de DIMACS Series on Discrete Mathematics and Theoretical Computer Science, p. 133-145, 1999.

Martins, S.L.; Ribeiro, C.C. \& Souza, M.C., A parallel GRASP for the Steiner problem in graphs. In: Ferreira, A. \& Rolim, J. (Eds.), Proceedings of 5th International Symposium on Solving Irregularly Structured Problems in Parallel. Heidelberg, Germany: Springer-Verlag, v. 1457 de LNCS, p. 285-297, 1998.

Mateus, G.; Resende, M. \& Silva, R., GRASP with path-relinking for the generalized quadratic assignment problem. Journal of Heuristics, 17:527-565, 2011.

Moura, A. \& Oliveira, J., A GRASP approach to the container-loading problem. IEEE Intelligent Systems, 20:50-57, 2005.

Murphey, R.A.; Pardalos, P.M. \& Pitsoulis, L.S., A parallel GRASP for the data association multidimensional assignment problem. In: Pardalos, P.M. (Ed.), Parallel Processing of Discrete Problems. New York, USA: SpringerVerlag, v. 106 de The IMA Volumes in Mathematics and Its Applications, p. 159-180, 1998.

Nascimento, M.C.V.; Resende, M.G.C. \& Toledo, F.M.B., GRASP with path-relinking for the multi-plant capacitated plot sizing problem. European Journal of Operational Research, 200(3):747 - 754, 2010.

Ochi, L.S.; Silva, M.B. \& Drummond, L., GRASP and VNS for solving traveling purchaser problem. In: Proceedings of The Fourth Metaheuristics International Conference. Porto, Portugal, p. 489-494, 2001.

Oliveira, C.A.; Pardalos, P.M. \& Resende, M.G.C., GRASP with path-relinking for the quadratic assignment problem. In: Ribeiro, C.C. \& Martins, S.L. (Eds.), Proceedings of III Workshop on Efficient and Experimental Algorithms. Heidelberg, Germany: Springer-Verlag, v. 3059 de LNCS, p. 356-368, 2004a.

Oliveira, C.A.S.; Pardalos, P.M. \& Resende, M.G.C., GRASP with path-relinking for the quadratic assignment problem. In: Ribeiro, C.C. \& Martins, S.L. (Eds.), Efficient and Experimental Algorithms. Heidelberg, Germany: SpringerVerlag, v. 3059 de LNCS, p. 356-368, 2004b.

Pardalos, P.M.; Pitsoulis, L.S. \& Resende, M.G.C., A parallel GRASP implementation for the quadratic assignment problem. In: Ferreira, A. \& Rolim, J. (Eds.), Parallel Algorithms for Irregularly Structured Problems. Boston, USA: Kluwer Academic Publishers, p. 115-130, 1995.

Pardalos, P.M.; Pitsoulis, L.S. \& Resende, M.G.C., A parallel GRASP for MAX-SAT problems. In: Wasniewski, J.; Dongarra, J.; Madsen, K. \& Olesen, D. (Eds.), Applied Parallel Computing Industrial Computation and Optimization. Heidelberg, Germany: Springer-Verlag, v. 1184 de LNCS, p. 575-585, 1996.

Pardalos, P.M.; Rendl, F. \& Wolkowicz, H., The quadratic assignment problem: A survey and recent development. In: Pardalos, P.M. \& Wolkowicz, H. (Eds.), The Quadratic Assignment and Related Problems. New Providence, USA: American Mathemaical Society, v. 16 de DIMACS Series in Discrete Matehematics and Theoretical Computer Science, p. 1-42, 1994.

Pitsoulis, L.S. \& Resende, M.G.C., Greedy randomized adaptive search procedures. In: Pardalos, P.M. \& Resende, M.G.C. (Eds.), Handbook of Applied Optimization. Oxford, UK: Oxford University Press, p. 168-183, 2002.

Prais, M. \& Ribeiro, C., Reactive GRASP: An application to a matrix decomposition problem in TDMA traffic assignment. INFORMS Journal on Computing, 12:164-176, 2000.

Pu, G.G.; Chong, Z.; Qiu, Z.Y.; Lin, Z.Q. \& He, J.F., A hybrid heuristic algorithm for HW-SW partitioning within timed automata. In: Proceedings of Knowledge-based Intelligent Information and Engineering Systems. Heidelberg, Germany: Springer-Verlag, v. 4251 de LNAI, p. 459-466, 2006.

Resende, M.G.C., Metaheuristic hybridization with Greedy Randomized Adaptive Search Procedures. In: Chen, Z.L. \& Raghavan, S. (Eds.), Tutorials in Operations Research. INFORMS, p. 295-319, 2008. 
Resende, M.G.C.; Martí, R.; Gallego, M. \& Duarte, A., GRASP and path relinking for the max-min diversity problem. Computers and Operations Research, 37(3):498 - 508, 2010a.

Resende, M.G.C. \& Ribeiro, C.C., Greedy randomized adaptive search procedures. In: Glover, F. \& Kochenberger, G. (Eds.), Handbook of Metaheuristics. Kluwer Academic Publishers, p. 219-249, 2003.

Resende, M.G.C. \& Ribeiro, C.C., GRASP with path-relinking: Recent advances and applications. In: Ibaraki, T.; Nonobe, K. \& Yagiura, M. (Eds.), Metaheuristics: Progress as Real Problem Solvers. Berlin, Germany: Springer, p. 29-63, 2005a.

Resende, M.G.C. \& Ribeiro, C.C., Parallel Greedy Randomized Adaptive Search Procedures. In: Alba, E. (Ed.), Parallel Metaheuristics: A new class of algorithms. New York, USA: John Wiley \& Sons, p. 315-346, 2005b.

Resende, M.G.C.; Ribeiro, C.C.; Glover, F. \& Marti, R., Scatter search and path-relinking: Fundamentals, advances, and applications. In: Gendreau, M. \& Potvin, J.Y. (Eds.), Handbook of Metaheuristics. New York, USA: Springer, v. 146 de Operations Research \& Management Science, p. 87-107, 2010b.

Resende, M.G.C. \& Werneck, R.F., A hybrid heuristic for the p-median problem. Journal of Heuristics, 10:59-88, 2004.

Resende, M.G.C. \& Werneck, R.F., A hybrid multistart heuristic for the uncapacitated facility location problem. European Journal of Operational Research, 174:54-68, 2006.

Ribeiro, C. \& Souza, M., Variable neighborhood search for the degree constrained minimum spanning tree problem. Discrete Applied Mathematics, 118:43-54, 2002.

Ribeiro, C. \& Urrutia, S., Heuristics for the mirrored traveling tournament problem. European Journal of Operational Research, 127:775-787, 2007.

Ribeiro, C. \& Vianna, D., A GRASP/VND heuristic for the phylogeny problem using a new neighborhood structure. International Transactions in Operational Research, 12:325-338, 2005.

Ribeiro, C.C. \& Rosseti, I., A parallel GRASP for the 2-path network design problem. In: Monien, B. \& Feldmann, R. (Eds.), Proceedings of the 8th International Euro-Par Conference on Parallel Processing. Heidelberg, Germany: Springer-Verlag, v. 2004 de LNCS, p. 922-926, 2002.

Ribeiro, C.C.; Uchoa, E. \& Werneck, R.F., A hybrid GRASP with perturbations for the Steiner problem in graphs. INFORMS Journal on Computing, 14:228-246, 2002.

Ross, G.T. \& Soland, R.M., A branch-and-bound algorithm for the generalized assignment problem. Mathematical Programming, 8:91-103, 1975.

Savelsbergh, M., A branch-and-price algorithm for the generalized assignment problem. Operational Research, 45:831841, 1997.

Serra, D. \& Colomé, R., Consumer choice and optimal location models: Formulations and heuristics. Papers in Regional Science, 80:439-464, 2001.

de Souza, M.C.; Duhamel, C. \& Ribeiro, C.C., A GRASP heuristic for the capacitated minimum spanning tree problem using a memory-based local search strategy. In: Resende, M.G.C. \& de Sousa, J.P. (Eds.), Metaheuristics: Computer Decision-making. Kluwer Academic Publishers, p. 627-658, 2003.

Souza, M.J.F.; Maculan, N. \& Ochi, L.S., A GRASP-tabu search algorithm to solve a school timetabling problem. In: Proceedings of The Fourth Metaheuristics International Conference. Porto, Portugal, p. 53-58, 2001.

Takahashi, H. \& Matsuyama, A., An approximate solution for the Steiner problem in graphs. Mathematica Japonica, 24:573-577, 1980.

Verhoeven, M.G.A. \& Aarts, E.H.L., Parallel local search. Journal of Heuristics, 1:43-66, 1995.

\section{Notas Biográficas}

Mauricio Guilherme de Carvalho Resende é graduado em Engenharia Elétrica (PUC-Rio, 1978), mestre em Pesquisa Operacional (Georgia Institute of Technology, 1979) e doutor em Pesquisa Operacional (University of California, Berkeley, 1987). Atualmente está no AT \& T Labs Research, Algorithms and Optimization Research Department. E-mail: mgcr@research.att.com.

Ricardo Martins de Abreu Silva é graduado, mestre e doutor em Ciência da Computação (Universidade Federal de Pernambuco, 1995, 1998 e 2003, respectivamente). Atualmente é professor do Centro de Informática da Universidade Federal de Pernambuco . 


\title{
Algoritmos Genéticos: Fundamentos e Aplicações
}

\author{
Alexandre Ferreira de Pinho*, José Arnaldo Barra Montevechi, \\ Fernando Augusto Silva Marins e Rafael de Carvalho Miranda
}

\begin{abstract}
Resumo: Os Algoritmos Genéticos foram inspirados no mecanismo da evolução das espécies, tendo como base os trabalhos de Darwin e Mendel. Tais algoritmos vêm sendo utilizados com sucesso para a resolução dos mais variados e complexos tipos de problemas. Isso é possível devido a sua estrutura genérica, que faz com que os Algoritmos Genéticos, ao contrário de outras meta-heurísticas, sejam aplicáveis aos mais variados problemas de otimização. Neste capítulo, os principais conceitos referentes a estes algoritmos e exemplos reais de sua aplicação, serão apresentados.
\end{abstract}

Palavras-chave: Meta-heurísticas, Algoritmo genético, Otimização.

\begin{abstract}
Genetic algorithms are based on concepts of evolution of species inspired by Darwin and Mendel. These algorithms are being utilized to resolve a wide range of complex problems with success. Due to its generic structure, Genetic Algorithms are applicable in most optimization problems, unlike other metaheuristic techniques. In this chapter, the main differences in these algorithms and real examples of their application are presented.
\end{abstract}

Keywords: Metaheuristics, Genetic algorithm, Optimization.

Os Algoritmos Genéticos (AG) vêm sendo usados com sucesso para encontrar boas soluções para uma ampla variedade de problemas de otimização (Gen \& Cheng, 1997) desde sua introdução por Holland na década de 1970 (Holland, 1975).

Costa et al. (2007), definem o AG como um método computacional de busca baseado em mecanismos de evolução natural e da genética. Em um AG, uma população de possíveis soluções para um dado problema evolui de acordo com operadores probabilísticos concebidos a partir de conceitos biológicos, de modo que há uma tendência de que os indivíduos representem soluções cada vez melhores à medida que o processo avança.

Desde sua criação há um interesse crescente na utilização dos AG como uma ferramenta para resolver problemas complexos de otimização (Gen \& Cheng, 2000; Haupt \& Haupt, 1998). E embora sejam mais gerais e abstratos do que outros métodos de otimização e, nem sempre ofereçam a solução ideal, eles são considerados flexíveis e aplicáveis a uma ampla variedade de problemas (Asllani \& Lari, 2007).

Linden (2006) destaca ainda as seguintes vantagens dos AG sob outras técnicas de otimização:

- Os AG não utilizam métodos de busca totalmente aleatórios;

- Os AG não são afetados por descontinuidades na função ou em suas derivadas. Isto faz com que os AG sejam adequados para funções com descontinuidades, ou para funções com as quais não se podem calcular derivadas;

- Os AG são capazes de lidar com funções discretas e contínuas, podendo inclusive trabalhar com funções mistas;

- Os AG são apropriados para resolver problemas de busca com espaços de busca grandes demais para serem resolvidos por técnicas de otimização tradicionais.

Este capítulo apresenta uma visão abrangente sobre os algoritmos genéticos. Sua estrutura de funcionamento e seus principais componentes serão apresentados. Na sequência, os fundamentos sobre seus parâmetros, e como esses parâmetros interferem no resultado final do problema serão mostrados. Por fim, exemplos de aplicações práticas dos AG também serão apresentados.

*Autor para contato: pinho@unifei.edu.br 


\section{Componentes de um Algoritmo Genético}

Segundo Barboza (2005), o AG adota uma terminologia original usada na teoria da evolução natural e da genética, na qual um indivíduo de uma população pode ser formado por um ou mais cromossomos. Pode se utilizar o termo indivíduo ou cromossomo indistintamente para o caso de um indivíduo ser representado por um único cromossomo. O cromossomo pode ser denominado de string e, em geral, implementados como vetores, onde cada elemento do vetor é conhecido como gene. Os valores que cada gene pode assumir é denominado de alelo, possuindo um local fixo no cromossomo denominado de lócus. Genes e alelos em conjunto formam então o genótipo, com suas características tratadas de fenótipo.

A relação entre a terminologia dos algoritmos genéticos e a biologia aparece resumida na Tabela 1.

Tabela 1. Relação da terminologia do AG com a biologia. Fonte: Barboza (2005).

\begin{tabular}{c|c}
\hline Biologia & Algoritmo genético \\
\hline Cromossomo & Indivíduo (string) \\
Gene & Bit \\
Alelo & Valor do bit \\
Lócus & Posição de um bit específico no indivíduo \\
Genótipo & Indivíduo candidato à solução $-x$ \\
Fenótipo & Valor da função para um dado indivíduo $-f(x)$ \\
\hline
\end{tabular}

Para Aytug et al. (2003), geralmente, os AG possuem oito componentes básicos, que são: sua representação genética, a população inicial, a função avaliação, o método de seleção de reprodução, os operadores genéticos, o método de seleção de gerações, os critérios de parada e os parâmetros de configuração dos AG. Todos esses componentes serão discutidos em maiores detalhes ao longo do texto.

Um fluxograma genérico capaz de englobar a maioria dos Algoritmos Genéticos existentes é apresentado na Figura 1. Nesta figura, em um primeiro momento uma população inicial, de possíveis soluções para um determinado problema é gerada. No passo seguinte, os indivíduos da população são avaliados segundo a função de avaliação. Após este passo, verifica-se o critério de parada do AG. Se este critério não for satisfeito, os indivíduos daquela geração são selecionados através de algum método de seleção para reprodução. Os indivíduos selecionados são expostos aos operadores genéticos e uma nova geração de filhos é gerada, a partir da geração pai. Este ciclo é repetido até que o critério de parada do algoritmo seja alcançado. Nesse momento, o algoritmo converge apresentando a solução encontrada para o problema.

\subsection{Representação genética}

Para Linden (2006) a representação genética consiste em uma maneira de traduzir as informações presentes no problema estudado para uma maneira que este possa ser compreendido por computadores. Quanto mais adequada ao problema esta representação for, maior a qualidade dos resultados obtidos.

Para Almeida et al. (2007) a representação do indivíduo na modelagem de um AG deve possuir a capacidade de descrever corretamente o espaço de busca relevante do problema. Concilio (2000) alerta que a representação é uma das etapas mais críticas na definição de um AG. Segundo o autor uma definição inadequada poderia levar a problemas de convergência prematura.

Duas abordagens distintas são as mais comumente utilizadas para realizar a codificação de um AG: a codificação binária (ou clássica) e a codificação real (Medeiros, 2002). Há ainda uma terceira abordagem, a codificação inteira, no entanto esta possui aplicação muito restrita.

A representação binária para o indivíduo é historicamente importante, uma vez que foi utilizada nos trabalhos pioneiros de Holland (1975). É a representação tradicional sendo fácil de utilizar e manipular, como também é simples de ser analisada teoricamente. Contudo, se um problema tem parâmetros contínuos e o usuário quer trabalhar com boa precisão numérica, ele precisará armazenar indivíduos relativamente longos na memória do computador.

Neste sentido, para Michalewicz (1996), a representação real apresenta vantagens sobre a binária no que diz respeito à velocidade de processamento, consistência dos resultados entre as rodadas e precisão.

Para Soares (1997) a representação por inteiros é mais indicada para problemas que envolvam números inteiros, como análise combinatória, arranjos e permutação.

Um indivíduo da população é a representação de uma possível solução em forma de uma sequência de símbolos, que no caso da representação binária é feita utilizando-se o alfabeto binário (0 ou 1). O tamanho da população é representado pelo conjunto de indivíduos.

A relação entre tamanho da população e o tamanho do indivíduo de uma população que utiliza a representação binária é mostrada na Figura 2. 


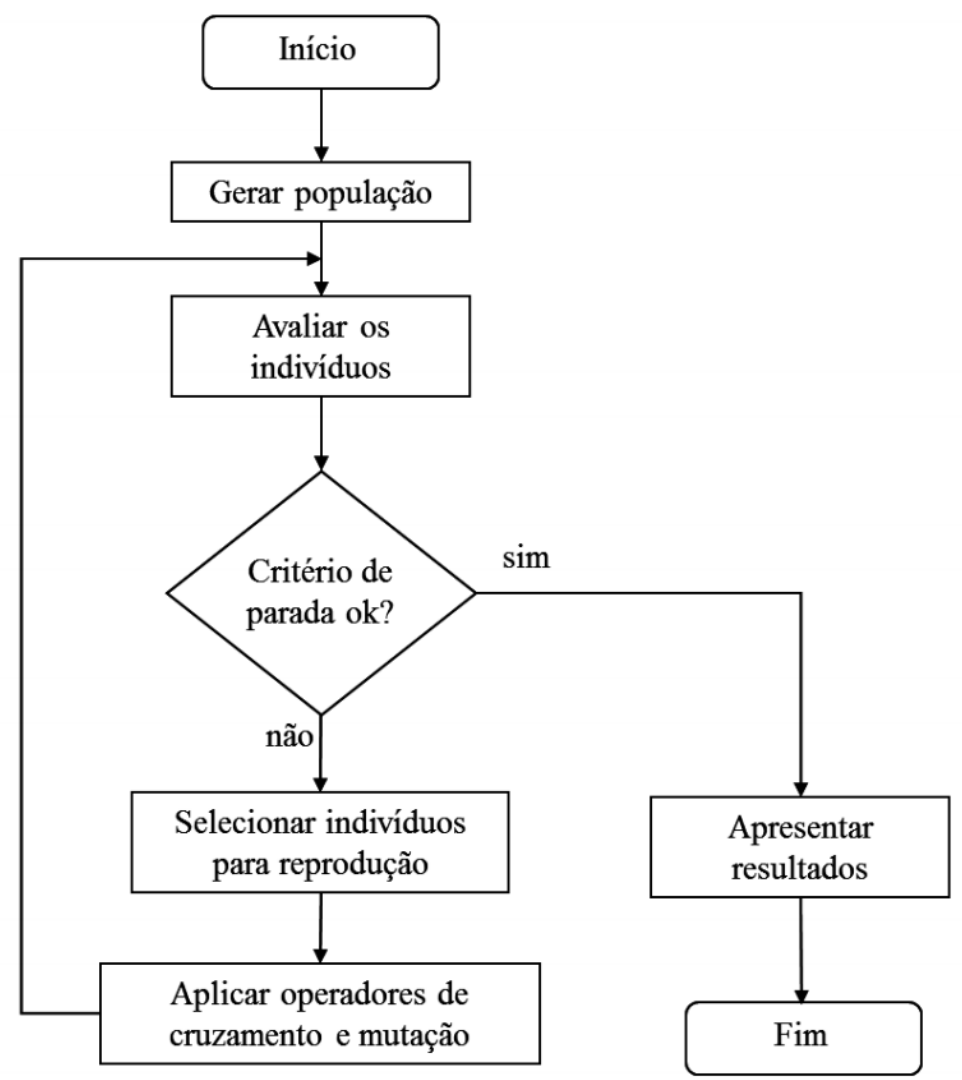

Figura 1. Fluxograma para o AG genérico.

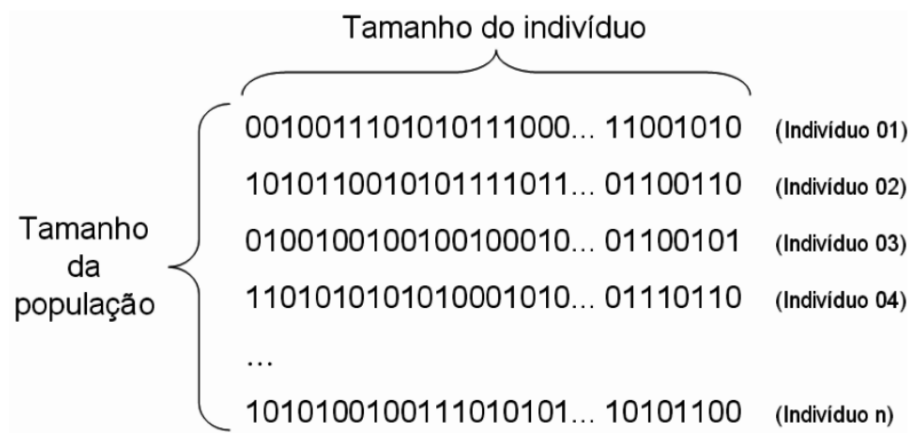

Figura 2. Tamanho da população x tamanho do indivíduo.

Davis (1991) afirma que o tamanho do indivíduo pode ser representado, nos algoritmos genéticos, através da quantidade de bits. Desta forma, um indivíduo de tamanho 5 bits poderia assumir $2^{5}$, ou seja, 32 valores diferentes.

Segundo Linden (2006), deve-se escolher a quantidade de bits necessária para o tamanho do indivíduo com base na variação entre seus limites inferiores e superiores e na precisão desejada.

A Equação 1, proposta por Mitchell (1996), apresenta a relação entre estes fatores:

$$
\text { Precisao }=\frac{\text { sup }_{i}-i n f_{i}}{2^{k}-1}
$$

Sendo:

- $k$ : o número de bits do indivíduo;

- $i n f_{i}$ e $\sup _{i}$ : os limitantes inferior e superior, respectivamente, da faixa de operação (variação).

Por exemplo, para uma variação de [-100, 100] e uma precisão de 0,0001, a quantidade de bits necessária para o indivíduo será 21, como pode ser observado na Equação 2: 


$$
0,0001=\frac{100-(-100)}{2^{k}-1} \Rightarrow k=20,93 \Rightarrow k=21
$$

Cabe ressaltar que é possível trabalhar com valores reais e inteiros utilizando-se da codificação binária. Para obter o valor real, é necessário obter o número inteiro correspondente a codificação binária e, em seguida, fazer a operação da Equação 3, retirada de Linden (2006).

$$
\text { ValorReal }=i n f_{i}+\frac{\sup _{i}-i n f_{i}}{2^{k}-1} \cdot \text { ValorInteiro }
$$

Sendo:

- $k$ : o número de bits do indivíduo;

- $i n f_{i}$ e $\sup _{i}$ : os limitantes inferior e superior, respectivamente, da faixa de operação.

Adicionalmente, Linden (2006) estabelece que, para a representação de mais de um valor dentro do mesmo indivíduo, colocam-se estes valores lado a lado, como uma concatenação de textos. Assim, os primeiros $k_{1}$ bits representam $x_{1}$, os $k_{2}$ bits seguintes representam $x_{2}$ e assim por diante. Usualmente têm-se $k_{1}=k_{2}=\ldots$ $=k_{n}$, mas é possível que as necessidades de precisão para cada valor sejam diferentes.

\subsection{Geração da população inicial}

Segundo Soares (2006), a população inicial pode ser obtida de duas formas. Na primeira delas os indivíduos são gerados aleatoriamente, já na segunda opção, a população é gerada por meio de uma heurística, relacionada às características específicas do problema.

Reeves (1995) relata que, ao direcionar a população inicial com o auxílio de alguma heurística, o AG pode chegar a soluções melhores e mais rapidamente quando comparado ao processo de geração aleatória. Por outro lado, pode ocorrer um processo de convergência prematura, para pontos de máximo local, o que não é conveniente para a resolução do problema. É importante lembrar que a população inicial deve cobrir a maior parte do espaço de busca da solução.

Para Torabi et al. (2006), uma boa definição de uma população inicial, com tamanho razoável, ajuda a aumentar a eficiência de um AG. Uma população pequena pode acarretar em uma convergência prematura, reduzindo as possibilidades de se atingir o ótimo global. Já populações muito grandes acarretam em maiores esforços computacionais, demandando muito tempo para se chegar a uma solução (Falcone, 2004; Lobo \& Goldberg, 2004; Michalewicz, 1996).

\subsection{Função de avaliação da população}

Segundo Koza et al. (2003), a função de avaliação da população deve refletir os objetivos a serem alcançados na resolução de um problema e é derivada diretamente das condições impostas por este.

A função de avaliação é obtida através da função a ser otimizada. Segundo Linden (2006), tal função é a maneira utilizada pelo AG para determinar a qualidade de um indivíduo como solução do problema em questão, ou seja, sua aptidão.

Para Barboza (2005), se o objetivo do problema for a maximização, a avaliação será diretamente proporcional ao valor da função. Caso o objetivo do problema seja a minimização, a avaliação será inversamente proporcional ao valor da função.

\subsection{Métodos de seleção}

Segundo Bäck et al. (2000), os métodos de seleção são usados para direcionar o processo de seleção para melhores regiões no espaço de busca. Para Hicks (2006), tais métodos são utilizados para selecionar os indivíduos que serão submetidos aos operadores genéticos. Alguns métodos de seleção são apresentados a seguir.

\subsubsection{Roleta simples ou seleção proporcional}

Este método foi proposto inicialmente por Holland (1975). Para Falcone (2004), no método da roleta cada indivíduo tem seu valor aptidão representado proporcionalmente em relação ao valor total das aptidões na população. Assim, a roleta é girada e selecionam-se os indivíduos pelo sorteio. Aqueles que apresentarem maior participação terão maiores chances de serem selecionados. Cada vez que a roleta é girada um novo indivíduo é selecionado. 
O método da roleta tem a desvantagem de possuir uma alta variância, podendo levar sorteios de um mesmo indivíduo que possui alto valor de aptidão, o que faz diminuir a diversidade da população. Esta falha pode ocasionar uma convergência prematura do algoritmo para uma solução local, e, por outro lado, quando a evolução está avançada, observa-se uma estagnação do algoritmo (Barboza, 2005).

\subsubsection{Seleção por torneio}

Para Teles \& Gomes (2010), a seleção por torneio é um método de seleção amplamente utilizado, devido principalmente à sua eficiência e a simplicidade em sua implementação. Este método preserva a diversidade da população, uma vez que a escolha é realizada comparando o valor da função de avaliação entre os indivíduos que participam do torneio.

Segundo Linden (2006), na seleção por torneio existe um parâmetro denominado tamanho do torneio $(K)$. Este parâmetro define quantos indivíduos serão selecionados de forma aleatória dentro da população para competir. Uma vez definidos os competidores, aquele que possuir a melhor aptidão é selecionado. Contudo, quanto maior o tamanho do torneio, maior a perda da diversidade.

Uma das vantagens do método é que os indivíduos são selecionados aleatoriamente para competir, não existindo nenhuma forma de favorecimento aos indivíduos com maior aptidão, como no caso da seleção por roleta (Linden, 2006).

\subsubsection{Seleção elitista}

A seleção elitista não é necessariamente um método de seleção, entretanto, segundo Barboza (2005), tal método pode se utilizado em conjunto com outros métodos de seleção.

Para Bento \& Kagan (2008), a maioria dos métodos de seleção descarta a geração anterior e consideram apenas os descendentes obtidos para composição da geração futura. Desta forma, a técnica elitista consiste em reintroduzir o indivíduo melhor avaliado de uma geração para a seguinte, evitando a perda de informações importantes presentes em indivíduos de alta aptidão e que podem ser perdidas durante o processo de seleção.

Além disto, é possível armazenar temporariamente o melhor resultado encontrado durante a evolução, para que no final este seja designado como o melhor indivíduo encontrado, mesmo que não esteja presente na última geração do processo (Barboza, 2005).

\subsection{Operadores genéticos}

Segundo Goldberg (1989) existem diversos operadores genéticos, entretanto, dois operadores são comumente utilizados: cruzamento e mutação.

\subsubsection{Cruzamento}

Segundo Konak et al. (2006), o operador de cruzamento (ou crossover) é o mais importante dos operadores genéticos. Nesta operação, dois indivíduos são combinados para formar novos indivíduos. Aplicando iterativamente este operador, é esperado que os genes dos indivíduos bons apareçam com maior frequência na população e eventualmente convirjam para uma boa solução.

Em uma operação de cruzamento uma posição no indivíduo é escolhida aleatoriamente e este é quebrado nesta posição, os fragmentos resultantes são recombinados e dois novos indivíduos são criados. Em outras formas de cruzamento, o indivíduo pode ser quebrado de forma aleatória em mais de uma posição e ser recombinado com outro indivíduo quebrado de forma semelhante (Azadivar \& Tompkins, 1999).

Existem vários métodos de cruzamento, e eles diferem entre si pela escolha do lócus (posição de um bit) do indivíduo a ser trocado entre os indivíduos pais, e pela maneira com será feita esta troca. A seguir são listados os tipos mais comuns de cruzamentos encontrados na literatura:

- Cruzamento uniforme: Este cruzamento consiste no emparelhamento de dois indivíduos pais, no qual cada lócus do indivíduo tem 50\% de chance de ser trocado (Linden, 2006). Observa-se no exemplo da Figura 3, que um determinado indivíduo, que possui 8 lócus, sofreu um cruzamento no primeiro, quarto e quinto lócus.

- Cruzamento de um ponto: Neste cruzamento um ponto de corte é escolhido aleatoriamente, e a partir deste ponto as informações do código genético dos pais serão trocados. Os filhos serão gerados de acordo com as informações anteriores a este ponto de um dos pais, e completados com as informações posteriores a este ponto do outro pai (Barboza, 2005). A Figura 4 mostra um exemplo de funcionamento do cruzamento de um ponto. 

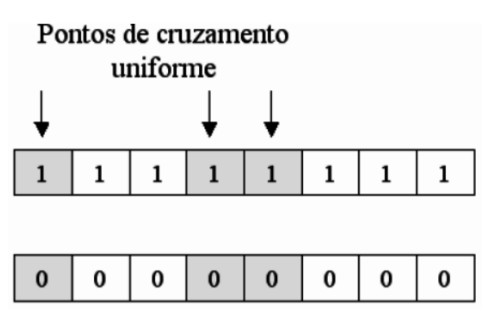

Pais
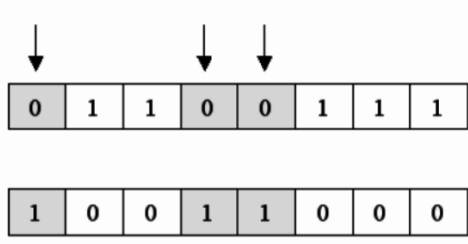

Filhos

Figura 3. Exemplo de cruzamento uniforme.

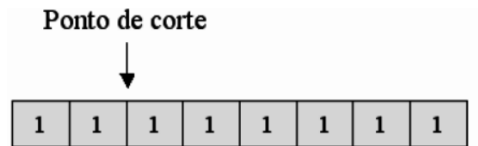

\begin{tabular}{|l|l|l|l|l|l|l|l|}
\hline 0 & 0 & 0 & 0 & 0 & 0 & 0 & 0 \\
\hline
\end{tabular}

Pais

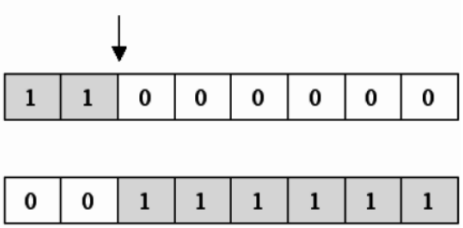

Filhos

Figura 4. Exemplo de um cruzamento de um ponto.

- Cruzamento de dois pontos: Aqui dois pontos são escolhidos aleatoriamente, e a partir destes pontos, as informações dos pais serão trocadas. Todos os materiais genéticos dos pais existentes limitados pelos pontos serão trocados entre eles, e o restante do material genético permanecerá inalterado (Linden, 2006). A Figura 5 mostra um exemplo de funcionamento do cruzamento de dois pontos.

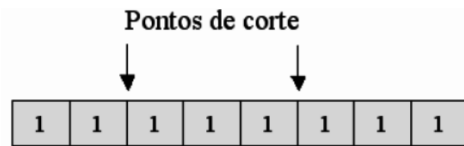

\begin{tabular}{|l|l|l|l|l|l|l|l|}
\hline 0 & 0 & 0 & 0 & 0 & 0 & 0 & 0 \\
\hline
\end{tabular}

Pais

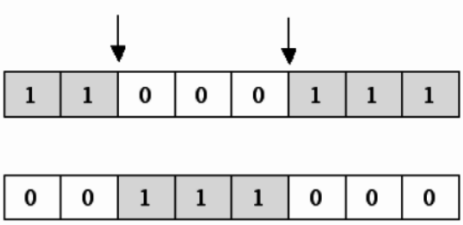

Filhos

Figura 5. Exemplo de um cruzamento de dois pontos.

\subsubsection{Mutação}

O operador de mutação introduz mudanças aleatórias em determinadas características dos indivíduos. Esta é aplicada ao nível do bit e, desta forma, os indivíduos produzidos por este operador não são muito diferentes dos originais. No entanto, a mutação reintroduz a diversidade genética de volta à população e auxilia o algoritmo a fugir de máximos ou mínimos locais (Konak et al., 2006).

Entre os operadores de mutação para codificação binária, o mais comumente utilizado é a mutação binária simples. Neste tipo de mutação, posições do indivíduo são sorteadas e os genes correspondentes são invertidos, ou seja, se o valor do gene for 1, então se muda este valor para 0, e vice-versa (Mitchell, 1996). A Figura 6 ilustra o funcionamento deste operador de mutação.

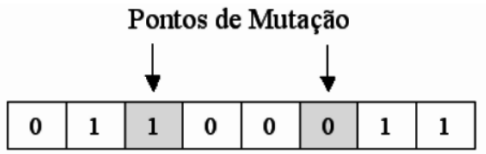

Pai

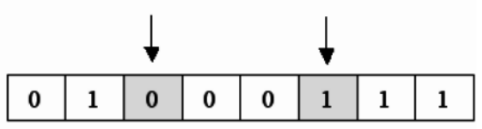

Filho

Figura 6. Exemplo de uma mutação binária simples. 


\subsection{Critérios de parada}

Segundo Hicks (2006), os critérios de parada são abordagens que delimitam o número de buscas depois que certo número de gerações são concluídas em um AG. Estes critérios podem ser implementados por meio de um tempo máximo, pela diminuição da diversidade populacional ou quando uma população não melhora em sucessivas gerações.

\subsection{Parâmetros dos algoritmos genéticos}

Segundo Yang et al. (2007), apesar dos AG resolverem problemas de otimização eficazmente, eles são sensíveis aos seus principais parâmetros de configuração: o tamanho da população, o número de gerações, a taxa de cruzamento e a taxa de mutação.

Para Neppalli et al. (1996) a determinação dos valores dos parâmetros de um AG é um processo complexo. Geralmente na maioria das aplicações os valores dos parâmetros são ajustados com base em trabalhos previamente conduzidos e relatados.

\subsubsection{Tamanho da população}

Barboza (2005) afirma que o número de indivíduos da população afeta o desempenho global e a eficiência do AG.

Experimentos realizados por De Jong (1975) apud Mitchell (1996) indicam que o melhor tamanho de uma população está entre 50 e 100 indivíduos. Estes autores citam que esta é a faixa mais comum usada em aplicações de AG.

\subsubsection{Número de gerações}

O número de gerações varia de acordo com a complexidade do problema em questão e deve ser determinado experimentalmente. Como o AG resolve problemas de otimização, o ideal seria que o algoritmo terminasse assim que a melhor solução possível fosse encontrada (Yun \& Gen, 2003).

Diversos autores divergem quanto à escolha do número de gerações ideal. Goldberg (1989) considera o desvio padrão dos valores de aptidão dos indivíduos como sendo um dos fatores mais interessantes. Assim, tem-se uma comparação do desempenho da geração atual com a anterior, e se o desvio padrão for igual ou menor que o estabelecido como aproximação aceitável, o processo então é encerrado. Neste caso o número de gerações não é fornecido no início do processo, e é conhecido somente quando o critério de parada for aceito.

\subsubsection{Taxa de cruzamento}

A taxa de cruzamento determina se será feito o cruzamento entre dois indivíduos de uma certa população. Isto é, gera-se um número aleatório entre 0 e 1 , e se este valor sorteado for menor que a taxa, o cruzamento entre estes indivíduos é realizado.

Pode-se observar experimentalmente que, quanto maior for esta taxa, mais rapidamente novos indivíduos serão introduzidos na população. Porém, se esta taxa for muito alta, a maior parte da população será substituída, e pode ocorrer perda de estruturas de boa aptidão, já com um valor muito baixo, a evolução pode se tornar muito lenta.

De Jong (1975) apud Mitchell (1996), sugere uma taxa de cruzamento de 0,6. Já Tanomaru (1995) sugere uma taxa de cruzamento superior a 0,7 .

\subsubsection{Taxa de Mutação}

Esta taxa determina se os genes dos indivíduos sofrerão mutação ou não, isto é, gera-se um número aleatório entre 0 e 1 para cada um dos genes dos indivíduos e compara-se com a taxa de mutação. Caso este valor seja menor que a taxa, realiza-se a mutação.

Em relação aos valores da taxa de mutação, pode-se observar que, para uma taxa de mutação muito baixa, pode acontecer que a busca fique estagnada em um valor, ou seja, um ótimo local. Em contrapartida, com uma taxa muito alta, a busca torna-se essencialmente aleatória.

De Jong (1975) apud Mitchell (1996) sugere uma taxa de mutação igual a 0,001. Já Tanomaru (1995) sugere uma taxa de mutação menor que 0,01 .

\section{Aplicações dos Algoritmos Genéticos}

Desde os conceitos básicos definidos por Holland (1975), inúmeras aplicações dos AG têm sido desenvolvidas em várias áreas de pesquisas, obtendo resultados satisfatórios. A seguir, serão citadas algumas dessas aplicações. 


\subsection{Otimização de funções matemáticas}

Este item, além de mostrar a aplicação do AG na otimização de funções matemáticas, também tem a intenção de ilustrar os procedimentos do AG através do exemplo escolhido.

A função matemática que se pretende otimizar (maximizar) é a $f(x)=x \operatorname{sen}(10 \pi x)+1$, retirada de Lacerda \& Carvalho (1999), e definida para o intervalo $-1 \leq x \leq 2$. Tal função tem seu ponto máximo global conhecido: $x=1,85055$ e $f(x)=2,85027$.

Embora aparentemente, simples esta função não é de fácil solução, uma vez que possui vários pontos de máximo local e apenas um ponto de máximo global, conforme pode ser observado na Figura 7.

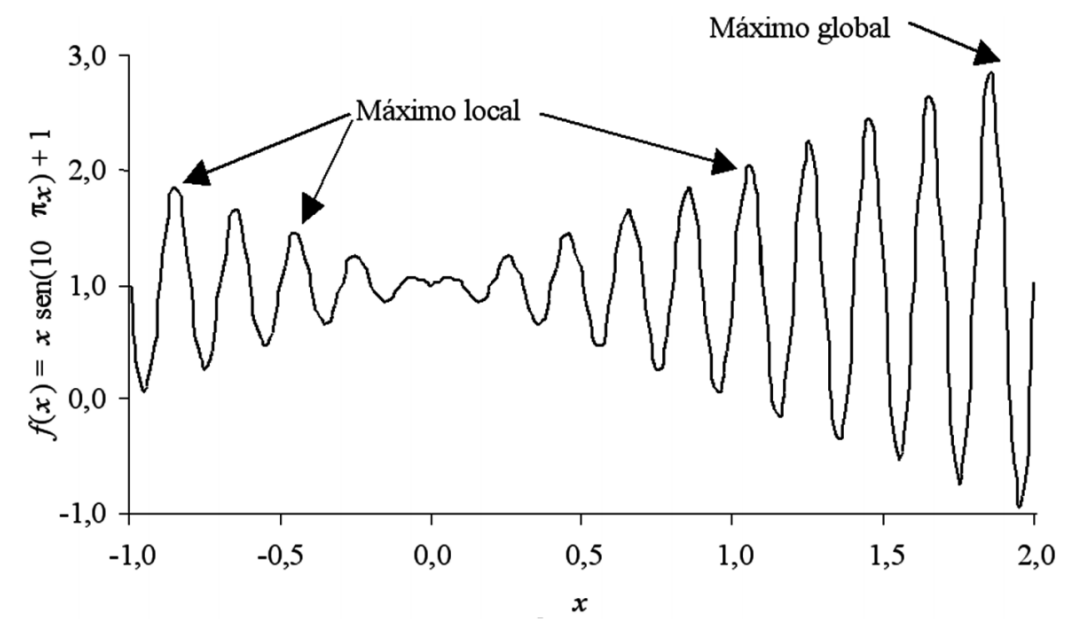

Figura 7. Gráfico da função $f(x)=x \sin (10 \pi x)+1$.

O ponto de partida para a utilização do AG neste problema é a definição da representação da variável $x$. Para uma precisão de 0,001, será necessário um indivíduo com 12 bits, conforme mostra a Equação 4.

$$
0,001=\frac{2-(-1)}{2^{k}-1} \Rightarrow k=11,55 \Rightarrow k=12
$$

Uma vez definido como a variável $x$ será representada, pode-se iniciar os procedimentos do AG. Conforme apresentado no fluxograma da Figura 1, tem-se como primeiro passo a geração da população e, na sequência, a avaliação do indivíduo.

A Tabela 2 mostra diversos indivíduos gerados aleatoriamente, seus valores de $x$ correspondentes e suas respectivas avaliações, que para este exemplo, é a própria função $f(x)$. Cabe ressaltar que a quantidade de indivíduos gerados é determinada pelo parâmetro do AG tamanho da população.

Tabela 2. Indivíduos gerados e suas respectivas avaliações.

\begin{tabular}{ccc}
\hline Indivíduo & Valor de $x$ & Avaliação \\
\hline 001001110101 & 0,46081 & 1,11520 \\
100011110010 & 1,67766 & 2,33463 \\
110011010011 & 2,40513 & 3,32914 \\
000111110010 & 0,36484 & 1,07250 \\
010101100000 & 1,00806 & 1,52924 \\
$\ldots$ & $\ldots$ & $\cdots$ \\
\hline
\end{tabular}

O próximo passo do AG é determinar se o critério de parada foi atendido. Neste exemplo, será adotado como critério de parada a não melhoria dos resultados de uma geração quando comparados a gerações anteriores. Uma vez que a Tabela 2 representa a primeira geração do AG, o critério de parada ainda não foi atendido.

Na sequência, o próximo passo do AG é selecionar os indivíduos para reprodução, através de algum método de seleção. Neste exemplo, será utilizado o método da roleta. A Tabela 3 acrescenta mais uma coluna na Tabela 2 com as avaliações acumuladas.

Em seguida, gera-se um número aleatório, através de uma distribuição uniforme, no intervalo entre zero e o total acumulado das avaliações. O indivíduo selecionado será o primeiro indivíduo que possuir a avaliação acumulada superior ao valor sorteado. Por exemplo, se o valor sorteado for 6 , seleciona-se o $3^{\circ}$ indivíduo da Tabela 3. Este sorteio é repetido até ter-se a quantidade de indivíduos que se pretende selecionar. 
Tabela 3. Avaliação acumulada dos indivíduos.

\begin{tabular}{cccc}
\hline Indivíduo & Valor de $x$ & Avaliação & Avaliação Acumulada \\
\hline 001001110101 & 0,46081 & 1,11520 & 1,11520 \\
100011110010 & 1,67766 & 2,33463 & 3,44983 \\
110011010011 & 2,40513 & 3,32914 & 6,77897 \\
000111110010 & 0,36484 & 1,07250 & 7,85147 \\
010101100000 & 1,00806 & 1,52924 & 9,38071 \\
$\ldots$ & $\ldots$ & $\ldots$ & $\ldots$ \\
\hline
\end{tabular}

Uma vez que todos os indivíduos foram selecionados, é possível aplicar os operadores de cruzamento e mutação nestes indivíduos. Neste exemplo será utilizado o cruzamento de um ponto e a mutação binária simples. Supondo que o $1^{\circ}$ e o $3^{\circ}$ indivíduo da Tabela 3 foram selecionados pelo método de seleção, o resultado dos indivíduos filhos após a aplicação do operador de cruzamento e mutação é mostrado na Figura 8.

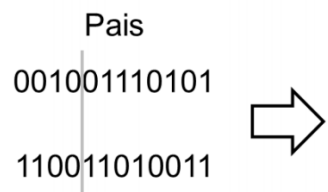

Filhos

001011010011

110001110101

$1 \longleftarrow$ Mutação

Figura 8. Indivíduos filhos após a aplicação dos operadores de cruzamento e mutação.

Cabe ressaltar que tanto as operações de cruzamento e de mutação só ocorrem mediante as probabilidades definidas pela taxa de cruzamento e pela taxa de mutação, respectivamente. Desta forma, tanto o cruzamento quanto a mutação podem não ocorrer, fazendo com que alguns indivíduos filhos sejam exatamente iguais aos pais.

Após os operadores de cruzamento e de mutação terem sidos aplicados a todos os indivíduos selecionados, todo o procedimento se repete até que o critério de parada seja alcançado.

\subsection{Outras aplicações}

Algumas outras aplicações dos AG podem ser citadas:

- Hwang \& He (2006) utilizaram AG em conjunto com a meta-heurística Recozimento Simulado (Simulated Annealing) em problemas de engenharia;

- Pendharkar (2007) desenvolveu em seu trabalho um algoritmo genético para resolução de problemas de programação da produção. Utilizou, também, algumas técnicas de simulação computacional para atingir os resultados desejados;

- James et al. (2006) desenvolveram um algoritmo genético para manipular funções objetivos sujeitas a diversas restrições. Eles acrescentaram certas características de programação nestes algoritmos que permitiram tirar proveito de computadores com vários processadores.

Finalizando, Barboza (2005) cita como exemplos de aplicações do AG em Pesquisa Operacional e outras áreas:

- Problemas de otimização complexos: AG aplicados a problemas com muitas variáveis e espaços de soluções de dimensões elevadas;

- Otimização evolutiva multicritério: AG adotado para a otimização de funções com múltiplos objetivos conflitantes entre si;

- Mineração de dados (Data Mining);

- Robótica: robôs utilizam AG para tomar decisões;

- Redes neurais: AG é combinado com redes neurais para treiná-las ou para encontrar sua topologia;

- Ciências biológicas: AG utilizado na modelagem de processos biológicos para o entendimento do comportamento de estruturas genéticas; 
- Engenharia de construções: AG possui aplicações na otimização discreta de estruturas;

- Síntese de circuitos analógicos: o AG é utilizado para gerar a topologia, o tipo e o valor dos componentes do circuito;

- Síntese de protocolos: determina as funções de protocolos de hardware e de software para que um certo desempenho seja alcançado;

- Gerenciamento de rede de comunicação: o AG faz a supervisão de tráfego nos links e das filas nos buffers de roteadores para descobrir caminhos ótimos e para reconfigurar as rotas existentes no caso de falha de algum link;

\section{Considerações Finais}

Este capítulo apresentou o princípio de funcionamento e os principais aspectos relacionados aos algoritmos genéticos. Apesar das constantes evoluções e pesquisas, o AG é uma meta-heurística e, como tal, não há garantias que a resposta encontrada num processo de otimização seja um ótimo global.

No entanto, os AG vêm sendo usados com sucesso há várias décadas, e seus resultados encontram aplicações nas mais variadas áreas.

\section{Agradecimentos}

Os autores agradecem à Fundação de Amparo à Pesquisa do Estado de Minas Gerais (FAPEMIG), ao CNPq e ao Programa de Pró-Engenharia da CAPES.

\section{Referências}

Almeida, L.F.; Valdivia, Y.T.; Vellasco, M.M.B.R. \& Pacheco, M.A.C., Otimização de alternativas para o desenvolvimento de campos de petróleo. Gestão \& Produção, 14(3):489-503, 2007.

Asllani, A. \& Lari, A., Using genetic algorithm for dynamic and multiple criteria web-site optimizations. European Journal of Operational Research, 176(3):1767-1777, 2007.

Aytug, H.; Khouja, M. \& Vergara, F., A review of the use of genetic algorithms to solve production and operations management problems. International Journal of Production Research, 41(17):3955-4009, 2003.

Azadivar, F. \& Tompkins, G., Simulation optimization with qualitative variables and structural model changes: A genetic algorithm approach. European Journal of Operational Research, 113:169-182, 1999.

Barboza, A.O., Simulação e Técnicas da Computação Evolucionária Aplicadas a Problemas de Programação Linear Inteira Mista. Tese de doutorado, Universidade Tecnológica Federal do Paraná (UTFPR), CPGEI, Curitiba, PR, 2005.

Bäck, T.; Fogel, D.B. \& Michalewicz, Z., Evolutionary Computation 2: Advanced Algorithms and Operators. London: IOP Publishing, 2000.

Bento, E.P. \& Kagan, N., Algoritmos genéticos e variantes na solução de problemas de configuração de redes de distribuição. Revista Controle $\&$ Automação, 19(3):302-315, 2008.

Concilio, R., Contribuições à Solução de Problemas de Escalonamento pela Aplicação Conjunta de Computação Evolutiva e Otimização com Restrições. Dissertação de mestrado, Universidade Estadual de Campinas (UNICAMP), Campinas, SP, 2000.

Costa, C.B.B.; Rivera, E.A.C.; Rezende, M.C.A.F.; Maciel, M.R.W. \& Filho, R.M., Prior detection of genetic algorithm significant parameters: Coupling factorial design technique to genetic algorithm. Chemical Engineering Science, 62:4780-4801, 2007.

Davis, L., Handbook of genetic algorithms. New York, USA: Van Reinhold Nostrand, 1991.

Falcone, M.A.G., Estudo Comparativo Entre Algoritmos Genéticos e Evolução Diferencial para Otimização de um Modelo de Cadeia de Suprimento Simplificada. Dissertação de mestrado, Pontifícia Universidade Católica do Paraná (PUC-PR), Curitiba, PR, 2004.

Gen, M. \& Cheng, R., Genetic algorithms and engineering design. New York, USA: John Wiley \& Sons, 1997.

Gen, M. \& Cheng, R., Genetic algorithms and engineering optimization. New York, USA: John Wiley \& Sons, 2000.

Goldberg, D.E., Genetic Algorithm in Search, Optimization and Machine Learning. Reading, USA: Addison-Wesley Publishing Company, 1989.

Haupt, R.L. \& Haupt, S.E., Practical Genetic Algorithms. New York, USA: John Wiley \& Sons, 1998.

Hicks, C., A genetic algorithm tool for optimising cellular or functional layouts in the capital goods industry. International Journal of Production Economics, 104(2):598-614, 2006.

Holland, J.H., Adaptation in Natural and Artificial Systems. East Lansing, USA: University of Michigan Press, 1975.

Hwang, S.F. \& He, R.S., A hybrid real-parameter genetic algorithm for function optimization. Advanced Engineering Informatics, 20(1):7-21, 2006. 
James, T.L.; Barkhi, R. \& Johnson, J.D., Platform impact on performance of parallel genetic algorithms: Design and implementation considerations. Engineering Applications of Artificial Intelligence, 19:843-856, 2006.

Konak, A.; Coit, D.W. \& Smith, A.E., Multi-objective optimization using genetic algorithms: A tutorial. Reliability Engineering and System Safety, 91(9):992-1007, 2006.

Koza, J.; Keane, M.A. \& Streeter, M.J., Genetic Programming IV: Routine Human-Competitive Machine Intelligence. Hingham, USA: Kluwer Academic Publishers, 2003.

Lacerda, E. \& Carvalho, A.C.P.L.F., Introdução aos algoritmos genéticos. In: Sistemas Inteligentes: Aplicações a Recursos Hídricos e Ciências Ambientais. Porto Alegre, RS: Editora da Universidade Federal do Rio Grande do Sul, v. 1, p. 99-148, 1999.

Linden, R., Algoritmos Genéticos: Uma Importante Ferramenta da Inteligência Computacional. Rio de Janeiro, RJ: Editora Brasport, 2006.

Lobo, F.G. \& Goldberg, D.E., The parameter-less genetic algorithm in practice. Information Sciences, 167:217-232, 2004.

Medeiros, F.L.L., Algoritmo Genético Híbrido como um Método de Busca de Estados Estacionários de Sistemas Dinâmicos. Dissertação de mestrado, Instituto Nacional de Pesquisas Espaciais (INPE), São José dos Campos, SP, 2002.

Michalewicz, Z., Genetic Algorithms + Data Structures = Evolution Programs. 3a edição. London, UK: Springer-Verlag, 1996.

Mitchell, M., An Introduction to Genetic Algorithms. Cambridge, USA: MIT Press, 1996.

Neppalli, R.V.; Chen, C.L. \& Gupta, J.N., Genetic algorithms for the two-stage bicriteria flow shop problem. European Journal of Operational Research, 95(2):356-373, 1996.

Pendharkar, P.C., The theory and experiments of designing cooperative intelligent systems. Decision Support Systems, 43:1014-1030, 2007.

Reeves, C.R., Modern Heuristic Techniques for Combinatorial Problems. New York, USA: McGraw-Hill, 1995.

Soares, G.L., Algoritmos Genéticos: Estudo, Novas Técnicas e Aplicações. Dissertação de mestrado em engenharia elétrica, Universidade Federal de Minas Gerais (UFMG), Belo Horizonte, MG, 1997.

Soares, M.M., Análise do Uso de Algoritmos Genéticos na Otimização do Planejamento Mestre da Produção. Dissertação de mestrado em engenharia de produção e sistemas, Pontifícia Universidade Católica do Paraná (PUC-PR), Curitiba, PR, 2006.

Tanomaru, J., Motivação, fundamentos e aplicações de algoritmos genéticos. In: Anais do II Congresso Brasileiro de Redes Neurais. Curitiba, PR, p. 373-403, 1995.

Teles, M.L. \& Gomes, H.M., Comparação de algoritmos genéticos e programação quadrática sequencial para otimização de problemas em engenharia. Teoria e Prática na Engenharia Civil, 10(15):29-39, 2010.

Torabi, S.A.; Ghomi, S.M.T.F. \& Karimi, B., A hybrid genetic algorithm for the finite horizon economic lot and delivery scheduling in supply chains. European Journal of Operational Research, 173(1):173-189, 2006.

Yang, T.; Kuo, Y. \& Cho, C., A genetic algorithms simulation approach for the multi-attribute combinatorial dispatching decision problem. European Journal of Operational Research, 176(3):1859-1873, 2007.

Yun, Y. \& Gen, M., Performance analysis of adaptive genetic algorithms with fuzzy logic and heuristics. Fuzzy Optimization and Decision Making, 2(2):161-175, 2003.

\section{Notas Biográficas}

Alexandre Ferreira de Pinho é graduado em Engenharia Mecânica (Universidade Federal de Itajubá - UNIFEI, 1995). Possui mestrado em Engenharia de Produção (UNIFEI, 1999) e doutorado em Engenharia Mecânica (Universidade Estadual Paulista - UNESP, 2008). Atualmente é professor do Instituto de Engenharia de Produção e Gestão (IEPG) da Universidade Federal de Itajubá.

José Arnaldo Barra Montevechi é graduado em Engenharia Mecânica (UNIFEI, 1985), mestre em Engenharia Mecânica (Universidade Federal de Santa Catarina - UFSC, 1989) e doutor em Engenharia Mecânica (Escola Politécnica da Universidade de São Paulo - USP, 1995). Fez pós-doutorado na University of Texas at Austin, Estados Unidos. Atualmente é professor titular do Instituto de Engenharia de Produção e Gestão (IEPG) da UNIFEI.

Fernando Augusto Silva Marins é graduado em Engenharia Mecânica (UNESP, 1976), mestre em Pesquisa Operacional (Instituto Tecnológico de Aeronáutica - ITA, 1981) e doutor em Engenharia Elétrica (Universidade Estadual de Campinas - UNICAMP, 1987). Fez pós-doutorado na Brunel University, Reino Unido. Atualmente é professor titular do Departamento de Produção da Faculdade de Engenharia da Universidade Estadual Paulista.

Rafael de Carvalho Miranda é graduado e mestre em Engenharia de Produção (Universidade Federal de Itajubá - UNIFEI, 2008 e 2012, respectivamente). Atualmente é doutorando em Engenharia de Produção na UNIFEI. 
Pinho et al. 


\title{
Uma Introdução à Busca Tabu
}

\author{
Vinícius Amaral Armentano* e Rodrigo Moretti Branchini
}

\begin{abstract}
Resumo: Este capítulo apresenta uma introdução à busca tabu na forma de um tutorial, em que os conceitos fundamentais são ilustrados por meio de um exemplo pequeno e testes computacionais em uma instância da literatura do problema de designação generalizada. São testadas alternativas para a escolha dos componentes da memória de curto prazo e da memória de longo prazo. Esses componentes envolvem vizinhanças, regras de ativação tabu que proibem movimentos, duração tabu de movimentos, trajetórias de soluções factíveis e infactíveis, e estratégias de diversificação. Sugestões para implementar busca tabu são apresentadas.
\end{abstract}

Palavras-chave: Busca tabu, Trajetórias de soluções factíveis e infactíveis, Memória de curto prazo, Memória de longo prazo.

\begin{abstract}
This chapter presents an introduction to tabu search in which the fundamental concepts are illustrated by means of a small example and computational tests on an instance from the literature of the generalized assignment problem. Alternatives for the selection of components of the short term memory and the long term memory are tested and analyzed. Such components involve neighborhoods, tabu activation rules to prohibit moves, tabu tenure of moves, trajectories of feasible and infeasible solutions, and diversification strategies. Tips for implementing tabu search are pointed out.
\end{abstract}

Keywords: Tabu search, Feasible and infeasible solution trajectories, Short term memory, Long term memory.

\section{Introdução}

Busca tabu é um método heurístico genérico, também chamado meta-heurística, proposto por Glover (1986) e descrito em detalhes em Glover \& Laguna (1997). Este método guia um procedimento heurístico de busca local pela utilização de características da solução corrente e da história da busca para explorar o espaço de soluções além da otimalidade local. A busca local é uma heurística de busca que usa uma operação definida movimento para definir uma vizinhança.

O uso sistemático de memória adaptativa constitui a propriedade que distingue busca tabu de outras metaheurísticas. A palavra "adaptativa" significa que a memória atualiza o armazenamento de elementos de soluções ou de soluções completas encontradas durante a exploração do espaço de soluções. A metodologia de busca tabu contém diversas estratégias associadas com memória adaptativa, o que permite muitas implementações distintas, ao contrário das demais meta-heurísticas puras (sem hibridização) tais como, simulated annealing e algoritmos genéticos ou evolucionários que têm uma estrutura bem definida.

O objetivo deste capítulo é apresentar uma introdução à busca tabu na forma de um tutorial, em que os conceitos fundamentais do método são ilustrados por meio da resolução de instâncias de um problema importante e desafiador de otimização inteira, conhecido como designação generalizada, apresentado na próxima seção. O resto do capítulo está organizado da seguinte maneira. A Seção 3 descreve uma heurística construtiva para obter uma solução inicial para a busca tabu. Esta heurística é ilustrada por um exemplo pequeno do problema de designação generalizada. A Seção 4 contém a descrição de conceitos básicos da memória de curto prazo da busca tabu, a saber, vizinhanças, atributo de soluções, regras de proibição de movimentos, critério de aspiração, e duração tabu, também ilustrados pelo mesmo exemplo pequeno. Outro aspecto importante envolve o caráter restritivo de visitar somente soluções factíveis e a necessidade de visitar soluções infactíveis, obtidas por meio de penalização de restrições adicionadas à função objetivo. A Seção 5 descreve a implementação de memória de curto prazo para uma instância da literatura. A Seção 6 aborda a memória de longo prazo que contém a frequência de atributos de todas as soluções visitadas. Atributos

*Autor para contato: vinicius@densis.fee.unicamp.br 
presentes com alta frequência podem ser penalizados para promover diversificação. Testes computacionais e gráficos são apresentados para análise de alternativas de decisões nestes conceitos básicos. A Seção 7 apresenta sugestões para implementação de busca tabu a novos problemas.

\section{Problema llustrativo}

O problema de designação generalizada (PDG) consiste de $m$ agentes e $n$ tarefas, com $m<n$, em que cada tarefa deve ser executada por um único agente, e um agente pode executar mais de uma tarefa. A execução da tarefa $j$ pelo agente $i$ requer uma quantidade $a_{i j}$ de recurso do agente $i$, com custo $c_{i j}$. O agente $i$ tem capacidade de recurso $b_{i}$. Este problema é encontrado em diversas aplicações de forma isolada ou como subproblema de problemas mais complexos, como destacado por Öncan (2007) que faz uma revisão de aplicações e métodos de solução. O método mais eficiente para resolver instâncias de baixa, média e alta dificuldade é baseado em enfoques heurísticos derivados de busca tabu e foi proposto por Yagiura et al. (2006). Recentemente, Woodcock \& Wilson (2010) propuseram um método híbrido com busca tabu e branch-andbound, que é relativamente competitivo com o anterior. Para formular este problema considere a variável binária

$$
x_{i j}= \begin{cases}1 & \text { se a tarefa } j \text { é designada ao agente } i \\ 0 & \text { caso contrário }\end{cases}
$$

O problema de designação generalizada é modelado da seguinte forma:

$$
\begin{gathered}
\text { minimizar } \sum_{i=1}^{m} \sum_{j=1}^{n} c_{i j} x_{i j} \\
\text { sujeito a } \sum_{i=1}^{m} x_{i j}=1, \quad j=1, \ldots, n \\
\\
\quad \sum_{j=1}^{n} a_{i j} x_{i j} \leq b_{i}, \quad i=1, \ldots, m \\
\quad x_{i j} \in\{0,1\}, i=1, \ldots, m ; j=1, \ldots, n .
\end{gathered}
$$

A função objetivo (1) minimiza o custo total de designação de tarefas a agentes. As restrições (2) garantem que cada tarefa $j$ é executada por um único agente, e as restrições (3) impõem que a capacidade $b_{i}$ de cada agente $i$ não é excedida. A restrição (4) indica o domínio das variáveis.

$\mathrm{Na}$ busca tabu, as restrições (3) são relaxadas e as violações são penalizadas e adicionadas à função objetivo, que resulta em

$$
\sum_{i=1}^{m} \sum_{j=1}^{n} c_{i j} x_{i j}+\operatorname{Pen}\left(\sum_{i=1}^{m} \max \left(\sum_{j=1}^{n} a_{i j} x_{i j}-b_{i}, 0\right)\right)
$$

em que Pen é um parâmetro de penalidade que pode variar durante a busca.

\section{Heurística Construtiva}

Uma heurística simples para a designação de uma tarefa $j$ a um agente $i$ é baseada em uma função $f(i, j)$ que define uma medida de atratividade $\rho$ de cada tarefa $j$ pelo seu melhor agente. Martello \& Toth (1990) propuseram as seguintes funções:

i) $f(i, j)=c_{i j}$

ii) $f(i, j)=a_{i j}$

iii) $f(i, j)=a_{i j} / b_{i}$

iv) $f(i, j)=-c_{i j} / a_{i j}$

A função (i) representa o desejo de designar uma tarefa a um agente para execução mais barata, e as funções (ii) e (iii) expressam a aspiração de de designar uma tarefa a um agente que possa executá-la por meio da menor utilização (absoluta ou relativa) de recurso. A função (iv) corresponde à versão de minimização para a restrição de mochila associada com o agente $i$. A utilização destas funções não garante a obtenção de uma solução factível para o problema. 
Em um algoritmo guloso estas funções são usadas para calcular a atratividade $\rho_{j}$ para cada tarefa $j$, definida como o menor valor de $f(i, j)$, e a seguir listar as tarefas em ordem não decrescente de $\rho_{j}$. Os agentes são, então, alocados a partir da primeira tarefa da lista. Este algoritmo é descrito como:

1. Faça $J=\{1, \ldots, n\}$ e $\hat{b}_{i}=b_{i}$ para $i \in I=\{1, \ldots, m\}$;

2. Seja $\mathcal{F}_{j}=\left\{i: a_{i j} \leq \hat{b}_{i}\right\}$ para $j \in J$. Se $\mathcal{F}_{j}=\emptyset$ para algum $j \in J$, pare, o algoritmo não encontrou uma solução factível. Caso contrário, seja $\rho_{j}=\min _{i \in \mathcal{F}_{j}} f(i, j)$ para $j \in J$ e $i_{j}=\arg \min _{i \in \mathcal{F}_{j}} f(i, j)$;

3. Seja $\hat{\jmath}=\arg \min _{i \in \mathcal{F}_{j}} \rho_{j}$, isto é, $\hat{\jmath}$ é a próxima tarefa a ser designada ao agente $i_{\hat{\jmath}}$ :

$$
\begin{aligned}
& x_{i_{\hat{\jmath} \hat{\jmath}}}=1, \\
& x_{i \hat{\jmath}}=0, \text { para } i \in I, i \neq i_{\hat{\jmath}}, \\
& \dot{b}_{i \hat{\jmath}}=\dot{b}_{i \hat{\jmath}}-a_{i_{\hat{\jmath}} \hat{\jmath}}, \\
& J=J \backslash\{\hat{\jmath}\} ;
\end{aligned}
$$

4. Se $J=\emptyset$, pare, $x$ é uma solução factível para o problema. Caso contrário, vá para o passo 2.

Outro algoritmo guloso, também proposto por Martello \& Toth (1990), utiliza, para cada tarefa $j$, a diferença entre o segundo menor valor de $f(i, j)$ e o menor valor de $f(i, j)$. Esta diferença representa o arrependimento (regret) associado com a escolha do agente que gera o segundo menor valor em lugar da escolha do agente associado ao menor valor. A diferença neste algoritmo em relação ao anterior está na atratividade $\rho_{j}$, calculada a partir da seguinte expressão:

$$
\rho_{j}=\min _{s \in \mathcal{F}_{j}, s \neq i_{\hat{\jmath}}} f(s, j)-f\left(i_{\hat{\jmath}}\right) \text { para } j \in J .
$$

Em seguida, a lista de tarefas é classificada em ordem não crescente de $\rho_{j}$ e a tarefa com máximo arrependimento é designada ao agente correspondente.

Para ilustrar esta heurística construtiva, considere o seguinte exemplo com três agentes $i \in\left\{A_{1}, A_{2}, A_{3}\right\}$ e oito tarefas $j \in\left\{T_{1}, T_{2}, \ldots, T_{8}\right\}$. As capacidades de recurso $b_{i}$ dos agentes $A_{1}, A_{2}$ e $A_{3}$ são 30,25 e 35 , respectivamente, e as Tabelas 1 e 2 indicam os custos $c_{i j}$ e a utilização de recursos $a_{i j}, i \in\left\{A_{1}, A_{2}, A_{3}\right\}$ e $j \in\left\{T_{1}, T_{2}, \ldots, T_{8}\right\}$.

Tabela 1 . Custo $c_{i j}$ ao designar a tarefa $T_{j}$ ao agente $A_{i}$.

\begin{tabular}{ccccccccc}
\hline Agente & \multicolumn{8}{c}{ Tarefa } \\
\cline { 2 - 9 } & T1 & T2 & T3 & T4 & T5 & T6 & T7 & T8 \\
\hline A1 & 23 & 38 & 33 & 34 & 26 & 19 & 12 & 37 \\
A2 & 36 & 45 & 13 & 41 & 14 & 25 & 49 & 16 \\
A3 & 17 & 15 & 30 & 40 & 29 & 27 & 47 & 22 \\
\hline
\end{tabular}

Tabela 2. Quantidade de recurso $a_{i j}$ para que a tarefa $T_{j}$ seja processada pelo agente $A_{i}$.

\begin{tabular}{ccccccccc}
\hline Agente & \multicolumn{8}{c}{ Tarefa } \\
\cline { 2 - 9 } & T1 & T2 & T3 & T4 & T5 & T6 & T7 & T8 \\
\hline A1 & 21 & 13 & 4 & 3 & 7 & 15 & 22 & 24 \\
A2 & 20 & 8 & 23 & 25 & 6 & 5 & 9 & 14 \\
A3 & 16 & 12 & 18 & 2 & 11 & 10 & 17 & 19 \\
\hline
\end{tabular}

A heurística construtiva que considera a medida de atratividade $f(i, j)=c_{i j}$ designa, a cada passo, uma tarefa a um agente de menor custo $c_{i j}$, sem violar as restrições de capacidade. Portanto, há oito passos a serem executados neste exemplo, e o primeiro consiste da designação factível de menor $c_{i j}$ da Tabela 1 . A designação escolhida é alocar $T_{7}$ a $A_{1}$ a um custo $c_{17}=12$, que consome 22 unidades de recurso do agente $A_{1}$ (vide Tabelas 1 e 2).

O segundo passo da heurística construtiva considera as opções de designação derivadas do primeiro passo, descartando as designações referentes às tarefas já alocadas $\left(T_{7}\right)$ e as designações infactíveis. Desta forma, após alocar $T_{7}$ a $A_{1}$, a capacidade disponível de $A_{1}$ é reduzida de 30 para 8, eliminando a possibilidade de alocação a $A_{1}$ de qualquer tarefa $T_{j}$ que consuma mais do que 8 unidades de recurso de $A_{1}$.

A Tabela 3 mostra as opções de designação do passo 2, indicando com "*” as alternativas que não podem ser mais escolhidas. O próximo passo designa $T_{3}$ a $A_{2}$ a um custo $c_{23}=13$, com consumo de 23 unidades de 
recurso do agente $A_{2}$. Esta designação reduz a capacidade disponível de $A_{2}$ de 25 para 2, impossibilitando quaisquer outras designações a $A_{2}$, como mostra a Tabela 4 do passo seguinte. No passo 3 , designa-se $T_{2}$ a $A_{3}$ a um custo de 15 e consumo de recurso de 12 .

Tabela 3. Passo 2 - Opções de designação para $f(i, j)=c_{i j}$.

\begin{tabular}{cccccccccccccccccc}
\hline Passo 2 & \multicolumn{1}{c}{ Designar } & \multicolumn{1}{c}{$T_{3}$ a $A_{2}$ : custo de 13 e consumo de recurso de 23 } \\
\cline { 2 - 6 } & $T_{1}$ & $T_{2}$ & $T_{3}$ & $T_{4}$ & $T_{5}$ & $T_{6}$ & $T_{7}$ & $T_{8}$ & $T_{1}$ & $T_{2}$ & $T_{3}$ & $T_{4}$ & $T_{5}$ & $T_{6}$ & $T_{7}$ & $T_{8}$ \\
\hline$T_{3} A_{2}$ & $*$ & $*$ & 33 & 34 & 26 & $*$ & $*$ & $*$ & $*$ & $*$ & 4 & 3 & 7 & $*$ & $*$ & $*$ \\
$A_{2}$ & 36 & 45 & 13 & 41 & 14 & 25 & $*$ & 16 & 20 & 8 & 23 & 25 & 6 & 5 & $*$ & 14 \\
$A_{3}$ & 17 & 15 & 30 & 40 & 29 & 27 & $*$ & 22 & 16 & 12 & 18 & 2 & 11 & 10 & $*$ & 19 \\
\hline
\end{tabular}

Disponibilidade dos agentes: $[8,25,35]-[0,23,0]=[8,2,35]$

Tabela 4. Passo 3 - Opções de designação $f(i, j)=c_{i j}$.

\begin{tabular}{ccccccccccccccccc}
\hline Passo 3 & \multicolumn{1}{c}{ Designar } & $T_{2}$ a $A_{3}$ : custo de 15 e consumo de recurso de 12 \\
\cline { 2 - 14 }$T_{2}-A_{3}$ & $T_{1}$ & $T_{2}$ & $T_{3}$ & $T_{4}$ & $T_{5}$ & $T_{6}$ & $T_{7}$ & $T_{8}$ & $T_{1}$ & $T_{2}$ & $T_{3}$ & $T_{4}$ & $T_{5}$ & $T_{6}$ & $T_{7}$ & $T_{8}$ \\
\hline$A_{1}$ & $*$ & $*$ & $*$ & 34 & 26 & $*$ & $*$ & $*$ & $*$ & $*$ & $*$ & 3 & 7 & $*$ & $*$ & $*$ \\
$A_{2}$ & $*$ & $*$ & $*$ & $*$ & $*$ & $*$ & $*$ & $*$ & $*$ & $*$ & $*$ & $*$ & $*$ & $*$ & $*$ & $*$ \\
$A_{3}$ & 17 & 15 & $*$ & 40 & 29 & 27 & $*$ & 22 & 16 & 12 & $*$ & 2 & 11 & 10 & $*$ & 19 \\
\hline
\end{tabular}

Disponibilidade dos agentes: $[8,2,35]-[0,0,12]=[8,2,23]$

Após a execução dos passos 4 a 6 de maneira similar aos passos executados anteriormente, as seguintes designações foram realizadas: $T_{7}-A_{1} ; T_{3}-A_{2} ; T_{2}-A_{3} ; T_{1}-A_{3} ; T_{5}-A_{1} ; T_{4}-A_{3}$. O próximo passo $(7)$ deveria designar uma das tarefas $T_{6}$ ou $T_{8}$. Entretanto, a capacidade disponível dos agentes (disponibilidade de 1,2 e 5 respectivamente) é insuficiente para acomodar a demanda de recursos de qualquer uma das duas tarefas, o que torna esta solução infactível.

Ao considerar a medida de atratividade $f(i, j)=c_{i j}$, a heurística construtiva prioriza a qualidade (menor custo) sobre a factibilidade (menor consumo de recursos) e pode, como neste exemplo, não encontrar uma solução factível. Para ilustrar a priorização da factibilidade, mostra-se a seguir a sequência de passos da heurística construtiva para a medida de atratividade $f(i, j)=a_{i j}$ com arrependimento. O primeiro passo é ilustrado na Tabela 5 .

Tabela 5. Passo 1 - Opções de designação $f(i, j)=a_{i j}$ com arrependimento.

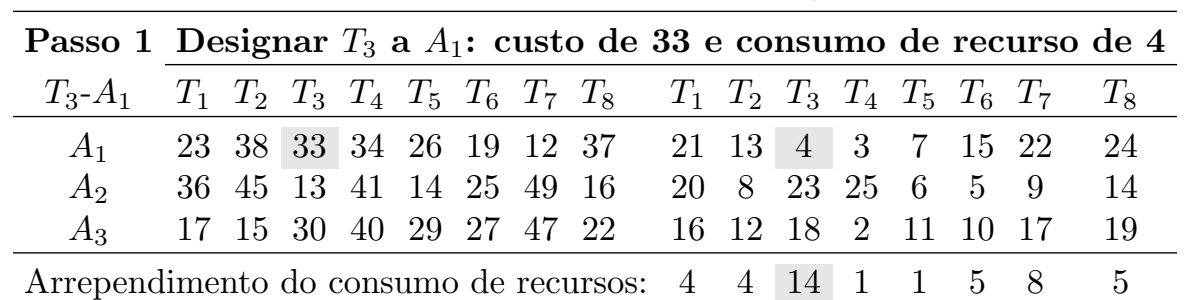

Disponibilidade dos agentes: $[30,25,35]-[4,0,0]=[26,25,35]$

O arrependimento do consumo de recursos é calculado como a diferença entre a primeira e segunda melhor opção (menor consumo de recursos) de cada tarefa. Por exemplo, a melhor opção para se alocar a tarefa $T_{3}$ é o agente $A_{1}$ com o consumo de 4 unidades de recursos. Caso esta opção não possa ser escolhida, a segunda melhor opção seria alocar a tarefa $T_{3}$ ao agente $A_{3}$ com o consumo de 18 unidades de recursos, ou seja, 14 unidades pior do que a primeira opção. Portanto, o "arrependimento" de não se executar a primeira opção neste passo da heurística construtiva para esta tarefa é de 14 unidades. Desta forma, em cada passo calcula-se o arrependimento para cada tarefa e seleciona-se a tarefa de maior arrependimento. O primeiro passo designa a tarefa $T_{3}$ ao agente $A_{1}$. Os próximos passos são ilustrados nas Tabelas 6 a 12 . 
Tabela 6. Passo 2 - Opções de designação $f(i, j)=a_{i j}$ com arrependimento.

\begin{tabular}{ccccccccccccccccc}
\hline Passo 2 & \multicolumn{1}{c}{ Designar } & $T_{7}$ a $A_{2}$ : custo de $\mathbf{4 9}$ e consumo de recurso de 9 \\
\cline { 2 - 15 }$T_{7}-A_{2}$ & $T_{1}$ & $T_{2}$ & $T_{3}$ & $T_{4}$ & $T_{5}$ & $T_{6}$ & $T_{7}$ & $T_{8}$ & $T_{1}$ & $T_{2}$ & $T_{3}$ & $T_{4}$ & $T_{5}$ & $T_{6}$ & $T_{7}$ & $T_{8}$ \\
\hline$A_{1}$ & 23 & 38 & $*$ & 34 & 26 & 19 & 12 & 37 & 21 & 13 & $*$ & 3 & 7 & 15 & 22 & 24 \\
$A_{2}$ & 36 & 45 & $*$ & 41 & 14 & 25 & 49 & 16 & 20 & 8 & $*$ & 25 & 6 & 5 & 9 & 14 \\
$A_{3}$ & 17 & 15 & $*$ & 40 & 29 & 27 & 47 & 22 & 16 & 12 & $*$ & 2 & 11 & 10 & 17 & 19 \\
\hline
\end{tabular}

\begin{tabular}{llllllllll}
\hline Arrependimento do consumo de recursos: & 4 & 4 & $*$ & 1 & 1 & 5 & 8 & 5 \\
\hline
\end{tabular}

Disponibilidade dos agentes: $[26,25,35]-[0,9,0]=[26,16,35]$

Tabela 7. Passo 3 - Opções de designação $f(i, j)=a_{i j}$ com arrependimento.

\begin{tabular}{ccccccccccccccccc}
\hline Passo 3 & \multicolumn{1}{c}{ Designar } & \multicolumn{1}{c}{$T_{6}$ a $A_{2}$ : custo de 25 e consumo de recurso de $\mathbf{5}$} \\
\cline { 2 - 14 }$T_{6} A_{2}$ & $T_{1}$ & $T_{2}$ & $T_{3}$ & $T_{4}$ & $T_{5}$ & $T_{6}$ & $T_{7}$ & $T_{8}$ & $T_{1}$ & $T_{2}$ & $T_{3}$ & $T_{4}$ & $T_{5}$ & $T_{6}$ & $T_{7}$ & $T_{8}$ \\
\hline$A_{1}$ & 23 & 38 & $*$ & 34 & 26 & 19 & $*$ & 37 & 21 & 13 & $*$ & 3 & 7 & 15 & $*$ & 24 \\
$A_{2}$ & $*$ & 45 & $*$ & $*$ & 14 & 25 & $*$ & 16 & $*$ & 8 & $*$ & $*$ & 6 & 5 & $*$ & 14 \\
$A_{3}$ & 17 & 15 & $*$ & 40 & 29 & 27 & $*$ & 22 & 16 & 12 & $*$ & 2 & 11 & 10 & $*$ & 19 \\
\hline
\end{tabular}

\begin{tabular}{llllllllll}
\hline Arrependimento do consumo de recursos: & 5 & 4 & $*$ & 1 & 1 & 5 & $*$ & 5
\end{tabular}

Disponibilidade dos agentes: $[26,16,35]-[0,5,0]=[26,11,35]$

Tabela 8. Passo 4 - Opções de designação $f(i, j)=a_{i j}$ com arrependimento.

\begin{tabular}{cccccccccccccccccc}
\hline Passo & \multicolumn{1}{c}{ Designar } & $T_{1}$ a $A_{3}$ : custo de $\mathbf{1 7}$ e consumo de recurso de 16 \\
\cline { 2 - 13 }$T_{1}-A_{3}$ & $T_{1}$ & $T_{2}$ & $T_{3}$ & $T_{4}$ & $T_{5}$ & $T_{6}$ & $T_{7}$ & $T_{8}$ & $T_{1}$ & $T_{2}$ & $T_{3}$ & $T_{4}$ & $T_{5}$ & $T_{6}$ & $T_{7}$ & $T_{8}$ \\
\hline$A_{1}$ & 23 & 38 & $*$ & 34 & 26 & $*$ & $*$ & 37 & 21 & 13 & $*$ & 3 & 7 & $*$ & $*$ & 24 \\
$A_{2}$ & $*$ & 45 & $*$ & $*$ & 14 & $*$ & $*$ & $*$ & $*$ & 8 & $*$ & $*$ & 6 & $*$ & $*$ & $*$ \\
$A_{3}$ & 17 & 15 & $*$ & 40 & 29 & $*$ & $*$ & 22 & 16 & 12 & $*$ & 2 & 11 & $*$ & $*$ & 19 \\
\hline \multicolumn{7}{l}{ Arrependimento do consumo de recursos: } & 5 & 4 & $*$ & 1 & 1 & $*$ & $*$ & 5
\end{tabular}

Disponibilidade dos agentes: $[26,11,35]-[0,0,16]=[26,11,19]$

Tabela 9. Passo 5 - Opções de designação $f(i, j)=a_{i j}$ com arrependimento.

\begin{tabular}{cccccccccccccccccc}
\hline Passo 5 & \multicolumn{1}{c}{ Designar } & $T_{8}$ & \multicolumn{1}{c}{$A_{3}$ : custo de 22 e consumo de recurso de 19 } \\
\cline { 2 - 13 }$T_{8} A_{3}$ & $T_{1}$ & $T_{2}$ & $T_{3}$ & $T_{4}$ & $T_{5}$ & $T_{6}$ & $T_{7}$ & $T_{8}$ & $T_{1}$ & $T_{2}$ & $T_{3}$ & $T_{4}$ & $T_{5}$ & $T_{6}$ & $T_{7}$ & $T_{8}$ \\
\hline$A_{1}$ & $*$ & 38 & $*$ & 34 & 26 & $*$ & $*$ & 37 & $*$ & 13 & $*$ & 3 & 7 & $*$ & $*$ & 24 \\
$A_{2}$ & $*$ & 45 & $*$ & $*$ & 14 & $*$ & $*$ & $*$ & $*$ & 8 & $*$ & $*$ & 6 & $*$ & $*$ & $*$ \\
$A_{3}$ & $*$ & 15 & $*$ & 40 & 29 & $*$ & $*$ & 22 & $*$ & 12 & $*$ & 2 & 11 & $*$ & $*$ & 19 \\
\hline
\end{tabular}

Arrependimento do consumo de recursos: $*$\begin{tabular}{lllllllll} 
& $*$ & $*$ & 1 & 1 & $*$ & $*$ & 5 \\
\hline
\end{tabular}

Disponibilidade dos agentes: $[26,11,19]-[0,0,19]=[26,11,0]$

Tabela 10. Passo 6 - Opções de designação $f(i, j)=a_{i j}$ com arrependimento.

\begin{tabular}{|c|c|c|c|c|c|c|c|c|c|c|c|c|c|c|c|c|}
\hline \multirow{2}{*}{$\begin{array}{c}\text { Passo } 6 \\
T_{4}-A_{1}\end{array}$} & \multicolumn{16}{|c|}{ Designar $T_{4}$ a $A_{1}:$ custo de 34 e consumo de recurso de 3} \\
\hline & $T_{1}$ & $T_{2}$ & $T_{3}$ & $T_{4}$ & $T_{5}$ & $T_{6}$ & $T_{7}$ & $T_{8}$ & $T_{1}$ & $T_{2}$ & $T_{3}$ & $T_{4}$ & $T_{5}$ & $T_{6}$ & $T_{7}$ & $T_{8}$ \\
\hline$A_{1}$ & $*$ & 38 & $*$ & 34 & 26 & $*$ & * & $*$ & * & 13 & $*$ & 3 & 7 & $*$ & $*$ & $*$ \\
\hline$A_{2}$ & $*$ & 45 & $*$ & $*$ & 14 & * & * & * & * & 8 & * & $*$ & 6 & $*$ & $*$ & $*$ \\
\hline$A_{3}$ & $*$ & $*$ & * & * & $*$ & $*$ & * & $*$ & * & * & * & * & * & * & $*$ & $*$ \\
\hline Arrepend & imel & ato & do $c$ & ons & umo & $\mathrm{de}$ & rec & ursos: & $*$ & 5 & * & MAX & 1 & $*$ & $*$ & $*$ \\
\hline
\end{tabular}

Note que o arrependimento é considerado como máximo quando existe somente uma designação possível para uma tarefa (vide Tabelas 10 e 12). Este tipo de priorização pode evitar que a solução se torne infactível 
Tabela 11. Passo 7 - Opções de designação $f(i, j)=a_{i j}$ com arrependimento.

\begin{tabular}{cccccccccccccccccc}
\hline Passo & \multicolumn{1}{c}{ Designar } & \multicolumn{1}{c}{$T_{2}$ a $A_{2}$ : custo de 45 e consumo de recurso de 8} \\
\cline { 2 - 13 }$T_{2} A_{2}$ & $T_{1}$ & $T_{2}$ & $T_{3}$ & $T_{4}$ & $T_{5}$ & $T_{6}$ & $T_{7}$ & $T_{8}$ & $T_{1}$ & $T_{2}$ & $T_{3}$ & $T_{4}$ & $T_{5}$ & $T_{6}$ & $T_{7}$ & $T_{8}$ \\
\hline$A_{1}$ & $*$ & 38 & $*$ & $*$ & 26 & $*$ & $*$ & $*$ & $*$ & 13 & $*$ & $*$ & 7 & $*$ & $*$ & $*$ \\
$A_{2}$ & $*$ & 45 & $*$ & $*$ & 14 & $*$ & $*$ & $*$ & $*$ & 8 & $*$ & $*$ & 6 & $*$ & $*$ & $*$ \\
$A_{3}$ & $*$ & $*$ & $*$ & $*$ & $*$ & $*$ & $*$ & $*$ & $*$ & $*$ & $*$ & $*$ & $*$ & $*$ & $*$ & $*$ \\
\hline
\end{tabular}

Disponibilidade dos agentes: $[23,11,0]-[0,8,0]=[23,3,0]$

Tabela 12. Passo 8 - Opções de designação $f(i, j)=a_{i j}$ com arrependimento.

\begin{tabular}{ccccccccccccccccc} 
Passo 8 & \multicolumn{1}{c}{ Designar } & $T_{5}$ & a & $A_{1}$ : custo de 26 & e consumo de recurso de 7 \\
\cline { 2 - 12 }$T_{5} A_{1}$ & $T_{1}$ & $T_{2}$ & $T_{3}$ & $T_{4}$ & $T_{5}$ & $T_{6}$ & $T_{7}$ & $T_{8}$ & $T_{1}$ & $T_{2}$ & $T_{3}$ & $T_{4}$ & $T_{5}$ & $T_{6}$ & $T_{7}$ & $T_{8}$ \\
\hline$A_{1}$ & $*$ & $*$ & $*$ & $*$ & 26 & $*$ & $*$ & $*$ & $*$ & $*$ & $*$ & $*$ & 7 & $*$ & $*$ & $*$ \\
$A_{2}$ & $*$ & $*$ & $*$ & $*$ & $*$ & $*$ & $*$ & $*$ & $*$ & $*$ & $*$ & $*$ & $*$ & $*$ & $*$ & $*$ \\
$A_{3}$ & $*$ & $*$ & $*$ & $*$ & $*$ & $*$ & $*$ & $*$ & $*$ & $*$ & $*$ & $*$ & $*$ & $*$ & $*$ & $*$ \\
\hline
\end{tabular}

Disponibilidade dos agentes: $[23,3,0]-[7,0,0]=[16,3,0]$

devido à designação de outra tarefa que consuma os recursos disponíveis e necessários para esta única opção. Após a conclusão dos oito passos, a solução factível de custo $\mathbf{2 5 1}$ da Tabela 13 é encontrada. Caso a mesma heurística seja executada com a medida de atratividade $f(i, j)=a_{i j}$ sem arrependimento, a solução factível de custo 258 da Tabela 14 é encontrada.

Tabela 13. Solução após a conclusão da heurística para $f(i, j)=a_{i j}$ com arrependimento.

\begin{tabular}{cccccccc}
\hline & & \multicolumn{5}{c}{ Capacidade dos agentes } \\
\cline { 3 - 8 } Agente & Tarefas & Inicial & Utilizada & Final (disponível) & Custo \\
\hline$A_{1}$ & $T_{3}$ & $T_{4}$ & $T_{5}$ & 30 & 14 & 16 & 93 \\
$A_{2}$ & $T_{2}$ & $T_{6}$ & $T_{7}$ & 25 & 22 & 3 & 119 \\
$A_{3}$ & $T_{1}$ & $T_{8}$ & & 35 & 35 & 0 & 39 \\
\hline \multicolumn{1}{c}{} & & & \multicolumn{4}{c}{ Custo Total: } & $\mathbf{2 5 1}$ \\
\hline
\end{tabular}

Tabela 14. Solução após a conclusão da heurística para $f(i, j)=a_{i j}$ sem arrependimento.

\begin{tabular}{cccccccc}
\hline & & \multicolumn{5}{c}{ Capacidade dos agentes } \\
\cline { 3 - 8 } Agente & & Tarefas & & Inicial & Utilizada & Final (disponível) & Custo \\
\hline$A_{1}$ & $T_{3}$ & $T_{8}$ & & 30 & 28 & 2 & 70 \\
$A_{2}$ & $T_{2}$ & $T_{5}$ & $T_{6}$ & 25 & 19 & 6 & 84 \\
$A_{3}$ & $T_{1}$ & $T_{4}$ & $T_{7}$ & 35 & 35 & 0 & 104 \\
\hline \multicolumn{1}{c}{} & & & & Custo Total: & $\mathbf{2 5 8}$ \\
\hline
\end{tabular}

\section{Busca Tabu Aplicada ao Exemplo}

A busca tabu parte de uma solução, em geral, gerada por uma heurística construtiva e guia um procedimento heurístico de busca local ou busca em vizinhança. Uma solução é transformada em uma solução vizinha por uma operação chamada movimento, e constitui uma iteração do método. A memória de curto prazo armazena atributos de soluções que mudaram nas últimas iterações ou no passado recente (recently-based memory). Um atributo de uma solução é uma parte da solução. No caso do PDG uma solução corresponde a identificar as tarefas designadas a cada agente, e um atributo da solução é uma tarefa $j$ e o agente $i$ a ela associado.

Atributos selecionados de soluções visitadas recentemente são denominados tabu-ativo, e os movimentos que levam a soluções que contêm atributos tabu-ativos tornam-se proibidos, isto é, são tabu por um determinado número de iterações, chamado duração tabu. O motivo principal da inclusão desta restrição tabu na vizinhança 
é permitir que o método escape de ótimos locais, induzindo a busca a percorrer uma nova trajetória. Sem esta restrição, o método pode escolher o melhor movimento correspondente à menor degradação da função objetivo, e na próxima iteração, ou após algumas iterações retornar ao ótimo local, o que caracteriza uma ciclagem, isto é um ciclo periódico com as mesmas soluções.

Para ilustrar o método de busca em vizinhança, a operação movimento e a memória de curto prazo, utilizase o exemplo da Seção 3. A vizinhança utilizada é a de inserção, composta de soluções vizinhas da solução corrente alcançadas ao se mover uma tarefa $j$ de um agente $r$ para outro agente $s$. Após a avaliação de todas as soluções vizinhas, escolhe-se aquela de melhor função objetivo (menor custo). Neste exemplo, considerou-se a duração tabu igual a 3 iterações.

Após o movimento da tarefa $j$ para o agente $s$, a memória de curto prazo é atualizada para que a tarefa $j$ seja obrigada a permanecer no agente $s$ por pelo menos duracão tabu=3 iterações. Em outras palavras, é proibido (tabu) mover a tarefa $j$ nas próximas 3 iterações. O objetivo desta proibição é evitar que a busca entre em ciclo visitando continuamente as mesmas soluções, por exemplo, mover repetidamente a tarefa $j$ de $r$ para $s$, de $s$ para $r$, de $r$ para $s$, etc.

Ao visitar uma solução vizinha, esta solução pode ser factível (a capacidade de nenhum agente é excedida) ou infactível (a capacidade de pelo menos um agente é excedida). Caso a solução vizinha seja infactível, pode-se descartá-la ou, então, pode ser avaliada pelo valor da função objetivo adicionado de uma penalidade associada com a soma das violações das capacidades dos agentes.

Este exemplo adota o critério de penalizar uma solução infactível, uma vez que, como é mostrado a seguir, uma vizinhança que considere somente soluções factíveis pode ser muito restritiva, com poucos vizinhos, ou até mesmo nenhum vizinho factível.

A penalização da infactibilidade é realizada pela multiplicação da quantidade total que excede as capacidades dos agentes por um parâmetro positivo Pen, por exemplo, Pen $=2$. Este produto é acrescentado ao valor da função objetivo resultando em uma função objetivo penalizada, que apresenta a informação ponderada entre a qualidade das alocações de tarefas a agentes (custo de designação) e a infactibilidade dos agentes (multiplicação entre Pen e a quantidade total do excesso de capacidade).

A escolha do valor do multiplicador Pen determina a tendência da busca em visitar soluções infactíveis. Um alto valor do multiplicador induz a busca a priorizar movimentos de baixa ou nenhuma infactibilidade enquanto um baixo valor de Pen incentiva movimentos de forte redução de custo de alocação que podem ser infactíveis. Testes empíricos são realizados para se determinar a faixa de valores do multiplicador que produz o comportamento desejado pela busca. Neste exemplo, foi considerado o valor de Pen $=2$, isto é, o custo de cada unidade de excesso de recurso, em qualquer agente, é avaliado em 2 unidades de custo.

Após a definição da vizinhança e movimentos (inserções que resultem em soluções factíveis ou infactíveis) e da memória de curto prazo (a tarefa deve, depois do movimento, permanecer no agente por pelo menos 3 iterações), a busca tabu pode ser iniciada. A solução de partida é a solução de custo 258 encontrada pela heurística construtiva da Tabela 14. Como esta solução é a melhor solução factível encontrada até o momento, esta solução é denominada de solução incumbente. O ponto de partida da busca tabu e a capacidade disponível em cada agente após a execução de todos os movimentos de inserção são mostrados na Tabela 15.

Tabela 15. Exemplo de Busca Tabu - Solução de partida.

\begin{tabular}{|c|c|c|c|c|c|c|c|c|c|c|c|c|c|}
\hline \multirow[b]{2}{*}{ Agente } & \multirow[b]{2}{*}{ Tarefas } & \multicolumn{2}{|c|}{ Capacidade } & \multicolumn{3}{|c|}{ Custo } & \multicolumn{7}{|c|}{ Cap. disp. após movimento } \\
\hline & & Disp. & Excesso & Alocação & Excesso & Total & $T_{1} T_{2}$ & $T_{3}$ & $T_{4}$ & $T_{5}$ & $T_{6}$ & $T_{7}$ & $T_{8}$ \\
\hline$A_{1}$ & $T_{3} T_{8}$ & 2 & 0 & 70 & 0 & 70 & $-19-11$ & $\bullet$ & -1 & -5 & -13 & -20 & $\bullet$ \\
\hline$A_{2}$ & $T_{2} T_{5} T_{6}$ & 6 & 0 & 84 & 0 & 84 & $-14 \bullet$ & -17 & -19 & $\bullet$ & $\bullet$ & -3 & -8 \\
\hline \multirow[t]{2}{*}{$A_{3}$} & $T_{1} T_{4} T_{7}$ & 0 & 0 & 104 & 0 & 104 & - -12 & -18 & $\bullet$ & -11 & -10 & $\bullet$ & -19 \\
\hline & & $\mathrm{Cus}$ & O lotal. & 258 & 0 & 258 & & & & & & & \\
\hline
\end{tabular}

Valor da solução incumbente: 258.

*alocação atual é representada por •

Valor negativo representa o valor da capacidade excedida

Cada linha da Tabela 15 corresponde à alocação de um conjunto de tarefas a um agente. Por exemplo, a primeira linha mostra a alocação das tarefas $T_{3}$ e $T_{8}$ ao agente $A_{1}$. As duas colunas de capacidade (disponibilidade e excesso) mostram, respectivamente, a capacidade disponível de cada agente e a quantidade de recursos alocados acima da capacidade. Tomando ainda como exemplo a primeira linha da Tabela 15, o valor 2 de disponibilidade indica que ainda restam 2 unidades de recurso disponíveis para $A_{1}$ e o valor zero de excesso indica que não foram alocados recursos acima da capacidade de $A_{1}$. As três colunas seguintes mostram os custos de alocação, excesso e total. O custo de alocação é o somatório dos custos de alocação das tarefas ao agente. Para o exemplo, o valor 70 foi calculado pela soma de $c_{13}=33$ com $c_{18}=37$. O custo de 
excesso é calculado pela multiplicação de Pen $=2$ pelo excesso de recursos alocados. A coluna total de custos é o somatório dos custo de alocação com o custo de excesso. As últimas oito colunas desta tabela indicam qual seria a disponibilidade de capacidade em cada agente se a tarefa de cada coluna fosse alocada ao agente da linha. Por exemplo, se $T_{2}$ fosse alocada a $A_{1}$, a disponibilidade de $A_{1}$ seria reduzida de 2 para -11 , uma vez que $a_{12}=13$. O símbolo $\bullet$ nestas colunas indica que a tarefa está alocada ao agente, por exemplo, $T_{3}$ e $T_{8}$ alocadas a $A_{1}$.

Todos os movimentos de inserção ilustrados na Tabela 15 produzem soluções infactíveis, uma vez que todos os valores de capacidade disponível após o movimento são negativos. Esta iteração mostra que, se uma vizinhança de somente soluções factíveis fosse considerada, não haveria nenhum movimento possível para a busca realizar.

Para avaliar as soluções vizinhas e selecionar a melhor solução, o custo do movimento de inserção é calculado somando a variação do custo de alocação (custo final - custo incial) ao custo da infactibilidade (valor da infactibilidade multiplicado por Pen $=2$ ). Por exemplo, o custo de inserir $T_{4}$ no agente $A_{1}$ é igual a $c_{14}-c_{34}+2(1)=34-40+2=-4^{1}$.

A Tabela 16 mostra o custo (variação do valor da função objetivo penalizada) de todas as inserções possíveis na primeira iteração. Como a busca tabu executa o melhor movimento possível que não seja tabu, a tarefa $T_{2}$ é designada ao agente $A_{3}$.

Tabela 16. Variação do custo para cada movimento de inserção - Iteração 1.

\begin{tabular}{ccccccccc}
\hline & \multicolumn{8}{c}{ Tarefa } \\
\cline { 2 - 9 } Agente & $T_{1}$ & $T_{2}$ & $T_{3}$ & $T_{4}$ & $T_{5}$ & $T_{6}$ & $T_{7}$ & $T_{8}$ \\
\hline$A_{1}$ & 44 & 15 & $\bullet$ & -4 & 22 & 20 & 5 & $\bullet$ \\
$A_{2}$ & 47 & $\bullet$ & 14 & 39 & $\bullet$ & $\bullet$ & 8 & -5 \\
$A_{3}$ & $\bullet$ & -6 & 33 & $\bullet$ & 37 & 22 & $\bullet$ & 23 \\
\hline
\end{tabular}

A designação de $T_{2}$ a $A_{3}$ reduz o custo da função penalizada em 6 unidades, $c_{32}-c_{22}+2(12)=15-45+24=$ -6, diminuindo o valor da função objetivo penalizada de 258 para 252 . A solução resultante é infactível porque a capacidade de $A_{3}$ é excedida em 12 unidades. Desta forma, a solução incumbente de valor 258 não é atualizada para 252. É esperado que nas iterações seguintes sejam encontradas outras soluções factíveis de custo inferior a 258. A Tabela 17 mostra a solução da iteração 1 e os movimentos disponíveis para a iteração 2, e a Tabela 18 mostra a variações de custo de cada movimento.

Tabela 17. Exemplo de Busca Tabu - Iteração 1.

\begin{tabular}{|c|c|c|c|c|c|c|c|c|c|c|c|c|c|}
\hline \multirow[b]{2}{*}{ Agente } & \multirow[b]{2}{*}{ Tarefas } & \multicolumn{2}{|c|}{ Capacidade } & \multicolumn{3}{|c|}{ Custo } & \multicolumn{7}{|c|}{ Cap. disp. após movimento } \\
\hline & & Disp. & Excesso & Alocação & Excesso & Total & $T_{1} T_{2}$ & $T_{3}$ & $T_{4}$ & $T_{5}$ & $T_{6}$ & $T_{7}$ & $T_{8}$ \\
\hline$A_{1}$ & $T_{3} T_{8}$ & 2 & 0 & 70 & 0 & 70 & $-19-11$ & $\bullet$ & -1 & -5 & -13 & -20 & $\bullet$ \\
\hline$A_{2}$ & $T_{5} T_{6}$ & 14 & 0 & 39 & 0 & 39 & $\begin{array}{ll}-6 & 6\end{array}$ & -9 & -11 & $\bullet$ & $\bullet$ & 5 & 0 \\
\hline$A_{3}$ & $\begin{array}{llll}T_{1} & T_{4} & T_{7} & T_{2} \\
\end{array}$ & 0 & 12 & 119 & 24 & 143 & $\bullet$ & -18 & $\bullet$ & -11 & -10 & $\bullet$ & -19 \\
\hline \multicolumn{4}{|c|}{ Custo Total: } & 228 & 24 & 252 & & & & & & & \\
\hline
\end{tabular}

$T_{2}$ está tabu até a iteração 4 .

Valor da solução incumbente: 258.

Tabela 18. Variação do custo para cada movimento de inserção - Iteração 2.

\begin{tabular}{ccccccccc}
\hline & \multicolumn{8}{c}{ Tarefa } \\
\cline { 2 - 9 } Agente & $T_{1}$ & $T_{2}$ & $T_{3}$ & $T_{4}$ & $T_{5}$ & $T_{6}$ & $T_{7}$ & $T_{8}$ \\
\hline$A_{1}$ & 20 & 21 & $\bullet$ & -8 & 22 & 20 & -19 & $\bullet$ \\
$A_{2}$ & 7 & 6 & -2 & 19 & $\bullet$ & $\bullet$ & -22 & -21 \\
$A_{3}$ & $\bullet$ & $\bullet$ & 33 & $\bullet$ & 37 & 22 & $\bullet$ & 23 \\
\hline
\end{tabular}

De forma similar à primeira iteração, o próximo movimento selecionado é designar $T_{7}$ a $A_{2}$, reduzindo o custo da função penalizada em 22 . A variação de custo de -22 da função penalizada é calculada a partir da diferença dos custos de alocação da tarefa $T_{7}$ aos agentes $A_{3}$ e $A_{2}$ e também da redução das 12 unidades de recurso em excesso no agente $A_{3}: c_{27}-c_{37}-2(12)=49-47-24=-22$.

\footnotetext{
1 Os valores de $c_{i j}$ são mostrados na Tabela 1.
} 
A solução resultante é factível, como mostrado na Tabela 19, e como seu custo é menor do que o custo da solução incumbente, o valor da incumbente é atualizado para 230. A Tabela 20 mostra a variação de custo dos movimentos desta iteração e as Tabelas 21 a 24 mostram as informações das duas iterações seguintes.

Tabela 19. Exemplo de Busca Tabu - Iteração 2.

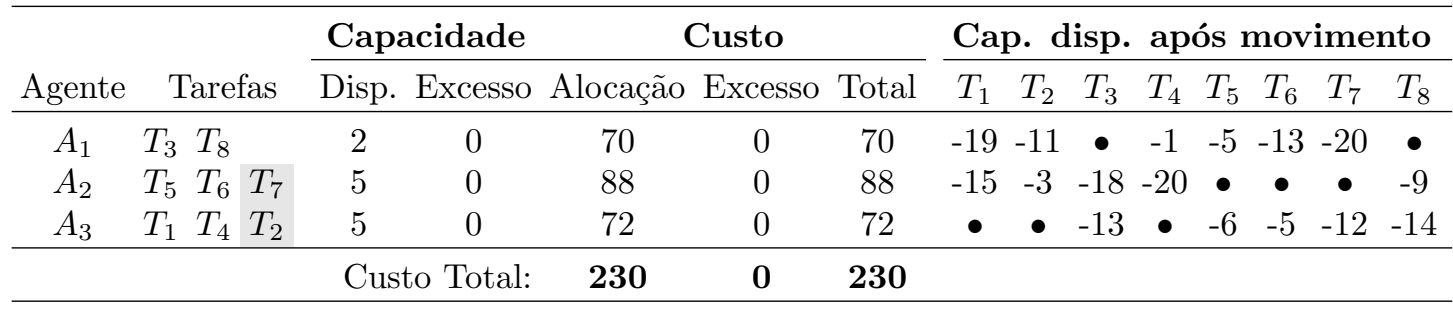

$T_{2}$ está tabu até a iteração 4 ;

$T_{7}$ está tabu até a iteração 5 ;

Valor da solução incumbente: 230.

Tabela 20. Variação do custo para cada movimento de inserção - Iteração 3.

\begin{tabular}{ccccccccc}
\hline & \multicolumn{8}{c}{ Tarefa } \\
\cline { 2 - 9 } Agente & $T_{1}$ & $T_{2}$ & $T_{3}$ & $T_{4}$ & $T_{5}$ & $T_{6}$ & $T_{7}$ & $T_{8}$ \\
\hline$A_{1}$ & 44 & 45 & $\bullet$ & -4 & 22 & 20 & 3 & $\bullet$ \\
$A_{2}$ & 49 & 36 & 16 & 41 & $\bullet$ & $\bullet$ & $\bullet$ & -3 \\
$A_{3}$ & $\bullet$ & $\bullet$ & 23 & $\bullet$ & 27 & 12 & 22 & 13
\end{tabular}

Tabela 21. Exemplo de Busca Tabu - Iteração 3.

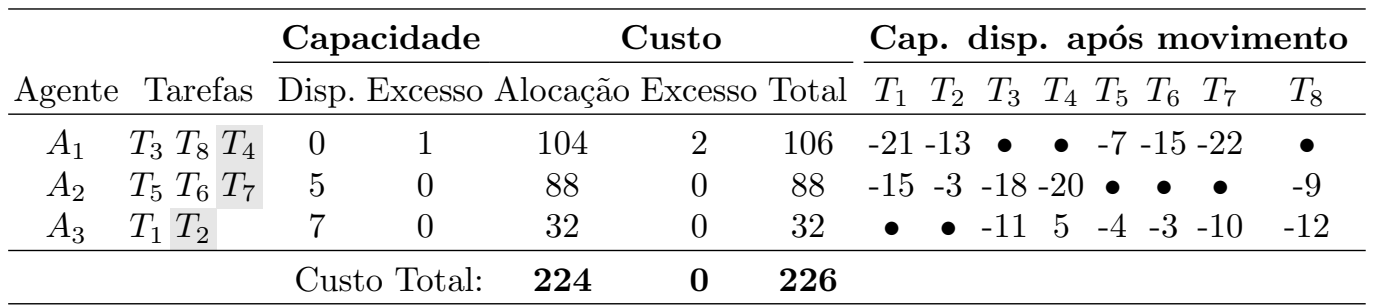

$T_{2}$ está tabu até a iteração 4 ;

$T_{7}$ está tabu até a iteração 5 ;

$T_{4}$ está tabu até a iteração 6 ;

Valor da solução incumbente: 230 .

Tabela 22. Variação do custo para cada movimento de inserção - Iteração 4.

\begin{tabular}{cccccccccc}
\hline & \multicolumn{1}{c}{ Tarefa } \\
\cline { 2 - 9 } Agente & $T_{1}$ & $T_{2}$ & $T_{3}$ & $T_{4}$ & $T_{5}$ & $T_{6}$ & $T_{7}$ & $T_{8}$ \\
\hline$A_{1}$ & 48 & 49 & $\bullet$ & $\bullet$ & 26 & 24 & 7 & $\bullet$ \\
$A_{2}$ & 49 & 36 & 14 & 45 & $\bullet$ & $\bullet$ & $\bullet$ & -5 \\
$A_{3}$ & $\bullet$ & $\bullet$ & 17 & 4 & 23 & 8 & 18 & 7 \\
\hline
\end{tabular}

Como indicado na Tabela 24, o melhor movimento da iteração 5 é designar $T_{7}$ ao agente $A_{1}$ gerando uma redução de custo de 55. Como $T_{7}$ está tabu nesta iteração, esta tarefa não poderia ser movida a outro agente e este movimento não poderia ser executado. Entretanto, como a execução deste movimento provoca a melhoria do valor da incumbente de 230 para 166, encontrando a melhor solução factível até o momento da busca, aplica-se o critério de aspiração para a execução deste movimento. O critério de aspiração permite que um movimento tabu seja executado se e somente se este movimento resulte em melhoria da incumbente. Desta forma, o movimento de designação de $T_{7}$ a $A_{1}$ é executado e a solução obtida na iteração é mostrada na Tabela 25.

A situação da busca no início da iteração 6 é semelhante à situação da busca na iteração 1 pois em ambas as iterações qualquer movimento produz uma solução infactível. Todavia, ao comparar as Tabelas 16 e 26, percebe-se que na iteração 1 havia movimentos que resultavam em melhoria da função objetivo penalizada 
Tabela 23. Exemplo de Busca Tabu - Iteração 4.

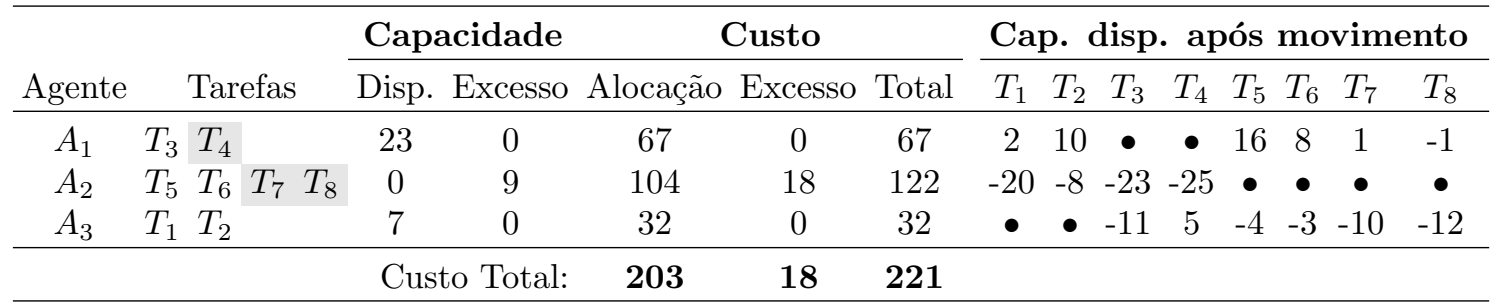

$T_{7}$ está tabu até a iteração 5 ;

$T_{4}$ está tabu até a iteração $6 ;$

$T_{8}$ está tabu até a iteração 7 ;

Valor da solução incumbente: 230.

Tabela 24. Variação do custo para cada movimento de inserção - Iteração 5.

\begin{tabular}{ccccccccc}
\hline & \multicolumn{7}{c}{ Tarefa } \\
\cline { 2 - 9 } Agente & $T_{1}$ & $T_{2}$ & $T_{3}$ & $T_{4}$ & $T_{5}$ & $T_{6}$ & $T_{7}$ & $T_{8}$ \\
\hline$A_{1}$ & 6 & 23 & $\bullet$ & $\bullet$ & 0 & -16 & -55 & 5 \\
$A_{2}$ & 59 & 46 & 24 & 55 & $\bullet$ & $\bullet$ & $\bullet$ & $\bullet$ \\
$A_{3}$ & $\bullet$ & $\bullet$ & 17 & 4 & 11 & -2 & 0 & 12 \\
\hline
\end{tabular}

Tabela 25. Exemplo de Busca Tabu - Iteração 5.

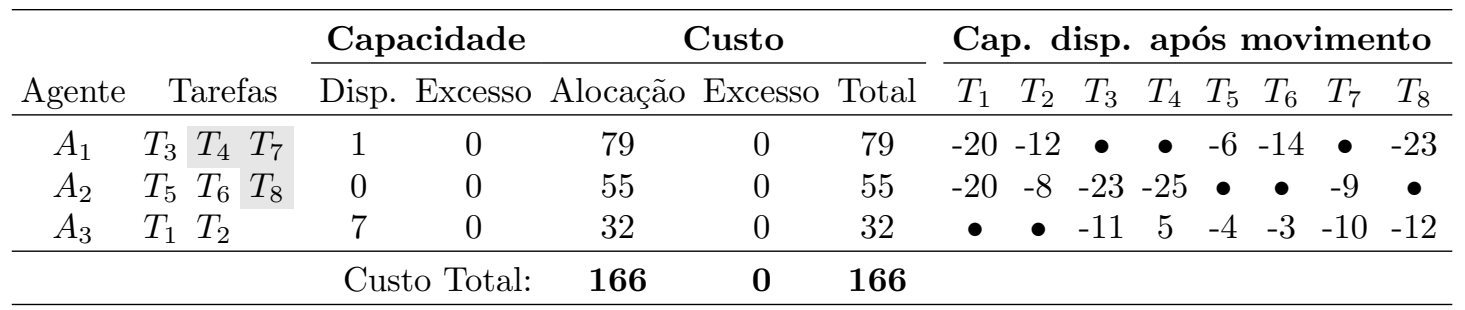

$T_{4}$ está tabu até a iteração 6 ;

$T_{8}$ está tabu até a iteração 7 ;

$T_{7}$ está tabu até a iteração 8;

Valor da solução incumbente: 166.

(por exemplo, designar $T_{2}$ a $A_{3}$ na iteração 1) enquanto todos os movimentos da iteração 6 resultam em piora da função objetivo penalizada (por exemplo, o melhor movimento da iteração 6 seria alocar $T_{4}$ a $A_{3}$ piorando o custo da função penalidade em 6 unidades). Quando a busca alcança uma região em que todas as soluções vizinhas são piores que a solução atual, conclui-se que a busca encontrou um ótimo local, ou mínimo local, pois o PDG é um problema de minimização. O mínimo local encontrado na iteração 5 é, coincidentemente, também o mínimo global, ou seja, a melhor solução factível que existe para este exemplo.

Pode-se permitir que a busca continue visitando outras soluções por mais iterações até que o limite máximo de iterações seja atingido. Por exemplo, o próximo movimento seria designar $T_{6}$ a $A_{3}$, uma vez que $T_{4}$ está tabu e o critério de aspiração não se aplica neste caso (Tabela 26). Outro critério de parada poderia ser estipular um tempo computacional máximo, ou então combinar critérios como tempo máximo e número máximo de iterações sem atualizar a solução incumbente.

Tabela 26. Variação do custo para cada movimento de inserção - Iteração 6.

\begin{tabular}{cccccccccc}
\hline & \multicolumn{8}{c}{ Tarefa } \\
\cline { 2 - 9 } Agente & $T_{1}$ & $T_{2}$ & $T_{3}$ & $T_{4}$ & $T_{5}$ & $T_{6}$ & $T_{7}$ & $T_{8}$ \\
\hline$A_{1}$ & 46 & 47 & $\bullet$ & $\bullet$ & 24 & 22 & $\bullet$ & 67 \\
$A_{2}$ & 59 & 46 & 26 & 57 & $\bullet$ & $\bullet$ & 55 & $\bullet$ \\
$A_{3}$ & $\bullet$ & $\bullet$ & 19 & 6 & 23 & 8 & 55 & 30 \\
\hline
\end{tabular}




\section{Memória de Curto Prazo para uma Instância da Literatura}

Esta seção aborda a resolução da instância d10200 da literatura com 10 agentes e 200 tarefas com melhor valor de solução encontrado até agora de $12432^{2}$. Para isto é necessário ampliar o escopo dos componentes da memória de curto prazo para o PDG.

\subsection{Vizinhança}

A vizinhança de inserção envolve o movimento que muda a designação de uma tarefa $j$ de um agente $r$ para um agente $s$. Este movimento é considerado influente no sentido que o número de tarefas do agente $r$ é reduzido de uma unidade, enquanto o número de tarefas do agente $s$ é aumentado de uma unidade. Além disso, o consumo de recursos do agente $r$ é reduzido de $a_{r j}$, enquanto o consumo de recursos é aumentado de $a_{s j}$ para o agente $s$.

A vizinhança de troca consiste do movimento de troca de uma tarefa $j$ designada ao agente $r$ com outra tarefa $k$ designada ao agente $s$ resultando na designação de $j$ a $s$ e de $k$ a $r$. Este movimento mantém o número de tarefas em cada agente, e permite variações positivas e negativas de consumo dos recursos dos agentes, ao contrário da inserção que resulta em variação negativa para o agente $r$ e variação positiva para o agente $s$. Esta variação de consumo em um movimento de troca para o agente $r$ é $a_{r k}-a_{r j}$ e para o agente $s$ é $a_{s j}-a_{s k}$.

Quando a busca possui duas vizinhanças, tais como troca e inserção, deve-se definir como usá-las para escolher o melhor movimento. São testados quatro critérios: (i) usar somente vizinhança de inserção, (ii) usar somente vizinhança de troca, (iii) escolher o melhor movimento de cada vizinhança de forma alternada a cada iteração, e (iv) escolher o melhor movimento entre todos os movimentos de troca e inserção a cada iteração.

\subsection{Regras de ativação tabu}

Associado ao atributo em que uma tarefa $j$ é designada ao agente $r$, existem três regras de ativação tabu que proíbem movimentos por um certo número de iterações. Suponha que a tarefa $j$ em uma dada iteração está associada ao agente $r$ e na próxima iteração esta tarefa deixa este agente e é designada ao agente $s$, por meio de um movimento de troca ou de inserção. Uma regra de proibição (a) impede que a tarefa $j$ saia do agente $s$ e a outra regra (b) impede que a tarefa $j$ volte a ser designada ao agente $r$. A terceira regra (c) é uma combinação das duas regras anteriores.

\subsection{Lista tabu}

Uma implementação conveniente para identificar as iterações em que um movimento (isto é, o atributo associado) é proibido por uma das três regras é a seguinte. Seja TabuInício = Iter, a iteração em que a tarefa $j$ é movida do agente $r$ para o agente $s$, TabuFim a iteração em que a proibição termina, e Duração Tabu o número de iterações em que o movimento é proibido. Então,

$$
\text { TabuFim }=\text { Iter }+ \text { DuraçãoTabu }
$$

Para a regra de proibição que impede que a tarefa $j$ saia do agente $s$, TabuFim pode ser implementado como um vetor em que cada elemento $j$ armazena a informação de Iter + DuraçãoTabu. Desta forma, para saber se um movimento não é tabu, basta comparar se a iteração atual é maior do que o valor do elemento $j$. Para a regra de proibição que impede que a tarefa $j$ volte a ser designada ao agente $r$, o valor TabuFim pode ser armazenado numa matriz em que o elemento $(r, j)$ indica a iteração até a qual a tarefa $j$ não pode ser novamente designada ao agente $r$.

\subsection{Critérios de aspiração}

Critérios de aspiração são usados em busca tabu para determinar quando regras de ativação tabu podem ser desconsideradas, o que permite que um movimento classificado como tabu possa ser executado. Dois critérios são largamente aplicados na literatura: o primeiro permite que um movimento tabu seja executado se o valor da solução incumbente é atualizado; o segundo libera o movimento de valor mínimo de TabuFim no caso em que todos os movimentos estejam classificados como tabu em uma iteração. Estes dois critérios são usados neste capítulo, e para outros critérios de aspiração veja Glover \& Laguna (1997).

\footnotetext{
2 Esta instância encontra-se na biblioteca OR-library http://people.brunel.ac.uk/ mastjjb/jeb/info.html e seu melhor resultado pode ser consultado em Yagiura et al. (2006).
} 


\subsection{Duração tabu}

A duração tabu para a regra de ativação tabu (a) é selecionada de forma aleatória dentro do intervalo [tabuMin, tabuMax] a cada iteração. O valor tabuMin é calculado a partir da expressão tabuMin $=\lfloor\ln ($ número de agentes $\times$ número de tarefas) $\rfloor$ e tabuMax $=$ tabuMin +5 . Portanto, para o exemplo de 10 agentes e 200 tarefas, o valor da duração tabu para o tipo de proibição (i) pertence ao intervalo [7, 12].

A duração tabu proposta para a regra de ativação tabu (b) é 2,5 vezes o valor da duração tabu para a regra de ativação (a), porque a regra (b) é menos restritiva e requer um valor maior de duração tabu para evitar ciclagem e obter melhores resultados na busca. A regra (a) é mais restritiva pois impede que uma tarefa seja movida, enquanto a regra (b) permite que a tarefa seja movida para outros agentes desde que não seja o agente de origem do movimento. Quando ambos os tipos de proibições (a) e (b) são utilizadas ao mesmo tempo, a duração tabu para o tipo de proibição (b) é reduzida para 2 vezes o valor da duração tabu para o tipo de proibição (a).

Caso a solução incumbente seja atualizada, a memória de curto prazo é zerada e os valores de duração tabu são atribuídos para o valor mínimo por pelo menos $\lfloor\sqrt{\text { número de agentes } \times \text { número de tarefas }}\rfloor$ iterações (44 iterações para este exemplo). Esta é uma estratégia de intensificação que permite que a busca possa explorar com menos restrições os vizinhos da solução que atualizou a incumbente, numa tentativa de encontrar nesta região soluções ainda melhores que a atual.

\subsection{Critério de parada}

O número máximo de iterações para a busca tabu foi estipulado em 57000 iterações. Em geral, o número máximo de iterações é função do tamanho da instância e o número de 57000 foi calculado pela expressão $(7500 \times \ln ($ número de agentes $\times$ número de tarefas) .

\subsection{Solução de partida}

A solução de partida para a busca tabu é obtida pela heurística construtiva com medida de atratividade $f(i, j)=a_{i j}$ com arrependimento, com valor de 20.300, que é $63 \%$ maior que o valor 12.432 , correspondente ao melhor resultado publicado na literatura, como mostrado em Yagiura et al. (2006).

\subsection{Resultados para busca somente com soluções factíveis}

A busca tabu foi implementada em $\mathrm{C}++$ e testes computacionais foram executados num computador Intel Xeon 2,83 GHz, 8Gb RAM, com sistema operacional Ubuntu. A Tabela 27 mostra os resultados das variantes da memória de curto prazo da busca tabu somente no espaço de soluções factíveis para esta instância de 10 agentes e 200 tarefas.

A qualidade das soluções encontradas é avaliada pelo desvio percentual entre o custo da solução encontrada e o custo da melhor solução mencionada anteriormente. Este desvio é calculado da seguinte forma:

$$
\text { Desvio }=\frac{(\text { custo encontrado }- \text { melhor custo da literatura })}{\text { melhor custo da literatura }} \times 100
$$

Na Tabela 27, a primeira coluna indica os tipos de vizinhança. As colunas 2, 3 e 4 mostram o desvio percentual para cada tipo de vizinhança e cada regra de ativação tabu. As colunas 4, 5 e 6 indicam o tempo computacional requerido, e as colunas 7, 8 e 9 mostram a iteração em que solução incumbente foi encontrada.

Tabela 27. Resultado da busca tabu para somente vizinhos factíveis.

\begin{tabular}{lllllllllll}
\hline & \multicolumn{3}{c}{$\begin{array}{c}\text { \% do melhor } \\
\text { valor da literatura }\end{array}$} & \multicolumn{3}{c}{ Tempo comp. } & \multicolumn{4}{c}{$\begin{array}{c}\text { Iteração } \\
\text { incumbente }\end{array}$} \\
\hline Vizinhança & (a) & (b) & (c) & (a) & (b) & (c) & (a) & (b) & (c) \\
\hline i) Inserção & $5,5 \%$ & $6,5 \%$ & $5,6 \%$ & 3 & 3 & 3 & 32845 & 35176 & 49966 \\
ii) Troca & $1,1 \%$ & $1,1 \%$ & $0,92 \%$ & 44 & 46 & 46 & 49600 & 39984 & 31421 \\
iii) 1 inserção, 1 troca & $2,0 \%$ & $1,9 \%$ & $2,3 \%$ & 47 & 48 & 48 & 48795 & 52236 & 38977 \\
iv) Melhor (i) e (ii) & $0,93 \%$ & $0,88 \%$ & $0,90 \%$ & 47 & 49 & 48 & 44315 & 32337 & 50762 \\
\hline
\end{tabular}

Regras de ativação tabu: a) tarefa deve permanecer no agente de destino; b) tarefa não pode retornar ao agente de origem; c) ambos os tipos de proibição.

Os melhores resultados são obtidos para as vizinhanças (ii) e (iv) e regras de ativação tabu (b) e (c). Os resultados também mostram as seguintes conclusões: 
- Qualquer configuração da busca tabu melhora drasticamente a solução obtida pela heurística construtiva, pois o custo inicial é $63 \%$ maior do que o melhor valor da literatura;

- Apesar do tempo computacional da vizinhança de inserção ser muito baixo, esta vizinhança não produz bons resultados quando a busca é restrita somente a vizinhos factíveis;

- O efeito da baixa qualidade das inserções numa busca em somente vizinhos factíveis também pode ser observado no resultado mediano da vizinhança (iii);

- A vizinhança (iv) com a regra de ativação tabu (b) alcança o melhor resultado na iteração 32337.

Para ilustrar os comportamentos de uma variante da busca tabu que consegue alcançar um bom resultado e de outra variante que não consegue, a melhor variante (iv)-(b) é comparada à variante (iii)-(c) na Figura 1.

O valor da função objetivo por iteração de cada busca é mostrado na Figura 1. A linha superior mostra os valores da busca (iii)-(c) que alcança a melhor solução de 12721 (com desvio de 2,3\% na Tabela 27) enquanto a linha inferior mostra os valores da busca (iv)-(b) que obtém a melhor solução de 12541 (com desvio de $0,88 \%$ na Tabela 27). Ambas as buscas apresentam um comportamento oscilatório (sobe-desce) resultante do efeito da duração tabu e dos encontro de mínimos locais tabu. Entretanto, a busca (iii)-(c) apresenta um comportamento de estagnação enquanto a busca (iv)-(b) apresenta um comportamento de descida. A visualização do valor da função objetivo por iteração de forma gráfica ou tabular é uma excelente ferramenta para avaliar o desempenho da busca tabu e também para calibrar os valores de seus parâmetros como, por exemplo, o intervalo [tabuMin, tabuMax].

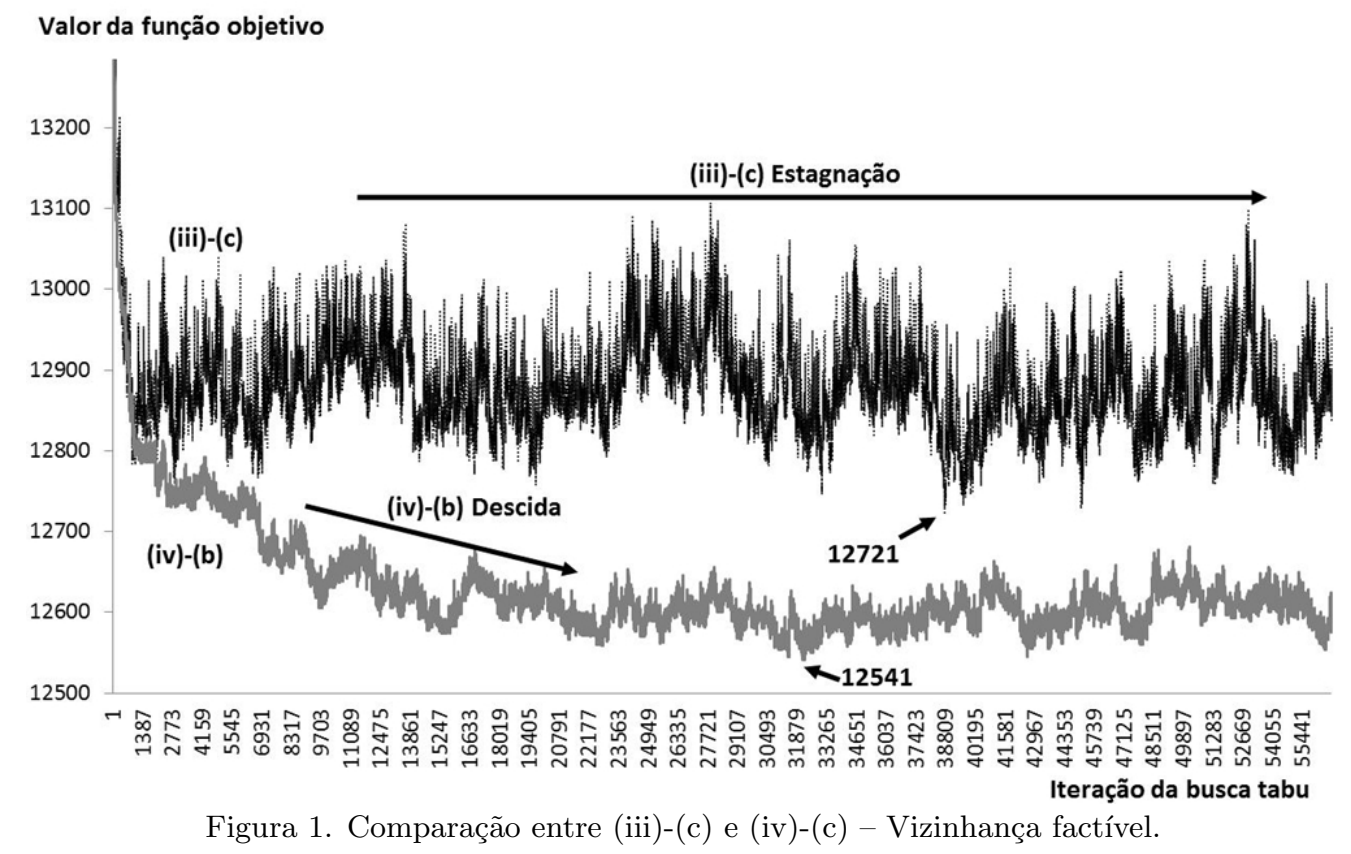

\subsection{Resultados para busca com soluções factíveis e infactíveis}

A seguir são mostrados os resultados das variantes da memória de curto prazo da busca tabu no espaço de soluções factíveis e infactíveis, da mesma forma que se aplicou a função objetivo penalizada no exemplo anterior de 3 agentes e 8 tarefas. Para tanto, é necessário definir a evolução do valor do multiplicador Pen e redefinir a duração tabu para sincronização com o valor de Pen.

O valor do multiplicador Pen proposto é sempre superior a $10^{-4}$ e é atualizado a cada $2 \times$ $\lfloor\ln ($ número de agentes $\times$ número de tarefas) $\rfloor$ iterações (15 iterações nesta instância), como mostrado a seguir. Note que existem outras formas mais simples para se controlar o multiplicador Pen. Por exemplo, pode-se atribuir um valor inicial para $P e n$ e, caso sejam encontradas 10 soluções factíveis em sequência, divide-se $P e n$ por 2. De forma similar, caso sejam encontradas 10 soluções infactíveis em sequência, multiplica-se o valor de Pen por 2, vide Gendreau et al. (1994).

a) Se a porcentagem de soluções factíveis de 15 iterações consecutivas for superior a 80\%, a busca está concentrada na região factível e, portanto, é desejável incentivá-la a visitar vizinhos infactíveis. Desta forma, Pen é reduzida para Pen=PenLimiteInferior; 
b) Se a porcentagem de soluções factíveis de 15 iterações consecutivas for inferior a 30\%, a busca está concentrada na região infactível. Então, o valor de penalidade é aumentado em um passo $($ Pen=Pen+passo $)$, sendo que:

$$
\text { passo }=\max \left(\frac{2^{10\left(\frac{\text { ExcessoCapacidade }}{\text { CapacidadeAgentes }}\right)}}{300} ; 0,01\right),
$$

em que, ExcessoCapacidade é igual à soma de todos os excessos de capacidade dos agentes e CapacidadeAgentes é igual a $\sum_{i=1}^{m} b i$;

c) Se ambos os casos (a) e (b) não ocorrerem, a busca é incentivada a buscar mais soluções factíveis aumentando Pen em um passo (Pen=Pen+passo).

O valor de PenLimiteInferior do item (a) é iniciado com o valor de $10^{-4}$ e é atualizado de forma dinâmica para que a percentagem de infactibilidade ( $\left.\frac{\text { ExcessoCapacidade }}{\text { CapacidadeAgentes }}\right)$ máxima seja por volta de $20 \%$. Logo, se a percentagem de infactibilidade máxima for inferior a 20\%, O valor de PenLimiteInferior precisa ser reduzido para permitir que a busca visite um maior número de soluções infactíveis. Desta forma, PenLimiteInferior $=$ PenLimiteInferior - passo. Por outro lado, caso a infactibilidade máxima seja superior a 20\%, o limitante precisa ser aumentado para reduzir o incentivo a visitas a soluções infactíveis, alterando o valor do limitante a partir da atribuição PenLimiteInferior = PenLimiteInferior + passo.

A expressão que calcula o tamanho do passo no item (b) faz com que passo cresça de forma exponencial em função da infactibilidade. Por exemplo, para percentuais de infactibilidade de 1\%, 50\%, 100\% e 120\%, o tamanho do passo é 0,$01 ; 0,1 ; 3,4$ e 13,7 , respectivamente ${ }^{3}$. Isto é desejável por dois motivos:

i. A busca deve retornar de forma rápida à região factível caso os vizinhos atuais sejam muito infactíveis (valor $\frac{\text { ExcessoCapacidade }}{\text { CapacidadeAgentes }}$ demasiadamente elevado), uma vez que a probabilidade de se atualizar a solução incumbente numa região muito infactível é baixa.

ii. A busca deve explorar bastante a região em que a factibilidade é baixa (valor $\frac{\text { ExcessoCapacidade }}{\text { CapacidadeAgentes }}$ reduzido), procurando a atualização da incumbente por meio da avaliação de um maior número de vizinhos pouco infactíveis.

A definição da duração tabu também depende da região (factível ou infactível) em que a busca se localiza. Quando a busca é levada para a região infactível no final do caso (a) (atribuição de Pen=PenLimiteInferior), a busca basicamente prioriza os movimentos de baixo custo de designação e possui a tendência de executar, para cada tarefa, os movimentos de designação mínima de forma cíclica. Desta forma, a duração tabu na região infactível é aumentada e está contida no intervalo [TabuMinInfact, TabuMaxInfact] em que:

$$
\text { TabuMinInfact }=\left\lfloor\ln (\text { agentes } \times \text { tarefas })\left(1+2\left(\frac{\text { ExcessoCapacidade }}{\text { CapacidadeAgentes }}\right)\right)\right\rfloor
$$

e

$$
\text { tabuMaxInfact }=\text { tabuMinInfact }+5
$$

Note que, quando ExcessoCapacidade $=0$ (a solução é factível), TabuMinInfact=tabuMin e TabuMaxInfact $=$ tabuMax.

A Figura 2 mostra a variação dos valores de passo e tabuMinInfact em função da alocação acima da capacidade.

A Tabela 28 mostra os resultados para a busca tabu que visita soluções factíveis e infactíveis. As seguintes conclusões são obtidas após a análise dos resultados da Tabela 28 e comparação com os resultados da Tabela 27:

- Todos os resultados da busca que visita soluções factíveis e infactíveis são melhores que os resultados da busca que não permite infactibilidade. Ao comparar as vizinhanças (ii), (iii) e (iv), o pior resultado da Tabela $28(0,43 \%)$ é melhor do que o melhor resultado da Tabela $27(0,88 \%)$;

- Diferentemente do que foi encontrado na Tabela 27, ao permitir a busca com infactibilidade, a vizinhança (iii) se mostrou melhor do que a vizinhança (ii), indicando que o uso da vizinhança inserção em conjunto com a vizinhança troca melhora o desempenho da busca tabu quando se permite vizinhos infactíveis;

\footnotetext{
3 Note que o percentual de infactibilidade pode ser superior a 100\%. Por exemplo, suponha que 5 tarefas sejam alocadas a um agente de capacidade 20 e que cada tarefa consuma 10 unidades de recurso deste agente. Neste caso, o percentual de infactibilidade será igual a $\frac{50-20}{20}=\frac{30}{20}=150 \%$.
} 


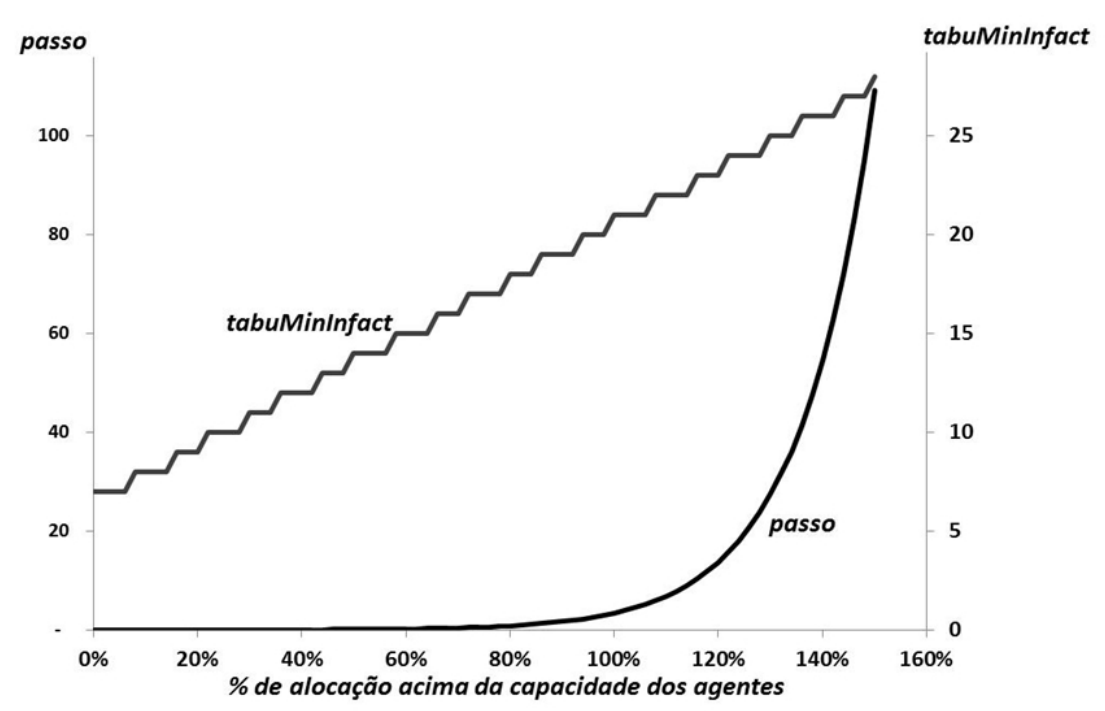

Figura 2. Passo e tabuMinInfact em função da alocação acima da capacidade.

Tabela 28. Resultado da busca tabu para vizinhos factíveis e infactíveis.

\begin{tabular}{llllllllllcc}
\hline & \multicolumn{3}{c}{$\begin{array}{c}\text { \% do melhor } \\
\text { valor da literatura }\end{array}$} & \multicolumn{2}{c}{$\begin{array}{c}\text { Tempo comp. } \\
\text { (seg.) }\end{array}$} & \multicolumn{3}{c}{$\begin{array}{c}\text { Iteração } \\
\text { incumbente }\end{array}$} \\
\hline Vizinhança & (a) & (b) & (c) & (a) & (b) & (c) & (a) & (b) & (c) \\
\hline i) Inserção & $4,43 \%$ & $4,02 \%$ & $4,28 \%$ & 4 & 5 & 5 & 1797 & 1331 & 1058 \\
ii) Troca & $0,43 \%$ & $0,43 \%$ & $0,43 \%$ & 52 & 59 & 60 & 49981 & 34643 & 20217 \\
iii) 1 inserção, 1 troca & $0,23 \%$ & $0,19 \%$ & $0,28 \%$ & 56 & 63 & 64 & 25576 & 46351 & 48510 \\
iv) Melhor (i) e (ii) & $0,16 \%$ & $0,19 \%$ & $0,19 \%$ & 56 & 63 & 64 & 56402 & 7661 & 54188 \\
\hline
\end{tabular}

a) tarefa deve permanecer no agente de destino; b) tarefa não pode retornar ao agente de origem; c) ambos os tipos de proibição.

- As vizinhanças (iii) e (iv) apresentaram os melhores resultados, sendo que a vizinhança (iv) com o tipo de proibição (a) chegou (na iteração 56402) ao melhor resultado (0,16\%) de todas as variantes.

Para ilustrar o comportamento da busca por regiões factíveis e infactíveis, a Figura 3 mostra o gráfico do valor da função objetivo penalizada por iteração, destacando as soluções factíveis e infactíveis, da busca (iv)-(a).

O gráfico mostra sucessivas entradas e saídas da busca na região factível. Quando a busca se localiza numa região muito infactível (por exemplo, o conjunto de soluções com valor de função objetivo penalizada inferior a 11500), o forte incremento do tamanho do passo aumenta às vezes o valor da função penalizada para acima de 13000 e motiva a busca a voltar rapidamente para a região factível. A solução incumbente com valor 12452 é, finalmente, encontrada nas últimas iterações da busca.

\section{Memória de Longo Prazo}

Além da memória de curto prazo, a busca tabu também pode armazenar atributos de suas soluções visitadas em sua trajetória para indicar quais foram as regiões e/ou soluções mais ou menos visitadas. Se a busca não encontra nenhuma solução melhor que a solução incumbente há muitas iterações, pode-se desejar que a busca procure soluções em outras regiões pouco visitadas. Esta procura por regiões pouco visitadas (ou pouco exploradas) chama-se diversificação e faz uso da memória de longo prazo.

Uma forma de se armazenar a memória de longo prazo para o PDG é criar uma matriz de residência em que o elemento $(i, j)$ representa o número de iterações em que a tarefa $j$ ficou designada ao agente $i$.

A partir da matriz de residência, pode-se encontrar o valor $\max R$, que representa o maior valor da matriz de residência, e também, para todo elemento $(i, j)$ da matriz, o valor $\operatorname{res}(i, j)=\frac{(i, j)}{\text { max } R}$ que representa o valor relativo da permanência de $(i, j)$ nas soluções durante a trajetória da busca. Um valor de $\operatorname{res}(i, j)$ próximo de 1 indica que uma tarefa $j$ ficou designada ao agente $i$ por um grande número de iterações. Por outro lado, um valor próximo de zero indica que a tarefa $j$ esteve designada ao agente $i$ por poucas iterações. 


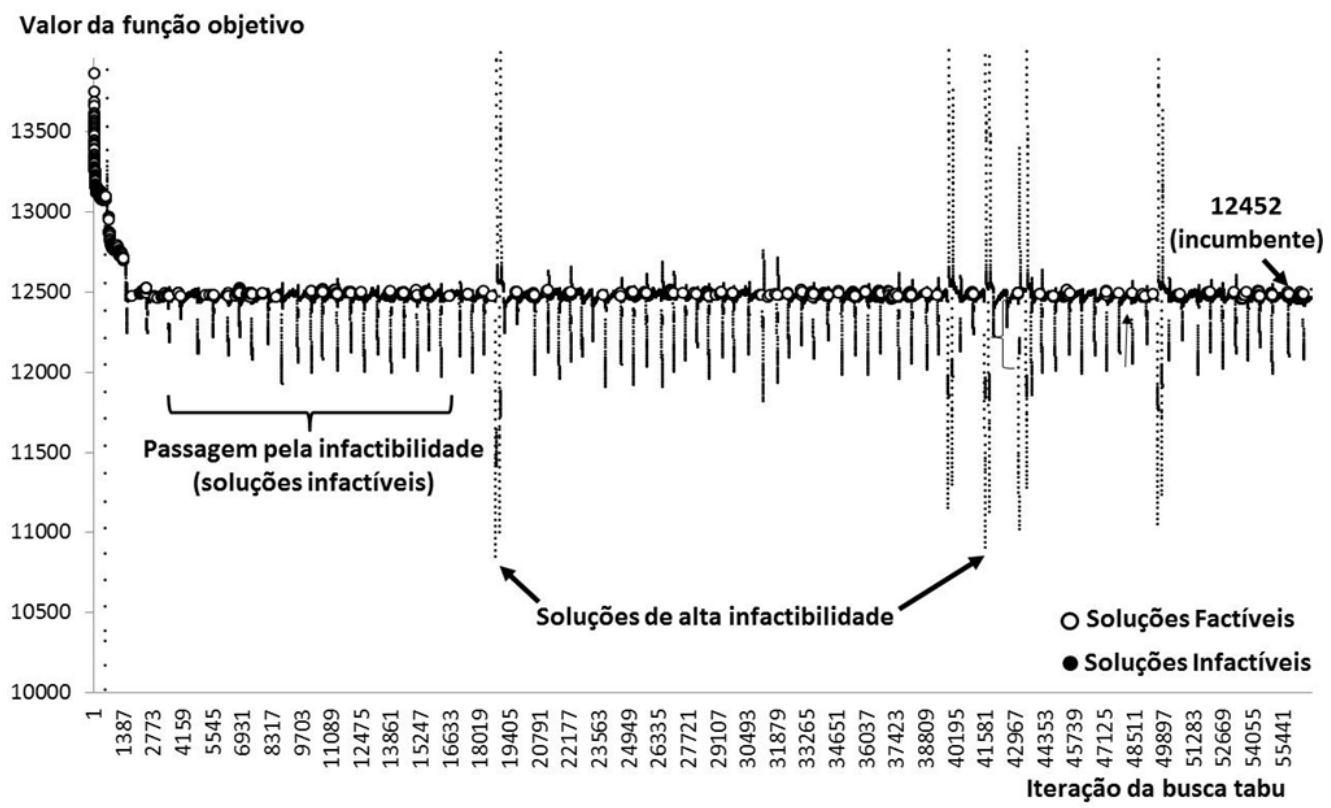

Figura 3. Busca tabu da vizinhança (iv), com proibição (a) - Vizinhança factível e infactível.

Outra forma de incentivar a busca a realizar movimentos pouco executados é armazenar as transições do atributo da solução ao longo da busca. Por exemplo, pode-se armazenar o número de vezes em que a tarefa $j$ foi inserida no agente $i$. Para tanto, utiliza-se a matriz de transição em que o elemento $(i, j)$ representa o número de vezes em que a tarefa $j$ foi designada ao agente $i$. Da mesma forma que a matriz de residência, define-se $\operatorname{trans}(i, j)=\frac{(i, j)}{\text { maxTrans }}$, em que maxTrans é o maior valor da matriz de transição, para representar o valor relativo do número de transições. Um valor de $\operatorname{trans}(i, j)$ próximo de 1 para uma tarefa $j$ e um agente $i$ significa que de todos os movimentos executados até o momento, alocar $j$ a $i$ foi um dos movimentos mais executados.

Uma vez ativada, a diversificação penalizará o valor da função objetivo nos movimentos em que os valores de $\operatorname{res}(i, j)$ e trans $(i, j)$ são elevados, induzindo a busca a evitar os movimentos de atributos muito frequentes. Entretanto, a qualidade do movimento, medida pelo custo de designação das tarefas aos agentes, continua sendo uma informação bastante relevante para direcionar a trajetória da busca. Desta forma, é necessária uma ponderação entre a qualidade do movimento e a intensidade da diversificação. Por exemplo, ao considerar a matriz de residência para o PDG, esta ponderação para um movimento de uma tarefa $j$ do agente $i$ para o agente $s$ é realizada com a expressão $c_{s j}-c_{i j}+\rho \Delta_{\max } r e s(i, s)$, em que $\rho$ é um parâmetro igual a 0,15 e $\Delta_{\max }$ é a maior variação do valor da função objetivo penalizada, que foi encontrada durante a busca em regiões infactíveis desde a última atualização da incumbente ou da última atualização de Pen. Logo, se a tarefa $j$ esteve presente em $s$ por muitas iterações, a expressão anterior aumenta o custo do movimento de forma proporcional à sua residência, reduzindo a atratividade deste movimento. Se o movimento da tarefa $j$ do agente $i$ para o agente $s$ também altera o excesso de capacidade dos agentes, acrescenta-se também a esta expressão a variação da penalização da infactibilidade, da mesma forma que a busca sem diversificação.

Nas iterações em que a diversificação está ativa, a penalização por meio da matriz de residência ou de transição é aplicada sempre que algum movimento, seja de troca ou de inserção, aumente o custo da solução. Caso o movimento reduza o custo, esta penalidade não é aplicada, ou seja, $\rho$ assume o valor zero. Este critério para o uso da penalidade de diversificação pode ser encontrado em Gendreau et al. (1994) e tem como objetivo liberar a busca para procurar soluções de alta qualidade, sem a interferência de matrizes de residência ou transição, quando o movimento melhora o valor da função objetivo.

Para ilustrar a memória de longo prazo, foi executado o teste com a vizinhança (iv) e regra de ativação tabu (b) aplicando-se a penalização da diversificação quando a busca se encontra em movimentos de degradação da função objetivo em regiões infactíveis.

A memória de longo prazo coleta as informações de residência e de transição desde a primeira iteração da busca tabu e as armazena em suas respectivas matrizes. Após percorrer $40 \%$ do total de iterações, a diversificação é ativada e os movimentos associados com atributos com alta frequência de residência ou transição são penalizados.

A Figura 4 mostra o comportamento desta busca para a matriz de residência e a Figura 5 para a matriz de transição. 


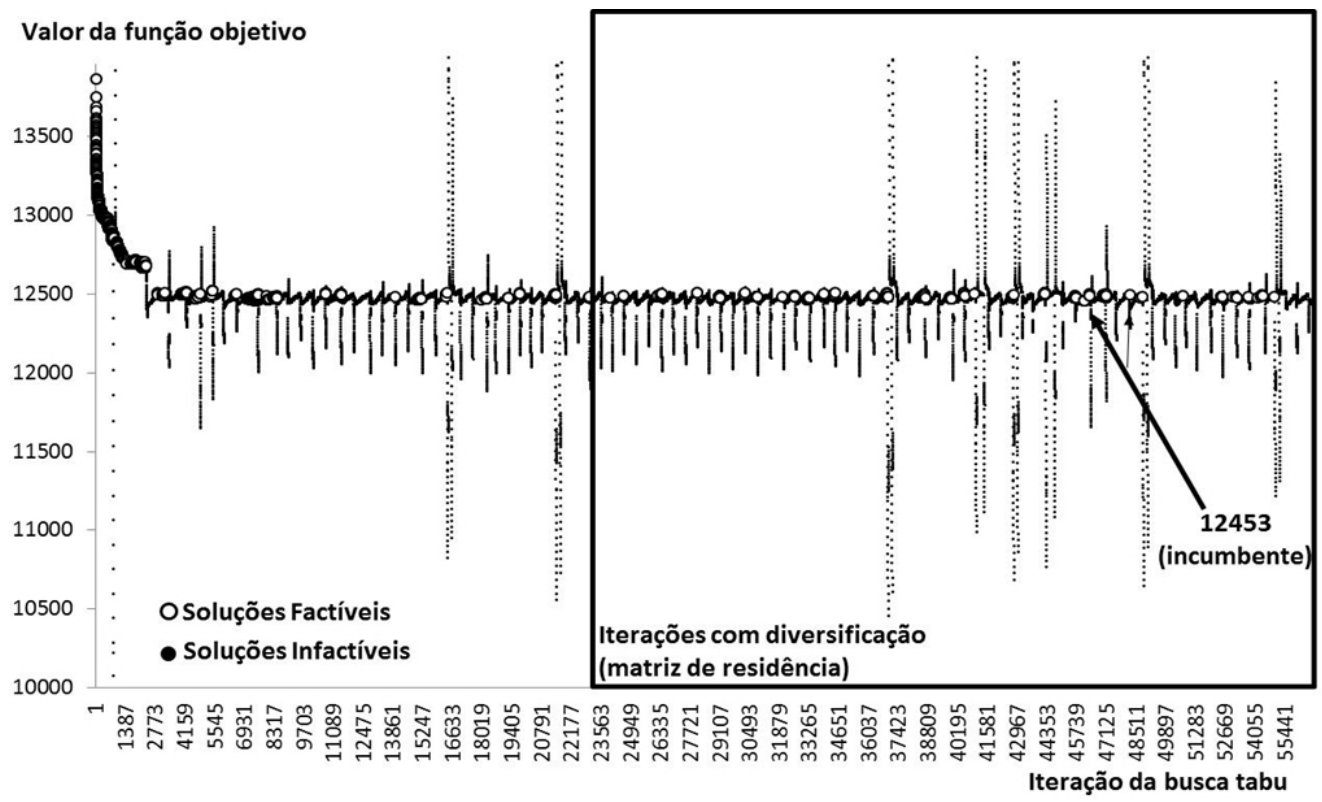

Figura 4. Busca tabu da vizinhança (iv), proibição (b) com diversificação - matriz de residência.

Mesmo com a introdução da diversificação e a melhora da incumbente de 12455 para 12453 (na Figura 4, matriz de residência) e 12454 (na Figura 5, matriz de transição), é possível notar, nas Figuras 4 e 5, a dificuldade de se explorar novas regiões atraentes. Esta é uma característica comum em métodos de otimização em que, quanto mais próximo se está do valor da melhor solução, mais difícil se torna a conquista deste acréscimo de qualidade. Tanto a complexidade de implementação dos métodos quanto o tempo computacional crescem, além de serem necessárias técnicas mais avançadas de diversificação e de intensificação, como, por exemplo, trabalhar com um conjunto de (boas e diferentes) soluções de elite durante a busca ao invés de se restringir somente a uma única solução. Outra maneira para aprimorar os resultados é investigar, com mais testes computacionais, quais são os parâmetros de penalidade mais adequados para cada tipo de diversificação e, também, a influência destes parâmetros nos outros componentes da busca tabu. Por exemplo, a Figura 4 pode indicar que, quando a penalização da matriz de residência é ativada, a vizinhança tende a explorar vizinhos muito infactíveis e, talvez, o tamanho do passo precise ser revisto.

\section{Sugestões para Implementação}

A seguir são listadas algumas sugestões sobre como projetar e implementar a busca tabu.

1. Projetar a busca tabu de tal forma que o método tire proveito da estrutura do problema. Procure por características que provavelmente estarão presente em boas soluções. Por exemplo, se for considerado que, para cada tarefa, há uma lista de possíveis alocações a agentes e que esta lista de alocações pode ser ordenada do menor ao maior custo, a busca pode ser projetada para não avaliar as alocações de custo muito elevado que provavelmente nunca estariam presente em boas soluções.

Outra opção é avaliar a possibilidade de divisão ou redução do tamanho do problema. Um exemplo para problemas de grande porte seria manter fixo, por um determinado número de iterações, um conjunto de boas alocações de tarefas a agentes de tal forma que a busca não precise avaliar toda a vizinhança a cada iteração. Estas alocações poderiam ser liberadas após executar um número de iterações sem atualizar a incumbente.

2. Investir bastante tempo no projeto e definição da vizinhança. Avalie o tamanho (número de vizinhos a cada iteração) e a influência (diferença entre a solução corrente e seus respectivos vizinhos) das vizinhanças nas quais a busca será baseada. Para o exemplo do PDG, o tamanho da vizinhança troca é da ordem de $n^{2}$, enquanto o tamanho da vizinhança inserção é da ordem de $n(m-1)$. Consequentemente, a vizinhança troca avalia mais vizinhos a cada iteração (o que pode representar uma maior probabilidade para encontrar uma solução melhor do que a incumbente) e requer um maior tempo computacional para ser explorada. Entretanto, como comentado anteriormente, movimentos de inserção são mais influentes, porque a diferença entre os vizinhos e a solução corrente é maior, tanto em número de tarefas por agente quanto na diferença da quantidade de recursos do par de agentes envolvidos no movimento. Para o PDG, é justamente a combinação destas duas vizinhanças (uma de maior tamanho com outra de maior influência) que produz bons resultados. 


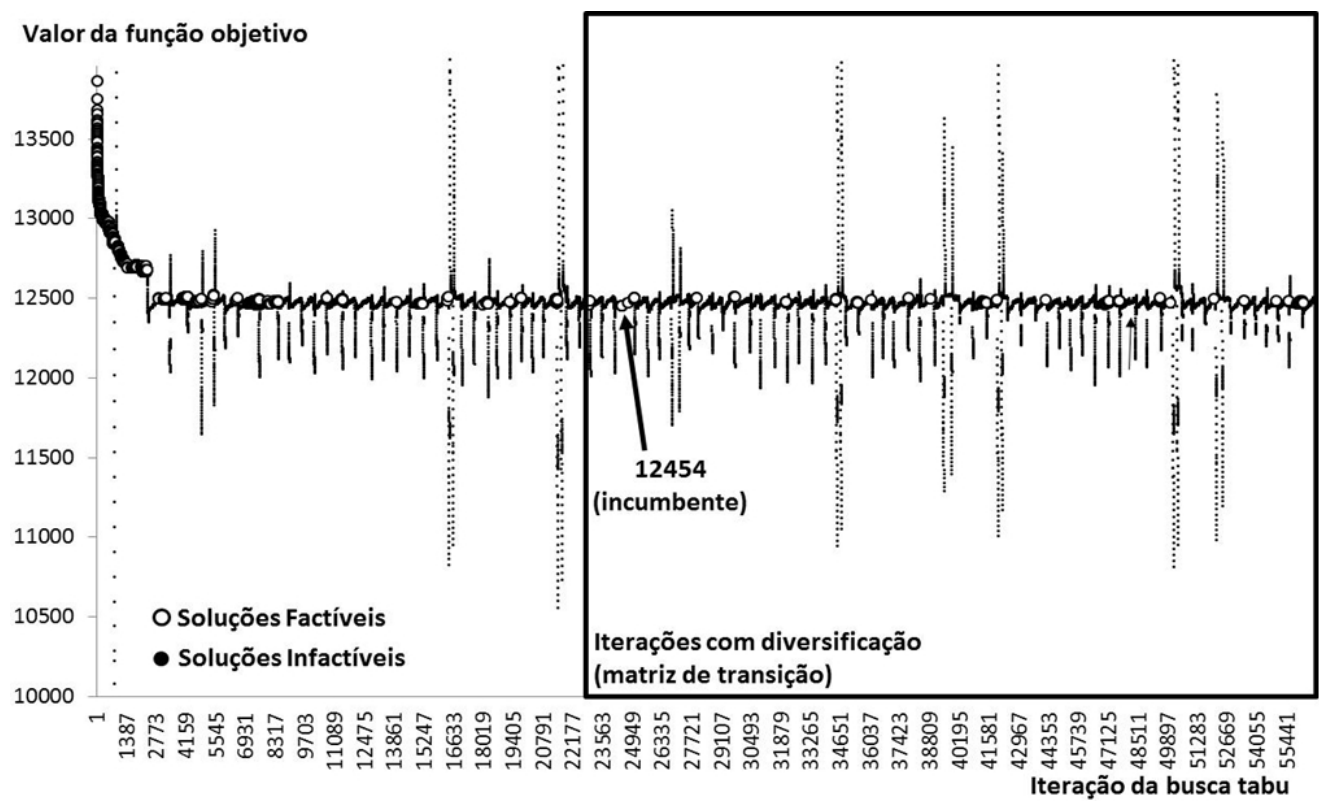

Figura 5. Busca tabu da vizinhança (iv), proibição (b) com diversificação - matriz de transição.

Outra decisão importante é sobre a inclusão de vizinhos infactíveis no espaço de busca. Às vezes, o tamanho da vizinhança é suficientemente grande para que somente vizinhos factíveis sejam considerados. Em outros casos, principalmente em problemas ou instâncias com fortes restrições, o número de vizinhos factíveis é muito pequeno. Nesta situação, a avaliação de soluções infactíveis pode ser mais interessante do que aumentar o número de vizinhanças.

\section{Depurar o algoritmo com instâncias de pequeno porte.}

Crie instâncias de pequeno porte e execute a depuração passo-a-passo em seu código. Esta etapa de teste é muito importante para a correção de erros de implementação (muito comuns nas primeiras implementações de busca tabu) e também na geração de idéias sobre como aprimorar o desempenho computacional de seu método. Como na maioria dos métodos de otimização combinatória, a busca tabu possui rotinas que são avaliadas repetidamente a cada iteração (por exemplo, a avaliação do custo de um movimento) que se otimizadas produzem grande melhoria no tempo computacional total.

Outro tópico muito relevante na etapa de projeto e testes que, apesar de sua importância, muitas vezes é negligenciado, é a estrutura de dados que armazena os atributos das soluções e dos movimentos. Esta estrutura de dados deve ser projetada (e testada) de tal forma que não seja necessário recalcular todos os vizinhos a cada iteração. Por exemplo, tanto para movimentos de inserção quanto para movimentos de troca, os atributos de somente um par de agentes são alterados a cada iteração. Ao avaliar os movimentos da iteração subsequente, somente os movimentos que envolvam as tarefas deste par de agentes precisam ser recalculados. Este e outros tipos de recálculos desnecessários ficam evidentes ao se depurar o método com instâncias de pequeno porte.

4. Desenvolver uma metodologia de teste para identificar ciclagem e ajustar os parâmetros da busca tabu para evitá-la.

Em geral, há duas formas de se melhorar rapidamente a qualidade da busca tabu: a primeira é evitar ciclagem e a segunda é evitar avaliações de vizinhos de regiões pouco promissoras. O desafio reside, então, em como visitar boas soluções evitando-se ciclos. Para auxiliar nesta tarefa, visualize o que sua busca tabu está executando a cada iteração, identificando o movimento executado e qual a solução antes e após o movimento. Compare soluções de iterações próximas entre si para verificar se há ciclagem (a busca visita repetidamente a mesma solução). Compare soluções de iterações distantes para verificar se as regiões exploradas são distintas (por exemplo, as soluções de cada região são bastante diferentes). Uma maneira para visualizar estas informações é gerar arquivos texto ou planilhas que permitam a identificação de atributos da solução a cada passo da busca.

5. Testar, de forma estruturada, as faixas de valores dos parâmetros aplicando a busca em um número razoável de instâncias diferentes em porte e em complexidade.

A definição dos parâmetros da busca pode determinar o sucesso ou o fracasso de seu método. Uma excelente implementação com os parâmetros inadequados provavelmente não produzirá bons resultados. 
É necessário explorar diferentes valores para os parâmetros da busca, principalmente para a duração tabu e os multiplicadores de penalização, e testar estes valores em uma série de instâncias antes de se concluir quais valores serão utilizados. Para tanto, crie um plano de teste das faixas de valores e identifique se há interferência entre os parâmetros (por exemplo, o aumento de um parâmetro implica no aumento ou redução de outro parâmetro). Outra sugestão é criar expressões que determinem os valores dos parâmetros em função de características da instância (e.g., tamanho) e da situação da busca (e.g., região factível ou infactível). Estas expressões são uma forma mais robusta de se calibrar a busca tabu, pois ajusta os parâmetros de forma estruturada e dinâmica.

6. Experimentar técnicas mais avançadas (p.ex., diversificação, intensificação e soluções de elite) somente após o método simples apresentar resultados razoáveis.

O seu primeiro objetivo deveria ser projetar e implementar uma busca tabu que produza bons resultados somente com a memória de curto prazo. Após a conquista deste objetivo deve-se pensar em componentes mais complexos e estratégias de memoria de longo prazo. As técnicas avançadas alavancam (mas não resolvem) o desempenho da busca tabu com memória de curto prazo. A vizinhança deve ser adequada, a ciclagem deve ser evitada e os parâmetros devem ser robustos e calibrados.

\section{Agradecimentos}

O primeiro autor agradece ao Conselho Nacional de Desenvolvimento Científico e Tecnológico - CNPq, pelo apoio financeiro por meio de bolsa de produtividade em pesquisa.

\section{Referências}

Gendreau, M.; Hertz, A. \& Laporte, G., A tabu search heuristic for the vehicle routing problem. Management Science, 40(10), 1994

Glover, F., Future paths for integer programming and links to artificial intelligence. Computers an Operations Research, 13(5):533-549, 1986.

Glover, F.W. \& Laguna, M., Tabu Search. Norwich, USA: Kluwer Academic Publishers, 1997.

Martello, S. \& Toth, P., Knapsack Problems: Algorithms and Computer Implementations. Chichester, USA: John Wiley \& Sons, 1990.

Öncan, T., A survey of the generalized assignment problem and its applications. INFOR: Information Systems and Operational Research, 45(3):123-141, 2007.

Woodcock, A.J. \& Wilson, J.M., A hybrid tabu search/branch \& bound approach to solving the generalized assignment problem. European Journal of Operations Research, 207:566-578, 2010.

Yagiura, M.; Ibaraki, T. \& Glover, F., A path relinking approach with ejection chains for the generalized assignment problem. European Journal of Operational Research, 169:548-569, 2006.

\section{Notas Biográficas}

Vinícius Amaral Armentano é graduado, mestre e doutor em Engenharia Elétrica (Universidade Mackenzie, 1974; Universidade Estadual de Campinas - UNICAMP, 1979; Imperial College London, 1983). Desde 1983 é docente da Faculdade de Engenharia Elétrica e de Computação (FEEC) da UNICAMP, e professor titular desde 1997. Foi professor visitante da Leeds School of Business da University of Colorado, Estados Unidos, em 2000. Tem experiência e interesse na área de otimização combinatória, com a modelagem e resolução de problemas práticos em logística, e desenvolvimento de métodos exatos e heurísticos em programação inteira. Orientou mais de 30 dissertações de mestrado e mais de 10 teses de doutorado. Tem publicado em diversos periódicos, incluindo Computers and Operations Research, European Journal of Operational Research, Journal of Heuristics, Journal of the Operational Research Society, Production and Operations Management e SIAM Journal on Control and Optimization. É titular de uma bolsa de produtividade em pesquisa do CNPq, nível 1A, desde 2001.

Rodrigo Moretti Branchini é graduado em Engenharia de Produção Mecânica (USP/São Paulo, 1998) e mestre em Engenharia Elétrica (UNICAMP, 2005). Atualmente é discente de doutorado no programa de pós-graduação da Faculdade de Engenharia Elétrica da UNICAMP na área de otimização combinatória e meta-heurísticas. 


\title{
Otimização por Colônia de Formigas
}

\author{
Mauro Henrique Mulati, Ademir Aparecido Constantino \\ e Anderson Faustino da Silva
}

\begin{abstract}
Resumo: Este capítulo apresenta uma fundamentação teórica e aplicações da meta-heurística Otimização por Colônia de Formigas. São apresentados algoritmos de aplicações desta meta-heurística para resolução do Problema do Caixeiro Viajante e do Problema de Cobertura de Conjunto. Enquanto o primeiro apresenta estrutura espacial, que é diretamente relacionado com a concepção da meta-heurística, o segundo necessita de uma modelagem diferente para que o algoritmo seja aplicado com sucesso. Os algoritmos apresentados também incluem a utilização de busca local para melhora da solução. Além disto, resultados de experimentos de várias aplicações são reportadas para ambos os problemas.
\end{abstract}

Palavras-chave: Otimização por colônia de formigas, Problema do caixeiro viajante, Problema de cobertura de conjunto.

\begin{abstract}
This chapter presents theoretical foundation and applications of the Ant Colony Optimization metaheuristic. We present algorithms of applications of this metaheuristic for the resolution of the Traveling Salesman Problem and the Set Covering Problem. While the former presents spatial structure, which is directly related to the design of the metaheuristic, the latter requires a different modeling in order to apply successfully the algorithm. The algorithms presented also include the use of local search procedure to improve the solution. Besides that, results of experiments of several applications are reported for both problems.
\end{abstract}

Keywords: Ant colony optimization, Traveling salesman problem, Set covering problem.

\section{Introdução}

Algoritmos exatos para resolução de problemas de otimização combinatória $\mathcal{N} \mathcal{P}$-difíceis possuem complexidade superpolinomial, a menos que $\mathcal{P}=\mathcal{N} \mathcal{P}$ (Cormen et al., 2009). Uma alternativa para resolver tais problemas em tempo polinomial é a utilização de algoritmos heurísticos, geralmente embasados em alguma meta-heurística.

Meta-heurística é definida como um conjunto de conceitos algorítmicos e de estruturas de dados genéricos para desenvolvimento e aplicação de algoritmos heurísticos à resolução satisfatória de problemas $\mathcal{N} \mathcal{P}$-difíceis (Dorigo \& Stützle, 2004). Em geral, tais algoritmos não garantem encontrar a solução ótima, porém, avaliações estatísticas mostram que eles tem alcançado com regularidade a finalidade de retornar uma solução de boa qualidade em tempo computacional aceitável.

A Otimização por Colônia de Formigas (do inglês Ant Colony Optimization - ACO) (Dorigo \& Stützle, 2004) é uma meta-heurística bio-inspirada que surgiu da observação do comportamento das formigas reais sendo que, posteriormente, foram agregadas técnicas de busca local. Em função desta analogia com o comportamento natural, as primeiras aplicações desta meta-heurística foram em problemas de otimização que tinham alguma associação com espaço físico, como o problema do caixeiro viajante (PCV).

O PCV pode ser descrito como o problema de um vendedor que necessita sair de sua cidade, percorrer todas as cidades contidas em uma área geográfica e retornar a sua cidade de origem de tal maneira que o percurso total seja mínimo e cada cidade seja visitada uma única vez. O PCV pode ser representado como um grafo completo $G=(V, E)$, sendo $V$ o conjunto de cidades e $E$ o conjunto de arestas que conectam todas as cidades. A cada aresta $(i, j)$ é atribuído um valor $d_{i j}$ que representa a distância entre as cidades $i$ e $j$.

Em contraste ao PCV, também há a aplicação de ACO ao problema de cobertura de conjunto (PCC), que não possui relação com espaço físico. O PCC pode ser definido por uma matriz binária $A=\left[a_{i j}\right]$ de ordem $m \times n$. A cada coluna de $A$ está associado um custo não-negativo $c_{j}$. Considera-se que uma coluna $j$ de $A$

\footnotetext{
*Autor para contato: mhmulati@gmail.com
} 
cobre uma linha $i$ se $a_{i j}=1$. O objetivo é selecionar um subconjunto de colunas $s \subseteq\{1, \ldots, n\}$ minimizando a soma de seus custos, de modo que cada linha seja coberta por ao menos uma coluna.

O objetivo deste capítulo é apresentar a meta-heurística ACO aplicada ao PCV e ao PCC, de forma a facilitar sua compreensão por meio da aplicação ao PCV e de modo a enfatizar a aplicação ao PCC, pelo fato de ser um problema de otimização combinatória que não possui uma associação direta com espaço físico, que é o caso de certos problemas de otimização formulados matematicamente. Destaca-se as características construtiva e melhorativa de ACO quando comparada com alguns algoritmos heurísticos encontrados na literatura. Do ponto de vista construtivo, este capítulo enfatiza o relacionamento da meta-heurística ACO com algoritmos gulosos aplicáveis aos problemas em estudo.

\section{Problemas de Otimização Combinatória}

Considera-se o problema de otimização combinatória de minimização ${ }^{1}$ dado por $P=(S, \Omega, f)$, onde: $S$ é o conjunto de soluções candidatas; $\Omega$ é um conjunto de restrições; e $f$ é a função objetivo que associa um custo $f(s)$ a cada solução candidata $s \in S$. O objetivo é encontrar uma solução $s^{*} \in S$ globalmente ótima, i.e., que seja factível (respeita todas as restrições em $\Omega$ ) e tenha o menor custo dentre todas as soluções candidatas. $\mathrm{O}$ modelo do problema de otimização combinatória é utilizado para definir o modelo de feromônio dos algoritmos ACO.

\subsection{Problema do caixeiro viajante}

O PCV pode ser representado como um grafo completo $G=(V, E)$, sendo $V$ o conjunto de vértices (cidades) e $E$ o conjunto de arestas (que conectam todas as cidades). A cada aresta $(i, j)$ é associado um valor $d_{i j}$ que representa a distância entre as cidades $i$ e $j$. O objetivo é encontrar o menor caminho Hamiltoniano do grafo, caminho este fechado que visita cada vértice do grafo uma única vez. Caso o problema não deva ser mapeado em um grafo completo, pode-se retirar arestas ou atribuir $d_{i j}=\infty$ para as arestas ausentes.

As variáveis de decisão são dadas por $x_{i j}, \forall i, j \in\{1,2, \ldots, n\}$, de modo que $x_{i j}=1$ indica que, deve-se visitar a cidade $i$ e imediatamente depois deve-se visitar a cidade $j$, utilizando assim a aresta $(i, j)$ na solução; caso contrário, $x_{i j}=0$. Para evitar soluções indesejadas, pode-se considerar $d_{i i}=\infty$ para $i=1,2, \ldots, n$, ou ainda, excluir as variáveis $x_{i i}$. De acordo com Colin (2007), o PCV pode ser modelado como segue:

$$
\min f(x)=\sum_{i=1}^{n} \sum_{j=1}^{n} d_{i j} \cdot x_{i j}
$$

sujeito a

$$
\begin{gathered}
\sum_{i=1}^{n} x_{i j}=1, j=1,2, \ldots, n \\
\sum_{j=1}^{n} x_{i j}=1, i=1,2, \ldots, n \\
u_{i}-u_{j}+n \cdot x_{i j} \leqslant n-1, i \neq j ; i=2,3, \ldots, n ; j=2,3, \ldots, n \\
x_{i j} \in 0,1, u_{j} \geqslant 0, j=1,2, \ldots, n ; i=1,2, \ldots, n
\end{gathered}
$$

A Equação 1 apresenta a função objetivo. As Equações 2 e 3 restringem que em uma solução cada vértice deve ter exatamente uma entrada e uma saída. Solução contendo todos os vértices mas com sub-rotas desconexas são evitadas pelas restrições da Equação 4, onde as variáveis $u_{i}$ e $u_{j}$ são auxiliares e não tem um significado físico. A Equação 5 apresenta as restrições de que as variáveis de decisão dadas por $x_{i j}$ sejam inteiras e binárias. $\mathrm{O}$ valor $u_{j}$ também é restringido.

Uma aplicação prática importante do PCV é o agendamento de uma máquina de fazer furos em uma placa de circuito impresso (Reinelt, 1994), onde os furos a serem feitos são representados pelas cidades e o custo da viagem é o tempo que se leva para mover a cabeça de perfuração de um orifício para o próximo. Deste modo, o objetivo é minimizar o tempo gasto para realizar todos os furos planejados para uma placa.

\footnotetext{
1 A conversão em um problema de maximização geralmente é simples.
} 


\subsection{Problema de cobertura de conjunto}

O PCC pertence à categoria de problemas de subconjunto, nos quais a solução é dada por um subconjunto de itens disponíveis, sujeita às restrições específicas do problema.

O PCC pode ser definido por uma matriz de ordem $m \times n$ definida por $A=\left[a_{i j}\right]$, na qual cada um dos elementos pode ser 0 ou 1 . Cada coluna da matriz $A$ possui um custo não-negativo $c_{j}$ associado. Considera-se que determinada coluna $j$ cobre uma linha $i$ se $a_{i j}=1$. O objetivo a ser alcançado no PCC é escolher um subconjunto solução $s \subseteq\{1, \ldots, n\}$ de colunas com custo mínimo, de modo que todas as linhas sejam cobertas. Este problema pode ser formulado como indicado a seguir:

$$
\min f(x)=\sum_{j=1}^{n} c_{j} \cdot x_{j}
$$

sujeito a

$$
\begin{gathered}
\sum_{j=1}^{n} a_{i j} \cdot x_{j} \geq 1, i=1 . . m \\
x_{j} \in\{0,1\}, j=1 . . n
\end{gathered}
$$

onde as restrições da Equação 7 definem que cada linha precisa ser coberta por ao menos uma coluna, e pelas restrições da Equação 8 tem-se que cada variável de decisão $x_{j}$ tem que assumir 0 ou 1 . A função objetivo é apresentada na Equação 6.

Algumas importantes aplicações do PCC são: escalonamento de pessoal em trânsito urbano (Desrochers \& Soumis, 1989), escalonamento de pessoal em aeronaves (Housos \& Elmroth, 1997), localização de serviços emergenciais (Toregas et al., 1971), recuperação de informação (Al-Sultan et al., 1996) e compactação de conjuntos de teste (Flores et al., 1999). Nestes casos reais, é comum encontrar instâncias do problema com centenas de linhas e milhares de colunas.

Em algumas situações, pode ser usado pré-processamento para reduzir uma instância de PCC, como descrito em de Oliveira (1999).

\subsection{Algoritmo guloso}

Conforme destacado por Dorigo et al. (1996), a meta-heurístca ACO possui três características básicas: uso de algoritmo construtivo guloso, comportamento auto-catalítico ${ }^{2}$ e computação distribuída.

Algoritmo guloso (greedy algorithm, em inglês), também conhecido como algoritmo míope, é um algoritmo construtivo usado em ACO para encontrar soluções viáveis para o problema investigado. Tal algoritmo constrói iterativamente uma solução para um problema de otimização combinatória $P$ a partir de uma solução vazia. A cada iteração o algoritmo escolhe um componente para compor a solução com base em uma "função gulosa" (também chamada de heurística gulosa). Uma função gulosa é uma função matemática que define heuristicamente a importância de um componente para entrar na solução a ser construída. A cada iteração, dentre os componentes candidatos, o componente com o maior valor da função gulosa é adicionado à solução. Empates podem ser resolvidos de maneira arbitrária. O algoritmo termina quando uma solução factível é construída. Nota-se, portanto, que a qualidade da solução construída depende de uma boa função gulosa.

Geralmente um algoritmo guloso é especializado para cada problema $P$. Há casos em que a ordem como os componentes são adicionados na solução é relevante, como para o PCV, pois a solução representa uma sequência de vértices (cidades). Porém, há casos em que a ordem não tem importância, como é o caso do PCC, pois a solução é um conjunto (não existe uma relação de ordem entre os componentes).

Um algoritmo baseado em ACO constrói as soluções utilizando duas informações numéricas (Dorigo et al., 1996): o valor da função gulosa e a quantidade de feromônio depositado pelas formigas. A escolha de cada componente para compor a solução é uma decisão tomada por cada formiga artificial baseada num valor probabilístico que combina estas duas informações numéricas.

Dentro do contexto dos algoritmos ACO esta função gulosa assume uma nova denominação chamada de "informação heurística" (algumas vezes denominada de visibilidade ${ }^{3}$ da formiga). Para o PCV, a informação heurística para selecionar uma aresta $(i, j)$, denotada por $\eta_{i j}$, pode-se basear, por exemplo, na ideia do clássico algoritmo vizinho mais próximo, que utiliza a função gulosa definida pela Equação 9:

$$
\eta_{i j}=\frac{1}{d_{i j}}
$$

$\overline{2}$ Um processo auto-catalítico (ou resposta positiva) é um processo de auto-reforço que ocorre com a utilização do feromônio depositado pelas formigas.

3 Esta visibilidade é uma capacidade dada às formigas artificias de "enxergar" os elementos que compõem a solução, fazendo uma analogia ao percurso realizado pela formigas. 
No caso do PCC, Chvàtal (1979) apresenta várias propostas como função gulosa, das quais destaca-se a função definida pela Equação 10, denotada por $\eta_{j}$, usada para selecionar uma coluna $j$ para entrar na solução.

$$
\eta_{j}=\frac{\operatorname{card}_{j}(s)}{c_{j}}
$$

onde $\operatorname{card}_{j}(s)$ é o número de linhas que são cobertas pela coluna $j$ mas não cobertas por nenhuma outra coluna na solução parcial $s$ em construção, e $c_{j}$ é o custo da coluna $j$.

Nota-se, ainda, que a informação heurística para o PCV é estática, pois ela não se modifica conforme a solução vai sendo construída. Já no caso do PCC a informação heurística é dinâmica, pois conforme a solução vai sendo construída o valor de $\operatorname{card}_{j}(s)$ pode ser modificado em função das colunas já adicionadas à solução.

\section{Otimização por Colônia de Formigas}

A meta-heurística ACO foi introduzida por Colorni et al. (1992) com o Ant System (AS), porém, ainda sem fazer uso de algoritmos de busca local (Colorni et al., 1992; Dorigo, 1992; Dorigo et al., 1996). AS foi inspirado no comportamento de formigas reais - na busca de alimento para sua colônia - criado para ser utilizado na busca de soluções para problemas de otimização combinatória. Após a sua criação muitas variações foram elaboradas como nos casos de MAX-MIN Ant System (MMAS) (Stützle \& Hoos, 1998), Ant Colony System (ACS) (Dorigo \& Gambardella, 1997b), ANTS (Maniezzo, 1999), MMAS-ACS-Hybrid (Stützle \& Hoos, 1997), HyperCube (Blum et al., 2001), BeamACO (Blum, 2005), dentre outros.

\subsection{Inspiração e surgimento}

Esta meta-heurística surgiu da observação do comportamento das formigas reais, ou seja, do estudo das formigas para entender como animais com pouca visão, como as formigas, poderiam conseguir uma rota mais curta partindo da colônia até uma fonte de comida. Foi descoberto que a comunicação entre as formigas que caminhavam pela trilha ocorria por meio de uma substância química, denominada feromônio, depositada por elas próprias. Enquanto as formigas caminham por uma trilha, inicialmente de forma aleatória, elas depositam uma certa quantidade de feromônio no solo. Assim, as próximas formigas tomam a decisão de seguir um caminho com probabilidade proporcional à quantidade feromônio depositada anteriormente. Ao decidir seguir um caminho com a presença da substância, ocorre então um reforço do caminho com o seu próprio feromônio. Este comportamento é denominado de auto-catalítico por ser um processo que reforça a si mesmo. O feromônio depositado tende a evaporar com o tempo, então quanto maior é a concentração de formigas passando pelo mesmo lugar, mais atrativo ele se torna para as próximas formigas. A Figura 1 ilustra um experimento com formigas reais.
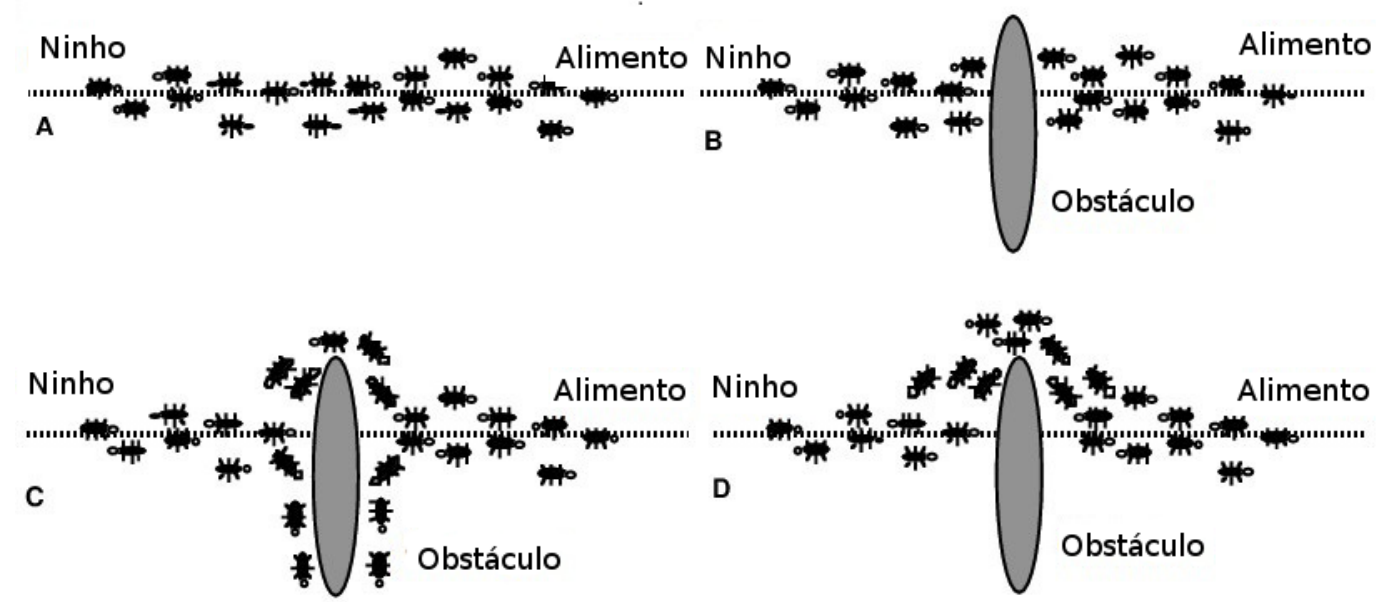

Figura 1. Ilustração do experimento com formigas. (A) As formigas seguem o caminho do ninho até o alimento.

(B) Um obstáculo é colocado no caminho. (C) As formigas iniciam o desvio. (D) O caminho com maior frequência de formigas ocorre no caminho mais curto.

Desta forma, as formigas conseguem obter um bom caminho entre dois pontos. Na primeira decisão após a inserção do obstáculo, as quantidades de formigas a escolher o caminho mais curto e o caminho mais longo devem ser aproximadamente a mesma, de modo que elas escolhem o caminho com base no feromônio encontrado, sendo que as probabilidades de ambos os lados devem ter valores próximos um do outro. Porém, na segunda decisão, as formigas que percorreram o caminho mais curto já estão voltando, depositando ainda 
mais feromônio, enquanto as que foram pelo caminho mais longo ainda estão completando a primeira transição. Desta forma, as formigas tendem a seguir caminho mais curto.

Com base no comportamento das formigas reais e com o objetivo de reproduzir tal comportamento, a Figura 2 introduz um esquema do ponto de vista das formigas artificias. Sendo que, $t$ representa o tempo do sistema, $d$ é a distância do caminho, $A$ e $E$ são os pontos extremos que as formigas devem atingir, e $H$ e $C$ são pontos intermediários, pelos quais as formigas devem decidir qual caminho tomar. O interessante é que escolham o mais curto, no caso, passando por $C$. De acordo com esta ilustração, no tempo $t=0$ temos que metade do número de formigas (15) decidem ir do ponto $B$ para o ponto $C$ e a outra metade de $B$ para $H$, considerando que ainda não há feromônio depositado no caminho. No tempo $t=1$ considera-se que ocorreu depósito de feromônio pelas formigas no tempo $t=0$. Porém, a quantidade de feromônio no caminho $B, H, D$ é menor que no caminho $B, C, D$ porque o primeiro caminho tem uma distância maior, portanto, as formigas consumiram mais tempo para percorrer, consequentemente houve maior evaporação do feromônio. Com a menor quantidade de feromônio no caminho $B, H, D$, há uma tendência de um menor número de formigas (no caso apenas 10) seguir tal caminho em relação a segunda alternativa. Desta forma, numa segunda iteração, $t=1$, há uma maior concentração de formigas no caminho mais curto entre $A$ e $B$.

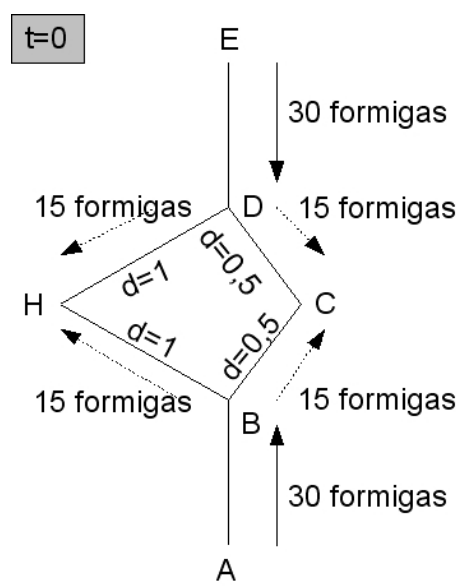

(a)

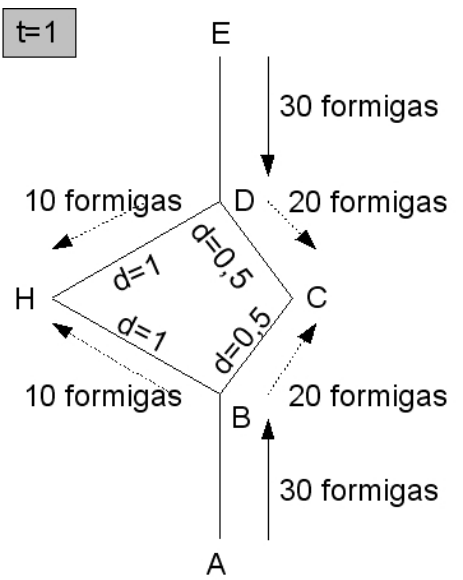

(b)

Figura 2. Exemplo de movimento das formigas artificiais.

A partir desta introdução nota-se que o tempo é discretizado em relação ao ambiente das formigas reais. Além disto, outras artificialidades são introduzidas em algoritmos ACO. As formigas artificiais são dotadas de boa capacidade de enxergar, diferente das formigas reais. Além do uso do feromônio já depositado (que será um valor numérico), na construção da solução (análoga ao processo de busca de alimento a partir do formigueiro) as formigas artificiais podem também se guiar pela informação heurística do caminho. No caso do PCV esta informação heurística é inversamente proporcional a distância entre dois vértices (Equação 9).

Outra artificialidade é o fato das formigas serem capazes de memorizar o caminho (solução) construído. Somente depois da construção da solução é que geralmente ocorre o depósito de feromônio pelas formigas artificiais com base em sua memória. Assim, como sugerido por Dorigo \& Caro (1999) e Dorigo \& Stützle (2004), a estrutura geral da meta-heurística ACO pode ser resumida pelo pseudo-código do Algoritmo 1, o qual possui três atividades (procedimentos): ConstruirSolucoesComFormigas(), AplicarBuscalocal() e Atualizarferomonio(). O procedimento principal da meta-heurística ACO é gerenciar o escalonamento dessas três atividades. Dorigo \& Caro (1999) salientam que estas três atividades não possuem uma forma rígida de como são escalonadas e sincronizadas. Isto significa que estas atividades podem ser executadas de maneira paralela e independente, inclusive com sincronismo.

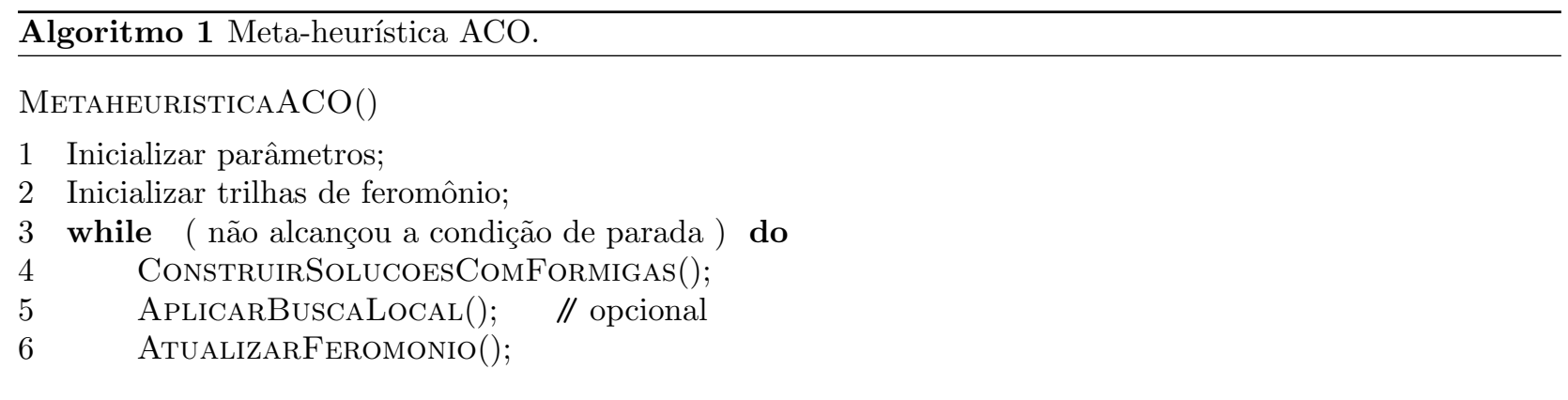


Os três procedimentos (atividades) são discutidos com mais profundidade nas seções de aplicações. O procedimento ConstruirSolucoesComformigas() é essencialmente um algoritmo construtivo (guloso) aleatorizado que utiliza o feromônio e a informação heurística de forma combinada. Neste procedimento é explorada ideia de algoritmo guloso discutido em seção anterior. O feromônio é atualizado pelo procedimento Atualizarferomonio(), podendo incluir o depósito e evaporação de feromônio. O procedimento AplicarBuscalocal() tem a função de aplicar alguma busca local para melhorar uma solução, ou mais soluções, construída(s) por uma ou mais formigas. Apesar de ser opcional, o seu uso tem sido cada vez mais frequente. A condição de parada do laço de repetição pode ser baseada num número fixo de iterações e/ou convergência das soluções, além de outros critérios.

O feromônio e a informação heurística são valores que influenciam probabilisticamente a decisão da formiga. Todo o processo resulta em um sistema que exibe comportamento auto-catalítico: as formigas vão reforçando o feromônio das melhores soluções fomentando a convergência para a solução ótima.

ACO pode ser considerada simultaneamente uma meta-heurística com característica construtiva e melhorativa. A característica construtiva advêm do fato de usar a informação heurística tipicamente utilizada em algoritmo (construtivo) guloso. Além disto, este processo construtivo é repetido, porém, cada vez mais influenciado pelo feromônio introduzido em iterações anteriores com o objetivo de construir soluções cada vez melhores (que corresponde à característica melhorativa).

Aspectos importantes na aplicação de algoritmos ACO para um problema (Dorigo \& Stützle, 2004) são: o grafo de construção, sobre o qual as formigas caminham; as restrições; a definição das trilhas de feromônio; a definição da informação heurística; a probabilidade de escolha; a construção da solução; a atualização de feromônio; e a busca local.

\section{Aplicações de ACO}

Na literatura podem ser encontradas diversas aplicações de algoritmos ACO em problemas de otimização combinatória, sendo alguns deles: problema do caixeiro viajante (PCV) (Dorigo et al., 1996), problema generalizado de atribuição (PGA) (Ramalhinho-Lourenço \& Serra, 1998), problema quadrático de alocação (PQA) (Maniezzo \& Colorni, 1999), problema de cobertura de conjunto (PCC) (Hadji et al., 2000), problema da mochila multidimensional (Alaya et al., 2004), problemas de clique máximo em grafos (Solnon \& Fenet, 2006) problema de roteamento de pacotes em redes de computadores (Dorigo \& Stützle, 2004), escalonamento de tripulações (Deng \& Lin, 2011) e problemas de roteirização de veículos (Wade \& Salhi, 2004).

Esta seção mostra a aplicação do ACO ao problema do caixeiro viajante e ao problema de cobertura de conjunto, com o objetivo de ilustrar duas aplicações distintas da meta-heurística ACO.

\subsection{Algoritmo ACO para o problema do caixeiro viajante}

Em Dorigo \& Stützle (2004) é realizada uma discussão sobre a aplicação de algoritmos ACO para o PCV. Nesta seção é apresentada uma proposta de implementação das particularidades dos procedimentos apresentados no Algoritmo 1.

No PCV, o grafo de construção - espaço utilizado pelas formigas artificiais - e o grafo que representa o problema são idênticos. Em cada passo de construção uma formiga deve visitar um vértice (cidade) adjacente entre aqueles que ainda não foram visitados e ao final deve retornar ao vértice inicial. Todos os vértices devem ser visitados uma única vez.

Neste problema, os resíduos de feromônio indicam a desejabilidade de visitar uma determinada cidade $i$, partindo da cidade $j$, sendo denotados por $\tau_{i j}$. Além disto, a informação heurística $\eta_{i j}$ é tipicamente inversamente proporcional à distância entre $i$ e $j$, como apresentada na Equação 9, inclusive sendo bastante utilizada em algoritmos gulosos. A informação de escolha é denotada por $\tau_{i j}{ }^{\alpha} \cdot \eta_{i j}{ }^{\beta}$, sendo $\alpha$ e $\beta$ parâmetros que indicam a importância do feromônio e da informação heurística, respectivamente.

Cada formiga é inicializada em uma cidade. A cidade pode ser escolhida aleatoriamente ou, caso a quantidade de formigas seja maior que a quantidade de cidades, serem distribuídas de modo que cada cidade possua ao menos uma formiga. Todas as formigas constroem sua solução executando seus passos de construção. A cada passo de uma formiga ela seleciona uma cidade vizinha da atual ainda não visitada para fazer parte da solução, seleção esta que ocorre levando em conta a informação de escolha. A construção da solução termina quando todas as cidades foram visitadas pela formiga. Para selecionar uma nova cidade a ser adicionada a sua solução, a formiga seleciona tal cidade de acordo com a probabilidade de escolha $p$ dada pela Equação 11:

$$
p_{i j}^{k}= \begin{cases}\frac{\tau_{i j}^{\alpha} \cdot \eta_{i j}^{\beta}}{\sum_{h \in N\left(i, s_{k}\right)} \tau_{i h}^{\alpha} \cdot \eta_{i h}^{\beta}} & \text { se } j \in N\left(i, s_{k}\right) \\ 0 & \text { se } j \notin N\left(i, s_{k}\right)\end{cases}
$$


onde $N\left(i, s_{k}\right)$ é o conjunto de cidades candidatas (novas) que podem ser selecionadas a partir da cidade $i$ com a solução parcial $s_{k}$ já construída pela formiga $k$, e $s_{k}$ é definida como uma estrutura vetorial de tamanho $n$, sendo $n$ o número de cidades (vértices). Assim, com este critério probabilístico de seleção de candidatos é possível construir um algoritmo guloso aleatorizado, em que cada vértice selecionado compõe uma solução (rota).

Um aspecto que chama atenção para um algoritmo ACO é a quantidade de parâmetros. Além dos parâmetros $\alpha$ e $\beta$, tem-se ainda:

- $\rho$ : taxa de evaporação de feromônio;

- $N I_{\max }$ : o número máximo de iterações do algoritmo;

- $\tau_{0}$ : a quantidade de feromônio a ser atribuída para as arestas na inicialização do algoritmo;

- $m$ : o número de formigas artificias utilizadas para este algoritmo.

Encontrar uma atribuição de valores para estes parâmetros é sempre um desafio para se projetar um algoritmo baseado em ACO. Por exemplo, em Dorigo et al. (1996) são sugeridos os seguintes valores de parâmetros: $m=n, \alpha=1, \beta=0,5, \rho=0,5$ e $N I_{\max }=5000$. Sugere-se usar $\tau_{0}=0,05$.

O procedimento ConstruirSolucoesComformigas() (usado pelo Algoritmo 1) realiza a tarefa de construção de soluções e é representado pelo Algoritmo 2.

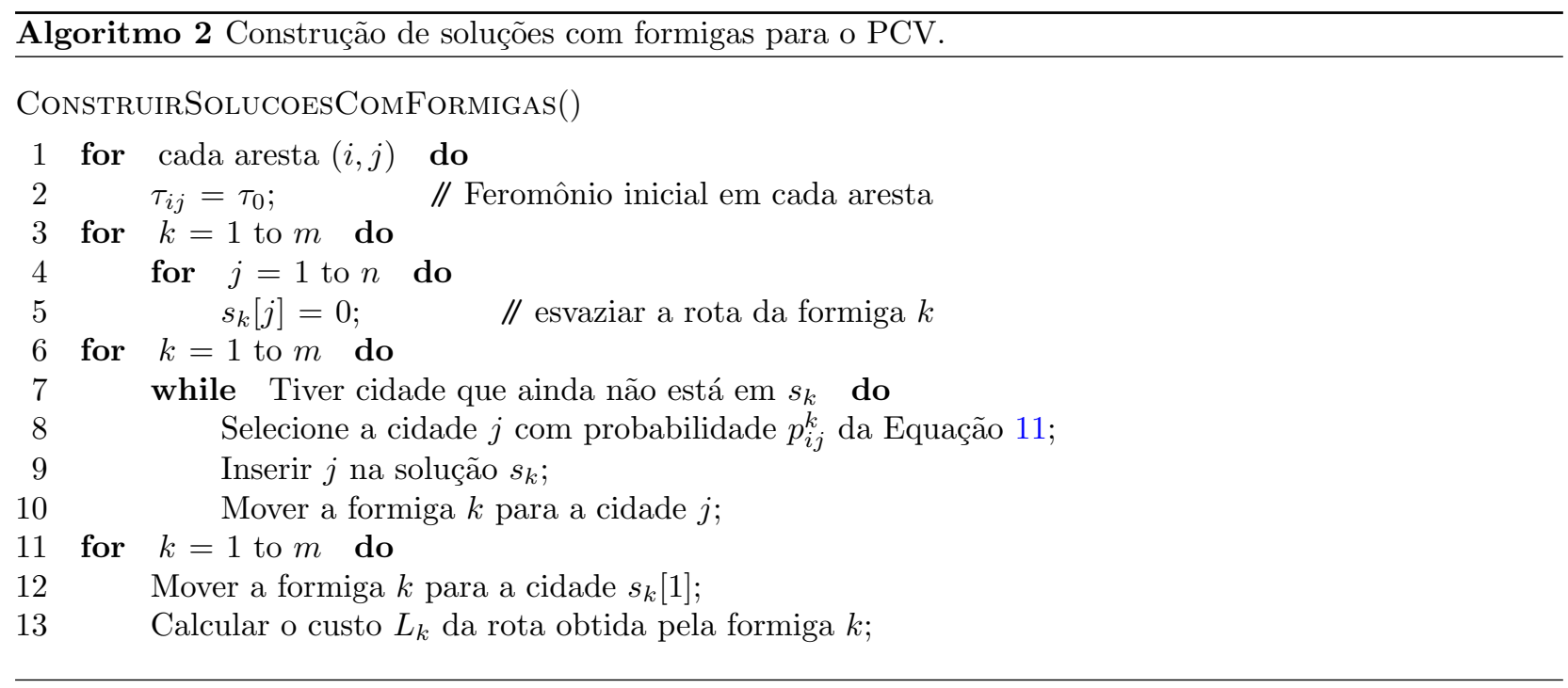

Após cada formiga ter construído sua solução, ocorre a atualização de feromônio por meio da evaporação e do depósito de feromônio. A atualização é dada pela Equação 12:

$$
\tau_{i j}=(1-\rho) \tau_{i j}+\sum_{k=1}^{m} \Delta \tau_{i j}^{k}, \quad \forall i, j \in E
$$

onde $\Delta \tau_{i j}^{k}$ é descrito pela Equação 13:

$$
\Delta \tau_{i j}^{k}= \begin{cases}\frac{1}{L^{k}} & \text { se a aresta }(i, j) \text { pertence a solução } s_{k} \\ 0 & \text { caso contrário }\end{cases}
$$

sendo que $L^{k}$ representa o custo da solução $s_{k}$, que é a soma dos custos de todas as arestas que fazem parte da rota construída pela formiga $k$. Assim, quanto melhor a solução, mais feromônio será depositado em suas arestas. Neste esquema, todas as formigas depositam feromônio. Com isto, o procedimento AtualizarFeromonio() (usado pelo Algoritmo 1) se resume na aplicação da Equação 12.

A inicialização é uma operação simples que estabelece as condições iniciais do algoritmo. Neste caso, é necessário realizar:

- $N I=0$, sendo que $N I$ define o número de iterações do algoritmo;

- Alocar arbitrariamente cada uma das $m$ formigas nos $n$ vértices (cidades), ou seja, $s_{k}[1]$ receberá a primeira cidade da rota para a formiga $k$. 
Este algoritmo adota dois critérios de parada:

- $N I \geq N I_{\max }$, que impõe um número máximo de iterações para o algoritmo;

- "Estagnação": a estagnação das soluções ocorre quando todas (ou quase todas) as soluções são equivalentes, ou seja, todas (ou quase todas) as formigas passaram a fazer a mesma rota. Quanto a estagnação ocorre é um sinal que o algoritmo deve parar porque não encontrará mais soluções diferentes. Esta estagnação pode estar relacionada com os parâmetros utilizados pelo algoritmo.

Embora a busca local seja opcional, ela é bastante recomendada por ser responsável por melhorar a qualidade da solução produzida pelas formigas. Exemplos bem conhecidos na literatura são 2-opt (Croes, 1958), 3-opt (Lin, 1965) e Lin-Kerninghan (Lin \& Kernighan, 1973).

\subsection{Algoritmo ACO para o problema de cobertura de conjunto}

Em Dorigo \& Stützle (2004) são revisitadas duas aplicações do algoritmo Ant-System (AS) ao PCC: o algoritmo AS-LM, com ideias de Leguizamon \& Michalewicz (1999), e o algoritmo AS-HRTB, de Hadji et al. (2000). O segundo trabalho teve resultados estendidos pelo algoritmo AntsLS em Rahoual et al. (2002), além da inclusão de uma versão paralela. Constam nos dois últimos trabalhos a utilização da busca local JB, embasada em esquema de Jacobs \& Brusco (1995). O trabalho de Lessing et al. (2004) faz comparativos de aplicação ao PCC dos algoritmos MMAS, ACS, MMAS-ACS-Hybrid e ANTS, com e sem a busca local 3-FLIP, baseada em Yagiura et al. (2006), avaliando também diferentes tipos da informação heurística.

Em Mulati \& Constantino (2011) é proposto e investigado o algoritmo Ant-Line (AL), que constrói soluções com base na seleção de linhas da instância do PCC, característica chamada "orientação a linha". AL também utiliza a busca local JB. Orientação a linha também foi trabalhada em Ren et al. (2008) com o Ant-Cover (AC), comparando seus resultados com o MMAS, com e sem busca local. Em Ren et al. (2010) o AC com busca local, esta embasada na eliminação de colunas redundantes, é comparado com outras meta-heurísticas e com abordagem ACO de Crawford \& Castro (2006), que inclui etapa de pós-processamento.

Estendendo o algoritmo heurístico genérico ACO apresentado no Algoritmo 1 e utilizando os conceitos introduzidos na aplicação de ACO para PCV apresentados na Seção 4.1, segue aprofundamento na aplicação de algoritmos $\mathrm{ACO}$ ao PCC.

\subsubsection{AS para o PCC}

No grafo de construção, as colunas são representadas pelos componentes do conjunto de vértices $C$, podendo existir um componente extra que não está relacionado com nenhuma das colunas do PCC. Em geral, o grafo de construção é completo, indicando que após a inserção de uma coluna, não há uma restrição rígida de colunas que não podem ser inseridas na sequencia. O componente extra geralmente serve de ponto de partida para as formigas, que normalmente não podem retornar a ele durante a construção de uma solução.

$\mathrm{O}$ algoritmo deve gerir como as restrições do problema serão tratadas, sendo que no PCC não faz sentido construir soluções com colunas repetidas. Deste modo, não é permitido à formiga adicionar à solução um componente que já se encontra nesta. Tal mecanismo é elaborado através do conjunto $N\left(s_{k}\right)$, que consiste dos componentes candidatos de serem inseridos na solução parcial $s_{k}$ pertencente à formiga $k$. Assim, a formiga $k$ deve procurar novos componentes para sua solução em $N\left(s_{k}\right)$, este que contém todos os componentes de $C$ (exceto o componente extra) que não estão na solução $s_{k}$.

Os resíduos de feromônio são associados com os componentes, desta forma o feromônio $\tau_{j}$ associado com o componente $j$ mede a desejabilidade de se incluir a coluna $j$ na solução. No PCC enfatiza-se a utilização da informação heurística dinâmica custo de cobertura, dada por $\eta_{j}$, como apresentada na Equação 10, onde devese considerar que $s=s_{k}$ antes da utilização da regra (e também antes de calcular $\operatorname{card}_{j}(s)$ ). A informação de escolha é expressa por $\tau_{j}{ }^{\alpha} \cdot \eta_{j}{ }^{\beta}$ usando valores de um componente (coluna) $j$, já com a utilização dos parâmetros $\alpha$ e $\beta$, que indicam a importância do feromônio e da informação heurística, respectivamente.

O Algoritmo 3 apresenta o procedimento ConstruirSolucoesComFormigas(), que é chamada em cada iteração do Algoritmo 1. Em tal procedimento, cada formiga constrói sua solução.

O procedimento AplicarPassoDeConstrucho $\left(s_{k}\right)$ é responsável por selecionar um componente $j$ e adicioná-lo em $s_{k}$ com base na probabilidade de escolha $p$, definida pela Equação 14:

$$
p_{j}^{k}= \begin{cases}\frac{\tau_{j}^{\alpha} \cdot \eta_{j}^{\beta}}{\sum_{h \in N\left(s_{k}\right)} \tau_{h}^{\alpha} \cdot \eta_{h}^{\beta}} & \text { se } j \in N\left(s_{k}\right) \\ 0 & \text { se } j \notin N\left(s_{k}\right)\end{cases}
$$

O conjunto $N\left(s_{k}\right)$ contém os componentes candidatos, que são aqueles ainda não selecionados para a solução $s_{k}$ da formiga $k$ e que cobrem ao menos uma linha ainda não coberta. No Algoritmo 1, a etapa de busca 


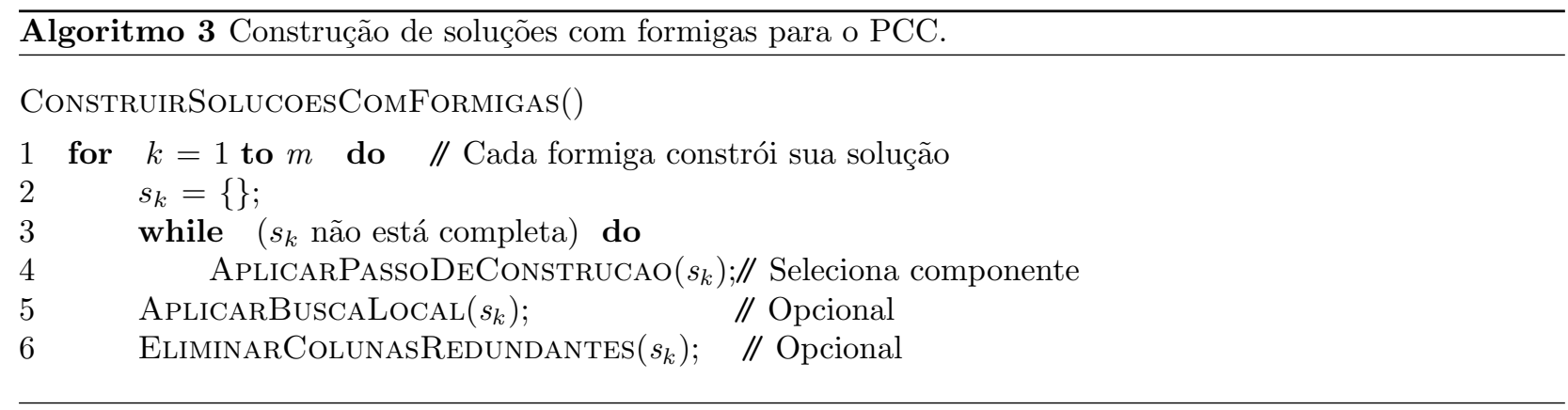

local aparece em bloco após todas as formigas terem construído suas soluções, ao passo que no Algoritmo 3 a busca local (Linha 5) é aplicada imediatamente após cada formiga ter construído sua solução. Porém, ressalta-se que a ideia do segundo se encaixa no esquema clássico apresentado pelo primeiro considerando que (no primeiro) após todas as formigas construírem suas soluções, a busca local é aplicada a cada uma das soluções obtidas pelas formigas. Isto também pode acontecer no Algoritmo 3, porém não se aguarda que todas as soluções sejam construídas para então aplicar a busca local. Em seguida, pode-se realizar a eliminação de colunas redundantes que possam existir na solução (Linha 6), i.e., aplicar procedimento para remover colunas cujas linhas cobertas já são cobertas por outras colunas, sendo que, removendo-se a referida coluna, implicará apenas em diminuição do custo sem prejuízo da cobertura de linhas da solução. A busca local e a eliminação de colunas redundantes são procedimentos opcionais.

O Ant-Line (Mulati \& Constantino, 2011) segue esquema próximo do apresentado no Algoritmo 3 e os algoritmos apresentados em Lessing et al. (2004) seguem esquema semelhante, porém as linhas 5 e 6 são invertidas. O AS-LM realiza o procedimento de seleção descrito, porém sem busca local e sem eliminação de colunas redundantes. O AS-HRTB realiza o processo semelhante, porém ao invés de começar com uma solução vazia, inicia com uma solução parcial contendo componentes selecionados aleatoriamente, a fim de aumentar a diversificação da solução. Outra diferença é que o AS-HRTB possui uma remoção de componentes redundantes da solução ao fim de cada passo de construção. O AS-HRTB aplica busca local somente ao fim do processo de construção de soluções.

$\mathrm{Na}$ atualização de feromônio, primeiro deve ocorrer a evaporação do feromônio para que então ocorra o depósito do mesmo. A evaporação é dada pela Equação 15 e o depósito é mostrado na Equação 16:

$$
\begin{gathered}
\tau_{j}=(1-\rho) \cdot \tau_{j}, \forall j \in C \\
\tau_{j}=\tau_{j}+\sum_{k=1}^{m} \Delta \tau_{j}^{k}
\end{gathered}
$$

A quantidade de formigas é dada por $m$, que normalmente é um parâmetro do algoritmo. Neste esquema, todas as formigas depositam feromônio. No AS-HRTB, o valor da a ser depositado é dado por $\Delta \tau_{j}^{k}=1 / f\left(s_{k}\right)$, onde $f\left(s_{k}\right)$ é o valor da função objetivo da solução $s_{k}$ da formiga $k$ se o componente $j$ é um elemento de $s_{k}$, e tem valor 0 caso contrário. O algoritmo AS-LM utiliza regra semelhante, com a diferença de que o feromônio depositado é multiplicado pela soma dos custos de todas as colunas na definição do problema.

Com respeito à busca local, o AS-HRTB aplica a busca local JB à melhor solução construída na última iteração do algoritmo. A JB efetua um perturbação da solução favorecendo a inclusão de colunas com bom custo-benefício.

O AS-HRTB utiliza como critério de parada, em Hadji et al. (2000), uma quantidade fixa de iterações $\left(N I_{\max }\right)$ definida como parâmetro, que foi definida com o valor 15. Ainda sobre os parâmetros, a quantidade de formigas $(m)$ também recebeu valor 15. Em parte dos experimentos $\alpha=1, \beta=5$ e $\rho=0,5$. Uma forma de se inicializar os resíduos de feromônio é fazendo $\tau_{0}=1$, como feito em Mulati \& Constantino (2011).

\subsubsection{O algoritmo Ant-line}

O algoritmo Ant-line - AL com aplicação no PCC, proposto em Mulati \& Constantino (2011), segue as linhas gerais da meta-heurística ACO apresentada no Algoritmo 1. Seu funcionamento se assemelha ao do AS, porém com significavas alterações. A estrutura da construção de solução é a mesma do Algoritmo 3, mas com diferenças fundamentais na seleção do próximo componente da solução efetuada no passo de construção.

Assim, na aplicação do passo de construção, o AL não leva em consideração apenas a informação de escolha. Cada formiga $k$ é um método construtivo que, a cada passo de construção deve: (1) selecionar aleatoriamente uma linha $e$ que ainda não é coberta por nenhuma coluna na solução $s_{k}$ e (2) escolher uma coluna para cobrir esta linha utilizando uma regra de decisão determinística baseada na informação de escolha. 
No estágio (1), a decisão seleciona uma linha e com probabilidade dada pela distribuição uniforme, conforme a Equação 17:

$$
p_{e}^{k}=\left\{\begin{array}{ll}
\frac{1}{\left|M \backslash R\left(s_{k}\right)\right|} & \text { se } e \notin R\left(s_{k}\right) \\
0 & \text { se } e \in R\left(s_{k}\right)
\end{array} \quad \forall e \in M\right.
$$

onde $R\left(s_{k}\right)$ é o conjunto de todas as linhas cobertas pelos componentes que já estão em $s_{k}$, e $M$ é o conjunto que contém todas as linhas.

Pela seleção da linha $e$, o algoritmo define um conjunto de componentes candidatos que é dado pela Equação 18:

$$
N\left(e, s_{k}\right)=\left\{j \mid\left(j \notin s_{k}\right) \wedge\left(e \notin R\left(s_{k}\right)\right) \wedge\left(a_{e j}=1\right)\right\}, \forall j \in C
$$

O estágio (2) deterministicamente seleciona um componente do conjunto de componentes candidatos $N\left(e, s_{k}\right)$. Isto é feito de acordo com a Equação 19:

$$
j=\operatorname{argmax}_{h \in N\left(e, s_{k}\right)}\left\{\tau_{h}^{\alpha} \cdot \eta_{h}^{\beta}\right\}
$$

A informação heurística utilizada é a custo de cobertura apresentada na Equação 10, onde é necessário considerar as mesmas observações feitas para o AS. O passo de construção de solução é ilustrada no Algoritmo 4.

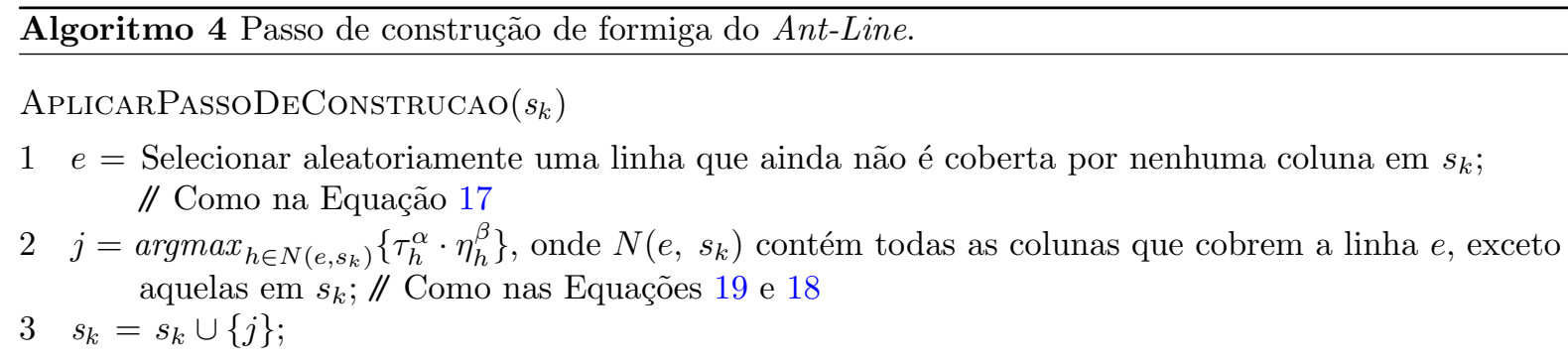

Quando todas as formigas tiverem construído suas soluções, os resíduos de feromônio são atualizados pela evaporação e depósito. A evaporação é feita de acordo com a Equação 15. Depois disto, o feromônio é depositado. Para embasar este procedimento, é necessário fazer a solução $s$ receber $s^{\prime}$ (melhor solução da iteração) ou $s^{*}$ (melhor solução da execução da tentativa), que é feito de forma que inicialmente $s^{\prime}$ reforça mais os resíduos do que $s^{*}$. Uma mudança gradual nesta frequência é feita com base na quantidade máxima de iterações do algoritmo que foi recebida como parâmetro. Assim, o depósito de feromônio é feito por uma única formiga de acordo com a Equação 20:

$$
\tau_{j}=\tau_{j}+\left(\frac{f\left(s^{*}\right)}{f(s)}\right)^{y}, \forall j \in s
$$

onde y é um parâmetro que regula o valor a ser depositado nos componentes da solução.

A busca local utilizada é a JB. O algoritmo também pode realizar a reinicialização de feromônio caso $s^{*}$ não tenha melhoria dentro de uma quantidade parametrizada de iterações. Mais detalhes do funcionamento do AL podem ser encontrados em Mulati \& Constantino (2011).

\section{Resultados}

A literatura apresenta diversas aplicações de algoritmos ACO a problemas de otimização combinatória (Dorigo \& Stützle, 2004). As aplicações e experimentos variam em diversos aspectos. As aplicações diferem entre si desde pequenas decisões nos projetos de algoritmo até mudanças substanciais no modo como as formigas trabalham, além de terem parâmetros diferentes. As instâncias utilizadas diferem em tamanho e características, por exemplo. Os equipamentos de hardware utilizados em cada experimento normalmente possuem características distintas. Dadas estas situações, a presente Seção apresenta alguns resultados de ACO aplicado a PCV e ao PCC de modo a ilustrar tais aplicabilidades e analisar algumas qualidades de soluções, sem se prender ao tempo de processamento nem a comparações rígidas entre abordagens diferentes.

\subsection{ACO para PCV}

Uma experiência relacionada com a aplicação da ACO ao PCV é reportada em Dorigo \& Gambardella (1997a) utilizando instâncias de PCV. As instâncias usadas são Oliver30 (Oliver et al., 1987), Eil50 e Eil75 (Eilon et al., 1971) e Kro100 da base de dados TSPLIB ${ }^{4}$. Os resultados são comparados com outras meta-heurísticas.

\footnotetext{
4 Disponível em http://comopt.ifi.uni-heidelberg.de/software/TSPLIB95/, acessado em abril de 2012.
} 
Os números que compõem os nomes das instâncias correspondem ao seus respectivos números de vértices (cidades). Estes resultados são resumidos na Tabela 1.

Tabela 1. Comparação do ACO com algoritmos genéticos (AG) e simulated annealing (SA) para o PCV reportada por Dorigo \& Gambardella (1997a). A última coluna representa o valor na melhor solução conhecida para a instância.

\begin{tabular}{ccccc}
\hline Nome do problema & ACO & AG & SA & Solução Ótima \\
\hline Oliver30 & $\mathbf{4 2 0}$ & 421 & 424 & 420 \\
Eil50 & $\mathbf{4 2 5}$ & 428 & 443 & 425 \\
Eil75 & $\mathbf{5 3 5}$ & 545 & 580 & 535 \\
Kro100 & $\mathbf{2 1 2 8 2}$ & 21761 & - & 21282 \\
\hline
\end{tabular}

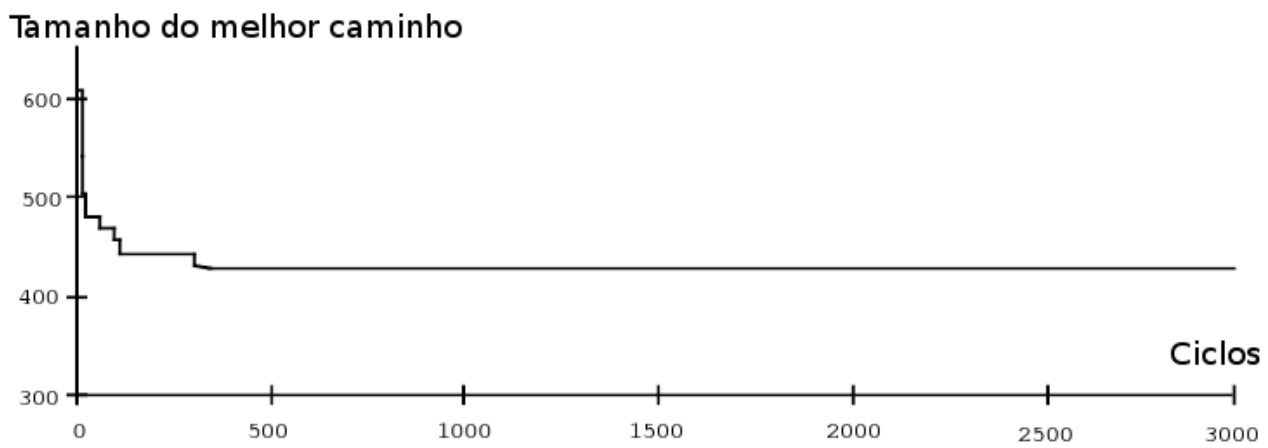

Figura 3. Evolução do custo do melhor caminho (Oliver30). Execução típica. Fonte: Dorigo et al. (1996)

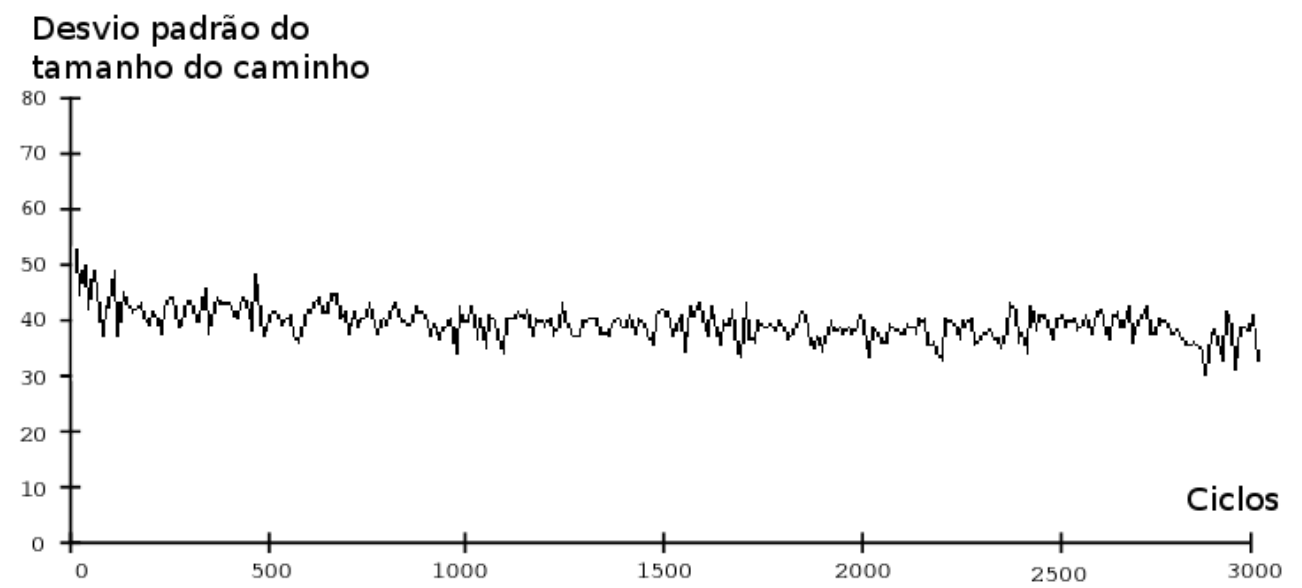

Figura 4. Evolução do desvio padrão dos custos de caminho da população (Oliver30). Execução típica. Fonte:

Dorigo et al. (1996)

Um aspecto interessante pode ser observado nas Figuras 3 e 4, que mostram a execução do algoritmo para a instância Oliver30. Pela Figura 3 é possível ver que o melhor caminho evolui até o ponto em que se estabiliza.

A Figura 3 mostra que este ponto ocorre com menos de 500 ciclos (iterações). Porém, a Figura 4 mostra que o desvio padrão do custo das soluções encontradas pelas formigas continua variando, o que demonstra que o algoritmo continua pesquisando por novas soluções, mesmo após a estabilização da melhor solução encontrada mostrada na Figura 3. Este é um aspecto importante de um algoritmo ACO: que não entre em estagnação e tenha condições de escapar de ótimos locais. 


\subsection{ACO para PCC}

Experimentos foram conduzidos em instâncias de PCC provenientes da OR-Library ${ }^{5}$ (Beasley, 1990). Estas instâncias estão divididas nas classes de PCC (C.PCC): 4, 5, 6, a, b, c, d, nre, nrf, nrg e nrh; além da classe e, que não é usada em todos os experimentos reportados. As classes 4 e 5 possuem 10 instâncias cada, ao passo que todas as demais possuem 5 instâncias. A classe 4 possui dimensão $200 \times 1000$ (linhas $\times$ colunas) e a classe 5 tem dimensão $200 \times 2000$, enquanto ambas possuem densidade de $2 \%$. A classe 6 tem dimensão $200 \times 1000$ com densidade $5 \%$. Nas classes a, b, c e d, as duas primeiras têm dimensão $300 \times 3000$ enquanto que as demais, $400 \times 4000$; com as densidades sendo $2 \%, 5 \%, 2 \%$ e $5 \%$, respectivamente. Estas classes serão referidas em conjunto como 4-d. A classe nre tem densidade $10 \%$ e nrf tem $20 \%$, de modo que ambas têm dimensão $500 \times 5000$. De dimensão $1000 \times 10000$ são as classes nrg e nrh, com densidades $2 \%$ e $5 \%$, respectivamente. As últimas quatro classes citadas serão referenciadas como nre-nrh. A classe e tem dimensão $50 \times 500$ com densidade de $20 \%$.

Todos os experimentos foram conduzidos de forma que em cada execução de uma configuração de algoritmo e instância de problema foram realizadas dez tentativas semelhantes, variando-se os apenas as sequencias de números aleatórios utilizados. É importante o fato de que os algoritmos foram executados em diferentes hardwares, e assim, a análise tem como enfoque as qualidades das soluções obtidas. Com respeito a uma execução e em relação à solução ótima ou melhor conhecida $(\mathrm{OMC})$, seguem designações que aparecem nos resultados: solução média em percentual de distância para a solução OMC (\%) (SMd(\%)), melhor solução (\%) (MS(\%)), e pior solução (\%) (PS(\%)). Aparecem também os tempos tempo médio da tentativa em segundos (s) $(\operatorname{TMdT}(\mathrm{s}))$ e tempo médio para encontrar a primeira melhor solução das tentativas (s) (TMdEP(s)).

Os resultados computacionais obtidos pelos algoritmos AS-LM e AS-HRTB (Hadji et al., 2000) são bons, porém não alcançam as melhores versões de algoritmos ACO. O mesmo vale para o AntsLS, de Rahoual et al. (2002), algoritmo cujos resultados são reportados na Tabela 2. Os tempos de execução do AntsLS variam de 50s a 460s para instâncias 4-d e de 46s a 3000s para nre-nrh.

Tabela 2. Resultados de AntsLS (Rahoual et al., 2002).

\begin{tabular}{ccc}
\hline C.PCC & SMd(\%) & MS(\%) \\
\hline $4(10)$ & 0,50 & 0,25 \\
$5(10)$ & 0,70 & 0,34 \\
$6(5)$ & 1,51 & 0,56 \\
a (5) & 0,98 & 0,26 \\
b (5) & 0,25 & 0,25 \\
c (5) & 1,03 & 0,36 \\
d (5) & 0,95 & 0,56 \\
\hline nre (5) & 0,74 & 0,74 \\
nrf (5) & 1,97 & 1,54 \\
nrg (5) & 2,21 & 0,97 \\
nrh (5) & 1,94 & 0,98 \\
\hline Média & 1,07 & 0,57 \\
\hline
\end{tabular}

Tabela 3. Resultados de Lessing et al. (2004) e de AL (Mulati \& Constantino, 2011), ambos com respectivas buscas locais.

\begin{tabular}{ccc}
\hline Algoritmo & \#OMC & REL \\
\hline MMAS & 685 & 699,6 \\
ACS & 679 & 699,5 \\
MAH & 684 & 699,6 \\
ANTS & 683 & 699,6 \\
\hline AL & 435 & 696,6 \\
\hline
\end{tabular}

Aplicações de vários algoritmos ACO para PCC são realizados em Lessing et al. (2004), e parte dos resultados referente à utilização com busca local e informação heurística custo de cobertura é mostrada na Tabela 3 (onde MAH refere-se a MMAS-ACS-Hybrid), que considera todas as instâncias apresentadas, incluindo as da classe e. O valor \#OMC indica a quantidade de soluções ótimas ou melhores conhecidas encontradas pelos algoritmos. O valor REL, estipulado pelo trabalho originário, é denotado por: a soma das divisões dos valores ótimos ou melhores conhecidos pelos valores das soluções encontradas em cada tentativa. Desta maneira, ocorre a avaliação do comportamento dos algoritmos de forma geral, de modo que quanto mais perto de 700, melhor é o resultado obtido. O tempo de execução foi fixado em 100s para todos os testes de Lessing et al. (2004) apresentados. Calculou-se o valor para execuções similares do AL, o que é mostrado na última linha da Tabela. O tempo do AL não é fixo como o dos outros algoritmos, com o TMdT consumindo $1689,37 \mathrm{~s}$ e o TMdEP com valor 22,04s. Assim AL é pouco pior em qualidade de solução e é pior que os outros em tempo de execução geral, mas o baixo TMdEP indica bom potencial para melhora geral do tempo.

Aplicações que utilizam a orientação a linha para o PCC ocorrem nos algoritmos ACO AC, de Ren et al. (2010) e AL, de Mulati \& Constantino (2011). Os resultados de AL são ilustrados na Tabela 4. É possível

\footnotetext{
5 Disponível em http://people.brunel.ac.uk/ mastjjb/jeb/orlib/scpinfo.html, acessado em abril de 2012.
} 
fazer comparação do AL com o AntsLS. O segundo possui médias $\mathrm{SMd}=1,07 \%$ e MS=0,57\%, enquanto que o primeiro tem $\mathrm{SMd}=0,53 \%$ e $\mathrm{MS}=0,12 \%$, denotando melhor qualidade de solução para o $\mathrm{AL}$.

Tabela 4. Resultados de AL com busca local (Mulati \& Constantino, 2011).

\begin{tabular}{cccccc}
\hline C.PCC & TMdT(s) & TMdEP(s) & PS(\%) & SM(\%) & MS(\%) \\
\hline $4(10)$ & 8,23 & 2,53 & 0,48 & 0,19 & $\mathbf{0}$ \\
$5(10)$ & 23,44 & 6,2 & 0,42 & 0,19 & $\mathbf{0}$ \\
6 (5) & 5,18 & 1,84 & 0,98 & 0,36 & $\mathbf{0}$ \\
a (5) & 221,78 & 43,66 & 0,75 & 0,38 & 0,08 \\
b (5) & 26,86 & 4,18 & 0,25 & 0,12 & $\mathbf{0}$ \\
c (5) & 401,18 & 71,62 & 0,63 & 0,36 & 0,17 \\
d (5) & 178,36 & 17,22 & 0,92 & 0,59 & $\mathbf{0}$ \\
\hline nre (5) & 2610,98 & 175,26 & 1,41 & 0,5 & $\mathbf{0}$ \\
nrf (5) & 2861,82 & 166,54 & 2,97 & 1,21 & $\mathbf{0}$ \\
nrg (5) & 8640,4 & 2130,54 & 1,81 & 0,91 & 0,37 \\
nrh (5) & 8640,68 & 1299,18 & 2,29 & 1,67 & 0,97 \\
\hline Média & 1819,28 & 280,54 & 1,06 & 0,53 & 0,12 \\
\hline
\end{tabular}

O AC é configurado com tempo máximo baixo, variando de 2s a 20s, além de utilizar informação heurística mais elaborada, que é embasada em relaxação Lagrangeana que trabalha com método subgradiente (Fisher, 1981) para obter limite inferior para solução ótima pelo problema dual. Por sua vez, o AL utiliza vários critérios de parada, dentre eles o tempo máximo, que é configurado em valores relativamente elevados. Os tempos médios do AC são $\mathrm{TMdT}=14,65 \mathrm{~s}$ e $\mathrm{TMdEP}=4,27 \mathrm{~s}$, ao passo que AL consome $\mathrm{TMdT}=1819,28 \mathrm{~s}$, $\mathrm{TMdEP}=280,54 \mathrm{~s}$. A grande diferença entre TMdEP e TMdT do AL indicam potencial de melhora do TMdT por ajuste dos critérios de parada. A média da qualidade de solução do AC fica em $\mathrm{PS}=0,33 \%, \mathrm{SMd}=0,17 \%$ e $\mathrm{MS}=0,02 \%$; enquanto que o $\mathrm{AL}$ tem valores próximos, que são $\mathrm{PS}=1,06 \%, \mathrm{SMd}=0,53 \%$ e $\mathrm{MS}=0,12 \%$.

\section{Conclusões}

A meta-heurística ACO tem sido aplicada com sucesso a vários problemas de otimização combinatória. Este capítulo apresentou a meta-heurística ACO, ilustrando sua estrutura básica e ilustrando sua aplicação em dois problemas clássicos de pesquisa operacional, sendo o problema do caixeiro viajante (PCV) e o problema de cobertura de conjunto (PCC).

O PCV e o PCC foram utilizados para exemplificar o uso de ACO por serem problemas clássicos e por apresentarem características bastante distintas. O primeiro explora o relacionamento espacial do problema em analogia com o comportamento das formigas reais, onde o grafo do problema é relacionado com o ambiente natural das formigas. Enquanto que o segundo caso explora um problema de otimização combinatória puramente matemático, em que não há relação com elementos espaciais que permita fazer analogia com o ambiente espacial das formigas reais.

Por outro lado, este estudo comparativo com dois tipos de problemas distintos possibilita demonstrar que a concepção de um algoritmo baseado em ACO para um problema de otimização não requer associação do problema com aspectos espaciais do ambiente das formigas reais.

Um aspecto fundamental, observado na concepção de algoritmo baseado em ACO, é a investigação de um algoritmo construtivo (guloso). Dorigo et al. (1996) observam que quando o parâmetro $\alpha=0$ (Equação 11), o algoritmo ACO torna-se um clássico algoritmo guloso aleatorizado, e que, quando $\beta=0$, tem-se um algoritmo baseado somente no feromônio, que geralmente converge rapidamente para um ótimo local. Esta observação salienta a importância de se ajustar estes dois parâmetros de forma que a função gulosa utilizada não seja ignorada. O uso de algoritmos gulosos também é observado na meta-heurística GRASP (Greedy Randomized Adaptive Search Procedure) (Resende et al., 1996). Portanto, a investigação de um algoritmo baseado em GRASP também pode ser uma fonte de informação importante para se projetar um algoritmo baseado em ACO.

\section{Referências}

Al-Sultan, K.S.; Hussain, M.F. \& Nizami, J.S., A genetic algorithm for the set covering problem. Journal of the Operational Research Society, 47(5):702-709, 1996.

Alaya, I.; Solnon, C. \& Ghedira, K., Ant algorithm for the multidimensional knapsack problem. In: Proceedings of International Conference on Bioinspired Optimization Methods and their Applications. p. 63-72, 2004. 
Beasley, J.E., OR-Library: distributing test problems by electronic mail. Journal of the Operational Research Society, 41(11):1069-1072, 1990.

Blum, C., Beam-ACO - hybridizing ant colony optimization with beam search: an application to open shop scheduling. Computers and Operations Research, 32(6):1565-1591, 2005.

Blum, C.; Roli, A. \& Dorigo, M., HC-ACO: the hyper-cube framework for ant colony optimization. In: Proceedings of Metaheuristics International Conference. p. 399-403, 2001.

Chvàtal, V., A greedy heuristic for the set-covering problem. Mathematics of Operations Research, 4(3):233-235, 1979.

Colin, E.C., Pesquisa Operacional: 170 Aplicações em Estratégia, Finanças, Logística, Produção, Marketing e Vendas. São Paulo, SP: Livros Técnicos e Científicos, 2007.

Colorni, A.; Dorigo, M.; Maniezzo, V. \& et al., Distributed optimization by ant colonies. In: Varela, F.J. \& Bourgine, P. (Eds.), Proceedings of the First European Conference on Artificial Life. Cambridge, USA: MIT Press, p. 134-142, 1992.

Cormen, T.H.; Leiserson, C.E.; Rivest, R.L. \& Stein, C., Introduction to Algorithms. 3a edição. Cambridge, USA: MIT Press, 2009.

Crawford, B. \& Castro, C., Integrating lookahead and post processing procedures with aco for solving set partitioning and covering problems. In: Rutkowski, L.; Tadeusiewicz, R.; Zadeh, L. \& Zurada, J. (Eds.), Artificial Intelligence and Soft Computing. v. 4029 de Lecture Notes in Computer Science, p. 1082-1090, 2006.

Croes, A., A method for solving traveling salesman problems. Operations Research, 6:791-812, 1958.

Deng, G.F. \& Lin, W.T., Ant colony optimization-based algorithm for airline crew scheduling problem. Expert Systems and Applications, 38(5):5787-5793, 2011.

Desrochers, M. \& Soumis, F., A column generation approach to the urban transit crew scheduling problem. Transportation Science, 23(1):1-13, 1989.

Dorigo, M., Optimization, Learning and Natural Algorithms [em italiano]. PhD thesis, Politecnico di Milano, Dipartimento di Elettronica ed Informatica, 1992.

Dorigo, M. \& Caro, G.D., Ant colony optimization: A new meta-heuristic. In: Proceedings of the Congress on Evolutionary Computation. Piscataway, USA: IEEE Press, p. 1470-1477, 1999.

Dorigo, M. \& Gambardella, L., Ant colonies for the traveling salesman problem. BioSystems, 43:73-81, 1997a.

Dorigo, M. \& Gambardella, L.M., Ant colony system: a cooperative learning approach to the traveling salesman problem. IEEE Transactions Evolutionary Computation, 1(1):53-66, 1997b.

Dorigo, M.; Maniezzo, V. \& Colorni, A., The ant system: Optimization by a colony of cooperating agents. IEEE Transactions on Systems, Man, and Cybernetics - Part B, 26(1):29-41, 1996.

Dorigo, M. \& Stützle, T., Ant Colony Optimization. Cambridge, USA: MIT Press, 2004.

Eilon, S.; Watson-Gandy, C.D.T. \& Christofides, N., Distribution management: mathematical modelling and practical analysis. London, UK: Griffin, 1971.

Fisher, M., The Lagrangian relaxation method for solving integer programming problems. Management Science, $27(1): 1-18,1981$.

Flores, P.F.; Neto, H.C. \& Marques-Silva, J.P., On applying set covering models to test set compaction. In: Proceedings of Ninth Great Lakes Symposium on VLSI. Washington, USA: IEEE Computer Society, p. 8-11, 1999.

Hadji, R.; Rahoual, M.; Talbi, E. \& Bachelet, V., Ant colonies for the set covering problem. In: Proceedings of ANTS2000 - From Ant Colonies to Artificial Ants: a Series of International Workshops on Ant Algorithms. p. 63-66, 2000.

Housos, E. \& Elmroth, T., Automatic optimization of subproblems in scheduling airline crews. Interfaces, 27(5):68-77, 1997.

Jacobs, L.W. \& Brusco, M.J., A local-search heuristic for large set-covering problems. Naval Research Logistics, 42(7):1129-1140, 1995.

Leguizamon, G. \& Michalewicz, Z., A new version of ant system for subset problems. In: Proceedings of the Congress on Evolutionary Computation. Piscataway, USA: IEEE Press, v. 2, 1999.

Lessing, L.; Dumitrescu, I. \& Stützle, T., A comparison between ACO algorithms for the set covering problem. In: Dorigo, M.; Birattari, M.; Blum, C.; Gambardella, L.M.; Mondala, F. \& Stützle, T. (Eds.), Ant Colony Optimizaton and Swarm Intelligence. Heidelberg, Germany: Springer-Verlag, v. 3172 de Lecture Notes in Computer Science, p. 1-12, 2004.

Lin, S., Computer solutions of the traveling salesman problem. Bell System Technical Journal, 44(10):2245-2269, 1965.

Lin, S. \& Kernighan, B.W., An effective heuristic algorithm for the travelling-salesman problem. Operations Research, 21:498-516, 1973.

Maniezzo, V., Exact and approximate nondeterministic tree-search procedures for the quadratic assignment problem. INFORMS Journal on Computing, 11(4):358-369, 1999.

Maniezzo, V. \& Colorni, A., The ant system applied to the quadratic assignment problem. IEEE Transactions on Knowledge and Data Engineering, 11(5):769-778, 1999.

Mulati, M.H. \& Constantino, A.A., Ant-line: A line-oriented aco algorithm for the set covering problem. In: Proceedings of XXX International Conference of the Chilean Computer Science Society. Curico, Chile, 2011. 
de Oliveira, N.V., Problema de Cobertura de Conjuntos - Uma Comparação Numérica de Algoritmos Heurísticos. Dissertação de mestrado, Universidade Federal de Santa Catarina, Programa de Pós-Graduação em Engenharia de Produção, 1999.

Oliver, I.M.; Smith, D.J. \& Holland, J.R.C., A study of permutation crossover operators on the traveling salesman problem. In: Proceedings of the Second International Conference on Genetic Algorithms and their Applications. Hillsdale, USA: L. Erlbaum Associates Inc., p. 224-230, 1987.

Rahoual, M.; Hadji, R. \& Bachelet, V., Parallel ant system for the set covering problem. In: Dorigo, M.; Di Caro, G. \& Sampels, M. (Eds.), Ant Algorithms. Heidelberg, Germany: Springer-Verlag, v. 2463 de Lecture Notes in Computer Science, p. 249-297, 2002.

Ramalhinho-Lourenço, H. \& Serra, D., Adaptive Approach Heuristics for the Generalized Assignment Problem. Economics Working Papers 288, Department of Economics and Business, Universitat Pompeu Fabra, 1998.

Reinelt, G., The Traveling Salesman: Computational Solutions for TSP Applications. Berlin, Germany: SpringerVerlag, 1994.

Ren, Z.; Feng, Z.; Ke, L. \& Chang, H., A fast and efficient ant colony optimization approach for the set covering problem. In: Proceedings of the IEEE World Congress on Computational Intelligence. Piscataway, USA: IEEE Press, p. 1839-1844, 2008.

Ren, Z.G.; Feng, Z.R.; Ke, L.J. \& Zhang, Z.J., New ideas for applying ant colony optimization to the set covering problem. Computers \& Industrial Engineering, 58(4):774-784, 2010.

Resende, M.G.C.; Thomas, \& Feo, T.A., A GRASP for satisfiability. In: Cliques, Coloring, and Satisfiability: The Second DIMACS Implementation Challenge. American Mathematical Society, v. 26 de DIMACS Series on Discrete Mathematics and Theoretical Computer Science, p. 499-520, 1996.

Solnon, C. \& Fenet, S., A study of ACO capabilities for solving the maximum clique problem. Journal of Heuristics, 12(3):155-180, 2006.

Stützle, T. \& Hoos, H., Max-Min ant system and local search for combinatorial optimization. In: Proceedings of 2 nd International Conference on Metaheuristics. Sophie-Antipolis, France, p. 1-15, 1997.

Stützle, T. \& Hoos, H., Improvements on the ant system: Introducing the Max-Min ant system. In: Albrecht, R.; Smith, G. \& Steele, N. (Eds.), Proceedings of 3rd International Conference on Artificial Neural Networks and Genetic Algorithms. Heidelberg, Germany: Springer-Verlag, p. 245-249, 1998.

Toregas, C.; Swain, R.; ReVelle, C. \& Bergman, L., The location of emergency service facilities. Operations Research, 19:1363-1373, 1971.

Wade, A. \& Salhi, S., An ant system algorithm for the mixed vehicle routing problem with backhauls. In: Resende, M.G.C.; de Sousa, J.P. \& Viana, A. (Eds.), Metaheuristics. Norwell, USA: Kluwer Academic, p. 699-719, 2004.

Yagiura, M.; Kishida, M. \& Ibaraki, T., A 3-flip neighborhood local search for the set covering problem. European Journal of Operational Research, 172(2):472-499, 2006.

\section{Notas Biográficas}

Mauro Henrique Mulati é graduado em Informática (Universidade Estadual de Maringá - UEM, 2005) e mestre em Ciência da Computação (UEM, 2009). Atualmente é Professor Assistente do Departamento de Ciência da Computação da Universidade Estadual do Centro-Oeste - UNICENTRO.

Ademir Aparecido Constantino é graduado em Matemática (UEM, 1990), mestre e doutor em Engenharia de Produção na área de Otimização e Simulação (UFSC, 1993 e 1997, respectivamente), além de Pós-doutorado na Universidade de Nottingham, Inglaterra. Atualmente é professor titular do Departamento de Informática da Universidade Estadual de Maringá.

Anderson Faustino da Silva é graduado em Ciência da Computação (Universidade Estadual do Oeste do Paraná - UNIOESTE, 1999), mestre e doutor em Engenharia de Sistemas e Computação (COPPE/UFRJ, 2003 e 2006, respectivamente). Atualmente é Professor Adjunto do Departamento de Informática da Universidade Estadual de Maringá. 
Mulati et al. 


\title{
Programação Genética
}

\author{
Douglas Adriano Augusto, Heder Soares Bernardino e Helio José Corrêa Barbosa
}

\begin{abstract}
Resumo: A programação genética é uma meta-heurística evolucionária destinada à geração automática de programas através de um processo iterativo inspirado pela teoria da seleção natural. Em pesquisa operacional, técnicas de programação genética são normalmente usadas para inferir heurísticas para problemas de tomada de decisão. Desta forma, a programação genética assume o papel de hiper-heurística criando novos métodos de busca mais eficientes que os tradicionalmente considerados. O presente capítulo descreve a programação genética e apresenta suas aplicações no campo da pesquisa operacional.
\end{abstract}

Palavras-chave: Programação genética, Pesquisa Operacional, Otimização.

Abstract: Genetic programming is an evolutionary metaheuristic designed to automatically generate programs by means of an iterative process inspired by the theory of natural selection. In operational research, genetic programming techniques are normally used to infer heuristics for decision-making problems. In this way, genetic programming is a hyper-heuristic creating new search methods which are more efficient that those traditionally considered. This chapter describes genetic programming and presents its applications in the operations research field.

Keywords: Genetic programming, Operations research, Optimization.

\section{Introdução}

A maioria dos problemas reais de pesquisa operacional são difíceis de serem resolvidos e, apesar de não haver garantia de encontrar a solução ótima, heurísticas podem fornecer uma boa resposta em tempo hábil. Todavia, sua elaboração é resultado de muita pesquisa além de envolver vários especialistas, o que faz emergir a questão: será possível automatizar a criação de heurísticas? A programação genética aparece aqui como uma ferramenta da inteligência computacional utilizada como uma hiper-heurística, ou seja, uma técnica de busca destinada a elaborar heurísticas.

A programação genética $(\mathrm{PG})$ é uma meta-heurística estocástica de otimização baseada no princípio Darwiniano de seleção natural e, assim, compõe o conjunto de técnicas da chamada computação evolucionária. As aplicações com PG iniciaram-se com Cramer (1985), mas foram os trabalhos de Koza, especialmente seu livro (Koza, 1992), que formalizaram e popularizam o método. A PG otimiza estruturas funcionais capazes de realizar operações diversas, tais como: lógicas, aritméticas, condicionais e de desvios. Em resumo, a PG destina-se à evolução de programas de computador em linguagens arbitrárias.

A literatura da PG tem demonstrado suas muitas qualidades importantes e que podem ser exploradas, dentre as quais pode-se destacar:

- Robustez - forte solidez na tolerância aos ruídos.

- Requer pouco conhecimento do domínio - basicamente, é necessária uma função capaz de comparar a qualidade relativa dos indivíduos.

- Produz soluções simbólicas - usualmente as soluções obtidas pela PG são legíveis e interpretáveis ("código-fonte disponível").

- Paralelismo natural - as demandas computacionais da PG podem ser trivialmente particionadas permitindo redução no tempo de execução e/ou escalabilidade para problemas mais complexos.

*Autor para contato: douglas@lncc.br 
- Facilmente extensível/modificável - sua versatilidade permite hibridizações com outras técnicas, integração de diferentes modelos evolucionários (p. ex., coevolução, nichos, múltiplos objetivos) e as mais diversas representações e linguagens para os programas (como representação formal por gramáticas).

O presente capítulo descreve o funcionamento da programação genética em sua forma mais comumente utilizada bem como apresenta suas diversas aplicações em pesquisa operacional.

\section{Programação Genética}

Assim como outras técnicas populacionais evolucionistas, a PG evolui um conjunto de indivíduos-programas candidatos - por meio de procedimentos baseados na teoria da seleção natural. Este processo é iterativo e a cada geração indivíduos promissores são selecionados para procriarem, novas soluções são formadas por meio de operações genéticas (como cruzamento e mutação) e indivíduos na população corrente são substituídos pelos novos programas criados. Embora não haja garantias da obtenção de soluções ótimas e nem mesmo de progresso, esta dinâmica tende a produzir soluções candidatas incrementalmente melhores ao longo das gerações.

Um grande diferencial da PG é sua aplicabilidade, ao menos teórica, à qualquer problema que atenda as seguintes propriedades:

1. a solução deve ser expressa como um programa em uma linguagem.

2. as soluções candidatas devem ser comparáveis - função de avaliação.

Entretanto, na prática existem problemas em que a PG fica limitada computacionalmente, inviabilizando o seu uso. É o caso de situações que envolvem avaliações/simulações custosas ou cuja estrutura da solução esperada é demasiadamente grande e intricada. Todavia, à medida que a tecnologia avança a programação genética amplia seu campo de aplicação. Em especial, uma alternativa é o uso da PG em ambientes computacionais de alto desempenho, servindo-se de implementações massivamente paralelas e/ou distribuídas. Apesar disto, a programação genética tem sido usada em diversas aplicações, podendo-se destacar em pesquisa operacional:

- Despacho de veículos - a solução esperada é uma heurística que selecione o veículo ideal (aquele que reduza os custos, por exemplo) para atender cada pedido de entrega.

- Agendamento de tarefas - o desafio envolve a escolha da tarefa a ser processada em um determinado instante de forma a otimizar uma medida, como o tempo total de operação.

- Planejamento de manutenção - busca-se por heurísticas que façam o planejamento de manutenções a fim de minimizar sua frequência mas que ao mesmo tempo evitem os custos associados à manutenção precária.

- Empacotamento ou corte - o objetivo é empacotar (ou cortar) peças mono, bi ou tridimensionais de maneira a reduzir o desperdício de espaço (ou material).

- Minimização de rota - procura-se por heurísticas capazes de ordenar uma sequência de visitas de forma que a distância total percorrida (ou tempo gasto) seja mínima.

O processo evolutivo da programação genética pode ser visualizado pelo fluxograma da Figura 1.

Considerando os algoritmos genéticos (AGs) como um pilar da programação genética, não é difícil verificar semelhanças entre o fluxograma de execução de ambos métodos. Pode-se destacar, pela sua similaridade, as condições de parada, as técnicas de seleção e as formas de substituição da população corrente. Sendo os AGs largamente difundidos como técnica de otimização, inclusive na pesquisa operacional, serão detalhados aqui apenas os passos da execução em que a PG se distingue de um AG.

\subsection{Representação dos programas}

Diversos tipos de estruturas são capazes de representar programas, mas três formas se destacam na literatura: linear (Oltean et al., 2009), árvore (Koza, 1992) ou grafo (Poli, 1999; Teller, 1996; Miller \& Smith, 2006). Por causa de seu poder de expressão de programas, relativa simplicidade e facilidade de operar modificações, a representação por árvore é a mais encontrada.

Apesar do seu enorme poder representativo, será possível perceber no decorrer deste capítulo que a representação de um programa utilizando uma estrutura de árvore simples pode limitar/dificultar sua aplicação a problemas mais complexos. Pensando nisto, trabalhos foram desenvolvidos no sentido de direcionar a 


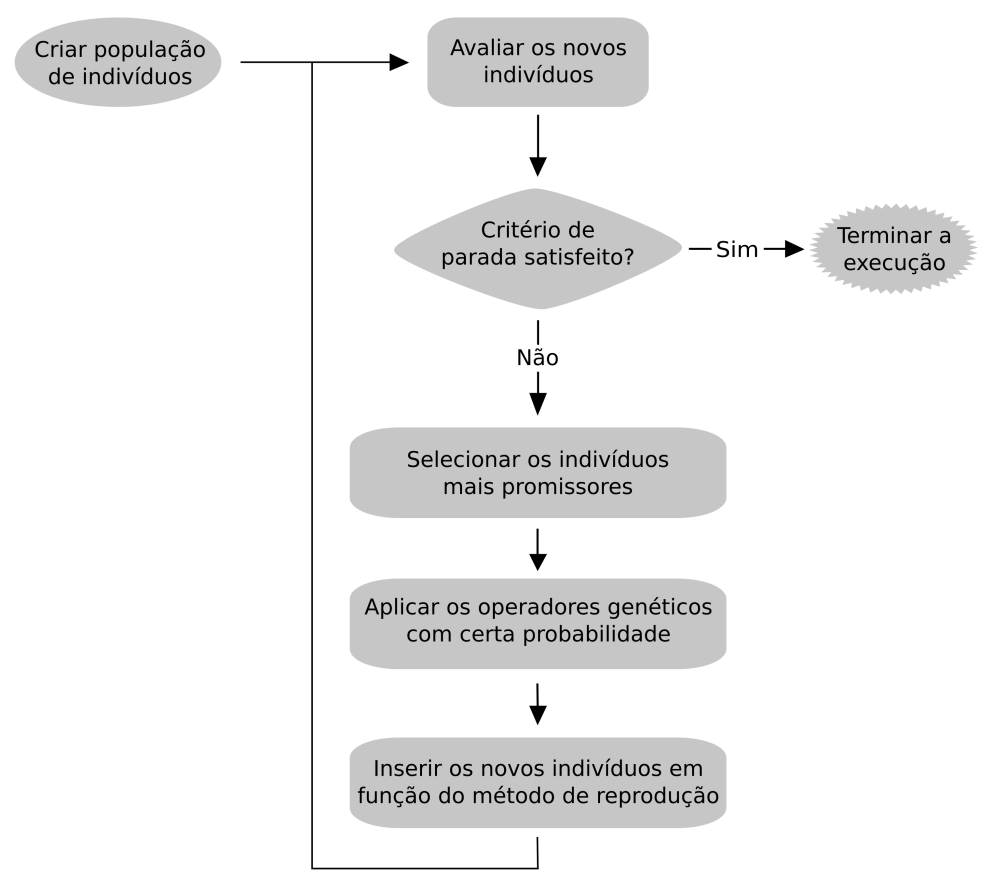

Figura 1. Fluxograma do funcionamento da programação genética.

formação de sub-estruturas das árvores considerando seu tipo (Montana, 1994) ou por meio de gramáticas formais (Whigham, 1995). Em especial, o uso de gramáticas formais para definir a linguagem pela qual os programas candidatos devem evoluir é de importância tal que adaptações para estruturas lineares foram posteriormente desenvolvidas (O'Neill \& Ryan, 2001).

Considerando seu emprego comum em PG, será utilizada neste capítulo a representação dos programas em estrutura de árvore. Dois exemplos de indivíduos, uma expressão condicional e outra matemática, representados por árvores são exemplificados na Figura 2. Estas expressões representam

$$
\text { A: se } A \vee B \text { então } C \text {, senão }(15,4 \times X) \quad \text { B: } \cos (\sqrt{2012}+\sin (X \times Y))
$$

A

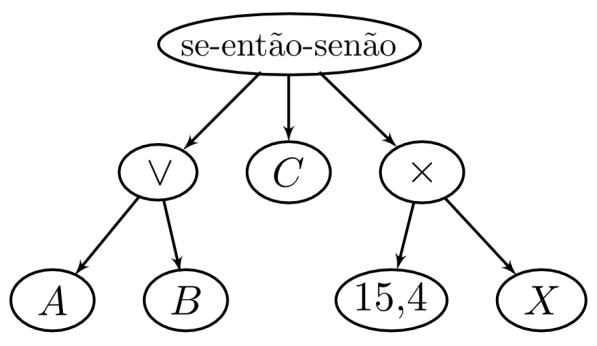

B

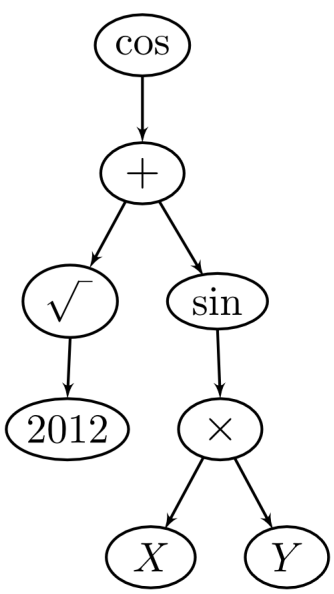

Figura 2. Indivíduos representados pela estrutura árvore.

Note que os programas como apresentados na Figura 2 são compostos por elementos fundamentais, tais como a variável $x$, a função $\sin (\cdot)$ e a constante 15,4. Estes componentes são agrupados nos chamados conjuntos de funções $(\mathbb{F})$ e terminais $(\mathbb{T})$. As definições dos conjuntos de funções e terminais são específicas do domínio da aplicação, pois são eles que definem as ferramentas/primitivas que estarão à disposição do processo de otimização de programas. Em outras palavras, são as primitivas que delimitam a linguagem em que os programas podem evoluir. 
O conjunto $\mathbb{F}$ é composto por funções que requerem argumentos, ou seja, os operadores. Dentre estes pode-se citar operadores aritméticos $\left(+, \times, \sin , \sqrt{ }, x^{y}\right)$, lógicos $(\vee, \wedge, \neg)$, relacionais $(<,>$, =), condicionais (se-então-senão) e laços iterativos (enquanto-faça).

Por outro lado, o conjunto $\mathbb{T}$ provê os operandos, tendo como exemplo as variáveis/atributos $(x, y$, tempo de processamento, data da requisição), constantes $(\pi, e, 3,14)$ e funções que não requerem argumentos (random(), tempo_decorrido()).

Assim, os conjuntos de funções e terminais podem ser combinados e todo programa, bem como seus fragmentos, nada mais é do que uma combinação particular entre elementos de $\mathbb{F}$ e $\mathbb{T}$. No entanto, a programação genética tradicional requer que duas propriedades sejam satisfeitas para que estes conjuntos possam ser livremente manipulados e permitam a execução dos programas candidatos:

Suficiência Como qualquer estrutura da população é um arranjo particular de $\mathbb{F}$ e $\mathbb{T}$, então é condição necessária que a solução do problema possa ser expressa como uma combinação das primitivas. Em outras palavras, a propriedade de suficiência define que, ao menos para uma combinação específica, a solução esperada possa ser descrita utilizando os elementos dos conjuntos $\mathbb{F}$ e $\mathbb{T}$. Entretanto, é fácil observar que na prática não se conhece o aspecto da solução, tornando a propriedade de suficiência difícil de ser devidamente atendida. Apesar de uma alternativa simples decorrer da adição de todas as primitivas possíveis, tal procedimento aumenta enormemente o espaço de busca, podendo degradar seriamente o processo de otimização.

Fechamento O fechamento é a segunda restrição nos conjuntos de primitivas e requer que os operadores do conjunto de funções tenham suas aridades ${ }^{1}$ obedecidas e aceitem como argumentos quaisquer terminais em $\mathbb{T}$ ou valores de retorno de qualquer função em $\mathbb{F}$. Em outras palavras, os conjuntos de terminais e funções têm que ser definidos de forma que quaisquer combinações sejam válidas. Em domínios onde as deficiências e limitações da noção dos conjuntos de terminais/funções mostram-se complexas é possível adotar representações mais sofisticadas, como a representação formal por gramática (Whigham, 1995).

\subsection{Criação da população}

O primeiro passo do processo evolutivo ilustrado na Figura 1 é gerar uma população inicial, o que deve ser feito de forma que se tenha uma amostragem representativa e bem distribuída do espaço dos programas factíveis. Entretanto, amostragens estritamente uniformes são muito difíceis de serem obtidas, já que que o espaço de possíveis programas pode assumir tamanho infinito. Logo, o que pode ser feito é evitar grandes distorções (Poli et al., 2008). Na prática, a criação dos indivíduos que compõem a população inicial é realizada de maneira essencialmente aleatória, compondo os programas com instruções básicas dos conjuntos $\mathbb{F}$ e $\mathbb{T}$. Além disto, é claro que a condição de fechamento deve ser mantida e, desta forma, métodos que delineiam a forma como as árvores iniciais são construídas foram propostos na tentativa de se criar uma boa amostragem inicial. Dentre estas técnicas mais comuns pode-se destacar:

\section{Criação Completa (Full Creation)}

$\mathrm{Na}$ PG é interessante que se imponha limites à profundidade das árvores ${ }^{2}$, evitando que as soluções candidatas cresçam indefinidamente. Este tamanho máximo factível é geralmente especificado por meio de um parâmetro de profundidade máxima. No método de criação completa, exemplificado pela Figura 3, todo comprimento entre o nó raiz e qualquer nó terminal deve ser igual à esta profundidade máxima. Para que esta situação seja obtida é suficiente que os nós sejam aleatoriamente escolhidos do conjunto de funções até se alcançar a profundidade máxima; quando alcançada, escolhe-se então do conjunto de terminais.
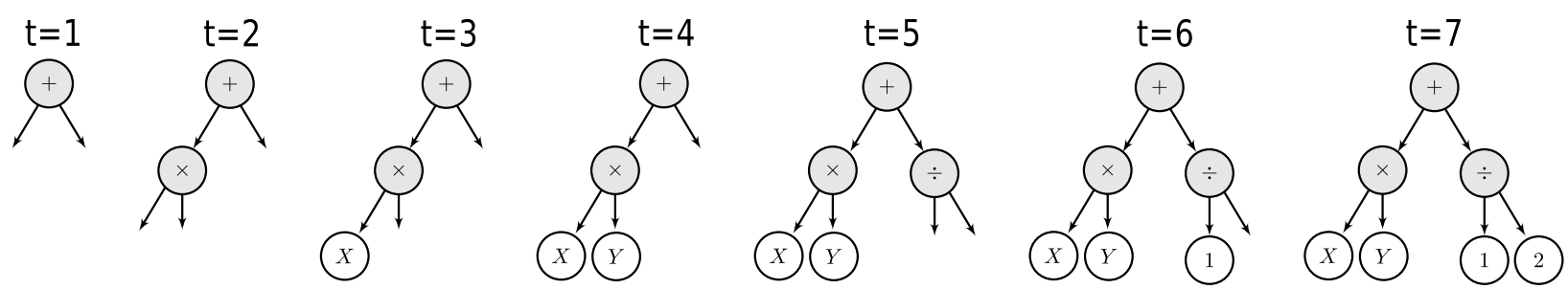

Figura 3. Exemplificação passo-a-passo do método de criação completa.

\footnotetext{
1 Número requerido de argumentos.

2 Profundidade é o maior comprimento (ramo) entre o nó raiz e qualquer outro nó de uma árvore.
} 


\section{Criação Livre (Grow Creation)}

Diferentemente do anterior, o método de criação livre permite que a árvore seja gerada com nós aleatoriamente sorteados entre quaisquer primitivas, mas respeitando-se sua profundidade máxima. Esta técnica permite que árvores com diferentes topologias, simetrias e profundidades sejam geradas, diversificando a amostragem inicial. Este processo de criação é ilustrado na Figura 4.

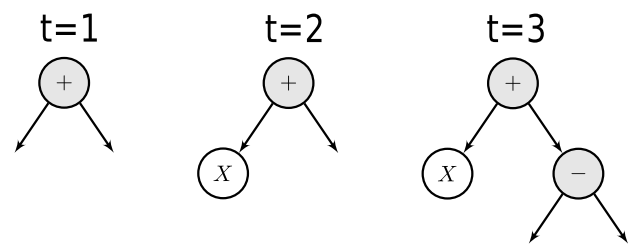

Figura 4. Exemplificação passo-a-passo do método de criação livre.

\section{Efeito Escada (Ramping)}

Aqui delimita-se a profundidade máxima entre dois valores e utiliza-se um valor dentro deste intervalo como limitador no tamanho das árvores a serem criadas em cada sub-conjunto da população inicial. Em geral, esta atribuição varia linearmente entre os valores mínimo e máximo definidos. Por exemplo, em uma população de 50 indivíduos, intervalo $[2,6]$ para a profundidade máxima e dividindo a criação da população em cinco etapas, então os primeiros 10 programas seriam criados com profundidade 2 , os próximos 10 com profundidade 3 , e assim por diante até uma profundidade máxima final de 6 .

\section{Criação Mista (Ramped Half-and-Half)}

A ideia desta técnica consiste em gerar metade das soluções em cada sub-conjunto do método ramping utilizando o método método completo $(f u l l)$ e a outra parte com o método livre (grow). Segundo Koza (1992), este é o método mais recomendado, sendo capaz de gerar uma ampla diversidade de indivíduos, produzindo várias formas e tamanhos distintos de árvores.

\subsection{Avaliação dos indivíduos}

A avaliação dos indivíduos mede a qualidade com a qual os programas candidatos realizam a tarefa alvo. Como comentado anteriormente, esta etapa é dependente do problema. Por exemplo, para o caso de um problema de classificação ou regressão, cada programa da população é executado sobre conjuntos de argumentos e os valores de retorno são comparados (sob alguma métrica) aos valores esperados (conhecidos). Assim, quanto mais similares aos valores esperados estão os valores de retorno do programa candidato, mais apto é o indivíduo em questão.

Para o caso de um problema de regressão, é comum se estar interessado em minimizar a discrepância absoluta entre os valores esperados e os valores obtidos pela execução do programa candidato. Desta forma, assumindo que maiores valores de aptidão são preferíveis (como ocorre na natureza), uma medida de avaliação pode ser o inverso da soma do quadrado dos erros (Koza, 1990):

$$
f_{\text {aptidão }}=\left[\sum_{i=1}^{k}\left[f\left(p_{i}\right)-Y_{i}\right]^{2}\right]^{-1},
$$

onde $k$ é o número de pontos, $p_{i} \in \mathbb{R}^{n}$ é o $i$-ésimo ponto, $f$ é a função codificada por um indivíduo e $Y_{i} \in \mathbb{R}$ é o $i$-ésimo valor esperado.

Por outro lado, se o problema a ser resolvido envolve a classificação de dados, o objetivo primário é medir a acurácia do modelo sobre um determinado conjunto de amostras (normalmente de treinamento) e, desta forma, a aptidão de um programa que represente um classificador $C\left(C: \mathbb{R}^{n} \mapsto \mathbb{N}\right)$ poderia ser dada pela taxa de acertos normalizada:

$$
f_{\text {aptidão }}=\frac{1}{k} \sum_{i=1}^{k} \mathbb{I}\left[C\left(a_{i}\right)=Y_{i}\right],
$$

onde $k$ é o número de amostras de treinamento, $Y_{i} \in \mathbb{N}$ é a classe esperada para a $i$-ésima amostra $a_{i} \in \mathbb{R}^{n} \mathrm{e}$ $\mathbb{I}[\pi]$ uma função que retorna 1 se a condição representada pelo argumento $\pi$ é satisfeita ou 0 , caso contrário.

Apesar do poder da PG em encontrar boas soluções para uma larga gama de problemas, seu processo evolutivo pode direcionar a busca no sentido de super-ajustar o modelo aos dados. Este comportamento é conflitante em razão do desejo tanto pela maximização da acurácia do modelo quanto, concorrentemente, 
pela minimização de sua complexidade (presumindo que a simplicidade esteja inversamente relacionada a super-ajustes). Para tratar esta situação é útil penalizar a aptidão do indivíduo em função de sua complexidade/tamanho, visando assim a obtenção de soluções mais compactas, legíveis e potencialmente com maior poder de generalização. A penalização da aptidão reduz a aptidão de um indivíduo proporcionalmente ao tamanho de sua estrutura, como:

$$
f_{\text {aptidão }}^{\prime}=f_{\text {aptidão }}-c \times \ell,
$$

onde $c$ é o coeficiente de penalização e $\ell$ é uma medida de complexidade (número de nós, por exemplo). Soluções mais sofisticadas para o controle são discutidas em (Poli et al., 2008).

\subsection{Operadores genéticos}

Assim como outros algoritmos de busca, a PG possui operadores para gerar novas soluções (potencialmente melhores) a partir de uma amostragem conhecida (população corrente). Como ocorre nos algoritmos genéticos, o espaço de busca é explorado através do processo de experimentação de recombinações e/ou variações sobre padrões promissores. A PG na sua concepção moderna possui dois principais operadores genéticos de modificação: cruzamento e mutação.

\subsubsection{Cruzamento}

O operador de cruzamento recombina partes de estruturas previamente escolhidas (pelo processo de seleção) derivando estruturas potencialmente melhores. O cruzamento é tipicamente aplicado com alta probabilidade, pois é considerado o operador primário na programação genética.

$\mathrm{Na}$ representação por árvore, este operador permuta sub-árvores de dois indivíduos gerando dois novos descendentes. Estas sub-estruturas são definidas pela escolha arbitrária de raízes nos programas que estão sendo cruzados. A Figura 5(a) ilustra a aplicação do operador de cruzamento sobre os pais A e B, produzindo os filhos A' e B'.

A

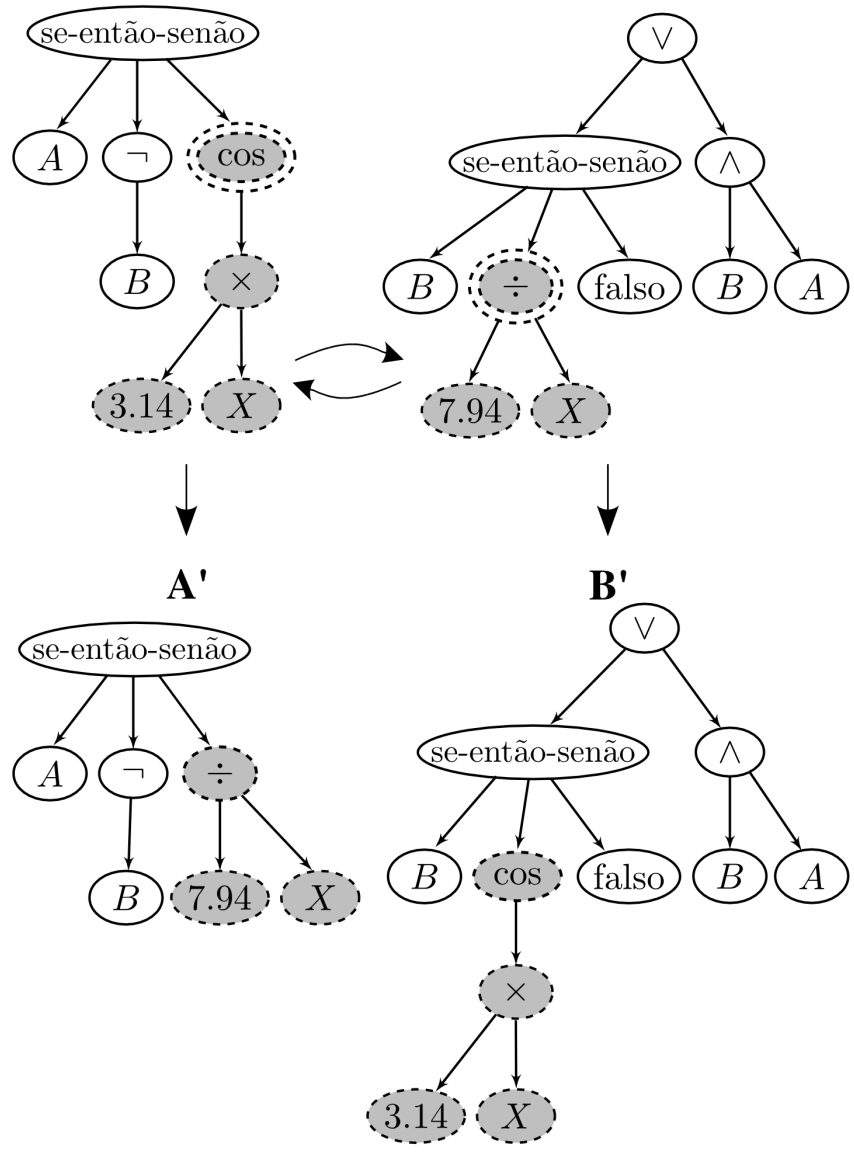

(a) Cruzamento.

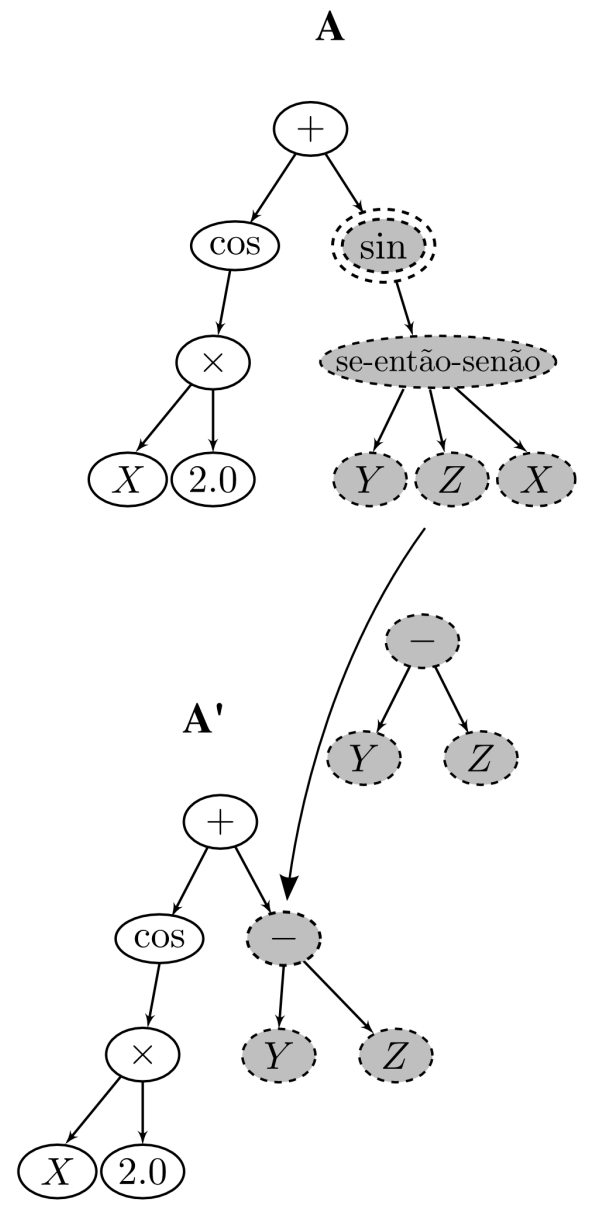

(b) Mutação.

Figura 5. Operadores genéticos usuais da programação genética. 


\subsubsection{Mutação}

A mutação deriva um novo descendente modificando a estrutura de um indivíduo selecionado, visando tanto explorar regiões vizinhas quanto a preservação de diversidade. Normalmente, estas modificações são realizadas de maneira absolutamente aleatória, apesar de existirem operadores especializados de mutação que agem deterministicamente. A Figura 5(b) mostra o operador padrão de mutação sendo aplicado na árvore A. O processo pode ser descrito como: uma sub-árvore do indivíduo $\mathbf{A}$ é escolhida aleatoriamente e removida, uma nova sub-árvore é arbitrariamente gerada e, por fim, é introduzida no local da sub-estrutura removida, gerando um descendente $\mathbf{A}^{\prime}$.

As mutações do tipo nó, encolhimento e permutação são variações do operador padrão e foram desenvolvidas a fim de promover a diversidade da população e explorar o espaço de busca. Como será observado nas descrições que seguem, é possível obter os mesmos resultados destas três variações via mutação padrão. Porém, o uso destas variantes pode acelerar a obtenção de algum comportamento ou forma esperada para o programa.

A mutação nó intuitivamente altera algum nó da árvore. Assim, neste processo um elemento é selecionado arbitrariamente e substituído por algum outro que utilize o mesmo número de argumentos.

A mutação tipo encolhimento reduz o tamanho da árvore, baseando-se na ideia de que soluções menos complexas são sempre desejáveis. Neste caso, após escolher aleatoriamente um elemento, seleciona-se um nó filho qualquer e utiliza-o para substituir o nó pai.

Finalmente, a mutação por permutação permuta duas sub-árvores de um argumento do programa candidato. Naturalmente, este operador só se aplica às funções com no mínimo dois argumentos.

\subsection{Algoritmo protótipo}

Para facilitar uma implementação e fixar o entendimento do fluxograma apresentado na Figura 1, o Algoritmo 1 trás um protótipo em pseudo-código da PG segundo a reprodução do tipo geracional - uma reprodução tipo steady-state também pode ser utilizada. Observa-se no algoritmo que, quando não ocorrem cruzamento e mutação, os indivíduos $p_{1}$ e $p_{2}$ são clonados, isto é, reproduzidos sem modificação (Koza, 1992).

1 Criar aleatoriamente a população inicial $P$

2 Avaliar todos indivíduos de $P$

3 enquanto critério de parada não for satisfeito faça

4 Copiar a elite de indivíduos de $P$ para a população temporária $P_{t m p}$

$5 \quad$ enquanto $\left|P_{t m p}\right|<|P|$ faça

$6 \quad$ Selecionar e copiar de $P$ dois indivíduos bem adaptados, $p_{1}$ e $p_{2}$

$7 \quad$ se [probabilisticamente] cruzamento então

$8 \quad \mid$ Cruzar $p_{1}$ com $p_{2}$, gerando os descendentes $p_{1}^{\prime}$ e $p_{2}^{\prime}$

$9 \quad p_{1} \leftarrow p_{1}^{\prime} ; p_{2} \leftarrow p_{2}^{\prime}$

10 fim

11 se [probabilisticamente] mutação então

12 Aplicar operadores de mutação em $p_{1}$ e $p_{2}$, gerando $p_{1}^{\prime}$ e $p_{2}^{\prime}$

$13 \quad p_{1} \leftarrow p_{1}^{\prime} ; p_{2} \leftarrow p_{2}^{\prime}$

$14 \quad$ fim

15 Avaliar $p_{1}$ e $p_{2}$ e inseri-los em $P_{t m p}$

16 fim

$17 \quad P \leftarrow P_{t m p}$; descartar $P_{t m p}$

18 fim

19 retorna melhor indivíduo encontrado

Algoritmo 1: Programação Genética (geracional).

\subsubsection{Parâmetros}

Apesar de nem sempre utilizado, Koza (1992) padronizou uma forma de listar os parâmetros adotados por uma PG. Na Tabela 1 são apresentados alguns parâmetros usuais cujos valores podem ser ajustados de acordo com o problema; normalmente a maximização da eficiência do processo evolutivo em um problema está condicionada à especialização dos parâmetros para o mesmo. Apesar dos parâmetros Número de gerações $\left(N_{G}\right)$ e Número de avaliações $\left(N_{A}\right)$, referentes a critérios de parada, estarem presentes nesta tabela, qualquer outro critério pode ser considerado. 


\begin{tabular}{ll}
\hline Parâmetro & Descrição \\
\hline Tamanho da população $(|P|)$ & Número de indivíduos em evolução \\
Número de gerações $\left(N_{G}\right)$ & Número máximo de gerações \\
Número de avaliações $\left(N_{A}\right)$ & Número máximo de avaliações \\
Probabilidade de cruzamento & $\begin{array}{l}\text { Probabilidade de aplicação do operador de cruzamento } \\
\text { (tipicamente alta) }\end{array}$ \\
Probabilidade de mutação & Probabilidade de aplicação do operador de mutação \\
& (tipicamente baixa) \\
Pressão de seleção & $\begin{array}{l}\text { Importância dada aos melhores indivíduos durante o } \\
\text { processo de seleção }\end{array}$ \\
Limites de profundidade & Profundidade máxima das árvores \\
Tamanho da elite (geracional) & Número de melhores indivíduos que serão copiados \\
& para geração seguinte \\
Conjuntos de funções e terminais & Operadores e operandos primitivos que estabelecem as \\
& instruções básicas \\
\hline
\end{tabular}

Tabela 1. Parâmetros usuais da programação genética.

\subsubsection{Execução de programas}

A execução do programa codificado é fundamental para sua avaliação, sendo por meio desta possível medir quão bem o indivíduo desenvolve sua tarefa. O Algoritmo 2 mostra um pseudo-código para uma função recursiva destinada à execução de programas codificados em estrutura de árvore.

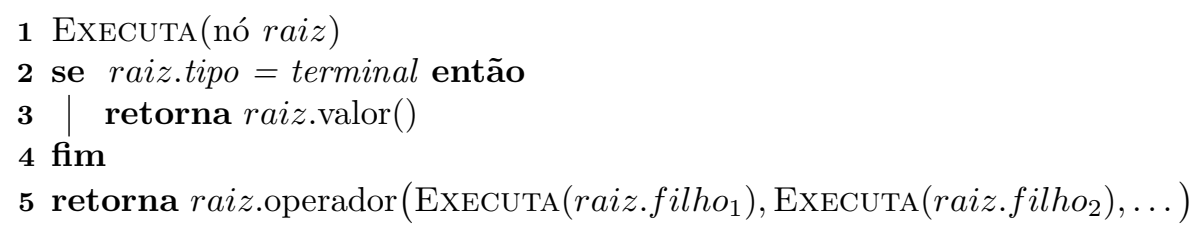

Algoritmo 2: Execução de um programa.

No caso do Algoritmo 2, a execução de um programa inicia-se pela chamada da função ExECUTA() sobre o nó raiz da árvore. O tipo do nó é então testado: se for um terminal (nó folha) o seu valor é retornado imediatamente e o percurso recursivo daquele ramo é finalizado; caso contrário, ou seja, uma função (nó interno), o operador codificado pelo nó é aplicado sobre os seus argumentos. É fácil observar que o número de argumentos requerido pelo operador deve coincidir com seu número de filhos e que seus valores são obtidos através da recursividade. Ao fim de todo processo, o valor computado pelo nó raiz é retornado. O valor da aptidão do indivíduo é obtido, como descrito na Seção 2.3, comparando-se o valor final retornado por Executa() (ou os valores de sucessivas execuções) com o esperado.

Como comentado anteriormente, um terminal pode codificar basicamente três espécies de valores: (i) constantes; (ii) variáveis; e (iii) funções que não requerem argumentos. Note que o tratamento da sentença "raiz.filho " ( $j$ é o índice de uma das sub-árvores) nos casos (i) e (iii) é trivial, bastando retornar o valor da constante ou da função (que neste caso não requer argumentos). Entretanto, o valor da variável precisa antes ser atribuído no caso (ii). Considerando os casos de classificação e regressão, um programa é executado sobre um conjunto finito de pontos (amostras de treinamento), e as variáveis correspondem aos valores do ponto em questão. Desta forma, os valores relativos ao ponto corrente são atribuídos imediatamente antes de cada execução do programa, isto é, para cada registro. Este procedimento assegura que os valores retornados das variáveis na $i$-ésima execução correspondem aos valores do $i$-ésimo ponto.

\section{Exemplo Hipotético de Aplicação}

Esta seção traz um exemplo didático do problema de gerenciamento de filas de processos através da obtenção de uma expressão que indique a prioridade com que estes devem ser executados. O objetivo é introduzir/reforçar conceitos práticos de PG. Dado seu sentido didático, o problema é simplificado ao caso em que há apenas trabalhos que são executados em uma única unidade/fila e apenas uma fila de execução.

Primeiro define-se o conceito de regressão simbólica e apresentam-se as técnicas tradicionais para resolução desta classe de problemas. Vantagens e desvantagens da utilização da PG quando aplicada a problemas de 
regressão simbólica também são destacados. Em seguida, descreve-se o problema de atraso mínimo em fila de execuções. Finalmente, ilustra-se a execução passo-a-passo de uma PG.

\subsection{Regressão simbólica de uma expressão}

A regressão simbólica é o ato de inferir, a partir de um conjunto finito de dados, uma expressão algébrica em forma simbólica. Em outras palavras, o objetivo é encontrar a forma de uma função que minimize uma medida de discrepância entre seus valores previstos e aqueles de fato observados.

Seja $F$ o conjunto de todas as funções $f: \mathbb{R}^{n} \mapsto \mathbb{R}$ admissíveis para o problema, $\left\{p_{1}, p_{2}, \ldots, p_{k}\right\}$ o conjunto de pontos da amostragem, $Y \in \mathbb{R}^{k}$ o vetor cuja componente $Y_{i}$ é o valor observado em $p_{i} \in \mathbb{R}^{n}$ e $k$ o tamanho da amostragem. Assim, pode-se entender por regressão simbólica a busca por uma função $f^{*}$ tal que $f^{*}=\arg \min _{f \in F} d(f, Y)$, onde $d(f, Y) \geq 0$ é a discrepância entre os valores previstos por $f$ e aqueles observados. Uma forma de avaliar as funções candidatas é somar a norma $q$ da diferença entre o predito e o observado

$$
f^{*}=\arg \min _{f \in F}\left[\sum_{i=1}^{k}\left|f\left(p_{i}\right)-Y_{i}\right|^{q}\right]^{\frac{1}{q}} \quad q \in \mathbb{R} \mid q \geq 1 .
$$

Note que o método dos mínimos quadrados ocorre quando $q=2$.

\subsection{Métodos clássicos versus programação genética}

Diversos métodos são conhecidos para resolver problemas de regressão, tais como regressão linear, quadrática e polinomial. A ideia destas técnicas é reduzir o problema de regressão à identificação paramétrica pela pré-definição de um modelo. Desta forma, estes métodos são fortemente dependentes deste modelo, muito específicos e pouco flexíveis.

Por exemplo, considere um problema hipotético em uma variável de entrada $(x)$ e uma dimensão de saída $(f)$. Supondo-se uma relação quadrática entre as entradas e saídas, pode-se predefinir a forma do modelo como $f(x)=c x^{2}$ de modo que apenas o coeficiente real $c$ precisaria ser encontrado. Outra possibilidade seria definir o modelo como $f(x)=c_{1} x^{c_{2}}$ e o método de regressão teria que ajustar os coeficientes $c_{1}$ e o expoente $c_{2}$. É possível perceber não só que a eficiência do método é diretamente proporcional ao modelo pré-definido (escolhido por um especialista), mas também o quão difícil é especificá-lo corretamente.

Entretanto, muitas vezes deseja-se identificar simultaneamente a estrutura da função bem como seus coeficientes, aumentando-se a complexidade do problema devido ao crescimento do espaço de busca. A programação genética é capaz de gerenciar grandes e intricados espaços de busca e não requer uma estrutura pré-definida para sua solução, tornando-a adequada aos problemas de regressão simbólica.

Assim, pode-se afirmar que conhecendo a forma do modelo de interesse a priori e utilizando-se uma medida de discrepância adequada, os métodos clássicos podem encontrar expressões com menor custo computacional. Entretanto, quando não há informação sobre o problema (comum em aplicações práticas com grandes quantidades de variáveis e/ou registros) ou a métrica de discrepância não pode ser explorada, a PG torna-se uma alternativa natural. Em especial, destaca-se o problema hipotético exemplificado aqui, onde o modelo ótimo não pode ser obtido por meio de técnicas tradicionais de regressão simbólica pois, como será mostrado na sequência, a avaliação de um programa candidato não é feita sobre uma trivial comparação registro-a-registro.

\subsection{Definição do problema hipotético}

O problema hipotético proposto aqui, similar aos apresentados por Dimopoulos \& Zalzala (2001), busca uma heurística que minimize o atraso no agendamento de tarefas em uma fila/máquina. Todavia, o problema é aqui simplificado buscando facilitar seu entendimento.

Um dos principais problemas de agendamento, e também da pesquisa operacional, é organizar a execução de um conjunto de tarefas antes de seus prazos limites (vencimentos). Em geral, supõe-se que atrasos nas execuções de tarefas gerem algum tipo de penalização.

Pode-se definir o atraso para a execução de uma tarefa $i$ como

$$
\operatorname{Atraso}_{i}=\max \left(0, c_{i}-v_{i}\right)
$$

onde $c_{i}$ e $v_{i}$ são, respectivamente, o momento em que a tarefa foi completada e seu vencimento. Como $k$ tarefas devem ser executadas, então é possível definir o atraso total de forma que

$$
\text { Atraso }=\sum_{i=1}^{k} \max \left(0, c_{i}-v_{i}\right) .
$$


Algumas informações são disponibilizadas para a criação da heurística de despacho: tempo de execução $\left(t_{i}\right)$ e vencimento $\left(v_{i}\right)$ da tarefa $i$ bem como o tempo total gasto por todas as tarefas $\left(T=\sum_{i=1}^{k} t_{i}\right)$. Valores para estas variáveis no corrente problema hipotético são apresentados na Tabela 2. Observe que a soma dos tempos de execução $(T)$ é igual a 420 .

\begin{tabular}{ccc}
\hline$i$ & Tempo de execução $(t)$ & Vencimento $(v)$ \\
\hline 1 & 20 & 285 \\
2 & 51 & 46 \\
3 & 14 & 236 \\
4 & 63 & 86 \\
5 & 41 & 24 \\
6 & 78 & 196 \\
7 & 22 & 64 \\
8 & 32 & 258 \\
9 & 28 & 327 \\
10 & 71 & 198 \\
\hline
\end{tabular}

Tabela 2. Dados das tarefas do exemplo hipotético.

Assim, pode-se definir o problema aqui abordado como: encontrar um meio de despachar as tarefas que minimize o atraso definido pela Equação 6, utilizando como base as informações contidas na Tabela 2. Note que na prática casos mais complexos podem ser abordados como disponibilização de múltiplos processadores (ou filas), tarefas a serem executadas em paralelo e tarefas com prioridades diferentes; além de mais informação estar disponível para ser utilizada no modelo, como número de processadores necessários para uma tarefa executar.

É importante observar que este problema não pode ser resolvido por técnicas clássicas de regressão, já que a medida de discrepância utilizada $(\max )$ é não-diferenciável. Aqui, um programa candidato é avaliado executado-o em todos os registros e somando-se os atrasos (máximos) em todas as tarefas (vide Equação 6).

\subsection{Execução hipotética passo-a-passo}

O problema de atraso no agendamento em uma máquina deve ser resolvido minimizando-se o atraso total, definido pela Equação 6, da execução das tarefas submetidas a partir dos dados apresentados na Tabela 2.

O problema será reformulado para que possa ser resolvido utilizando PG. Neste caso, o objetivo será encontrar uma expressão simbólica que indique a prioridade de uma tarefa $i$ e, com isto, possa-se gerar uma fila de despacho para que sejam executadas. Considera-se aqui que as tarefas com menores valores de retorno do programa são executadas primeiro. Para ilustrar a ideia, presume-se que um programa defina as prioridades como $p_{i}=t_{i}$, ou seja, as tarefas com tempos de execução menores devem ser despachadas primeiro. Desta forma, gera-se uma fila de despacho como apresentada pela Figura 6. Depois, basta somar os atrasos nas execuções das tarefas para avaliar a solução candidata $p_{i}=t_{i}$, o que totaliza um atraso de 848 para o exemplo mostrado.

\begin{tabular}{l|l|l|l|l|l|l|l|l|l}
\hline 3 & 1 & 7 & 9 & 8 & 5 & 2 & 4 & 10 & 6 \\
\hline
\end{tabular}

Figura 6. Fila de despacho (da esquerda para a direita) das tarefas da Tabela 2 considerando a função de prioridade $p_{i}=t_{i}$.

Antes de iniciar o processo de execução da PG, faz-se necessário definir seus parâmetros. Alguns parâmetros e definições são assumidos irrelevantes neste exemplo didático: modo de criação da população, esquema e pressão de seleção, probabilidades de aplicação dos operadores genéticos e limites de tamanho. Os parâmetros que possuem alguma relevância neste exemplo são listados na Tabela 3, onde é possível notar a simplicidade dos valores a fim de manter o problema ilustrativo. Foram escolhidas para o conjunto primitivo de funções as operações aritméticas básicas, enquanto que o conjunto de terminais possui apenas a constante numérica 1 e as variáveis $t, v$ e $T$.

Sejam os quatro programas A, B, C e D, codificados por árvore e exibidos na Figura 7. Eles representam a população inicial e, portanto, foram criados aleatoriamente por algum dos métodos de criação. Para facilitar a visualização, uma notação linear em que o nome/letra do indivíduo será utilizado para definir sua expressão correspondente, de modo que: $A=t, B=v+1, C=t+v$ e $D=T-v$. Os atrasos totais para cada um dos programas da população inicial são então calculados e seus valores podem ser encontrados na Tabela 4 . Note que todos os programas diferem tanto em forma quanto em qualidade.

Com base na qualidade dos ajustes, suponha que os indivíduos $\mathbf{B}$ e $\mathbf{C}$, que pode-se dizer são relativamente bem adaptados, foram selecionados para cruzarem e assim deixar descendentes. Este processo é ilustrado 


\begin{tabular}{ll}
\hline Parâmetro & Valor \\
\hline Número de gerações $\left(N_{G}\right)$ & 2 \\
Tamanho da população & 4 indivíduos \\
Tipo de reprodução & geracional \\
Tamanho da elite & 0 (sem elitismo) \\
Operadores genéticos & cruzamento e mutação padrão \\
Conjunto de funções & $\mathbb{F}=\{+,-, \times, \div\}$ \\
Conjunto de terminais & $\mathbb{T}=\{1, t, v, T\}$ \\
Critério de parada & discrepância nula (ajuste perfeito) \\
\hline
\end{tabular}

Tabela 3. Parâmetros do exemplo hipotético.

A

(t)
B

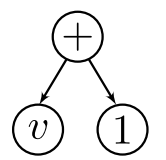

C

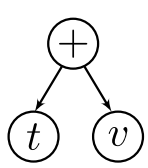

D

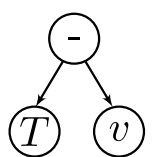

Figura 7. População inicial.

na Figura 8(a), onde os nós escurecidos denotam os pontos de cruzamento sorteados. Neste caso, a árvore inteira substitui o nó (ou sub-árvore, se fosse um nó interno) selecionado do indivíduo $\mathbf{B}$, enquanto que o descendente $\mathbf{C B}$ será o próprio nó (ou sub-árvore) escolhido de B. Esta recombinação deu origem aos indivíduos BC e CB, que então foram alocados na próxima geração (segunda geração, Figura 9).

Considere também que o indivíduo $\mathbf{C}$ da população inicial foi novamente selecionado. No entanto, desta vez ele foi submetido ao operador de mutação, como consta na Figura 8(b), onde a raiz da árvore (o operador + ) foi substituído por $\div$, dando origem ao indivíduo C'. Para finalizar a aplicação dos operadores de movimento desta geração, considera-se que o indivíduo D foi também selecionado e submetido ao operador de mutação, mas que nenhuma modificação foi realizada e o indivíduo D’ gerado é igual a D. É importante ressaltar que o programa $\mathbf{C}$ foi selecionado duas vezes para reprodução, o que é previsível dado que é a solução de melhor qualidade na população atual. Percebe-se que, devido à baixa aptidão do indivíduo $\mathbf{A}$ da população inicial, este em nenhuma oportunidade foi escolhido pelo processo de seleção como genitor, logo, o seu material genético não foi passado adiante - este processo de procriação a favor dos mais aptos é uma característica fundamental dos algoritmos da computação evolutiva.

Como é considerado neste exemplo hipotético que todas as soluções geradas formam a população seguinte, então a Figura 9 apresenta o conjunto de soluções da segunda geração, composta pelos indivíduos BC, CB, C' e D'. Logo, os programas da segunda geração são as expressões: $B C=t+v+1, C B=v, C^{\prime}=t \div v$ e $D^{\prime}=T-v$. Passa-se para a próxima etapa: calcular os atrasos para os programas da população. Estes valores são apresentados na Tabela 4.

Completada a primeira geração e dando sequência à execução hipotética, suponha que agora foram selecionados os indivíduos promissores BC e CB para cruzamento. A combinação destas duas soluções gera os indivíduos BCCB e CBBC como mostrado na Figura 10(a).

Por sua vez, mesmo não sendo boas soluções, os outros dois indivíduos (C' e D') também foram escolhidos para um cruzamento, como ilustrado pela Figura 10(b). Mais dois programas são gerados (C'D' e D'C'), completando o conjunto de quatro novas soluções.

De posse da nova população, apresentada na Figura 11, pode-se então avaliar seus indivíduos. Os valores calculados para os atrasos são listados na Tabela 4 e assim finaliza-se a segunda geração da evolução. As expressões correspondentes às soluções da população são: $B C C B=v+v+1, C B B C=t, C^{\prime} D^{\prime}=t \div(T-v)$ e $D^{\prime} C^{\prime}=v$. Como o critério de parada escolhido foi a execução de duas gerações, então o processo finaliza e a melhor solução encontrada até este instante, $C^{\prime} D^{\prime}=t \div(T-v)$, é retornada.

Apesar de simples, a aplicação hipotética descrita passo-a-passo aqui mostra a capacidade da PG em encontrar boas soluções para um problema tipicamente encontrado em pesquisa operacional. De fato, o uso da programação genética para resolver um problema de atraso mínimo no agendamento de uma máquina foi

\begin{tabular}{c|c|c|c|c|c}
\hline $\mathrm{A}$ & $\mathrm{B}$ & $\mathrm{C}$ & $\mathrm{D}$ & $\mathrm{BC}$ & $\mathrm{CB}$ \\
848 & 809 & 698 & 821 & 698 & 809 \\
\hline $\mathrm{C}^{\prime}$ & $\mathrm{D}^{\prime}$ & $\mathrm{BCCB}$ & $\mathrm{CBBC}$ & $\mathrm{C}^{\prime} \mathrm{D}^{\prime}$ & $\mathrm{D}^{\prime} \mathrm{C}^{\prime}$ \\
1092 & 821 & 809 & 848 & 628 & 809 \\
\hline
\end{tabular}

Tabela 4. Valores de atraso para os todos os programas avaliados. 


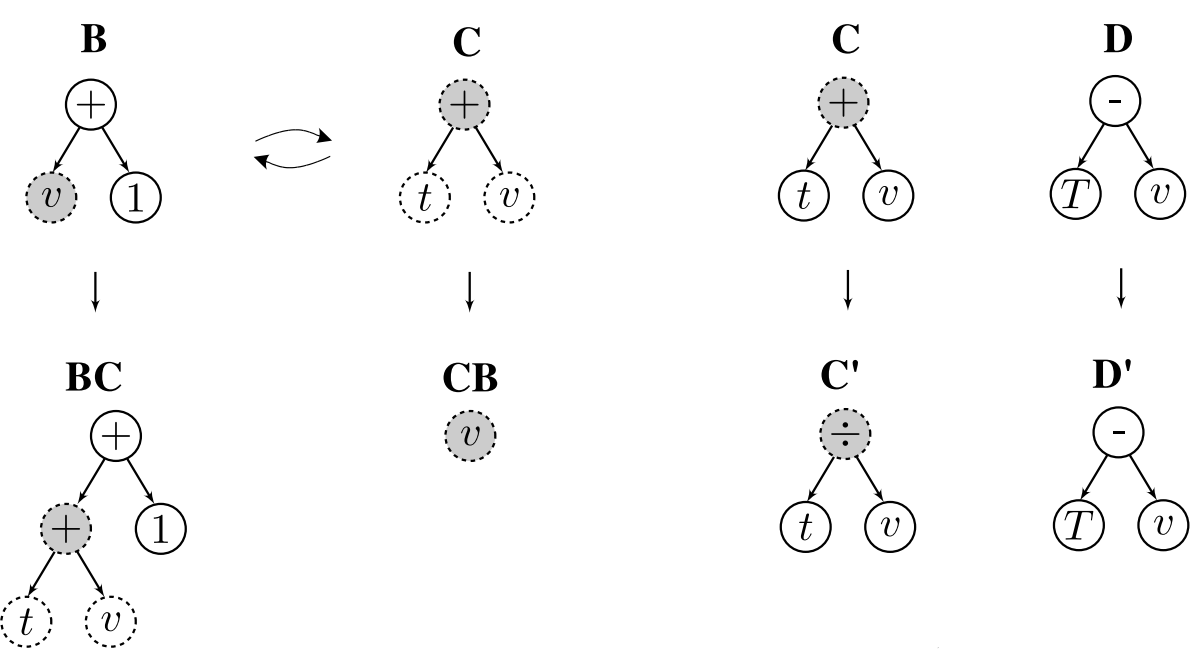

(a) Cruzamento entre $\mathbf{B}$ e $\mathbf{C}$.

(b) Mutação em $\mathbf{C}$ e $\mathbf{D}$.

Figura 8. Operadores genéticos utilizados na primeira geração.

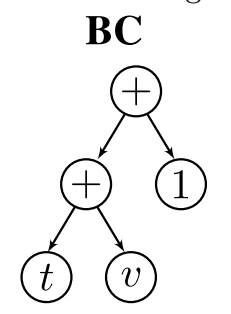

CB

(v)

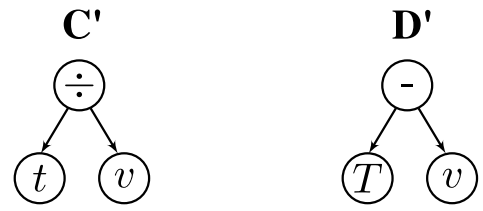

Figura 9. População no início segunda geração.

explorado por Dimopoulos \& Zalzala (2001). Além disto, é interessante observar que a solução encontrada neste exemplo hipotético, não por acaso, é a mesma formulada por Montagne (1969).

\section{Aplicações em Pesquisa Operacional}

A parcela majoritária das aplicações de programação genética em pesquisa operacional compreende a inferência de heurísticas, que são essencialmente "regras de ouro" para tomada de decisão. Neste contexto, classifica-se a atuação da PG como hiper-heurística, diferindo-se da abordagem usualmente empregada pelos AGs onde a otimização ocorre no espaço de soluções.

Há diversas classes de problemas em pesquisa operacional cuja solução pode ser expressa como uma heurística. Dentre estas tem-se problemas de despacho, corte, empacotamento, agendamento, entre outros. As seções que se seguem apresentam exemplos de modelagem de problemas em pesquisa operacional por meio da PG.

\subsection{Modelagem}

A exata modelagem, naturalmente, depende do problema. No entanto, em princípio a aplicação da PG é direta; basicamente, a modelagem incide na definição dos conjuntos de funções e terminais, função de avaliação, bem como dos parâmetros do algoritmo.

Usualmente são empregadas funções e terminais atômicos, em outras palavras, cada qual representando uma única operação ou conceito, como no caso das constantes numéricas e funções aritméticas básicasvariáveis consideradas importantes para a tomada de decisão são acrescidas a estes operadores e operandos. Pouco conhecimento sobre o problema é requerido nesta estratégia de modelagem por blocos primitivos de construção. Entretanto, uma alternativa para quando se dispõe de conhecimento prévio, na forma por exemplo de heurísticas pré-existentes (possivelmente simples e limitadas), é a incorporação deste conhecimento nos conjuntos de funções e terminais, como primitivas sofisticadas. Neste sentido, o objetivo passa a ser a evolução de combinações de heurísticas, partindo-se do pressuposto de que uma combinação particular destas pode produzir uma heurística superior, idealmente ótima.

A função de avaliação de soluções candidatas está fortemente atrelada ao problema, depende fundamentalmente da distinção entre uma má e boa heurística, do que se pretende otimizar. Normalmente, subdividem-se em (i) aproximação de conhecimento prévio, como a emulação de tomadas de decisão feitas por um especialista, e (ii) otimização de uma medida, tal como a minimização de custos operacionais. 


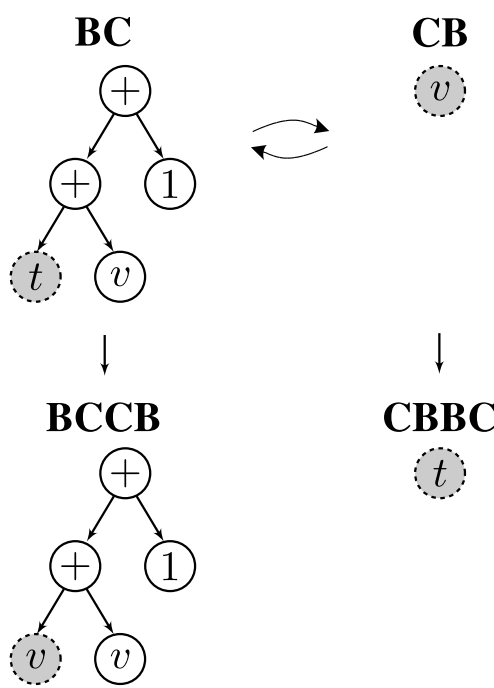

(a) Cruzamento entre BC e CB.

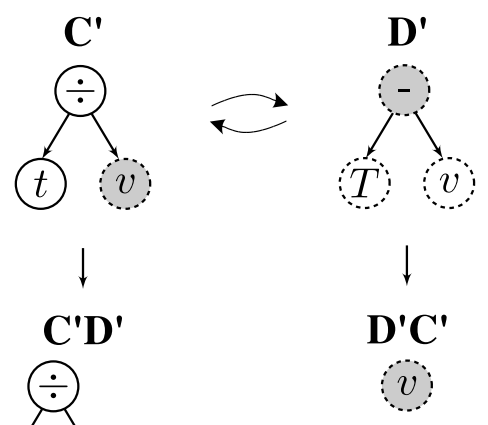

(b) Cruzamento entre C' e D'.

Figura 10. Cruzamentos ocorridos na segunda geração.

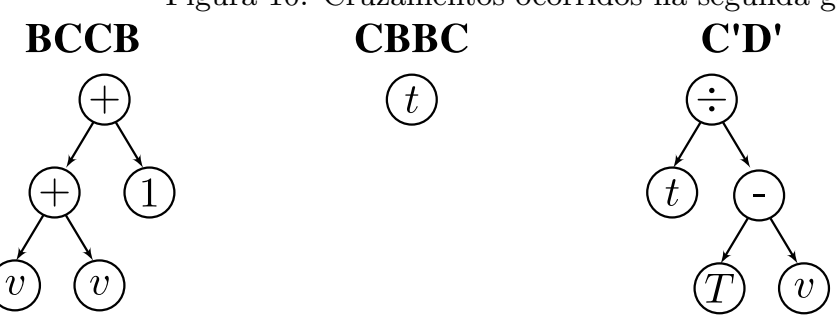

Figura 11. População final.

\subsection{Aplicações}

A primeira aplicação de PG em PO que será apresentada neste capítulo é a resolução do clássico problema do caixeiro-viajante (Traveling Salesman Problem - TSP) (Applegate et al., 2011). Dado um conjunto $C$ de $n_{c}$ cidades e uma matriz de distâncias $D$, onde $D_{i j}=D\left(c_{i}, c_{j}\right), i, j \in\left\{1, \ldots, n_{c}\right\}, D_{i j}=D_{j i}$ e $D_{i i}=0$, o objetivo do problema é encontrar a permutação $\pi \in S_{n_{c}}=\left\{s:\left\{1, \ldots, n_{c}\right\} \rightarrow\left\{1, \ldots, n_{c}\right\}\right\}$ que minimize a distância de um ciclo simples, a partir de uma dada cidade inicial. No trabalho de Oltean (2005) uma PG linear é adotada com o objetivo de gerar heurísticas evolutivas que, entre outros objetivos, melhor resolvessem o problema do caixeiro-viajante. Outro estudo neste sentido foi desenvolvido por Keller \& Poli (2008), em que os autores utilizaram uma PG gramatical para evoluir heurísticas para o dado problema. Apesar de ambos trabalhos terem o mesmo objetivo, duas diferenças são facilmente detectadas: (i) tipo de PG adotada (linear e gramatical) e (ii) primitivas disponíveis (operações de movimento típicas em algoritmos evolutivos contra componentes básicos de modificação das soluções candidatas).

Em Benyahia \& Potvin (1997), os autores aplicam PG ao problema de despacho de veículos. O desafio consistia na evolução de uma heurística que imitasse o comportamento de um certo especialista, cujas decisões relativas à escolha de qual veículo atenderia cada um dos pedidos de entrega foram anotadas anteriormente. Para tanto, além das funções e terminais tradicionais, foram incluídas variáveis que descreviam o estado (em tempo real) de cada veículo, como por exemplo o tempo necessário para desviarem suas rotas atuais a fim de atenderem um novo pedido. Durante a avaliação, cada heurística candidata é aplicada veículo a veículo, estimando-se a utilidade de cada um destes frente à tarefa, e então o ranking de preferência dos veículos fornecido pela heurística é comparado com o do especialista. A heurística perfeita seria, portanto, aquela que concordasse com todas as decisões prévias do especialista no que diz respeito a qual veículo estaria encarregado de atender cada pedido. Os autores encontraram resultados bastante acurados, embora as melhores heurísticas evoluídas fossem complexas a ponto de inviabilizar a interpretação de suas regras de decisão. Este trabalho foi posteriormente estendido em Benyahia \& Potvin (1998), onde os resultados encontrados pela PG mostraram-se competitivos com aqueles obtidos por uma rede neuronal artificial.

Baykasoğlu et al. (2010) realizaram estudos na mesma direção dos trabalhos de Benyahia \& Potvin (1997, 1998). Todavia, Baykasoğlu et al. (2010) trabalharam sobre um espaço maior de possíveis regras, adicionando condicionais ao conjunto de funções. Os resultados evoluídos pela PG apresentaram desempenho superior às políticas tradicionais de despacho. 
Uma modelagem com características similares, porém aplicada ao problema de agendamento de dinâmico ${ }^{3}$ de tarefas em uma única máquina foi empregada em Jakobović \& Budin (2006). Posteriormente, este trabalho foi estendido em Jakobović et al. (2007), onde a PG foi utilizada para resolver problemas de agendamento, estático e dinâmico, e em múltiplas máquinas. Dada uma máquina ociosa, uma heurística é aplicada a todas as tarefas em espera para determinar aquela, estimando-se suas prioridades, que deverá ser agendada no momento, a fim de minimizar o atraso e tempo de espera de tarefas individuais, e tempo geral de processamento. Os operadores incluíam soma, multiplicação, subtração e divisão, enquanto que os operandos forneciam informações como o tempo de processamento, prazo e importância relativas das tarefas. Quando comparadas com heurísticas existentes, as evoluídas apresentaram melhor capacidade de generalização, produzindo políticas de decisão superiores. Recentemente, Jakobović \& Marasović (2012) atacaram problemas mais complexos e realísticos, como aqueles com restrição de precedência.

Em Tay \& Ho (2008) os autores descrevem uma aplicação semelhante à anterior, contudo em uma variação mais complexa do problema na qual as tarefas podem ser agendadas a qualquer máquina ociosa, e desta forma torna-se também parte da otimização a escolha da máquina. Os resultados foram encorajadores e demonstraram que heurísticas evoluídas via PG podem superar o desempenho de heurísticas clássicas da literatura.

Ainda neste contexto, Hildebrandt et al. (2010) aplicam a PG ao problema de agendamento dinâmico de múltiplas máquinas, e evoluem heurísticas robustas significativamente superiores às melhores até então desenvolvidas por especialistas. Diferentemente de outros trabalhos, onde avaliações de heurísticas candidatas dão-se por meio de bases de treinamento de benchmark, neste os autores usam simulação computacional visando melhor aproximar o cenário de agendamentos continuados de longo prazo.

Dados reais do departamento de produção de uma indústria de metais foram utilizados por Abednego \& Hendratmo (2011). Neste cenário, o desempenho da PG é pelo menos equivalente ao das regras de despacho comumente adotadas, sendo por vezes superior.

Uma aplicação da PG para o planejamento ótimo da manutenção preventiva de redes elétricas de alta voltagem foi proposta em Langdon \& Treleaven (1997). Em sua modelagem, o conjunto de primitivas é composto por várias informações acerca da rede de transmissão (como número de nós e capacidade das linhas), operadores aritméticos, condicionais e laços iterativos. Heurísticas prévias, desenvolvidas por especialistas, foram usadas para semear a população inicial. Cada heurística candidata estima a semana do ano em que a linha deverá sofrer manutenção. No cálculo de aptidão são considerados três componentes: o custo da manutenção, uma recompensa caso o agendamento seja feito em uma semana com menos atividades e uma penalização caso a heurística seja demasiadamente complexa. A heurística evoluída obteve um custo de manutenção bem mais baixo quando comparado ao resultado da aplicação de um AG.

O conhecimento embutido em heurísticas pré-existentes foi explorado em Pillay \& Banzhaf (2007) no problema de determinação do agendamento ótimo de exames escolares, onde $n$ exames devem ser agendados em $m$ períodos respeitando-se certas restrições. Em vez de usarem as heurísticas prévias para semear a população inicial, os autores optaram por usá-las como primitivas, em substituição às tradicionais. Cada uma destas heurísticas agenda os exames segundo critérios particulares. Por exemplo, uma delas prioriza o agendamento de exames com o maior número de estudantes, enquanto outra prefere agendar inicialmente aqueles que mais tendem a violar restrições. Um vetor linear de tamanho variável, onde cada elemento corresponde a uma heurística primitiva, foi adotado como codificação das soluções candidatas. ${ }^{4}$ O objetivo é, portanto, evoluir a sequência ótima de heurísticas que respeite as restrições duras e minimize as flexíveis. ${ }^{5}$ Comparado com outros métodos hiper-heurísticos, a modelagem proposta desempenhou-se melhor em 6 das 9 instâncias de problemas avaliadas. Em Pillay (2008), três tipos de soluções são permitidas: combinações de heurísticas com tamanho fixo, combinações com tamanho variado e combinações com indicação do número de vezes que cada heurística deve ser utilizada.

O problema de agendamento ótimo de exames escolares foi também explorado por Bader-El-Den \& Poli (2009), onde adotou-se uma PG gramatical. Seus resultados mostraram-se competitivos quando comparados com outras hiper-heurísticas ou heurísticas da literatura. Uma extensão deste trabalho, incluindo uma análise do algoritmo proposto em relação ao tamanho da população, pode ser encontrada em Bader-El-Den et al. (2009).

A classe de problemas representada por empacotamento ou corte, em uma, duas e três dimensões, foi extensivamente tratada em Burke et al. (2006, 2007); Allen et al. (2009); Burke et al. (2010, 2012). O primeiro trabalho, Burke et al. (2006), foi uma prova-de-conceito acerca da capacidade da PG em redescobrir heurísticas clássicas, como a first fit, que aloca um objeto no primeiro pacote com espaço livre suficiente.

\footnotetext{
3 No agendamento estático as tarefas estão todas disponíveis inicialmente, enquanto que no dinâmico não necessariamente.

4 Muito embora esta forma de representação aproxime-se da usada nos AGs, conceitualmente o que se evolui são programas.

5 Restrições duras devem ser rigorosamente respeitadas enquanto que as flexíveis podem ser violadas, mas desejavelmente não deveriam.
} 
Além de primitivas específicas do problema, como a ocupação corrente do contêiner e o tamanho do objeto em questão, os demais operadores e operandos eram os usuais. Fornecido um objeto, a função da heurística era decidir a qual pacote ele seria destinado.

Apesar dos bons resultados obtidos em Burke et al. (2006), Burke et al. (2007) definiram uma nova medida de qualidade para as heurísticas de empacotamento/corte. Segundo os autores, este novo cálculo diminui os platôs no espaço de busca, pois não utiliza apenas o número de pacotes como medida de desempenho, mas também suas proporções de completude.

Já em Burke et al. (2010), os autores aplicaram a PG em uma versão bi-dimensional do problema na qual há um retângulo de largura fixa e os objetos devem ser ali acomodados de maneira a minimizar a altura final requerida para cobri-los. Objetivou-se neste problema a evolução de heurísticas que não apenas decidissem qual objeto deveria ser manipulado no momento, mas também onde ele seria posicionado dentro do retângulo. Os autores não só demonstraram que a PG pode ser uma ferramenta com potencial para substituir o trabalho do ser humano na criação de heurísticas, como também em alguns casos ser capaz de produzir melhores soluções. O caso tridimensional é abordado por Allen et al. (2009).

Ainda, em Burke et al. (2012) os autores generalizam o papel da PG e argumentam que uma mesma metodologia, incluindo mesmos conjuntos de funções/terminais e parâmetros, é suficiente para inferir boas heurísticas independentemente da dimensão do problema de empacotamento, seja este mono, bi ou tridimensional. Os experimentos mostram que tal aplicação generalizada da PG evolui, automaticamente, heurísticas altamente competitivas com o estado da arte da criação humana. ${ }^{6}$

Finalmente, métodos de busca são evoluídos por meio de uma PG em Nguyen et al. (2011). Os componentes possíveis para as soluções incluem a técnica de recozimento simulado (simulated annealing), bem como buscas locais e operadores de mutação. Dentre os problemas utilizados para medir o desempenho dos métodos evoluídos encontram-se o de empacotamento e agendamento.

\section{Conclusão}

Este capítulo apresentou a programação genética (PG), uma meta-heurística evolucionária cuja especialidade é a otimização de estruturas funcionais, isto é, programas. Tais estruturas produzem resultados a partir de operações (lógicas, aritméticas, condicionais e laços iterativos) computadas sobre argumentos, ou variáveis do problema, sendo portanto capazes de processar informações e tomar decisões.

A inferência de programas faz da PG uma técnica bastante atraente do ponto de vista da solução de problemas em pesquisa operacional, especialmente no que tange à evolução automatizada de heurísticas. Quando comparada aos métodos que operam pontualmente no espaço de soluções, como uma aplicação canônica de um AG, embora sendo possivelmente uma tarefa mais complexa, as técnicas hiper-heurísticas destacam-se pois: (i) são gerais, e logo contemplam distintas instâncias ou variações do problema; e (ii) expõem a estrutura simbólica das soluções, facultando análises e interpretação das regras de tomada de decisão.

A literatura de aplicações de programação genética em pesquisa operacional revela que, para uma parcela substancial de problemas, a técnica evolucionária já produz heurísticas competitivas face às melhores criadas por humanos, eventualmente até superiores. Pode-se imaginar que em um futuro próximo torne-se prática estabelecida delegar às máquinas a tarefa de desenvolvimento de heurísticas, enquanto que o especialista vê-se livre para concentrar-se em outras questões.

\section{Agradecimentos}

Os autores agradecem o apoio financeiro do CNPq (grants 308317/2009-2 e 300192/2012-6) e da FAPERJ (E-26/102.025/2009).

\section{Referências}

Abednego, L. \& Hendratmo, D., Genetic programming hyper-heuristic for solving dynamic production scheduling problem. In: Proceedings of the International Conference on Electrical Engineering and Informatics. p. 1-4, 2011.

Allen, S.; Burke, E.K.; Hyde, M. \& Kendall, G., Evolving reusable 3d packing heuristics with genetic programming. In: Proceedings of the Conference on Genetic and Evolutionary Computation. New York, USA: ACM, p. 931-938, 2009.

Applegate, D.L.; Bixby, R.E.; Chvátal, V. \& Cook, W.J., The Traveling Salesman Problem: A Computational Study. Princeton Series in Applied Mathematics. Princeton University Press, 2011.

Bader-El-Den, M. \& Poli, R., Grammar-based genetic programming for timetabling. In: Proceedings of the Congress on Evolutionary Computation. p. 2532-2539, 2009.

6 Os autores validam a modelagem nos problemas bin packing e knapsack, em todas as três dimensões. 
Bader-El-Den, M.; Poli, R. \& Fatima, S., Evolving timetabling heuristics using a grammar-based genetic programming hyper-heuristic framework. Memetic Computing, 1(3):205-219, 2009.

Baykasoğlu, A.; Göçken, M. \& Özbakir, L., Genetic programming based data mining approach to dispatching rule selection in a simulated job shop. Simulation, 86(12):715-728, 2010.

Benyahia, I. \& Potvin, J.Y., Genetic programming for vehicle dispatching. In: IEEE International Conference on Evolutionary Computation. p. 547-552, 1997.

Benyahia, I. \& Potvin, J.Y., Decision support for vehicle dispatching using genetic programming. IEEE Transactions on Systems, Man and Cybernetics, Part A: Systems and Humans, 28(3):306-314, 1998.

Burke, E.; Hyde, M. \& Kendall, G., Evolving bin packing heuristics with genetic programming. In: Runarsson, T.; Beyer, H.G.; Burke, E.; Merelo-Guervós, J.; Whitley, L. \& Yao, X. (Eds.), Parallel Problem Solving from Nature. Springer Berlin / Heidelberg, v. 4193 de Lecture Notes in Computer Science, p. 860-869, 2006.

Burke, E.; Hyde, M.; Kendall, G. \& Woodward, J., A genetic programming hyper-heuristic approach for evolving 2-D strip packing heuristics. IEEE Transactions on Evolutionary Computation, 14(6):942-958, 2010.

Burke, E.K.; Hyde, M.R.; Kendall, G. \& Woodward, J., Automatic heuristic generation with genetic programming: evolving a jack-of-all-trades or a master of one. In: Proceedings of the Conference on Genetic and Evolutionary Computation. New York, USA: ACM, p. 1559-1565, 2007.

Burke, E.K.; Hyde, M.R.; Kendall, G. \& Woodward, J., Automating the packing heuristic design process with genetic programming. Evolutionary Computation, 20(1):63-89, 2012.

Cramer, N.L., A representation for the adaptive generation of simple sequential programs. In: Proceedings of the 1st International Conference on Genetic Algorithms. Hillsdale, USA: L. Erlbaum Associates, p. 183-187, 1985.

Dimopoulos, C. \& Zalzala, A.M.S., Investigating the use of genetic programming for a classic one-machine scheduling problem. Advances in Engineering Software, 32(6):489-498, 2001.

Hildebrandt, T.; Heger, J. \& Scholz-Reiter, B., Towards improved dispatching rules for complex shop floor scenarios: a genetic programming approach. In: Proceedings of the 12th Annual Conference on Genetic and Evolutionary Computation. New York, USA, p. 257-264, 2010.

Jakobović, D. \& Budin, L., Dynamic scheduling with genetic programming. In: Proceedings of the European Conference on Genetic Programming. Heidelberg, Germany: Springer-Verlag, v. 3905 de Lecture Notes in Computer Science, p. $73-84,2006$.

Jakobović, D.; Jelenkovic, L. \& Budin, L., Genetic programming heuristics for multiple machine scheduling. In: Proceedings of the 10th European Conference on Genetic Programming. Heidelberg, Germany: Springer-Verlag, p. 321-330, 2007.

Jakobović, D. \& Marasović, K., Evolving priority scheduling heuristics with genetic programming. Applied Soft Computing, 12(9):2781 - 2789, 2012.

Keller, R. \& Poli, R., Cost-benefit investigation of a genetic-programming hyperheuristic. In: Proceedings of the International Conference on Artificial Evolution. Heidelberg, Germany: Springer-Verlag, v. 4926 de Lecture Notes in Computer Science, p. 13-24, 2008.

Koza, J.R., Genetic Programming: a paradigm for genetically breeding populations of computer programs to solve problems. Technical Report, Computer Science Department, Stanford University, Stanford, USA, 1990.

Koza, J.R., Genetic Programming: On the Programming of Computers by Means of Natural Selection. Cambridge, USA: MIT Press, 1992.

Langdon, W.B. \& Treleaven, P.C., Scheduling maintenance of electrical power transmission networks using genetic programming. In: Warwick, K.; Ekwue, A. \& Aggarwal, R. (Eds.), Artificial Intelligence Techniques in Power Systems. Stevenage, UK: IEE, p. 220-237, 1997.

Miller, J.F. \& Smith, S.L., Redundancy and computational efficiency in cartesian genetic programming. IEEE Transactions on Evolutionary Computation, 10(2):167-174, 2006.

Montagne, E., Sequencing With Time Delay Costs. Industrial Engineering Research Bulletin 5, Arizona State University, Phoenix, USA, 1969

Montana, D.J., Strongly Typed Genetic Programming. Technical Report \#7866, Bolt Beranek and Newman, Inc., Cambridge, USA, 1994.

Nguyen, S.; Zhang, M. \& Johnston, M., A genetic programming based hyper-heuristic approach for combinatorial optimisation. In: Proceedings of the Conference on Genetic and Evolutionary Computation. New York: ACM, p. 1299-1306, 2011.

Oltean, M., Evolving evolutionary algorithms using linear genetic programming. Evolutionary Computation, 13(3):387410, 2005.

Oltean, M.; Grosan, C.; Diosan, L. \& Mihaila, C., Genetic programming with linear representation: a survey. International Journal on Artificial Intelligence Tools, 18(2):197-238, 2009.

O'Neill, M. \& Ryan, C., Grammatical evolution. IEEE Transactions on Evolutionary Computation, 5(4):349-358, 2001. 
Pillay, N., An analysis of representations for hyper-heuristics for the uncapacitated examination timetabling problem in a genetic programming system. In: Proceedings of the Annual Research Conference of the South African Institute of Computer Scientists and Information Technologists on IT Research in Developing Countries: Riding the Wave of Technology. New York, USA: ACM, p. 188-192, 2008.

Pillay, N. \& Banzhaf, W., A genetic programming approach to the generation of hyper-heuristics for the uncapacitated examination timetabling problem. In: Proceedings of the 13th Portuguese Conference on Artificial Intelligence. Heidelberg, Germany: Springer-Verlag, p. 223-234, 2007.

Poli, R., Parallel distributed genetic programming. In: Corne, D.; Dorigo, M. \& Glover, F. (Eds.), New Ideas in Optimization. Maidenhead, England: McGraw-Hill, Advanced Topics in Computer Science, p. 403-431, 1999.

Poli, R.; Langdon, W.B. \& McPhee, N.F., A field guide to genetic programming. Morrisville, USA: Lulu Press, 2008.

Tay, J.C. \& Ho, N.B., Evolving dispatching rules using genetic programming for solving multi-objective flexible jobshop problems. Computers \& Industrial Engineering, 54(3):453-473, 2008.

Teller, A., Evolving programmers: The co-evolution of intelligent recombination operators. In: Angeline, P.J. \& Kinnear, Jr., K.E. (Eds.), Advances in Genetic Programming 2. Cambridge, USA: MIT Press, p. 45-68, 1996.

Whigham, P.A., Grammatically-based genetic programming. In: Rosca, J.P. (Ed.), Proceedings of the Workshop on Genetic Programming: From Theory to Real-World Applications. Tahoe City, USA, p. 33-41, 1995.

\section{Notas Biográficas}

Douglas Adriano Augusto é bacharel em Informática (Universidade Federal de Juiz de Fora - UFJF, 2000), mestre e doutor interdisciplinar em Engenharia Civil com concentração em Sistemas Computacionais pela (Universidade Federal do Rio de Janeiro -UFRJ, 2004 e 2009, respectivamente). Atualmente é bolsista FAPERJ de pós-doutorado vinculado ao Laboratório Nacional de Computação Científica (LNCC/MCTI), atuando em meta-heurísticas bio-inspiradas, computação paralela de alto desempenho e problemas de grande porte.

Heder Soares Bernardino é graduado em Ciência da Computação e mestre em Modelagem Computacional (UFJF, 2006 e 2008, respectivamente) e doutor em Modelagem Computacional (LNCC/MCTI, 2012). Interessa-se por metaheurísticas, em especial para a descoberta de conhecimento, inferência de modelos e geração automática de projetos estruturais,bem como por computação de alto desempenho. Atualmente é professor do departamento de Ciência da Computação da UFJF.

Helio José Corrêa Barbosa é graduado, mestre e doutor em Engenharia Civil (UFJF, 1974; COPPE/UFRJ, 1978 e COPPE/UFRJ, 1986, respectivamente). Atualmente é Tecnologista Senior no Laboratório Nacional de Computação Científica e Professor Associado do Departamento de Ciência da Computação da Universidade Federal de Juiz de Fora. Tem interesse no desenho e aplicação de meta-heurísticas em engenharia e biologia. 
Augusto et al. 


\title{
Comparação de Métodos de Computação Evolucionária para o Problema da Mochila Multidimensional
}

\author{
Jonas Krause, Jelson André Cordeiro e Heitor Silvério Lopes*
}

\begin{abstract}
Resumo: O Problema 0-1 de Múltiplas Mochilas (PMM) é um problema de otimização combinatória NP-completo bastante difundido na literatura devido à sua grande aplicabilidade no mundo real. O uso de algoritmos meta-heurísticos é uma prática comum para a resolução do PMM. Este capítulo apresenta os seguintes métodos de computação evolucionária para resolver o PMM: Algoritmos Genéticos (AG), uma versão binária da Evolução Diferencial (EDB), o algoritmo Colônia de Abelhas Artificiais (CAA) e o Algoritmo do Morcego (AM), estes dois últimos discretizados do domínio real para o binário. São apresentados e discutidos os resultados da aplicação destes métodos para algumas instâncias de teste do PMM. Os resultados e a análise estatística mostram que o EDB é o melhor método dentre os analisados.

Palavras-chave: Problema da mochila, Algoritmos genéticos, Evolução diferencial, Colônia de abelhas artificiais, Algoritmo do morcego.

Abstract: The 0-1 Multiple Knapsacks Problem (MKP) is a NP-complete combinatorial optimization problem widely found in the literature due to its applicability to real-world problems. The use of metaheuristic algorithms is a common practice to solve the MKP. This paper presents the following evolutionary computation methods for solving the MKP: Genetic Algorithms (GA), a binary version of Differential Evolution (BDE), Artificial Bee Colony (ABC) and Bat Algorithm (BA), these last two discretized from continuous to binary domains. The results and discussion of the application of these methods for some benchmark instances of the MKP are presented. Results and statistical analysis show that BDE is the best method, when compared with the other algorithms.
\end{abstract}

Keywords: Knapsack problems, Genetic algorithms, Differential evolution, Artificial bee colony, Bat algorithm.

\section{Introdução}

A otimização de recursos é um dos principais objetivos nas mais diversas áreas da logística, transporte e produção (Chu \& Beasley, 1998). A busca de métodos eficientes e rápidos de otimização visa o aumento direto do lucro das empresas e a diminuição do uso de matéria prima. Um problema desta natureza bastante conhecido na literatura recente é o Problema da Mochila (PM). As diversas variantes do PM podem ser facilmente adaptadas para problemas reais, como por exemplo, problemas de corte e de empacotamento (Egeblad \& Pisinger, 2009). Assim, este problema tem sido foco de diversas pesquisas utilizando programação inteira (Beasley, 1985) e contínua (Mclay \& Jacobson, 2007).

Dependendo das dimensões de uma instância do PM, o número de possíveis combinações cresce exponencialmente e demanda um enorme esforço computacional para testar todas as soluções viáveis. Assim, este problema é considerado NP-completo e, em virtude disto, métodos heurísticos tem sido usados para encontrar soluções suficientemente boas (ou eventualmente ótimas) para o problema. Geralmente associadas à evolução de soluções iniciais aleatórias, tais soluções suficientemente boas são a melhor aproximação possível da otimalidade.

A maioria dos métodos da área de Computação Evolucionária (incluindo aqui, aqueles denominados de Inteligência de Enxames) foram concebidos para a otimização de problemas definidos no espaço contínuo de suas variáveis. Poucos são aqueles criados ou adaptados para trabalhar com espaços discretos, notadamente binários. Baseando-se em um exaustivo estudo anterior (Krause et al., 2013), neste trabalho são descritos métodos para a adaptação destes algoritmos, permitindo que os memos possam ser aplicados ao PM e outros problemas de otimização discreta.

*Autor para contato: hslopes@utfpr.edu.br 
Os métodos propostos neste capitulo utilizam Algoritimos Genéticos (AG) com codificação binária, uma versão modificada da Evolução Diferencial adaptada para processamento binário e a discretização de dois métodos de inteligência de enxames: o algoritmo Colônia de Abelhas Artificiais (CAA) e o Algoritmo do Morcego (AM). Estes métodos serão descritos em detalhes nas próximas seções.

\section{Modelagem do Problema}

O Problema da Mochila (PM) é um problema clássico de otimização combinatorial e consiste em organizar $n$ itens com diferentes restrições e lucros dentro de um recipiente limitado (mochila, caixa, contêiner, etc). O objetivo é maximizar o lucro resultante do somatório dos $n$ itens carregados no recipiente, respeitando-se a sua capacidade máxima.

O PM pode ser interpretado de acordo com as dimensões dos $n$ itens (Egeblad \& Pisinger, 2009). O PM de uma única dimensão consiste na representação de um único valor para as restrições de cada item. Assim, todos os $n$ itens possuem um valor inteiro como restrição, geralmente associado ao seu custo de transporte. Esta versão uni-dimensional do PM é facilmente encontrada no corte de barras metálicas, canos, etc.

Para os itens com duas dimensões (altura e largura) este problema pode ser interpretado com um problema de corte, onde a mochila é um espaço bi-dimensional. No problema de corte, o objetivo também é maximizar o lucro encaixando o maior número de itens e consequentemente minimizando o espaço não utilizado. Considerando a mochila uma peça de tecido, uma chapa metálica ou de madeira para corte, a otimização desta matéria prima é fundamental para maximizar os lucros e minimizar o material de sobra. O PM de natureza bi-dimensional é encontrado, por exemplo, na indústria têxtil, metalúrgica, gráfica, etc.

O PM também pode ser tri-dimensional, quando utilizado para itens com restrições de altura, largura e profundidade. Assim, cada mochila deve ter as três dimensões máximas bem definidas e cada item é associado a um volume. Outras dimensões podem ser associadas à outras restrições, como a ordem em que cada item é colocado na mochila, itens que podem ser levados em diversas posições diferentes (em pé, deitado ou de lado), itens agrupados, etc. Esta versão do PM é encontrada, por exemplo, no carregamento de contêiners, navios e caminhões, ou, ainda no armazenamento industrial.

As variantes do PM também podem ser associadas à quantidade de cada item $n$ a ser levado (Martello \& Toth, 1990). No Problema da Mochila Inteiro (PMI) não há limitação na quantidade de itens a serem levados, podendo o mesmo item ser levado várias vezes ou até encher toda a mochila. Caso o item só possa ser levado uma única vez, este problema passa a ser um problema binário e denominado como Problema 0-1 da Mochila. Esta variante é uma das mais estudadas em problemas de programação discreta, devido ao fato de poder representar uma gama muito grande de situações práticas. O Problema 0-1 da Mochila pode ser visto como um problema de programação inteira e como um subproblema de muitos outros problemas mais complexos. Uma variante mais completa do Problema 0-1 da Mochila considera a existência de múltiplas mochilas com restrições diferentes para cada item. Esta variante é conhecida como o Problema 0-1 de Múltiplas Mochilas, foco deste trabalho.

Algumas variantes apresentam condições adicionais, como por exemplo, a limitação da quantidade de itens a serem levados. Neste caso, o problema passa a ser chamado de Problema da Mochila Restrito. Outra variante busca selecionar um subconjunto de itens cuja soma total dos pesos dos itens escolhidos se aproxime ao máximo da capacidade da mochila. Esta variante é chamada de Problema da Soma de Subconjuntos. Pode-se também adicionar a condição de que o número total de itens selecionados seja o mínimo possível, criando outra variante do problema conhecida como Problema do Troco.

O Problema de Atribuição Generalizada (Generalized Assignment Problem) pode ser descrito utilizando a terminologia do Problema da Mochila. O problema consiste em associar cada item a exatamente uma mochila, visando maximizar o ganho total sem associar a nenhuma mochila um peso total que ultrapasse sua capacidade. O Problema Bin-Packing é outra variante do PM muito similar ao Problema de Atribuição Generalizada. Cada item é associado a uma mochila, porém o número total de mochilas usadas deve ser o mínimo possível.

Existe ainda uma variante que utiliza uma função objetivo não linear ou que envolve restrições não lineares. Esta variante é chamada de Problema da Mochila Quadrático. Outras variantes podem ser compreendidas como o Problema da Mochila Compartimentada. Neste caso são considerados diferentes compartimentos dentro de cada mochila e cada item é associado a um ou mais compartimentos, criando assim possíveis agrupamentos.

Como mencionado anteriormente, este trabalho tem como foco uma das variantes binárias mais conhecidas do PM, o Problema 0-1 de Múltiplas Mochilas (PMM), também conhecido na literatura como: 0-1 Multi-KnapsackProblem (MKP), MulticonstraintKnapsackProblem, MultipleKnapsackProblem ou 0/1 MultidimensionalKnapsackProblem (Khuri et al., 1994).

O PMM possui um único valor associado a cada item $n$, portanto uni-dimensional. Por ter múltiplas mochilas, cada valor associado também depende da mochila $m$, montando um problema com variáveis 
multidimensionais $(n \times m)$. Krause et al. (2012) definem o problema como o transporte de $n$ itens ou cargas a ser realizado em $m$ mochilas diferentes (ou meios diferentes de transporte). Suas respectivas restrições $W_{i j},(i=1,2, \ldots, n)$ e $(j=1,2, \ldots, m)$ são representadas por uma matriz com $n$ linhas e $m$ colunas. Cada item $n$ pode ter sua restrição diferenciada dependendo em qual meio de transporte $m$ ele melhor se encaixa. Em outras palavras, cada item $n$ pode ser transportado de diferentes maneiras: avião, barco, containers, caminhões, etc. e cada meio de transporte possui uma restrição diferente $W_{i j}$ associada a cada item $n$.

O objetivo do PMM é maximizar o somatório do lucro $P$ que cada item $n$ levado possui, representado pela variável multidimensional $P i$. Cada item $n$ é representado por uma variável binária $X_{i}$ que pode assumir o valor de zero (0) ou um (1), representando se o item $n$ será levado $(1=\mathrm{SIM})$ ou não será levado $(0=\mathrm{N} \tilde{A} \mathrm{O})$. A Equação 1 representa matematicamente este objetivo.

$$
\max \left(\sum\left(P_{i} . X_{i}\right)\right) \quad i=1,2, \ldots, n
$$

Porém, cada mochila $m$ possui uma capacidade máxima $C_{j}$ e seu limite deve ser respeitado. Consequentemente, o somatório das restrições $W_{i j}$ multiplicado pela variável binária $X_{i}$ deve ser menor ou igual ao valor de $C_{j}$ de cada mochila $m$. Tal limite máximo é representado matematicamente na Equação 2.

$$
\sum\left(W_{i j} \cdot X_{i}\right) \leq C_{j} \quad j=1,2, \ldots, m
$$

As variáveis $P_{i}, C_{j}$ e $W_{i j}$ são definidas como valores inteiros positivos. A forte interação entre as variáveis $W_{i j}$ e $C_{j}$ restringe os valores máximos de $W_{i j}$ e mínimo de $C_{j}$. Isto pode ser compreendido como: nenhum item $n$ deve ter a sua restrição $W_{i j}$ maior do que o tamanho de $C_{j}$ para o mesmo valor de $j$, como mostrado na Equação 3. Esta equação garante que nenhum item pode ter sua restrição $W_{i j}$ maior do que o tamanho total da mochila $j$.

$$
W_{i j} \leq \max \left(C_{j}\right)
$$

A Equação 4 demonstra que toda capacidade $C_{j}$ deve ser maior que o valor mínimo de $W_{i j}$. Isto pode ser interpretado como a limitação de haver mochilas menores que o menor valor de restrição.

$$
C_{j} \geq \min \left(W_{i j}\right)
$$

A codificação do vetor solução $X_{i}$ para o PMM pode ser representada por um vetor binário de dimensão $n$ para a utilização dos métodos de computação evolucionária. A melhor combinação binária do vetor solução $X_{i}$ indicará quais itens devem ser levados para que o maior lucro seja atingido e, consequentemente, a melhor solução para o problema. Tal combinação é uma das possibilidades criadas pelo vasto Espaço de Busca (EB) do problema, definido pelo número $n$ de itens e o número $m$ de mochilas, sendo representado matematicamente pela Equação 5 .

$$
E B=m \cdot 2^{n}
$$

O número de itens $n$ do problema leva a uma equação exponencial de base dois e expoente $n$. Caso a instância do problema utilize uma única mochila, o EB é então definido como $2^{n}$. O número de mochilas $m$, quando maior do que 1, leva a um EB maior, elevando o grau de complexidade do problema.

\section{Métodos}

A busca da solução exata para problemas combinatoriais NP-completos é uma tarefa que exige um extraordinário esforço computacional, tornando-se inviável o uso de um método determinístico para instâncias com valores grandes de $n$ e $m$. Como alternativa, diversos algoritmos heurísticos podem ser utilizados para este tipo de problema. Tais métodos são, em geral, populacionais. Isto é, trabalham com diversas soluções possíveis ao mesmo tempo e, através de um processo iterativo, podem alcançar soluções de boa qualidade (eventualmente a solução ótima), dentro de um tempo computacional aceitável.

\subsection{Algoritmo Genético}

Algoritmo Genético (AG) é um método heurístico de busca e otimização introduzido por Holland (1975) e desde então vem sendo largamente utilizado para problemas reais de alta complexidade. Baseados na teoria da evolução de Darwin, os AGs buscam convergir uma população inicial aleatória para uma solução de boa qualidade usando conceitos de seleção natural e evolução. Transições probabilísticas atuam sobre os indivíduos 
da população por diversas gerações objetivando a sua evolução de acordo com a sua capacidade de adaptação. AGs usam esta evolução como um processo inteligente de busca de soluções de boa qualidade para problemas difíceis.

O AG aplicado no PMM busca encontrar a melhor combinação de $n$ itens a serem levados, respeitando suas restrições do problema. Cada indivíduo da população inicial do AG é representado por um cromossomo de dimensão $n$, onde cada elemento deste vetor solução é uma variável binária representando o $n$-ésimo item.

Utilizando-se de uma população inicial aleatória, o AG avalia como cada indivíduo se adapta ao problema através da função de fitness, associada ao objetivo do problema. Esta função fornece um valor considerado a qualidade do indivíduo. A partir disto, os indivíduos de melhor qualidade têm maiores chances de serem selecionados para o processo reprodutivo. A seleção é realizada pelo método do torneio estocástico. A geração de novos indivíduos ocorre através da aplicação de operadores genéticos de crossover e mutação aos indivíduos anteriormente selecionados. Os novos indivíduos constituem uma nova população e são avaliados pela função de fitness e o processo se repete por um número pré-definido de gerações.

Dependendo como os indivíduos foram codificados e como as restrições do problema foram tratadas, é possível que indivíduos inválidos sejam gerados ao longo do processo evolutivo. Tais indivíduos podem representar soluções promissoras mas que não satisfazem todas as restrições de valores do problema. Entretanto, é usual permitir indivíduos inválidos na população, penalizando seu valor de fitness proporcionalmente à violação das restrições das mochilas. Isto é feito com a expectativa de que tais indivíduos contenham material genético útil para as próximas gerações. O Algoritmo 1 mostra o pseudocódigo do AG canônico.

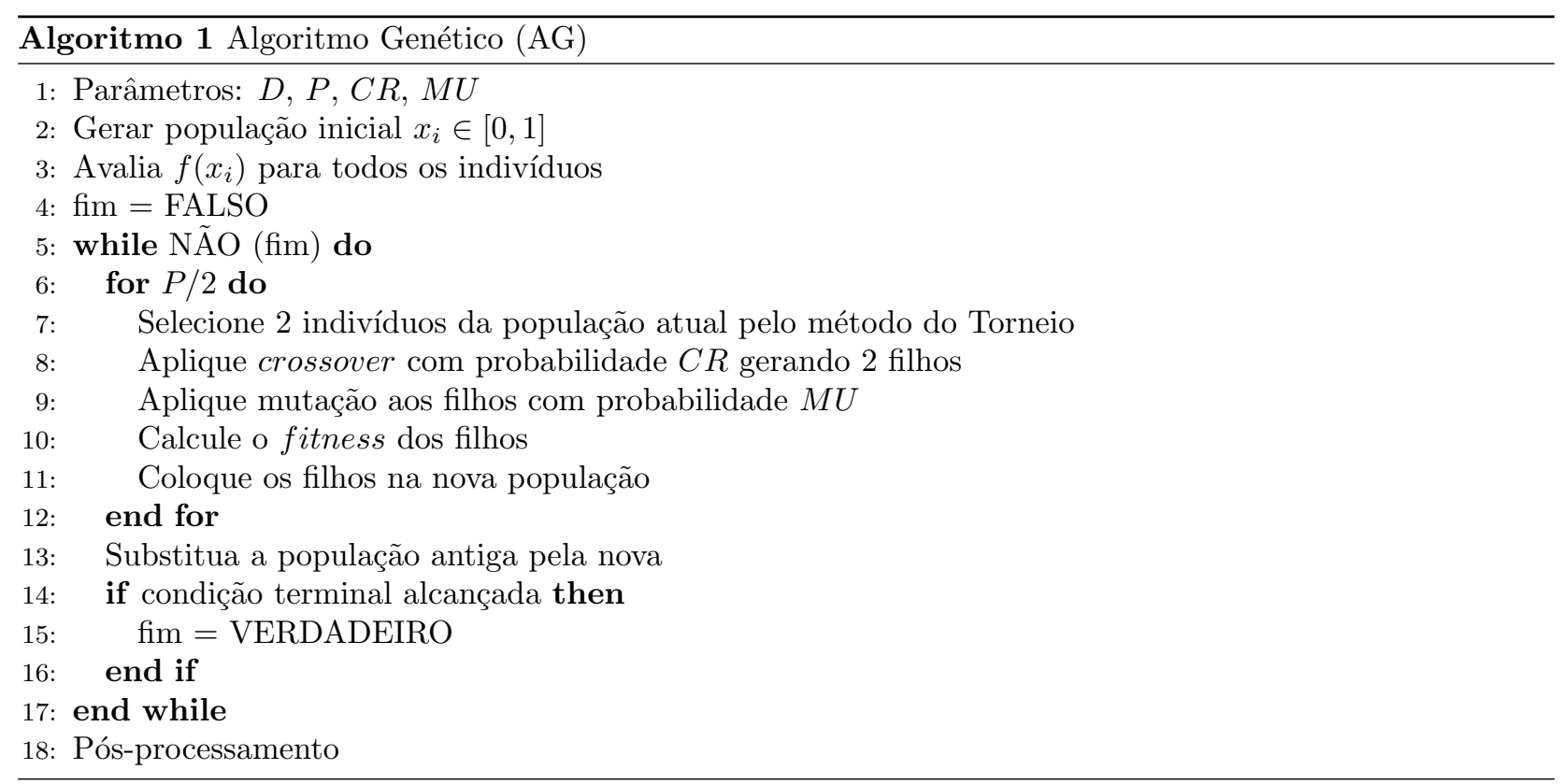

Inicialmente são determinados os parâmetros $D, P, C R$ e $M U$, representando respectivamente a dimensão $D$ do cromossomo, o número de indivíduos da população $P$, a taxa de crossover $C R$ e a taxa de mutação $M U$ (linha 1). Logo após é gerado aleatoriamente uma população de indivíduos (linha 2) e calculada sua função de fitness (linha 3), que representa a adequabilidade do indivíduo para a solução do problema. É definido um bloco repetitivo de comandos (linhas 5-17) para criar e selecionar uma nova população (linhas 7-11) até que seja alcançada uma condição terminal definida. A seleção de dois indivíduos da população atual (linha 7) simula a reprodução gerando dois filhos através do método de crossover, que consiste em dividir cada um dos cromossomos pais em duas partes e associá-las entre si gerando novos indivíduos. Aplica-se a mutação (linha 9) que é uma mudança aleatória em um dos elementos do cromossomo. Depois calcula-se o valor de fitness dos indivíduos filhos gerados (linha 11). Estes indivíduos filhos são incorporados à nova população, que substitui a população antiga (linha 13). O Algoritmo 1 finaliza quando sua condição terminal é alcançada. Esta condição pode ser um número pré-determinado de gerações ou quando o melhor indivíduo gerado até então satisfaz um critério de qualidade mínimo.

\subsection{Evolução Diferencial Binária}

O algoritmo de Evolução Diferencial Binária (EDB) é um algoritmo meta-heurístico baseado em populações de vetores proposto por Krause et al. (2012). A EDB é uma variante da Evolução Diferencial (ED) original 
(Price et al., 2005) que utiliza o processo de mutação do AG e foi adaptado para problemas com representação binária.

A ED foi introduzida por Storn \& Price (1995) para a otimização de funções matemáticas multidimensionais no espaço contínuo. Entretanto, diferentemente de outros métodos, a ED não utiliza o gradiente da função sendo otimizada, permitindo, assim, sua utilização para problemas complexos, não diferenciáveis, ruidosos, etc. Por esta razão, a ED tem sido aplicada com sucesso para uma vasta gama de problemas, como por exemplo, projetos de filtros digitais (Storn, 1996), problemas inversos de transferência radiativa (Lobato et al., 2011), dobramento de proteínas (Kalegari \& Lopes, 2010), e otimização de cadeia de suprimentos (Falcone et al., 2008).

Em geral, as variantes da ED são caracterizadas por diferentes processos de mutação e crossover da população. A mutação acontece quando um indivíduo é perturbado pela diferença de outros dois indivíduos e pelo processo de mutação. Tal mutação pode ser aleatória, utilizando o melhor indivíduo, ou ainda utilizando as duas técnicas juntas. Por outro lado, o processo de crossover acontece de duas maneiras diferentes, binomialmente ou exponencialmente.

A EDB utilizada neste trabalho é baseada na variante mais utilizada da ED: $D E / r a n d / 1 / b i n$, o que consiste em utilizar uma mutação diferencial aleatória a cada indivíduo da população e um crossover binomial.

Sendo a ED original concebida para espaços contínuos (variáveis reais), esta variante do problema teve sua codificação adaptada para o espaço discreto (variáveis binárias). A codificação do indivíduo pode ser interpretada como um vetor binário, analogamente à codificação tradicioinal do AG. Porém, como o processo de mutação da ED utiliza a diferença de dois vetores, na EDB foi adaptada como a troca de um ou mais bit(s) do vetor. Esta modificação cria um algoritmo com uma capacidade maior de busca global, criando soluções não testadas anteriormente e possibilitando uma maior diversidade. Este processo de mutação foi inspirado no AG e adaptado para a sua utilização dentro da ED original. Todo o processo de crossover foi mantido como na ED original.

Utilizando uma codificação binária, todos os indivíduos da população inicial gerada aleatoriamente são vetores binários sendo possíveis soluções sendo evoluídas para o problema.

$\mathrm{Na}$ EDB, uma população de $N$ vetores, cada um com dimensão $D$, interage entre si. Cada vetor binário $\vec{x}=\left[x_{i 1}, x_{i 2}, \ldots, x_{i D}\right]$ é uma possível solução para o problema, e é avaliado pela função de fitness $f\left(\vec{x}_{i}\right)$ $(i=1, \ldots, N)$. O pseudocódigo da EDB é mostrado no Algoritmo 2.

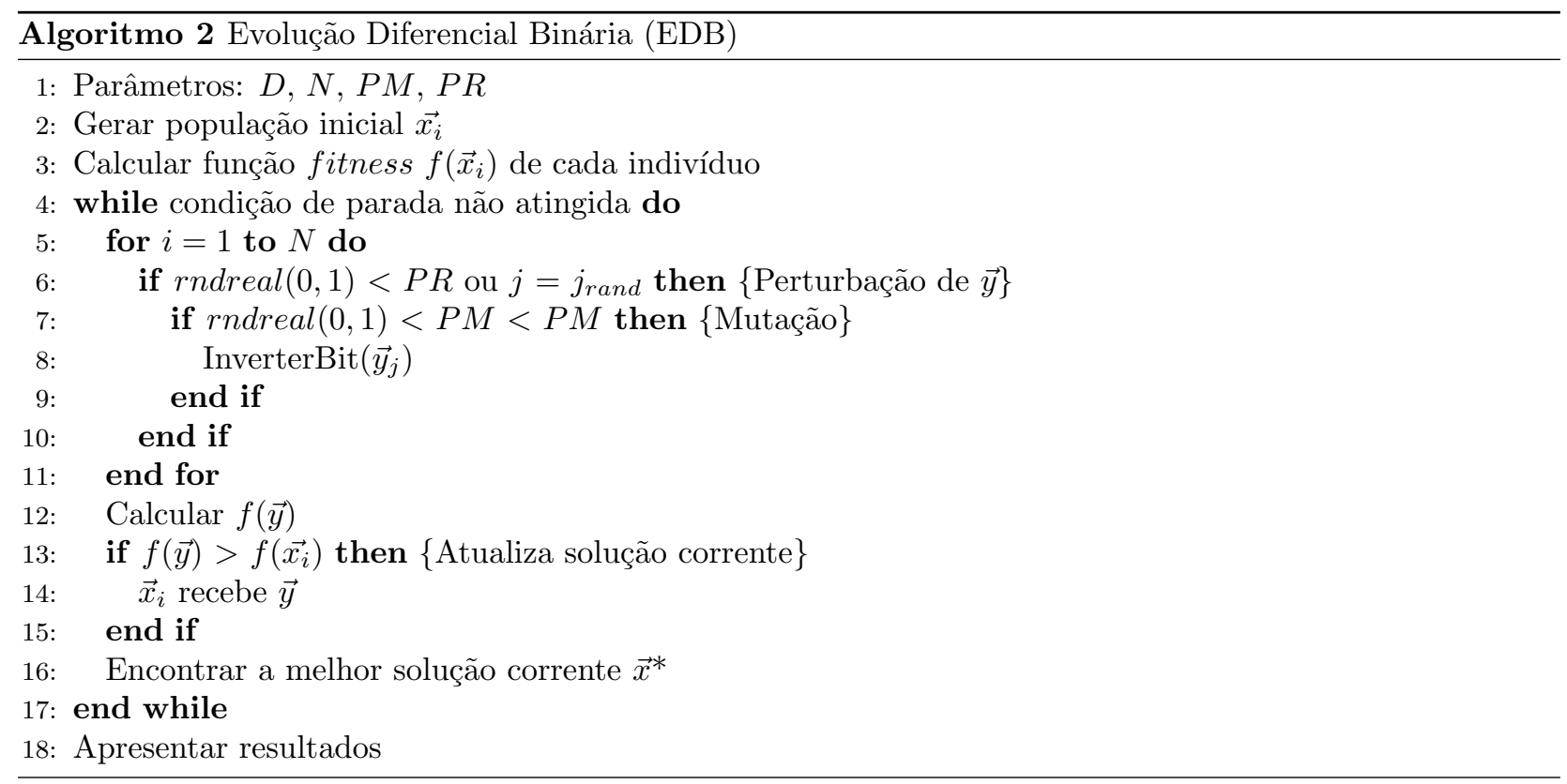

O algoritmo tem os seguintes parâmetros: $D$ como número de variáveis do problema (no presente trabalho corresponde ao número de bits), $N$ como número de indivíduos (vetores binários) da população, $P M$ como parâmetro de mutação e $P R$ como taxa de perturbação (todos definidos na linha 1).

Inicialmente gera-se uma população aleatória $i$ (linha 2) e calcula-se a função de fitness para cada indivíduo (linha 3). Uma estrutura de repetição é executada até ser atingida a condição de parada (linhas 4-5), esta estrutura consiste em criar novos indivíduos através dos processos de perturbação (mutação e crossover). Dentro desta estrutura são selecionados os índices $s$ e $j$ aleatórios, onde rndint e rndreal são números aleatórios inteiros e reais respectivamente. O valor de $s$ corresponde a um número inteiro entre 1 e 
o número de indivíduos da população $N$ ou igual do valor corrente de $i$ (linha 6). O valor de $j$ corresponde a um número inteiro entre 1 e a dimensão $D$ (linha 7 ).

O vetor solução teste $\vec{y}$ recebe o vetor do indivíduo $\vec{x}_{i}$ (linha 8 ) que sofrerá uma perturbação em seus $D$ elementos caso um valor aleatório real entre 0 e 1 seja menor do que a taxa de perturbação $P R$, ou o índice $j$ seja igual ao índice $j_{\text {rand }}$ (linha 10). Esta perturbação será uma mutação (inversão de bit) caso um valor aleatório real entre 0 e 1 seja menor que a taxa de mutação $P M$ (linha 11-12). Caso contrário, é aplicado um crossover na solução teste $j$ (linhas 13-14).

O valor de adaptabilidade ou função fitness da solução teste é calculada após as perturbações (linha 18). Caso o valor do fitness do novo indivíduo seja maior que o valor de fitness do indivíduo antigo (linha 19), a solução $i$ recebe a nova solução (linha 20). Deste vetor de soluções é encontrada a melhor solução corrente $\vec{x}$ (linha 23). Esta estrutura é repetida até que a condição de parada seja atingida (linha 24), normalmente definida como um número pré-determinado de iterações do algoritmo. O Algoritmo 2 finaliza mostrando os resultados da melhores soluções $\vec{x}$ (linha 25).

\subsection{Colônia de Abelhas Artificiais}

O algoritmo de Colônia de Abelhas Artificiais (Artificial Bee Colony - CAA) é inspirado no comportamento de coleta de alimento pelas abelhas (Karaboga \& Akay, 2009). As abelhas têm como objetivo a descoberta de locais que sejam fontes de alimento com quantidade elevada de néctar. A função fitness avalia os possíveis locais encontrados pelas abelhas. Existem três tipos de abelhas: as abelhas escoteiras voam aleatoriamente no espaço de busca sem orientação específica; as abelhas empregadas exploram a vizinhança de sua localização para selecionar uma solução aleatória para ser perturbada; e as abelhas espectadoras que selecionam probabilisticamente uma solução para explorar a sua vizinhança.

Caso a quantidade de néctar de uma nova fonte encontrada seja maior do que a anterior na sua memória, a abelha se desloca para a nova posição e esqueçe a anterior. Se uma solução não for melhorada por um número pré-determinado de iterações, a fonte de alimento é abandonada pela correspondente abelha empregada e esta se torna uma abelha escoteira. O algoritmo CAA equilibra exploração (busca global) e intensificação (busca local) usando as abelhas empregadas e espectadoras para a primeira tarefa e as abelhas escoteiras para a segunda.

Originalmente, o CAA foi concebido para trabalhar com variáveis contínuas (Karaboga \& Akay, 2009) e a sua aplicabilidade tem sido muito ampla, principalmente nas áreas de engenharia e computação, por exemplo: na determinação da estrutura de proteínas (Benítez et al., 2012), no planejamento da recarga de reatores nucleares (Lima et al., 2011), e no reconhecimento de imagens faciais (Chidambaram \& Lopes, 2010). O Algoritmo 3 apresenta o pseudocódigo do CAA.

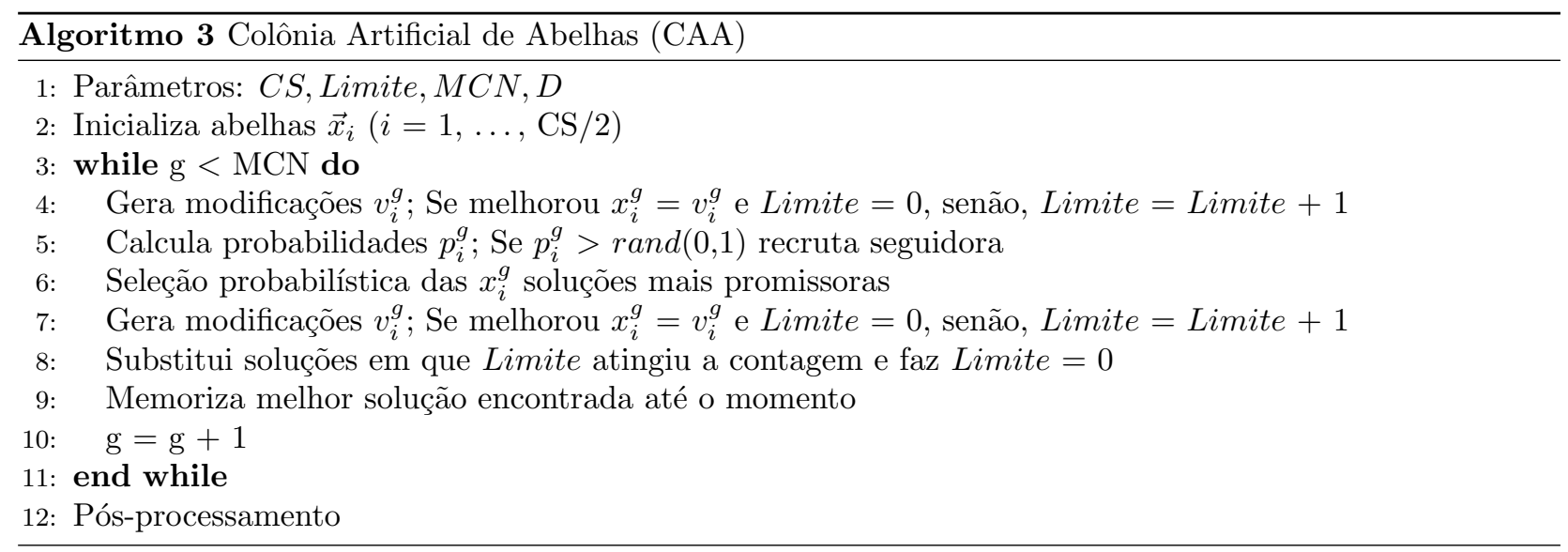

O algoritmo começa definindo os parâmetros: população da colônia $(C S)$, quantidade de variáveis $(D)$, número máximo de gerações $(M C N)$ e o limite para abandono de uma fonte de alimento (Limite) (linha 1). A população inicial é criada e dividida igualmente entre abelhas escoteiras e empregadas (linha 2). Uma estrutura de repetição (linhas 3 a 11) é utilizada com um contador $(g)$ até o número máximo de ciclos $(M C N)$ ). Esta estrutura gera modificações (linha 4) buscando melhores soluções, calcula a probabilidade da abelha se tornar uma seguidora (linha 5) e seleciona as soluções mais promissoras (linha 6). Gera novamente modificações (linha 7), substitui soluções que atingiram o limite (linha 8), memoriza a melhor solução encontrada (linha 9) e atualiza o contador (linha 10).

Utilizando o pseudocódigo do CAA para espaços contínuos, este artigo utiliza uma das técnicas de discretização proposta em Krause et al. (2013) para converter o vetor solução de real para binário. Uma 
função sigmóide foi utilizada para converter cada dimensão do indivíduo, transformando ele em um indivíduo binário. Assim o algoritmo continua processando e posicionando as abelhas com valores reais, porém a fonte de alimento (objetivo do problema) discretizada para binário passa a ser uma possível solução para o problema.

\subsection{Algoritmo do Morcego}

O algoritmo do morcego (BatAlgorithm - AM) é inspirado no processo de eco-localização desempenhado pelos morcegos durante o seu vôo para detectar presas e evitar obstáculos e foi criado por Yang (2010b). A eco-localização se baseia na emissão de ondas ultrassônicas e a correspondente medição do tempo gasto para estas ondas voltarem à fonte após serem refletidas pelo alvo (presa ou obstáculo). A taxa de pulso e amplitude dos sons emitidos pelos morcegos variam com a estratégia de caça. Quando identificada uma presa, a taxa de pulso $(r)$ é acelerada e a amplitude $(A)$ é aumentada para evitar a perda da presa. Por outro lado, quando a presa está sob domínio, a amplitude diminui.

No modelo computacional do AM, cada morcego representa uma possível solução para o problema codificado sob a forma de um vetor. Uma população de morcegos então se move no espaço de busca do problema, atualizando continuamente a frequência, velocidade e posição de cada elemento buscando encontrar a solução ótima. A cada nova interação, cada morcego é atualizado seguindo a melhor solução encontrada pela população. Além da atualização da posição, existe o controle de exploração e intensificação como nos outros algoritmos de computação evolucionária. A exploração e a intensificação são realizadas, respectivamente, pela variação da amplitude e da taxa de pulso.

Embora o criador do algoritmo disponibilize uma versão do seu pseudocódigo (Yang, 2010b,a), muitos detalhes para a sua implementação são omitidos. Posteriomente, Cordeiro et al. (2012) publicaram uma versão mais completa do pseudocódigo, que é apresentado a seguir no Algoritmo 4.

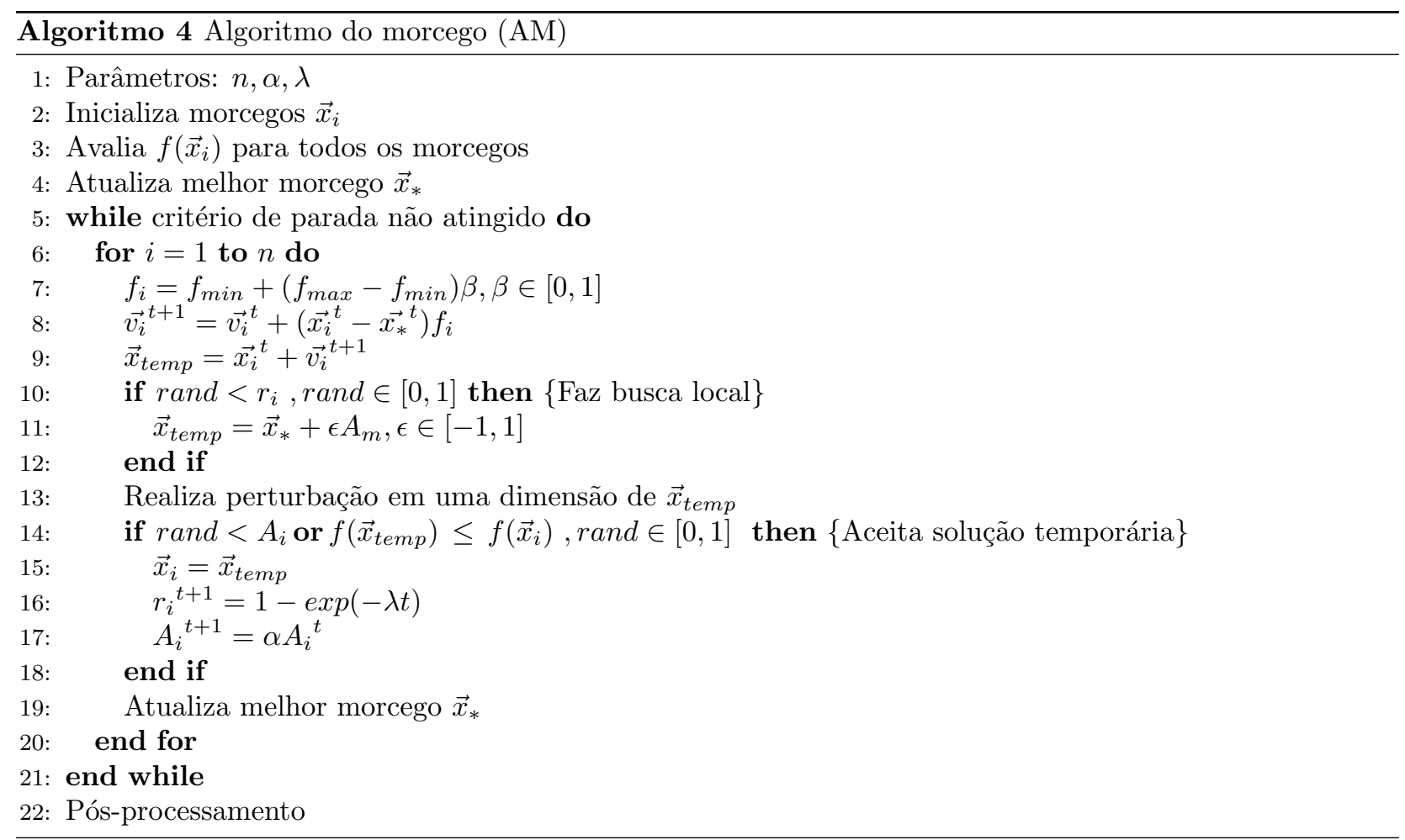

O AM inica no instante $t=0$ e todos os $n$ morcegos $\vec{x}_{i}(i=1, \ldots, n)$ são inicializados com taxa de pulso $r_{i}=0$, velocidade $\vec{v}_{i}=0$, amplitude $A_{i}=1$, frequência $f_{i}=0$ e posição $\vec{x}_{i}$ aleatória (linha 2 ). O ciclo principal representa a evolução da população no tempo (linhas 5-21). O primeiro passo no interior do ciclo é atualizar a posição temporária $\vec{x}_{t e m p}$ até ser aceita. Para isto, a frequência $f_{i}$ é atualizada (linha 7 ), onde $f_{\min }$ e $f_{\max }$ são, respectivamente, os limites inferiores e superiores da função de fitness. O valor de $\beta \in[0,1]$ é um número aleatório extraído de uma distribuição uniforme. A nova frequência $f_{i}$ é utilizada para determinar a nova velocidade $\vec{v}_{i}^{t+1}$ (linha 8), onde $\vec{x}_{*}$ é a melhor solução encontrada até o instante $t$. Com a nova velocidade $\vec{v}_{i}^{t+1}$, é possível determinar a nova posição temporária $\vec{x}_{t e m p}$ (linha 9 ).

Na linha 10 é realizada a busca local, que pode ser implementada de diversas maneiras. Um passeio aleatório (random walk) pode ser usado tanto para exploração quanto intensificação, dependendo do tamanho do passo. Outra maneira é utilizar o operador de mutação não uniforme. Nesta implementação foi utilizado 
um terceiro método sugerido por Yang (2010b) (linha 11), onde $\epsilon \in[-1,1]$ é um número aleatório extraído de uma distribuição uniforme e $A_{m}$ a média da amplitude de todos os morcegos em um dado instante $t$. Ainda na linha 11, o valor de $\vec{x}_{t e m p}$ é atualizado pela busca local, desconsiderando o valor anterior da posição e velocidade. Na linha 13 uma das dimensões de $\vec{x}_{t e m p}$ (um dos elementos deste vetor), escolhida dentre $d$ dimensões é modificada aleatoriamente dentro dos limites da função de avaliação.

Se a condição (linha 14) for verdadeira e rand $\in[0,1]$ um número aleatório extraído de uma distribuição uniforme, a solução temporária $\vec{x}_{t e m p}$ é aceita (linha 15) e ocorre o aumento da taxa de pulso (linha 16). Caso $t \rightarrow \infty$ e $r_{i} \rightarrow 1$, a busca local se intensifica com o passar do tempo. Outro valor atualizado é a amplitude $A$ (linha 17). Para controlar a diminuição gradual de $A$, dois métodos (linear e geométrico) foram propostos por Yang (2010a). Para o método linear, a equação é $A=A_{0}-\beta t$, onde $A_{0}$ é a amplitude inicial, $t$ é o número da interação e $\beta$ é taxa de diminuição, tal que $\beta=\left(A_{0}-A_{f}\right) / t_{f}$, sendo $A_{f}$ a amplitude final e $t_{f}$ o número máximo de interações. Assim, $A \rightarrow 0$ quando $t \rightarrow \infty$. Para o método geométrico $A$ diminui com uma taxa de diminuição $0<\alpha<1$, utilizando a equação $A=A_{0} \alpha^{t}, t=1,2, \ldots, t_{f}$.

Nesta implementação do AM foi utilizado o segundo método para a diminuição gradual de $A$, pois tem a vantagem de não precisar especificar o número máximo de interações. É necessário apenas determinar o valor de $\alpha$ e o valor inicial de $A$. Foi observado que quando a diminuição for suficientemente lenta, o valor encontrado ao final da execução do algoritmo tende a se aproximar do ótimo global (Yang, 2010a).

O ciclo principal continua até que a sucessão evolutiva da população de morcegos atinja o critério de parada estabelecido (linha 5), geralmente um número máximo de iterações. Os valores de $\alpha$ e $\lambda$ são os parâmetros do AM que serão analisados na Seção 4.3.

Assim como o CAA, o AM também foi discretizado utilizando uma função sigmóide. Isto mantêm os morcegos buscando sua presa em espaços contínuos, porém a solução encontrada é discretizada para o espaço discreto, tornando válida a possível solução.

\section{Experimentos}

Este capítulo utiliza implementações em ANSI C para todos os métodos propostos. Para o AG, foi utilizado o software de domínio público GALLOPS ${ }^{1}$ (Genetic ALgorithm Optimized for Portability and Parallelism System), versão 3.2.4. A EDB utilizou a mesma implementação original proposta em Krause et al. (2012), de acordo com o pseudocódigo do Algoritmo 2. Para o CAA foi utilizado o código implementado por Karaboga \& Akay (2009) ${ }^{2}$ e descrito no Algoritmo 3. O AM, introduzido por Yang (2010b) e adaptado por Cordeiro et al. (2012), utiliza o pseudocódigo do Algoritmo 4.

\subsection{Codificação e Discretização}

Por ser um algoritmo que trabalha com codificação discreta, o AG pode representar as possíveis soluções do problema utilizando valores inteiros ou binários. Portanto, a implementação deste algoritmo para o PMM não necessitou de adaptações. Seu vetor solução (cromossomo) foi codificado em binário para representar quais itens devem ser levados na mochila. Cada posição do vetor $X_{i}$ representa a presença do item $\left(X_{i}=1\right)$ ou não $\left(X_{i}=0\right)$.

A EDB é uma adaptação do algoritmo original de ED que foi concebido para otimização em espaços contínuos. Por utilizar valores reais contínuos, a ED teve que ser modificada para trabalhar com indivíduos binários. Portanto, a EDB busca a evolução da sua população em espaços discretos. A mudança de espaço contínuo para discreto tem por consequência um algoritmo adaptado. Assim, o vetor solução só aceita valores binários e o processo de mutação foi modificado para o mesmo processo do AG, invertendo um ou mais bit(s) do vetor solução. A alteração da codificação do algoritmo é uma das técnicas para o uso de algoritmos contínuos em problemas discretos. O uso desta técnica geralmente resulta em versões discretas do algoritmo original, como é o caso da EDB.

Uma técnica bastante utilizada é a discretização somente do vetor solução (Krause et al., 2013). Assim o algoritmo continua trabalhando em espaços contínuos, mas cada solução é convertida para valores discretos. Este foi o caso tanto do CAA quanto do AM utilizados neste capítulo. Em ambos os casos uma função sigmoidal foi utilizada para transformar cada elemento do vetor de números reais para valores binários 0,1 . Com esta estratégia, ambos os algoritmos conservam suas características originais, com processamento no espaço contínuo, mas buscando soluções no espaço discreto.

\footnotetext{
1 http://garage.cse.msu.edu/software/galopps/

2 http://mf.erciyes.edu.tr/abc/
} 


\subsection{Benchmarks}

Benchmarks são instâncias de teste do problema para as quais se conhece o valor ótimo. Utilizando estes benchmarks, cada algoritmo é testado e a relevância de seus resultados se dá pela proximidade da solução encontrada com o valor ótimo conhecido.

As diversas instâncias disponíveis na literatura oferecem uma grande variedade de testes. Cada benchmarkstem seu espaço de busca como função do úmero de itens $n$ e mochilas $m$ (veja Equação 5). Algumas instâncias variam também as restrições $W_{i j}$ e a capacidade das mochilas $C_{j}$, criando problemas com diferentes níveis de complexidade.

A Tabela 1 lista os benchmarks utilizados para testes dos algoritmos. Eles foram escolhidos por configurarem diferentes espaços de busca, como função de variados itens $n$ e mochilas $m$. Assim, os métodos utilizados serão testados em instâncias com diferentes níveis de complexidade. O valor ótimo conhecido também é apresentado, tais valores são o lucro máximo possível conhecido para cada instância. Todos os benchmarks utilizados foram criados por Freville \& Plateau (1990) e estão disponíveis na biblioteca digital do Jornal da Sociedade de Pesquisa Operacional ${ }^{3}$ (Beasley, 1990).

Tabela 1. Benchmarks para teste dos algoritmos (Freville \& Plateau, 1990).

\begin{tabular}{ccccc}
\hline Instância & $m$ & $n$ & EB & Ótimo \\
\hline PB1 & 4 & 27 & $4 \times 2^{27}$ & 3090 \\
PB2 & 4 & 34 & $4 \times 2^{34}$ & 3186 \\
PB4 & 2 & 29 & $2 \times 2^{29}$ & 95168 \\
PB5 & 10 & 20 & $10 \times 2^{20}$ & 2139 \\
PB6 & 30 & 40 & $30 \times 2^{40}$ & 776 \\
PB7 & 30 & 37 & $30 \times 2^{37}$ & 1035 \\
\hline
\end{tabular}

\subsection{Parâmetros de Controle dos Algoritmos}

Cada um dos algoritmos meta-heurísticos apresentados na Seção 3 possui diversos parâmetros que controlam, por exemplo, a quantidade de indivíduos, o critério de parada e as probabilidades de modificação dos indivíduos. O comportamento de cada algoritmo pode ser fortemente influenciado pela escolha destes parâmetros. Os parâmetros utilizados nesta comparação são aqueles usuais na literatura (Goldberg, 1989; Krause et al., 2012; Karaboga \& Akay, 2009; Yang, 2010b). É possível que um ajuste mais refinado dos parâmetros possa gerar resultados melhores, no entanto, isto está fora do escopo deste trabalho.

Com o intuito de fazer uma comparação o mais justa possível, os parâmetros similares dos quatro métodos foram identicamente configurados. Todos os métodos apresentaram um total de 30 mil avaliações (100 indivíduos x 300 gerações). Isto faz com que o esforço computacional seja o mesmo para todos. O AG e a EDB utilizam a mesma probabilidade de mutação de $5 \%$. Os demais parâmetros são individuais de cada método. A Tabela 2 lista os parâmetros configurados. A quantidade de indivíduos, vetores, abelhas e morcegos que constitui a população de cada método e a quantidade de gerações/iterações. As taxas de mutação, crossover e perturbação, quando aplicáveis, e os valores de $\alpha$ e $\lambda$ específicos do Algoritmo do Morcego.

Tabela 2. Parâmetros de controle dos algoritmos.

\begin{tabular}{lcccc}
\hline Parâmetro & AG & EDB & CAA & AM \\
\hline População & 100 & 100 & 100 & 100 \\
Gerações & 300 & 300 & 300 & 300 \\
Mutação & 0,05 & 0,05 & - & - \\
Crossover & 0,8 & - & - & - \\
Perturbação & - & 0,5 & - & - \\
$\alpha$ & - & - & - & 0,9 \\
$\lambda$ & - & - & - & 0,1 \\
\hline
\end{tabular}

\section{Resultados}

A Tabela 3 apresenta os resultados para os benchmarks. Por serem métodos heurísticos com valores iniciais aleatórios, os resultados finais podem variar de acordo com a semente aleatória usada para gerar os primeiros indivíduos. Ou seja, os métodos apresentados podem gerar soluções diferentes a cada execução. Isto cria a necessidade de se avaliar o método proposto várias vezes, e não somente em uma execução. Assim, para cada um dos métodos foram calculados os valores de média e desvio-padrão (DP) de uma amostra de 100 soluções

\footnotetext{
3 http://people.brunel.ac.uk/ mastjjb/jeb/orlib/files/mknap2.txt
} 
(melhor resultado de cada execução independente com sementes aleatórias diferentes). A média e o DP são dados importantes e mostram a robustez de cada algoritmo.

Na tabela é apresentada a melhor solução encontrada (Melhor) entre as 100 rodadas de cada método. Esta solução é mostrada em negrito caso a melhor solução seja o valor ótimo conhecido do problema, identificando que o algoritmo conseguiu encontrar a melhor combinação de itens e mochilas daquela instância. Apresentase, também, a taxa de sucesso (Sucesso), calculada como a porcentagem de vezes que um método é capaz de chegar à solução ótima conhecida.

Tabela 3. Resultados encontrados pelo AG, EDB, CAA e AM.

\begin{tabular}{|c|c|c|c|c|c|c|}
\hline & \multicolumn{3}{|c|}{ AG } & \multicolumn{3}{|c|}{ EDB } \\
\hline Instância & Média $\pm \mathrm{DP}$ & Melhor & Sucesso & Média $\pm \mathrm{DP}$ & Melhor & Sucesso \\
\hline PB1 & $3036,91 \pm 27,23$ & 3090 & $6,00 \%$ & $3075,79 \pm 12,97$ & 3090 & $98,00 \%$ \\
\hline PB2 & $3150,82 \pm 32,55$ & 3186 & $23,00 \%$ & $3183,76 \pm 8,41$ & 3186 & $100,00 \%$ \\
\hline PB4 & $91711,67 \pm 1421,59$ & 95168 & $11,00 \%$ & $94702,39 \pm 926,28$ & 95168 & $48,00 \%$ \\
\hline PB5 & $2097,60 \pm 24,59$ & 2139 & $8,00 \%$ & $2132,88 \pm 8,16$ & 2139 & $100,00 \%$ \\
\hline PB6 & $723,81 \pm 17,44$ & 765 & $0,00 \%$ & $767,33 \pm 13,08$ & 776 & $45,00 \%$ \\
\hline \multirow[t]{2}{*}{ PB7 } & $965,84 \pm 21,64$ & 1000 & $0,00 \%$ & $1033,01 \pm 2,73$ & 1035 & $98,00 \%$ \\
\hline & \multicolumn{3}{|c|}{ CAA } & \multicolumn{3}{|c|}{ AM } \\
\hline Instância & Média $\pm \mathrm{DP}$ & Melhor & Sucesso & Média $\pm \mathrm{DP}$ & Melhor & Sucesso \\
\hline PB1 & $2982,26 \pm 26,05$ & 3026 & $0,00 \%$ & $3029,72 \pm 34,50$ & 3090 & $4,00 \%$ \\
\hline PB2 & $3054,18 \pm 31,81$ & 3148,00 & $0,00 \%$ & $3109,89 \pm 45,49$ & 3186 & $2,00 \%$ \\
\hline $\mathrm{PB} 4$ & $84941,28 \pm 2040,17$ & 89432 & $0,00 \%$ & $90828,86 \pm 2320,05$ & 95168 & $9,00 \%$ \\
\hline PB5 & $2093,73 \pm 19,30$ & 2139 & $3,00 \%$ & $2086,95 \pm 24,00$ & 2139 & $4,00 \%$ \\
\hline PB6 & $598,81 \pm 32,48$ & 672,00 & $0,00 \%$ & $712,94 \pm 41,71$ & 776 & $2,00 \%$ \\
\hline PB7 & $887,87 \pm 29,83$ & 976 & $0,00 \%$ & $976,55 \pm 36,07$ & 1035 & $1,00 \%$ \\
\hline
\end{tabular}

Utilizando as informações do EB (Tabela 1) e os resultados encontrados, pode-se analisar o desempenho de cada algoritmo. Para a instância PB5, por exemplo, todos os algoritmos foram capazes de encontrar o valor ótimo. Devido às restrições a cada mochila e o menor EB dos benchmarks analisados, esta instância é a que apresenta a menor complexidade. De maneira oposta, a instância PB6 é a que tem o maior EB e para qual, de maneira geral, os algoritmos tiveram o pior desempenho.

O AG apresentou resultados muito bons, encontrando o valor ótimo para quase todos os benchmarks propostos (exceto PB6 e PB7). No entanto, a repetibilidade do método, observada pela taxa de sucesso, ainda não é satisfatória, especialmente para as instâncias mais complexas. Por outro lado, o EDB apresentou-se como o método mais eficiente, não só encontrando os valores ótimos para todas as instâncias, como também as maiores taxas de sucesso. Isto sugere que é um algoritmo robusto com uma boa escalabilidade para problemas combinatoriais com grandes EB. Possivelmente, a eficiência do EDB se deve à sua codificação binária, as estratégias de mutação e crossover.

A discretização do vetor solução dos dois algoritmos contínuos (CAA e AM) adapta os métodos para problemas binários e mantêm suas principais características individuais, o que pode ser bastante vangajoso. Porém, ao analisar os resultados do CAA, observa-se um desempenho muito ruim, com uma taxa de sucesso nula, exceto para PB5. Talvez um ajuste refinado dos parâmetros do algoritmo, incluindo o aumento do número de gerações, poderia torná-lo um pouco mais eficiente. Os resultados encontrados pelo AM indicam que o algoritmo encontrou o ótimo para todas as instâncias e com uma repetibilidade melhor do que a do CAA, porém muito aquém daquela do EDB. No entanto, os resultados sugerem que o AM seja um método promissor. De maneira geral, os métodos AG, CAA e AM necessitam de ajustes nos seus parâmetros, de modo a ter um melhor equilíbrio entre busca global e local. Além disto, certamente estes métodos requerem uma quantidade maior de avaliações para obter melhores resultados, pelo menos para os benchmarks utilizados.

Para testar a relevância dos dados encontrados, dois testes estatísticos foram aplicados. O teste ShapiroWilk para determinar se a distribuição observada se aproxima de uma distribuição normal e o teste KruskalWallis para comparar mais de duas amostras que são independentes ou não relacionadas, para o caso de amostras que não tenham distribuição normal.

O teste Shapiro-Wilk testa a hipótese de que a amostra veio de uma população com distribuição normal, verificando se os dados são normais ou ordinais. Neste teste todos os resultados encontrados de cada método em cada instância rejeitam esta hipótese, portanto não é assumida uma distribuição normal em nenhum dos resultados encontrados. Sendo assim, as distribuições observadas possuem dados do tipo ordinal.

O teste Kruskal-Wallis é um método não-paramétrico que analisa a variância dos dados por ranking, este é um método não-paramétrico para testar se os dados ordinais são provenientes de uma mesma distribuição. Estabelecendo o nível de significância em 5\%, o teste Kruskal-Wallis dos resultados encontrados rejeita a 


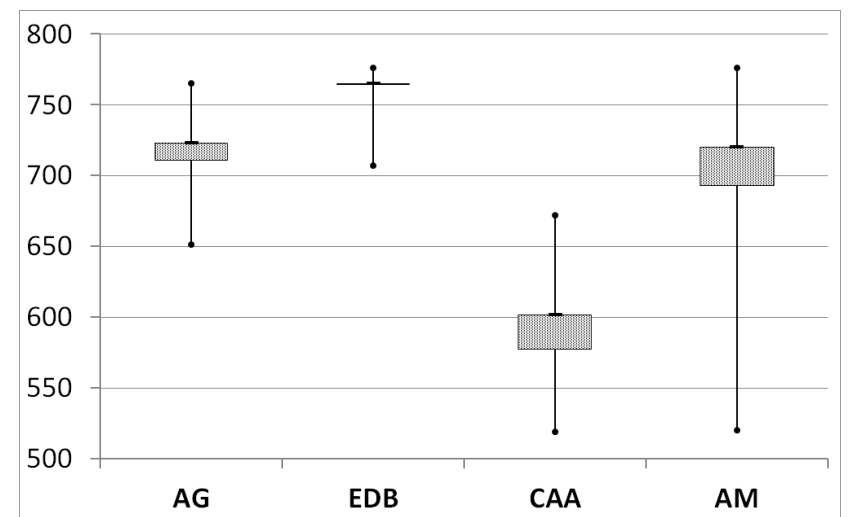

Figura 1. Boxplot dos resultados de cada método para a instância PB6.

hipótese dos valores serem provenientes da mesma distribuição populacional. Tais resultados confirmam que pelo menos uma das amostras são diferentes das outras e, consequentemente, os resultados encontrados podem ser considerados significativos.

Para corroborar a análise estatística, o gráfico boxplot da Figura 1 compara os resultados obtidos. As extremidades dos intervalos neste gráfico demonstram o máximo e mínimo encontrado por cada método. Os retângulos horizontais representam os primeiros e segundos quartis das amostras analisadas. Tais quartis não se sobrepõem quando se compara o EDB com os demais algoritmos, significando que o mesmo é, comparativamente o melhor método, sendo diferente dos demais.

\section{Conclusões}

A busca de novos métodos de solução para problemas NP-completos tem sido o foco de estudos de pesquisadores no mundo inteiro. As aplicações do PMM em problemas do mundo real criam a necessidade de algoritmos cada vez mais rápidos e eficientes. Os resultados encontrados apontam as meta-heurísticas como alternativas eficazes e interessantes para este problema. O método de discretização para os algoritmos com representação contínuua apresentou-se eficiente, criando a possibilidade do uso de outros algoritmos de mesma natureza na solução do PMM.

Os algoritmos apresentados neste capítulo buscam melhores alternativas para problemas binários. A comparação entre os métodos concebidos para espaços binários, a adaptação da codificação e a discretização do vetor solução buscam compreender as limitações de cada método e seu comportamento em espaços diferentes. O AG e sua codificação binária apresentaram resultados satisfatórios em quase todas as instâncias, apesar de não ter sido adaptado e ter utilizado os parâmetros sugeridos na literatura. A EDB também alcançou o valor ótimo na maioria das instâncias e mostrou ser um método promissor para problemas binários, principalmente por ter atingido uma alta taxa de sucesso, de maneira geral. O CAA discretizado não alcançou bom desempenho, necessitando de outras adaptações e possíveis ajustes de parâmetros. O AM encontrou a solução ótima para todas as instâncias, graças à sua forte busca global, mas sua repetibilidade ainda é inferior à EDB, sendo, então, um método bastante promissor caso seus parâmetros de controle sejam melhor ajustados.

O uso de outros métodos de discretização e a codificação de outros algoritmos projetados para espaços contínuos serão foco de trabalhos futuros. Com o sucesso do AM discretizado, o uso de processamento em espaço contínuo para gerar soluções discretizadas para problemas combinatoriais passa a ser uma diretriz de estudos. A hibridização dos métodos também é uma tendência em métodos heurísticos, gerando, assim, outras vertentes para trabalhos futuros.

\section{Referências}

Beasley, J.E., Algorithms for unconstrained two-dimensional guillotine cutting. Journal of the Operational Research Society, 36:297-306, 1985.

Beasley, J.E., OR-Library: distributing test problems by electronic mail. Journal of the Operational Research Society, 41(11):1069-1072, 1990.

Benítez, C.V.; Parpinelli, R.S. \& Lopes, H.S., Parallelism, hybridism and coevolution in a multi-level ABC-GA approach for the protein structure prediction problem. Concurrency and Computation, 24(6):635-646, 2012.

Chidambaram, C. \& Lopes, H.S., An improved artificial bee colony algorithm for the object recognition problem in complex digital images using template matching. International Journal of Natural Computing Research, 1(2):5470, 2010.

Chu, P.C. \& Beasley, J.E., A genetic algorithm for the multidimensional knapsack problem. Journal of Heuristics, 4(1):63-86, 1998. 
Cordeiro, J.A.; Parpinelli, R. \& Lopes, H., Análise de sensibilidade dos parametros do Bat Algorithm e comparação de desempenho. In: Anais do IX Encontro Nacional de Inteligência Artificial - ENIA. Curitiba, PR: SBC, 2012.

Egeblad, J. \& Pisinger, D., Heuristic approaches for the two- and three-dimensional knapsack packing problem. Computers in Operations Research, 36(4):1026-1049, 2009.

Falcone, M.A.; Lopes, H.S. \& Coelho, L.S., Supply chain optimisation using evolutionary algorithms. International Journal of Computer Applications in Technology, 31(3/4):158-167, 2008.

Freville, A. \& Plateau, G., Hard 0-1 multiknapsack test problems for size reduction methods. Investigación Operativa, 1:251-270, 1990.

Goldberg, D.E., Genetic Algorithms in Search, Optimization and Machine Learning. Boston, USA: Addison-Wesley, 1989.

Holland, J.H., Adaptation in natural and artificial systems: An introductory analysis with applications to biology, control, and artificial intelligence. Ann Arbor, USA: University of Michigan Press, 1975.

Kalegari, D.H. \& Lopes, H.S., A differential evolution approach for protein structure optimisation using a 2D off-lattice model. International Journal of Bio-Inspired Computation, 2(3/4):242-250, 2010.

Karaboga, D. \& Akay, B., A comparative study of artificial bee colony algorithm. Applied Mathematics and Computation, 214:108-132, 2009.

Khuri, S.; Back, T. \& Heitkotter, J., The zero/one multiple knapsack problem and genetic algorithms. In: Proceedings of the 1994 ACM Symposium on Applied Computing. ACM Press, p. 188-193, 1994.

Krause, J.; Cordeiro, J.A.; Parpinelli, R.S. \& Lopes, H.S., A survey of swarm algorithms applied to discrete optimization problems. In: Yang, X.S.; Cui, Z.; Xiao, R. \& Gandomi, A.H. (Eds.), Swarm Intelligence and Bio-Inspired Computation. New York, USA: Elsevier, 2013, a ser publicado.

Krause, J.; Parpinelli, R. \& Lopes, H., Proposta de um algoritmo inspirado em evolução diferencial aplicado ao problema multidimensional da mochila. In: Anais do IX Encontro Nacional de Inteligência Artificial - ENIA. Curitiba, PR: SBC, 2012.

Lima, A.M.M.; Nicolau, A.S.; Oliveira, I.M.S.; Medeiros, J.A.C.C.; Silva, M.H. \& Schirru, R., Computação evolucionária aplicada ao problema da recarga de reatores nucleares. In: Lopes, H.S. \& Takahashi, R.H.C. (Eds.), Computação Evolucionária em Problemas de Engenharia. Curitiba, PR: Omnipax, p. 147-171, 2011.

Lobato, F.S.; Steffen Jr., V. \& Silva Neto, A.J., Resolução de problemas inversos em processos difusivos e transferência radiativa usando o algoritmo de evolução diferencial. In: Lopes, H.S. \& Takahashi, R.H.C. (Eds.), Computação Evolucionária em Problemas de Engenharia. Curitiba, PR: Omnipax, p. 173-195, 2011.

Martello, S. \& Toth, P., Knapsack problems: algorithms and computer implementations. New York, USA: John Wiley \& Sons, 1990.

Mclay, L.A. \& Jacobson, S.H., Algorithms for the bounded set-up knapsack problem. Discrete Optimization, 4(2):206212, 2007.

Price, K.; Storn, R.M. \& Lampinen, J.A., Differential Evolution: A Practical Approach to Global Optimization. Natural Computing Series. New York, USA: Springer-Verlag, 2005.

Storn, R., Differential evolution design of an IIR-filter. In: Proceedings of IEEE International Conference on Evolutionary Computation. p. 268-273, 1996.

Storn, R. \& Price, K., Differential Evolution: A simple and efficient adaptive scheme for global optimization over continuous spaces. Technical Report TR-95-012, International Computer Science Institute, Berkeley University, Berkeley, USA, 1995.

Yang, X.S., Nature-Inspired Metaheuristic Algorithms. 2a edição. Frome, UK: Luniver Press, 2010a.

Yang, X.S., A new metaheuristic bat-inspired algorithm. In: Gonzalez, J.R. (Ed.), Nature Inspired Cooperative Strategies for Optimization. Berlin, Germany: Springer-Verlag, v. 284 de Studies in Computational Intelligence, p. $65-74,2010 \mathrm{~b}$.

\section{Notas Biográficas}

Jonas Krause é graduado em Matemática (Universidade Federal do Paraná, 2005) e especialista em Tecnologia da Informação (IBPEX, 2007). Atualmente é mestrando do Programa de Pós-Graduação em Engenharia e Informática (CPGEI) da Universidade Tecnológica Federal do Paraná (UTFPR).

Heitor Silvério Lopes é graduado em Engenharia Industrial Eletrônica e mestre em Engenharia Biomédica (Universidade Tecnológica Federal do Paraná - UTFPR, 1984 e 1990, respectivamente), e doutor em Engenharia Elétrica (Universidade Federal de Santa Catarina, 1996). Desde 2003 é bolsista de produtividade em pesquisa do CNPq na área de Ciência da Computação, e até o momento concluiu a orientação de 33 mestrandos e 6 doutorandos. Tem interesse em computação evolucionária e métodos bioinspirados com aplicações em problemas de engenharia, otimização, visão computacional e bioinformática, bem como computação de alto desempenho. Atualmente é Professor Associado IV da UTFPR, no câmpus de Curitiba. 


\title{
Transgenética Computacional
}

\author{
Marco César Goldbarg* e Elizabeth Ferreira Gouvêa Goldbarg
}

\begin{abstract}
Resumo: Este capítulo apresenta uma metaheurística evolucionária inspirada em processos naturais nos quais a cooperação é a principal estratégia evolutiva. A técnica introduzida se baseia em duas reconhecidas forças motrizes da evolução natural: a transferência horizontal de genes e a endossimbiose. Os algoritmos transgenéticos simulam interações endossimbióticas entre um hospedeiro e uma população de endossimbiontes a fim de realizar uma busca estocástica no espaço de soluções de problemas de otimização. Os componentes básicos da técnica são ilustrados com um exemplo didático no bem conhecido Problema do Caixeiro Viajante.
\end{abstract}

Palavras-chave: Transgenética computacional, Problema do Caixeiro Viajante, Otimização.

\begin{abstract}
This chapter introduces an evolutionary metaheuristic inspired on natural processes where cooperation is the main evolutionary strategy. The proposed technique is called Computational Transgenetics and is based on two recognized driving forces of natural evolution: the horizontal gene transfer and the endosymbiosis. Transgenetic algorithms simulate endosymbiotic interactions between a host and a population of endosymbionts to perform a stochastic search on the solution space of optimization problems. The basic components of the technique are illustrated with a textbook example in the well known Traveling Salesman Problem.
\end{abstract}

Keywords: Computational transgenetics, Traveling Salesman Problem, Optimization.

\section{Introdução}

A Transgenética Computacional é uma metaheurística evolucionária baseada na evolução endossimbiótica intracelular mutualista. A endossimbiose significa uma relação simbiótica em que uma espécie denominada hospedeiro abriga no interior de seu corpo ou de suas células uma segunda espécie denominada endossimbionte. Quando os endossimbiontes vivem dentro da célula (ou células) do hospedeiro o fenômeno é dito intracelular. Quando este processo de vida embutida se dá entre dois organismos complexos a endossimbiose é denominada extracelular. No caso da endossimbiose beneficiar hospedeiro e endossimbiontes ela é dita mutualista.

A endossimbiose mutualista não é a regra mais comum na natureza para resolver a situação de um condomínio intracelular (Werren et al., 2008). De fato a maioria dos processos endossimbióticos intracelulares ou resultam em prejuízo para o hospedeiro (endossimbiose parasitária) ou são neutros (endossimbiose comensal) (Werren et al., 2008).

O maior obstáculo da constituição de uma unidade intracelular híbrida e funcional é modular o metabolismo das diferentes células do condomínio. Um conflito metabólico intracelular levará, certamente, a extinção de uma das partes ou de toda a unidade. Existindo as pré-condições necessárias para a modulação, o estado da arte afirma que existe a possibilidade de que hospedeiro e endossimbiontes entrem em uma espiral de co-evolução que pode resultar na formação de um novo indivíduo - uma nova espécie.

A integração do endossimbionte ao hospedeiro, caso o condomínio seja viável, é facilitada pela intimidade biológica que cerca o fenômeno. Em rápidas palavras: habitando o citoplasma do hospedeiro os endossimbiontes são expostos à ação dos mecanismos intracelulares do hospedeiro que, naturalmente, são projetados com o objetivo de realizarem movimentação e edição de material genético. Como o endossimbionte habita o citoplasma, as defesas da parede celular já não existem e os mecanismos de movimentação genética do hospedeiro poderão, eventualmente, identificar o endossimbionte como constituinte próprio da célula. Caso os mecanismos do hospedeiro não acabem produzindo efeitos letais para alguma das partes ao movimentar material genético não legítimo, podem produzir uma crescente sincronização metabólica entre hospedeiro e endossimbiontes e a conseqüente reacomodação de funções vitais no condomínio formado. Em

*Autor para contato: marcocgold@gmail.com 
função da demanda ambiental, esta reacomodação funcional poderá produzir vantagens evolucionárias para o endossimbionte (parasitose ou comensalismo) ou para hospedeiro e endossimbionte (mutualismo). Um condomínio biologicamente estável e formado por duas ou mais células geneticamente diferentes - no caso hospedeiro e endossimbiontes - é denominado usualmente de quimera (Cavalier-Smith, 2003).

A Transgenética Computacional é uma abordagem da computação evolucionária que propõe imitar o processo de adaptação endossimbiótica intracelular mutualista. Como tal processo é supostamente capaz de formar novas espécies, diversos autores o entendem como uma forma especial de evolução (Moran et al., 2008). Alguns autores vão mais longe e reconhecem nesta forma de evolução um papel fundamental para a vida (Cavalier-Smith, 2010). O nome Transgenético foi adotado na época da criação da metáfora em virtude de se permitir o uso de plasmídos recombinados para intermediar as trocas de material genético entre hospedeiro e endossimbionte. Na ocasião da proposta da abordagem, o estado da arte em biologia não reconhecia claramente a recombinação de plasmídeos como um caminho natural para a formação de novas espécies, considerando tal via com o pertencente ao contexto da Engenharia Genética.

Recentemente o entendimento sobre a formação de plasmídeos recombinados na endossimbiose intracelular está claramente se alterando (Stewart et al., 2009). Trabalhos atuais comprovam mecanismos naturais em que a recombinação de plasmídeos viabiliza, inclusive, mistura de genes entre diferentes espécies de modo extremamente parecido com os mecanismos artificiais da Engenharia Genética (Hea et al., 2007). Apesar disto o nome da metaheurística foi mantido em virtude dos vários trabalhos anteriormente publicados.

A modulação metabólica é tipicamente um fenômeno intracelular e acontece através de trocas horizontais de material genético. O plano central da modulação metabólica é que ela resulta em um entrelaçamento genético capaz de dividir as funções metabólicas da quimera entre hospedeiro e endossimbiontes (McCutcheon \& Moran, 2010).

O modelo natural da evolução endossimbiótica intracelular mutualista fornece diversos exemplos reais que permitem comprovar que o fenômeno da reprodução do hospedeiro ou do endossimbionte não desempenha o papel principal na evolução metabólica (Gray et al., 2001).

Apenas para ilustrar este embasamento biológico, o processo de adaptação dos endossimbiontes pode, inclusive, independer da reprodução como no caso de endossimbiontes que deixam o hospedeiro no momento da reprodução e o retornam logo a seguir (Dyková et al., 2008). Observe-se também que hospedeiro e endossimbiontes são seres unicelulares, de forma que mesmo sua reprodução natural ocorre por clonagem, sem o emprego de processos de recombinação. Neste caso a reprodução seria simplesmente um hiato no processo de troca genética - que seria retomado, após a reprodução, praticamente no mesmo ponto antes desta ocorrência.

Como o processo de adaptação metabólica não está vinculado aos mecanismos de reprodução e de mutação, a mimetização computacional pode ser desenvolvida através de um conjunto de operadores genéticos diferentes da abordagem clássica. A transgenética está assentada exclusivamente em mecanismos artificiais de troca horizontal de genes.

\section{Fundamentos da Transgenética Computacional}

Basicamente a Teoria da Evolução Endossimbiótica Serial ou Serial Endosymbiotic Theory (SET) explica o surgimento de novas espécies, especialmente unicelulares, através do emprego de mecanismos de endossimbiose intracelular mutualista. Essa teoria remonta seus primeiros trabalhos aos pesquisadores alemães Sachs (1882) e Altmann (1890). Posteriormente o tema também foi articulado por Mereschkowsky (1905). Ivan Wallin em seu livro Symbiogenesis and the Origin of Species publicado em 1926 (Fausto-Sterling, 1993) propõe o que veio a ser conhecido como a teoria da Simbiogênese. Vários autores trabalharam atualmente no tema (McFadden, 2001; Witzany, 2006), todavia a abordagem foi popularizada por Lynn Margulis a partir de 1981 com a divulgação de seu ensaio Symbiosis in Cell Evolution que posteriormente foi incorporado em Margulis (1992).

A SET propõe um processo evolucionário que incorpora a possibilidade de que associações endossimbióticas entre diferentes indivíduos evoluam para formar um único indivíduo (Taylor, 1974; Margulis, 1998, 2004).

A SET afirma que se organismos vivem um dentro do outro por um longo período de tempo, irão certamente trocar genes. O processo pode resultar na fusão das unidades vivas, constituindo-se o que a literatura denomina quimera (Cavalier-Smith, 2003). Nesta nova unidade, as antigas criaturas independentes agora viverão definitivamente associadas, ainda que possam manter suas próprias membranas e, eventualmente, os seus próprios genomas.

O termo endossimbiose também é utilizado na literatura em referência à vida de um organismo complexo dentro de outro organismo, como os vermes vivendo no intestino de hospedeiros. Neste caso a endossimbiose é denominada extracelular. 
O termo serial, que pode ser entendido em português como seqüencial, diz respeito ao fato de que através de uma série de eventos de endossimbiose a célula poderia tornar-se cada vez mais complexa, caracterizando-se um fenômeno de especiação evolutiva.

A endossimbiose intracelular mutualista representa uma situação em que a evolução pode ocorrer fora da árvore filogenética clássica. A teoria responde coerentemente a diversas situações evolucionárias de constatação real, principalmente, entre criaturas mais simples como os eucariotas (Witzany, 2006). A descoberta de organismos que evoluíram segundo o modelo proposto pela SET é considerada uma das maiores contribuições modernas para o entendimento da evolução (Smith \& Szathmáry, 1995).

As perspectivas de que a SET se consolide como uma importante teoria evolucionária parece ser promissora. Recentemente as pesquisas comprovaram a existência de diversas outras associações endossimbióticas intracelulares mutualistas em processo de formação de novos organismos (Dyková et al., 2008).

Em 2009 foi verificado o primeiro caso real de endossimbiose entre dois organismos procariotas. James A. Lake da Universidade da California comprova um caso de endossimbiose procariota com preservação das membranas do procariota endossimbionte dentro do procariota hospedeiro (Lake, 2009).

\section{Mecanismos Intracelulares de THG}

A evolução clássica é realizada principalmente com auxílio de mecanismos de transferência genética que seguem o sentido vertical - que ocorrem entre gerações de uma mesma espécie (como a reprodução sexual, por exemplo). Modernamente a biologia identificou e bem comprovou a existência de poderosos mecanismos de trocas genéticas que ocorrem entre diferentes espécies e sem o uso de reprodução (Koonin et al., 2001).

A Transferência Horizontal de Genes (THG) ou também denominada transferência lateral de genes se refere à aquisição de genes exógenos aos organismos por vias diferentes daquelas que correspondem à herança por reprodução ou transferência vertical (Elsas et al., 2003). Esse tipo de aquisição genética é considerada, atualmente, um mecanismo fundamental para a evolução das espécieis (Gogarten et al., 2002) por fornecer aos organismos acesso a genes específicos que podem enriquecer ou diversificar seu repositório genético (Jain et al., 2003).

A transferência horizontal foi primeiramente descrita em 1951 (Freeman, 1951) para organismos unicelualres. Recentemente a importância da THG foi comprovada também para a evolução de organismos multicelulares e mesmo animais. Gladyshev et al. (2008) e Jain et al. (1999) identificam vários mecanismos que demonstram a atuação e a importância da THG em animais multicelulares (Rumpho et al., 2008).

Como era de se esperar, a THG é realmente dos principais mecanismos atuantes na evolução endosimbiótica (Pierce et al., 2003) e especialmente importante quando esta evolução ocorre no contexto intracelular (Huang et al., 2004). De fato a troca horizontal de genes na endossimbiose é tão importante e peculiar que adquire denominação própria: Transferência Endossimbiótica de Genes (Henze et al., 2001).

A classificação aprofundada dos mecanismos envolvidos na THG escapa, por sua complexidade, ao contexto do presente trabalho. Alguns pesquisadores propõem uma simplificação bastante útil, denominando os vetores (ou agentes) deste transporte horizontal pelo nome genérico de elementos genômicos móveis ou partículas genéticas móveis (Zaneveld et al., 2008). Dois destes elementos são os plasmídeos e os transposons.

Os plasmídeos são anéis de DNA que podem se replicar independente dos cromossomos. Os transposons, ou genes saltitantes (jumping genes), são elementos genéticos que podem mover-se espontaneamente entre diferentes posições de uma molécula de DNA (Nanjundiah, 1996). Os transponsons são seqüências de DNA que fazem parte de outros elementos genéticos como cromossomos ou plasmídeos. Os transposons formam suas seqüências através de dois mecanismos diferentes de edição do DNA. O primeiro permite cortar e colar trechos de DNA (Bouuaert \& Chalmers, 2010) enquanto o segundo executa uma cópia e cola (Choi \& Kim, 2009). A composição dos dois mecanismos de transposição anteriormente descritos pode resultar em um efeito semelhante à execução de permutações entre trechos restritos do DNA (Shapiro, 1999). As permutações podem ocorrer exclusivamente sobre a informação contida no cromossomo ou em composição com informações oriundas de outros microorganismos (como, por exemplo, em composição com informações exógenas codificadas em plasmídeos).

A Figura 1 visa sintetizar os canais que podem ser utilizados no processo de THG (Elsas \& Bailey, 2002), mostrando uma pintura simplificada e geral destas vias, aplicada ao contexto intracelular. O fluxo horizontal no sentido do hospedeiro para os endossimbiontes pode ocorrer através de plasmídios, plasmídios recombinados e vírus. A figura mostra que o processo poderá ser facilmente realimentado no sentido dos endossimbiontes para o hospedeiro pela simples excreção de material genético. Os transposons podem atuar sobre o DNA dos endossimbiontes reorganizando seu código genético.

\section{Algoritmos Transgenéticos}

A criação de Algoritmos Transgenéticos segue quatro diretrizes: 


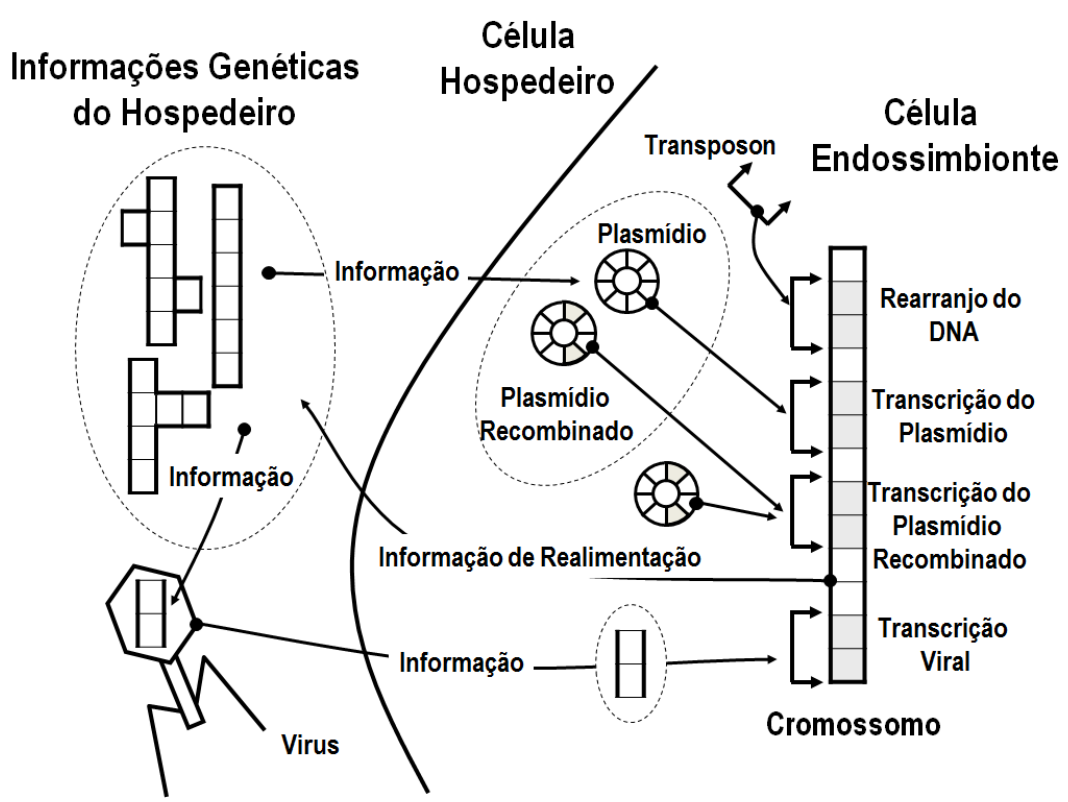

Figura 1. Transferência horizontal intracelular.

\section{A evolução ocorre através de transformações genéticas no interior de uma célula hospedeiro que foi invadida ou que fagocitou outras unidades vivas.}

Para atender a primeira diretriz o processo de evolução dos ATs é organizado através de uma unidade denominada hospedeiro e unidades que habitam o citoplasma do hospedeiro e que serão denominadas de endossimbiontes. Por se tratarem de espécies diferentes, tanto o DNA do hospedeiro quanto o DNA dos endossimbiontes são pré-existentes e independentes. Portanto, o DNA de endossimbiontes e do hospedeiro podem admitir diferentes conteúdos ou formas de representação.

\section{A evolução da quimera formada pelo hospedeiro / endossimbiontes ocorre de forma guiada e influenciada pelo DNA do hospedeiro.}

As soluções do problema que está sendo solucionado são representadas através dos endossimbiontes. Já o repositório genético do hospedeiro pode representar outros tipos de informações a cerca do problema. As informações do hospedeiro podem ser codificadas de forma semelhante à codificação utilizada nos endossimbiontes ou não. A população inicial de endossimbiontes pode ser formada através de estratégias semelhantes às empregadas para a formação da população inicial dos algoritmos genéticos. O hospedeiro, todavia, poderá possuir informações obtidas a priori do desenvolvimento do processo evolucionário. A obtenção de informações a priori não é condição indispensável para o funcionamento da metaheurística todavia, contrariamente ao paradigma clássico, representa o melhor alinhamento para a mimetização biológica proposta. No modelo natural o hospedeiro possui informações genéticas que influenciam fortemente na transformação dos endossimbiontes. Imitando o processo natural que otimiza o DNA dos endossimbiontes através da eliminação das funções redundantes com as do hospedeiro (Wernegreen, 2005), o processo artificial busca a melhoria de adequação dos cromossomos artificiais. Ao final do processo os endossimbiontes serão considerados absorvidos pelo hospedeiro, caracterizando-se pelo melhor valor de adequação alcançado. Diferentemente dos algoritmos endossimbióticos clássicos, ao desenvolver a mimetização da endossimbiose intracelular o modelo transgenético não realiza divisão das variáveis do problema entre hospedeiro e endossimbionte. Os endossimbiontes representam soluções completas do problema. O hospedeiro é um repositório genético diversificado e responsável pelo guiamento da busca.

\section{O processo de troca de informações genéticas necessário à evolução é realizado exclusivamente através de mecanismos de transferência horizontal de genes.}

A troca de informação genética que resultará na modulação metabólica é realizada através de vetores que mimetizam os processos naturais de THG. Os vetores da transgenética mais usuais são os plasmídeos, transposons e plasmídeos recombinados.

Como conseqüência das diretrizes anteriores os ATs pressupõem a interação de três contextos: 
- Uma população de cromossomos, denominados cromossomos endossimbiontes.

- Um hospedeiro que possui informações capazes de influenciar a evolução da população de cromossomos endossimbiontes.

- Uma população de vetores, ditos vetores transgenéticos, que transportam informação do hospedeiro para os cromossomos endossimbiontes, alterando os códigos dos endossimbiontes, e por conseqüência, promovendo a variação necessária ao processo de busca.

Observe-se que a população de vetores é volátil. Estes elementos podem ser criados, preservados ou destruídos livremente ao longo do processo evolucionário.

O processo evolucionário é realimentado na medida em que emergem novas e melhores soluções na população de endossimbiontes. A realimentação pode alcançar o repositório do hospedeiro. A realimentação mimetiza o processo de excreção e reaproveitamento de material genético típico de muitos microorganismos (Matsui et al., 2003).

Com já ressaltado anteriormente, o processo transgenético não necessariamente exige a reprodução dos endossimbiontes ou do hospedeiro. A dispensa do exame da reprodução da quimera se dá em virtude do fato de que o mecanismo evolucionário prevalente deste tipo de evolução está fundamentado na troca de informações entre hospedeiro e endossimbiontes.

A reprodução independente dos endossimbiontes e a reprodução do hospedeiro (com a respectiva reprodução dos endossimbiontes associados) não são proibidas pela endossimbiose intracelular mutualista natural. Verifica-se, entretanto, que os casos reais apontam para sua ocorrência apenas em situações iniciais do processo de formação da quimera, onde a absorção do endossimbionte ainda não se caracterizou.

Como conseqüência da terceira diretriz, são os vetores transgenéticos que promovem tanto o esforço de diversificação quanto o de intensificação da busca algorítmica.

As informações a priori no caso da evolução artificial podem ser obtidas a partir de algum conhecimento prévio sobre o problema tais como, limites inferiores ou superiores, soluções heurísticas, resultados de análise estatística do problema, entre outros. Já as informações a posteriori emergem durante o processo de evolução artificial.

A mimetização da transgenética possui um modelo natural que pode bem representar o seu processo evolucionário. Trata-se do Paramecium Aurélia e seus endossiombiontes Kappa (Stevenson, 1972). A Figura 2 exemplifica o mapeamento da metáfora da endossimbiose intracelular mutualista e a abordagem da Transgenética Computacional.

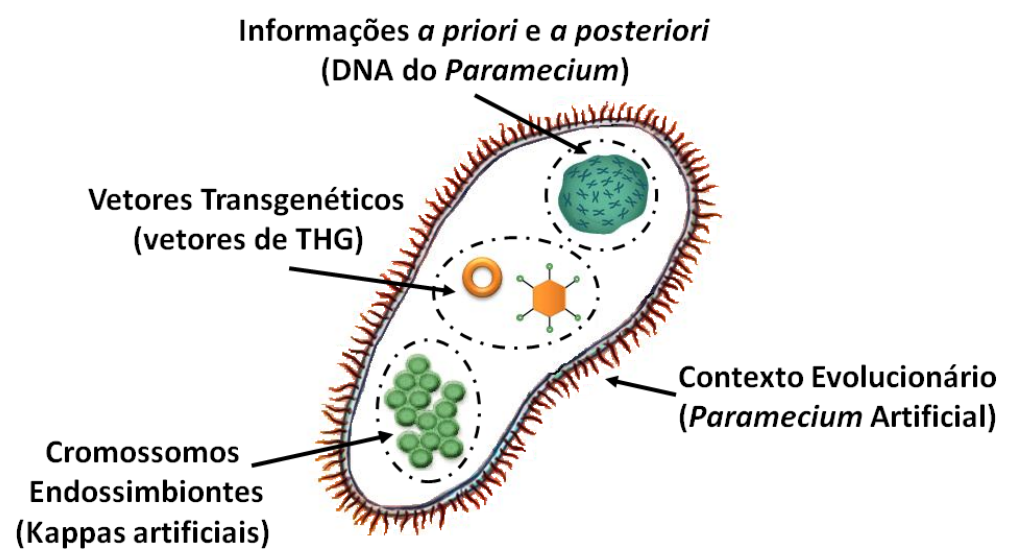

Figura 2. A mimetização da Transgenética Computacional.

\section{Formalização dos Algoritmos Transgenéticos}

Um vetor transgenético, $\lambda$, é uma tripla $\lambda=\left(I, \Phi^{\lambda}, \Delta^{\lambda}\right)$, onde $I$ é a informação transportada, $\Phi^{\lambda}$ é o método através do qual o vetor $\lambda$ manipula o cromossomo alvo e $\Delta^{\lambda}$ é o método utilizado pelo vetor $\lambda$ para obter a informação $I$.

Denomina-se manipulação do cromossomo Crom qualquer alteração de seu DNA causada por força da atuação de um vetor transgenético $\lambda$. Uma manipulação resulta sempre em uma alteração do DNA. Uma manipulação pode ser realizada através da transcrição de uma cadeia de DNA previamente conhecida sobre a cadeia de DNA de Crom ou pelo rearranjo de genes no DNA de Crom. 
O método $\Phi^{\lambda}$ é composto por um conjunto de procedimentos, isto é, $\Phi^{\lambda}=\left\{p_{1}, \ldots, p_{r}\right\}$, onde $\Phi^{\lambda} \subseteq P^{*}$ e $P^{*}=\left\{p_{j}\right\}, j=1, \ldots, s$ representa o conjunto de todos os $s$ possíveis procedimentos de manipulação. O método $\Phi^{\lambda}$ define como o vetor realiza a manipulação do DNA do endossimbionte.

Um vetor não realiza uma manipulação em um cromossomo sem antes avaliar a viabilidade desta ação. Essa sondagem é denominada ataque. A sondagem pode avaliar, por exemplo, o valor da adequação do cromossomo após sofrer a manipulação. Contudo a sondagem pode utilizar qualquer outra métrica de avaliação.

Quando o resultado da simulação da manipulação aponta para a viabilidade desta manipulação, o ataque é dito bem sucedido e a função que mede a eficiência do ataque - $A()$, recebe o valor verdadeiro. No caso de um ataque de um plasmídeo, plasmídeo recombinado ou vírus obter sucesso, a manipulação é expressa através da transcrição da cadeia de informação no DNA do endossimbionte. Por outro lado, a manipulação do transposon resulta em rearranjo do DNA. Os métodos de transcrição de cada vetor serão exemplificados na seção 6 .

O fluxo de informações genéticas no sentido do hospedeiro para o endossimbionte é sempre composto por cadeias de DNA. As manipulações dos transposons ocorrem também sempre em trechos limitados do código do endossimbionte. A Figura 2 deixa claro o fato de que as informações do hospedeiro não necessitam ser codificadas no mesmo formato da codificação dos cromossomos endossimbiontes.

O método $\Delta^{\lambda}$ é composto por um conjunto de procedimentos que definem como o vetor $\lambda$ obtém sua cadeia de informação $I$. Esses procedimentos são muito flexíveis. Como podem envolver uma série de decisões específicas, não são formalizados da mesma forma que os procedimentos de transcrição ou rearranjo de genes.

A Tabela 1 resume os procedimentos de manipulação mais comuns da transgenética computacional.

Tabela 1. Procedimentos utilizados pelos vetores transgenéticos.

\begin{tabular}{ll}
\hline Procedimento & Caracterização \\
\hline$p_{1}$ - Ataque $(A)$ & Define o critério de avaliação que estabelece quando \\
& um cromossomo, Crom, é suscetível à manipulação \\
& de um vetor transgenético, $\lambda$. $A:($ Crom, $\lambda) \rightarrow$ \\
& $\{$ falso, verdadeiro $\}$ \\
& Se $A($ Crom, $\lambda)=$ verdadeiro, o procedimento define \\
$p_{2}-$ Transcrição $(\Gamma)$ & como a informação $I$, transportada pelo vetor será \\
& transferida (transcrita) para o cromossomo. \\
$p_{3}-$ Bloqueio / Desbloqueio da Transcrição & $\begin{array}{l}\text { Torna o resultado da manipulação inviolável por um } \\
\text { determinado período de tempo - número de iterações, }\end{array}$ \\
& gerações de cromossomos, etc. \\
& Identifica posições que serão utilizadas para limitar a \\
& operação do vetor.
\end{tabular}

Ao concretizar uma manipulação em um cromossomo - Crom, o vetor transgenético alterará o código de Crom e, por conseqüência, provavelmente alterará sua adequação. Assim, o resultado da alteração na adequação do cromossomo decorrente de uma manipulação em potencial é uma métrica que permite avaliar a atratividade desta operação. A operação que avalia o resultado de uma manipulação de um vetor transgenético é denominada ataque e representada por $A()$. Se $A(C r o m, \lambda)=$ verdadeiro, significa que a manipulação do vetor $\lambda$ sobre o cromossomo Crom pode ser concretizada. Caso $A($ Crom, $\lambda)=$ falso, significa que o cromossomo resiste à manipulação do vetor e esta operação não deverá ser concretizada. Em uma analogia à terminologia empregada pela microbiologia são definidos vários tipos de vetores transgenéticos, dentre eles destacam-se os plasmídeos, plasmídeos recombinados, transposons e vírus.

Os vetores transgenéticos são descritos na Tabela 2.

Um vetor $\lambda$ é dito um vírus quando sua cadeia de informação $I$ é descrita no mesmo formato que os cromossomos endossimbiontes (uma subcadeia de DNA) e o seu método utiliza os procedimentos $p_{1}, p_{2}$ e $p_{3}$. De forma simplificada, os vírus transcrevem uma cadeia de DNA nos cromossomos endossimbiontes e marcam a cadeia de forma que ela não possa ser alterada durante um dado número de iterações do algoritmo.

Um vetor $\lambda$ é dito um plasmídeo quando sua cadeia de informação $I$ é descrita no mesmo formato que os cromossomos endossimbiontes, uma subcadeia de DNA, e seu método emprega os procedimentos $p_{1}$ e $p_{2}$. De forma simplificada, os plasmídeos transcrevem uma cadeia de DNA nos cromossomos endossimbiontes sem marcar a cadeia como inviolável durante um dado número de iterações do algoritmo. Os plasmídeos podem possuir os mesmos operadores de transcrição de um vírus com exceção do fato de nunca portarem o procedimento $p_{3}$. 
Tabela 2. Definição dos vetores transgenéticos.

\begin{tabular}{|c|c|c|c|}
\hline Vetor & Método $\Psi^{\lambda}$ & Método $\Delta^{\lambda}$ & $\begin{array}{ll}\text { Tipo } & \text { da } \\
\text { Informação }(I)\end{array}$ \\
\hline Vírus & $\Psi^{V}=\left(p_{1}, p_{2}, p_{3}\right)$ & $\begin{array}{l}\text { Forma a cadeia no } \\
\text { DNA do hospedeiro }\end{array}$ & Trecho de DNA \\
\hline Plasmídeo & $\Psi^{P}=\left(p_{1}, p_{2}\right)$ & $\begin{array}{l}\text { Forma a cadeia no } \\
\text { DNA do hospedeiro }\end{array}$ & Trecho de DNA \\
\hline Plasmídeo Recombinado & $\Psi^{P R}=\left(p_{1}, p_{2}\right)$ & $\begin{array}{l}\text { Forma a cadeia de } \\
\text { DNA através de ações } \\
\text { heurísticas }\end{array}$ & Trecho de DNA \\
\hline Transposon & $\Psi^{V}=\left(p_{1}, p_{2}, p_{4}\right)$ & $\begin{array}{l}\text { Formado por uma } \\
\text { vizinhança de busca }\end{array}$ & $\begin{array}{l}\text { Intervalo de busca e } \\
\text { método de exame da } \\
\text { vizinhança }\end{array}$ \\
\hline
\end{tabular}

Um vetor $\lambda$ é dito um plasmídeo recombinado quando sua cadeia de informação $I$ é descrita no mesmo formato que os cromossomos endossimbiontes, uma subcadeia de DNA, e seu método de manipulação emprega os procedimentos $p_{1}$ e $p_{2}$. No sentido do método de transcrição e do formato de representação da cadeia de informação transportada um plasmídeo e um plasmídeo recombinado são exatamente iguais. Os plasmídeos diferenciam-se dos plasmídeo recombinados no modo que obtém a sua cadeia de informação. Os plasmídeos obtêm sua cadeia diretamente de uma fonte de DNA residente no hospedeiro através de cópia. Os plasmídeos recombinados podem mesclar ou concatenar cadeias de informação obtidas de mais de uma fonte do DNA do hospedeiro, bem como formar a cadeia ou parte dela também através de procedimentos construtivos ou heurísticos.

Um vetor $\lambda$ é dito transponson quando sua informação $I$ é um Intervalo de busca ou um método de exame da vizinhança. Os transposons utilizam os procedimentos $p_{1}, p_{2}$ e $p_{4}$. O método de manipulação dos transposons comporta examinar o rearranjo sistemático de certos trechos do DNA dos endossimbionte, trechos demarcados pelo seu identificador de posição $(\Lambda)$. Os transposons transportam regras de recombinação do DNA. Atuam somente em trechos selecionados do DNA, não representando tipicamente um procedimento de busca local. O Algoritmo 1 descreve a arquitetura geral de um AT.

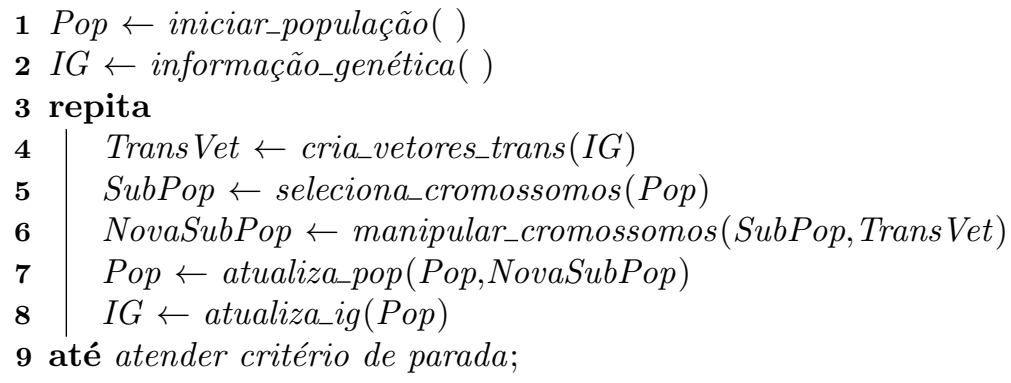

Algoritmo 1: Algoritmo Transgenético - arquitetura genérica.

O passo 1 cria a população de cromossomos endossimbiontes, Pop. O passo 2 carrega as informações genéticas a priori - $(I G)$ no hospedeiro. Observar que tanto a população de endossimbiontes quanto as informações ditas a priori também podem ser constituídas de forma aleatória. A evolução transgenética é beneficiada com informações a priori de boa qualidade, todavia sua ausência não impede o processo. No passo 3 são criados os vetores transgenéticos que irão atuar sobre a população. O procedimento cria_vetores_trans define a quantidade, tipo método e informação transportada pelos vetores. O passo 5 seleciona um subconjunto de cromossomos da população, SubPop, que serão alvo do ataque dos vetores transgenéticos. No passo 6 o procedimento manipular_cromossomos() implementa a manipulação dos cromossomos de SubPop pelos vetores em TransVet e atualiza NovaSubPop com o resultado obtido. No passo 7 a população corrente Pop é atualizada com os cromossomos manipulados. Se alguma informação julgada significativa é criada durante a manipulação dos cromossomos endossimbiontes, esta informação é preservada no repositório das informações genéticas do hospedeiro no passo 8 . 


\section{Exemplo de Constituição de um Algoritmo Transgenético}

Para exemplificar o processo de projeto e desenvolvimento de um algoritmo transgenético será examinada uma aplicação deste algoritmo na solução do clássico problema do Caixeiro Viajante. O problema do Caixeiro Viajante (PCV) é um dos clássicos problemas da otimização combinatória, consistindo em determinar em um grafo ponderado $G=(N, M)$ onde $N=1, \ldots, n$ representa o conjunto de vértices do grafo e $M=1, \ldots, m$ o conjunto de arestas, um ciclo Hamiltoniano de menor custo. O PCV é NP-Difícil (Garey \& Johnson, 1979), sendo um dos problemas de otimização combinatória mais intensamente pesquisados. A Figura 3(a) apresenta um grafo ponderado representando uma instância do Problema do Caixeiro Viajante.

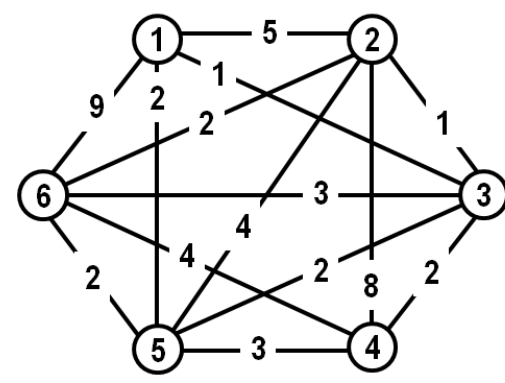

(a)

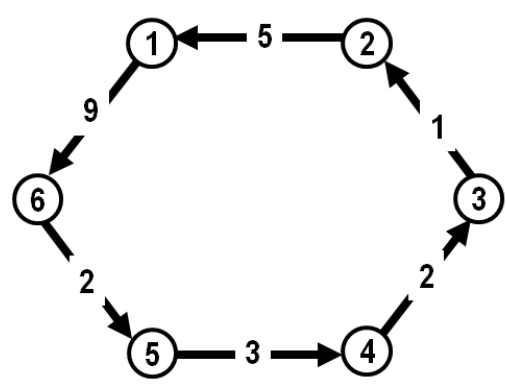

(b)

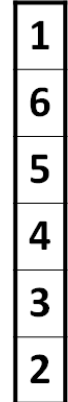

(c)

Figura 3. Grafo do exemplo numérico e o cromossomo da solução.

A Figura 3(b) exibe uma solução viável e o cromossomo associado é mostrado na Figura 3(c). Os endossimbiontes representarão, no presente exemplo, soluções viáveis do Caixeiro Viajante. O objetivo do processo evolucionário será minimizar o valor do ciclo associado a cada cromossomo.

\subsection{DNA do hospedeiro}

No caso do Caixeiro Viajante existem várias estruturas em um grafo $G=(N, A)$ que podem ser úteis na formação de um ciclo hamiltoniano mínimo em $G$. Dentre elas destacam-se os caminhos mais curtos entre pares de vértices em $G$, a árvore geradora mínima de $G$ e arborescências minimais. A Figura 4 exemplifica duas destas estruturas. A Figura 4(a) mostra uma árvore e o cromossomo associado e a (b) mostra um caminho e o cromossomo associado.

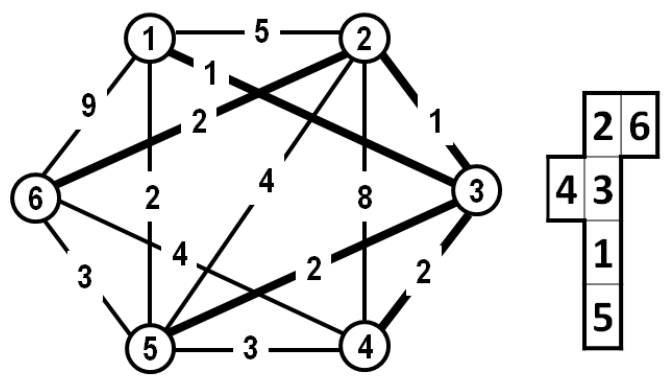

(a)

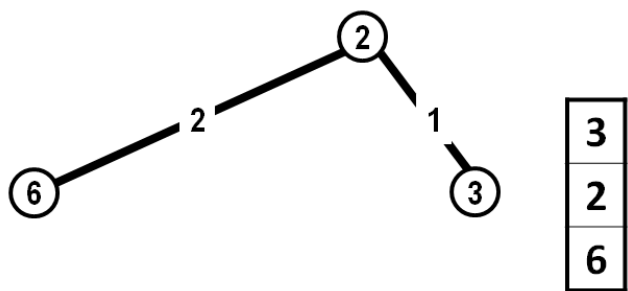

(b)

Figura 4. Exemplo de fontes de informação a priori.

Obter as informações a priori da Figura 4 exigem baixo investimento computacional. A Figura 5 exemplifica como estas informações podem ser compostas no DNA do hospedeiro.

O DNA do hospedeiro conterá informações de realimentação derivadas da população de endossimbiontes como o ciclo 1 e o ciclo 2 .

\subsection{Transcrição dos plasmídeos/plasmídeos recombinados/vírus}

A Figura 6 mostra como a árvore 1 pode gerar um plasmídeo e como este plasmídeo pode ser transcrito em um endossimbionte que represente uma solução do Caixeiro Viajante. Neste caso o operador do plasmídeo 


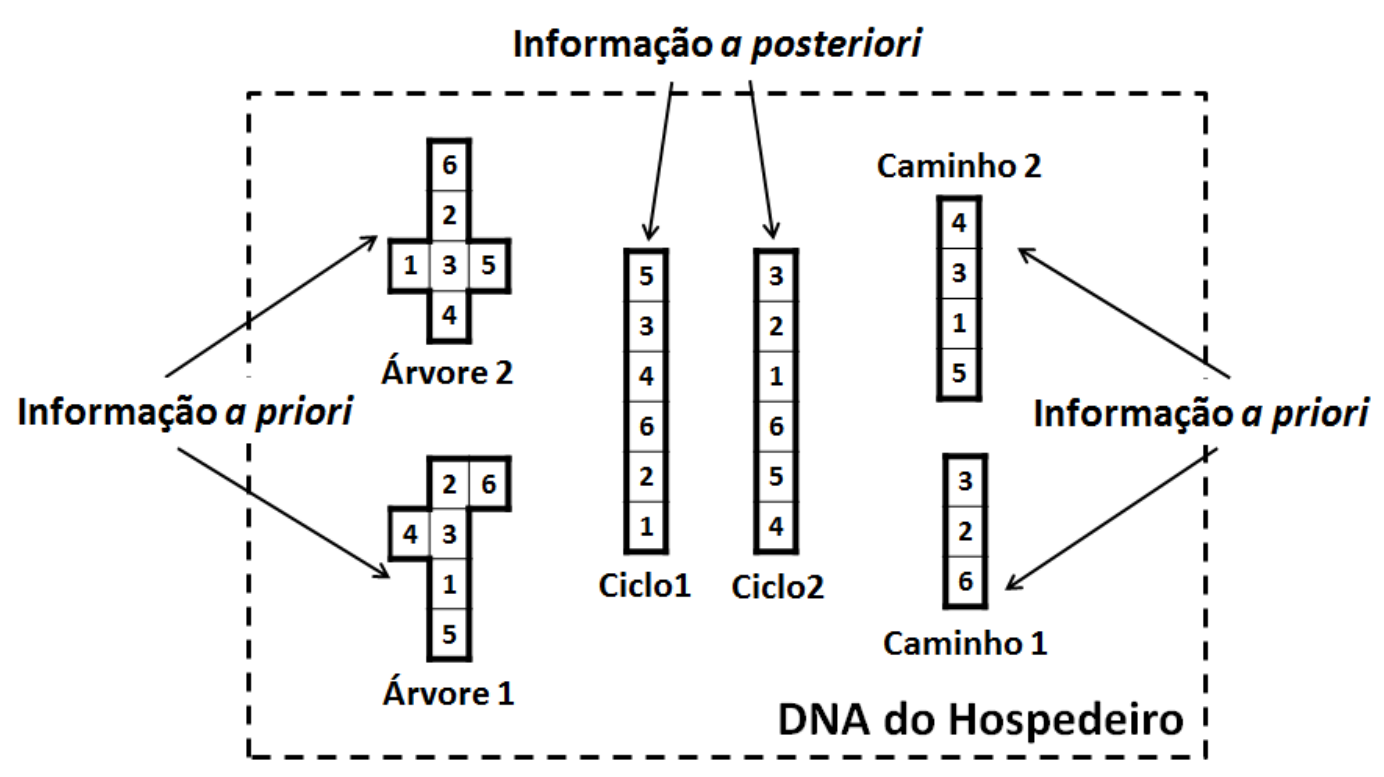

Figura 5. Exemplo de conteúdo genético no DNA do hospedeiro.

insere a cadeia a partir de um alelo do cromossomo que represente uma das cidades da cadeia do plasmídeo um alelo compartilhado ou também chamado de alelo emparelhando. No exemplo, o alelo escolhido foi o que corresponde a cidade 6. O operador de inserção transcreve os alelos da cadeia de informação do plasmídeo a partir do alelo emparelhado. Assim, será necessário reparar o cromossomo de forma a torná-lo novamente viável. Isso se processa, por exemplo, transcrevendo as cidades cujos alelos foram ocupados pelos da cadeia do plasmídeo, na posição em que estas cidades se encontravam anteriormente no cromossomo. Exemplificando no caso: como a transcrição posicionou a cidade 5 do plasmídeo sobre a cidade 2 do cromossomo, a cidade 2 do cromossomo é transcrita sobre a posição da cidade 5 no cromossomo. Ao lado do cromossomo transcrito, a Figura 6 exibe a correspondente solução no grafo $G$.

A transcrição do plasmídeo recombinado é processada de forma semelhante. A transcrição dos vírus é igual a dos plasmídeos, todavia torna a cadeia transcrita inviolável por um dado número de iterações do algoritmo. Observar que na transgenética computacional as iterações do processo de troca de informações genéticas não podem ser denominadas de gerações. Hospedeiro e endossimbiontes não nascem ou morrem.

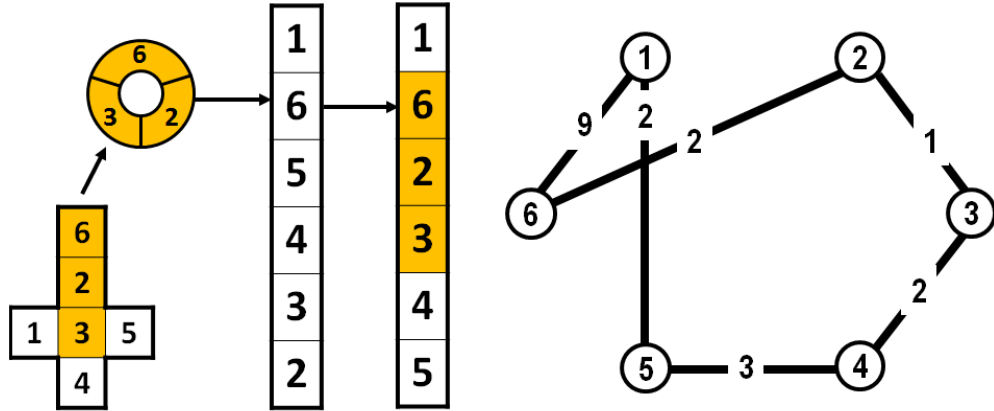

Figura 6. Exemplo de uma transcrição de um plasmídeo.

\subsection{Manipulação dos transposons}

Um transposon natural pode copiar trechos de DNA e também cortar o DNA e remover o trecho cortado. Tanto a escolha do fragmento de DNA como o ponto de transcrição são quimicamente regulados por outros mecanismos intracelulares. Na versão artificial proposta pela transgenética, este vetor intracelular examina várias reconfigurações de um dado trecho do cromossomo e concretiza a configuração que atender (ou melhor atender) aos critérios de julgamento que forem definidos no algoritmo. Portanto, uma interpretação possível para este vetor, quando consideradas as técnicas conhecidas de busca algorítmica, é o de uma busca local restrita ao trecho de atuação do vetor. 
A Figura 7(a) exemplifica, parcialmente, o exame de configurações que é desenvolvido por um transposon que baseia seu processo de rearranjo genético em um operador do tipo shift. A Figura 7(b) mostra o transposon aplicado ao exemplo e a Figura 7(c) mostra a solução associada à transcrição, o custo desta solução é 17 . As posições do DNA fora de sua região de atuação não são alteradas. Noticia-se que são possíveis diversos tipos de transposons.

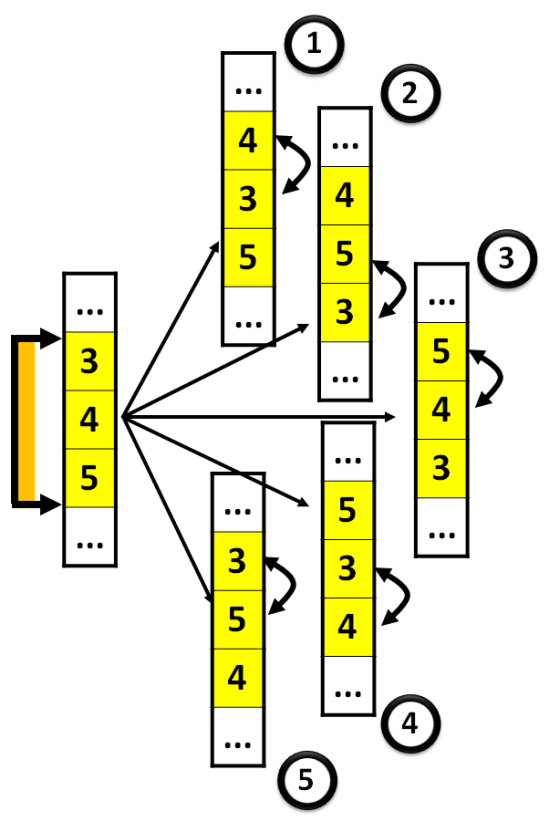

(a)

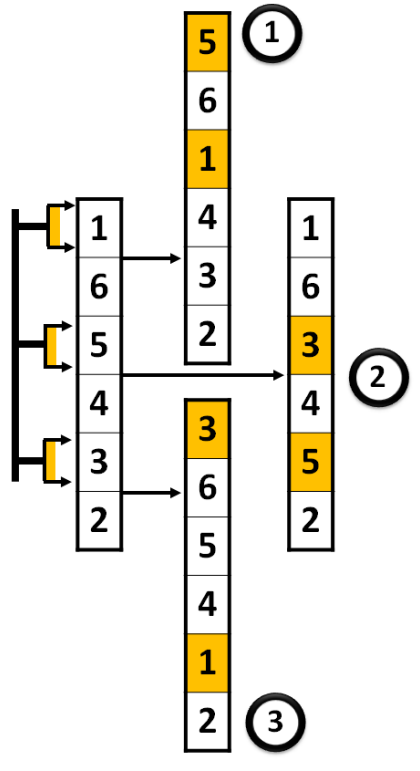

(b)

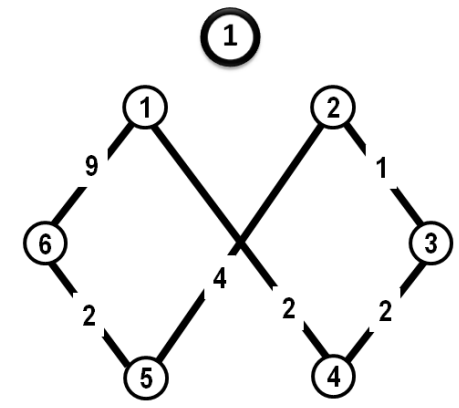

(c)

Figura 7. Transposon e sua forma de transcrição.

Os transposons são exclusivamente dedicados à adaptação do código dos endossimbiontes. Os plasmídeos e os vírus, por outro lado, são plataformas exclusivamente dedicadas às trocas de informações.

Quando existem fortes motivos para que uma informação seja preservada - indicação provável de sua pertinência à solução ótima, por exemplo, o vetor mais indicado para ser utilizado é o vírus, pois realiza transcrições no DNA que não podem ser facilmente alteradas pelos demais mecanismos intracelulares. Os plasmídios recombinados permitem a introdução de diversificação no repositório genético da quimera sem a necessidade de procedimentos de mutação. Os plasmídeos recombinados permitem, por exemplo, que procedimentos heurísticos de construção de cadeias de DNA sejam mesclados com DNA já existente. Em última análise este vetor garante a introdução de novas informações genéticas cuidando para minimizar a introdução de lixo genético.

\section{Aplicações}

A transgenética demonstrou ser uma fonte inspiradora de algoritmos eficientes para diversas aplicações. Os seguintes temas na área do petróleo e gás foram motivo de pesquisa:

1. O Problema do Passeio do Pistoneio (Goldbarg et al., 2006a);

2. O Passeio do Pistoneio Dinâmico (Goldbarg et al., 2010);

3. O Problema de Otimização dos Diâmetros das Malhas Urbanas de Distribuição de Gás Natural (Goldbarg et al., 2004a);

4. O Problema de Localização de Poços e Manifolds em Campos Submarinos de Petróleo (Goldbarg et al., $2002 b)$;

5. O Problema de Programação de Sondas de Produção Terrestre (Goldbarg et al., 2002a);

6. O Problema de Elevação de Petróleo por Injeção de Gás (Castro et al., 2002).

Nas seguintes aplicações a transgenética logrou obter, conclusivamente, os melhores resultados da literatura na ocasião de sua publicação: 
1. Otimização do Dobramento de Proteínas (Almeida et al., 2007);

2. O Problema do Caixeiro Comprador Biobjetivo (Almeida et al., 2012);

3. Árvore Geradora Biobjetivo (Monteiro et al., 2009);

4. O Problema do Caixeiro Comprador (Goldbarg et al., 2009a);

5. Prize Collecting Steiner Tree Problem (Goldbarg et al., 2008).

Nas aplicações que se seguem a Transgenética Computacional obteve resultados promissores:

1. O Problema Quadrático de Alocação (Goldbarg \& Goldbarg, 2002);

2. O Problema de Coloração em Grafos (Goldbarg et al., 2001);

3. O Problema do Caixeiro Viajante (Goldbarg et al., 2003);

4. O Problema do Flow-Shop de Permutação (Goldbarg et al., 2004b);

5. O Problema da Configuração de um Serviço de Distribuição de Vídeo Baseado em Replicação Móvel (Leite et al., 2004);

6. O Problema de Otimização de Configurações em Sistemas de Co-Geração (Goldbarg et al., 2005);

7. O Problema do Posicionamento de Sementes Radioativas no Tratamento de Câncer de Próstata (Goldbarg et al., 2006b);

8. Posicionamento de Beams em Radioterapia Conformal 3D (Goldbarg et al., 2009b);

9. O Problema do Caixeiro Alugador (Asconavieta et al., 2011).

\section{Conclusões}

Os Algoritmos Transgenéticos introduzem uma nova forma de evolução artificial baseada na mimetização da endossimbiose intraelular mutualista. Esse tipo de evolução tende a formar um ser vivo híbrido - uma quimera - derivado da união entre um hospedeiro e endossimbiontes invasores do citoplasma do hospedeiro. O processo adaptativo é guiado pela necessidade de harmonizar o metabolismo dos componentes da quimera.

Nesta forma de evolução a reprodução e as mutações desempenham papeis diferentes daqueles desempenhados na evolução baseada na reprodução sexual. A recombinação da informação genética entre hospedeiro e endossimbiontes ocorre de forma a reaproveitar e preservar ao máximo a informação genética pré-existente.

O método utilizado para organizar e conduzir o processo evolucionário transgenético permite novos insightspara a constituição de algoritmos evolucionários. A arquitetura da transgenética torna possível, de um modo simples, a composição evolucionária de diferentes tipos de informações associadas ao problema a ser solucionado.

\section{Agradecimentos}

Os autores agradecem o apoio do CNPq a várias pesquisas no tema nos projetos 300778/2010-4 e 302819/20118.

\section{Referências}

Almeida, C.P.; Goldbarg, E.F.G.; Gonçalves, R.A.; Delgado, M.R. \& Goldbarg, M.C., TA-PFP. a transgenetic algorithm to solve the protein folding problem. In: Proceedings of ISDA'07 'th International Conference on Intelligent System Design and Application. Rio de Janeiro, p. 163-168, 2007.

Almeida, C.P.; Gonçalves, R.A.; Goldbarg, E.F.G.; Goldbarg, M.C. \& Delgado, M.R., An experimental analysis of evolutionary heuristics for the biobjective traveling purchaser problem. Annals of Operation Research, (1):305-341, 2012.

Altmann, R., Die Elementarorganismen und ihre Beziehungen zu den Zellen. Leipzig: Verlag von Veit \& Comp., 1890. Asconavieta, P.H.S.; Goldbarg, M.C. \& Goldbarg, E.F.G., Evolutionary algorithm for the car renter salesman. In: Proceedings of IEEE CEC 2011 Congress on Evolutionary Computation. New Orleans, p. 593-600, 2011.

Bouuaert, C.C. \& Chalmers, R.M., Gene therapy vectors: the prospects and potentials of the cut-and-paste transposons. Genetica, 138(5):473-484, 2010. 
Castro, M.; Goldbarg, E.F.G. \& Goldbarg, M.C., Gas lift optimization problem: a transgenetic approach. In: Proceedings of 17th World Petroleum Congress. Rio de Janeiro, RJ, 2002.

Cavalier-Smith, T., Genomic reduction and evolution of novel genetic membranes and protein-targeting machinery in eukaryote-eukaryote chimaeras (meta-algae). Philosophical Transactions of the Royal Society of London Series B Biological Sciences, 358(1429):109-133, 2003.

Cavalier-Smith, T., Origin of the cell nucleus, mitosis and sex: roles of intracellular coevolution. Biology Direct, $5(7): 1-78,2010$.

Choi, K.H. \& Kim, K.J., Applications of transposon-based gene delivery system in bacteria. Journal of Microbiology and Biotechnology, 19(3):217-228, 2009.

Dyková, I.; Fiala, I. \& Pecková, H., Neoparamoeba spp. and their eukaryotic endosymbionts similar to Perkinsela amoebae (hollande, 1980): Coevolution demonstrated by SSU rRNA gene phylogenies. European Journal of Protistology, 44(4):269-277, 2008.

Elsas, J.D.V. \& Bailey, M.J., The ecology of transfer of mobile genetic elements. FEMS Microbiology and Ecology, 42(2):187-197, 2002.

Elsas, J.D.V.; Turner, S. \& Bailey, M.J., Horizontal gene transfer in the phytosphere. New Phytologist, 157(3):525-537, 2003.

Fausto-Sterling, A., Is nature really red in tooth and claw? Discover, 14:24-27, 1993.

Freeman, V.J., Studies on the virulence of bacteriophage-infected strains of Corynebacterium diphtheria. Journal of Bacteriology, 61(6):675-688, 1951.

Garey, M. \& Johnson, D., Computers and Intractability: A Guide to the Theory of NP-completeness. New York, USA: W. H. Freeman \& Co., 1979.

Gladyshev, E.A.; Meselson, M. \& Arkhipova, I.R., Massive horizontal gene transfer in bdelloid rotifers. Science, 320(5880):1210-1213, 2008

Gogarten, J.P.; Doolittle, W.F. \& Lawrence, J.G., Prokaryotic evolution in light of gene. Molecular Biology and Evolution, 19(12):2226-2238, 2002.

Goldbarg, E.F.G.; Castro, M.P. \& Goldbarg, M.C., Transgenetic algorithm for the gas network pipe sizing problem. In: Proceedings of the Brazilian Symposium on Neural Networks. São Luís, MA, 2004a.

Goldbarg, E.F.G.; Goldbarg, M.C. \& Costa, W.E., A transgenetic algorithm for the permutation flow-shop sequencing problem. WSEAS Transactions on Systems, 3(1):40-45, 2004b.

Goldbarg, E.F.G.; Goldbarg, M.C. \& Schmidt, C.C., A hybrid transgenetic algorithm for the prize collecting steiner tree problem. Journal of Universal Computer Science, 14(15):2491-2511, 2008.

Goldbarg, M.C.; Bagi, L.B. \& Goldbarg, E.F.G., Transgenetic algorithm for the traveling purchaser problem. European Journal of Operational Research, 119(1):36-45, 2009a.

Goldbarg, M.C.; Duarte, H.M. \& Goldbarg, E.F.G., Algoritmo transgenético para a solução do problema do passeio do pistoneio. In: Annals of XIII CLAIO Latin Iberoamerican Operations Research Conference. Montevideo, Uruguay, $2006 \mathrm{a}$.

Goldbarg, M.C.; Duarte, H.M. \& Goldbarg, E.F.G., Transgenetic algorithm for the periodic mobile piston pump unit routing problem with continuous oil replenishment. International Journal of Innovative Computing and Applications, 2(4):203-214, 2010.

Goldbarg, M.C. \& Goldbarg, E.F.G., Transgenética computacional: uma aplicação ao problema quadrático de alocação. Pesquisa Operacional, 22(3):359-386, 2002.

Goldbarg, M.C.; Goldbarg, E.F.G. \& Costa, W.E., Algorimos evolucionários na solução do problema de otimização do emprego de sondas de produção em poços de petróleo. In: XXXIV Simpósio Brasileiro de Pesquisa Operacional SBPO. Rio de Janeiro, RJ, 2002a.

Goldbarg, M.C.; Goldbarg, E.F.G.; Mendes, C.R.A.; F. S. L. N. Araújo, N.M.O. \& Corso, G., Algoritmo evolucionário para otimização do plano de tratamento em radioterapia conformal 3D. Pesquisa Operacional, 29(2):239-267, 2009b.

Goldbarg, M.C.; Goldbarg, E.F.G. \& Neto, F.D.M., Algoritmos evolucionários na determinação da configuração de custo mínimo de sistemas de co-geração de energia com base no gás natural. Pesquisa Operacional, 25(2):231-259, 2005.

Goldbarg, M.C.; Goldbarg, E.F.G. \& Ramos, I.C.O., A ProtoG algorithm applied to the traveling salesman problem. WSEAS Transactions on Computers, 2(2):299-304, 2003.

Goldbarg, M.C.; Gouvêa, E.F. \& Silva, L.M., Extra-intracellular transgenetic algorithm applied to the graph coloring problem. In: Annals of the Fourth Metaheuristics International Conference. Porto, p. 321-326, 2001.

Goldbarg, M.C.; Gouvêa, E.F. \& Souza, C.M.P., An evolutionary approach to the manifolds and wells placement problem in offshore fields. In: Annals of XI Latin-Iberian American Congress of Operations Research. Concepción, Chile, 2002b.

Goldbarg, M.C.; Jesus, R.M.C.S. \& Goldbarg, E.F.G., Algoritmo viral no planejamento de braquiterapia de alta dose. In: Workshop em Informática Médica - V Simpósio Brasileiro de Qualidade de Software. Vila Velha, ES, p. 321-326, 2006b. 
Gray, M.W.; Burger, G. \& Lang, B.F., The origin and early evolution of mitochondria. Genome Biology, 2(6):1018.11018.5, 2001.

Hea, C.Q.; Ding, N.Z.; Chenb, J.G. \& Li, Y.L., Evidence of natural recombination in classical swine fever virus. Virus Research, 126:179-185, 2007.

Henze, K.; Schnarrenberger, C. \& Martin, W., Endosymbiotic gene transfer: A special case of horizontal gene transfer germane to endosymbiosis, the origins of organelles and the origins of eukaryotes. In: Syvanen, M. \& Kado, C. (Eds.), Horizontal Gene Transfer. London: Academic, p. 343-352, 2001.

Huang, J.; Mullapudi, N.; Lancto, C.A.; Scott, M.; Abrahamsen, M.S. \& Kissinger, J.C., Phylogenomic evidence supports past endosymbiosis, intracellular and horizontal gene transfer in Cryptosporidium parvum. Genome Biology, 5(11):R88, 2004.

Jain, R.; Rivera, M.C. \& Lake, J.A., Horizontal gene transfer among genomes: The complexity hypothesis. Proceedings of the National Academy of Sciences, 96(7):3801-3806, 1999.

Jain, R.; Rivera, M.C.; Moore, J.E. \& Lake, J.A., Horizontal gene transfer accelerates genome innovation and evolution. Molecular Biology and Evolution, 20(10):1598-1602, 2003.

Koonin, E.V.; Makarova, K.S. \& Aravind, L., Horizontal gene transfer in prokaryotes: quantification and classification. Annual Review of Microbiology, 55:709-742, 2001.

Lake, J.A., Evidence for an early prokaryotic endosymbiosis. Nature, 460:967-971, 2009.

Leite, L.E.C.; Filho, G.S.; Goldbarg, M.C. \& Goldbarg, E.F.G., Comparando algoritmos genéticos e transgenéticos para otimizar a configuração de um serviço de distribuição de vídeo baseado em replicação móvel. In: 22 Simpósio Brasileiro de Redes de Computadores. Gramado, p. 129-132, 2004.

Margulis, L., Symbiosis in Cell Evolution: Microbial Communities in the Archean and Proterozoic Eons. W.H. Freeman, 1992.

Margulis, L., Symbiotic Planet. New York, USA: Basic Books, 1998.

Margulis, L., Serial endosymbiotic theory (SET) and composite individuality. Microbiology Today, 31:172-174, 2004.

Matsui, K.; Ishii, N. \& Kawabata, Z., Release of extracellular transformable plasmid DNA from Escherichia coli cocultivated with algae. Applied and Enviromental Microbiology, 69(4):2399-2404, 2003.

McCutcheon, J.P. \& Moran, N.A., Functional convergence in reduced genomes of bacterial symbionts spanning 200 My of evolution. Genome Biology and Evolution, 2:708-718, 2010.

McFadden, G.I., Primary and secondary endosymbiosis and the origin of plastids. Journal of Physiology, 37(6):951-959, 2001.

Mereschkowsky, C., über natur und ursprung der chromatophoren im pflanzenreiche. Biologisches Centralblatt, 25:593604, 1905.

Monteiro, S.M.D.; Goldbarg, E.F.G. \& Goldbarg, M.C., A plasmid based transgenetic algorithm for the biobjective minimum spanning tree problem. In: Proceedings of EVOCOP09 - European Conference on Evolutionary Computation in Combinatorial Optimization, Lecture Notes in Computer Science. Springer-Verlag, Berlin, Germany, v. 5482, p. 49-60, 2009.

Moran, N.A.; McCutcheon, J.P. \& Nakabachi, A., Genomics and evolution of heritable bacterial symbionts. Annual Review of Genetics, 42:165-190, 2008.

Nanjundiah, V., Barbara McClintock and the discovery of jumping genes. Resonance, 1(10):56-62, 1996.

Pierce, S.K.; Massey, S.E.; Hanten, J.J. \& Curtis, N.E., Horizontal transfer of functional nuclear genes between multicellular organisms. Biological Bulletin, 204(3):237-240, 2003.

Rumpho, M.E.; Worful, J.M.; Lee, J.; Tyler, M.S.; Bhattacharya, D.; Moustafa, A. \& Manhart, J.R., Horizontal gene transfer of the algal nuclear gene psbO to the photosynthetic sea slug Elysia chlorotica. PNAS - Proceedings of the National Academy of Sciences of the United States of America, 105(46):17867-17871, 2008.

Sachs, J., Vorlesungen Über Pflanzen-Physiologie. Leipzig, Germany: W. Engelmann, 1882.

Shapiro, J.A., Transposable elements as the key to a 21st century view of evolution. Genetica, 107(1-3):171-179, 1999.

Smith, J.M. \& Szathmáry, E., The Major Transitions in Evolution. Oxford, England: Oxford University Press, 1995.

Stevenson, I., Bacterial endosymbiosis in Paramecium aurelia : bacteriophage-like inclusions in a Kappa symbiont. Journal of General Microbiology, 71:69-76, 1972.

Stewart, F.J.; Young, C.R. \& Cavanaugh, C.M., Evidence for homologous recombination in intracellular chemosynthetic clam symbionts. Molecular Biology and Evolution, 26(6):1391-1404, 2009.

Taylor, F.R.J., Implications and extensions of the serial endosymbiosis theory of the origin of eukaryotes. Taxon, 23(2/3):229-258, 1974 .

Wernegreen, J.J., For better or worse: genomic consequences of intracellular mutualism and parasitism. Genetics $\mathcal{6}$ Development, 15(6):572-583, 2005.

Werren, J.H.; Baldo, L. \& Clark, M.E., Wolbachia: master manipulators of invertebrate biology. Nature Reviews Microbiology, 6:741-751, 2008.

Witzany, G., Serial endosymbiotic theory (SET): The biosemiotic update. Acta Biotheoretica, 54(2):103-117, 2006.

Zaneveld, J.R.; Nemergut, D.R. \& Knight, R., Are all horizontal gene transfers created equal? prospects for mechanismbased studies of HGT patterns. Microbiology, 154, part I:1-15, 2008. 


\section{Notas Biográficas}

Marco César Goldbarg é Engenheiro de Fortificação e Construção mestre em Sistemas e Computação (Instituto Militar de Engenharia, 1982 e 1987, respectivamente), doutor em Sistemas e Computação (COPPE/UFRJ, 1990). Tem pós-doutorado em Ciência da Computação (UFMG, 1999). Atualmente é professor associado na Universidade Federal do Rio Grande do Norte.

Elizabeth Ferreira Gouvêa Goldbarg é graduada em Engenharia Industrial (Centro Federal de Educação Tecnológica - Celso Suckow da Fonseca, 1985), mestre em Sistemas e Computação (Instituto Militar de Engenharia, 1993) e doutor em Engenharia de Produção (COPPE/UFRJ, 2001). Tem pós-doutorado em Sistemas e Computação (COPPE/UFRJ, 2006). Atualmente é professor associado na Universidade Federal do Rio Grande do Norte. 


\title{
Introdução aos Sistemas Imunológicos Artificiais
}

\author{
Grazziela Patrocinio Figueredo, Heder Soares Bernardino* \\ e Helio José Corrêa Barbosa
}

\begin{abstract}
Resumo: Este capítulo descreve as principais abordagens empregadas nos sistemas imunológicos artificiais (SIAs). Como um novo campo da inteligência computacional, os SIAs vêm obtendo significativo sucesso desde o inicio da década de 90. Portanto, serão apresentados aqui alguns dos mais importantes algoritmos imuno-inspirados encontrados na literatura, tais como: (i) algoritmos de seleção negativa, (ii) redes imunológicas artificiais, (iii) algoritmos de seleção clonal e (iv) algoritmos baseados na teoria do perigo e células dendríticas. Embora sua inspiração natural sugira que os SIAs sejam aplicáveis a problemas de segurança computacional, abordaremos neste capítulo sua aplicação na pesquisa operacional (PO).
\end{abstract}

Palavras-chave: Sistemas imunológicos artificiais, Otimização, Pesquisa operacional.

\begin{abstract}
This chapter describes the main approaches adopted in the artificial immune systems (AISs). This is a field in computational intelligence which has been achieving significant success since the early nineties. We present, therefore, some of the main immuno-inspired algorithms from the literature, based on (i) negative selection, (ii) artificial immune networks, (iii) clonal selection, and (iv) danger theory and dendritic cells. Although their natural inspiration suggests that AISs are applicable to computational security problems, here we will study their application in the operations research field.
\end{abstract}

Keywords: Artificial immune systems, Optimization, Operational research.

\section{Introdução}

Já há algum tempo que a natureza vem servindo de inspiração para a solução de problemas computacionais. Em particular, os sistemas biológicos têm se destacado e, entre eles, está o sistema imunológico. Os Sistemas Imunológicos Artificiais (SIAs) interligam as áreas da imunologia, ciência da computação, matemática e engenharia, através de pesquisas envolvendo os aspectos teóricos, de modelagem e de aplicações.

O objetivo deste capítulo é introduzir as técnicas mais populares inspiradas no sistema imunológico e suas aplicações. Em especial, destaca-se a revisão da literatura desta classe de técnicas aplicadas a problemas de pesquisa operacional (PO), foco do presente livro.

\section{Sistema Imunológico Natural}

A vida é baseada em um frágil equilíbrio de milhões de reações químicas simultâneas e eventos inerentes a um ser vivo, como as interações deste com o ambiente e outros seres. Um acidente corriqueiro, como uma pequena farpa que penetre a pele de um indivíduo cria uma instabilidade no seu organismo. Neste caso, só existem duas possibilidades, ou o ser vivo reconhece que existiu uma agressão, o tipo de agressor e a melhor forma de combatê-lo, ou sucumbe. Ao aparato de reconhecimento, ação e controle do organismo frente às agressões bioquímicas dá-se o nome de Sistema Imunitário, Imunológico, ou também, Imune (Janeway et al., 2001).

O Sistema Imunológico (SI) é um dos sistemas biológicos mais complexos de que se tem conhecimento. Apesar da especificação da sua função ser a princípio bastante simples - detectar e eliminar qualquer organismo estranho - a execução desta tarefa não é trivial. Ainda hoje não se sabe exatamente como o SI funciona, nem mesmo qual a dimensão do seu papel dentro das interações do organismo (Golub, 1992). Entretanto, à luz do que atualmente é conhecido sobre a sua dinâmica, muito se tem feito na tentativa de construir sistemas artificiais inteligentes contendo algumas de suas propriedades (Hofmeyr \& Forrest, 2000). Isto por duas razões: a primeira é tentar trazer para o computador partes do SI através de modelos mais rudimentares e simulações

*Autor para contato: hedersb@gmail.com 
do seu funcionamento, no intuito de entender melhor as tarefas que ele executa. A segunda, utilizar o SI como inspiração para a construção de sistemas computacionais inteligentes.

Há muito interesse neste segundo tópico, pois existem propriedades buscadas por projetistas na construção de sistemas que estão naturalmente presentes no SI. Estas são robustez, tolerância a erros, reconhecimento de padrões, distribuição, memória, adaptabilidade, auto-organização, e autonomia.

Esta seção tem como objetivo discutir os conceitos fundamentais, as principais propriedades do SI e os mecanismos mais importantes das respostas imunes, a fim de fornecer subsídios para que o leitor entenda melhor os modelos artificiais apresentados neste capítulo.

\subsection{Aspectos gerais das respostas imunológicas}

Ao se tentar enxertar um pequeno fragmento de tecido vivo extraído de um animal em outro de espécie diferente, observa-se que em poucos dias este tecido será destruído e eliminado pelo organismo do indivíduo receptor. Este processo, conhecido como resposta imunológica, é caracterizado pela capacidade que o organismo possui de reconhecer e destruir material estranho, sem implicar em uma consequência fisiológica ou patológica de tal reação. Ao estudo das respostas imunológicas, suas consequências e mecanismos dá-se o nome de Imunologia (Janeway et al., 2001).

O exemplo de rejeição de tecido representa apenas uma das formas nas quais a resposta imunológica está presente. Entretanto, ele também é um indicador importante da existência de um sistema eficiente de detecção e eliminação de células e moléculas que se apresentam estruturalmente diferentes daquelas tidas como normais e pertencentes ao organismo. Portanto, existe uma espécie de "sistema de vigilância constante", responsável pela identificação e remoção de células anormais, que podem ser pertencentes a outros seres vivos, como bactérias, ou mesmo células do próprio organismo contendo má formação ou defeitos, como por exemplo, aquelas presentes em tumores. Quanto mais eficaz for este sistema de localização e posterior remoção de irregularidades dentro do organismo, maiores são as suas chances de sobrevivência às invasões de parasitas e micro-organismos nocivos.

\subsubsection{Imunidade inata e adaptativa}

O SI dispõe de meios para se adaptar e tentar se proteger de agentes danosos - denominados antígenos - que se infiltram no organismo ao longo da existência do indivíduo. Entretanto, existem também mecanismos de defesa não condicionados a estímulos externos e que já fazem parte do organismo do indivíduo desde o seu nascimento. Esta é a chamada imunidade natural (nativa ou inata) e sua estrutura básica é inerente a toda uma espécie, e não a um exemplar apenas; é de caráter geral e proporciona um tipo de defesa amplo, porém, não discriminado. Fazem parte desta classe as barreiras físico-químicas da pele, membranas, saliva, lágrima, mucosas, enzimas digestivas, algumas células brancas e várias moléculas originadas no sangue (Abbas et al., 1998).

O outro tipo de imunidade é aquele que confere ao sistema imunológico a robustez de se proteger especificamente contra substâncias estranhas, a chamada imunidade específica, adaptativa ou adquirida. Este mecanismo de defesa é induzido ou estimulado pela exposição a fatores estranhos ao organismo.

Tanto na imunidade inata como específica, há duas classes distintas que se diferenciam pela forma como a resposta imune se dá. São elas a resposta imunitária humoral - presente no soro sanguíneo - e a resposta mediada por células.

Os elementos do soro sanguíneo que conferem resistência ao organismo a agentes ofensivos, como venenos e toxinas, são os chamados anticorpos, e sua produção é incitada pela substância danosa, ou antígeno. Um antígeno é qualquer molécula que pode ligar-se especificamente a um anticorpo. Seu nome deriva de sua propriedade de GErar ANTIcorpos. Os anticorpos atuam reagindo quimicamente com os antígenos, de forma a neutralizar o seu princípio ativo e impedir que ele cause mais malefícios ao organismo. Os anticorpos são antígeno-específicos. Para um determinado antígeno, há um anticorpo produzido especificamente para se ligar a ele. Da mesma forma, quando o antígeno penetra o organismo, somente o anticorpo específico terá sua produção estimulada (Tizard, 1985).

Em uma primeira infestação de um certo antígeno no organismo (por exemplo, uma certa toxina), observase um período de latência (janela imunológica ou retardo) de vários dias, onde não há nenhum tipo de alteração no soro. Em seguida, surge uma alta concentração de anticorpos ${ }^{1}$ que pode, no decorrer de alguns dias, atingir o seu grau máximo e cair rapidamente, o que caracteriza a chamada resposta imunitária primária. Se uma nova dose do antígeno for injetada após algum tempo decorrido desde a primeira reação, observa-se que o período de retardo é bem mais curto, e a quantidade de anticorpos aumenta rapidamente, caindo de forma lenta. Esta diferença entre as respostas primária e secundária indica a existência de um aparato produtor de anticorpos capaz de gravar, em uma forma de memória, exposições anteriores a antígenos, provendo o SI

\footnotetext{
1 Quantidade determinada pela capacidade de neutralização de uma certa medida de antígenos.
} 
da capacidade de se proteger mais rapidamente quando re-exposto a um agente danoso. Esta memória, em certos casos, pode ter sua dimensão reduzida com o passar do tempo. Entretanto, ela continua conferindo um tempo de latência mais curto em reações imunes secundárias, quando contrastado com as primárias.

A capacidade do organismo de reagir contra um tecido estranho, por exemplo, é dada através de células imunes chamadas células brancas. As células brancas do sistema inato mais importantes são as células fagocitárias, dentre as quais se destacam os macrófagos e as células dendríticas.

O papel das células dendríticas é capturar e apresentar o antígeno aos linfócitos, a fim de que ele seja reconhecido e combatido. Existem em sua superfície receptores capazes de reconhecer estruturas comuns a diversos tipos de antígenos. Assim, quando estes receptores encontram um antígeno, a célula dendrítica é estimulada a englobá-lo e degradá-lo. Ao ingerir o antígeno, a célula se ativa, amadurecendo em uma célula apresentadora de antígenos (APC) e migra até o linfonodo mais próximo. Já amadurecida, a célula é capaz de ativar os linfócitos (células brancas adaptativas) antígeno-específicos que determinam quando e como o sistema imune deverá responder aos agentes infecciosos. Pode-se dizer que os linfonodos são órgãos que atuam como "centros de inteligência" do SI, onde é procurado qual o linfócito mais apto a combater o antígeno apresentado pela APC (como as células dendríticas) e onde se dá o início à resposta ao agressor.

Linfócitos são células imunocompetentes recirculantes responsáveis pela imunidade específica. Estas células realizam um intercurso contínuo entre corrente sanguínea e linfa, e em seguida no sentido inverso, num processo chamado recirculação (Cormack, 1991). Durante o movimento de recirculação do sangue para a linfa e novamente para a corrente sanguínea, é provável que os linfócitos encontrem antígenos que possam ter penetrado o organismo. Um encontro de tal natureza pode, muitas vezes, desencadear uma resposta imune, pois este tipo de célula, em sua maioria, dispõe da capacidade funcional para reconhecer e responder a antígenos. Quando um pequeno linfócito reconhece um antígeno, ele aumenta de tamanho, replica o seu DNA e passa por uma série de divisões dando origem aos chamados clones, que são conjuntos de células identicamente programadas para o combate a um determinado agente agressor (Cormack, 1991). É possível destacar duas classes principais de linfócitos. Aqueles cuja diferenciação se dá no Timo são chamados linfócitos T e os outros cujo desenvolvimento se dá na medula óssea (bone marrow) - são os linfócitos B .

Os linfócitos $\mathrm{T}$ representam a maioria dos linfócitos do sangue e são os principais responsáveis pela imunidade adaptativa. Assim como os linfócitos B, eles tem sua origem na medula óssea. Entretanto, sua fase de maturação se dá no Timo. É nesta fase de maturação que o linfócito terá a sua função e especificidade antigênica definidos. Apesar do seu aspecto microscópico de maneira geral ser uniforme, os linfócitos T se subdividem em diversas classes funcionais distintas (Cormack, 1991).

Cabe aos linfócitos B a produção de anticorpos, sendo que cada clone de linfócitos B é responsável por um antígeno específico. Antes de sua ativação, cada linfócito B apresenta em sua superfície pequenas áreas de anticorpos específicas, também chamadas de parátopos. Estas áreas são responsáveis pelo reconhecimento do antígeno através da identificação do seu determinante antigênico, ou epítopo, que são as áreas contra as quais a resposta imunitária tende a se dirigir e onde os anticorpos costumam se ligar (Tizard, 1985). Assim, quando um linfócito B encontra e reconhece um antígeno, ele se torna ativado. Durante o seu processo de ativação, o linfócito aumenta, reproduz e sua progênie se diferencia em células secretoras de anticorpos, os plasmócitos, e algumas células de memória de mesma especificidade antigênica determinada pelos anticorpos da superfície celular do primeiro linfócito.

A explicação para que a capacidade de reconhecimento dos linfócitos B seja tão abrangente, cobrindo praticamente todos os antígenos existentes, está na forma como é estruturada uma molécula de anticorpo. O anticorpo é o receptor da célula B em sua forma solúvel, com sua molécula em formato de Y. O local de reconhecimento dos antígenos (parátopo), específico para cada tipo diferente de antígeno, fica localizado na ponta de cada um dos braços do Y. O repertório de anticorpos é gerado durante o desenvolvimento das células B por rearranjos do DNA (Janeway et al., 2001). Outro fator que potencializa esta diversidade são as hipermutações somáticas, que ocorrem nos linfócitos B ativados. As hipermutações, além de serem um mecanismo gerador de diversidade na população de anticorpos, são responsáveis também pelo refinamento da afinidade do anticorpo com relação ao seu antígeno específico. Elas operam sobre células B maduras localizadas nos órgãos linfóides secundários. Sua função é introduzir mutações pontuais nos parátopos, em uma taxa muito elevada (Janeway et al., 2001). O objetivo deste mecanismo é produzir anticorpos mutantes na superfície das células B, a fim de que algumas destas variações resultem em anticorpos de maior conformidade físico-química contra o antígeno quando comparados à anticorpo original. Aqueles linfócitos capazes de produzir anticorpos com poder de neutralização superior tendem a ser privilegiados no processo de escolha das células B que irão se diferenciar em plasmócitos. Este fenômeno de seleção dos melhores anticorpos é chamado maturação de afinidade. 


\subsection{Distinção entre próprio e não-próprio}

O repertório de linfócitos presente no organismo é amplo o suficiente para reconhecer todos os possíveis invasores que apareçam ao longo de sua existência, o que é próprio do organismo (self), e o que é próprio e apresenta anomalias.

A especificidade dos linfócitos é determinada nas primeiras etapas de sua diferenciação, quando o RNA mensageiro codificador dos receptores das células B e T é montado a partir de segmentos gênicos rearranjados.

Dado o potencial criador dos rearranjos gênicos, associado aos outros fatores que geram diversidade, é possível admitir três classes de repertórios celulares (de Castro, 2001). O repertório potencial representa tudo que pode ser gerado pelos mecanismos de expressão genética associados às variações obtidas pelas mutações. O repertório expresso engloba moléculas disponíveis para tornarem-se receptores e o repertório ativo são os linfócitos que participam das respostas imunes.

Em uma fase seguinte à expressão do receptor antigênico na superfície do linfócito, há uma avaliação que verifica as propriedades de reconhecimento antigênico da célula com relação às moléculas do ambiente. Os resultados deste teste de especificidade e afinidade do receptor determinam se o linfócito está apto a sobreviver ou se deve ser eliminado.

\subsection{Seleção positiva e seleção negativa}

Em geral, linfócitos em desenvolvimento que interagem fracamente com antígenos próprios, ou auto-antígenos, recebem sinais de sobrevivência. A escolha dos linfócitos que permanecerão vivos é chamada seleção positiva. Particularmente para as células T, a seleção positiva escolhe aquelas cujos receptores são capazes de reconhecer e se ligar a moléculas de MHC-próprio (de Castro, 2001; de Castro \& Timmis, 2002b), o que constitui uma premissa para que uma célula T seja capaz de armar uma resposta contra um antígeno. MHC é um complexo de genes que codifica várias proteínas receptoras trans-membranas celulares, que atuam no reconhecimento e na apresentação de constituintes dos agentes estranhos. Através do contato com estas proteínas, as células T iniciam a sua resposta imunológica ou estabelecem a tolerância ao antígeno.

A seleção positiva nas células B maduras ocorre após a hipermutação, quando a célula filha mutante é mais eficiente na neutralização do anticorpo e é preferida para expansão. Produtos ineficientes da hipermutação são eliminados do organismo.

Linfócitos de alta reatividade com antígenos próprios são sinalizados para morte, o que caracteriza a seleção negativa. Desta forma, linfócitos auto-agressivos são removidos do repertório antes de amadurecerem e desencadearem reações auto-imunes. Da mesma forma, antígenos que não apresentam malefícios ao organismo (como bactérias da flora intestinal, pelo de gato, etc.) em geral não são atacados pelo SI. Esta seleção estabelece a tolerância imunológica para auto-antígenos.

A sobrevivência dos linfócitos para a fase de ativação é condicionada a sinais enviados para os seus receptores. Aqueles que não receberem estes sinais são programados para a morte. A maior parte das combinações dos genes codificadores gera linfócitos auto-reativos. Desta forma, somente uma pequena parcela de linfócitos estão destinados a amadurecer e compor o repertório linfocitário do sistema adaptativo. Ainda assim, esta pequena fração restante é capaz de responder, em termos práticos, a qualquer antígeno apresentado (Janeway et al., 2001).

\subsection{A teoria da seleção clonal}

A teoria da Seleção Clonal (Burnet, 1957; Ada \& Nossal, 1987) conjecturou que o antígeno, ao penetrar no corpo do hospedeiro, recrutaria um subconjunto de linfócitos capazes de reconhecê-lo. Linfócitos com maior reatividade com o antígeno seriam selecionados para expansão em clones em detrimento daqueles com menor capacidade de neutralização. Cada clone seria portador de um receptor único, ou seja, que não estaria presente em nenhum outro.

A seleção clonal inicia no momento em que um antígeno penetra o organismo e ativa o complexo inato. Aqueles linfócitos que apresentam maior poder de ligação com os antígenos se proliferam, na chamada expansão clonal. Ambas células B e T passam pelo processo de seleção clonal, com a diferença que linfócitos do tipo B sofrem hipermutações somáticas durante a expansão clonal. Aquelas células que apresentarem melhor ligação ao antígeno, sem serem auto-reativas, recebem estímulos para sobrevivência e proliferação, em detrimento de linfócitos menos aptos, que tendem a ser eliminados.

\section{Técnicas Imuno-Inspiradas}

O comportamento do sistema imunológico natural vêm inspirando o desenvolvimento de vários algoritmos computacionais. A Tabela 1 apresenta as classes de métodos imuno-inspirados mais comuns na literatura, bem como os tipos de problemas aos quais são normalmente aplicados. 
Tabela 1. Classificação dos modelos computacionais imuno-inspirados comumente encontradas em aplicações de PO.

\begin{tabular}{ll}
\hline Algoritmo imuno-inspirado & Problema \\
\hline Seleção Negativa & Detecção de anomalias, falhas e alterações \\
Rede imunológica & Aprendizagem de máquina e otimização \\
Algoritmos de seleção clonal & Busca e otimização \\
Teoria do perigo & Segurança de redes \\
Células Dendríticas & Segurança de redes, aprendizagem de máquina e robótica \\
\hline
\end{tabular}

As sub-seções que se seguem descrevem os algoritmos não em ordem cronológica, mas sim visando (i) apresentar primeiro e mais detalhadamente as técnicas imuno-inspiradas mais comumente encontradas na literatura de PO (algoritmos de seleção clonal e rede imunológica), e (ii) facilitar o entendimento do leitor, já que algumas técnicas mais recentes incrementam os métodos de seleção clonal com ideias da rede imunológica.

\subsection{Algoritmos de seleção clonal}

As técnicas que simulam o princípio de seleção clonal são aplicáveis a problemas de aprendizagem de máquina, reconhecimento de padrões e otimização (Bernardino \& Barbosa, 2009). Como a maioria dos casos de PO recaem em situações onde se deseja obter uma solução ótima, o presente capítulo se concentra na aplicação dos algoritmos de seleção clonal a problemas de otimização. Além disto, a otimização é a principal área em que os algoritmos de seleção clonal são aplicados atualmente. Outras aplicações dos algoritmos de seleção clonal podem ser encontradas no trabalho de de Castro \& Timmis (2002c).

Ao invés de reconhecer uma população de antígenos (como ocorreria em problemas de reconhecimento de padrões), quando se busca resolver um problema de otimização o objetivo é substituído por otimizar uma função (ou várias delas, no caso multi-objetivo). A ideia inspiradora desses métodos é a que somente células com capacidade de reconhecer antígenos irão sobreviver e gerar descendentes, ou seja, o processo geralmente ocorre como a maturação do sistema imunológico. A principal diferença é que, ao contrário do que ocorre na natureza, todos os passos de evolução dos linfócitos são aplicados apenas em anticorpos, já que normalmente as técnicas computacionais não fazem distinção entre anticorpos e linfócitos, tornando o sistema mais simples de ser representado.

\subsubsection{CLONALG}

Imitando o princípio de seleção clonal, o CLONALG (CLOnal selection ALGorithm, ou algoritmo de seleção clonal) foi proposto por de Castro \& von Zuben (2000, 2002) como um método a ser aplicado tanto em otimização, como será detalhado aqui, quanto a problemas de aprendizagem de máquina. O processo de melhora das soluções candidatas no CLONALG segue as etapas de clonagem destas soluções, hipermutação das novas células geradas e seleção daquelas com maior afinidade em relação ao antígeno (melhores soluções em relação ao objetivo).

A primeira versão do CLONALG, denominada CSA, foi proposta por de Castro \& von Zuben (2000) e aplicada com sucesso a problemas de otimização multimodal e a uma instância de 30 cidades do problema do Caixeiro Viajante. Todavia, o CLONALG é hoje largamente referenciado pelo estudo apresentado em de Castro \& von Zuben (2002), em que a sensibilidade em relação aos seus parâmetros e seu desempenho em um conjunto de problemas-teste foram analisados.

Um pseudo-código do CLONALG, elaborado com base no fluxograma e descrição contidos em de Castro \& von Zuben (2002), pode ser encontrado no Algoritmo 1. Os parâmetros de entrada do usuário são: um valor $\beta$ que determina o número de clones gerados por cada anticorpo (Equação 1), um fator $\rho$ que ajusta a intensidade da hipermutação aplicada aos clones (Equação 2), o tamanho tamanhoPopulacao de soluções candidatas da população anticorpos, o número nAleatorio de anticorpos de menor afinidade que devem ser substituídos por novos anticorpos aleatoriamente gerados e a quantidade nSelecao de anticorpos a serem selecionados para a clonagem. Note que nAleatorio pode ser definido como uma proporção do tamanho da população, mesmo tendo sido inicialmente proposto como um parâmetro absoluto. Apesar de geralmente utilizado com código de Gray, como originalmente proposto, estudos também podem ser encontrados adotando codificação real (Garrett, 2004; Bernardino et al., 2011). As variáveis afinidades, afinidadesNormalizadas e a finidadesClones armazenam a qualidade das soluções candidatas (anticorpos), esses valores normalizados e a qualidade dos clones hipermutados, respectivamente.

Além das variáveis de entrada definidas previamente, o pseudo-código também utiliza as seguintes funções/métodos: "inicializaPopulacao", cria (aleatoriamente) uma nova população de soluções candidatas; 


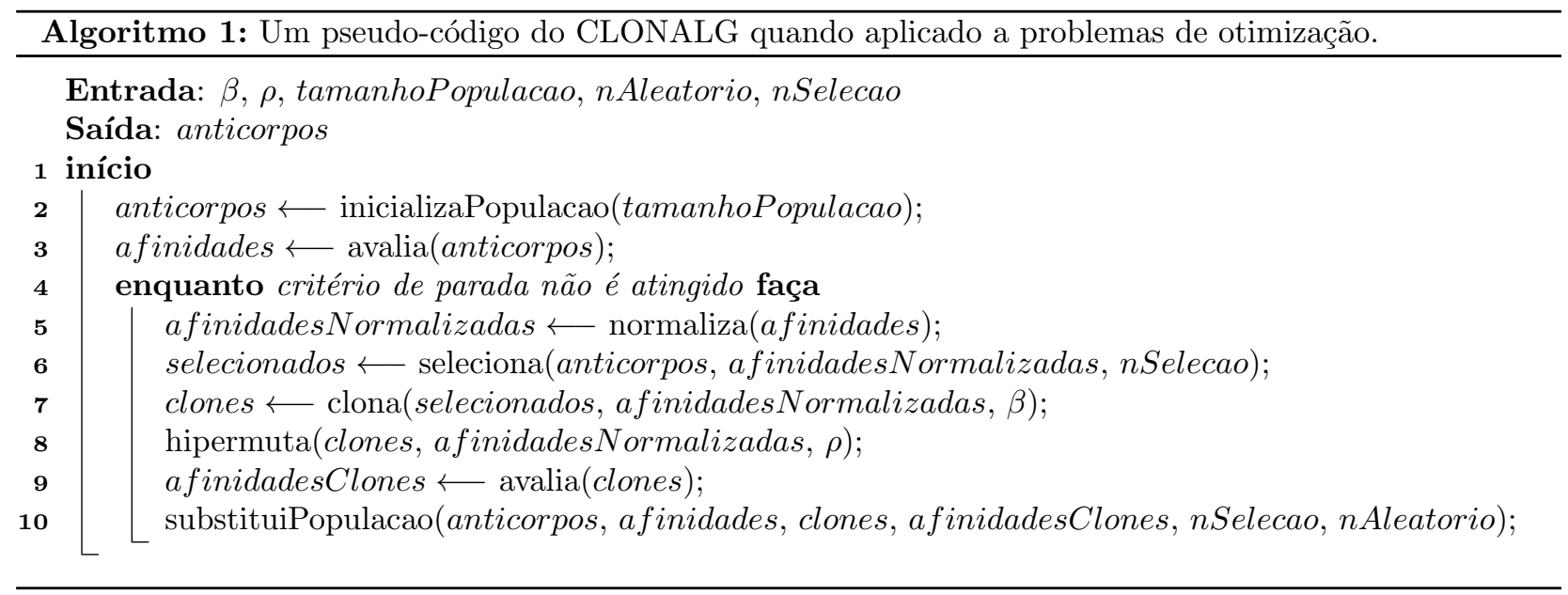

"avalia", avalia as soluções em relação à função objetivo; "normaliza", normaliza as afinidades em [0;1]; "seleciona", seleciona os anticorpos que serão clonados; "clona", clona as soluções candidatas; "hipermuta", aplica o operador de hipermutação nos clones gerados; "substituiPopulacao", substitui os piores nSelecao anticorpos pelos melhores clones gerados e gera nAleatorio novas soluções candidatas aleatoriamente também substituindo-as na população (cálculos adicionais da função objetivo são requeridos aqui).

Não é difícil perceber que, além do Algoritmo 1 e das descrições apresentadas anteriormente, especificações de como calcular o número de clones gerados por cada anticorpo e de como hipermutar estes clones ainda são necessárias para que se possa implementar uma versão do CLONALG para otimização. Segundo de Castro \& von Zuben (2002), o número de clones $n_{\text {clones }}$ que o anticorpo anticorpo $i$ gera é definido pela Equação (1):

$$
n_{\text {clones }}\left(\operatorname{anticorpo}_{i}\right)=\operatorname{arredonda}\left(\frac{\beta \cdot \mid \text { anticorpos } \mid}{i}\right) \text {, }
$$

onde arredonda é um operador que retorna o valor inteiro mais próximo do seu argumento e $i$ é a posição do anticorpo anticorpo $_{i}$ na lista ordenada de forma decrescente pela afinidade normalizada, ou seja, o primeiro anticorpo da lista corresponde à melhor solução candidata. Também segundo a mesma referência, a hipermutação é aplicada com uma taxa $\alpha$ proporcional à afinidade do anticorpo que deu origem ao clone clone $_{i}$, como definida na Equação (2):

$$
\alpha\left(\text { clone }_{i}\right)=\exp \left(-\rho \cdot \bar{f}_{i}\right)
$$

com $\bar{f}_{i}$ sendo a afinidade normalizada do anticorpo $i$ correspondente.

A adaptabilidade a diversos tipos de problemas é a principal vantagem do CLONALG. Um algoritmo evolutivo, por exemplo, precisa ser estendido com alguma técnica de nicho (Bäck et al., 2000), tais como Fitness sharing (Goldberg \& Richardson, 1987) e Crowding (Mahfoud, 1995), quando aplicado a problemas de otimização multimodais, enquanto que o CLONALG não requer tais técnicas adicionais para manter a diversidade de suas soluções. Apenas os seguintes ajustes precisam ser realizados (de Castro \& von Zuben, 2002):

- $n$ Selecao $=\mid$ anticorpos $\mid$, ou seja, todos os anticorpos da população são selecionados para o processo de clonagem;

- $n_{\text {clones }}$ é igual para todas as soluções candidatas;

- a população é atualizada substituindo-se os anticorpos pelo seu melhor clone quando uma melhora ocorre (este item foi inicialmente utilizado em um algoritmo imuno-inspirado no trabalho de Kelsey \& Timmis (2003) e é hoje largamente utilizado tanto no CLONALG quanto em outros algoritmos de seleção clonal).

CLONALG é um dos algoritmos imuno-inspirados mais conhecidos para resolver problemas de otimização e suas ideias podem ser facilmente encontradas em aplicações de PO (de Castro \& von Zuben, 2000, 2002; Agarwal et al., 2007; van Peteghem \& Vanhoucke, 2009; van Peteghem \& Vanhoucke, 2013), como poderá ser verificado na Seção 4. 


\subsection{2 opt-IMMALG}

O algoritmo imuno-inspirado para problemas de otimização, opt-IMMALG, pode ser facilmente encontrado na literatura. Esta técnica foi originalmente proposta por Cutello \& Nicosia (2002) como IA (Immune Algorithm), mas outros nomes foram elaborados enquanto melhorias e diversidade de aplicações do método imuno-inspirado iam sendo desenvolvidas. Neste progresso, pode-se citar o trabalho de Cutello et al. (2003) como o primeiro a apresentar o algoritmo com as características que possui atualmente (como a presença de um operador de idade). Cutello et al. (2005a) compararam o então chamado opt-IA com o CLONALG. Cutello et al. (2005b) elaboraram a versão com codificação real opt-IMMALG e Cutello et al. (2007) incluíram uma busca local específica do problema no então chamado IMMALG. No artigo de Pavone et al. (2012) foram definidas as nomenclaturas de opt-IMMALG e opt-IMMALG01, respectivamente, para as versões com codificação real e binária. Por fim, ressalta-se o MIA (Memetic Immunological Algorithm) uma versão deste algoritmo que foi analisada em um problema de alocação de recursos em uma rede de comunicação.

O MIA (Costanza et al., 2011) inclui uma busca local em seu processo de melhora das soluções candidatas. A primeira versão do algoritmo, encontrada em Cutello \& Nicosia (2002), é similar ao CLONALG (veja Seção 3.1.1), possuindo inclusive um passo no procedimento responsável por gerar aleatoriamente novas soluções candidatas a cada iteração, denominado operador de nascimento. Um operador de idade, utilizado pelas versões atuais do método, bem como um operador de busca local e critério de parada específicos do problema foram adicionados ao método em Cutello et al. (2003). Cutello et al. (2004) analisaram diversos operadores de hipermutação para o algoritmo enquanto que Cutello et al. (2005b) elaboraram sua versão com codificação real. Uma versão atual do método, como apresentada em Pavone et al. (2012), é apresentada no Algoritmo 2.

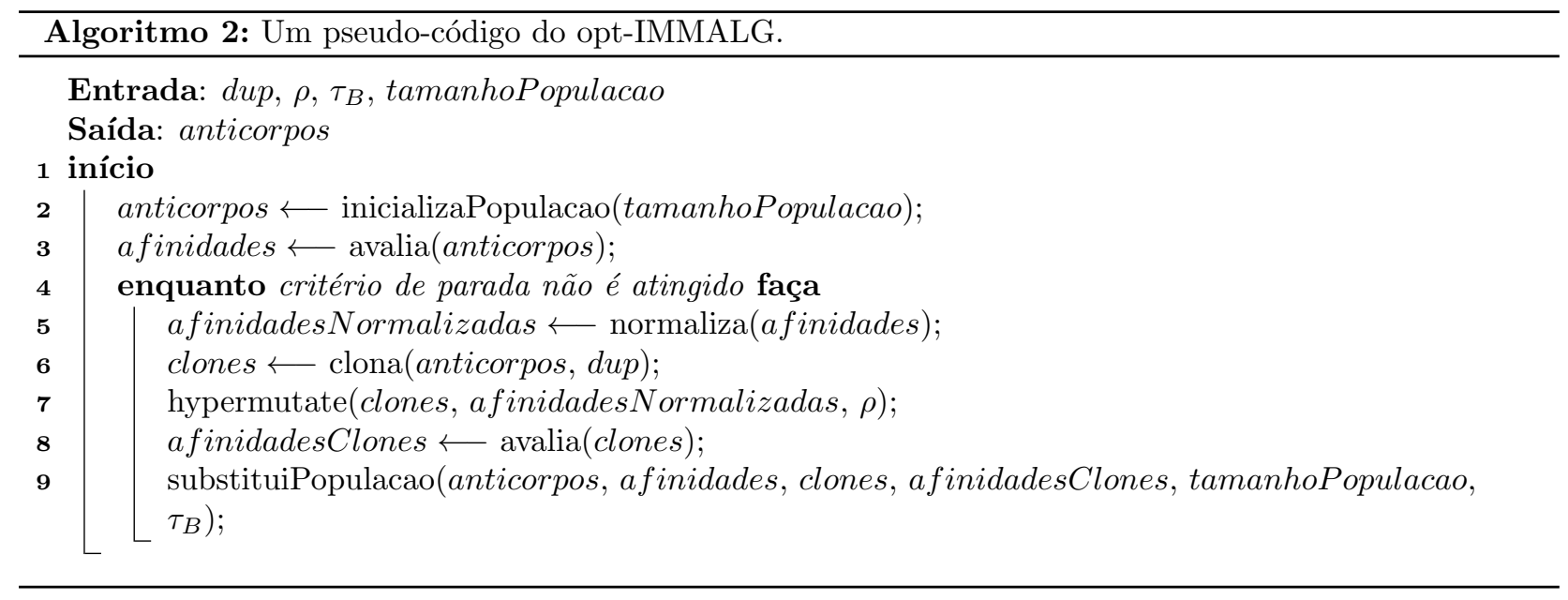

Além de $\rho$ e tamanhoPopulacao, já observados no Algoritmo 1, o Algoritmo 2 utiliza parâmetros referentes ao número de clones gerados por cada anticorpo $(d u p)$ e uma idade máxima para as soluções candidatas $\left(\tau_{B}\right)$. As funções utilizadas no pseudo-código do algoritmo opt-IMMALG foram previamente descritas na Seção 3.1.1. Entretanto, existem algumas diferenças em suas definições que serão apresentadas a seguir.

A primeira diferença que pode ser observada entre os algoritmos CLONALG e opt-IMMALG está na função "clona", que neste último gera por padrão dup clones para quaisquer anticorpos da população corrente. Além disto, como o opt-IMMALG inclui um operador de idade (função "substituiPopulacao") os novos anticorpos possuem um atributo correspondente à sua idade que deve ser inicializado com um valor aleatório uniforme em $\left[0 ; \frac{2}{3} \tau_{B}\right]$ (Pavone et al., 2012). Outra pequena mudança ocorre na função "normaliza" da versão com codificação real do opt-IMMALG, onde a normalização é feita em $[0 ; 1]$ utilizando a melhor função objetivo encontrada até o momento decrescida de $\theta \%$, que é um parâmetro a ser definido pelo usuário.

A hipermutação aqui também pode ser aplicada de maneira diferente. Ao invés de utilizar uma taxa de mutação, como acontece no CLONALG, aqui $\alpha$ é utilizado para indicar o número de elementos $M$ a serem modificados na solução candidata, como definido pela Equação (3):

$$
M(\alpha)=\lfloor\alpha l+1\rfloor,
$$

tomando $l$ como a dimensão da representação do anticorpo (seja binária ou real, onde $l$ é igual à dimensão do problema). Além da Equação 2, $\alpha$ também pode ser calculado utilizando a Equação (4):

$$
\alpha\left(\text { clone }_{i}\right)=\frac{\exp \left(-\bar{f}_{i}\right)}{\rho},
$$


que usa parâmetros já definidos. É importante destacar que a utilização desta equação como meio de definir o potencial do operador de movimento de um algoritmo imuno-inspirado foi proposta por de Castro \& Timmis (2002a) (veja Seção 3.2). Para o caso em que a codificação da solução candidata é real, os elementos $i$ de um clone são modificados como definido pela Equação (5):

$$
\alpha\left(\text { clone }_{i}\right)=(1-\beta) \text { clone }_{i}+\beta \text { clone }_{j},
$$

onde $\beta \in[0 ; 1]$ é um número aleatoriamente gerado de uma distribuição uniforme, $1 \leq i \neq j \leq l=n$ e $n$ é a dimensão do problema.

Tem-se por fim a função "substituiPopulacao", que no opt-IMMALG inclui inicialmente um operador de idade, responsável por eliminar soluções candidatas antigas. Existem dois tipos de operadores de idade: (i) estático, que remove da população anticorpos com idade superior a $\tau_{B}$; e (ii) elitista, em que a melhor solução é mantida mesmo com idade superior a $\tau_{B}$. A próxima população de soluções candidatas será composta pelas melhores soluções restantes, ou seja, pelos anticorpos de melhor afinidade não eliminados pela idade.

O MIA (Costanza et al., 2011), que é a versão aplicada ao problema de alocação de recursos, inclui a mesma busca local utilizada em Cutello et al. (2003), bem como seus custos adicionais de avaliação da função objetivo, entre as linhas 8 e 9 do Algoritmo 2.

\subsubsection{Outros algoritmos de seleção clonal}

Diversos outros algoritmos inspirados pela teoria da seleção clonal já foram propostos como métodos de otimização; em particular para problemas de PO. Em geral, a diferença entre estas técnicas reside nas definições de cada etapa da evolução dos linfócitos do sistema imunológico.

O BCA (B-Cell algorithm, ou Algoritmo da Célula B) foi proposto por Kelsey \& Timmis (2003) e, mesmo sendo muito parecido com o CLONALG, utiliza um operador de hipermutação ímpar. Ao invés da modificação na solução candidata ocorrer em múltiplos alelos (bits) aleatoriamente selecionados, o chamado operador de mutação contígua aplica a mutação sobre um trecho (contínuo e de tamanho escolhido aleatoriamente) da representação binária da solução candidata. O BCA também define o operador de metadinâmica que opera selecionando um dos clones e modificando-o aleatoriamente. Nota-se que esse operador é similar à geração aleatória de novas soluções candidatas do CLONALG (simulando a medula óssea). Entretanto, o operador de metadinâmica é utilizado como um operador de movimento adicional, não adicionando cálculos da função objetivo. Finalmente, é importante destacar que por padrão o processo de substituição da população no BCA troca a solução candidata corrente por seu melhor clone hipermutado, no caso de haver melhora. Atualmente, esse modelo de substituição é normalmente adotado no CLONALG.

\subsection{Redes imunológicas}

Outros modelos, como Modelo B e Shape Space, também são baseados nesta ideia que serviu, além disto , para o desenvolvimento de diversos algoritmos computacionais para a resolução de problemas de análise de dados, classificação, agrupamento e otimização.

de Castro \& von Zuben (2001) propuseram um algoritmo para análise de dados inspirado pela teoria da rede imunológica chamado aiNet. Uma versão aplicável a problemas de otimização foi posteriormente elaborada por de Castro \& Timmis (2002a). O então chamado opt-aiNet é uma extensão do CLONALG (veja a Seção 3.1.1) com codificação tipicamente real e incluindo no procedimento de melhora das soluções candidatas um passo que envolve a interação entre as células da rede. No opt-aiNet, uma rede é formada pelas distâncias entre as soluções candidatas e um processo de supressão elimina as piores soluções candidatas entre as consideradas similares. Assim, a população não mais possui tamanho pré-fixado. Um pseudo-código do opt-aiNet é apresentado no Algoritmo 3.

É fácil verificar que os Algoritmos 1 e 3 são muito similares. À primeira vista, é possível notar que o algoritmo do opt-aiNet não possui o parâmetro nSelecao nem a função "seleciona" pois todas soluções candidatas são selecionadas (como na adaptação a problemas multi-modais apresentada na Seção 3.1.1). Além disto , $\alpha$ é calculado utilizando a Equação 4 e o operador de hipermutação é agora aplicado a soluções candidatas com codificação real, como definido pela Equação (6):

$$
\text { clone }_{i}=\text { clone }_{i}+\alpha N(0,1), \quad \forall 1 \leq i \leq n,
$$

onde $N(0,1)$ é uma variável aleatória Gaussiana de uma distribuição com média zero e desvio padrão unitário.

A função "substituiPopulacao" inicia pela inclusão de todos os clones hipermutados na população e segue com a criação da rede imunológica calculando a distância entre todas as células deste conjunto. As piores soluções candidatas entre as ditas similares (com base no parâmetro $\sigma$ ) são suprimidos da rede. É importante ressaltar que de Castro \& Timmis (2002a) propuseram o uso do espaço de afinidade para verificação da 


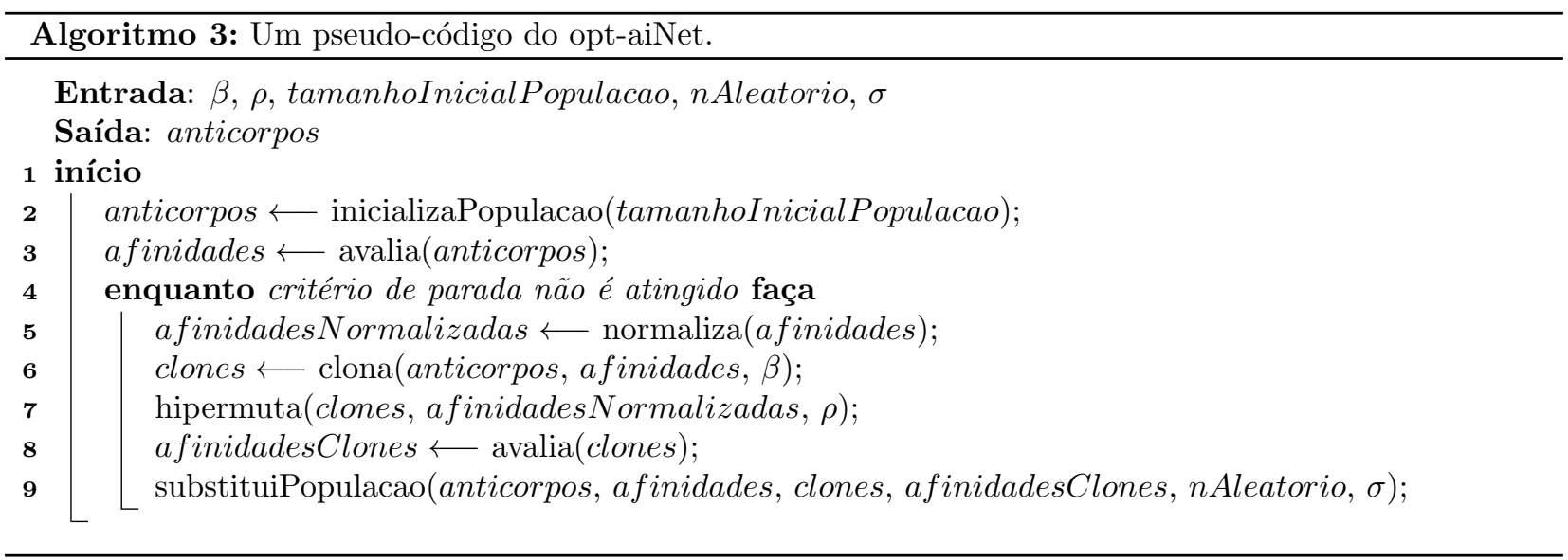

similaridade, mas outros trabalhos como o de Lee \& Zomaya (2008) utilizam distância no espaço de busca. Por fim, novas soluções candidatas são aleatoriamente geradas e incluídas na população.

Novas versões bem como diferenças entre implementações do opt-aiNet podem ser observadas na literatura. Um exemplo refere-se a quando utilizar o operador de supressão e de geração de novas soluções candidatas. Apesar de alguns trabalhos considerarem ambos passos em todas as iterações (Kelsey \& Timmis, 2003; Lee \& Zomaya, 2008), a versão proposta originalmente por de Castro \& Timmis (2002a) apenas o faz quando não se observa mais melhora média das soluções candidatas.

\subsection{Outras técnicas imuno-inspiradas}

Além daquelas técnicas apresentados nas Seções 3.1 e 3.2, existem muitos outros métodos que são inspirados pela ideia da seleção negativa, teoria do perigo e das células dendríticas. Entretanto, dada a sua maior aplicabilidade a problemas de detecção e segurança, escapando assim ao escopo de pesquisa operacional, este capítulo apenas as descreve brevemente.

\subsubsection{Seleção negativa}

Os métodos computacionais baseados neste processo são denominados algoritmos de seleção negativa e estão entre os métodos imuno-inspirados mais antigos, aplicados a vários tipos de problemas. O algoritmo, aplicado ao reconhecimento de anomalias, inicia-se com uma etapa geracional, onde os detectores são gerados por um processo aleatório e depois testados contra amostras próprias. Caso um detector defina o próprio como anomalia, este é eliminado da população de detectores. Na segunda etapa, chamada de deteç̧ão, a coleção de detectores é utilizada para discriminar o que é próprio e o que é anômalo.

\subsubsection{Teoria do perigo}

Esta teoria introduzida por Polly Matzinger (Matzinger (1994)) inspirou pesquisadores a desenvolverem sistemas computacionais para a segurança de redes (Aickelin \& Cayzer (2002)). O princípio é que deve haver uma célula apresentadora de antígenos, capaz de capturar e apresentar o sinal de perigo apropriado. Além disto, é necessário estabelecer o que é um sinal de perigo e como este perigo se modifica ao longo do tempo. É preciso também estabelecer as medidas de tempo e espaço para a implementação de um algoritmo baseado nesta inspiração. Os esforços em pesquisas nesta área culminaram com o desenvolvimento dos algoritmos de células dendríticas.

\subsubsection{Algoritmos de células dendríticas}

Os algoritmos de células dendríticas são baseados em um modelo abstrato do comportamento das células dendríticas humanas (Greensmith et al. (2005)). Constituem-se de componentes baseados nas principais propriedades de reconhecimento destas células, dentre as quais se destacam a fusão de dados e correlação. Foram inicialmente concebidos como parte do projeto da teoria do perigo para a detecção de anomalias na área de segurança de redes e depois suas potencialidades foram expandidas a diversas áreas, como aprendizado de máquina e robótica. 


\section{Aplicações em Pesquisa Operacional}

\subsection{Agendamento de tarefas}

O problema de agendamento ou programação de tarefas consiste em alocar recursos limitados visando a realização de um conjunto de tarefas dentro de certo intervalo de tempo. Torna-se um problema de otimização quando se busca o melhor agendamento das atividades. Diferentes funções objetivo podem ser consideradas, tais como minimizar o tempo total gasto (makespan) ou minimizar penalidades por adiantamentos e atrasos em relação às datas de entrega das tarefas. O JSSP (job-shop scheduling problem) consiste em $n$ tarefas a serem processadas por $m$ máquinas. Cada tarefa tem operações que atendem a relações de precedência pré-definidas. Ao processamento da $j$-ésima tarefa na $r$-ésima máquina denota-se como a operação $O_{j r}$ que usará esta máquina durante o período de processamento $p_{j r}$. Uma programação é então um conjunto de tempos de processamento $c_{j r}$ para cada operação satisfazendo as restrições existentes, e um objetivo comum é a minimização do makespan.

A aplicação de SIAs a problemas deste tipo parece ter iniciado com Hart et al. (1998) e Hart \& Ross (1999). Aqui abordaremos o trabalho de Coello et al. (2003), baseado em dois mecanismos dos SIAs: (i) o princípio da seleção clonal; (ii) cada anticorpo é formado pela concatenação de segmentos oriundos de uma biblioteca gênica. Cada elemento desta biblioteca representa um sequência de tarefas processadas por uma máquina e um anticorpo é uma cadeia com a sequência de tarefas processadas por cada máquina. A representação adotada é a de permutações com repetições proposta por Yamada \& Nakano (1997). Além disto, o procedimento inclui um mecanismo de busca local que busca alocar tarefas aproveitando eventuais espaços disponíveis na programação de cada máquina.

O algoritmo inicia gerando aleatoriamente uma biblioteca de anticorpos e, em seguida, um antígeno (solução candidata) também aleatoriamente. Combinando segmentos tomados da biblioteca, um único anticorpo é gerado, decodificado e submetido a uma busca local que visa eliminar hiatos entre as tarefas de uma dada máquina. Se a solução codificada por este anticorpo for superior à codificada pelo antígeno este passa a armazenar o conteúdo do anticorpo. Em seguida $N$ clones são gerados e submetidos à mutação. Os melhores segmentos destas soluções são então usados para atualizar a biblioteca. Neste ponto são feitas comparações entre as sequências de cada máquina com aquelas que compõem o antígeno, procurando pelas melhores soluções parciais para tentar recombiná-las, gerando um novo anticorpo. Observe que a representação adotada torna difícil a definição de uma medida de afinidade entre soluções e, assim, o valor da função objetivo (makespan) é usado para tal. Mais detalhes e um exemplo de aplicação podem ser encontrados em (Coello et al., 2003).

SIAs mais complexos para os problemas de sequenciamento de tarefas vêm sendo desenvolvidos ao longo dos anos como, por exemplo, em (Luh \& Chueh, 2009) e (Bagheri et al., 2010), para o caso de job shop flexível. $\mathrm{O}$ caso de mais de um objetivo (makespan e earliness/tardiness, por exemplo) também vem sendo abordado via SIAs (Gao, 2010).

\subsection{Problemas de roteamento}

Várias problemas reais em PO podem ser enquadrados como problemas de roteamento e a literatura contém diversas aplicações de SIAs a estes casos.

Em (Keko et al., 2003) a ideia de vacinação é introduzida para melhorar o desempenho de um algoritmo genético no problema do caixeiro viajante. A vacinação corresponde ao uso de informação prévia sobre o problema. No caso, pares de cidades conectadas pelas arestas mais curtas (menos custosas) são determinadas e "inoculadas" nas soluções candidatas partindo da hipótese de que tais arestas tem maior probabilidade de estarem presentes na solução ótima. As soluções obtidas nesta primeira fase da busca podem ser melhoradas com o uso da heurística de Lin-Kernighan (Lin \& Kernighan, 1973). Uma possível sofisticação do processo corresponde a gerar e modificar as vacinas durante a busca e selecionar as mais eficazes.

Ma et al. (2009) aplicam um algoritmo de seleção clonal para a resolução do problema de roteamento de um grupo de veículos que devem partir de um depósito central e atender às demandas de vários clientes de maneira a minimizar a distância total percorrida pelos veículos. Além disto, as restrições de capacidade e de comprimento de rota de cada veículo devem ser satisfeitas bem como a restrição de que a demanda de cada cliente deve ser atendida por um único veículo.

Um problema prático complexo é o planejamento de redes de distribuição de energia elétrica. A sua modelagem e resolução podem ser feitas a partir do problema de roteamento de veículos com múltiplos depósitos. Keko et al. (2004) mostram como este problema pode ser modificado para representar adequadamente a estrutura das redes de distribuição de energia e utilizam um algoritmo genético equipado com a ideia de vacinação previamente usada em (Keko et al., 2003) para aumentar seu desempenho.

Uma situação bem mais complexa surge no caso de roteamento dito dinâmico onde alguma característica ou parâmetro do problema não mais se mantem fixa: o ambiente operacional varia ao longo do tempo. Lau 
\& Wong (2005) propõem um arcabouço complexo (AISDR: AIS-Based Dynamic Routing) para o caso de expedição global e transbordo (global shipment and transshipment) de maneira a prover apoio ao processo de planejamento e avaliação de rotas de transporte a fim de eliminar limitações decorrentes da operação manual destes sistemas. A proposta do AISDR se apoia na seleção clonal, memória imunológica, regulação imune, reação imunológica cruzada e propriedades de redes imunológicas (Lau \& Wong, 2005). Um paralelo entre cada caraterística do AISDR e seu correspondente no sistema imune biológico é apresentado nesta referência.

Finalmente, uma abordagem híbrida (neuro-imune) é apresentada por Masutti \& de Castro (2009) para os casos do caixeiro viajante e de múltiplos caixeiros viajantes. O algoritmo RABNET-TSP(Real-Valued Antibody Network to solve the TSP), baseado nas ideias de mapas auto-organizáveis de Kohonen, utiliza o princípio de seleção clonal e maturação da afinidade para o desenvolvimento da rede neuronal.

\subsection{Movimentação global de contêineres}

Devido ao desequilíbrio da balança comercial entre países, contêineres vazios devem ser movidos de um local onde haja excesso deles para outro onde haja um défict. Este reposicionamento deve ser feito da maneira mais econômica possível e Wong et al. (2010) consideram dois objetivos a serem minimizados: o custo total de reposicionamento $\left(f_{1}\right)$ e e demanda não-satisfeita total $\left(f_{2}\right)$ que podem ser escritos como na Equação (7):

$$
C(Q)=\sum_{i=1}^{|S|} \sum_{j=1}^{|D|} \sum_{k=1}^{|V|} c_{i j k} q_{i j k} \quad \text { e } \quad U(Q)=\sum_{j=1}^{|D|} U_{j}
$$

onde $c_{i j k}$ é o custo de mover um contêiner vazio da região de excesso $i \in S$ para o local de deficit $j \in D$ através do navio $k \in V$ e $q_{i j k}$ é a respectiva quantidade de contêineres a serem movidos. $U_{j}$ é a demanda não-satisfeita no $j$-ésimo local de deficit e |.| denota cardinalidade do conjunto. Entretanto a minimização de $C$ e $U$ está sujeita a uma série de restrições sobre as variáveis de decisão $q_{i j k}$ :

1. Restrições de disponibilidade: a quantidade de contêineres a serem movidos do $i$-ésimo local não pode exceder sua disponibilidade $Q_{i}$, como definido pela Equação (8):

$$
\sum_{j=1}^{|D|} \sum_{k=1}^{|V|} q_{i j k} \leq Q_{i} \quad i=1,2, \ldots,|S|
$$

2. Restrições de capacidade: a quantidade total de contêineres transportados pelo $k$-ésimo navio não pode exceder sua capacidade $Q_{k}$, como definido pela Equação (9):

$$
\sum_{i=1}^{|S|} \sum_{j=1}^{|D|} q_{i j k} \leq Q_{k}
$$

3. Restrições de integralidade e não-negatividade das quantidades de contêineres, como definido pela Equação (10):

$$
q_{i j k} \in Z \quad \text { e } \quad q_{i j k} \geq 0
$$

Os problemas de otimização multiobjetivo buscam encontrar soluções ótimas que apresentem a melhor relação entre diversos objetivos, onde cada um deve ser minimizado ou maximizado. Sua formulação matemática pode ser escrita como na Equação (11):

$$
\begin{aligned}
& \operatorname{minimizar} \mathbf{f}(\mathbf{x})=\left[f_{1}(\mathbf{x}), f_{2}(\mathbf{x}), \ldots, f_{k}(\mathbf{x})\right] \\
& \text { sujeito a } \mathbf{x}=\left(x_{1}, x_{2}, \ldots, x_{n}\right) \in \mathcal{S}
\end{aligned}
$$

onde $k(\geq 2)$ é o número de funções objetivo, $\mathcal{S}$ é chamado conjunto ou região viável, f é o vetor das funções objetivo com $f_{i}: \mathbb{R}^{n} \rightarrow \mathbb{R}, \mathbf{x}$ é o vetor de decisão; se $\mathbf{x} \in \mathcal{S}$, então $\mathbf{x}$ é uma solução viável. O conjunto $\mathcal{Z}(=f(\mathcal{S}))$ corresponde ao conjunto imagem da região viável, e cada elemento de $\mathcal{Z}$, chamado de objetivo, é escrito como $\mathbf{z}=\left(z_{1}, z_{2}, \ldots, z_{k}\right)$, onde $z_{i}=f_{i}(\mathbf{x})$ para todo $i=1, \ldots, k$, são chamados valores dos objetivos.

Em geral, os objetivos são conflitantes e não-comensuráveis, impossibilitando que uma única solução otimize todos os objetivos. Assim, faz-se importante o conceito de otimalidade de Pareto, definido a seguir.

Dado $\mathbf{x} \in \mathcal{S}$ um vetor de decisão qualquer, diz-se que $\mathbf{x}$ domina um outro vetor de decisão $\mathbf{x}^{\prime} \in \mathcal{S}$, e escreve-se $\mathbf{x} \prec \mathbf{x}^{\prime}$, se e somente se

$$
f_{i}(\mathbf{x}) \leq f_{i}\left(\mathbf{x}^{\prime}\right) \quad \forall i \in\{1, \ldots, k\} \wedge \exists j \in\{1, \ldots, k\}: f_{j}(\mathbf{x})<f_{j}\left(\mathbf{x}^{\prime}\right)
$$


onde $k$ é o número de objetivos. O vetor de decisão x é dito não-dominado com relação a um conjunto $\mathcal{S}^{\prime} \subseteq \mathcal{S}$, se e somente se, não existir nenhum vetor em $\mathcal{S}^{\prime}$ que domina $\mathbf{x}$. O vetor objetivo $\mathbf{z} \in \mathbb{Z}$ é dito não-dominado, se o seu vetor de decisão $\mathbf{x}$ correspondente é não-dominado. Um vetor de decisão x é um ótimo de Pareto, se e somente se, $\mathbf{x}$ é não-dominado com relação a $\mathbb{S}$. O vetor objetivo $\mathbf{z} \in \mathbb{Z}$ é dito ótimo de Pareto, se o seu vetor de decisão $\mathbf{x}$ correspondente é um ótimo de Pareto. A melhoria de um vetor ótimo de Pareto em qualquer objetivo provoca a degradação em pelo menos algum outro objetivo.

O conjunto ótimo de Pareto contém todas as soluções ótimas de Pareto e o conjunto de vetores objetivos correspondente é denominado fronteira ótima de Pareto.

No caso de problemas com restrições, Wong et al. (2010) adotam o seguinte esquema de dominância: o anticorpo $a_{1}$ domina o anticorpo $a_{2}$ se uma das condições seguintes se verifica:

1. o anticorpo $a_{1}$ é factível (satisfaz às restrições) e $a_{2}$ infactível;

2. ambos são infactíveis mas $a_{1}$ viola menos restrições do que $a_{2}$;

3. ambos são infactíveis, violam a mesma quantidade de restrições mas $a_{1}$ domina $a_{2}$ segundo o conceito básico, envolvendo apenas $f_{1}$ e $f_{2}$;

4. ambas soluções são factíveis mas $a_{1}$ domina $a_{2}$ segundo o conceito básico.

Os principais passos do algoritmo podem então ser sumarizados como:

1. Inicialização da população com soluções geradas aleatoriamente;

2. Avaliação da afinidade de cada solução da população em relação ao seu nível de dominância (medido pelo número de soluções pelas quais ela é dominada) e de diversidade (dada pela medida de densidade populacional na região da solução);

3. Ordenamento da população de acordo com a dominância e, em caso de empate, de acordo com a densidade;

4. Divisão da população em três grupos: um subconjunto com os $30 \%$ de mais alta afinidade (SAA), os próximos $40 \%$ de afinidade média $(\mathrm{SAM})$ e, finalmente, os de baixa afinidade (SAB);

5. Clonagem das soluções em SAA gerando o subconjunto SC;

6. Mutação das soluções em SAM gerando o subconjunto SM;

7. Supressão da população: as $10 \%$ piores soluções são eliminadas, gerando o subconjunto SS;

8. Recrutamento: geração aleatória de novas soluções, criando o subconjunto SR;

9. Reprodução: soluções em SR participam de crossover com as de SC gerando o conjunto SD

10. Iteração: a combinação dos conjuntos SC (clones), SM (mutações) e SD (diversificados) vão compor a próxima população.

Mais detalhes, bem como uma aplicação real deste algoritmo, podem ser encontrados em (Wong et al., 2010).

\subsection{Outras aplicações}

As aplicações de SIAs na Pesquisa Operacional, isoladamente ou hibridizadas com outras heurísticas, não se limitam, obviamente, a estas aqui destacadas. Muitas outras podem ser encontradas na literatura como, por exemplo, na programação de projetos sujeita a restrições de recursos (Agarwal et al., 2007; van Peteghem \& Vanhoucke, 2009; van Peteghem \& Vanhoucke, 2013; Mobini et al., 2011), na alocação de recursos numa rede de comunicações (Costanza et al., 2011) e na programação de estoque e produção (Wang et al., 2007).

\section{Conclusões}

Após uma apresentação geral dos principais aspectos do sistema imunológico, este capítulo apresentou um conjunto de técnicas computacionais imuno-inspiradas e finalizou descrevendo suas aplicações a problemas em Pesquisa Operacional.

\section{Agradecimentos}

Os autores agradecem o apoio financeiro do CNPq (Processos 308317/2009-2 e 300192/2012-6). 


\section{Referências}

Abbas, A.K.; Lichman, A.H. \& Pober, J.S., Imunologia Celular e Molecular. 2a edição. Rio de Janeiro, RJ: Revinter, 1998.

Ada, G.L. \& Nossal, G.J.V., The clonal selection theory. Scientific American, 257(2):50-57, 1987.

Agarwal, R.; Tiwari, M. \& Mukherjee, S., Artificial immune system based approach for solving resource constraint project scheduling problem. International Journal of Advanced Manufacturing Technology, 34(5-6):584-593, 2007.

Aickelin, U. \& Cayzer, S., The danger theory and its application to artificial immune systems. In: Proceedings of the 1st International Conference on Artificial Immune Systems. p. 141-148, 2002.

Bäck, T.; Fogel, D.B. \& Michalewicz, Z. (Eds.), Evolutionary Computation 2: Advanced Algorithms and Operations. Bristol, UK: Institute of Physics Publishing, 2000.

Bagheri, A.; Zandieh, M.; Mahdavi, I. \& Yazdani, M., An artificial immune algorithm for the flexible job-shop scheduling problem. Future Generation Computer Systems, 26(4):533-541, 2010.

Bernardino, H.S. \& Barbosa, H.J.C., Artificial immune systems for optimization. In: Chiong, R. (Ed.), Nature-Inspired Algorithms for Optimisation. Berlin, Germany: Springer, p. 389-411, 2009.

Bernardino, H.S.; Barbosa, H.J.C. \& Fonseca, L.G., Surrogate-assisted clonal selection algorithms for expensive optimization problems. Evolutionary Intelligence, 4:81-97, 2011.

Burnet, F.M., A modification of Jerne's theory of antibody production using the concept of clonal selection. Australian Journal of Science, 20:67-69, 1957.

Coello, C.A.C.; Rivera, D.C. \& Cortés, N.C., Use of an artificial immune system for job shop scheduling. In: Timmis, J.; Bentley, P.J. \& Hart, E. (Eds.), Proceedings of the International Conference on Artificial Immune Systems. Heidelberg, Germany: Springer-Verlag, v. 2787 de Lecture Notes in Computer Science, p. 1-10, 2003.

Cormack, D.H., HAM Histologia. 9a edição. Rio de Janeiro, RJ: Guanabara Koogan, 1991.

Costanza, J.; Cutello, V. \& Pavone, M., A memetic immunological algorithm for resource allocation problem. In: Liò, P.; Nicosia, G. \& Stibor, T. (Eds.), Proceedings of the International Conference on Artificial Immune Systems. Heidelberg, Germany: Springer-Verlag, v. 6825 de Lecture Notes in Computer Science, p. 308-320, 2011.

Cutello, V.; Narzisi, G.; Nicosia, G. \& Pavone, M., Clonal selection algorithms: A comparative case study using effective mutation potentials. In: Jacob, C.; Pilat, M.L.; Bentley, P.J. \& Timmis, J.I. (Eds.), Proceedings of the International Conference on Artificial Immune Systems. Heidelberg, Germany: Springer-Verlag, v. 3627 de Lecture Notes in Computer Science, p. 13-28, 2005a.

Cutello, V.; Narzisi, G.; Nicosia, G. \& Pavone, M., An immunological algorithm for global numerical optimization. In: Talbi, E.G.; Liardet, P.; Collet, P.; Lutton, E. \& Schoenauer, M. (Eds.), Proceedings of the International Conference on Artificial Evolution. Heidelberg, Germany: Springer-Verlag, v. 3871 de Lecture Notes in Computer Science, p. 284-295, 2005b.

Cutello, V. \& Nicosia, G., An immunological approach to combinatorial optimization problems. In: Garijo, F.J.; Riquelme, J.C. \& Toro, M. (Eds.), Proceedings of the Ibero-American Conference on Artificial Intelligence. Heidelberg, Germany: Springer-Verlag, v. 2527 de Lecture Notes in Computer Science, p. 361-370, 2002.

Cutello, V.; Nicosia, G. \& Pavone, M., A hybrid immune algorithm with information gain for the graph coloring problem. In: Cantú-Paz, E. (Ed.), Proceedings of the Genetic and Evolutionary Computation Conference. Heidelberg, Germany: Springer-Verlag, Lecture Notes in Computer Science, 2003.

Cutello, V.; Nicosia, G. \& Pavone, M., Exploring the capability of immune algorithms: A characterization of hypermutation operators. In: Nicosia, G.; Cutello, V.; Bentley, P.J. \& Timmis, J. (Eds.), Proceedings of the International Conference on Artificial Immune Systems. Heidelberg, Germany: Springer-Verlag, v. 3239 de Lecture Notes in Computer Science, p. 263-276, 2004.

Cutello, V.; Nicosia, G. \& Pavone, M., An immune algorithm with stochastic aging and Kullback entropy for the chromatic number problem. Journal of Combinatorial Optimization, 14(1):9-33, 2007.

de Castro, L.N., Engenharia Imunológica: Desenvolvimento e Aplicações de Ferramentas Computacionais Inspiradas em Sistemas Imunológicos Artificiais. Tese de doutorado, Universidade Estadual de Campinas, Campinas, SP, 2001.

de Castro, L.N. \& Timmis, J., An artificial immune network for multimodal function optimization. In: Proceedings of the Congress on Evolutionary Computation. Piscataway, USA: IEEE Press, v. 1, p. 699-704, 2002a.

de Castro, L.N. \& Timmis, J., Artificial Immune Systems: A New Computational Intelligence Approach. London, UK: Springer, 2002b.

de Castro, L.N. \& Timmis, J., An Introduction to Artificial Immune Systems: A New Computational Intelligence Paradigm. Berlin, Germany: Springer-Verlag, 2002c.

de Castro, L.N. \& von Zuben, F.J., The clonal selection algorithm with engineering applications. In: Proceedings of the Genetic and Evolutionary Computation Conference. p. 37, 2000.

de Castro, L.N. \& von Zuben, F.J., aiNet: An artificial immune network for data analysis. In: Abbass, H.A.; Sarker, R.A. \& Newton, C.S. (Eds.), Data Mining: A Heuristic Approach. Hershey, USA: Idea Group Publishing, p. 231-259, 2001. 
de Castro, L.N. \& von Zuben, F.J., Learning and optimization using the clonal selection principle. IEEE Transactions on Evolutionary Computation, 6(3):239-251, 2002.

Gao, J., A novel artificial immune system for solving multiobjective scheduling problems subject to special process constraint. Computers \& Industrial Engineering, 58(4):602-609, 2010.

Garrett, S.M., Parameter-free, adaptive clonal selection. In: Proceedings of the Congress on Evolutionary Computation. Piscataway, USA: IEEE Press, v. 1, p. 1052-1058, 2004.

Goldberg, D.E. \& Richardson, J., Genetic algorithms with sharing for multimodal function optimization. In: Proceedings of the Conference on Genetic Algorithms on Genetic Algorithms and Their Application. Mahwah, USA: Lawrence Erlbaum Associates, p. 41-49, 1987.

Golub, E.S., Is the function of the immune system only to protect? In: Theoretical and Experimental Insights into Immunology. Berlin, Germany, v. 66 de NATO ASI Series, p. 15-26, 1992.

Greensmith, J.; Aickelin, U. \& Cayzer, S., Introducing dendritic cells as a novel immune-inspired algorithm for anomaly detection. In: Jacob, C.; Pilat, M.L.; Bentley, P.J. \& Timmis, J.I. (Eds.), Proceedings of the 4th International Conference on Artificial Immune Systems. Heidelberg, Germany: Springer-Verlag, v. 3627 de Lecture Notes in Computer Science, p. 153-167, 2005.

Hart, E. \& Ross, P., The evolution and analysis of potential antibody library for use in job-shop scheduling. In: Corne, D.; Dorigo, M.; Glover, F.; Dasgupta, D.; Moscato, P.; Poli, R. \& Price, K.V. (Eds.), New ideas in optimization. Maidenhead, UK: McGraw-Hill, p. 185-202, 1999.

Hart, E.; Ross, P. \& Nelson, J., Producing robust schedules via an artificial immune system. In: Proceedings of the International Conference on Computational Intelligence. Piscataway, USA: IEEE Press, p. 464-469, 1998.

Hofmeyr, S.A. \& Forrest, S., Architecture for an artificial immune system. Evolutionary Computation, 8(4):443-473, 2000.

Janeway, C.A.; Travers, P.; Walport, M. \& Shlomchik, M., Immunobiologia: O sistema imune na saúde e na doença. 5a edição. Porto Alegre, RS: Artes Médicas, 2001.

Keko, H.; Skok, M. \& Skrlec, D., Artificial immune systems in solving routing problems. In: Proceedings of the International Conference on Computer As A Tool. v. 1, p. 62-66, 2003.

Keko, H.; Skok, M. \& Skrlec, D., Solving the distribution network routing problem with artificial immune systems. In: Proceedings of the Mediterranean Electrotechnical Conference. v. 3, p. 959-962, 2004.

Kelsey, J. \& Timmis, J., Immune inspired somatic contiguous hypermutation for function optimisation. In: Cantú-Paz, E. (Ed.), Proceedings of the Genetic and Evolutionary Computation Conference. Heidelberg, Germany: SpringerVerlag, v. 2723 de Lecture Notes in Computer Science, 2003.

Lau, H. \& Wong, E., An AIS-based dynamic routing (AISDR) framework. In: Jacob, C.; Pilat, M.; Bentley, P. \& Timmis, J. (Eds.), Proceedings of the International Conference on Artificial Immune Systems. Heidelberg, Germany: Springer-Verlag, v. 3627 de Lecture Notes in Computer Science, p. 56-71, 2005.

Lee, Y.C. \& Zomaya, A.Y., Immune system support for scheduling. In: Prokopenko, M. (Ed.), Advances in Applied Self-organizing Systems. Springer London, Advanced Information and Knowledge Processing, p. 247-270, 2008.

Lin, S. \& Kernighan, B.W., An effective heuristic algorithm for the traveling-salesman problem. Operations Research, 21(2):498-516, 1973.

Luh, G.C. \& Chueh, C.H., A multi-modal immune algorithm for the job-shop scheduling problem. Information Sciences, 179(10):1516-1532, 2009.

Ma, J.; Gao, L. \& Shi, G., An improved immune clonal selection algorithm and its applications for VRP. In: Proceedings of the International Conference on Automation and Logistics. p. 2097 -2100, 2009.

Mahfoud, S.W., Niching methods for genetic algorithms. PhD Thesis, University of Illinois at Urbana-Champaign, Champaign, USA, 1995.

Masutti, T.A. \& de Castro, L.N., Neuro-immune approach to solve routing problems. Neurocomputing, 72(10-12):21892197, 2009.

Matzinger, P., Tolerance, danger, and the extended family. Annual review of immunology, 12(1):991-1045, 1994.

Mobini, M.; Mobini, Z. \& Rabbani, M., An artificial immune algorithm for the project scheduling problem under resource constraints. Applied Soft Computing, 11(2):1975-1982, 2011.

Pavone, M.; Narzisi, G. \& Nicosia, G., Clonal selection: an immunological algorithm for global optimization over continuous spaces. Journal of Global Optimization, 53(4):769-808, 2012.

van Peteghem, V. \& Vanhoucke, M., An artificial immune system algorithm for the resource availability cost problem. Flexible Services and Manufacturing Journal, 25(1-2):122-144, 2013.

Tizard, I., Introdução à Imunologia Veterinária. 2a edição. São Paulo, SP: Roca, 1985.

van Peteghem, V. \& Vanhoucke, M., An artificial immune system for the multi-mode resource-constrained project scheduling problem. In: Cotta, C. \& Cowling, P. (Eds.), Proceedings of the European Conference on Evolutionary Computation in Combinatorial Optimization. Heidelberg, Germany: Springer-Verlag, v. 5482 de Lecture Notes in Computer Science, p. 85-96, 2009. 
Wang, X.P.; Zhao, H. \& Shang, H.Y., Simulation and optimization of a production/inventory system based on immune evolutionary algorithm. In: Proceedings International Conference on Management Science and Engineering. Piscataway, USA: IEEE Press, p. 796-801, 2007.

Wong, E.; Lau, H. \& Mak, K., Immunity-based evolutionary algorithm for optimal global container repositioning in liner shipping. OR Spectrum, 32:739-763, 2010.

Yamada, T. \& Nakano, R., Job-shop scheduling. In: Genetic Algorithms in Engineering Systems. Stevenage, UK: The Institution of Electrical Engineers, Control engineering, p. 134-160, 1997.

\section{Notas Biográficas}

Grazziela Patrocinio Figueredo é graduada em Informática (Universidade Federal de Juiz de Fora, 2002), mestre em Engenharia de Sistemas e Computação e doutor em Computação de Alto Desempenho (COPPE/UFRJ, 2004 e 2008, respectivamente). Atualmente trabalha como pesquisadora na Universidade de Nottingham. Tem experiência na área de Ciência da Computação, com ênfase em Inteligência Artificial, atuando principalmente em modelagem e simulação computacional, sistemas imunes artificiais e mineração de dados.

Heder Soares Bernardino é graduado em Ciência da Computação e mestre em Modelagem Computacional (Universidade Federal de Juiz de Fora, 2006 e 2008, respectivamente). Atualmente é aluno de doutorado no programa de pós-graduação do Laboratório Nacional de Computação Científica (LNCC/MCTI). Interessa-se em meta-heurísticas, em especial para a descoberta de conhecimento, inferência de modelos e geração automática de projetos estruturais, bem como em computação de alto desempenho. Atualmente é professor do departamento de Ciência da Computação da UFJF.

Helio José Corrêa Barbosa é graduado em Engenharia Civil (Universidade Federal de Juiz de Fora, 1974), mestre e doutor em Engenharia Civil (COPPE/UFRJ, 1978 e 1986, respectivamente). Atualmente é Tecnologista Senior no Laboratório Nacional de Computação Científica e Professor Associado do Departamento de Ciência da Computação da Universidade Federal de Juiz de Fora. Tem interesse no desenho e aplicação de meta-heurísticas em engenharia e biologia. 
Figueredo et al. 


\title{
Times Assíncronos
}

\author{
Jesmmer da Silveira Alves e Humberto José Longo*
}

\begin{abstract}
Resumo: Times Assíncronos são organizações de software que visam a interação eficiente entre vários algoritmos para a resolução de problemas adequados à abordagem multi-algorítmica. Apesar do conceito simples e das evidentes vantagens deste método, é importante que o projetista escolha uma disposição de agentes e memórias adequada para melhor cooperação dos elementos no time e, com isto, melhor aproveitamento das estratégias utilizadas. Este capítulo descreve o conceito de Times Assíncronos, destacando suas principais características e vantagens, o projeto e a implementação de um $A$-Team mínimo.
\end{abstract}

Palavras-chave: Times assíncronos, A-teams, Multi-algorítmico.

Abstract: Asynchronous Teams are software organizations aimed at allowing an efficient interaction among various algorithms. Despite its simple concept and its obvious advantages, it is important that the designer set an adequate agents and memories architecture for better cooperation of elements in the team and, thus, better use of the selected strategies. This chapter describes the concept of Asynchronous Teams, highlighting its key features and advantages, the project and implementation of a minimum A-Team.

Keywords: Asynchronous Teams, A-Teams, Multi-algorithmic.

\section{Introdução}

Ao considerar-se a classe de problemas $\mathcal{N} \mathcal{P}$-difíceis, observa-se que, para um grande espectro de problemas, são conhecidas heurísticas que fornecem soluções de boa qualidade para um certo conjunto de instâncias desses problemas. Mais ainda, quando o estudo concentra-se em casos particulares de um problema, algoritmos exatos e "rápidos" podem até existir. Por outro lado, estes algoritmos podem falhar, seja por não se adequarem à instância que se deseja resolver, seja pela dificuldade de se identificar que a instância corresponde a um caso particular.

Esses problemas, para os quais nenhum algoritmo conhecido é completamente satisfatório, têm motivado a proposição de métodos multi-algorítmicos de resolução. O princípio de tais métodos é que, para problemas com certo grau de dificuldade de resolução, algoritmos "simples" podem cooperar entre si de modo a gerar soluções de qualidade equivalente, ou mesmo superiores, à qualidade das soluções geradas por um algoritmo muito mais complexo. Esses algoritmos "simples", em geral, são heurísticas que implementam uma intuição sobre o problema e têm como característica básica um tempo reduzido de processamento.

Entretanto, a simples ideia de se combinar diferentes técnicas para a resolução de um problema não é suficiente para que se obtenha um algoritmo que garanta uma eficiência aceitável na resolução de qualquer instância do problema. A dificuldade está na interação entre diferentes algoritmos, pois nem sempre uma determinada combinação destes permite uma boa utilização do tempo disponível para o processamento, ou mesmo uma colaboração eficiente entre os algoritmos.

Esta dificuldade é reduzida quando utiliza-se uma arquitetura como a de Times Assíncronos (Souza, 1993; Talukdar, 1993). Estes são organizações de software que visam a interação eficiente entre vários algoritmos para a resolução de problemas adequados à abordagem multi-algorítmica. Um A-Team (do termo em inglês Asynchronous Team) é basicamente composto por agentes autônomos e repositórios ou memórias compartilhadas de soluções. Os agentes são algoritmos encapsulados com um protocolo de comunicação, mas que se comunicam de forma assíncrona, ou seja, um agente não troca informações diretamente com outro agente, o que ocorre exclusivamente através das memórias compartilhadas.

A característica mais atraente do paradigma de $A$-Teams está na sua flexibilidade. Os agentes em um $A$-Team, ao atuarem de forma autônoma, são suscetíveis de serem introduzidos ou retirados da organização a qualquer momento. Outro ponto importante é que a comunicação assíncrona entre os agentes permite que

*Autor para contato: longo@inf.ufg.br 
estes sejam executados em paralelo, com a comunicação entre eles gerando um fluxo contínuo de modificações no conteúdo das memórias compartilhadas.

O objetivo deste Capítulo é mostrar importância de A-Teams na resolução de problemas complexos da pesquisa operacional. Assim, a Seção 2, além de caracterizar os A-Teams, descreve os seus principais componentes e uma representação gráfica usual para os mesmos; a Seção 3 descreve as principais etapas que devem ser observadas durante o projeto de um A-Team; a Seção 4 descreve os passos básicos para implementação de um $A$-Team através do padrão MPI e os elementos básicos de um $A$-Team Mínimo; a Seção 5 apresenta a aplicação deste paradigma aos mais diferentes problemas encontrados na literatura; e a Seção 6 expõe as considerações finais dos autores sobre a utilização de $A$-Teams.

\section{Times Assíncronos}

\subsection{Conceitos básicos}

Um Dado pode ser definido como qualquer elemento com algum significado. Quando um dado é manipulado, processado ou organizado, passa a ser considerado uma Informação. Aqui serão utilizados os termos Solução Viável para referenciar dados processados que satisfaçam requisitos pré-definidos de algum problema, Solução Ótima para referenciar uma solução viável que satisfaça da melhor forma possível todos os requisitos pré-definidos de um problema, Solução Ideal para referenciar uma solução ótima ou suficientemente próxima da ótima e Solução Promissora para referenciar uma solução com possibilidade de se tornar uma solução ideal.

O conjunto de soluções ideais para problemas multi-objetivos também é conhecido como Pareto Ótimo ou Não-Dominadas. O termo não-dominadas é devido ao fato de tais soluções possuírem critérios que não são dominados por nenhum outro critério presente em soluções no conjunto. Quando um conjunto de soluções possui critérios individuais que não podem ser otimizados sem o declínio de outros critérios, diz-se que tal conjunto pertence à fronteira do Pareto Ótimo.

\subsection{Caracterização de A-teams}

Times Assíncronos ou A-Teams são organizações de software compostas por Agentes, Memórias e Relações (entre memórias). Os agentes são responsáveis pela geração de novas soluções ou manipulação de soluções nas memórias (inserir, eliminar ou modificar uma solução). As memórias são repositórios de soluções e são também a única forma de comunicação entre os agentes. As relações definem como as soluções fluem no A-Team e a forma de acesso de agentes ao conjunto de memórias compartilhadas (fluxo de soluções).

A ideia básica por trás dos $A$-Teams é considerar um conjunto inicial de soluções (soluções candidatas) e efetuar transformações nestas soluções até se alcançar um conjunto de soluções ideais. O agente, o principal elemento neste processo, encapsula um algoritmo "simples" e possui habilidades que determinam que tipo de tarefas pode executar. A combinação de agentes de mesmo tipo (mas que podem executar tarefas diferentes) constituem organizações, que são responsáveis pela forma como os agentes vão trabalhar, interagir e cooperar uns com os outros.

As principais características deste tipo de organização de software são (Souza, 1993):

Autonomia: inexistência de agentes supervisores. Embora possam existir diferentes classes de agentes, não pode haver relacionamento hierárquico entre eles e todos os agentes devem atuar de forma autônoma;

Comunicação Assíncrona: nenhum tipo de sincronismo é permitido na execução dos agentes, ou seja, os agentes não podem esperar pela execução ou processamento de soluções por outros agentes. Além disso, um agente não troca informações diretamente com outro agente, isto ocorre exclusivamente através das memórias compartilhadas;

Fluxo de Dados Cíclico: as soluções geradas e/ou modificadas por um agente são depositadas nas memórias e disponibilizadas a outros agentes para serem novamente modificadas (os dados de saída de um agente são dados de entrada para outro agente);

Consenso Gradual: no início uma grande variedade de soluções é considerada, mas após algum tempo de processamento o consenso emerge, restando somente algumas alternativas que são disponibilizadas a todos os agentes. O bom desempenho de alguns agentes pode direcionar o trabalho dos demais a um conjunto promissor de soluções;

Sinergia: a combinação de algoritmos de maneira cooperativa produz melhores resultados que a execução dos mesmos individualmente; e 
Eficiência em escala: a quantidade de agentes e memórias no time influencia na qualidade e na velocidade em que soluções ideais são geradas.

Tais características lembram alguns sistemas naturais, como sociedades de insetos e comunidades celulares (Cicirello \& Smith, 2001), muitas das quais apresentam estas mesmas características básicas ou uma boa parte delas. Nas colônias de formigas, por exemplo, a perda de um grupo pequeno de formigas não compromete a colônia, uma vez que todo o trabalho é feito de forma autônoma pelos membros da colônia. O trabalho em paralelo e independente de seus agentes (formigas) permite que a organização (colônia) atinja o seu objetivo (sobrevivência da colônia).

Algumas organizações de software podem apresentar um subconjunto destas características. Entretanto, nenhuma outra organização, além dos A-Teams, apresenta todas estas características ao mesmo tempo. Isto faz dos $A$-Teams uma importante ferramenta na busca de soluções de boa qualidade para problemas complexos, como problemas de otimização combinatória e problemas multi-objetivos, para os quais heurísticas aplicadas isoladamente não conseguem alcançar bons resultados.

\subsection{Representação gráfica de A-teams}

A representação gráfica mais usual para os elementos de um A-Team utiliza retângulos para memórias básicas e/ou composições destas e setas para os agentes. A direção das setas indica a direção do fluxo de soluções que são manipuladas pelos agentes.

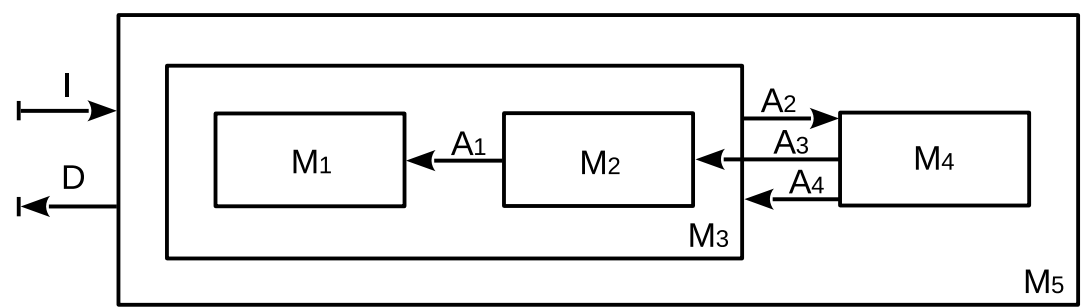

Figura 1. A-Team com 5 memórias e 6 agentes (setas representando agentes e retângulos representando memórias).

No exemplo da Figura 1 a memória $M_{3}$ é composta pelas memórias básicas $M_{1}$ e $M_{2}$, o agente $A_{1}$ lê da memória $M_{2}$ e escreve na memória $M_{1}, A_{2}$ lê de $M_{3}$ (de $M_{1}$ e/ou $M_{2}$ ) e escreve em $M_{4}, A_{3}$ lê de $M_{4}$ e escreve em $M_{2}$ e o agente $A_{4}$ lê de $M_{4}$ e escreve em $M_{3}$ (em $M_{1}$ e/ou $M_{2}$ ). Para alguns agentes com funções específicas não há necessidade de se representar a origem ou o destino das soluções e podem ser omitidos um desses ambientes, como os agentes $I$, que faz um preenchimento inicial das memórias, e $D$, que tem a função de eliminar soluções das memórias.

Esta representação gráfica evidencia os ambientes de entrada e saída dos agentes, ou seja, os conjuntos de memórias de onde e para onde os agentes podem ler e escrever soluções, respectivamente. Um mesmo ambiente pode servir como entrada e saída de soluções para um agente e ser um ambiente composto, como uma memória que possui outras memórias em sua estrutura. Neste caso, todos os agentes que têm acesso para leitura e/ou escrita a uma composição, também podem acessar todas as soluções em memórias internas à mesma. Tomando-se como exemplo o agente $A_{4}$, o seu ambiente de entrada é a memória $M_{4}$ e o seu ambiente de saída é composto pelas memórias $M_{1}$ e $M_{2}$.

Além dos agentes normalmente usados em um A-Team, como aqueles mostrados na Figura 1, há um conjunto de agentes utilizados durante a sua execução (agentes de manutenção) que, em geral, não são representados graficamente. O motivo é que esses agentes não são usados para resolver o problema em si, mas para realizar ações especificadas pelo projetista ou usuário durante a execução do $A$-Team, ou seja, ações como:

- Iniciar e parar o $A$-Team;

- Emitir relatórios sobre os elementos na estrutura; ou

- Ativar e/ou desativar elementos presentes no A-Team.

Uma representação gráfica para estes elementos é mostrada na Figura 2. Um retângulo tracejado é usado para representar todo o $A$-Team; setas unidirecionais são usadas para representar a aplicação de ações em um único sentido pelo projetista/usuário do A-Team; setas bi-direcionais representam ações nos dois sentidos, geralmente o projetista/usuário executa uma ação e aguarda o resultado do processamento da mesma pelo A-Team. 


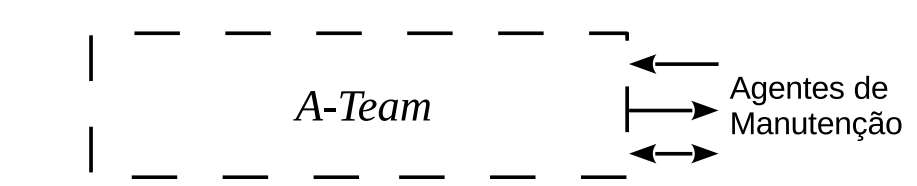

Figura $\overline{2 .}$ Representação de agentes de manutenção de um $A$-Team.

\section{O Projeto de um A-Team}

Alguns aspectos básicos, discutidos nas próximas seções, devem ser observados durante o projeto de um $A$-Team para permitir que diferentes formas de implementação, configuração e execução do mesmo sejam identificadas. Dentre esses aspectos, destacam-se a análise e decomposição do problema a ser resolvido, a definição dos parâmetros de configuração, a definição da topologia da rede de agentes e memórias, a garantia de fluxos cíclicos de dados entre os agentes e a sequência de execução dos agentes.

\subsection{Análise e decomposição do problema}

O primeiro passo no projeto de um A-Team é definir o problema a ser tratado. Nesta etapa são identificadas as características do problema, tais como suas variáveis, domínios e restrições. Depois disto, é necessário identificar os resultados esperados na execução do A-Team. Tais resultados não necessariamente devem ser ótimos, pois dependendo do tipo do problema o usuário pode ter que selecionar um conjunto de soluções que considerar ideais. Em problemas multi-objetivos, por exemplo, diversas funções objetivo devem ser satisfeitas e dificilmente se encontra uma única solução que satisfaça cada uma das funções objetivo.

Dada a especificação de um problema e a correta identificação do padrão de qualidade desejado, uma tarefa óbvia na tentativa de diminuir a complexidade é tentar decompor o problema original em subproblemas, ou relaxações do mesmo. A decomposição do problema e a diversificação dos algoritmos utilizados permite que projetistas manipulem propriedades que podem influenciar a eficácia do projeto em desenvolvimento.

Esta é uma tarefa bastante específica e difícil de formalizar, pois depende muito das características do problema a ser resolvido. Cada decomposição pode ser associada a uma ou mais memórias, desta forma, projetistas podem fazer uso dos diversos métodos na literatura para resolver cada decomposição. Entretanto, dois critérios importantes devem ser observados, a habilidade em prover soluções e a satisfação das restrições especificadas por cada subdivisão do problema original.

\subsection{Topologia do A-team}

A topologia do A-Team é definida pela disposição dos agentes e memórias e pelo fluxo de dados entre esses elementos, e pode influenciar diretamente o desempenho do mesmo. É evidente que diferentes topologias permitem que diferentes sequências de agentes sejam aplicadas sobre as soluções nas memórias e, consequentemente, diferentes resultados podem ser alcançados. Ainda mais, o conjunto de agentes pode ser aplicado de diversas formas, dentre elas:

- Um time formado por várias cópias do mesmo algoritmo, possivelmente com diferentes configurações para os seus parâmetros;

- Um time formado por vários tipos de algoritmos. Neste caso, geralmente os algoritmos possuem funções distintas; e

- Uma terceira alternativa seria a combinação das duas opções anteriores, ou seja, vários tipos de algoritmos com várias cópias de cada tipo de algoritmo.

Uma topologia básica contém uma única memória e o conjunto de agentes trabalham sobre as soluções desta memória (Figura 3(a)). Esta topologia, embora simples, pode ser bastante útil e bem fácil de projetar. Entretanto, todo o conjunto de soluções nesta memória deve possuir a mesma representação (estrutura).

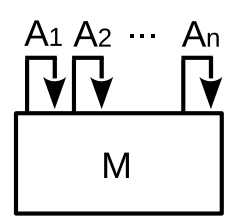

(a)

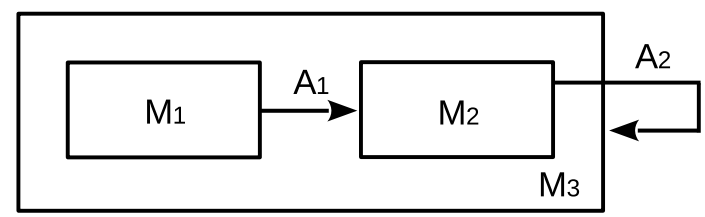

(b)

Figura 3. Estrutura de um A-Team com (a) uma única memória e (b) mais de uma memória.

Quando as soluções têm a mesma representação, é evidente a possibilidade de se usar uma única memória. Entretanto, a população de soluções pode ter diferentes representações e podem ser armazenadas em diferentes 
memórias, dependendo da aplicação e dos algoritmos a serem utilizados. A opção por utilizar mais de um repositório de dados, na maioria das vezes, é escolhida através de um estudo das características tanto dos subproblemas e/ou relaxações do problema original, quanto das características das soluções produzidas pelas heurísticas disponíveis.

No exemplo da Figura 3(b), uma solução armazenada na memória $M_{1}$ somente estaria disponível ao agente $A_{2}$, através da memória $M_{2}$, após ser processada pelo agente $A_{1}$. Outra característica importante desta estrutura é que uma solução que acabou de ser trabalhada pelo agente $A_{1}$ não será mais selecionada pelo mesmo antes de ser trabalhada pelo agente $A_{2}$. Esta característica é bastante relevante quando se utiliza agentes de comportamento determinístico, pois evita o processamento de uma solução que acabou de ser gerada.

No exemplo da Figura 4, o deslocamento de uma solução ou conjunto de soluções da memória $M_{1}$ para a memória $M_{2}$, é resultante da seguinte sequência de transformações:

- zero ou mais transformações pelo agente $A_{1}$;

- uma transformação pelo agente $A_{2}$; e

- zero ou mais transformações pelo agente $A_{3}$.

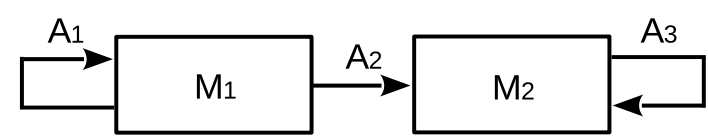

Figura 4. Controlando a sequência de transformações.

Outras estruturas diferentes, com características peculiares, podem ser utilizadas no projeto do $A$-Team. O projetista pode, por exemplo, usar a própria estrutura para restringir a leitura e/ou a escrita (de soluções) a um conjunto limitado de soluções (Figuras 5(a) e 5(b)).

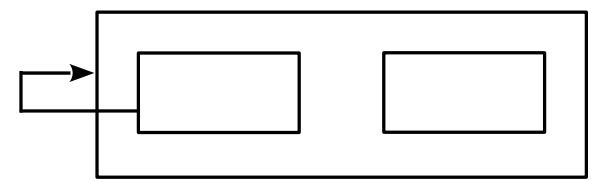

(a)

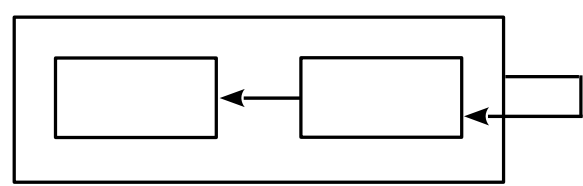

(b)

Figura 5. Restrição de leitura e/ou escrita a um conjunto limitado de soluções: (a) leitura de uma memória e (b) escrita em uma memória.

Em algumas situações o projetista pode ter a necessidade de garantir o processamento de uma determinada solução por um agente ou conjunto de agentes. No exemplo da Figura 6 , suponha que $M_{4}$ trabalha com uma estrutura sequencial de organização das soluções (first in - first out). Neste caso, qualquer solução oriunda das memórias $M_{1}$ e/ou $M_{2}$, ao ser processada pelos agentes $A_{1}$ e $A_{2}$, deve ser processada pelo agente $A_{3}$ antes de novamente ser colocada a disposição dos dois primeiros agentes. Note-se que agora, diferentemente da situação mostrada na Figura 1, não há necessidade de atuação dos agentes $I$ e $D$ na memória $M_{4}$.

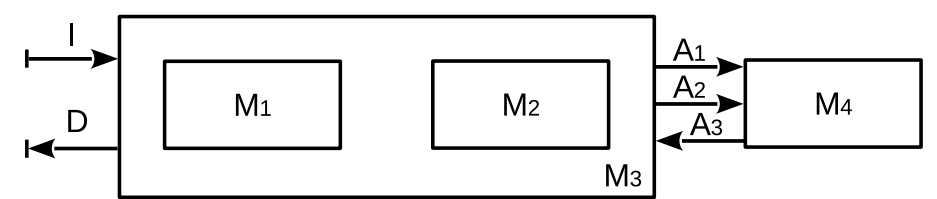

Figura 6. Garantia de processamento de uma solução por um agente ou conjunto de agentes.

O atendimento de vários requisitos previamente definidos, como a restrição de acesso a soluções pelos agentes ou a obrigatoriedade de se realizar uma sequência de transformações nas soluções armazenadas nas memórias, pode ser necessário ao se definir a topologia de um A-Team. O projetista pode usar as relações de processamento entre pares de agentes no atendimento de tais requisitos. A relação de processamento entre um par de agentes descreve qual dos agentes do par, possivelmente, trabalhará com soluções produzidas ou manipuladas pelo outro agente. O conjunto destas relações de processamento também define todas as possíveis sequências de transformações nas soluções.

Uma representação gráfica das relações de processamento (somente com agentes construtores e modificadores) do $A$-Team da Figura 1 pode ser visto na Figura 7. Cada seta representa um relacionamento entre dois agentes, sendo que a direção de uma seta determina uma possível sequência de processamento de uma solução. 


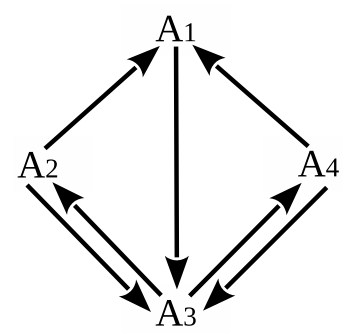

Figura 7. Exemplo de relações de processamento entre pares de agentes.

\subsection{Fluxo de dados cíclico}

A sequência com que as soluções fluem determina a sequência de transformações efetuadas pelos agentes e a forma como os agentes vão interagir e cooperar uns com os outros. Este fluxo de soluções das memórias para os agentes, e vice-versa, deve ser Cíclico, de modo que as alterações realizadas por um agente sejam depositadas nas memórias e novamente disponibilizadas a outros agentes do A-Team.

Um fluxo de dados é Fortemente Cíclico se todas as possíveis sequências de execução dos agentes formam laços (caminhos fechados). Garantir em um A-Team o fluxo de dados cíclico, ou fortemente cíclico, é permitir que todos os agentes troquem informações entre si e consequentemente cooperem uns com os outros, ou seja, a interação e cooperação são ações possíveis entre todos os agentes do time. Um dos modos de garantir a cooperação entre agentes é definir a topologia sempre se preocupando em construir memórias cíclicas. Uma memória $M$ é uma Memória Cíclica se todos os agentes que podem escrever (depositar soluções) em $M$ também podem ler soluções de $M$ (Talukdar et al., 1998).

Claramente, memórias em que todos os agentes possuem o espaço de entrada igual ao espaço de saída são memórias cíclicas (ver Figura 3(a)). Ainda mais, para dois agentes, $A_{1}$ e $A_{2}$, e duas memórias, $M_{1}$ e $M_{2}$, se o espaço de entrada de $A_{1}\left(M_{1}\right)$ for igual ao espaço de saída de $A_{2}$, e reciprocamente, o espaço de entrada de $A_{2}\left(M_{2}\right)$ for igual ao espaço de saída de $A_{1}$, ambos os agentes formam um laço e ambas as memórias são memórias cíclicas (Figura 8).

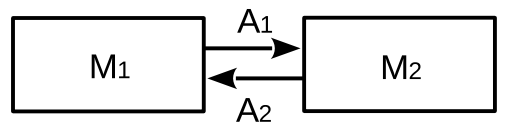

Figura 8. Memórias $M_{1}$ e $M_{2}$ cíclicas, com agentes $A_{1}$ e $A_{2}$ em um laço.

Em estruturas mais complexas, com um número considerável de memórias e agentes, o projetista pode garantir o fluxo de dados cíclico. Neste caso, para todo agente no fluxo de dados, deve existir um caminho $P(M, M)$ em que o espaço de entrada do primeiro agente no caminho é a memória $M$ e o espaço de saída do último agente no caminho também é a memória $M$ (ver Figura 9(a)). Se esta proposição for verdadeira para todos os agentes no fluxo de dados, a topologia construída corresponde a um fluxo de dados cíclico. A argumentação para isto é a seguinte: se para todo agente no fluxo de dados existe um caminho $P(M, M)$ que pode ser substituído por um super-agente hipotético $A_{s}$, que é a concatenação de todos os agentes no caminho, então a memória $M$ é uma memória cíclica (ver Figura 9(b)).

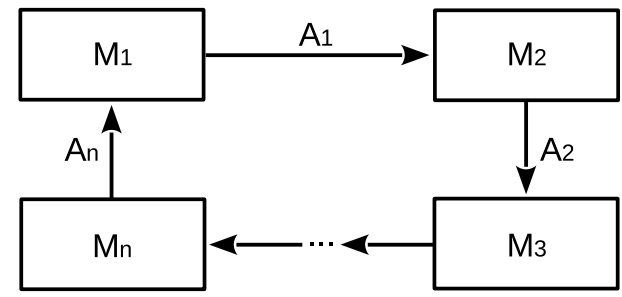

(a)

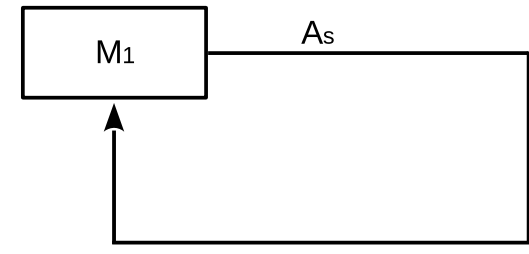

(b)

Figura 9. A-Team com memória cíclica representada por (a) caminho $P\left(M_{1}, M_{1}\right)=\left(A_{1}, A_{2}, \ldots, A_{n}\right)$ e (b) super-agente hipotético $A_{s}=A_{1}+A_{2}+\cdots+A_{n}$.

Apesar de, na maioria das vezes, não ser uma tarefa muito árdua verificar se todos os agentes do $A$-Team formam um laço, algumas representações podem dificultar a análise e até mesmo passar uma visualização "enganosa" para o projetista. Este é o caso de composições e intersecções entre memórias (na Figura 10(b), $M_{3}$ é a composição das memórias $M_{1}$ e $M_{2}, M_{2}$ é a intersecção das memórias $M_{3}$ e $M_{5}$ ), que podem dificultar a verificação do fluxo de dados cíclico. No exemplo da Figura 10(a) soluções nunca são lidas de $M_{1}$ e no exemplo da Figura 10(b) soluções nunca são lidas de $M_{1}$ ou escritas em $M_{4}$. Em ambos os casos, não se pode garantir o fluxo de dados cíclico no A-Team. 


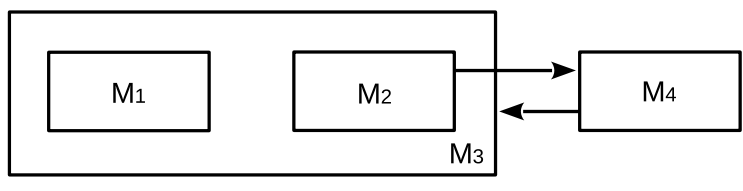

(a)

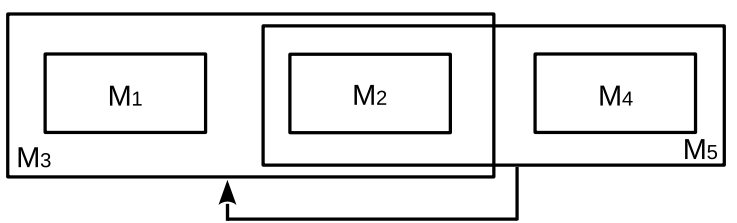

(b)

Figura 10. Quebra do fluxo cíclico de soluções: (a) soluções nunca são lidas de $M_{1}$ e (b) soluções nunca são lidas de $M_{1}$ ou escritas em $M_{4}$.

\subsection{Inicialização das memórias}

A diversidade de soluções em uma memória é caracterizada pelas diferenças entre as mesmas, sendo que baixa diversidade representa um conjunto de soluções com poucas diferenças entre si e alta diversidade representa um conjunto de soluções bem distintas umas das outras. O percentual de preenchimento inicial das memórias é um atributo que pode influenciar muito o desempenho de um A-Team e está diretamente relacionado ao nível de diversidade das soluções.

Com o objetivo de aumentar a diversidade poderia se pensar em um preenchimento total da memória, mas, dependendo da política de exclusão/inclusão adotada, muitas soluções podem ser substituídas antes mesmo de serem processadas por algum agente. Entretanto, a inicialização com pouco uso do tamanho disponível da memória pode reduzir muito a diversidade das soluções e prejudicar o desempenho e a convergência do A-Team.

Uma opção aceitável é preencher inicialmente apenas um certo percentual do tamanho da memória e deixar o restante do espaço livre para a inserção de novas soluções durante o processamento do $A$-Team. Isto porque, após a inicialização, os agentes utilizam as soluções disponíveis nas memórias compartilhadas para produzir novas soluções, as quais são novamente colocadas a disposição dos agentes do $A$-Team, inclusive de quem as gerou. Um objetivo básico no projeto de um $A$-Team é estabelecer este percentual, de modo que se mantenha alta a diversidade na memória mas sem tornar lento o processo de convergência para soluções ideais.

\subsection{Agentes}

Os agentes em um A-Team são os elementos responsáveis por criar, manipular e remover soluções das memórias, podendo ser classificados da seguinte forma:

Iniciadores: agentes designados a fazer o preenchimento inicial das memórias no A-Team (ver agente $I$ na Figura 1). Estes criam novas soluções a partir da definição do problema que está sendo resolvido, utilizando ou não informações localizadas em diferentes memórias;

Construtores: tais agentes têm a função de gerar novas soluções durante a execução do A-Team. Como estes têm essencialmente o mesmo comportamento que os agentes iniciadores, ambos podem até mesmo ser agrupados em uma única categoria;

Modificadores: tais agentes têm função específica de tentar melhorar a qualidade das soluções nas memórias. Uma solução processada por este tipo de agente é depositada novamente na memória, possivelmente substituindo a solução antiga; e

Destrutores: o conteúdo das memórias deve ser constantemente monitorado para evitar que as mesmas recebam uma quantidade indesejada de soluções, este controle é feito por agentes Destrutores (ver agente $D$ na Figura 1). Este agente é usado para remover as soluções que não sejam promissoras na busca de soluções ideais, ou seja, decidir quando soluções devem ser eliminadas de um espaço de memória ou não.

O trabalho dos agentes iniciadores, se não for bem elaborado, pode ter um efeito negativo durante a execução do $A$-Team. Um preenchimento inicial deve evitar gerar soluções limitadas a um subconjunto do espaço de soluções, pois pode levar a uma baixa diversidade inicial. Um A-Team pode conter vários agentes iniciadores, construtores, modificadores e destrutores trabalhando em memórias distintas e manipulando soluções intermediárias. Todos os resultados produzidos pelos agentes, exceto os destrutores, são disponibilizados aos outros agentes via memórias.

A estrutura de um $A$-Team pode contar não só com memórias com soluções viáveis para o problema em questão, mas também com memórias que armazenam soluções parciais ou infactíveis, o que expande o número de possíveis algoritmos passíveis de serem utilizados. Dado que as possíveis soluções para determinado problema podem ser bem distintas umas das outras, o projetista pode, por exemplo, fazer uso de algoritmos de 
consenso para aproveitar as similaridades ou as diferenças entre soluções, construindo novas soluções parciais ou infactíveis. Tais algoritmos podem usar duas ou mais soluções para gerar uma ou mais soluções novas, incorporando informações de todas as entradas (soluções lidas nas memórias). Os critérios para criar novas soluções podem ser baseados na intersecção, quando determinados atributos coincidem (assumem os mesmos valores) em várias soluções lidas (ver Figura 11(a)), e na diferença, quando os atributos diferem nas soluções lidas (Figura 11(b)).

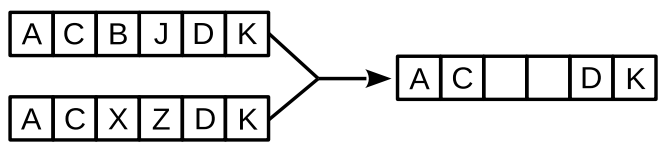

(a)

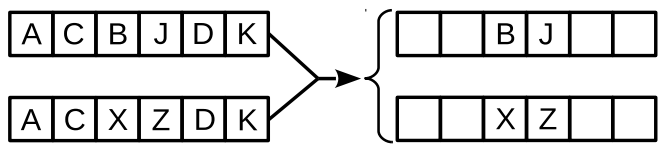

(b)

Figura 11. Novas soluções criadas a partir de alternativas de critérios de consenso: (a) intersecção e (b) diferença de soluções (Souza, 1993).

Uma possibilidade deste processo é mostrado na Figura 12. Agentes de consenso, Deconstrutores, lêem duas ou mais soluções factíveis na memória Soluções Completas para gerar soluções infactíveis, através das características em comum destas soluções, e então armazena o resultado na memória Soluções Parciais. Agentes Construtores, também baseados em algoritmos de consenso, fazem o processo inverso.

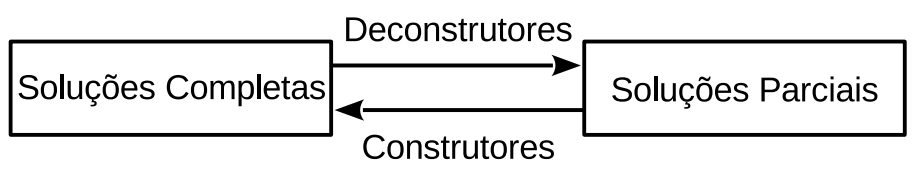

Figura 12. Exemplo de uso de agentes de consenso para decomposição de soluções viáveis em soluções parciais e vice-versa (Souza, 1993).

\subsection{Políticas de seleção}

Algumas características podem influenciar o desempenho do A-Team e devem ser consideradas, como a diversidade das soluções. Uma baixa diversidade pode acarretar em uma rápida convergência do processo, o que acontece quando nemhum melhoramento pode ser alcançado sobre as melhores soluções, e consequentemente prejudicar a busca pelo conjunto de soluções ideais. Entretanto, alta diversidade pode representar uma lenta convergência do processo, podendo levar um grande tempo antes que uma solução ideal seja descoberta.

Outra característica importante é a forma como os agentes se comportam ao selecionar novas soluções. Quando trabalhando com agentes de comportamento determinístico, deve-se evitar que uma solução que acabou de ser gerada seja selecionada novamente pelo mesmo agente que a gerou, pois tal solução não sofrerá mudança em sua estrutura (ver Figura 3(b), onde uma solução processada pelo agente $A_{1}$ não é mais selecionada pelo mesmo antes de ser processada pelo agente $A_{2}$ ).

O efeito negativo destas características pode ser minimizado com a escolha correta da política de seleção e devida associação aos agentes na estrutura. Uma política de seleção representa um conjunto de regras a serem consideradas quando é preciso selecionar soluções da memória, seja para processamento pelos agentes construtores e modificadores ou para serem eliminadas pelos agentes destrutores. Existem várias destas políticas, a maioria delas adaptadas a problemas específicos. As três principais são:

$\mathbf{P}_{1}$ - Seleção "gulosa": uma estratégia que sempre pega a melhor ou a pior solução candidata na memória;

$\mathbf{P}_{2}$ - Seleção com distribuição uniforme de probabilidade: neste caso todas as soluções na memória têm a mesma probabilidade de serem selecionadas, independente de quão boas sejam para o problema em questão; e

$\mathbf{P}_{3}$ - Seleção com distribuição linear de probabilidade: as soluções possuem uma probabilidade crescente de serem selecionadas, podendo ser da pior para a melhor ou da melhor para a pior.

Se o objetivo do uso de tais políticas é a seleção de soluções para processamento pelos agentes e a política usada é uma estratégia com maior probabilidade de selecionar as piores soluções, então soluções não promissoras podem ser processadas antes de uma possível eliminação. Esta estratégia, em relação a uma com maior probabilidade de selecionar as melhores soluções, pode reduzir o tempo de convergência para soluções ideais e manter maior diversidade nas memórias. Desta forma, o uso da política $P_{2}$ pode ser interessante quando não se sabe quais soluções candidatas na memória são consideradas promissoras;

O outro objetivo básico do uso de tais políticas é a seleção de soluções para serem eliminadas pelos agentes destrutores. Este objetivo é tão importante quanto o anterior, já que ambos devem ser considerados para o 
balanceamento entre construção e destruição das soluções candidatas e manutenção da diversidade de soluções na memória. Entretanto, memórias que funcionam como estruturas simples de armazenamento não necessitam de uma política de seleção complexa. Uma organização simples do tipo FIFO (First In, First Out), em geral, é suficiente para controlar a quantidade de soluções neste tipo de memória.

A forma de implementação da política de seleção pode revelar características interessantes e oferecer ao projetista diferentes estratégias para selecionar soluções nas memórias. Para executar tal tarefa, o projetista pode escolher entre implementar:

- uma política para cada memória (todos os agentes que a acessam utilizam a mesma política); ou

- políticas diferentes para cada agente (diferentes políticas podem ser implementadas para diferentes agentes na mesma memória).

Quando o objetivo é selecionar uma solução a ser processada por agentes construtores ou modificadores, uma opção bastante usada é associar a cada agente uma política de seleção em particular. Entretanto, quando o objetivo é selecionar uma solução a ser eliminada, a maioria dos projetistas implementa uma única política para cada memória. Uma possível justificativa para este fato é que as memórias no $A$-Team geralmente trabalham com um único agente destrutor.

Um aspecto importante a ser considerado na implementação de políticas de seleção é a definição de quando uma nova solução deve ser incorporada ao conjunto de soluções factíveis (soluções promissoras). No caso de problemas multi-objetivos, por exemplo, dois critérios básicos para a inserção de novas soluções em uma memória são (Rodrigues, 1996):

- a solução original não domine a solução gerada a partir dela; ou

- a solução gerada domine a solução original.

No primeiro caso a solução deve pertencer ao mesmo conjunto de Pareto da solução original ou a uma camada de Pareto mais inferior. O segundo caso exige que os valores da solução gerada tenham necessariamente que ser melhores do que os valores da solução original para todas as funções objetivo, o que pode restringir muito a diversidade das soluções.

Outro aspecto importante é o controle do tamanho da população de soluções. Embora a maioria das pesquisas feitas com $A$-Teams determine que alguma estratégia deve ser usada para controlar a quantidade de soluções na memória quando novas soluções são geradas, este tipo de controle às vezes não é necessário. Ao invés de gerar uma nova solução e então encontrar uma posição na memória para adicioná-la, podese pensar em simplesmente substituir a última solução (solução selecionada pelo agente) pela nova solução gerada. Este tipo de estratégia torna desnecessária a preocupação com o tamanho da população de soluções e consequentemente não requer o uso de agentes destrutores (Salman et al., 2002).

\section{A Implementação de A-Teams}

Em uma implementação de $A$-Teams segundo uma arquitetura cliente-servidor, os agentes funcionam como clientes e as memórias como servidores de dados. Os clientes (agentes) requisitam informações a processos que atuam como servidores (memórias), através de chamadas a procedimentos remotos. Assim, usando-se este modelo de implementação, todos os algoritmos (clientes e servidores) podem ser executados concorrentemente em um computador, com um ou mais processadores, ou distribuídos em uma rede, com um computador alocado para cada algoritmo. Isto sem esforço adicional de programação (alteração de código). Alguns dos fatores que justificam a escolha desta estrutura são a inexistência de restrições quanto ao número de clientes e servidores; a garantia de integridade dos dados nas memórias, decorrente do tratamento, pelo servidor, das requisições dos clientes segundo a política FIFO (First In, First Out); e a existência de várias ferramentas de programação e suporte a esta abordagem.

Aplicações complexas, como uma resultante da implementação de um A-Team, em geral, exigem elevado grau de processamento, resultando num tempo de resposta muito grande quando colocadas para serem executadas em sistemas convencionais (um computador com poucos processadores). Desta forma, o ideal é que o código a ser desenvolvido para um $A$-Team utilize facilidades de programação e suporte a aplicações distribuídas oferecidas por diversas ferramentas atualmente disponíveis. Na Seção 4.1 é descrita, brevemente, uma das várias interfaces de programação que permitem a comunicação entre diversas partes de uma aplicação (processos) que estejam dispersas em um ambiente distribuído. Na Seção 4.2 são discutidos alguns dos aspectos da implementação de um $A$-Team usando-se esta ferramenta. 


\subsection{MPI (Message Passing Interface)}

O padrão MPI é o resultado do esforço conjunto entre várias organizações (usuários e vendedores de sistemas paralelos) para o desenvolvimento de uma interface padrão de troca de mensagens. No padrão resultante destacam-se, dentre outros aspectos, a portabilidade de código fonte, a implementação eficaz em uma série de arquiteturas, a existência de conjunto extenso de funcionalidades, o suporte para arquiteturas paralelas heterogêneas, a existência de inúmeras implementações gratuitas e uma comunidade ativa de desenvolvedores em torno do padrão.

O padrão MPI foi desenvolvido a partir do paradigma Message-Passing, ou troca de mensagens, no qual várias instâncias de processadores, cada um com sua própria memória, são vistas conjuntamente e cooperam entre si na resolução de tarefas. Tal cooperação é conquistada com a comunicação entre os processos através do envio e recebimento de mensagens, invocando-se rotinas definidas no MPI para isso. Qualquer conceito de comunicação fora desta ideia, como processos acessando diretamente memórias de outros processos, não faz parte do modelo. Este padrão tem como base quatro conceitos principais:

Processo: cada parte, em execução, de um programa, as quais podem estar executando distribuídas em uma ou mais diferentes máquinas;

Grupo: um conjunto de processos. Inicialmente, todos os processos pertencem a um único grupo que está associado a um comunicador;

Rank: número inteiro que identifica unicamente um processo em um grupo. Esta identificação varia de zero até $N-1$, onde $N$ é o número de processos do grupo; e

Comunicador: escopo de uma operação de comunicação. Define o grupo de processos que podem se comunicar e viabiliza a troca de mensagens entre os mesmos.

De forma geral, um programa em MPI faz uso de rotinas de inicialização e finalização da biblioteca e também de rotinas de controle. Estas últimas são utilizadas para a obtenção de informações sobre o ambiente paralelo/distribuído que está em execução, tais como a identificação de um processo ou a quantidade de processos em um grupo.

Uma mensagem em MPI é composta de duas partes: dados (informações que se deseja enviar e receber) e envelope (informação da rota dos dados). Um dado é um conjunto de três parâmetros: endereço de sua localização (a posição de memória em que está alocado), número de elementos que serão enviados na mensagem e o seu tipo (o seu tipo de dado em MPI). Um envelope é formado pela identificação do processo remetente, a identificação do processo destinatário, um rótulo identificador da mensagem e o comunicador que irá viabilizar o procedimento.

As mensagens em MPI podem ser enviadas de um processo para outro, na chamada comunicação ponto a ponto, ou de um processo para todos os outros do seu grupo, representando a comunicação coletiva. Quando um grupo de processos é iniciado, um comunicador predefinido é criado (inter-comunicador) e a troca de mensagens naquele grupo passa a ser permitida.

O MPI permite a gestão dinâmica de processos (criação, inserção em um comunicador e comunicação com o restante dos grupos). Para viabilizar tal procedimento, são disponíveis rotinas para iniciar um conjunto de processos de um único programa e para iniciar conjuntos de processos de diversos programas. Durante a execução de uma aplicação MPI, quando um grupo cria um outro grupo de processos, ele é considerado o grupo pai e o grupo iniciado dinamicamente é considerado o grupo filho. Um novo comunicador passa a existir (inter-comunicador) e, assim, a troca de mensagens entre pai e filho é viabilizada. Entretanto, em alguns casos, é necessário mais do que a comunicação entre grupo pai e grupo filho. Tal situação pode ser ilustrada quando dois grupos filhos precisam trocar mensagens entre si. Neste cenário, apesar da existência de um mesmo pai, não existe nenhum comunicador entre eles.

Para tais situações o MPI oferece, como alternativa de estabelecimento de comunicação entre processos, rotinas baseadas no modelo cliente-servidor, ou seja, processos aceitando e iniciando conexões com outros processos. Este procedimento acontece da seguinte forma: os processos escolhidos para serem servidores abrem uma porta e publicam um nome para ela, podendo, a partir daí, serem encontrados. Os processos clientes procuram por um nome de servidor, obtêm a porta correspondente e iniciam uma conexão com a mesma. O resultado desta sequência de ações é um novo inter-comunicador, que permite a troca de dados até que a conexão seja desativada. A troca de mensagens continua acontecendo da mesma forma, ou seja, através das rotinas de envio e recebimento. 


\subsection{Um A-team mínimo}

Na Figura 13 é mostrado um exemplo de um A-Team mínimo, formado pelos componentes iniM, M, agM, paraAteam e listaM. Este pequeno conjunto de componentes é bastante relevante, pois contém todos os elementos (memória, agente e iniciador de memória) de um A-Team. Além disso, ele implementa a estrutura básica de qualquer $A$-Team, ou seja, uma memória que recebe, armazena e envia soluções para os agentes (M), um agente que requisita, modifica e envia soluções para a memória (agM), e agentes responsáveis por iniciar (iniM) e parar (paraAteam) o $A$-Team e listar o conteúdo corrente da memória (listaM).

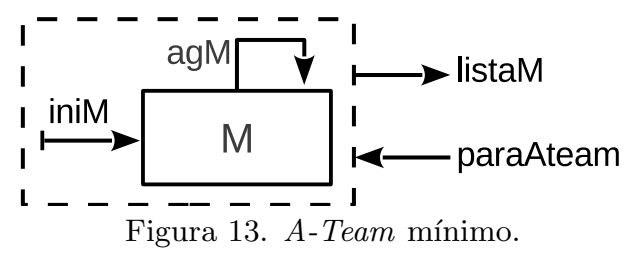

Neste caso, a memória M é iniciada com uma quantidade determinada de soluções e o agente agM (uma ou mais cópias dele) tenta melhorar a qualidade das soluções em M. Dado que os agentes implementados são modificadores, é dispensável o uso de políticas de destruição e agentes destrutores para o controle da quantidade de soluções armazenadas na memória.

Adicionalmente, uma interface gráfica poderia ser incluída no projeto, para proporcionar ganhos como a alteração dos parâmetros de configuração do A-Team em tempo de execução, um maior controle sobre os processos relativos aos agentes distribuídos na rede ou uma melhor forma de visualização dos resultados obtidos. Além disso, a interface pode ser encarregada de iniciar dinamicamente cada agente e cada memória.

A Figura 14 mostra um modelo de arquitetura cliente/servidor, para o exemplo mínimo da Figura 13, já com uma interface gráfica. Para a implementação desta arquitetura, a interface gráfica deve contar com um comunicador direto definido para a troca de mensagens com todos os demais componentes do $A$-Team, uma vez que a mesma será responsável, durante a execução do $A$-Team, por iniciar dinamicamente cada agente e cada memória. Por outro lado, a comunicação entre os agentes e a memória necessita do estabelecimento de uma conexão, já que eles fazem parte de grupos de processos diferentes.

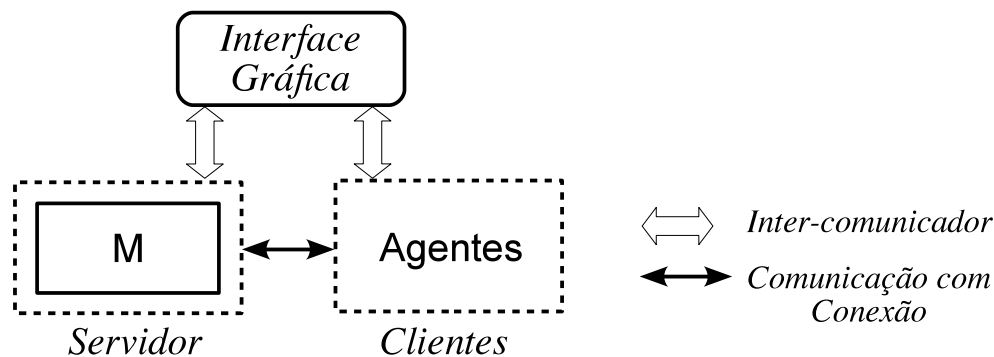

Figura 14. Arquitetura cliente/servidor com interface gráfica para um A-Team mínimo.

O servidor deve ficar sempre à espera de requisições de conexões. Além disso, o servidor deve ser multithread, para que vários agentes possam ter suas requisições atendidas ao mesmo tempo, e deve ser incluído algum mecanismo de controle de concorrência, para garantir a integridade dos dados armazenados na memória. Desta forma, cada thread que precise executar a operação de escrita na memória entra em uma fila de espera para obter o acesso a tal rotina e, só após realizar a atividade, ela retorna para seu fluxo de execução.

Para finalização do execução do $A$-Team, o agente paraAteam deve enviar uma mensagem de parada para ao servidor (tal tarefa pode ser realizada a partir da interface gráfica). Recebida a mensagem, o servidor a envia para os agentes e continua ativo. Os agentes, por sua vez, finalizam sua execução, desconectam-se do servidor e enviam uma mensagem de aviso de paralização para o agente paraAteam. Este, após ser notificado de que todos os agentes já finalizaram, envia uma última mensagem para o servidor, de finalização imediata.

Agora descreveremos como ocorre em MPI a comunicação com conexão entre componentes do $A$ Team (troca de mensagens entre um emissor e um receptor). No exemplo a seguir é demonstrado o empacotamento/envio de uma mensagem com o conteúdo INIT_VARS por um emissor e o seu recebimento/desempacotamento pelo receptor.

Inicialmente, a mensagem é empacotada em um buffer de envio. A chamada à rotina MPI_Pack empacota o dado contido na variável method, ou seja, INIT_VARS. Além deste dado, consta também a quantidade de dados que será empacotada, o tipo destes dados, o buffer de envio, o tamanho em bytes do buffer de envio, a posição no buffer em que o dado será empacotado e o comunicador para a troca da mensagem: 


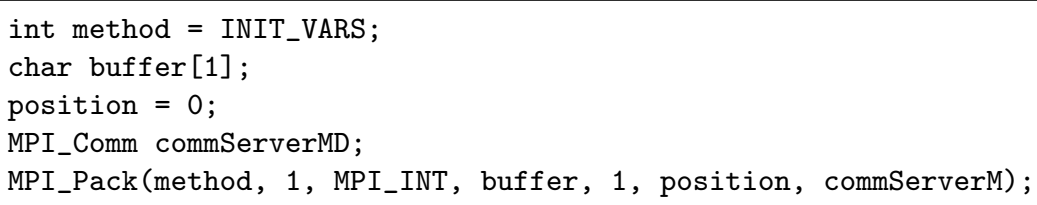

O envio da mensagem para o servidor $\mathrm{M}$, através do comunicador commServerM, pode ser feita com a chamada à rotina MPI_Send. Na chamada a esta rotina os parâmetros são os dados a serem enviados, o número de elementos contidos no buffer, os tipos dos dados, o rank do processo que irá receber a mensagem, o identificador da mensagem e o comunicador para a troca da mensagem:

MPI_Send(buffer, position, MPI_PACKED, 0, 1, commServerM);

A mensagem é recebida pelo receptor através da rotina MPI_Recv. Os seus parâmetros são o endereço inicial do buffer de entrada, o tamanho do buffer de entrada, o tipo de dado recebido, o rank do processo que enviou a mensagem, o identificador da mensagem, o comunicador por onde a mensagem chegará e uma variável que armazena dados da situação de recebimento:

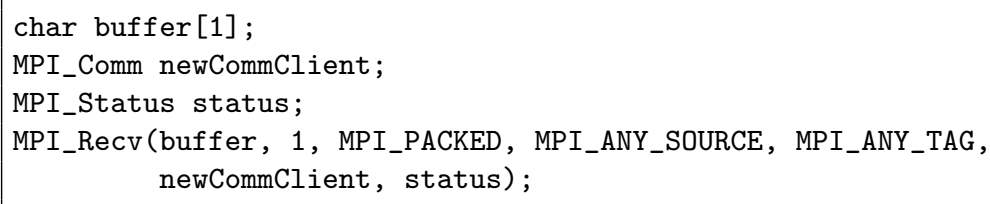

Uma vez recebida a mensagem, o receptor deve desempacotá-la para para ter acesso ao valor realmente enviado (INIT_VARS). A rotina MPI_Unpack desempacota os dados contidos na mensagem e a variável method passa a conter o valor inteiro INIT_VARS, completando a troca de mensagens. Os seus parâmetros são o endereço inicial da mensagem a ser desempacotada, o tamanho em bytes da mensagem, a posição em bytes que se deve desempacotar, o local para o armazenamento do valor desempacotado, a quantidade de dados que deve ser desempacotada, o tipo do dado que será desempacotado e o comunicador por onde a mensagem chegou:

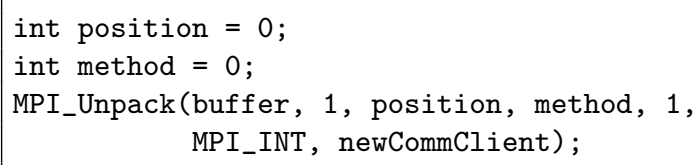

No caso de um A-Team com mais componentes, grande parte do trabalho constitui-se apenas na replicação da solução adotada neste subconjunto de elementos para os demais, considerando-se os ascpectos de projeto destacados na Seção 3 .

\section{Aplicações de A-Teams}

O modelo de $A$-Teams tem sido aplicado na resolução de uma grande variedade de problemas oriundos da Pesquisa Operacional. Além disso, vários desses estudos procuraram validar aspectos e/ou características importantes do modelo. Um dos estudos pioneiros foi conduzido por Souza (1993) sobre a resolução do problema do Caixeiro Viajante (TSP - Traveling Salesman Problem). Este trabalho identificou a importância da correta definição da estrutura dos times na busca pela eficiência em escala. Rodrigues (1996) mostrou que o modelo de $A$-Teams é eficiente na detecção do pareto ótimo ou quase ótimo de instâncias de uma generalização do TSP, o Problema do Caixeiro Viajante com Várias Matrizes de Distância (MDTSP - MutiDistance Traveling Salesman Problem).

Outro problema clássico é o de escalonamento de tarefas (FSP - Flow Shop Problem). Neste caso, o objetivo é encontrar uma sequência de execução de tarefas (jobs) em um conjunto de máquinas, de forma a minimizar o tempo entre o início do processamento do primeiro job, na primeira máquina, e o término do último job na última máquina. Peixoto (1995) apresentou uma especificação de $A$-Teams para o $F S P$ que destacou-se por encontrar eficiência em escala e speed up próximo do linear. Além disso, obteve resultados iguais ou melhores aos já conhecidos para o problema. No LCSP (Labor Constraint Satisfaction Problem) uma tarefa está sujeita a restrições de precedência e restrições de escala de trabalhadores. Cada tarefa tem um tempo de processamento especificado e um perfil de trabalho (que denota o número de trabalhadores necessários para executar a tarefa) que pode variar de acordo com o processamento das tarefas. Cavalcante et al. (2002) encontraram soluções de alta qualidade e identificaram a presença de sinergia na execução paralela dos algoritmos usados no time desenvolvido para este problema. 
Longo (1995), em estudos sobre a aplicação de A-Teams ao Problema de Recobrimento de um Conjunto (SCP - Set Covering Problem), identificou a sensibilidade de uma implementação de $A$-Teams em relação à variação de alguns de seus parâmetros. O objetivo deste $A$-Team foi encontrar, conjuntamente, limites inferiores e superiores para os valores das soluções ótimas de instâncias do problema em questão. Esta abordagem é descrita na Seção 5.2 por ser um bom exemplo da utilização de diferentes heurísticas na composição do time. Antes, o SCP é detalhado na Seção 5.1.

\section{$5.1 S C P$}

O Problema de Recobrimento de um Conjunto (SCP - Set Covering Problem) é equivalente à busca pelo menor número de subconjuntos, de um determinado conjunto, que unidos geram este conjunto principal. Formalmente, dado um conjunto $I=\{1, \ldots, m\}$ e uma família $F=\left\{I_{1}, \ldots, I_{n}\right\}$ de subconjuntos de $I$ e $J=\{1, \ldots, n\}$, qualquer subconjunto $J^{*} \subseteq J$ define um recobrimento de $\mathrm{I}$, se $\bigcup_{j \in J^{*}} I_{j}=I$. Ao se associar a cada conjunto $j$ da família $F$ um custo $c_{j}>0$, o objetivo passa a ser encontrar um recobrimento $J^{*}$ cujo custo total $\sum_{j \in J^{*}} c_{j}$ seja mínimo. Uma formulação como um problema de programação inteira 0-1 é:

$$
(S C P)\left\{\begin{aligned}
\min \sum_{j \in J} c_{j} x_{j}, & \\
\text { s.a. } \sum_{j \in J} a_{i j} x_{j} \geq 1, & i \in I, \\
x_{j} & \in\{0,1\}, \quad j \in J,
\end{aligned}\right.
$$

onde $a_{i j}$ tem valor 1 se $i \in I_{j}$ e 0 caso contrário.

O Problema de Recobrimento de um Conjunto é computacionalmente difícil de ser resolvido e claramente pertencente à classe dos problemas NP-Completos. Garey \& Johnson (1979) observam que, mesmo se $\left|I_{j}\right| \leq$ $3, I_{j} \subseteq I$, o problema continua pertencendo à classe NP-Difícil. Só é possível garantir que seja resolvido em tempo polinomial se $\left|I_{j}\right| \leq 2, \forall I_{j} \subseteq I$.

A importância do $S C P$ na Pesquisa Operacional vem do seu modelo teórico, em particular suas interconexões com outros ramos da matemática discreta, tais como hipergrafos, funções boolenas ou satisfatibilidade; e do grande número de situações reais que podem ser modeladas com o problema. Podese definir apropriadamente um conjunto finito $I$ que represente ações a serem executadas, decisões a serem tomadas ou alguma outra modelagem de uma situação real; uma família $F$ de subconjuntos de $I$, onde cada subconjunto represente diferentes meios, recursos ou métodos para atingir, total ou parcialmente, o objetivo desejado; e um custo associado a cada membro de $F$. A busca da melhor solução para a situação real reduz-se então a encontrar um conjunto de membros de $F$ que seja de custo mínimo e recubra o conjunto $I$.

Tomando-se, por exemplo, o problema de recuperação de informações em $n$ arquivos $I_{j}$, onde $c_{j}=\left|I_{j}\right|, j=$ $1, \ldots, n$, é o tamanho de cada arquivo. Cada unidade de informação $i$ é armazenada em pelo menos um arquivo $I_{j}\left(i \in I_{j}\right)$. Supondo-se existirem $m$ requisições de informações, então um recobrimento ótimo fornece um subconjunto de arquivos, minimizando o volume total de informações que necessita ser pesquisado para garantir a recuperação das informações requisitadas.

Outras situações que podem ser modeladas com este problema são definições de escalas para tripulações de linhas aéreas, roteamento de veículos, recuperação de informações, investimento de capital, projeto de circuitos, coloração de mapas, análise PERT/CPM e lógica simbólica, dentre outras.

\subsection{Um A-team para o SCP}

Na figura 15 é mostrada uma proposta de $A$-Team para resolução do $S C P$. A abordagem primal-dual do $A$ Team desenvolve, conjuntamente, limites superiores e limites inferiores (que correspondem a valores inferiores ou iguais ao da relaxação linear do modelo $(S C P)$ descrito na Seção 5.1) para o valor da solução ótima.

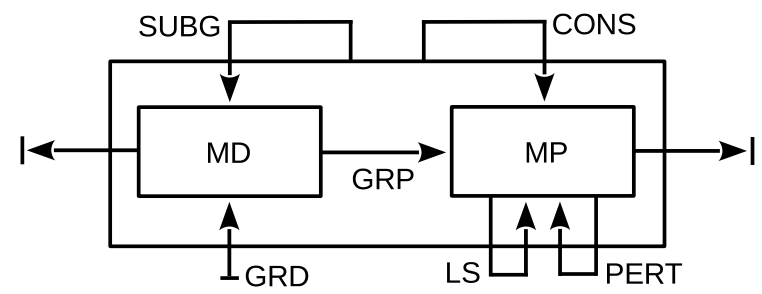

Figura 15. A-Team primal-dual para resolução do $S C P$.

A estrutura do A-Team é composta de duas memórias compartilhadas e seis agentes. Uma das memórias (MP) armazena soluções factíveis para a instância do $S C P$ que está sendo tratada (limites superiores). A outra memória (MD) armazena soluções para o dual da relaxação linear da instância (limites inferiores). Os 
agentes descritos a seguir são compostos de algoritmos que trabalham em cima destas populações de soluções, melhorando-as e acrescentando novos elementos às memórias:

GRD : Construtor de soluções duais. A função deste agente é a construção de soluções duais e o envio das mesmas para a memória correspondente. Este agente utiliza um procedimento baseado em heuríssticas gulosas duais, propostas por Balas \& Ho (1980) e Fisher \& Kedia (1990)), para gerar as soluções.

SUBG : Modificador de soluções duais. Este agente utiliza o método de otimização por subgradientes (Camerini et al. (1975); Held et al. (1974)) para a resolução de uma relaxação Lagrangeana associada ao problema. O agente busca informações, necessárias ao método dos subgradientes, nas duas memórias: um limite superior no valor da solução ótima do $S C P$ é obtido na memória de soluções primais e da memória de soluções duais é obtida uma solução, cujos valores das variáveis duais funcionam como os multiplicadores Lagrangeanos. A nova solução dual, obtida com a resolução da relaxação Lagrangeana, é enviada pelo agente para a memória de soluções duais.

GRP : Construtor de soluções primais. Este agente utiliza um conjunto de heurísticas gulosas. O critério guloso utilizado pode considerar somente os dados que definem a instância do $S C P\left(c_{j}, I_{j}\right)$ como utilizada por Balas \& Ho (1980) ou utiliza também informações da solução dual como em Fisher \& Kedia (1990).

LS : Modificador de soluções primais. Este agente busca uma solução na memória de soluções primais e tenta melhorá-la com o uso de uma heurística de busca local baseada em busca tabu. A vizinhança da solução corrente é o subconjunto de soluções que podem ser obtidas, a partir da corrente, com a inversão de valores de duas das variáveis. O "tabu" é fixado às trocas de valores de variáveis que levam a valores da função objetivo não menores do que o da solução corrente.

PERT : Modificador de soluções primais. O processo de aprimoramento de uma solução primal baseia-se na perturbação da mesma, ou seja, a transformação de uma solução em outra redundante (adicionando-se novas variáveis a solução), e o posterior descarte do máximo de variáveis, desta solução perturbada, de modo que o recobrimento não seja afetado. Este processo é repetido um certo número de vezes, para uma mesma solução inicial, e a melhor solução obtida nas várias iterações é armazenada na memória de soluções primais.

CONS : Modificador/Construtor de soluções primais. A ação deste agente tem por base algoritmos genéticos de consenso e consiste na determinação da interseção (variável a variável) entre três soluções armazenadas na memória de soluções primais. Considerando-se que $x^{1}$ é a melhor solução ali armazenada, $x^{2}$ e $x^{3}$ duas outras quaisquer, e $x^{0}$ a nova solução a ser gerada, então o critério de consenso utilizado pelo agente é: $x_{j}^{0}=1$ se $x_{j}^{1}=x_{j}^{2}=1$ ou $x_{j}^{1}=x_{j}^{3}=1$, caso contrário $x_{j}^{0}=0(j \in J)$. Esta solução parcial pode não corresponder a um recobrimento. Neste caso é completada com as mesmas heurísticas gulosas utilizadas no agente GRP.

\section{Considerações Finais}

O modelo de A-Teams tem sido aplicado com sucesso a uma grande variedade de problemas de otimização, comprovando que são melhores que qualquer estratégia isolada na busca por soluções ótimas globais para problemas complexos.O sucesso da aplicação deste paradigma deve-se em muito à simplicidade da sua arquitetura. Esta permite que agentes utilizarem diferentes estratégias para resolver problemas específicos e até mesmo combinar a velocidade e a perícia de agentes de software com o conhecimento e as habilidades de humanos na busca por melhores resultados. Além disso, memórias, como estruturas simples de armazenamento, podem facilmente armazenar informações referentes a configuração de agentes e/ou outras memórias.

Apesar do conceito simples e evidentes vantagens deste paradigma, o projetista de um A-Team pode enfrentar vários desafios ao projetar os seus elementos. Estes, se não forem corretamente definidos, podem prejudicar o desempenho de toda a organização e consequentemente influenciar na qualidade e velocidade em que os resultados são alcançados. As informações mantidas nas memórias compartilhadas, por exemplo, sofrem uma série de modificações durante o processo de execução. Para tais modificações serem benéficas ao desempenho do time, é necessário um controle preciso do conteúdo das memórias. Este controle se estende desde a inicialização, quando é feito um preenchimento inicial das memórias, até o momento de decidir quais delas não devem mais fazer parte do processamento do time. 


\section{Referências}

Balas, E. \& Ho, A., Set covering algorithms using cutting planes, heuristics and subgradient optimization: A computational study. In: Padberg, M.W. (Ed.), Combinatorial Optimization. New York, USA: Elsevier NorthHolland, v. 12 de Mathematical Programming Studies, p. 37-60, 1980.

Camerini, P.M.; Fratta, L. \& Maffioli, F., On Improving Relaxation Methods by Modified Gradiente Techniques. v. 3 de Mathematical Programming Studies, p. 26-34, 1975.

Cavalcante, C.C.B.; Cavalcante, V.F.; Ribeiro, C.C. \& de Souza, C.C., Parallel cooperative approaches for the labor constrained scheduling problem. In: Ribeiro, C.C. \& Hansen, P. (Eds.), Essays and Surveys in Metaheuristics. Norwell, USA: Kluwer Academic, p. 201-225, 2002.

Cicirello, V.A. \& Smith, S.F., Insect societies and manufacturing. In: Proceedings of IJCAI-01 Workshop on Artificial Intelligence and Manufacturing: New AI Paradigms for Manufacturing. San Francisco, USA: Morgan Kaufmann, p. 328-329, 2001.

Fisher, M.L. \& Kedia, P., Optimal solution of set covering/partitioning problems using dual heuristics. Management Science, 36(6):674-688, 1990.

Garey, M.R. \& Johnson, D.S., Computers and Intractability. A Guide to the Theory of NP-Completeness. New York, USA: W. H. Freeman, 1979.

Held, M.; Wolfe, P. \& Crowder, H.P., Validation of subgradient optimization. Mathematical Programming, 6(1):62-88, 1974.

Longo, H.J., Aplicação de A-Teams ao Problema de Recobrimento de um Conjunto. Dissertação de Mestrado, Universidade Estadual de Campinas, Instituto de Matemática, Estatística e Computação Científica, Campinas, SP, 1995.

Peixoto, H.P., Uma Metodologia de Especificação de Times Assíncronos para Problemas de Otimização Combinatória. Dissertação de Mestrado, Universidade Estadual de Campinas, Instituto de Computação, Campinas, SP, 1995.

Rodrigues, R.F., Times Assíncronos para a Resolução de Problemas de Otimização Combinatória com Múltiplas Funções Objetivo. Dissertação de Mestrado, Universidade Estadual de Campinas, Instituto de Computação, Campinas, SP, 1996.

Salman, F.S.; Kalagnanam, J.R.; Murthy, S. \& Davenport, A., Cooperative strategies for solving the bicriteria sparse multiple knapsack problem. Journal of Heuristics, 8(2):215-239, 2002.

Souza, P.S., Asynchronous Organizations for Multi-Algorithm Problems. PhD Thesis, Department of Electrical and Computer Engineering, Carnegie Mellon University, Pittsburgh, USA, 1993.

Talukdar, S., Asynchronous Teams. Technical Report 207, Carnegie Mellon University. Engineering Design Research Center. Department of Electrical and Computer Engineering, 1993.

Talukdar, S.; Baerentzen, L.; Gove, A. \& Souza, P.S., Asynchronous teams: Cooperation schemes for autonomous agents. Journal of Heuristics, 4(4):295-321, 1998.

\section{Notas Biográficas}

Jesmmer da Silveira Alves é graduado em Tecnologia em Processamento de Dados (Faculdades Unidas de Itumbiara, 2000), especialista em Redes de Computadores (Universidade Salgado de Oliveira, 2003) e mestre em Ciência da Computação (Universidade Federal de Goiás, 2009). Atualmente é professor de ensino técnico e tecnológico no Instituto Federal de Educação, Ciência e Tecnologia Goiano. Principais áreas de interesse: desenvolvimento Web e análise de algoritmos.

Humberto José Longo é graduado em Ciência da Computação (Universidade Federal de Goiás, 1990), mestre em Ciência da Computação (Universidade Estadual de Campinas, 1995) e doutor em Informática (Pontifícia Universidade Católica do Rio de Janeiro, 2004). Atualmente é professor adjunto no Instituto de Informática da Universidade Federal de Goiás. Principais áreas de interesse: Algoritmos e Otimização. 


\title{
Métodos Penalizados e Não-Penalizados para o Problema do Caixeiro Viajante com Grupamentos
}

\author{
Mário Mestria*
}

\begin{abstract}
Resumo: Este capítulo propõe diversos métodos heurísticos para resolver o Problema do Caixeiro Viajante com Grupamentos (PCVG). No PCVG os vértices são divididos em grupos e todos os vértices de cada grupo devem ser visitados de forma contígua. As abordagens desenvolvidas foram baseadas no GRASP, Iterated Local Search, Reconexão de Caminhos, Método de Descida em Vizinhança Variável e Inserção mais Próxima. Os resultados mostraram que os métodos heurísticos utilizando a penalização nas arestas intergrupos apresentam os melhores resultados. O desempenho dos métodos heurísticos foi comparado com um algoritmo exato usando o software CPLEX paralelo e um Algoritmo Genético da literatura.
\end{abstract}

Palavras-chave: Meta-heurísticas, Reconexão de caminhos, Método de descida em vizinhança variável, Problema do caixeiro viajante com grupamentos.

\begin{abstract}
This chapter proposes several heuristic methods to solve the Clustered Traveling Salesman Problem (CTSP). In the CTSP the vertices are partitioned into clusters and all vertices of each cluster must be visited continuously. The developed approaches were based on the GRASP, Iterated Local Search, Path Relinking, Variable Neighborhood Descent, and Nearest Insertion. The results showed that the heuristic methods using a penalization for inter-clusters edges achieve the best results. The performance of the heuristic methods was compared with an exact algorithm using the Parallel CPLEX software and a Genetic Algorithm of literature.
\end{abstract}

Keywords: Metaheuristics, Path relinking, Variable neighborhood descent, Clustered traveling salesman problem.

\section{Introdução}

O Problema do Caixeiro Viajante (PCV) é um problema clássico mais estudado na área de pesquisa operacional. O Problema do Caixeiro Viajante com Grupamentos (PCVG) é uma extensão do PCV. Desta forma, podemos afirmar que o PCVG também pertence à classe $\mathcal{N} \mathcal{P}$-difícil e limita o uso exclusivo de métodos exatos. Neste contexto a metodologia para solucionar o PCVG neste trabalho será através de métodos heurísticos.

O PCVG aparece na literatura em duas versões. Na primeira mais explorada, supõe-se que a ordem de visitas aos grupos já é previamente definida (Anily et al., 1999; Gendreau et al., 1994; Laporte et al., 1996; Potvin \& Guertin, 1995), informação esta, que geralmente não é conhecida em muitas aplicações. Na segunda versão, para o qual existe reduzido número de trabalhos, esta ordem de visitas não é definida previamente e esta escolha é deixada para o algoritmo. Para este caso são encontrados na literatura métodos utilizando Algoritmos Genéticos (Ding et al., 2007; Potvin \& Guertin, 1996) e Algoritmos $\alpha$-aproximados (Arkin et al., 1997; Guttmann-Beck et al., 2000). A segunda versão é mais complexa, pois na busca da melhor sequência de visitas dos vértices de cada grupo, deve-se também analisar a melhor ordem de visitas aos grupos que correspondem a encontrar os vértices de entrada e saída de cada grupo. O capítulo deste livro tem como foco apresentar métodos heurísticos para este segundo caso.

O PCVG foi proposto por Chisman (1975) para resolver um problema real de roteamento automático em sistemas de armazenagem. Outras aplicações do PCVG podem ser encontradas em planejamento da produção (Lokin, 1979), despacho de veículos de emergência numa empresa de eletricidade (Weintraub et al., 1999), desfragmentação de discos rígidos, sistemas de manufaturas (Laporte \& Palekar, 2002) e em transações comerciais envolvendo supermercados, lojas e fornecedores de mercadorias (Ghaziri \& Osman, 2003).

\footnotetext{
*Autor para contato: mmestria@ifes.edu.br; mmestria@ic.uff.br
} 
$\mathrm{Na}$ literatura encontramos alguns trabalhos para o PCVG. Limites inferiores utilizando Relaxação Lagrangeana foram desenvolvidos em (Jongens \& Volgenant, 1985) para o PCVG. Os valores médios dos limites inferiores alcançaram gap igual a 0,35\%. Em (Laporte et al., 1996) uma Busca Tabu combinada com uma fase de diversificação usando um Algoritmo Genético foi proposta para o PCVG, mas a ordem de visita dos grupos já era definida a priori. Um Algoritmo Genético (AG) básico (sem componentes que realizam uma busca mais intensiva, tais como, Reconexão de Caminhos (RC) e/ou Variable Neighborhood Descent (VND)) foi proposto para o PCVG por Potvin \& Guertin (1996). No artigo apresentado por Ding et al. (2007) um outro AG, também básico, usa o critério de visita aos vértices de cada grupo de forma aleatória sem estabelecer uma relação com as distâncias entre os vértices. A escolha da ordem de visita de cada grupo também é aleatória. Observamos nestes trabalhos da literatura que a maioria parte do princípio que já existe uma ordem pré-fixada de visita dos grupos e com isso limita problemas reais que necessitam encontrar a melhor ordem de visitas dos grupos.

Neste capítulo foram desenvolvidos diversos métodos heurísticos utilizando Greedy Randomized Adaptive Search Procedures (GRASP) e Reconexão de Caminhos (Resende et al., 2010), Iterated Local Search (ILS) (Lourenço et al., 2002) e Método de Descida em Vizinhança Variável (Hansen \& Mladenović, 2003) para resolver o PCVG sem estabelecer a priori a ordem de visita dos grupos. Foram desenvolvidos dois algoritmos construtivos baseado na heurística Inserção mais Próxima (IMP), um que penaliza as arestas intergrupos e outro que não penaliza. Estes construtivos serão inseridos nos métodos heurísticos para avaliar o impacto da penalização na solução do PCVG.

Na Seção 2 apresenta-se a definição do problema e a formulação matemática para o PCVG. A metodologia para resolver o PCVG é apresentada na Seção 3. Os resultados computacionais, as análises de desempenho dos métodos heurísticos, as comparações entre os métodos penalizados e não-penalizados são apresentados na Seção 4. Finalmente na Seção 5 descrevem-se as conclusões e sugestões dos trabalhos futuros.

\section{Problema do Caixeiro Viajante com Grupamentos}

O PCV é um problema $\mathcal{N} \mathcal{P}$-difícil (Garey \& Johnson, 1979). Neste contexto, para o PCV não são conhecidos algoritmos que o resolvam em tempo polinomial. Admitindo que um conjunto de vértices represente as cidades, necessita-se construir um ciclo passando por todos os vértices uma única vez. Quantas soluções são possíveis nesta sequência de vértices? A resposta no caso simétrico é que o número total de soluções possíveis é $n$ !/2, onde $n$ é o total de vértices.

\subsection{Definição do problema}

O Problema do Caixeiro Viajante com Grupamentos (PCVG) é uma extensão do PCV. O PCV é um caso particular do PCVG, onde existe somente um grupo ou analogamente um vértice em cada grupo. Por ser uma generalização do PCV torna-o também $\mathcal{N} \mathcal{P}$-difícil (Guttmann-Beck et al., 2000) e (Ding et al., 2007).

Uma descrição do PCVG (Laporte \& Palekar, 2002) na estrutura de um grafo é dado a seguir: seja $G=(V, A)$ um grafo completo, direcionado, simétrico e ponderado com um conjunto de vértices $V=\left\{v_{1}, v_{2}, \ldots, v_{n}\right\}$ e um conjunto de $\operatorname{arcos} A=\left\{\left(v_{i}, v_{j}\right): v_{i}, v_{j} \in V, i \neq j\right\}$ em ambas as direções com mesmo peso. O conjunto de vértices $V$ é particionado em $m$ grupos $V_{1}, V_{2}, \ldots, V_{m}$, onde: $V=\bigcup_{i=1}^{m} V_{i}, \forall i$ e $V_{i} \cap V_{j}=\emptyset$ para todos $i$ e $j, i \neq j$. Assumindo que um custo não-negativo $c_{i j}$ é associado com o $\operatorname{arco}\left(v_{i}, v_{j}\right) \in A$, o PCVG consiste em determinar um ciclo Hamiltoniano de custo mínimo em $G$, tal que os vértices de cada grupo são visitados contiguamente. O custo $c_{i j}$ é a distância Euclidiana que corresponde, neste trabalho, a distância geométrica $d_{i j}$ entre dois vértices $v_{i}$ e $v_{j}$ no plano bidimensional. Neste contexto, instâncias Euclidianas significam que quando os métodos utilizam estas instâncias para resolução do PCVG fazem o uso das distâncias Euclidianas.

Para exemplificar o PCVG, mostra-se nas Figuras 1 e 2 os vértices e os grupos a que estes pertencem. O Grupo 1 contém os seguintes vértices: 1, 4 e 6 . O Grupo 2 os vértices 2, 3 e 7 e o Grupo 3 os vértices 5 e 8 .

Uma solução viável para este exemplo é mostrado pela Figura 1, onde a solução para o PCVG forma um ciclo Hamiltoniano que passa por todos os vértices, visitando todos os vértices de cada grupo contiguamente. As arestas (linha cheia) (4,1) e (1,6) mostram as arestas do Grupo 1, para o Grupo $2(3,2)$ e $(2,7)$ e a aresta $(5,8)$ no Grupo 3. Por último, as linhas tracejadas mostram as ligações entre os grupos. Outra solução viável, utilizando os mesmos vértices e grupos da Figura 1, mas de custo maior é mostrado pela Figura 2.

As Figuras 1 e 2 mostram que a escolha dos vértices extremos de entrada e de saída para cada grupo é um fator importante para encontrar soluções de melhor qualidade para o PCVG. Através deste exemplo é demonstrada a dificuldade em resolver o PCVG, porque não são conhecidos estes vértices extremos de cada grupo, principalmente na versão onde não é pré-definida a visita dos grupos. Pois, nesta versão mais complexa para o PCVG, os algoritmos devem buscar a melhor sequência de visitas aos vértices de cada grupo e também analisar a melhor sequência de visitas aos grupos. 


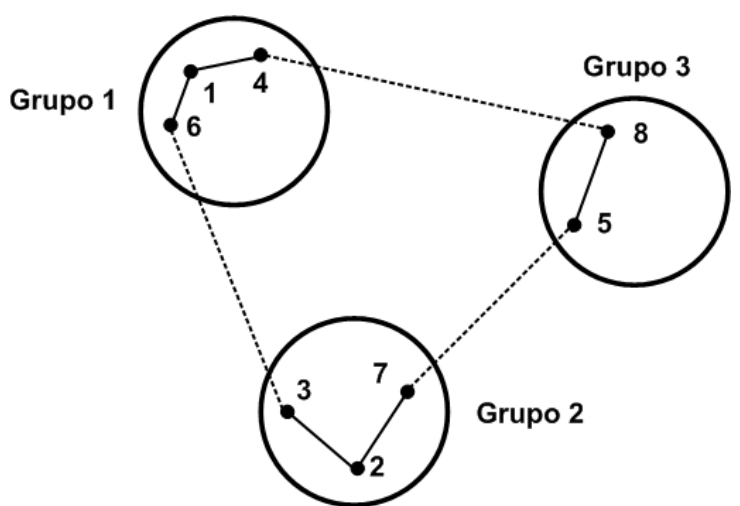

Figura 1. Uma solução viável para o PCVG.

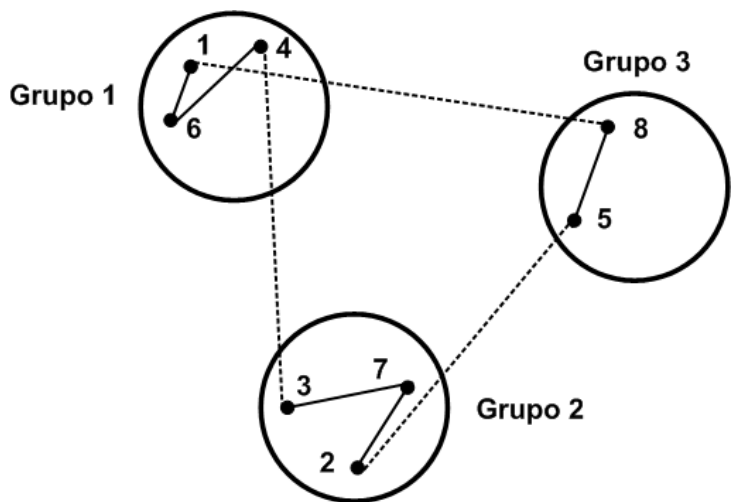

Figura 2. Uma outra solução viável do PCVG de custo maior.

\subsection{Formulação matemática}

Diversas formulações do PCV podem ser encontradas em (Dantzig et al., 1954; Miller et al., 1960; Lawler et al., 1985). Muitas destas, podem ser adaptadas para o PCVG. Para isto, basta incorporarem-se as restrições que mantém os vértices dos grupos a serem visitados de uma forma contígua. Em Chisman (1975) especificam-se as restrições a serem incorporadas.

Uma formulação para o PCVG utilizando programação inteira 0-1 está descrita em Chisman (1975) e em Miller et al. (1960), e é denominada "Miller/Chisman". Esta formulação é um problema de programação inteira 0-1 através de um grafo completo, direcionado, simétrico e ponderado $G=(V, A)$, onde $V=\left\{v_{1}, v_{2}, \ldots, v_{n}\right\}$ representa o conjunto de vértices e $A$ o conjunto de arcos, sendo $\left(v_{i}, v_{j}\right) \in A, v_{i}, v_{j} \in V$ e $i \neq j$. Seja um caixeiro viajante partindo da origem da cidade 1 sem perda de generalidade. A seguir, mostra-se a formulação dada por Miller/Chisman:

$$
\begin{array}{cl}
\text { Min } & \\
\text { s.a. } & \\
\sum_{j=1}^{n} x_{i j}=1, \sum_{j=1}^{n} c_{i j} x_{i j} & \\
\sum_{i=1}^{n} x_{i j}=1, & \forall j \in V \\
u_{i}-u_{j}+(n-1) x_{i j} \leq(n-2), & 2 \leq i \neq j \leq n \\
\sum_{i \in V_{k}} \sum_{j \in V_{k}} x_{i j}=\left|V_{k}\right|-1, & \forall V_{k} \subset V,\left|V_{k}\right| \geq 1, k=1, \ldots, m \\
u_{i} \geq 0 & 2 \leq i \leq n \\
x_{i j} \in\{0,1\} & \forall i, j \in V
\end{array}
$$

A função objetivo 1 requer que se minimize o custo total percorrido pelo caixeiro viajante. As restrições 2 garantem que de cada cidade $i$ só pode sair para uma única cidade $j$. As restrições 3 significam que para cada cidade $j$ há uma única origem em $i$. Estes dois conjuntos de restrições implicam que somente duas arestas podem ser conectadas a cada vértice formando um conjunto de ciclos possivelmente disjuntos. 
As restrições 4 garantem não haver subciclo na solução e que o caixeiro viajante parte da cidade de número 1 (vértice origem). As variáveis $u_{i}, i=2, \ldots, n$ representam a sequência das cidades $i$ a serem visitadas tendo a relação $u_{j}-u_{k} \leq-1, \forall j, k \in V$ sendo $k$ e $j$ cidades contíguas na solução, $x_{j k}=1$. As restrições 4 utilizam variáveis contínuas $u_{i}$ que representam o número de arcos menos uma unidade (1) entre o vértice origem e o vértice $i$. São necessários num ciclo que começa na cidade 1 e termina na última cidade a ser visitada, no máximo $(n-1)$ arcos. Se uma cidade $j$ for visitada após a cidade $k$, a diferença entre os valores das variáveis contínuas $\left(u_{k}\right.$ e $\left.u_{j}\right)$ é da ordem de uma unidade (1). Assim, a diferença entre quaisquer duas cidades, exceto a cidade origem, adquire um limite superior igual a $(n-2)$. Este limite superior é mostrado nas restrições 4. Observe que no caso trivial com $x_{i j}=0$, as restrições 4 são satisfeitas utilizando este limite superior.

As restrições 5 indicam que a soma das variáveis $x_{i j}$ na partição do grupo $V_{k}, k=1, \ldots, m$, sendo $m$ o número total de grupos, alcançam o valor da cardinalidade $\left|V_{k}\right|$ deste grupo menos 1 , forçando em conjunto com as restrições 2 e 3, a formação de um caminho dentro deste grupo. As variáveis binárias $x_{i j}$ assumem o valor igual a 1 se a cidade $i$ for conectada a cidade $j$ na solução. Caso contrário, será igual a 0 . Esta formulação envolve $n^{2}-n+2+m$ restrições e $n^{2}$ variáveis inteiras e $n-1$ variáveis contínuas.

\section{Metodologia}

Para solucionar o PCVG adotamos uma metodologia que utiliza heurísticas construtivas e métodos heurísticos baseados nos frameworks das meta-heurísticas. Estes últimos métodos são constituídos de forma básica de três fases: na primeira fase é construída uma solução, na segunda fase uma busca local é realizada e na terceira fase um mecanismo de memória é utilizado. Neste capítulo de livro são mostrados diversos métodos heurísticos baseados no GRASP, RC, ILS e método de descida em vizinhança variável, além da heurística de inserção mais próxima, para solucionar o PCVG genérico onde a sequência de visitas aos grupos de vértices não é pré-fixada. Através dos algoritmos construtivos baseados na heurística de inserção mais próxima serão estabelecidos os métodos Penalizados (P) e os não-Penalizados (nP).

\subsection{Heurística de inserção mais próxima}

O Algoritmo 1 foi desenvolvido para construir soluções ao PCVG utilizando-se o conceito da heurística de inserção mais próxima. O Algoritmo 1 penaliza as arestas intergrupos tratando o PCVG como um PCV. No Algoritmo 1, o conjunto de vértices $V=\left\{v_{1}, v_{2}, \ldots, v_{n}\right\}$ é definido para representar os elementos pertencentes a solução $S$.

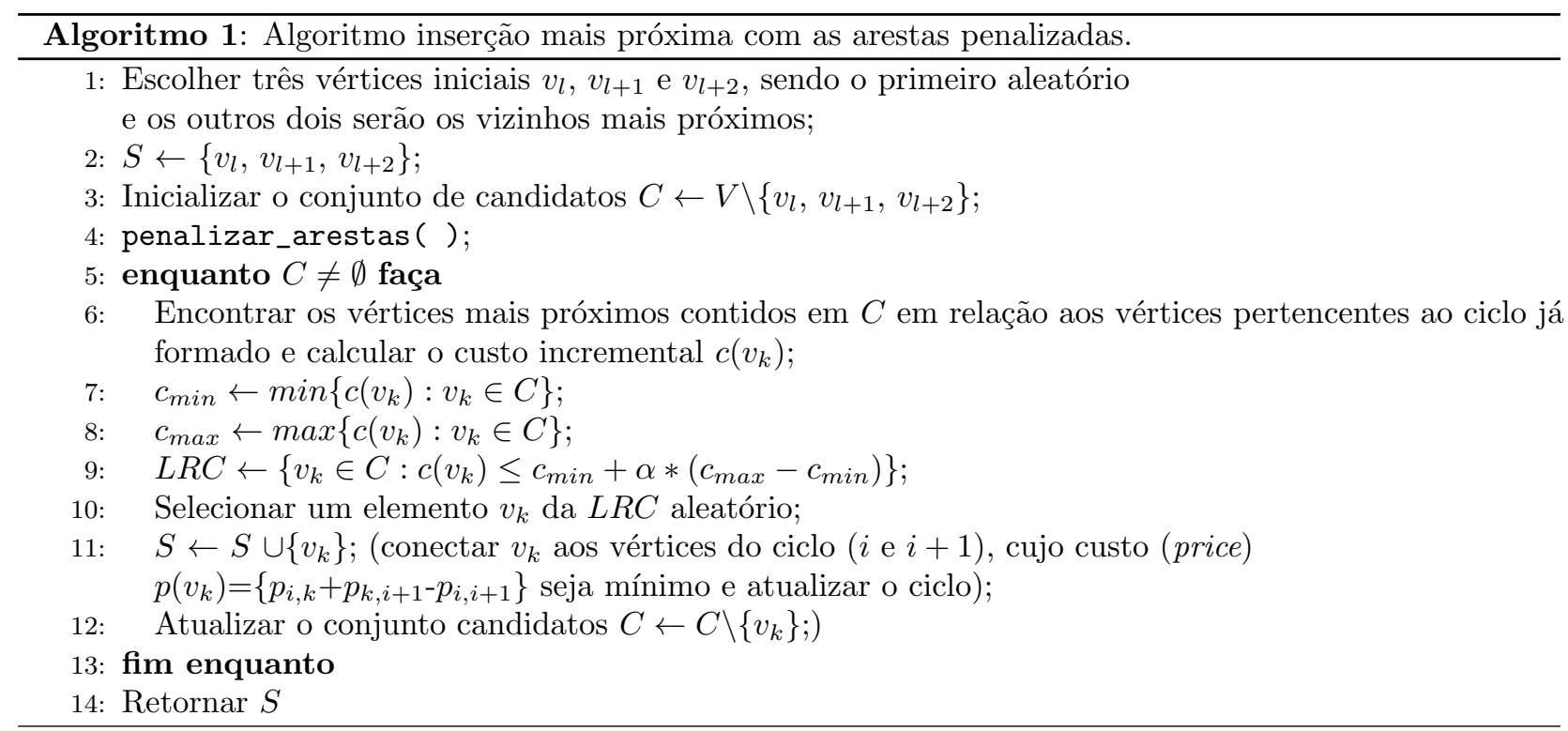

No início do Algoritmo 1 são escolhidos três vértices, sendo o primeiro aleatório e os dois outros usando o conceito de vizinho mais próximo. No passo 4 o procedimento penalizar_arestas ( ) é utilizado para alterar os valores das arestas intergrupos. A alteração penaliza os custos entre os vértices que pertencem a grupos distintos somando um valor constante igual a $L$, onde $L>>\max \left\{c_{i j}\right\}$. Em seguida, os vértices pertencentes ao conjunto de candidatos são avaliados pelos custos incrementais (passo 6), computando-se as distâncias destes vértices contidos no conjunto em relação aos vértices da solução parcial. $\mathrm{O}$ valor de $c_{\text {min }}$, menor custo incremental e o valor de $c_{\max }$, maior custo incremental são armazenados para calcular a LRC 
(Lista Restrita de Candidatos) (Seção 3.3.1). A seguir, no passo 10, seleciona-se aleatoriamente um vértice da LRC que é conectado aos vértices do ciclo da solução parcial, onde o custo de inserção seja mínimo, passo 11. Atualiza-se o conjunto de candidatos e se repetem os passos 6 até 12 . O algoritmo termina quando o conjunto de candidatos estiver vazio.

Um segundo algoritmo construtivo, foi desenvolvido para o PCVG que o trata na forma original, no qual não penaliza as arestas intergrupos (não realiza o passo 4 do Algoritmo 1) na formação do conjunto de candidatos. Neste segundo algoritmo, semelhante o passo 6 do Algoritmo 1, primeiro são escolhidos os vértices que irão compor o conjunto de candidatos sendo aqueles que pertencem ao mesmo grupo corrente dos vértices contidos na solução parcial. Quando todos os vértices do grupo corrente já estão na solução parcial, todos os outros vértices restantes que ainda não foram selecionados são considerados candidatos.

\subsection{Método de descida em vizinhança variável}

Vários métodos heurísticos híbridos utilizam como busca local o método de Descida em Vizinhança Variável (VND - Variable Neighborhood Descent) (Hansen \& Mladenović, 2003) para solucionar problemas de otimização combinatória tais como o problema do caixeiro viajante com coleta e entrega de uma comodidade (Hernández-Pérez et al., 2009). Para o PCVG, propõe-se verificar o impacto de incluir nas meta-heurísticas (GRASP e ILS) módulos de buscas locais mais eficientes utilizando os conceitos do VND. Neste contexto foram desenvolvidas várias estruturas de vizinhanças para realizar uma fase de busca local baseadas no VND.

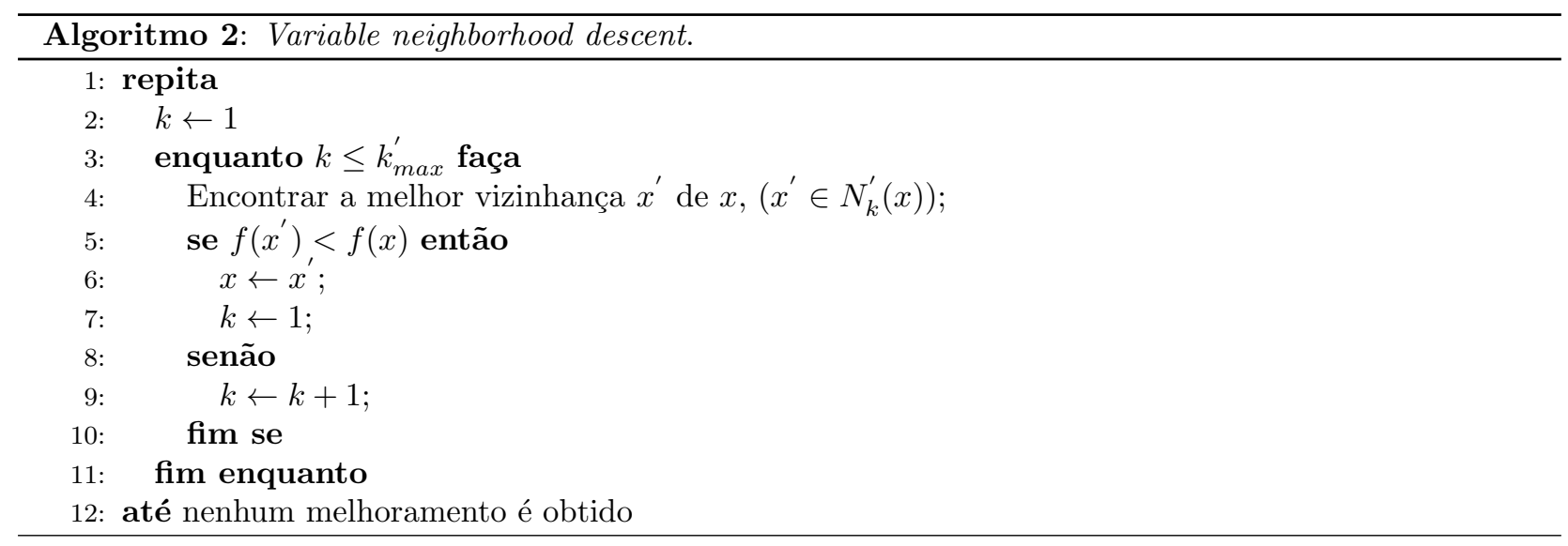

O Algoritmo 2 descreve o VND e define-se o conjunto de vizinhanças $N_{k}^{\prime}, k=1,2, \ldots, k_{\text {max }}^{\prime}$ e uma solução inicial $x$.

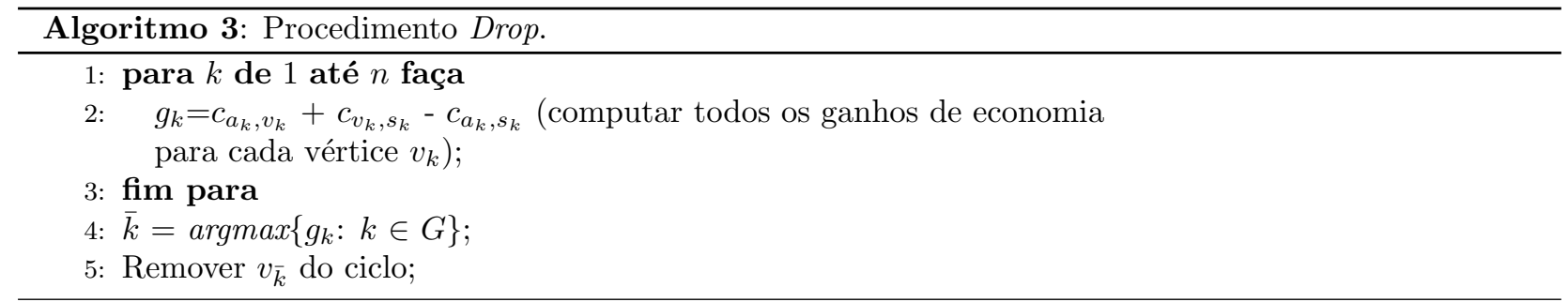

Para realizar o método de Descida em Vizinhança Variável propõem-se neste trabalho, quatro tipos de estruturas de vizinhanças. A primeira $N_{1}^{\prime}$ é obtida através de um movimento de deslocamento do vértice semente no ciclo de uma posição para outra, 1-Shift. Para definir a segunda estrutura $N_{2}^{\prime}$ precisa-se definir dois tipos de procedimentos: Drop e Cheap. O procedimento Drop varre o ciclo de uma solução e retira deste o vértice que proporcionará a maior economia com sua retirada.

O procedimento Cheap insere um vértice não pertencente a um ciclo parcial entre dois vértices adjacentes pertencentes ao ciclo, cuja inserção permita um custo adicional mínimo a solução. O ciclo construído após a inserção do vértice deverá permanecer viável. Esse procedimento está relacionado à heurística de construção inserção mais barata desenvolvida para o PCV (Reinelt, 1994).

Diante destas duas definições de procedimentos pode-se estabelecer a segunda estrutura de vizinhança $N_{2}^{\prime}$, 1-DropCheap. Uma sequência de procedimentos Drop e Cheap é realizada sobre uma solução até que nenhum melhoramento seja encontrado. Estruturas de vizinhanças semelhantes a do tipo 1-DropCheap são vistas em (Gomes et al., 2000; de Assumpção Drummond et al., 2002). O Algoritmo 3 mostra o procedimento Drop 


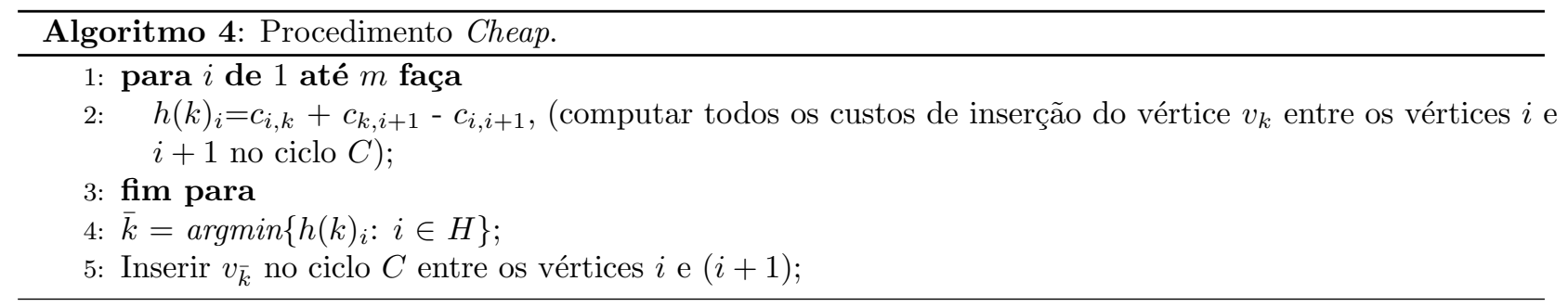

considerando-se: $V=\left\{v_{1}, v_{2}, \ldots, v_{n}\right\}$ o conjunto de vértices de um ciclo; $g_{k}$ o ganho da economia pela retirada do vértice $v_{k}$ do conjunto $V ; a_{k}$ e $s_{k}$ o antecessor e sucessor, respectivamente do vértice $v_{k}$; e o conjunto de ganhos $g_{k}$ para cada vértice $k, G=\left\{g_{1}, g_{2}, \ldots, g_{n}\right\}$.

O Algoritmo 4 apresenta o procedimento Cheap com as seguintes definições: $v_{k}$ o vértice a ser inserido; $n$ o total de vértices; o conjunto de vértices $V=\left\{v_{1}, v_{2}, \ldots, v_{n}\right\}$ e $W=\left\{v_{1}, v_{2}, \ldots, v_{m}\right\}$, sendo $W=\left(V \backslash v_{k}\right) ; C$ o ciclo formado pelos vértices em $W ; h(k)_{i}$ o custo de inserção do vértice $v_{k}$ entre os vértices $i$ e $(i+1)$ em $C$; e $H=\left\{h(k)_{1}, h(k)_{2}, \ldots, h(k)_{m}\right\}$ o conjunto de custos $h(k)_{i}$ de inserção do vértice $k$ entre os vértices $i$ e $(i+1)$.

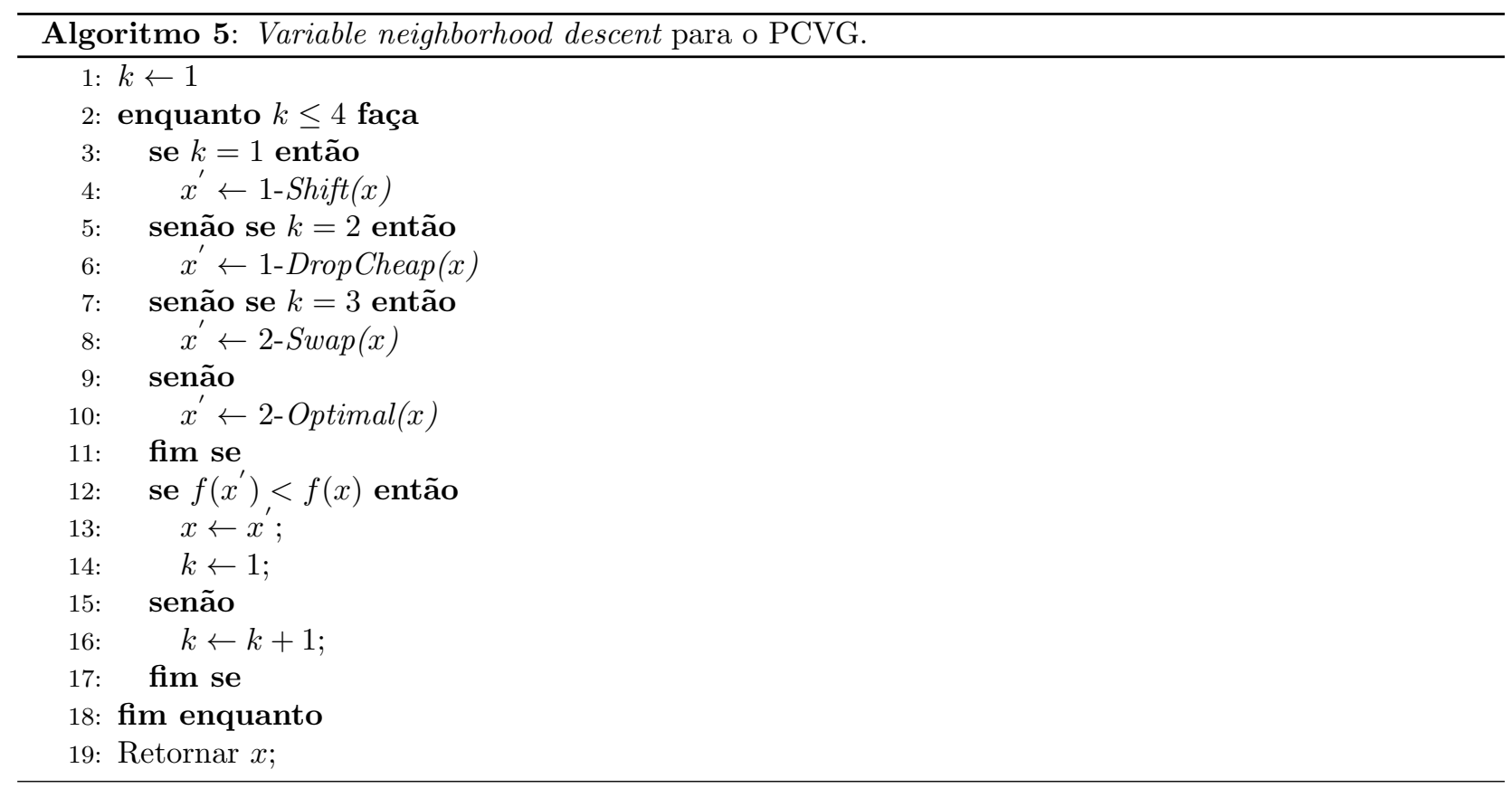

A terceira vizinhança $N_{3}^{\prime}$ é obtida através de uma permuta entre os vértices de um mesmo grupo (cluster), 2-Swap. A 2-Swap foi aplicada em outras variantes do PCV (de Assumpção Drummond et al., 2002; HernándezPérez et al., 2009). A quarta vizinhança $N_{4}^{\prime}$ utiliza a heurística 2-Opt (Reinelt, 1994) para trocar as arestas intragrupos e as intergrupos. Nesta quarta vizinhança quando são retiradas as arestas intragrupos e é reconstruída uma nova solução, somente a sequência dos vértices dentro do grupo é alterada. Quando as arestas intergrupos são trocadas, somente a sequência dos grupos é alterada. Diante das definições anteriores, o método de descida VND proposto neste trabalho a ser incluído nos métodos heurísticos baseados no GRASP e ILS como módulo de busca local é descrito pelo Algoritmo 5.

\subsection{GRASP - Greedy Randomized Adaptive Search Procedure}

Dentre as meta-heurísticas existentes na literatura, uma que tem se destacado é o GRASP. GRASP é um algoritmo iterativo no qual cada iteração consiste de duas fases: uma de construção e outra de busca local. Na fase de construção, uma solução viável é construída, e na fase de busca local sua vizinhança é investigada até um mínimo local ser encontrado. A melhor solução obtida ao final de um determinado número de iterações é retornada como a solução do algoritmo. Neste trabalho utiliza-se memória adaptativa no GRASP através do uso e atualização dinâmica de um conjunto elite (CE), uma técnica de busca denominada Reconexão de Caminhos (RC) (Resende et al., 2010).

$\mathrm{Na}$ fase de construção, a cada iteração, o conjunto de elementos candidatos é formado por todos os elementos que podem ser incorporados à solução parcial sem destruir a sua viabilidade. A seleção do próximo 
elemento a ser incorporado é determinada pela avaliação de todos os elementos candidatos, através de uma função de avaliação gulosa. Essa função gulosa usualmente representa, num problema de minimização, o aumento incremental na função custo devido à incorporação desse elemento dentro da solução construída (aspecto guloso do algoritmo). A avaliação dos elementos por essa função conduz a criação da Lista Restrita de Candidatos (LRC) formada por um subconjunto dos elementos melhor avaliados. O elemento a ser incorporado à solução parcial é selecionado aleatoriamente da LRC (aspecto probabilístico do algoritmo). O elemento selecionado é incorporado à solução parcial, a lista de candidatos é atualizada e os custos incrementais são reavaliados (aspecto adaptativo do algoritmo).

As soluções geradas pela construção aleatória gulosa do GRASP não representam necessariamente ótimos locais. A fase de busca local visa tentar melhorar a solução construída. Um algoritmo de busca local trabalha em um modo iterativo substituindo sucessivamente a solução corrente por uma solução melhor na vizinhança da solução corrente. O algoritmo termina quando nenhuma solução melhor é encontrada na vizinhança.

\subsubsection{Construção da lista restrita de candidatos}

Uma característica atraente do GRASP é a facilidade para a implementação e a existência de poucos parâmetros a serem ajustados. GRASP possui basicamente dois parâmetros principais, um relacionado ao critério de parada e outro à cardinalidade da LRC. O critério de parada pode ser determinado pelo número máximo de iterações ou um tempo limite de processamento.

O parâmetro $\alpha$ relacionado a construção da LRC usada na primeira fase do GRASP é descrito a seguir. Considere o problema como sendo de minimização sem perda de generalidade e um conjunto $V$, $V=\left\{v_{1}, v_{2}, \ldots, v_{n}\right\}$, composto de elementos a serem inseridos numa solução. Designa-se por $c\left(v_{i}\right)$ o custo incremental associado com a incorporação do elemento $v_{i} \in V$ dentro da solução construída. Representa-se por $c_{\text {min }}$ e $c_{\max }$, o menor e o maior custo incremental, respectivamente.

A LRC é construída com elementos $v_{i} \in V$ com os melhores custos incrementais $c\left(v_{i}\right)$. Esta lista pode ser limitada pelo número de elementos ou por sua qualidade. No primeiro caso, a LRC é construída de $l$ elementos com os melhores custos incrementais, onde $l$ é um parâmetro. No segundo caso, considera-se a LRC associada com um parâmetro limiar $\alpha \in[0,1]$. A LRC é formada por todos os elementos viáveis $v_{i} \in V$, os quais podem ser inseridos dentro da solução parcial construída sem destruir a viabilidade e cuja qualidade é superior ao valor limiar. Assim, verifica-se: $\left\{c\left(v_{i}\right) \in\left[c_{\min }, c_{\min }+\alpha\left(c_{\max }-c_{\min }\right)\right]\right\}$. O caso $\alpha=0$ corresponde ao algoritmo puramente guloso, enquanto $\alpha=1$ equivale ao algoritmo totalmente aleatório.

A versão reativa do GRASP tenta determinar dinamicamente os valores de $\alpha$ a serem utilizados. A seguir, a estratégia da escolha do parâmetro $\alpha$ de modo reativo (Resende \& Ribeiro, 2002) é descrita sucintamente. Esta estratégia procura incorporar um mecanismo de aprendizado usando os valores das soluções produzidas ao longo das iterações. Neste caso, o valor de $\alpha$ não será fixo. Seja, $\Psi=\left\{\alpha_{1}, \ldots, \alpha_{m}\right\}$, o conjunto dos possíveis valores para $\alpha$ de tamanho $m$. A probabilidade inicial associada com a escolha de cada valor $\alpha_{i}$ será igual a $p_{i}=1 / m, \operatorname{com} i=1, \ldots, m$. Seja também $z^{*}$ a melhor solução encontrada até o momento e $z_{m_{i}}$ o valor médio de todas as soluções encontradas usando $\alpha=\alpha_{i}, i=1, \ldots, m$. As probabilidades de seleção serão periodicamente reavaliadas, com $p_{i}=q_{i} / \sum_{j=1}^{m} q_{j}, q_{i}=z^{*} / z_{m_{i}}$ para $i=1, \ldots, m$. O valor de cada $q_{i}$ será maior quando o valor médio $z_{m_{i}}$ diminuir. Os maiores valores de $q_{i}$ correspondem aos valores mais adequados para os $\alpha_{i}$. As probabilidades associadas com estes valores mais apropriados aumentam à medida que os valores de $\alpha$ são reavaliados.

\subsubsection{Reconexão de caminhos}

A Reconexão de Caminhos (RC) foi originalmente proposta por Glover (1996) como uma estratégia de intensificação que explora trajetórias conectando soluções elite obtidas pela Busca Tabu e Scatter Search. O uso da Reconexão de Caminhos com o GRASP foi primeiro proposto por Laguna \& Martí (1999) como uma estratégia de intensificação. Partindo de uma ou mais soluções elites, a Reconexão de Caminhos permite que outras soluções sejam geradas e exploradas percorrendo-se novos caminhos no espaço de solução. Isso é efetuado selecionando-se os movimentos que introduzem atributos contidos nas soluções guias a serem inseridos nas soluções base. Basicamente duas estratégias são usadas com o uso da Reconexão de Caminhos com o GRASP: uma aplicada numa etapa de pós-otimização para todos os pares de soluções elite e outra, aplicada num processo de intensificação para cada ótimo local obtido depois da fase de busca local.

Na segunda estratégia, a Reconexão de Caminhos é aplicada ao pares $\left(x_{1}, x_{2}\right)$ de soluções extremos, onde $x_{1}$ é a solução obtida usualmente por uma busca local e $x_{2}$ é uma das soluções elite (conjunto das $k$ melhores soluções obtidas até o momento pelo GRASP) escolhida aleatoriamente deste conjunto construído ao longo das iterações (Resende \& Ribeiro, 2002). A cardinalidade deste conjunto é limitada a um valor máximo (Max_Elite). 


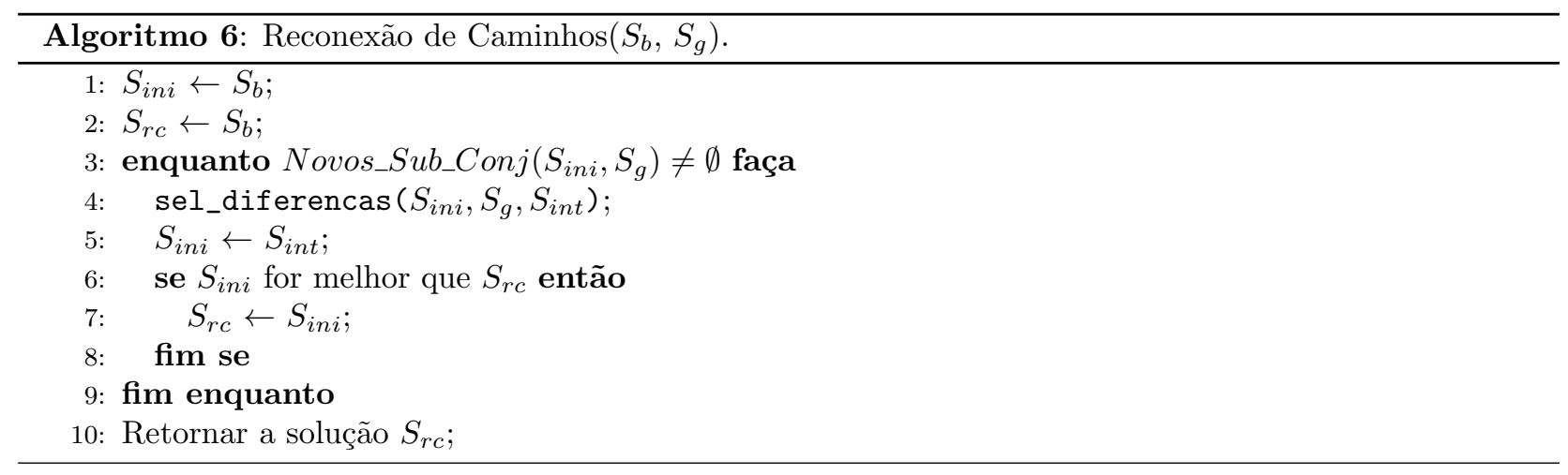

O Algoritmo 6 mostra a Reconexão de Caminhos realizada entre duas soluções elites, solução base $S_{b}$ e solução guia $S_{g}$. O procedimento Novos_Sub_Conj $\left(S_{k}, S_{j}\right)$ estabelece os subconjuntos novos entre as soluções $S_{k}$ e $S_{j}$ definidos pelas diferenças entre estas duas soluções. O Algoritmo 6 estabelece no passo 1 que $S_{b}$ será a solução inicial $\left(S_{\text {ini }}\right)$. Em seguida, o Algoritmo 6 analisa todas as diferenças existentes entre a solução base e a solução guia (passos 3 a 9). Depois de escolhido o par de soluções, $S_{i n i}$ e $S_{g}$, percorre o caminho de $S_{i n i}$ a $S_{g}$ e uma diferença entre $S_{i n i}$ a $S_{g}$ é retornada pela solução $S_{i n t}$ (solução intermediária) através do procedimento sel_diferencas $\left(S_{i n i}, S_{g}, S_{i n t}\right)$. A solução $S_{i n t}$ será a solução inicial da próxima etapa, passo 5. A melhor de todas as soluções intermediárias nas etapas da Reconexão de Caminhos será a solução de saída, passos 6 a 8 .

Na versão proposta para a RC foi escolhida como solução base $S_{b}$, a solução cujo custo seja menor entre as duas soluções extremos $\left(S_{b}\right.$ e $\left.S_{g}\right)$. A solução de pior qualidade será a solução guia $S_{g}$.

Uma das principais características para realização da Reconexão de Caminhos é a construção de um conjunto elite (CE). A cardinalidade do conjunto elite é formada por um número fixo pré-definido de soluções e a estratégia para escolher as soluções que irão pertencer ao conjunto elite é a seguinte: primeiro, se o conjunto elite estiver incompleto, a solução gerada na iteração do GRASP simplesmente é inserida neste e segundo, se o conjunto elite já estiver completo, a solução gerada na iteração do GRASP é inserida no conjunto elite, caso seu custo da função objetivo seja menor que o custo da solução de pior qualidade do conjunto elite e a solução apresente uma diferença mínima na sua estrutura para cada solução presente no CE. Depois de verificada as duas condições, necessita-se saber qual será a solução que deve ser retirada do conjunto elite. A solução que irá sair deverá ter em relação à solução que entra no conjunto elite um custo maior e uma menor diferença na estrutura entre as duas soluções. A ideia da construção do conjunto elite é ter um conjunto de soluções de boa qualidade.

A diferença na estrutura é calculada pelo número de arestas. Assim, dada duas soluções $\left(S_{i}\right.$ e $\left.S_{j}\right)$ computase esta diferença pelo número de arestas necessárias a serem inseridas em uma solução $S_{i}$ para se transformar em outra solução $S_{j}$. A versão proposta para a RC realiza uma busca mais intensiva, onde a reconexão é feita entre cada par de soluções elite. Caso surjam novas soluções nesta recombinação que atualizem o CE, uma nova etapa será realizada entre as novas soluções obtidas. O processo termina quando o CE não for mais atualizado. Esta RC é ativada durante as iterações do GRASP sempre que o CE for totalmente renovado. A RC é realizada em cada iteração do GRASP somente quando muda todas as soluções do CE. Esta versão combina as duas estratégias básicas expostas anteriormente: etapa de pós-otimização e processo de intensificação.

\subsubsection{Método heurístico baseado no GRASP para o PCVG}

O GRASP desenvolvido para o PCVG utiliza parte da estrutura do GRASP tradicional (Resende \& Ribeiro, 2002), onde em cada iteração executa-se uma fase de construção de uma solução e uma fase de busca local. Na etapa de construção, utiliza-se o método de Inserção mais Próxima com as arestas penalizadas ou Inserção mais Próxima com as arestas não penalizadas, ambos com valor de $\alpha$ calculado pela versão reativa e na busca local o VND. No GRASP será inserido ainda uma Reconexão de Caminhos durante suas iterações. O GRASP será denominado de G-IMPP quando utiliza o algoritmo construtivo (Algoritmo 1) que penalizada as arestas intergrupos e de G-IMPnP quando não penaliza tais arestas.

Durante a execução do GRASP é gerado e atualizado um CE que armazena as num_eli melhores soluções distintas encontradas pelo GRASP. Tal procedimento equivale a usar uma memória que armazene no CE informações relevantes encontradas em iterações passadas. Como este conjunto sofre atualizações sempre que uma nova solução de boa qualidade é encontrada entre as iterações do GRASP, esta memória é adaptativa. 
O GRASP utiliza para a busca local a meta-heurística VND (Hansen \& Mladenović, 2003). No VND são utilizados quatro tipos de estruturas de vizinhanças definidas anteriormente na Seção 3.2. A primeira $N_{1}^{\prime}$ denominada de 1-Shift, a segunda $N_{2}^{\prime}$ (1-DropCheap), a terceira $N_{3}^{\prime}$ (2-Swap) e a quarta $N_{4}^{\prime}$ utiliza a heurística 2-Opt. Nesta proposta de trabalho foram adotadas as seguintes estratégias ao VND para reduzir o esforço computacional decorrente do uso das estruturas de vizinhanças. Quando são utilizadas as vizinhanças $N_{1}^{\prime}$ e $N_{3}^{\prime}$, adota-se a estratégia first improvement (ou seja, na primeira melhora ocorre o movimento para esta solução aprimorante) (Hansen \& Mladenović, 2003), enquanto que, quando são utilizadas $N_{2}^{\prime}$ e $N_{4}^{\prime}$, adota-se o método best improvement (são analisadas todas as soluções vizinhas e ocorre o movimento para a melhor solução).

O método heurístico baseado no GRASP para o PCVG está representado no Algoritmo 7 com todos os componentes: construção da solução, busca local e Reconexão de Caminhos. Para o Algoritmo 7 considera-se: $S^{*}$ a melhor solução; maxprob o $n^{\mathrm{O}}$ máximo de iterações para mudar a distribuição de probabilidade dos alfas; num_iter o $n^{\mathrm{O}}$ máximo de iterações; e num_eli o $n^{\mathrm{O}}$ máximo da cardinalidade do conjunto elite; $\mathrm{O}$ procedimento Max_Sol_Elite $\left(S^{\prime}\right.$, iter) (Algoritmo 8) representa a construção do conjunto de soluções elites e o Rec_Cam $\left(U^{\text {elite }}, S^{\prime}\right)$ representa a Reconexão de Caminhos durante as iterações do GRASP. O Algoritmo 7 mostra ainda os procedimentos calcularalfa( ), utilizado para selecionar o alfa a ser utilizado pela versão reativa e atualizardisalfas ( ), para atualizar a distribuição de probabilidade dos alfas.

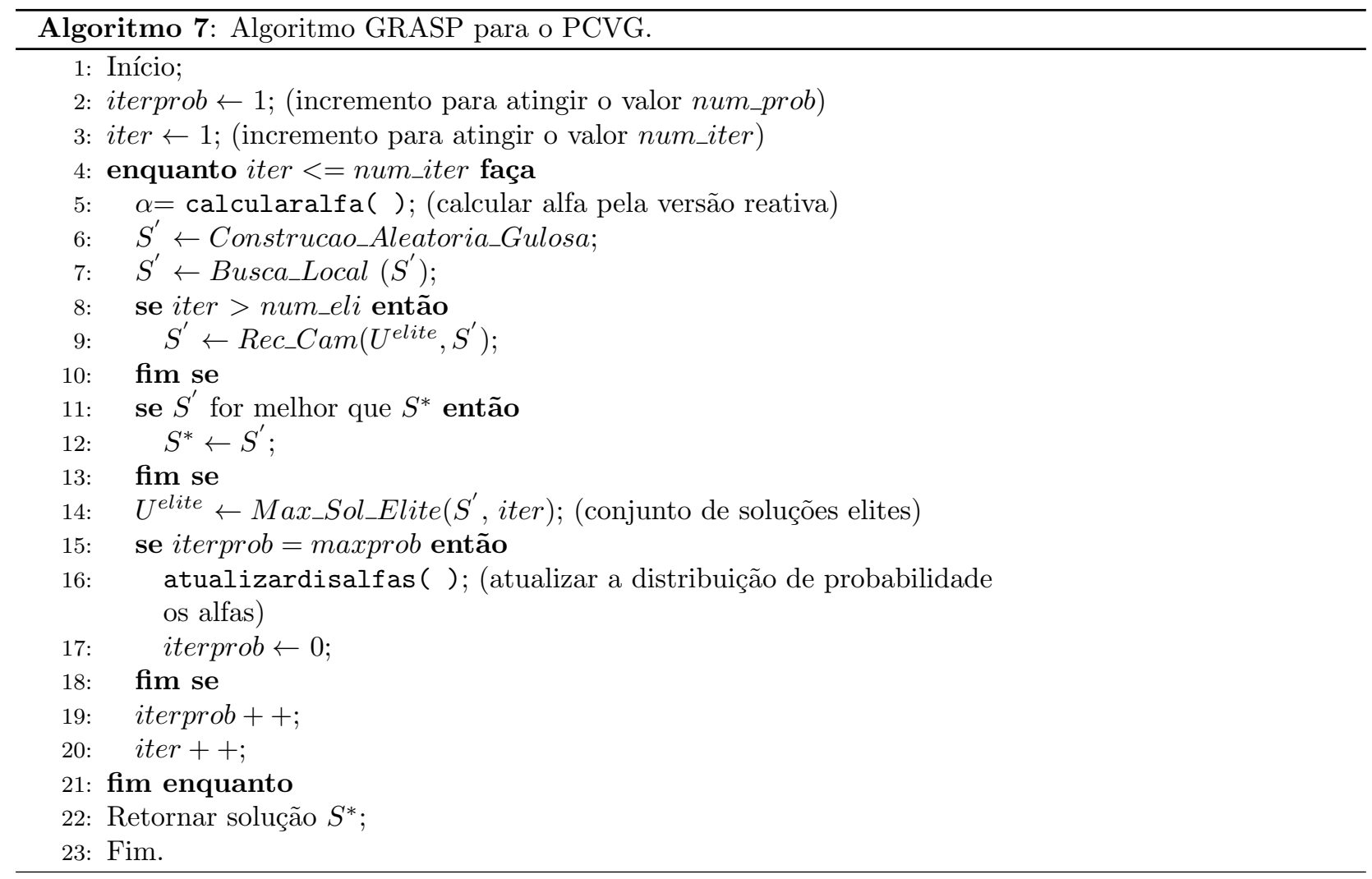

O Algoritmo 8 descreve o procedimento para construção do conjunto elite. Os parâmetros de entrada são: $S^{\prime}$ a solução do GRASP e num é uma variável que contabiliza a ordem no qual as soluções são geradas. O retorno deste algoritmo é o conjunto de soluções elites $\left(U^{\text {elite }}=\left\{S_{1}, \ldots, S_{\text {maxelite }}\right\}\right)$. Ainda para o Algoritmo 8 necessita-se definir os parâmetros: maxelite o $n^{\mathrm{O}}$ máximo de soluções do conjunto elite; mindif a mínima diferença permitida entre duas soluções; valordif o valor da diferença entre as soluções; cont contador das soluções, cuja diferença mínima foi alcançada; e $\operatorname{dif}\left(S_{i}, S_{j}\right)$ o cálculo da diferença entre a solução $S_{i}$ e $S_{j}$.

Ainda, para o Algoritmo 8, caso o conjunto elite (CE) esteja incompleto, a solução $\left(S^{\prime}\right)$ é inserida neste (passos de 1 a 4). Caso o CE estiver completo, a solução a ser inserida $\left(S^{\prime}\right)$ no conjunto deverá ter o seu custo da função objetivo $f\left(S^{\prime}\right)$ menor do que o custo da solução de pior qualidade $\left(S_{\text {maxelite }}\right)$ do CE e deve apresentar uma diferença mínima (mindif) na estrutura de seus elementos para cada solução presente no conjunto $U^{\text {elite }}=\left\{S_{1}, \ldots, S_{\text {maxelite }}\right\}$ (passos de 5 a 12 ).

Após as duas condições terem sido atendidas, necessita-se encontrar a solução a ser retirada $S_{\text {out }}$ do conjunto elite. A solução que irá ser retirada deve ter em relação à solução a ser inserida no CE um custo maior e a menor diferença (valordif) nos elementos entre estas duas soluções (passos 13 a 26). O Algoritmo 8 no final retorna o conjunto $U^{\text {elite }}$, passo 29. 


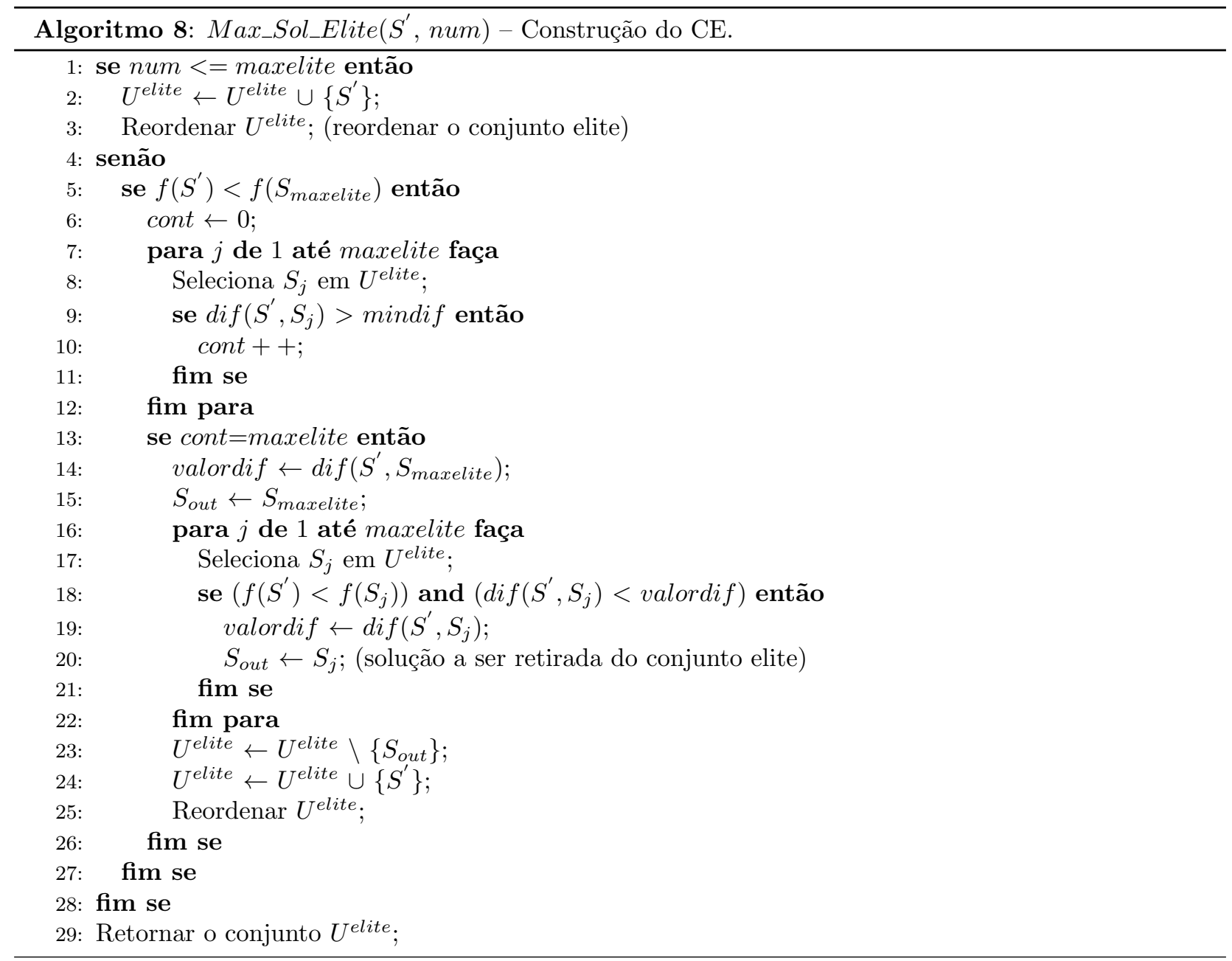

\subsection{ILS - Iterated Local Search}

Outra meta-heurística que vem se mostrando eficiente para obter soluções aproximadas de boa qualidade para problemas de otimização combinatória é o método ILS (Lourenço et al., 2002). As características da metaheurística ILS são simplicidade, eficiência, facilidade de implementação e robustez. Sua estrutura canônica é formada por quatro módulos principais: construção da solução, busca local, perturbação e critério de aceitação. Cada módulo pode ser tratado de forma independente possibilitando maior facilidade em sua atualização. É claro que o sucesso do ILS depende exclusivamente do projeto de cada módulo.

A maneira como ILS explora o espaço de soluções de ótimos locais é definido a seguir: primeiro aplica-se uma perturbação à solução corrente $S$ que permite um estado intermediário $S^{\prime}$. Sobre $S^{\prime}$, aplica-se uma busca local obtendo-se $S^{\prime \prime}$. Se a solução $S^{\prime \prime}$ for considerada pelo critério de aceitação, esta será a próxima solução a sofrer a perturbação, caso contrário é retornada a solução $S$ (Lourenço et al., 2002).

Como as perturbações dependem sensivelmente das soluções obtidas nas etapas anteriores guiadas pelo critério de aceitação, pode-se dizer que ILS incorpora mecanismo de memória. Uma das grandes vantagens do ILS está na estrutura modular de cada componente. Assim, pode-se desenvolver os módulos independentes e incorporar complexidades maiores a cada um com a finalidade de tentar obter soluções de alta qualidade. ILS é descrito pelo Algoritmo 9 baseada no framework de Lourenço et al. (2002). No Algoritmo 9, a solução $S^{*}$ representa a melhor solução encontrada e o módulo Construcao_Aleatoria_Gulosa representa a construção de solução. No Algoritmo 9 são mostrados ainda, os módulos perturbação, busca local, e critério de aceitação, passos 6,7 e 8 , respectivamente.

\subsubsection{Método heurístico baseado no ILS para o PCVG}

Um tipo de perturbação utilizada no PCV com sucesso foi o movimento double-bridge (Martin et al., 1992). Este tipo de perturbação remove quatro arestas na solução e reconstrói uma nova solução substituindo as arestas removidas por outras arestas para obter um movimento não sequencial nas novas arestas inseridas. Para o PCVG a perturbação utilizada foi realizada sob duas formas: a primeira denominada (Perttc) realiza 


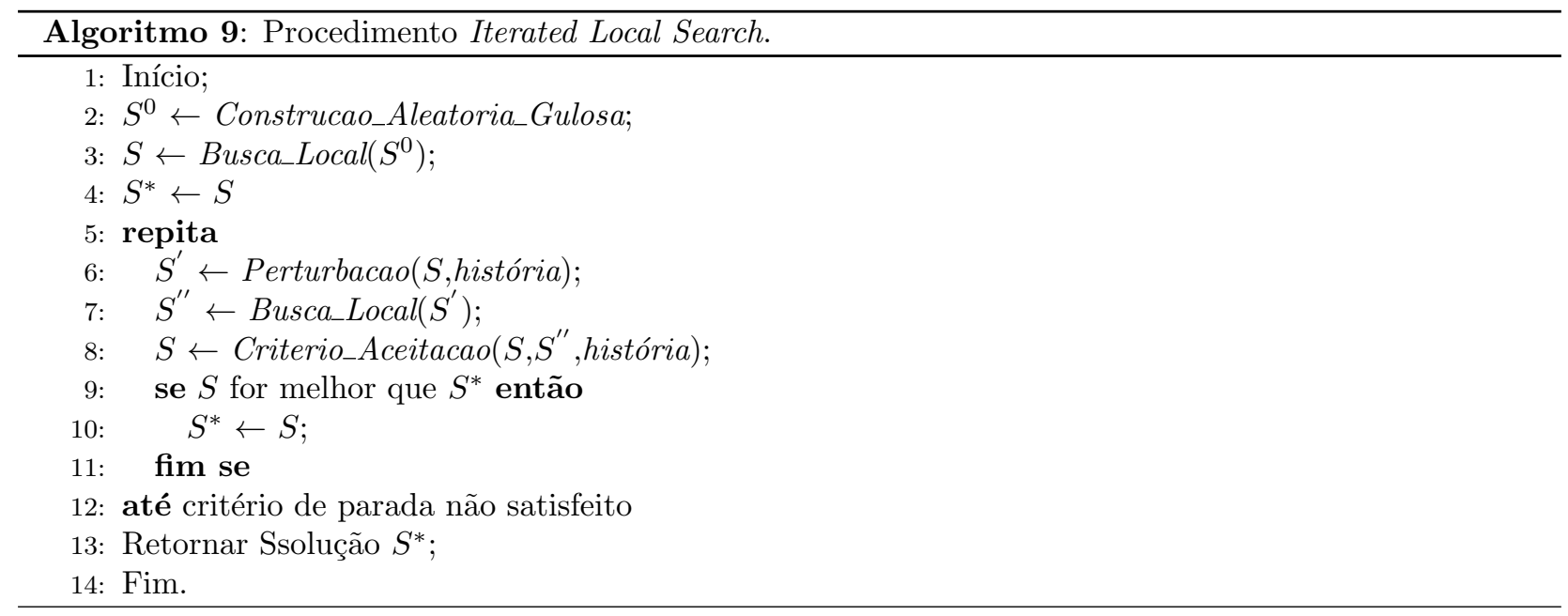

uma troca aleatória entre dois grupos (two clusters) sem alterar os vértices internos dos grupos. A segunda (Pert) realiza o movimento double-bridge aplicado aos vértices em um grupo escolhido aleatório. A sequência dos grupos não é alterada, somente a sequência dos vértices do grupo escolhido é modificada.

O critério de aceitação (CritAceit) construído na etapa seguinte da perturbação foi escolhido entre as duas soluções ótimas locais, $S$ e $S^{\prime \prime}$, descritas anteriormente pelo Algoritmo 9 e a solução $S^{*}$, a melhor solução até a etapa corrente do algoritmo. Para o critério de aceitação (CritAceit) a solução que tiver o menor custo entre a três soluções $\left(S, S^{\prime \prime}, S^{*}\right)$ será escolhida como solução para a etapa seguinte da perturbação. Assim, tem-se:

$$
\operatorname{CritAceit}\left(S, S^{\prime \prime}, \text { história }\right)=\left\{\begin{array}{ccccc}
S & \text { se } & c(S)<c\left(S^{\prime \prime}\right) & \text { e } & c(S)<c\left(S^{*}\right), \\
S^{\prime \prime} & \text { se } & c\left(S^{\prime \prime}\right)<c(S) & \text { e } & c\left(S^{\prime \prime}\right)<c\left(S^{*}\right), \\
S^{*} & & \text { caso contrário, }
\end{array}\right.
$$

O método heurístico baseado no ILS para o PCVG é representado pelo Algoritmo 10. Neste algoritmo, o número máximo de iterações para mudar a distribuição de probabilidade dos alfas é representado pelo parâmetro maxprob, o parâmetro iterprob representa o incremento para atingir o valor maxprob, o iterext denota o número máximo de iterações externas e o maxiter o número máximo de iterações internas.

No Algoritmo 10, a solução $S^{0}$ representa uma solução construída pelo módulo Construcao_Aleatoria_Gulosa, no qual é utilizada para iniciar o algoritmo e para gerar soluções diversificadas a cada iteração mais externa. A solução $S$ corresponde a solução corrente no qual é aplicada uma perturbação, a solução $S^{\prime}$ é a solução que está num estado intermediário, onde é aplicada uma busca local obtendo a solução $S^{\prime \prime}$ e a solução $S^{*}$ representa a melhor solução encontrada. No Algoritmo 10 são mostrados ainda os módulos: de perturbação (Pert), de busca local ( $V N D)$ e critério de aceitação (CritAceit). Estes módulos foram os que permitiram os métodos heurísticos utilizando o ILS a encontrar as melhores soluções para o PCVG. O procedimento calcularalfa( ) seleciona o alfa $(\alpha)$ na versão reativa a ser utilizado pelo módulo construtivo e o procedimento atualizardisalfas( ) atualiza a distribuição de probabilidade dos alfas, sempre que iterprob atingir seu valor máximo igual a maxprob.

No Algoritmo 10, no passo 3, inicialmente é obtida uma solução $S^{0}$. Para cada iteração externa do algoritmo, passos 6 a 23, tem-se que: no passo 7 é selecionado um valor para $\alpha$ através de uma distribuição de probabilidade, uma nova solução $S^{0}$ é construída no passo 8 e, no passo 9 , a busca local é executada pelo VND obtendo a solução $S$. Para cada iteração interna do algoritmo, passos 10 a 17 , a perturbação é aplicada gerando a solução $S^{\prime}$ (passo 11) e a busca local é executada de novo pelo VND produzindo a solução $S^{\prime \prime}$, passo 12. No passo 13 , é executado o critério de aceitação e a melhor solução $S^{*}$ é atualizada no passo 15 . No passo 19, os alfas são atualizados pela distribuição de probabilidade na versão reativa e, finalmente, no passo 24 , a melhor solução $S^{*}$ é retornada.

\section{Resultados Computacionais}

Para avaliar os métodos heurísticos e um método exato ao PCVG foram utilizadas as instâncias descritas em (Mestria, 2011), por apresentar uma biblioteca pública com instâncias para este problema. Todas as instâncias são Euclidianas e estão disponíveis na internet ${ }^{1}$. O CPLEX paralelo foi executado num computador com 4 núcleos Intel Core 2 Quad, 2,83 GHz com 8 GB de RAM. O sistema operacional utilizado foi Linux Ubuntu

\footnotetext{
1 http://labic.ic.uff.br/Instance/index.php
} 


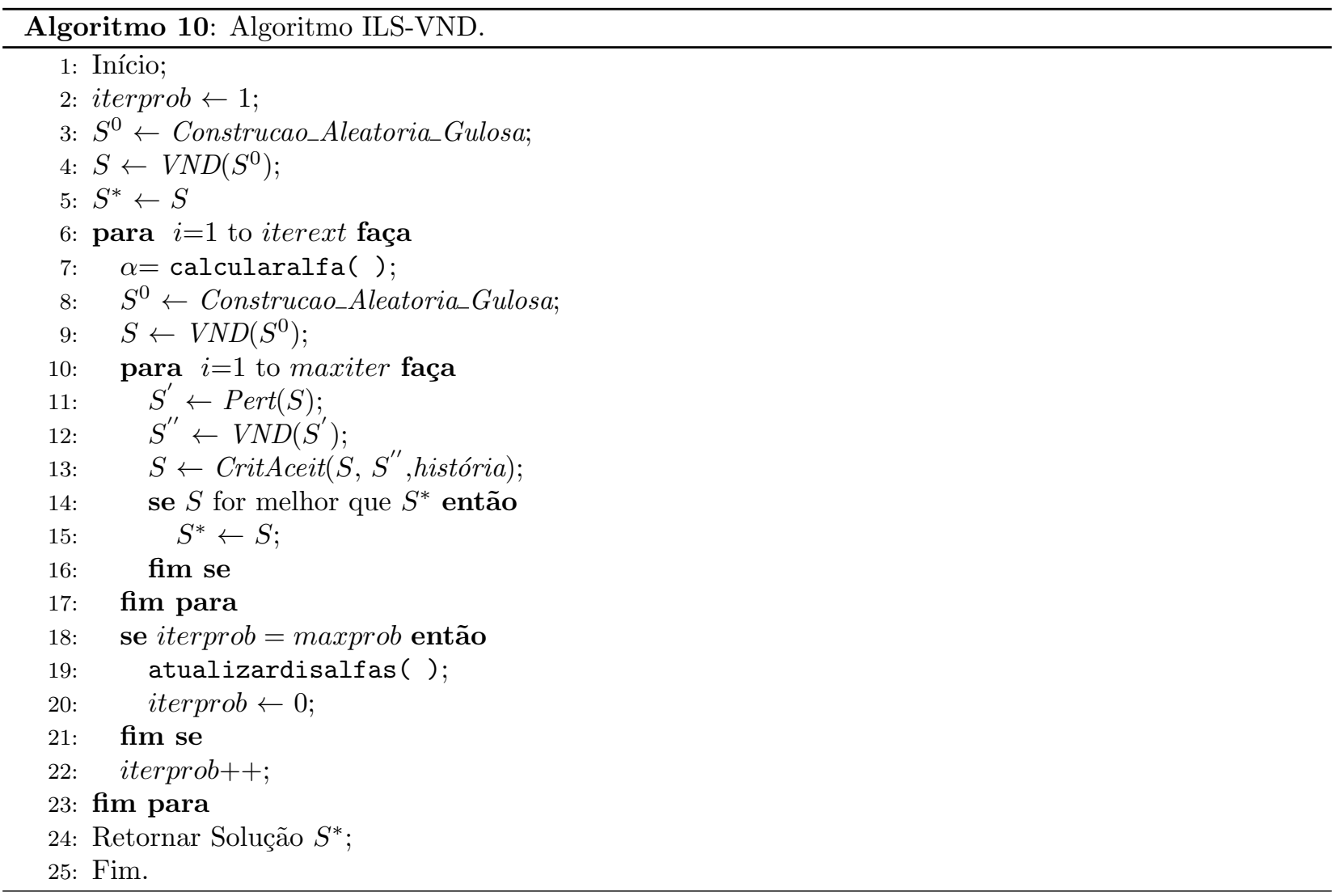

versão 4.3.2-1. Os métodos heurísticos foram codificados em linguagem de programação $\mathrm{C}$ e executados no mesmo computador descrito anteriormente, mas utilizando somente um núcleo.

\subsection{Testes utilizando um método exato}

A Tabela 1 mostra as instâncias (coluna 1) com os seus identificadores (coluna 2), seguido do número de vértices (nós), número de grupos e tipo. Na Tabela 1 são mostradas ainda, as soluções e os limites inferiores gerados pelo método exato através do software CPLEX. Na última coluna é mostrado o percentual do gap ${ }_{l i}$ (\%) entre valor da solução e limite inferior calculado da seguinte forma:

$$
\operatorname{gap}_{l i}=100 *\left(\frac{\text { best }-l i}{\text { best }+\epsilon}\right)
$$

onde, best é o melhor valor encontrado pelo CPLEX, $l i$ o limite inferior dado pelo CPLEX e $\epsilon$ igual $10^{-10}$.

Devido às longas iterações ocorridas no CPLEX para a maioria das instâncias, um tempo limite de $7200 \mathrm{~s}$ foi determinado para sua execução. Para a instância $I_{3}$, a solução ótima foi encontrada pelo CPLEX em 442s. Todas as outras execuções utilizaram 7200s, sendo, portanto abortadas antes de se encontrar ou confirmar uma solução ótima.

\subsection{Testes dos métodos construtivos e do VND}

A Figura 3 mostra os gaps alcançados pelas heurísticas IMPP, IMPnP e pelo método VND utilizando a heurística IMPP, denominado de VND-IMPP, além do VND combinado com a IMPnP (VND-IMPnP). Foram escolhidas várias instâncias de diversos tipos variando o número de vértices entre 200 e 1000 e o número de grupos entre cinco e 144 vértices, totalizando 53 instâncias. Para cada execução dos métodos heurísticos foram utilizadas 200 iterações com o parâmetro $\alpha$ na versão reativa que gerencia o tamanho da LRC na etapa de construção. Os valores de $\alpha$ variam no intervalo de [0,1]. O valor para atualizar periodicamente as probabilidades dos $\alpha$ s foi igual a 50. Todos os métodos foram executadas dez vezes. Assim, tem-se 2120 testes computacionais. O desempenho dos algoritmos construtivos (IMPP e IMPnP) e com buscas locais (VND-IMPP e VND-IMPnP) para os valores médios são mostrados na Figura 3 através do gaph médio (eixo $y$ ), Equação 10, para cada tipo de instância. Observa-se que os algoritmos (eixo $x$ ) que utilizaram penalização mostram-se com melhores resultados na média do que os algoritmos que não aplicaram a estratégia de penalização. 
Tabela 1. Instâncias com seus identificadores $\left(J_{k}\right)$, número de nós, número de grupos, tipo e valores alcançados pelo CPLEX com limite de duas horas.

\begin{tabular}{|c|c|c|c|c|c|c|c|}
\hline \multirow{2}{*}{ Instâncias } & \multirow{2}{*}{ Id. } & \multirow{2}{*}{\multicolumn{2}{|c|}{$\#$ nós \# $V_{i}$}} & \multirow{2}{*}{ Tipo } & \multicolumn{3}{|c|}{ CPLEX } \\
\hline & & & & & Valor & Lim. Inf. & $(\%)$ \\
\hline i-50-gil262 & $J_{1}$ & 262 & 50 & 1 & 135529 & 135374,68 & 0,11 \\
\hline 10-lin318 & $J_{2}$ & 318 & 10 & 1 & 534640 & 526412,07 & 1,54 \\
\hline 10-pcb442 & $J_{3}$ & 442 & 10 & 1 & 547152 & 536478,33 & 1,95 \\
\hline C1k.0 & $J_{4}$ & 1000 & 10 & 2 & 134025123 & 131354923,50 & 1,99 \\
\hline C1k.1 & $J_{5}$ & 1000 & 10 & 2 & 130750874 & 128540131,50 & 1,69 \\
\hline C1k.2 & $J_{6}$ & 1000 & 10 & 2 & 144341485 & 141501445 & 1,97 \\
\hline $300-6$ & $J_{7}$ & 300 & 6 & 3 & 8969 & 8915,18 & 0,60 \\
\hline $400-6$ & $J_{8}$ & 400 & 6 & 3 & 9117 & 9021,51 & 1,05 \\
\hline $700-20$ & $J_{9}$ & 700 & 20 & 3 & 41638 & 41274,00 & 0,87 \\
\hline 200-4-h & $J_{10}$ & 200 & 4 & 4 & 63429 & 62244,84 & 1,87 \\
\hline 200-4-x1 & $J_{11}$ & 200 & 4 & 4 & 60797 & 60242,96 & 0,91 \\
\hline $600-8-z$ & $J_{12}$ & 600 & 8 & 4 & 132897 & 127901,75 & 3,76 \\
\hline $600-8-x 2$ & $J_{13}$ & 600 & 8 & 4 & 132228 & 127901,75 & 3,27 \\
\hline $300-5-108$ & $J_{14}$ & 300 & 5 & 5 & 68361 & 67128,93 & 1,80 \\
\hline $300-20-111$ & $J_{15}$ & 300 & 20 & 5 & 311286 & 308595,45 & 0,86 \\
\hline 500-15-306 & $J_{16}$ & 500 & 15 & 5 & 196001 & 193522,8 & 1,26 \\
\hline 500-25-308 & $J_{17}$ & 500 & 25 & 5 & 367586 & 364108,13 & 0,95 \\
\hline 25-eil101 & $J_{18}$ & 101 & 25 & 6 & 23671 & 23668,63 & 0,01 \\
\hline $42-\mathrm{a} 280$ & $J_{19}$ & 280 & 42 & 6 & 130043 & 129560,53 & 0,37 \\
\hline \multirow[t]{2}{*}{ 144-rat783 } & $J_{20}$ & 783 & 144 & 6 & 916174 & 913715,52 & 0,27 \\
\hline & & & & & & $g a p_{l i}$ médio $=$ & 1,36 \\
\hline
\end{tabular}

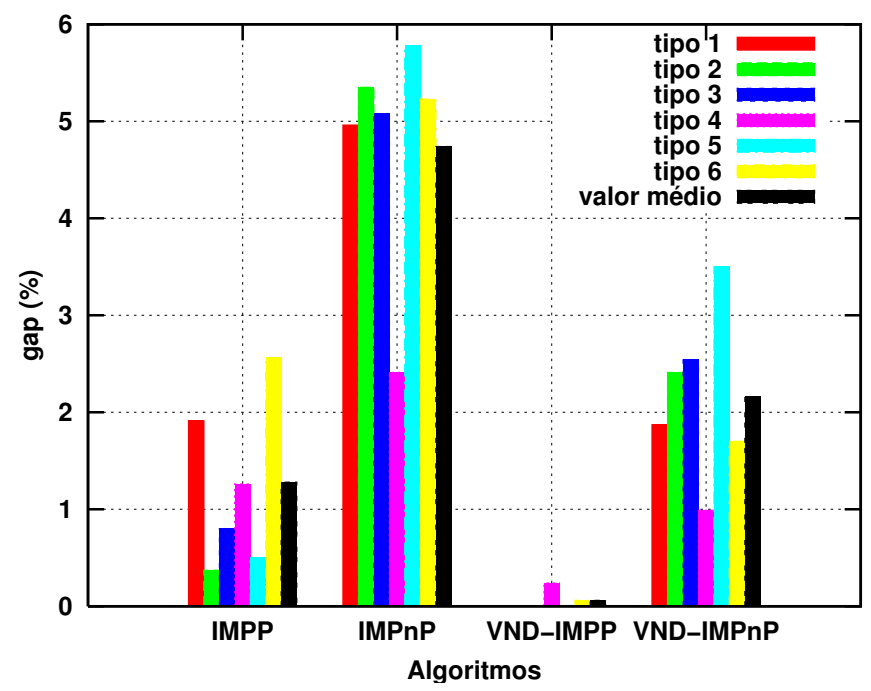

Figura 3. Gap médio para cada tipo de instância alcançados pelos algoritmos: IMPP, IMPnP, VND-IMPP e VND-IMPnP, sobre os valores médios.

O percentual do $g a p_{h}$ utilizado na Figura 3 é cálculado conforme a Equação 10 descrita abaixo:

$$
g a p_{h}=100 *\left(\frac{v h-m v}{m v}\right)
$$

onde, $v h$ é o valor médio encontrado pela heurística e $m v$ é o melhor valor médio alcançado entre as heurísticas IMPP, IMPnP, VND-IMPP e VND-IMPnP.

$\mathrm{Na}$ Figura 3 temos, por exemplo, que para cada algoritmo e para as instâncias do tipo 1 (primeiros dados em barras no gráfico na cor vermelha), o gap ${ }_{h}$ médio dos valores médios do algoritmo IMPP foi igual a 1,91\%, de IMPnP com o valor de 4,96\%, de VND-IMPP com $\boldsymbol{0 , 0 0 \%}$ e VND-IMPnP com 1,87\%. Observe que o gap médio do algoritmo VND-IMPP foram todos iguais a zero, exceto para as instâncias do tipo 4 e do tipo 6 , cujos valores foram iguais a $0,24 \%$ e $0,06 \%$, respectivamente. Na Figura 3 também são mostrados em barras, 
na cor preta, os valores médios alcançados pelos algoritmos para todos os tipos de instâncias representando o gap $_{h}$ médio individual de cada algoritmo.

\subsection{Testes dos métodos heurísticos utilizando GRASP e ILS}

Os principais parâmetros do GRASP são descritos a seguir. O valor para penalizar os custos das arestas $(L)$ foi de $10^{*} \max \left\{c_{i j}\right\}$. A expressão $\max \left\{c_{i j}\right\}$ significa o maior custo entre todos os custos das arestas $\left(v_{i}, v_{j}\right)$. O valor de $10^{*} \max \left\{c_{i j}\right\}$ adotado para o parâmetro $L$ não ocasionou nenhum problema para os algoritmos gerar as soluções. Todas as soluções geradas foram viáveis. O parâmetro $\alpha$ para gerenciar a LRC na etapa de construção utiliza a versão reativa, onde os seus valores variam no intervalo de $[0,1]$.

O número de iterações do GRASP foi fixado em 200 (critério de parada limitado pelas iterações). A cardinalidade do conjunto de soluções elites, num_eli, foi igual a 10 e o valor de maxprob com valor igual a 10. Para o critério de parada do GRASP limitado pelo tempo foi estabelecido 720 segundos a cada execução. Todos os valores dos parâmetros do GRASP foram estabelecidos após experimentos preliminares utilizando as instâncias da Tabela 1.

Para o ILS-VND, os parâmetros que foram ajustados após experimentos preliminares são mostrados, a seguir: total de soluções novas geradas iguais a $40($ iterext $=40)$, este parâmetro designa o número máximo de iterações externas. O número máximo de iterações internas foi igual a 35 (maxiter $=35$ ). O valor de maxprob foi igual a 10. Para o critério de parada do ILS-VND limitado pelo tempo, também foi estabelecido 720 segundos a cada execução.

Devido à natureza aleatória do GRASP e do ILS foram executadas dez (10) vezes cada heurística aqui proposta para cada instância. Na Tabela 2 é mostrada a comparação entre os métodos G-IMPP e G-IMPnP e entre ILS-VND-P e ILS-VND-nP com critério de parada estabelecido pelo limite de tempo. A primeira coluna da Tabela 2 mostra os identificadores das instâncias da Tabela 1, na segunda coluna o gap li, calculado pela Equação 9, do melhor valor encontrado por G-IMPP e na terceira o gap $p_{l i}$ do melhor valor encontrado por G-IMPnP.

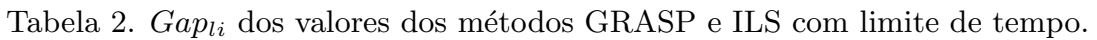

\begin{tabular}{|c|c|c|c|c|c|c|c|c|}
\hline \multirow{2}{*}{ Id. } & \multicolumn{2}{|c|}{ Melhores Valores } & \multicolumn{2}{|c|}{ Valores Médios } & \multicolumn{2}{|c|}{ Melhores Valores } & \multicolumn{2}{|c|}{ Valores Médios } \\
\hline & G-IMPP & G-IMPnP & G-IMPP & G-IMPnP & ILS-VND-P & ILS-VND-nP & ILS-VND-P & ILS-VND-nP \\
\hline$J_{1}$ & 0,07 & 0,08 & 0,28 & 0,32 & 0,11 & 0,10 & 0,15 & 0,15 \\
\hline$J_{2}$ & 0,76 & 0,81 & 1,08 & 1,64 & 0,73 & 0,73 & 0,82 & 0,83 \\
\hline$J_{3}$ & 0,70 & 0,76 & 1,08 & 1,63 & 0,56 & 0,46 & 0,79 & 0,65 \\
\hline$J_{4}$ & 1,38 & 1,47 & 1,58 & 1,94 & 1,30 & 1,45 & 1,52 & 1,81 \\
\hline$J_{5}$ & 1,12 & 1,07 & 1,24 & 1,6 & 0,88 & 0,99 & 1,06 & 1,28 \\
\hline$J_{6}$ & 1,48 & 1,48 & 1,82 & 1,83 & 1,29 & 1,24 & 1,46 & 1,41 \\
\hline$J_{7}$ & 0,52 & 0,53 & 0,83 & 1,32 & 0,24 & 0,21 & 0,35 & 0,31 \\
\hline$J_{8}$ & 0,82 & 0,79 & 1,39 & 1,53 & 0,33 & 0,33 & 0,52 & 0,46 \\
\hline$J_{9}$ & 0,42 & 0,63 & 0,50 & 0,82 & 0,51 & 0,43 & 0,55 & 0,51 \\
\hline$J_{10}$ & 1,35 & 1,36 & 2,46 & 3,45 & 0,89 & 0,89 & 1,16 & 1,29 \\
\hline$J_{11}$ & 1,04 & 1,04 & 2,97 & 3,21 & 0,55 & 1,13 & 0,92 & 1,85 \\
\hline$J_{12}$ & 1,83 & 1,67 & 2,29 & 2,63 & 1,05 & 1,17 & $\mathbf{1 , 3 0}$ & 1,56 \\
\hline$J_{13}$ & 1,83 & 1,81 & 2,81 & 2,70 & 1,43 & 1,04 & 1,79 & 1,38 \\
\hline$J_{14}$ & 1,47 & 1,33 & 2,18 & 2,46 & 1,03 & 1,01 & 1,23 & 1,18 \\
\hline$J_{15}$ & 0,43 & 0,47 & 0,64 & 1,02 & 0,46 & 0,52 & 0,54 & 0,59 \\
\hline$J_{16}$ & 0,95 & 1,01 & 1,33 & 1,49 & 0,80 & 0,86 & 1,02 & 0,98 \\
\hline$J_{17}$ & 0,56 & 0,57 & 0,74 & 0,9 & 0,51 & 0,47 & 0,59 & 0,54 \\
\hline$J_{18}$ & 0,01 & 0,04 & 0,06 & 0,36 & 0,02 & 0,04 & 0,04 & 0,09 \\
\hline$J_{19}$ & 0,17 & 0,17 & 0,45 & 0,48 & 0,12 & 0,12 & 0,13 & 0,21 \\
\hline$J_{20}$ & 0,14 & 0,15 & 0,17 & 0,24 & 0,16 & 0,16 & 0,16 & 0,18 \\
\hline $\begin{array}{l}g^{a p} p_{l i} \\
\text { médio }\end{array}$ & 0,85 & 0,86 & 1,30 & 1,58 & 0,65 & 0,67 & 0,80 & 0,86 \\
\hline
\end{tabular}

Nas duas colunas seguintes são mostrados os gap $_{l i} \mathrm{~s}$ dos valores médios alcançados por G-IMPP e G-IMPnP. Na sexta e sétima colunas os gap $_{l i} \mathrm{~s}$ dos melhores valores de ILS-VND-P e ILS-VND-nP, respectivamente. Nas duas últimas colunas os valores médios obtidos por ILS-VND-P e ILS-VND-nP calculados através do $g a p_{l i}$. Valores em negrito mostram o melhor desempenho comparando cada método Penalizado e não-Penalizado.

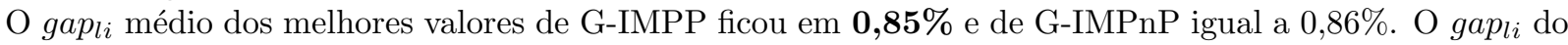
CPLEX para estas instâncias com o critério de parada estabelecido de duas horas foi igual 1,36\%. G-IMPP 
obteve o melhor desempenho obtendo as melhores soluções em quatorze de um total de vinte instâncias, GIMPnP com sete e CPLEX com duas. O gap li $_{i}$ médio dos valores médios de G-IMPP foi igual a 1,30\% e de G-IMPnP em 1,58\%. O ILS-VND-P alcançou onze melhores soluções, enquanto que o ILS-VND-nP alcançou treze melhores soluções. O CPLEX alcançou uma única solução melhor quando comparado ao ILS. O gap $p_{l i}$ médio do ILS-VND-P foi igual a 0,65\%, do ILS-VND-nP ficou em 0,67\% e do CPLEX em 1,36\%. O gap $p_{l i}$ médio dos valores médios do ILS-VND-P alcançou o valor de $0,80 \%$ e do ILS-VND-nP foi igual a $0,86 \%$.

Estes resultados mostram a uma leve superioridade da versão G-IMPP em relação a G-IMPnP e de ILS-VND-P sobre ILS-VND-nP. No entanto, ressalta-se o bom comportamento médios dos quatros métodos heurísticos propostos mostrando que ambos possuem robustez necessária para fins práticos.

A Tabela 3 mostra os resultados obtidos com os algoritmos ILS-VND-P, ILS-VNP-nP e o método exato CPLEX, restritos às instâncias menores sem limitação de tempo para o CPLEX. Os algoritmos ILS foram executados 10 vezes. Na primeira coluna da Tabela 3 encontram-se as instâncias, na segunda o valor obtido pelo CPLEX, na terceira, o tempo demandado pelo CPLEX em segundos $t_{C P L E X}(\mathrm{~s})$ e na quarta o gap (Equação 11) do melhor valor obtido por ILS-VND-P (\%) em relação ao valor obtido pelo CPLEX. Na quinta coluna o tempo médio de execução do ILS-VND-P $t_{I L S-P}(\mathrm{~s})$ medido em segundos. Na sexta o gap $p_{h c}$ do melhor valor obtido por ILS-VND-nP $(\%)$ e sétima coluna o tempo médio de execução do ILS-VND-nP $t_{I L S-n P}(\mathrm{~s})$. Na última coluna, é mostrada a perturbação utilizada pelos algoritmos ILS-VND. A razão para executar a perturbação Perttc em algumas instâncias deve-se ao fato que estas não têm vértices suficientes nos grupos para realizar a perturbação Pert, pois se deve ter oito vértices no mínimo em um grupo para realizar esta perturbação. A Perttc foi realizada em 11 instâncias do total de 27.

O percentual do $g a p_{h c}$ é calculado da seguinte forma:

$$
\operatorname{gap}_{h c}=100 *\left(\frac{v h-v c p l e x}{\text { vcplex }}\right),
$$

onde, vh é o melhor valor alcançado pela heurística e vcplex o valor da solução ótima encontrada pelo CPLEX.

Para todas as instâncias de pequeno porte (Tabela 3), o CPLEX encontrou soluções ótimas. ILS-VND-P encontrou soluções ótimas em 21 de um total de 27 instâncias e o gaphc médio total dos valores obtidos pelo

Tabela 3. Comparação de ILS-VND-P e ILS-VNP-nP com o CPLEX para instâncias do tipo 1 de pequeno porte.

\begin{tabular}{|c|c|c|c|c|c|c|c|}
\hline Instâncias & CPLEX & $t_{C P L E X}(\mathbf{s})$ & ILS-P(\%) & $t_{I L S-P}(\mathbf{s})$ & ILS-nP(\%) & $t_{I L S-n P}(\mathbf{s})$ & perturbação \\
\hline 5-eil51 & 437 & 12,31 & 0,00 & 5,20 & 0,00 & 3,80 & Pert \\
\hline 10-eil51 & 440 & 74,38 & 0,00 & 4,40 & 0,00 & 5,50 & Perttc \\
\hline 15-eil51 & 437 & 2,04 & 0,00 & 4,90 & 0,00 & 5,00 & Perttc \\
\hline 5-berlin52 & 7991 & 201,80 & 0,00 & 2,90 & 0,11 & 4,50 & Pert \\
\hline 10-berlin52 & 7896 & 89,17 & 0,00 & 2,50 & 0,52 & 5,10 & Pert \\
\hline 15-berlin52 & 8049 & 75,93 & 0,00 & 4,30 & 0,00 & 4,00 & Pert \\
\hline $5-\mathrm{st} 70$ & 695 & 13790,11 & 0,00 & 5,40 & 0,00 & 6,90 & Pert \\
\hline 10 -st70 & 691 & 4581,00 & 0,00 & 6,60 & 0,43 & 3,70 & Pert \\
\hline 15 -st70 & 692 & 883,50 & 0,00 & 5,40 & 0,87 & 6,40 & Pert \\
\hline 5-eil76 & 559 & 83,70 & 0,00 & 6,70 & 0,00 & 5,10 & Pert \\
\hline 10-eil76 & 561 & 254,30 & 0,36 & 5,50 & 1,07 & 8,60 & Pert \\
\hline 15 -eil76 & 565 & 49,66 & 0,00 & 6,90 & 0,88 & 6,80 & Pert \\
\hline 5 -pr76 & 108590 & 99,29 & 0,00 & 8,20 & 0,00 & 6,30 & Pert \\
\hline $10-p r 76$ & 109538 & 238,13 & 0,00 & 8,40 & 0,00 & 8,30 & Pert \\
\hline $15-p r 76$ & 110678 & 261,94 & 0,49 & 10,00 & 0,00 & 9,70 & Pert \\
\hline 10-rat99 & 1238 & 650,67 & 0,00 & 13,40 & 0,00 & 12,60 & Pert \\
\hline 25-rat99 & 1269 & 351,15 & 0,00 & 23,80 & 0,00 & 21,40 & Perttc \\
\hline 50-rat99 & 1249 & 2797,58 & 0,00 & 23,40 & 0,00 & 18,60 & Perttc \\
\hline 25-kroA100 & 21917 & 3513,57 & 0,00 & 18,40 & 0,00 & 21,70 & Perttc \\
\hline 50-kroA100 & 21453 & 947,55 & 0,00 & 19,90 & 0,00 & 21,70 & Perttc \\
\hline 10-kroB100 & 22440 & 4991,44 & 0,16 & 9,40 & 0,91 & 12,40 & Pert \\
\hline 50-kroB100 & 22355 & 2579,22 & 0,00 & 17,70 & 0,00 & 22,40 & Perttc \\
\hline 25-eil101 & 663 & 709,45 & 0,45 & 21,20 & 1,06 & 21,10 & Perttc \\
\hline 50-eil101 & 644 & 275,33 & 1,09 & 21,10 & 0,16 & 20,80 & Perttc \\
\hline $25-\operatorname{lin} 105$ & 14438 & 6224,55 & 0,00 & 8,10 & 1,38 & 16,70 & Pert \\
\hline $50-\operatorname{lin} 105$ & 14379 & 1577,21 & 0,00 & 21,50 & 0,00 & 22,60 & Perttc \\
\hline $75-\operatorname{lin} 105$ & 14521 & 15886,77 & 0,15 & 21,90 & 0,00 & 23,70 & Perttc \\
\hline val. médios & - & 2266,73 & 0,10 & 11,37 & 0,27 & 12,05 & - \\
\hline
\end{tabular}


ILS-VND-P em relação ao ótimo foi de 0,10\% com tempo médio igual a 11,37s. O ILS-VND-nP conseguiu 17 soluções ótimas. O gap $p_{h c}$ médio total dos valores obtidos pelo ILS-VND-nP em relação ao ótimo foi de $0,27 \%$ com tempo médio igual a 12,05s. Observa-se que o tempo médio de 12,05s do ILS-VND-nP foi um pouco maior do que o tempo médio de 11,37s do ILS-VND-P. Isto ocorre porque em IMPnP, a Lista de Candidatos que auxilia a elaboração da solução parcial considera em cada etapa todos os vértices pertencentes ao grupo dos vértices contidos na solução parcial. Em oposição, IMPP considera somente os $k=10$ vértices mais próximos pertencentes ou não ao mesmo grupo dos vértices da solução parcial já construída.

Pelos resultados apresentados nas Tabelas 2 e 3 constata-se que o algoritmo construtivo IMPP quando utilizado para construir soluções para o algoritmo ILS-VND-IMPP permite alcançar resultados melhores, mas bem próximos do algoritmo ILS-VND-IMPnP. Neste sentido, verifica-se que ao tratar o PCVG transformandoo em PCV é uma alternativa eficaz para conseguir bons resultados.

\subsection{Comparações entre os métodos heurísticos propostos com um algoritmo genético}

Os métodos heurísticos propostos foram comparados com Algoritmo Genético (AG) da literatura (Ding et al., 2007) que resolve o PCVG sem a prefixação da sequência dos grupos visitados. O AG foi implementado neste trabalho pois não foi possível acesso ao código original e seguiu todas as sugestões de parâmetros dado pelos autores.

O AG é denominado de (Two-Level Genetic Algorithm - TLGA) (Ding et al., 2007) e constrói soluções para o PCVG em dois níveis, um denominado de nível baixo e outro de nível alto. No nível baixo um método evolutivo utilizando operadores de cruzamento e mutação produz um ciclo $T_{k}, k=1, \ldots, \mathrm{m}$, em cada grupo utilizando uma população de cromossomos. No nível baixo os operadores de cruzamento e mutação são aplicados somente aos vértices e não operam sobre os grupos. No nível alto uma sequência dos grupos $\left(V_{1}, V_{2}, \ldots, V_{m}\right)$ é gerada aleatoriamente. Em seguida, um caminho $P_{k}$ sobre o ciclo $T_{k}$ para cada grupo é encontrado quebrando o ciclo $T_{k}$ através da escolha de dois vértices aleatórios consecutivos. Um vértice start $v_{s_{k}}$ representa o início do caminho no grupo $k$ e um outro end $v_{e_{k}}$ o fim. O ciclo Hamiltoniano $C$ para o PCVG é encontrado designando cada caminho $P_{k}$ ao grupo correspondente $V_{k}$, iniciando o caminho em cada grupo pelo vértice $v_{s_{k}}$ e finalizando no vértice $v_{e_{k}}$. O algoritmo TLGA gera uma população inicial de cromossomos nos quais cada um representa um ciclo $C$ para o PCVG. O TLGA termina se após um número máximo consecutivos de gerações (maxger), a melhor solução da população não é atualizada. Mais detalhes sobre o TLGA mostrado em Ding et al. (2007).

Os resultados computacionais, apresentados a seguir, comparando o TLGA com os métodos heurísticos foram obtidos com o mesmo software e hardware descritos no início da Seção 4.

Os primeiros testes foram efetuados entre G-IMPP, ILS-VND-P e TLGA, restritos às instâncias menores, mostrados na Tabela 4, vistos que os dois primeiros métodos obtiveram melhor desempenho entre todos os métodos. Nestes testes foram utilizados como critério de parada o número máximo de iterações dos métodos heurísticos. No G-IMPP o número de iterações foi igual a 200 e no ILS-VND-P para o número de iterações internas maxiter foi igual a 35 e o parâmetro iterext (número máximo de iterações externas) igual a 40. No TLGA, o critério de parada é o número máximo consecutivos de gerações onde a melhor solução da população não é atualizada (maxger). O valor de maxger foi igual 10. O número de execuções para cada instância foi de 10 para G-IMPP e ILS-VND-P e cinco para TLGA (valor utilizado pelos autores Ding et al. (2007)).

Na primeira coluna da Tabela 4 são mostradas as instâncias, na segunda coluna encontra-se o gap $p_{h c}$ do melhor valor obtido por TLGA(\%). Na terceira coluna o tempo médio demandado pelo TLGA em segundos $t_{T L G A}$, na quarta o gap $_{h c}$ do melhor valor obtido por G-P(\%) (G-IMPP), na quinta o tempo médio de execução $t_{G-P}(\mathrm{~s})$ de G-P medido em segundos. Na sexta e sétima colunas são mostradas o gap $p_{h c}$ ILS-P (\%) e o tempo

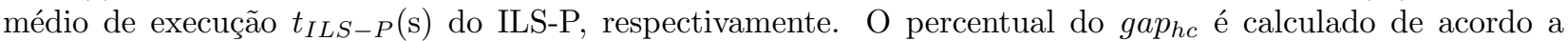
Equação 11, onde os valores das soluções ótimas são apresentados na Tabela 3.

Observa-se que na Tabela 4, o TLGA produz soluções de baixa qualidade quando comparado ao G-IMPP e ILS-VND-P. O gap g $_{h c}$ médio das soluções produzidas pelo TLGA ficou em 12,29\%, enquanto G-P alcançou 0,21\% e ILS-VND-P com 0,10\%. O TLGA nunca alcançou uma solução ótima. O tempo médio total avaliado sobre todas as instâncias do TLGA foi melhor do que G-IMPP e ILS-VND-P alcançando 1,8s, G-IMPP ficou em 6,05s e ILS-VND-P com 11,37s. Mesmo que o tempo médio do TLGA seja menor, a opção pela heurística G-IMPP torna-se mais promissora, porque aglutina pequeno esforço computacional com soluções de alta qualidade.

Nos resultados apresentados até o momento, onde o critério de parada é o número de iterações, observa-se que G-IMPP e ILS-VND-P obtiveram os melhores resultados, mas exigiram tempos computacionais maiores que TLGA, mesmo para instâncias de pequeno porte. Novos testes computacionais para instâncias maiores foram executados.

O critério de parada estabelecido para os três métodos heurísticos neste novo teste foi definido por um tempo máximo de 720 segundos a cada execução, porque, para cada instância, os métodos são executados 
Tabela 4. Comparação do TLGA com G-IMPP e ILS-VND-P utilizando como critério de parada estabelecido pelo número de iterações.

\begin{tabular}{lcccccc}
\hline Instâncias & TLGA (\%) & $t_{T L G A}(\mathbf{s})$ & $\mathbf{G - P}(\mathbf{\%})$ & $t_{G-P}(\mathbf{s})$ & ILS-P(\%) & $t_{I L S-P}(\mathbf{s})$ \\
\hline 5-eil51 & 8,47 & $\mathbf{0 , 4}$ & $\mathbf{0 , 0 0}$ & 1,50 & $\mathbf{0 , 0 0}$ & 5,20 \\
10-eil51 & 2,73 & $\mathbf{0 , 4}$ & $\mathbf{0 , 0 0}$ & 1,30 & $\mathbf{0 , 0 0}$ & 4,40 \\
15-eil51 & 7,78 & $\mathbf{0 , 4}$ & $\mathbf{0 , 0 0}$ & 1,40 & $\mathbf{0 , 0 0}$ & 4,90 \\
5-berlin52 & 1,44 & $\mathbf{0 , 6}$ & $\mathbf{0 , 0 0}$ & 1,80 & $\mathbf{0 , 0 0}$ & 2,90 \\
10-berlin52 & 10,18 & $\mathbf{0 , 4}$ & $\mathbf{0 , 0 0}$ & 1,60 & $\mathbf{0 , 0 0}$ & 2,50 \\
15-berlin52 & 14,69 & $\mathbf{0 , 4}$ & $\mathbf{0 , 0 0}$ & 1,60 & $\mathbf{0 , 0 0}$ & 4,30 \\
5-st70 & 0,86 & $\mathbf{1 , 6}$ & $\mathbf{0 , 0 0}$ & 3,40 & $\mathbf{0 , 0 0}$ & 5,40 \\
10-st70 & 1,88 & $\mathbf{1 , 0}$ & $\mathbf{0 , 0 0}$ & 2,50 & $\mathbf{0 , 0 0}$ & 6,60 \\
15-st70 & 7,23 & $\mathbf{0 , 8}$ & $\mathbf{0 , 0 0}$ & 2,90 & $\mathbf{0 , 0 0}$ & 5,40 \\
5-eil76 & 3,94 & $\mathbf{1 , 8}$ & 0,54 & 3,80 & $\mathbf{0 , 0 0}$ & 6,70 \\
10-eil76 & 9,45 & $\mathbf{1 , 2}$ & 0,71 & 3,20 & $\mathbf{0 , 3 6}$ & 5,50 \\
15-eil76 & 2,48 & $\mathbf{1 , 2}$ & 0,53 & 3,60 & $\mathbf{0 , 0 0}$ & 6,90 \\
5-pr76 & 1,78 & $\mathbf{2 , 0}$ & $\mathbf{0 , 0 0}$ & 5,50 & $\mathbf{0 , 0 0}$ & 8,20 \\
10-pr76 & 1,02 & $\mathbf{1 , 2}$ & $\mathbf{0 , 0 0}$ & 4,00 & $\mathbf{0 , 0 0}$ & 8,40 \\
15-pr76 & 5,95 & $\mathbf{1 , 2}$ & $\mathbf{0 , 1 5}$ & 4,40 & 0,49 & 10,00 \\
10-rat99 & 6,70 & $\mathbf{3 , 4}$ & $\mathbf{0 , 0 0}$ & 9,70 & $\mathbf{0 , 0 0}$ & 13,40 \\
25-rat99 & 23,48 & $\mathbf{2 , 4}$ & $\mathbf{0 , 0 0}$ & 9,80 & $\mathbf{0 , 0 0}$ & 23,80 \\
50-rat99 & 37,15 & $\mathbf{2 , 4}$ & 0,80 & 10,50 & $\mathbf{0 , 0 0}$ & 23,40 \\
25-kroA100 & 5,69 & $\mathbf{2 , 2}$ & $\mathbf{0 , 0 0}$ & 8,60 & $\mathbf{0 , 0 0}$ & 18,40 \\
50-kroA100 & 22,23 & $\mathbf{2 , 8}$ & $\mathbf{0 , 0 0}$ & 9,60 & $\mathbf{0 , 0 0}$ & 19,90 \\
10-kroB100 & 2,49 & $\mathbf{3 , 8}$ & $\mathbf{0 , 0 0}$ & 9,30 & 0,16 & 9,40 \\
50-kroB100 & 25,36 & $\mathbf{2 , 2}$ & 0,54 & 9,50 & $\mathbf{0 , 0 0}$ & 17,70 \\
25-eil101 & 6,33 & $\mathbf{2 , 2}$ & 1,21 & 7,80 & $\mathbf{0 , 4 5}$ & 21,20 \\
50-eil101 & 20,34 & $\mathbf{2 , 2}$ & $\mathbf{1 , 0 9}$ & 9,10 & $\mathbf{1 , 0 9}$ & 21,10 \\
25-lin105 & 19,39 & $\mathbf{2 , 0}$ & $\mathbf{0 , 0 0}$ & 10,50 & $\mathbf{0 , 0 0}$ & 8,10 \\
50-lin105 & 26,29 & $\mathbf{3 , 2}$ & $\mathbf{0 , 0 0}$ & 12,40 & $\mathbf{0 , 0 0}$ & 21,50 \\
75-lin105 & 56,62 & $\mathbf{4 , 6}$ & 0,23 & 14,10 & $\mathbf{0 , 1 5}$ & 21,90 \\
\hline valores médios & 12,29 & $\mathbf{1 , 8}$ & 0,21 & 6,05 & $\mathbf{0 , 1 0}$ & 11,37 \\
\hline & & & & & & \\
\hline
\end{tabular}

10 vezes. Mesmo para o TLGA que no algoritmo original executa cinco vezes, nessa nova bateria de testes, o algoritmo foi executado 10 vezes. A melhor solução encontrada e a solução média nestas execuções são retornadas. Somente a execução da instância $J_{18}$ não foi limitada por duas horas, devido à solução ótima ser encontrada antes pelo CPLEX.

Os melhores valores e valores médios obtidos pelas heurísticas com o critério de parada limitado pelo tempo são mostrados na Tabela 5, onde na primeira coluna apresentam-se os identificadores das instâncias. Na segunda coluna o $g a p_{l i}$ alcançado pelo TLGA, onde este gap é calculado pela Equação 9. Na terceira coluna o gapli alcançado por G-IMPP e na quarta coluna o gap $p_{l i}$ de ILS-VND-P. Nas três últimas colunas temos gap $_{l i}$ para os valores médios.

Na Tabela 5 foi observado que mesmo estabelecendo tempos limites iguais para os três métodos heurísticos, o algoritmo TLGA não consegue melhorar a qualidade da solução para o PCVG. O TLGA continua produzindo soluções de baixa qualidade comparadas ao G-IMPP e ILS-VND-P, onde o gap $_{l i}$ médio ficou em 9,31\%, enquanto G-IMPP alcançou 0,85\% e ILS-VND-P com 0,65\%. Para algumas instâncias, o algoritmo TLGA obteve $g_{a p}$ próximos de G-IMPP e ILS-VND-P. Por exemplo, para a instância $J_{18}$ o gap $p_{l i}$ de TLGA foi de $0,05 \%$, enquanto G-IMPP e ILS-VND-P obtiveram $0,01 \%$ e $0,02 \%$, respectivamente. Para as instâncias $J_{1}, J_{15}$ e $J_{19}$, o gap gli $_{l i}$ de TLGA alcançou $0,12 \%, 0,56 \%$ e $0,14 \%$, respectivamente, enquanto que G-IMPP obteve para $J_{1}$ o valor de $0,07 \%$, para $J_{15}$ igual a $0,43 \%$ e para $J_{19}$ o valor $0,17 \%$. O valor em itálico para a instância $J_{19}$ mostra que TLGA foi melhor do que G-IMPP. Para ILS-VND-P o gap $p_{l i}$ da instância $J_{1}$ foi igual a $0,11 \%$, para $J_{15}$ igual a $0,46 \%$ e $J_{19}$ em $0,12 \%$. As melhores soluções sempre são encontradas por G-IMPP ou ILS-VND-P. O gap $_{l i}$ médio dos valores médios de TLGA ficou em 12,30\%, enquanto G-IMPP alcançou 1,30\% e ILS-VND-P com 0,80\%. Em algumas instâncias os gap $_{l i}$ s dos valores médios dos custos das soluções encontradas pelo algoritmo TLGA são menores do que $1 \%$. Por exemplo, o TLGA obteve gap $_{l i}$ dos valores médios para as instâncias $J_{1}, J_{18}$ e $J_{19}$, iguais a $0,32 \%, 0,33 \%$ e $0,82 \%$, respectivamente. 
Tabela 5. Gap li $_{\text {dos }}$ melhores valores e valores médios de TLGA, G-IMPP e ILS-VND-P com limite de tempo.

\begin{tabular}{ccccccc}
\hline \multirow{2}{*}{ Id. } & \multicolumn{3}{c}{ Melhores Valores } & \multicolumn{3}{c}{ Valores Médios } \\
\cline { 2 - 7 } & TLGA (\%) & G-P(\%) & ILS-P(\%) & TLGA (\%) & G-P(\%) & ILS-P(\%) \\
\hline$J_{1}$ & 0,12 & $\mathbf{0 , 0 7}$ & 0,11 & 0,32 & 0,28 & $\mathbf{0 , 1 5}$ \\
$J_{2}$ & 1,08 & 0,76 & $\mathbf{0 , 7 3}$ & 6,27 & 1,08 & $\mathbf{0 , 8 2}$ \\
$J_{3}$ & 9,07 & 0,70 & $\mathbf{0 , 5 6}$ & 16,86 & 1,08 & $\mathbf{0 , 7 9}$ \\
$J_{4}$ & 26,32 & 1,38 & $\mathbf{1 , 3 0}$ & 27,26 & 1,58 & $\mathbf{1 , 5 2}$ \\
$J_{5}$ & 25,84 & 1,12 & $\mathbf{0 , 8 8}$ & 26,85 & 1,24 & $\mathbf{1 , 0 6}$ \\
$J_{6}$ & 23,61 & 1,48 & $\mathbf{1 , 2 9}$ & 24,72 & 1,82 & $\mathbf{1 , 4 6}$ \\
$J_{7}$ & 0,81 & 0,52 & $\mathbf{0 , 2 4}$ & 4,72 & 0,83 & $\mathbf{0 , 3 5}$ \\
$J_{8}$ & 4,71 & 0,82 & $\mathbf{0 , 3 3}$ & 15,01 & 1,39 & $\mathbf{0 , 5 2}$ \\
$J_{9}$ & 6,99 & $\mathbf{0 , 4 2}$ & 0,51 & 8,22 & $\mathbf{0 , 5 0}$ & 0,55 \\
$J_{10}$ & 1,72 & 1,35 & $\mathbf{0 , 8 9}$ & 4,34 & 2,46 & $\mathbf{1 , 1 6}$ \\
$J_{11}$ & 1,46 & 1,04 & $\mathbf{0 , 5 5}$ & 4,01 & 2,97 & $\mathbf{0 , 9 2}$ \\
$J_{12}$ & 33,71 & 1,83 & $\mathbf{1 , 0 5}$ & 38,66 & 2,29 & $\mathbf{1 , 3 0}$ \\
$J_{13}$ & 33,34 & 1,83 & $\mathbf{1 , 4 3}$ & 38,57 & 2,81 & $\mathbf{1 , 7 9}$ \\
$J_{14}$ & 1,61 & 1,47 & $\mathbf{1 , 0 3}$ & 6,60 & 2,18 & $\mathbf{1 , 2 3}$ \\
$J_{15}$ & 0,56 & $\mathbf{0 , 4 3}$ & 0,46 & 1,84 & 0,64 & $\mathbf{0 , 5 4}$ \\
$J_{16}$ & 7,93 & 0,95 & $\mathbf{0 , 8 0}$ & 11,15 & 1,33 & $\mathbf{1 , 0 2}$ \\
$J_{17}$ & 4,39 & 0,56 & $\mathbf{0 , 5 1}$ & 6,08 & 0,74 & $\mathbf{0 , 5 9}$ \\
$J_{18}$ & 0,05 & $\mathbf{0 , 0 1}$ & 0,02 & 0,33 & 0,06 & $\mathbf{0 , 0 4}$ \\
$J_{19}$ & 0,14 & 0,17 & $\mathbf{0 , 1 2}$ & 0,82 & 0,45 & $\mathbf{0 , 1 3}$ \\
$J_{20}$ & 2,70 & $\mathbf{0 , 1 4}$ & 0,16 & 3,28 & 0,17 & $\mathbf{0 , 1 6}$ \\
\hline gap $_{l i}$ médio & 9,31 & 0,85 & $\mathbf{0 , 6 5}$ & 12,30 & 1,30 & $\mathbf{0 , 8 0}$ \\
\hline & & & & & & \\
\hline
\end{tabular}

\subsection{Análise dos métodos penalizados e não-penalizados}

Para analisar os resultados dos métodos heurísticos que penalizam ou não, as arestas intergrupos, são classificados como métodos Penalizados (P) aqueles que utilizam a penalização intergrupos e de métodos não-Penalizados (nP) os que não penalizam. Dentre os métodos Penalizados são destacados: IMPP, VND-P, G-IMPP e ILS-VND-P. Para os métodos não-Penalizados são apresentados: IMPnP, VND-nP, G-IMPnP e ILS-VND-nP.

A Tabela 6 mostra para cada tipo de instância uma comparação do desempenho de cada método (Penalizado ou não-Penalizado). Foi realizado um total de 173 experimentos. Para cada experimento realizado com uma instância e os dois métodos, foram atribuídos um valor igual a um (1) se um método obteve melhor desempenho, zero (0) se obteve pior desempenho e meio $(1 / 2)$ a cada método se o desempenho for igual em ambos. Para os métodos construtivos, VND, GRASP e ILS-VND é considerado de melhor desempenho, o gap da melhor solução encontrada por estes métodos.

Tabela 6. Desempenho (\%) dos métodos penalizados e não-penalizados para cada tipo de instância.

\begin{tabular}{c|cccccccc}
\hline Tipo & IMPP & IMPnP & VND-P & VND-nP & G-IMPP & G-IMPnP & ILS-P & ILS-nP \\
\hline 1 & $\mathbf{7 7 , 8}$ & 22,2 & 33,3 & $\mathbf{6 6 , 7}$ & $\mathbf{1 0 0 , 0}$ & 0,0 & $\mathbf{6 3 , 0}$ & 37,0 \\
2 & $\mathbf{1 0 0 , 0}$ & 0,0 & $\mathbf{8 0 , 0}$ & 20,0 & 50,0 & 50,0 & $\mathbf{6 6 , 7}$ & 33,3 \\
3 & $\mathbf{9 0 , 0}$ & 10,0 & $\mathbf{5 5 , 0}$ & 45,0 & $\mathbf{6 6 , 7}$ & 33,3 & 16,7 & $\mathbf{8 3 , 3}$ \\
4 & 40,0 & $\mathbf{6 0 , 0}$ & 40,0 & $\mathbf{6 0 , 0}$ & 37,5 & $\mathbf{6 2 , 5}$ & $\mathbf{6 2 , 5}$ & 37,5 \\
5 & $\mathbf{9 0 , 0}$ & 10,0 & 50,0 & 50,0 & $\mathbf{7 5 , 0}$ & 25,0 & 50,0 & 50,0 \\
6 & $\mathbf{7 7 , 8}$ & 22,2 & $\mathbf{6 6 , 7}$ & 33,3 & $\mathbf{8 3 , 3}$ & 16,7 & $\mathbf{6 6 , 7}$ & 33,3 \\
\hline
\end{tabular}

Na primeira coluna da Tabela 6 é apresentado o tipo de instância analisada, na segunda coluna a soma dos valores (em porcentagem) obtidos pelo algoritmo construtivo IMPP para todas as instâncias deste tipo, na terceira a soma dos valores para o algoritmo construtivo IMPnP, na quarta e quinta colunas as somas dos valores dos método VND com IMPP (VND-P) e do VND com IMPnP (VND-nP), respectivamente. Na sexta coluna a soma dos valores obtidos para G-IMPP, na sétima a soma obtida pelo G-IMPnP e nas últimas colunas os valores de somas do ILS-VND-IMPP (ILS-P) e ILS-VND-IMPnP (ILS-nP), respectivamente.

São observados na Tabela 6 para as instâncias do tipo 2, 5 e 6 que os Métodos Penalizados sempre ganham. Na maioria dos casos, as instâncias do tipo 3 apresentam porcentagens melhores com os Métodos Penalizados, exceto ao utilizar o algoritmo ILS-nP, já as instâncias do tipo 4 com os não-Penalizados. Para as instâncias 
do tipo 1, em algumas situações, são obtidas de melhor desempenho para alguns Métodos Penalizados e em outras situações aos Métodos não-Penalizados.

\section{Discussão e Conclusões}

Neste capítulo foram propostos diversos métodos heurísticos para resolver o PCVG. Todos os métodos heurísticos encontram soluções de boa qualidade num tempo computacional baixo. Nas comparações dos métodos heurísticos com o CPLEX foi verificado que na maior parte das instâncias de pequeno porte, estes métodos alcançaram soluções ótimas. Ao estabelecer limites de tempo para o CPLEX, os valores dos $g a p_{l i} \mathrm{~S}$ alcançados pelos métodos heurísticos (G-IMPP, G-IMPnP, ILS-VND-P e ILS-VND-nP) para as instâncias de porte maior, foram melhores do que os obtidos pela formulação exata, em sua grande maioria. Ao comparar os métodos heurísticos com um Algoritmo Genético (AG) da literatura, verifica-se que tanto o G-IMPP quanto o ILS-VND-P obtiveram melhor desempenho do que o AG.

Ao analisar os Métodos Penalizados (IMPP, VND-P, G-IMPP, ILS-VND-P) com os Métodos nãoPenalizados (IMPnP, VND-nP, G-IMPnP e ILS-VND-nP) verificou-se que para as instâncias do tipo 2, 5 e 6 foi obtido melhor desempenho quando as arestas intergrupos são penalizadas.

Foi observado também, nos resultados dos Métodos Penalizados e não-Penalizados, que para diversas instâncias, alguns métodos heurísticos obtêm melhor desempenho quando a estratégia que não penaliza as arestas intergrupos é aplicada. Assim, pode-se afirmar que a penalização não é uma estratégia boa, principalmente as do tipo 1, tipo 3 e do tipo 4 que necessitam utilizar algoritmos não-Penalizados. As características das instâncias do tipo 1, 3 e 4 são: primeiro, os vértices não são dispersos e segundo, em cada grupo os vértices são agrupados com melhor distribuição geométrica em torno de um centro.

Trabalhos futuros incluem a adaptação dos módulos deste trabalho como RC e VND para outras metaheurísticas tais como os Algoritmos Evolutivos e Variable Neighborhood Search, bem como outras formas híbridas envolvendo GRASP, RC, VND e ILS combinando-os em diversas estratégias.

Novas alternativas poderão ser estudadas para utilizar novos algoritmos construtivos com penalização nas arestas e sem penalização, ajustando-os com as buscas locais (2-Optimal, 3-Optimal e VND) e novas formas de Reconexão de Caminhos para formar módulos que se adaptem aos métodos heurísticos baseados no GRASP e ILS a serem implementados.

\section{Agradecimentos}

Este trabalho tem o apoio parcial da CAPES (Programa PIQDTec).

\section{Referências}

Anily, S.; Bramel, J. \& Hertz, A., A 5/3-approximation algorithm for the clustered traveling salesman tour and path problems. Operations Research Letters, 24(1-2):29-35, 1999.

Arkin, E.M.; Hassin, R. \& Klein, L., Restricted delivery problems on a network. Networks, 29(4):205-216, 1997.

Chisman, J.A., The clustered traveling salesman problem. Computers $\mathcal{E}$ Operations Research, 2(2):115-119, 1975.

Dantzig, G.; Fulkerson, R. \& Johnson, S., Solution of a large-scale traveling-salesman problem. Journal of the Operations Research Society of America, 2:393-410, 1954.

Ding, C.; Cheng, Y. \& He, M., Two-level genetic algorithm for clustered traveling salesman problem with application in large-scale TSPs. Tsinghua Science and Technology, 12(4):459-465, 2007.

de Assumpção Drummond, L.M.; Vianna, L.S.; da Silva, M.B. \& Ochi, L.S., Distributed parallel metaheuristics based on GRASP and VNS for solving the traveling purchaser problem. In: Proceedings of the Ninth International Conference on Parallel and Distributed Systems. Piscataway, USA: IEEE Press, v. 1, p. 257-263, 2002.

Garey, M.R. \& Johnson, D.S., Computers and Intractability: A Guide to the Theory of NP-Completeness. New York, USA: W. H. Freeman, 1979.

Gendreau, M.; Laporte, G. \& Potvin, J.Y., Heuristics for the Clustered Traveling Salesman Problem. Technical Report CRT-94-54, Centre de Recherche sur les Transports, Université de Montréal, Montréal, Canada, 1994.

Ghaziri, H. \& Osman, I.H., A neural network for the traveling salesman problem with backhauls. Computers 86 Industrial Engineering, 44(2):267-281, 2003.

Glover, F., Tabu search and adaptive memory programing - advances, applications and challenges. In: Barr, R.S.; Helgason, R.V. \& Kennington, J.L. (Eds.), Interfaces in Computer Science and Operations Research. Dordrecht, Netherlands: Kluwer Academic Publishers, p. 1-75, 1996.

Gomes, L.M.; Diniz, V.B. \& Martinhon, C.A., A hybrid GRASP+VNS metaheuristic for the prize collecting traveling salesman problem. In: Anais do XXXII Simpósio Brasileiro de Pesquisa Operacional (SBPO). N. 32, p. 1656-1666, 2000.

Guttmann-Beck, N.; Hassin, R.; Khuller, S. \& Raghavachari, B., Approximation algorithms with bounded performance guarantees for the clustered traveling salesman problem. Algorithmica, 28(4):422-437, 2000. 
Hansen, P. \& Mladenović, N., Variable neighborhood search. In: Glover, F.W. \& Kochenberger, G.A. (Eds.), Handbook of Metaheuristics. Boston, USA: Kluwer Academic Publishers, p. 145-184, 2003.

Hernández-Pérez, H.; Rodríguez-Martín, I. \& Salazar-González, J.J., A hybrid GRASP/VND heuristic for the onecommodity pickup-and-delivery traveling salesman problem. Computers E Operations Research, 36(5):1639-1645, 2009.

Jongens, K. \& Volgenant, T., The symmetric clustered traveling salesman problem. European Journal of Operations Research, 19(1):68-75, 1985.

Laguna, M. \& Martí, R., GRASP and path relinking for 2-layer straight line crossing minimization. INFORMS Journal on Computing, 11(1):44-52, 1999.

Laporte, G. \& Palekar, U., Some applications of the clustered travelling salesman problem. Journal of the Operational Research Society, 53(9):972-976, 2002.

Laporte, G.; Potvin, J.Y. \& Quilleret, F., A tabu search heuristic using genetic diversification for the clustered traveling salesman problem. Journal of Heuristics, 2(3):187-200, 1996.

Lawler, E.L.; Lenstra, J.K.; Kan, A.H.G.R. \& Shmoys, D.B., The Traveling Salesman Problem: A Guided Tour of Combinatorial Optimization. New York, USA: J. Wiley \& Sons, 1985.

Lokin, F.C.J., Procedures for travelling salesman problems with additional constraints. European Journal of Operations Research, 3(2):135-141, 1979.

Lourenço, H.R.; Martin, O.C. \& Stützle, T., Iterated local search. In: Glover, F. \& Kochenberger, G. (Eds.), Handbook of Metaheuristics. Boston, USA: Kluwer Academic Publishers, p. 321-353, 2002.

Martin, O.; Otto, S.W. \& Felten, E.W., Large-step markov chains for the TSP incorporating local search heuristics. Operations Research Letters, 11(4):219-224, 1992.

Mestria, M., Proposta e avaliação de heurísticas GRASP para o problema do caixeiro viajante com grupamentos. In: Anais do X Congresso Brasileiro de Inteligência Computacional. Fortaleza, CE: SBRN, v. 1, 2011.

Miller, C.E.; Tucker, A.W. \& Zemlin, R.A., Integer programming formulation of traveling salesman problems. Journal of the ACM, 7(4):326-329, 1960.

Potvin, J.Y. \& Guertin, F., A Genetic Algorithm for the Clustered Traveling Salesman Problem with an A Priori Order on the Clusters. Technical Report CRT-95-06, Centre de Recherche sur les Transports, Université de Montréal, Montréal, Canada, 1995.

Potvin, J.Y. \& Guertin, F., The clustered traveling salesman problem: A genetic approach. In: Osman, I.H. \& Kelly, J. (Eds.), Meta-heuristics: Theory \& Applications. Norwell, USA: Kluwer Academic Plublishers, p. 619-631, 1996.

Reinelt, G., The Traveling Salesman: Computational Solutions for TSP Applications. v. 840 de Lecture Notes in Computer Science. Heidelberg, Germany: Springer-Verlag, 1994.

Resende, M.G.C.; Martí, R.; Gallego, M. \& Duarte, A., GRASP and path relinking for the max-min diversity problem. Computers \& Operations Research, 37(3):498-508, 2010.

Resende, M.G.C. \& Ribeiro, C.C., Greedy randomized adaptive search procedures. In: Glover, F. \& Kochenberger, G. (Eds.), Handbook of Metaheuristics. Dordrecht, Netherlands: Kluwer Academic Publishers, p. 219-249, 2002.

Weintraub, A.; Aboud, J.; Fernandez, C.; Laporte, G. \& Ramirez, E., An emergency vehicle dispatching system for an electric utility in Chile. Journal of the Operational Research Society, 50:690-696, 1999.

\section{Notas Biográficas}

Mário Mestria é graduado e mestre em Engenharia Elétrica (UFES, 1991 e 1995, respectivamente) e doutor em Computação (IC/UFF, 2011). Atualmente é professor da coordenadoria do curso de Eletrotécnica, da Engenharia Elétrica e da Pós-Graduação em Engenharia Elétrica, câmpus Vitória, do Instituto Federal de Educação, Ciência e Teconologia do Espírito Santo. Atua na área de computação e tem interesse em meta-heurísticas, otimização combinatória, aplicações modeladas num PCVG e layout de sistemas de manufaturas. Trabalha nas áreas acadêmicas de linguagem de programação, eletricidade, eletrônica, robótica assistiva e educacional. 


\title{
Um Algoritmo Heurístico Baseado em Iterated Local Search para Problemas de Roteamento de Veículos
}

\author{
Anand Subramanian, Puca Huachi Vaz Penna*, \\ Luiz Satoru Ochi e Marcone Jamilson Freitas Souza
}

\begin{abstract}
Resumo: Este capítulo apresenta um algoritmo heurístico, baseado na meta-heurística Iterated Local Search, para resolver diversas variantes do Problema de Roteamento de Veículos. São descritos os procedimentos de construção das soluções iniciais, as estruturas de vizinhança para explorar o espaço de soluções, o esquema de busca local, assim como os mecanismos de perturbação. Foram realizados experimentos computacionais em conjuntos consagrados de problemas-teste da literatura referente às variantes consideradas. Os resultados mostraram que o algoritmo desenvolvido produz soluções finais de alta qualidade e baixa variabilidade. Além disto, considerando o conjunto de problemas-teste usados, ele detém mais de $80 \%$ dos melhores resultados da literatura.
\end{abstract}

Palavras-chave: Problemas de Roteamento de Veículos, Iterated Local Search, Meta-heurística.

Abstract: This work presents a heuristic algorithm, based on the Iterated Local Search (ILS) metaheuristic, for solving different variants of the Vehicle Routing Problem. The construction procedures, the neighborhood structures to explore the solution space, the local search scheme and the perturbation mechanisms are described. Computational experiments were carried out in well-known benchmark instances of the variants considered. The results showed that the developed algorithm produces high quality solutions with small variability. In addition, when considering the set of test-problems used, the proposed algorithm holds more than $80 \%$ of the best known results of the literature.

Keywords: Vehicle Routing Problem, Iterated Local Search, Metaheuristic.

\section{Contextualização}

O Problema de Roteamento de Veículos - PRV (Vehicle Routing Problem - VRP) teve sua origem associada ao trabalho desenvolvido por Dantzig \& Ramser (1959). Desde então, tem sido, particularmente nas últimas décadas, um dos problemas mais abordados nas áreas de Otimização Combinatória e Pesquisa Operacional. Isso se deve, em parte, ao grande desenvolvimento de métodos de resolução e da enorme variedade de aplicações existentes.

Outro aspecto que tem contribuído para este sucesso é a eficiência destes métodos no sentido operacional, ou seja, as técnicas desenvolvidas têm se mostrado eficientes quando implementadas em situações reais em diferentes empresas da área de transporte.

A importância no desenvolvimento de Sistemas Automatizados, para estas empresas de transporte, se deve também ao fato de eles propiciarem economias médias entre $5 \%$ a $10 \%$ nos custos finais de transporte (Toth \& Vigo, 2002). Em muitas empresas de médio e grande porte, esses percentuais representam valores altamente significativos.

Atualmente, na literatura, existe uma gama enorme de variantes do problema de roteamento que consideram diversas restrições espaciais e/ou temporais encontradas em aplicações reais. Essas variantes têm em comum uma elevada complexidade computacional. Mesmo observando um enorme desenvolvimento de métodos exatos de otimização para a resolução do PRV e suas variantes, a maioria dos problemas, caracterizados por elevadas dimensões, ainda tendem a serem resolvidos por meio de métodos heurísticos.

Na literatura são apresentados diversos algoritmos heurísticos, cada qual destinado, em geral, à resolução de uma única variante do PRV. Neste capítulo apresenta-se um algoritmo unificado, baseado na meta-heurística

*Autor para contato: ppenna@ic.uff.br 
Iterated Local Search - ILS (Lourenço et al., 2003), capaz de resolver eficientemente vários problemas de roteamento. Versões parciais do algoritmo proposto foram publicados nos seguintes trabalhos: Subramanian et al. (2010), Souza et al. (2010b), Penna et al. (2011), Silva et al. (2012) e Subramanian \& Battarra (2013).

O restante deste capítulo está organizado como segue. Na Seção 2 são descritos os problemas abordados. Na Seção 3 é apresentada a fundamentação teórica da meta-heurística Iterated Local Search (ILS). Na Seção 4 é descrito o algoritmo heurístico, baseado em ILS, proposto para resolver os problemas abordados. Na Seção 5 são mostrados os resultados da aplicação do algoritmo proposto a instâncias desses problemas encontradas na literatura. A Seção 6 apresenta as considerações finais.

\section{Descrição dos Problemas}

Para a definição das diversas variantes dos PRVs, seja $D=\{1, \ldots, d\}$ o conjunto de depósitos, $V^{\prime}=\{1, \ldots, n\}$ o conjunto de clientes, $G=(V, E)$ um grafo completo com $V=D \cup V^{\prime}$ representando o conjunto de $n+d$ vértices, $E=\{(i, j): i, j \in V, i \neq j\}$ o conjunto de arestas, $q_{i}$ a demanda do cliente $i \in V^{\prime}, p_{i}$ a quantidade de produtos a serem coletados no cliente $i \in V^{\prime}, T=\{1, \ldots, t\}$ o conjunto de tipos de veículos, $m_{k}$ o número de veículos do tipo $k \in T, Q_{k}$ a capacidade do veículo do tipo $k, f_{k}$ o custo fixo do veículo do tipo $k, g_{k}$ o custo variável do veículo do tipo $k, l_{i j}$ o comprimento da $\operatorname{aresta}(i, j) \in E, c_{i j}^{k}=f_{k}+g_{k} \times l_{i j}$ o custo de percorrer o caminho $(i, j) \in E$ com o veículo do tipo $k \in T$. Assume-se que a demanda dos depósitos é nula e a distância $l_{i j}=\infty, \forall i, j \in D$.

\subsection{Problema de roteamento de veículos capacitado}

Considerada a versão clássica dos PRVs, no Problema de Roteamento de Veículos Capacitado (PRVC) tem-se um único depósito, um único tipo de veículo (sem custo a ele associado, sem perda de generalidade), demanda de somente coleta ou somente entrega para todos os clientes e matriz de custos simétrica, isto é, $|D|=1$, $|T|=1, f_{k}=0, g_{k}=1, p_{i}=0, c_{i j}^{k}=c_{j i}^{k}$. Por envolver um único tipo de veículo, diz-se que a frota é homogênea e composta por $m$ veículos. Para simplicidade de notação o depósito será referenciado pelo índice $0, c_{i j}$ representará o custo de transporte entre o depósito e os clientes ou entre os clientes e $Q$ denotará a capacidade dos veículos da frota homogênea.

O PRVC consiste em determinar um conjunto $R$ de rotas para os veículos, de tal modo que: (i) toda rota $r \in R$ começa e termina no depósito, isto é, dada a sequência $r$ de visitas, em que $r=\left\{i_{1}, i_{2}, \ldots, i_{|r|}\right\}$, tem-se $i_{1}=i_{|r|}=0$ e $\left\{i_{2}, \ldots, i_{|r|-1}\right\} \subseteq V^{\prime}$; (ii) a demanda de todos os clientes deve ser atendida pelos veículos; (iii) cada cliente é atendido por um único veículo; (iv) a capacidade de cada veículo não pode ser violada, isto é, $\sum_{h=2}^{|r|-1} q_{i_{h}} \leqslant Q ;(\mathrm{v})$ a soma total dos custos das operações de transporte deve ser minimizada.

Seja $x_{i j}$ uma variável inteira que armazena o número de vezes que a aresta $\{i, j\} \in E$ aparece em uma rota. Tal variável assumirá valor 2 para rotas que contém apenas um cliente. Dado um conjunto $S \subseteq V^{\prime}$, defina $q(S)$ como sendo a soma das demandas de todos os clientes em $S$ e $e(S)=\lceil q(S) / Q\rceil$. Finalmente, considere $\bar{S}$ como sendo o conjunto complementar de $S$, incluindo o depósito $\{0\}$. O PRVC pode ser modelado da seguinte forma:

$$
\begin{array}{cc}
\min \sum_{i \in V} \sum_{j \in V, j>i} c_{i j} x_{i j} & \\
\text { s.a: } \sum_{i \in V, i<k} x_{i k}+\sum_{j \in V, j>k} x_{k j}=2 & \forall k \in V^{\prime} \\
\sum_{j \in V^{\prime}} x_{0 j}=2 m & \\
\sum_{i \in S} \sum_{j \in \bar{S}, i<j} x_{i j}+\sum_{i \in \bar{S}} \sum_{j \in S, i<j} x_{i j} \geq 2 e(S) & \forall S \subseteq V^{\prime} \\
x_{i j} \in\{0,1\} & \forall\{i, j\} \in E, i>0 \\
x_{i j} \in\{0,1,2\} & \forall\{0, j\} \in E .
\end{array}
$$

A função objetivo (1) minimiza os custos de viagem. As restrições (2) asseguram que cada cliente possui duas arestas incidentes. As restrições (3) determinam que o número de arestas incidentes no depósito deve ser igual ao dobro da quantidade de veículos $m$. As restrições (4) impedem a formação de subrotas. Por fim, as restrições (5-6) definem o domínio das variáveis.

Vale ressaltar que as formulações matemáticas das variantes descritas a seguir podem ser derivadas do modelo apresentado nesta seção. 


\subsection{Problema de roteamento de veículos capacitado assimétrico}

O Problema de Roteamento de Veículos Capacitado Assimétrico (PRVCA) difere do PRVC com relação à matriz de custos, que neste caso é assimétrica, ou seja, $\exists i, j \in V^{\prime} \mid c_{i j} \neq c_{j i}$.

\subsection{Problema de roteamento de veículos aberto}

O Problema de Roteamento de Veículos Aberto (PRVA) é uma variante do PRVC em que o veículo não necessita retornar ao depósito, o que equivale a adotar o custo de retorno do veículo ao depósito nulo. A maioria dos autores da literatura assume que o objetivo primário é minimizar o número de veículos.

\subsection{Problema de roteamento de veículos com coleta e entrega simultânea}

O Problema de Roteamento de Veículos com Coleta e Entrega Simultânea (PRVCES) é uma variante do PRVC em que cada cliente $i \in V^{\prime}$ requer a coleta e a entrega simultânea de $p_{i}$ e $q_{i}$ unidades de um produto, respectivamente.

\subsection{Problema de roteamento de veículos com coleta e entrega mista}

Ao contrário do PRVCES, no Problema de Roteamento de Veículos com Coleta e Entrega Mista (PRVCEM) cada cliente tem uma demanda de somente coleta ou somente entrega.

\subsection{Problema de roteamento de veículos com múltiplos depósitos}

O Problema de Roteamento de Veículos com Múltiplos Depósitos (PRVMD) envolve um conjunto $V^{\prime}$ de clientes, em que todos demandam operações de somente entrega ou somente coleta de unidades de um produto, um conjunto $D$ de depósitos e uma frota homogênea de veículos para cada depósito. O problema consiste em estabelecer um conjunto de rotas para os veículos, de forma a atender a demanda dos clientes com o menor custo de transporte. Neste problema assume-se que cada veículo está sediado em um dado depósito, previamente conhecido. Desta forma, a rota de cada veículo deve iniciar e terminar no mesmo depósito.

\subsection{Problema de roteamento de veículos com múltiplos depósitos com coleta e entrega mista}

O Problema de Roteamento de Veículos com Múltiplos Depósitos com Coleta e Entrega Mista (PRVMDCEM) é uma variante do PRVMD em que cada cliente requer a demanda de somente coleta ou somente entrega, tal como no PRVCEM.

\subsection{Problema de roteamento de veículos com frota heterogênea}

O Problema de Roteamento de Veículos com Frota Heterogênea (PRVFH) envolve um conjunto $V^{\prime}$ de clientes, em que todos demandam operações de somente entrega ou somente coleta de unidades de um produto, um único depósito $(|D|=1)$ e um conjunto $T$ de tipos diferentes de veículos. Para cada tipo $k \in T$ existem $m_{k}$ veículos disponíveis no depósito, de capacidade $Q_{k}$, custo fixo $f_{k}$ e custo variável $g_{k}$. Há duas variantes consideradas para este problema. A primeira considera conhecido o número de veículos disponíveis e, na segunda, este número é ilimitado. Em ambas, procura-se estabelecer um conjunto de rotas para os veículos, de forma a atender a demanda dos clientes no menor custo de transporte. Observa-se que na segunda variante, além do roteamento, é feito o dimensionamento da frota.

\section{A Meta-Heurística Iterated Local Search}

A meta-heurística Iterated Local Search - ILS (Lourenço et al., 2003) é um método de busca local que explora o espaço de soluções por meio de perturbações em ótimos locais gerados durante a busca.

Para descrever o ILS, considere um ótimo local obtido por um método de busca local. Em seguida, uma solução intermediária é obtida por meio da aplicação de uma perturbação na solução ótima local previamente visitada. A ideia principal do ILS está em utilizar ótimos locais como novas soluções de partida, ao invés de começar de uma solução completamente nova. Desta forma, o ILS concentra sua busca em um conjunto reduzido de soluções, no caso, apenas ótimos locais, em vez de considerar todo o espaço de busca.

Para aplicar um algoritmo ILS, quatro elementos devem ser especificados: (i) Procedimento GeraSoluçãoInicial(), que constrói uma solução inicial para o problema; (ii) Procedimento BuscaLocal(), que recebe uma solução e retorna um ótimo local; (iii) Procedimento Perturbação(), que modifica, ou seja, perturba a solução corrente gerando, assim, uma solução intermediária e (iv) Procedimento CritérioAceitação(), que decide a partir de qual solução será aplicada a próxima perturbação. O Algoritmo 1 descreve como combinar estes elementos para utilizar a meta-heurística ILS. 


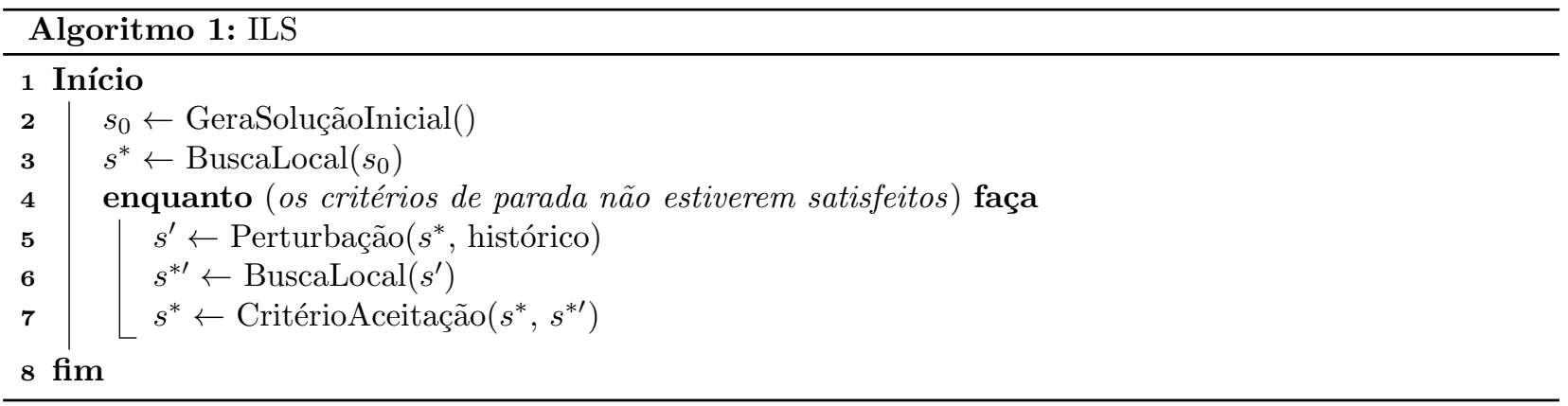

Pelo Algoritmo 1 gera-se, na linha 2, uma solução inicial $s_{0}$. Essa solução é, a seguir, na linha 3, refinada por um método de busca local, conduzindo a um ótimo local $s^{*}$. O procedimento iterativo do método ocorre nas linhas 5 a 7 . Na linha 5 , o ótimo local $s^{*}$ passa por uma perturbação gerando uma solução intermediária $s^{\prime}$, a qual, por sua vez, passa por um processo de refinamento (linha 6), resultando em um novo ótimo local $s^{* \prime}$. Na linha 7 , verifica-se de qual solução a busca prosseguirá, se do ótimo local $s^{*}$ corrente ou do novo ótimo local $s^{* \prime}$. O critério de aceitação mais utilizado é partir do ótimo local de melhor qualidade, ou seja, $s^{* \prime}$ é aceita como nova solução de partida se $f\left(s^{* \prime}\right)<f\left(s^{*}\right)$ para um problema de minimização, sendo $f(s)$ o custo associado à solução $s$.

Para obter sucesso com o ILS, uma atenção especial deve ser dada na escolha do método de busca local, das perturbações e do critério de aceitação. Em princípio, qualquer método de busca local pode ser utilizado. Entretanto, o desempenho do ILS, em termos de qualidade da solução e esforço computacional, dependem fortemente do método adotado. A perturbação por sua vez, consiste em um conjunto de modificações feitas no ótimo local para gerar soluções progressivamente mais "distantes" desse ótimo local. A ideia principal é aumentar o nível de perturbação se a busca local não for bem sucedida, isto é, não estiver gerando ótimos locais melhores. A variável histórico controla o nível de perturbação e estabelece um balanço entre intensificação e diversificação. Quando o nível de perturbação é baixo, há uma exploração mais efetiva da região do espaço de busca em que se encontra o ótimo local corrente, isto é, aplica-se a intensificação. Por outro lado, à medida que esse nível de perturbação é aumentado a busca se direciona para outras regiões do espaço de soluções, ou seja, aplica-se a estratégia de diversificação.

\section{Descrição do Algoritmo Proposto}

Esta seção descreve o algoritmo desenvolvido para resolver uma ampla classe de Problemas de Roteamento de Veículos. O algoritmo proposto, denominado MILS-RVND, é uma heurística multi-start baseada na metaheurística Iterated Local Search - ILS, tendo como busca local o método Randomized Variable Neighborhood Descent - RVND. Seu pseudocódigo é apresentado no Algoritmo 2.

Contrariamente ao método Variable Neighborhood Descent (VND) clássico (Hansen et al., 2010), que trabalha com um conjunto de vizinhanças previamente ordenadas, o RVND utiliza uma ordem aleatória de vizinhanças a cada chamada. Essa é uma vantagem, uma vez que não é necessário fazer experimentos para descobrir qual a melhor ordem (Penna et al., 2011; Souza et al., 2010a).

Observa-se, pelo Algoritmo 2, que o MILS-RVND começa calculando, na linha 4, a frota de veículos necessária para resolver o problema (veja Seção 4.1). A seguir, a heurística Multi-start é executada MaxIterMS vezes (linhas 6 - 19), onde a cada iteração, na linha 7, uma solução inicial é construída por um método construtivo (veja Seção 4.2). O parâmetro MaxIterILS representa o número máximo de perturbações consecutivas sem melhora. O laço principal do ILS (linhas 10 - 16) envolve três procedimentos. No primeiro, linha 11, busca-se aprimorar a solução corrente pela aplicação do algoritmo RVND (veja Seção 6 ) como método de busca local. No segundo, linha 12, é verificado se o ótimo local gerado pelo RVND será aceito como novo ótimo local. Uma solução é aceita se houver melhora na função de avaliação ou se houver redução no número de veículos, dependendo de qual for o objetivo do problema proposto. No terceiro procedimento do laço do ILS, linha 15, aplica-se um mecanismo de perturbação (veja Seção 4.4). Finalizado o ILS, atualiza-se a melhor solução gerada até então (linha 17).

Nas seções seguintes os componentes principais do MILS-RVND são descritos.

\subsection{Estimativa do número de veículos}

Em alguns casos, o número de veículos disponíveis não é especificado no problema. Como o método construtivo depende dessa informação, um algoritmo de estimativa do número inicial de veículos foi desenvolvido. Seja LC a Lista de Candidatos composta pelos clientes que não foram adicionados à solução parcial. Inicialmente, 


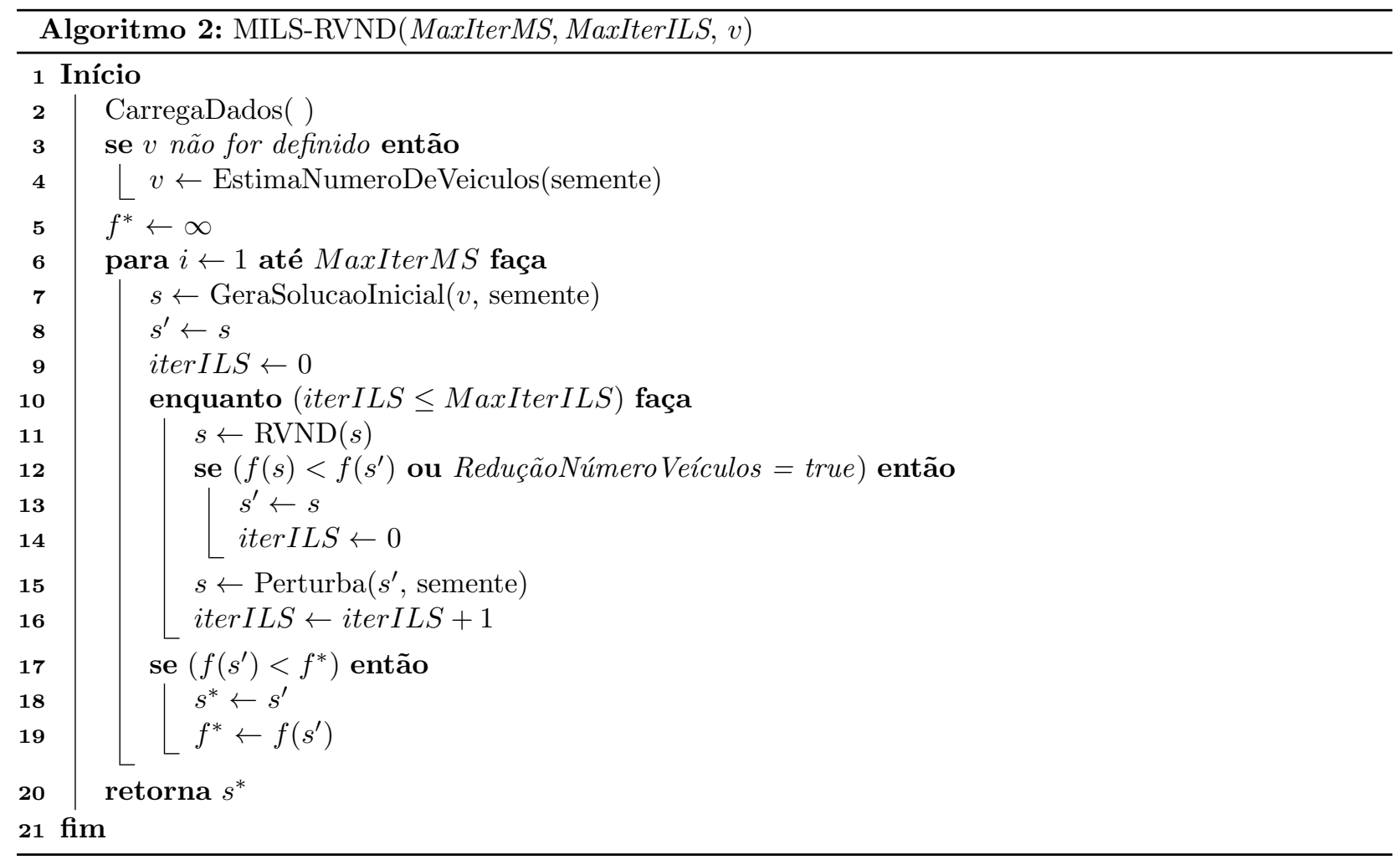

somente um veículo é considerado. Um cliente $i \in \mathrm{LC}$ é escolhido aleatoriamente e inserido nesta única rota. Em seguida, enquanto a LC não for vazia, um critério de inserção, descrito na Seção 4.2.1, é selecionado aleatoriamente para calcular a inclusão do cliente $i \in \mathrm{LC}$ em cada posição da rota e a inserção de menor custo é aplicada. Se o veículo estiver cheio um novo veículo é adicionado.

O número de veículos usados no algoritmo de construção varia de acordo com a variante do PRV. No PRVFH limitado, esse número é a soma da quantidade de veículos disponíveis de cada tipo; nos PRVs com múltiplos depósitos, ele é obtido somando-se a quantidade de veículos disponíveis em cada depósito; no PRVFH ilimitado, esse número inicia-se com um veículo de cada tipo e é acrescido durante o algoritmo de construção, conforme descrito na próxima seção. Finalmente, no PRVA é utilizado um limite inferior para o número de veículos $\left(v_{\min }\right)$, sendo ele o menor inteiro maior ou igual ao resultado da divisão entre a soma das demandas dos clientes e a capacidade do veículo.

\subsection{Construção da solução inicial}

O algoritmo de construção da solução inicial foi adaptado de métodos existentes na literatura. Duas estratégias de inserção foram adotadas: a Estratégia de Inserção Sequencial (EIS) e a Estratégia de Inserção Paralela (EIP). Com a finalidade de gerar soluções iniciais diversificadas, para cada uma dessas estratégias, dois critérios de inserção foram utilizados, a saber, o Critério de Inserção Mais Barata Viável Modificada (CIMBVM) e o Critério de Inserção Mais Próxima Viável (CIMPV).

O pseudocódigo do algoritmo GeraSoluçãoInicial() é apresentado no Algoritmo 3. Inicialmente, a Lista de Candidatos (LC) é preenchida com todos os clientes (linha 3). Em seguida, cada rota $r^{\prime}$ é preenchida com um cliente $i$ selecionado, aleatoriamente, da LC (linhas $5-7$ ). Também aleatoriamente são selecionados, a estratégia e o critério de inserção (linhas 8 - 9). A solução inicial é gerada (linhas 10 - 13) usando o critério e a estratégia previamente selecionados.

Se a solução $s$ for inviável e a frota for conhecida (isto é, limitada) o algoritmo tenta obter uma nova solução que seja viável (linha 20). Caso a solução $s$ seja inviável e a frota seja ilimitada, somente após um certo número de tentativas sem sucesso é que o algoritmo adiciona um novo veículo à frota e tenta reconstruir uma solução viável (linhas 15 - 20).

Ao final do algoritmo, para as variantes com frota heterogênea e ilimitada, onde é necessário dimensioná-la, para cada tipo de veículo, é adicionada à solução $s$ uma rota vazia (linhas 21 e 22). Este artifício permite o redimensionamento da frota durante a fase de busca local. 


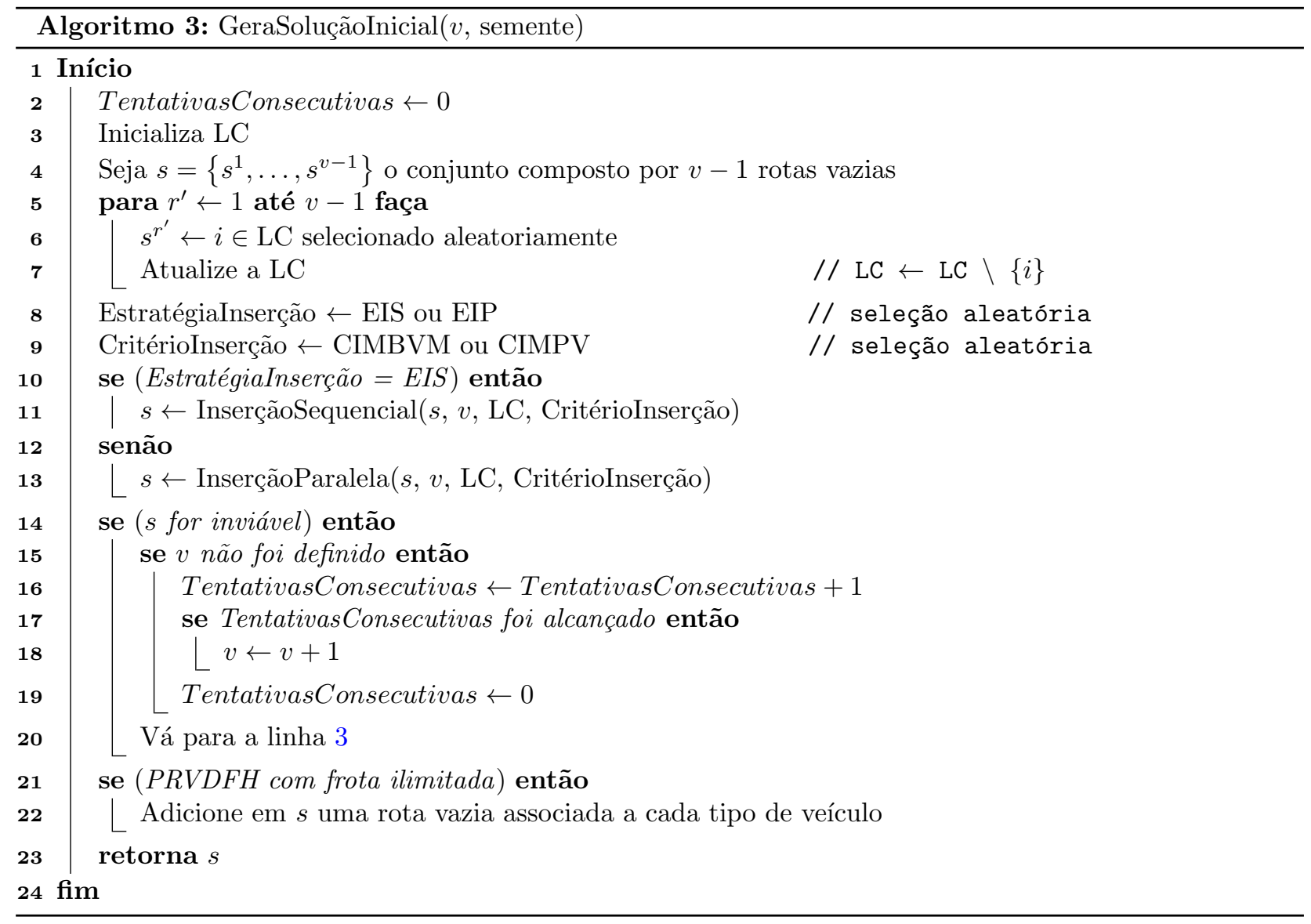

\subsubsection{Critérios de inserção}

No critério CIMBVM, o custo de inserção de um cliente não roteado $h \in \mathrm{LC}$ em uma dada rota é expresso pela Equação (7), na qual a função $g(h)$ representa o custo de inserção. O valor de $g(h)$ é calculado pela soma de dois termos. O primeiro computa o custo de inserção do cliente $h$ entre cada par clientes adjacentes $i$ e $j$, enquanto o segundo corresponde à penalização usada para desestimular inserções tardias de clientes localizados distantes do depósito. O fator $\gamma$ define o peso do custo de ida e volta ao depósito.

$$
g(h)=\left(c_{i h}^{k}+c_{h j}^{k}-c_{i j}^{k}\right)-\gamma\left(c_{0 h}^{k}+c_{h 0}^{k}\right)
$$

O critério CIMPV calcula a distância entre um cliente $h \in \mathrm{LC}$ e todos os clientes que já tenham sido incluídos na solução parcial, ou seja $g(h)=c_{i h}^{k}$ (Equação (8)). Assume-se que a inserção de $h$ é sempre realizada após $i$.

$$
g(h)=c_{i h}^{k}
$$

Nos dois critérios adotados, o cliente $i_{\min }$ inserido é aquele associado ao menor custo, isto é, $i_{\min } \leftarrow$ $\arg \min \{g(h) \mid h \in \mathrm{LC}\}$.

\subsubsection{Estratégias de inserção}

São duas as estratégias de inserção utilizadas para adicionar um cliente a uma rota: a Estratégia de Inserção Sequencial (EIS) e a Estratégia de Inserção Paralela (EIP).

Na EIS, cujo pseudocódigo é apresentado no Algoritmo 4, uma única rota é considerada a cada iteração. Se o critério de inserção selecionado for o CIMBVM, um valor de $\gamma$ é escolhido, aleatoriamente, no conjunto $\{0,00,0,05,0,10, \ldots, 1,65,1,70\}$ (linha 4), conforme experimentos empíricos de Subramanian et al. (2010). Em seguida, enquanto a LC não estiver vazia e existir pelo menos um cliente $i \in \mathrm{LC}$ que possa ser adicionado à solução parcial corrente, sem violar qualquer restrição (linhas 7-15), cada rota é preenchida com um cliente selecionado pelo critério de inserção previamente definido (linhas 8-14). Se ao final do laço anterior ainda restar cliente não atendido, dois casos podem ocorrer. Se a frota for heterogênea e ilimitada (linhas 21-23), 


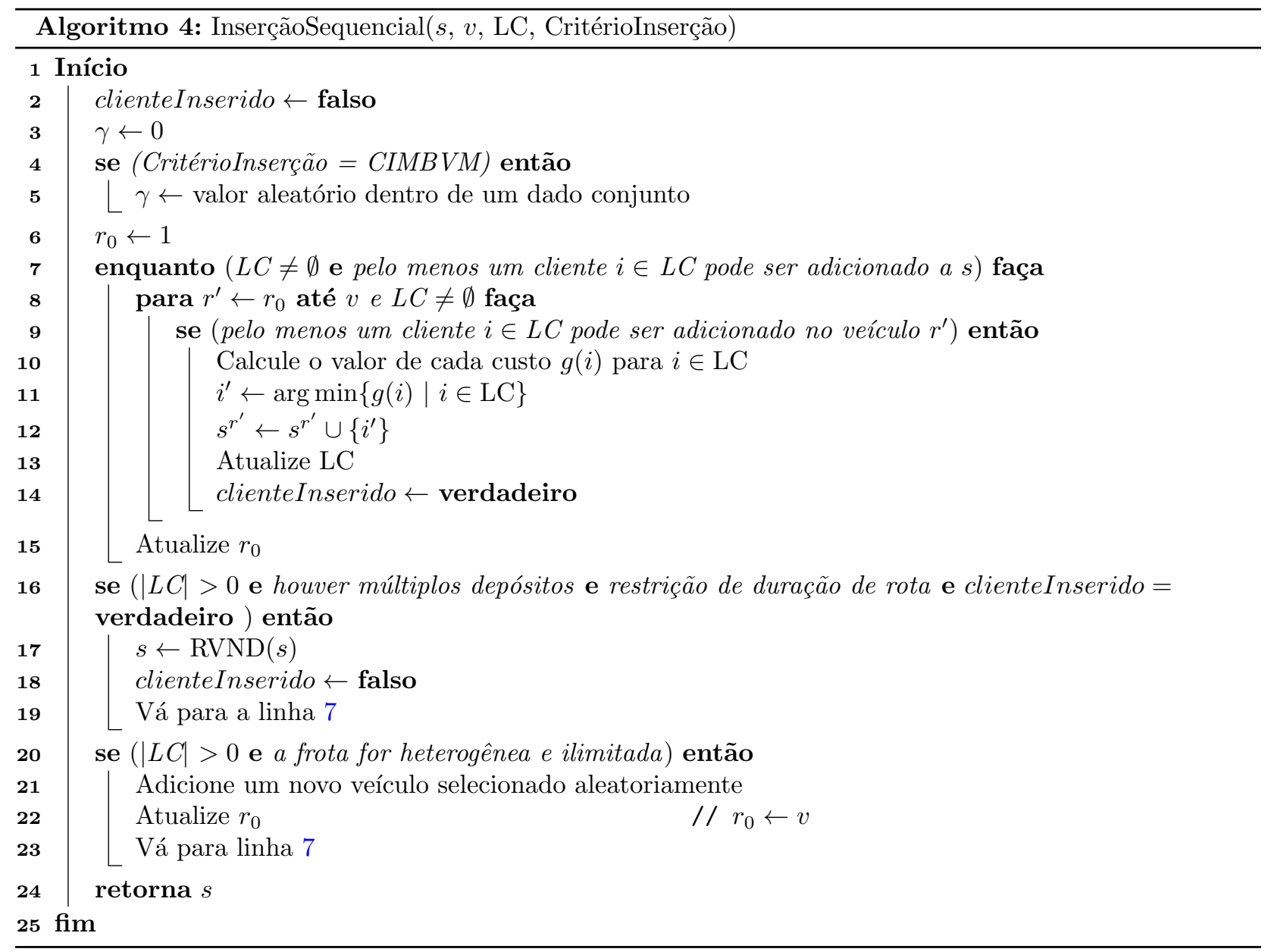

um novo veículo, selecionado aleatoriamente entre os tipos existentes, é adicionado e o algoritmo é reiniciado a partir da linha 7; em qualquer outro caso, é realizado um novo procedimento de construção.

A Figura 1 ilustra um exemplo de uma iteração do procedimento construtivo utilizando a EIS com CIMPV. Neste caso, considere $r_{1}=0 \rightarrow 1 \rightarrow 2 \rightarrow 0$ como sendo a rota na qual a melhor inserção deverá ser avaliada. No exemplo em questão, o algoritmo avalia a melhor possibilidade de inserção dentre todas as possíveis, conforme pode ser observado nas Figuras 1.b - 1.g. A inserção de menor custo ocorre quando o cliente 3 é inserido após o cliente 2 (veja Figura 1.d)

O funcionamento da EIP é similar a da EIS, porém ela difere da anterior por considerar todas as rotas durante o processo de avaliação da inserção de um cliente. O Algoritmo 5 ilustra o seu pseudocódigo. Neste caso, um cliente é adicionado à rota $r$ de menor custo de inserção, segundo o critério de inserção selecionado (linhas 7 -10). Este procedimento é repetido enquanto a LC não estiver vazia e existir pelo menos um cliente $k \in \mathrm{LC}$ que possa ser incluído em $s$ (linhas $6-12$ ). O restante do código é semelhante ao EIS.

\subsection{Busca local}

A busca local é feita pelo algoritmo Randomized Variable Neighborhood Descent - RVND (Subramanian et al., 2010). O RVND é uma variação do método Variable Neighborhood Descent - VND (Hansen et al., 2010), que ao invés de usar uma ordem pré-definida de vizinhanças para explorar o espaço de soluções, utiliza uma ordem aleatória a cada chamada. Mais especificamente, sempre que em uma determinada vizinhança não for possível melhorar a solução corrente, o RVND seleciona, aleatoriamente, outra vizinhança para continuar a busca pelo espaço de soluções. Esta abordagem, utilizada em Subramanian et al. (2010), Penna et al. (2011), Silva et al. (2012) e Subramanian \& Battarra (2013), produz, em média, resultados melhores do que a versão com ordem determinística das vizinhanças e tem a vantagem de não necessitar de um estudo de qual a melhor ordem de vizinhanças.

O pseudocódigo do algoritmo RVND é apresentado no Algoritmo 6. Para explicar seu funcionamento, seja $L V$ uma Lista de Vizinhanças inter-rotas. A $L V$ é inicializada com vizinhanças associadas aos movimentos descritos na Seção 4.3.1 (linha 3). A cada iteração (linhas $4-16$ ) uma vizinhança $\mathcal{N}^{(\eta)} \in L V$ é selecionada aleatoriamente (linha 5) e o melhor movimento viável é determinado (linha 6). Em caso de melhora da solução 


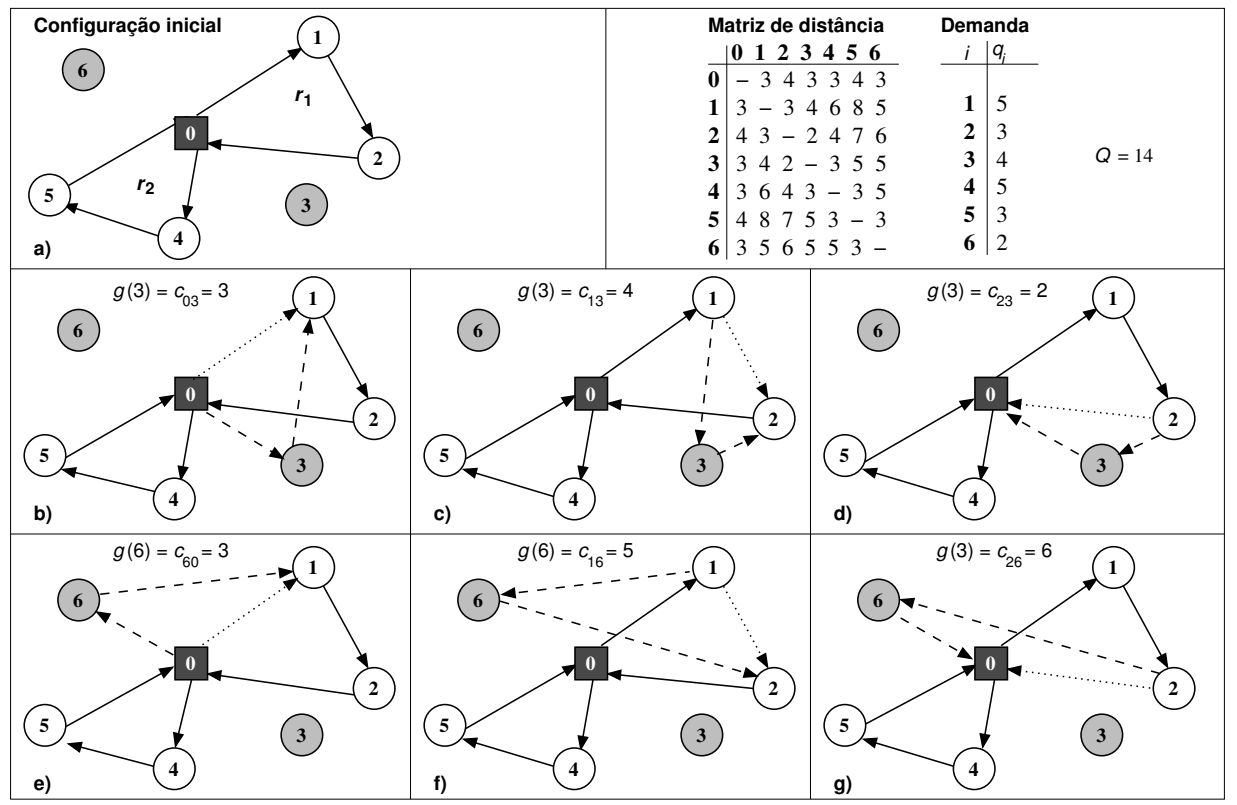

Figura 1. Exemplo de uma iteração do EIS com CIMPV.

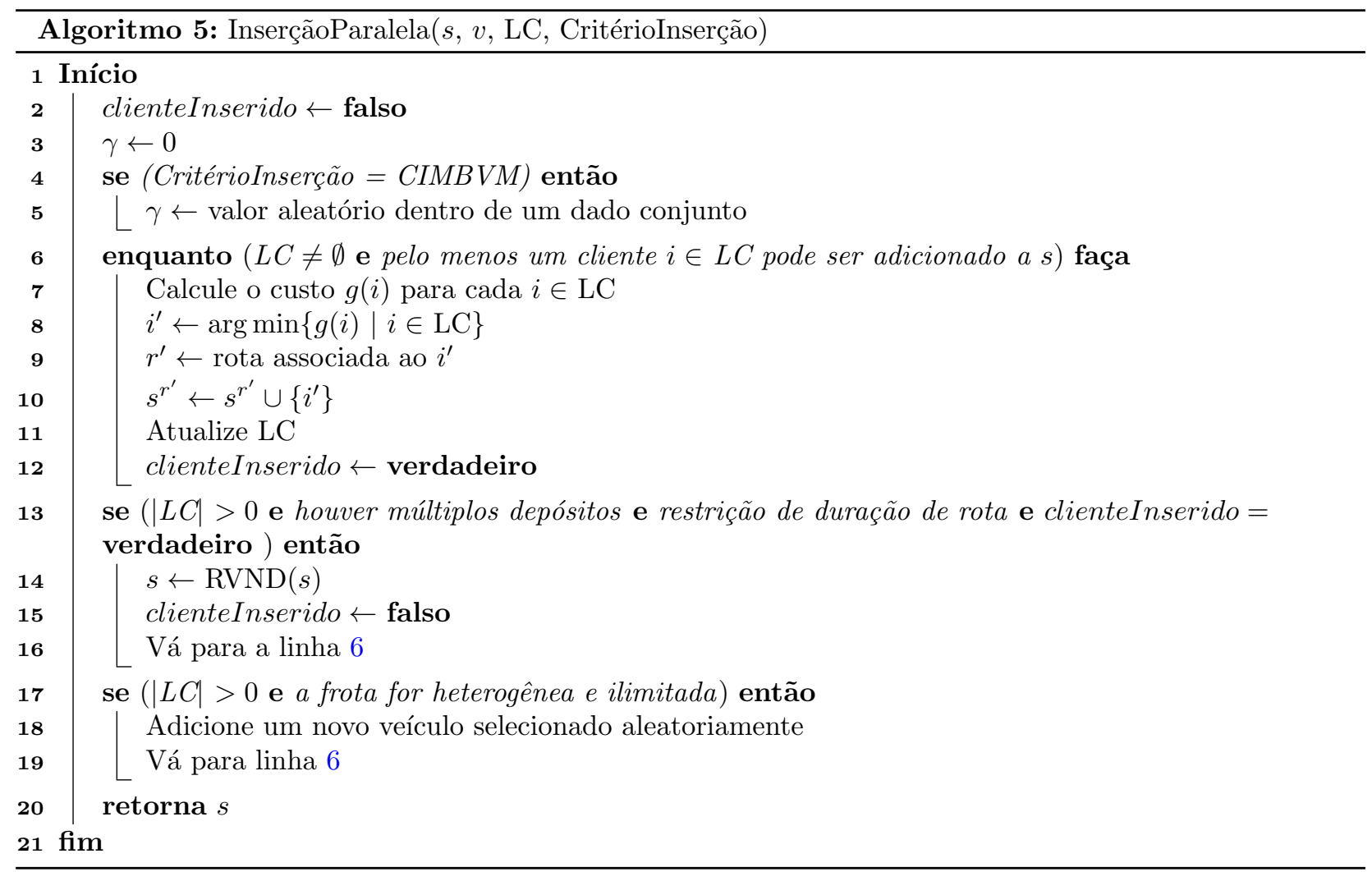

corrente, uma busca local intra-rota é executada (Algoritmo 7), a frota é atualizada e $L V$ é reinicializada com todas as vizinhanças (linhas $7-13$ ). Caso contrário, $\mathcal{N}^{(\eta)}$ é removida da $L V$ (linha 14). Se o problema possuir como objetivo principal a minimização do número de veículos, linha 16, como é o caso do PRVA, então um algoritmo específico é aplicado para tentar esvaziar rotas (veja Algoritmo 9). Um conjunto de Estruturas de Dados Auxiliares (EDAs), implementadas com a finalidade de acelerar a busca e evitar a avaliação desnecessária de movimentos nas vizinhanças, é atualizado no início (linha 2) e durante a execução do método (linha 15). Uma descrição detalhada dessas estruturas e suas aplicações em cada vizinhança pode ser encontrada em Subramanian (2012). 

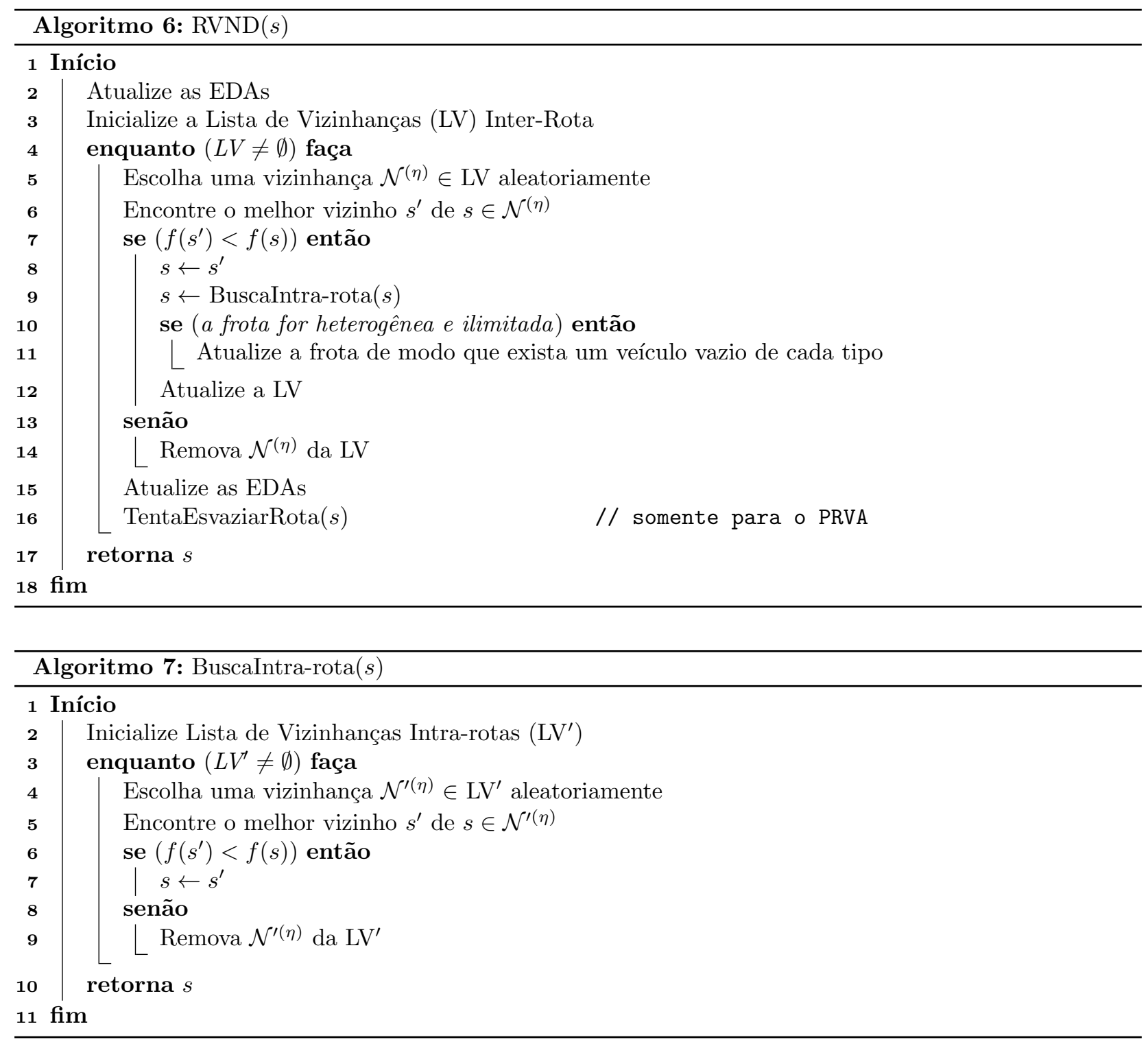

\subsubsection{Estruturas de vizinhança inter-rotas}

Um conjunto $\mathcal{N}$ de nove diferentes tipos de movimentos é usado para fazer modificações entre clientes de rotas distintas. Esses movimentos definem as estruturas de vizinhanças inter-rotas, sendo que as seis primeiras vizinhanças foram aplicadas em todas as variantes (Figura 2) e as três restantes em variantes específicas. Entre as seis estruturas, cinco delas são baseadas em movimentos $\lambda$-interchanges (Osman, 1993), que consiste na troca de até $\lambda$ clientes consecutivos entre duas rotas. Para minimizar o esforço computacional $\lambda$ foi limitado a 2. De acordo com Cordeau \& Laporte (2005), essas trocas são melhores explicadas como duplas $\left(\lambda_{1}, \lambda_{2}\right)$ ( com $\lambda_{1} \leqslant \lambda$ e $\lambda_{2} \leqslant \lambda$ ), sendo que os $\lambda_{1}$ clientes são transferidos da rota $r_{1}$ para a rota $r_{2}$ e os $\lambda_{2}$ clientes da rota $r_{2}$ para a rota $r_{1}$. Portanto, desconsiderando as simetrias, são possíveis as seguintes combinações de movimentos 2-interchanges: $((1,0),(1,1),(2,0),(2,1),(2,2))$. Observe que tais combinações incluem movimentos de realocação $((1,0),(2,0))$ e de troca $((1,1),(2,1),(2,2))$. A sexta vizinhança considerada é baseada no operador Cross-exchange (Taillard et al., 1997), que consiste em trocar dois segmentos de diferentes rotas. Estas vizinhanças são apresentadas na Figura 2. Para as variantes do PRVFH ilimitada, uma sétima vizinhança implementada é a denominada $\tau$-Shift, que consiste em transferir um conjunto de $\tau$ clientes consecutivos de uma rota para outra (Figura 3). Por fim, duas vizinhanças para as variantes contendo múltiplos depósitos, denominadas ShiftDepot e SwapDepot, foram utilizadas (Figura 4). As estruturas de vizinhanças inter-rotas estão descritas a seguir.

Shift $(\mathbf{1}, \mathbf{0})-\mathcal{N}^{(1)}$ : Um cliente $i$ é transferido de uma rota $r_{1}$ para outra rota $r_{2}$. A Figura 2.b, que exemplifica o movimento, mostra que o cliente 7 retirado de uma rota é reinserido em outra. A carga do 


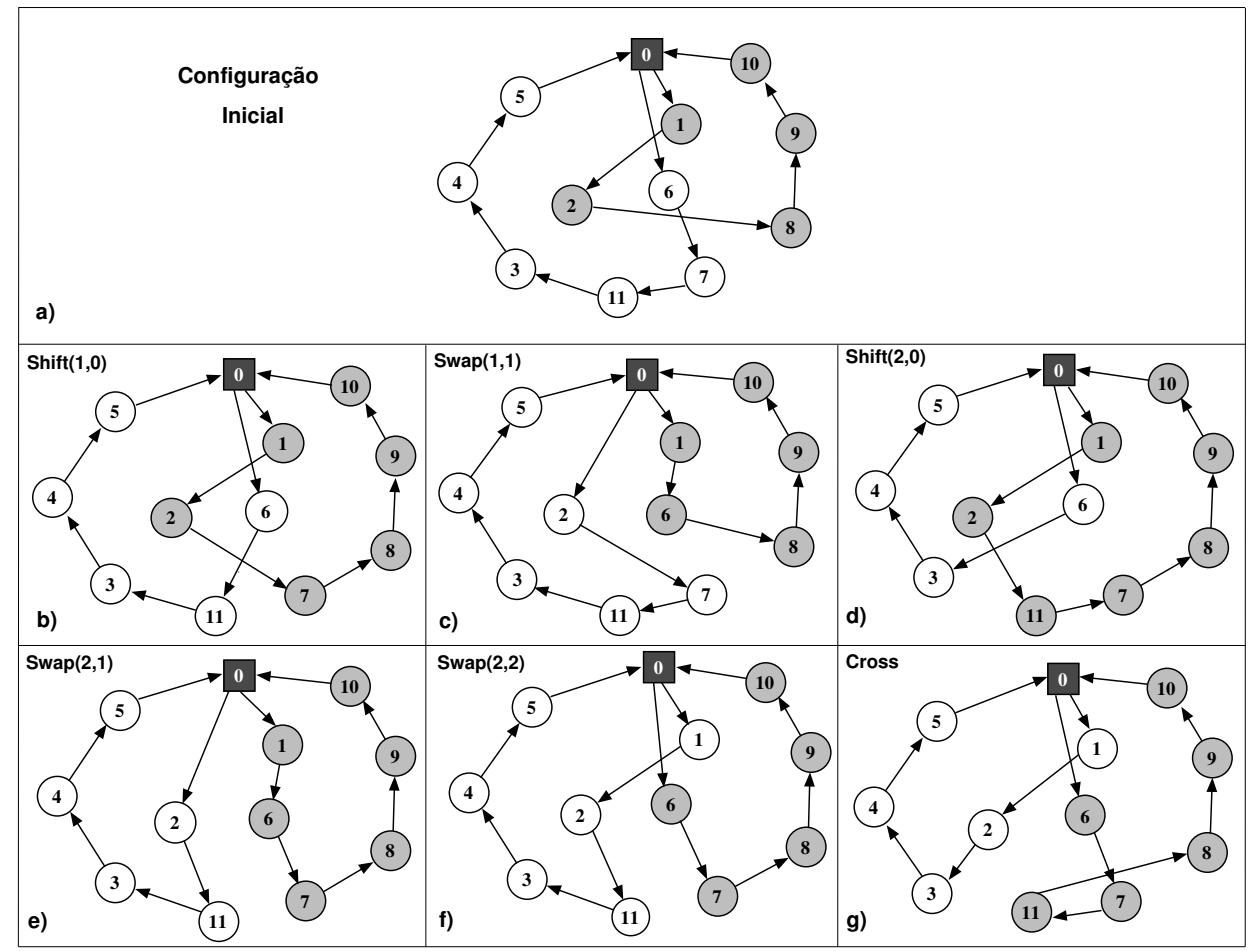

Figura 2. Vizinhanças inter-rotas.

veículo é verificada como segue. Todos os clientes localizados antes da posição de inserção têm suas cargas acrescidas em $q_{i}$ unidades, enquanto que os localizados depois possuem suas cargas adicionadas em $p_{i}$ unidades.

$\boldsymbol{S} \boldsymbol{w a p}(\mathbf{1}, \mathbf{1})-\mathcal{N}^{(2)}$ : Executa uma permutação entre um cliente $i$ de uma rota $r_{1}$ e um cliente $j$ pertencente a uma outra rota $r_{2}$. Na Figura 2.c, o cliente 2 é trocado com o cliente 6 . As cargas dos veículos das duas rotas são examinadas de modo similar. Por exemplo, no caso de $r_{2}$, todos os clientes, situados antes da posição que $j$ foi encontrado (agora substituído por $i$ ), têm suas cargas acrescidas de $q_{i}$ e diminuídas de $q_{j}$ unidades, enquanto que as cargas dos clientes posicionados após $i$ aumentarão de $p_{i}$ e diminuirão de $p_{j}$ unidades.

Shift $\left(\mathbf{2 , 0 )}-\mathcal{N}^{(3)}\right.$ : Dois clientes consecutivos $i$ e $j$ são transferidos de uma rota $r_{1}$ para outra $r_{2}$. Na Figura 2.d, os clientes adjacentes 7 e 11 são movidos de uma rota para outra. Todos os clientes localizados antes da posição de inserção em $r_{2}$ têm suas cargas somadas em $q_{i}+q_{j}$, enquanto que aqueles localizados depois têm suas cargas adicionadas em $p_{i}+p_{j}$. A nova carga do arco $(i, j)$ também deve ser verificada.

$\boldsymbol{S w a p}\left(\mathbf{2 , 1 )}-\mathcal{N}^{(4)}\right.$ : Dois clientes consecutivos, $i$ e $j$, pertencentes a uma rota $r_{1}$ são permutados com um cliente $i^{\prime}$ de outra rota $r_{2}$. Na Figura 2.e, os clientes adjacentes 6 e 7 de uma rota são trocados com o cliente 2 de outra rota. A carga é verificada de modo similar às abordagens usadas nas vizinhanças $\operatorname{Shift}(2,0)$ e $\operatorname{Swap}(1,1)$.

$\operatorname{Swap}(\mathbf{2}, \mathbf{2})-\mathcal{N}^{(5)}$ : Dois clientes consecutivos, $i$ e $j$, pertencentes a uma rota $r_{1}$ são permutados com outros dois clientes consecutivos $i^{\prime}$ e $j^{\prime}$ de outra rota $r_{2}$. Na Figura 2.f, os clientes adjacentes 6 e 7 de uma rota são trocados com os clientes adjacentes 1 e 2 de outra rota. A carga é verificada como na vizinhanças $\operatorname{Swap}(2,1)$.

Cross $-\mathcal{N}^{(6)}:$ O arco entre os clientes adjacentes $i$ e $i+1$ de uma rota $r_{1}$, e o arco entre os clientes adjacentes $j$ e $j+1$ de outra rota $r_{2}$ são removidos. Em seguida, para se inserir novos arcos, os clientes $i$ e $j+1$ são conectados, assim como os clientes $j$ e $i+1$. Na Figura 2.g, os arcos $(2,8)$ e $(11,3)$ são removidos e os arcos $(11,8)$ e $(2,3)$ inseridos. O algoritmo para testar a carga do veículo de cada rota é feita como segue. A carga inicial $\left(\mathcal{L}_{0}\right)$ e final $\left(\mathcal{L}_{f}\right)$ dos veículos das duas rotas é calculado em tempo constante utilizando-se as EDAs. Se os valores de $\mathcal{L}_{0}$ e $\mathcal{L}_{f}$ não excederem a capacidade do veículo $Q_{k}$, então as cargas intermediárias são verificadas pela seguinte expressão: $\mathcal{L}_{i}=\mathcal{L}_{i-1}+p_{i}-q_{i}$. Consequentemente, se $\mathcal{L}_{i}$ ultrapassar $Q_{k}$, o movimento é inviável.

$\tau$-Shift $-\mathcal{N}^{(7)}$ : um subconjunto de $\tau$ clientes consecutivos é transferido de uma rota $r_{1}$ de maior capacidade para outra rota $r_{2}$ de menor capacidade. É assumido que os custos fixos e variáveis de $r_{2}$ são menores que aqueles de $r_{1}$. O valor de $\tau$ é iniciado por 3 e varia progressivamente até alcançar o número de clientes que compõem a rota $r_{1}$. Esse movimento é específico para problemas de roteamento com frota heterogênea e tem o objetivo de esvaziar as rotas feitas por veículos de custo mais elevado. Ele é aplicado mesmo que a rota $r_{2}$ esteja vazia. Na Figura 3, os clientes consecutivos 1, 2 e 7 são transferidos de uma rota para outra. 


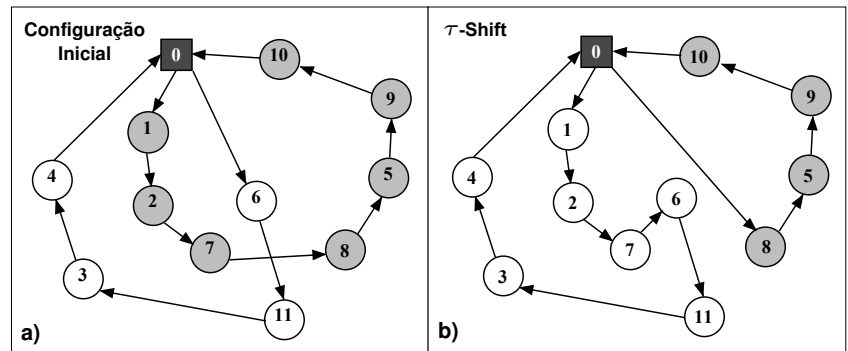

Figura 3. Vizinhança inter-rota $\tau$-Shift.

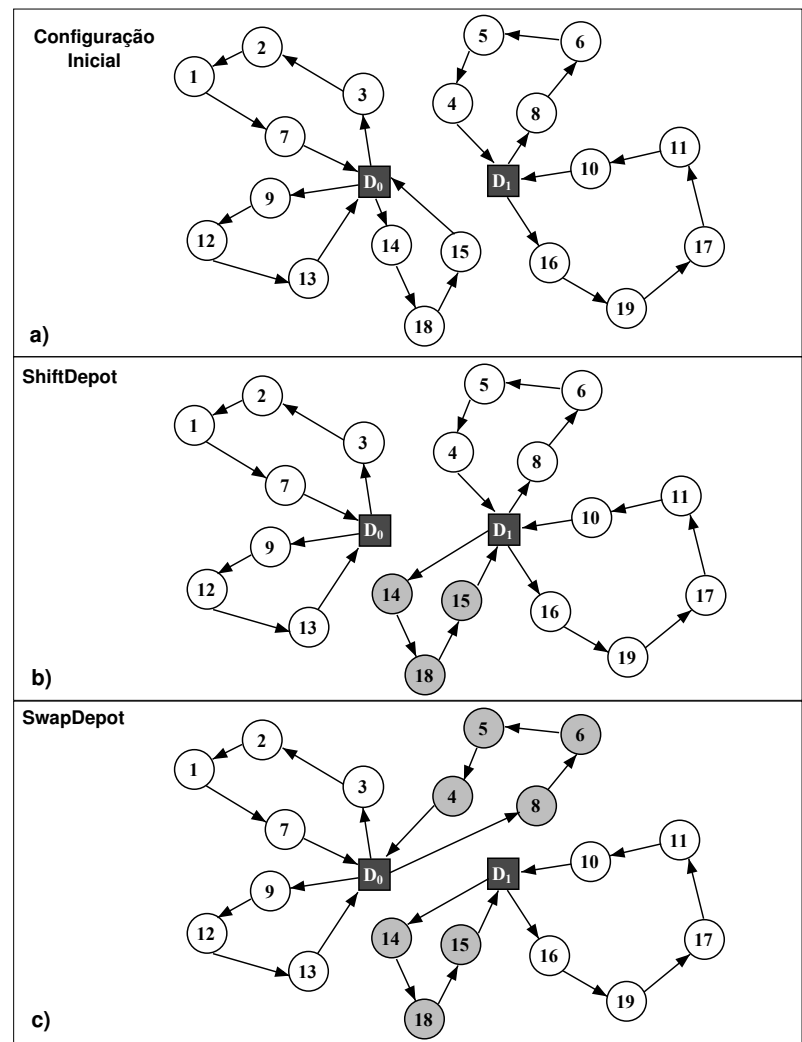

Figura 4. Vizinhanças inter-rotas para multi-depósitos.

ShiftDepot $-\mathcal{N}^{(8)}$ : Uma rota $r$ é transferida de um depósito $d_{1}$ para um outro depósito $d_{2}$, desde que exista um veículo disponível no segundo. Em princípio, qualquer movimento é considerado viável. Na Figura 4.b, a rota composta pelos clientes 14, 18 e 15 é transferida de um depósito para outro.

SwapDepot $-\mathcal{N}^{(9)}$ : Permutação entre uma rota $r_{i}$ de um depósito $d_{1}$ e uma rota $r_{j}$ de um depósito $d_{2}$. Assim como no caso anterior, qualquer movimento é considerado viável. Na Figura 4.c, a rota composta pelos clientes 14, 18 e 15, pertencente ao depósito $D_{0}$ é trocada com a rota composta pelos clientes 4, 5, 6 e 8, pertencente ao depósito $D_{1}$.

O pseudocódigo do algoritmo geral das estruturas de vizinhanças $\mathcal{N}^{(1)}$ a $\mathcal{N}^{(7)}$ é descrito no Algoritmo 8. Para cada par de rotas $r_{1}$ e $r_{2}$ (linhas 2 e 3), o algoritmo verifica se há movimentos viáveis ou que não foram examinados previamente (linha 4). Se uma das duas condições for satisfeita, um cliente (ou subconjunto de clientes consecutivos, dependendo da vizinhança) da rota $r_{1}$ é selecionado para ter seu movimento avaliado no caso de ser transferido ou permutado por outro cliente (ou subconjunto de clientes consecutivos, dependendo da vizinhança), desde que as condições de viabilidade sejam atendidas (linhas $5-8$ ). Se o movimento for viável e, ao mesmo tempo, conduzir a uma solução de melhor qualidade em relação à solução incumbente $(\bar{s})$ da iteração corrente do MILS-RVND, então a solução $\bar{s}$ é atualizada (linhas 9 - 11).

A busca local em todas as vizinhanças é realizada de forma exaustiva, considerando apenas soluções viáveis. A estratégia de best improvement foi utilizada. Em princípio, a checagem de viabilidade das cargas deve ser verificada apenas no(s) depósito(s), com exceção das variantes envolvendo coleta e entrega, em que as cargas devem ser verificadas ao longo da rota. 


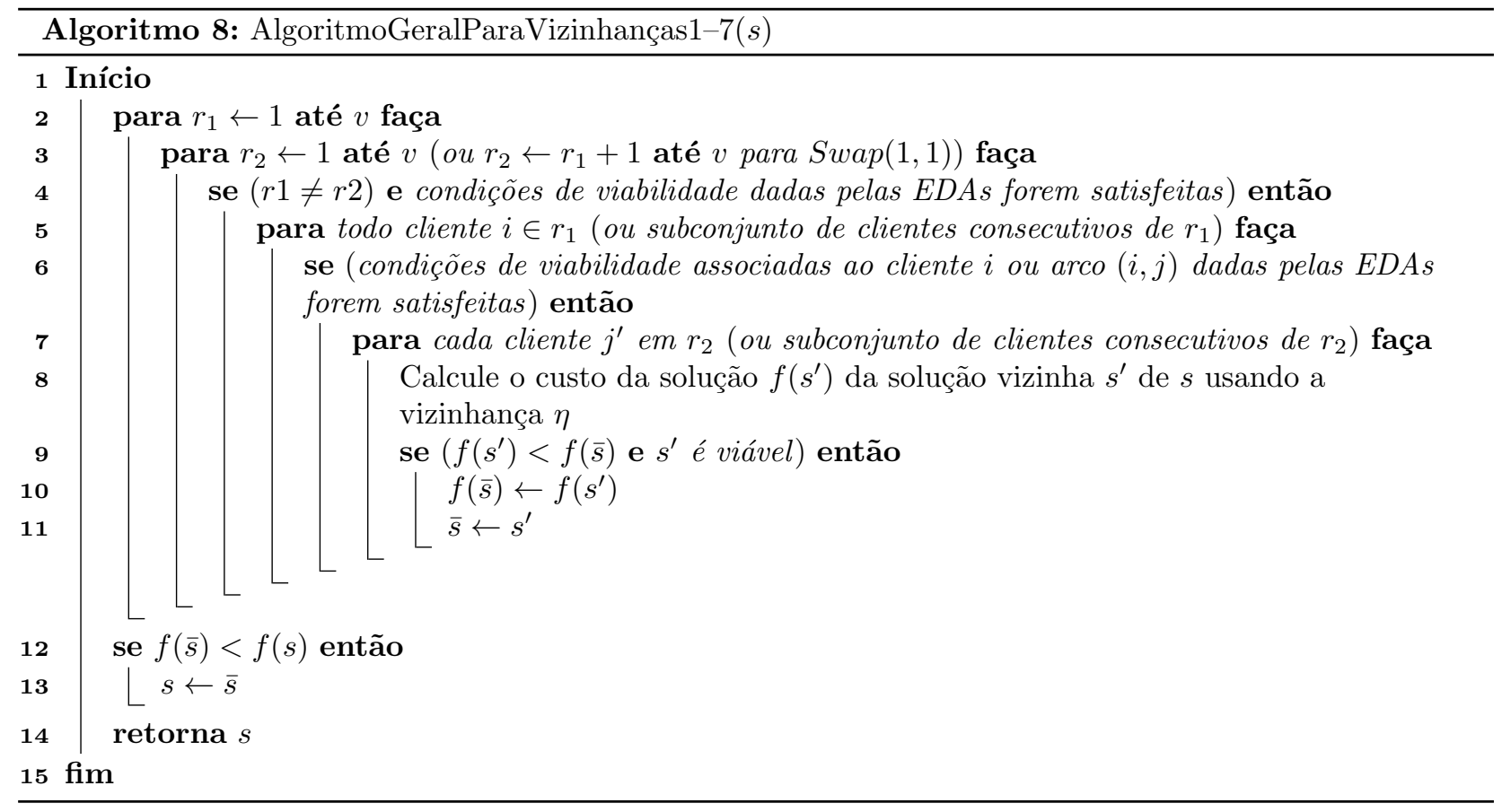

\subsubsection{Estruturas de vizinhança intra-rotas}

Um conjunto $\mathcal{N}^{\prime}$ de seis diferentes tipos de movimentos encontrados na literatura é usado para fazer modificações entre clientes de uma mesma rota. Esses movimentos, baseados em Reinsertion, Or-opt (Or, 1976), 2-opt e Swap, definem as estruturas de vizinhanças intra-rotas.

Reinsertion $-\mathcal{N}^{\prime(1)}$ : Um cliente é removido e reinserido em outra posição da rota. Na Figura 5.b, o cliente 3 , na rota original $0 \rightarrow 1 \rightarrow 2 \rightarrow 3 \rightarrow 4 \rightarrow 5 \rightarrow 6 \rightarrow 7 \rightarrow 0$ é realocado para outra posição na rota, sendo a nova rota a sequência $0 \rightarrow 1 \rightarrow 2 \rightarrow 4 \rightarrow 5 \rightarrow 3 \rightarrow 6 \rightarrow 7 \rightarrow 0$.

Or-opt2 $-\mathcal{N}^{\prime(2)}$ : Dois clientes consecutivos são removidos e reinseridos em outra posição da rota. Na Figura 5.c, os clientes adjacentes 2 e 3 são realocados para outra posição na sequência, formando a nova rota $0 \rightarrow 1 \rightarrow 4 \rightarrow 5 \rightarrow 2 \rightarrow 3 \rightarrow 6 \rightarrow 7 \rightarrow 0$.

Or-opt3 $-\mathcal{N}^{\prime(3)}$ : Três clientes consecutivos são removidos e reinseridos em outra posição da rota. Na Figura 5.d, apresenta a nova rota $0 \rightarrow 4 \rightarrow 5 \rightarrow 1 \rightarrow 2 \rightarrow 3 \rightarrow 6 \rightarrow 7 \rightarrow 0$, com os clientes adjacentes 1 , 2 e 3 realocados em outra posição, em relação a rota original.

2-opt $-\mathcal{N}^{\prime(4)}$ : Dois arcos não-adjacentes são removidos e outros dois são adicionados de modo a formarem uma nova rota. Na Figura 5.e, os arcos $(2,3)$ e $(5,6)$ são excluídos e os novos arcos $(2,5)$ e $(3,6)$ são inseridos, de modo a obter a nova rota $0 \rightarrow 1 \rightarrow 2 \rightarrow 5 \rightarrow 4 \rightarrow 3 \rightarrow 6 \rightarrow 7 \rightarrow 0$. Esta estrutura de vizinhança não é aplicada na variante assimétrica.

Swap $-\mathcal{N}^{\prime(5)}$ : Consiste em permutar dois clientes de uma mesma rota. Na Figura 5.f, os clientes 2 e 6 são trocados, formando a rota $0 \rightarrow 1 \rightarrow 6 \rightarrow 5 \rightarrow 4 \rightarrow 3 \rightarrow 2 \rightarrow 7 \rightarrow 0$.

Reverse $-\mathcal{N}^{\prime(6)}$ : Este movimento inverte a sequência de visitas de uma rota se o valor total da carga correspondente à rota for reduzido. Na Figura 5.g, todos os arcos tiveram seus sentidos invertidos, obtendo-se a rota $0 \rightarrow 7 \rightarrow 6 \rightarrow 5 \rightarrow 4 \rightarrow 3 \rightarrow 2 \rightarrow 1 \rightarrow 0$. Esta vizinhança é aplicada somente aos problemas envolvendo coleta e entrega.

\subsubsection{Tentativa de esvaziar rotas}

Em algumas variantes do PRV, minimizar o número de veículos é o objetivo principal. Por isso, um algoritmo guloso e randomizado foi desenvolvido para tratar este caso, o qual é apresentado no Algoritmo 9. A ideia é fazer uso da capacidade residual e da duração residual das rotas de uma dada solução $s$ por meio de uma busca local, com a finalidade de diminuir o número de rotas de $s$. O algoritmo começa criando uma cópia da solução $s$ em $s^{\prime}$ (linha 2). Na linha 3, a Lista de Rotas (LR) é criada, sendo essa lista composta pelas rotas da solução $s$. Enquanto $|\mathrm{LR}|$ for maior que 1 (linhas 4 -11), uma tentativa de esvaziar uma rota é realizada. Para tal, uma rota $r$ é selecionada para ser removida de LR, de acordo com um dos seguintes critérios: (i) rota com a maior carga; (ii) rota com a maior duração; (iii) seleção aleatória. O critério de seleção de rota é escolhido aleatoriamente (linha 5). Em seguida, nas linhas 9 - 11, enquanto for possível mover um cliente de qualquer rota $r^{\prime} \in$ LR para $r$ ou ainda for possível trocar um cliente de qualquer rota $r^{\prime} \in$ LR com outro em 


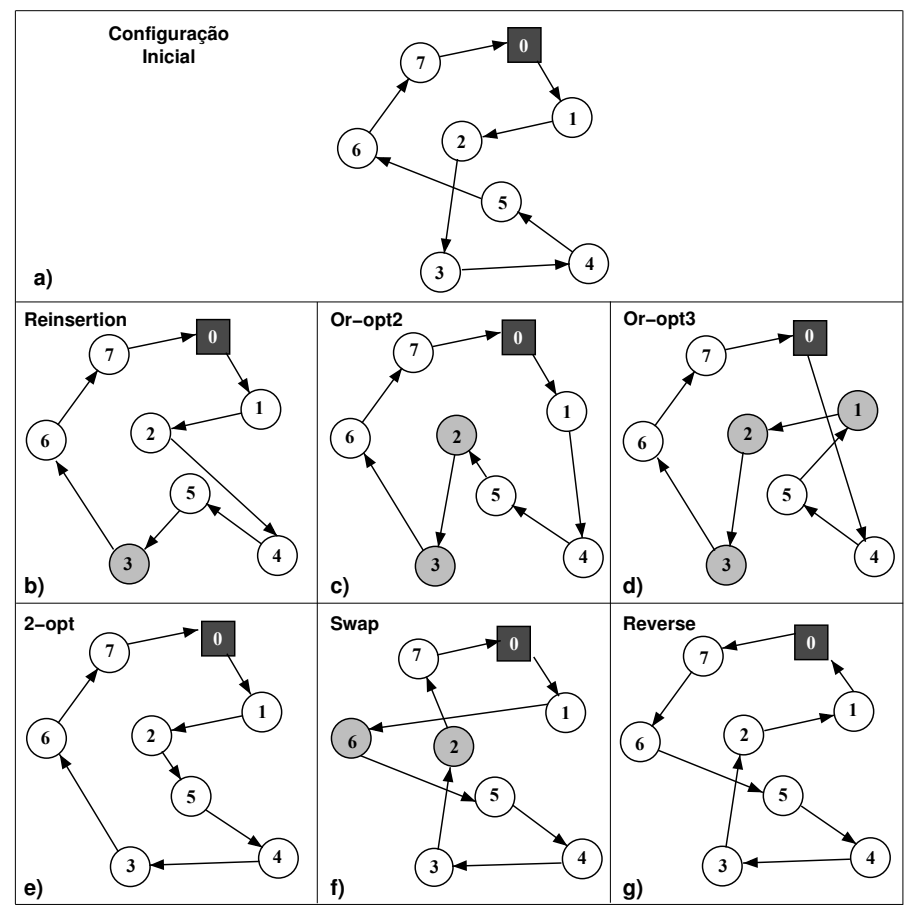

Figura 5. Vizinhanças intra-rotas.

$r$, de tal modo que a carga de $r$ aumente, uma busca local é feita entre a rota $r$ e aquela em LR usando as estruturas de vizinhanças Shift(1,0), Shift $(2,0)$ e $\operatorname{Swap}(1,1)$. O melhor movimento possível é considerado para cada uma dessas três vizinhanças. Além disso, no caso do Shift $(1,0)$ e $\operatorname{Shift}(2,0)$ o movimento é imediatamente aceito se a rota $r^{\prime} \in \mathrm{LR}$ ficar vazia, enquanto que, no caso do $\operatorname{Swap}(1,1)$, o movimento é aceito somente se a carga do veículo $r$ for incrementada. Uma busca local intra-rota é realizada em cada rota modificada usando as estruturas de vizinhanças 2-opt e Shift. Se o algoritmo não for capaz de esvaziar uma rota, então a solução corrente é restaurada (linhas $12-13$ ).

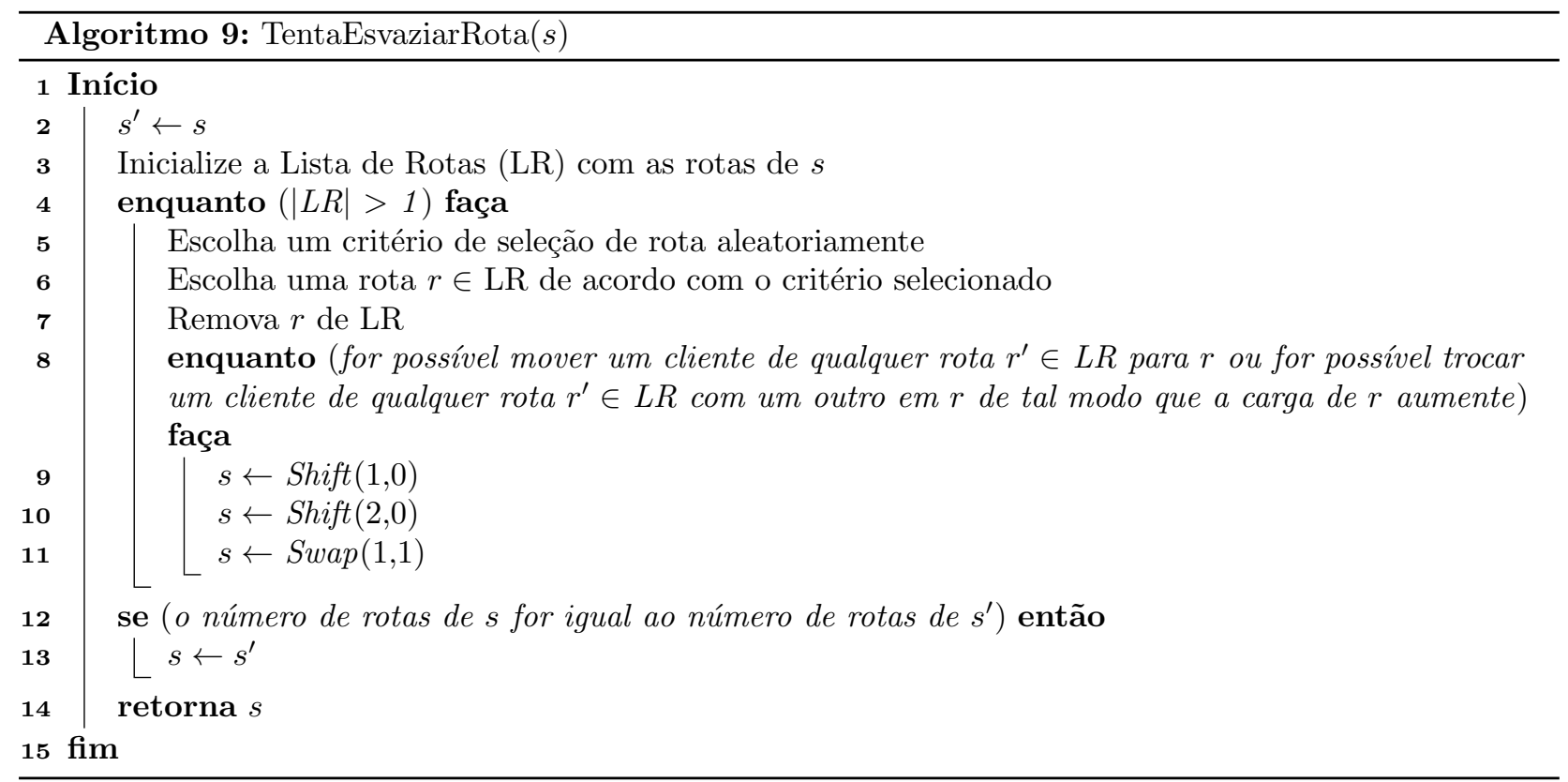

\subsection{Mecanismos de perturbação}

Três mecanismos de perturbação $P=\left\{P^{(1)}, P^{(2)}, P^{(3)}\right\}$, que aceitam somente modificações que geram soluções viáveis, foram implementados. Quando a função Perturba() (linha 15 do Algoritmo 2) é executada, uma 
destas perturbações é selecionada aleatoriamente. A perturbação $P^{(3)}$ é aplicada somente na variante com frota heterogênea e ilimitada.

Multi-Swap $(\mathbf{1}, \mathbf{1})-P^{(1)}$ : Múltiplos movimentos $\operatorname{Swap}(1,1)$ são executados aleatoriamente. Isto é, sorteiase um número $n_{v}$ no conjunto $\left\{1, \ldots, n_{\text {swap }}\right\}$ e aplica-se esse movimento $n_{v}$ vezes consecutivas. Nos testes realizados, $n_{\text {swap }}$ foi fixado em 2 .

Multi-Shift $(\mathbf{1 , 1})-P^{(2)}$ : Múltiplos movimentos Shift(1,1) são executados aleatoriamente. O Shift(1,1) consiste em transferir um cliente $i$ de uma rota $r_{1}$ para outra rota $r_{2}$, enquanto que um cliente $j$ de $r_{2}$ é transferido para $r_{1}$. Esta perturbação é aplicada tal como no caso anterior.

$\boldsymbol{S p l i t}-P^{(3)}$ : Consiste em dividir uma rota em rotas menores. Para tal, seja $T^{\prime}=\{2, \ldots, t\}$ um subconjunto de $T$ composto por todos os veículos, exceto pelo de menor capacidade. Inicialmente, uma rota $r \in s$ associada com um veículo $k \in T^{\prime}$ é selecionada aleatoriamente. Em seguida, enquanto $r$ não estiver vazia, os clientes de $r$ são transferidos sequencialmente para uma nova rota $r^{\prime} \notin s$ associada a um veículo $k^{\prime} \in\{1, \ldots, k-1\}$ sem que a capacidade do veículo $k^{\prime}$ seja violada. As novas rotas geradas são adicionadas à solução $s$, enquanto que a rota $r$ é excluída de $s$. O procedimento descrito é repetido um determinado número de vezes, sendo o número de repetições selecionado aleatoriamente no conjunto $\{1,2, \ldots,|R|\}$. Esta perturbação, normalmente, aumenta o número de rotas e é aplicada somente ao PRVFH ilimitada.

\section{Experimentos Computacionais}

$\mathrm{O}$ algoritmo proposto foi desenvolvido em $\mathrm{C}++$ (compilador g++ 4.4.3). Para testá-lo foram usadas instâncias clássicas da literatura para cada um dos problemas de roteamento elencados na Seção 2. Os testes relativos às instâncias com frota homogênea foram executados 50 vezes para cada instância em um computador Intel Core 2 Quad 2,4 GHz com 4 GB de RAM, enquanto aquelas com frota heterogênea foram executadas 30 vezes para cada problema em um computador Intel Core i7 2,93 GHz com 8 GB de RAM. Em todas as variantes foram utilizadas instâncias bem conhecidas da literatura.

Uma descrição mais detalhada da calibração dos parâmetros, apresentada na Seção 5.1, e dos resultados do MILS-RVND, contidas na Seção 5.2, são disponibilizadas em Subramanian (2012).

\subsection{Calibração dos parâmetros}

Um conjunto representativo contendo diferentes tipos de instâncias foi selecionado para calibrar os dois parâmetros do MILS-RVND: MaxIterMS e MaxIterILS. Foi possível observar, por meio de experimentos empíricos, que o MaxIterILS variou de acordo com o tamanho das instâncias, mais precisamente, com o número de clientes e veículos. Com a finalidade de simplificar o cálculo do MaxIterILS foi adotada uma expressão linear em função de $n$ e $v$, dada pela Equação (9).

$$
\text { MaxIterILS }=n+\beta \times v
$$

O Parâmetro $\beta$ na Equação (9) corresponde a um valor inteiro não-negativo, que indica o nível de influência do número de veículos $v$ no valor de MaxIterILS.

Pelos experimentos realizados, verificou-se que os melhores valores para os parâmetros do algoritmo MILSRVND são os seguintes: $\beta=5$ e MaxIter $M S=50$ para as variantes com frota homogênea e $\beta=5$ e MaxIterMS $=400$ para as variantes com frota heterogênea.

\subsection{Resultados}

A Tabela 1 resume o resultado da aplicação do algoritmo MILS-RVND na resolução de diversas variantes do PRV. Nesta tabela, Desvio Méd. corresponde ao desvio médio entre os valores médios (obtidos após as execuções do algoritmo) e o melhor valor conhecido para cada uma das instâncias testadas; \#Instâncias representa o número de problemas-teste usados por um determinado autor, \#Melhoras indica o número de soluções que o algoritmo proposto conseguiu melhorar e \#Empates o número de empates.

Pela Tabela 1, verifica-se que, dentre as 508 instâncias testadas, o algoritmo MILS-RVND superou os melhores resultados até então existentes em 43 instâncias e alcançou as melhores soluções em outras 395 instâncias. Além disso, o desvio médio foi sempre menor que 0,66\%, exceto no caso das instâncias de Golden et al. (1998), nas quais esse desvio foi $1,03 \%$.

\section{Conclusões}

Neste capítulo foi apresentado um algoritmo heurístico unificado, chamado MILS-RVND, baseado na metaheurística Iterated Local Search (ILS), para resolver uma ampla classe de problemas de roteamento de veículos. O algoritmo tem como procedimento de busca local o método Randomized Variable Neighborhood Descent (RVND) e é aplicado em uma estratégia Multi-Start. O MILS-RVND tem a vantagem de possuir uma estrutura 
Tabela 1. Resumo dos Resultados do MILS-RVND

\begin{tabular}{|c|c|c|c|c|c|}
\hline Variante & \#Instâncias & \#Melhoras & \#Empates & Desvio Méd. (\%) & Tempo Méd. (s) \\
\hline $\mathrm{PRVC}^{1}$ & ${ }^{a} 90,{ }^{b} 14,{ }^{c} 20$ & ${ }^{a} 0,{ }^{b} 0,{ }^{c} 0$ & ${ }^{a} 87,{ }^{b} 10,{ }^{c} 1$ & ${ }^{a} 0,10,{ }^{b} 0,26,{ }^{c} 1,03$ & ${ }^{a} 8,04,{ }^{b} 23,56,{ }^{c} 798,49$ \\
\hline PRVCA $^{1}$ & $d_{24}$ & ${ }^{d} 1$ & $d_{23}$ & ${ }^{d} 0,15$ & $d_{2,54}$ \\
\hline $\mathrm{PRVA}^{1}$ & ${ }^{a} 90,{ }^{e} 16,{ }^{f} 8$ & ${ }^{a} 1,{ }^{e} 2,{ }^{f} 6$ & ${ }^{a} 85,{ }^{e} 12,{ }^{f} 1$ & ${ }^{a} 0,09,{ }^{e} 0,62,{ }^{f} 0,19$ & ${ }^{a} 9,31,{ }^{e} 24,50,{ }^{f} 843,25$ \\
\hline PRVCES $^{1}$ & ${ }^{g} 40,{ }^{h} 28,{ }^{i} 18$ & ${ }^{g} 0,{ }^{h} 3,{ }^{i} 2$ & ${ }^{g} 40,{ }^{h} 20,{ }^{i} 10$ & ${ }^{g} 0,02,{ }^{h} 0,28,{ }^{i} 0,26$ & ${ }^{g} 2,04,{ }^{h} 32,34,{ }^{i} 433,89$ \\
\hline PRVCEM $^{1}$ & ${ }^{h} 42$ & ${ }^{h} 12$ & ${ }^{h} 26$ & ${ }^{h} 0,09$ & 30,05 \\
\hline $\mathrm{PRVMD}^{1}$ & ${ }^{j} 23,{ }^{k} 10$ & ${ }^{j} 0,{ }^{k} 0$ & ${ }^{j} 16,{ }^{k} 4$ & ${ }^{j} 0,47,{ }^{k} 0,66$ & ${ }^{j} 225,11,{ }^{k} 292,16$ \\
\hline PRVMDCEM $^{1}$ & ${ }^{h} 33$ & ${ }^{h} 14$ & ${ }^{h} 17$ & ${ }^{h} 0,23$ & ${ }^{h} 188,62$ \\
\hline $\mathrm{PRVFH}^{2}$ & ${ }^{l} 16,{ }^{m} 36$ & ${ }^{l} 1,{ }^{m_{2}}$ & ${ }^{l} 14,{ }^{m} 29$ & ${ }^{l} 0,23,{ }^{m} 0,16$ & ${ }^{l} 32,39,{ }^{m} 28,51$ \\
\hline Total & 508 & 43 & 395 & & \\
\hline \multicolumn{6}{|c|}{${ }^{a}$ : Conjuntos A, B, E, F, M, P; ${ }^{b}$ : Christofides et al. (1979); ${ }^{c}$ : Golden et al. (1998). } \\
\hline \multicolumn{6}{|c|}{${ }^{d}$ : Fischetti et al. (1994) e Pessoa et al. (2008). } \\
\hline \multicolumn{6}{|c|}{${ }^{e}:$ Christofides et al. (1979) e Fisher $(1994) ;{ }^{f}:$ (Li et al., 2007). } \\
\hline \multicolumn{6}{|c|}{${ }^{g}$ : Dethloff $(2001){ }^{h}$ : (Salhi \& Nagy, 1999); ${ }^{i}$ : Montané \& Galvão (2006); } \\
\hline \multicolumn{6}{|c|}{${ }^{j}$ : Cordeau et al. (1997) (old); ${ }^{k}$ : Cordeau et al. (1997) (new). } \\
\hline \multicolumn{6}{|c|}{${ }^{l}:$ Taillard (1999); ${ }^{m}:$ Golden et al. (1984). } \\
\hline \multicolumn{6}{|c|}{ 1: Core 2 Quad $2.4 \mathrm{GHz}$ (executado em um único processador). } \\
\hline${ }^{2}:$ Core i7 2.93 & Z (executado & & & & \\
\hline
\end{tabular}

extremamente simples e requerer poucos parâmetros. Os resultados computacionais mostraram sua eficiência, especialmente em termos de qualidade das soluções finais produzidas, assim como de sua flexibilidade em resolver diversas variantes do PRV. De acordo com os resultados obtidos, o algoritmo proposto detém os melhores resultados da literatura em 86,2\% das instâncias, sendo que em 8,5\% delas, ele foi capaz de apresentar novos melhores resultados. Este desempenho notável merece destaque, uma vez que os melhores resultados conhecidos estão distribuídos entre vários algoritmos de diversos autores e não concentrados em um único.

\section{Agradecimentos}

Os autores agradecem à CAPES e ao CNPq pelo apoio no desenvolvimento deste trabalho e aos colegas Marcos Melo Silva, Edcarllos Santos e Renatha Capua pelas correções efetuadas no texto.

\section{Referências}

Christofides, N.; Mingozzi, A. \& Toth, P., The vehicle routing problem. In: Christofides, N.; Mingozzi, A.; Toth, P. \& Sandi, C. (Eds.), Combinatorial Optimization. New York, USA: J. Wiley \& Sons, p. 315-338, 1979.

Cordeau, J.F.; Gendreau, M. \& Laporte, G., A tabu search heuristic for periodic and multi-depot vehicle routing problems. Networks, 30(2):105-119, 1997.

Cordeau, J.F. \& Laporte, G., New heuristics for the vehicle routing problem. In: Rego, C. \& Alidaee, B. (Eds.), Metaheuristic Optimization via Memory and Evolution: Tabu Search and Scatter Search. Norwell, USA: Kluwer Academic Publishers, p. 145-163, 2005.

Dantzig, G.B. \& Ramser, J.H., The truck dispatching problem. Management Science, 6(1):80-91, 1959.

Dethloff, J., Vehicle routing and reverse logistics: the vehicle routing problem with simultaneous delivery and pick-up. OR Spektrum, 23:79-96, 2001.

Fischetti, M.; Toth, P. \& Vigo, D., A branch-and-bound algorithm for the capacitated vehicle routing problem on directed graphs. Operations Research, 42(5):846-859, 1994.

Fisher, M.L., Optimal solutions of vehicle routing problems using minimum K-trees. Operations Research, 42(4):626642, 1994.

Golden, B.L.; Assad, A.A.; Levy, L. \& Gheysens, F.G., The feet size and mix vehicle routing problem. Computers \& Operations Research, 11(1):49-66, 1984.

Golden, B.L.; Wasil, E.A.; Kelly, J.P. \& Chao, I.M., Metaheuristics in vehicle routing. In: Crainic, T.G. \& Laporte, G. (Eds.), Fleet Management and Logistics. Boston, USA: Kluwer Academic Publishers, p. 33-56, 1998.

Hansen, P.; Mladenović, N. \& Moreno Pérez, J., Variable neighbourhood search: methods and applications. Annals of Operations Research, 175(1):367-407, 2010. 
Li, F.; Golden, B. \& Wasil, E., The open vehicle routing problem: Algorithms, large-scale test problems, and computational results. Computers $\&$ Opertions Research, 34(10):2918-2930, 2007.

Lourenço, H.R.; Martin, O.C. \& Stützle, T., Iterated local search. In: Glover, F. \& Kochenberger, G.A. (Eds.), Handbook of Metaheuristics. Norwell, USA: Kluwer Academic Publishers, p. 321-353, 2003.

Montané, F.A.T. \& Galvão, R.D., A tabu search algorithm for the vehicle routing problem with simultaneous pick-up and delivery service. European Journal of Operational Research, 33(3):595-619, 2006.

Or, I., Traveling Salesman-type Combinational Problems and their Relation to the Logistics of Blood Banking. PhD Thesis, Northwestern University, Evanston, USA, 1976.

Osman, I.H., Metastrategy simulated annealing and tabu search algorithms for the vehicle routing problem. Annals of Operations Research, 41(1-4):421-451, 1993.

Penna, P.H.V.; Subramanian, A. \& Ochi, L.S., An iterated local search heuristic for the heterogeneous fleet vehicle routing problem. Journal of Heuristics, 2011(Aceito para publicação).

Pessoa, A.; Uchoa, E. \& de Aragão, M.P., Robust branch-and-cut-and-price algorithms for vehicle routing problems. In: Golden, B.; Raghavan, S. \& Wasil, E. (Eds.), The Vehicle Routing Problem: Latest Advances and New Challenges. New York, USA: Springer, p. 297-325, 2008.

Salhi, S. \& Nagy, G., A cluster insertion heuristic for single and multiple depot vehicle routing problems with backhauling. Journal of the Operational Research Society, 50:1034-1042, 1999.

Silva, M.M.; Subramanian, A.; Vidal, T. \& Ochi, L.S., A simple and effective metaheuristic for the minimum latency problem. European Journal of Operational Research, 221(3):513 - 520, 2012.

Souza, M.J.F.; Coelho, I.M.; Ribas, S.; Santos, H.G. \& Merschmann, L.H.C., A hybrid heuristic algorithm for the open-pit-mining operational planning problem. European Journal of Operational Research, 207(2):1041-1051, 2010a.

Souza, M.J.F.; Mine, M.T.; Silva, M.S.A.; Ochi, L.S. \& Subramanian, A., A hybrid heuristic, based on iterated local search and GENIUS, for the vehicle routing problem with simultaneous pickup and delivery. International Journal of Logistics Systems Management, 10(2):142-156, 2010b.

Subramanian, A., Heuristic, Exact and Hybrid Approaches for Vehicle Routing Problems. Tese de doutorado, Instituto de Computação, Universidade Federal Fluminense, 2012.

Subramanian, A. \& Battarra, M., An iterated local search algorithm for the travelling salesman problem with pickups and deliveries. Journal of the Operational Research Society, 64(3):402-409, 2013.

Subramanian, A.; Drummond, L.M.A.; Bentes, C.; Ochi, L.S. \& Farias, R., A parallel heuristic for the vehicle routing problem with simultaneous pickup and delivery. Computers $\&$ Operations Research, 37(11):1899-1911, 2010.

Taillard, E.D., A heuristic column generation method for heterogeneous fleet. RAIRO, 33(1):1-14, 1999.

Taillard, E.D.; Badeau, P.; Gendreau, M.; Guertin, F. \& Potvin, J.Y., A tabu search heuristic for the vehicle routing problem with soft time windows. Transportation Science, 31(2):170-186, 1997.

Toth, P. \& Vigo, D. (Eds.), The Vehicle Routing Problem. Monographs on Discrete Mathematics and Applications. Philadelphia, USA: SIAM, 2002.

\section{Notas Biográficas}

Anand Subramanian é graduado em Engenharia de Produção Mecânica e mestre em Engenharia de Produção (Universidade Federal da Paraíba - UFPB, 2006 e 2008, respectivamente), e doutor em Computação (Universidade Federal Fluminense - UFF, 2012). Atualmente é professor Adjunto I do departamento de Engenharia de Produção da UFPB e atua nos seguintes temas: otimização combinatória, meta-heurísticas, programação inteira, algoritmos híbridos (Matheuristics), problemas de roteamento de veículos e otimização aplicada à gestão de atividades acadêmicas.

Puca Huachi Vaz Penna é graduado em Ciência da Computação e mestre em Engenharia Mineral (UFOP, 1995 e 2009, respectivamente). Atualmente é doutorando em Computação (UFF) e professor Assistente da UFF, atuando em nos seguintes temas: meta-heurística, roteamento de veículos e sequenciamento em uma máquina.

Luiz Satoru Ochi é graduado em Matemática (Universidade Estadual Paulista Júlio de Mesquita Filho, 1977), mestre em Matemática Aplicada (Universidade Estadual de Campinas, 1981) e doutor em Engenharia de Sistemas e Computação (Universidade Federal do Rio de Janeiro, 1989). Atualmente é pesquisador nível 1D do CNPq e professor Titular do Instituto de Computação da UFF, e atua nos seguintes temas: inteligência computacional, programação meta-heurística, programação matemática, algoritmos paralelos e distribuídos em otimização, grafos e algoritmos, inteligência artificial e pesquisa operacional.

Marcone Jamilson Freitas Souza é graduado em Engenharia Metalúrgica (UFOP, 1982), mestre e doutor em Engenharia de Sistemas e Computação (UFRJ, 1989 e 2000, respectivamente) e tem pós-doutorado (UFF, 2009). Atualmente é bolsista de produtividade em pesquisa do CNPq, na área de Engenharia de Produção e Transportes, e professor Associado III da UFOP, atuando principalmente em meta-heurísticas, planejamento da produção, planejamento de lavra, programação de horários (timetabling), transporte público e roteamento de veículos. 


\title{
Problema de Roteamento de Veículos Multiobjetivo com Coleta Seletiva
}

\author{
Luciana Pereira de Assis,, André Luiz Maravilha Silva, \\ Felipe Campelo Franca Pinto, Alessandro Vivas Andrade e Jaime Arturo Ramírez
}

\begin{abstract}
Resumo: Este capítulo apresenta uma abordagem multiobjetivo para o problema de roteamento de veículos com coleta seletiva, cujos objetivos são a minimização dos custos das rotas e das demandas de coletas não atendidas. Propõe-se uma estrutura de dados que melhor se ajusta ao problema, estruturas de vizinhanças que exploram ambos objetivos do problema e um algoritmo que verifica a viabilidade de uma solução com menor custo computacional. Para solucionar o problema, são discutidas três metaheurísticas: o ILS multiobjetivo (MOILS), NSGA-II e o método $\epsilon$-Restrito, as quais são aplicadas à 14 instâncias contendo entre 50 e 199 consumidores. Os resultados indicam que o MOILS é superior aos outros algoritmos, obtendo valores médios para cobertura, hipervolume e cardinalidade significativamente melhores.
\end{abstract}

Palavras-chave: Problema de roteamento de veículos, Meta-heurística, Otimização multiobjetivo.

\begin{abstract}
This chapter presents a multiobjective approach for the vehicle routing problem with optional collections, whose objectives are the minimization of the route costs and of the not fulfilled collection demands. It proposes a data structure that best suits the problem, neighborhood structures that exploit both goals of the problem and an algorithm that checks the feasibility of a solution with lower computational cost. To solve the problem, three metaheuristics are discussed: the multiobjective iterated local search (MOILS), NSGA-II and the $\epsilon$-Constrained method, which are applied to fourteen instances containing between 50 and 199 customers. The results indicate that the MOILS outperforms the other approaches, obtaining significantly better average values for coverage, hypervolume and cardinality over the set of used test problems.
\end{abstract}

Keywords: Vehicle Routing problem, Metaheuristics, Multiobjective optimization.

\section{Introdução}

O problema de roteamento de veículos (VRP, Vehicle Routing Problem) é um dos mais importantes e mais amplamente estudados no contexto da otimização combinatória, por englobar grande parte dos problemas reais de logística de transporte. Em geral, este problema consiste em definir rotas otimizadas que atendam às demandas de um conjunto de consumidores considerando uma frota finita de veículos capacitados.

Uma vez que existe um custo de transporte associado entre cada par de consumidores, e entre cada consumidor e o depósito, o objetivo do problema é definir rotas de menor custo total. Este problema é caracterizado por uma natureza combinatória, ou seja, o domínio da função a ser otimizada é dada pela permutação ideal de um conjunto de arestas que conectam os pares de consumidores e conectam os consumidores ao depósito. Com o aumento no número de consumidores, torna-se extremamente difícil encontrar soluções ótimas a partir de métodos exatos.

Assim sendo, diversas meta-heurísticas têm sido propostas para solucionar problemas para os quais métodos exatos não são capazes de fornecer soluções em um tempo computacional viável. Dentre estas, destacam-se os métodos baseados em buscas locais, como a Busca Local Iterativa (ILS, Iterated Local Search) (Lourenço et al., 2003), e os métodos baseados em população como os Algoritmos Genéticos (Holland, 1992).

Em alguns problemas de roteamento encontrados na literatura as demandas dos consumidores podem ser tanto de entrega quanto de coleta de mercadorias. O estudo deste fluxo de material está inserido no contexto da logística reversa, que planeja toda a atividade de entrega dos produtos e, também, o caminho inverso, ou

*Autor para contato: lpassis@ufvjm.edu.br 
seja, o retorno dos produtos à central de distribuição. Algumas indústrias estão cada vez mais preocupadas com o gerenciamento do retorno do material consumido para o depósito a fim de reciclá-los, remanufaturá-los ou agregar novos valores aos mesmos.

O problema de roteamento de veículos com coletas e entregas simultânea (VRPSPD, Vehicle Routing Problem with Simultaneous Pickup and Delivery) é um problema básico de logística reversa. O objetivo deste problema é minimizar os custos de transporte, atendendo a todas as demandas de coleta e entrega simultaneamente (Subramanian et al., 2011).

O problema de roteamento de veículos com serviço de coleta e entrega, proposto por Sural \& Bookbinder (2003), ilustra situações onde o atendimento das demandas de coleta não é obrigatório. Este problema, denominado Single-Vehicle Routing Problem with Unrestricted Backhauls, associa um lucro a cada demanda de coleta, caso esta seja atendida. O objetivo consiste em definir um percurso que atenda a todas as demandas de entrega e, também, realize as coletas que forem consideradas lucrativas, minimizando uma função objetivo denominada custo líquido (custo total da rota subtraído do lucro total obtido através das coletas realizadas). Um algoritmo exato (Branch-and-Bound) é aplicado para solucionar instâncias do problema com poucos consumidores. Gutiérrez-Jarpa et al. (2010) apresentam uma abordagem exata (Branch-and-Price) para solucionar problemas de roteamento de veículos com entrega e coleta seletiva e janela de tempo. Outro problema similar é apresentado por Gribkovskaia et al. (2007), denominado Single Vehicle Routing Problem With Delivery and Selective Pickups. Neste problema, os consumidores podem ser visitados duas vezes; uma vez para realização das entregas e outra para coletas. O objetivo do problema também é a minimização do custo líquido.

Apesar da natureza multiobjetivo destes problemas, os trabalhos citados apresentam uma modelagem mono-objetivo e fazem uso de um lucro associado às demandas para diferenciá-las. Contudo, o estudo de problemas de roteamento de veículos com múltiplos objetivos vem apresentando maior destaque nos últimos anos (Jozefowiez et al., 2008), mostrando que em algumas situações reais é necessário visualizar diversos cenários, dados os diversos objetivos do problema, para se tomar uma decisão. Assim sendo, ao modelar problemas de maneira multiobjetivo, estes se tornam mais interessantes para aplicações práticas.

Este capítulo aborda o problema de roteamento de veículos multiobjetivo com coleta seletiva (MOVRPSP, Multiobjective Vehicle Routing Problem with Selective Pickup) cujos objetivos são: minimização dos custos de transporte e minimização das demandas de coletas não atendidas. Esta formulação pode ser vista como uma generalização do VRPSPD, uma vez que a restrição de atendimento de todas as demandas de coleta se transforma em um objetivo do problema.

Para avaliar diferentes estratégias de resolução do MOVRPSP, este trabalho apresenta três algoritmos: Busca Local Iterativa Multiobjetivo (MOILS, Multiobjective Iterated Local Search) (Geiger, 2006), Algoritmo Genético de Ordenação Não-Dominante II (NSGA-II, Non-Dominated Sorting Genetic Algorithm-II) (Deb et al., 2002) e heurística $\mathrm{P}_{\epsilon}$-ILS, baseada no método $\epsilon$-Restrito (Chankong \& Haimes, 1983). Estes algoritmos exploram as características dos algoritmos baseados em busca local, em população e nos métodos tradicionais de resolução de problemas multiobjetivo, respectivamente.

Este capítulo está organizado como se segue. A Seção 2 apresenta a definição do problema e sua modelagem matemática multiobjetivo. Em seguida, na Seção 3, as estruturas de dados e os algoritmos aplicados na resolução do problema são apresentados. Os resultados computacionais são mostrados na Seção 4 e, por fim, na Seção 5 são feitas as conclusões deste trabalho.

\section{Definição do Problema}

O problema de roteamento de veículos multiobjetivo com coleta seletiva (MOVRPSP) consiste em definir um conjunto de rotas que atenda a todas as demandas de entrega, minimizando os custos de transporte e o número de coletas não realizadas. Cada consumidor deve ser visitado uma única vez e o atendimento parcial das demandas não é permitido.

Os dois objetivos a serem otimizados são conflitantes, ou seja, melhorias em um provocam degradações no outro, não existindo uma solução que seja ótima para ambos os objetivos simultaneamente. Assim, não é uma tarefa trivial identificar se uma determinada solução é de melhor qualidade em relação a outra. Isto leva ao conceito de dominância de Pareto (Definição 1), sendo a solução do problema um conjunto de soluções não dominadas. Neste trabalho existe uma diferença entre um conjunto de soluções não dominadas e um conjunto Pareto-ótimo. Um conjunto de soluções não dominadas é definido no contexto de uma amostra do espaço de busca, enquanto que o conjunto ótimo de Pareto é definido em relação a todo o espaço de busca (Definições 2 e 3$)$.

Definição 1 (Dominância de Pareto) Dado um vetor objetivo $Z(x)=\left(f_{1}(x), \ldots, f_{m}(x)\right)$, com $m$ funções objetivo para minimização. Uma solução $x^{\prime}$ domina uma outra solução $x^{\prime \prime}$ se, e somente se, para todos os 
objetivos $f_{i}\left(x^{\prime}\right) \leq f_{i}\left(x^{\prime \prime}\right)$ com $i=1, \ldots, m$ e, existe pelo menos um objetivo $f_{i}\left(x^{\prime}\right)<f_{i}\left(x^{\prime \prime}\right)$. Esta relação de dominância é representada pela notação $x^{\prime} \prec x^{\prime \prime}$ (Coello Coello et al., 2007).

Definição 2 (Solução Pareto-Ótima) $x^{*}$ é uma solução Pareto-Ótima se não existe qualquer outra solução $x$ tal que $x \prec x^{*}$, ou seja, $x^{*}$ não é dominada por nenhuma outra solução (Coello Coello et al., 2007).

Definição 3 (Conjunto Pareto-Ótimo) O conjunto $\mathcal{X}^{*}$ é um conjunto Pareto-Ótimo se é composto por todas as soluções Pareto-Ótimas. O conjunto-imagem $\mathcal{Y}^{*}$ associado ao conjunto Pareto-Ótimo é denominado fronteira Pareto-Ótima (Coello Coello et al., 2007).

\subsection{Modelagem matemática}

A modelagem matemática apresentada nesta seção é uma adaptação da modelagem proposta por Montané \& Galvão (2006) para o VRPSPD.

Seja $V=\{1 \ldots n\}$ o conjunto de consumidores e $V_{0}$ o conjunto de consumidores mais o depósito $\left(V_{0}=\right.$ $V \cup\{0\})$. Um custo $c_{i j} \geq 0$ é associado a cada arco que conecta os pares de consumidores e os consumidores ao depósito. As demandas de coleta e entrega do consumidor $j$ são representadas por $p_{j}$ e $d_{j}$, respectivamente. O número de veículos disponíveis é dado por $\bar{k}$, sendo $Q$ a capacidade destes. O parâmetro $y_{i j}$ é o somatório das cargas coletadas entre o depósito e o nó $i$ (inclusive) dirigida ao nó $j \in V_{0}$. Já $z_{i j}$ é o somatório das demandas de entrega dos consumidores visitados após o nó $i$ (exclusive) e dirigida ao nó $j \in V_{0}$. A variável de decisão binária $x_{i j}^{k}$ assume valor 1 se a $\operatorname{aresta}(i, j)$ é transposta pelo veículo $k$ e 0 , caso contrário. A variável de decisão binária $\ell_{j}$ recebe valor unitário se a demanda de coleta do consumidor $j$ é satisfeita e 0 , caso contrário.

O modelo matemático pode ser expresso por:

$$
\operatorname{Minimize}\left\{\begin{array}{l}
\sum_{k=1}^{\bar{k}} \sum_{i=0}^{n} \sum_{j=0}^{n} c_{i j} x_{i j}^{k} \\
\sum_{j=1}^{n} p_{j}\left(1-\ell_{j}\right)
\end{array}\right.
$$

Sujeito a:

$$
\begin{array}{ll}
\sum_{i=0}^{n} \sum_{k=1}^{\bar{k}} x_{i j}^{k}=1, & j=1, \ldots, n \\
\sum_{i=0}^{n} x_{i j}^{k}-\sum_{i=0}^{n} x_{j i}^{k}=0, & j=0, \ldots, n \text { e } k=0, \ldots \bar{k} \\
\sum_{j=1}^{n} x_{0 j}^{k} \leq 1, & k=1, \ldots, \bar{k} \\
\sum_{i=0}^{n} z_{i j}-\sum_{i=0}^{n} z_{j i}=d_{j}, & \forall j \neq 0 \\
\sum_{i=0}^{n} y_{i j}-\sum_{i=0}^{n} y_{j i}=p_{j} \ell_{j}, & \forall j \neq 0 \\
y_{i j}+z_{i j} \leq Q \sum_{k=1}^{k} x_{i j}^{k}, & \\
x_{i j}, \ell_{j} \in\{0,1\}, & i, j=0, \ldots, n \\
y_{i j}, z_{i j} \geq 0, & i, j=0, \ldots, n
\end{array}
$$

As duas funções objetivo, dadas na Equação (1), representam o custo total das rotas e as coletas não realizadas, ambas devem ser minimizadas.

Estas funções objetivo devem satisfazer algumas restrições. Cada ponto de demanda deve ser visitado por um único veículo (Equação (2)). A Equação (3) representa a restrição de conservação do fluxo. A Equação (4) indica que $\bar{k}$ veículos, no máximo, podem ser utilizados. A Equação (5) obriga a satisfação de todas as demandas de entrega. A Equação (6) garante o atendimento da demanda de coleta do consumidor $j$ quando a variável de decisão $\ell_{j}$ assumir valor unitário. A Equação (7) define que as demandas devem ser transportadas 
nos arcos incluídos na solução e ainda impõem um limite para a carga total transportada pelo veículo. A Equação (8) representa a restrição de integralidade e, finalmente, a Equação (9) representa as restrições de não-negatividade para demandas de coleta e entrega.

\section{Estratégias de Solução}

Nesta seção serão apresentadas as ferramentas e métodos utilizados para resolução de problemas de roteamento de veículos multiobjetivo com coleta seletiva.

\subsection{Estrutura de dados}

A maneira como os dados de entrada de um problema são armazenados interferem diretamente na eficiência dos algoritmos implementados. Os problemas de roteamento de veículos podem ser representados através de um grafo completo, onde os consumidores e o depósito compõem o conjunto de vértices e as arestas representam as conexões entre consumidores e entre consumidores e depósito. Existem diversas formas de representar um grafo e este capítulo apresenta uma nova estrutura a fim de unir as vantagens de duas estruturas bem tradicionais: matriz de adjacência e lista de adjacência.

Para a nova estrutura, foi implementada uma matriz de adjacência, onde cada elemento $(i, j)$ da matriz é uma célula de uma lista duplamente encadeada composta por: vértice adjacente a $i$, o custo da aresta $(i, j)$ e dois ponteiros. Partindo da diagonal principal da matriz, os ponteiros criam uma lista duplamente encadeada, sendo que os ponteiros da direita e esquerda ordenam crescente e decrescente, respectivamente, os vértices adjacentes a $i$ pelo custo da aresta $(i, j)$. A Figura 1 ilustra como os dados são mantidos na estrutura de dados proposta. Nesta Figura foi representado apenas um dos ponteiros para facilitar a visualização. A matriz, à direita, apresenta os vértices e, entre parênteses, os custos das arestas.
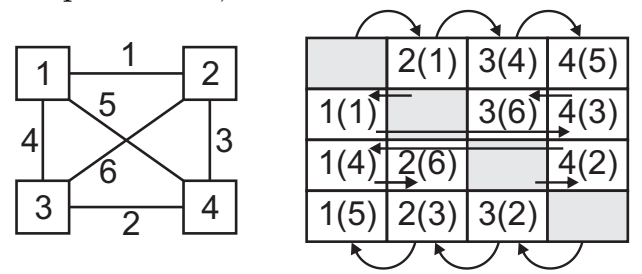

Figura 1. Nova estrutura de dados para armazenar um grafo.

\subsection{Representação de uma solução}

A representação de uma solução para problemas de roteamento de veículos pode ser feita através de um conjunto de vetores, cada um indicando uma rota e armazenando os consumidores na ordem em que devem ser visitados.

Porém, nos problemas de roteamento multiobjetivo com coleta seletiva, além da ordem em que os consumidores são visitados, deve-se armazenar quais demandas de coleta serão atendidas. Para isso, utilizase um vetor binário informando, para cada consumidor, o estado de sua demanda de coleta, atendida ou não atendida. A Figura 2 apresenta uma solução para o problema de roteamento de veículos multiobjetivo com coleta seletiva. Nessa ilustração, os dois primeiros vetores mostram as rotas que compõem a solução, indicando a ordem em que os consumidores devem ser visitados, sempre começando e terminado no depósito, representado pelo número 0. O último vetor informa o estado da demanda de coleta de cada consumidor, sendo representada pelo valor 1 , demanda de coleta atendida, ou 0 , demanda de coleta não atendida.

\subsection{Análise da viabilidade das rotas}

Durante a construção, ou na alteração de uma solução de um problema de roteamento de veículos com serviços de coleta e entrega de mercadorias, é necessário verificar se o atendimento de uma demanda não extrapola a capacidade máxima do veículo.

Uma implementação simples para este procedimento pode ser feita calculando-se a carga do veículo após o atendimento de cada demanda dos consumidores da rota modificada, verificando, assim, se a capacidade do veículo não será extrapolada com a inserção das demandas de entrega e coleta do novo consumidor. Apesar de sua fácil implementação, o desempenho do algoritmo para geração de rotas válidas pode ser prejudicado, já que este processo tem complexidade $O(l)$, sendo $l$ o comprimento da rota.

Como a avaliação da viabilidade é realizada inúmeras vezes, qualquer aperfeiçoamento realizado melhora o desempenho dos algoritmos que o utilizam. Assim, é proposto o armazenamento de algumas informações 


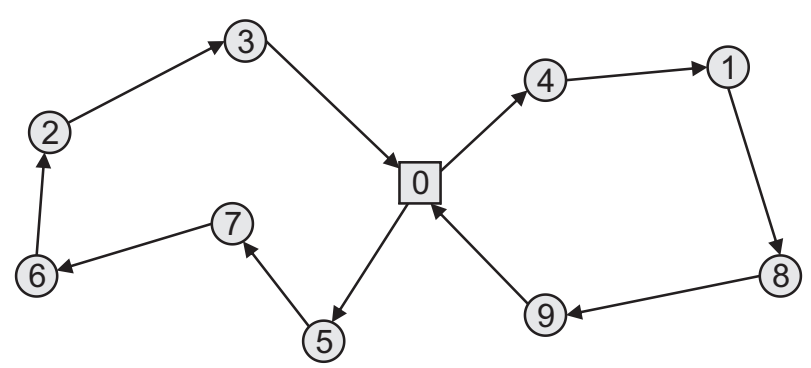

Rota 1: [0-4-1-8-9-0] - Rota 2: [0-5-7-6-2-3-0]

Estado Coleta: [1-1-0-1-0-0-1-1-1]

Figura 2. Representação de uma solução para o problema de roteamento de veículos multiobjetivo com coleta seletiva.

adicionais sobre a carga do veículo ao longo da rota, tornando mais eficiente esta análise de viabilidade. O Algoritmo 1 apresenta o pseudo-código do procedimento proposto para análise de viabilidade das rotas.

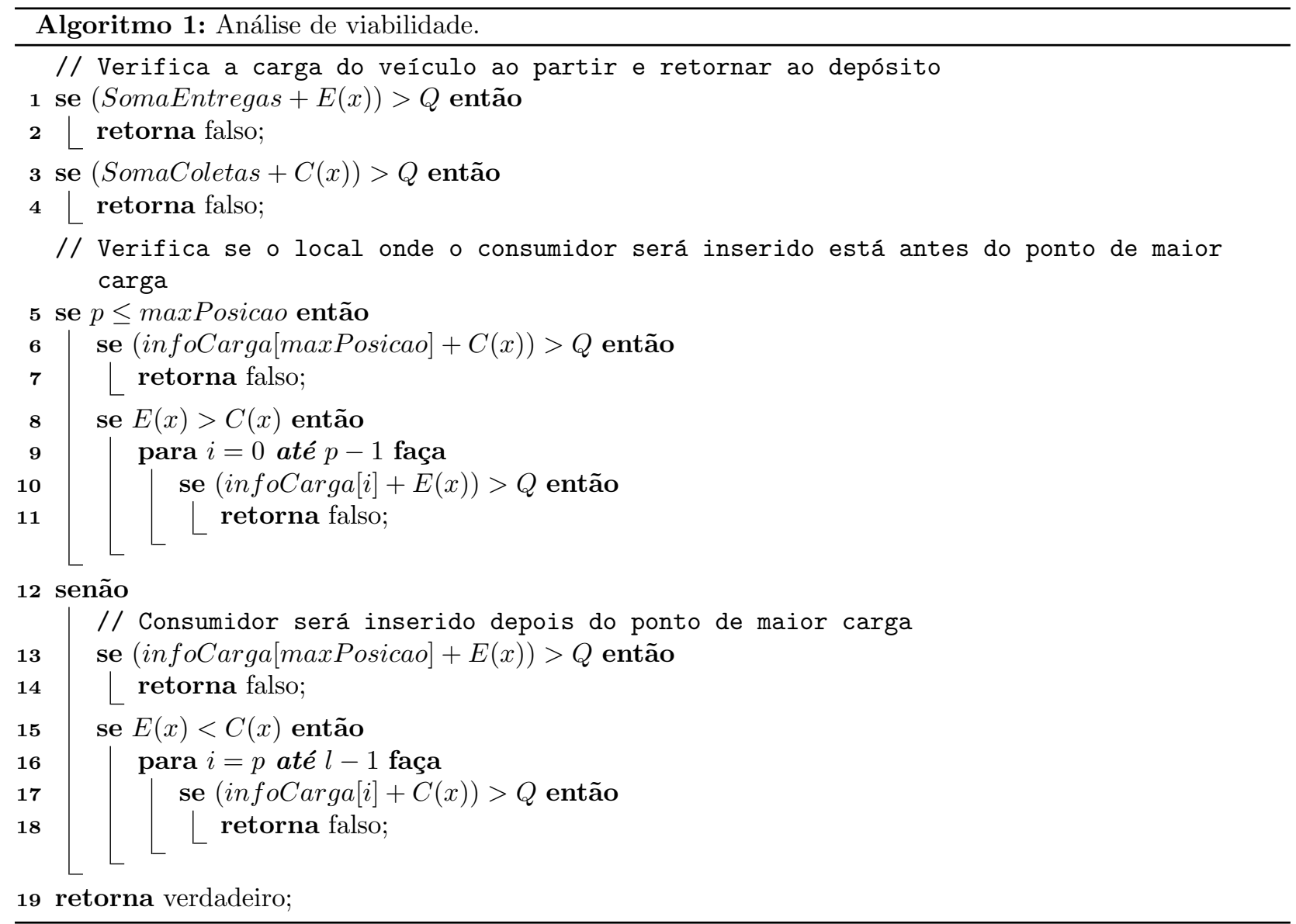

Sejam $E(x)$ e $C(x)$ as demandas de entrega e coleta do consumidor $x$, respectivamente. O Algoritmo 1 analisa, inicialmente, se a carga do veículo não extrapola a capacidade máxima $(Q)$, quando o veículo parte do depósito e quando ele retorna ao depósito (linhas 2-7). Em seguida, verifica se a posição onde o veículo apresenta maior carga está antes ou depois da posição $p$ que se deseja inserir o consumidor $x$ (linha 9).

Caso o consumidor seja inserido antes da posição na qual o veículo atinge o ponto de maior carga ( $\max$ Posicao), então a carga máxima do veículo será acrescida apenas da demanda de coleta do consumidor. O vetor infoCarga armazena a carga presente no veículo em cada posição da rota (linhas 6-7). A Figura reffig:viabilidade11.a exemplifica uma rota na qual o depósito está representado por um quadrado, os consumidores representados por circunferências, as demandas de entrega e coleta de cada consumidor representadas entre parênteses, respectivamente. O valor nas arestas indica a carga presente no veículo 
(infoCarga), sendo a carga máxima do veículo destacada em negrito. Na Figura 3.b, pretende-se inserir um vértice (6) antes do ponto no qual o veículo atinge sua carga máxima (9). Na situação ilustrada, a carga máxima do veículo será acrescida apenas da demanda de coleta do consumidor $6, C(6)=4$.

Se a carga máxima do veículo acrescido da demanda de coleta do consumidor inserido for maior que a capacidade do veículo, então o consumidor $x$ não pode ser inserido na posição $p$ (linhas 6-7). Caso contrário, o algoritmo verifica se a demanda de entrega $E(x)$ é menor que a demanda de coleta $C(x)$ (linhas 8-11). Desta maneira, garante-se que a carga máxima do veículo permanecerá na mesma aresta e, assim, a inserção no consumidor não inviabiliza a solução. Senão, torna-se necessário verificar a carga do veículo no trajeto entre o depósito e o vértice inserido, pois a carga máxima do veículo pode agora estar neste intervalo.

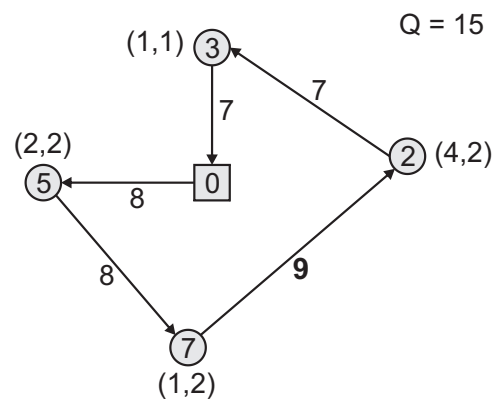

(a) Solução Inicial.

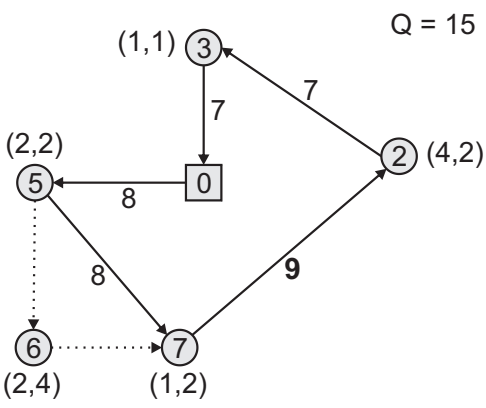

(b) Inserção de um novo vértice (6).

Figura 3. Análise de viabilidade.

Quando o ponto de inserção $p$ estiver após o ponto de maior carga, o procedimento é análogo (linhas 12-18). No fim, se o veículo não extrapola sua capacidade máxima, então é retornado verdadeiro, indicando que a inserção do consumidor na posição $p$ é viável (linha 19).

Neste procedimento, quando $p \leq$ maxPosicao e $E(x) \leq C(x)$ ou $p>$ maxPosicao e $C(x) \leq E(x)$, tem-se o melhor caso, com complexidade $O(1)$, pois ele não executa nenhum bloco de repetição. Apenas no pior caso o Algoritmo 1 apresenta complexidade $O(l)$.

O pior caso ocorre em duas situações: (i) quando se trata da inserção de um consumidor $x$ imediatamente anterior à posição de maior carga, a posição de maior carga ocorre no final da rota e a demanda de entrega do consumidor $x$ é maior que a demanda de coleta $x$; (ii) quando ocorre a inserção de um consumidor $x$ logo após a posição de maior carga e a posição de maior carga ocorre no início da rota, e a demanda de coleta do consumidor $x$ é maior que a demanda de coleta de $x$. Em ambos casos, as linhas 9-11 ou 16-18 serão executadas aproximadamente $l$ vezes.

\subsection{Busca local iterativa multiobjetivo (MOILS)}

A meta-heurística busca local iterativa (ILS, Iterated Local Search) consiste em aprimorar o procedimento de busca local gerando novas soluções de partidas através de mecanismos de perturbações aplicados à solução ótima local (Lourenço et al., 2003).

Ao se tratar de problemas de roteamento de veículos mono-objetivo com serviços de coleta e entrega, heurísticas baseadas no ILS apresentam bons resultados, sem a necessidade de ajuste de muitos parâmetros (Subramanian et al., 2010). Além disso, adaptações desta meta-heurística, quando utilizadas para resolução de outros problemas de otimização combinatória multiobjetivo, também apresentam bons resultados (Geiger, 2006). Assim, este capítulo irá apresentar uma heurística baseada na meta-heurística ILS para resolução de problemas multiobjetivo utilizando o conceito de Dominância de Pareto, possibilitando, assim, a resolução de problemas de otimização combinatória multiobjetivo, em especial o MOVRPSP. À adaptação proposta é dado o nome de busca local iterativa multiobjetivo (MOILS, Multiobjective Iterated Local Search).

O algoritmo proposto possui 5 etapas: (i) geração de uma solução inicial; (ii) seleção de uma solução da fronteira de Pareto aproximada para ser explorada; (iii) busca local, que retorna uma solução melhorada; (iv) perturbação, que modifica uma solução; e (v) atualização da fronteira de Pareto aproximada dada uma solução para o problema.

O funcionamento desta heurística é ilustrado no Algoritmo 2. O MOILS inicia seu funcionamento com a geração de soluções iniciais (linha 1). As soluções geradas são inseridas no conjunto Front que mantém um conjunto de soluções não dominadas. Em seguida, são executados maxIter iterações, onde uma solução em Front é selecionada e o bloco de repetição principal do algoritmo (linhas 6-15) é executado. Neste bloco, as etapas de perturbação (linha 7) e busca local (linha 8), semelhantes ao ILS, são aplicadas à solução escolhida. 
Dada a solução gerada, o conjunto Front é atualizado (linha 9). Se a solução gerada após a perturbação e busca local for inserida em Front (indicada pela variável lógica inserido), então cont é reiniciado (linha 11); senão cont é incrementado de uma unidade (linha 14). O parâmetro maxCount representa o número máximo de vezes que uma solução será explorada sem a inserção de uma solução não dominada no conjunto Front.

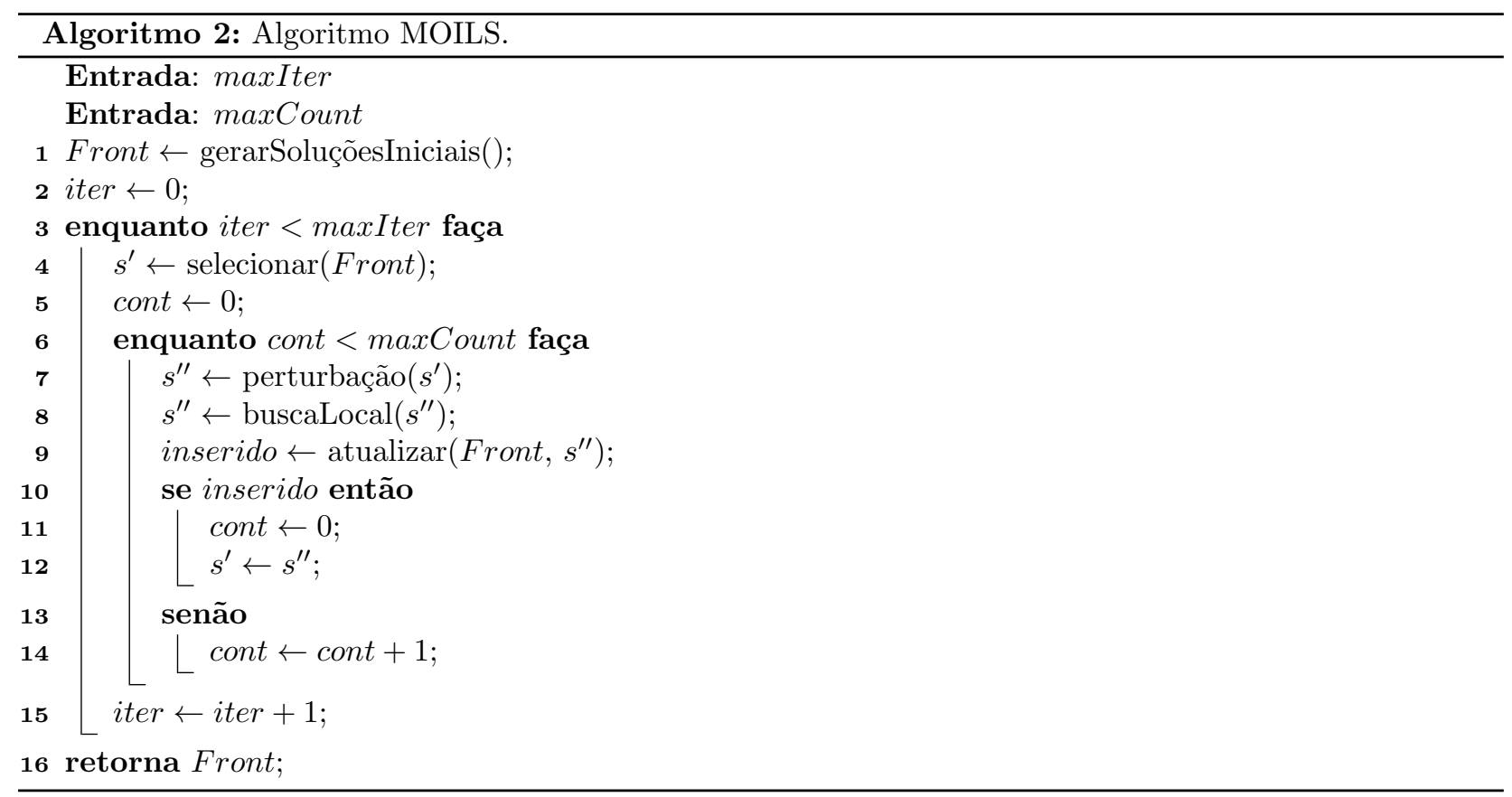

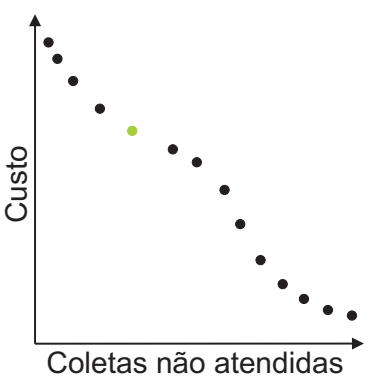

(a) Seleção.

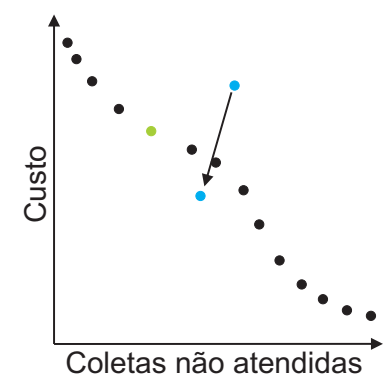

(c) Busca Local.

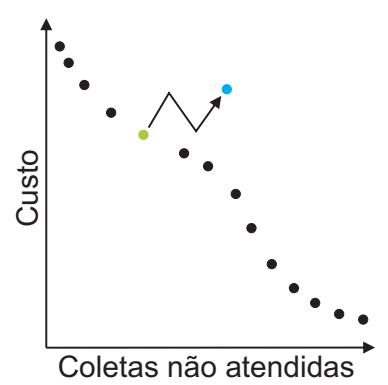

(b) Perturbação.

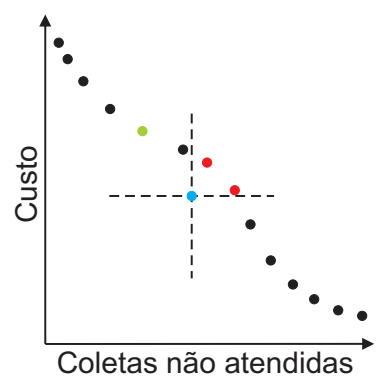

(d) Atualização.

Figura 4. Etapas do algoritmo MOILS.

A Figura 4 ilustra as etapas do algoritmo MOILS. Na Figura 4.a, uma solução contida na fronteira de Pareto aproximada é selecionada. Nas Figuras 4.b e 4.c, esta solução passa pelos procedimentos de perturbação e busca local, respectivamente. Por fim, a fronteira é atualizada com a nova solução gerada, Figura 4.d.

Os procedimentos de geração da solução inicial, seleção, busca local, perturbação e atualização são detalhados nas subseções seguintes. 


\subsubsection{Solução inicial}

A solução inicial para o MOVRPSP consiste em encontrar uma solução para o problema de roteamento de veículos com coleta e entrega simultânea (VRPSPD) e para o problema de roteamento de veículo capacitado (CVRP, Capacitated Vehicle Routing Problem), sendo estas soluções extremos da fronteira de Pareto aproximada. A solução para ambos problemas é obtida aplicando o algoritmo baseado no ILS, proposto por Penna et al. (2012). Assim sendo, o ILS é executado duas vezes, sendo uma para solucionar o VRPSPD, no qual todas as demandas de coleta do problema são consideradas e outra para solucionar o CVRP, desconsiderando as demandas de coleta dos consumidores.

As soluções encontradas representam os pontos extremos da fronteira de Pareto aproximada, conforme Figura 5. Uma vez encontrados os extremos e sendo estes de boa qualidade, os demais passos do algoritmo consistem em encontrar as soluções contidas no intervalo entre os dois pontos extremos já definidos.

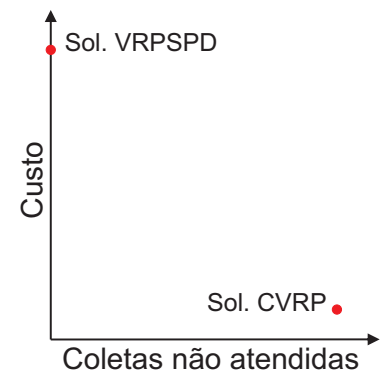

Figura 5. Pontos extremos da fronteira de Pareto aproximada.

\subsubsection{Seleção}

O procedimento de seleção utilizado é baseado na crowding-distance do algoritmo NSGA-II, proposto por Deb et al. (2002). Quanto mais distante das outras soluções uma determinada solução estiver, maior a probabilidade desta ser escolhida. Assim, é possível realizar a exploração do espaço de soluções de forma mais inteligente, onde é dado prioridade a regiões pouco exploradas, evitando a concentração da busca em determinados nichos.

Neste trabalho, o cálculo da crowding-distance é um pouco diferente do realizado no NSGA-II. No MOILS as soluções presentes nos extremos da fronteira têm a crowding-distance igual a duas vezes a distância entre elas e a solução mais próxima, enquanto no NSGA-II, as soluções presentes nas extremidades da fronteira recebem um valor infinito. Esta alteração é necessária já que após a geração das soluções iniciais, a fronteira é composta apenas pelas duas soluções que se encontram nas extremidades da fronteira (solução do CVRP e solução do VRPSPD). Assim, para reduzir a possibilidade de serem demasiadamente selecionadas durante todo o procedimento, o valor da crowding-distance dessas soluções precisa ser reduzido.

\subsubsection{Busca Local}

A etapa de busca local realiza a exploração da vizinhança de uma solução com o objetivo de encontrar outras soluções não dominadas para o problema. No algoritmo apresentado, foi utilizado o método busca em descida em vizinhança variável aleatória (RVND, Randomized Variable Neighborhood Descent), proposta por Penna et al. (2012), que explora uma solução aplicando aleatoriamente diferentes estruturas de vizinhanças.

Neste trabalho, foram utilizadas um conjunto de estruturas de vizinhanças que podem ser divididas em dois grupo: inter-rotas e intra-rota. As estruturas de vizinhança inter-rotas são aquelas que envolvem duas ou mais rotas no movimento. Já as intra-rotas envolvem apenas uma única rota. A busca realizada em todas as estruturas de vizinhança foi baseada na estratégia melhor aprimorante que avalia todas as soluções vizinhas antes do movimento ser aplicado. As Subseções 3.4.3.1 e 3.4.3.2 descrevem estas estruturas.

\subsubsection{Estruturas de vizinhança inter-rotas}

Foram implementadas dois tipos de estruturas de vizinhança inter-rotas: que exploram soluções levando em consideração apenas o objetivo custo de transporte e outras que consideram, além do custo de transporte, o objetivo de minimização das demandas de coleta não atendidas.

As seguintes buscas locais visam a redução do custo de transporte e podem ser aplicadas a diversos problemas de roteamento mono-objetivo.

- Shift(1,0): um consumidor é transferido de uma rota para outra rota. Na Figura 6.b, o consumidor 5 é removido de sua rota e inserido em outra rota. 
- Shift(2,0): dois consumidores adjacentes são transferidos de uma rota para outra rota, continuando adjacentes, mas não necessariamente na mesma ordem. Na Figura 6.c, os consumidores 5 e 6 são removidos e inseridos em outra rota.

- $\boldsymbol{S w a p}(\mathbf{1 , 1 )}$ : permutação entre dois consumidores de duas rotas distintas. Na Figura 6.d, os consumidores 3 e 5 são permutados.

- $\boldsymbol{S w a p}(2,1)$ : permutação de dois consumidores adjacentes de uma rota com um consumidor de outra rota. Os dois consumidores adjacentes removidos devem permanecer adjacentes quando inseridos na outra rota, porém não necessariamente na mesma ordem. Na Figura 6.e, o consumidor 3 é trocado com os consumidores 4 e 5 .

- $\boldsymbol{S w a p}(\mathbf{2 , 2 ) :}$ permutação de dois consumidores adjacentes de uma rota com outros dois consumidores, também adjacentes, de outra rota. Assim como na Swap(2,1), os consumidores adjacentes devem permanecer adjacentes mas não necessariamente na mesma ordem. Na Figura 6.f, os consumidores 4 e 5 são trocados com os consumidores 2 e 3.

- Crossover: uma aresta $(i, j)$ de uma rota $r_{1}$ e outra aresta $\left(i^{\prime}, j^{\prime}\right)$ de uma rota $r_{2}$ são removidas. Em seguida as arestas $\left(i, j^{\prime}\right)$ e $\left(i^{\prime}, j\right)$ são inseridas. Na Figura 6.g, as arestas $(3,0)$ e $(5,6)$ são removidas e as arestas $(3,6)$ e $(5,0)$ são inseridas.

- TryEmptyRoute: remove os consumidores de uma determinada rota e tenta reinseri-los nas demais rotas pertencentes à solução a fim e reduzir o número de veículos utilizados na solução.

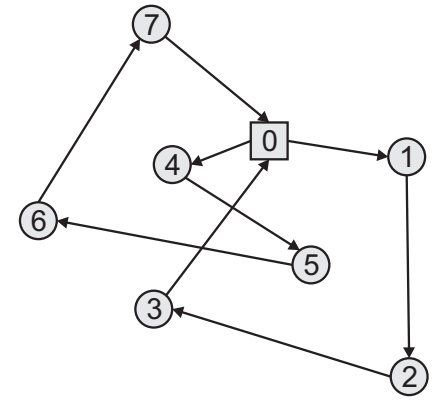

(a) Solução original.

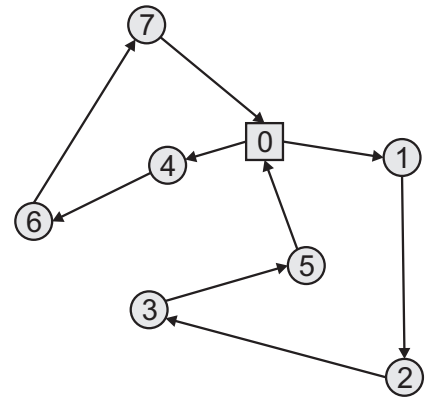

(b) Shift $(1,0)$

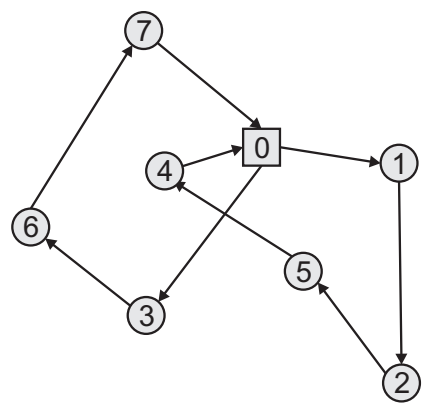

(e) $\operatorname{Swap}(2,1)$.

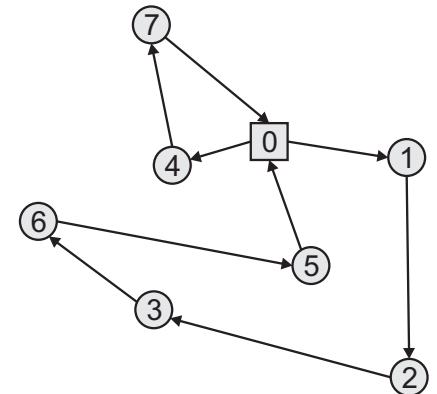

(c) Shift $(2,0)$.

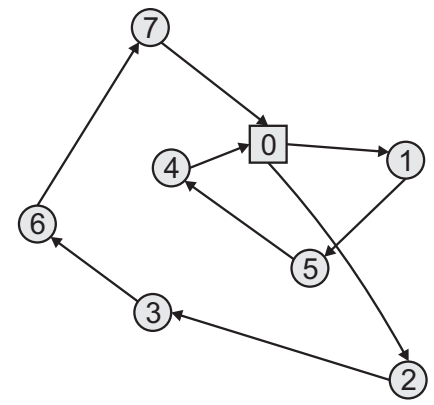

(f) $\operatorname{Swap}(2,2$.

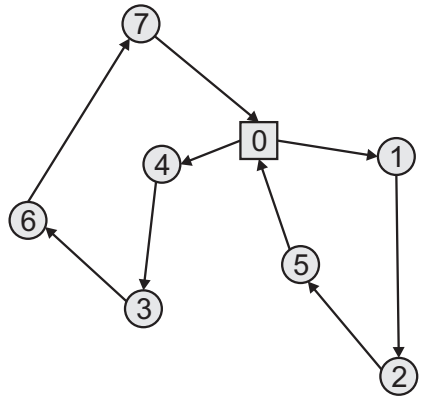

(d) $\operatorname{Swap}(1,1)$.

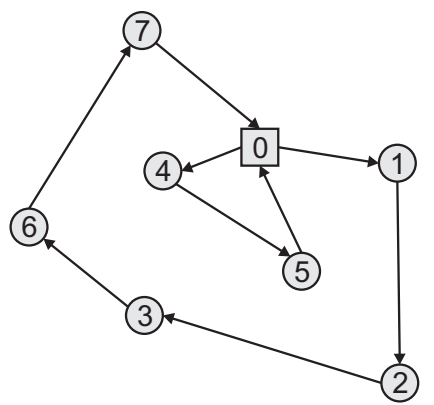

(g) Crossover.

Figura 6. Estruturas de vizinhança inter-rotas. 
Devido à natureza multiobjetivo do MOVRPSP, proposto neste trabalho, faz-se necessária a utilização de estruturas de vizinhança que atuem nos outros objetivos e não apenas no custo de transporte. Este capítulo apresenta duas estruturas inter-rotas que atuam tanto na redução do custo de transporte quanto na minimização das demandas de coletas não atendidas. O objetivo é melhorar a diversidade das soluções e aproximá-las da fronteira de Pareto ótima.

Estas estruturas de vizinhanças são adaptações da $\operatorname{Shift}(1,0)$ e $\operatorname{Swap}(1,1)$, descritas anteriormente. O procedimento é similar, modificando apenas o estado da demanda de coleta (satisfeita ou não satisfeita) dos consumidores envolvidos no movimento. Assim, ao invés de retornar uma única solução, retornarão um conjunto de soluções não dominadas.

- MOShift(1,0): um consumidor é transferido de uma rota para outra rota. A transferência é feita considerando o estado de coleta atual do consumidor e, em seguida, a busca local é aplicada novamente alterando o estado de coleta do consumidor envolvido no movimento. Logo, para cada consumidor pertencente à solução, duas soluções vizinhas são encontradas.

- $\operatorname{MOSwap}(\mathbf{1}, \mathbf{1})$ : permutação entre dois consumidores de duas rotas distintas. A permutação é feita considerando os estados atuais das demandas de coleta dos consumidores e alternando estes estados. Logo, para cada consumidor pertencente à solução, quatro novas soluções vizinhas são geradas: uma considerando os estados atuais das demandas de coleta de ambos consumidores, a segunda alterando o estado da demanda de coleta de um dos consumidores, a terceira alterando o estado do outro consumidor e, por fim, alterando os estados das demandas de coletas dos dois consumidores envolvidos no movimento.

A Figura 7 exemplifica os movimentos MOShift(1,0) e MOSwap(1,1). Nesta figura, o valor nas arestas representa a carga do veículo naquele ponto e os valores entre parênteses indicam a demanda de entrega e coleta de cada consumidor, respectivamente. As Figuras 7.b e 7.c mostram as duas possíveis soluções retornadas pela estrutura de vizinhança MOShift(1,0). Na Figura 7.b, o consumidor 3 é realocado em outra rota desconsiderando a sua demanda de coleta e, na Figura 7.c, o consumidor 3 é realocado considerando o atendimento desta demanda. As Figuras 7.d, 7.e, 7.f e 7.g representam as quatro soluções geradas pela estrutura de vizinhança $M O S w a p(1,1)$. Na Figura 7.d, os consumidores 3 e 5 são permutados desconsiderando a demanda de coleta de ambos. Na Figura 7.e, estes mesmos consumidores são permutados desconsiderando a demanda de coleta do consumidor 3 e, na Figura 7.f, desconsiderando a demanda de coleta do consumidor 5. Na Figura 7.g, estes consumidores são permutados considerando o atendimento da demandas de coleta de ambos. Nas duas estruturas de vizinhança, dadas as soluções geradas, apenas as soluções não dominadas são retornadas.

Para evitar que movimentos inter-rota sejam executados desnecessariamente, uma estrutura de dados auxiliar, proposta por Penna et al. (2012), foi utilizada indicando se uma determinada busca local poderá ser aplicada à uma rota específica. Se, em uma iteração anterior, a estrutura de vizinhança $i$ foi aplicada à rota $j$ e não houve nenhuma melhoria da solução, então a estrutura de vizinhança $i$ fica desabilitada para a rota $j$ até que esta rota sofra alguma modificação.

\subsubsection{Estruturas de vizinhança intra-rota.}

Um dos objetivos das estruturas de vizinhança intra-rota é reduzir os custos de transporte das rotas. Assim, quando as estruturas de vizinhança inter-rotas não puderem gerar soluções na fronteira de Pareto aproximada, aplica-se, então, as estruturas de vizinhança intra-rota a fim de reduzir ainda mais os custos de transporte. As estruturas de vizinhança intra-rota implementadas são descritas a seguir.

- Or-Opt: um consumidor é inserido em outra posição da mesma rota. Na Figura 8.b, o consumidor 5 é alterado de posição.

- $\boldsymbol{O r - O p t ~ 2 : ~ d o i s ~ c o n s u m i d o r e s ~ a d j a c e n t e s ~ s a ̃ o ~ r e m o v i d o s ~ e ~ i n s e r i d o s ~ e m ~ o u t r a ~ p o s i c ̧ a ̃ o ~ d a ~ m e s m a ~ r o t a . ~}$ Na Figura 8.c, os consumidores 4 e 5 são removidos e inseridos em outra posição.

- $\boldsymbol{O r}$ - $\boldsymbol{O p t ~ 3 : ~ t r e ̂ s ~ c o n s u m i d o r e s ~ a d j a c e n t e s ~ s a ̃ o ~ r e m o v i d o s ~ e ~ i n s e r i d o s ~ e m ~ o u t r a ~ p o s i c ̧ a ̃ o ~ d a ~ m e s m a ~ r o t a . ~}$ Na Figura 8.d, os consumidores adjacentes 2, 3 e 4 são removidos e inseridos em outra posição.

- 2- $\boldsymbol{O p} \boldsymbol{t}$ : duas arestas $(i, j)$ e $\left(i^{\prime}, j^{\prime}\right)$ não consecutivas da mesma rota são removidas. Em seguida as arestas $\left(i, i^{\prime}\right)$ e $\left(j, j^{\prime}\right)$ são inseridas. Na Figura 8.e, as arestas $(3,4)$ e $(5,6)$ são removidas e as arestas $(3,5)$ e $(4,6)$ são inseridas.

- Exchange: realiza a permutação entre dois consumidores de uma mesma rota. Na Figura 8.f, os consumidores 3 e 6 são permutados. 


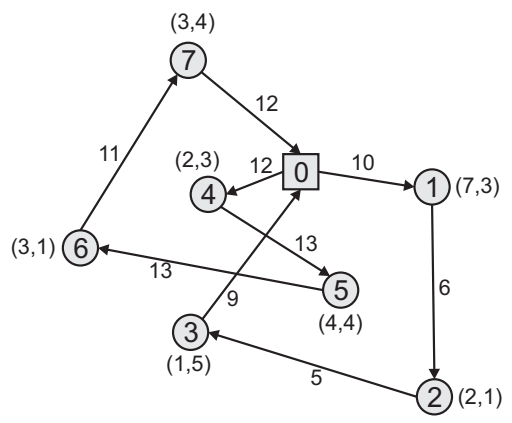

(a) Solução original.

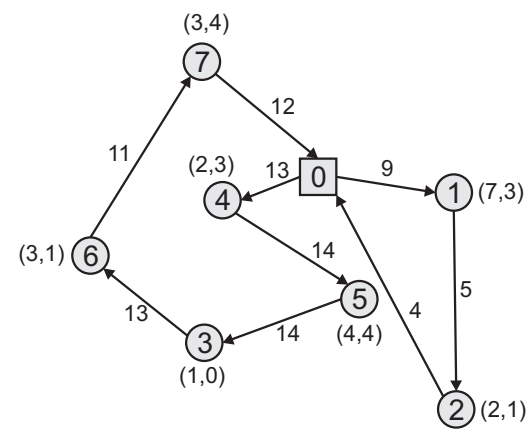

(b) MOShift $(1,0) \quad$ Solução 1.

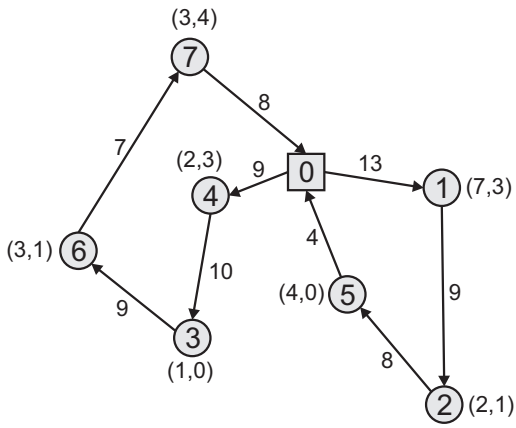

(d) $\operatorname{MOSwap}(1,1) \quad$ Solução 1 .

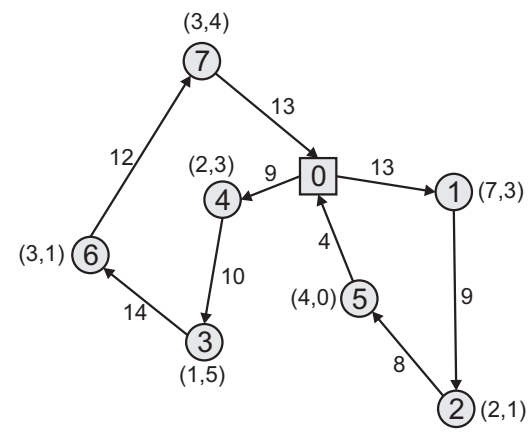

(f) $\operatorname{MOSwap}(1,1) \quad$ Solução 3 .

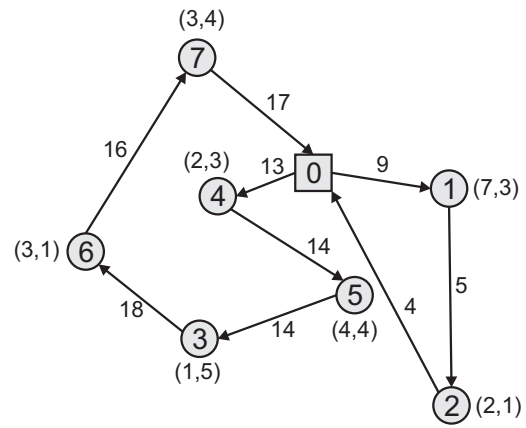

(c) MOShift $(1,0) \quad$ Solução 2 .

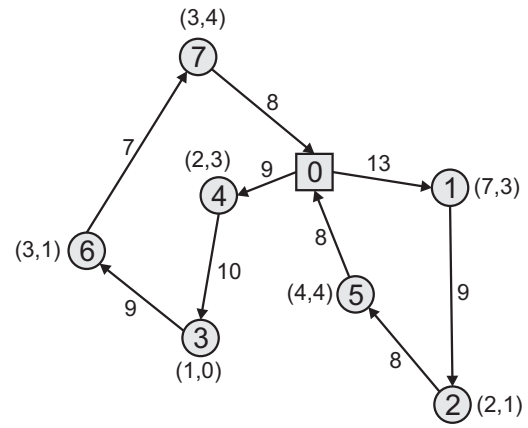

(e) $\operatorname{MOSwap}(1,1) \quad$ Solução 2 .

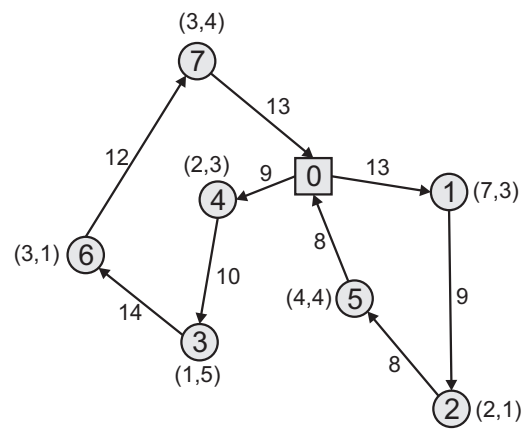

(g) $\operatorname{MOSwap}(1,1) \quad$ Solução 4 .

Figura 7. Estruturas de vizinhança inter-rotas.

- Reverse: inverte a direção da rota visando reduzir a carga máxima no veículo. Na Figura 8.g, todas as arestas têm a direção alterada, invertendo o sentido da rota.

Para reduzir o número de demandas de coleta não atendidas, foi criada uma estrutura de vizinhança denominada Adiciona Coleta. Esta estrutura verifica se a demanda de coleta de cada consumidor pode ser satisfeita sem extrapolar a capacidade do veículo, dada a demanda de coleta deste consumidor. Desta forma, o consumidor não precisará ser realocado em outra posição ou rota. 


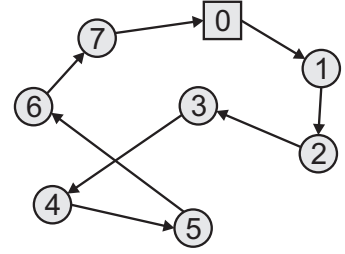

(a) Solução original.

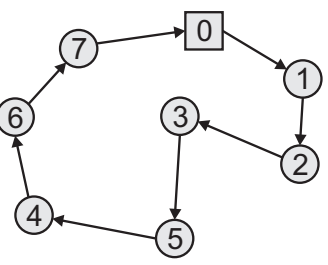

(b) Or-Opt.

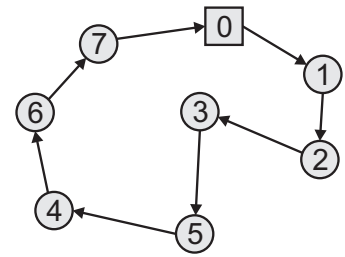

(e) 2-Opt

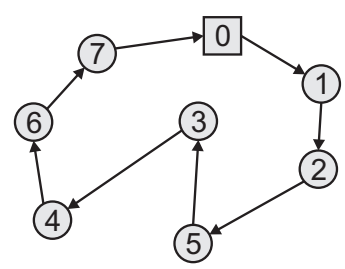

(c) Or-Opt 2 .

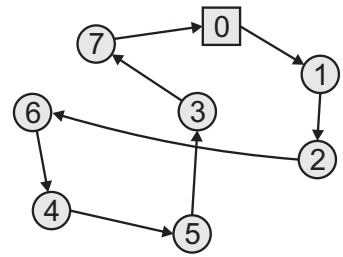

(f) Exchange.

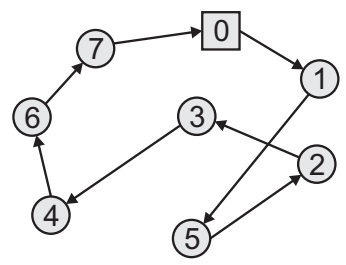

(d) Or-Opt 3 .

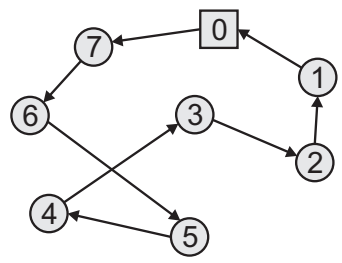

(g) Reverse.

Figura 8. Estruturas de vizinhança intra-rotas.

\subsubsection{Perturbação}

Na etapa de perturbação do algoritmo são utilizados mecanismos que realizam modificações em uma solução, escapando de ótimos locais, permitindo a exploração de outras áreas do espaço de busca. Neste trabalho, foram criadas perturbações que modificam as soluções em relação a ambos os objetivos do problema de roteamento de veículos multiobjetivo com coleta seletiva.

Assim sendo, o método de perturbação do algoritmo MOILS consiste em aplicar, primeiramente, o procedimento Altera Coleta que visa a modificação da solução em relação ao atendimento da demanda de coleta. Neste método, se o consumidor tiver a sua coleta realizada, então esta demanda não será mais atendida, e vice-versa. Quando a demanda de coleta de um consumidor deixar de ser atendida, o consumidor permanece na mesma posição. Caso contrário, ao passar a atender uma demanda de coleta, a capacidade do veículo pode ser extrapolada, inviabilizando a solução. Nestes casos, procura-se uma posição viável para inserir o consumidor. Caso não seja encontrada nenhuma posição viável, uma nova rota é criada para que este consumidor possa ser inserido.

Após a realização do procedimento Altera Coleta, a etapa de perturbação do algoritmo MOILS seleciona aleatoriamente e executa, ainda, um dos mecanismos de perturbação, descritos a seguir, que modificam a posição dos consumidores na solução.

- Multiple Swap: realiza trocas entre consumidores de rotas distintas escolhidos aleatoriamente;

- Multiple Shift: realoca um consumidor escolhido aleatoriamente de uma rota para outra rota;

- Ejection Chain: realoca um consumidor de uma rota $R_{1}$ em uma rota $R_{2}$, outro da rota $R_{2}$ em uma rota $R_{3}$, e assim sucessivamente até que um consumidor da última rota seja inserido na primeira rota.

- Or-Opt: mover 1 a 3 consumidores consecutivos de uma rota para outra.

Em todos estes quatro mecanismos de perturbação listados, a inserção dos consumidores é feita na primeira posição viável encontrada.

\subsubsection{Atualização}

A etapa de atualização verifica se uma determinada solução $s$ não é dominada pelas soluções presentes na fronteira de Pareto aproximada, no Algoritmo 2 representada pelo conjunto Front. Se $s$ não é dominada por nenhuma solução em Front, então ela é inserida no conjunto e as soluções por ela dominadas são removidas. 


\subsection{Heuristica $\mathbf{P}_{\epsilon}$-ILS}

Um método bastante comum para solucionar problemas com múltiplos objetivos baseia-se na transformação deste problema em diversos problemas com um único objetivo, onde as soluções ótimas destes problemas representam as soluções da fronteira de Pareto. Estes métodos definem um conjunto de problemas parametrizados de diferentes formas, sendo que os valores nos quais se parametrizam estes problemas determinarão quais soluções do conjunto Pareto serão alcançadas. Desta forma, a tarefa de escolher esta sequência de valores de parâmetros é extremamente difícil. Em muitos casos é impossível definir valores tais que toda a fronteira de Pareto seja encontrada.

O método $\epsilon$-Restrito, proposto por Chankong \& Haimes (1983), é baseado na escalarização no qual um dos objetivos é minimizado, enquanto os demais objetivos são limitados por meio de restrições. As soluções pertencentes a fronteira de Pareto são obtidas através de uma variação sistemática do limite destas restrições.

Definição 4 Seja $m$ o número de objetivos para determinado problema multiobjetivo, se $x^{*} \in \mathcal{F}_{x}$ é eficiente, então existem $i \in\{1,2, \ldots, m\}$ e números reais $\epsilon_{j}, j=1, \ldots, m(j \neq i)$ tais que $x^{*}$ resolve (Chankong $\mathcal{G}^{\circ}$ Haimes, 1983):

$x^{*}=\arg \min _{x \in \mathcal{F}_{x}} f_{i}(x)$

Sujeito $a:\left\{f_{j}(x) \leq \epsilon_{j}, j=1, \ldots, m(j \neq i)\right.$

Segundo a definição 4, o conjunto de soluções eficientes é constituído por cada solução $x^{*}$ obtida para cada $\epsilon_{j}$. Assim, a principal vantagem do método $\epsilon$-Restrito é que o mesmo possibilita encontrar a fronteira de Pareto independente da estrutura do problema multiobjetivo, podendo ele ser não-convexo e discreto (Chankong \& Haimes, 1983).

Baseada nos princípios básicos do método $\epsilon$-Restrito, a heurística $\mathrm{P}_{\epsilon}$ consiste em definir, a cada iteração, um conjunto de consumidores no qual suas demandas de coleta serão atendidas. Desta forma, este sub-problema gerado é solucionado utilizando um algoritmo baseado no ILS.

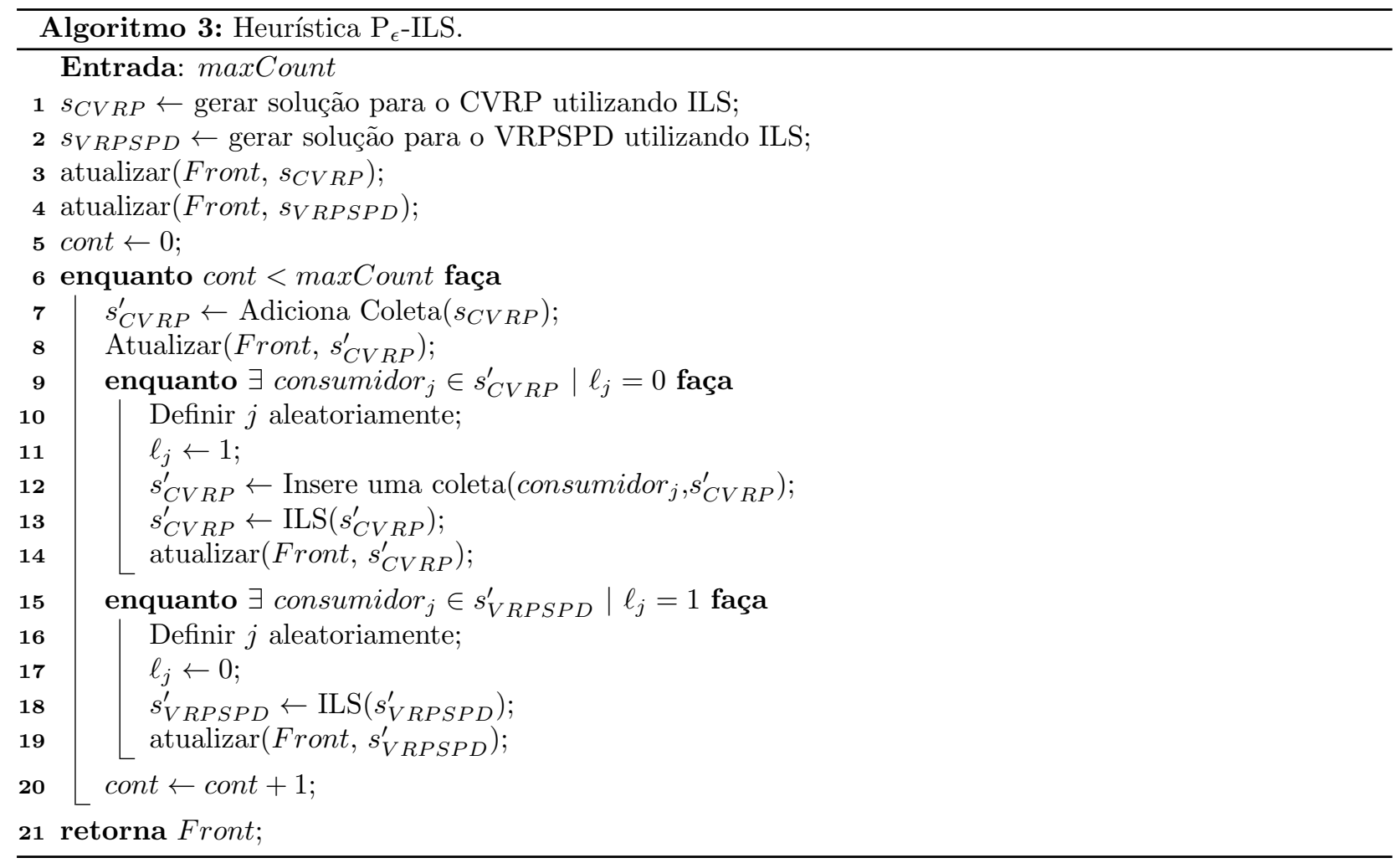

O passo inicial define os pontos de partida do algoritmo (linhas 1 e 2). Estes pontos consistem nas soluções do CVRP e VRPSPD, nos quais nenhuma demanda de coleta é atendida e todas as demandas de coletas são atendidas, respectivamente. A busca local iterativa, apresentada em Penna et al. (2012), foi utilizada para resolver ambos problemas. As duas soluções são, então, incluídas na fronteira de Pareto aproximada.

O algoritmo irá executar maxCount iterações (linhas 4-14), no qual a solução do CVRP será modificada gradativamente até que todas as demandas de coleta sejam satisfeitas. Por outro lado, a solução do VRPSPD será também modificada gradativamente até que nenhuma demanda de coleta seja atendida. 
Iniciando pela solução $s_{C V R P}^{\prime}$, na linha 7, para cada rota aplica-se a busca local intra-rota Adiciona Coleta, definida na Subseção 3.4.3.2. Dessa forma, sem alterar a posição dos consumidores na rota, busca-se atender o máximo de demandas de coleta possível. Dada esta solução, a fronteira Front é atualizada aplicando o mesmo procedimento do algoritmo MOILS.

Em seguida, enquanto houver demandas de coleta não atendidas na solução $s_{C V R P}^{\prime}$, as demandas de coleta não atendidas serão selecionadas aleatoriamente, uma a uma, para serem satisfeitas. Este procedimento resulta na realocação do consumidor, uma vez que o atendimento de uma demanda de coleta pode acarretar na extrapolação da capacidade do veículo. Assim, este consumidor é realocado na melhor posição encontrada dentre todas as rotas, considerando o custo de transporte. Quando nenhuma posição viável é encontrada, uma nova rota é criada para a inclusão deste consumidor. Para refinar a solução obtida, aplica-se o método ILS (Penna et al., 2012) à esta solução. Finalmente, atualiza-se o conjunto de soluções não dominadas Front. A Figura 9.a ilustra os passos da heurística $\mathrm{P}_{\epsilon}$-ILS partindo da solução do CVRP.

O procedimento descrito para a solução $s_{C V R P}^{\prime}$ é repetido para a solução $s_{V R P S P D}^{\prime} \operatorname{com}$ algumas modificações. Cada demanda de coleta satisfeita é selecionada aleatoriamente, uma a uma, para deixarem de ser atendidas. Este procedimento não requer a realocação do consumidor, uma vez que o mesmo não acarreta em nenhuma inviabilidade da solução. Da mesma forma, para refinar a solução, o método ILS é utilizado e o conjunto Front é atualizado. A Figura 9.b mostra as soluções geradas pela heurística $\mathrm{P}_{\epsilon}$-ILS, partindo de uma solução do VRPSPD.

Como a seleção das coletas a serem atendidas ou não atendidas é feita de forma aleatória, o método é executado várias vezes ( $\max C o u n t)$ a fim de encontrar soluções mais diversificadas e aproximadas da fronteira de Pareto ótima.

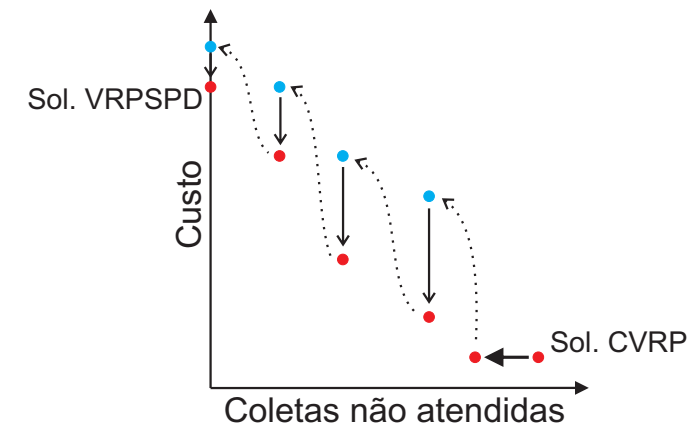

- Soluções que passam pelo procedimento "Atualizar"

- Soluções geradas após procedimento "insere uma Coleta"

$\rightarrow$ Procedimento "Adicionar Coleta"

...> Procedimento "Insere uma Coleta"

$\rightarrow$ ILS

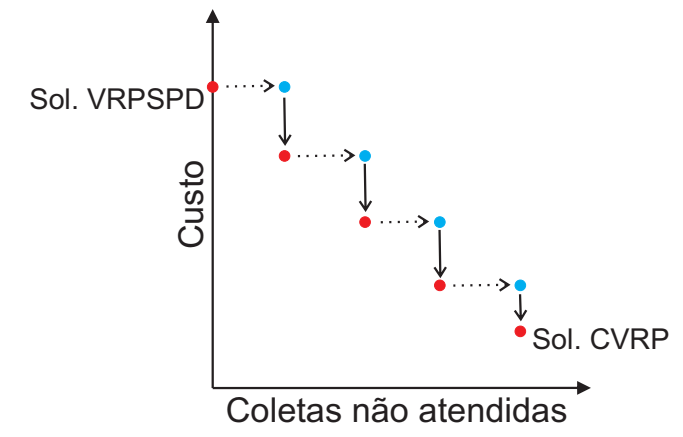

- Soluções que passam pelo procedimento "Atualizar"

- Soluções geradas após não atendimento de alguma demanda de coleta

...> Modificação do estado de coleta (1 para 0 )

$\rightarrow$ ILS

(a) Partindo de Sol. CVRP

(b) Partindo de Sol. VRPSPD

Figura 9. Etapas da heurística $\mathrm{P}_{\epsilon}$-ILS.

\subsection{Algoritmo genético de ordenação não-dominante II (NSGA-II)}

O algoritmo genético de ordenação não-dominante II (NSGA-II, Non-Dominated Sorting Genetic AlgorithmII) foi adaptado a fim de solucionar o MOVRPSP. Os passos do algoritmo seguem os princípios básicos do NSGA-II, proposto por Deb et al. (2002).

Para o MOVRPSP, os indivíduos da população representam uma solução completa do problema tratado, ou seja, um conjunto de rotas e um vetor binário que armazena o estado da demanda de coleta dos consumidores (atendida ou não atendida). O método de geração da população inicial $P$, assim como nos algoritmos MOILS e $\mathrm{P}_{\epsilon}$-ILS, inicia buscando soluções para o VRPSPD e CVRP para então inserí-las em $P$. Para uma população com $p$ indivíduos, as demais soluções são obtidas a partir da alteração do estado das demandas de coletas das soluções obtidas para o CVRP e VRPSPD, sendo que metade dos indivíduos da população serão gerados a partir da solução do CVRP e a outra metade a partir do VRPSPD. Iniciando o procedimento pela solução do CVRP, o algoritmo calcula uma taxa $(2 n / p$, sendo $n$ é o número de consumidores) no qual as demandas de coleta serão atendidas. Ao término do procedimento, o último indivíduo terá todas ou quase todas as demandas de coleta satisfeitas. Procedimento similar é executado para gerar as soluções iniciais partindo do VRPSPD, sendo que, ao término do procedimento, o último indivíduo definido terá poucas ou nenhuma demanda de coleta satisfeita. 
A população filha $Q$ é gerada a partir da recombinação de indivíduos da população $P$. Dois operadores de cruzamento são considerados neste trabalho, tendo eles igual probabilidade de serem selecionados. Cada indivíduo filho pode sofrer mutação, dada uma probabilidade de mutação $p_{m u t}$. Os operadores de mutação utilizados neste trabalho são Or-opt e Altera Coleta, descritos na Seção 3.4.4. Estes também têm igual probabilidade de serem selecionados para serem aplicados.

A fase de seleção do NSGA-II ocorre em dois momentos distintos do algoritmo. O primeiro deles, após a população inicial ser gerada, o algoritmo utiliza a técnica torneio binário da seguinte forma: dados dois indivíduos $a$ e $b$, se um indivíduo $a$ domina o indivíduo $b$, então o indivíduo $a$ é selecionado para o processo de recombinação, caso contrário, o indivíduo $b$ é selecionado. Se $a$ não domina $b$ e $b$ não domina $a$, ambos indivíduos são selecionados. A partir de então, o método de seleção realiza uma ordenação por não-dominância dos indivíduos pertencentes a $P \cup Q$, retornando um conjunto de fronteiras não dominadas. Seguindo esta ordenação, as fronteiras são incluídas na nova população $P$, preservando as melhores soluções da população anterior (elitismo). Quando um fronteira não puder ser totalmente incluída em $P$, os indivíduos dessa fronteira são selecionados de acordo com o método Crowding-Distance. Em seguida, a técnica torneio de multidão é aplicada para seleção dos indivíduos a serem recombinados e inseridos na população $Q$.

No torneio de multidão uma solução $s_{i}$, pertencente a fronteira $i$ após a ordenação de dominância, é considerada melhor que a solução $s_{j}$, pertencente a fronteira $j$, se (Deb et al., 2002):

1. $s_{i}$ possui um nível de não dominância melhor que $s_{j}$, ou seja, se $i<j$.

2. $i=j$ e a distância de multidão de $s_{i}$ é maior que distância de multidão de $s_{j}$.

O Algoritmo 4 e a Figura 10 ilustram o funcionamento do NSGA-II implementado.

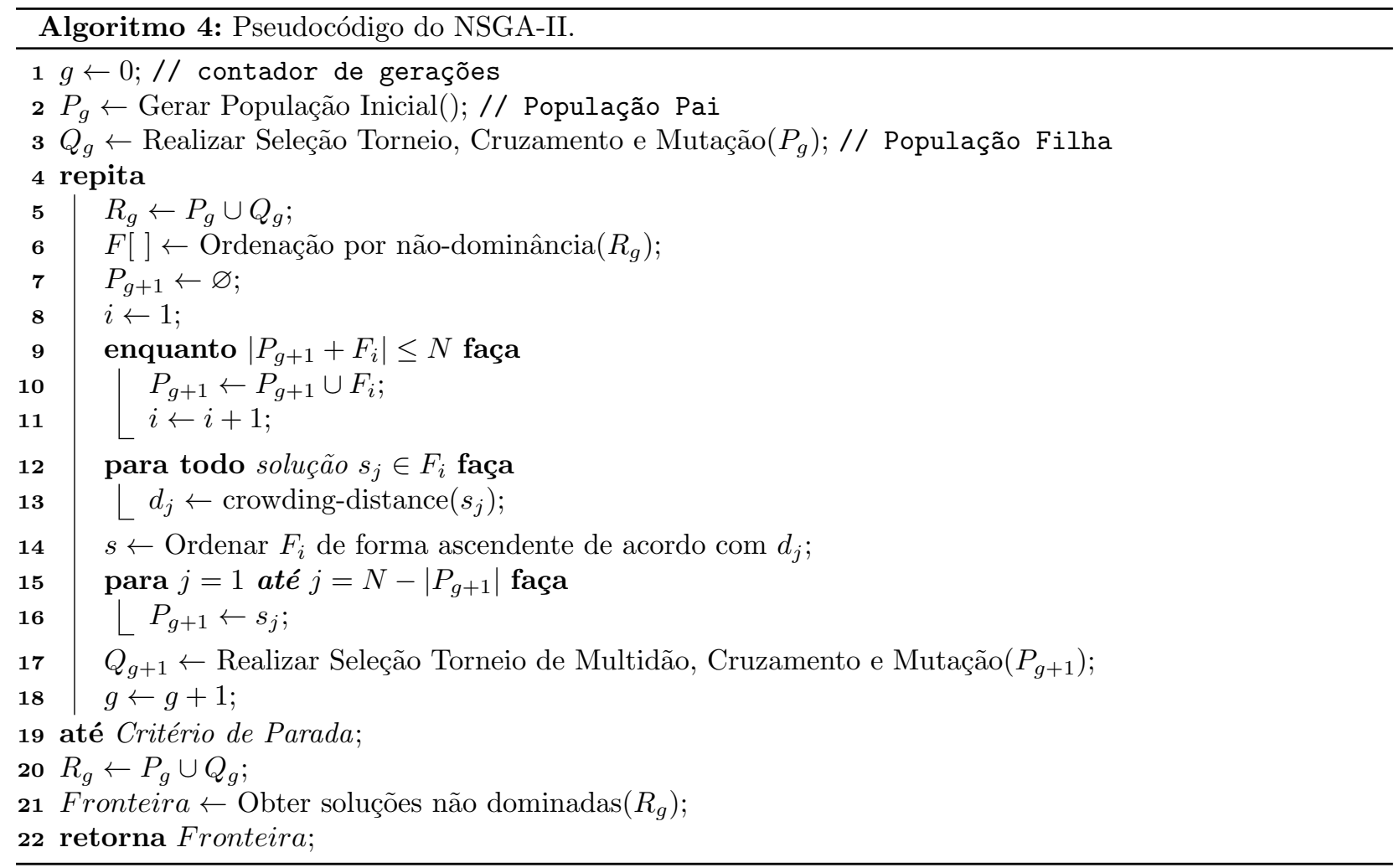

\subsubsection{Operadores de cruzamento}

Neste trabalho foram adotados dois métodos de cruzamento: cruzamento baseado em rota e split, descritos a seguir.

\subsubsection{Cruzamento baseado em rota}

O cruzamento baseado em rota (RBX, Route Based Crossover) seleciona aleatoriamente algumas rotas de um indivíduo pai $_{1}$ para serem incluídas no indivíduo $f i l h o_{1}$. Em seguida, os demais consumidores não contidos na solução do $f i l h o_{1}$ são inseridos de acordo com a solução do indivíduo $p a i_{2}$. De forma similar, algumas rotas do indivíduo pai $_{2}$ são selecionadas aleatoriamente para serem incluídas no indivíduo $f i l h o_{2}$ e este indivíduo é completado de acordo com as rotas do indivíduo $p a i_{1}$. 


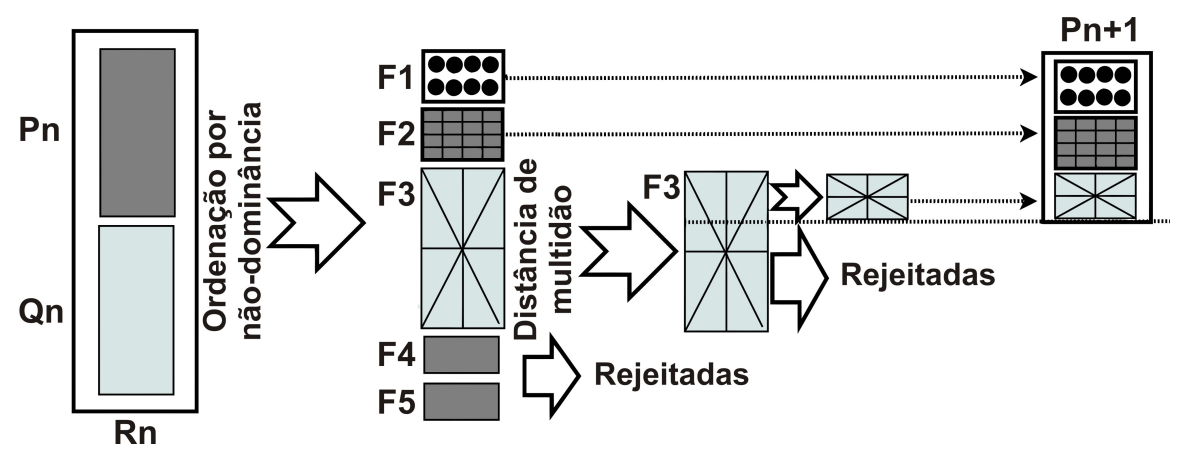

Figura 10. Algoritmo NSGA-II.

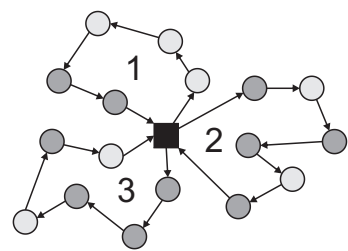

(a) $\mathrm{Pai}_{1}$

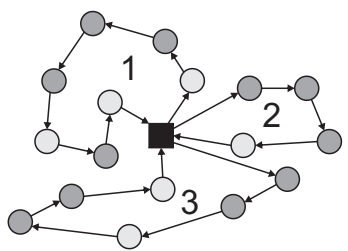

(b) $\mathrm{Pai}_{2}$

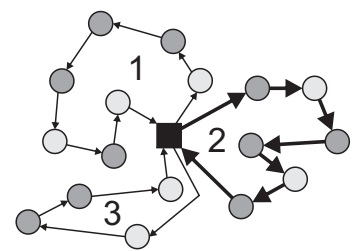

(c) Filho 1

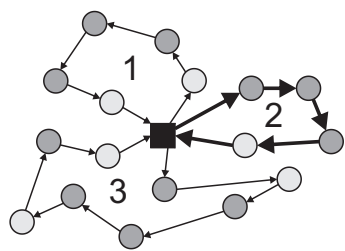

(d) $\mathrm{Filho}_{2}$

Figura 11. Cruzamento baseado em rota (RBX).

Este método é utilizado por recombinar tanto a posição dos consumidores nas rotas quanto o estado de coleta dos consumidores. A Figura 11 exemplifica o funcionamento do método de cruzamento RBX. O quadrado negro indica a posição do depósito e as circunferências na cor clara representam os consumidores, tais que suas demandas de coletas são atendidas, e as circunferências na cor escura representam os consumidores com coletas não satisfeitas. As Figuras 11.a e 11.b são os dois indivíduos $\left(P a i_{1}\right.$ e $\left.P a i_{2}\right)$ selecionados para o cruzamento. O indivíduo $F i l h o_{1}$ é gerado a partir da recombinação dos indivíduos $P a i_{1}$ e $P a i_{2}$, no qual a rota 2 é totalmente mantida do $P a i_{1}$ e as demais são inseridas do $P a i_{2}$. Da mesma forma, o indivíduo Filho $_{2}$ mantém a rota 2 do $P a i_{2}$ e o restante é inserido conforme $P a i_{1}$. Quando um consumidor é copiado de uma solução Pai para uma solução Filho, o estado de coleta desse consumidor é mantido do indivíduo Pai.

\subsubsection{Cruzamento split}

O método de cruzamento split, proposto por Prins (2004), consiste da transformação dos indivíduos pais em soluções para o problema do caixeiro viajante (TSP, Traveling Salesman Problem). A estas soluções, aplica-se o método de cruzamento sequencial (OX) e, então, a solução para o TSP é novamente transformada em uma solução para o VRP através de um procedimento denominado split.

$\mathrm{O}$ processo de transformação de um problema do caixeiro viajante em um problema de roteamento de veículo, inicialmente, constrói um grafo direcionado acíclico (DAG), $\mathrm{D}=(\mathrm{V}, \mathrm{A})$ com $\mathrm{V}=\{0,1, \ldots, \mathrm{n}\}$, sendo $n$ o número de consumidores e o vértice 0 representando o depósito. As arestas contidas na DAG representam diferentes rotas viáveis, definidas como: para todo vértice $i$ e $j$ pertencente $V$, tal que $i<j$, o arco $(i, j)$ pertence ao conjunto de arestas $A$ se a capacidade do veículo nesta rota não é extrapolada.

A Figura 12 mostra como gerar um grafo direcionado acíclico (Figura 12.b) a partir de uma solução do problema do caixeiro viajante (Figura 12.a). Na solução do TSP (Figura 12.a), os números indicados entre parênteses representam a demanda de entrega de cada consumidor e os valores nas arestas representam o custo de percorrê-la. Na DAG, cada aresta indica uma rota possível de ser gerada a partir da solução do TSP. Por exemplo, na aresta $a: 40$ indica que a rota $0-a-0$ tem custo 40 , a aresta $b c d: 120$ indica que a rota $0-b-c-d-0$ tem custo 120 . A aresta $a b c: 90$, por exemplo, não aparece na DAG, pois a carga do veículo extrapola sua capacidade máxima $(\mathrm{Q}=10)$.

Assim sendo, dado o grafo direcionado acíclico, busca-se, então, o caminho mais curto neste grafo. Na Figura 12.b, os valores indicados acima do vértice mostram o valor do caminho mais curto de alcançar este vértice a partir do vértice 0 . O valor 205 acima do último vértice indica que o caminho mais curto para alcançálo, partindo do vértice 0 , tem custo 205, sendo que este caminho passa pelas arestas: $a b: 55, c: 60$, de: 90 .

Portanto, dado o caminho mais curto, é possível definir as partições que serão aplicadas à solução do problema do caixeiro viajante. Serão criadas as seguintes rotas: $0-a-b-0,0-c-0$ e $0-d-e-0$, como mostrado na Figura 12.c. 


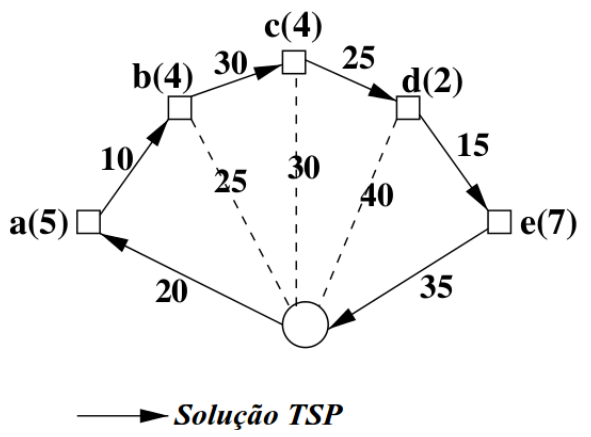

(a)

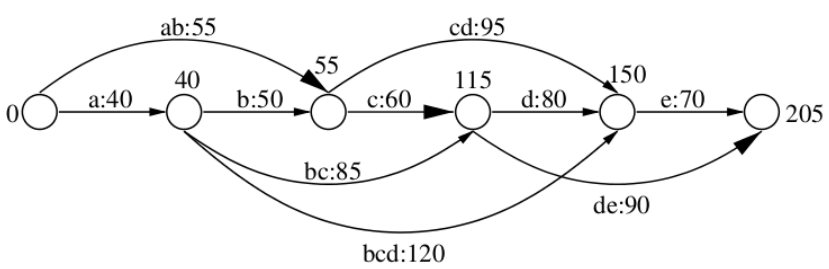

Possíveis Rotas

(b)

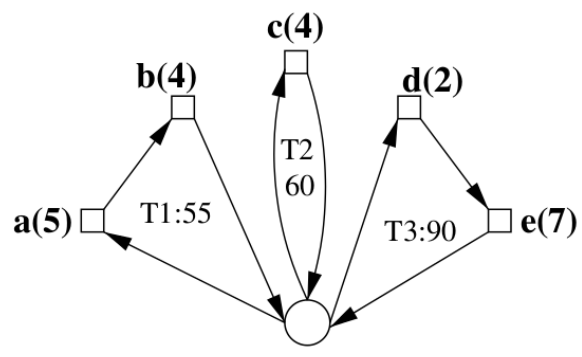

(c)

Figura 12. Transformando uma solução do TSP em uma solução para o VRP, de acordo com o cruzamento split (Prins, 2004).

\section{Resultados Experimentais}

Para avaliar o desempenho dos algoritmos MOILS, NSGA-II e $\mathrm{P}_{\epsilon}$-ILS, os testes foram realizados a partir da execução de cada algoritmo em um conjunto de 14 instâncias contendo entre 50 e 199 consumidores, mais o depósito (Salhi \& Nagy, 1999). O custo de transporte é calculado como a distância Euclidiana entre os pontos. Nos problemas CMT1 a CMT5, os consumidores estão aleatoriamente distribuídas no plano, enquanto nos problemas CMT11 e CMT12, estes aparecem em grupos, no qual o depósito não está centralizado.

Os parâmetros livres dos algoritmos comparados foram ajustados com o objetivo de proporcionar a cada método, aproximadamente, o mesmo tempo de execução. Uma análise estatística similar à empregada nesta seção não apontou diferenças significativas no tempo de execução dos algoritmos.

Para solucionar os problemas teste, foram atribuídos os seguintes valores aos parâmetros livres dos algoritmos:

1. MOILS: após testes preliminares, às constantes do algoritmo foram atribuídos os seguintes valores: maxIter $=100$ e $\max C o u n t=15$;

2. $P_{\epsilon}$ : testes preliminares sugeriram $\max C o u n t=50$;

3. NSGA-II: O número de gerações do algoritmo e o tamanho da população foi definido como 250 e 500 , respectivamente. A taxa de mutação $\left(p_{m u t}\right)$ é igual a 0,3 ;

4. ILS: o algoritmo, baseado no ILS, utilizado em todos os algoritmos para encontrar soluções dos problemas de roteamento de veículos mono-objetivo foi definido conforme apresentado por Penna et al. (2012).

Para avaliar o desempenho relativo para os três algoritmos, três métricas foram consideradas: Cardinalidade (Card), Hipervolume (S), Cobertura de dois conjuntos (CS) que são definidos a seguir.

- Cardinalidade (Card): número de soluções contidas na fronteira de Pareto.

- Hipervolume (S): é dado pela soma dos hipercubos formados pelas soluções não dominadas obtidas pelos algoritmos. Esta métrica calcula o volume da região coberta entre os pontos das soluções na fronteira encontrada e um determinado ponto de referência (W). Para problemas de minimização, maiores hipervolumes indicam melhores soluções. 
- Cobertura (C): dadas duas fronteiras de Pareto aproximadas A e B, C(A,B) calcula o número de soluções em B que são fracamente dominadas por outra fronteira A, dada a cardinalidade de B. Se C(A,B) é igual a 1, então todas as soluções em B são dominadas por soluções da fronteira A. Por outro lado, se o valor retornado é igual a 0 , isso aponta para uma situação oposta na qual nenhuma das soluções de B são dominadas por A. Para aplicação destas métricas, é necessário avaliar tanto C $(\mathrm{A}, \mathrm{B})$ quanto $\mathrm{C}(\mathrm{B}, \mathrm{A})$, pois estes valores não são complementares. A Equação 10 apresenta como se obtém o valor da cobertura dadas duas fronteira Pareto aproximadas A e B (Zitzler, 1999).

$$
C(A, B)=\frac{|\{y \in B: \exists x \in A, x \preceq y\}|}{|B|}
$$

Neste trabalho, a métrica hipervolume é calculada considerando como ponto de referência (W) o maior valor de cada objetivo do problema, obtido após a execução de todas as replicações de todos os algoritmos. O valor do Hipervolume foi normalizado no intervalo $(0,1)$, independentemente, para cada problema. Para ambas as métricas, Hipervolume e Cobertura, os valores obtidos representam a diferença entre porcentagem, enquanto a métrica Cardinalidade fornece valores absolutos.

\subsection{Planejamento estatístico}

Foram empregados testes estatísticos a fim de detectar diferenças significativas entre os algoritmos e estimar sua magnitude, os quais foram realizados, independentemente, para cada métrica avaliada. Esta análise foi aplicada em um conjunto de dados composto pela avaliação das métricas dadas às soluções obtidas em 8 replicações de cada algoritmo em cada problema teste.

Para cada métrica, o experimento foi projetado como um planejamento completo em blocos aleatorizados (RCBD, Randomized Complete Bloc Design), sendo os algoritmos os níveis do fator experimental e os problemas como um fator de blocagem (Montgomery, 2008). Ao considerar os problemas como blocos, é possível modelar e remover os efeitos das diferentes instâncias nos resultados, e obter as diferenças reais no desempenho dos algoritmos, dados os múltiplos problemas teste utilizados. A hipótese nula de ausência de diferença entre os algoritmos foi testada contra a hipótese alternativa bilateral. Para evitar a necessidade de se atender às premissas de normalidade do teste F, foi utilizado o teste de Gore (Parsad, 2002), uma alternativa não-paramétrica robusta para análise de variância em blocos.

Após os testes de significância, os estimadores dos efeitos dos blocos (instâncias) foram obtidos (Montgomery, 2008) e subtraídos das amostras, permitindo, assim, uma estimativa problema-independente dos tamanhos dos efeitos de cada algoritmos. As magnitudes das diferenças de desempenho foram obtidas através do estimador de Hodges-Lehmann (HL) (Hodges \& Lehmann, 1963), que fornece uma medida da mediana das diferenças entre duas amostras independentes. Uma descrição mais detalhada dos métodos estatísticos estão disponíveis em Batista et al. (2011).

\subsection{Resultados e discussões}

Os resultados obtidos nos testes aplicados mostram diferenças estatisticamente significativas entre os algoritmos avaliados. A média e o desvio padrão dos valores obtidos estão sumarizados na Tabela 1 . A Tabela 2 sintetiza os resultados das análises estatísticas, mostrando a grandeza das diferenças estatisticamente significativas.

Para a métrica Hipervolume, todos os algoritmos apresentaram diferenças relativamente pequenas, como mostrado na Tabela 1, com o algoritmo $P_{\epsilon}$ apresentando um desempenho um pouco pior que os demais métodos. A análise estatística, apresentada na Tabela 2, confirma esta observação, mostrando que todos os algoritmos apresentaram diferenças relativamente pequenas, mas estatisticamente significantes, com o MOILS mostrando os melhores resultados (11\% superior ao $\mathrm{P}_{\epsilon}$-ILS e $8 \%$ melhor que o NSGA-II). Estes resultados indicam que o MOILS, em geral, é capaz de obter melhores fronteiras por retornar um conjunto de soluções melhor distribuídas ou pontos mais próximos da fronteira Pareto-ótima.

As diferenças médias obtidas pela métrica Cardinalidade também foram relativamente modestas. A Tabela 1 mostra que, para cada problema, todos os algoritmos retornaram aproximadamente o mesmo número médio de soluções. A Tabela 2 mostra que, quando considerado todos os problemas, diferenças pequenas mas estatisticamente significantes foram observadas. Os resultados obtidos a partir do algoritmo MOILS apresentam um número maior de soluções presentes na fronteira de Pareto aproximada. Em média, o MOILS retorna 2.56 soluções a mais que o $\mathrm{P}_{\epsilon}$-ILS e 4.32 a mais que o NSGA-II.

Diferenças mais significativas nos resultados dos algoritmos podem ser observadas para a métrica de Cobertura. O MOILS supera a heurística $\mathrm{P}_{\epsilon}$-ILS por uma média de 0.7 e o NSGA-II por 0.32. Este é um indicador muito evidente de superioridade, uma vez ele indica que as fronteiras geradas pelos MOILS 
Tabela 1. Média e desvio padrão (entre parênteses) dos valores obtidos pelas métricas avaliadas.

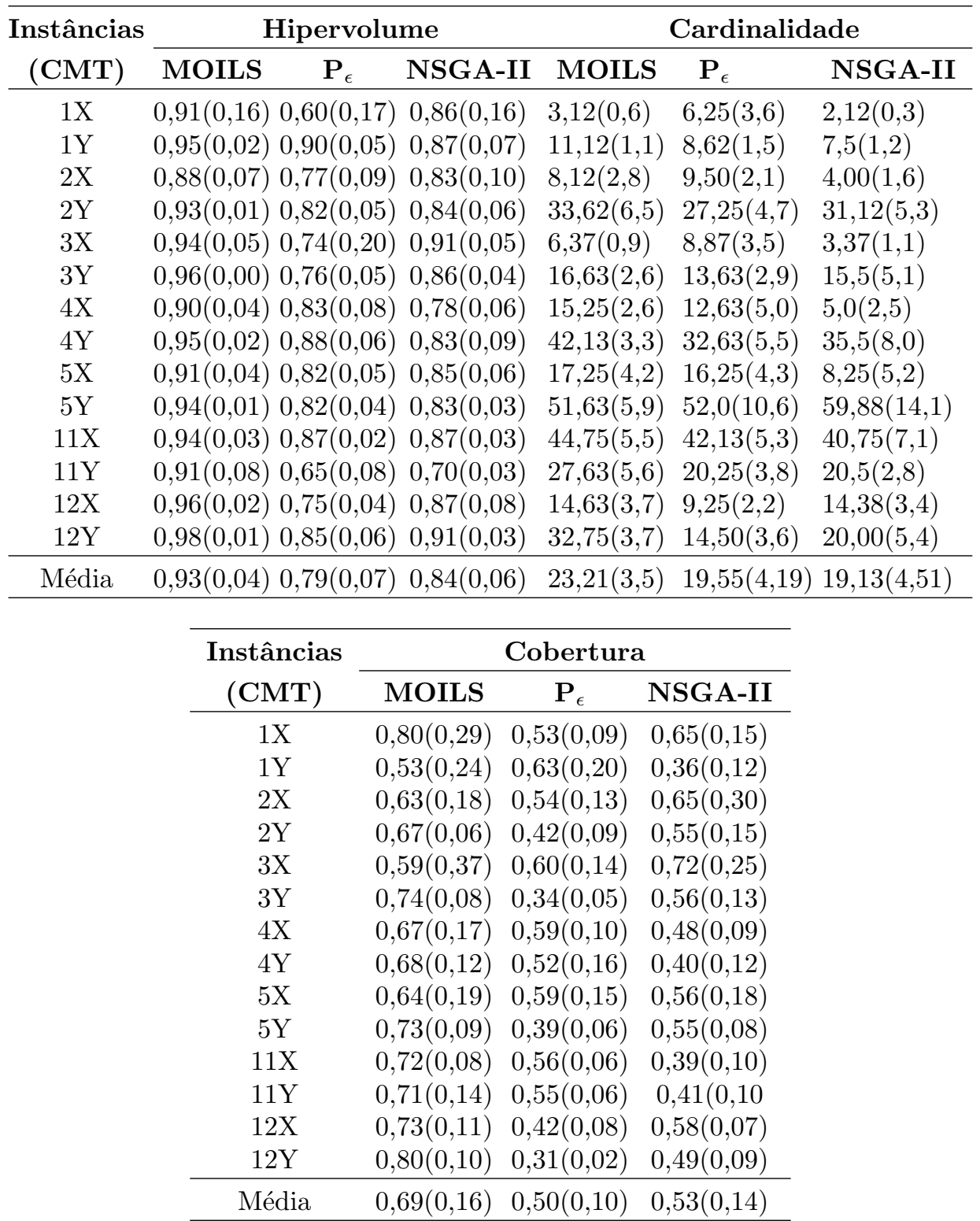

Tabela 2. Diferenças estimadas no desempenho médio entre os algoritmos (linha $\times$ coluna) para as métricas consideradas. Somente os efeitos estatisticamente significativos a um nível de confiança de 95\% (ajustado para o teste de múltiplas hipóteses usando Correção Dunn-Šidák (Dunn, 1961)) são apresentados. Os valores positivos indicam um valor médio maior para o algoritmo da linha. Informações redundantes foram removidas da tabela a fim de melhorar a legibilidade.

\begin{tabular}{lcccccc}
\cline { 2 - 6 } & \multicolumn{2}{c}{ Hipervolume } & \multicolumn{2}{c}{ Cobertura } & \multicolumn{2}{c}{ Cardinalidade } \\
\cline { 2 - 6 } & $\mathbf{P}_{\epsilon}$-ILS & NSGA-II & P $_{\epsilon}$-ILS & NSGA-II & P $_{\epsilon}$-ILS & NSGA-II \\
\hline MOILS & 0,11 & 0,08 & 0,70 & 0,32 & 2,56 & 4,32 \\
P $_{\epsilon}$-ILS & - & $-0,03$ & - & $-0,28$ & - & n.s \\
\hline \multicolumn{3}{c}{ * "n.s." } & significa "estatisticamente não significativo".
\end{tabular}

foram capazes de dominar, em média, cerca de $70 \%$ das fronteiras correspondentes obtidas pelo $\mathrm{P}_{\epsilon}$-ILS, e $32 \%$ no caso do NSGA-II. Para simplificar a apresentação dos valores relativos de cobertura, uma versão generalizada da métrica Cobertura de Dois Conjuntos, denominada Cobertura de Vários Conjuntos (Batista et al., 2012), foi utilizado para gerar os dados apresentados na Tabela 1. Ao invés de quantificar o quanto um 
determinado algoritmo abrange outra, essa métrica generalizada calcula a quantidade que um determinado algoritmo cobre a união das fronteiras finais retornados por todos os algoritmos, exceto em a fronteira obtida por ele mesmo.

A Figura 13 mostra dois exemplos de fronteiras obtidas pelos três algoritmos. Uma vez que a fronteira Pareto-ótima é desconhecida para o problema considerado, não é possível avaliar a quantidade absoluta da fronteira retornada pelos algoritmos propostos neste capítulo. Contudo, um ponto extremo da fronteira é equivalente à instância correspondente do VRPSPD. A Tabela 3 apresenta uma comparação deste ponto extremo com os melhores resultados conhecidos para o VRPSPD (Subramanian et al., 2010). Pode-se perceber que, neste ponto, o MOILS encontra soluções muito próximas da melhor solução conhecida da literatura.

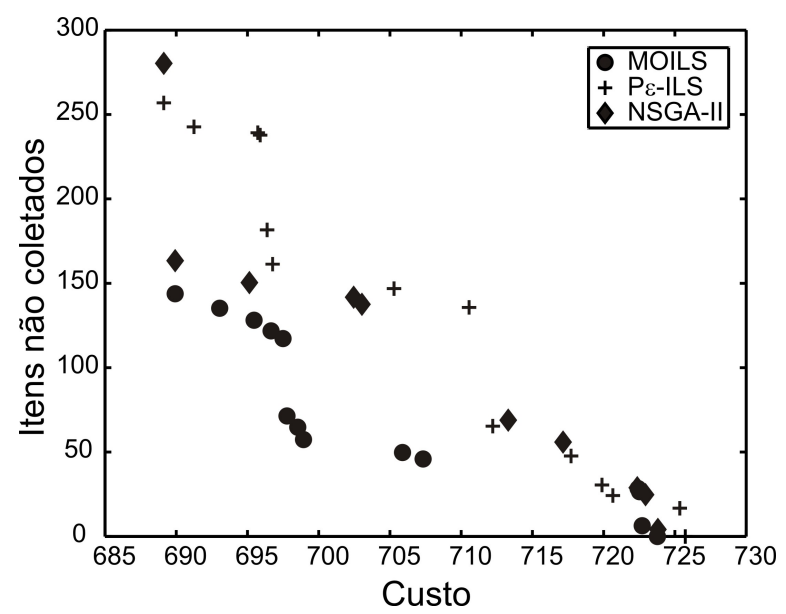

(a) CMT3Y.

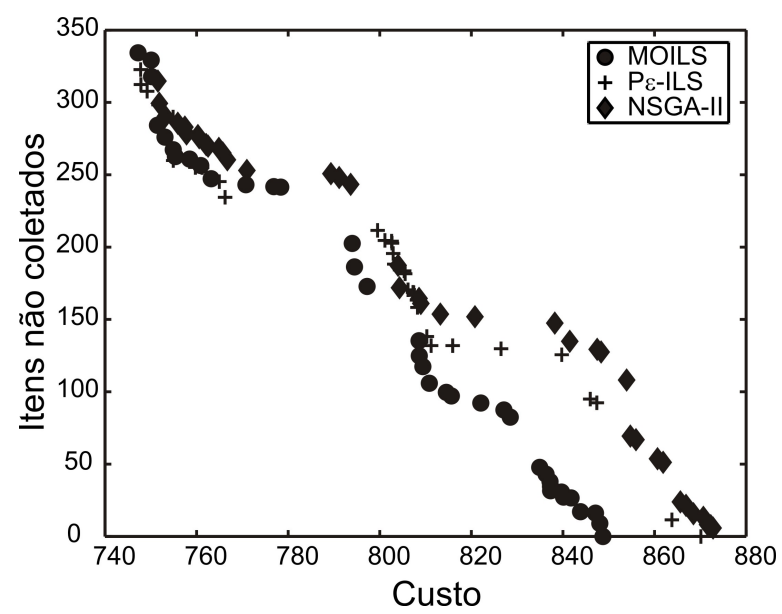

(b) CMT11X.

Figura 13. Exemplo das fronteiras obtidas pelos algoritmos implementados.

Tabela 3. Comparação do MOILS com os melhores resultados conhecidos para o VRPSPD mono-objetivo (100\% das coletas atendidas).

\begin{tabular}{|c|c|c|c|c|c|c|c|}
\hline & \multicolumn{7}{|c|}{ Instâncias (CMT) } \\
\hline & $1 \mathrm{X}$ & $1 Y$ & $2 \mathrm{X}$ & $2 Y$ & $3 \mathrm{X}$ & $3 \mathrm{Y}$ & $12 \mathrm{X}$ \\
\hline MOILS & 466,77 & 466,77 & 688,05 & 693,09 & 721,40 & 723,28 & 665,85 \\
\hline Melhor & $466,77^{2}$ & $466,77^{2}$ & $668,77^{1}$ & $663,25^{1}$ & $721,27^{2}$ & $721,27^{2}$ & $644,70^{1}$ \\
\hline \multirow[t]{3}{*}{ Erro* $(\%)$} & 0,00 & 0,00 & 2,88 & 4,50 & 0,02 & 0,28 & 3,28 \\
\hline & \multicolumn{7}{|c|}{ Instâncias (CMT) } \\
\hline & $12 \mathrm{Y}$ & $11 \mathrm{X}$ & $11 \mathrm{Y}$ & $4 \mathrm{X}$ & $4 \mathrm{Y}$ & $5 \mathrm{X}$ & $5 \mathrm{Y}$ \\
\hline MOILS & 664,00 & 848,72 & 850,67 & 857,44 & 855,74 & 1037,25 & 1032,68 \\
\hline Melhor & $659,52^{1}$ & $833,92^{1}$ & $830,39^{1}$ & $852,46^{1}$ & ${ }^{1} 852,35^{1}$ & $1029,25^{1}$ & $1029,25^{1}$ \\
\hline $\operatorname{Erro}^{* *}(\%)$ & 0,68 & 1,77 & 2,44 & 0,58 & 0,40 & 0,78 & 0,33 \\
\hline
\end{tabular}

\section{Conclusões}

Diversos problemas reais de roteamento de veículos com serviços de coleta e entrega possuem uma natureza multiobjetivo, mas, apesar disso, esta abordagem é ainda pouco explorada na literatura. Este capítulo apresentou uma formulação matemática adaptada ao problema de roteamento de veículos multiobjetivo denominado problema de roteamento de veículos multiobjetivo com coleta seletiva.

Devido à complexidade computacional do problema tratado, foi apresentado um conjunto de métodos heurísticos para solucioná-lo. Assim, explorou-se as especificidades das meta-heurísticas baseadas em 
busca local, em população e nos métodos tradicionais de resolução de problemas multiobjetivo, resultando, respectivamente, nos algoritmos: MOILS, NSGA-II e $\mathrm{P}_{\epsilon}$-ILS

Após análises estatísticas, os testes de hipótese mostram diferenças significativas no desempenho dos algoritmos, apontando uma superioridade do MOILS em relação aos outros algoritmos. O bom desempenho do algoritmo baseado no MOILS pôde ser também observado na comparação com os resultados da literatura. Neste trabalho, um dos pontos extremos da fronteira, no qual todas as demandas de coleta são atendidas, é comparado com os melhores resultados conhecidos do problema de roteamento de veículos com coleta e entrega simultânea. Os resultados mostraram que as soluções obtidas pelo MOILS se aproximam das melhores da literatura com um erro relativo médio de $0,9 \%$, sendo que, em muitas instâncias, este erro é quase nulo, confirmando o bom desempenho deste algoritmo.

\section{Agradecimentos}

Os autores agradecem ao Conselho Nacional de Desenvolvimento Científico e Tecnológico (CNPq) pelo apoio financeiro (edital 004/2010/PIBIT-CNPq-UFVJM, projeto PQ:306910/2006-3 e 472446/2010-0) e à Coordenação de Aperfeiçoamento de Pessoal de Nível Superior (CAPES) pela concessão de bolsa de estudos por meio do Programa de Fomento à Pós-Graduação (PROF).

\section{Referências}

Batista, L.S.; Campelo, F.; Guimarães, \& F. G. Ramírez, J.A., Pareto cone $\epsilon$-dominance: Improving convergence and diversity in multiobjective evolutionary algorithms. In: Proceedings of the 6th international conference on Evolutionary Multi-criterion Optimization. Heidelberg, Germany: Springer-Verlag, v. 6576 de Lecture Notes in Computer Science, p. 76-90, 2011.

Batista, L.S.; Campelo, F.; Guimarães, \& F. G. Ramírez, J.A., The cone $\epsilon$-dominance: An approach for evolutionary multiobjective optimization evolutionary computation. Evolutionary Computation, 2012 [Submitted].

Chankong, V. \& Haimes, Y.Y., Multiobjective Decision Making: Theory and Methodology. New York, USA: Elsevier Science, 1983.

Coello Coello, C.A.; Lamont, G.B. \& van Veldhuizen, D.A., Evolutionary Algorithms for Solving Multi-Objective Problems. 2a edição. New York, USA: Springer Science, 2007.

Deb, K.; Pratap, A.; Agarwal, S. \& Meyarivan, T., A fast and elitist multiobjective genetic algorithm: NSGA-II. IEEE Transactions on Evolutionary Computation, 6(2):182-197, 2002.

Dunn, O., Multiple comparisons among means. Journal of the American Statistical Association, 56(293):52-64, 1961.

Geiger, M.J., Foundations of the pareto iterated local search metaheuristic. In: Proceedings of the 18th International Conference on Multiple Criteria Decision Making. Chania, Greece, p. 19-23, 2006.

Gribkovskaia, I.; Halskau, O.; Laporte, G. \& Vlcek, M., General solutions to the single vehicle routing problem with pickups and deliveries. European Journal of Operational Research, 180(2):568 - 584, 2007.

Gutiérrez-Jarpa, G.; Desaulniers, G.; Laporte, G. \& Marianov, V., A branch-and-price algorithm for the vehicle routing problem with deliveries, selective pickups and time windows. European Journal of Operational Research, 206(2):341 $-349,2010$.

Hodges, J.L. \& Lehmann, E.L., Estimation of location based on ranks. Annals of Mathematical Statistics, 34:598-611, 1963.

Holland, J.H., Adaptation in Natural and Artificial Systems. Cambridge, USA: MIT Press, 1992.

Jozefowiez, N.; Semet, F. \& Talbi, E.G., From single-objective to multi-objective vehicle routing problems: Motivations, case studies, and methods. In: Golden, B.L.; Raghavan, S. \& Wasil, E.A. (Eds.), The Vehicle Routing Problem: Latest Advances and New Challenges. Berlin, Germany: Springer, v. 43 de Operations Research/Computer Science Interfaces Series, p. 445-471, 2008.

Lourenço, H.R.; Martin, O.C. \& Stützle, T., Iterated local search. AIROnews, VIII(3):11-14, 2003.

Montané, F.A.T. \& Galvão, R.D., A tabu search algorithm for the vehicle routing problem with simultaneous pick-up and delivery service. Computers and Operations Research, 33(3):595-619, 2006.

Montgomery, D.C., Design and Analysis of Experiments. 7a edição. New York, USA: J. Wiley \& Sons, 2008.

Parsad, R., Non-parametric methods in analysis of experimental data. In: R. Parsad R. Srivastava, V.K.G. (Ed.), Design and Analysis of Agricultural Experiments. New Delhi, India: Indian Agricultural Statistics Research Institute, Mod. V, p. 693-694, 2002.

Penna, P.H.V.; Subramanian, A. \& Ochi, L.S., An iterated local search heuristic for the heterogeneous fleet vehicle routing problem. Journal of Heuristics, :1-322012Http://dx.doi.org/10.1007/s10732-011-9186-y.

Prins, C., A simple and effective evolutionary algorithm for the vehicle routing problem. Computers 6 Operations Research, 31(12):1985-2002, 2004.

Salhi, S. \& Nagy, G., A cluster insertion heuristic for single and multiple depot vehicle routing problems with backhauling. Journal of Operational Research Society, 50(10):1034-1042, 1999. 
Subramanian, A.; Drummond, L.M.A.; Bentes, C.; Ochi, L.S. \& Farias, R., A parallel heuristic for the vehicle routing problem with simultaneous pickup and delivery. Computers $\&$ Operations Research, 37(11):1899 - 1911, 2010.

Subramanian, A.; Uchoa, E.; Pessoa, A.A. \& Ochi, L.S., Branch-and-cut with lazy separation for the vehicle routing problem with simultaneous pickup and delivery. Operations Research Letters, 39(5):338-341, 2011.

Sural, H. \& Bookbinder, J.H., The single-vehicle routing problem with unrestricted backhauls. Networks, 41(3):127136, 2003.

Zitzler, E., Evolutionary Algorithm for Multiobjective Optimization: Methods and Applications. PhD Thesis, Swiss Federal Institute of Technology Zurich, Computer Engineering and Networks Laboratory, Zurich, Switzerland, 1999.

\section{Notas Biográficas}

Luciana Pereira de Assis é graduada em Ciência da Computação (Centro Universitário de Belo Horizonte, 2004) e mestre em Ciência da Computação (UFMG, 2007). Atualmente é professora Assistente do departamento de Computação da UFVJM e doutoranda junto ao Programa de Pós-Graduação em Engenharia Elétrica da UFMG.

André Luiz Maravilha Silva é graduado em Sistemas de Informação (UFVJM, 2011) e atualmente é mestrando junto ao Programa de Pós-Graduação em Engenharia Elétrica da UFMG.

Felipe Campelo Franca Pinto é graduado em Engenharia Elétrica (UFMG, 2003), mestre e doutor em Engenharia (Hokkaido University, Japão, 2006 e 2009, respectivamente). Atualmente é professor Adjunto do departamento de Engenharia Elétrica da UFMG, atuando também como co-investigador junto ao Laboratory of Hybrid Systems, Hokkaido University.

Alessandro Vivas Andrade é graduado, mestre e doutor em Engenharia Elétrica (UFMG, 1999, 2002 e 2008, respectivamente). Atualmente é professor Adjunto do Departamento de Computação da UFVJM.

Jaime Arturo Ramírez é graduado e mestre em Engenharia Elétrica (UFMG, 1986 e 1990, respectivamente) e doutor em Engenharia Elétrica (Imperial College London, UK, 1994). Atualmente é professor Titular do Departamento de Engenharia Elétrica da UFMG. 


\title{
Metodologia para o PRV: um Estudo de Caso para a Distribuição de Água Mineral
}

\author{
Sheila Margot Gonçalves*, Maria Teresinha Arns Steiner e Luzia Vidal de Souza
}

\begin{abstract}
Resumo: A metodologia proposta é constituída pelas seguintes etapas: 1) algoritmo de Teitz \& Bart, para a determinação de medianas, cuja quantidade varia de acordo com a quantidade de pontos de demanda a serem atendidos e com a capacidade dos veículos que fazem a entrega; 2) algoritmo de Gillett e Johnson modificado, para a definição dos agrupamentos de pontos de demanda a serem atendidos pelos veículos; 3) algoritmos heurísticos dos Savings de Clarke e Wright, da Inserção do Mais Próximo, da metaheurística Busca Tabu e algumas de suas combinações, comparativamente, para a obtenção da sequência de atendimento aos pontos de demanda.
\end{abstract}

Palavras-chave: Problemas de roteamento de veículos (PRV), Algoritmos heurísticos e Meta-heurístico, Estudo de caso.

\begin{abstract}
The methodology proposed is constituted by the following phases: 1) Teitz 8 Bart's algorithm, in order to determine the medians which quantity varies according to the quantity of demand points as well as the capacity of the vehicles used on the delivery; 2) modified Gillet and Johnson's algorithm, in order to define the clusters of demand points to be supplied by the vehicles; 3) Clarke E Wright's savings algorithm as well as the Nearest Insertion heuristics, the Tabu Search metaheuristic and by their combination, comparatively, in order to get the sequence in which the demand points will be supplied.
\end{abstract}

Keywords: Vehicle routing problems, Heuristics and metaheuristic algorithms, Case study.

\section{Introdução}

É notório que o nível de competitividade tem aumentado sensivelmente em todos os setores da economia brasileira em função das transformações observadas a partir dos anos 90. Do ponto de vista macroeconômico, neste período tem-se vivenciado a estabilização monetária, a abertura de mercado, a desregulamentação e a privatização de setores chave. No dia-a-dia das empresas, em virtude da sua importância cada vez maior no contexto logístico, os Problemas de Roteamento de Veículos (PRV), que estão diretamente relacionados com os seus custos operacionais, vêm recebendo uma atenção especial por parte de planejadores e pesquisadores. A impossibilidade de obter soluções ótimas para instâncias encontradas no mundo real, devido as diferentes características e restrições vem trazendo o desafio da busca de novos procedimentos heurísticos de maneira a produzir resultados próximos do ótimo.

O objetivo principal deste capítulo é apresentar uma metodologia para realizar a tarefa de roteamento no serviço de entrega, aplicado aos mais diversos problemas de distribuição e, mais especificamente, na distribuição de água mineral para o município de Itú, SP. Esta metodologia faz uso de ferramentas da Programação Matemática, através das quais possa se apresentar uma solução para o atendimento a todos os clientes minimizando as distâncias percorridas pela frota de veículos.

São centenas de trabalhos na literatura que tratam dos PRV, alguns dos quais são citados a seguir, dando desta forma, um respaldo adicional à metodologia apresentada na seção 3 que pode resolver, dentre outros, o problema apresentado na Seção 2. Os resultados da metodologia aplicada ao problema real são mostrados na seção 4 e, finalmente, na seção 5 são apresentadas as conclusões.

Breedam (2001) apresenta uma comparação entre as meta-heurísticas Simulated Annealing e Busca Tabu para solucionar o PRV. Seus estudos mostram que, em condições semelhantes, os referidos algoritmos apresentam resultados semelhantes, sendo que o que determina a escolha de uma ou outra meta-heurística

*Autor para contato: sheilamargot@up.com.br 
é o tempo computacional. O autor propõe também, uma combinação dos resultados obtidos pelas duas heurísticas.

Já Toth \& Vigo (2003) implementaram uma modificação no algoritmo da Busca Tabu e a denominaram de Busca Tabu granular. Em sua metodologia realizam uma restrição na busca pela vizinhança, analisando apenas os vizinhos potencialmente capazes de oferecer uma boa solução para o problema. Os testes computacionais mostraram a importância de se utilizar uma estratégia para criar uma lista apropriada de candidatos promissores e seu impacto na criação de métodos mais eficientes.

Boulduc et al. (2010) propõem uma heurística baseada em Busca Tabu para o integrar o PRV com a programação da produção e a data de entrega. Este novo problema consiste em determinar quais clientes serão atendidos por um transportador comum, bem como os que serão atendidos por uma frota privada, de forma a minimizar os custos com transporte. O problema foi modelado como um Problema de Programação Inteiro Misto e foi resolvido utilizando a meta-heurística Busca Tabu com divisão de entregas. Os resultados demonstram que é possível obter uma excelente solução para atendimento aos clientes dentro do prazo estabelecido. Foram utilizadas estratégias de redução da vizinhança para a redução do tempo computacional.

Leung et al. (2011) apresentam um algoritmo de Busca Tabu estendido para combinar o PRV com o problema do empacotamento de cargas bi-dimensionais. No algoritmo denominado Extended Guided Tabu Search (EGTS), é proposta uma melhoria para guiar a Busca Tabu utilizando a ideia de busca local guiada. Além disto, é implementado um critério de aspiração no sentido de evitar a perda de boas soluções. Por outro lado, propõem um algoritmo para o carregamento das cargas que aumenta a probabilidade de apresentar soluções viáveis, adotando uma estratégia híbrida de empacotamento para verificar a factibilidade do carregamento. Foram realizados testes para 180 bancos de dados e a eficiência da metodologia ficou comprovada.

Choi \& Tcha (2007) apresentam uma metodologia baseada na técnica de geração de colunas para o PRV com frota heterogênea. Um modelo de Programação Inteira é apresentado e o relaxamento da Programação Linear é resolvido através da geração de colunas. Alguns problemas de Programação Dinâmica são desenvolvidos para o PRV clássico e são propostas algumas modificações para a geração de colunas viáveis; em seguida foi aplicado o algoritmo branch-and-bound com as colunas geradas. A metodologia foi testada para 36 problemas da biblioteca de Golden et al, 2003, apud Choi \& Tcha (2007), de forma comparativa. As soluções apresentadas confirmam a eficiência da técnica.

Valle \& Cunha (2009) apresentam um estudo sobre o PRV no qual, nem todos os clientes precisam ser visitados, sendo que o objetivo é minimizar o comprimento da maior rota. O problema é formulado como um Problema de Programação Inteira e os métodos branch-and-cut e local branching são utilizados para resolver o problema. Os limites superiores foram obtidos utilizando a meta-heurística GRASP (Greedy Randomized Adaptative Search Procedure), usada na inicialização dos métodos. O resultado ótimo foi obtido em diversas instâncias testadas e o tempo computacional foi limitado em 4 horas.

Du \& He (2012) combinam duas meta-heurísticas: vizinho mais próximo e Busca Tabu para a solução do PRV. Na primeira etapa, o algoritmo do vizinho mais próximo é utilizado para a construção das rotas iniciais e a Busca Tabu é utilizada para implementar melhorias nas rotas obtidas. Os resultados demonstram que a metodologia apresenta resultados satisfatórios.

\section{Descrição do Problema Real}

O trabalho de roteamento em uma empresa é um dos fatores que determinam a sua eficiência, face à competitividade do mercado. Sendo assim, todos os pontos de demanda referentes a uma determinada empresa devem estar roteirizados, prevendo em alguns casos, inclusive, a possibilidade de pedidos extras a serem adicionados em alguma rota. Definir um bom roteiro considerando problemas de trânsito, acesso, circulação e estacionamento de veículos nos centros urbanos não é um problema de fácil solução, no entanto, com a utilização de técnicas da área de Pesquisa Operacional, esta tarefa pode tornar-se mais segura e eficiente, podendo ser realizada em poucos minutos.

O interesse e a demanda pela aplicação de modelos de roteamento para problemas reais têm crescido muito nos últimos anos. As principais razões para a procura deste tipo de trabalho relacionam-se às exigências dos clientes com relação a prazos de entrega, datas e horários de atendimento; a competitividade do mercado e a busca pela eficiência, acarretando a redução de custos e melhor desempenho na prestação dos serviços oferecidos.

Este estudo de caso foi realizado na Empresa de Mineração Clarita Ltda, concessionária da extração e comercialização da água mineral Clarita, localizada na cidade de Itú, no estado de São Paulo, fundada em 26 de fevereiro de 1991. O envasamento desta água mineral é feito em galões de 10 e 20 litros. A empresa vende em torno de 200.000 litros por mês. Por ocasião da pesquisa, a distribuição era terceirizada e atendia, além de Itú, também as cidades de Salto, Porto Feliz, Sorocaba, Jundiaí e Indaiatuba. 
O objetivo deste estudo é apresentar uma metodologia para o problema de roteamento de veículos com as características aqui apresentadas, ilustrando-a na distribuição dos garrafões de água mineral para a referida empresa. Na cidade de Itú, as ruas são, de uma forma geral, estreitas e geralmente de mão dupla e com estacionamento nas laterais, o que dificulta o tráfego de caminhões de grande porte e, por este motivo, o caminhão a ser utilizado é de pequeno porte, sendo que a sua capacidade é de 59 garrafões de 20 litros por viagem.

A empresa realiza a distribuição dos galões de água aos 46 clientes, aqui tratados como pontos de demanda, entregando em torno de 14 garrafões de 20 litros por semana para cada cliente, sendo que esta entrega deverá ser realizada duas vezes na semana. Desta forma, os 46 pontos de demanda são responsáveis pela comercialização de aproximadamente 3.000 garrafões de 20 litros por mês.

A entrega é realizada, atualmente, através de nove rotas, sendo cada uma delas percorrida duas vezes na semana. A quantidade de pontos em cada rota varia de 4 a 6 pontos atendidos, sendo que a distância total percorrida pelos veículos é de cerca de 90.360 metros diários. Devido ao fato da distribuição ser realizada duas vezes na semana, ficou definido neste trabalho que cada ponto de demanda de cada rota receberá 7 garrafões a cada entrega, totalizando 14 garrafões por semana. Como a capacidade do transporte utilizado é de 59 garrafões, para entregar sete garrafões por ponto, a quantidade de pontos atendidos por veículo será de oito pontos $(59 \div 7)$, com uma folga de 3 garrafões.

Tendo sido definida a quantidade de pontos de demanda a serem atendidos por veículo, determinou-se o número de rotas necessárias. Como o número de clientes a serem atendidos é de 46 e como só podem ser efetuadas oito visitas a cada viagem, teremos que ter, então, a formação de seis rotas. Destas, cinco atenderão a oito pontos de demanda e uma atenderá a seis pontos, satisfazendo assim os 46 pontos de demanda existentes. Desta maneira, contabilizando os garrafões das folgas, para os quais quase sempre há uma demanda também, com a percorrida das seis rotas duas vezes por semana, a quantidade entregue por semana será de 708 garrafões por semana, e, portanto, de 2.832 garrafões por mês.

Na Figura 1, a seguir, são apresentadas as nove rotas desenvolvidas pela empresa por ocasião da pesquisa e na Tabela 1, as distâncias percorridas por cada uma das nove rotas.

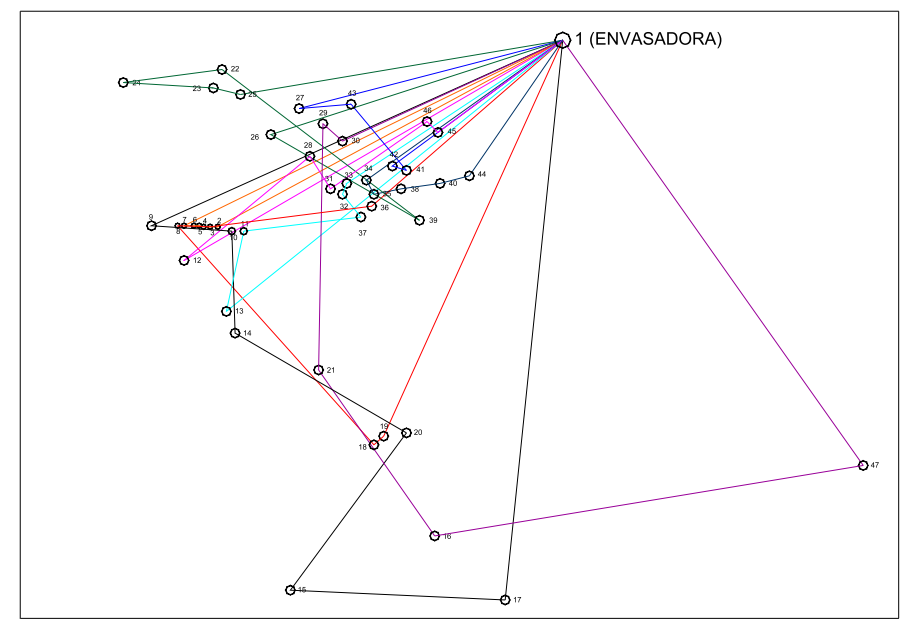

Figura 1. Roteamento desenvolvido pela empresa por ocasião da pesquisa (9 rotas).

\section{Metodologia Proposta para a Solução do PRV}

É aqui apresentada uma metodologia para realizar o roteamento de veículos, sendo que a mesma é ilustrada a um estudo de caso - problema de distribuição de água mineral na cidade de Itú. Embora a quantidade de pontos de demanda a ser atendida neste problema específico não seja muito grande, optou-se pela utilização dos algoritmos heurísticos e meta-heurísticos, afim de que esta metodologia possa, de fato, ser aplicada em problemas de qualquer ordem.

A metodologia está dividida em quatro etapas: na primeira etapa é aplicado o Algoritmo de Teitz \& Bart (Teitz \& Bart, 1968) para a determinação de medianas, cuja quantidade varia de acordo com a quantidade de pontos a serem atendidos e, também com a capacidade dos veículos que fazem a entrega; na segunda etapa, propõe-se a aplicação do algoritmo de Gillett e Johnson modificado (Bodin et al., 1983; Corrêa, 2000), definindo os diversos clusters de pontos a serem atendidos por cada um dos veículos. Na terceira etapa é definido o roteamento para cada veículo, ou seja, a sequência em que os pontos deverão ser atendidos e, para 
Tabela 1. Distâncias percorridas em cada uma das rotas apresentadas na Figura 1.

\begin{tabular}{cclllllllll}
\hline Rotas & Distância $(\mathbf{m})$ & \multicolumn{1}{c}{ Sequência de atendimento } \\
\hline 1 & 16.639 & 1 & 9 & 10 & 14 & 20 & 15 & 17 & 1 \\
2 & 10.972 & 1 & 36 & 3 & 8 & 18 & 19 & 1 & \\
3 & 8.593 & 1 & 33 & 32 & 37 & 11 & 13 & 1 & \\
4 & 5.875 & 1 & 42 & 41 & 43 & 27 & 1 & & \\
5 & 11.717 & 1 & 25 & 23 & 24 & 22 & 39 & 26 & 1 \\
6 & 8.554 & 1 & 45 & 46 & 31 & 28 & 12 & 1 & \\
7 & 7.812 & 1 & 2 & 4 & 5 & 6 & 7 & 1 & \\
8 & 4.785 & 1 & 34 & 35 & 38 & 40 & 44 & 1 & \\
9 & 15.414 & 1 & 47 & 16 & 21 & 29 & 30 & 1 & \\
\hline Total & $\mathbf{9 0 . 3 6 1}$ & & & & & & & & \\
\hline
\end{tabular}

isto, faz-se uso dos algoritmos heurísticos dos Savings de Clarke \& Wright (Bodin et al., 1983), da Inserção do Ponto Mais Próximo (Bodin et al., 1983), da meta-heurística Busca Tabu (Glover \& Laguna, 1997) e de algumas de suas combinações, comparativamente. Finalmente, na quarta e última etapa é realizada a análise e comparação entre as rotas obtidas verificando-se a melhor opção de resolução para o caso aqui abordado.

\subsection{Etapa 1: localização das medianas}

De acordo com Minieka (1978), dado um grafo, a mediana é o vértice cuja distância dele a todos os outros é a menor possível. Historicamente, os estudos relativos à aplicação de medianas na resolução de problemas, tiveram início com Weber que, em 1929, estudou a localização de uma fábrica visando minimizar a distância desta aos diversos pontos de matéria-prima e o mercado consumidor. A extensão deste problema deu origem à metodologia das $p$-medianas. A busca de $p$-medianas em um grafo é um problema clássico de localização, que tem por objetivo localizar $p$ facilidades (medianas) de forma a minimizar a soma das distâncias de cada vértice a sua facilidade mais próxima, sendo comumente chamados de "problemas de localização de soma mínima (minisum)".

\subsubsection{Formulação matemática para o problema das $p$-medianas:}

A formulação proposta por Christofides (1975), resolve o problema de localização das p-medianas como um Problema de Programação Linear Inteiro Binário (PPLIB).

Seja $\left[\xi_{i j}\right]$ uma matriz de alocações, onde:

$$
\xi_{i j}= \begin{cases}1, & \text { se o vértice } x_{j} \text { é alocado ao vértice } x_{i} ; \\ 0, & \text { caso contrário. }\end{cases}
$$

Além disto,

$$
\xi_{i i}= \begin{cases}1, & \text { se o vértice } x_{i} \text { é uma mediana; } \\ 0, & \text { caso contrário. }\end{cases}
$$

O problema das $p$-medianas pode então ser formulado como segue.

$$
\begin{array}{ccl}
\min & Z=\sum_{i=1}^{n} \sum_{j=1}^{n} d_{i j} \xi_{i j} & \\
\text { sa } & \sum_{i=1}^{n} \xi_{i j}=1 & \text { para } j=1 . . n \\
& \sum_{i=1}^{n} \xi_{i i}=p & \\
& \xi_{i j} \leq \xi_{i i}=1 & \text { para todo } i, j=1 . . n \\
& \xi_{i j} \in\{0,1\} &
\end{array}
$$

onde $[d i j]$ é a matriz de distâncias ponderadas, isto é, a matriz de distâncias com cada coluna $j$ multiplicada pelo peso $v_{j}$, cujos valores serão determinados por cada problema. A função objetivo (3) minimiza a soma das distâncias dos vértices de demanda até o conjunto de medianas. As restrições (4) asseguram que todo vértice $x_{j}$ é alocado a um, e somente um, vértice mediana $x_{i}$. As restrições (5) asseguram que existem exatamente $p$ 
vértices medianas. As restrições (6) garantem que as alocações só podem ser feitas a vértices-medianas. As restrições (7) garantem a integralidade, ou seja, $\xi_{i j}$ é variável binária, podendo assumir o valor "0" ou " 1 ".

Se as restrições (7) forem reformuladas para $\xi_{i j} \geq 0$, então o problema resultante é um Problema de Programação Linear. Em função de o problema ser formulado como um PPLIB, por si só já é bastante complexo, dependendo da cardinalidade de nós do grafo, sua resolução torna-se inviável. Desta forma, são propostas heurísticas para resolver o problema.

Diversas heurísticas têm sido desenvolvidas para o problema das $p$-medianas. Apresenta-se a seguir o Algoritmo de Teitz \& Bart aplicado na primeira etapa da resolução do caso real, objeto deste estudo.

\subsubsection{Descrição do algoritmo de Teitz \& Bart}

Entre as heurísticas desenvolvidas para o problema das $p$-medianas, a mais conhecida foi desenvolvida por Teitz \& Bart (1968), denominada de Algoritmo das p-medianas de Teitz \& Bart. Esta heurística baseia-se na substituição de vértices. Sua finalidade é melhorar o valor da função objetivo a cada iteração, partindo-se de uma solução inicial. Além de produzir boas soluções para problemas pequenos, principalmente quando aplicada várias vezes ao mesmo problema com diferentes soluções iniciais, esta heurística é de fácil implementação.

O Algoritmo de Teitz \& Bart para o problema das $p$-medianas pode ser definido como segue: $\operatorname{seja} G(V, A)$ um grafo não direcionado onde $V$ são os seus vértices e $A$ as suas arestas. Seja $v_{i}$ um vértice qualquer pertencente a $V$ e sejam conhecidas as distâncias euclidianas entre todos os vértices de $V$. Denomina-se número de transmissão do vértice $v_{i}, \sigma\left(v_{i}\right)$, a soma do produto entre as menores distâncias existentes do vértice $v_{i}$ a todos os demais vértices $v_{j}$ do grafo e o peso $w_{j}$ associado a cada vértice $v_{j}$. Sendo $n$ o número total de vértices do grafo, o número de transmissão é dado pela equação (8) a seguir.

$$
\sigma\left(v_{i}\right)=\sum_{j=1}^{n} w_{j} d\left(v_{i}, v_{j}\right), \quad v_{i}, v_{j} \in V
$$

Assim sendo, $v_{m}$ é uma mediana se (9) for atendida,

$$
\sigma\left(v_{m}\right)=\min \left\{\sigma\left(v_{i}\right)\right\}, \forall v_{i} \in V
$$

ou seja, entre todos os vértices do grafo, $v_{m}$ é aquele que produz a menor soma total das distâncias desde si próprio até cada um dos demais vértices do grafo.

Para o problema de encontrar $p$-medianas $(p>1)$, toma-se um conjunto de vértices $\left(V_{p}\right)$ pertencentes a $V$ escolhidos aleatoriamente, onde a quantidade de vértices em $V_{p}$ é igual ao número de medianas procuradas $\left(\left|V_{p}\right|=p\right)$.

$$
\begin{gathered}
d\left(V_{p}, v_{j}\right)=\min \left\{d\left(v_{i}, v_{j}\right)\right\} \forall v_{i} \in V_{p}, v_{j} \in V \\
\sigma\left(V_{p}\right)=\sum_{j=1}^{n} w_{j} d\left(V_{p}, v_{j}\right), \forall v_{j} \in V .
\end{gathered}
$$

Desta maneira, um conjunto de $p$ vértices é a solução ótima para o problema das $p$-medianas se, entre todos os outros conjuntos de $p$ vértices do grafo, é aquele que produz a menor distância total desde si próprio até todos os outros vértices do grafo. Portanto, deve-se ter 12.

$$
\sigma\left(V_{p_{\text {solução ótima }}}\right)=\min \left\{\sigma\left(V_{p}\right)\right\}, \forall V_{p} \subset V .
$$

O objetivo do algoritmo das $p$-medianas de Teitz \& Bart é, portanto, encontrar um conjunto $V_{p}$ em $V$ para o qual o número de transmissão seja mínimo. A seguir é descrito o procedimento básico executado pelo algoritmo das p-medianas de Teitz \& Bart (Teitz \& Bart, 1968).

\section{Algoritmo de Teitz \& Bart:}

Passo 1: Selecione aleatoriamente um conjunto $V_{p} \subset V$ com $\left|V_{p}\right|=p$ para formar uma solução inicial para o problema.

Passo 2: Rotule todos os vértices $v_{i} \in\left\{V-V_{p}\right\}$ como "não analisados".

Passo 3: Enquanto existirem vértices não analisados em $\left\{V-V_{p}\right\}$ faça: Selecione um vértice não analisado $v_{i} \in\left\{V-V_{p}\right\}$, e calcule a redução $\Delta_{i j}$ do número de transmissão, para todos os vértices $v_{j}$ pertencentes a $V_{p}$, conforme equação (13) a seguir.

$$
\Delta_{i j}=\sigma\left(V_{p}\right)-\sigma\left(V_{p} \cup\left\{v_{i}\right\}-\left\{v_{j}\right\}\right), \forall v_{j} \in V_{p}
$$


Faça $\Delta_{i j \text { máximo }}=\max \left[\Delta_{i j}\right], \forall \Delta_{i j}$ calculado anteriormente.

Se $\Delta_{i j \text { máximo }}>0$ então:

Faça $V_{p}=\left(V_{p} \cup\left\{v_{i}\right\}-\left\{v_{j}\right\}\right)$ e insira $v_{j}$ em $\left\{V-V_{p}\right\}$.

Rotule $v_{j}$ como "analisado" e inicie o Passo 3 novamente

Caso contrário , rotule $v_{i}$ como "analisado" e inicie o Passo 3 novamente.

Não existindo mais vértices a serem analisados, apresente o conjunto $V_{p}$ obtido.

Passo 4: Utilize o conjunto $V_{p}$ obtido no Passo 3 e inicie novamente pelo Passo 2.

Se durante a execução do Passo 3, houver alguma modificação no conjunto $V_{p}$, então volte ao Passo 2 e continue a execução do algoritmo. Caso contrário, pare e apresente o conjunto $V_{p}$ como uma solução aproximada para o problema das $p$-medianas.

\subsection{Etapa 2: formação dos clusters (agrupamentos)}

Após a obtenção das medianas, a próxima etapa é a determinação dos diversos clusters (grupos) de pontos de demanda a serem atendidos por cada um dos veículos. Esta etapa é realizada utilizando o algoritmo de Gillett e Johnson modificado (Bodin et al., 1983; Corrêa, 2000). Trata-se de um procedimento heurístico para designar um ponto de demanda a depósitos, que neste problema são representados pelas medianas.

Inicialmente, todos os pontos de demanda encontram-se sem designação. Para cada ponto $i$ sejam $L_{1}(i)$ e $L_{2}(i)$ o primeiro e o segundo depósitos mais próximos a $i$ respectivamente.

Para cada ponto $i$, a diferença: $d(i)=L_{2}(i)-L_{1}(i)$ é calculada e todos os pontos são colocados numa "lista de designação" em ordem decrescente pelos valores de $d(i)$. A designação começa pelos primeiros elementos da lista (pontos com maior diferença $d(i)$ ), e é feita obedecendo-se a capacidade dos depósitos. Durante a designação, sempre que a última vaga restante em um depósito for preenchida, a diferença $d(i)$ é recalculada para todos os pontos de demanda que ainda não foram designados, considerando-se apenas os depósitos cuja capacidade não esteja esgotada. Estes pontos de demanda são novamente colocados na "lista de designação", em ordem decrescente pelos valores de $d(i)$, e a designação continuará até que todos os pontos de demanda tenham sido designados para algum depósito.

\section{Algoritmo de Gillett e Johnson modificado:}

Passo 1: Para todo ponto $i$ não designado, faça: Encontre $L_{1}(i)$ e $L_{2}(i)$ respectivamente o primeiro e o segundo depósitos (medianas) mais próximos do ponto de demanda $i$ cujas capacidades não estejam esgotadas. Calcule a diferença $d(i)=L_{2}(i)-L_{1}(i)$ e coloque o ponto $i$ na "lista de designação" pela ordem decrescente dos valores de $d(i)$. Iniciando pelo topo da "lista de designação" designe o ponto de demanda $i$ para o depósito (mediana) mais próximo.

Passo 2: Enquanto existirem pontos de demanda sem designação, faça: designe o ponto de demanda atual para o depósito (mediana) mais próxima de sua localização que dispuser de capacidade; diminua uma unidade da capacidade do depósito (mediana) para o qual o ponto de demanda atual foi designado; se a capacidade do depósito (mediana) que recebeu o ponto de demanda atual ficou esgotada (igual a zero), então, volte ao Passo 1 e recalcule a "lista de designação"; caso contrário, continue.

\subsection{Etapa 3: roteamento de veículos}

A etapa de roteamento para cada veículo, ou seja, a seqüência em que os pontos de demanda pertencentes a um mesmo cluster devem ser atendidos foi realizada utilizando os algoritmos heurísticos: Savings de Clarke e Wright (Bodin et al., 1983; Clarke \& Wright, 1964); Inserção do Ponto de Demanda mais Próximo (Bodin et al., 1983); da meta-heurística Busca Tabu (Glover \& Laguna, 1997) e através de algumas de suas combinações, comparativamente.

\subsubsection{Descrição do algoritmo dos savings de Clarke e Wright}

O algoritmo dos savings (ecomomias) de Clarke e Wright é um dos algoritmos heurísticos clássicos de construção de rotas, sendo muito aplicado na resolução tanto do Problema do Caixeiro Viajante Simples, como na dos Múltiplos Caixeiros Viajantes. O procedimento deste algoritmo é a construção de rotas simultaneamente, sendo que a sua característica principal é o conceito de "economia" obtido através da ligação de dois nós de forma sucessiva num grafo, ou seja, a cada iteração vai-se efetuando trocas nestas rotas objetivando um conjunto melhor de rotas. 
O processo é inicializado com tantas rotas quantas forem o número de pontos de demanda, supondo-se assim, que existam $n$ veículos a fim de atender as demandas de cada um dos pontos individualmente. O cálculo da economia de distâncias resultantes da inserção de pontos de demanda, entre o depósito e outro ponto de demanda é determinado para todos os pontos de demanda. Verifica-se, assim, a possibilidade de trocar dois veículos que atendem aos pontos de demanda $i$ e $j$ por apenas um, visando a maximizar as economias.

\section{Algoritmo dos savings de Clarke e Wright:}

Passo 1: Selecione o nó que será definido como depósito (nó 1), inicialize as $n$ rotas ligando cada ponto de demanda exclusivamente ao depósito, obtendo-se as rotas $(1-i-1)$, para $i=2, \ldots, n$.

Passo 2: Calcule os savings para todos os pares $(i, j)$ da seguinte maneira: $s_{i j}=0$ se $i=j ; i=1 ; j=1$. Nos demais caso calcule: $s_{i j}=c_{1 i}+c_{1 j}-c_{i j}$, para $i, j=2,3, \ldots, n$.

Passo 3: Ordene os savings dos pares $(i, j)$ em ordem decrescente.

Passo 4: Iniciando do topo da lista dos savings forme sub-rotas maiores ligando os pontos de demanda $i$ e $j$ apropriados. Os pontos de demanda só podem ser incluídos "nas pontas" das sub-rotas. Repetir este procedimento até que todos os pontos de demanda tenham sido "designados".

\subsubsection{Descrição do algoritmo de inserção do mais próximo:}

Segundo Goldbarg \& Luna (2000), o algoritmo da inserção do mais próximo é uma heurística que possui um processo onde três níveis de decisão são envolvidos: a escolha do vértice a ser inserido na solução; a posição de inserção deste novo vértice; a decisão de um ciclo inicial.

Normalmente este tipo de heurística parte de uma sub-rota (subtour) inicial (um ciclo normalmente de comprimento igual a três) e vai selecionando e inserindo vértices ainda não incluídos na solução até completar um ciclo. No algoritmo aplicado neste trabalho, o critério utilizado para a seleção dos vértices a serem acrescidos ao subtour é a inserção do vértice mais próximo.

\section{Algoritmo de inserção do mais próximo:}

Passo 1: Comece com um sub-grafo consistindo somente do nó $i$.

Passo 2: Ache o nó $k$ tal que $c_{i k}$ seja mínimo e forme a sub-rota $i-k-i$.

Passo 3: (Passo de seleção): Dada uma sub-rota, encontre o nó $k$ que não esteja na sub-rota e que esteja mais próximo de qualquer nó da sub-rota.

Passo 4: (Passo de inserção): Encontre o $\operatorname{arco}(i, j)$ da sub-rota que minimize: $c_{i k}+c_{k j}-c_{i j}$. Insira $k$ entre $i$ e $j$.

Passo 5: Volte ao Passo 3 até obter um ciclo Hamiltoniano.

\subsubsection{Busca tabu}

A meta-heurística Busca Tabu (Tabu Search), segundo Viana (1998), teve origem a partir de uma solução de Glover (1986) para problemas de Programação Inteira. Glover é considerado o criador do Algoritmo Tabu Search devido aos seus inúmeros trabalhos publicados.

Segundo Glover \& Laguna (1997) em seu livro especializado neste assunto, Busca Tabu é uma metaheurística que guia um procedimento heurístico de busca local para explorar o espaço solução além do "ótimo local".

A Busca Tabu pode ser caracterizada como sendo uma busca através das soluções vizinhas. Dada uma solução $x \in X$ em um conjunto associado de soluções vizinhas $V(x) \subset X$ chamadas soluções vizinhas a $x$, toda solução $x^{\prime} \in V(x)$ pode ser gerada a partir de $x$ por certo tipo de operação denominada movimento. Normalmente em Busca Tabu, soluções vizinhas são simétricas, ou seja, $x^{\prime}$ é solução vizinha a $x$ se, e somente se, $x$ é solução vizinha a $x^{\prime}$.

Este método tem como base as noções de "movimento" e "vizinhança". O "movimento" é uma função que transforma uma solução em outra. A "vizinhança" é o conjunto de soluções obtidas aplicando a uma determinada solução um subconjunto dos movimentos possíveis.

A Busca Tabu, que foi projetada para encontrar boas aproximações para a solução ótima global de qualquer problema de otimização, basicamente norteia-se por três princípios: uso de uma estrutura de dados (fila ou lista) para "guardar" o histórico da evolução do processo de busca; uso de um mecanismo de controle para fazer um balanceamento entre a aceitação, ou não de uma nova configuração, com base nas informações registradas 
na "lista tabu" referentes às restrições e aspirações desejadas; incorporação de procedimentos que alternam as estratégias de diversificação e oscilação.

O procedimento da meta-heurística Busca Tabu começa a partir de uma solução inicial. Em cada passo gera-se a vizinhança da solução atual e faz-se uma pesquisa para determinar o vizinho com as melhores características. Este vizinho passa a ser a nova solução atual e efetua-se um novo passo.

Para prevenir ciclos e guiar o algoritmo para regiões "boas" do espaço de procura, mantém-se um histórico das soluções já visitadas em memória de curta duração designado por "lista tabu" que tem um papel fundamental. Esta lista não permite que o algoritmo volte para trás e revisite uma solução pela qual tenha passado nos passos anteriores. Na prática, a lista tabu contém os atributos de soluções revisitadas ou os movimentos que lhe deram origem em vez das soluções propriamente dita. O tempo que um movimento deve permanecer nesta lista, em geral, está relacionado com o número de iterações do algoritmo e com o número de movimentos possíveis a partir da solução que está sendo analisada.

Pelo fato de se ter os movimentos proibidos, podendo-se proibir por vezes soluções interessantes, define-se também os critérios de aspiração, que têm o papel de avaliar se, apesar de proibido, vale a pena (ou não) realizar um movimento proibido. Os critérios de aspiração são introduzidos em Busca Tabu a fim de determinar quando uma restrição tabu pode ser "quebrada", ou seja, quando a restrição pode ser ignorada e o movimento, mesmo classificado como proibido, pode ser executado. Um critério de aspiração bastante utilizado é o de ignorar a restrição tabu sempre que a solução formada por um determinado movimento proibido for melhor do que a melhor solução encontrada até o momento. A aplicação adequada deste procedimento é fundamental para se atingir altos níveis de desempenho em Busca Tabu.

O algoritmo termina quando é atingido um critério de parada. Normalmente o critério de parada é um número pré-especificado de iterações ou um número pré-especificado de iterações após a última melhoria ter sido encontrada.

Como na maior parte dos outros algoritmos, é importante que o algoritmo esteja bem adaptado ao problema a resolver e, para tal, a implementação dos conceitos definidos anteriormente deve ser feita com o cuidado de possuir a estrutura particular do problema em questão.

\section{Implementação da Metodologia ao Problema Real e Análise dos Resultados}

Objetivando a solução para o caso real apresentado na seção 2, os algoritmos descritos na seção 3 foram devidamente modelados ao mesmo. O procedimento desenvolveu-se segundo as seguintes fases:

$1^{a}$ fase: Nesta fase realizou-se uma visita a empresa, objetivando conhecer os procedimentos atualmente realizados em relação ao roteamento e o levantamento dos dados necessários para o estudo pretendido.

$2^{a}$ fase: O objetivo desta fase foi a determinação, dentre os pontos de demanda, de seis medianas de tal forma que a soma das distâncias de cada ponto até a mediana mais próxima fosse a menor possível. Dentre as várias heurísticas disponíveis, optou-se pela aplicação do Algoritmo das p-medianas de Teitz \& Bart.

$3^{a}$ fase: A partir da determinação das medianas, o próximo passo executado foi a formação de agrupamentos (clusters) em torno das medianas, de maneira que haja uma distribuição uniforme dos pontos de demanda entre as medianas. A finalidade deste procedimento é obter um melhor roteamento ( $4^{a}$. Fase). Aplicouse para tal, o procedimento heurístico de Gillett e Johnson modificado.

$4^{a}$ fase: Esta fase é a de roteamento. Objetivando uma solução que resulte numa maior eficiência com o menor custo possível. Aplicou-se para tal, duas heurísticas e uma meta-heurística: Algoritmo dos savings de Clarke e Wright, Algoritmo de Inserção do Mais Próximo e Busca Tabu. A Figura 2, a seguir, apresenta a esquematização destas quatro fases.

Em virtude de não haver software disponível no mercado que permitisse a resolução deste problema, todos os algoritmos utilizados para resolver o problema apresentado foram implementados em Visual Basic.

\subsection{Levantamento de dados: $1^{a}$ fase}

Inicialmente, procedeu-se a um trabalho manual de localização dos pontos de demanda e da envasadora no mapa digitalizado/Google Earth, determinando-se as coordenadas de cada um deles. Ainda nesta fase, obtiveram-se os dados referentes à quantidade de garrafões entregues em cada ponto de demanda, a frequência desta entrega e a sequência de atendimento dos pontos de demanda, como já descrito na seção 2. A localização da envasadora, denotada como ponto 1, e dos pontos de demanda, numerados de 2 a 47, são mostrados na Figura 3 . 


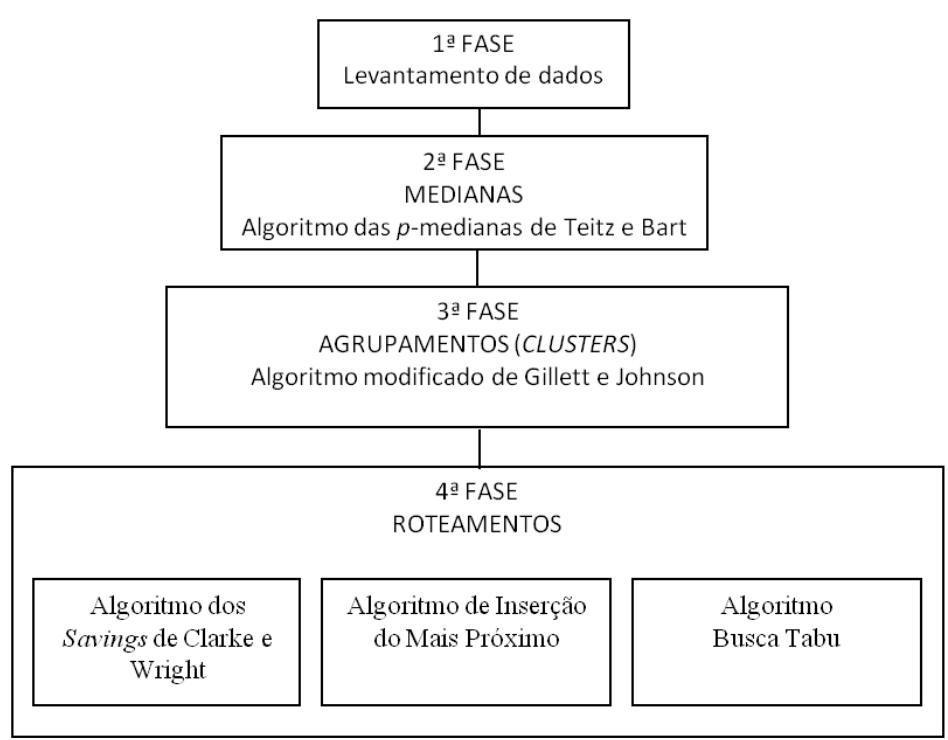

Figura 2. Esquema da metodologia para a resolução do problema de distribuição abordado.

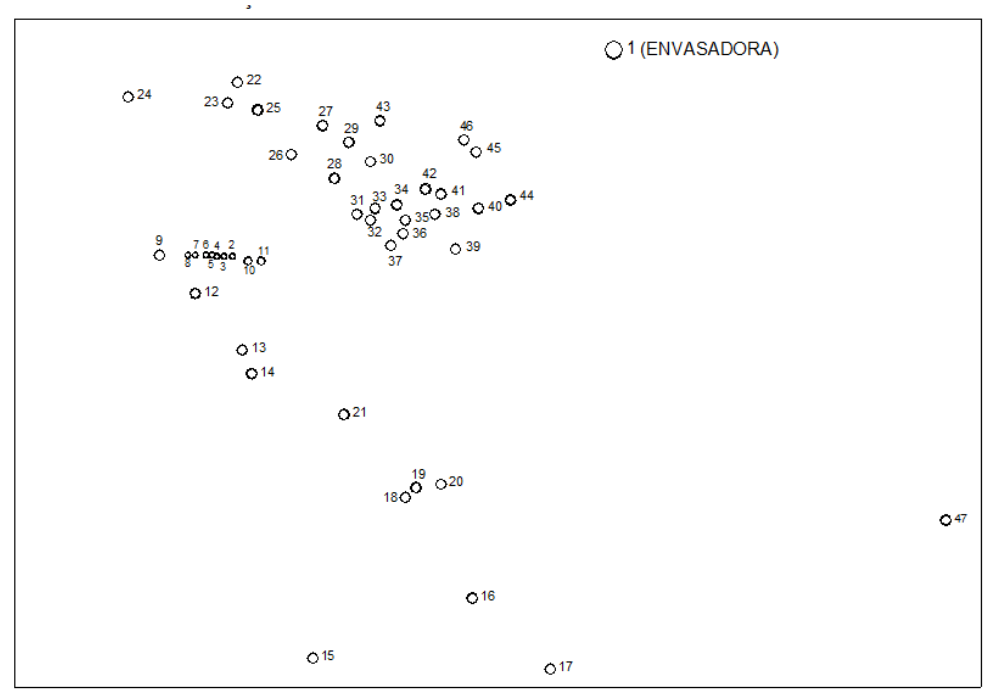

Figura 3. Localização dos pontos de demanda. 


\subsection{Determinação das medianas: $2^{a}$ fase}

Em virtude de serem 6 rotas, como já mencionado, buscou-se encontrar 6 medianas dentre os 46 pontos de demanda existentes. Após uma análise dos resultados obtidos com a aplicação do Algoritmo de Teitz \& Bart contendo todos os pontos de demanda, seguido dos procedimentos para agrupamento e roteamento, entendeuse que para uma melhor eficiência, seria necessário que o ponto de número 47, devido a sua localização em relação aos demais pontos, fosse excluído da lista de candidatos à mediana. Procedeu-se, então, a uma nova aplicação do Algoritmo de Teitz \& Bart, obtendo-se como medianas, os pontos: 23, 29, 19, 4, 16, 38, mostradas na Figura 4.

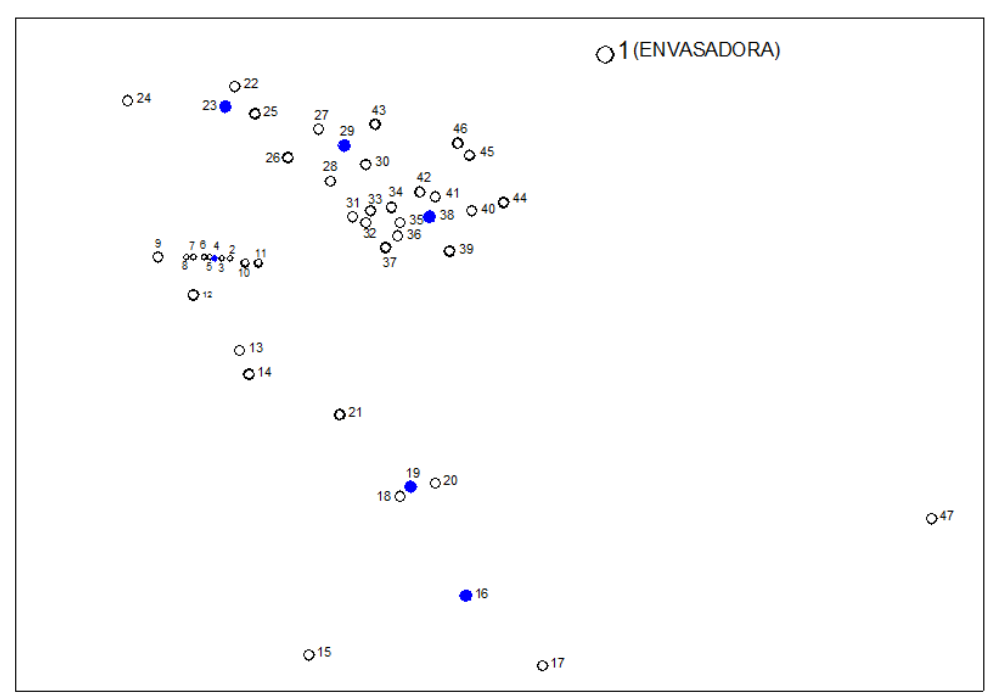

Figura 4. Localização das medianas (obtidas através do algoritmo de Teitz \& Bart).

\subsection{Formação dos agrupamentos clusters: $3^{a}$ fase}

Após a determinação das 6 medianas, procedeu-se a aplicação do algoritmo modificado de Gillett e Johnson modificado para a formação dos agrupamentos em torno destas medianas, objetivando uma alocação uniforme dos pontos de demanda a serem atendidos. Os resultados obtidos podem ser visualizados na Figura 5, sendo que os pontos designados a cada rota estão no Tabela 2.

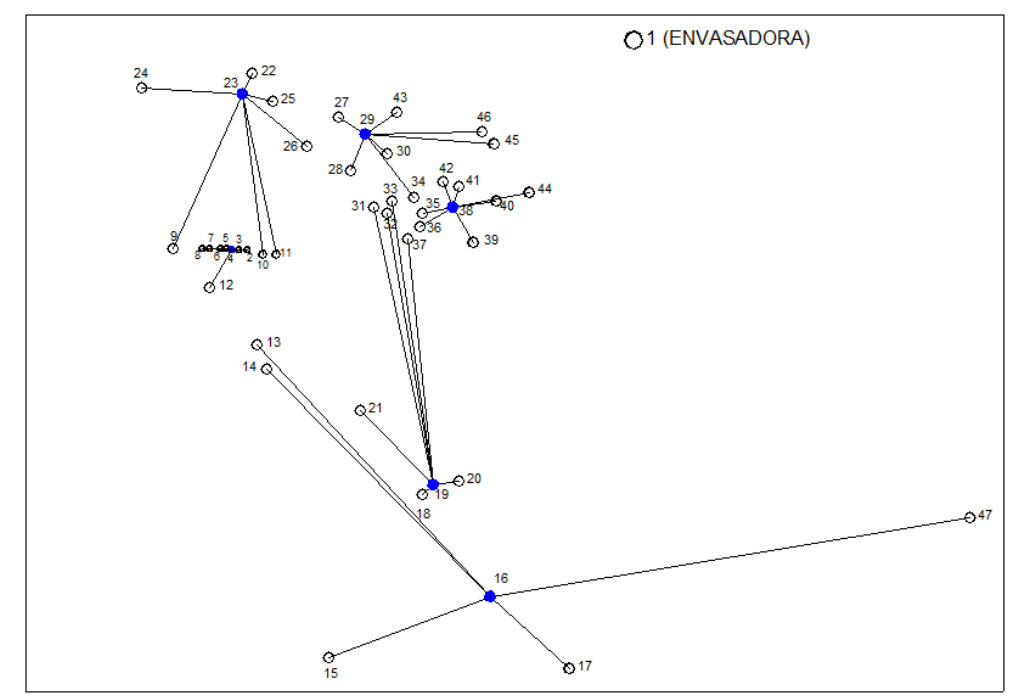

Figura 5. Obtenção dos agrupamentos (algoritmo de Gillett e Johnson). 
Tabela 2. Agrupamentos obtidos através do algoritmo de Gillettt e Johnson.

\begin{tabular}{cllllllll}
\hline Cluster & \multicolumn{4}{c}{ Pontos de demanda designados a cada cluster } \\
\hline 1 & 4 & 12 & 5 & 3 & 6 & 2 & 7 & 8 \\
2 & 23 & 24 & 22 & 25 & 26 & 9 & 10 & 11 \\
3 & 16 & 17 & 13 & 14 & 47 & 15 & & \\
4 & 19 & 21 & 18 & 20 & 31 & 32 & 33 & 37 \\
5 & 38 & 39 & 40 & 44 & 41 & 36 & 35 & 42 \\
6 & 29 & 43 & 28 & 27 & 45 & 30 & 46 & 34 \\
\hline
\end{tabular}

\subsection{Roteamento: $4^{a}$ fase}

Após a formação dos agrupamentos, procedeu-se a fase de roteamento onde foram aplicados os algoritmos dos Savings de Clarke e Wright, inserção do mais próximo e busca Tabu.

\section{A. Algoritmo dos savings de Clarke e Wright}

A Figura 6 apresenta as rotas determinadas pelo algoritmo dos savings de Clarke e Wright. Já a Tabela 3 apresenta para cada rota a distância percorrida e a sequência dos pontos de demanda a serem atendidos, além da distância total percorrida.

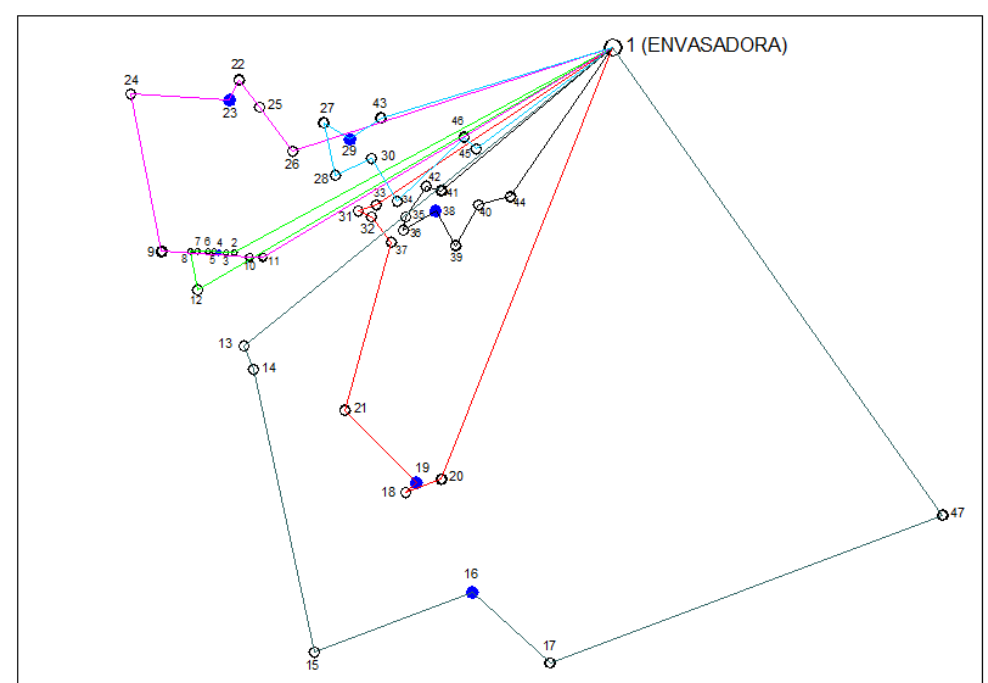

Figura 6. Ilustração do roteamento (algoritmo dos savings de Clarke e Wright).

Tabela 3. Distância percorrida em cada uma das rotas da Figura 6.

\begin{tabular}{|c|c|c|c|c|c|c|c|c|c|c|c|}
\hline Rotas & Distância (m) & & $q u$ & nci & a de & ate & ndi & mer & to & & \\
\hline 1 & 8.349 & 1 & 2 & 3 & 4 & 5 & 6 & 7 & 8 & 12 & 1 \\
\hline 2 & 17.245 & 1 & 13 & 14 & 15 & 16 & 17 & 47 & 1 & & \\
\hline 3 & 9.592 & 1 & 20 & 18 & 19 & 21 & 37 & 32 & 31 & 33 & 1 \\
\hline 4 & 10.221 & 1 & 26 & 25 & 22 & 23 & 24 & 9 & 10 & 11 & 1 \\
\hline 5 & 6.167 & 1 & 43 & 29 & 27 & 28 & 30 & 34 & 46 & 45 & 1 \\
\hline 6 & 5.268 & 1 & 41 & 42 & 35 & 36 & 38 & 39 & 40 & 44 & 1 \\
\hline Total & 56.842 & & & & & & & & & & \\
\hline
\end{tabular}

\section{B. Algoritmo de inserção do mais próximo}

A Figura 7 mostra as rotas definidas pleo algoritmo de inserção do mais próximo. A Tabela 4 apresenta para cada rota a sequência de atendimento e a distância percorrida, além de fornecer a distância total percorrida. 


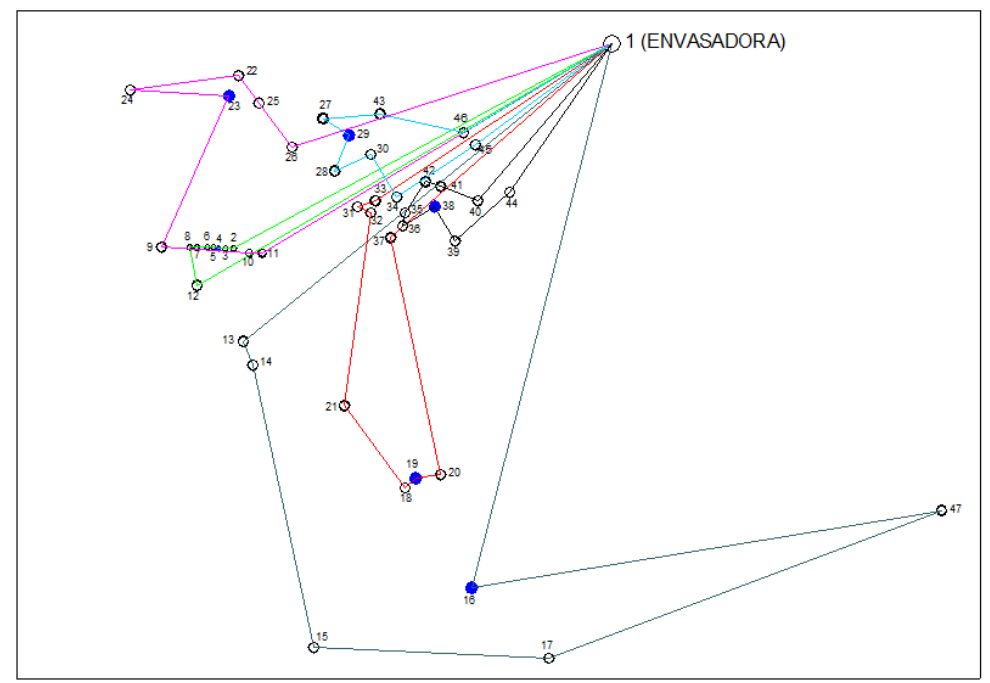

Figura 7. Ilustração do roteamento (algoritmo da inserção do mais próximo).

Tabela 4. Distância percorrida em cada uma das rotas da Figura 7.

\begin{tabular}{ccclllllllllll}
\hline Rotas & Distância $(\mathbf{m})$ & \multicolumn{1}{c}{ Sequência de atendimento } \\
\hline 1 & 8.349 & 1 & 12 & 8 & 7 & 6 & 5 & 4 & 3 & 2 & 1 \\
2 & 20.851 & 1 & 16 & 47 & 17 & 15 & 14 & 13 & & & \\
3 & 9.999 & 1 & 33 & 31 & 32 & 21 & 18 & 19 & 20 & 37 & 1 \\
4 & 10.998 & 1 & 11 & 10 & 9 & 23 & 24 & 22 & 25 & 26 & 1 \\
5 & 6.218 & 1 & 45 & 34 & 30 & 28 & 29 & 27 & 43 & 46 & 1 \\
6 & 5.412 & 1 & 44 & 39 & 38 & 36 & 35 & 42 & 41 & 40 & 1 \\
\hline Total & $\mathbf{6 1 . 8 2 7}$ & & & & & & & & & &
\end{tabular}

\section{Busca tabu}

Em seguida procedeu-se o roteamento através de Busca Tabu, também utilizando os agrupamentos formados através do Algoritmo de Gillett e Johnson. Aplicou-se Busca Tabu em 3 rotas iniciais diferentes. Em cada uma das rotas iniciais, aplicou-se Busca Tabu definindo-se 5 trocas em cada iteração. Foram realizados vários testes com relação ao número de iterações, sendo que a melhor solução foi obtida com 300 iterações. A seguir, na Figura 8 e Tabela 5 estão os resultados para uma destas situações.

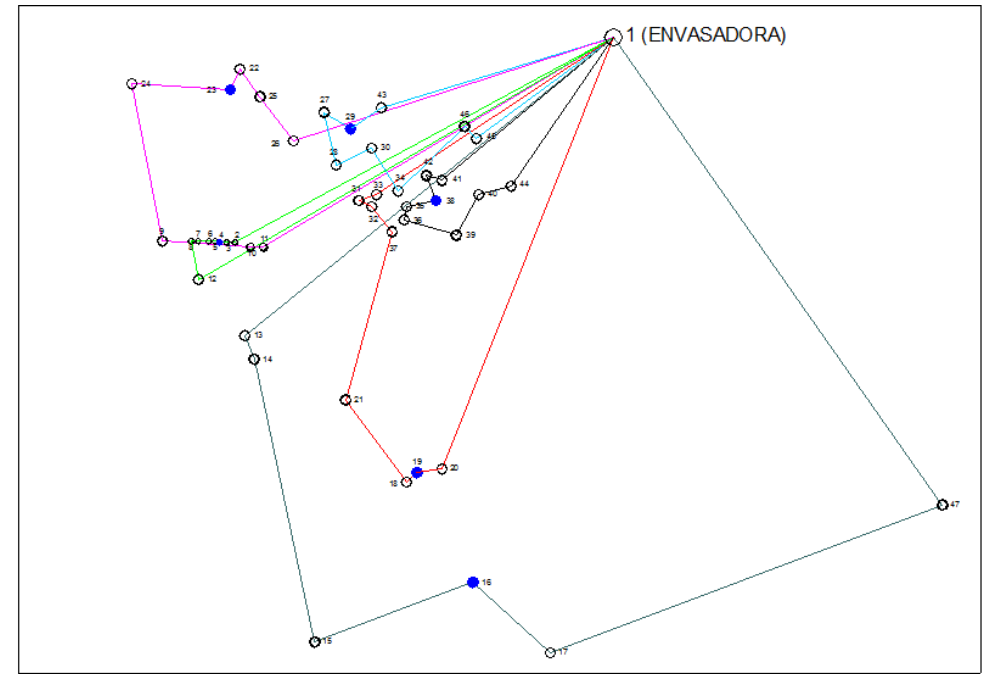

Figura 8. Ilustração do roteamento (busca tabu - 300 iterações).

Diversas simulações adicionais foram realizadas utilizando a busca tabu: 
Tabela 5. Distância percorrida em cada uma das rotas da Figura 8.

\begin{tabular}{|c|c|c|c|c|c|c|c|c|c|c|c|}
\hline \multirow{2}{*}{$\frac{\text { Rotas }}{1}$} & \multirow{2}{*}{$\frac{\text { Distância (m) }}{8.349}$} & \multicolumn{10}{|c|}{ Sequência de atendimento } \\
\hline & & 1 & 2 & 3 & 4 & 5 & 6 & 7 & 8 & 12 & 1 \\
\hline 2 & 17.245 & 1 & 13 & 14 & 15 & 16 & 17 & 47 & 1 & & \\
\hline 3 & 9.486 & 1 & 33 & 31 & 32 & 37 & 21 & 18 & 19 & 20 & 1 \\
\hline 4 & 10.221 & 1 & 26 & 25 & 22 & 23 & 24 & 9 & 10 & 11 & 1 \\
\hline 5 & 6.167 & 1 & 43 & 29 & 27 & 28 & 30 & 34 & 46 & 45 & 1 \\
\hline 6 & 5.246 & 1 & 44 & 40 & 39 & 36 & 35 & 38 & 42 & 41 & 1 \\
\hline Total & 56.714 & & & & & & & & & & \\
\hline
\end{tabular}

1. Tomando-se como rotas iniciais, as formadas pelo algoritmo de Clarke e Wright. Da mesma maneira, definiu-se 5 trocas para cada iteração e aplicou-se Busca Tabu variando-se o número de iterações;

2. Tomando-se como rotas iniciais, as formadas pelo algoritmo de Inserção do Mais Próximo. Analogamente, definiu-se 5 trocas para cada iteração e aplicou-se Busca Tabu variando-se o número de iterações.

Após a implementação dos algoritmos pôde-se realizar a análise dos resultados e a comparação entre as diferentes técnicas aplicadas, conforme apresentado na Tabela 6 mais adiante.

Aplicando-se o Algoritmo dos Savings de Clarke e Wright, obteve-se uma distância total percorrida de $56.842 \mathrm{~m}$, sendo que a economia em relação ao roteamento atual $(90.361 \mathrm{~m})$ é de $33.519 \mathrm{~m}$, os quais em termos percentuais reduz o total percorrido em 37,09\%. Esta redução por si só é significativa para qualquer empresa do ramo de distribuição. Com a aplicação do Algoritmo de Inserção do mais Próximo, a distância percorrida obtida foi de $61.827 \mathrm{~m}$. A redução em relação ao roteamento atual é de $28.534 \mathrm{~m}$, ou $31,58 \%$.

O roteamento através de Busca Tabu foi realizado variando-se as rotas iniciais e o número de iterações. Primeiro as rotas iniciais foram formadas seguindo a ordem de designação obtida para os agrupamentos formados através do algoritmo modificado de Gillett e Johnson. Fixando-se estas rotas iniciais obteve-se uma distância total percorrida de $56.714 \mathrm{~m}$ após 300 iterações que, dentre diversos testes realizados, apresentou o melhor resultado. Em seguida tomou-se como rotas iniciais as obtidas através do algoritmo dos Savings de Clarke e Wright. Da mesma forma, fixando-se estas rotas iniciais, obteve-se após 300 iterações, uma distância total percorrida de $56.714 \mathrm{~m}$. Por último, tomou-se como rotas iniciais as obtidas através do algoritmo de Inserção do Mais Próximo. Fixando-se as rotas iniciais, obteve-se uma distância total percorrida de $56.714 \mathrm{~m}$ após 300 iterações.

Em relação à distância total percorrida, o melhor roteamento encontrado $(56.714 \mathrm{~m})$ foi obtido através da técnica de Busca Tabu; do Algoritmo dos Savings de Clarke e Wright seguido da Busca Tabu e do Algoritmo de Inserção do Mais Próximo seguido da Busca Tabu (hachuriado na Tabela 5). A economia resultante do roteamento obtido através de Busca Tabu em relação ao do Algoritmo dos Savings de Clarke e Wright (puro, ou seja, sem a aplicação da Busca Tabu) foi de $128 \mathrm{~m}$, ou 0,23\%, enquanto que em relação ao Algoritmo de Inserção do mais Próximo (puro) foi de 5.113, ou 8,27\%.

\section{Conclusões}

O objetivo principal deste trabalho foi apresentar uma metodologia, composta de vários algoritmos, que permita a resolução de um problema real de roteamento de veículos de forma rápida e eficiente.

Aplicou-se para tal propósito os seguinte algoritmos: o Algoritmo das p-medianas de Teitz \& Bart (para a determinação de $p$-medianas), o Algoritmo modificado de Gillett e Johnson (para a clusterização dos pontos de demanda em torno das p-medianas), e os algoritmos dos Savings de Clarke e Wright, da Inserção do Mais Próximo, da Busca Tabu e algumas de suas combinações (para a obtenção das rotas, ou seja, da seqüência dos pontos dentro de cada cluster, de distância mínima) comparativamente.

A melhor solução obtida para o caso real abordado (distribuição de água mineral) foi através da aplicação da Busca Tabu e, também, através do algoritmo dos Savings de Clarke e Wright seguido da Busca Tabu e, ainda, através do algoritmo da Inserção do mais Próximo seguido da Busca Tabu. Todas estas três alternativas forneceram a distância total percorrida igual a $56.714 \mathrm{~m}$. Têm-se, assim, fortes indicativos de que, além do fato da meta-heurística Busca Tabu (pura) fornecer a solução ótima para o problema de pequeno porte aqui abordado, também o fato de que ela pode ser bastante promissora ao utilizá-la em conjunto com os procedimentos heurísticos aqui contemplados para problemas de maior porte. 
Tabela 6. Resultados comparativos (distâncias em m) para o problema real abordado.

\begin{tabular}{cccccc}
\hline \multicolumn{5}{c}{ Algoritmos } \\
\hline & A & B & C & A+C & B+C \\
\hline 1 & 8.349 & 8.349 & 8.349 & 8.349 & 8.349 \\
2 & 17.245 & 20.851 & 17.245 & 17.245 & 17.245 \\
3 & 9.592 & 9.999 & 9.486 & 9.592 & 9.592 \\
4 & 10.221 & 10.998 & 10.221 & 10.221 & 10.221 \\
5 & 6.167 & 6.218 & 6.167 & 6.167 & 6.167 \\
6 & 5.267 & 5.412 & 5.246 & 5.267 & 5.267 \\
\hline Total & $\mathbf{5 6 . 8 4 2}$ & $\mathbf{6 1 . 8 2 7}$ & $\mathbf{5 6 . 7 1 4}$ & $\mathbf{5 6 . 7 1 4}$ & $\mathbf{5 6 . 7 1 4}$ \\
\hline
\end{tabular}

A: Savings de Clarke e Wright;

B: Inserção do Ponto Mais Próximo;

C: Busca Tabu.

A solução ótima para o caso abordado, obtida através da resolução de um modelo matemático de Programação Inteira, com o uso do software comercial LINGO (Language for Interactive General Optimizer) forneceu exatamente a solução obtida através da metodologia apresentada, mostrando com isto a eficácia da mesma.

A vantagem da metodologia em relação a solução exata está na eficiência da mesma, ou seja, enquanto o software precisa de algumas horas para resolver o problema de roteamento de 46 pontos de demanda, a metodologia o faz em poucos segundos. Vale salientar que para problemas maiores, com um maior número de pontos de demanda, a adoção do modelo matemático seria totalmente inviável, enquanto que a metodologia aqui apresentada pode tolerar o número de pontos que for necessário.

\section{Referências}

Bodin, L.; Golden, B.; Assad, A. \& Ball, M., Routing and scheduling of vehicles and crews: the state of the art. Computers \& Operations Research, 10(2):63-211, 1983.

Boulduc, M.C.; Laporte, G.; Renaud, J. \& Boctor, F.F., A tabu search heuristic for the split delivery vehicle routing problem with production and demand calendars. European Journal of Operations Research, 202(1):122-130, 2010.

Breedam, A.V., Comparing descent heuristics and metaheuristics for the vehicle routing problem. Computers 86 Operations Research, 28(4):289-315, 2001.

Choi, E. \& Tcha, D.W., A column generation approach to the heterougeneous fleet vehicle routing problem. Computers ES Operations Research, 34(7):2080-2095, 2007.

Christofides, N., Graph Theory - An Algorithmic Approach. New York, USA: Academic Press, 1975.

Clarke, G. \& Wright, J.W., Scheduling of vehicles from a central depot to a number of delivery points. Operations Research, 12(4):568-581, 1964.

Corrêa, E.S., Algoritmos Genéticos e Busca Tabu Aplicados ao Problema das p-medianas. Dissertação de mestrado, Programa de Pós-Graduação em Métodos Numéricos em Engenharia, Universidade Federal do Paraná, Curitiba, PR, 2000.

Du, L. \& He, R., Combining nearest neighbor search with tabu search for large scale vehicle routing problem. Physics Procedia, 25:1536-1546, 2012.

Glover, F., Future paths for integer programming and links to artificial inteligence. Computers 6 Operations Research, 13(5):533-549, 1986.

Glover, F. \& Laguna, M., Tabu Search. University of Colorado, USA: Kluwer, Boulder, Academic Publishers, 1997.

Goldbarg, M.C. \& Luna, H.P.L., Otimização Combinatória e Programação Linear - Modelos e Algoritmos. Rio de Janeiro, RJ: Editora Campus, 2000.

Leung, S.C.H.; Zhou, X.; Zhang, D. \& Zheng, J., Extended guided tabu search and a new packing algorithm for two-dimensional loading vehicle routing problem. Computers \& Operations Research, 38:205-215, 2011.

Minieka, E., Optimization Algorithms for Networks and Graphs. New York, USA: Marcel Dekker, Inc., 1978.

Teitz, M.B. \& Bart, P., Heuristics methods for estimating the generalized vertex median of a weighted graph. operations research. Operations Research, 16:955-961, 1968.

Toth, P. \& Vigo, D., The granular tabu search and its application to the vehicle-routing problem. Journal on Computing, 15(4):333-346, 2003.

Valle, A. \& Cunha, A.S., Exact algorithms for a selective vehicle routing problem where the longest route is minimized. Discrete Mathematics, 35:133-138, 2009.

Viana, G.V.R., Meta-Heurísticas e Programação Paralela em Otimização Combinatória. Fortaleza, CE: UFC Edições, 1998. 


\section{Notas Biográficas}

Sheila Margot Gonçalves é graduada em Licenciatura em Matemática (UFPR, 1990); especialista em Matemática (UFPR, 1999); mestre em Métodos Numéricos em Engenharia (UFPR, 2003). Atualmente é docente da Universidade Positivo (UP) e da Faculdade Educacional Araucária (FACEAR).

Maria Teresinha Arns Steiner é graduada em Licenciatura em Matemática e em Engenharia Civil (UFPR, 1978 e 1981, respectivamente), mestre e doutor em Engenharia de Produção, na área de Pesquisa Operacional (UFSC, 1988 e 1995, respectivamente). Tem pós-doutorado em Pesquisa Operacional (ITA, 2005). De 1978 a 2010 foi docente dos departamentos de Matemática e de Engenharia de Produção da UFPR. Desde 2011 é docente do programa de Engenharia de Produção e Sistemas da PUCPR.

Luzia Vidal de Souza Zamboni é graduada em Licenciatura em Matemática (UFPR, 1988), mestre e doutor em Métodos Numéricos em Engenharia (UFPR, 1997 e 2006, respectivamente). Atualmente é docente da UFPR, do departamento de Expressão Gráfica e do programa de Pós-Graduação em Métodos Numéricos em Engenharia. 


\title{
Roteamento de Veículos Utilizando Otimização por Colônia de Formigas e Algoritmo Genético
}

\author{
Silvely Salomão Néia; Almir Olivette Artero, \\ Luiza Amalia Pinto Cantão e Cláudio Barbieri da Cunha
}

\begin{abstract}
Resumo: Este capítulo apresenta duas metaheurísticas evolucionárias, Algoritmo Genético e Otimização por Colônia de Formigas, aplicadas ao Problema de Roteamento de Veículos. Um exemplo é apresentado com objetivo de ilustrar o uso destas meta-heurísticas.
\end{abstract}

Palavras-chave: Problema de roteamento de veículos, Otimização por colônia de Formigas, Algoritmo genético.

\begin{abstract}
This chapter presents two evolutionary metaheuristics, Genetic Algorithms and Ant Colony Optimization applied to the Vehicle Routing Problem. An example is presented in order to illustrate the use of these metaheuristics.
\end{abstract}

Keywords: Vehicle routing problem, Ant colony optimization, Genetic algorithms.

\section{Introdução}

Em 1934, o matemático Karl Menger enunciou o problema de um caixeiro que necessita viajar a fim de visitar $n$ cidades, partindo e retornando de sua cidade de origem, de forma que, em sua viagem, seja percorrida a menor distância possível. Embora outros autores tenham apresentado problemas semelhantes, como o problema das pontes de Könisberg citado por Leonhard Euler em 1957, o artigo de Menger foi o primeiro a apresentar este problema do ponto de vista matemático. Este problema se tornou um clássico conhecido como o Problema do Caixeiro Viajante (PCV) e consiste no primeiro problema de roteamento apresentado na literatura científica. Até os dias de hoje o problema é classificado como NP-difícil, ou seja, não se conhece um algoritmo computacional que o resolva em tempo eficiente e é muito difícil que este algoritmo exista.

O Problema de Roteamento de Veículos (PRV) pode ser visto como uma generalização do PCV, em que são necessários $m$ caixeiros para atender $n$ cidades, tendo em vista restrições como duração máxima da viagem, capacidade do caixeiro carregar mercdorias para as cidades a serem visitadas, entre outras. No enunciado do PRV são considerados clientes no lugar de cidades e veículos no lugar de caixeiros. Neste capítulo, será considerado o caso do Problema de Roteamento de Veículos Capacitado (PRVC) em que os veículos possuem limites de capacidade de carregamento e devem atender os clientes que têm demandas a serem transportadas.

Nos casos reais, surge uma diversidade de problemas dependendo da particularidade de cada situação, por exemplo, se o tipo de mercadorias a serem transportadas é homogêneo ou não, se são produtos deterioráveis ou não, entre outras características.

Resumidamente, este capítulo apresenta o modelo matemático do PRVC, e apresenta as meta-heurísticas Algoritmo Genético e Otimização por Colônia de Formigas, como métodos de resolução do mesmo.

As seções deste capítulo estão organizadas da seguinte maneira: na próxima seção é apresentado o Problema de Roteamento de Veículos e suas características principais. Na Seção 3 apresenta-se o modelo matemático do problema definindo suas variáveis de decisão. Na Seção 4 é apresentada a meta-heurística Algoritmo Genético e na seção seguinte a meta-heurística Otimização por Colônia de Formigas. Na última seção são feitas algumas considerações comparativas dessas meta-heurísticas quando aplicadas ao PRV, no caso capacitado e no caso com um único veículo sem limite de capacidade.

\footnotetext{
*Autor para contato: silvelysalomao@fct.unesp.br
} 


\section{O Problema de Roteamento de Veículos e suas Variações}

O problema de roteamento ou roteirização de veículos consiste em determinar o(s) roteiro(s) para atender um conjunto de clientes situados em pontos distintos, buscando minimizar o custo total, assegurando que cada cliente seja visitado exatamente uma vez, e que a quantidade transportada por cada veículo não exceda seu limite de capacidade. Em outras palavras, quais os atendimentos, que podem ser coletas, entregas ou visitas de serviço, devem ser alocados a cada veículo de uma frota disponível, e qual o roteiro de visitas de cada veículo, de forma a minimizar o custo total do serviço, geralmente composto da soma ponderada dos custos fixos e dos custos proporcionais às distâncias percorridas pelos veículos e ao tempo de viagem.

Este é um problema simples de ser enunciado e compreendido, mas muito difícil de ser resolvido até a otimalidade. É uma das histórias de maior sucesso da Pesquisa Operacional, tendo em vista o impressionante número de artigos publicados na literatura científica ao longo de mais de quatro décadas (Assad (1988)).

Quando a definição dos roteiros também envolve aspectos temporais, tais como restrições de horários de atendimento, conhecidas como janelas de tempo ou de duração máxima de roteiros, o problema é então denominado roteamento e programação de veículos.

O problema de programação de veículos pode ser visto como um caso particular do problema de roteamento e programação de veículos, no qual os roteiros (ou sequências de viagem) são conhecidos a priori. Neste caso, busca-se determinar a alocação (ou programação) dos veículos que minimize a frota necessária para a realização dos serviços, tendo como possível segundo objetivo a minimização da distância ou do tempo ocioso. Por exemplo, na programação de veículos no transporte coletivo por ônibus busca-se determinar o número mínimo de veículos necessários para realizar um dado conjunto de viagens programadas de uma ou mais linhas, assim como, também, definir a sequência de viagens a ser executada por cada veículo da frota mínima, tal que o custo da operação seja minimizado (Bodin \& Golden (1981)). Neste caso, os locais e horários de início e término de cada viagem, assim como os itinerários já estão determinados previamente, cabendo apenas a programação dos veículos que vão realizá-las.

Muitos autores apresentaram taxonomias para classificar o PRV em uma forma sistemática, tais como, Bodin \& Golden (1981), Christofides (1985), Assad (1988) e Ronen (1988). Em um texto mais recente, Eksioglu et al. (2009) apresentaram uma taxonomia mais completa conforme mostra a Tabela 1. Os autores classificaram o PRV em relação ao cenário, aos aspectos físicos do problema, aos tipos de estudo realizados, às informações e aos tipos de dados usados.

Neste capítulo será considerado o caso clássico do PRV, que consiste em determinar os melhores roteiros de viagem para um conjunto de veículos homogêneos com capacidade de carga limitada, localizados em um único depósito, que devem atender um conjunto finito de clientes com demandas conhecidas e retornar ao depósito, cujo modelo é apresentado na Seção seguinte.

\section{O Modelo Matemático do PRVC}

O modelo matemático proposto por Fisher \& Jaikumar (1981) trata do PRVC e considera como variáveis de decisão:

e

$$
x_{i j}^{v}= \begin{cases}1 & , \text { se o veículo } v \text { atende o cliente } j \text { após o cliente } i \\ 0 & , \text { caso contrário }\end{cases}
$$

$$
y_{i}^{v}= \begin{cases}1 & , \text { se a demanda do cliente } i \text { foi atendida pelo veículo } v \\ 0 & , \text { caso contrário }\end{cases}
$$

A formulação do problema é dada por:

$$
\min \sum_{i=1}^{n} \sum_{j=1}^{n} \sum_{v=1}^{V} c_{i j} x_{i j}^{v}
$$

Sujeito ás seguintes restrições:

$$
\begin{gathered}
\sum_{v=1}^{V} y_{i}^{v}=1 \quad \mathrm{i}=1, \ldots, \mathrm{n} \\
\sum_{v=1}^{V} y_{i}^{v}=V \quad \mathrm{i}=0 \\
\sum_{i=1}^{n} d_{i} y_{i}^{v} \leqslant C_{v} \quad \mathrm{v}=1, \ldots, \mathrm{V} \\
\sum_{i=1}^{n} x_{i j}^{v}=y_{j}^{v} \quad \mathrm{j}=0, \ldots, \mathrm{n} \quad \mathrm{v}=1, \ldots, \mathrm{V}
\end{gathered}
$$




\begin{tabular}{|c|c|c|}
\hline \multirow{9}{*}{$\begin{array}{l}\text { Características } \\
\text { do } \\
\text { cenário }\end{array}$} & Número de paradas na rota & $\begin{array}{l}\text { Determinístico } \\
\text { Determinístico e probabilístico }\end{array}$ \\
\hline & Fracionamento de entregas & $\begin{array}{l}\text { Permitido } \\
\text { Não permitido }\end{array}$ \\
\hline & Tipo da demanda do cliente & $\begin{array}{l}\text { Determinística } \\
\text { Estocástica } \\
\text { Desconhecida }\end{array}$ \\
\hline & $\begin{array}{l}\text { Quantidade de requisições de } \\
\text { novos clientes }\end{array}$ & $\begin{array}{l}\text { Determinística } \\
\text { Estocástica } \\
\text { Desconhecida }\end{array}$ \\
\hline & Tempo de serviço e de espera & $\begin{array}{l}\text { Determinístico } \\
\text { Dependente do tempo } \\
\text { Dependente do tipo de veículo } \\
\text { Estocástico } \\
\text { Desconhecido }\end{array}$ \\
\hline & Estrutura da janela de tempo & $\begin{array}{l}\text { Janela de tempo leve } \\
\text { Janela de tempo restrita } \\
\text { Ambas }\end{array}$ \\
\hline & Horizonte de tempo & $\begin{array}{l}\text { Período simples } \\
\text { Períodos múltiplos }\end{array}$ \\
\hline & Backhauls & $\begin{array}{l}\text { Requisição de coletas e } \\
\text { entregas simultâneas dos nós } \\
\text { Requisição de linehaul ou } \\
\text { backhaul não simultâneas dos nós }\end{array}$ \\
\hline & Restrições nos arcos ou nos nós & $\begin{array}{l}\text { Precedência e restrições de agrupamento } \\
\text { Restrições de subconjunto } \\
\text { Permitido refazer rota }\end{array}$ \\
\hline \multirow{10}{*}{$\begin{array}{l}\text { Aspectos } \\
\text { físicos } \\
\text { do } \\
\text { problema }\end{array}$} & Esquema da rede de transporte & $\begin{array}{l}\text { Rede direcionada } \\
\text { Rede não direcionada }\end{array}$ \\
\hline & Endereços das localidades & $\begin{array}{l}\text { Clientes nos nós } \\
\text { Instâncias do arco de roteamento }\end{array}$ \\
\hline & Localização geográfica dos clientes & $\begin{array}{l}\text { Urbana (dispersa com padrão) } \\
\text { Rural (dispersa aleatoriamente) } \\
\text { Combinado }\end{array}$ \\
\hline & Número de origens & $\begin{array}{l}\text { Única origem } \\
\text { Múltiplas origens }\end{array}$ \\
\hline & $\begin{array}{l}\text { Número de instalações de carregamento } \\
\text { e descarregamento (depósito) }\end{array}$ & $\begin{array}{l}\text { Único depósito } \\
\text { Múltiplos depósitos }\end{array}$ \\
\hline & Tipo de janela de tempo & $\begin{array}{l}\text { Restrições nos clientes } \\
\text { Restrições nas vias } \\
\text { Restrições nos depósitos/hubs } \\
\text { Restrições nos motoristas/veículos }\end{array}$ \\
\hline & Número de veículos & $\begin{array}{l}\text { Exatamente } n \text { veículos } \\
\text { Até } \mathrm{n} \text { veículos } \\
\text { Ilimitado }\end{array}$ \\
\hline & Consideração de capacidade & $\begin{array}{l}\text { Veículos capacitados } \\
\text { Veículos não capacitados }\end{array}$ \\
\hline & Tipo de veículos & $\begin{array}{l}\text { Veículos homogêneos } \\
\text { Veículos para tipos específicos de carga } \\
\text { Veículos heterogêneos } \\
\text { Exigência de um tipo específico de veículo }\end{array}$ \\
\hline & Tempo de viagem & $\begin{array}{l}\text { Determinístico } \\
\text { Função do horário atual } \\
\text { Estocástico } \\
\text { Desconhecido }\end{array}$ \\
\hline
\end{tabular}

Tabela 1. Taxonomia de Eksioglu et al. (2009). 


\begin{tabular}{|c|c|c|}
\hline $\begin{array}{l}\text { Aspectos } \\
\text { físicos } \\
\text { do } \\
\text { problema } \\
\text { (continuação) }\end{array}$ & Custo & $\begin{array}{l}\text { Dependente do tempo de viagem } \\
\text { Dependente da distância } \\
\text { Dependente do veículo } \\
\text { Dependente da operação } \\
\text { Função do atraso } \\
\text { Relacionado ao risco/perigo }\end{array}$ \\
\hline \multirow{4}{*}{$\begin{array}{l}\text { Tipo } \\
\text { de } \\
\text { estudo }\end{array}$} & Métodos aplicados & $\begin{array}{l}\text { Exatos } \\
\text { Heurísticos } \\
\text { Simulações } \\
\text { Em tempo real } \\
\end{array}$ \\
\hline & Implementação & \\
\hline & Levantamento, revisão ou meta-pesquisa & \\
\hline & Teórico & \\
\hline \multirow{4}{*}{$\begin{array}{l}\text { Características } \\
\text { da } \\
\text { informação }\end{array}$} & Evolução da informação & $\begin{array}{l}\text { Estática } \\
\text { Parcialmente dinâmica }\end{array}$ \\
\hline & Qualidade da informação & $\begin{array}{l}\text { Determinístico } \\
\text { Estocástico } \\
\text { Previsão } \\
\text { Desconhecido (tempo real) }\end{array}$ \\
\hline & Disponibilidade da informação & $\begin{array}{l}\text { Local } \\
\text { Global }\end{array}$ \\
\hline & Processamento da informação & $\begin{array}{l}\text { Centralizado } \\
\text { Descentralizado }\end{array}$ \\
\hline \multirow{2}{*}{$\begin{array}{l}\text { Características } \\
\text { dos } \\
\text { dados }\end{array}$} & Dados usados no problema & $\begin{array}{l}\text { Dados do mundo real } \\
\text { Dados sintéticos } \\
\text { Combinado (real e sintético) }\end{array}$ \\
\hline & Não utilizam dados & \\
\hline
\end{tabular}

Tabela 1. (continuação) Taxonomia de Eksioglu et al. (2009).

$$
\begin{gathered}
\sum_{j=1}^{n} x_{i j}^{v}=y_{i}^{v} \quad \mathrm{i}=0, \ldots, \mathrm{n} \quad \mathrm{v}=1, \ldots, \mathrm{V} \\
\sum_{i \in S} x_{i j}^{v}=x_{i j}^{v} \leqslant|S|-1 \quad S \subseteq\{1, \ldots, n\} \quad \mathrm{v}=1, \ldots, \mathrm{V} \\
x_{i j}=0 \text { ou } 1 \quad \mathrm{i}=0, \ldots, \mathrm{n} \quad \mathrm{j}=0, \ldots, \mathrm{n} \quad \mathrm{v}=1, \ldots, \mathrm{V} \\
y_{i}^{v}=0 \text { ou } 1 \quad \mathrm{i}=0, \ldots, \mathrm{n} \quad \mathrm{v}=1, \ldots, \mathrm{V}
\end{gathered}
$$

onde $n$ corresponde ao número total de clientes a serem atendidos com demanda $d_{i}(i=1,2, \ldots, n) ; i=0$ corresponde ao depósito, $C_{v}$ a capacidade máxima de cada veículo $v(v=1, \ldots, V)$ e $c_{i j}$ o custo de viagem do cliente $i$ ao cliente $j$.

A função objetivo (Equação 3) impõe que o custo variável total, proporcional á distância percorrida, seja minimizado. Deve-se notar que este custo independe do veículo $v$ utilizado e que existem outras formulações em que os custos variam de acordo com os veículos utilizados. Pode-se ainda considerar a parcela de custo fixo dos veículos efetivamente utilizados.

As restrições (4) garantem que cada cliente seja visitado por apenas um veículo e as restrições (5) que todos os veículos saiam do depósito $(i=0)$. As restrições $(6)$ não permitem que os veículo sejam carregados além de seus limites de capacidade. As restrições (7) e (8) são as que ligam as variáveis $x$ e $y$ e fazem com que os veículos não interrompam suas viagens em um cliente, se $y=1$. As restrições (9) evitam que subrotas façam parte da solução. E as restrições (10) e (11) definem as variáveis de decisão.

Considerando um nó 0 representando o depósito, e os nós $\{1,2, \ldots, n\}$ representando os $n$ clientes, o PRVC pode ser representado pelo grafo completo $G=(C, L)$, sendo $C=\{0,1, \ldots, n\}$ o conjunto de nós e $L=\{(i, j): i \neq j\}$ o conjunto de arcos que ligam $i$ a $j$, e deseja-se encontrar um trajeto que forme um circuito fechado, ou seja, percorra todos os nós do grafo e volte ao nó 0. Além disso, cada nó está associado à demanda $d_{i}$ do cliente $i\left(d_{0}=0\right.$ está associada ao depósito 0$)$. Para cada arco $(i, j)$ há um valor $c_{i j}$ representando a 
distância entre $i$ e $j$. Cada roteiro começa e termina no depósito 0, cada nó $i$ precisa ser visitado exatamente uma vez e a quantidade de demanda tem de ser entregue em uma determinada rota, que não poderá exceder a capacidade do veículo, correspondendo ao PRVC.

\section{Problemas de benchmark}

O PRVC tem na literatura, instâncias usadas para efeito de comparação da eficiência dos métodos, que são conhecidas por instâncias de benchmark. Neste capítulo, a título de ilustração, foi escolhida uma das instâncias propostas por Augerat et al. (1998) ${ }^{1}$, que é referenciada por A-n32-k5.

A Figura 1 mostra localização do depósito e dos 31 clientes da instância e a solução dada pelos autores para essa instância. Observa-se que cinco veículos estão disponíveis e que, considerando os retornos ao depósito e precisão de quatro casas decimais, a distância total percorrida nesta solução é igual a 856,7941.

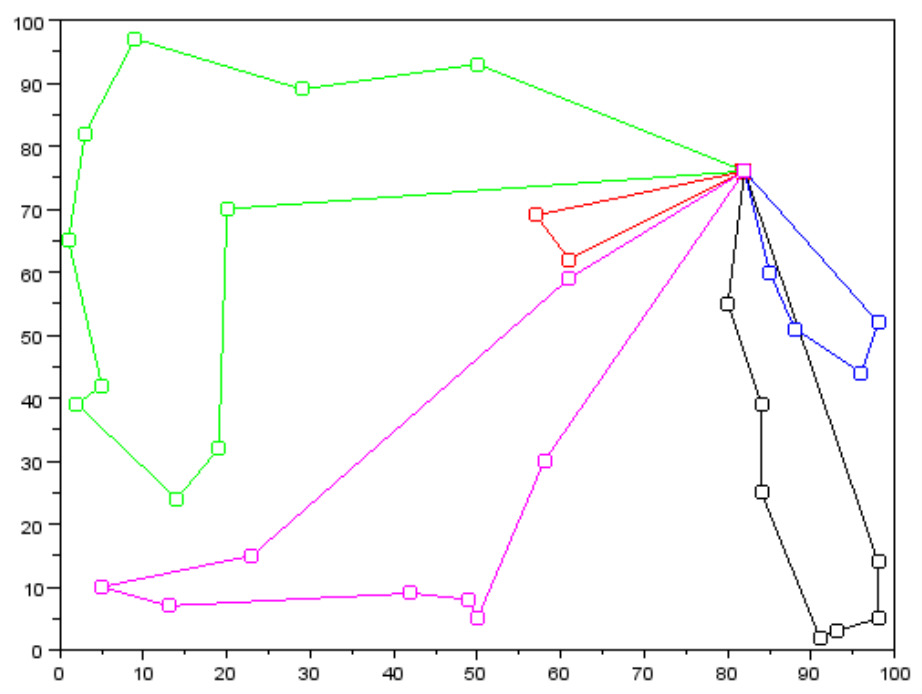

Figura 1. Instância A-n32-k5 de Augerat et al. (1998) e a solução ótima.

\section{Algoritmos Genéticos}

De acordo com Reeves (2003), o Algoritmo Genético é uma meta-heurística proposta por Holland (1975), no livro intitulado Adaptation in Natural and Artificial Systems. Algoritmos genéticos inspiram-se na teoria da evolução Darwiniana, que considera que, quanto mais um indivíduo se adapta ao seu meio ambiente, maior será sua chance de sobreviver e gerar descendentes. Segundo Beasley (2002), pertencem a uma classe geral de algoritmos de busca probabilística inteligente, que se baseiam no processo evolucionário de organismos biológicos na natureza, tratando de uma população de soluções e da combinação delas, de modo a gerar novas soluções.

Em linhas gerais, algoritmos genéticos trabalham com um grupo de potenciais soluções, que correspondem a uma população, em que cada solução corresponde a um indivíduo e é representado por um cromossomo. Essses cromossomos, são compostos por genes, os quais são responsáveis pelas características dos seres e são trocados ou transmitidos durante o processo de reprodução. Algoritmicamente, um cromossomo é representado por um vetor de valores reais ou inteiros, dependendo do problema.

A cada iteração, os indivíduos são avaliados segundo sua aptidão e os mais aptos da população são selecionados para a reprodução, enquanto que os menos aptos são eliminados, de acordo com o princípio darwiniano de seleção natural e sobrevivência do mais forte. De um modo geral, os Algoritmos Genéticos produzem resultados melhores para problemas de natureza combinatória quando comparados com heurísticas baseadas na melhoria de uma única solução (Beasley (2002)).

Uma possível solução para um problema deve ser representada através de um vetor de genes, formando um cromossomo, ou seja, um indivíduo da população. Tradicionalmente, os genes são valores binários, mas outras codificações podem ser usadas.

\footnotetext{
1 Disponíveis em: http://neo.lcc.uma.es/radi-aeb/WebVRP
} 
Exemplos:

$$
\begin{array}{ll}
\text { cromossomo1 }=100001011101 & \text {, com valores binários; } \\
\text { cromossomo } 2=4,8 ; 3,2 ; 5,3 & \text {, com valores reais. }
\end{array}
$$

Em um problema com $n$ variáveis de decisão binárias, uma representação natural corresponde a um cromossomo com $n$ genes do tipo 0-1, como no caso de um problema da mochila binária (Martello \& Toth, 1988), em que se deve selecionar um subconjunto de $n$ itens de forma a maximizar o lucro dos objetos selecionados, respeitando-se a restrição de capacidade da mochila. Considerando $n=10$ objetos, enumerados de 1 a 10, uma possível solução seria inserir os objetos 1, 3, 4, 7, 8 e 10, que é representada pelo seguinte cromossomo:

\begin{tabular}{|l|l|l|l|l|l|l|l|l|l|}
\hline 1 & 2 & 3 & 4 & 5 & 6 & 7 & 8 & 9 & 10 \\
\hline $\mathbf{1}$ & $\mathbf{0}$ & $\mathbf{1}$ & $\mathbf{1}$ & $\mathbf{0}$ & $\mathbf{0}$ & $\mathbf{1}$ & $\mathbf{1}$ & $\mathbf{0}$ & $\mathbf{1}$ \\
\hline
\end{tabular}

Para um problema de caixeiro viajante com $n=10$ cidades, numeradas de 1 a 10 , uma representação possível para uma sequência viável de cidades visitadas seria:

\begin{tabular}{|l|l|l|l|l|l|l|l|l|l|}
\hline 5 & 3 & 2 & 1 & 7 & 8 & 4 & 10 & 9 & 6 \\
\hline
\end{tabular}

que indica a sequência de cidades visitadas: 5-3-2-1-7-8-4-10-9-6-5.

A Figura 2 ilustra o fluxograma do Algoritmo Genético, que envolve a inicialização da população, a avaliação da população, teste de parada, a seleção de indivíduos para reprodução, o cruzamento ou reprodução, a mutação e a atualização da população. A seguir estas etapas são detalhadas.

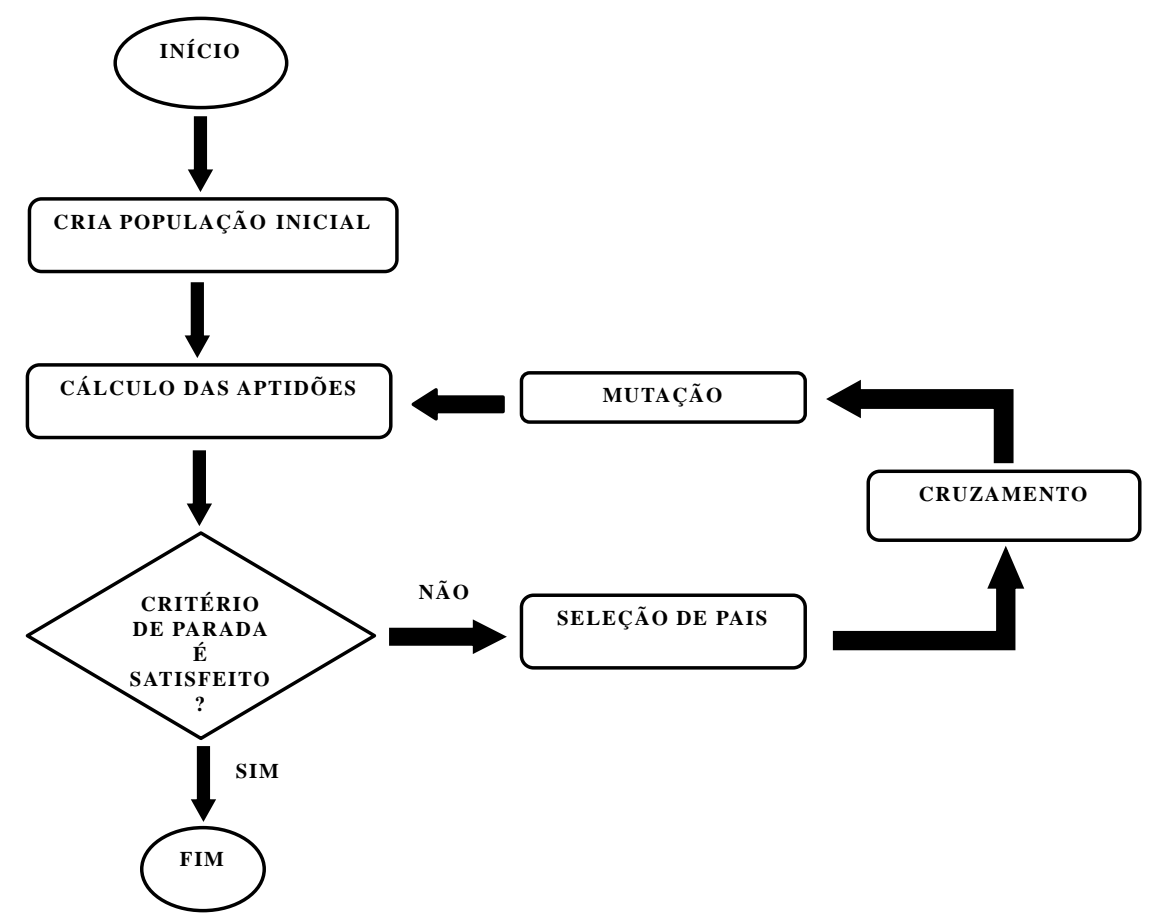

Figura 2. Esquema geral de funcionamento do Algoritmo Genético.

\section{Geração da população inicial}

A população inicial pode ser gerada de forma totalmente aleatória. Entretanto, recomenda-se incluir soluções obtidas através de uma ou mais boas heurísticas ou, então, assegurar que a populaçõ esteja bem distribuída ao longo do espaço de soluções.

\section{Avaliação e validação das soluções}

A avaliação dos cromossomos ou soluções é feita pela função de aptidão, usada para medir a habilidade do indivíduo de sobreviver e se reproduzir. Nos algoritmos genéticos esta função é uma função matemática, que deve ser maximizada ou minimizada, de acordo com o problema a ser resolvido. Por exemplo, supondo que o problema seja encontrar a raiz quadrada $x$ de um valor $n$, uma possível função de aptidão seria: $f=1 /\left(x^{2}-n\right)$, que tende a valores altos, quando $x$ se aproxima da solução. 
Nesta etapa, ocorre também a validação dos cromossomos, que consiste em verificar se o indivíduo da população corresponde a uma boa solução para o problema. Observando que, para muitos problemas, existe uma grande dificuldade para se encontrar uma solução, porém, não é muito difícil avaliar a sua qualidade. Novamente, um exemplo muito simples é o caso do algoritmo para calcular a raiz quadrada $x$ de um número $n$, que é razoavelmente difícil, enquanto que o teste da solução encontrada, que consiste em verificar se $\left(x^{2}-n\right)$ tende a 0 , é fácil.

Quando o cromossomo representa uma sequência de clientes a serem visitados por um único veículo, a função para o cálculo da aptidão pode ser, por exemplo, o inverso da distância total percorrida pelo veículo, incluindo a saída e o retorno ao depósito. No entanto, no caso com mais de um veículo, para se saber a distância total percorrida pela sequência apresentada no cromossomo, é necessário fazer a divisão dos clientes entre os veículos e indicar quando começa e quando termina a rota de um veículo. Desta forma é possível incluir os custos de saída e retorno ao depósito de todos os veículos e, assim, encontrar a distância total percorrida na solução representada pelo cromossomo.

Prins (2004) propôs uma heurística denominada split, que significa fracionar, para fazer a divisão dos clientes de cromossomo entre os veículos disponíveis. Seja um dado cromossomo $1-2-3-\ldots-n$ representando os $n$ clientes de um roteiro, ou seja, a ordem de visita aos clientes seria: cliente 1 , cliente 2 , cliente 3 , ... e cliente $n$, sem perda de generalidade. O algoritmo gera um grafo auxiliar $H=(X, A, Z)$, onde $X$ representa o conjunto dos $n$ nós, $A$ o conjunto de $\operatorname{arcos}(i, j)$ e $Z$ contém os custos $z_{i j}$ da viagem de $i$ até $j$, calculados por:

$$
z_{i j}=c_{0, i+1}+\sum_{k=i+1}^{j-1}\left(s_{k}+c_{k, k+1}\right)+s_{j}+c_{j, 0} \leqslant L \quad \forall(\mathrm{i}, \mathrm{j}) \in \mathrm{A}
$$

onde $L$ é o tempo máximo de operação de cada veículo e $s_{i}$ é o tempo de serviço no cliente i. $z_{i j}$ representa o custo de ir do nó $i$ ate o nó $j$, respeitando a ordem e incluindo custo para ir até $i$.
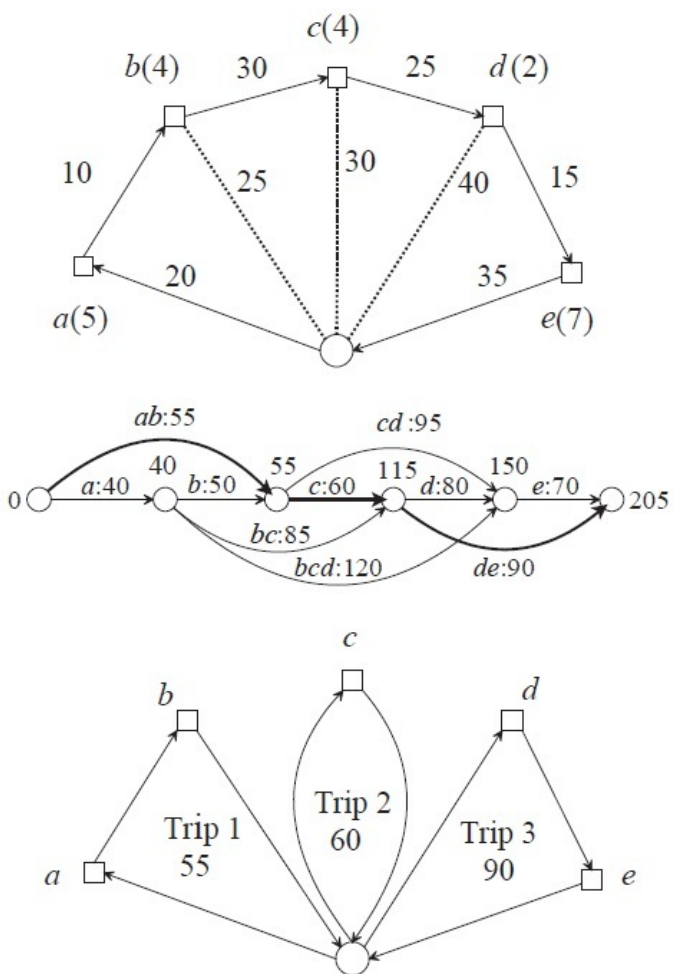

Figura 3. Exemplo de fracionamento do cromossomo pela heurística de Prins (2004).

Sempre considerando que o total das demandas atendidas em cada cliente não exceda a capacidade do veículo, ou seja:

$$
\sum_{k=i+1}^{j} d_{k} \leqslant C_{v} \quad \forall \mathrm{v} \in \mathrm{V}
$$

A Figura 3 mostra o exemplo dado por Prins (2004). Neste exemplo, a solução é representada pelo cromossomo $S=a-b-c-d-e$, cujos clientes tem demandas 5, 4, 4, 2 e 7, respectivamente. Os veículos 
são homogêneos com limite de capacidade de 10 unidades. As distâncias entres os pontos são mostradas na figura.

Na primeira parte do algoritmo, cujo pseudo-código é mostrado na Figura 4, são calculados os custos mínimos para ir até cada cliente, respeitando a sequência dada no cromossomo. Para o exemplo considerado, os custos $V_{i}$ são inicializados por $V_{a}=V_{b}=V_{c}=V_{d}=V_{e}=+\infty$, representando o custo conhecido para se chegar ao cliente $i$. Para o depósito, faz-se $V_{0}=0$.

Considerando o primeiro cliente $a$, calcula-se o custo de, a partir do depósito, ir até $a$ e retornar, e o total carregado pelo veículo. Desprezando o custo de serviços, ou seja, fazendo $f_{i}=0,(i=a, b, c, d, e)$, temos que cost $=40$ e load $=d_{a}=5$. Como este custo é menor que $V_{a}$ e não excede a capacidade de 10 itens, $V_{a}$ é atualizado por $V_{a}=40$ e faz-se $P_{a}=0$. Isso significa que o melhor caminho, conhecido até o momento, para ir até $a$ tem início no depósito.

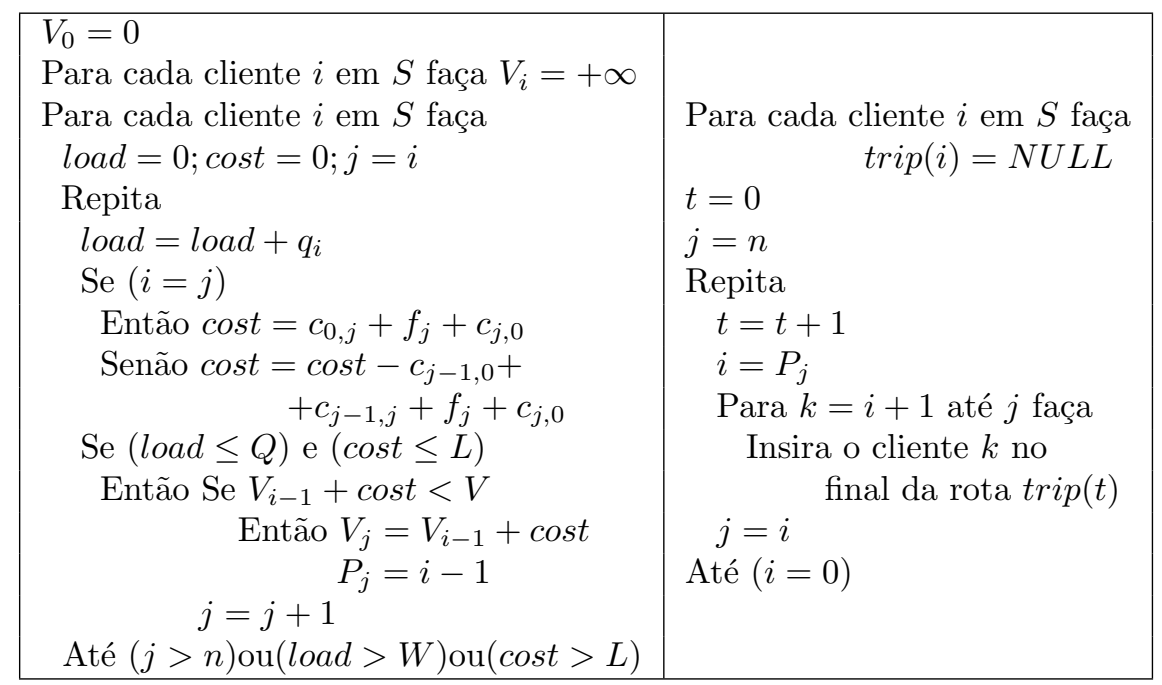

Figura 4. Algoritmo de fracionamento do cromossomo de Prins (2004).

Em seguida, considera-se a possibilidade de continuar a viagem e passar por $b$. Neste caso, o custo passa a ser 55 , pois o roteiro seria $0-a-b-0$, cuja distância total é dada pela soma $(20+10+25)=55$. De modo análogo a $a$, atualiza-se $V_{b}$ e $P_{b}$ por $V_{b}=55$ e $P_{b}=0$. No entanto, não é possível incluir $c$, pois a soma das demandas excede a capacidade do veículo (load $\left.=d_{a}+d_{b}+d_{c}=13>10\right)$. Repete-se o processo, considerando o veículo saindo do depósito e indo diretamente para $b$. Sequencialmente, considera-se a possibilidade $(0-b-0)$, depois $(0-b-c-0)$, e assim por diante enquanto a capacidade do veículo não for excedida. Como neste caso o início deste roteiro se dá em $b$, deve-se somar ao custo cost, o custo do melhor caminho até o cliente $a$, conhecido até esta iteração.

Ao final, os valores de $V_{i}$ serão as menores distâncias para se chegar até o cliente $i$, considerando que em $P_{i}$ o veículo retornou ao depósito. Observa-se que é respeitada a sequência dada no cromossomo. Para o exemplo dado, obtém-se: $V_{a}=40, P_{a}=0, V_{b}=55, P_{b}=0, V_{c}=115, P_{c}=b, V_{d}=150, P_{d}=b, V_{e}=205$ e $P_{e}=c$. Aplicando a segunda parte do pseudo-algoritmo da Figura 4, o menor custo para se chegar até e é de 205 e considerando que o veículo retornou ao depósito em $c$, pois $\left(P_{e}=c\right)$, resulta o roteiro $(0-d-e-0)$. Fazendo o mesmo para $c$, como $P_{c}=b$, inclui-se o roteiro $(0-c-0)$ e, por fim, como $P_{b}=0$, inclui-se $(0-a-b-0)$. A solução é mostrada na parte inferior da Figura 3.

Para o PRVC com janelas de tempo indicamos a leitura de Cheng (2005) que possui adequações desse algoritmo para os requisitos de janelas de tempo.

\section{Seleção de indivíduos para a reprodução}

Existem diversos métodos para a seleção dos indivíduos para o cruzamento, porém, todos levam em consideração a aptidão de cada um dos $\mathrm{N}$ indivíduos da população. Os principais métodos são:

Torneio: sorteiam-se aleatoriamente $k$ indivíduos e seleciona-se o melhor, com base na função de aptidão. Na maioria das vezes, $k=2$.

Seleção truncada: a seleção truncada consiste em definir somente uma fração T de melhores indivíduos que podem ser selecionados, e todos eles possuem a mesma probabilidade de seleção.

Roleta: as aptidões de todos os indivíduos da população são calculadas e os valores obtidos corresponderão, proporcionalmente, aos setores de uma roleta. Assim, girando a roleta, a chance dos setores maiores 


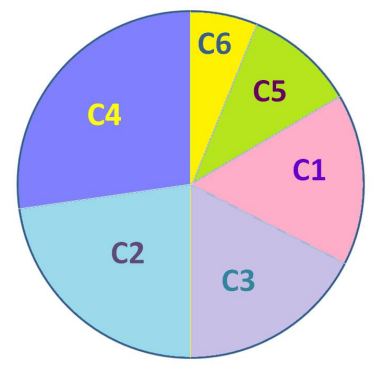

Figura 5. Técnica de seleção da roleta.

serem selecionados será maior. A roleta, da Figura 5, ilustra o caso em que o cromossomo C4, seguido de C2, são os que apresentam a maior habilidade para sobreviver e, por isto, têm mais chances de serem selecionados pela roleta, ainda que os demais também possam ser selecionados.

Seleção por ranking linear: consiste em inicialmente ordenar os indivíduos de acordo com a sua aptidão, sendo que o melhor indivíduo encontra-se na N-ésima posição, isto é, $r(1)=N$, enquanto que o pior indivíduo está na primeira posição $r(N)=1$. A probabilidade de cada indivíduo é determinada pelo quociente entre a sua posição no ranking e a soma de todas as posições. Assim, o melhor indivíduo da população de tamanho $N$ tem probabilidade $N / \sum_{i=1}^{N} r(i)$ de ser escolhido, o pior indivíduo tem probabilidade $1 / \sum_{i=1}^{N} r(i)$ de ser escolhido e os demais $r(i) / \sum_{i=1}^{N} r(i)$

Seleção por amostragem universal estocástica: semelhante ao método da roleta. Para selecionar $k$ indivíduos, utilizam-se $k$ ponteiros igualmente espaçados ao redor da roleta. Girando-se a roleta são selecionados $k$ indivíduos apontados pelos $k$ ponteiros, como ilustrado na Figura 6, considerando-se os mesmos indivíduos e probabilidades apresentados na Tabela 2 e na Figura 5.

Tabela 2. Seleção por amostragem universal estocástica.

\begin{tabular}{ccccccccccc}
\hline Indivíduo & 1 & 2 & 3 & 4 & 5 & 6 & 7 & 8 & 9 & 10 \\
\hline Aptidão & 2 & 1,8 & 1,6 & 1,4 & 1,2 & 1 & 0,8 & 0,6 & 0,4 & 0,2 \\
Probabilidade de seleção & 0,18 & 0,16 & 0,15 & 0,13 & 0,11 & 0,09 & 0,07 & 0,06 & 0,03 & 0,02 \\
\hline
\end{tabular}

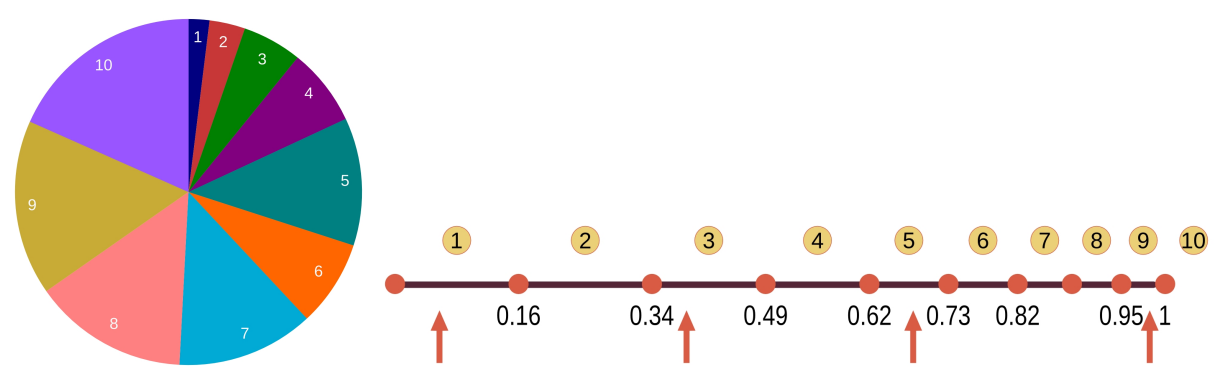

Figura 6. Seleção por amostragem universal estocástica.

\section{Operador de cruzamento}

O operador de cruzamento tem por finalidade combinar as informações genéticas de dois indivíduos, denominados pais, para gerar novos indivíduos, denominados filhos, formando assim a nova geração.

O método mais comum para combinar dois indivíduos é o cruzamento com um único ponto, chamado de ponto de corte ou cruzamento. Uma posição para cruzamento $k$ do vetor indivíduo é selecionada aleatoriamente e os genes de cada indivíduo, após este ponto $k$, são trocados, produzindo dois novos descendentes, conforme mostra a Figura 7, para o caso do ponto de cruzamento ser $k=4$.

Dependendo do problema considerado, e da forma de codificação das soluções, os operadores anteriores podem não ser aplicáveis, uma vez que podem gerar indivíduos inconsistentes. Este é o caso do problema do caixeiro viajante, em que um cromossomo de solução é representado por uma sequência ordenada de cidades a serem visitadas. Sejam A e B dois pais selecionados para cruzamento, sendo: 


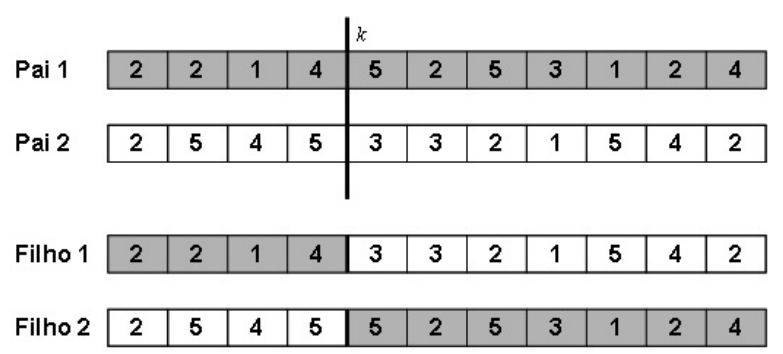

Figura 7. Cruzamento em um único ponto.

\begin{tabular}{|c|c|c|c|c|c|c|c|c|c|}
\hline $\mathrm{A}=$ & 3 & 5 & 7 & 1 & 2 & 4 & 8 & 6 & 9 \\
\hline$=$ & 1 & 9 & 2 & 3 & 4 & 6 & 8 & 7 & 5 \\
\hline
\end{tabular}

Em outras palavras, A corresponde à seguinte sequência de cidades: 3-5-7-1-2-4-8-6-9-3. Suponha que seja aplicado um operador de cruzamento em dois pontos, após a $2^{a}$ e a $6^{a}$ posições, gerando os seguintes filhos:

$$
\begin{aligned}
& \mathrm{A}=\begin{array}{|l|l|l|l|l|l|l|l|l|}
\hline 3 & 5 & 2 & 3 & 4 & 6 & 8 & 6 & 9 \\
\hline
\end{array} \\
& \mathrm{B}=\begin{array}{|l|l|l|l|l|l|l|l|l|}
\hline 1 & 9 & 7 & 1 & 2 & 4 & 8 & 7 & 5 \\
\hline
\end{array}
\end{aligned}
$$

Ambas as soluções acima não representam Filhos válidos para o problema do caixeiro viajante, uma vez que algumas cidades aparecem repetidas nos filhos, enquanto outras cidades não são visitadas. A fim de evitar esse tipo de problema, existem operadores específicos para tratar cromossomos que representam uma permutação.

O operador PMX (partially matched crossover) é uma extensão do operador de cruzamento em dois pontos que busca preservar a ordem e a posição de alguns genes do cromossomo. Trata-se de um procedimento de reparo para evitar a ocorrência de elementos repetidos e funciona da seguinte maneira:

(i) escolhem-se aleatoriamente dois pontos de corte aplicados a ambos os pais;

(ii) geram-se dois Pré-filhos, trocando-se os segmentos centrais entre os pais;

(iii) alguns elementos podem estar duplicados e outros faltando. Através dos segmentos centrais estabelecese uma relação de mapeamento, corrigindo-se os Pré-filhos e obtendo os dois filhos, conforme ilustrado na Figura 8. Os pares de genes 3-6, 9-4, 2-5 e 1-6 ocupam as mesmas posições relativas nos pais, definindo a relação de mapeamento. Assim, o gene 5 repetido do Pré-filho 2 é substituído pelo gene 2 , seu correspondente na relação de mapeamento, o gene 4 pelo 9 , o gene 3 pelo 1 e, assim, sucessivamente, para cada um dos filhos gerados.

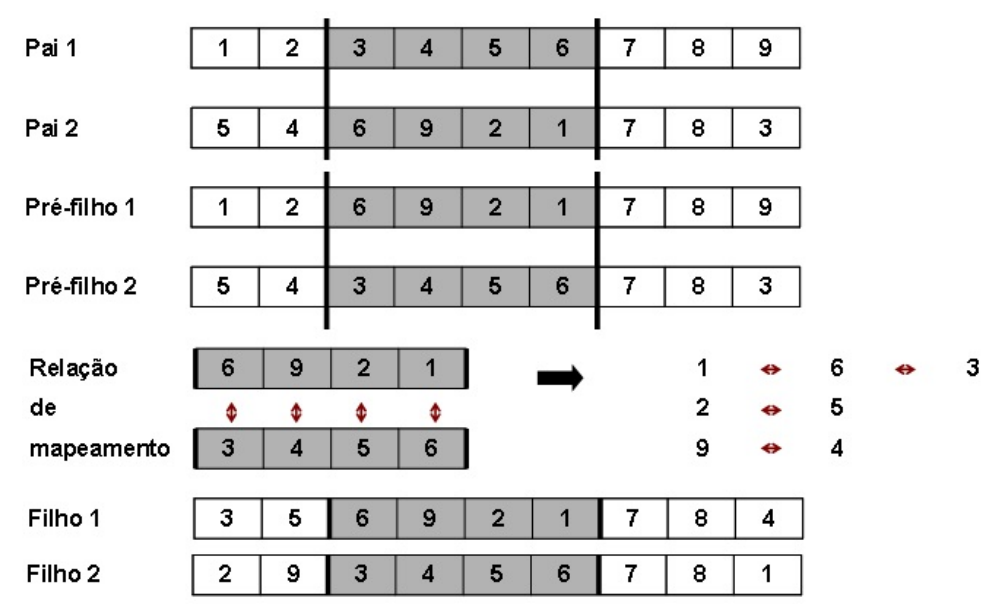

Figura 8. Operador de cruzamento PMX (Gen \& Cheng (1997)).

O operador OX (order crossover) é uma variação do operador PMX com um procedimento de reparo diferente: 
(i) escolhem-se aleatoriamente dois pontos de corte que irão determinar uma sub-rota;

(ii) um Pré-filho é criado copiando-se a sub-rota na posição correspondente do Pai 1;

(iii) os elementos da sub-rota são excluídos do Pai 2;

(iv) a partir do segundo ponte de corte, as posições vazias são preenchidas com os elementos não excluídos do Pai 2;

(v) quando o fim do cromossomo for atingido, continua-se a partir da primeira posição deste;

(vi) o segundo filho é construído seguindo-se o mesmo procedimento.

No exemplo da Figura 9, o Pré-filho 1 é gerado mantendo-se os genes centrais [3 45 6] do Pai 1. Esses genes são eliminados do Pai 2 e os demais utilizados para preencher as demais posições do Pré-filho 1, na ordem, a partir do $2^{o}$ ponto de corte. Assim, o gene 2 do Pai 2 preenche a sétima posição, o gene 8 a $8^{a}$ posição, o gene 7 (próximo da sequência) a $9^{a}$, o gene 9 a $1^{a}$ posição e, assim, sucessivamente.

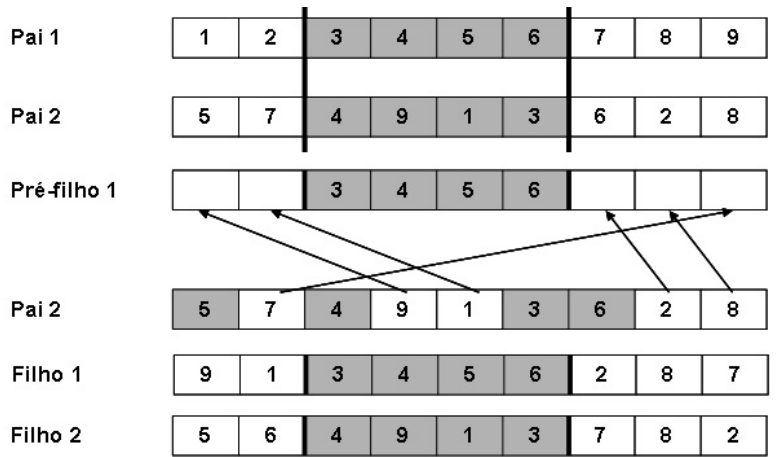

Figura 9. Operador de cruzamento OX (Gen \& Cheng (1997)).

O operador CX (cycle operator) toma alguns pontos de um dos pais e seleciona os pontos remanescentes do outro pai. Os pontos do primeiro pai não são selecionados aleatoriamente e, sim, aqueles que ocupam o mesmo conjunto de posições nos dois cromossomos pais, como ilustrado na Figura 10: 1-5, 5-2, 2-4, 4-9, 9-1, fechando o ciclo. Assim, mantêm-se os genes 1, 5, 2, 4 e 9 do Pai 1, gerando o Filho 1. As demais posições são preenchidas com os demais genes faltantes na sequência em que eles aparecem no Pai 2 (6, 3, 7 e 8). O mesmo procedimento é utilizado para gerar o Filho 2.

\begin{tabular}{|c|c|c|c|c|c|c|c|c|c|}
\hline \multirow[t]{2}{*}{ Pai 1} & 1 & 2 & 3 & 4 & 5 & 6 & 7 & 8 & 9 \\
\hline & $\downarrow$ & $\downarrow$ & & $\downarrow$ & $\downarrow$ & \multicolumn{4}{|r|}{$\downarrow$} \\
\hline Pai 2 & 5 & 4 & 6 & 9 & 2 & 3 & 7 & 8 & 1 \\
\hline Ciclo & 1 & $\rightarrow$ & 5 & $\rightarrow$ & 2 & $\rightarrow$ & 4 & $\rightarrow$ & 9 \\
\hline Filho 1 & 1 & 2 & & 4 & 5 & & & & 9 \\
\hline Pai 2 & 5 & 4 & 6 & 9 & 2 & 3 & 7 & 8 & 1 \\
\hline Filho 1 & 1 & 2 & 6 & 4 & 5 & 3 & 7 & 8 & 9 \\
\hline Filho 2 & 5 & 4 & 3 & 9 & 2 & 6 & 7 & 8 & 1 \\
\hline
\end{tabular}

Figura 10. Operador de cruzamento CX (Gen \& Cheng (1997)).

\section{Operador de mutação}

O operador de mutação tem por finalidade manter a variedade genética das populações geradas. A idéia é que cada gene dos descendentes gerados pode sofrer mutação com uma pequena probabilidade, de modo a evitar que o processo de busca torne-se puramente aleatório. Busca-se, desta forma, recuperar boas características, eventualmente, perdidas nos processos de seleção e cruzamento, e também evita-se ficar preso em determinadas regiões do espaço de busca ou em pontos de ótimo locais.

O método de mutação depende do tipo de representação adotada. Para cromossomos com representação binária, pode-se mutar aleatoriamente alguns genes de 1 para 0 e vice versa. Em geral, a probabilidade de mutação de cada gene é baixa (1 a $5 \%$ ). 
Para cromossomos que têm sua representação baseada na ordem, como no PRV, existem operadores de mutação específicos, semelhante ao que ocorre no cruzamento.

Na mutação por inversão, dois pontos de corte são selecionados aleatoriamente e a sequência entre estas duas posições do cromossomo é invertida, como mostrado na Figura 11.

\begin{tabular}{|c|c|c|c|c|c|c|c|c|c|}
\hline Indivíduo & 1 & 2 & 3 & 4 & 5 & 6 & 7 & 8 & 9 \\
\hline Indivíduo m utado & 1 & 2 & 6 & 5 & 4 & 3 & 7 & 8 & 9 \\
\hline
\end{tabular}

Figura 11. Mutação por inversão (Gen \& Cheng (1997)).

A mutação por substituição consiste em selecionar uma sequência ao acaso e inserí-la em uma posição aleatória, como mostrado na Figura 12. Uma variação para esse operador de mutação consiste na inversão da sequência quando inserida na posição aleatoriamente escolhida.

\begin{tabular}{|c|c|c|c|c|c|c|c|c|c|}
\hline Indivíduo & 1 & 2 & 3 & 4 & 5 & 6 & 7 & 8 & 9 \\
\hline Indivíduo mutado & 1 & 2 & 7 & 8 & 3 & 4 & 5 & 6 & 9 \\
\hline
\end{tabular}

Figura 12. Mutação por substituição (Gen \& Cheng (1997)).

A mutação por inserção é um caso particular da mutação por substituição em que a sequência selecionada para inserção em uma posição aleatória contém apenas um gene.

$\mathrm{Na}$ mutação de troca recíproca selecionam-se aleatoriamente duas posições no mesmo cromossomo e os respectivos elementos são trocados, como mostrado na Figura 13.

\begin{tabular}{|c|c|c|c|c|c|c|c|c|c|}
\hline Indivíduo & 1 & 2 & 3 & 4 & 5 & 6 & 7 & 8 & 9 \\
\hline In divíduo mutado & 1 & 2 & 6 & 4 & 5 & 3 & 7 & 8 & 9 \\
\hline
\end{tabular}

Figura 13. Mutação de troca recíproca (Gen \& Cheng (1997)).

A mutação heurística consiste em escolher $\lambda$ genes ao acaso e gerar as soluções vizinhas considerando-se todas as possíveis permutações dos $\lambda$ genes selecionados, escolhendo-se a melhor, como ilustrado na Figura 14. Foram escolhidos $\lambda=3$ genes (3, 6 e 8) e testadas todas as possibilidades de permutação desses 3 genes, devendo ser escolhida a melhor.

\begin{tabular}{|c|c|c|c|c|c|c|c|c|c|}
\hline Cromossomo inicial & 1 & 2 & 3 & 4 & 5 & 6 & 7 & 8 & $\mathbf{9}$ \\
\hline \multirow{5}{*}{ Vizinhança } & 1 & 2 & 3 & 4 & 5 & 8 & 7 & 6 & 9 \\
\hline & 1 & 2 & 8 & 4 & 5 & 3 & 7 & 6 & 9 \\
\hline & 1 & 2 & 8 & 4 & 5 & 6 & 7 & 3 & 9 \\
\hline & 1 & 2 & 6 & 4 & 5 & 8 & 7 & 3 & 9 \\
\hline & 1 & 2 & 6 & 4 & 5 & 3 & 7 & 8 & 9 \\
\hline
\end{tabular}

Figura 14. Mutação heurística (Gen \& Cheng (1997)).

\section{Elitismo}

A quantidade necessária de cruzamentos é determinada de modo a se manter a população sempre com o mesmo tamanho. Assim, a maneira mais simples de fazer isto é, simplesmente, substituir toda a população antiga pela nova, independentemente da sua aptidão. Entretanto, é recomendável preservar a informação genética dos melhores indivíduos dentre os ascendentes, repassando-a para a próxima geração, operação esta chamada de elitismo. Isto pode ser feito substituindo os descendentes menos aptos pelos ascendentes mais aptos.

\section{Otimização por Colônia de Formigas}

Esta seção aborda a Otimização por Colônia de Formigas em sua forma clássica, idealizada na aplicação do PRVC. A meta-heurística Otimização por Colônia de Formigas foi proposta por Marcos Dorigo e colegas 
(Dorigo et al., 1996; Dorigo \& Gambardella, 1997) para problemas de otimização combinatória, em particular para o problema do caixeiro viajante simétrico e assimétrico. Sua aplicação em outros problemas como job-shop scheduling e roteamento de veículos, comprovaram sua eficiência e robustez. A proposta algorítmica é baseada no comportamento de formigas reais, que buscam por alimento inicialmente de maneira aleatória. Após encontrarem uma fonte de alimento, voltam para o ninho formando uma trilha e depositando uma substância química, conhecida como feromônio. O feromônio serve como guia para as outras formigas, levando-as à fonte de alimento. À medida que mais formigas seguem esta trilha, mais feromônio é depositado, intensificando o caminho. Como inicialmente a busca é aleatória, a trilha de menor distância até a fonte de alimento mantém maior quantia de feromônio, ao contrário das trilhas mais longas, pois ao longo do tempo, o feromônio se evapora.

Considerando o PRV em um grafo G, como descrito anteriormente, na meta-heurística Otimização por Colônia de Formigas, em cada iteração, cada formiga constrói uma solução do problema, passo a passo. Em cada passo, a formiga faz um movimento com a finalidade de completar a solução parcial corrente escolhendo entre elementos de um conjunto de nós viáveis, denominado de lista tabu, como apresentado em Dorigo et al. (1996).

A decisão sobre a combinação de nós é baseada em uma regra probabilística que visa tanto a visibilidade como a quantidade de feromônio. Assim, como segue em Dorigo et al. (1996), para selecionar o próximo nó $j$ pela $k$-ésima formiga, a partir do nó $i$, as formigas usam a seguinte função de probabilidade:

$$
p_{i j}^{k}= \begin{cases}\frac{\left[\tau_{i j}\right]^{\alpha}\left[\eta_{i j}\right]^{\beta}}{\sum_{\substack{j \in \text { tabu }_{k} \\ 0,}}\left[\tau_{i j}\right]^{\alpha}\left[\eta_{i j}\right]^{\beta}}, & \text { se } j \in \mathrm{tabu}_{k} \\ & \text { caso contrário }\end{cases}
$$

onde

$\tau_{i j}$ : é a quantidade de feromônio presente na trilha $(i, j)$;

$\eta_{i j}=\frac{1}{d_{i j}}$ : visibilidade do nó $j$ com relação ao nó $i$;

$\alpha$ e $\beta$ : são parâmetros que controlam a importância relativa da trilha versus visibilidade, respectivamente;

$k$ : o índice (identificador único) da formiga;

$\operatorname{tabu}_{k}$ : é a lista de nós viáveis para a formiga $k$ (isto é, o conjunto de nós ainda não visitados pela formiga $k)$.

Associado a cada aresta $(i, j)$ existe um valor heurístico $\eta_{i j}$ dado por:

$$
\eta_{i j}=\frac{1}{d_{i j}}
$$

que representa a atratividade da formiga passar pelo nó $j$ depois de passar pelo nó $i$, que é inversamente proporcional à distância $d_{i j}$, entre os nós $i$ e $j$, neste caso, a distância Euclidiana $\left(d_{i j}=\sqrt{\left(x_{i}-x_{j}\right)^{2}+\left(y_{i}-y_{j}\right)^{2}}\right)$. O feromônio $\tau_{i j}$ associado à aresta $(i, j)$ atua de duas maneiras:

1. Na evaporação, pois evita que haja o acúmulo infinitamente e permite esquecer decisões ruins do passado de busca;

2. No depósito de feromônio de todas as formigas que passaram sobre a aresta $(i, j)$.

Depois que todas as formigas construíram suas rotas, o feromônio é atualizado. Primeiramente, estima-se a quantidade de feromônio a ser depositado sobre as arestas $(i, j)$, dado pela equação:

$$
\Delta \tau_{i j}^{k}=\left\{\begin{aligned}
\frac{1}{L_{B e s t}}, & \text { se a aresta }(i, j) \text { pertence à rota } S_{k} \\
0, & \text { caso contrário }
\end{aligned}\right.
$$

onde:

- $\Delta \tau_{i j}^{k}$ : é a quantidade de feromônio depositado pela formiga $k$ sobre a aresta $(i, j)$;

- $L_{B e s t}$ : representa o valor da melhor solução encontrada até o momento; 
- $S_{k}$ : representa o conjunto de nós que são percorridos pela formiga $k$ para a construção da solução.

Finalmente, a atualização de $\tau_{i j}$ associado à aresta $(i, j)$ é dada por:

$$
\tau_{i j}^{n o v o}=\rho \tau_{i j}^{a n t i g o}+\sum_{k=1}^{K} \Delta \tau_{i j}^{k}
$$

onde:

- $\tau_{i j}^{\text {novo }}$ representa o feromônio no $\operatorname{arco}(i, j)$ depois da atualização;

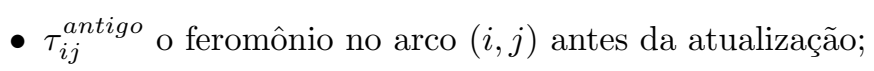

- $\rho \in(0,1)$ é a constante que representa a taxa de evaporação;

- $\Delta \tau_{i j}^{k}$ representa o aumento do feromônio na aresta $(i, j)$ da rota $k$ encontrado pela formiga.

\subsection{Otimização por colônia de formigas para o PRVC}

As principais características da Otimização por Colônia de Formigas para o PRV, como em Mazzeo \& Loiseau (2004), são:

1. Construção da rota: em cada iteração da Otimização por Colônia de Formigas, cada formiga constrói uma solução para o PRVC, movendo para o próximo nó (ou cliente) de acordo com uma regra de transição baseada na combinação da quantidade de feromônio em cada arco e de seu tamanho. A lista tabu é usada para verificar quais clientes podem ser escolhidos pela formiga na iteração corrente. Assim, uma implementação sequencial é usada, pois cada formiga inicia sua solução determinando a rota para o primeiro veículo enquanto a restrição de capacidade não for violada. Quando isto acontece, repete-se o processo para outra formiga, desconsiderando os clientes já visitados e assim por diante até completar a solução. Cada formiga corresponde a um veículo é iniciada em um cliente diferente, que pode ser gerado como descrito a seguir.

\section{Regra de transição:}

- Regra proporcional aleatória: um cliente vizinho é escolhido aleatoriamente de acordo com a função de probabilidade $p_{i j}^{k}$ (Equação (14)).

- Regra pseudo aleatória proporcional: esta regra escolhe o próximo cliente para visitar combinando a seleção aleatória com a melhor opção. Seja $q_{0} \in[0,1]$ um parâmetro e $q \in[0,1]$ gerado de forma aleatória. Se $q$ estiver abaixo do parâmetro $q_{0}$, caracterizamos a busca das formigas como exploração simples; neste caso o próximo cliente a ser visitado é escolhido através de uma regra probabilística modificada, mas similar à Equação (14). Caso $q>q_{0}$, usa-se, de fato, a regra como em (14). Assim o próximo cliente $j$ é escolhido como:

$$
j=\left\{\begin{array}{c}
\max _{u \in \Gamma(i)} \tau_{i u}^{\alpha} \eta_{i u}^{\beta} \text { se } q \leq q_{0} \text { (exploração) } \\
J \text { se } q>q_{0}(\text { exploração tendenciosa) }
\end{array}\right.
$$

onde $J$ é escolhido aleatoriamente de acordo com a Equação (14) e $\Gamma(i)$ é a lista tabu de clientes que devem ser visitadas pela $k$-ésima formiga posicionada no nó $i$ (para construir uma solução viável).

\section{Atualização do feromônio:}

(a) Atualização global: realizada depois de cada iteração da Otimização por Colônia de Formigas estar completa, onde os níveis de feromônio são atualizados em cada iteração, depois de todas formigas completarem as suas rotas (ver Equação (17)).

(b) Atualização local: executada cada vez que uma formiga move de um cliente $i$ para o próximo $j$, diminuindo a quantia de feromônio de uma aresta usada $(i, j)$, com a finalidade de obter soluções diversificadas, obtidas pelas formigas. Uma variação da Equação (17), apresentada em Mazzeo \& Loiseau (2004), é dada por:

$$
\tau_{i j}^{\text {novo }}=\rho \tau_{i j}^{\text {antigo }}+(1-\rho) \sum_{k=1}^{K} \Delta \tau_{i j}^{k}
$$

sendo, $\Delta \tau_{i j}^{k}=\frac{\tau_{0}}{d_{i j}}$ e $\tau_{0}$ um nível de feromônio inicial. 
4. Critério de parada: O critério de parada desta meta-heurística é o número máximo de iterações ou estagnação da solução.

A Figura 15 apresenta um fluxograma do algoritmo de Otimização por Colônia de Formigas.

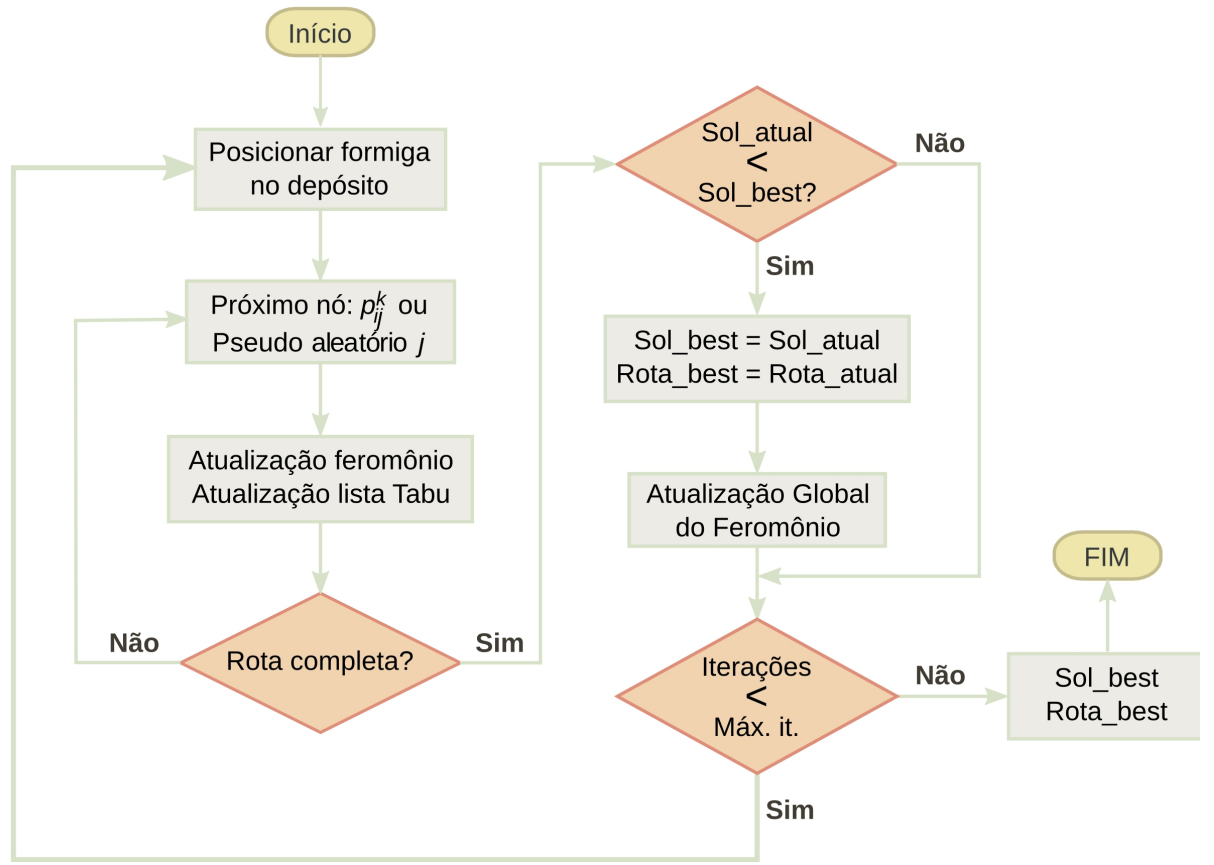

Figura 15. Fluxograma representando o pseudo-algoritmo de Otimização por Colônia de Formigas.

\section{Considerações Finais}

Na literatura científica tanto o PRV, como as meta-heurísticas Algoritmo Genético e Otimização por Colônia de Formigas, têm sido bastante exploradas pela comunidade científica. E novas ideias continuam surgindo na literatura, o que mostra que ainda há muito o que se fazer quando se trata do PRV. Pela finalidade didática que se trata este capítulo, foi escolhida a instância A-n32-k5 de Augerat et al. (1998) para a realização dos testes computacionais.

Num primeiro momento, as meta-heurísticas abordam a instância com uma alteração na quantidade de veículos disponíveis da instância, passando a um único veículo com capacidade ilimitada, ou seja, temos um PCV em que o depósito corresponde a cidade origem do caixeiro viajante e os clientes como as cidades a serem visitadas, sem perda de generalidade. E, num segundo momento, as meta-heurísticas abordam a instância em sua forma original, ou seja, considerando cinco veículos com capacidades de carregamento limitadas a 100 ítens cada um.

Para o Algoritmo Genético, foi considerado como tamanho máximo da população 500 cromossomos e critério de paradas 2000 iterações. Foram aplicados os operadores de cruzamento PMX, OX e CX, alternadamente, foram considerados também os operadores de mutação por inversão, por substituição e troca recíproca, taxa de $10 \%$.

Os parâmetros usados nos testes da Otimização por Colônia de Formigas, foram $\alpha=1, \beta=4, \rho=0,95$, $\tau_{0}=\frac{1}{\text { número de cidades } \times 1200}, q_{0}=0,95,200$ formigas (número de soluções construídas em cada iteração) e 200 iterações.

As Figuras 16 e 17 ilustram as melhores soluções obtidas para a instância quando considerado apenas um veículo com a distância total igual a 478,4453 e 475,2846, para as meta-heurísticas do Algoritmo Genético e Otimização por Colônia de Formigas. As Figuras 18 e 19 ilustram a melhor solução obtida para a instância A-n32-k5 em sua forma original, ou seja, com cinco veículos com capacidade limitada a 100 ítens. As soluções obtidas pelo Algoritmo Genético e Otimização por Colônia de Formigas são, respectivamente, 833,8447 e 977,9643.

Isto mostra o potencial de ambas as meta-heurísticas que, apesar de não garantirem a otimalidade na solução, apresentam boa qualidade, levando em conta o esforço computacional. São procedimentos intuitivos que exploram as especificações do PRV de forma inteligente. Esses resultados podem ainda ser melhorados. 


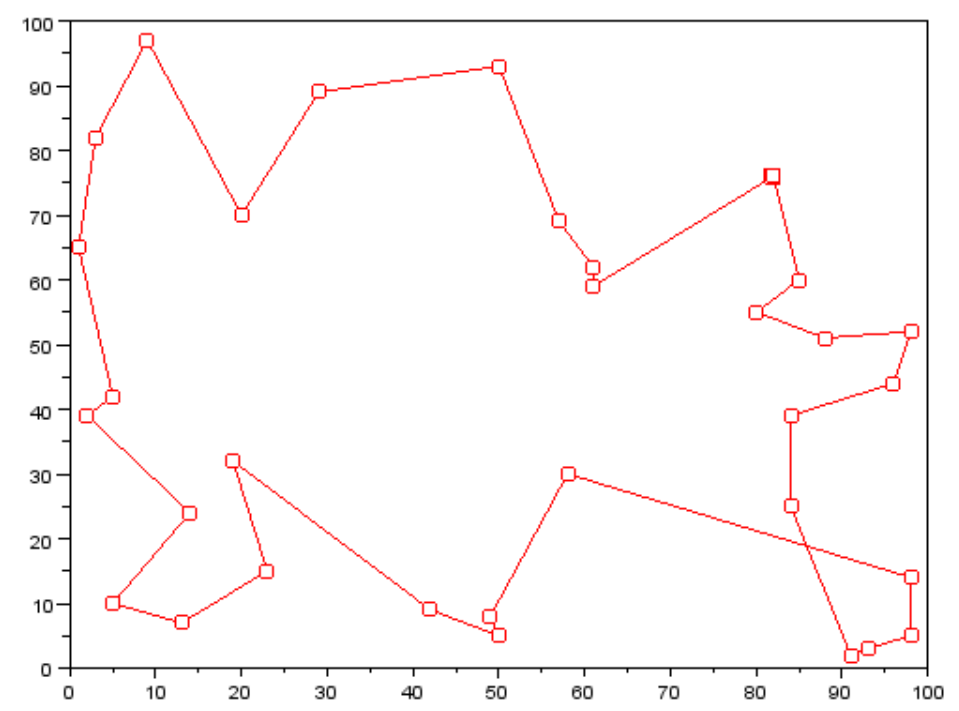

Figura 16. Melhor solução obtida para o problema A-n32-k5, com um único veículo, pelo Algoritmo Genético.

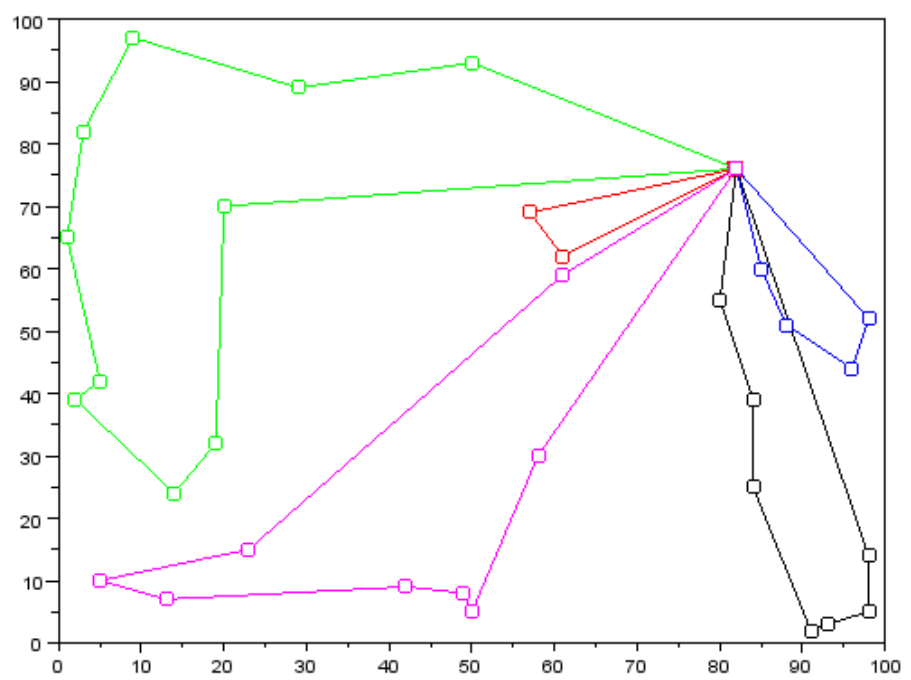

Figura 17. Melhor solução obtida para o problema A-n32-k5, com um único veículo, pela Otimização por Colônia de Formigas.

Por exemplo, no caso da Otimização por Colônia de Formigas, Mazzeo \& Loiseau (2004) propõem uma regra de transição pseudo randômica proporcional, além de uma atualização local e global do feromônio.

Bullnheimer et al. (1999) apresentam um cálculo alternativo para a visibilidade da trilha $\left(\eta_{i j}\right)$, pois a probabilidade de escolha do próximo nó depende de sua visibilidade. Também podem ser aplicadas técnicas de pós otimização como o $\lambda$ - interchange (Psaraftis (1983)) ou o $k$-opt (Baker \& Schaffer, 1986), ou então, criar formas de diversificar os cromossomos usados no Algoritmo Genético e evitar possíveis estagnações.

Como os problemas de Roteamento de Veículos inicializam suas rotas no depósito, ou seja, em um nó fixo, não há a aleatoriedade inicial intrínseca da meta-heurística Otimização por Colônia de Formigas. Permitindo, assim, uma inicialização determinística. Alguns autores, como Yu et al. (2009), Bullnheimer et al. (1999) e Mazzeo \& Loiseau (2004), entre outros, propõem alterações no algoritmo base de Colônia de Formigas com a finalidade de introduzir uma diversificação da solução no processo do cálculo da função probabilidade e atualização local e global do feromônio.

Como já citado anteriormente, há muito interesse pelo PRV do ponto de vista computacional, por serem NP-difíceis e não se conhecer nenhum algoritmo que os resolva em tempo polinomial. Assim, a pesquisa por métodos híbridos eficientes, deve permanecer contínua na ciência. 


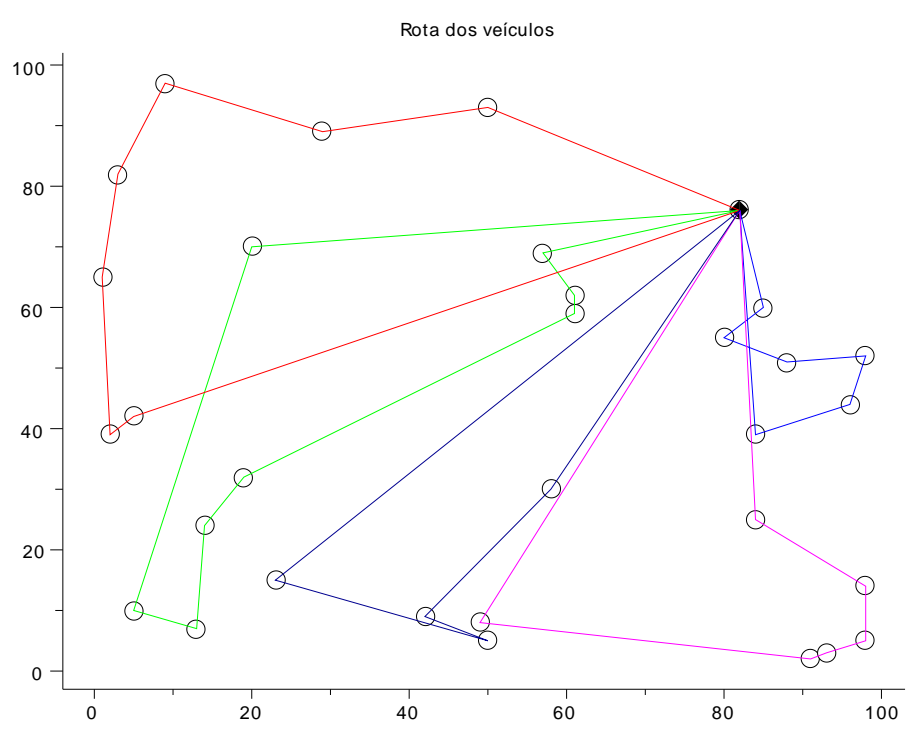

Figura 18. Melhor solução para o problema A-n32-k5, obtida pela Otimização por Colônia de Formigas.

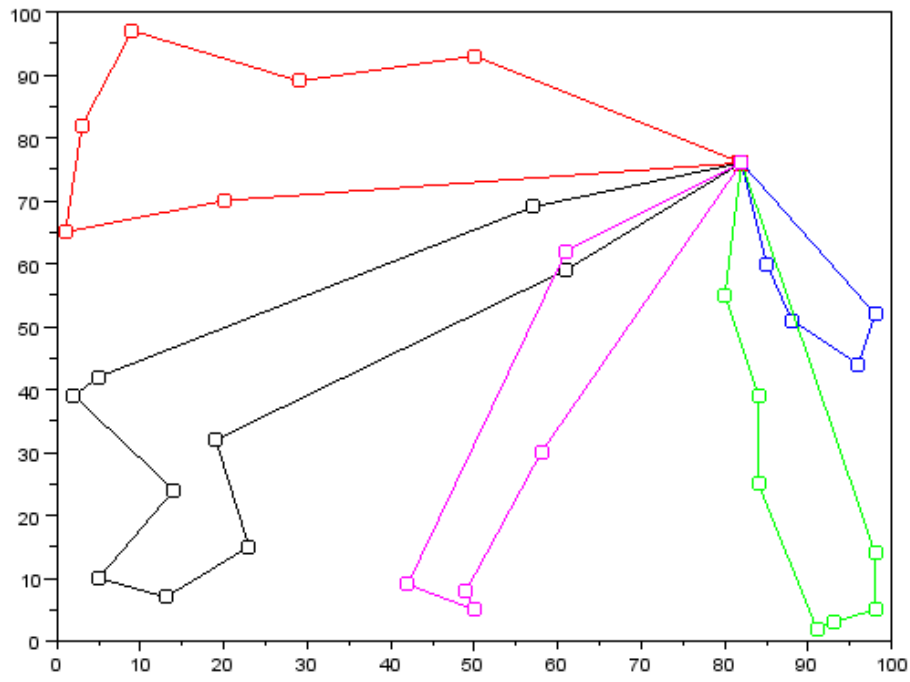

Figura 19. Melhor solução obtida pelo Algoritmo Genético.

\section{Referências}

Assad, A.A., Modeling and implementation issues in vehicle routing. $1^{\text {st }}$ edição. Amsterdam, Netherlands: NorthHolland, 1988.

Augerat, P.; Belenguer, J.; Benavent, E.; Corberán, A. \& Naddef, D., Separating capacity constraints in the CVRP using tabu search. European Journal of Operations Research, 106(2-3):546-557, 1998.

Baker, E. \& Schaffer, J., Computational experience with branch exchange heuristics for vehicle routing problems with time windows constraints. American Journal of Mathematical and Management Sciences, 6:261-300, 1986.

Beasley, J.E., Population heuristics. In: Pardalos, P.M. \& Resende, M.G.C. (Eds.), Handbook of Applied Optimization. Oxford, UK: Oxford University Press, p. 138-157, 2002.

Bodin, L.D. \& Golden, B., Classification in vehicle routing and scheduling. Networks, 11(2):97-108, 1981.

Bullnheimer, B.; Hartl, R.F. \& Strauss, C., An improved ant system algorithm for the vehicle routing problem. Annals of Operations Research, 89(1):319-328, 1999.

Cheng, L., A Genetic Algorithm for the Vehicle Routing Problem with time Windows. Thesis for the Degree of Master of Science, University of North Carolina Wilmington, 2005. 
Christofides, N., Vehicle routing. In: Lawer, E.L.; Lenstra, J.K.; Rinnooy Kan, A.H.G. \& Shmoys, D.B. (Eds.), The Traveling Salesman Problem: a Guided Tour of Combinatorial Optimization. New York, USA: J. Wiley \& Sons, p. 431-448, 1985.

Dorigo, M. \& Gambardella, L.M., Ant colony aystem: a cooperative learning approach to the traveling salesman problem. IEEE Transactions on Evolutionaty Computation, 1(1):53-66, 1997.

Dorigo, M.; Maniezzo, V. \& Colorni, A., Ant system: optimization by a colony of cooperating agents. IEEE Transactions on Systems, Man, and Cybernetics - Part B: Cybernetics, 26(1):29-41, 1996.

Eksioglu, B.; Vural, A.V. \& Reisman, A., The vehicle routing problem: a taxonomic review. Computers 8 Industrial Engineering, 57(4):1472-1486, 2009.

Fisher, M.L. \& Jaikumar, R., A generalized assignment heuristic for vehicle routing. Networks, 11(2):109-124, 1981.

Gen, M. \& Cheng, R., Genetic Algorithms and Engineering Design. New York, USA: J. Wiley \& Sons, 1997.

Holland, J.H., Adaptation in natural and artificial systems. Ann Arbor, USA: University of Michigan Press, 1975.

Martello, S. \& Toth, P., A new algorithm for the 0-1 knapsack problem. Management Science, 34(5):633-644, 1988.

Mazzeo, S. \& Loiseau, I., An ant colony algorithm for the capacitated vehicle routing. Eletronic Notes in Discrete Mathematics, 18:181-186, 2004.

Prins, C.A., A simple and effective evolutionary algorithm for the vehicle routing problem. Computers and Operations Research, 31(12):1985-2002, 2004.

Psaraftis, H.N., $k$-interchange procedures for local search in precedence-constrained routing problem. European Journal of Operational Research, 13(4):391-402, 1983.

Reeves, C.R., Genetic algorithms. In: Glover, F. \& Kochenberger, G.A. (Eds.), Handbook of Metaheuristics. Boston, USA: Kluwer Academic Publishers, p. 55-82, 2003.

Ronen, D., Perspectives on pratical aspectos of truck routing and scheduling. European Journal of Operational Research, 35(2):137-145, 1988.

Yu, B.; Yang, Z.Z. \& Yao, B., An improved ant colony optimization for vehicle routing problem. European Journal of Operational Research, 196(1):171-176, 2009.

\section{Notas Biográficas}

Silvely Salomão Néia é graduada em Licenciatura em Matemática (UNESP/Presidente Prudente, 1989), mestre em Matemática Aplicada e Computacional (USP/São Carlos, 1993) e doutor em Computação Aplicada (INPE, 2005). Atualmente é professora assistente doutor da UNESP, câmpus de Presidente Prudente finaliza estágio de pós-doutorado junto ao Departamento de Engenharia de Transportes da Escola Politécnica da USP (2013).

Almir Olivette Artero é graduado em Licenciatura em Matemática (UNESP/Presidente Prudente, 1989), mestre em Ciências Cartográficas (UNESP, 1999) e doutor em Ciências da Computação e Matemática Computacional (USP/São Carlos, 2005). Atualmente é professor assistente doutor da UNESP, campus de Presidente Prudente.

Luiza Amalia Pinto Cantão é graduada em Licenciatura em Matemática (UNESP/Bauru, 1995), mestre em Matemática Aplicada e Computacional (UNESP/São José do Rio Preto, 1999) e doutor em Engenharia Elétrica (UNICAMP, 2003). Atualmente é professora assistente doutor da UNESP, campus Experimental de Sorocaba e tem interesse na área de otimização em ambiente nebuloso, meta-heurísticas para problemas de roteamento de veículos.

Cláudio Barbieri da Cunha é graduado em Engenharia Civil (USP, 1983), mestre e doutor em Engenharia de Transportes (USP, 1991 e 1997, respectivamente). Possui, também, pós-doutorado no Department of Industrial and Systems Engineering, University of Florida, EUA (2003-2004). Atualmente é Professor Associado 3 junto ao Departamento de Engenharia de Transportes da Escola Politécnica da USP. 


\title{
Modelagem Matemática para Coleta Seletiva no Município de Passo Fundo - RS
}

\author{
Fábio Roberto Barão, Moacir Kripka e Rosana Maria Luvezute Kripka *
}

\begin{abstract}
Resumo: As decisões administrativas envolvem elementos objetivos e subjetivos que impõem desafios significativos quanto à busca de solução apropriada para os problemas reais da sociedade. Neste sentido, o uso de técnicas da Pesquisa Operacional tem se tornado uma alternativa interessante, como ferramenta auxiliar em processos de tomadas de decisão com intuito de prover soluções otimizadas para as mais diversas atividades, inclusive a alocação de recursos. Neste capítulo apresenta-se uma aplicação dos problemas de localização de facilidades por $p$-medianas com o propósito de determinar o posicionamento mais eficiente de postos de entrega voluntária de materiais recicláveis na região central do município de Passo Fundo, aliado à aplicação do problema do caixeiro viajante que visa modelar o roteiro mais econômico para coleta e destinação destes resíduos. Os resultados apontam um modelo de fácil reprodução e que poderá ser repetido quando necessário, tanto para a inserção de novos postos de coleta como para a aplicação do estudo em diferentes áreas urbanas.
\end{abstract}

Palavras-chave: Pesquisa operacional, Problema de localização de facilidades, Problema do caixeiro viajante, Gerenciamento de resíduos sólidos urbanos.

\begin{abstract}
The decision making process often involves objective and subjective elements whose combination imposes severe challenges toward the solution of the problems imposed. The use of management science as a way to support decision making has become more and more common in the most diverse activities, such as resource allocation. This paper contemplates the application of facility location problems by p-medians aiming to determine the most efficient placement for voluntary deliver spots containers for recyclable wastes in the downtown area of Passo Fundo, along with the application of the classic traveling salesmen problem aiming to model the most economic route for collecting such wastes towards its proper destination. The final result shows a model that can be easily reproduced and that can be repeated whenever necessary, both for the insertion of new collection points as well as the application of such study in different urban areas.
\end{abstract}

Keywords: Management science, Facility location problem, Traveling salesmen problem, Urban solid waste management.

\section{Introdução}

No cerne do tão almejado desenvolvimento sustentável reside a questão de se aliar o crescimento econômico à preservação e uso racional dos recursos naturais, assegurando condições às presentes e futuras gerações do atendimento de suas necessidades básicas. Neste contexto, a apropriada destinação dos resíduos sólidos de origem doméstica, gerados nas regiões urbanas municipais, destaca-se como um dos principais temas de discussão, uma vez que o mesmo tem impacto direto na qualidade de vida das comunidades.

Segundo Cheremisinoff (2003) os governos, que são os principais responsáveis pelos programas de gerenciamento de resíduos sólidos, usualmente dispõem de três estratégias principais para a destinação dos resíduos: compostagem, incineração e aterros sanitários. A compostagem, um processo que envolve bactérias como agentes de decomposição dos resíduos em aditivos ao solo, são úteis na destinação de certos resíduos orgânicos, auxiliando assim na redução do volume de resíduos a serem destinados. Já a incineração envolve a queima dos resíduos sólidos que, além de diminuir consideravelmente o volume de resíduos, também pode gerar energia na forma de vapor ou de eletricidade (gerando, todavia, uma perigosa emissão de substâncias tóxicas como dioxinas, furanos, dióxidos de enxofre e óxido de nitrogênio, bem como as cinzas resultantes do processo). Devido ao fato destas alternativas deixarem parte dos resíduos sem tratamento, ou produzirem

*Autor para contato: rkripka@upf.br 
algum tipo de resíduo, a adoção de aterros sanitários vem se mostrando como uma abordagem definitiva à questão do gerenciamento de resíduos.

Com o aumento na escassez de espaço para a construção de aterros sanitários e com os extensos, complexos e caros processos de localização e construção de incineradores, a reciclagem, aliada à coleta seletiva dos resíduos, vem se tornando uma alternativa significativa no que tange aos sistemas de gestão dos resíduos sólidos em diversos países. Atualmente, uma das práticas mais comumente utilizadas para se obter uma redução efetiva dos custos de coleta está na separação desde a fonte geradora, aliada ao uso de contêineres específicos e de veículos dedicados ao transporte destes materiais até a sua área de destinação (Chang \& Wei, 2000).

A exemplo de tais abordagens, o município de Passo Fundo, localizado na região do Planalto Médio do Estado do Rio Grande do Sul, região sul do Brasil, também conta com um sistema integrado de coleta e destinação de seus resíduos sólidos, provido de um aterro sanitário controlado. No entanto, até a conclusão do presente estudo, o município ainda não se servia de um programa efetivo de separação de resíduos na fonte geradora, valendo-se predominantemente de uma pré-seleção dos resíduos imediatamente anterior à sua destinação final. Esta estratégia torna o processo pouco eficaz sob o ponto de vista de se estender a vida útil do aterro sanitário, minimizando os impactos ambientais de tal atividade.

O presente capítulo aborda a utilização das ferramentas de Pesquisa Operacional, através da modelagem matemática e de técnicas de otimização, com o foco em aprimorar os esforços empreendidos pela administração pública. De acordo com Mohd et al. (2004) e Morrisey \& Browne (2004), os modelos matemáticos de otimização podem desempenhar um papel proeminente no planejamento efetivo de custos no longo prazo para estes sistemas, pois a disposição destes contêineres para separação de materiais deve ser meticulosamente planejada para garantir a quantidade e densidade do material a ser coletado. Duas ferramentas foram empregadas para a resolução do problema, quais sejam, o software LINGO (Language for Interactive General Optimizer) e um programa desenvolvido pelos autores utilizando o método Simulated Annealing. O presente trabalho dá ênfase a este último, uma vez que foi o único que efetivamente permitiu a obtenção de boas soluções em tempo aceitável.

Diversos estudos têm sido desenvolvidos visando a aplicação de técnicas de otimização a problemas envolvendo coleta e destinação de resíduos sólidos urbanos, com as mais diversas estratégias e objetivos. Dentre estes, destacam-se os trabalhos de Clark \& Gillean (1977), Golden \& Wong (1981), Bath (1996), Moura et al. (2001) e Paes (2004).

Na Seção 2 do presente capítulo são apresentados conceitos fundamentais sobre modelagem matemática e sobre Pesquisa Operacional, incluindo a descrição do método de otimização Simulated Annealing, empregado neste trabalho, bem como a descrição dos problemas de localização de facilidades e de roteamento de veículos. Na Seção 3 apresenta-se a aplicação do modelo para a região central do município de Passo Fundo, RS, bem como os resultados obtidos. Por fim, na Seção 4 apresenta as conclusões e considerações finais.

\section{Modelagem Matemática e Pesquisa Operacional}

Segundo Goldbarg \& Luna (2005), um modelo matemático é uma representação quantitativa, ou uma aproximação, de um problema real, sendo que tal representação pode ser expressa em termos de expressões matemáticas (equações e/ou inequações) ou através de uma série de células inter-relacionadas em uma planilha de cálculo. Seu propósito é representar a essência de um problema de forma concisa, permitindo uma melhor compreensão da situação analisada, ajudando a definir o escopo, bem como suas possíveis soluções.

Ao desenvolvimento do modelo segue-se o uso de uma variedade de procedimentos de resolução matemática, dos quais muitos já vêm sendo desenvolvidos há mais de um século.

Segundo Andrade (2004) os modelos matemáticos podem ser divididos em dois grupos: os modelos de simulação e os modelos de otimização. Afirma que nos modelos de simulação o objetivo consiste na representação simplificada da realidade visando gerar cenários alternativos futuros, buscando analisar e escolher a melhor possibilidade frente a simulações de ambientes possíveis. Já em relação aos modelos de otimização, esclarece que o objetivo consiste em otimizar uma determinada função, chamada de objetivo, que pode ou não estar sujeita à restrições impeditivas, que descrevem os fatores limitantes das soluções possíveis. Na resolução do problema de otimização busca-se, os melhores valores possíveis para as variáveis do problema, que respeite as condições reais existentes do problema, e que torne o valor da função objetivo máxima ou mínima, de acordo com o critério estabelecido. Neste caso, busca-se calcular a solução que proporcionará o melhor valor possível para o objetivo proposto, através de técnicas de otimização específicas. Assim, em modelos de otimização existe somente um resultado possível para a função objetivo escolhida pelo administrador e, através de análise matemática, busca-se calcular a melhor alternativa para resolver o problema em questão.

A confiabilidade da solução obtida através dos modelos matemáticos, seja ele de simulação ou de otimização, depende da confirmação dos resultados obtidos, quando comparados às soluções reais conhecidas. As diferenças entre a solução real praticada e a solução teórica proposta depende diretamente da precisão do 
modelo ao descrever o comportamento original do sistema. Os problemas pequenos geralmente são resolvidos facilmente, mas problemas mais complexos requerem modelos mais elaborados e reoluções mais sofisticadas.

Atualmente, devido à complexidade dos problemas existentes na sociedade, a aplicação da modelagem matemática torna-se uma ferramenta importante no processo de tomada de decisão, pois, possibilita representar fenômenos físicos e realizar planejamentos de ações futuras.

Neste trabalho, a proposta consiste em abordar conceitos específicos sobre Pesquisa Operacional, relativos a resolução de problemas de otimização. Os algoritmos empregados para a solução de problemas de otimização são classificados, basicamente, em determinísticos ou probabilísticos. Os métodos de otimização baseados em algoritmos determinísticos geram uma sequência de soluções possíveis, requerendo na maioria das vezes que a função objetivo seja contínua e diferenciável, como é o caso da maioria dos métodos da programação matemática, porém não representa a maioria dos problemas práticos de engenharia, dificultando, assim, a sua aplicação.

Desde a década de 1970, tem aumentado o interesse por algoritmos inspirados no comportamento da natureza, com base na física e na biologia, para se resolverem problemas complexos de otimização, principalmente em situações em que métodos tradicionais se mostram pouco eficientes. Os estudos dos métodos heurísticos com estratégias de busca controlada por critérios probabilísticos, conhecidos como meta-heurísticos (no grego, "meta" significa nível superior e "heurístico", encontrar), vêm desempenhando importante papel, uma vez que envolvem apenas valores das funções no processo, não importando se existe unimodalidade ou mesmo continuidade em suas derivadas.

Os primeiros estudos com algoritmos heurísticos, baseados em critérios probabilísticos, surgiram com Holland (1975) considerado o criador do Método dos Algoritmos Genéticos, o qual é baseado na evolução das espécies. Kirkpatrick et al. (1983) apresentaram um método heurístico, o Simulated Annealing, no qual os parâmetros são variados de acordo com dados probabilísticos e é fundamentado na simulação do processo mecânico de recozimento de metais. Segundo Cortes (2010), este trabalho coincidiu com o aumento da capacidade de processamento dos computadores, ocorrido na década de 1980, contribuindo para que este fosse o primeiro método de otimização heurística a se popularizar no meio científico. Em função principalmente dos bons resultados já obtidos pelos autores a partir da aplicação do Simulated Annealing a problemas de naturezas distintas, este foi o método adotado no desenvolvimento do presente estudo.

\subsection{Método simulated annealing}

O Simulated Annealing é um método heurístico inspirado na natureza e tem sua origem fundamentada na simulação do processo mecânico de recozimento de metais. Quando um metal é aquecido a altas temperaturas, provocando a fusão, este processo é chamado de recozimento (annealing) e os átomos se movimentam livremente. A solidificação se dá pelo resfriamento lento e controlado e leva a que estes átomos se organizem numa configuração ordenada e estável, formando uma estrutura uniforme e com energia mínima, tendo como resultado uma redução de defeitos no material. Caso o metal seja resfriado de forma brusca, a microestrutura tende a um estado instável. Metropolis et al. (1953) apresentaram um algoritmo para modelagem do processo de recozimento de metais, citado anteriormente, simulando as mudanças de energia em um sistema de partículas à medida que a temperatura diminui até um estado estável, como descrito a seguir.

Dado um estado corrente $i$ do material com energia $E_{i}$, o estado subsequente $j$ será gerado por um mecanismo de perturbação que transforma o estado corrente em $E_{j}$, agora com uma pequena distorção. A cada geração de $E_{j}$, é testada a variação do valor da função objetivo, isto é:

$$
\Delta E=E_{j}-E_{i}
$$

sendo:

- $\Delta E<0$ : houve redução de energia, sendo a nova solução melhor que a anterior. Logo, $E_{j}$ passa a ser a nova solução corrente e

- $\Delta E>0$ : houve um aumento de energia. A aceitação deste tipo de solução depende de uma probabilidade conhecida como "critério de Metrópolis", calculada pela função:

$$
p(\Delta E)=\exp \left(\frac{-\Delta E \cdot K}{T}\right)
$$

onde: $T$ é a temperatura do corpo e $K$, a constante de Boltzmann.

Da mesma maneira que no método original de recozimento na termodinâmica, o processo inicia com um alto valor de $T$, para o qual uma nova solução é gerada e $T$ passa a ser um parâmetro de controle, e a constante de Boltzmann não tem analogia num problema de otimização, sendo eliminada. 
O aceite desta nova solução dar-se-á automaticamente caso acarrete redução no valor da função; em oposição, sendo o novo valor da função maior que o anterior, o aceite dar-se-á por um critério probabilístico, sendo a função de aceite:

$$
p=\exp \left(\frac{-\Delta E}{T}\right)
$$

Gera-se um número randômico $r$ a partir de uma distribuição uniforme no intervalo [0,1]. Se este número for menor ou igual a $p$, aceita-se a solução; em caso contrário, a solução é rejeitada.

A temperatura $T$ assume, inicialmente, um valor elevado, em que a maioria das soluções é aceita. Após cada série de tentativas de obtenção de uma melhor solução, a temperatura é gradativamente diminuída por uma razão de resfriamento $\alpha$, sendo $0<\alpha<1$, conforme a equação 4 .

$$
T_{n} \leftarrow \alpha T_{n}
$$

Valores baixos de $\alpha$ levam a uma solução rápida, podendo chegar a soluções pouco eficientes; ao contrário, se tender a "1", o tempo de execução é maior, levando a uma melhor solução final.

O programa tenta restabelecer o equilíbrio a cada redução de temperatura executando um número fixo $L$ de iterações pela vizinhança. O número de transições requeridas para restabelecer este equilíbrio depende da variação da temperatura e do tamanho do problema.

O procedimento é finalizado quando a temperatura chega a um valor próximo de zero, ou "congelado", e nenhuma solução que piore o valor da melhor solução seja aceita, ou seja, quando o sistema estiver estável. A solução obtida quando o sistema se encontra nesta situação evidencia o encontro de um mínimo global.

\subsection{Problemas de localização de facilidades}

Problemas de localização de facilidades tratam de decisões sobre onde localizar facilidades, considerando clientes que devem ser servidos de forma a otimizar um certo critério. O termo "facilidades" pode ser substituído por fábricas, depósitos, escolas, etc., enquanto que clientes se referem a depósitos, unidades de vendas ou estudantes, entre outros. Em geral, as facilidades podem tanto ser selecionadas como centros a serem localizados como podem também ser alocadas ao subconjunto de centros abertos.

Os primeiros trabalhos sobre problemas de localização tiveram origem no século XVII com os trabalhos do advogado e matemático Pierre de Fermat (Goldbarg \& Luna, 2005).

Outras contribuições neste campo incluem o trabalho de Alfred Weber com sua teoria da localização das indústrias de 1909, além da idéia dos procedimentos iterativos para a localização de uma nova facilidade para minimizar a soma dos pesos das distâncias Euclidianas para um número existente de facilidades, apresentada por Weisfeld em 1937.

De acordo com Ducati (2003), uma das características principais dos problemas de localização é o número de facilidades a serem localizadas. Outra característica importante é a maneira como as demandas e a localização das facilidades candidatas são representadas. Nos modelos matemáticos as demandas podem ocorrer em qualquer lugar de um plano e, sendo assim, as facilidades também podem ser alocadas em qualquer lugar de um plano. Já em outros modelos de localização em redes, as demandas e as facilidades ocorrem em um grafo composto de nós e arestas e, então, pode-se assumir que a demanda pode ser localizada apenas nos nós da rede, embora alguns modelos de localização de redes permitam que as demandas sejam localizadas também nas arestas. Neste último caso, as facilidades são designadas aos nós ou arestas da rede.

A distância cliente-facilidade é um diferencial importante entre os modelos de localização, sendo que em certos modelos a distância máxima permitida entre cliente e facilidade é dada a priori (são conhecidos como problemas de distância máxima). Já os modelos de localização onde o objetivo é encontrar um conjunto de facilidades de mínimo custo, tal que cada cliente seja atendido por pelo menos uma facilidade, são conhecidos como problemas de recobrimento de conjuntos. Uma das principais questões envolvidas neste tipo de problema é que o número de facilidades necessárias para atender toda a demanda muitas vezes excede o número realmente possível de facilidades a serem construídas (por questões financeiras ou outras razões) tratando todos os nós de demanda de maneira idêntica (Ducati, 2003).

Nos problemas de recobrimento os clientes são, geralmente, designados às facilidades mais próximas. Desta forma, julga-se adequado atender (cobrir) o cliente se o mesmo estiver dentro de uma dada distância da facilidade. Considera-se o atendimento inadequado se a distância excede um valor crítico estipulado, sendo então o objetivo, neste caso, encontrar um conjunto de facilidades de mínimo custo dentre uma infinidade de 
facilidades candidatas, tal que cada cliente seja atendido por pelo menos uma facilidade. Vale ressaltar que o modelo de recobrimento de conjuntos trata todos os nós de maneira idêntica com relação à demanda, ou seja, para o modelo são igualmente importantes os nós cuja demanda seja de 10 chamadas de serviço por ano ou nós que possuam 10.000 chamadas de serviço por ano.

Uma variante dos problemas de recobrimento é o problema de $p$-centros, cujo objetivo é localizar $p$ facilidades tais que a máxima distância (ou tempo) de qualquer demanda para sua facilidade mais próxima seja mínima. Este modelo também é conhecido como minmax.

Uma segunda classe de problemas que também trabalha com o fator distância cliente-facilidade é a classe de modelos de distância total ou média. Muitas situações de planejamento de localização de facilidades nos setores público e privado tratam da distância total viajada entre as facilidades e os nós de demanda.

Arenales et al. (2007) destacam a localização de facilidades como um aspecto crítico do planejamento estratégico de empresas privadas e públicas e citam como exemplos de aplicações reais no setor público a localização de postos de saúde, hospitais ou escolas e no setor privado, as localização de lojas comerciais, fábricas ou similares.

Ducati (2003) apresenta como um exemplo no setor privado a localização de facilidades de produção que recebam sua matéria prima de fontes estabelecidas através de entrega por caminhões. Já no setor público, exemplifica com a necessidade de se localizar uma rede de provedores de serviços de forma a minimizar a distância total que os consumidores precisam percorrer para encontrar a facilidade mais próxima.

No contexto dos modelos de distância total ou média estão os problemas de p-medianas, que consistem em encontrar a localização de $p$ facilidades em uma rede tal que o custo total (soma dos custos de atendimento dos clientes) seja minimizado. O custo de atendimento de cada cliente é dado pelo produto da demanda do cliente versus a distância cliente-facilidade mais próxima.

O algoritmo de Floyd encontra as distâncias mínimas (e os correspondentes caminhos mínimos) entre todos os pares de nós do grafo e funciona mesmo que existam arestas com comprimentos negativos, apesar de não ser possível, na realidade, existirem circuitos com comprimentos negativos. Possibilita determinar as distâncias mínimas entre os pares de nós do grafo de maneira recursiva, onde na iteração $k$ se determina o caminho mínimo entre dois nós quaisquer utilizando somente os $k$ primeiros nós.

O algoritmo constrói, sucessivamente, $n$ matrizes a partir de uma matriz de custos inicial $D^{0}$, através das modificações efetuadas de acordo com a seguinte expressão:

$$
d_{i j}^{k}=\operatorname{Min}\left(d_{i j}^{k-1},\left(d_{i k}^{k-1}+d_{k j}^{k-1}\right)\right)
$$

onde, para um vértice $k$ do grafo, se realiza a análise da distância relativa à cada par $(i, j)$ de nós, onde se verifica se o menor caminho já conhecido entre os nós $(i, j)$ supera ou não a soma do tamanho do caminho de $i$ para $k$ com o de $k$ para $j$. Caso supere, o tamanho do menor caminho passa a ser esta soma.

Para a determinação do caminho, parte-se do final para o início, levando em conta os vértices intermediários incluídos durante o processo.

O problema das $p$-medianas pode ser formulado como um problema de programação inteira binária, a partir de um grafo fechado para uma dada instância, com o conjunto de vértices indexados resultantes $1, \ldots, n$.

O problema pode ser descrito matematicamente como segue:

Minimizar

$$
\sum_{i=j}^{n} \sum_{j=1}^{n} D_{i j} X_{i j}
$$

Sujeito à

$$
\begin{aligned}
& \sum_{i=1}^{n} X_{i j}=1, j=1, \ldots, n \\
& \sum_{i=1}^{n} X_{i i}=p \\
& X_{i j} \leq X_{i i}, i=1, \ldots, n, j=1, \ldots, n \\
& X_{i j} \in\{0,1\}, i=1, \ldots, n, j=1, \ldots, n
\end{aligned}
$$

onde:

$\left[D_{i j}\right]_{n \times n}$ : matriz simétrica de custo (distância), com $d_{i i}=0, \forall i$ 
$\left[X_{i j}\right]_{n \times n}$ : matriz de alocação, com:

$x_{i j}= \begin{cases}1, & \text { se o nó } i \text { é alocado ao nó } j \\ 0, & \text { caso contrário; }\end{cases}$

$x_{i i}= \begin{cases}1, & \text { se o nó } i \text { é uma mediana e } \\ 0, & \text { caso contrário. }\end{cases}$

$p:$ número de facilidades (medianas) a serem localizadas e

$n:$ número de nós na rede.

As restrições referentes às Equações 7 e 9 garantem que cada nó $j$ é alocado a somente um nó $i$, que deve ser uma mediana. Já a Equação 8 determina o número exato de medianas a ser localizado $(p)$, e a Equação 10 corresponde às condições de integralidade.

Vale destacar que algumas suposições são consideradas para a validade deste modelo, tais como:

- Toda a demanda de um vértice é atendida por um único centro (mediana).

- Todo ponto de demanda deve ser servido pelo centro mais próximo.

- Os vértices coincidem com os pontos de demanda.

- Não existem restrições de capacidade nos vértices.

- Os custos fixos de implementação não são considerados.

\subsection{Problemas de roteamento de veículos}

O problema de roteamento de veículos consiste em definir roteiros de veículos em redes que minimizem o custo total de atendimento, onde cada um deles inicia ou termina no depósito ou base dos veículos, assegurando que cada ponto seja visitado exatamente uma vez e a demanda em qualquer rota não exceda a capacidade do veículo que a atende.

Os problemas de roteamento lidam em sua maior parte com passeios ou tours sobre pontos de demanda e oferta. Estes pontos podem representar cidades, postos de trabalho ou atendimento, depósitos, etc.

Dentre os tipos de passeios um dos mais importantes é o denominado Hamiltoniano. Seu nome é devido a Willian Rowan Hamilton que, em 1857, propôs um jogo que denominou Around the World (do inglês Volta ao Mundo). O jogo era proposto sobre um dodecaedro, onde cada vértice estava associado a uma cidade importante da época e o desafio consistia em encontrar uma rota, através dos vértices do dodecaedro, que iniciasse e terminasse em uma mesma cidade sem nunca repetir uma visita, ou seja que não passasse pelo mesmo vértice duas vezes. Uma solução do jogo de Hamilton é chamada de ciclo Hamiltoniano. Inspirado neste tipo de problema é que foi idealizado um dos mais tradicionais e conhecidos problemas de otimização, chamado de problema do caixeiro viajante (PCV), sendo classificado como um problema de roteamento em nós.

Goldbarg \& Luna (2005), salientam que Hamilton não foi o primeiro a propor este problema, mas o seu jogo ajudou a divulgá-lo. Afirmam que foi Hassler Whitney que, em 1934, fez a primeira menção do Problema do Caixeiro Viajante.

Uma variação do problema do caixeiro viajante é chamado de problema do carteiro chinês, que diferentemente do PCV, trata-se de um problema de roteamento em arcos, ou seja, busca-se encontrar um roteiro para um carteiro de modo que visite todas as ruas (arcos), buscando encontrar o menor caminho possível a ser percorrido pelo carteiro. Neste problema, diferentemente do PCV, é possível passar duas vezes pela mesma aresta, visando percorrer todas as arestas da rede. Segundo Arenales et al. (2007) este problema foi proposto por um matemático chamado Guan que trabalhava num correio, no ano de 1962, durante a revolução cultural chinesa.

Existem diversos tipos de problemas de roteamento, com diferentes objetivos. Nos chamados problemas de roteamento puros, condicionantes temporais não são importantes para a definição dos roteiros e das seqüências de atendimentos, sendo as estratégias de solução direcionadas aos aspectos espaciais da localização dos pontos a serem atendidos. Os principais tipos de problemas de roteamento puros, adaptado de Cunha (2000), são relacionados na Tabela 1.

Deve-se observar que os problemas listados na Tabela 1 derivam do problema clássico do caixeiro viajante, com exceção do problema do carteiro chinês. Neste a demanda se localiza nas arestas ao invés de estar localizada nos nós. Além disto, sua otimização envolve percursos ociosos, já que, por necessitar passar em todas as arestas, normalmente percorre várias delas mais de uma vez, para garantir o atendimento completo da rede. 
Tabela 1. Classificação dos problemas de roteamento puros.

\begin{tabular}{|c|c|c|c|c|c|}
\hline Denominação do Problema & $\begin{array}{l}\text { Num. de } \\
\text { Roteiros }\end{array}$ & $\begin{array}{c}\text { Loc. } \\
\text { Clientes }\end{array}$ & $\begin{array}{l}\text { Lim. Cap. } \\
\text { Veículos }\end{array}$ & $\begin{array}{l}\text { Num. de } \\
\text { Bases }\end{array}$ & Demandas \\
\hline Caixeiro viajante & $\mathrm{Um}$ & Nós & Não & Uma & Determinísticas \\
\hline Problema do carteiro chinês & $\mathrm{Um}$ & Arestas & Não & Uma & Determinísticas \\
\hline Múltiplos caixeiros viajantes & Múltiplos & Nós & Não & Uma & Determinísticas \\
\hline $\begin{array}{l}\text { Roteamento em nós com uma } \\
\text { única base }\end{array}$ & Múltiplos & Nós & Sim & Uma & Determinísticas \\
\hline $\begin{array}{l}\text { Roteamento em nós com } \\
\text { múltiplas bases }\end{array}$ & Múltiplos & Nós & Sim & Múltiplas & Determinísticas \\
\hline $\begin{array}{l}\text { Roteamento em nós com } \\
\text { demandas incertas }\end{array}$ & Múltiplos & Nós & Sim & Uma & Estocásticas \\
\hline $\begin{array}{l}\text { Roteamento em arestas com } \\
\text { limite de capacidade }\end{array}$ & Múltiplos & Arestas & Sim & Uma & Determinísticas \\
\hline
\end{tabular}

O problema do caixeiro viajante (PCV) foi formulado por Dantzig et al. (1954) como um problema de forma binária sobre um grafo $G=(N, A)$, como segue:

Minimizar

$$
\sum_{j=1}^{n} \sum_{i=1}^{n} c_{i j} X_{i j}
$$

Sujeito à

$$
\begin{gathered}
\sum_{i=1}^{n} X_{i j}=1, \forall j \in N \\
\sum_{j=1}^{n} X_{i j}=1, \forall i \in N \\
\sum_{i, j \in S}^{n} X_{i j} \leq|S|-1, \forall S \subset N \\
X_{i j} \in\{0,1\}, \forall i, j \in N
\end{gathered}
$$

onde a variável binária $x_{i j}$ assume o valor " 1 ", se a aresta $(i, j) \in A$ for escolhida para integrar a solução, e "0" em caso contrário. $S$ é um subgrafo de $G$, com $|S|$ representando o número de vértices deste sub-grafo. Nesta formulação é assumido implicitamente que $x_{i i}$ não existe e que existem $n(n-1)$ variáveis inteiras binárias e $O\left(2^{n}\right)$ restrições.

O terceiro conjunto de restrições, definido pela equação 14, determina a eliminação dos circuitos préHamiltonianos (sub-rotas dentro da rota total). Para cada circuito pré-Hamiltoniano possível é necessário uma restrição como a apresentada, justificando-se assim o número de $O\left(2^{n}\right)$ restrições. Visando contornar este problema, uma proposta computacional interessante do PVC é apresentada por Lachtermacher (2007), onde as restrições relativas aos circuitos pré-Hamiltonianos são inseridas no decorrer do processso de otimização, conforme são identificados.

A formulação apresentada destaca um importante aspecto do PCV que é sua natureza combinatória, pois pela formulação matemática proposta é possível perceber que solucionar um PCV consiste em determinar, dentre as permutações possíveis entre os nós da rede, aquela que tenha um custo mínimo avaliado pela função objetivo proposta.

\section{Aplicação do Modelo}

Com o objetivo de ilustrar a aplicabilidade das técnicas de otimização à resolução de problemas reais de ordem da administração e gerenciamento público, foi proposta a modelagem de uma rede de coleta seletiva de resíduos sólidos urbanos para implantação na região central do município de Passo Fundo, no Estado do Rio Grande do Sul. 
As formulações para os problemas abordados no presente trabalho foram otimizadas com o emprego do método Simulated Annealing. Além disto, com o objetivo de estudar o desempenho de métodos determinísticos quando aplicados aos mesmos problemas, foi efetuada a implementação das mesmas formulações no software LINGO.

\subsection{Caracterização da área estudada}

De acordo com dados prestados pela Prefeitura Municipal, atualmente o município de Passo Fundo conta com um sistema integrado de coleta e destinação de seus resíduos sólidos, sendo que tais atividades são delegadas a uma empresa particular contratada por meio de licitação pública. Por ocasião do presente estudo, a coleta de resíduos se estendia a $98 \%$ da zona urbana, o equivalente a uma área de 117,60 km², dividida em 14 setores, sendo que em dois destes setores a coleta era diária e nos 12 restantes era executada de forma alternada, sendo o município servido pelo serviço de coleta porta a porta.

Em um contato prévio estabelecido com a Secretaria de Serviços Urbanos do município, esboços estavam sendo conduzidos para um projeto de implantação de contêineres plásticos com capacidade de 1.000 litros, com o intuito de se efetuar um processo de separação de resíduos na fonte e coleta seletiva desses resíduos. Tais planos objetivavam abranger apenas a área central do município. Desta forma, os estudos conduzidos neste trabalho foram pautados na localização e roteamento de 20 postos de entrega voluntária de material na referida região, representada pela Figura 1.

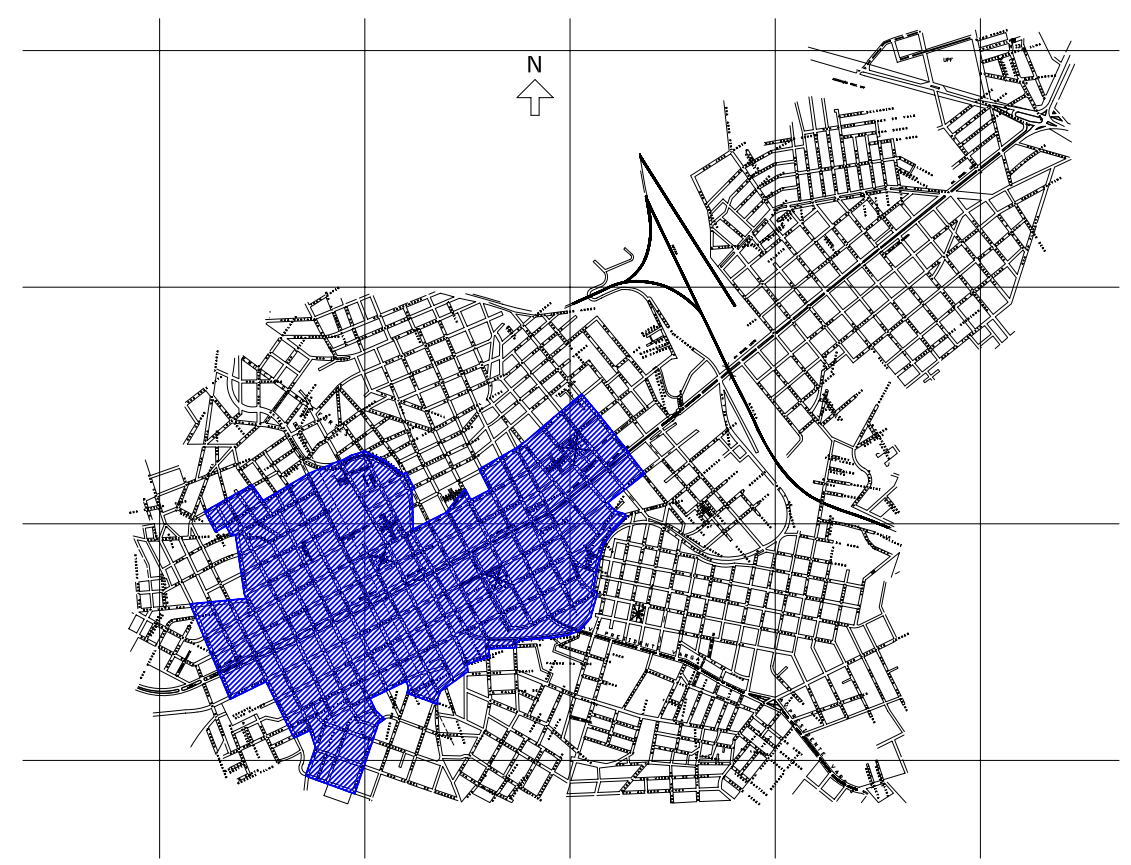

Figura 1. Área estudada dentro do município de Passo Fundo.

\subsection{Elaboração da rede}

De acordo com a proposta de McDougall et al. (2001), uma das formas mais plausíveis para a disposição dos bancos de coleta de materiais está na localização destes nas esquinas, uma vez que os moradores poderiam caminhar até os pontos de coleta desde suas residências.

A partir desta determinação foram numeradas individualmente todas as intersecções viárias da área de estudo, resultando assim em 240 pontos possíveis candidatos a receber um dos contêineres.

Uma vez numerados cada um dos 240 vértices do grafo, através do programa AutoCad@ foi então determinado o custo da aresta/arco, equivalente às distâncias entre cada um dos vértices e o seu par mais próximo. Desta forma, considerando as distâncias obtidas, foi construída uma matriz de distâncias com 57.600 pontos, relacionando todos os vértices com seus pares diretos, resultando assim em uma matriz simétrica. Nesta matriz foi aplicado o algoritmo matricial de Floyd, com o objetivo de se determinar as distâncias mínimas (e os correspondentes caminhos mínimos) entre todos os pares de nós do grafo, gerando assim um grafo fechado. 


\subsection{Resultados obtidos para a localização dos contêineres}

A formulação para o problema de localização de facilidades, anteriormente descrita, foi implementada em linguagem Fortran, para a resolução pelo Simulated Annealing. Durante a fase de teste, problemas com número variável de facilidades foram também analisados pelo LINGO, chegando-se aos mesmos resultados com o emprego das duas estratégias. Após diversos experimentos, os valores para os parâmetros do Simulated Annealing foram fixados como: temperatura inicial igual a 1000 e redutor de temperatura igual a 0,98 .

Após o processamento da formulação no software desenvolvido, foi obtida a localização ótima das 20 facilidades, a qual é apresentada na Figura 2.

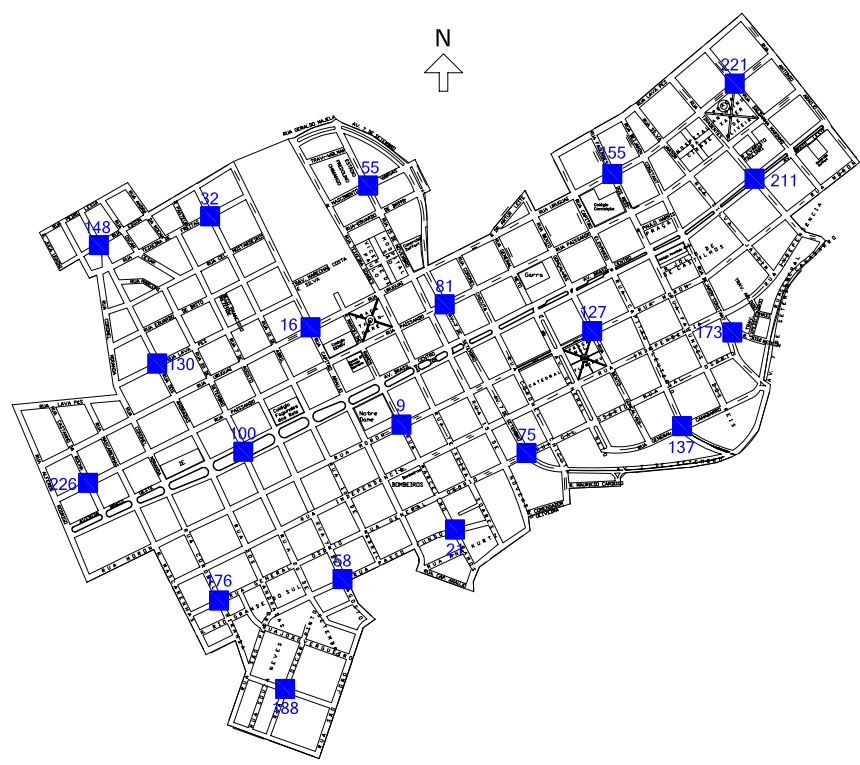

Figura 2. Localização ótima dos 20 contêineres para recebimento de resíduos.

Cada ponto atende a um número variável de facilidades, sendo que o valor total da função custo, para o modelo proposto, foi de 44.835 metros, resultando em uma distância média a ser percorrida, para se alcançar os 20 contêineres, de 186,81 metros. Uma representação gráfica das 20 facilidades e seus respectivos pontos de atendimento pelo método das p-medianas está expressa na Figura 3.

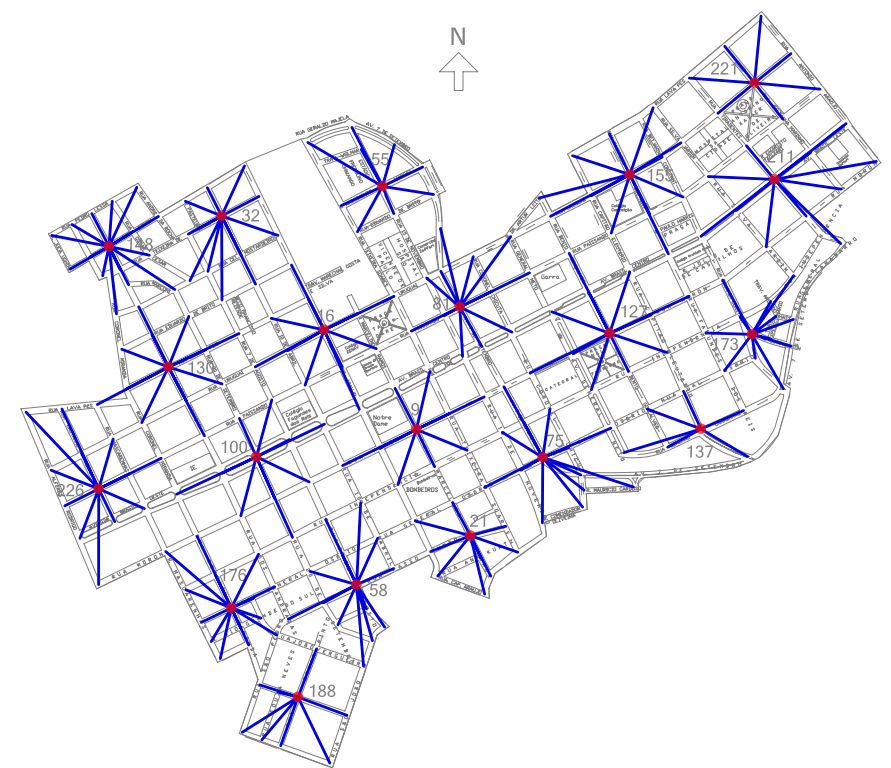

Figura 3. Representação das 20 facilidades e seus respectivos pontos de atendimento.

Com o objetivo de estudar a influência do aumento do número de facilidades na redução da distância a ser percorrida, o cálculo das p-medianas foi repetido considerando um número cada vez maior de contêineres (pontos ótimos), partindo de 10 contêineres até o limite de um contêiner a cada duas esquinas (120 contêineres para 240 pontos candidatos). Tais resultados estão representados no gráfico da Figura 4. 


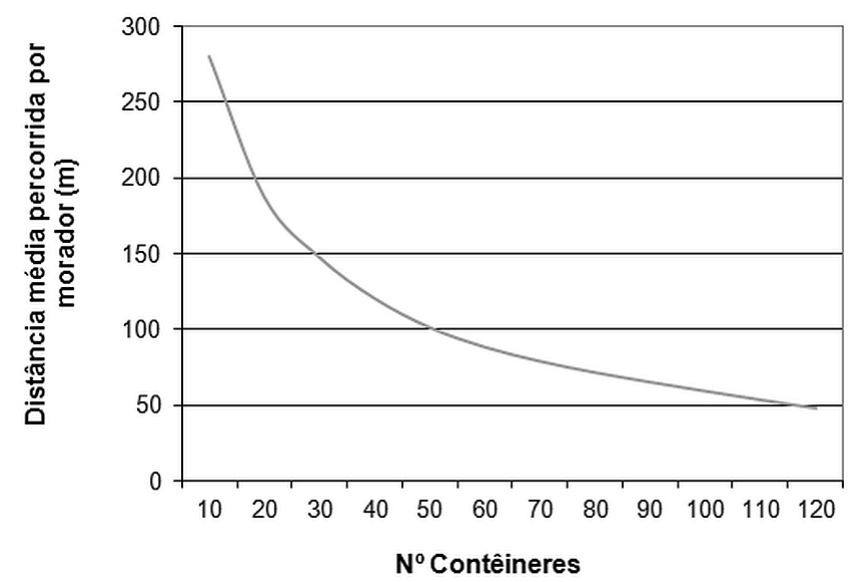

Figura 4. Gráfico da distância média percorrida em metros versus número de contêineres.

Observa-se que a distância média a ser percorrida por morador não diminui de forma linear, conforme representado pela Figura 4, de modo que não necessariamente o aumento em um contêiner no sistema representa uma diminuição direta na distância percorrida.

Assim, a investigação realizada busca subsidiar a determinação do número mínimo de facilidades, lembrando que não é considerado o custo de aquisição das facilidades (contêineres) e que não existe consenso na literatura sobre a distância ideal a ser percorrida pelos moradores em localidades, uma vez que esta distância média está ligada diretamente à densidade dos postos de coleta distribuídos pela área.

\subsection{Aplicação da formulação para roteirização da coleta}

Uma vez que a operação de coleta dos contêineres não está sujeita a condicionantes de capacidade e temporais, ou seja, não existe um horário determinado para a coleta de cada ponto, a estratégia de solução passa a ser direcionada somente aos aspectos de distância entre os pontos a serem atendidos, o que remete ao clássico problema do caixeiro viajante (PCV) como melhor forma de se propor um roteiro.

Conforme apresentado, o problema do caixeiro viajante pode ser modelado matematicamente de diversas formas. No entanto, ao se levar em consideração que os pontos de coleta que deverão ser visitados estão localizados nos nós do grafo e não em suas arestas, e que o número de roteiros que se procura determinar é somente um, partindo e retornando a uma base única (no caso, o aterro sanitário municipal), a formulação matemática clássica do PCV, elaborada por Dantzig et al. (1954) foi considerada ideal para a busca de tal solução.

Cabe observar que, na elaboração da matriz de custos (distâncias) para os moradores até os pontos de coleta, não se faz necessário levar em consideração o sentido do tráfego, uma vez que se assume que os moradores deverão caminhar até os postos. Todavia, em se tratando do roteamento do veículo coletor, tal informação se torna imprescindível, uma vez que o veículo é obrigado a seguir o sentido do trânsito. Cabe ainda destacar, neste ponto, a importância da matriz de precedentes, fruto da aplicação do algoritmo de Floyd, uma vez que, ao apresentar uma solução ótima para o problema de roteamento, determina-se somente a seqüência que deverá ser cumprida entre os pontos, cabendo ainda identificar exatamente por quais vias o veículo deverá trafegar até alcançar o próximo ponto de coleta por meio da matriz de precedentes.

Para fins de estudo e comparação foram criadas três matrizes distintas, todas compostas pelos 20 pontos obtidos como resultado do problema de localização.

A primeira matriz foi construída através da determinação, com o emprego do AutoCad®, das distâncias Euclidianas entre os 20 pontos ótimos, localizados na rede considerada. Apesar da questionável utilização prática quanto ao roteamento, o uso de distâncias Euclidianas é bastante difundido para modelos de maiores dimensões, bem como para modelos que buscam somente prover uma instrução geral sobre o objeto de estudo, dada sua condição de não considerar os contornos da região em estudo.

A rota ótima obtida a partir da matriz de distâncias Euclidianas apresentou uma distância total percorrida de 8.881 metros e está representada na Figura 5.

A segunda matriz foi construída através da eliminação de todos os pontos não selecionados como ótimos, pela aplicação do problema das p-medianas, nas matrizes de valor e de precedência que deram origem ao cálculo de localização, formando assim duas matrizes simétricas, compostas por 400 elementos em cada uma, que estabelecem a distância entre todos os 20 pontos ótimos sem considerar o sentido do tráfego (matriz de custos). 


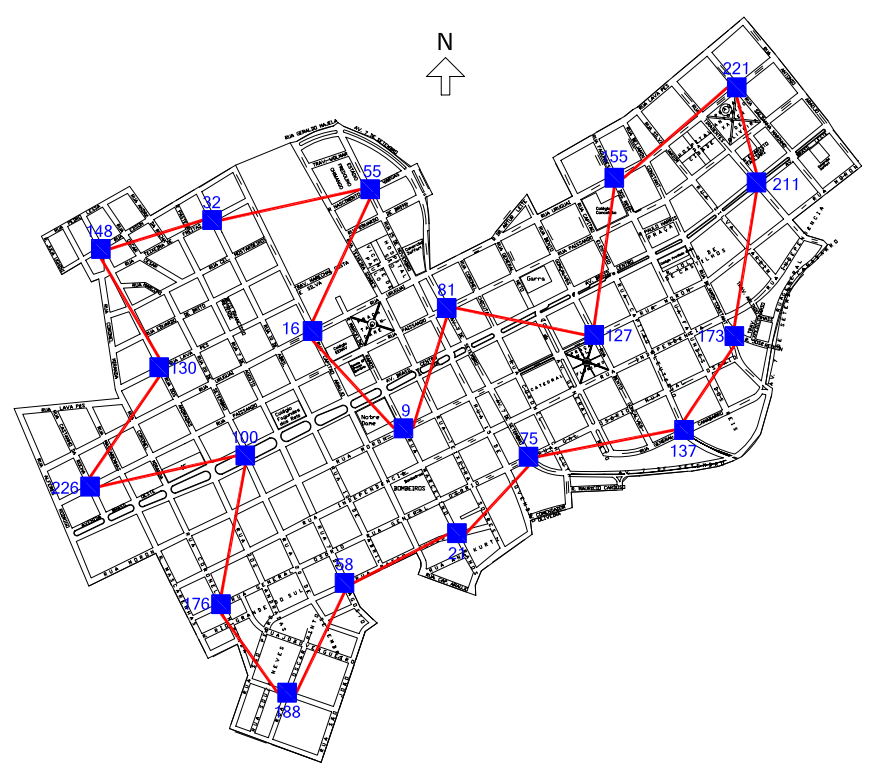

Figura 5. Rota ótima para veículo coletor baseado em distâncias Euclidianas.

Ao se aplicar o problema do PCV à matriz simétrica de distâncias, sem mão de direção, a distância total percorrida aumentou para então 10.995 metros, cuja rota ótima correspondente está representada na Figura 6.

Cabe observar que, apesar de existir um aumento percentual não muito significativo (23,8\%) na distância percorrida, a rota ótima não é mais coincidente com a obtida na situação anterior.

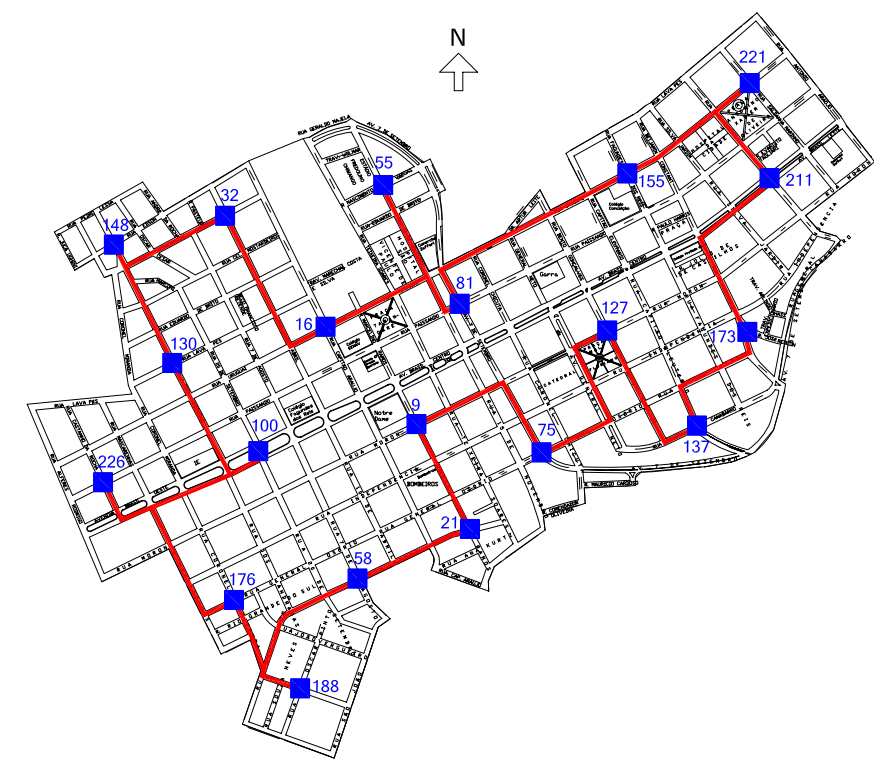

Figura 6. Rota ótima para veículo coletor sem considerar sentido do tráfego.

Por fim, o mesmo procedimento de eliminação foi aplicado às matrizes de custo e precedentes considerando o sentido do trânsito, obtendo-se, assim, uma matriz assimétrica também composta por 400 elementos cada. A distância total mínima percorrida obtida foi de 11.681 metros, cuja rota ótima está representada na Figura 7.

No entanto, ao se verificar a exequibilidade desta rota, observou-se que a solução proposta acarretava na execução, por parte do veículo coletor, de uma manobra de retorno de difícil execução, logo após coletar o ponto 75 (conforme o detalhe representado na Figura 8.).

Apesar de não representar uma movimentação ilegal, uma vez que a Rua General Osório transita nos dois sentidos, como mostra a Figura 8, tal manobra pode se tornar inviável para um veículo coletor de grande porte. Assim, foi proposto que o veículo realizasse o contorno continuando pela Rua Sete de Setembro e dobrando à esquerda na Rua Coronel Chicuta, para, então, retomar a Rua General Osório e prosseguir com seu roteiro, como demonstra a Figura 8. Como tal ajuste implica em um aumento na distância total percorrida pelo modelo proposto de 322 metros, tal custo teve então de passar a ser considerado na matriz de distâncias e a formulação mais uma vez foi analisada, desta vez obtendo-se uma rota com distância total percorrida de 11.796 metros com exequibilidade assegurada, conforme apresentado na Figura 9. 


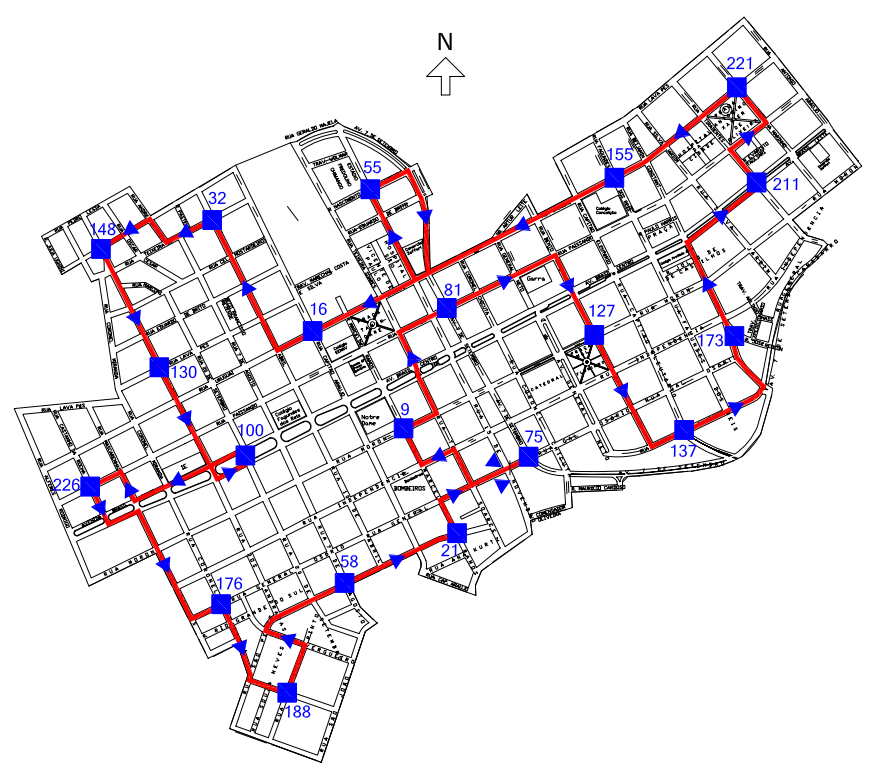

Figura 7. Rota para veículo coletor considerando o sentido do tráfego.

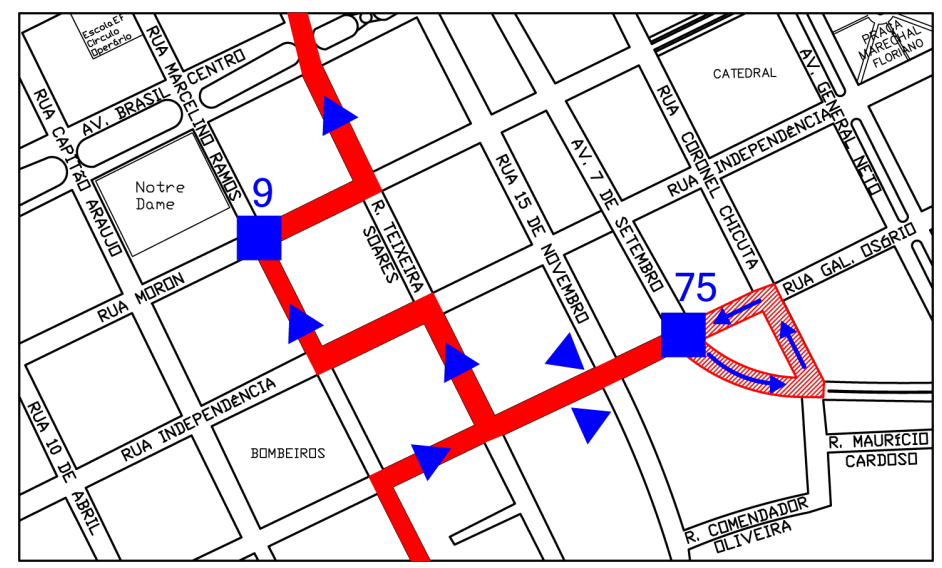

Figura 8. Detalhe do ponto 75 na rota ótima proposta pelo sentido do tráfego.

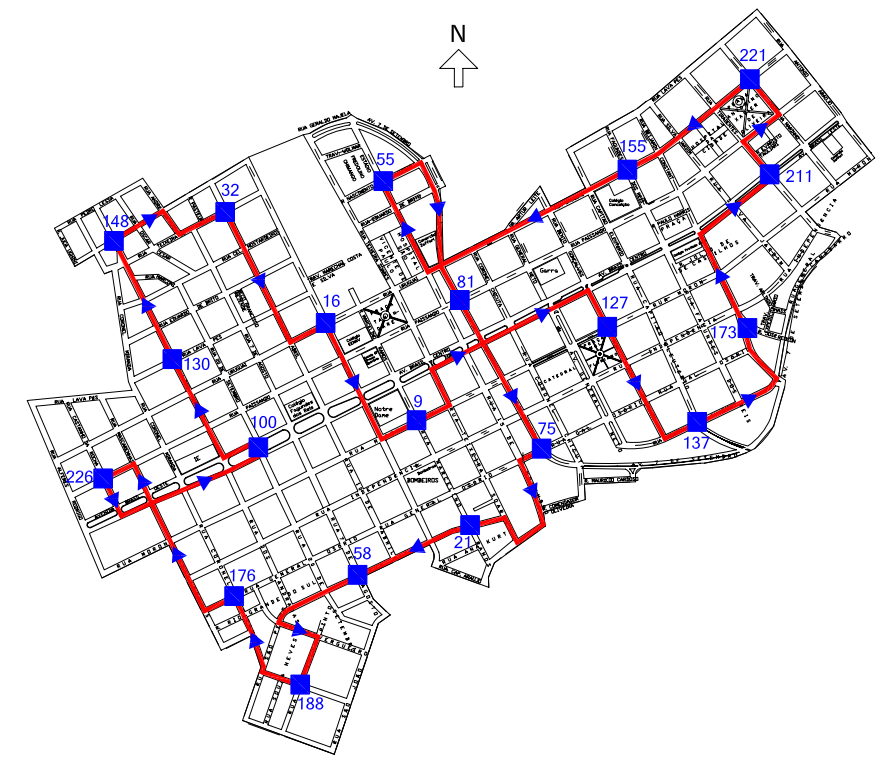

Figura 9. Rota final corrigida para veículo coletor considerando sentido do tráfego.

É importante ressaltar que todas as rotas propostas apresentam um roteiro circular, partindo e retornando do mesmo ponto (ponto 137). Isto se dá devido ao fato do aterro sanitário, de onde partem os veículos coletores vazios e retornam cheios (base), estar localizado a cerca de 8,5 quilômetros de distância ao sul da 
área objeto de estudo. Assim, os veículos coletores devem iniciar e encerrar o circuito pelo ponto de coleta indicado, o qual se encontra na interseção com a única via de acesso ao aterro sanitário.

Ao se comparar as distâncias totais obtidas através da matriz de distâncias Euclidianas (8.881 metros) com as distâncias totais obtidas através da matriz simétrica, sem mãos de direção (10.995 metros) podese considerar um coeficiente de ajustamento de 1,238 e um coeficiente de 1,328 para a matriz assimétrica, com mãos de direção exequível (11.796 metros). Este último coeficiente é bastante próximo do coeficiente de ajustamento aproximado de 1,35 obtido através de técnicas de regressão linear, aplicado para matrizes Euclidianas para uso em áreas urbanas apresentado por Novaes, citado por Graciolli (1994), e proposto para situações onde as distâncias reais sejam impraticáveis de se obter. Destaca-se, no entanto, que as rotas ótimas não são as mesmas para as situações analisadas, uma vez que o coeficiente de ajustamento proposto corrige somente o valor da distância total a ser percorrida pelo veículo, não provendo uma rota efetiva. Ficando a construção desta rota a cargo do motorista ou responsável pelo departamento, novamente é introduzido um fator de subjetividade à tomada de decisões, fator este que justamente busca-se minimizar com a aplicação das técnicas de Pesquisa Operacional.

\subsection{Uma abordagem para o número ideal de contêineres no sistema}

Uma vez que o enfoque dado ao problema dos resíduos no Brasil é, em sua maioria, sob o ponto de vista exclusivo da coleta e do transporte do resíduo para posterior destinação (IBAM, 2001), pode-se assumir então que tais atividades são as mais dispendiosas e críticas dentro de todas as atividades de gerenciamento dos resíduos sólidos urbanos.

Sendo a participação da população impreterível para o bom andamento de um programa de coleta seletiva, quanto maior o número de contêineres disponíveis, menor deverá ser a distância percorrida pelos moradores até o ponto de coleta mais próximo, o que claramente aumenta o índice de sucesso do programa. Todavia, McDougall et al. (2001) destaca que o aumento no número de contêineres certamente aumentará as taxas de participação da população e, consequentemente, as taxas de recuperação de resíduos. Por outro lado diminuirá a taxa de retorno sobre a operação uma vez que a quantidade extra coletada diminuirá com cada contêiner extra que é adicionado ao sistema, até que em um determinado ponto, o custo econômico adicional e o passivo ambiental gerados no processo, como o maior consumo de combustível pelo veículo coletor, façam com que este aumento no número de contêineres venha a exceder os ganhos ambientais deste tipo de coleta diferenciada.

Além disto, conforme apresentado anteriormente, tendo em vista que as distâncias totais percorridas pelos moradores diminuem de forma não linear, na medida em que o número de contêineres aumenta, e que a distância total percorrida pelo veículo coletor tende a aumentar uma vez que o número de contêineres no sistema aumenta, as tendências apresentadas para estes dois casos poderiam ajudar, apesar de não de forma absoluta, na orientação para se obter um número ideal de contêineres no sistema, de tal modo que se tivessse um equilíbrio entre os dois custos.

Com este objetivo procurou-se ampliar o estudo para um número crescente de contêineres, determinando não apenas a distância a ser percorrida pelos usuários, mas também a distância total do percurso efetuado pelo veículo coletor. É interessante destacar que, a exemplo do que foi feito para o problema de localização de facilidades, buscou-se a comparação dos valores fornecidos pelo Simulated Annealing com os resultados obtidos com o emprego do LINGO. No entanto, o custo computacional resultante da utilização do LINGO mostrou-se proibitivo, não permitindo análises para maior número de facilidades. A título de exemplo, o problema do caixeiro viajante para 40 facilidades demandou tempo superior a dezessete horas de processamento. Já a análise no Simulated Annealing para 70 facilidades consumiu um tempo pouco inferior a 25 minutos.

A Figura 10 apresenta os resultados correspondentes, em contraposição aos valores obtidos para o problema de localização de facilidades.

O problema de roteamento de veículos não foi analisado para um número maior de facilidades pois se observou que, uma vez que a área total a ser coberta não muda em função do número de facilidades a serem atendidas, o aumento na distância total a ser percorrida pelo veículo coletor varia de forma pouco significativa.

\section{Considerações Finais}

Através da aplicação de modelos matemáticos referentes ao problema de localização de facilidades, neste capítulo são apresentadas sugestões orientadas ao processo de tomada de decisões na área da administração pública como emprego da Pesquisa Operacional.

É importante destacar que a construção e aplicação dos modelos aqui apresentados é bastante genérica. Desta forma, tais modelos podem ser facilmente adaptados para resolver outros problemas de natureza correlata, mostrando-se extremamente versáteis e úteis para as mais diversas aplicações. 


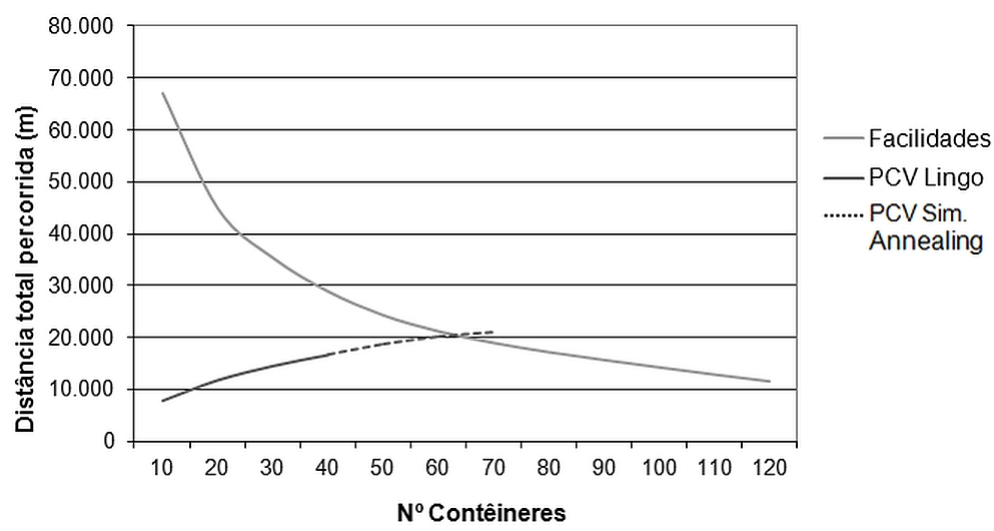

Figura 10. Gráfico da variação das distâncias totais (em metros) envolvendo localização e roteirização em função do número de contêineres.

Face ao seu caráter multidisciplinar, a Pesquisa Operacional é uma disciplina científica de características horizontais, com suas contribuições estendendo-se por praticamente todos os domínios da atividade humana, da engenharia à medicina, passando pela economia e a gestão empresarial.

No âmbito das decisões de infra-estrutura inerentes aos serviços de administração pública, a Pesquisa Operacional tem se mostrado uma ferramenta muito importante para ajudar a prover informações concretas e bem fundamentadas. Através de desenvolvimentos de base quantitativa, a Pesquisa Operacional possibilita a introdução de elementos de objetividade e racionalidade nos processos de tomada de decisão, sem descuidar no entanto dos elementos subjetivos e de enquadramento organizacional que caracterizam os problemas.

\section{Agradecimentos}

Os autores agradecem à Fundação Universidade de Passo Fundo pelo apoio financeiro ao projeto de pesquisa que possibilitou gerar os resultados apresentados.

\section{Referências}

Andrade, E.L., Introdução à pesquisa operacional: métodos e modelos para análise de decisões. 3a edição. Rio de Janeiro, RJ: Editora LTC, 2004.

Arenales, M.; Armentano, V.; Morabito, R. \& Yanasse, H., Pesquisa Operacional para cursos de Engenharia. Rio de Janeiro, RJ: Elsevier, 2007.

Bath, V.N., A model for the optimal allocation of trucks for solid waste management. Waste Management $\mathcal{E}$ Research, 14(1):87-96, 1996.

Chang, N.B. \& Wei, Y.L., Siting recycling drop-off stations in urban area by genetic algorithm-based fuzzy multiobjective nonlinear integer programming modeling. Fuzzy Sets and Systems, 114(1):133-149, 2000.

Cheremisinoff, N.P., Handbook of solid waste management and waste minimization technologies. Amsterdam, Netherlands: Butterworth Heinemann, 2003.

Clark, R.M. \& Gillean, J.I., Solid waste collection: a case study. Operacional Research Quarterly, 28(4):795-806, 1977.

Cortes, C.F.M., Otimização do projeto da superestrutura de pontes pré-fabricadas pelo método dos algoritmos genéticos. Tese de Doutorado, Programa de Pós-Graduação em Engenharia Civil, COPPE, Universidade Federal do Rio de Janeiro, Rio de Janeiro, RJ, 2010.

Cunha, C.B., Aspectos práticos da aplicação de modelos de roteirização de veículos a problemas reais. Transportes, $8(2): 51-74,2000$.

Dantzig, G.B.; Fulkerson, D.R. \& Johnson, S., Solution of a large scale traveling salesman problem. Operations Research, 2:393-410, 1954.

Ducati, E.A., Busca tabu aplicada ao problema de localização de facilidades com restrições de capacidade. Dissertação de Mestrado, Universidade Estadual de Campinas, Campinas, SP, 2003.

Goldbarg, M.C. \& Luna, H.P., Otimização combinatória e Programação Linear. 2a edição. Rio de Janeiro, RJ: Elsevier, 2005.

Golden, B.L. \& Wong, R.T., Capacited arc routing problems. Networks, 11(3):305-315, 1981.

Graciolli, O.D., Otimização de roteiros de veículos coletores de resíduos sólidos de serviços de saúde. Dissertação de Mestrado em Engenharia de Produção, Universidade Federal de Santa Catarina, Florianopólis, SC, 1994.

Holland, J.H., Adaptation in Natural and Artificial Systems. Ann Arbor, USA: University of Michigan Press, 1975. 
IBAM, , Manual de Gerenciamento Integrado de Resíduos sólidos. Rio de Janeiro, RJ: Instituto Brasileiro de Administração Municipal, 2001.

Kirkpatrick, S.; Gelatt, C.D. \& Vecchi, M., Optimization by simulated annealing. Science, 220(4598):671-680, 1983.

Lachtermacher, G., Pesquisa Operacional na tomada de Decisões: Modelagem em Excel. 3a edição. Rio de Janeiro, RJ: Elsevier, 2007.

McDougall, F.R.; White, P.; Franke, M. \& Hindle, P., Integrated solid waste management: a life cycle inventory. Oxford, UK: Blackwell Science, 2001.

Metropolis, N.; Rosenbluth, A.W.; Rosenbluth, M.N.; Teller, A.H. \& Teller, E., Equation of state calculations by fast computing machines. The Journal of Chemical Physics, 21(6):1087-1092, 1953.

Mohd, S.G.; Jamal, E.; Garba, M.L. \& Ali, S.M., Mathematical model for optimal development and transportation of recycled waste materials. Environmental Informatics Archives, 2(2):233-241, 2004.

Morrisey, A.J. \& Browne, J., Waste management models and their application to sustainable waste management. Waste Management, 24(3):297-308, 2004.

Moura, C.M.; Fontes, A.A. \& Ribeiro, S.A.A.C., Determinação da melhor rota para coleta seletiva de lixo no campus da universidade federal de viçosa utilizando dos sistemas de informações geográficas. In: Anais do X Simpósio Brasileiro de Sensoriamento Remoto. Foz do Iguaçu, PR: INPE, p. 1119-1125, 2001.

Paes, F.G., Otimização de rotas para coleta do lixo doméstico: um tratamento GRASP do problema do carteiro chinês misto (PCCM). Dissertação de Mestrado em Ciências de Engenharia, Universidade Estadual do Norte Fluminense, Campos dos Goytacazes, RJ, 2004.

\section{Notas Biográficas}

Fábio Roberto Barão é graduado em Administração de Empresas, Habilitação Comércio Exterior (Centro Universitário Municipal de São Caetano do Sul, 1996), tem MBA em Logística e Gestão Empresarial e mestrado em Engenharia (Universidade de Passo Fundo, 2004 e 2008, respectivamente). Atualmente é professor do curso de Administração de Empresas da Faculdade de Ciências Econômicas, Administrativas e Contábeis da Universidade de Passo Fundo.//

Moacir Kripka é graduado em Engenharia Civil (PUC-RS, 1986), mestre e doutor em Engenharia Civil (COPPE/UFRJ, 1990 e EESC/USP, 1998, respectivamente). Atualmente é professor do curso de Engenharia Civil e Coordenador do Programa de Pós-Graduação em Engenharia da Universidade de Passo Fundo.

Rosana Maria Luvezute Kripka é graduada em Matemática com ênfase em Computação e mestre em Ciência da Computação e Matemática Computacional (USP/São Carlos, 1992 e 1995, respectivamente). Atualmente é professora do curso de Matemática do Instituto de Ciências Exatas e Geociências da Universidade de Passo Fundo. 
Barão et al. 


\title{
Resolução de um Problema de Projeto de Cadeia de Suprimentos de Remanufatura Usando Algoritmos Evolutivos
}

\author{
Ernesto Del Rosario Santibañez Gonzalez, Henrique Pacca Loureiro Luna \\ e Geraldo Robson Mateus
}

\begin{abstract}
Resumo: Neste capítulo propõe-se um método de otimização baseado em algoritmos evolutivos para resolver um problema NP-hard de projeto de cadeia de suprimentos de remanufatura. O algoritmo combina uma pesquisa estocástica tradicional (algoritmo genético e algoritmo Particle Swarm Optimization binário) com um método de solução ótimo para resolver um problema de Programação Linear (LP) associado. Problemas de projeto e gerenciamento de Cadeias de Suprimentos (CS) têm sido um tema crescente de interesse para os pesquisadores. São relatados os resultados computacionais para instâncias geradas aleatoriamente para redes de até 350 instalações de coleta, 100 locais candidatos para localizar unidades de reprocessamento e 40 instalações de remanufatura $(350 \times 100 \times 40)$.
\end{abstract}

Palavras-chave: Cadeia de suprimentos reversa, Logística reversa, Otimização combinatória, Algoritmos evolutivos.

\begin{abstract}
In this chapter, an optimization method based on evolutionary algorithms is proposed to solve a NP-hard problem of designing a remanufacturing supply chain. The algorithm combines a traditional stochastic search (Genetic Algorithm and Binary Particle Swarm Optimization algorithm) with an optimal solution method to solve the associated Linear Programming problem. Issues of design and management of supply chains have been a topic of growing interest to researchers. We report computational results for randomly generated instances for networks of up to 350 points of origin, 100 candidate sites to locate reprocessing units and 40 remanufacturing facilities $(350 \times 100 \times 40)$.
\end{abstract}

Keywords: Reverse supply chain, Reverse logistics, Combinatorial otimization, Evolutionary algorithms.

\section{Introdução}

Embora exista muita pesquisa sobre o projeto e gerenciamento de cadeias de suprimentos, o conceito não está claramente definido e falta consenso sobre os seus alcances (Frankel et al., 2008; Giunipero et al., 2008; Larson et al., 2007). Neste capítulo, o projeto e gerenciamento de cadeias de suprimento envolve gerenciar de forma eficaz e eficiente múltiplas organizações e processos que interagem e compartilham um fluxo de informação, recursos, produtos e matéria prima para satisfazer a demanda dos clientes (Mentzer et al., 2001; SantibañezGonzalez \& Souza, 2010). Em particular, o interesse é estudar o projeto de cadeias de suprimento sustentáveis, onde, além dos objetivos econômicos, deve-se preocupar com os objetivos sociais e meio-ambientais.

Em 1987, um relatório das Nações Unidas definiu desenvolvimento sustentável como "desenvolvimento que satisfaz as necessidades do presente sem comprometer a capacidade das gerações futuras satisfazerem suas próprias necessidades". Este relatório foi um pontapé inicial para uma série de estudos interdisciplinares no campo da sustentabilidade. A sustentabilidade das cadeias de suprimentos pode ser considerada parte da área multi-disciplinar de sustentabilidade computacional com foco no desenvolvimento de modelos matemáticos e métodos computacionais para abordar os problemas complexos que emergem no projeto de cadeias de suprimentos em equilibrio com a sustentabilidade do planeta.

No contexto da sustentabilidade, a gestão dos fluxos de retorno de produtos tem recebido atenção crescente na última década. A administração eficiente dos resíduos e fluxos de retorno de produtos está preocupada com o destino final dos produtos e seus componentes, e qual é seu impacto sobre a poluição do ar, água e terra, além dos custos de tratamento e a eliminação em aterro. Existem regras específicas em algumas regiões como

*Autor para contato: santibanez.ernesto@gmail.com 
a União Européia, onde The European Waste Electrical and Electronic Equipment Directive (WEEE) e End of Life Vehicles Directive ( $V F V$ ) estão incentivando às empresas na indústria automotiva para colaborar com outras empresas e organizações na cadeia de fornecimento, de forma a garantir que os produtos possam ser desmontados e reutilizados, ou recondicionados, ou reciclados ou eliminados de forma segura no final de sua vida. A este respeito, este capítulo se concentra em como projetar uma cadeia de suprimentos para atender as necessidades de retorno de produtos usados, minimizando os custos de instalação, operação e transporte existentes nessa cadeia de fornecimento.

Há uma ligação clara entre os modelos de localização de instalações e as decisões estratégicas de gestão da cadeia de suprimentos (GCS) (Simchi-Levi et al., 2007). Agências governamentais e empresas perceberam que comprometer-se com práticas sustentáveis poderia implicar alterações nos critérios para projetar e gerenciar as cadeias de suprimentos. Isto é, além de se preocupar com os custos de transporte e de operação de instalações, e considerações sobre o nível de serviço, atender as exigências de sustentabilidade requer que os modelos considerem o gerenciamento dos produtos que retornam e os custos associados a essas atividades.

O campo do projeto e gestão sustentável da cadeia de suprimentos é ainda novo (Seuring \& Muller, 2008) se comparado com outras aplicações. Dada a complexidade das redes que representam as cadeias de suprimentos, o foco da literatura tem sido em redes do tipo diádicas (fornecedor-cliente). Nas últimas décadas, algoritmos evolucionários (AE) têm sido amplamente utilizadas como técnicas robustas para resolver uma série de problemas difíceis de otimização combinatória (OC). Um AE é dirigido pela evolução de uma população na busca de uma boa solução para os problemas de OC. Neste capítulo são estudados dois algoritmos evolutivos: Algoritmo Genético (AG) e Particle Swarm Optimization (PSO). O primeiro é um algoritmo amplamente estudado que tem sido aplicado com sucesso na solução de vários problemas de OC (Goldberg, 1989; Osman \& Kelly, 1996). Ele é inspirado na evolução de populações de seres vivos e segue o princípio da sobrevivência do indivíduo mais apto (melhor). O segundo é um algoritmo evolutivo que também tem sido aplicado com sucesso em muitas áreas, e parece ser uma abordagem adequada para vários problemas de otimização. Como apontado por alguns autores, embora esta técnica seja usada exitosamente para resolver muitos problemas contínuos, em problemas discretos ou binários ainda existem algumas dificuldades (Engelbrecht, 2005).

Este capítulo propõe e compara dois algoritmos evolutivos que combinam busca estocástica com métodos de otimização para resolver um problema NP-hard de projeto de uma cadeia de suprimentos de remanufatura de produtos usados. Também é apresentado um modelo misto-inteiro 0-1 deste problema.

Na sequência, o capítulo está organizado como segue. Na Seção 2 é apresentada uma revisão da literatura com uma breve introdução à cadeia de suprimentos sustentável e reversa e, particularmente, para o caso de remanufatura em conexão com a logística reversa. Na Seção 3 é descrito um modelo matemático para o problema. Na Seção 4 é proposto o esquema de otimização que combina algoritmos de otimização com algoritmos genético e PSO binário para resolvê-lo. Na Seção 5 são apresentados os resultados experimentais para redes geradas aleatoriamente. A Seção 6 contém as conclusões.

\section{Revisão da Literatura}

Acima e além de outros aspectos, existem essencialmente dois tipos de questões relacionadas com a sustentabilidade. Uma delas é a gestão eficiente dos resíduos e fluxos de retorno de produtos que tem como objetivo reduzir o impacto desses produtos sobre a poluição do ar, água e terra. Este capítulo se concentra no projeto de cadeias de suprimentos de remanufatura. Para uma revisão dos conceitos integrando práticas ambientais na cadeia de suprimentos, ver Srivastava (2007). A modelagem matemática para resolver o projeto de cadeia de suprimentos sustentável está atraindo muitos pesquisadores a esse campo. Até agora, a pesquisa tem se focado, principalmente, no campo da teoria de localização de instalações em empresas privadas e, portanto, aplicações de cadeias de suprimento envolvendo relações entre empresas privadas.

O problema da localização de instalações não é novo para a comunidade de pesquisa operacional e abrange os aspectos chaves do projeto de cadeias de suprimentos (Daskin et al., 2005). Simchi-Levi et al. (2007) estabeleceram uma ligação clara entre modelos de localização e GCS estratégica, enquanto Altiparmak et al. (2009) observaram que este problema é um dos "problemas de decisão estratégica mais complexos que precisam ser otimizados para uma operação de longo prazo eficiente da cadeia de fornecedores". Observe que algumas pequenas mudanças para modelos de localização de instalações clássicas são bastante difíceis de resolver (Farahani \& Hekmatfar, 2009). Por exemplo, em Lai-Jun et al. (2009), um algoritmo genético foi usado para resolver um problema de localização de instalações em redes de teste com 10 locais de instalação potenciais e 30 pontos de demanda. Neste capítulo, o interesse é na logística reversa como parte do problema de projeto de uma cadeia de suprimentos sustentável. A logística reversa compreende uma série de atividades para o tratamento de produtos devolvidos, até que estes sejam devidamente recuperados ou simplesmente eliminados (Rogers \& Tibben-Lembke, 1998). Essas atividades incluem coleta, limpeza, desmontagem, teste e classificação, armazenamento, transporte e operações de recuperação. Em relação às operações de 
recuperação, é possível encontrar uma combinação de várias opções de recuperação, como a reutilização, reparação, recondicionamento, remanufatura e reciclagem (Dekker \& van der Laan, 1999).

Há, ainda, outro tipo importante de problemas de projeto de redes logísticas, um caso particular de cadeias de suprimentos de circuito fechado ou closed-loop supply chain. Normalmente, o problema de projeto de rede logística é do tipo cadeias de suprimentos forward ou cadeias de suprimentos reversa, como no caso mencionado anteriormente. Quando são integradas as cadeias de suprimentos forward e reversa, obtém-se um sistema fechado (closed-loop) e uma nova classe de problemas englobados pelo termo gestão (e projeto) da cadeia de suprimentos de circuito fechado.

Para uma revisão da pesquisa sobre modelos quantitativos para a logística reversa e cadeias de suprimentos de circuito fechado antes de 2000, ver Dekker et al. (2004). Rubio et al. (2008) fizeram uma compilação de pesquisas publicadas sobre a logística reversa dentro do período de 1995-2005. Eles estudaram o tema com base na classificação proposta por Dekker et al. (2004). Por ordem cronológica, os modelos de logística reversa são discutidos recentemente, por exemplo, por Jayaraman et al. (2003), Zhou \& Wang (2008), Salema et al. (2010) e Gomes et al. (2011). Quase todos os autores propuseram modelos de programação linear inteira mista (MILP). A maioria dos métodos de solução estão baseados no uso de pacotes comerciais.

Modelos para o projeto de cadeias de suprimentos de circuito fechado são tratados nos trabalhos de Lu \& Bostel (2007), Barbosa-Povoa et al. (2007), Mutha \& Pokharel (2009), Zarei et al. (2010) e Amin \& Zhang (2012). Modelos estocásticos, em combinação com funções multiobjetivo foram estudados por Pishvaee \& Torabi (2010).

Quanto aos algoritmos evolucionários propostos para resolver problemas relacionados, têm sido estudados, por exemplo, os seguintes: Simulated Annealing (Lee \& Dong, 2008), Algoritmo Genético (Min et al., 2006; Lee et al., 2009; Zarei et al., 2010), Algoritmo Memético (Pishvaee et al., 2010) e Busca Tabu (Lee \& Dong, 2008). Note-se que Lee et al. (2009) resolveram problemas de até 15 centros de retorno, 10 centros de desmontagem e 14 centros de processamento $(15 \times 10 \times 14)$. Eles não relataram resultados computacionais em relação a tempo ou a qualidade do gap de otimalidade obtido. Lee \& Dong (2008) resolveram problemas em redes de até $100 \times 40 \times 30$ com um tempo de computação máximo de 2.939 segundos e um gap máximo (em comparação com um limite inferior) de $15 \%$.

Neste capítulo, é tratado o problema de rede de remanufatura na cadeia de suprimentos reversa. A remanufatura é definida como um dos métodos de recuperação pelo qual produtos (usados) ou componentes são recuperados para produzir uma unidade equivalente, em qualidade e desempenho, ao produto original novo e que, em seguida, podem ser revendidos como novos produtos ou peças. Como as atividades de remanufatura são, frequentemente, implantadas pelo produtor inicial desta rede, é provável que seja um sistema de circuito fechado. Atividades de remanufatura são reconhecidas como a principal opção de recuperação em termos de factibilidade e benefícios que trazem para a empresa. Esta atividade fornece às firmas uma maneira de controlar a eliminação dos seus produtos usados, para reduzir, eficazmente, os custos de produção e poupar matérias-primas.

\section{Formulação do Problema}

Nesta seção é apresentado o modelo MILP, para o problema de projetar uma cadeia sustentável de suprimentos. Este problema pode ser classificado como um modelo de localização capacitado com demanda conhecida, com um produto único, estático e de três camadas. A cadeia de suprimentos de remanufatura é composta por três tipos de empresas: instalações de suprimentos (instalações de origem, por exemplo, uma loja de varejo), locais de coleta e processamento e instalações de remanufatura. Ao nível dos clientes, produtos usados são disponibilizados para serem recuperados, por exemplo, telefones celulares. Ou seja, os clientes devolvem produtos às instalações de origem ou de compra como uma loja de varejo. Na segunda camada da cadeia de suprimentos, existem centros de reprocessamento (locais de coleta e processamento) utilizados apenas no canal reverso e eles são responsáveis por atividades, tais como a limpeza, desmontagem, verificação e classificação dos produtos de retorno, antes que estes produtos (devolvidos) sejam enviados de volta para as instalações de remanufatura. Na terceira camada, as instalações de remanufatura recebem os produtos retornados e verificados provenientes de centros de reprocessamento e são responsáveis pelo processo de recondicionamento. Neste trabalho foi abordado o fluxo reverso de produtos retornados provenientes de instalações de origem que vão para as instalações de remanufatura através de instalações de reprocessamento adequadamente localizadas em locais pré-definidos. Em tal rede, o fluxo reverso é formado por produtos disponibilizados pelos clientes, encaminhados, através de pontos de coleta e processamento até as instalações de remanufatura, enquanto o outro fluxo (forward) desde as instalações de remanufatura diretamente para ponto de vendas é composto por produtos "novos". 


\subsection{Modelo matemático}

No modelo proposto é assumido que a demanda por produtos remanufaturados e as quantidades disponíveis de produtos de retorno nos clientes são conhecidas. São apresentados os seguintes dados de entrada e conjuntos para o modelo:

$I=$ conjunto de instalações de origem $i$ pertencentes à primeira camada;

$J=$ conjunto de instalações de remanufatura $j$ pertencentes à terceira camada;

$K=$ conjunto de locais candidatos $k$ para localizar instalações de reprocessamento, pertencentes à camada intermediária;

$a_{i}=$ capacidade de produtos de retorno no local de origem $i \in I$;

$b_{j}=$ quantidade de produtos demandados no local de remanufatura $j \in J$;

$f_{k}=$ custo fixo de abrir uma instalação de reprocessamento no local candidato $k \in K$;

$g_{k}=$ custo unitário de reprocessamento no local candidato $k \in K$;

$c_{i k}=$ custo unitário de entrega de produtos em $k \in K$ a partir de uma instalação de origem localizada em $i$ $\in I$

$d_{k j}=$ custo unitário de distribuição desde uma instalação em $k \in K$ para $j \in J$;

$m_{k}=$ capacidade de reprocessamento no local $k \in K$;

Foram consideradas as variáveis de decisão a seguir:

$w_{k}=1$ se localizar uma instalação de reprocessamento se localizar no local candidato $k \in K$; 0 , caso contrário;

$x_{i k}=$ fluxo de retorno desde a origem $i \in I$ para a instalação de reprocessamento localizada em $k \in K$;

$y_{k j}=$ fluxo desde a instalação de remanufatura localizada em $k \in K$ para a instalação $j \in J$;

Seguindo o modelo proposto por Li (2011) e Santibañez-Gonzalez et al. (2012), o problema de projeto de uma cadeia de suprimentos de remanufatura (ou RSCP - Remanufacturing Supply Chain Problem) é definido por:

$$
\text { Minimizar } \sum_{k \in K} f_{k} w_{k}+\sum_{i \in I} \sum_{k \in K} c_{i k} x_{i k}+\sum_{i \in I} \sum_{k \in K} g_{k} x_{i k}+\sum_{k \in K} \sum_{j \in J} d_{k j} y_{k j}
$$

sujeito a:

$$
\begin{gathered}
\sum_{i \in I} x_{i k} \leq m_{k} w_{k} \text { para todo } k \in K \\
\sum_{k \in K} x_{i k} \leq a_{i} \text { para todo } i \in I \\
\sum_{k \in K} y_{k j} \geq b_{j} \text { para todo } j \in J \\
\sum_{i \in I} x_{i k}=\sum_{j \in J} y_{k j} \text { para todo } k \in K \\
x_{i k}, y_{k j} \geq 0, \text { para todo } i \in I, j \in J, k \in K \\
w_{k} \epsilon\{0,1\} \text { para todo } k \in K
\end{gathered}
$$

A função objetivo (1) minimiza a soma dos custos de localização de instalações de reprocessamento, mais os custos de transporte desde as instalações de origem para às instalações de reprocessamento e destas para às instalações de remanufatura. A restrição (2) garante a capacidade de processamento para cada instalação $k \in K$ localizada. A restrição (3) garante que todos os produtos de retorno desde a instalação $i \in I$ para todas as instalações $k \in K$ é menor que a capacidade. A restrição (4) garante que a demanda na instalação de remanufatura $j \in J$ é satisfeita. A restrição (5) garante que todos os produtos de retorno que chegam à instalação $k$ também são entregues às instalações de remanufatura. A restrição (6) é uma restrição padrão de não-negatividade das variáveis. A restrição (7) é uma restrição padrão de variáveis binárias. Este modelo tem $O\left(n^{2}\right)$ variáveis contínuas, onde $n=\max \{|I|,|J|,|K|\}$ e $|K|$ variáveis binárias. O número de restrições é $O(n)$. 
A Figura 1 apresenta um exemplo do problema RSCP com três (3) instalações de reprocessamento abertas, oito (8) locais candidatos para localizar unidades de reprocessamento e duas (2) instalações de remanufatura. A figura mostra seis (6) grupos de clientes. Foram usados só três (de oito) locais candidatos para abrir unidades de reprocessamento.

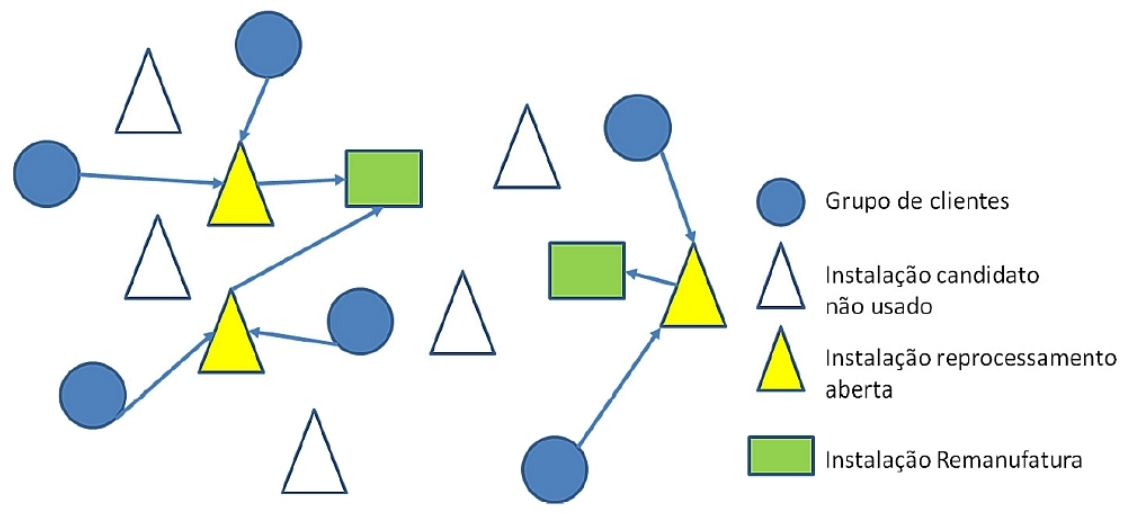

Figura 1. Exemplo de solução problema $R S C P$.

\section{Algoritmo Evolucionário}

O algoritmo proposto para solução do problema de projeto da cadeia de suprimentos de remanufatura considera a integração de algoritmos evolutivos com outros algoritmos de otimização, aproveitando as características particulares do problema. Em geral, os algoritmos evolutivos orientam a busca pela solução do problema, fornecendo a informação necessária a cada iteração para resolver o problema de programação linear (PL) associado ao problema de projeto de rede.

Nesta implementação foi aproveitada a estrutura do problema e dividiu-se a solução em duas partes:

1. A parte de localização de instalações é resolvida pelo algoritmo evolutivo. Esta parte atua como guia de todo o processo de busca da solução ótima do problema RSCP, e repassa a informação para que a segunda parte possa ser realizada;

2. Uma vez resolvida a primeira parte, a segunda parte é resolvida otimamente aproveitando a estrutura mais simples do subproblema RSCPR (Remanufacturing Supply Chain Problem - Relaxed), explicado a seguir, que é um problema de programação linear (PL).

Observe que, após a etapa (1) as variáveis $w_{k}, \forall k \in K$, foram definidas, chamando-as $w_{k}^{*}$. Então, pode-se re-escrever o modelo RSCP como segue:

$$
\text { Minimizar } \sum_{k \in K} f_{k} w_{k}^{*}+\sum_{i \in I} \sum_{k \in K} c_{i k} x_{i k}+\sum_{i \in I} \sum_{k \in K} g_{k} x_{i k}+\sum_{k \in K} \sum_{j \in J} d_{k j} y_{k j}
$$

Sujeito a:

$$
\sum_{i \in I} x_{i k} \leq m_{k} w_{k}^{*} \text { para todo } k \in K
$$

Seja $k \in K^{\prime}$ o conjunto de instalações já abertas, onde $w_{k}^{*}=1 \forall k \in K^{\prime}$. As restrições 9 continuam garantindo a capacidade das instalações de reprocessamento abertas. As demais restrições permanecem as mesmas do modelo RSCP original. Além disso, observe que este problema associado é um problema de programação linear.

Desta forma, neste trabalho são propostos e comparados dois algoritmos evolutivos: algoritmo genético e algoritmo PSO. Ambos os algoritmos são explicados em detalhe nesta seção. O esquema geral do algoritmo é apresentado na Figura 2. Observe que, o passo (1) é típico de um AE e podem usar usadas diferentes estratégias para gerar o conjunto inicial de soluções, por exemplo, uma estratégia de geração aleatória. O passo (1a) é necessário quando é usada uma estratégia do tipo aleatória. Para cada solução gerada deve ser conferida sua factibilidade. No caso de uma solução não factível, um procedimento para transformar esta solução em uma solução factível é necessário. O passo (1b) é utilizado para completar o procedimento de factibilidade da solução gerada. Para isto é resolvido o problema RSCPR definido previamente. O passo (2) é também típico de um AE, só que neste caso, como no passo (1) anterior, ele é alterado usando um procedimento de factibilidade baseado no problema RSCPR. 
1. Gerar uma população inicial de soluções ao problema de localização;

(a) Verificar factibilidade de cada solução

i. Não: Aplicar procedimento de factibilidade

(b) Resolver otimamente problema RSCPR e completar solução ao problema

2. While não convergência do

(a) Aplicar algoritmo evolutivo parcial;

(b) Resolver otimamente problema RSCPR e completar solução ao problema;

3. Endwhile;

Figura 2. Esquema geral do Algoritmo Evolucionário.

\subsection{Algoritmos genéticos}

Algoritmos Genéticos (AG) são um tipo de algoritmo evolucionário usados para resolver uma série de problemas de otimização combinatória. Veja para mais detalhes os trabalhos de (Goldberg, 1989) e (Osman \& Kelly, 1996). Um AG é composto por cinco componentes básicos: (a) uma representação genética das soluções para o problema; (b) uma maneira de criar uma população inicial de soluções; (c) uma função de avaliação; (d) Os operadores genéticos que alteram a composição genética dos filhos durante a reprodução e (e) os valores dos parâmetros. Descrevemos brevemente estes componentes e a implementação de um algoritmo genético híbrido (AG) para resolver o problema de projeto de uma cadeia de suprimentos de remanufatura.

Na Figura 3 se apresenta o pseudo-código do algoritmo genético. Para iniciar um AG é necessário definir a representação (codificação) de uma solução do problema (factível ou infactível) através de um cromossomo. Uma vez definida a estrutura do cromossomo, isto é, o significado de cada um de seus genes, no primeiro passo (1) é necessário gerar uma população de cromossomos. Normalmente, a população inicial de cromossomos está formada por um número predefinido de cromossomos, os quais são gerados aleatoriamente. De acordo com o explicado nas Seções 4.1 e 4.2, no algoritmo proposto, o cromossomo é divido em duas partes: cabeça e cauda. Os genes da cabeça do cromossomo são gerados em forma aleatória e basicamente representam a localização das instalações (4.1). Os genes da cauda do cromossomo são gerados a partir da solução do problema RSCPR (4.2). Durante o processo de evolução dessa população inicial, passo (2), os cromossomos são avaliados segundo uma função de aptidão definida para o problema. A melhor opção é fazer a função de aptidão corresponder à função objetivo do problema, o que propicia uma avaliação direta da qualidade de solução. Uma vez que os cromossomos são avaliados, é aplicado um processo de seleção (2a), onde os cromossomos mais aptos passam por uma etapa de reprodução. Nesta etapa de reprodução, os cromossomos são modificados pelos operadores genéticos de crossover e mutação (2b). Novamente é necessário verificar a factibilidade das soluções representadas pelos cromossomos obtidos durante o processo de reprodução. Observe que essa factibilidade tem relação com a cabeça do cromossomo. Caso seja necessário, para alguns cromossomos, um procedimento de factibilidade é aplicado (2d). Para completar o cromossomo é resolvido o problema RSCPR (2e). O ciclo se repete até que uma solução satisfatória seja encontrada.

\subsubsection{Representação dos cromossomos}

Como fora mencionado anteriormente nesta seção, o problema RSCP foi divido em duas partes. Para a primeira parte, a representação da solução para o problema é codificada como um cromossomo, de forma que cada gene corresponde a uma variável de decisão para a localização de instalações de reprocessamento (cabeça do cromossomo). Para tanto, o gene tem valor um (1) se uma instalação for aberta, e zero (0) em caso contrário. Foi utilizado um string dimensional $(|K|)$ para representar as instalações localizadas. Para a segunda parte (cauda do cromossomo), que representa o fluxo de produtos de retorno entre as diferentes instalações, usa-se uma representação de dimensão $\left(|I|^{*}\left|K^{\prime}\right|+\left|K^{\prime}\right| *|J|\right)$. Esta segunda parte do cromossomo é obtida resolvendo otimamente o problema RSCPR.

Para o exemplo da Figura 4, os produtos de retorno somam um total de 500 unidades, e o fluxo desses produtos é mostrado na figura. Observe que, neste exemplo, existem quatro (4) grupos de clientes, quatro (4) locais candidatos para localizar instalações de reprocessamento e uma (1) instalação de remanufatura. Suponha, ainda, que a capacidade de qualquer instalação de reprocessamento é de 400 unidades.

Para este exemplo, a Figura 5 mostra o cromossomo que representa a solução. Observe que os primeiros quatro genes representam a localização das instalações de reprocessamento. As instalações foram abertas nos 
1. Gerar uma população inicial de cromossomos (cabeça);

(a) Verificar factibilidade de cada solução

i. Não: Aplicar procedimento de factibilidade

(b) Resolver otimamente problema RSCPR e completar cromossomo

2. While não convergência do

(a) Aplicar processo seleção;

(b) Fazer crossover parcial dos cromossomos;

(c) Gerar indivíduos usando processo de mutação;

(d) Verificar factibilidade

i. Não: Aplicar procedimento de factibilidade

(e) Resolver otimamente problema RSCPR e completar cromossomo (cauda);

3. Endwhile;

Figura 3. Pseudo-código do algoritmo genético.

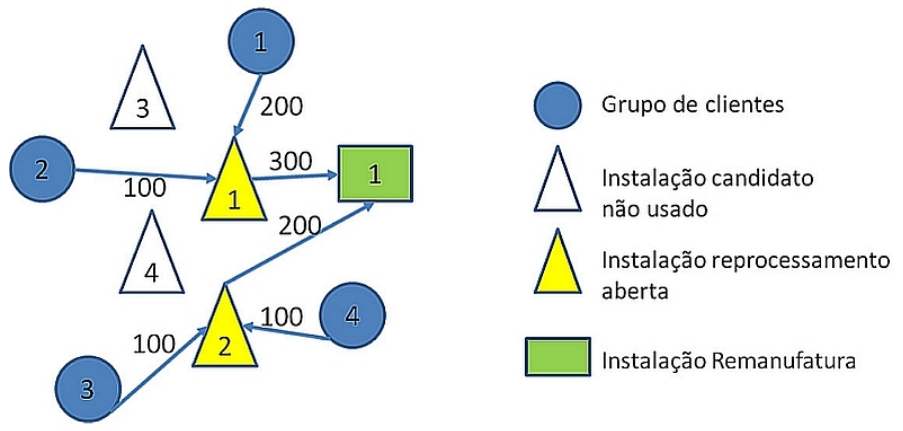

Figura 4. Exemplo de problema $R S C P$ com fluxo de produtos de retorno entre instalações.

locais 1 e 2, o resto das instalações estão fechadas. Os oito genes seguintes $\left(\left|I^{*}\right| K^{\prime} \mid\right)$ representam o fluxo entre as instalações de coleta e as instalações de reprocessamento. Os últimos dois genes $\left(\left|K^{\prime}\right| *|J|\right)$ representam o fluxo entre as instalações de reprocessamento e as instalações de remanufatura. Para propósitos didáticos, supõe-se que a cabeça do cromossomo seja descrita pelo bit string 1100, indicando, na ordem dos bits do string, que os locais 1 e 2 foram ativados (bit 1) e que os locais 3 e 4 não foram ativados (bit 0 ).

\begin{tabular}{|l|l|l|l|l|l|l|l|l|l|l|l|l|l|}
\hline $\mathbf{1}$ & $\mathbf{1}$ & $\mathbf{0}$ & $\mathbf{0}$ & 200 & 0 & 100 & 0 & 0 & 100 & 0 & 100 & 300 & 200 \\
\hline
\end{tabular}

Figura 5. Representação de um cromossomo.

\subsubsection{População inicial e soluções factíveis}

De acordo com o passo (1), no algoritmo básico, a população inicial é gerada aleatoriamente. Para a primeira parte do cromossomo, cada gene é gerado por uma distribuição de probabilidade uniforme $[0,1]$. Observe que existe o risco de gerar cromossomos que representam soluções infactíveis, pois a soma das capacidades de todas as instalações abertas pode ser menor que a capacidade de remanufatura (demanda). Introduziu-se um procedimento simples para obter cromossomos factíveis. A partir do cromossomo infactível, começa-se a abrir novas instalações até que a capacidade de reprocessamento seja maior ou igual à capacidade de remanufatura.

Com a parte do cromossomo que representa as instalações abertas, o algoritmo fixa as variáveis $w$ a valores 0 ou 1, segundo explicado anteriormente. Essas variáveis com valores fixos (agora parâmetros) são passadas para o problema RSCPR. A parte seguinte do cromossomo, que representa os fluxos de produtos de retorno entre as diversas instalações, é obtida resolvendo o problema RSCPR. Com isto, acaba-se a geração da população inicial de cromossomos. A aptidão de um cromossomo é calculada usando a função objetivo. 
Para o exemplo da Figura 4, supõe-se que no passo (1) do algoritmo foram gerados aleatoriamente 5 (cabeças) cromossomos 1100; 0101; 0010; 1001 e 0110. No passo (1a), pode-se verificar que as cabeças de cromossomos 1, 2, 4 e 5 são factíveis de acordo com o explicado previamente, pois as instalações têm capacidade suficiente para atender o fluxo de retorno. O cromossomo 3 é infactível, pois a instalação aberta no local 1 não tem capacidade suficiente para atender toda a demanda, que soma 500.

Para o cromossomo 3 deve ser aplicado o procedimento de factibilidade. Neste caso, como foi explicado previamente, é necessário abrir novas instalações até que a soma das capacidades totais das instalações abertas seja maior ou igual à demanda total. Dependendo da implementação do algoritmo de factibilidade, pode-se começar a abrir instalações a partir do local candidato seguinte na lista. Para este caso, o local candidato seguinte é o 4. Assim, abrindo uma instalação no local 4 resolve o problema de factibilidade. O cromossomo 3 então passa a ser 0011 .

O passo (1b) corresponde a resolver o problema RSCPR associado a cada cromossomo. Os dados para resolver cada problema RSCPR são os seguintes:

Cromossomo 1: o conjunto $K^{\prime}=1,2$, isto é, $w_{1}^{*}=1$ e $w_{2}^{*}=1$;

Cromossomo 2: o conjunto $K^{\prime}=2,4$, isto é, $w_{2}^{*}=1$ e $w_{4}^{*}=1$;

Cromossomo 3: o conjunto $K^{\prime}=3,4$, isto é, $w_{3}^{*}=1$ e $w_{4}^{*}=1$;

Cromossomo 4: o conjunto $K^{\prime}=1,4$, isto é, $w_{1}^{*}=1$ e $w_{4}^{*}=1$;

Cromossomo 5: o conjunto $K^{\prime}=2,3$, isto é, $w_{2}^{*}=1$ e $w_{3}^{*}=1$;

Supõe-se, ainda, que considerando os dados de custos associados, as soluções para os problemas RSCPR associadas aos cromossomos 1 e 2 são mostradas na Figura 6. Por exemplo, para o cromossomo 1, a solução do problema RSCPR recomenda que o grupo de clientes 1 envie 200 unidades de produto para a instalação de reprocessamento aberta no local 1; o grupo de clientes 2 envie 100 unidades para a instalação de reprocessamento aberta no local 1; os grupos de clientes 3 e 4 enviem 100 unidades para a instalação de reprocessamento aberta no local 2. Finalmente, as instalações de reprocessamento 1 e 2 abertas enviam à instalação de remanufatura 300 e 200 unidades respectivamente.

\begin{tabular}{|l|l|l|l|l|l|l|l|l|l|l|l|l|l|}
\hline $\mathbf{1}$ & $\mathbf{1}$ & $\mathbf{0}$ & $\mathbf{0}$ & 200 & 0 & 100 & 0 & 0 & 100 & 0 & 100 & 300 & 200 \\
\hline
\end{tabular}

\begin{tabular}{|l|l|l|l|l|l|l|l|l|l|l|l|l|l|l|}
\hline 0 & 1 & 0 & 1 & 100 & 0 & 100 & 0 & 0 & 200 & 0 & 100 & 200 & 300 & Cromossomo 2 \\
\hline
\end{tabular}

Figura 6. Representação cromossomos 1 e 2.

\subsubsection{Os operadores genéticos de cruzamento e mutação}

Para o passo 2 do algoritmo, neste trabalho são usados os operadores genéticos padrão de cruzamento (crossover) e mutação para gerar a evolução da população (novas gerações) e explorar o espaço de busca.

O cruzamento gera novos indivíduos (cromossomos) a partir da troca do material genético de dois indivíduos pais esperando que "boas" soluções possam gerar "melhores" indivíduos. Foi selecionado um indivíduo pai aleatoriamente, a partir da população de indivíduos que foi gerada inicialmente e que vai mudando a cada iteração. O outro indivíduo pai para cruzamento é sempre o melhor indivíduo da população na iteração (geração) anterior. Não foi limitado o número de cruzamentos nem o número de novos indivíduos gerados a partir dos cruzamentos. Um cruzamento é realizado segundo uma probabilidade predefinida. Neste trabalho, foi usado o valor de $0,7(70 \%)$ como probabilidade de cruzamento. Neste capítulo também foi utilizado o cruzamento de um ponto no cromossomo. O procedimento de cruzamento opera da seguinte forma: Foi escolhido, em ordem, um indivíduo da população. Logo é gerado um valor aleatório entre [0,1] usando uma distribuição uniforme, se o valor probabilidade de cruzamento é maior que o valor aleatório gerado, então foi realizado um cruzamento de esse indivíduo com o melhor indivíduo da iteração (geração) anterior. O cruzamento é gerado em um ponto do cromossomo. Para fazer isto, foi gerado outro valor aleatório entre um e o número de locais onde potencialmente pode ser aberta uma instalação de reprocessamento, ou seja, um ponto de corte dividindo cada indivíduo (pai) em dois segmentos. Um filho único é criado pela combinação do primeiro segmento do primeiro pai (melhor indivíduo) e o segundo segmento do segundo pai (indivíduo selecionado). É verificado se este novo indivíduo representa uma solução factível. Caso de não representar uma solução factível, aplica-se o procedimento para viabilizar o indivíduo. Se o valor de aptidão deste novo indivíduo for melhor do que o valor de aptidão do indivíduo selecionado, então substitui-se este indivíduo pelo filho. 
O operador de mutação altera o valor de um gene do cromossomo com uma probabilidade pequena. Normalmente, é usada uma probabilidade de 0,1 (10\%) e permanece constante ao longo de gerações do AG. Neste trabalho usou-se uma probabilidade de zero, descartando a operação de mutação.

Como fora mencionado no procedimento de cruzamento, foi usada a seleção elitista, passando de geração em geração o melhor indivíduo. Portanto, privilegiam-se os indivíduos de melhor valor da função de avaliação (aptidão) para se reproduzir com mais frequência, do que os piores, ao gerar a nova população.

Veja o seguinte exemplo apresentado na Figura 7. Temos dois cromossomos, cada um representando uma solução para um problema com as características como mostrado na Figura 5. Neste problema existem quatro instalações de coleta de produtos de retorno, quatro locais candidatos para localizar instalações de reprocessamento e só uma instalação de remanufatura. O melhor cromossomo da geração anterior (pai 1) tem aberta instalações de reprocessamento $\left(w_{k}^{*}=1\right)$ nos locais 1 e 2 , enquanto o cromossomo selecionado (pai 2) tem aberto instalações $\left(w_{k}^{*}=1\right)$ nos locais 2 e 4 . Os fluxos entre as diversas instalações podem ser observados nos valores indicados em cada cromossomo. Para este exemplo, o ponto de cruzamento é igual a 2, como está indicado na figura. O novo indivíduo (filho 1) recebe a primeira parte do pai 1 e a segunda parte do cruzamento do pai 2. O resto do cromossomo é obtido segundo explicado anteriormente, isto é, verificando a factibilidade do cromossomo e logo resolvendo o subproblema RSCPR.

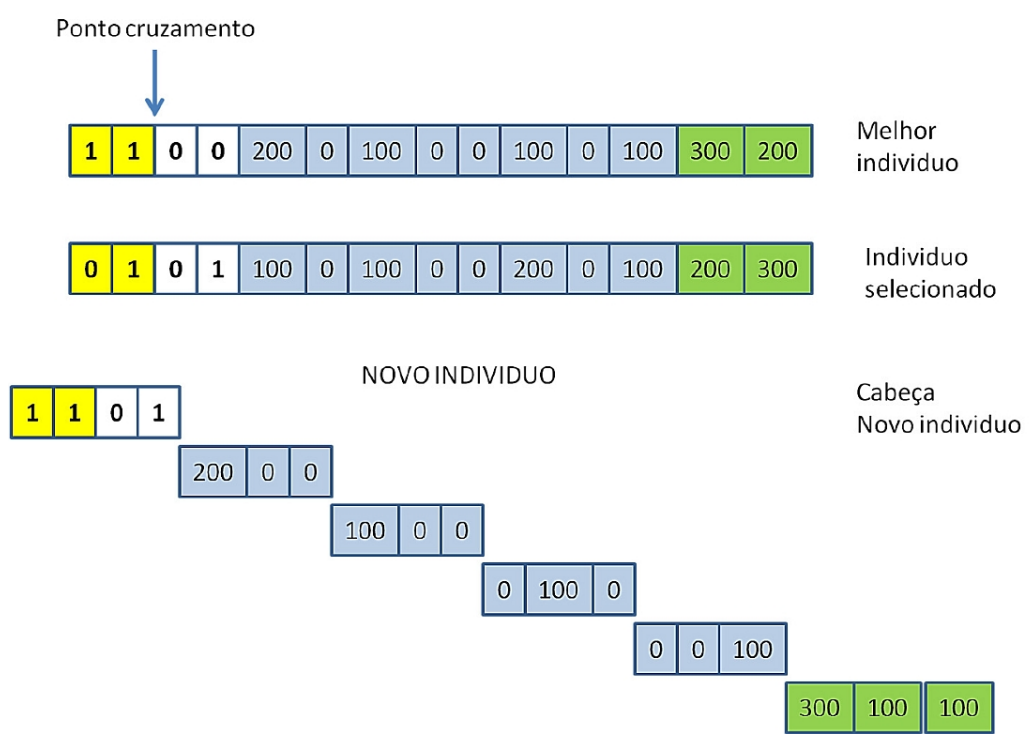

Figura 7. Exemplo de operação de cruzamento de cromossomos.

\subsection{Algoritmo de particle swarm optimization}

Particle Swarm Optimization (PSO) é um método de computação evolutiva, para resolver problemas de otimização contínua (Kennedy \& Eberhart, 2001). Este é um algoritmo de otimização baseado na teoria de enxame onde a ideia principal de um PSO clássico é modelar o bando de pássaros voando em torno de um pico em uma paisagem. Em PSO, as aves são substituídas por seres artificiais chamados partículas e o pico na paisagem é o pico (máximo ou mínimo) de uma função objetivo (aptidão). As partículas do enxame estão voando através do espaço de solução de busca com uma velocidade para a formação de (sub)bandos de forma a atingir os picos das funções de aptidão. Em um PSO contínuo, o estado de uma partícula individual $i$ em um espaço de busca da solução $D$ é caracterizado por dois fatores: a sua posição $u$ e velocidade $v$. A posição $u$ e velocidade $v$ da $i$-ésima partícula no espaço de solução $d$-dimensional de busca pode ser representado como segue:

$$
\begin{gathered}
v_{i d}^{(t+1)}=c_{1} v_{i d}^{t}+c_{2} r_{1}\left(p_{i d}-u_{i d}^{t}\right)+c_{3} r_{2}\left(p_{g d}-u_{i d}^{t}\right) \\
u_{i d}^{(t+1)}=u_{i d}^{t}+v_{i d}^{(t+1)}
\end{gathered}
$$

onde $c_{1}$ é chamado de fator de ponderação de inércia; $c_{2}$ e $c_{3}$ são constantes chamados coeficientes de aceleração; $r_{1}$ e $r_{2}$ são dois números independentes aleatórios uniformemente distribuídos no intervalo [0,1]; $p_{i d}$ correspondente à melhor posição individual da partícula $i$ obtido até o tempo $t$; $p_{g d}$ representa, entre todas as partículas, a partícula com a melhor posição encontrada até o instante $t$. A Equação 10 é usada para o cálculo da nova velocidade de cada partícula $i$ no tempo $(t+1)$. A Equação 11 é usada para a atualização da posição da partícula $i$ no tempo $(t+1)$. Cada $v_{i d}^{t} k \in\left[-v_{\max },-v_{\max }\right]$ e $u_{i d}^{t} k \in\left[-x_{\max }, x_{\max }\right]$ são definidas 
pelo usuário para controlar um excessivo perambular de partículas fora do espaço de solução. As partículas vão "voar" para uma nova posição de acordo com a Equação 11. O processo é repetido até que um critério de parada seja atingido.

\subsubsection{Algoritmo PSO binário}

A fim de resolver os problemas de otimização discreta, Kennedy \& Eberhart (1997) propuseram um algoritmo PSO binário (BPSO). A diferença entre um algoritmo BPSO e algoritmo PSO tradicional é que a Equação 11 foi substituída pela seguinte expressão:

$$
u_{i d}^{(t+1)}=\left\{\begin{array}{lll}
1, & \text { se } & \operatorname{rand}() \leq S\left(v_{i d}^{t+1}\right), \\
0, & \text { se } & \operatorname{rand}()>S\left(v_{i d}^{t+1}\right) .
\end{array}\right.
$$

onde $S($.$) é a função sigmóide e \operatorname{rand}()$ é um número aleatório uniformemente distribuído no intervalo [0,1]. Utilizou-se este método neste capítulo.

O algoritmo PSO típico codifica uma solução (factível) para o modelo RSCP como uma (posição) de partícula e, em seguida, aplica-se o algoritmo tradicional para resolver o problema. Seguiu-se uma abordagem diferente no presente documento, aproveitando a estrutura do modelo RSCP e subdividindo a solução como já foi descrito nas Seções 4.1 e 4.2.

No esquema evolutivo proposto, foi usado um algoritmo BPSO para orientar todo o processo de busca por uma solução ótima para o problema RSCP. No entanto, uma parte da partícula é obtida resolvendo o problema de otimização RSCPR já descrito. Desta forma, foi usado um algoritmo BPSO decomposto, com base em dois grupos de enxames, onde um deles orienta a busca global para uma solução ótima. Seja $L$ o tamanho de enxame (número) de partículas, cada partícula $i$ com uma posição de $u_{i} \in\{0,1\}^{n}$ no espaço de pesquisa e uma velocidade $v_{i} \in R^{n}$. Seja $p_{i}$ a melhor posição conhecida da partícula $i$ e $u_{g}$ a melhor posição conhecida do enxame. A função de aptidão $f($.$) corresponde ao valor da função objetivo para a partícula. \mathrm{O}$ pseudo-código do algoritmo PSO binário básico é mostrado na Figura 8.

1. Gerar o enxame de particulas ;

(a) Para cada partícula $i=1, \ldots, L$ fazer:

(b) Inicializar posição da partícula $i$ com um vetor aleatório gerado a partir de uma distribuição uniforme: $u_{i}^{t} \sim U(-4,4)$;

(c) Analisar factibilidade de cada partícula $i$. Caso necessário aplicar procedimento de factibilidade;

(d) Resolver otimamente problema RSCPR e completar dimensão de partícula $i$;

(e) Inicializar melhor posição da partícula $i$ para a sua posição inicial: $p_{i} \leftarrow u_{i}$;

(f) Se $\left(f\left(p_{i}\right)<f\left(p_{g}\right)\right)$ atualizar melhor posição do enxame: $p_{g} \leftarrow p_{i}$; Inicializar velocidade da partícula: $v_{i}^{t} \sim U(-4,4)$

2. While critério de parada não for atendida $d o$ :

(a) Atualizar o valor de $t$;

i. Para cada partícula $i=1, \ldots, L$ fazer:

A. Para cada dimensão $d=1, \ldots, n$ fazer:

B. Escolha números aleatórios: $r_{1}, r_{2} \sim U(0,1)$

C. Atualize velocidade da partícula usando a Equação 10

D. Atualize posição da partícula usando a Equação 12

E. Resolver otimamente problema RSCPR e completar dimensão de partícula;

F. Se $\left(f\left(x_{i}\right)<f\left(p_{i}\right)\right)$ fazer:

G. Atualize melhor posição da partícula: $p_{i} \leftarrow x_{i}$

H. Se $\left(f\left(p_{i}\right)<f\left(p_{g}\right)\right)$ atualizar melhor posição do enxame conhecido: $p_{g} \leftarrow p_{i}$;

(b) Agora $p_{g}$ armazena a melhor solução encontrada.

(c) Endwhile;

Figura 8. Pseudo-código do algoritmo BPSO. 


\subsubsection{Esquema de codificação da posição das partículas}

Como já foi explicado para o AG, neste caso, encontrar um bom método de codificação para o problema de otimização é o problema mais crítico na definição do algoritmo PSO (Kennedy \& Eberhart, 2001). Neste documento, o espaço da partícula $n$-dimensional é dividido em dois conjuntos $u_{1}$ e $u_{2}$. O comprimento de cada partícula no primeiro conjunto (vetor), corresponde ao número de locais candidatos para localizar instalações de reprocessamento $|K|$. Enquanto, na segunda parte, as partículas representam a solução para o problema de programação linear RSCPR associado. No primeiro grupo de partículas, cada componente pode ter apenas valores 1 ou 0 . Se o $k$-ésimo componente de $u_{1}$ é igual a 1 , então uma instalação de reprocessamento no local candidato $k$ deve ser aberta. Caso contrário, seu valor será 0. O segundo grupo de partículas representa os fluxos de produtos de retorno, entre a instalação de coleta dos retornos e as instalações de reprocessamento, e entre as instalações de reprocessamento e as instalações de remanufatura. Conforme descrito anteriormente neste capítulo, esta parte é obtida resolvendo o problema de otimização RSCPR. Veja a seguir um exemplo de codificação das partículas, para um problema de três (3) instalações de coleta, três (3) locais candidatos para localizar instalações de reprocessamento e duas (2) instalações de remanufatura.

\subsubsection{Geração do bando inicial de partículas}

Para o passo (1), o bando inicial de partículas de tamanho $L$, com a posição de cada partícula $i$ é gerado da seguinte forma:

Passos (1b) e (1c)

Para as partículas do primeiro bando, a posição é gerada de forma aleatória. Primeiro é usada uma distribuição uniforme no intervalo $[0,1]$ para gerar um valor $\operatorname{rand}($.$) . Cada posição d$ do vetor velocidade $v_{i d}^{t}, t=0$, é gerada aleatoriamente no intervalo [-4,4], como no método contínuo. Para obter a posição inicial de cada partícula $i$ é usada a Equação 12. Alternativamente, pode-se gerar a posição inicial de $u_{i}$ a partir de uma distribuição uniforme binária $[0,1]$. Cada posição de partícula $u_{i}$ é representada por um vetor $K$-dimensional de 0 - 1 , sendo $|K|$ o número de locais candidatos para localizar uma instalação de reprocessamento. É claro que este procedimento pode originar soluções infactíveis. Por exemplo, para o problema da Figura 4 anterior, seria possível ter a seguinte posição de partícula: (1;0;0;0). A posição dessa partícula indica que só uma instalação de reprocessamento deve ser aberta no local 1. Se a capacidade dessa instalação for inferior a 500 unidades, essa posição é "infactível". Por este motivo, foi usado um procedimento de viabilização similar ao usado para o caso do algoritmo genético, para dar uma posição factível à partícula, segundo explicado mais adiante nesta seção. Por exemplo, suponha que $L=5$ e foram gerados para cada $u_{i}$ os seguintes valores de $\operatorname{rand}()$ :

$$
\begin{array}{llllll}
u_{11}: 0,7 ; u_{12} & : 0,5 ; u_{13}: 0,6 ; u_{14}: 0,3 ; \\
u_{21}: 0,8 ; u_{22} & : 0,6 ; u_{23}: 0,6 ; u_{24}: 0,4 ; \\
u_{31}: 0,7 ; u_{32}: 0,1 ; u_{33}: 0,2 ; u_{34} & : 0,5 ; \\
u_{41}: 0,4 ; u_{42} & : 0,7 ; u_{43}: 0,5 ; u_{44}: 0,3 ; \\
u_{51} & : 0,2 ; u_{52}: 0,7 ; u_{53}: 0,5 ; u_{54}: 0,4 ;
\end{array}
$$

Para cada $v_{i}$ os seguintes valores foram gerados:

$$
\begin{aligned}
& v_{11}:-4,0 ; v_{12}: 2,6 ; v_{13}: 1,3 ; v_{14}: 3,4 ; \\
& v_{21}: 3,7 ; v_{22}: 0,6 ; v_{23}: 0,3 ; v_{24}: 2,4 ; \\
& v_{31}: 0,5 ; v_{32}:-2,6 ; v_{33}:-1,3 ; v_{34}: 4,0 \text {; } \\
& v_{41}:-0,7 ; v_{42}: 1,6 ; v_{43}: 3,3 ; v_{44}:-1,4 \text {; } \\
& v_{51}: 2,7 ; v_{52}: 0,6 ; v_{53}:-0,3 ; v_{54}: 0,4 ;
\end{aligned}
$$

Usando a Equação 10 obtém-se as seguintes posições para as partículas $u_{i}$ :

$$
\begin{aligned}
& u_{11}=1 ; u_{12}=0 ; u_{13}=0 ; u_{14}=0 ; \\
& u_{21}=0 ; u_{22}=0 ; u_{23}=1 ; u_{24}=0 ; \\
& u_{31}=1 ; u_{32}=1 ; u_{33}=0 ; u_{34}=0 ; \\
& u_{41}=1 ; u_{42}=0 ; u_{43}=0 ; u_{44}=1 ; \\
& u_{51}=0 ; u_{52}=1 ; u_{53}=1 ; u_{54}=0 ;
\end{aligned}
$$

Pode ser observado que as partículas $u_{1}$ e $u_{2}$ são infactíveis, pois não existe capacidade suficiente nas instalações de reprocessamento para atender a demanda total. Para ambas as partículas, é necessário aplicar um procedimento de factibilidade como descrito na Seção 4.2.1.4. A posição da partícula 3, mostra que duas instalações de reprocessamento são abertas, uma no local candidato 1 e outra no local candidato 2.

Passo (1d)

A cada partícula do primeiro bando corresponde uma partícula do segundo bando. Para as partículas 
do segundo bando, a posição é gerada a partir da solução do problema associado de PL que considera a posição de cada partícula do primeiro bando. Suponha que para a partícula $u_{3}$ é resolvido o problema RSCPR, da mesma forma como foi explicado também para ao algoritmo AG. Suponha que a solução deste problema seja representada na Figura 4 anterior. A posição para partícula $u_{3}$ deste bando pode ser a seguinte:

\section{$(100 ; 0 ; 150 ; 0 ; 0 ; 150 ; 0 ; 100 ; 250 ; 0 ; 0 ; 250)$.}

Esta posição para um problema com 4 instalações de coleta, 2 instalações de reprocessamento abertas e 2 instalações de remanufatura, indica que 100 unidades de produto de retorno vão desde a primeira instalação de coleta para a primeira instalação de reprocessamento aberta, 150 unidades de produto de retorno são transportadas desde a segunda instalação de coleta para a primeira instalação de reprocessamento aberta, 150 unidades são transportadas desde a terceira instalação de coleta para a segunda instalação de reprocessamento aberta e 100 unidades são transportadas desde a quarta instalação de coleta para a segunda instalação de reprocessamento aberta. Logo, desde a primeira instalação de reprocessamento aberta são transportadas 250 unidades para a primeira instalação de remanufatura e outras 250 unidades são transportadas desde a segunda instalação de reprocessamento para a segunda instalação de remanufatura.

Deve-se lembrar que, na inicialização, a melhor posição de cada partícula corresponde à posição inicial da partícula.

\subsubsection{Atualização da posição de cada partícula}

Para ilustrar os cálculos do passo (2) que atualiza a posição de cada partícula do primeiro bando, são feitas algumas suposições.

Suponha que a partícula com melhor posição no enxame é a número 3. Então $p_{g}=p_{3}$. Como exemplo, apresenta-se para a particula 4 o detalhe dos cálculos necessários para atualizar sua posição. O coeficiente de aceleração $c_{2}$ é definido com valor 2 e $c_{3}$ com valor 1 . O coeficiente de inércia começa com um valor de 0,9 . Os valores gerados para $r_{1}$ e $r_{2}$ são 0,3 e 0,7 respectivamente. Para atualizar a velocidade das partículas, foi usada a Equação 10. Para o caso da partícula 4, a Tabela 1 ilustra este cálculo.

$$
v_{i d}^{(t+1)}=c_{1} v_{i d}^{t}+c_{2} r_{1}\left(p_{i d}-u_{i d}^{t}\right)+c_{3} r_{2}\left(p_{g d}-u_{i d}^{t}\right)
$$

Tabela 1. Exemplo atualização velocidade e posição de partícula 4.

\begin{tabular}{ccccccc}
\hline $\boldsymbol{v}_{i d}^{t}$ & $\boldsymbol{u}_{i d}^{t}$ & $\boldsymbol{p}_{i d}$ & $\boldsymbol{p}_{g d}$ & Novo $\boldsymbol{v}_{i d}^{(t+1)}$ & $\operatorname{rand}()$ & $\boldsymbol{u}_{i d}^{(t+1)}$ \\
\hline$-0,7$ & 1 & 1 & 1 & $-0,63$ & 0,2 & 0 \\
1,6 & 0 & 0 & 1 & 2,14 & 0,9 & 1 \\
3,3 & 0 & 0 & 0 & 2,97 & 0,5 & 0 \\
$-1,4$ & 1 & 1 & 0 & $-1,96$ & 0,2 & 1 \\
\hline
\end{tabular}

A Tabela 1 também mostra a atualização da posição da partícula 4 usando a Equação 12. Lembre-se que os valores $\operatorname{rand}()$ são gerados aleatoriamente, para propósitos de ilustrar adequadamente o algoritmo estes dados foram gerados de forma de mudar a posição da partícula 4. O procedimento é aplicado a cada partícula para atualizar primeiro a velocidade e logo a posição. Uma vez atualizada a posição de cada partícula desse enxame, é necessário agora resolver o problema RSCPR para completar a posição de cada partícula. Realizado esse cálculo, são comparados os valores das funções objetivos de cada partícula, para atualizar a melhor posição de cada partícula $p_{i}$ e a partícula com melhor posição no enxame $p_{g}$. Finalmente, mais uma iteração do ciclo While é executada e todos os cálculos são repetidos.

\subsubsection{4 $O$ procedimento de factibilidade}

O algoritmo BPSO padrão pode gerar algumas partículas do primeiro grupo (enxame) representando soluções inviáveis, o que pode dar origem a posições inviáveis das partículas do segundo bando. Para resolver este problema, para cada partícula do primeiro bando aplica-se um procedimento simples para projetar a posição de cada partícula no espaço de soluções viáveis do problema. Este procedimento consiste em duas etapas. Na primeira etapa verifica-se se o número de instalações já aberto é suficiente para satisfazer toda a demanda. No segundo passo, para aquelas partículas que não satisfazem a procura, obtemos uma solução viável para RSCP com base na partícula inicial. Este procedimento é bastante simples, começa por abrir instalações até que a demanda seja satisfeita. O enxame é composto de apenas soluções viáveis. A aptidão de uma partícula é calculada resolvendo simultaneamente o problema RSCPR e usando a função objetivo da Equação 8. 


\subsubsection{Outras considerações}

O algoritmo é inicializado com um tamanho de enxame de $L=20$ partículas. O número máximo de iterações foi também ajustado para 10. Utilizou-se esta configuração de parâmetros porque o teste inicial proporcionou bons resultados para a complexidade do problema estudado neste capítulo. O coeficiente de aceleração $c_{2}$ é definido com valor 2 e $c_{3}$ com valor 1 . O coeficiente de inércia começa com um valor de 0,9 e diminui até chegar a 0,4 dependendo do número de iterações realizadas. O enxame inicial é composto de apenas soluções viáveis. Cada partícula do primeiro grupo é gerado aleatoriamente usando uma distribuição uniforme no intervalo [0,1]. Em seguida é aplicado o procedimento binário e, depois disso, é aplicado o procedimento de factibilidade. Em relação ao segundo grupo de partículas, para cada partícula resolvemos o problema de otimalidade LP descrito anteriormente neste capítulo. O vetor velocidade $v_{i d}^{t}$ é gerado aleatoriamente no intervalo [-4,4], como no método contínuo. Em cada iteração, o algoritmo utiliza o método descrito anteriormente e atualiza o vetor de posição $u_{i d}^{(t+1)}$ de acordo com a Equação 12. O vetor velocidade $v_{i d}^{t}$ é atualizado a cada iteração de acordo com a Equação 10. A função de aptidão é dada pela expressão (1). Em cada iteração, atualiza-se a melhor posição de uma partícula e a melhor posição global do enxame. Observe que não foram exploradas estruturas de vizinhança, ou seja, a forma como a informação é distribuída entre os seus membros.

\section{Experimentação Computacional}

Nesta seção são discutidos e comparados os resultados computacionais obtidos pelos algoritmos evolutivos propostos. A proposta deste trabalho é analisar o desempenho em termos de tempo computacional para obter a solução e da qualidade do limite superior (solução) obtido.

Foi implementado o algoritmo em GAMS e utilizado o CPLEX (versão 12.3) como uma sub-rotina (chamado de dentro do GAMS) para resolver o problema de otimização RSCPR. Todos os experimentos foram desenvolvidos em um PC com 4 GB RAM e 2.3GHz. Na literatura, não há conjuntos de dados disponíveis para o problema. Foram gerados aleatoriamente 10 problemas testes seguindo metodologias similares utilizadas para conhecidos problemas de cadeias de suprimentos relacionados com o problema (por exemplo, (Lu \& Bostel, 2007)). Estes problemas de teste são dados que correspondem a redes de até 350 instalações de coleta, 100 locais candidatos à localização de instalações de reprocessamento e 40 instalações de remanufatura. O conjunto de dados para os problemas de teste são apresentados na Tabela 1 e estão disponíveis com os autores. Todos os custos de transporte foram gerados aleatoriamente, usando uma distribuição uniforme com parâmetros [1,40]. Os custos de gestão foram definidos em 30 para todas as instâncias de problemas, exceto para instância 1. Instâncias 7 e 8 são as mesmas que os casos 4 e 5 , respectivamente, exceto que o valor dos custos fixos $\left(f_{k}\right)$ foram obtidos multiplicando por 10 os custos fixos das instâncias 4 e 5. Instâncias 9 e 10 são as mesmas que os casos 7 e 8, respectivamente, mas a capacidade de cada local foi aumentada em 50\%. Produtos disponíveis para retorno $\left(a_{j}\right)$, capacidade de instalações de reprocessamento $\left(m_{k}\right)$ e a capacidade das instalações remanufatura $\left(b_{l}\right)$ são mostrados na Tabela 2.

Tabela 2. Dados dos problemas testes.

\begin{tabular}{ccccccccc}
\hline No. & Problemas & $\mathbf{I}$ & $\mathbf{K}$ & $\mathbf{J}$ & $\boldsymbol{f}_{k}$ & $\boldsymbol{a}_{j}$ & $\boldsymbol{m}_{k}$ & $\boldsymbol{b}_{l}$ \\
\hline 1 & $40 \times 20 \times 15$ & 40 & 20 & 15 & 300 & 150 & 400 & 400 \\
2 & $100 \times 40 \times 20$ & 100 & 40 & 20 & 500 & 150 & 400 & 400 \\
3 & $150 \times 40 \times 20$ & 100 & 40 & 20 & 1000 & 200 & 800 & 1500 \\
4 & $200 \times 80 \times 20$ & 200 & 80 & 20 & 1000 & 300 & 800 & 3000 \\
5 & $300 \times 80 \times 40$ & 300 & 80 & 40 & 2000 & 200 & 800 & 1500 \\
6 & $350 \times 100 \times 40$ & 350 & 100 & 40 & 2000 & 200 & 800 & 1750 \\
7 & $200 \times 80 \times 20$ & 200 & 80 & 20 & 10000 & 300 & 800 & 3000 \\
8 & $300 \times 80 \times 40$ & 300 & 80 & 40 & 20000 & 200 & 800 & 1500 \\
9 & $200 \times 80 \times 20$ & 200 & 80 & 20 & 10000 & 300 & 1200 & 3000 \\
10 & $300 \times 80 \times 40$ & 300 & 80 & 40 & 20000 & 200 & 1200 & 1500 \\
\hline
\end{tabular}

Foram realizados cinco ensaios para cada instância de teste. As Tabelas 3 e 4 mostram os resultados obtidos utilizando como base o algoritmo genético (GA) e o algoritmo Binário de PSO (BPSO) respectivamente. Para cada instância do problema, as tabelas mostram o valor máximo, mínimo e a média da solução fornecida pela fase inicial do algoritmo aleatório $\left(z_{\text {ran }}\right)$, da solução fornecida pelo algoritmo GA $\left(z_{G A}\right)$ ou BPSO $\left(z_{p}\right)$, os tempos computacionais (em segundos) e o gap $\left(100\left[z_{p}-z^{*}\right] / z^{*}\right)$, obtido comparando o $z_{G A}\left(z_{p}\right)$ com o valor ótimo inteiro da função objetivo $\left(z^{*}\right)$, obtido por GAMS. Todos os valores foram arredondados para um gap de duas casas decimais. Para o caso do AG, na Tabela 3, pode-se observar que o gap médio máximo é de $3,65 \%$ (instância \#1), enquanto o máximo e mínimo gap é de 3,93\% e 0,10\%, respectivamente. O gap médio 
mínimo é de 0,17\% (instância \#2). Em relação aos tempos de CPU gastos, o tempo médio máximo é de 100,43 segundos. O tempo máximo e mínimo é de 105,74 e 19,73 segundos, respectivamente. Observe que, na Tabela 4, para o algoritmo BPSO, considerando todas as instâncias de teste, a gap médio máximo é de 1,58\% (instância \# 9) e o gap médio mínimo é de 0,04\% (instância \# 2). Os máximo e mínimo gaps são de $1,69 \%$ e $0,0 \%$, respectivamente. Quanto ao tempo de computação, note que todas as instâncias de teste foram resolvidos em menos de 58 segundos. O tempo médio máximo é de 56,35 segundos. Os tempos máximo e mínimo são de 58,32 e 13,4 segundos, respectivamente.

Tabela 3. Resultados Algoritmo Genético - valor solução fase aleatória $\left(z_{\text {ran }}\right)$, valor solução GA $\left(z_{G A}\right)$, tempo CPU (segs) e gap\%.

\begin{tabular}{|c|c|c|c|c|c|}
\hline No. & & $z_{\text {ran }}$ & $z_{G A}$ & segs & gap\% \\
\hline \multirow{3}{*}{1} & Mínimo & 147800 & 147250 & 19,73 & 3,30 \\
\hline & Máximo & 149500 & 148150 & 21,88 & 3,93 \\
\hline & Média & 148550 & 147760 & 20,70 & 3,65 \\
\hline \multirow{3}{*}{2} & Mínimo & 520600 & 520600 & 24,11 & 0,10 \\
\hline & Máximo & 521200 & 521200 & 27,49 & 0,21 \\
\hline & Média & 521080 & 520960 & 25,29 & 0,17 \\
\hline \multirow{3}{*}{3} & Mínimo & 1065400 & 1064400 & 24,94 & 0,15 \\
\hline & Máximo & 1067600 & 1069100 & 32,24 & 0,59 \\
\hline & Média & 1066280 & 1066100 & 28,44 & 0,31 \\
\hline \multirow{3}{*}{4} & Mínimo & 2090600 & 2086000 & 52,71 & 0,16 \\
\hline & Máximo & 2092600 & 2092000 & 60,19 & 0,45 \\
\hline & Média & 2091720 & 2088720 & 57,27 & 0,29 \\
\hline \multirow{3}{*}{5} & Mínimo & 2131500 & 2129200 & 74,39 & 0,31 \\
\hline & Máximo & 2132900 & 2132800 & 90,45 & 0,48 \\
\hline & Média & 2132200 & 2131120 & 79,53 & 0,40 \\
\hline \multirow{3}{*}{6} & Mínimo & 2470000 & 2469500 & 96,00 & 0,44 \\
\hline & Máximo & 2473050 & 2470900 & 105,74 & 0,50 \\
\hline & Média & 2471430 & 2470060 & 100,43 & 0,46 \\
\hline \multirow{3}{*}{7} & Mínimo & 2766700 & 2766700 & 55,44 & 0,33 \\
\hline & Máximo & 2768500 & 2768500 & 64,06 & 0,39 \\
\hline & Média & 2767380 & 2767380 & 59,27 & 0,35 \\
\hline \multirow{3}{*}{8} & Mínimo & 3480700 & 3480700 & 75,87 & 0,23 \\
\hline & Máximo & 3482400 & 3482400 & 84,88 & 0,28 \\
\hline & Média & 3481860 & 3481620 & 79,90 & 0,26 \\
\hline \multirow{3}{*}{9} & Mínimo & 2528600 & 2525000 & 50,71 & 1,84 \\
\hline & Máximo & 2533700 & 2530400 & 60,09 & 2,06 \\
\hline & Média & 2530520 & 2527700 & 55,37 & 1,95 \\
\hline \multirow{3}{*}{10} & Mínimo & 2993600 & 2991000 & 74,33 & 1,06 \\
\hline & Máximo & 3000900 & 3000900 & 91,87 & 1,39 \\
\hline & Média & 2997260 & 2995800 & 82,19 & 1,22 \\
\hline
\end{tabular}

Na Tabela 5, pode-se observar os tempos e gaps médios de cada algoritmo. Para o conjunto de dados e testes realizados, o algoritmo BPSO baseado em PSO binário apresenta um melhor desempenho tanto em tempo de CPU gasto quanto no gap obtido.

\section{Conclusões}

Neste capítulo foi apresentado um esquema de otimização que combina algoritmos estocásticos (AG e PSO binário) com a solução ótima de um subproblema relaxado para resolver o problema de projeto de cadeia de suprimentos de remanufatura de produtos de retorno. O problema foi formulado como um problema de programação linear inteira mista. Aproveitando a estrutura do problema, nos propomos uma decomposição em dois subproblemas. Um primeiro subproblema é resolvido usando algoritmo estocástico clássico (AG ou BPSO). Este algoritmo guia o processo de busca da solução, definindo a localização das instalações de reprocessamento. O segundo subproblema, considerando sua estrutura mais simples é resolvido otimamente. Os dados desta solução são complementados com a solução do primeiro subproblema para obter, finalmente, 
Tabela 4. Resultados Algoritmo Binário de PSO - valor solução fase aleatória $\left(z_{\text {ran }}\right)$, valor solução $\operatorname{BPSO}\left(z_{p}\right)$, tempo CPU (segs) e gap\%.

\begin{tabular}{|c|c|c|c|c|c|}
\hline No. & $\boldsymbol{z}_{\text {ran }}$ & $z_{p}$ & segs & gap\% & \\
\hline \multirow{3}{*}{1} & Mínimo & 148500 & 146900 & 13,40 & 0,00 \\
\hline & Máximo & 150050 & 149000 & 13,87 & 1,43 \\
\hline & Média & 149310 & 148000 & 13,59 & 0,75 \\
\hline \multirow{3}{*}{2} & Mínimo & 520300 & 520250 & 15,73 & 0,03 \\
\hline & Máximo & 521350 & 520300 & 15,98 & 0,04 \\
\hline & Média & 520750 & 520290 & 15,88 & 0,04 \\
\hline \multirow{3}{*}{3} & Mínimo & 1065400 & 1065200 & 19,01 & 0,23 \\
\hline & Máximo & 1066600 & 1065800 & 20,10 & 0,28 \\
\hline & Média & 1065960 & 1065440 & 19,75 & 0,25 \\
\hline \multirow{3}{*}{4} & Mínimo & 2090500 & 2089000 & 32,40 & 0,30 \\
\hline & Máximo & 2091400 & 2090500 & 34,85 & 0,37 \\
\hline & Média & 2090740 & 2089800 & 33,45 & 0,34 \\
\hline \multirow{3}{*}{5} & Mínimo & 2130800 & 2130800 & 54,80 & 0,38 \\
\hline & Máximo & 2132400 & 2131100 & 58,32 & 0,40 \\
\hline & Média & 2131780 & 2130920 & 56,35 & 0,39 \\
\hline \multirow{3}{*}{6} & Mínimo & 2468750 & 2467350 & 53,82 & 0,35 \\
\hline & Máximo & 2471900 & 2469550 & 54,70 & 0,44 \\
\hline & Média & 2470920 & 2468400 & 54,29 & 0,40 \\
\hline \multirow{3}{*}{7} & Mínimo & 2765500 & 2764100 & 35,75 & 0,23 \\
\hline & Máximo & 2768700 & 2765600 & 40,01 & 0,29 \\
\hline & Média & 2766400 & 2765120 & 36,71 & 0,27 \\
\hline \multirow{3}{*}{8} & Mínimo & 3481300 & 3480200 & 54,33 & 0,22 \\
\hline & Máximo & 3483000 & 3481400 & 56,52 & 0,25 \\
\hline & Média & 3482300 & 3480900 & 55,28 & 0,24 \\
\hline \multirow{3}{*}{9} & Mínimo & 2525300 & 2513600 & 35,46 & 1,38 \\
\hline & Máximo & 2727700 & 2521400 & 36,79 & 1,69 \\
\hline & Média & 2570520 & 2518640 & 36,27 & 1,58 \\
\hline \multirow{3}{*}{10} & Mínimo & 2994500 & 2990900 & 38,97 & 1,05 \\
\hline & Máximo & 3003400 & 2999600 & 48,01 & 1,35 \\
\hline & Média & 2998880 & 2994420 & 45,68 & 1,17 \\
\hline
\end{tabular}

Tabela 5. Resultado comparativo Algoritmo GA e BPSO - tempos (segs) e gap (\%) médios.

\begin{tabular}{ccccc}
\hline \multirow{2}{*}{ No. } & \multicolumn{2}{c}{ tempo $($ segs $)$} & \multicolumn{2}{c}{$\boldsymbol{g a p}(\boldsymbol{\%})$} \\
\cline { 2 - 5 } & $G A$ & $B P S O$ & $G A$ & BPSO \\
\hline 1 & 20,70 & 13,59 & 3,65 & 0,75 \\
2 & 25,29 & 15,88 & 0,17 & 0,04 \\
3 & 28,44 & 19,75 & 0,31 & 0,25 \\
4 & 57,27 & 33,45 & 0,29 & 0,34 \\
5 & 79,53 & 56,35 & 0,40 & 0,39 \\
6 & 100,43 & 54,29 & 0,46 & 0,40 \\
7 & 59,27 & 36,71 & 0,35 & 0,27 \\
8 & 79,90 & 55,28 & 0,26 & 0,24 \\
9 & 55,37 & 36,27 & 1,95 & 1,58 \\
10 & 82,19 & 45,68 & 1,22 & 1,17 \\
\hline
\end{tabular}

a solução do problema original. Foi realizado um estudo experimental com instâncias de grande porte geradas aleatoreamente. Em geral, observou-se que, em termos de tempo de CPU gasto e gap (\%) obtido, o algoritmo baseado em BPSO tem um comportamento superior ao outro para as instâncias testadas. Em geral, o esquema de otimização aproveitando a estratégia de decomposição do problema apresentou resultados promissores para redes de grande porte. Ainda pode ser explorado, no futuro, o comportamento dos algoritmos com estruturas 
de busca mais complexas. Por exemplo, no caso do PSO binário, não foi explorado neste capítulo o impacto das estruturas de vizinhanças no desempenho geral do algoritmo. Também não foi aprofundado no algoritmo genético o impacto das operações de mutação, diferentes estratégias de seleção de indivíduos e alternativas para definição de ponto de cruzamento.

\section{Agradecimentos}

Os autores agradecem à Fundação Estadual de Amparo à Pesquisa do Estado de Minas Gerais (FAPEMIG) e a PROPP/UFOP pelo apoio financeiro ao projeto de pesquisa que deu origem a este capítulo.

\section{Referências}

Altiparmak, F.; Gen, M.; Lin, L. \& Karaoglan, I., A steady-state genetic algorithm for multi-product supply chain network design. Computers $\mathcal{E}$ Industrial Engineering, 56(2):521-537, 2009.

Amin, S.H. \& Zhang, G., A proposed mathematical model for closed-loop network configuration based on product life cycle. The International Journal of Advanced Manufacturing Technology, 58(5-8):791-801, 2012.

Barbosa-Povoa, A.P.; Salema, M.I.G. \& Novais, A.Q., Design and planning of closed loop supply chains. In: Papageorgiou, L.G. \& Georgiadis, M.C. (Eds.), Supply Chain Optimization. New York, USA: J. Wiley \& Sons, p. 187-218, 2007.

Daskin, M.S.; Snyder, L.V. \& Berger, R.T., Facility location in supply chain design. In: Langevin, A. \& Riopel, D. (Eds.), Logistics Systems: Design and Optimization. New York, USA: Springer Science, p. 39-65, 2005.

Dekker, R.; Fleischmann, M.; Inderfurth, K. \& Van Wassenhove, L.N., Reverse Logistics: Quantitative Models for Closed-Loop Supply Chains. v. 35 de Lecture Notes in Economics and Mathematical Systems. Berlin, Germany: Springer, 2004.

Dekker, R. \& van der Laan, E.A., Gestion des stocks pour la fabrication et la refabrication simultanées: synthèse de resultants récents. Logistique and Management, 7(2):59-64, 1999.

Engelbrecht, A.P., Fundamentals of Computational Swarm Intelligence. New York, USA: J. Wiley \& Sons, 2005.

Farahani, R.Z. \& Hekmatfar, M. (Eds.), Facility location: concepts, models, algorithms and case studies. Contributions to Management Science. Berlin, Germany: Springer-Verlag, 2009.

Frankel, R.; Bolumole, Y.A.; Eltantawy, R.A.; Paulraj, A. \& Gundlach, G.Y., The domain and scope of SCM'S foundational disciplines insights and issues to advance research. Journal of Business Logistics, 29(1):1-30, 2008.

Giunipero, L.C.; Hooker, R.E.; Joseph-Matthews, S.; Yoon, T. \& Brudvig, S., A decade of SCM literature: past, present and future implications. Journal of Supply Chain Management, 44(4):66-86, 2008.

Goldberg, D.E., Genetic Algorithms in Search, Optimization and Machine Learning. Reading, USA: Addison-Wesley, 1989.

Gomes, M.I.; Barbosa-Povoa, A.P. \& Novais, A.Q., Modelling a recovery network for WEEE: a case study in Portugal. Waste Management, 31(7):1645-60, 2011.

Jayaraman, V.; Patterson, R.A. \& Rolland, E., The design of reverse distribution networks: Models and solution procedures. European Journal of Operational Research, 150(1):128-149, 2003.

Kennedy, J. \& Eberhart, R.C., A discrete binary version of the particle swarm algorithm. In: Proceedings of the IEEE International Conference on Computational Cybernetics and Simulation. Piscataway, USA: IEEE Press, p. 4104-4108, 1997.

Kennedy, J. \& Eberhart, R.C., Swarm Intelligence. San Francisco, USA: Morgan Kaufmann, 2001.

Lai-Jun, W.; Xiao-Ling, S. \& Zhongke, S., New evolutionary algorithm applying to a type of facility location problem. Information Technology Journal, 8(4):605-609, 2009.

Larson, P.D.; Poist, R. \& Halldórsson, A., Perspectives on logistics vs. SCM: a survey of SCM professionals. Journal of Business Logistics, 28(1):1-24, 2007.

Lee, D.H. \& Dong, M., A heuristic approach to logistics network design for end-of-lease computer products recovery. Transportation Research Part E: Logistics and Transportation Review, 44(3):455-474, 2008.

Lee, J.E.; Gen, M. \& Rhee, K.G., Network model and optimization of reverse logistics by hybrid genetic algorithm. Computers $\&$ Industrial Engineering, 56(3):951-964, 2009.

Li, N., Research on location of remanufacturing factory based on particle swarm optimization. In: Proceedings of International Conference on Management Science and Industrial Engineering (MSIE). Piscataway, USA: IEEE Press, p. 1016-1019, 2011.

Lu, Z. \& Bostel, N., A facility location model for logistics systems including reverse flows: The case of remanufacturing activities. Computers \& Operations Research, 34(2):299-323, 2007.

Mentzer, J.T.; Dewitt, W.; Keebler, J.S.; Min, S.; Nix, N.W.; Smith, C. \& Zazharia, Z.G., Defining supply chain management. Journal of Business Logistics, 22(2):1-25, 2001.

Min, H.; Jeung Ko, H. \& Seong Ko, C., A genetic algorithm approach to developing the multi-echelon reverse logistics network for product returns. Omega, 34(1):56-69, 2006. 
Mutha, A. \& Pokharel, S., Strategic network design for reverse logistics and remanufacturing using new and old product modules. Computers \& Industrial Engineering, 56(1):334-346, 2009.

Osman, I.H. \& Kelly, J.P., MetaHeuristics: Theory \& Applications. Norwell, USA: Kluwer Academic Publishers, 1996.

Pishvaee, M.S.; Farahani, R.Z. \& Dullaert, W., A memetic algorithm for bi-objective integrated forward/reverse logistics network design. Computers \& Operations Research, 37(6):1100-1112, 2010.

Pishvaee, M.S. \& Torabi, S.A., A possibilistic programming approach for closed-loop supply chain network design under uncertainty. Fuzzy Sets and Systems, 161(20):2668-2683, 2010.

Rogers, D.S. \& Tibben-Lembke, R.S., Going backwards: reverse logistics trends and practices. Reno, USA: Reverse Logistics Executive Council, 1998.

Rubio, S.; Chamorro, A. \& Miranda, F.J., Characteristics of the research on reverse logistics (1995 - 2005). International Journal of Production Research, 46(4):1099-1120, 2008.

Salema, M.I.G.; Barbosa-Povoa, A.P. \& Novais, A.Q., Simultaneous design and planning of supply chains with reverse flows: A generic modelling framework. European Journal of Operational Research, 203(2):336-349, 2010.

Santibañez-Gonzalez, E.D.R.; Luna, H.P.L. \& Mateus, G.R., Um algoritmo evolucionário combinado com otimização para resolver o problema de projeto de uma supply chain de remanufatura. In: Anais XLIV Simpósio Brasileiro de Pesquisa Operacional. Rio de Janeiro, 2012.

Santibañez-Gonzalez, E.D.R. \& Souza, M.J.F., A conceptual analysis of supply chain management. In: Proceedings XVI ICIEOM International Conference on Industrial Engineering and Operations Management. São Carlos, SP, 2010.

Seuring, S. \& Muller, M., From a literature review to a conceptual framework for sustainable supply chain management. Journal of Cleaner Production, 16(15):1699-1710, 2008.

Simchi-Levi, D.; Kaminsky, P. \& Simchi-Levi, E., Designing and managing the supply chain. 3a edição. New York, USA: McGraw-Hill/Irwin, 2007.

Srivastava, S., Green supply chain management: A state of the art literature review. International Journal of Management Reviews, 9(1):53-80, 2007.

Zarei, M.; Mansour, S.; Hosseinzadeh Kashan, A. \& Karimi, B., Designing a reverse logistics network for end-of-life vehicles recovery. Mathematical Problems in Engineering, (ID 649028):1-17, 2010.

Zhou, Y. \& Wang, S., Generic model of reverse logistics network design. Journal of Transportation Systems Engineering and Information Technology, 8(3):71-78, 2008.

\section{Notas Biográficas}

Ernesto Del Rosario Santibañez Gonzalez é graduado em Ingenieria Civil Industrial (Universidade Católica del Norte / Universidad de Tarapacá, Chile, 1984), mestre em Pesquisa Operacional (COPPE, Universidade Federal do Rio de Janeiro, 1988) e doutor em Engenharia de Produção (Universidade Federal do Rio de Janeiro / London School of Economics, 1992). Atualmente é professor adjunto na Universidade Federal de Ouro Preto - UFOP. Realiza atividades de pesquisa nas áreas de otimização, programação matemática e biologia computacional para resolver problemas de redes, supply chain, sustentabilidade, marketing viral e concorrência de empresas. Está interessado no desenvolvimento de projetos de inovação tecnológica nas área de Ciência da Computação e Engenharia de Produção combinando, para isto, programação matemática, algoritmos aproximados e tecnologias disruptivas.

Henrique Pacca Loureiro Luna é graduado em Engenharia Mecânica (Instituto Tecnológico da Aeronáutica, 1969), mestre em Informática (Pontifícia Universidade Católica do Rio de Janeiro, 1972) doutor em AutomáticaOtimização (Université de Toulouse III Paul Sabatier, 1978). Atualmente é professor titular em atividade no Instituto de Computação da Universidade Federal de Alagoas, sendo também professor titular aposentado do Departamento de Ciência da Computação da Universidade Federal de Minas Gerais. Desde 2003 lidera na UFAL o grupo de pesquisa NExOS (Núcleo de Excelência em Otimização de Sistemas Complexos).

Geraldo Robson Mateus é graduado em Engenharia Mecânica (Universidade Federal de Minas Gerais, 1977), mestre e doutor em Engenharia de Sistemas e Computação (Universidade Federal do Rio de Janeiro, 1980 e 1986 , respectivamente). Tem também pós-doutorado pela University of Ottawa, Canadá. É professor titular da Universidade Federal de Minas Gerais e consultor da Fundação de Desenvolvimento da Pesquisa. Tem experiência na área de Ciência da Computação, com ênfase em otimização, algoritmos e redes, atuando principalmente nos seguintes temas: combinatória, programação matemática, telecomunicações, logística e transporte, computação móvel. 
Gonzalez et al. 


\title{
Comparação de Heurísticas para a Solução do Problema de Carregamento e Descarregamento 3D de Navios via Representação por Regras
}

\author{
Anibal Tavares de Azevedo*, Cassilda Maria Ribeiro, Galeno José de Sena, \\ Antônio Augusto Chaves, Luiz Leduino de Salles Neto, e Antônio Carlos Moretti
}

\begin{abstract}
Resumo: Neste capítulo são apresentados uma nova formulação e uma nova representação compacta para a solução do problema de carregamento de contêineres 3D em terminais portuários, e que consiste em determinar como carregar e descarregamento um conjunto de contêineres de um navio porta-contêiner, visando a minimização do número de movimentos e da distância do centro de massa ao centro de gravidade. Assim como o problema 2D é NP-Completo, o problema 3D também o é, e três métodos heurísticos combinados com uma nova representação das soluções, representação por regras, são propostos e comparados: Beam Search, Algoritmo Genético e Simulated Annealing.
\end{abstract}

Palavras-chave: Planejamento de manejo de contêineres em navios, Beam search, Algoritmo genético, Simulated Annealing.

Abstract: This chapter presents a new formulation and a new compact representation to solve the $3 D$ Container Ship Loading Planning Problem, which consists in determining how to unload and load containers on board of a container ship in order to minimize the total number of movements performed, and also the distance between the geometric center and the mass center. Since the $2 D$ problem is NPComplete, so it is the $3 D$ problem, and then three heuristic methods were, combined with representation by rules, were proposed and compared: Beam Search, Genetic Algorithm and Simulated Annealing.

Keywords: 3D Container ship loading planning problem, Beam search, Genetic algorithm, Simulated Annealing.

\section{Introdução}

A eficiência de um terminal portuário especializado em movimentação de contêineres depende da ordenação e agilidade do processo de lidar com os contêineres, especialmente durante o processo de carregamento dos navios. A estiva e o plano de carregamento associado são determinados fundamentalmente por dois critérios: instabilidade do navio e o número mínimo de remanejo requerido nos diversos pontos de entrega (Avriel et al., 2000; Wilson \& Roach, 2000; Ambrosino et al., 2006). O último critério é baseado no fato de que muitos navios possuem uma estrutura celular, conforme pode ser observado na Figura 1, e os contêineres devem ser carregados de modo a formarem pilhas verticais, o que acarreta, em muitos casos, a necessidade de movimentar alguns contêineres para descarregar outros posicionados na parte inferior da pilha.

Concomitantemente, outra restrição emerge durante a escolha dos contêineres para carregamento no pátio do terminal, onde geralmente os contêineres são empilhados formando blocos a espera do momento de serem carregados. Se os contêineres alvos, que devem ser carregados mais tarde, são posicionados nas pilhas abaixo de outros, então a tarefa de carregamento requer remanejo de modo a remover e reposicionar os contêineres alvos. Esta situação ocorre com frequência, uma vez que a ordem de carregamento não é conhecida quando as cargas chegam ao pátio do terminal e é denominada de realocação. No entanto, mesmo quando esta informação é disponibilizada a tempo, o arranjo ideal de contêineres na área de armazenamento é praticamente impossível de ser obtido devido à chegada aleatória de diversas outras cargas. Mais especificamente, o problema de carregamento de contêineres em terminais portuários (PCCTP) consiste em determinar como carregar um

*Autor para contato: atanibal@yahoo.com 

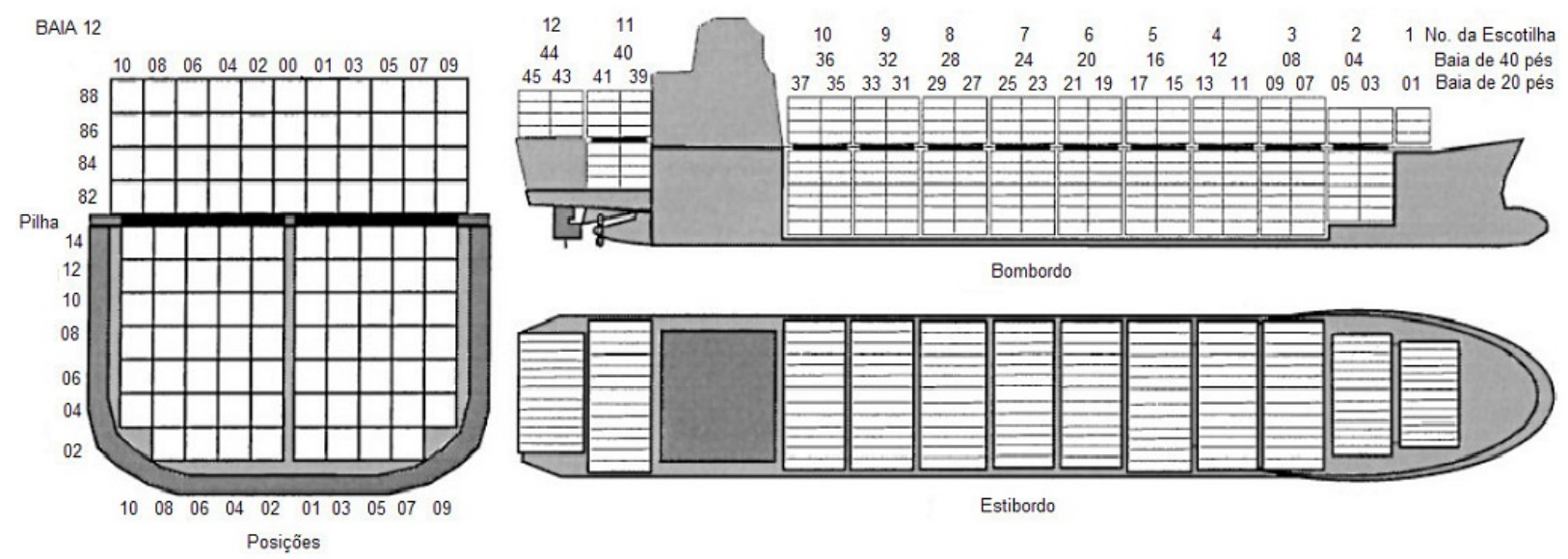

Figura 1. Estrutura celular de um navio. Fonte: Wilson \& Roach (2000).

conjunto de contêineres de diferentes tipos em um navio porta-contêiner (containership), respeitando restrições operacionais relacionadas aos contêineres, navio e pátio do terminal portuário.

Neste capítulo serão comparados os desempenhos de um Algoritmo Genético (AG), um Simulated Annealing (SA) e um Beam Search (BS) para a solução do PCCTP 3D para a minimização do número de movimentos de carregamento e descarregamento de contêineres em terminais portuários, bem como a minimização da medida de instabilidade. Na Seção 2 é apresentado o problema 3D a ser resolvido bem como sua formulação matemática binária. Na Seção 3 é apresentada a representação por regras que será combinada com a implementação meta-heurísticas. Na Seção 4 são citados o Algoritmo Genético, o Simulated Annealing e o Beam Search, respectivamente. Na Seção 5 são apresentados os resultados computacionais obtidos e na Seção 6 as conclusões e sugestões de trabalhos futuros.

\section{Apresentação do Problema}

Um navio porta contêiner tem sua capacidade medida em TEU (Twenty-foot Equivalent Units) ou Unidade Equivalente de Vinte pés. Por exemplo um navio com capacidade de 8000 TEUs pode carregar 8000 contêineres de vinte pés. Nos navios tem uma estrutura celular (ver Figura 1) onde são alojados os contêineres. Estas células são agrupadas por seções ou baias (em inglês bays) e os contêineres são empilhados nestas seções formando pilhas verticais. Então uma baia é um agrupamento de células, com capacidade de se empilhar um certo número de contêineres. A baia tem então linhas horizontais numeradas $r=1,2, \ldots R$, (a linha 1 é a linha que está em baixo, e a linha $R$ é a linha do topo da pilha) e colunas numeradas $c=1,2, \ldots, C$ (coluna 1 é a primeira coluna da esquerda).

O PCCTP 3D que será resolvido aqui consiste em reduzir ao máximo possível dois objetivos: o número de realocações dos contêineres para um certo número de portos $N$ e a instabilidade do arranjo dos contêineres. Para o primeiro objetivo, minimiza-se a realocação decorrente do descarregamento temporário de contêineres, da pilha de contêineres, com a finalidade de descarregar, num terminal portuário $p$, um contêiner que está na parte inferior da pilha. Isto é necessário porque os contêineres que estão numa pilha só podem ser acessados pelo topo. Então um contêiner que está no meio da pilha só pode ser descarregado num determinado porto $p$ se os contêineres que estão acima dele forem removidos. Para o segundo objetivo define-se a distância do centro de massa ao centro geométrico como medida da instabilidade do navio em cada porto (Avriel et al., 2000) . A seguir será apresentada a formulação deste problema como sendo um problema de programação linear inteira com variáveis binárias 0 - 1. Esta formulação respeita as restrições operacionais relacionadas aos contêineres.

\subsection{Modelo matemático}

Considere um navio de transporte de contêineres que possui $D$ baias numeradas $d=1, \ldots, D$. Cada baia tem $R$ linhas horizontais numeradas $r=1,2, \ldots R$, (a linha 1 é a linha que está em baixo, e a linha $R$ é a linha do topo da pilha) e $C$ colunas verticais numeradas $c=1,2, \ldots, C$ (coluna 1 é a primeira coluna da esquerda). Apesar da baia ter um formato tridimensional com baias de diferentes tamanhos, a mesma pode ser representada, sem perda de generalidade, por um formato tridimensional com baias de mesma capacidade, em particular um vetor de matrizes. Então, uma baia pode alocar no máximo $R \times C$ contêineres. É assumido também que todos os contêineres têm o mesmo tamanho e peso. O navio chega no porto 1 completamente vazio e sequencialmente ele visita os portos $2,3, \ldots, N$. Em cada porto $i=1, \ldots, N-1$, o navio recebe o carregamento de contêineres 
com destino aos portos $i+1, \ldots, N$. No último porto ele descarrega os contêineres e fica totalmente vazio. Seja $T=\left[T_{i j}\right]$ a matriz de transporte de dimensão $(N-1) \times(N-1)$, onde $T_{i j}$ é o número de contêineres com origem em $i$ e destino em $j$. A matriz é triangular superior porque $T_{i j}=0$ para todo $i>j$.

A formulação de programação linear inteira do PCCTP 3D é dada pelas Equações 1-6.

subject to

$$
\min f(x)=\alpha \phi_{1}(x)+\beta \phi_{2}(y)
$$

$$
\begin{array}{r}
\sum_{v=i+1}^{j} \sum_{r=1}^{R} \sum_{c=1}^{C} \sum_{d=1}^{D} x_{i j v}(r, c, d)-\sum_{k=1}^{i-1} \sum_{r=1}^{R} \sum_{c=1}^{C} \sum_{d=1}^{D} x_{k i j}(r, c, d)=T_{i j} \\
i=1, \cdots, N-1 ; j=i+1, \cdots, N \\
\sum_{k=1}^{i} \sum_{j=i+1}^{N} \sum_{v=i+1}^{j} x_{k j v}(r, c, d)=y_{i}(r, c, d) \\
i=1, \cdots, N-1 ; r=1, \cdots, R ; c=1, \cdots, C ; d=1, \cdots, D \\
i=1, \cdots, N-1 ; r=1, \cdots, R ; c=1, \cdots, C ; d=1, \cdots, D \\
\sum_{i=1}^{j-1} \sum_{p=j}^{N} x_{i p j}(r, c, d)+\sum_{i=1}^{j-1} \sum_{p=j+1}^{N} \sum_{v=j+1}^{p} x_{i p v}(r+c, d)-y_{i}(r+1, c, d) \leq 1 \\
i=1, \cdots, N ; r=1, \cdots, R ; c=1, \cdots, C ; d=1, \cdots, D .
\end{array}
$$

onde: a variável binária $x_{i j v}(r, c, d)$ é definida de forma que assume o valor 1 se existir um contêiner no compartimento $(r, c, d)$ que foi ocupado no porto $i$ e tem como destino final o porto $j$ e movido no porto $v$; caso contrário assume valor zero. Por compartimento $(r, c, d)$ entende-se a linha $r$, a coluna $c$ e a baia $d$ no compartimento de carga do navio. É necessário salientar que a numeração das linhas é feita de cima para baixo, assim a linha de número 5 está abaixo da linha de número 4, a numeração das colunas é feita da esquerda para a direita e a profundidade é iniciada da proa até a popa. Similarmente, a variável $y_{i}(r, c, d)$ possui valor 1 se saindo do porto $i$ o compartimento $(r, c, d)$ for ocupado por um contêiner; caso contrário assume valor 0 . A restrição (2) é a restrição de conservação de fluxo, onde $T_{i j}$ é o elemento da matriz de transporte que representa o número de contêineres que embarcam no porto $i$ com destino ao porto $j$. A restrição (3) em cada compartimento $(r, c, d)$ será ocupado por no máximo um contêiner. A restrição (4) é necessária para garantir que existem contêineres embaixo do contêiner que ocupa o compartimento $(r, c, d)$. A restrição (5) é responsável por definir a movimentação dos contêineres: se um contêiner que ocupa a posição $(r, c, d)$ é descarregado no porto $j$, então, ou não existem contêineres acima dele, ou o índice $v$ do contêiner que ocupa o compartimento $(r+1, c, d)$ não é maior que $j$.

A função objetivo da Equação 1 possui é uma composição de dois diferentes critérios: o primeiro depende da movimentação dos contêineres, $\phi_{1}(x)$, e o segundo depende posição ocupada pelos contêineres em cada porto, $\phi_{2}(y)$. Os dois critérios podem ser combinados através de valores escalares fornecidos para os pesos $\alpha$ e $\beta$ dentro de um modelo de otimização bi-objetivo.

O termo $\phi_{1}(x)$ relativo ao custo total de movimentação dos contêineres (assumindo que a movimentação de um contêiner possui um custo unitário e igual para todos os portos) em todos os portos é dado pela Equação 7 .

$$
\phi_{1}(x)=\sum_{i=1}^{N-1} \sum_{j=i+1}^{N} \sum_{v=i+1}^{j-1} \sum_{r=1}^{R} \sum_{c=1}^{C} \sum_{d=1}^{D} x_{i j v}(r, c, d)
$$

O termo $\phi_{2}(y)$ é relativo à instabilidade do navio de acordo com a posição dos contêineres (assumindo que cada contêiner possui um peso unitário e igual para todos os portos) e calcula a distância entre o centro de massa e o centro geométrico de cada baia do navio depois de descarregar e depois de carregar em todos os portos tal como dado pela Equação 8.

$$
\phi_{2}(y)=\sum_{i=1}^{N}\left(\sum_{d=1}^{D}\left(\Delta x_{d, i}\right)^{2}+\sum_{d=1}^{D}\left(\Delta z_{d, i}\right)^{2}\right)
$$


onde:

$$
\begin{array}{r}
\Delta x_{d, i}=x m_{d, i}-R / 2 \\
\Delta z_{d, i}=z m_{d, i}-C / 2 \\
x m_{d, i}=\frac{\left(\sum_{r=1}^{R} \sum_{c=1}^{C} y_{i}(r, c, d) \cdot(r-0,5)\right)}{\left(\sum_{r=1}^{R} \sum_{c=1}^{C} y_{i}(r, c, d)\right)} \\
z m_{d, i}=\frac{\left(\sum_{c=1}^{C} \sum_{r=1}^{R} y_{i}(r, c, d) \cdot(c-0,5)\right)}{\left(\sum_{r=1}^{R} \sum_{c=1}^{C} y_{i}(r, c, d)\right)}
\end{array}
$$

A formulação dada pelas Equações 1-8 é um problema 3D e pode ser considerada uma extensão da formulação 2D apresentada por Avriel et al. (1998). Para a formulação 2D foi provado (Avriel et al., 2000) que é um problema NP-Completo tal que o problema 3D também o é. A formulação 3D aqui apresentada é uma contribuição deste trabalho para a literatura, tendo em vista que o modelo proposto (Avriel et al., 1998) não considera a avaliação simultânea do número de movimento e da instabilidade através de uma função objetivo bi-objetivo.

As mesmas desvantagens existentes na formulação 2D também ocorrem com a formulação 3D. Em particular, as formulações demandam um grande número de restrições e variáveis binárias para instâncias cujo porte é próximo de problemas reais. Para ilustrar esta afirmação, a representação de uma solução, através da formulação apresentada pelas Equações 1-8, de uma instância que tenha $D=5, R=6, C=50$, e $N=30$ portos, demandará $D \times R \times C \times N^{3}$ variáveis $x_{i j v}(r, c, d)$, ou seja, 40.050 .000 variáveis $x$, e $D \times R \times C \times N$ variáveis $y_{i}(r, c, d)$, ou seja, 45.000 variáveis $y$, somando um total de 40.545 .000 variáveis para representar uma única solução. Deste modo, o problema assume um tamanho muito grande, tornando proibitivo o uso desta formulação para problemas reais.

Uma alternativa para resolver este problema é empregar uma representação, que também é uma contribuição original deste trabalho, denominada de Representação por Regras, que diminui consideravelmente o número de variáveis. Para se ter uma ideia de quanto é esta redução, a instância que no exemplo acima necessita de 40.545.000 variáveis, na formulação apresentada, necessitará de 29 variáveis ao se utilizar à Representação por Regras, ou seja, o número de variáveis é igual ao número de portos, menos 1. Além de ser compacta, a Representação por Regras tem a vantagem de assegurar que todas as soluções geradas pelo método utilizado sejam factíveis. Ainda que a representação por regras seja empregada, o problema para encontrar a melhor combinação de regras também é um problema combinatório e é necessário empregar heurísticas para encontrar boas soluções também para o PCCTP 3D. Em particular, serão empregados o BS, o AG e o SA.

\section{Representação por Regras}

A principal motivação para empregar a representação por regras é observar o crescimento da quantidade de variáveis necessárias para se representar uma solução no modelo binário conforme cresce o número de portos. Isto ocorre porque o modelo binário apresenta uma descrição detalhada sobre como cada contêiner deve ser posicionado ou movido em cada porto para cada célula $(r, c, d)$ do navio, mas sem garantir a consistência das várias restrições físicas:

- Ao longo dos portos, a quantidade de contêineres que entra no navio é igual a quantidade de contêineres que sai (Equação 2).

- Dois ou mais contêineres não podem ocupar o mesmo espaço (Equação 3).

- Contêineres não podem "flutuar" (Equação 4).

- A remoção de um contêiner em uma pilha só pode ser realizada se não houver outros contêineres impedindo sua retirada naquela pilha ou, se houver contêineres, que estes também sejam retirados (Equação 5).

Para evitar que soluções infactíveis sejam encontradas duas metodologias tradicionais são:

- Construir uma função de penalidade de modo a eliminar ou reduzir a quantidade de soluções infactíveis. 
- Empregar uma estratégia de factibilização tal que soluções infactíveis sempre sejam transformadas em soluções factíveis.

A primeira metodologia encontra problemas na definição dos pesos para a penalização das soluções infactíveis, pois os valores podem ser dependentes para cada instância tratada. A segunda metodologia exige a elaboração de um mapeamento entre soluções infactíveis e factíveis que nem sempre é trivial e é dependente do problema.

Uma alternativa é empregar uma representação que não se preocupa em detalhar a posição do contêiner e sim em uma descrição geral do que deve ocorrer em cada porto com duas das principais operações de um navio: o descarregamento (ao se chegar ao porto) e o carregamento (antes de sair do porto).

Para determinar os efeitos do que irá ocorrer com o arranjo do contêineres no navio, após uma regra de descarregamento ou uma regra de carregamento, será necessário empregar:

- Um vetor de matrizes $B$ que representa o arranjo dos contêineres no navio em cada espaço $(r, c, d)$. Esta matriz será modificada após a tomada de decisões em cada porto e representa uma memória de como as decisões tomadas em portos anteriores podem influenciar no arranjo do navio no porto atual.

- Um processo de simulação que transforma a instrução geral, ou regra, de carregamento ou descarregamento na movimentação de um contêiner específico e, portanto, modifica a matriz B. A partir do processo de simulação é possível extrair informações como o número de movimentos de contêineres ou a medida de instabilidade do navio. O processo de simulação garante que a movimentação do contêiner seja realizada sem que haja violação das restrições físicas descritas anteriormente e, portanto, somente soluções factíveis são consideradas.

A justificativa para empregar o vetor de matrizes $B$ está relacionada com a estrutura celular do navio (ver Figura 1), pois os locais onde os contêineres são alocados estão pré-determinados e devem formar pilhas verticais. Este empilhamento é o que permite usar o vetor de matrizes de ocupação $B$ para fornecer a quantidade de espaços disponíveis e a localização dos contêineres no navio em cada porto. A matriz $B_{d r c}$ representa o estado de uma célula $(r, c, d)$, isto é se $B_{d r c}=0$ significa que a célula que ocupa a baia $d$, a linha $r$ e a coluna $c$ está vazia e se $B_{d r c}=j$ significa que a célula contém um contêiner cujo destino é o porto $j$. Assim, no exemplo da Figura $2(\mathrm{a})$, o elemento $(1,2,2)$ pertence a baia $1\left(B_{1, r, c}\right)$, linha $2(r=2)$ e coluna $2(c=2)$ é igual a 2 significando que neste local existe um contêiner que será descarregado no porto 2 . De modo análogo, o elemento $B_{3,1,1}=5$ significa que esta é uma célula da terceira baia $\left(B_{3, r, c}\right)$, linha $1(r=1)$ e coluna $1(c=1)$ contém um contêiner cujo destino é o porto 5 . Duas observações podem ser feitas: o vetor de matrizes $B_{d r c}$ mostrado na Figura $2(\mathrm{a})$ pode ser associado ao desenho tridimensional da Figura 2(b); a linha 1 representa o topo da pilha de carregamento e a linha 2 representa a parte inferior da pilha.

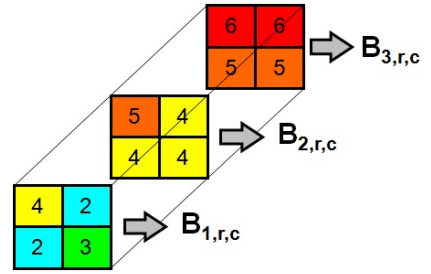

(a) Matriz $B$

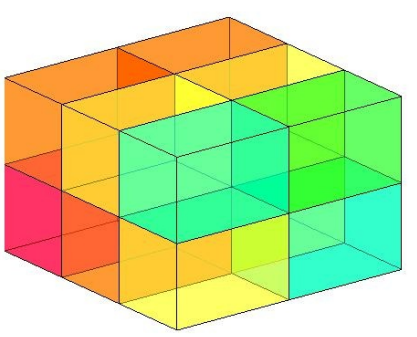

(b) Navio 3D

Figura 2. Como representar a matriz de ocupação $B$ para o navio 3D.

É importante observar que a matriz de carregamento $B$ é modificada em cada porto devido a entrada e saida de novos contêineres em cada porto, pois quando o navio chega num porto $j$ é necessário realizar dois movimentos obrigatórios, a saber: descarregar os contêineres cujo destino é o porto $j$ em questão e carregar os contêineres com destinos aos portos $j+1, j+2, \ldots, N$. Então, para cada porto $j$ foram estabelecidas regras para se fazer o carregamento e descarregamento dos contêineres.

Muitas vezes, para se fazer o descarregamento no porto $j$, de um contêiner cujo destino é o porto $j$, é necessário fazer operações de remanejamento dos contêineres cujo destino são os portos de $j+1$ até $N$, porque a posição que eles ocupam na pilha está acima da posição do contêiner do porto $j$. Veja por exemplo que na matriz $B$ da Figura 2(b), para se descarregar os contêineres do porto 2, será necessário descarregar os contêineres contidos nas células $(1,1,1),(1,2,1)$ e $(1,2,2)$. Assim, com intuito de reduzir o número de remanejamentos, ao se fazer o carregamento de contêineres num dado porto $j$ deve-se levar em conta os 
contêineres que já estão no navio, porque foram embarcados nos portos anteriores (portos de 1 até $j-1$ ) com destino aos portos $j+1$ até $N$. Observe então que existe uma relação íntima entre as operações de carregamento e descarregamento, tendo em vista que, a forma como é realizado o carregamento num porto $j$ vai influenciar no descarregamento a ser efetuado nos demais portos (portos de $j+1$ até $N$ ). Portanto, para reduzir as operações de remanejamento é necessário estabelecer regras para o carregamento e descarregamento de contêineres em cada porto que leve em conta esta relação. Para tanto foram criadas doze regras, sendo seis para o carregamento (Rc1, Rc2, Rc3, Rc4, Rc5, Rc6) e duas para o descarregamento (Rd1, Rd2). A combinação de uma regra de carregamento com uma de descarregamento fornece a regra $k$ para o porto $j$ tal como dado na Tabela 1.

Tabela 1. Regras produzidas pela combinação de regras de carregamento e descarregamento.

\begin{tabular}{ccc}
\hline Regras de Carregamento & Regras de Descarregamento & Regras \\
\hline \multirow{2}{*}{ Rc1 } & $\mathrm{Rd} 1$ & 1 \\
& $\mathrm{Rd} 2$ & 2 \\
\hline \multirow{2}{*}{$\mathrm{Rc} 2$} & $\mathrm{Rd} 1$ & 3 \\
& $\mathrm{Rd} 2$ & 4 \\
\hline \multirow{2}{*}{$\mathrm{Rc} 3$} & $\mathrm{Rd} 1$ & 5 \\
& $\mathrm{Rd} 2$ & 6 \\
\hline \multirow{2}{*}{$\mathrm{Rc} 4$} & $\mathrm{Rd} 1$ & 7 \\
& $\mathrm{Rd} 2$ & 8 \\
\hline \multirow{2}{*}{$\mathrm{Rc} 5$} & $\mathrm{Rd} 1$ & 9 \\
& $\mathrm{Rd} 2$ & 10 \\
\hline \multirow{2}{*}{$\mathrm{Rc} 6$} & $\mathrm{Rd} 1$ & 11 \\
& $\mathrm{Rd} 2$ & 12 \\
\hline
\end{tabular}

Observe na Tabela 1 que a regra 2 foi obtida utilizando a regra Rc1 para o carregamento dos contêineres e a regra Rd2 para o descarregamento. Isto foi feito com objetivo de se obter uma representação ainda mais compacta da solução.

A aplicação destas regras em cada porto $j$ vai atualizar a Matriz de Ocupação $B_{r c d}$ no porto $j$. Vale lembrar que inicialmente a matriz $B$ está com todos seus elementos iguais a zero e ela começa a ser preenchida no porto 1. Para melhor ilustrar a utilização das regras, será utilizada a matriz de transporte $T$, que fornece a quantidade de contêineres que devem ser embarcados em cada porto $i$ com destino a cada porto $j$, tal como dado na Figura 3. A capacidade e as dimensões adotadas para o navio são as mesmas apresentadas na Figura $2(\mathrm{a})$.

\begin{tabular}{|l|c|c|c|c|}
\hline & D2 & D3 & D4 & D5 \\
\hline O1 & 2 & 5 & 0 & 0 \\
\hline O2 & 0 & 2 & 3 & 1 \\
\hline O3 & 0 & 0 & 2 & 2 \\
\hline O4 & 0 & 0 & 0 & 1 \\
\hline
\end{tabular}

Figura 3. Matriz de transporte $T$.

Para fins de clareza na descrição do funcionamento das regras será suposto que o navio está no porto 1 para as regras de carregamento e porto 2 para as regras de descarregamento.

\subsection{Regras de carregamento}

- Regra Rc1: Esta regra preenche a matriz de ocupação $B$ (no porto $p$ ) por baia, começando da última até a primeira linha, da esquerda para a direita, colocando na parte inferior da pilha de cada baia as cargas cujo destino é mais distante. A Aplicação desta regra considerando a matriz $T$ da Figura 3 e que o navio se encontra no porto 1 , resultará na matriz $B$ da Figura 4(a).

- Regra Rc2: Esta regra preenche a matriz de ocupação $B$ (no porto $p$ ) por linha começando da última até a primeira baia, da esquerda para a direita, colocando na parte inferior da pilha de cada linha as cargas cujo destino é mais distante. A Aplicação desta regra considerando a matriz $T$ da Figura 3 e que o navio se encontra no porto 2, resultará na matriz $B$ da Figura 4(b). 
- Regra Rc3: Esta regra é o espelho da regra Rc1, isto é, no porto $p$ a matriz de ocupação $B$ será preenchida por baia, da direita para a esquerda, colocando na parte inferior da pilha de cada baia as cargas cujo destino é mais distante. A Figura 4(c) ilustra o resultado obtido com esta regra considerando a matriz $T$ da Figura 3 e o navio no porto 2.

- Regra Rc4: Esta regra é o espelho da regra Rc2, isto é, no porto $p$ a matriz de ocupação $B$ será preenchida por linha, da direita para a esquerda, colocando na parte inferior da pilha de cada baia as cargas cujo destino é mais distante. A Figura 4(d) ilustra o resultado obtido com esta regra considerando a matriz $T$ da Figura 3 e que o navio no porto 2.

- Regra Rc5: Nesta regra o preenchimento da matriz de ocupação $B$ em um porto $p$ é feito por baia até uma linha $p$, começando pela coluna da esquerda e colocando-se em primeiro lugar os contêineres cujos destinos são os portos mais distantes. A linha $p$ é calculada pegando-se a função teto, resultante da soma do total de contêineres que estavam no navio e foram embarcados nos portos anteriores; menos a quantidade de contêineres que serão desembarcados em $p$, mais a quantidade de contêineres que a serem embarcados em $p$, dividido pelo número de baias da matriz $B$. O número desta linha pode ser calculado sobre a matriz de transporte $T$, através da Equação (9).

$$
\theta_{p}=\left\lceil\frac{\sum_{i=1}^{p} \sum_{j=p+1}^{N} T_{i j}}{D \times C}\right\rceil
$$

onde: $p$ é o porto atual do navio, $T_{i j}$ é o número total de contêineres a serem embarcados no porto $i$ com destino ao porto $j$ e $D$ é o número total de baias da matriz $B$ de ocupação do navio.

Supondo que a matriz de ocupação $B$ quando o navio chega ao porto 2 seja a da Figura 4(b). Depois, os contêineres cujo destino é o porto 2 são descarregados e o navio move-se para o porto 3 , e a regra de carregamento Rc5 é aplicada resultando na matriz de ocupação na Figura 4(e).

- Regra Rc6: Esta regra também é o espelho da regra Rc5. Ela faz o preenchimento da matriz de ocupação $B$ em um porto $p$ preenchendo cada coluna até a linha $p$, começando pela coluna da direita e colocandose em primeiro lugar os contêineres cujos destinos são os portos mais distantes. A linha $p$ é calculada pela Equação (9), de modo idêntico ao calculado na regra Rc5. Depois, os contêineres cujo destino é o porto 2 são descarregados e o navio move-se para o porto 3 , e a regra de carregamento Rc5 é aplicada resultando na matriz de ocupação da Figura 4(f).

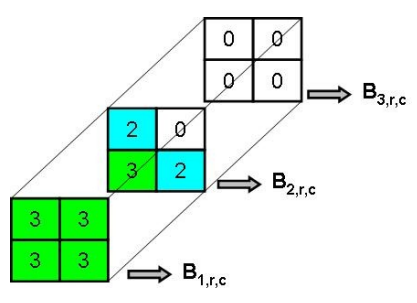

(a) Regra Rc1

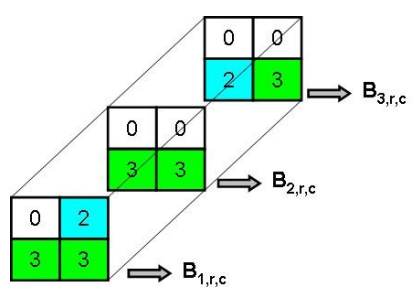

(d) Regra Rc4

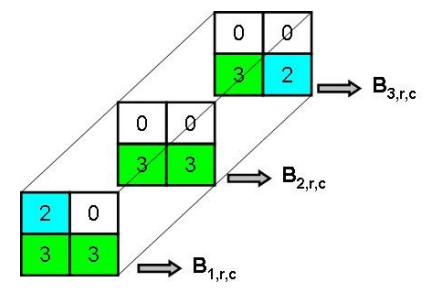

(b) Regra Rc2

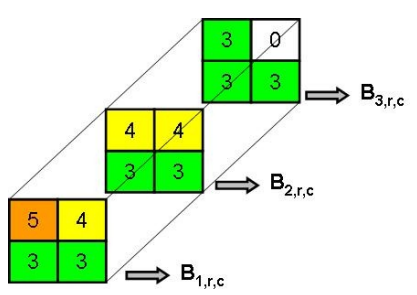

(e) Regra Rc5

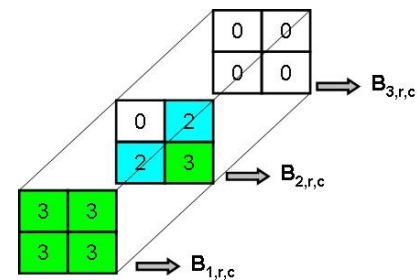

(c) Regra Rc3

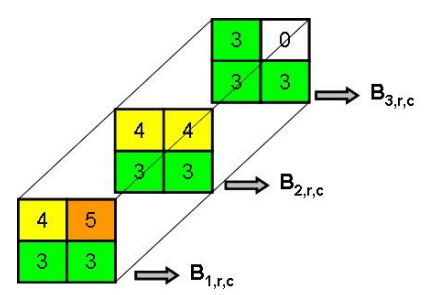

(f) Regra Rc6

Figura 4. A matriz de estado $B$ associada a arrumação dos contêineres no navio no porto 2. 


\subsection{Regras de descarregamento}

- Regra Rd1: Nesta regra quando o navio chega a um porto $p$, são removidos todos os contêineres cujo destino é $p$ e todos os contêineres que estão acima dos contêineres do porto $p$ e cujos destinos são os portos $p+j$, para $j=1, \cdots, N$ tal que $(p+j) \leq N$. Suponha por exemplo que ao se chegar no porto 2 a matriz de Ocupação $B$ seja a dada na Figura $5($ a). De acordo com esta regra a matriz $B$ ficaria como mostrada na Figura 5(b). Além disto, após a aplicação da regra a matriz de transporte $T$ é atualizada como na Figura 5(c).

- Regra Rd2: Nesta regra quando o navio chega ao porto $p$, todos os contêineres são removidos para permitir que todas as pilhas sejam reordenadas por alguma regra de carregamento a ser aplicada posteriormente. Assim, os contêineres removidos com destinos a portos além do porto 2 são contabilizados na matriz de transporte $T$, gerando a nova matriz de transporte tal como dado na Figura $5(\mathrm{~d})$.

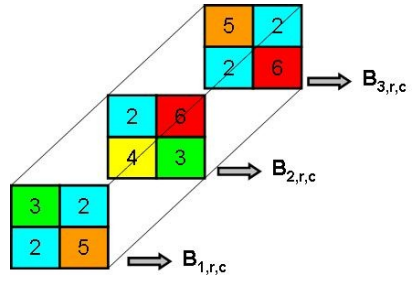

(a) Antes da Regra Rd1

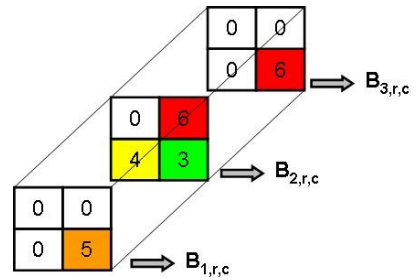

(b) Depois da Regra Rd1

\begin{tabular}{|c|c|c|c|c|c|c|c|c|c|}
\hline & D2 D3 & D4 & D5 & D6 & & & 33 & D5 & D6 \\
\hline & \begin{tabular}{l|l}
$+0+3$ \\
\end{tabular} & +0 & +2 & +0 & 02 & $+0+$ & \begin{tabular}{l|l}
+2 & +
\end{tabular} & +3 & +1 \\
\hline
\end{tabular}
$\operatorname{Rd} 1$ $\operatorname{Rd} 2$

Figura 5. A matriz de estado $B$ associada a arrumação dos contêineres no navio no porto 2 .

\subsection{Avaliação do número de movimentos e instabilidade}

As regras, que são combinações de regras de carregamento e descarregamento ilustradas nas seções anteriores, podem fornecer o número de movimentos realizados e a instabilidade do navio em um dado porto. Assim, após a aplicação de uma sequência de regras em um navio até um certo porto é possível determinar o número de movimentos e a instabilidade do navio até aquele porto. Para tanto, é necessário empregar um procedimento de simulação que transforma as regras em movimentos dos contêineres dentro do navio. Tal procedimento de simulação é dado na Figura 6.

Os símbolos e funções empregados no procedimento da Figura 6 são descritos a seguir:

$p$ - Variável contadora, que indica o porto atual da simulação.

$N$ - Número total de portos.

$S$ - Vetor tal que o elemento $s(i)$ contém a regra $k$, a ser aplicada no porto $i$ e modificar a matriz $B$ adequadamente.

Nmov - Número de movimentos realizados para carregar ou descarregar o navio ao longo dos $N$ portos.

$B$ - Matriz de ocupação que indica o estado do navio em cada porto $i$.

$r c$ - Variável que contém o nome da regra de carregamento a ser aplicada.

rd - Variável que contém o nome da regra de descarregamento a ser aplicada.

inicializar - Função que preenche a matriz $B$, com valores iguais a zero.

extrairRegras - Função que define a correspondência entre a regra $k$, contida em $s(i)$, com as regras de descarregamento e carregamento a serem armazenadas nas variáveis $r d$ e $r c$, respectivamente.

descarregar - Função que aplica a regra de descarregamento contida em $r d$ na matriz $B$ no porto $i$, e retorna o número de movimentos realizados, e $B$ e $T$ atualizadas.

carregar - Função que aplica a regra de carregamento contida em $r c$, na matriz $B$, no porto $i$ e retorna o número de movimentos realizados e $B$ e $T$ atualizadas. 


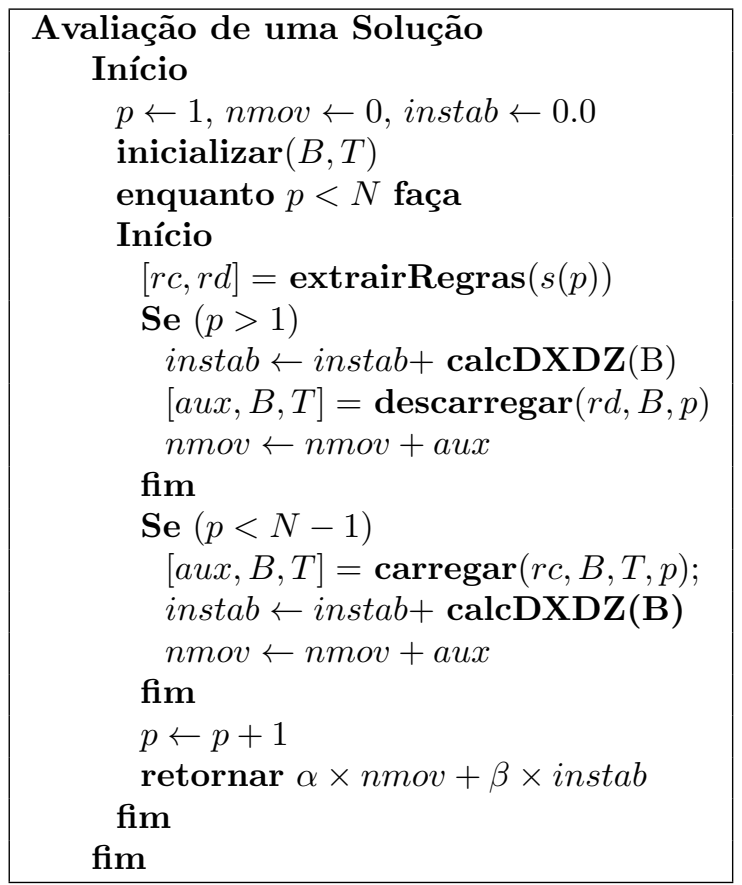

Figura 6. Detalhamento da avaliação de uma solução do PCCTP 3D através de simulação.

calcDXDZ - Função que realiza o cálculo da distância entre o centro de massa e o centro geométrico por baia $d$, para o navio, antes de ser descarregado e depois de ser carregado em cada porto $p$.

As funções carregar e descarregar, empregadas no procedimento da Figura 6, utilizam as regras descritas nas Seções 3.1 e 3.2, respectivamente, e fornecem o número de movimentos realizados (dado em aux). A instabilidade do navio é calculada através da função calcDXDZ. Para melhor ilustrar o funcionamento da função calcDXDZ, suponha que o navio tenha o arranjo de contêineres, tal como ilustrado na Figura 7.
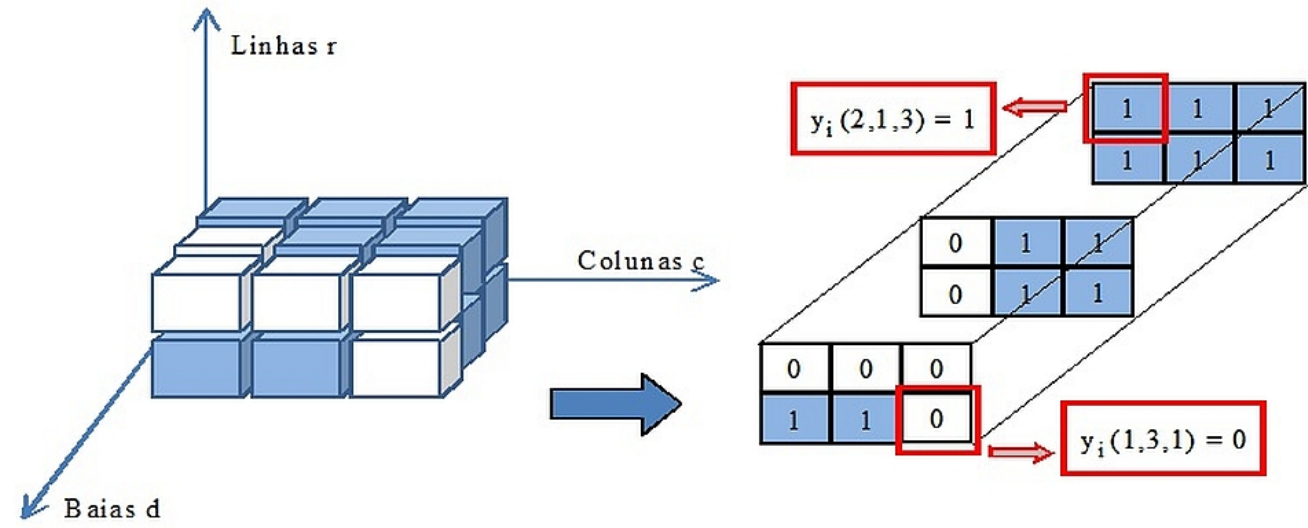

Figura 7. Ocupação do navio porta-contêiner e sua matriz de estado $B$ correspondente.

Define-se $x_{3} \mathrm{~cm}_{3}$ como a coordenada do centro de massa relativa às linhas da baia e $z \mathrm{~cm}_{3}$ a coordenada do centro de massa relativa às colunas da baia 3 . Os valores $x \mathrm{~cm}_{3}$ e $z \mathrm{~cm}_{3}$ podem ser calculados, usando a Equação 8 e a informação contida na Figura 7, como dado na Figura 8.

$$
\begin{array}{r}
x c m_{3}=\frac{(2 \times 0,5+2 \times 1,5+2 \times 2,5)}{(2+2+2)}=\frac{9}{6}=1,5 \\
z c m_{3}=\frac{(3 \times 0,5+3 \times 1,5)}{(6)}=\frac{6}{6}=1,0
\end{array}
$$

Cálculos semelhantes podem ser realizados para a baia 2, para a obtenção de $x c m_{2}$ e $z c m_{2}$ empregando-se a Equação 8 e a informação contida na Figura 9. 


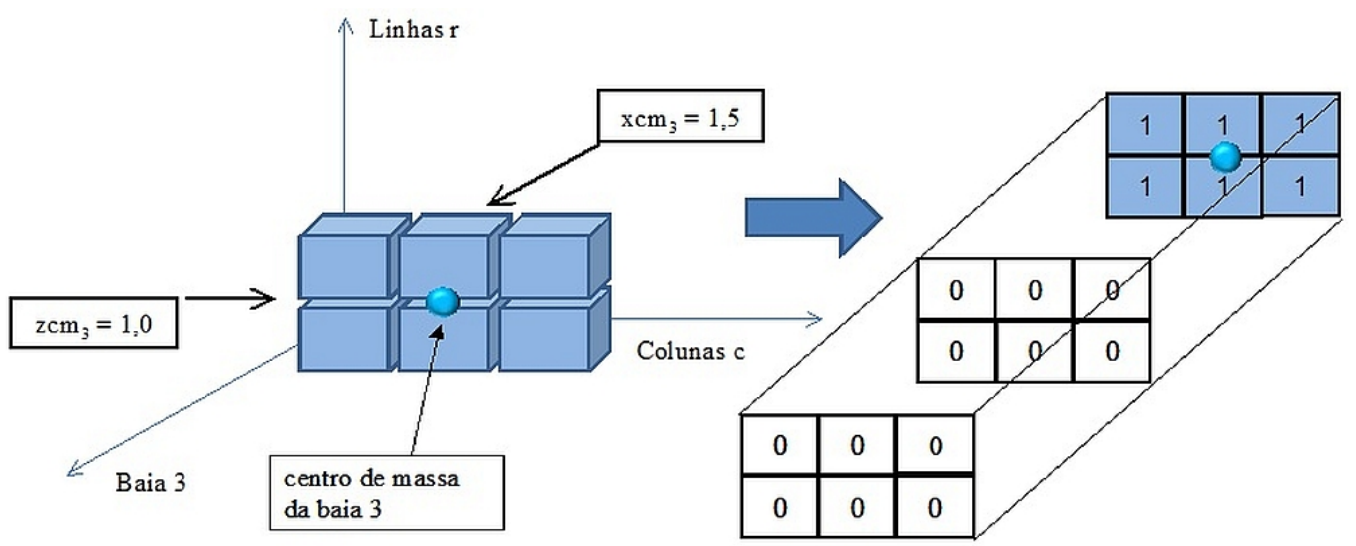

Figura 8. Cálculo das coordenadas do centro de massa da baia 3.

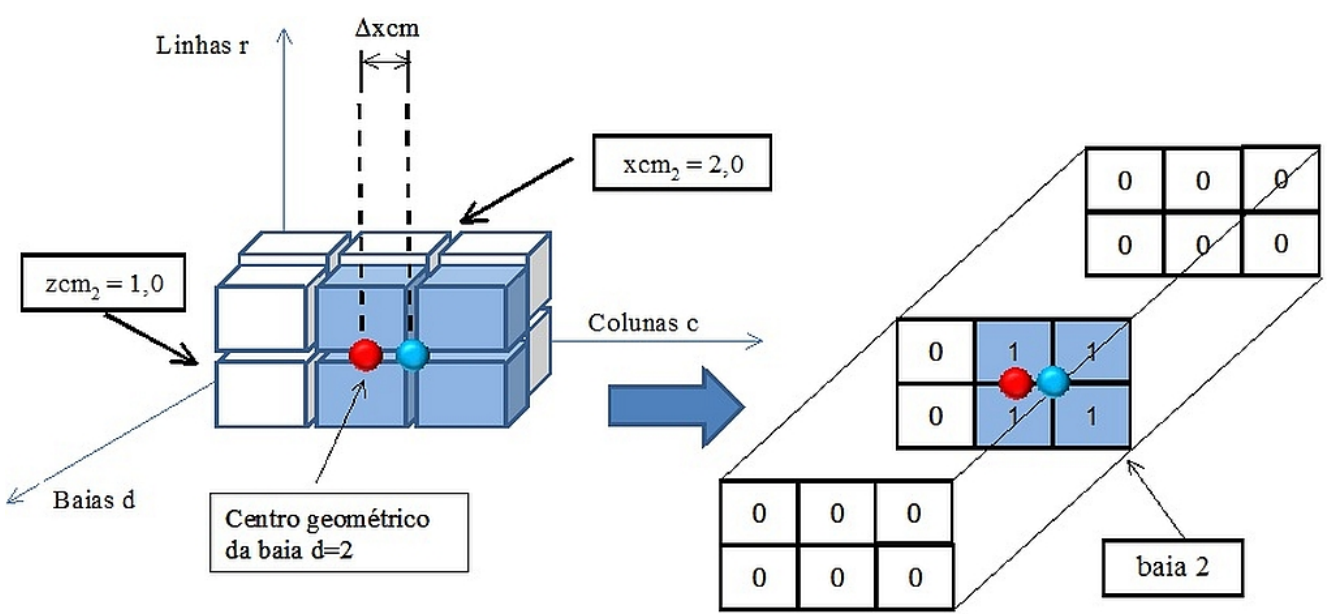

Figura 9. Cálculo das coordenadas do centro de massa da baia 2.

$$
\begin{array}{r}
x c m_{2}=\frac{(0 \times 0,5+2 \times 1,5+2 \times 2,5)}{(0+2+2)}=\frac{8}{4}=2,0 \\
z c m_{2}=\frac{(2 \times 0,5+2 \times 1,5)}{(4)}=\frac{4}{4}=1,0
\end{array}
$$

Finalmente, para a baia 1 , as coordenadas $x c m_{1}$ e $z c m_{1}$ podem ser calculadas, usando-se a Equação 8 e a Figura 10, como dado a seguir.

$$
\begin{array}{r}
x c m_{1}=\frac{(1 \times 0,5+1 \times 1,5+0 \times 2,5)}{(1+1+0)}=\frac{2}{2}=1,0 \\
z c m_{1}=\frac{(2 \times 0,5+0 \times 1,5)}{(2+0)}=\frac{1}{2}=0,5
\end{array}
$$

De posse dos cálculos anteriores, é possível obter a medida de instabilidade para o navio, empregando a Equação 8 e a configuração de contêineres apresentada na Figura 7 e como dado a seguir.

$$
\begin{array}{r}
\phi_{2}(y)=\left[(1,5-1,5)^{2}+(2,0-1,5)^{2}+(1,0-1,5)^{2}\right]+ \\
{\left[(1,0-1,0)^{2}+(1,0-1,0)^{2}+(0,5-1,0)^{2}\right]=0,75}
\end{array}
$$

\subsection{Avaliação de uma solução por regras (vetor de regras)}

Suponha que as dimensões do navio são tais como a que são apresentadas na Figura 2(a), isto é, 3 baias, 2 linhas e 2 colunas. Os dados da matriz de transporte $T$ são dados na Tabela 2.

Cada elemento $T(i, j)=n c$ da Tabela 2 indica que $n c$ contêineres deverão embarcar no porto (linha) $i$ para o porto (coluna) $j+1$. Por exemplo, o elemento $T(2,3)=3$ significa que, no porto 2,3 contêineres, cujo destino é o porto 4 , deverão embarcar. 


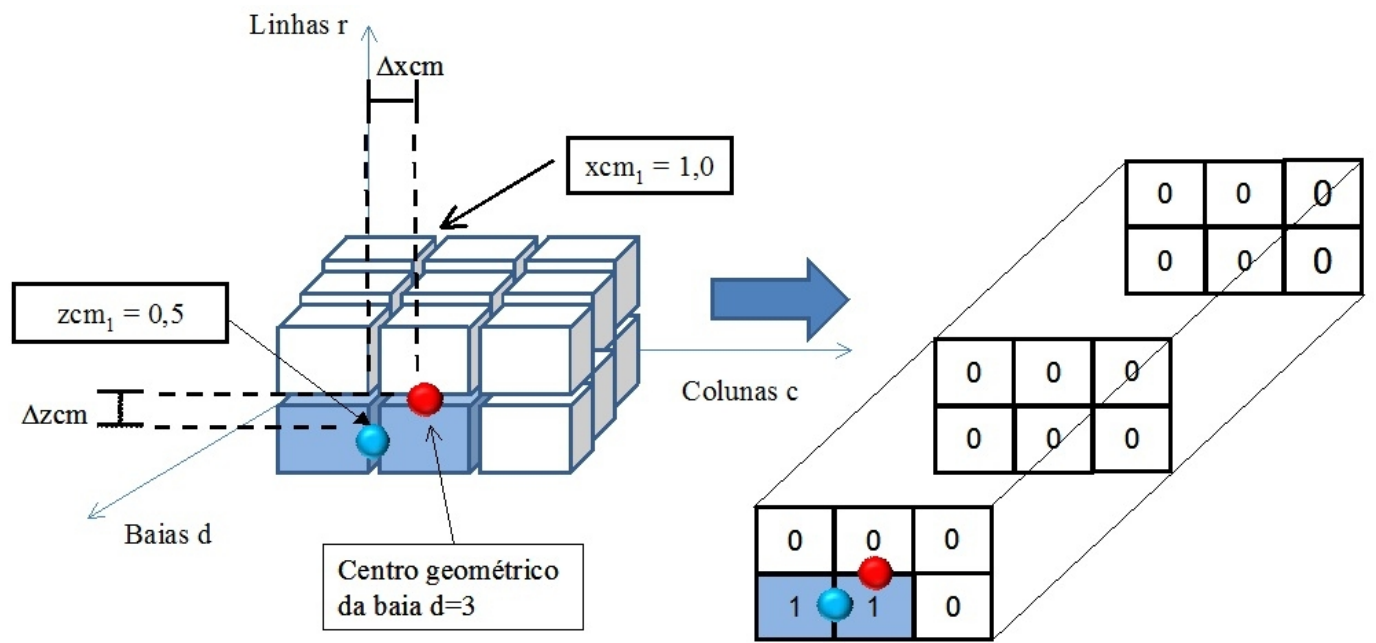

Figura 10. Cálculo das coordenadas do centro de massa da baia 1.

Tabela 2. Dados para a matriz de transporte $T$.

\begin{tabular}{c|c|c|c}
\hline & $D 2$ & $D 3$ & $D 4$ \\
\hline O1 & 2 & 4 & 3 \\
\hline O2 & 0 & 1 & 3 \\
\hline O3 & 0 & 0 & 4 \\
\hline
\end{tabular}

Agora, suponha que um vetor $v=[153]$ é proposto para este problema e que deseja-se avaliar o mesmo em termos do número de movimentos e da medida de instabilidade a partir do procedimento de simulação descrito na Figura 6. Neste caso, tal procedimento funcionaria tal como descrito a seguir.

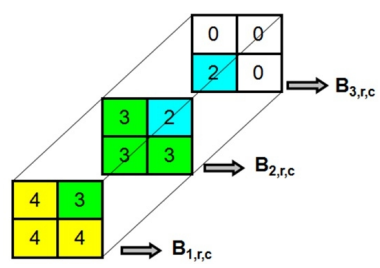

(a) $B$ após LR1

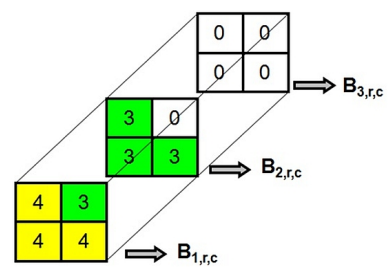

(b) $B$ após UR1

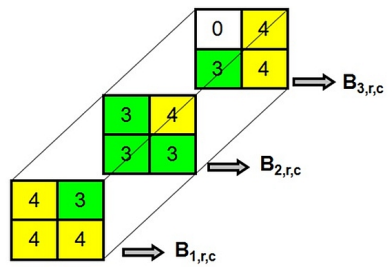

(c) $B$ após LR3

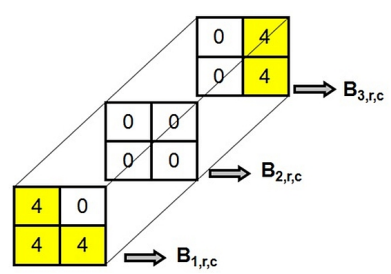

(d) $B$ após UR1

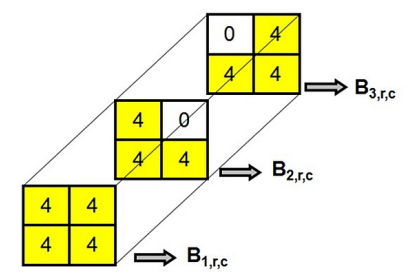

(e) $B$ após LR2

Figura 11. A matriz de estado $B$ associada a arrumação dos contêineres no navio após a aplicação das regras.

- Porto 1 - Carregamento:

De acordo com o vetor de solução $v, v[1]=1$, ou seja, para o porto 1 a regra 1 deve ser aplicada tal que, de acordo com a Tabela 1, a regra de carregamento $L R 1$ deve ser usada como ilustrado na Figura 11(a). Após esta operação, as variáveis que medem o número de movimentos e a instabilidade terão os seguintes valores:

- instab $=2 \times(0.5)^{2}=0.5$,

- nmov $=9$. 


\section{- Porto 2 - Descarregamento:}

De acordo com o vetor de solução $v, v[2]=5$, ou seja, para o porto 2 a regra 5 deve ser aplicada tal que, de acordo com a Tabela 1, a regra de carregamento $U R 1$ deve ser usada como ilustrado na Figura 11(b).

Após esta operação, as variáveis que medem o número de movimentos e a instabilidade terão os seguintes valores:

- instab $=0,5+\left(2 \times 0,166^{2}+2 \times 1,0\right)=0,5+(0,055+2,0)=2,555$,

$-n m o v=9+2=11$.

- Porto 2 - Carregamento:

De acordo com o vetor de solução $v, v[2]=5$, ou seja, para o porto 2 a regra 5 deve ser aplicada tal que, de acordo com a Tabela 1, a regra de carregamento LR3 deve ser usada como ilustrado na Figura 11(c). Após esta operação, as variáveis que medem o número de movimentos e a instabilidade terão os seguintes valores:

$$
\begin{aligned}
& - \text { instab }=2,555+\left(2 \times 0,166^{2}\right)=2,555+0,055=2,610, \\
& - \text { nmov }=11+4=15 .
\end{aligned}
$$

- Porto 3 - Descarregamento:

De acordo com o vetor de solução $v, v[3]=3$, ou seja, para o porto 3 a regra 3 deve ser aplicada tal que, de acordo com a Tabela 1, a regra de carregamento $U R 1$ deve ser usada como ilustrado na Figura 11(d).

Após esta operação, as variáveis que medem o número de movimentos e a instabilidade terão os seguintes valores:

- instab $=2,610+\left(2 \times 0,166^{2}+2 \times 1,0+0,5^{2}\right)=4,91$,

- nmov $=15+6=21$.

- Porto 3 - Carregamento:

De acordo com o vetor de solução $v, v[3]=3$, ou seja, para o porto 3 a regra 3 deve ser aplicada tal que, de acordo com a Tabela 1, a regra de carregamento LR2 deve ser usada como ilustrado na Figura 11(e).

Após esta operação, as variáveis que medem o número de movimentos e a instabilidade terão os seguintes valores:

- instab $=4,91+\left(2 \times 0,166^{2}+2 \times 0,166^{2}\right)=5,57$,

- nmov $=21+5=26$.

- Porto 4 - Descarregamento:

Para o último porto, existe apenas uma opção que é o descarregamento de contêineres do navio, e esta ação produz um número de movimentos igual a quantidade de contêineres cujo destino é o porto 4 . Neste caso, os novos valores de instabilidade e número de movimentos serão:

$$
\text { - instab }=4,91+\left(2 \times 0,166^{2}+2 \times 0,166^{2}\right)=5,57,
$$$$
- \text { nmov }=21+5=26 \text {. }
$$

A avaliação de um solução representada por regras, nos moldes do que foi descrito anteriormente, será empregada pelas meta-heurísticas e heurísticas descritas nas próximas seções. Tendo em vista que a principal contribuição do trabalho é o emprego da representação por regras e seu acoplamento com metaheurísticas, não foram realizados estudos detalhados sobre os melhores parâmetros a serem empregados por cada método. Assim, foi escolhido para cada método as opções mais rápidas e fáceis de serem codificadas, pois o propósito é mostrar que mesmo nestes casos, um resultado satisfatório pode ser obtido em pequeno tempo computacional. Deste modo, por exemplo, foi escolhido para o AG o método da roleta devido a sua facilidade de implementação. 


\section{Abordagem via Algoritmo Genético, Simulated Annealing e Beam Search}

Um Algoritmo Genético mantém uma população de indivíduos $A(t)=\left\{A_{1 t}, \cdots, A_{n t}\right\}$ na iteração (geração) $t$ e cada indivíduo representa um candidato à solução do problema em questão. Na implementação computacional aqui utilizada, o indivíduo é representado através da coluna $A_{i}$, da matriz $A$ (Holland, 1975; Michalewicz, 1996). Cada solução $A_{i t}$ é avaliada e produz alguma medida de adaptação, ou fitness, então, uma nova população é formada na iteração $t+1$ pela seleção dos indivíduos mais adaptados. Alguns indivíduos da população são submetidos a um processo de alteração por meio de operadores genéticos para formar novas soluções. Existem transformações unárias $m_{i}$ (mutação) que criam novos indivíduos através de pequenas modificações de atributos em um indivíduo $\left(m_{i}: A_{i} \rightarrow A_{i}\right)$, e transformações de ordem superior $c_{j}($ crossover $)$, que criam novos indivíduos através da combinação de dois ou mais indivíduos $\left(c_{j}: A_{j} \ldots A_{k} \rightarrow A_{j}\right)$. Após um número de gerações, a condição de parada deve ser atendida, seja porque existe, na população, um indivíduo que represente uma solução aceitável para o problema, seja porque o número máximo de gerações foi atingido.

O Algoritmo Genético deste capítulo combina a representação de soluções com o esquema de regras descrito na Seção 3. Com isto os indivíduos são codificados em uma notação compacta que sempre fornece soluções factíveis. Esta estratégia permite o tratamento de problemas de maior porte em tempo computacional razoável. Maiores detalhes sobre o Algoritmo Genético para o PCCTP 3D é dado em Azevedo et al. (2011b).

A meta-heurística Simulated Annealing (SA) é um algoritmo de busca local capaz de escapar de ótimos locais, permitindo movimentos para soluções com valor da função objetivo piores que o valor da função objetivo da solução corrente. A facilidade de implementação, as propriedades de convergência e o uso de movimentos de "subida" (hill-climbing) com o objetivo de escapar de ótimos locais contribuíram para que se tornasse uma técnica muito popular em Otimização Combinatória (Henderson et al., 2003). As origens do algoritmo se fundamentam na Mecânica Estatística, a idéia da meta-heurística tendo sido inspirada no processo de recozimento de metais e vidro, o qual assume uma configuração de baixa energia quando inicialmente aquecido e então resfriado lentamente (Aguilera et al., 2008). O algoritmo SA foi inicialmente apresentado como um algoritmo de busca para problemas de Otimização Combinatória em Kirkpatrick et al. (1983). Detalhes sobre o SA para o PCCTP 3D são fornecidos em Azevedo et al. (2011a).

O algoritmo do Beam Search (BS) é um método do tipo Enumeração Implícita para resolver problemas de Otimização Combinatória (Sabuncuoglu \& Baviz, 1999; Croce \& T'Kindt, 2002; Fox, 1983; Valente et al., 2005). Pode-se dizer que ele é uma adaptação do método de Branch and Bound onde somente os nós mais promissores de cada nível da árvore de decisões (atribuições) são guardados na memória para serem visitados, enquanto que os demais nós são descartados permanentemente.

Como uma grande parte dos nós da árvore de atribuições é descartada, sem ser analisado, o tempo de execução do BS é polinomial com relação ao tamanho do problema. Em resumo pode-se dizer que o BS é uma técnica de busca em árvore de decisão que em cada nível da árvore é analisado um número fixo de nós e, por conseguinte, um número fixo de soluções. Maiores detalhes acerca da implementação do BS para o problema PCCTP 3D podem ser encontrados em Azevedo et al. (2012).

\section{Resultados Obtidos}

Para testar o algoritmo desenvolvido, foram geradas automática e aleatoriamente 15 instâncias ${ }^{1}$. Estas instâncias são classificadas de acordo com o número de portos e o tipo da matriz de transporte. Para cada instância é gerada uma matriz de transporte $T$, tal que a capacidade do navio não será excedida em nenhum porto, isto é, o valor de $p$ dado pela Equação 10 deve ser menor ou igual a $D \times R \times C$ para todo porto $p$, isto porque a matriz de transporte é factível desde que a Equação 10 seja satisfeita.

$$
\sum_{i=1}^{p} \sum_{j=p+1}^{N} \leq D \times R \times C, \forall p=1, \cdots, N .
$$

De acordo com Avriel et al. (1998) podem ser gerados três tipos de matriz de transporte: 1-Mista, 2Longa distância e 3-Curta distância. Uma matriz do tipo 3 se refere ao transporte de contêineres que vão percorrer poucos portos antes de serem desembarcados. Já uma matriz do tipo 2 se refere a contêineres que vão percorrer muitos portos antes de serem desembarcados. Uma matriz do tipo mista combina os dois tipos anteriores. As instâncias foram classificadas de acordo com a quantidade de portos a serem percorridos, o tipo da matriz de transporte e a capacidade do navio. Neste trabalho foi suposto um navio com as seguintes dimensões $(D \times R \times C): 5 \times 6 \times 50$, resultando na seguinte capacidade máxima: 1500 contêineres.

1 As instâncias utilizadas nos testes estão disponíveis em: https://sites.google.com/site/3dcontainershipproject/home. 
As Tabelas 3, 4 e 5 mostram os resultados obtidos com a melhor solução após 5 rodadas de AG, 5 rodadas de SA e 1 rodada do BS para as 15 instâncias, respectivamente. As tabelas possuem as colunas relacionadas a seguir: $I$ : o número da instância; $M$ : o tipo da matriz de transporte; $N$ : o número de portos; $N M i n$ : o número mínimo de movimentos a serem realizados com os contêineres; F.O.1: os valores da função objetivo em termos do número total de movimentos realizados com os contêineres até a chegada no último porto (como dado pela Equação 7); F.O.2: os valores de instabilidade de acordo com o arranjo de contêineres e com a Equação 8; e T: tempo computacional em segundos.

Tabela 3. Resultados do AG para dois pares de valores de $\alpha$ e $\beta$.

\begin{tabular}{ccccrrrrrr}
\hline \multirow{2}{*}{$\mathbf{I}$} & \multirow{N}{*}{} & $\mathbf{M}$ & \multirow{2}{*}{$\mathbf{N m i n}$} & \multicolumn{2}{c}{$\alpha=1 \mathbf{e} \beta=0$} & \multicolumn{2}{c}{$\alpha=0 \mathbf{e} \beta=1$} \\
\cline { 5 - 10 } & & & & $\mathbf{F O 1}$ & $\mathbf{F O 2}$ & $\mathbf{T}$ & $\mathbf{F O 1}$ & $\mathbf{F O 2}$ & $\mathbf{T}$ \\
\hline 1 & 10 & 1 & 6994 & 7072 & 564,45 & 146 & 10106 & 39,12 & 152 \\
2 & 10 & 2 & 4172 & 4214 & 542,88 & 139 & 6374 & 13,88 & 145 \\
3 & 10 & 3 & 17060 & 17116 & 566,89 & 149 & 18018 & 63,31 & 153 \\
4 & 15 & 1 & 9974 & 10584 & 237,62 & 234 & 12766 & 30,01 & 241 \\
5 & 15 & 2 & 4824 & 5030 & 514,54 & 210 & 9078 & 36,12 & 232 \\
6 & 15 & 3 & 24902 & 25046 & 578,56 & 221 & 25844 & 113,35 & 258 \\
7 & 20 & 1 & 10262 & 10802 & 229,31 & 300 & 14658 & 77,21 & 360 \\
8 & 20 & 2 & 4982 & 5500 & 439,95 & 277 & 9784 & 17,13 & 317 \\
9 & 20 & 3 & 32602 & 32638 & 792,20 & 279 & 33700 & 488,88 & 330 \\
10 & 25 & 1 & 11014 & 11848 & 252,34 & 353 & 17302 & 19,02 & 558 \\
11 & 25 & 2 & 5002 & 5466 & 573,02 & 322 & 10564 & 98,93 & 440 \\
12 & 25 & 3 & 43722 & 44082 & 659,70 & 387 & 44964 & 161,29 & 455 \\
13 & 30 & 1 & 11082 & 12580 & 188,38 & 476 & 16556 & 32,45 & 513 \\
14 & 30 & 2 & 4720 & 5312 & 156,04 & 381 & 7098 & 10,43 & 402 \\
15 & 30 & 3 & 53592 & 54398 & 427,08 & 461 & 56290 & 166,05 & 472 \\
\hline
\end{tabular}

Tabela 4. Resultados do SA para dois pares de valores de $\alpha$ e $\beta$.

\begin{tabular}{rrrrrrrrrr}
\hline \multirow{2}{*}{$\mathbf{I}$} & $\mathbf{N}$ & $\mathbf{M}$ & $\mathbf{N}$ Nmin & \multicolumn{3}{c}{$\alpha=1 \mathbf{e} \beta=0$} & \multicolumn{3}{c}{$\alpha=0 \mathbf{e} \beta=1$} \\
\cline { 5 - 10 } & & & & $\mathbf{F O 1}$ & $\mathbf{F O 2}$ & $\mathbf{T}$ & $\mathbf{F O 1}$ & $\mathbf{F O 2}$ & $\mathbf{T}$ \\
\hline 1 & 10 & 1 & 6994 & 7068 & 507,14 & 1654 & 11122 & 14,20 & 1385 \\
2 & 10 & 2 & 4172 & 4208 & 492,45 & 1531 & 6672 & 11,55 & 1318 \\
3 & 10 & 3 & 17060 & 17088 & 583,18 & 1431 & 17554 & 92,85 & 1094 \\
4 & 15 & 1 & 9974 & 10420 & 221,40 & 2054 & 13910 & 30,10 & 1850 \\
5 & 15 & 2 & 4824 & 5082 & 532,23 & 2044 & 8098 & 34,49 & 1761 \\
6 & 15 & 3 & 24902 & 24998 & 595,22 & 1887 & 25896 & 154,01 & 1607 \\
7 & 20 & 1 & 10262 & 10749 & 202,09 & 2485 & 16396 & 13,60 & 2286 \\
8 & 20 & 2 & 4982 & 5458 & 451,71 & 2482 & 10022 & 14,57 & 2258 \\
9 & 20 & 3 & 32602 & 32632 & 1000,11 & 2554 & 33378 & 575,36 & 2299 \\
10 & 25 & 1 & 11014 & 11590 & 200,89 & 2866 & 14674 & 12,69 & 2767 \\
11 & 25 & 2 & 5002 & 5430 & 561,69 & 2495 & 9456 & 106,50 & 2499 \\
12 & 25 & 3 & 43722 & 44078 & 543,47 & 2624 & 45120 & 218,75 & 2727 \\
13 & 30 & 1 & 11082 & 12146 & 183,97 & 3158 & 18180 & 17,99 & 3158 \\
14 & 30 & 2 & 4720 & 5246 & 168,66 & 2687 & 8604 & 13,99 & 2708 \\
15 & 30 & 3 & 53592 & 54454 & 519,62 & 3076 & 55754 & 299,82 & 3082 \\
\hline
\end{tabular}

Note-se que os valores de F.O.1, F.O.2 e $T$ são apresentados para dois pares de $\alpha$ e $\beta$ : $(\alpha=1, \beta=0)$ e $(\alpha=0, \beta=1)$. Note-se ainda que os resultados apresentados para $(\alpha=1, \beta=0)$ correspondem à melhor solução obtida com o objetivo de minimizar o número de movimentos para cada instância e que para 7 instâncias o número de movimentos $(F O 1)$ encontrado é até $2 \%$ maior que o número mínimo $(N m i n)$, para 5 instâncias o número mínimo é até $10 \%$ maior e apenas 3 instâncias até $14 \%$. Já para $(\alpha=0, \beta=1)$ como o objetivo é minimizar a medida de instabilidade, apresenta maior número de movimentos (FO1), mas soluções com medida de instabilidade significativa menor (FO2). Estes dados confirmam que a minimização do número de movimentos e da instabilidade são objetivos conflitantes. O número mínimo de movimentos é obtido multiplicando-se por dois o valor do somatório de $T_{i j}$ calculado de acordo com a Equação 7 . Observe-se que este valor é o limitante inferior para o número total de movimentos a serem realizados ao longo do percurso do navio. Os resultados de todos os métodos foram obtidos com um programa desenvolvido em Matlab 7.0 e executado num computador Intel Core 2Duo 2.20 GHz (E4500), 2GB RAM, Windows XP 2002 (SP3). 
Tabela 5. Resultados do BS para dois pares de valores de $\alpha$ e $\beta$.

\begin{tabular}{ccccrrrrrr}
\hline \multirow{2}{*}{$\mathbf{I}$} & \multirow{2}{*}{$\mathbf{N}$} & \multirow{2}{*}{$\mathbf{M}$} & \multirow{2}{*}{$\mathbf{N m i n}$} & \multicolumn{3}{c}{$\alpha=1 \mathbf{e} \beta=0$} & \multicolumn{3}{c}{$\alpha=0 \mathbf{e} \beta=1$} \\
\cline { 5 - 10 } & & & & $\mathbf{F O 1}$ & $\mathbf{F O 2}$ & $\mathbf{T}$ & $\mathbf{F O 1}$ & $\mathbf{F O 2}$ & $\mathbf{T}$ \\
\hline & & & & FO1 & FO2 & T & FO1 & FO2 & T \\
1 & 10 & 1 & 6994 & 7072 & 588,45 & 429 & 10432 & 17,59 & 507 \\
2 & 10 & 2 & 4172 & 4202 & 478,22 & 403 & 7172 & 12,52 & 522 \\
3 & 10 & 3 & 17060 & 17074 & 577,54 & 453 & 17642 & 15,83 & 618 \\
4 & 15 & 1 & 9974 & 10234 & 194,24 & 1752 & 15058 & 12,59 & 2872 \\
5 & 15 & 2 & 4824 & 4936 & 603,19 & 1550 & 9560 & 9,93 & 2274 \\
6 & 15 & 3 & 24902 & 24992 & 420,96 & 1808 & 25952 & 17,38 & 2022 \\
7 & 20 & 1 & 10262 & 10432 & 163,64 & 4275 & 16374 & 6,68 & 5723 \\
8 & 20 & 2 & 4982 & 5152 & 447,15 & 3946 & 8652 & 10,21 & 4863 \\
9 & 20 & 3 & 32602 & 32610 & 1146,09 & 4102 & 33544 & 431,16 & 4651 \\
10 & 25 & 1 & 11014 & 11154 & 285,08 & 8217 & 14058 & 4,59 & 9684 \\
11 & 25 & 2 & 5002 & 5156 & 553,64 & 7576 & 10240 & 92,11 & 9455 \\
12 & 25 & 3 & 43722 & 43942 & 613,83 & 9506 & 45304 & 32,45 & 10397 \\
13 & 30 & 1 & 11082 & 11430 & 198,93 & 15756 & 18972 & 6,04 & 18073 \\
14 & 30 & 2 & 4720 & 5598 & 126,63 & 14468 & 7544 & 6,59 & 15066 \\
15 & 30 & 3 & 53592 & 53896 & 701,56 & 17335 & 55062 & 29,81 & 18301 \\
\hline
\end{tabular}

A primeira observação importante acerca dos resultados das Tabelas 3, 4 e 5 é sobre o tempo computacional gasto pelos métodos. É importante observar que para a formulação dada pelas Equações 1-8 as instâncias com 30 portos são problemas tais que uma única solução deve ser representada por 40.545 .000 variáveis inteiras (30 portos, 5 baias, 6 linhas e 50 colunas). Para estas instâncias o SA, por exemplo, consegue produzir boas soluções em menos de 1 hora. Pode-se observar também que, de forma geral, um aumento de 5 no número de portos a serem percorridos, de uma instância para outra, produz em média um aumento de mais ou menos 7 minutos no tempo computacional gasto pelo SA. Por exemplo, em instâncias com 10 portos leva-se 27 minutos e 30 segundos para se obter uma solução, ao passo que em instâncias com 15 portos leva-se, em média, 34 minutos. O BS apesar de ter apresentado os maiores tempos computacionais também foi o que apresentou os melhores resultados para a maioria das instâncias e para as duas funções objetivo. Espera-se, ainda, que futuras implementações em linguagem $\mathrm{C}$ venham a reduzir o tempo computacional de solução para todos os métodos.

Os resultados indicam que para as instâncias em que a função objetivo visa minimizar o número de movimentos $(\alpha=1, \beta=0)$ e a matriz de transporte é do tipo curta distância (tipo 3) as regras são bastante adequadas e produzem resultados muito próximos do limite inferior do número de movimentos, e chegam mesmo a quase atingir este limite, como no caso para 10, 15 e 20 portos produzem soluções com distância de $0,16 \%, 0,32 \%$ e 0,09\%, respectivamente. Já para as instâncias em que a matriz de transporte é do tipo média distância (tipo 1) e longa distância (tipo 2), todos os métodos apresentaram soluções cujo número de movimentos é ligeiramente maior que o limitante inferior. Estes resultados indicam a necessidade de se incorporar ao sistema um número maior de regras que levem em consideração a arrumação de contêineres que permanecerão um longo período de tempo dentro do navio. Porém, quando a função objetivo visa minimizar a medida de instabilidade $(\alpha=0, \beta=1)$ as soluções apresentadas por todos os métodos têm um razoável aumento no número de movimentos, mas com uma significativa melhora na medida de instabilidade. Em algumas instâncias esta medida pode ser até 50 vezes menor em comparação com a solução encontrada na minimização do número de movimentos (instância 2).

As Figuras 12, 13 e 14 ajudam a melhor ilustrar este tradeoff entre as duas funções objetivo, bem como a natureza bi-objetivo do problema.

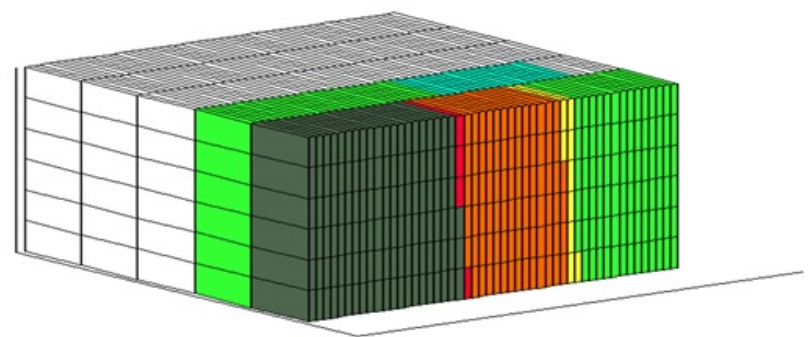

Figura 12. Disposição dos contêineres no navio para o porto 2 para a melhor solução encontrada com o AG, o SA e o BS para $(\alpha=1, \beta=0)$. 


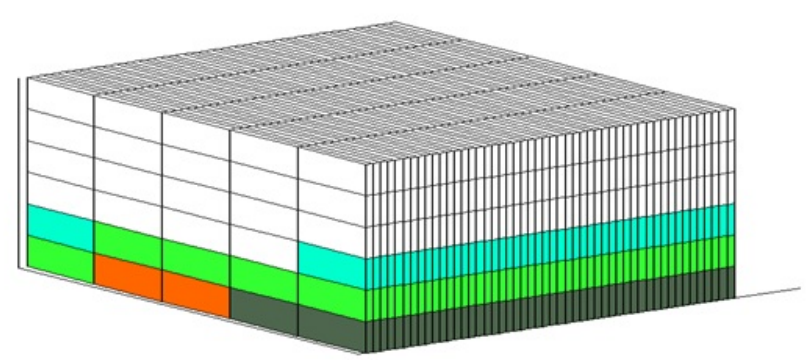

Figura 13. Disposição dos contêineres no navio para o porto 2 para a melhor solução encontrada com o AG e o SA para $(\alpha=0, \beta=1)$.

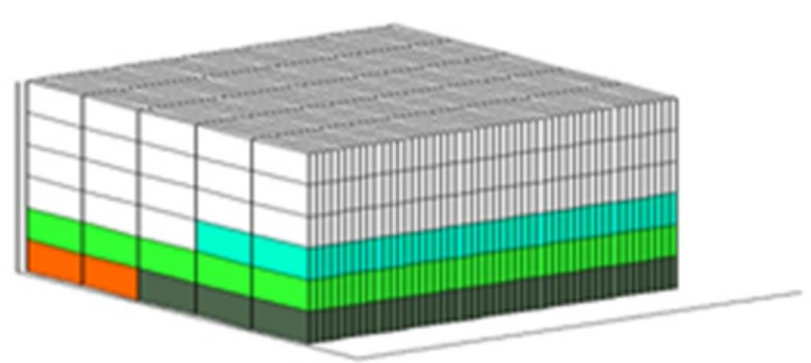

Figura 14. Disposição dos contêineres no navio para o porto 2 para a melhor solução encontrada com o BS para $(\alpha=0, \beta=1)$.

\section{Conclusões}

Este capítulo apresentou uma nova representação de soluções para o problema de carregamento de contêineres 3D em terminais portuários (PCCTP 3D). Esta nova representação permite reduzir a quantidade de informações necessárias para se representar uma solução tal que soluções próximas do limitante inferior do número de movimentos podem ser obtidas em pequeno tempo computacional. Este capítulo tem três inovações, a saber: a primeira delas é que ele apresenta uma nova formulação tridimensional para o problema de carregamento de contêineres em terminais portuários (PCCTP 3D). Esta nova representação permite a consideração de medidas de instabilidade acerca do arranjo dos contêineres no navio, além da medida acerca do número de movimentos para carregar e descarregar um navio.

A segunda inovação é o uso da representação com regras, cuja aplicação teve êxito no problema 2D, e que também no problema 3D reduz consideravelmente o número de variáveis do problema reduzindo assim a quantidade de informações necessárias para se representar uma solução. Na formulação dada pelas Equações 18 as informações devem ser armazenadas num vetor de tamanho $(D \times R \times C) \times\left(N+N^{3}\right)$. Na representação aqui utilizada o tamanho do vetor é $N-1$. Tendo em vista que $D \times R \times C$ expressa o número de contêineres que podem ser armazenados em um navio e que $N$ representa o número de portos, a representação da solução aqui utilizada permite uma enorme redução do tempo computacional para instâncias com grande número de portos. Para tanto, a representação emprega regras que definem como será carregado e descarregado o navio e as regras garantem que as soluções obtidas são sempre factíveis.

A terceira inovação é que a utilização de regras de carregamento e descarregamento permite a incorporação, no sistema computacional, do conhecimento do profissional responsável por este serviço no porto. Esta incorporação é feita através da criação e implantação de novas regras. Esta maneira de representar o PCCTP em conjunto com a aplicação de regras, é uma alternativa promissora na resolução deste problema, até porque assim como se podem acrescentar novas regras, também se podem utilizar outras heurísticas, como por exemplo, o ILS ou o VNS. Futuramente pretende-se testar uma abordagem multiobjetivo na obtenção de soluções e testes com outras medidas de instabilidade do navio.

\section{Agradecimentos}

Os autores agradecem à FAPESP pelo apoio financeiro através dos processos 2009/15107-0, 2010/51274-5, 2010-16517-4, 2010/16622-2 e 2011/01667-3. 


\section{Referências}

Aguilera, M.J.B.; Roli, A. \& Sampels, M., Hybrid Metaheuristics: an Emerging Approach to Optimization. $1^{\text {st }}$ edição. Berlin, Germany: Springer, 2008.

Ambrosino, D.; Sciomachen, A. \& Tanfani, E., A decomposition heuristics for the container ship stowage problem. Journal of Heuristics, 12(3):211-233, 2006.

Avriel, M.; Penn, M. \& Shpirer, N., Container ship stowage problem: complexity and connection to the coloring of circle graphs. Discrete Applied Mathematics, 103(1-3):271-279, 2000.

Avriel, M.; Penn, M. \& Wittenboon, S., Stowage planning for container ships to reduce the number of shifts. Annals of Operations Research, 76(1):55-71, 1998.

Azevedo, A.T.; Ribeiro, C.M.; Chaves, A.A.; Sena, G.J.; Leduino, L.S.N. \& Moretti, A.C., Solving the 3D container ship stowage problem by using simulated annealing and representation by rules. In: Proceedings of XXXII Iberian Latin American Congress on Computational Methods in Engineering. p. 1-15, 2011a.

Azevedo, A.T.; Ribeiro, C.M.; Chaves, A.A.; Sena, G.J.; Leduino, L.S.N. \& Moretti, A.C., Solving the 3D containership stowage loading planning problem by representation by rules and beam search. In: Proceedings of First International Conference on Operations Research and Enterprise Systems. p. 132-141, 2012.

Azevedo, A.T.; Ribeiro, C.M.; Leduino, L.S.N.; Silva, M.P.E. \& Sivestre, M.C., Resolução do problema de carregamento e descarregamento 3D de contêineres em terminais portuários via representação por regras e algoritmo genético. Gestão da Produção, Operações e Sistemas, 1(4):91-110, 2011b.

Croce, F.D. \& T'Kindt, V., A recovering beam search algorithm for the one-machine dynamic total completion time scheduling problem. Journal of the Operational Research Society, 53(11):1275-1280, 2002.

Fox, M.S., Constraint-Directed Search: A case Study of Job-Shop Scheduling. PhD thesis, 1983.

Henderson, D.; Jacobson, S.H. \& Johnson, A.W., The theory and practice of simulated annealing. In: Glover, F. \& Kochenberger, G.A. (Eds.), Handbook of Metaheuristics. New York, USA: Kluwer Academic Publishers, v. 57, $1^{\text {st }}$ edição, p. 287-319, 2003.

Holland, J.H., Adaptation in natural and artificial systems. $1^{\text {st }}$ edição. Ann Arbor, USA: The University of Michigan Press, 1975.

Kirkpatrick, S.; Gelatt, C.D. \& Vecchi, M.P., Optimization by simulated annealing. Journal of the Operational Research Society, 220(4598):671-680, 1983.

Michalewicz, Z., Genetic Algorithms + Data Structures = Evolution Programs. $3^{\text {rd }}$ edição. Berlin/Heidelberg, Germany: Springer-Verlag, 1996.

Sabuncuoglu, I. \& Baviz, M., Job shop scheduling with beam search. European Journal of Operational Research, 118(2):390-412, 1999.

Valente, J.M.; Alves, R.A.F.S. \& Rui, A.F.S., Filtered and recovering beam search algorithm for the early/tardy scheduling problem with no idle time. Computers $\mathcal{E}$ Industrial Engineering, 48(2):363-375, 2005.

Wilson, I. \& Roach, P., Container stowage planning: a methodology for generating computerised solutions. Journal of the Operational Research Society, 51(11):1248-1255, 2000. 


\section{Notas Biográficas}

Anibal Tavares de Azevedo é graduado em Matemática Aplicada e Computacional, tem mestrado, doutorado e pósdoutorado em Engenharia Elétrica (UNICAMP, 1999, 2002, 2006 e 2007, respectivamente). Foi Professor Assistente da UNESP-Guaratinguetá (2007-2011) e atualmente é Professor Assistente da Faculdade de Ciências Aplicadas da UNICAMP. Tem interesse na área de meta-heurísticas e otimização combinatória, como aplicações em problemas de sistemas de potência, planejamento e controle da produção, telecomunicações e logística portuária.

Cassilda Maria Ribeiro é graduada em Engenharia Mecânica (UNESP, 1982), mestre em Engenharia Elétrica (UNICAMP, 1985) e doutor em Automação Industrial e Informática (LAAS-Toulouse-França, 1991). Atualmente é Professora Assistente do Departamento de Matemática da Faculdade Engenharia de Guaratinguetá da UNESP. Tem interesse na área de meta-heurísticas e otimização combinatória, como aplicações em problemas de telecomunicações e logística.

Galeno José de Sena é graduado em Engenharia Mecânica (UNESP, 1983), mestre e doutor em Informática (PUCRio, 1987 e 1992, respectivamente). Realizou pós-doutorado na NIME em Chiba-Chi, Japão entre 2003 e 2004 . É Professor Assistente do Departamento de Matemática da Faculdade Engenharia de Guaratinguetá da UNESP. Seus interesses são computação, aprendizagem baseada em projetos e novas metodologias e técnicas para aprendizado em ambientes web, bem como meta-heurísticas e otimização combinatória.

Antônio Augusto Chaves é graduado em Ciência da Computação (UFOP, 2003), tem doutorado e pós-doutorado em Computação Aplicada (INPE, 2009 e 2010, respectivamente). Foi Professor Assistente da UNESP-Guaratinguetá (2010) e atualmente é Professor Assistente da UNIFESP-São José dos Campos. Seus interesses são computação, aprendizado para pesquisa operacional, problemas de otimização combinatória, formulações matemáticas, heurísticas e meta-heurísticas.

Luiz Leduino de Salles Neto é graduado em Matemática, mestre e doutor em Matemática Aplicada (UNICAMP, 1997, 2000 e 2005, respectivamente). Realizou pós-doutorado na Universidade de Sevilla em 2010. Atualmente é Professor Assistente da UNIFESP-São José dos Campos. Seus interesses são pesquisa operacional, problemas de corte e empacotamento, problemas combinatórios, não-lineares e multiobjetivo.

Antônio Carlos Moretti é graduado em Ciência da Computação e mestre em Matemática Aplicada (UNICAMP, 1980 e 1983, respectivamente) e mestre e doutor em Engenharia Industrial e Sistemas (Georgia Institute of Technology, 1989 e 1992, respectivamente). Atualmente é Professor Assistente da Faculdade de Ciências Aplicadas da UNICAMP. Seus interesses são pesquisa operacional, problemas de corte e empacotamento, problemas combinatórios, não-lineares e multiobjetivo. 


\title{
Heurísticas para o Problema de Sequenciamento de Carros em Linhas de Montagem
}

\author{
Daniel Brasil;, Thiago Ferreira de Noronha, Caroline Rocha
}

\begin{abstract}
Resumo: Este capítulo trata do Problema do Sequenciamento de Carros, que consiste em determinar a ordem em que carros devem ser produzidos, de forma a minimizar o número de violações às restrições de capacidade da linha de montagem. As principais heurísticas e estruturas de dados existentes na literatura para o problema são descritas e avaliadas experimentalmente, utilizando instâncias de teste com dados obtidos de fábricas reais. O resultado é um estudo comparativo entre os algoritmos e estruturas de dados, identificando os pontos fortes e fracos de cada um.
\end{abstract}

Palavras-chave: Problema do sequenciamento de carros, Heurísticas, Meta-heurísticas, Buscal local, Estruturas de dados.

\begin{abstract}
This chapter deals with the Car Sequencing Problem, which consists in defining the order in which cars must be produced so as to minimize the number of violations to the capacity constraints of the assembly line. The main heuristics and data structures existing in the literature for the problem are described and experimentally evaluated by using test instances with data obtained from real factories. The result is a comparative study of the algorithms and data structures, identifying the strengths and weaknesses of each one.
\end{abstract}

Keywords: Car sequencing problem, Heuristics, Metaheuristics, Local search, Data structures.

\section{Introdução}

O problema de sequenciamento de carros (PSC) em linhas de produção de indústrias automobilísticas foi descrito pela primeira vez por Parello et al. (1986) e pode ser visto como uma espécie muito particular de problema de escalonamento.

O número de opcionais disponíveis aos compradores tem propiciado o crescimento considerável da diversidade dos carros manufaturados. Devido aos custos da linha de produção, os diferentes veículos são todos montados usando a mesma unidade de montagem. Já que qualquer modificação do fluxo físico dentro da fábrica implica em custo muito elevado, muitos esforços têm sido concentrados na otimização do gerenciamento de recursos de produção. Desta forma, os clientes podem ser supridos com os carros desejados nas datas acordadas a custos mais baixos.

A linha de produção pode ser considerada como um processo de manufatura linear composto por três oficinas (shops): oficina de armação de carroceria, oficina de pintura e oficina de montagem. Para programar a linha de produção, o trabalho é dividido em duas etapas:

(1) determinar o dia de produção para cada carro encomendado, de acordo com as capacidades da linha de produção e com os prazos de entrega prometidos aos clientes;

(2) sequenciar os carros a serem produzidos na linha de montagem em cada dia de produção, respeitando os requisitos das oficinas de armação de carroceria, pintura e montagem.

O PSC considera que o conjunto de carros a ser produzido em um determinado dia de produção já é conhecido, restringindo-se, então, ao desenvolvimento da etapa (2) do trabalho de produção nas fábricas. Vale salientar que o conjunto de carros de cada dia de produção, que é determinado na etapa (1), não pode ser mudado na etapa de sequenciamento.

*Autor para contato: daniel@dcc.ufmg.br 
Somente os requisitos da linha de montagem são considerados na versão clássica do PSC. Desta forma, o problema consiste em encontrar a sequência que melhor satisfaz tais requisitos. O problema de decisão associado ao PSC, que consiste em decidir se é possível encontrar uma sequência satisfazendo todos os requisitos de montagem, foi demonstrado ser NP-Completo por Gent (1998) e por Kis (2004).

Quanto às estratégias de solução, o PSC tem sido tratado frequentemente usando técnicas de programação por restrições (Dincbas et al., 1988; van Hentenryck et al., 1992), que exploram o espaço de busca de uma maneira sistemática. A fim de reduzir o espaço de busca, esta estratégia é combinada com técnicas de filtragem para restringir o domínio das variáveis (Règin \& Puget, 1997). Mesmo assim, em algumas instâncias, estas abordagens não conseguem reduzir o domínio suficientemente a ponto de tornar a busca completa tratável. Diante disto, o problema tem atraído a atenção para o desenvolvimento de estratégias que buscam soluções aproximadas (Drexl et al., 2006; Gottlieb et al., 2003; Smith, 1996; Solnon, 2000; Warwick \& Tsang, 1995).

O presente trabalho tem como objetivo revisitar as principais heurísticas para resolver o problema de sequenciamento de carros, discutindo os detalhes envolvidos na implementação dos algoritmos, sobretudo no que diz respeito ao uso de estruturas de dados eficientes.

\subsection{Requisitos de montagem}

A linha de montagem pode ser vista como uma sequência de estações ou unidades de produção projetadas para trabalhar com um carro por vez. Os carros em produção são colocados na linha de montagem, que se move através das unidades de produção para a instalação de opcionais. Alguns opcionais, tais como condicionador de ar, teto solar e equipamentos de som, requerem operações especiais de montagem. No entanto, as unidades de produção tem capacidades limitadas e precisam de tempo para configurar os opcionais a serem instalados à medida que a sequência de carros se move na linha de montagem. Portanto, os carros não podem ser sequenciados arbitrariamente.

A fim de suavizar a carga de trabalho, os carros que requerem operações especiais de montagem precisam ser distribuídos equitativamente ao longo da sequência de carros a serem produzidos, pois estes carros são considerados difíceis de montar. De fato, o total de ocorrência destes carros não deve exceder uma certa quota em qualquer subsequência de carros na linha de montagem, de forma a respeitar as capacidades das unidades de produção.

O requisito de capacidade da unidade para a instalação de um opcional $o_{i}$ é modelado por uma restrição de capacidade de razão $N_{i} / P_{i}$, o que significa que no máximo $N_{i}$ carros com o opcional $i$ devem ser produzidos em cada subsequência consecutiva de $P_{i}$ carros na linha de montagem. Por exemplo, se um determinado opcional está associado a uma restrição de capacidade de razão 1/3, não deve existir mais que um carro com este opcional em qualquer sequência consecutiva formada por 3 carros. De forma geral, se existe uma restrição de capacidade de razão $1 / P$ para um opcional, dois carros com este opcional devem ser separados por no mínimo $P-1$ carros consecutivos que não possuam este opcional. A Figura 1 ilustra esta situação, onde um carro é representado pelo símbolo " $X$ ", se requer o referido opcional, e pelo símbolo "_", caso contrário.

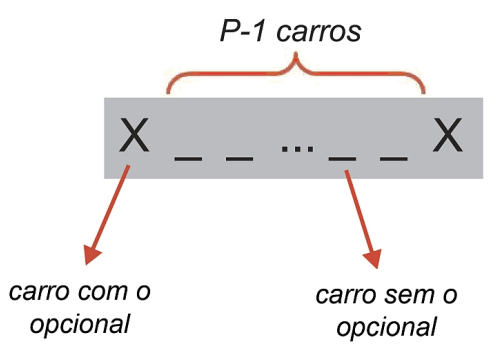

Figura 1. Sequência de carros satisfazendo a restrição de capacidade $1 / P$.

As restrições de capacidade mais difíceis de satisfazer são aquelas representadas por razões menores, ou seja, uma restrição da capacidade de razão $1 / 5$ é mais restritiva que uma restrição de capacidade de razão 2/3. Deve-se notar também que uma razão $1 / 3$ é diferente de $2 / 6$, conforme mostra a Figura 2 . A sequencia (a) viola a restrição de capacidade de razão $1 / 3$, mas não viola a restrição da capacidade de razão $2 / 6$, como se pode ver na sequência (b).

Uma vez determinado o conjunto de carros para um dia de produção, não se pode garantir de antemão que exista um sequenciamento que respeite todas as restrições de capacidade. Desta forma, tem-se como objetivo minimizar o número de violações destas restrições. 


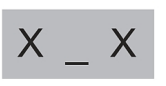

(a)

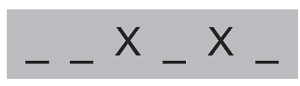

(b)

Figura 2. Diferença entre restrições de capacidade $1 / 3$ (a) e $2 / 6$ (b).

\subsubsection{Cálculo do número de violações de restrições de capacidade}

Sabe-se que a solução ideal para uma restrição de capacidade $N_{i} / P_{i}$ associada ao opcional $o_{i}$ consiste em um dia de produção onde existem no máximo $N_{i}$ carros com este opcional em qualquer sequência consecutiva de $P_{i}$ carros. Entretanto, quando não é possível gerar um sequenciamento sem nenhuma violação, os carros associados à mesma restrição devem ser distribuídos da melhor maneira possível. A qualidade da distribuição é dada pelo número de violações nas sequências consecutivas ao longo da linha de produção.

Seja $C$ o número de carros associados a uma restrição de capacidade de razão $N / P$ em uma sequência de tamanho $P$. O número de violações desta restrição ao longo desta sequência é dado por $N-C$, se $C<N ; 0$, caso contrário. A Figura 3 mostra o número de violações de uma restrição de capacidade de razão $1 / 5$ para quatro subsequências de carros.

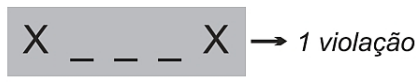

(a)

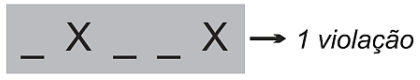

(c)

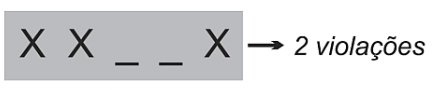

(b)

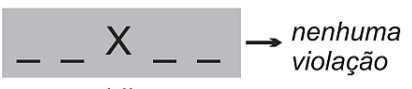

(d)

Figura 3. Cálculo do número de violações de uma restrição de capacidade de razão 1/5.

O número total de violações de restrições de capacidade em um dia de produção é igual à soma do número de violações de cada restrição em todas as sequências consecutivas de carros daquele dia. Vale salientar que, para se calcular o número de violações em um dia de produção $D$, leva-se em consideração os últimos carros do dia anterior, chamado de $D-1$. Ou seja, para uma restrição de capacidade $N / P$, a primeira sequência considerada para cálculo das violações contém os $P-1$ últimos carros sequenciados do dia de produção $D-1$ e o primeiro carro do dia $D$.

A Figura 4 mostra um exemplo do número total de violações de uma restrição de capacidade $1 / 5$ ao longo de um dia de produção $D$ em que 6 carros devem ser sequenciados. Para o cálculo do número total de violações da restrição de capacidade $1 / 5$, considera-se um total de 10 subsequências de carros, cujos números de violações podem ser visto na figura, obtendo-se um total de 8 violações desta restrição ao longo do dia de produção.

O objetivo de se calcular o número de violações de restrições de capacidade desta maneira é que violações nas primeiras e últimas sequências contribuam de forma semelhante àquelas ocorridas em sequências intermediárias, uma vez que as violações causadas pelos carros intermediários aparecem em várias sequências consecutivas.

\section{Heurísticas Construtivas}

Esta seção descreve as principais heurísticas construtivas para PSC encontradas na literatura. Em todos os trabalhos descritos, uma sequência de carros é construída de forma gulosa, escolhendo-se iterativamente o carro que causa o menor número de violações adicionais à sequência em construção. Como muitos carros podem atender a este critério, Gottlieb et al. (2003) propõem uma série de critérios gulosos para decidir empates. Ribeiro et al. (2008) propõem um heurística gulosa que considera critérios de desempate de forma hierárquica, enquanto a heurística construtiva de Solnon (2008) utiliza uma função para atribuir probabilidades de escolha aos carros candidatos. Para facilitar a descrição dos algoritmos, a mesma formalização para PSC proposta em Gottlieb et al. (2003) foi utilizada a seguir. 


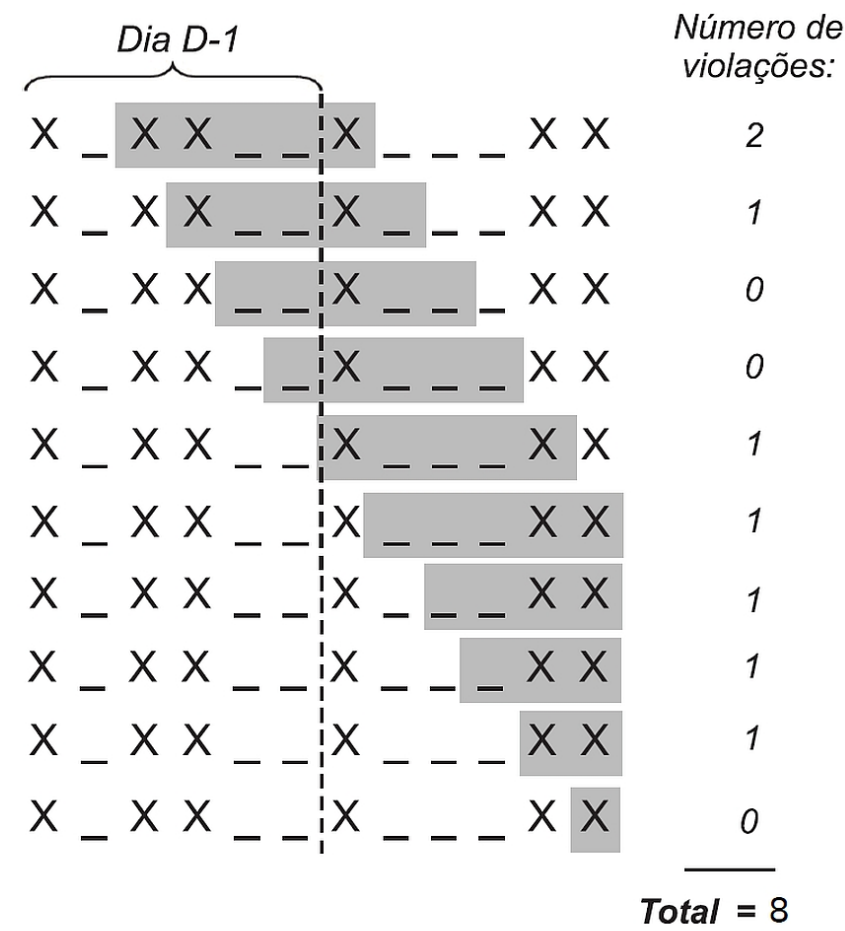

Figura 4. Número de violações de uma restrição de capacidade $1 / 5$ em todas as sequências consecutivas de carros do dia de produção.

\subsection{Formalização do problema}

O problema de sequenciamento de carros pode ser definido como uma tupla $(C, O, p, q, r)$, onde $C=$ $\left\{c_{1}, \ldots, c_{n}\right\}$ é o conjunto de carros a serem sequenciados e $O=\left\{o_{1}, \ldots, o_{m}\right\}$ é o conjunto dos possíveis opcionais requeridos pelos carros. As restrições de capacidade associadas a cada opcional $o_{j} \in O$ são representadas por uma razão $p_{j} / q_{j}$, que denota que no máximo $p_{j}$ carros podem demandar o opcional $o_{j}$ em cada sequência de carros consecutivos de tamanho $q_{j}$. As demandas de opcionais são definidas pela função $r: C \times O \rightarrow\{0,1\}$, ou seja, $r\left(c_{i}, o_{j}\right)$ retorna 1 se o opcional $o_{j}$ deve ser instalado no carro $c_{i}$, e retorna 0 caso contrário.

Uma sequência de carros é denotada por $\pi=\left\langle c_{i_{1}}, c_{i_{2}}, \ldots, c_{i_{k}}\right\rangle$, onde $\left\{i_{1}, \ldots, i_{k}\right\} \subseteq\{1, \ldots, n\}$. O número de carros em uma sequência $\pi$, denotado por $|\pi|$, é chamado de "tamanho de $\pi$ ". A concatenação de duas sequências $\pi_{1}$ e $\pi_{2}$, denotada por $\pi_{1} \mid \pi_{2}$, é a sequência formada pelos carros de $\pi_{1}$ seguidos pelos carros de $\pi_{2}$. O número de carros que requerem um opcional $o_{j}$ em uma sequência $\pi=\left\langle c_{i_{1}}, c_{i_{2}}, \ldots, c_{i_{k}}\right\rangle$ é dado por

$$
r\left(\pi, o_{j}\right)=\sum_{\ell=1}^{|\pi|} r\left(c_{i_{\ell}}, o_{j}\right)
$$

O custo de uma sequência $\pi=\left\langle c_{i_{1}}, c_{i_{2}}, \ldots, c_{i_{k}}\right\rangle$ corresponde ao número de violções de restrições de capacidade, o qual é dado por:

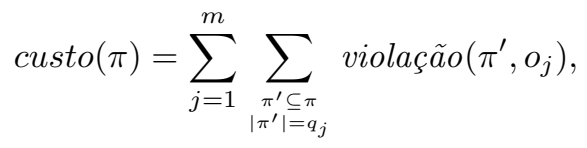

onde

$$
\text { violação }\left(\pi^{\prime}, o_{j}\right)=\left\{\begin{array}{l}
0, \text { se } r\left(\pi^{\prime}, o_{j}\right) \leq p_{j} ; \\
r\left(\pi^{\prime}, o_{j}\right)-p_{j}, \text { caso contrário. }
\end{array}\right.
$$

Para efeito de simplificação, o número de carros que requerem um opcional $o_{j}$ em um subconjunto $W \subseteq C$ é denotado por:

$$
r\left(W, o_{j}\right)=\sum_{c_{i} \in W} r\left(c_{i}, o_{j}\right) .
$$

Dada uma tupla $(C, O, p, q, r)$, o PSC consiste em encontrar uma sequência $\pi^{*}$ tal que custo $\left(\pi^{*}\right)$ é mínimo.

Além da notação acima, existe um conceito importante utilizado pelas heurísticas construtivas que é o da taxa de utilização de um opcional $o_{j} \mathrm{em}$ um conjunto ou uma sequência de carros. Este conceito, apresentado 
em Smith (1996), fornece um indicativo do grau de dificuldade de um dado opcional e do problema como um todo. A taxa de utilização de um opcional $o_{j}$ no conjunto de carros $C$ é dado por:

$$
\operatorname{taxaUtil}\left(o_{j}\right)=\left(\frac{r\left(C, o_{j}\right)}{n}\right) /\left(\frac{p_{j}}{q_{j}}\right) ;
$$

ou seja, é dada pela razão entre o número de carros demandando o opcional $o_{j}$ e o número de carros a serem sequenciados, dividida pela razão da restrição de capacidade envolvida. Isto significa que, se a taxa de utilização é maior que 1, a demanda é maior do que a capacidade e, logo, a restrição será violada. Se, por outro lado, a taxa de utilização é muito pequena e próxima de 0, a demanda é muito baixa em relação à capacidade da linha de produção.

\subsection{Critérios gulosos}

As heurísticas construtivas constroem uma solução inicial escolhendo iterativamente o próximo carro a ser adicionado à sequência de acordo com um critério muito intuitivo: em cada iteração, escolhe-se o carro que causa o menor número de novas violações de restrições quando inserido no final da sequência parcial. De uma maneira mais formal, dada uma sequência parcialmente construída $\pi$, o próximo carro $c_{i}$ a ser adicionado é aquele que minimiza:

$$
\delta\left(\pi, c_{i}\right)=\sum_{j=1}^{m} r\left(c_{i}, o_{j}\right) \cdot \operatorname{violação}\left(\text { últimos }\left(\pi \mid\left\langle c_{i}\right\rangle, q_{j}\right), o_{j}\right),
$$

onde últimos $\left(\pi^{\prime}, k\right)$ retorna a sequência formada pelos últimos $k$ carros de $\pi^{\prime}$, se $\left|\pi^{\prime}\right| \geq k$ ou retorna $\pi^{\prime}$, caso contrário. Entretanto, geralmente existem vários carros candidatos que minimizam o número de novas violações, o que faz necessária a utilização de critérios gulosos adicionais que são usados para resolver os empates. Tais critérios podem ser:

1. Escolha aleatória: um carro é escolhido aleatoriamente dentre o conjunto de carros candidatos;

2. Maior taxa de utilização estática (Smith, 1996): seleciona-se o carro que requer o opcional com maior taxa de utilização. Se empates persistirem, seleciona-se o carro que requer o opcional com a segunda maior taxa de utilização, e assim por diante;

3. Maior taxa de utilização dinâmica (Gottlieb et al., 2003): é similar ao critério 2, mas a taxa de utilização é atualizada sempre que um novo carro é adicionado à sequência. A taxa de utilização dinâmica de um opcional $o_{j}$ em relação à sequência parcial $\pi$ é dada pela seguinte função:

$$
\operatorname{taxaUtilDin}\left(o_{j}, \pi\right)=\frac{\left[r\left(C, o_{j}\right)-r\left(\pi, o_{j}\right)\right] \cdot q_{j}}{[|C|-|\pi|] \cdot p_{j}} ;
$$

4. Soma estática de taxas de utilização (Gottlieb et al., 2003): seleciona-se o carro $c_{i} \in C \backslash \pi$ que maximiza:

$$
\eta_{S S}\left(c_{i}, \pi\right)=\sum_{j=1}^{m} r\left(c_{i}, o_{j}\right) \cdot \operatorname{taxaUtil}\left(o_{j}\right)
$$

5. Soma dinâmica de taxas de utilização (Gottlieb et al., 2003): seleciona-se o carro $c_{i} \in C \backslash \pi$ que maximiza:

$$
\eta_{S D}\left(c_{i}, \pi\right)=\sum_{j=1}^{m} r\left(c_{i}, o_{j}\right) \cdot \operatorname{taxaUtilDin}\left(o_{j}, \pi\right)
$$

6. Distribuição equitativa (Gottlieb et al., 2003): se o número médio de carros que demandam um opcional é menor na sequência em construção $\pi$ do que no conjunto total de carros $C$, então estes carros são favorecidos para entrar na sequência. Formalmente, escolhe-se o carro $c_{i} \in C \backslash \pi$ que maximiza a função:

$$
\eta_{D E}\left(c_{i}, \pi\right)=\sum_{j=1}^{m}\left\{\left(r\left(c_{i}, o_{j}\right)=0\right) \operatorname{XOR}\left(\frac{r\left(C, o_{j}\right)}{n}>\frac{r\left(\pi, o_{j}\right)}{|\pi|}\right)\right\} .
$$

O resultado do operador XOR será verdadeiro em dois casos: quando já existirem muitos carros sequenciados com o opcional $o_{j}$ e o carro $c_{i}$ não possuir este opcional, ou quando existirem poucos carros sequenciados com o opcional $o_{j}$ e o carro $c_{i}$ possuir o opcional. Portanto, o carro cujos opcionais atenderem mais vezes a esta condição será escolhido para entrar na solução. O primeiro carro a ser sequenciado é escolhido aleatoriamente entre os carros com o número máximo de opcionais, uma vez que a fórmula acima não pode ser aplicada quando $|\pi|=0$. 
Em Gottlieb et al. (2003), diferentes heurísticas construtivas são propostas usando cada um dos seis critérios de desempate. Em Ribeiro et al. (2008), é desenvolvida uma heurística que usa os critérios 6 e 5 , nesta ordem, para decidir empates. Se, ainda assim, houver mais de um carro candidato, um dentre eles é escolhido aleatoriamente. Em Solnon (2008), os carros que minimizam o número de violações adicionais à sequência em construção $\pi$ formam uma lista de candidatos, denotada por cand. Então, o próximo carro a ser inserido é escolhido aleatoriamente a partir de cand baseado em uma função de probabilidade dada por:

$$
p\left(c_{i}, \text { cand }, \pi\right)=\frac{\left[\eta_{S D}\left(c_{i}, \pi\right)\right]^{\beta}}{\sum_{c_{k} \in \text { cand }}\left[\eta_{S D}\left(c_{k}, \pi\right)\right]^{\beta}},
$$

para todo $c_{i} \in$ cand, onde $\beta$ é um parâmetro que permite ajustar a intensidade do critério guloso. Quanto maior o valor de $\beta$, mais gulosa será a estratégia.

\section{Estruturas de Vizinhança}

As principais heurísticas de busca local encontradas na literatura para o problema de sequenciamento de carros exploram a vizinhança de uma solução $\pi=\left\langle c_{k_{1}}, \ldots, c_{k_{n}}\right\rangle$ através da aplicação dos seguintes tipos de movimento:

- $\operatorname{troca}(\pi, i, j)$ : troca os carros que estão nas posições $i$ e $j$. Por exemplo, se $i<j$, este movimento resulta na sequência $\pi^{\prime}=\left\langle c_{k_{1}}, \ldots, c_{k_{i-1}}, c_{k_{j}}, c_{k_{i+1}}, \ldots, c_{k_{j-1}}, c_{k_{i}}, c_{k_{j+1}}, \ldots, c_{k_{n}}\right\rangle$.

- insere $(\pi, i, j)$ : remove um carro de sua posição atual $i$ e o insere em uma nova posição $j$. Por exemplo, se $i<j$, a aplicação deste movimento resulta na sequência $\pi^{\prime}=\left\langle c_{k_{1}}, \ldots, c_{k_{i-1}}\right.$, $\left.c_{k_{i+1}}, \ldots, c_{k_{j-1}}, c_{k_{j}}, c_{k_{i}}, c_{k_{j+1}}, \ldots, c_{k_{n}}\right\rangle$.

- inverte $(\pi, i, j)$ : inverte a subsequência de carros da posição $i$ até a posição $j$, com $i<j$. Por exemplo, se $i=1$ e $j=4$, a aplicação deste movimento resulta na sequência $\pi^{\prime}=\left\langle c_{k_{4}}, c_{k_{3}}, c_{k_{2}}, c_{k_{1}}, c_{k_{5}}, c_{k_{6}}, \ldots, c_{k_{n}}\right\rangle$.

- embaralha $(\pi, i, j)$ : embaralha de forma aleatória a subsequência de carros começando na posição $i$ e terminando na posição $j$, com $i<j$. Por exemplo, se $i=1$ e $j=4$, a aplicação deste movimento pode resultar na sequência $\pi^{\prime}=\left\langle c_{k_{3}}, c_{k_{1}}, c_{k_{4}}, c_{k_{2}}, c_{k_{5}}, c_{k_{6}}, \ldots, c_{k_{n}}\right\rangle$.

\section{Meta-Heurísticas}

Diversas heurísticas têm sido propostas para o PSC, dentre as quais pode-se citar algoritmos baseados nas meta-heurísticas Colônia de Formigas (Solnon, 2000, 2008; Gagné et al., 2006), Algoritmos Genéticos (Warwick \& Tsang, 1995; Cheng et al., 1999), Busca em Vizinhança Variável (Ribeiro et al., 2008; Gavranovic, 2008), Busca Tabu (Gavranovic, 2008), Busca Local Iterativa (Ribeiro et al., 2008) e abordagens híbridas (Estellon et al., 2008). Foram selecionadas três destas heurísticas, descritas a seguir.

\subsection{Algoritmo de colônia de formigas}

O algoritmo de colônia de formigas proposto por Solnon (2008) para o PSC é baseado em uma combinação de duas estruturas de feromônio utilizadas para guiar a busca no espaço de soluções: a primeira tem o objetivo de identificar sequências promissoras de carros; a segunda, de identificar carros mais difíceis de serem sequenciados.

Usando a primeira estrutura, trilhas de feromônio $\tau_{1}\left(c_{i}, c_{j}\right)$ são depositadas em pares de carros $\left(c_{i}, c_{j}\right) \in$ $C \times C$, representando a experiência passada da colônia de formigas com relação a sequenciar o carro $c_{j}$ $\operatorname{logo}$ após o carro $c_{i}$. Para esta estrutura de feromônio, as trilhas são limitadas pelo intervalo $\left[\tau_{\min _{1}}, \tau_{\text {max }_{1}}\right]$, começando no limite superior do intervalo. Em cada ciclo, após todas as formigas terem construído uma sequência completa, as trilhas de feromônio sofrem evaporação e somente as formigas mais aptas depositam feromônio, respeitando os limites do intervalo $\left[\tau_{\min _{1}}, \tau_{\max _{1}}\right]$, conforme descrito pelo pseudocódigo da Figura 5. O parâmetro $\rho_{1}$ na linha 2 representa a taxa de evaporação do feromônio.

Usando a segunda estrutura de feromônio, as formigas depositam uma quantidade de feromônio $\tau_{2}(c c)$ em classes de carros $c c \in$ classes $(C)$, onde uma classe de carros é o subconjunto de carros que requerem os mesmos opcionais e classes $(C)$ é o conjunto de todas as classes existentes em $C$. A função classeDe $\left(c_{i}\right)=$ $\left\{o_{j} \in O \mid r\left(c_{i}, o_{j}\right)=1\right\}$ diz qual a classe do carro $c_{i}$. A quantidade de feromônio $\tau_{2}(c c)$ representa a experiência passada com relação à dificuldade de sequenciar carros desta classe sem violar restrições de capacidade. Um limite inferior $\tau_{\text {min }_{2}}$ é imposto para $\tau_{2}(c c)$ e usado como valor inicial no algoritmo. Ao contrário da atualização da primeira estrutura de feromônio, toda formiga deposita feromônio enquanto constrói uma sequência. Ou seja, em cada iteração do processo construtivo, o feromônio é depositado antes de escolher o próximo carro 


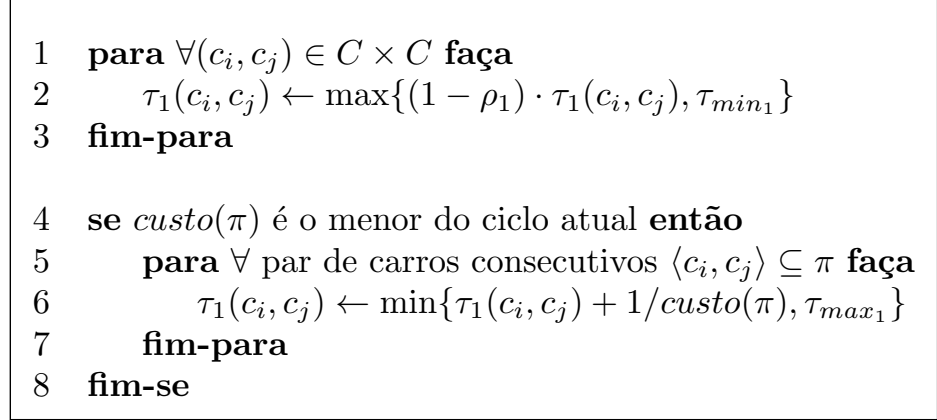

Figura 5. Pseudocódigo da evaporação (linhas 1-3) e do depósito (linhas 4-8) da primeira estrutura de feromônio.

a ser inserido, de acordo com o pseudocódigo da Figura 6 , onde $\delta\left(\pi, c_{j}\right)$ é a variação no custo da sequência $\pi$ com a adição do carro $c_{j}$, como mostra a Equação 6 . No entanto, o processo de evaporação é similar ao anterior, ou seja, acontece somente após a construção de cada sequência.

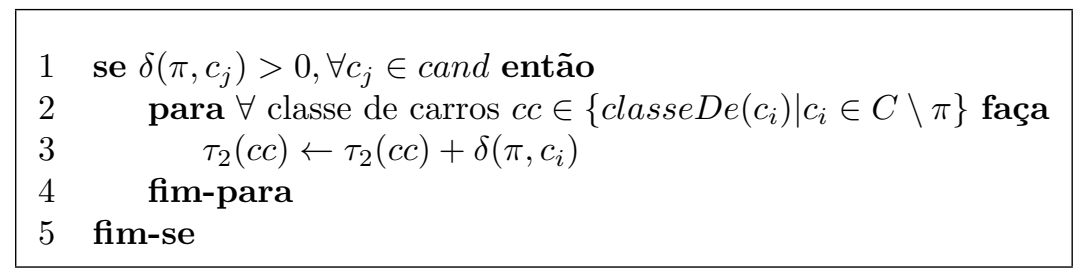

Figura 6. Pseudocódigo do depósito da segunda estrutura de feromônio.

As formigas constroem sequências de carros conforme o algoritmo descrito na Seção 2. No entanto, a função de probabilidade, usada na escolha do próximo carro $c_{i}$ adicionado à sequência em construção $\pi$, depende de dois fatores de feromônio, como expresso abaixo:

$$
p\left(c_{i}, \text { cand }, \pi\right)=\frac{\left[\tau_{1}\left(c_{j}, c_{i}\right)\right]^{\alpha_{1}} \cdot\left[\tau_{2}\left(\text { classeDe }\left(c_{i}\right)\right)\right]^{\alpha_{2}}}{\sum_{c_{k} \in \text { cand }}\left[\tau_{1}\left(c_{j}, c_{k}\right)\right]^{\alpha_{1}} \cdot\left[\tau_{2}\left(\text { classeDe }\left(c_{k}\right)\right)\right]^{\alpha_{2}}},
$$

onde $c_{j}$ é o último carro da sequência $\pi$ e classe $D e\left(c_{j}\right)$ representa a classe de carros à qual $c_{j}$ pertence. Os parâmetros $\alpha_{1}$ e $\alpha_{2}$ são usados para atribuir pesos relativos aos dois fatores de feromônio.

\subsection{Algoritmo de busca local rápida}

O algoritmo de busca local rápida, do inglês Very Fast Local Search (VFLS), foi proposto por Estellon et al. (2008) para o desafio ROADEF 2005, uma competição organizada bienalmente pela Sociedade Francesa de Pesquisa Operacional (ROADEF, 2005). O problema de sequenciamento de carros abordado na competição considera restrições adicionais relacionadas à cor dos carros a fim de minimizar o uso de solventes, além de considerar diferentes níveis de prioridade entre as restrições de capacidade. A heurística VFLS descrita a seguir foi adaptada em Solnon (2008) para resolver a versão clássica do problema.

A heurística VFLS é um método de busca baseado na exploração rápida de pequenas vizinhanças, cujo pseudocódigo pode ser visto na Figura 7. Inicialmente, uma sequência de carros é construída usando uma heurística construtiva baseada no critério guloso $\eta_{S D}$ descrito na Seção 2.2. Em cada iteração, o algoritmo seleciona o primeiro vizinho que não deteriora o custo da solução atual. Para tanto, escolhe-se uma dentre cinco estruturas de vizinhança (linha 3) e uma solução vizinha de acordo com a estrutura selecionada (linhas 4 e 5). As quatro estruturas de vizinhança descritas na Seção 3 são consideradas no algoritmo. A estrutura de vizinhança a ser explorada em cada iteração é selecionada aleatoriamente de acordo com probabilidades definidas previamente. O algoritmo termina quando a condição de parada, que pode ser, por exemplo, tempo limite máximo ou numero máximo de iteração, for satisfeita.

O modo mais simples de se escolher as posições $i$ e $j$ para se obter uma solução vizinha é sorteálos aleatoriamente. Esta estratégia é muito usada no algoritmo VFLS, sobretudo nas primeiras iterações. Entretanto, estratégias mais agressivas são adotadas à medida que a busca por melhores soluções torna-se mais difícil. A estratégia de escolha das posições envolvidas no movimento depende da estrutura de vizinhança na qual o movimento é aplicado, conforme mostrado na Tabela 1. Uma vez selecionada a estrutura de vizinhança, valores de probabilidades são utilizados para definir a chance de se escolher cada uma das estratégias para a obtenção de um vizinho da solução atual. 


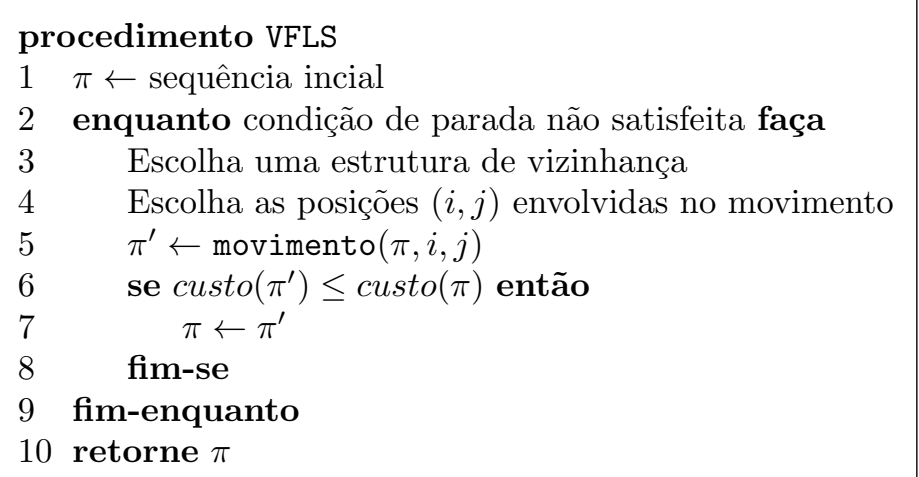

Figura 7. Algoritmo VFLS para o PSC (Estellon et al., 2008).

\begin{tabular}{lll}
\hline Estratégia & Descrição & Vizinhanças \\
\hline Genérica & Seleciona $i$ e $j$ aleatoriamente & $\begin{array}{l}\text { troca, } \\
\text { insere, } \\
\text { inverte, } \\
\text { embaralha }\end{array}$ \\
\hline Similar & $\begin{array}{l}\text { Seleciona } i \quad \text { e } j \text { tais que ambos } \\
\text { compartilhem algum opcional }\end{array}$ & troca \\
\hline Consecutiva & Seleciona $i$ aleatoriamente e faz $j=i+1$ & troca \\
\hline Violação & $\begin{array}{l}\text { Seleciona } i \text { em uma posição onde ocorre } \\
\text { uma violação e } j \text { aleatoriamente }\end{array}$ & troca \\
\hline Denominador & $\begin{array}{l}\text { Seleciona } i \quad \text { e um opcional } k \\
\text { aleatoriamente e faz } j=i+q(k)\end{array}$ & insere \\
\hline
\end{tabular}

Tabela 1. Estratégias de seleção das posições envolvidas nos movimentos.

\subsection{Algoritmo de busca local iterativa}

Ribeiro et al. (2008) desenvolveram um sofisticado algoritmo para o PSC baseado na meta-heurística de busca local iterativa, do inglês Iterated Local Search (ILS), também para o desafio ROADEF (ROADEF, 2005). A heurística ILS prosposta é baseada na exploração rápida de vizinhanças graças ao uso de estrutura de dados eficientes, utilizando os quatro procedimentos fundamentais descritos a seguir:

- Pertubação $(\pi)$ : realiza um pequeno número de movimentos do tipo insere com carros envolvidos em violações na solução $\pi$;

- BuscaLocal $(\pi)$ : realiza busca local exaustiva na solução $\pi$ usando movimentos do tipo troca;

- Intensificação $(\pi)$ : consiste na aplicação sucessiva de dois procedimentos de busca local: o primeiro realiza movimentos do tipo insere e o segundo com movimentos do tipo troca, nesta ordem;

- Diversificação $(\pi)$ : consiste em reiniciar a busca a partir de uma nova solução, que pode ser obtida através da aplicação de uma grande perturbação na solução $\pi$ (removendo e reinserindo um grande número de carros) ou da aplicação da heurística construtiva.

O pseudocódigo da Figura 8 apresenta uma descrição geral da heurística ILS. A melhor solução conhecida $\pi^{*}$ é inicializada com a solução inicial vinda da heurística construtiva, conforme descrita na Seção 2. Cada iteração da heurística ILS começa com uma perturbação na solução atual $\pi$ (linha 3), seguida de busca local na solução vinda da perturbação (linha 4). A nova solução $\pi^{\prime}$ é aceita se seu custo for menor ou igual ao da solução atual $\pi$ (linha 5). O procedimento de intensificação é executado na linha 7 se nenhuma melhoria for realizada na solução atual $\pi$ após $\alpha$ iterações. O procedimento de diversificação é realizado na linha 11 se a solução atual $\pi$ não tiver sido aprimorada nas últimas $\beta$ iterações ( $\operatorname{com} \alpha<\beta$ ) e se o custo de $\pi$ é igual ao da melhor solução conhecida. Caso contrário, recomeça-se a busca a partir da melhor solução conhecida (linha 12). A melhor solução $\pi^{*}$ é atualizada, se necessário, na linha 14. Por fim, $\pi^{*}$ é retornada na linha 16. 


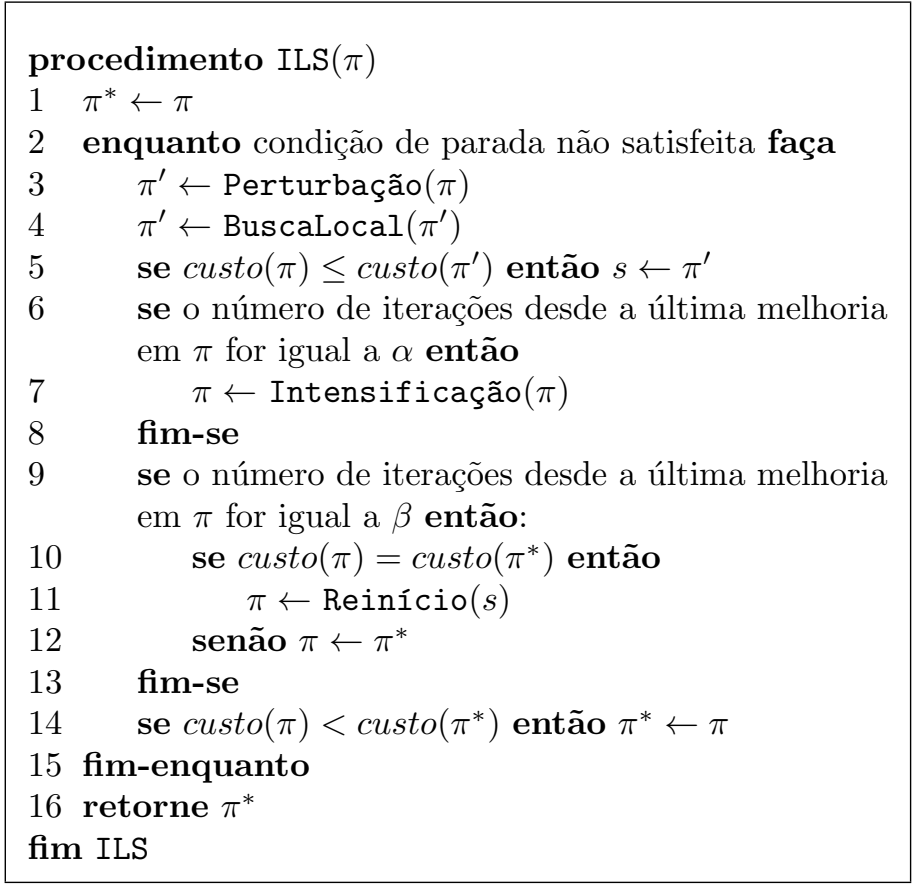

Figura 8. Pseudocódigo da heurística ILS para PSC (Ribeiro et al., 2008).

\section{Detalhes de Implementação}

As estruturas de dados para representar as informações e a solução atual do problema são um aspecto importante na implementação das heurísticas e têm um papel crucial em sua complexidade computacional e, consequentemente, no seu desempenho. As estruturas de dados devem ser eficientes do ponto de vista das operações que deverão ser realizadas sobre elas, principalmente no caso dos métodos de busca local, uma vez que, normalmente, esta é a componente das heurísticas que demanda mais tempo computacional. Esta seção concentra-se nas estruturas de dados utilizadas na implementação da busca local troca, já que esta é a mais utilizada dentre todas as buscas locais para o PSC. As estruturas de dados utilizadas em Estellon et al. (2008) são apresentadas na Seção 5.1, enquanto as estruturas de dados propostas em Ribeiro et al. (2008) são apresentadas na Seção 5.2 .

\subsection{Estruturas de dados de Estellon et al. (2008)}

Uma solução para o problema, ou seja, uma sequencia $\pi$ de carros, é representada por um vetor, aqui denotado por $V$, onde cada posição guarda um número que representa o carro que deve ser produzido naquela posição ao longo da linha de montagem. Além deste vetor, para cada uma das restrições de capacidade $o_{j} \in O$, um outro vetor, denotado por $X_{j}$, armazena em cada posição o valor 1 (" $X$ ") se o carro que está naquela posição requer o opcional $o_{j}$; ou 0 ("-"), caso contrário. Desta forma, o cálculo do custo de um vizinho obtido pela troca dos carros nas posições $i$ e $k$ da solução pode ser calculado para cada restrição de capacidade separadamente. O custo total do vizinho é dado pela soma do custo das violações para todos os opcionais.

Trocar dois carros que não estão associados a uma determinada restrição certamente não altera o número de violações desta restrição. O mesmo acontece quando se deseja trocar dois carros que estão associados a uma mesma restrição. Portanto, é necessário analisar apenas trocas de dois carros em que um dos carros está associado a uma dada restrição e o outro não. Para se obter a variação no número de violações a uma restrição $p_{j} / q_{j}$ geradas pela retirada ou inserção de um carro, varrem-se todas as $q_{j}$ sequências às quais o carro pertence. Para cada sequência que violar a restrição de capacidade, adiciona-se 1, no caso da inserção, ou subtrai-se 1, no caso da remoção.

Sejam $n$ o número de carros na solução, $m$ o número de restrições de capacidade e $Q$ o denominador máximo dentre todas as restrições, a complexidade de pior caso da avaliação de um movimento troca $(\pi, i, k)$ é $O(Q \cdot m)$, uma vez que a variação no custo do vizinho tem que ser feito para cada uma das $m$ restrições de capacidade.

A aplicação do movimento na solução, ou seja, a atualização das estruturas de dados é feita em tempo $O(1)$ para os vetores $V$ e $X_{j}$, já que consiste apenas em trocar os valores armazenados nas posições $i$ e 
$k$ envolvidas na troca. Desta forma, a complexidade de pior caso da aplicação de um movimento troca é $O(1)+m \cdot O(1)=O(m)$.

\subsection{Estruturas de dados de Ribeiro et al. (2008)}

As estruturas de dados utilizadas em Estellon et al. (2008) são as mais intuitivas para representar uma solução para o PSC, mas não necessariamente as mais eficientes para a implementação dos algoritmos de busca local. Além dos vetores $V$ e $X_{j}, \forall o_{j} \in O$, Ribeiro et al. (2008) propuseram a utilização de três vetores adicionais para cada $o_{j} \in O$. Estes vetores auxiliam na avaliação da variação de custo causada pela aplicação de um movimento de troca na solução.

O primeiro vetor associado a uma restrição de capacidade de razão $p_{j} / q_{j}$, denominado $A_{j}, \forall o_{j} \in O$, armazena o número de carros que requerem o opcional $o_{j}$ em cada sequência consecutiva da solução corrente. $\mathrm{O}$ valor armazenado na posição $i$ deste vetor representa o número de carros associados à restrição na sequência de $q_{j}$ carros consecutivos que começa na posição $i$.

O exemplo da Figura 9 ajuda a entender melhor os valores que são armazenados em $A_{j}$. Neste exemplo, a restrição de capacidade considerada tem razão 1/4. As sequências consideradas ao longo da solução são ilustradas na figura e o número de carros associados à restrição em cada sequência bem como a posição correspondente no vetor de sequências podem ser vistos ao lado. Por exemplo, na primeira posição do vetor, tem-se o valor 3, que corresponde ao número de carros associados à restrição na sequência formada pelos quatro primeiros carros da solução. A segunda posição do vetor de sequências ter armazenado o valor 2 , correspondendo ao número de carros associados à restrição na sequência que começa no carro sequenciado na segunda posição, e assim sucessivamente, até a última sequência da solução.

\begin{tabular}{|c|c|c|}
\hline & Posição: & Valo \\
\hline$x_{-} x x_{-}-x_{-} x$ & 1 & 3 \\
\hline$x_{-} x^{x} x_{-} x_{-} x$ & 2 & 2 \\
\hline$x_{-} X x_{-}{ }_{-} x_{-} x$ & 3 & 2 \\
\hline$x_{-} x x_{-} x_{-} x$ & 4 & 1 \\
\hline$x_{-} x x_{-}-x_{-} x$ & 5 & 1 \\
\hline$x_{-} X x_{-}{ }_{-} x_{-} x$ & 6 & 1 \\
\hline$x_{-} x x_{-}-x_{-} x$ & 7 & 2 \\
\hline$x_{-} X x_{-} x_{-} X$ & 8 & 2 \\
\hline$x_{-} x x_{-} x_{-} x$ & 9 & 1 \\
\hline$X_{-} X x_{-}{ }_{-} X_{-} X$ & 10 & 1 \\
\hline
\end{tabular}

Figura 9. Vetor que guarda o número de carros associados a uma restrição em cada sequência.

O segundo vetor utilizado, denominado $B_{j}, \forall o_{j} \in O$, armazena em cada posição o número de sequências em que o número de carros associados a uma certa restrição na sequência é maior que o numerador da razão desta restrição, ou seja, o número de sequências que estão violando a restrição desde o início da solução até aquela posição. O valor armazenado na posição $i$ do vetor $B_{j}$ associado a uma restrição de razão $p_{j} / q_{j}$ corresponde ao número de sequências que violam esta restrição, considerando-se a sequência que começa na posição 1 até a sequência da posição $i$.

A Figura 10 ilustra o vetor $B_{j}$ referente à mesma restrição de capacidade de razão $1 / 4$ para a mesma solução apresentada na Figura 9. Com o auxílio do vetor $A_{j}$, que guarda o número de carros associados à restrição em cada sequência, pode-se ver que a primeira posição de $B_{j}$ tem o valor 1 , o que corresponde a uma sequência violando a restrição até esta posição do vetor $A_{j}$, ou seja, uma sequência que possui valor em $A_{j}$ maior que $p_{j}=1$. Na segunda posição, o valor armazenado é 2 , correspondendo às duas primeiras sequências e, na terceira posição, tem-se três sequências violando a restrição até esta posição. Na quarta posição, o valor continua igual a três, pois a sequência desta posição não viola a restrição. Desta forma, todas as posições de $B_{j}$ são calculadas.

O terceiro vetor, denominado $C_{j}, \forall o_{j} \in O$, é construído de forma análoga ao vetor $B_{j}$. A diferença é que são contabilizadas as sequências cujo valor em $A_{j}$ é maior ou igual ao numerador da razão da restrição 


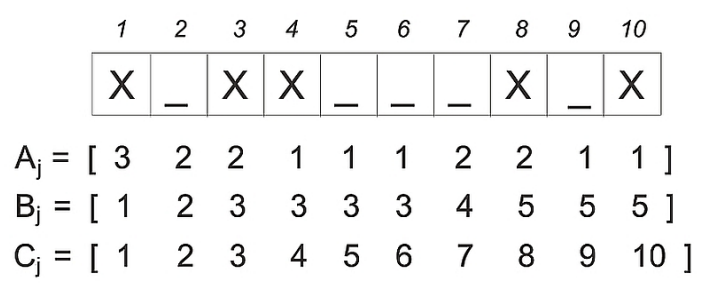

Figura 10. Vetores auxiliares correspondentes a uma solução.

considerada. A ideia é contabilizar as sequências em que a entrada de mais um carro associado à restrição aumenta o número de violações. Pode-se observar que isto inclui sequências que não violam a restrição, porém cujo valor no vetor $A_{j}$ é igual ao numerador da razão, valor máximo permitido para respeitar a restrição. Se um carro associado a esta restrição é adicionado a estas sequências, elas passam então a violar a restrição. A Figura 10 apresenta o vetor $C_{j}$ referente à mesma restrição de razão $1 / 4$ para a mesma solução apresentada na Figura 9.

O cálculo do custo de um vizinho obtido pela troca dos carros nas posições $i$ e $k$ da solução é apresentado a seguir. Assim como no caso de Estellon et al. (2008), este cálculo pode ser feito para cada um dos opcionais separadamente. O custo total do vizinho é dado pela soma das violações para todos os opcionais. A aplicação do movimento de trocar dois carros que não estão associados a uma determinada restrição, certamente, não causa variação no custo da solução. O mesmo acontece quando se deseja trocar dois carros que estão associados a uma mesma restrição. Portanto, é analisada apenas a troca de dois carros onde um dos carros está associado a uma dada restrição e o outro não. O número de violações de uma restrição de capacidade de razão $p_{j} / q_{j}$ que é decrescido no custo da solução com a retirada do carro associado a esta restrição da posição $i$ é obtido a partir do vetor $B_{j}$ correspondente e é denotado por $\Delta_{1}$. Como um carro pode diminuir ou aumentar somente uma violação em uma sequência, então é suficiente calcular quantas sequências, que possuem este carro, estão violando a restrição considerada. Desta forma, o valor de $\Delta_{1}$ é dado por:

$$
\Delta_{1}=\left\{\begin{array}{l}
B_{j}[i]-B_{j}\left[i-q_{j}\right], \text { se } i-q_{j}>0 \\
B_{j}[i], \text { caso contrário. }
\end{array}\right.
$$

O valor contido em $B_{j}[i]$ corresponde ao número de sequências violando a restrição desde a primeira sequência até a sequência que começa na posição $i$, que é a última sequência que contém o carro na posição $i$ da solução. A posição $i-q_{j}$ refere-se à última sequência à qual o carro da posição $i$ não pertence, uma vez que um carro está contido em exatamente $q_{j}$ sequências. Portanto, a subtração destes dois valores resulta no número de sequências que contêm o carro da posição $i$ e que violam a restrição. Se o valor de $i-q_{j}$ é menor que zero, significa que o carro aparece no início da solução e, portanto, $B_{j}[i]$ é o valor desejado. Então, $\Delta_{1}$ representa o número de violações da restrição que é reduzido se a troca dos carros considerados for realizada.

De maneira análoga, o número de violações adicionais de uma restrição decorrente da entrada de um carro associado à restrição na posição $k$, que não continha um carro associado a ela, é calculado a partir do vetor $C_{j}$ e denotado por $\Delta_{2}$ :

$$
\Delta_{2}=\left\{\begin{array}{l}
C_{j}[k]-C_{j}\left[k-q_{j}\right], \text { se } k-q_{j}>0 \\
C_{j}[k], \text { caso contrário. }
\end{array}\right.
$$

Conforme foi dito anteriormente, este vetor guarda o número de sequências em que a entrada de um carro associado à restrição correspondente aumenta o número de violações. Finalmente, a variação no custo causada pela troca destes dois carros é dada por $\Delta=\Delta_{2}-\Delta_{1}$.

No exemplo da Figura 10, suponha que se deseja avaliar a variação no custo causada pela inversão dos carros das posições 3 e 7 . Vale lembrar que a restrição de capacidade considerada tem razão $1 / 4$. O valor que será acrescido devido à entrada de um carro com a restrição na posição 7 é dado por $\Delta_{2}=C_{j}[7]-C_{j}[3]=4$. Por outro lado, o valor que será reduzido decorrente da entrada de um carro sem a restrição na posição 3 é dado por $\Delta_{1}=B_{j}[3]=3$. Assim, a aplicação deste movimento na solução resultará no acréscimo de uma violação desta restrição.

Uma atenção especial deve ser dada quando a distância entre as posições $i$ e $k$ dos carros que se deseja trocar é menor do que o denominador da razão da restrição que se está considerando, ou seja, quando $|i-k|<q_{j}$. Quando isto acontece, os dois carros pertencem a uma ou mais sequências em comum e estas sequências não devem ser consideradas na avaliação do movimento, uma vez que ambos os carros continuarão nestas sequências e, por conseguinte, o número de violações nelas não sofrerá alteração se o movimento for aplicado. Diante disto, as violações decrescidas decorrentes da troca do carro da posição $i$ associado a uma restrição 
de capacidade de razão $p_{j} / q_{j}$ com o carro da posição $k$, que não está associado a esta restrição, se $i<k$ e $k-i<q_{j}$, é dado por:

$$
\Delta_{1}=\left\{\begin{array}{l}
B_{j}\left[k-q_{j}\right]-B_{j}\left[i-q_{j}\right], \text { se } i-q_{j}>0 \text { e } k-q_{j}>0 \\
B_{j}\left[k-q_{j}\right], \text { se } i-q_{j} \leq 0 \text { e } k-q_{j}>0 \\
0, \text { caso contrário. }
\end{array}\right.
$$

Por sua vez, o número de violações que será aumentado em decorrência da aplicação do movimento, quando $i<k$ e $k-i<q_{j}$, é dado por:

$$
\Delta_{2}=C_{j}[k]-C_{j}[i] .
$$

Observa-se que a última sequência considerada no cálculo de $\Delta_{1}$ começa na posição $k-q_{j}$, que é a última sequência que contém o carro em $i$ antes do intervalo de sequências em comum. $\mathrm{O}$ valor de $\Delta_{1}$ pode ser $B_{j}\left[k-q_{j}\right]$ ou 0 , quando um ou ambos os carros estão na primeira sequência do dia de produção, respectivamente. Analogamente, pode-se observar que o cálculo de $\Delta_{2}$ começa com a sequência da posição $k-i+1$, pois esta é a primeira sequência após o intervalo de sequências em comum entre os dois carros. Quando $i>k$, a forma como os vetores são acessados é invertida: $B_{j}$ é acessado de forma análoga a $C_{j}$, e vice-versa.

Na Figura 11, continua-se com o exemplo das Figuras 9 e 10. Deseja-se trocar os carros da posição $i=4$, que está associado à restrição, e da posição $k=6$, que não está associado a ela. Tem-se, portanto, as sequências das posições 3 e 4 como sequências em comum entre os carros. Como o carro da posição 4 está na primeira sequência, mas o outro carro não está, pela Equação 15 , tem-se que $\Delta_{1}=B_{j}[6-4]=2$, enquanto que, pela Equação $16, \Delta_{2}=C_{j}[6]-C_{j}[4]=2$. Portanto, este movimento não causa alteração no número de violações desta restrição $\left(\Delta=\Delta_{2}-\Delta_{1}=0\right)$.

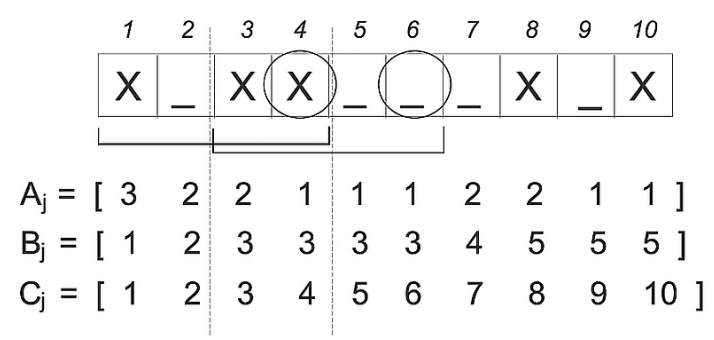

Figura 11. Vetores auxiliares correspondentes a uma solução.

Sejam $n$ o número de carros na solução, $m$ o número de restrições de capacidade e $Q$ o denominador máximo dentre todas as restrições. A complexidade da avaliação de um movimento demanda tempo $O(m)$, uma vez que ela é feita através das fórmulas dadas anteriormente em tempo $O(1)$ para cada uma das $m$ restrições de capacidade.

A aplicação de movimento troca na solução, ou seja, a atualização das estruturas de dados tem a seguinte complexidade assintótica no pior caso. O custo computacional de atualizar o vetor $V$ é $O(1)$ e o custo computacional de atualizar todos os vetores $X_{j}$ é $O(m)$, tal como calculado na Subseção anterior. Para atualizar o vetor $A_{j}$ de uma restrição de razão $p_{j} / q_{j}$, deve-se atualizar exatamente $q_{j}$ posições do vetor para cada um dos carros trocados, correspondendo a cada uma das sequências a que eles pertencem. Assim, a atualização dos vetores $A_{j}$ de todas as restrições resulta em uma complexidade $O(Q \cdot m)$, pois $q_{j} \leq Q$ para todo $o_{j} \in O$. A atualização dos vetores $B_{j}$ e $C_{j}$ de uma restrição de razão $p_{j} / q_{j}$, decorrente da troca dos carros das posições $i$ e $k$, implica, de forma geral, na alteração de todas as posições dos vetores a partir da posição $i-q_{j}$, se $i<k$, ou $k-q_{j}$, caso contrário. Esta atualização é necessária pois os valores armazenados nestes vetores correspondem a valores que são acumulados desde o início da solução e a alteração de qualquer posição deste vetor influenciará em todas as posições subsequentes. Desta forma, a atualização dos vetores $B_{j}$ e $C_{j}$ de todas as restrições demanda tempo computacional $O(n \cdot m)$. Isto implica que toda a atualização necessária após a aplicação de um movimento troca é $O(1)+O(m)+O(Q \cdot m)+O(n \cdot m)+O(n \cdot m)=O(n \cdot m)$, pois $Q \leq n$.

\section{Experimentos Computacionais}

Na seção anterior, observou-se que o custo computacional de se consultar o custo de um vizinho obtido pela troca de dois carros utilizando as estruturas de dados de Estellon et al. (2008) é $O(Q \cdot m)$, enquanto o custo 
de efetuar a troca de dois carros em uma solução e atualizar as respectivas estruturas de dados é $O(m)$, onde $n$ é o número de carros na solução, $m$ é o número de restrições de capacidade e $Q$ é o denominador máximo dentre todas as restrições de capacidade. Também observou-se que o custo computacional de se consultar o custo de um vizinho obtido pela troca de dois carros utilizando as estruturas de dados de Ribeiro et al. (2008) é $O(m)$, enquanto o custo de efetuar a troca de dois carros em uma solução e atualizar as respectivas estruturas de dados é $O(n \cdot m)$. Desta forma, pode-se dizer que as estruturas de dados de Ribeiro et al. (2008) são mais eficientes do que as de Estellon et al. (2008) quanto ao cálculo do custo de um vizinho. Por outro lado, pode-se dizer que as estruturas de dados de Estellon et al. (2008) são mais eficientes do que as de Ribeiro et al. (2008) quanto à atualização das estruturas de dados, uma vez que uma troca é efetivamente realizada.

Nesta seção, observa-se o impacto destas estruturas de dados em dois contextos diferentes. Na Seção 6.1, as duas estruturas de dados são comparadas num contexto de uma heurística de busca local, onde o número de consultas de custo de vizinhos é geralmente bem maior que a quantidade de trocas de carro que são efetivamente realizadas. Em seguida, na Seção 6.2 as duas estruturas de dados são comparadas num contexto de uma heurística VFLS, onde o número de consultas de custo de vizinhos é próximo do número de trocas que são efetivamente realizadas.

Os experimentos foram executados em um processador Intel Core 2 Duo CPU P8600 a 2.40GHz, com 3072 KBytes de memória cache e 3 GBytes de memória RAM. O sistema operacional utilizado foi o Ubuntu versão 11.10. Os algoritmos foram codificados em $\mathrm{C}++$ e compilados com a versão 4.6.1 do GNU/GCC.

As instâncias utilizadas nos experimentos foram geradas a partir do conjunto de instâncias de teste fornecido pela montadora Renault para o ROADEF Challenge 2005 (ROADEF, 2005) e tratam-se de instâncias semelhantes às de fábricas reais. As instâncias do ROADEF contêm dois tipos de restrição, descritas como restrições de alta prioridade (HPRC - High Priority Ratio Constraint) e baixa prioridade (LPRC - Low Priority Ratio Constraint). A Tabela 2 mostra as especificações de cada instância. A primeira coluna apresenta o identificador da instância e a segunda mostra todas as restrições de razão daquela instância. Por uma questão de espaço, as restrições que possuem o mesmo numerador são agrupadas. A terceira coluna contém o número de carros da instância.

\begin{tabular}{llc}
\hline Instâncias & Restrições de razão & Carros \\
\hline HPRC_022 & $1 /(3) ; 5 /(6)$ & 526 \\
HPRC_023 & $1 /(2,2,3,6,8,10) ; 3 /(4) ; 4 /(5) ; 6 /(7)$ & 1110 \\
HPRC_024 & $1 /(2,2,3,8,10,50)$ & 1270 \\
HPRC_025 & $1 /(4,8) ; 2 /(3,3)$ & 1161 \\
HPRC_028_1 & $1 /(2,3,6,7,8,10,10,12,20)$ & 365 \\
HPRC_028_2 & $1 /(6)$ & 65 \\
HPRC_029 & $1 /(6,7) ; 3 /(5) ; 2 /(5)$ & 730 \\
HPRC_035_1 & $1 /(5,6)$ & 1284 \\
HPRC_035_3 & $1 /(2,15) ; 2 /(3)$ & 269 \\
HPRC_039 & $1 /(3,5)$ & 1000 \\
HPRC_048_1 & $1 /(2,2,3,4,4) ; 2 /(3)$ & 591 \\
HPRC_048_2 & $1 /(2,3,4,4,6,8,12)$ & 546 \\
HPRC_064_1 & $1 /(2,4,5,7,8,14,30) ; 3 /(4) ; 2 /(3) ; 4 /(5) ; 16 /(24)$ & 825 \\
HPRC_064_2 & $1 /(2,2,5,40)$ & 412 \\
\hline LPRC_022 & $1 /(3,3,4,4,6,10) ; 10 /(15)$ & 526 \\
LPRC_023 & $1 /(2,2,2,2,2,3,4) ; 2 /(3)$ & 1110 \\
LPRC_024 & $1 /(5,7,25,40,40,40,50)$ \\
LPRC_025 & $1 /(2,2,3,3,3,6,7,18,20,97) ; 3 /(5) ; 2 /(3)$ & 1270 \\
LPRC_028_1 & $1 /(2,5,8,8,10,12,13,14) ; 2 /(3,7) ; 4 /(5)$ & 1161 \\
LPRC_028_2 & $1 /(2,2,3,4,5,5,28) ; 2 /(3)$ & 365 \\
LPRC_029 & $1 /(2,3) ; 36 /(43)$ & 65 \\
LPRC_035_1 & $1 /(2,3)$ & 730 \\
LPRC_035_3 & $1 /(2,25)$ & 1284 \\
LPRC_039 & $1 /(11,12,13,13,36,90,120) ; 40 /(60,60)$ & 269 \\
LPRC_048_1 & $1 /(3,4,4,4,5,6,6,7,8,8,10,12,12,50,310,310,310) ; 9 /(10) ; 2 /(3)$ & 591 \\
LPRC_048_2 & $1 /(3,3,4,5,5,5,6,8,8,8,10,11,16,20,50,50)$ & 546 \\
LPRC_064_1 & $1 /(3,6,22)$ & 825 \\
LPRC_064_2 & $1 /(21)$ & 412 \\
\hline
\end{tabular}

Tabela 2. Especificação do conjunto de instâncias de teste utilizadas nos experimentos computacionais. 


\subsection{Buscas locais}

Nesta seção observa-se o impacto das estruturas de dados de Estellon et al. (2008) e de Ribeiro et al. (2008) no desempenho de um algoritmo de busca local sob a vizinhança troca. Foram implementadas duas variações da busca local. A busca local Primeiro Aprimorante (PA) realiza efetivamente a troca de dois carros assim que for encontrada uma troca que diminui o custo da solução. Já a busca local Melhor Aprimorante (MA) testa todas as trocas de carros possíveis e só então realiza a melhor troca, ou seja, aquela dentre todos os vizinhos que mais reduz o número de violações na solução.

As buscas locais PA e MA foram implementadas com as duas estruturas de dados descritas na seção anterior. A geração de soluções iniciais foi feita utilizando uma permutação aleatória dos carros da instância. Foi medido o tempo computacional de cada implementação até que um ótimo local fosse atingido. Vale salientar que, independente da estrutura de dados utilizadas, PA e MA realizam, respectivamente, as mesmas operações ao longo da sua execução. Entretanto, o tempo computacional para realizar cada operação varia com a estrutura de dados utilizada.

Os resultados deste experimento são apresentados na Tabela 3. A primeira coluna mostra o identificador da instância. As quatro colunas seguintes apresentam a média do tempo de cinco execuções da busca local Melhor Aprimorante implementada com as estruturas de dados de Estellon et al. (2008) e de Ribeiro et al. (2008), respectivamente. A razão entre o número de consultas de vizinhos e o número de trocas de carros efetivamente efetuados, chamado aqui de Fator de Atualização (FA), da busca local Melhor Aprimorante é exibido na coluna 4. Os mesmos dados são mostrados nas cinco últimas colunas para a busca local Primeiro Aprimorante. Em negrito, estão destacados os tempos de execução obtidos pela estrutura de dados mais rápida. Pode-se observar que a implementação da busca local Melhor Aprimorante com as estruturas de dados de Ribeiro et al. (2008) gerou média de tempo menor do que a implementação com as estruturas de dados de Estellon et al. (2008) em 21 das 28 instâncias testadas. Isto se deve ao fato de que, nesta busca local, o número de consultas de custo de vizinhos é muito maior que o número de atualizações, o que beneficia as estruturas de dados de Ribeiro et al. (2008). No caso da busca local Primeiro Aprimorante, a implementação com estruturas de dados de Ribeiro et al. (2008) gerou média de tempo menor do que a implementação com as estruturas de dados de Estellon et al. (2008) em apenas 15 das 28 instâncias testadas. Isto se deve ao fato de que, nesta busca local, o número de consultas de custo de vizinhos é bem menor do que o mesmo número na busca local Melhor Aprimorante, já que uma troca é efetivamente realizada toda vez que um vizinho aprimorante é encontrado. Neste caso, apesar da complexidade assintótica de pior caso para se calcular um vizinho com as estruturas de dados de Ribeiro et al. (2008) ser menor do que com as estruturas de dados de Estellon et al. (2008), o maior custo computacional de atualizar as estruturas de dados da primeira resulta em um custo computacional semelhante ao da segunda.

\subsection{VFLS}

Neste seção, observa-se o impacto das estruturas de dados de Estellon et al. (2008) e de Ribeiro et al. (2008) no desempenho de uma heurística VFLS baseada na busca local troca. A cada iteração, um vizinho que consiste da troca de dois carros da solução é gerado aleatoriamente. Se o custo do vizinho for melhor ou igual que o custo da solução corrente, esta última é atualizada. Vale salientar que, ao contrário dos algoritmos de busca local, são realizadas trocas de carros que resultam em soluções de mesmo custo que a solução corrente. Para cada instância, um valor alvo para o custo da solução da heurística foi fixada e a heurística foi programada para executar até que uma solução com custo igual ou melhor que o custo alvo fosse encontrada.

Duas implementações desta heurística foram testadas, usando as estruturas de dados de Estellon et al. (2008) e as de Ribeiro et al. (2008). Vale salientar, que independente da estrutura de dados utilizada, a heurística VFLS resultante realiza as mesmas decisões ao longo da sua execução. Entretanto, o tempo computacional de realizar cada operação varia com a estrutura de dados utilizada.

Os resultados deste experimento podem ser observados na Figura 12, onde são traçados os gráficos da distribuição empírica de probabilidade das duas implementações atingirem o alvo em função do tempo para as instâncias HPRC_23, HPRC_24, HPRC_29 e HPRC_48_2. Os gráficos para as outras instâncias apresentam o mesmo comportamento. Estes gráficos foram traçados utilizando-se a metodologia descrita em Aiex et al. (2002, 2007), conhecida como Time-to-Target value plots. Primeiramente, os tempos de 100 execuções de cada heurística são ordenados. Em seguida, associa-se ao $i$-ésimo menor tempo $\tau_{i}$ uma probabilidade $\phi_{i}=(i-$ $\left.\frac{1}{2}\right) / 200$. Por fim, traçam-se os pontos $b_{i}=\left(\tau_{i}, \phi_{i}\right)$, para $i=1, \ldots, 200$. Pode-se observar que a probabilidade da implementação de VFLS com as estruturas de dados de Estellon et al. (2008) atingir o alvo é sempre maior que a da implementação de VFLS com as estruturas de dados de Ribeiro et al. (2008) em todas as instâncias apresentadas na Figura 12. O grande número de vizinhos de troca com o mesmo custo, e, consequentemente, o grande número de atualizações das estruturas de dados, explica o fato da implementação de VFLS com as estruturas de dados de Estellon et al. (2008) ser bem mais eficiente do que aquela com as estruturas de dados 


\begin{tabular}{|c|c|c|c|c|c|c|c|c|c|c|}
\hline \multirow[b]{2}{*}{ Instâncias } & \multicolumn{5}{|c|}{ Melhor Aprimorante } & \multicolumn{5}{|c|}{ Primeiro Aprimorante } \\
\hline & $\begin{array}{l}\text { Estellon } \\
\text { et al. }\end{array}$ & $\begin{array}{l}\text { Desvio } \\
\text { padrão }\end{array}$ & $\begin{array}{r}\text { Ribeiro } \\
\text { et al. }\end{array}$ & $\begin{array}{l}\text { Desvio } \\
\text { padrão }\end{array}$ & FA & $\begin{array}{l}\text { Estellon } \\
\text { et al. }\end{array}$ & $\begin{array}{l}\text { Desvio } \\
\text { padrão }\end{array}$ & $\begin{array}{r}\text { Ribeiro } \\
\text { et al. }\end{array}$ & $\begin{array}{l}\text { Desvio } \\
\text { padrão }\end{array}$ & FA \\
\hline HPRC_022 & 3,21 & 0,46 & 3,28 & 0,37 & $0,07 \%$ & 0,91 & 0,31 & 0,73 & 0,33 & $1,26 \%$ \\
\hline HPRC_023 & 490,82 & 48,76 & 459,89 & 34,93 & $0,02 \%$ & 11,70 & 1,12 & 11,44 & 1,33 & $2,84 \%$ \\
\hline HPRC_024 & 641,19 & 25,16 & 596,75 & 21,35 & $0,01 \%$ & 13,36 & 1,33 & 13,08 & 1,58 & $2,52 \%$ \\
\hline HPRC_025 & 225,20 & 14,62 & 219,25 & 5,25 & $0,01 \%$ & 5,96 & 0,69 & 5,70 & 0,77 & $1,78 \%$ \\
\hline HPRC_028_1 & 20,29 & 1,63 & 17,02 & 1,76 & $0,15 \%$ & 1,70 & 0,25 & 1,65 & 0,23 & $8,84 \%$ \\
\hline HPRC_028_2 & 0,58 & 0,08 & 0,60 & 0,08 & $3,66 \%$ & 0,04 & 0,03 & 0,05 & 0,03 & $12,58 \%$ \\
\hline HPRC_029 & 36,60 & 1,84 & 33,27 & 1,95 & $0,04 \%$ & 2,18 & 0,33 & 2,16 & 0,32 & $2,28 \%$ \\
\hline HPRC_035_1 & 0,48 & 0,33 & 0,61 & 0,34 & $1,16 \%$ & 0,47 & 0,11 & 0,51 & 0,11 & $16,35 \%$ \\
\hline HPRC_035_3 & 2,72 & 0,26 & 3,13 & 1,47 & $0,27 \%$ & 0,63 & 0,21 & 0,64 & 0,32 & $7,78 \%$ \\
\hline HPRC_039 & 34,84 & 3,08 & 32,65 & 1,56 & $0,02 \%$ & 2,45 & 0,27 & 2,39 & 0,26 & $0,38 \%$ \\
\hline HPRC_048_1 & 60,33 & 3,90 & 56,13 & 5,23 & $0,06 \%$ & 2,40 & 0,37 & 2,46 & 0,49 & $4,88 \%$ \\
\hline HPRC_048_2 & 35,97 & 3,62 & 35,18 & 3,50 & $0,07 \%$ & 2,57 & 0,19 & 2,63 & 0,24 & $4,23 \%$ \\
\hline HPRC_064_1 & 245,93 & 17,02 & 220,46 & 10,75 & $0,03 \%$ & 7,14 & 0,75 & 6,86 & 0,77 & $2,87 \%$ \\
\hline HPRC_064_2 & 8,14 & 0,67 & 7,72 & 1,39 & $0,12 \%$ & 1,21 & 0,11 & 0,74 & 0,11 & $2,76 \%$ \\
\hline LPRC_022 & 17,42 & 2,19 & 17,09 & 2,37 & $0,07 \%$ & 2,09 & 0,30 & 1,93 & 0,39 & $2,43 \%$ \\
\hline LPRC_023 & 123,02 & 7,40 & 120,90 & 5,87 & $0,02 \%$ & 9,04 & 1,23 & 9,51 & 1,97 & $0,65 \%$ \\
\hline LPRC_024 & 512,91 & 15,16 & 454,27 & 18,53 & $0,01 \%$ & 18,27 & 1,90 & 16,79 & 1,78 & $1,82 \%$ \\
\hline LPRC_025 & $1,209,53$ & 25,59 & $1,110,16$ & 22,97 & $0,01 \%$ & 18,05 & 1,85 & 19,11 & 2,84 & $4,31 \%$ \\
\hline LPRC_028_1 & 34,89 & 2,20 & 31,97 & 1,39 & $0,15 \%$ & 1,87 & 0,26 & 1,88 & 0,39 & $15,48 \%$ \\
\hline LPRC_028_2 & 0,52 & 0,30 & 0,58 & 0,30 & $4,24 \%$ & 0,45 & 0,31 & 0,48 & 0,30 & $29,71 \%$ \\
\hline LPRC_029 & 2,84 & 0,16 & 2,96 & 0,42 & $0,03 \%$ & 1,63 & 0,27 & 1,41 & 0,44 & $0,79 \%$ \\
\hline LPRC_035_1 & 0,72 & 0,38 & 0,48 & 0,27 & $1,17 \%$ & 0,59 & 0,26 & 0,62 & 0,26 & $19,00 \%$ \\
\hline LPRC_035_3 & 1,74 & 0,26 & 1,82 & 0,28 & $0,27 \%$ & 0,48 & 0,31 & 0,62 & 0,33 & $6,61 \%$ \\
\hline LPRC_039 & 244,16 & 7,86 & 176,09 & 4,53 & $0,02 \%$ & 19,20 & 3,00 & 14,29 & 2,11 & $2,17 \%$ \\
\hline LPRC_048_1 & 124,24 & 12,61 & 118,37 & 12,60 & $0,06 \%$ & 12,67 & 0,72 & 11,66 & 1,97 & $4,90 \%$ \\
\hline LPRC_048_2 & 68,10 & 3,85 & 66,42 & 4,33 & $0,07 \%$ & 4,76 & 0,44 & 4,76 & 0,42 & $4,31 \%$ \\
\hline LPRC_064_1 & 51,89 & 1,56 & 47,98 & 1,34 & $0,03 \%$ & 3,95 & 1,61 & 3,36 & 0,81 & $1,91 \%$ \\
\hline LPRC_064_2 & 0,77 & 0,29 & 0,87 & 0,30 & $0,10 \%$ & 0,70 & 0,31 & 0,78 & 0,24 & $1,04 \%$ \\
\hline
\end{tabular}

Tabela 3. Comparação do tempo de execução das busca locais Primeiro Aprimorante e Melhor Aprimorante implementadas com as estruturas de dados de Estellon et al. (2008) e de Ribeiro et al. (2008).

de Ribeiro et al. (2008), pois a primeira pode ser atualizada em $O(m)$ após a troca de dois carros, enquanto a atualização da segunda custa $O(n \cdot m)$.

\section{Considerações Finais}

Este capítulo apresentou o Problema do Sequenciamento de Carros, que consiste em determinar a ordem em que carros devem ser produzidos, de forma a minimizar o número de violações às restrições de capacidade da linha de montagem. Ademais, foram descritas as principais heurísticas e estruturas de dados existentes na literatura para o problema. Realizou-se uma série de experimentos computacionais baseados em dados reais que permitiu elaborar um estudo comparativo entre os algoritmos revisitados e suas estruturas de dados, identificando os pontos fortes e fracos de cada um.

Além da revisão da literatura sobre o PSC, percorrendo as heurísticas mais bem-sucedidas para o problema até então, este capítulo teve como objetivo principal mostrar que a escolha das estruturas de dados é um aspecto importante na implementação de heurísticas pois têm um papel crucial em seu desempenho. As estruturas de dados devem ser eficientes do ponto de vista das operações que deverão ser realizadas sobre elas, sobretudo as operações executadas com maior frequência.

\section{Referências}

Aiex, R.M.; Resende, M.G.C. \& Ribeiro, C.C., Probability distribution of solution time in GRASP: An experimental investigation. Journal of Heuristics, 8(3):343-373, 2002.

Aiex, R.M.; Resende, M.G.C. \& Ribeiro, C.C., TTTPLOTS: A Perl program to create time-to-target plots. Optimization Letters, 1(4):355-366, 2007.

Cheng, J.; Lu, Y.; Puskorius, G.; Bergeon, S. \& Xiao, J., Vehicle sequencing based on evolutionary computation. In: Proceedings of the Congress on Evolutionary Computation. Piscataway, USA: IEEE Press, v. 3, p. 1207-1215, 1999. 

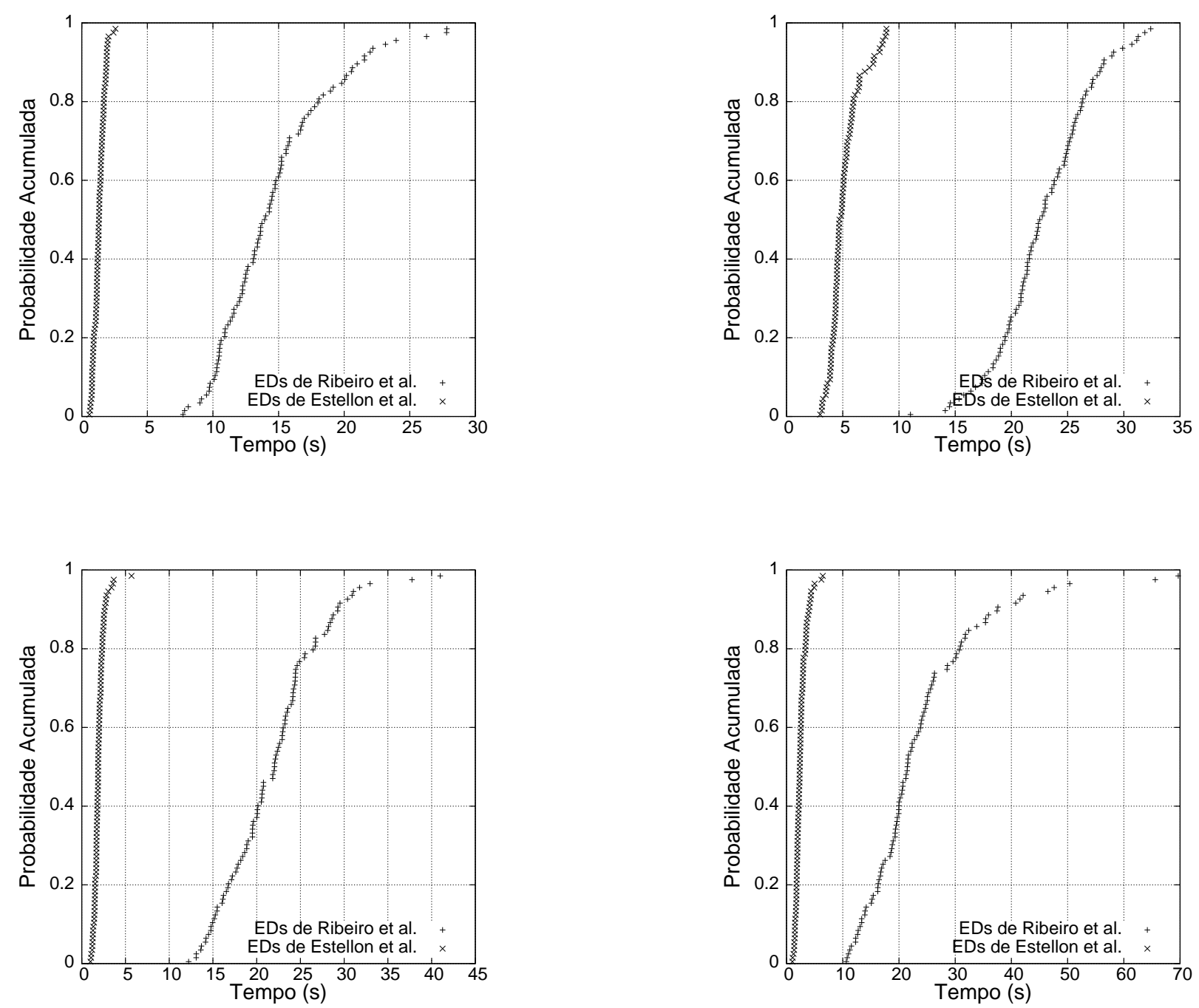

Figura 12. Gráficos da distribuição empírica de probabilidade das duas implementações atingirem o alvo em função do tempo para as instâncias HPRC_23 (a), HPRC_24 (b), HPRC_29 (c) e HPRC_48_2 (d).

Dincbas, M.; Simonis, M. \& van Hentenryck, P., Solving the car sequencing problem in constraint logic programming. In: Kodratoff, Y. (Ed.), Proceedings of the 8th European Conference on Artificial Intelligence. London, UK: Pitman, p. 290-295, 1988.

Drexl, A.; Kimms, A. \& Matthießen, L., Algorithms for the car sequencing and the level scheduling problem. Journal of Scheduling, 9(2):153-176, 2006.

Estellon, B.; Gardi, F. \& Nouioua, K., Two local search approaches for solving real-life car sequencing problems. European Journal of Operational Research, 191(3):928-944, 2008.

Gagné, C.; Gravel, M. \& Price, W.L., Solving real car sequencing problems with ant colony optimization. European Journal of Operational Research, 174(3):1427-1448, 2006.

Gavranovic, H., Local search and suffix tree for car sequencing problem with colors. European Journal of Operational Research, 191(3):972-980, 2008.

Gent, I.P., Two Results on Car Sequencing Problems. Technical Report APES-02-1998, Department of Computer Science, University of Strathclyde, Glasgow, UK, 1998.

Gottlieb, J.; Puchta, M. \& Solnon, C., A study of greedy, local search, and ant colony optimization approaches for car sequencing problems. In: Cagnoni, S.; Johnson, C.G.; Marchiori, E.; Corne, D.W. \& Gottlieb, J. (Eds.), Applications of Evolutionary Computing. Heidelberg, Germany: Springer-Verlag, v. 2611 de Lecture Notes in Computer Science, p. 246-257, 2003.

Kis, T., On the complexity of the car sequencing problem. Operations Research Letters, 32(4):331-335, 2004.

Parello, B.D.; Kabat, W.C. \& Wos, L., Job-shop scheduling using automated reasoning: a case study of the car sequencing problem. Journal of the Automated Reasoning, 2(1):1-42, 1986. 
Règin, J.C. \& Puget, J.F., A filtering algorithm for global sequencing constraints. In: Smolka, G. (Ed.), Principles and Pratice of Constraint Programming. Heidelberg, Germany: Springer-Verlag, v. 1330 de Lecture Notes in Computer Science, p. 32-46, 1997.

Ribeiro, C.C.; Aloise, D.; Noronha, T.F.; Rocha, C. \& Urrutia, S., An efficient implementation of a VNS/ILS heuristic for a real-life car sequencing problem. European Journal of Operational Research, 191(3):596-611, 2008.

ROADEF, , Roadef challenge 2005. http://challenge.roadef.org/2005/en/, 2005. Visitado em: 07/11/2012.

Smith, B.M., Succeed-first or fail-first: a case study in variable and value ordering. Report 96.26, University of Leeds, Division of Artificial Intelligence, Leeds, UK, 1996.

Solnon, C., Solving permutation constraint satisfaction problems with artificial ants. In: Horn, W. (Ed.), Proceedings of the 14th European Conference on Artificial Intelligence. Amsterdam, Netherlands: IOS Press, p. 118-122, 2000.

Solnon, C., Combining two pheromone structures for solving the car sequencing problem with ant colony optimization. European Journal of Operational Research, 191(3):1043-1055, 2008.

van Hentenryck, P.; Simonis, H. \& Dincbas, M., Constraint satisfation using constraint logic programming. Artificial Intelligence, 58:113-159, 1992.

Warwick, T. \& Tsang, E., Tacking car sequencing problems using a genetic algorithm. Evolutionary Computation, $3(3): 267-298,1995$.

\section{Notas Biográficas}

Daniel Brasil é graduado em Ciência da Computação (Universidade Federal de Minas Gerais, 2011). Atualmente cursa o Mestrado do Programa de Pós-Graduação do Departamento de Ciência da Computação da UFMG.

Thiago Ferreira de Noronha é graduado em Ciência da Computação (Universidade Federal do Rio Grande do Norte, 2001), mestre e doutor em Informática (Pontifícia Universidade Católica do Rio de Janeiro, 2004 e 2008, respectivamente). Trabalhou na Google Brasil como engenheiro de software de 2008 a 2009. Atualmente é professor pesquisador do Departamento de Ciência da Computação da Universidade Federal de Minas Gerais.

Caroline Rocha é graduada em Ciência da Computação (Universidade Federal do Rio Grande do Norte, 2002), mestre em Computação (Universidade Federal Fluminense, 2005) e doutora em Informática (Université de Montréal, Canadá). Atualmente é professora adjunta da Escola de Ciências e Tecnologia da UFRN. 
Brasil et al. 


\title{
Algoritmo Genético e Evolução Diferencial para a Resolução do Problema de Planejamento Hidrelétrico
}

\author{
Priscila Cristina Berbert Rampazzo, Akebo Yamakami, Fabrício Olivetti de França
}

\begin{abstract}
Resumo: O planejamento hidrelétrico é um problema de otimização de grande porte, dinâmico, estocástico, interconectado e não-linear. No modelo estudado, considerou-se a minimização da complementação térmica como função-objetivo e a vazão turbinada pelas usinas hidrelétricas em cada período como variáveis de decisão. Duas Metaheurísticas Evolutivas para a resolução do Problema de Planejamento da Operação de Sistemas Hidrelétricos são propostas: Algoritmo Genético e Evolução Diferencial. Os métodos consideram simultaneamente um conjunto de soluções e, através da integração da ampla exploração do espaço de soluções com um processo de busca mais localizada, permitem encontrar soluções alternativas e de qualidade. Os testes foram realizados com Subsistemas Brasileiros.
\end{abstract}

Palavras-chave: Algoritmo genético, Evolução diferencial, Planejamento hidrelétrico, Otimização.

\begin{abstract}
The operation planning of hydroelectric systems is a large, dynamic, stochastic, interconnected and nonlinear optimization problem. In the model studied here, the minimization of thermal complement was considered as the objective function and the water discharge of hydroelectric plants at each period was considered as the decision variables. Two Evolutionary Metaheuristics were applied to solve this problem: Genetic Algorithm and Differential Evolution. The methods consider a set of solutions in order to perform exploration and exploitation of the search space allowing them to find several good quality solutions. Tests were performed with Brazilian subsystems.
\end{abstract}

Keywords: Genetic algorithm, Differential evolution, Hydroelectric planning, Optimization.

\section{Introdução}

O Planejamento da Operação de Sistemas Hidrelétricos é um problema de otimização de grande porte, dinâmico, estocástico, interconectado e não-linear. Como definido no Manual do Programa de Pesquisa e Desenvolvimento Tecnológico do Setor de Energia Elétrica ${ }^{1}$, são de interesse da Agência Nacional de Energia Elétrica (ANEEL) projetos destinados ao desenvolvimento de metodologias, técnicas e ferramentas de auxílio que integrem modelos matemáticos, técnicas de programação matemática e de inteligência artificial, visando o planejamento e a melhor aplicação dos recursos que necessitam de suporte à tomada de decisões. A partir destas considerações e conhecendo a importância e a relevância do problema, surgiu o interesse em estudar a aplicação de Metaheurísticas para sua resolução, mais especificamente, Algoritmo Genético (AG) e Evolução Diferencial (ED).

O processo de geração de energia hidrelétrica baseia-se na transformação da energia potencial hidráulica resultante do aproveitamento de quedas d'água. Em sistemas com grande participação de geração hidrelétrica, como no caso do Brasil, pode-se gerenciar a energia potencial da água armazenada nos reservatórios para atender à demanda e substituir de forma racional a geração dispendiosa das unidades térmicas.

O volume de água armazenado nos reservatórios depende das afluências que ocorrerão no futuro (Figura 1). Isto introduz uma relação entre a decisão de operação no presente e suas consequências futuras (Leite et al., 2006a). Se a decisão for utilizar energia hidrelétrica para atender o mercado, deplecionando os reservatórios, e no futuro ocorrer uma seca, pode haver a necessidade de utilizar a geração térmica ou interromper o fornecimento de energia. Se a opção for conservar os reservatórios cheios e utilizar a geração térmica, na ocorrência de grandes vazões afluentes, pode haver vertimento no sistema, ou seja, desperdício de energia e, em consequência, um aumento desnecessário do custo de operação. O planejamento deve estabelecer um

\footnotetext{
* Autor para contato: pberbert@dt.fee.unicamp.br

1 http://www.aneel.gov.br/visualizar_texto.cfm?idtxt=1615
} 


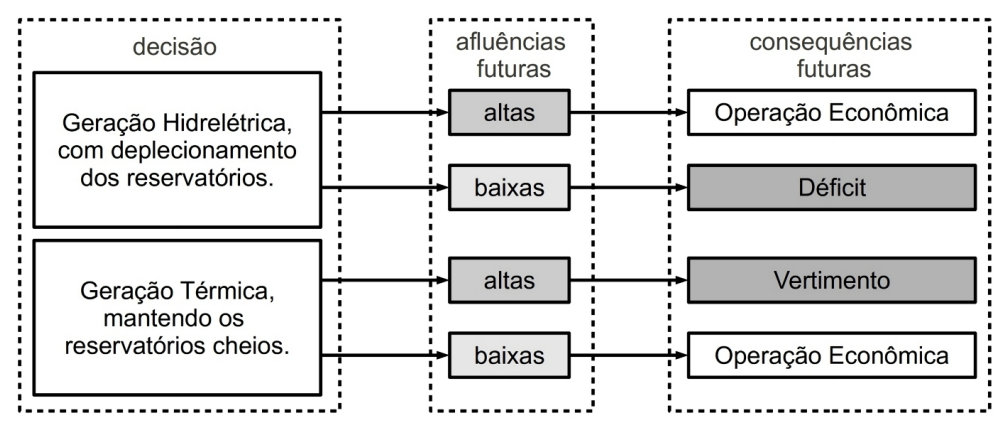

Figura 1. Cronograma de decisão.

compromisso entre a geração hidrelétrica no momento da decisão e a disponibilidade de água nos intervalos de tempo seguintes, respeitando as restrições do problema.

$\mathrm{Na}$ área de Pesquisa Operacional existem várias técnicas de Programação Matemática para a resolução de problemas de otimização. Algumas técnicas tem alta complexidade e dificuldade no tratamento de certos tipos de problemas, por serem fundamentadas em informações que restringem ou dificultam uma aplicação geral. No Planejamento da Operação de Sistemas Hidrelétricos, as funções de geração apresentam não-linearidades; para resolução através de métodos de Programação Linear (PL) recorre-se, então, às linearizações por partes ou aproximações lineares, simplificando o problema, o que pode não apresentar uma precisão aceitável. Nas técnicas de Programação Não-Linear (PNL), em muitos problemas, o método converge a um "ótimo local", sem a garantia que o método atingiu o "ótimo global". As técnicas de Programação Dinâmica (PD) consistem em dividir o período de planejamento em estágios e a melhor decisão em cada estágio é determinada de acordo com o estado em que o sistema se encontra. A desvantagem é a necessidade da discretização em estados, ocasionando um esforço computacional que cresce exponencialmente com o número de variáveis de estado consideradas; é o problema da "maldição da dimensionalidade".

Dentre os Métodos Metaheurísticos, estão os Algoritmos Evolutivos: Algoritmos Genéticos, Evolução Diferencial, Estratégias Evolutivas, Programação Evolutiva, etc. Inspirados em mecanismos da evolução biológica, estes algoritmos vem sendo amplamente utilizados em diversas aplicações, principalmente na área de otimização. Alguns pesquisadores tem apontado problemas nos quais os Algoritmos Evolutivos tem desempenho melhor do que outras estratégias de busca (Toro et al., 2006). Algumas características destes métodos merecem ser destacadas: flexibilidade, generalidade, exploração, explotação, paralelismo, capacidade de escapar de ótimos locais, capacidade de lidar com problemas complexos para os quais não é possível, ou é difícil, obter uma descrição detalhada, além de serem menos susceptíveis à forma ou continuidade das funções (Bäck et al., 2000b,a; Coello-Coello, 2002). Estes métodos trabalham com um conjunto de soluções, simultaneamente. Combinando a ampla exploração do espaço de busca com um processo de busca mais localizada, os Algoritmos Evolutivos possuem alto grau de robustez, o permite aplicá-los em vários problemas práticos, junto aos quais outras estratégias de solução se mostram inócuas (Bäck et al., 2000b,a). Além disto, os problemas reais tem se tornado cada vez mais complexos, sem funções definidas ou bem comportadas e, na maioria das vezes, descontínuas e com domínios não-convexos, dificultando a utilização de métodos exatos na resolução.

Existem muitos fatores que envolvem o Planejamento de Sistemas Hidrelétricos e é natural que várias abordagens sejam propostas (Scola et al., 2011). Na literatura, dentre os trabalhos que utilizam métodos de programação matemática para a resolução do problema (Rosenthal, 1981; Catalão et al., 2009a,b; Dias et al., 2010), destaca-se o modelo de otimização a usinas individualizadas, HydroMax, (Carvalho \& Soares, 1987; Oliveira \& Soares, 1995; Cicogna, 1999, 2003; Cicogna \& Soares, 2005) baseado em um algoritmo determinístico de fluxos em rede não-linear com arcos capacitados. Dentre as metodologias envolvendo métodos metaheurísticos, destacam-se propostas de Algoritmo Genético (Leite et al., 2006b; Zoumas et al., 2004; Leite et al., 2006a; Ferreira \& Silva, 2011), Simulated Anealling (Ferreira \& Silva, 2011) e Algoritmo Genético Híbrido com operador genético baseado no método do gradiente (Leite \& Carvalho, 2006).

A Seção 2 apresenta a formulação matemática do problema. Na Seção 3, os fundamentos e os operadores evolutivos das abordagens estudadas, respectivamente, Algoritmo Genético e Evolução Diferencial são apresentados. A Seção 4 apresenta os dois algoritmos propostos e implementados: hidroGA (Algoritmo Genético) e hidroDE (Evolução Diferencial). A Seção 5 traz a aplicação dos algoritmos na resolução do problema, juntamente com a discussão e comparação dos resultados obtidos. Finalmente, a Seção 6 apresenta as conclusões e considerações finais. 


\section{Formulação do Problema}

As variáveis e os parâmetros envolvidos na formulação matemática do modelo de múltiplas usinas hidrelétricas individualizadas para Sistemas Hidrelétricos de geração são:

$T$ : número de intervalos de tempo.

$N$ : número de usinas hidrelétricas.

$\Delta t$ : tamanho de cada intervalo de tempo $[s]$.

$\Omega_{i}$ : conjunto das usinas imediatamente a montante da usina $i$.

$k(i)$ : produtividade específica ${ }^{2}$ da usina $i$.

$\mathcal{C}($.$) : função de custo da geração termelétrica [\$].$

$\lambda(t)$ : coeficiente de valor presente para o intervalo $t$.

$D(t)$ : demanda a ser atendida no intervalo $t[\overline{M W}]$.

$H(t)$ : geração hidrelétrica total no intervalo $t[\overline{M W}]$.

$G(t)$ : geração termelétrica total no intervalo $t[\overline{M W}]$.

$q(i, t)$ : vazão turbinada pela usina $i$ no intervalo $t\left[\mathrm{~m}^{3} / \mathrm{s}\right]$.

$z(i, t)$ : vazão vertida pela usina $i$ no intervalo $t\left[\mathrm{~m}^{3} / \mathrm{s}\right]$.

$u(i, t)$ : vazão defluente da usina $i$ no intervalo $t\left[\mathrm{~m}^{3} / \mathrm{s}\right]$.

$y(i, t)$ : vazão incremental afluente à usina $i$ no intervalo $t\left[\mathrm{~m}^{3} / \mathrm{s}\right]$.

$x(i, t)$ : volume do reservatório da usina $i$ no início do intervalo $t\left[\mathrm{hm}^{3}\right]$.

$x_{\text {med }}(i, t)$ : volume médio do reservatório da usina $i$ no intervalo $t\left[\mathrm{hm}^{3}\right]$.

$p(i, t)$ : geração da usina hidrelétrica $i$ no intervalo $t[\overline{M W}]$.

$h(i, t)$ : altura da queda bruta da usina $i$ no intervalo $t[m]$.

$\phi(i, x(i, t))$ : cota de montante do reservatório da usina $i$.

$\theta(i, u(i, t))$ : cota de jusante do canal de fuga da usina $i$.

$x_{m i n}(i)$ : volume mínimo do reservatório da usina $i\left[\mathrm{hm}^{3}\right]$.

$x_{\max }(i)$ : volume máximo do reservatório da usina $i\left[\mathrm{hm}^{3}\right]$.

$q_{\max }(i)$ : máxima vazão turbinada pela usina $i\left[\mathrm{~m}^{3} / \mathrm{s}\right]$.

$u_{\text {min }}(i)$ : mínima vazão defluente da usina $i\left[\mathrm{~m}^{3} / \mathrm{s}\right]$.

$$
\begin{array}{ll}
\text { Minimizar } \quad & \sum_{t=1}^{T}[\lambda(t) \cdot \mathcal{C}(G(t))] \\
\text { Sujeito a } \quad & G(t)=D(t)-H(t) \\
& H(t)=\sum_{i=1}^{N} p(i, t) \\
& p(i, t)=k(i) \cdot h(i, t) \cdot q(i, t) \\
& h(i, t)=\phi\left(i, x_{m e d}(i, t)\right)-\theta(i, u(i, t)) \\
& x_{m e d}(i, t)=\frac{x(i, t)+x(i, t+1)}{2} \\
& x(i, t+1)=x(i, t)+\left\{y(i, t)-q(i, t)-z(i, t)+\sum_{k \in \Omega_{i}}[q(k, t)+z(k, t)]\right\} \frac{\Delta t}{10^{6}} \\
& u(i, t)=q(i, t)+z(i, t)
\end{array}
$$

\footnotetext{
2 constante que engloba aceleração da gravidade, densidade da água, rendimento turbina-gerador e fatores de conversão.
} 


$$
\begin{aligned}
& x_{\min }(i) \leqslant x(i, t) \leqslant x_{\max }(i) \\
& q(i, t) \leqslant q_{\max }(i) \\
& u(i, t) \geqslant u_{\min }(i) \\
& \quad \forall i=1, \ldots, N \quad, \forall t=1, \ldots, T
\end{aligned}
$$

De forma geral, o sistema brasileiro explora intensamente a geração hidrelétrica, enquanto minimiza a necessidade de complementação com a geração térmica (Zambon, 2008). Com o intuito de evitar o deplecionamento do volume final dos reservatórios na solução do problema, adotou-se um método de penalização da função-objetivo:

$$
\text { Minimizar } \quad \sum_{t=1}^{T}[\lambda(t) \cdot \mathcal{C}(G(t))]-\sum_{i=1}^{N} \mathcal{M}(i) \cdot x(i, T)
$$

onde o vetor de constantes positivas de penalização $\mathcal{M}($.$) é obtido empiricamente, de maneira que os$ reservatórios de todas as usinas consigam recuperar seus volumes.

O sistema termelétrico é representado por uma única usina térmica com capacidade de geração ilimitada e função de custo convexa crescente, próxima de um polinômio de segundo grau (El-Hawary \& Christensen, 1979). Por simplificação:

$$
\mathcal{C}(G(t))=(G(t))^{2}
$$

Deve-se considerar uma taxa de juros na manipulação deste custo. O principal objetivo é poder trazer para o início do horizonte (valor presente dos custos) o custo total resultante do planejamento energético (Cicogna, 1999). O coeficiente de valor presente para o intervalo $t$ é então definido como:

$$
\lambda(t)=\frac{1}{(1+i)^{t}}
$$

onde $i$ é a taxa de juros efetiva para cada intervalo do horizonte de planejamento. Esta taxa afeta a operação diminuindo os níveis dos reservatórios no início do horizonte e adiando a geração térmica para o final do período de planejamento.

A função de geração hidrelétrica (Equação 4) também é não-linear. Isto porque a queda líquida $h(i, t)$ é função da cota de montante $\phi(i, x(i, t))$ e da cota de jusante $\theta(i, u(i, t))$, que são, respectivamente, funções aproximadas por polinômios de quarto grau.

\section{Metaheurísticas Evolutivas}

Metaheurísticas Evolutivas são procedimentos computacionais para a resolução de problemas resultantes da aplicação de técnicas heurísticas baseadas na seguinte sequência básica: realização de reprodução com herança genética, introdução de variações aleatórias, promoção de competição e seleção de indivíduos de uma dada população. Isto é feito através de processos iterativos, onde cada iteração é chamada de geração. Esse processo é repetido um determinado número de vezes.

Os Algoritmos Evolutivos trabalham com uma população formada por um conjunto aleatório de indivíduos, ou seja, possíveis soluções para o problema. Durante as gerações, esta população é avaliada. Os mais adaptados são selecionados e podem sofrer modificações em suas características através de cruzamentos (crossover) e mutações, gerando descendentes. Finalmente, os mais adaptados entre indivíduos pais e filhos passam para a próxima geração, resultando em indivíduos cada vez mais aptos, enquanto indivíduos menos aptos tendem a desaparecer.

A codificação dos indivíduos e a definição da função de adaptação ou fitness são as etapas mais importantes do algoritmo, mas o desempenho do processo evolutivo também depende dos parâmetros envolvidos, tais como: tamanho da população, probabilidade de aplicação dos operadores genéticos, critérios dos operadores de seleção e condição de parada. A função de adaptação permite atribuir a cada elemento do espaço de busca um valor que é usado como medida de desempenho. Em problemas de otimização, esta função incorpora todos os aspectos presentes na função-objetivo.

A população inicial (da primeira geração) pode ser formada por indivíduos aleatórios ou incorporar conhecimento a priori sobre o problema. Alguns indivíduos podem ser reinicializados durante as gerações, nos casos de queda da diversidade ou diminuição da taxa de melhoria.

Em problemas de otimização com restrições, a codificação adotada pode fazer com que indivíduos modificados sejam infactíveis. Nestes casos, cuidados especiais devem ser tomados na definição da codificação 
e dos operadores (Bäck et al., 2000a). Os operadores evolutivos dependem diretamente da definição do espaço de busca e da codificação do problema. Nas Seções a seguir, são discutidos os operadores específicos de cada uma das abordagens: Algoritmo Genético e Evolução Diferencial.

Embora possam parecer simplistas do ponto de vista biológico, estes algoritmos são suficientemente complexos para fornecer mecanismos de busca adaptativos, eficientes e robustos. Em Bäck et al. (2000b,a), pode-se encontrar conceitos fundamentais e aplicações dos Algoritmos Evolutivos. Em Goldberg (1989), Michalewicz (1996) e Price et al. (2005) são descritos mais detalhes sobre as duas abordagens estudadas neste capítulo.

\subsection{Algoritmo genético}

O trabalho pioneiro de J. H. Holland nos anos 70, com a publicação de seu livro, Adaptation in Natural and Artificial Systems, provou a significante contribuição do Algoritmo Genético (Goldberg, 1989) para a ciência e para as aplicações na área de engenharia. Desde então, os trabalhos de pesquisa neste campo vem crescendo exponencialmente (Man et al., 1996).

Algoritmos Genéticos são algoritmos de otimização baseados em uma estratégia de busca paralela, estruturada e aleatória por soluções com maior desempenho. Apesar de aleatória, a busca é direcionada, pois explora informações históricas para encontrar novas soluções. Um conjunto de operações é necessário para que, dada uma população, se consiga gerar populações sucessivas com melhores desempenhos que as anteriores.

Operadores unários, como a mutação, criam um novo indivíduo partindo de um único progenitor, mantendo a diversidade genética da população. Operadores de ordem mais elevada, como o cruzamento, geram novos indivíduos através da recombinação de características de dois ou mais indivíduos progenitores (herança). O cruzamento é considerado o operador genético predominante, por isto é aplicado com probabilidade maior que a mutação. Quanto maior for a probabilidade de cruzamento, mais rapidamente novas soluções são introduzidas na população; porém, valores muito altos podem resultar em perda de soluções com boa aptidão; com valores muito baixos, o algoritmo pode tornar-se muito lento. Uma baixa probabilidade de mutação evita que as soluções fiquem estagnadas em um valor (busca local). Uma probabilidade muito alta torna a busca essencialmente aleatória.

Os métodos de seleção podem ser determinísticos ou probabilísticos. A ideia básica é privilegiar indivíduos com valores de fitness mais elevados. Para prevenir que os melhores indivíduos não desapareçam da população pela manipulação dos operadores genéticos, eles podem passar para a próxima geração através da seleção elitista.

A forma geral e simplificada de um Algoritmo Genético é apresentada a seguir.

\{

Procedimento AlgoritmoGenetico(populacao, GERACOES)

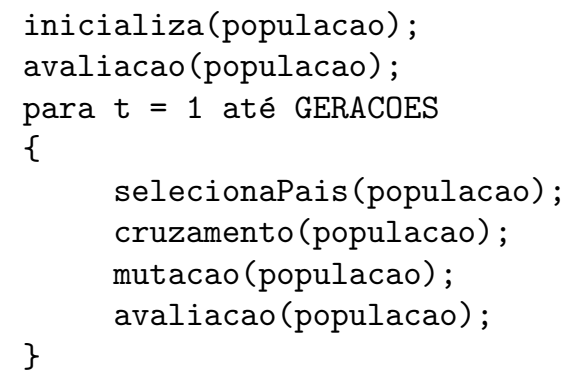

\subsection{Evolução diferencial}

A Evolução Diferencial (Price et al., 2005) foi apresentada como uma versão melhorada do Algoritmo Genético, resolvendo de forma mais rápida os problemas de otimização. É uma meta-heurística desenvolvida para ser um método de busca paralela, direta e estocástica (Storn \& Price, 1997).

A Evolução Diferencial gera um novo indivíduo através da adição da diferença ponderada entre duas soluções a uma terceira solução (Figura 2). A ponderação previne duplicações de soluções existentes; esta operação é considerada como uma mutação. A solução mutada (donor) é então combinada com outra solução pré-determinada, a solução target, para gerar a solução trial. Esta combinação corresponde ao cruzamento (crossover) e tem a finalidade de aumentar a diversidade das soluções mutadas ao mesmo tempo que incorpora soluções boas de gerações anteriores. 

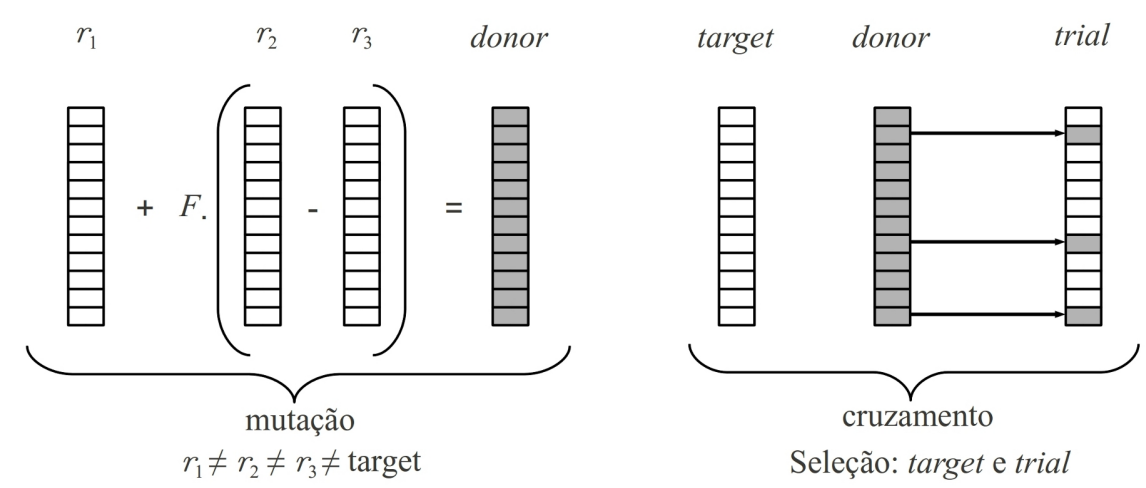

Figura 2. Mutação, cruzamento e seleção da evolução diferencial.

É importante ressaltar que cada solução presente na população atual deve ser usada uma vez como target (ou seja, toda solução da população deve ser utilizada no cruzamento e, por consequência, na seleção). Caso a solução trial forneça um valor de fitness menor (problema de minimização) que aquele associado à respectiva solução target, esta última dará lugar à primeira na próxima geração (critério guloso). Esta operação corresponde à seleção. Uma das vantagens da Evolução Diferencial é a necessidade de poucos parâmetros de controle para os operadores, os quais tem seus valores ajustados de maneira relativamente simples.

A forma geral e simplificada de um algoritmo de Evolução Diferencial é apresentada a seguir.

\{

Procedimento EvolucaoDiferencial (populacao, GERACOES)

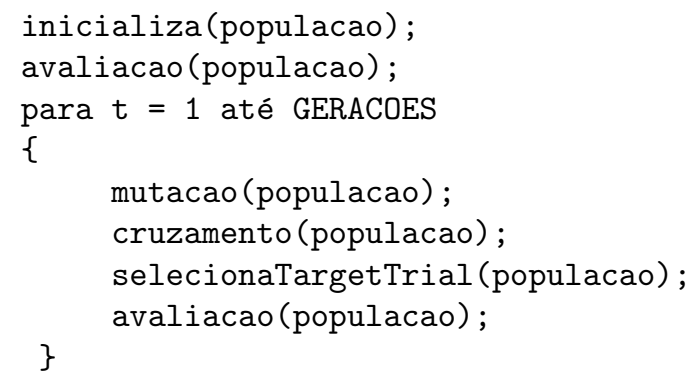

\section{Algoritmos Propostos}

O desenvolvimento e as funcionalidades dos Algoritmos Evolutivos propostos para a solução do problema de Planejamento da Operação de Sistemas Hidrelétricos são descritos a seguir. Alguns operadores foram implementados com a preocupação de respeitar as características físicas e operacionais do sistema.

Primeiramente, são apresentadas as considerações comuns aos dois algoritmos: Algoritmo Genético e Evolução Diferencial. Considerações específicas de cada algoritmo são apresentados nas Seções 4.1 e 4.2 , respectivamente.

\section{Codificação}

Adotou-se a codificação real para a representação do problema. Um indivíduo $k$ representa a vazão turbinada, $q_{k}(i, t)$, de cada usina em cada período de tempo, ou seja, cada indivíduo da população é uma matriz bidimensional (Figura 3).

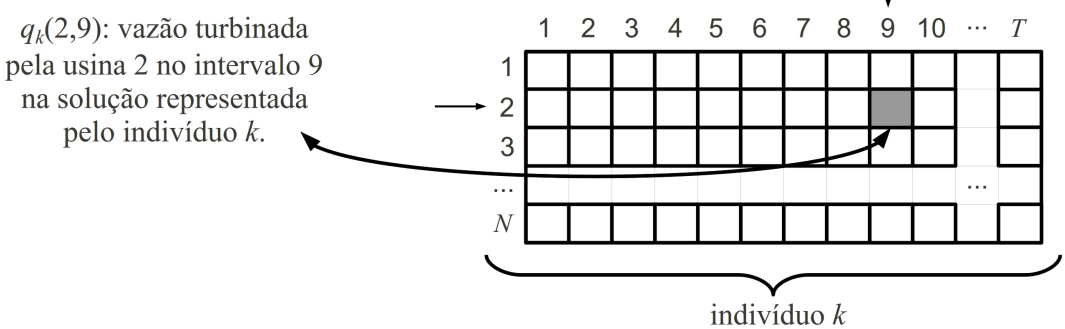

Figura 3. Representação de um indivíduo da população. 


\section{Inicialização}

O tamanho da população $(T P)$ e o número de gerações $(G)$ foram definidos empiricamente, de acordo com as análises (Seção 5) realizadas durante os testes. A inicialização de cada invidivíduo da população é aleatória, ou seja, para cada usina e período de tempo, de cada indivíduo $k$, a vazão turbinada $q_{k}(i, t)$ é um número aleatório pertencente ao intervalo $\left[u_{\min }(i), q_{\max }(i)\right]$.

\section{Avaliação da População}

Para cada indivíduo $k$ da população:

1. para cada usina $i$ com reservatório, o volume inicial $x_{k}(i, 1)$ é igual ao máximo $x_{\max }(i)$;

2. para cada usina $i$ a fio d'água, considerou-se que $x_{k}(i, t)=x_{\max }(i), \forall t$ e a equação de balanceamento (Equação 7) se reduz a:

$$
y(i, t)-q_{k}(i, t)-z_{k}(i, t)+\sum_{j \in \Omega_{i}}\left[q_{k}(j, t)+z_{k}(j, t)\right]=0
$$

3. a vazão vertida $z_{k}(i, t)$ de cada usina, em cada período de tempo é inicializada com zero.

A vazão vertida foi interpretada como variável de folga: só ocorre se a vazão turbinada atingiu o limite máximo $q_{\max }(i)$ e o reservatório também está no volume máximo $x_{\max }(i)$.

Para cada indivíduo $k$ da população calcula-se:

1. $x_{k}(i, t)$ volume do reservatório de cada usina para $t=2$ até $T+1$, utilizando a Equação 7 ;

2. $u_{k}(i, t)$ vazão defluente de cada usina em cada período de tempo, utilizando a Equação 8;

3. $p_{k}(i, t)$ geração hidrelétrica de cada usina em cada período de tempo, utilizando as Equações 4 e 5;

4. $H_{k}(t)$ geração hidrelétrica total em cada período de tempo, utilizando a Equação 3.

\section{Operadores de Factibilização}

Após a avaliação da população, faz-se a verificação da factibilidade das soluções em relação às restrições operacionais (Equações 9, 10 e 11) e em relação à equação de balanceamento para as usinas a fio d'água (Equação 15). Caso ocorra infactibilidade, operadores de factibilização são acionados. Estes operadores aumentam ou diminuem $(i)$ o volume do reservatório, (ii) a vazão turbinada, (iii) a vazão defluente e $(i v)$ a vazão vertida, até que as soluções se tornem factíveis. Nesta etapa, também são realizadas verificações em relação à vazão vertida ${ }^{3}$, caso $z_{k}(i, t)>0$ e poderia estar turbinando ou guardando no reservatório.

\section{Função de Desempenho}

Considerou-se a minimização do custo da complementação térmica penalizada (Equação 12) como função de desempenho (fitness) de cada indivíduo. A população é ordenada em ordem crescente segundo esta função (a função-objetivo do problema é de minimização).

\section{Operadores de Uniformização}

Operadores de uniformização dos volumes dos reservatórios das usinas a jusante também foram implementados. Sabe-se que as usinas a montante sofrem maior variação de volume por terem a função de regularizar o sistema (Soares \& Carneiro, 1991; Cicogna \& Soares, 2005). Este operador foi implementando utilizando uma informação já conhecida da operação em cascata com o intuito de acelerar o processo de convergência da solução.

\section{Operador de Manutenção da Diversidade}

A cada geração, todos os indivíduos infactíveis ${ }^{4}$ são substituídos por outros gerados aleatoriamente (reinicialização). Isto permite que outras regiões do espaço de busca possam ser exploradas. Além disto, outro operador para manutenção da diversidade das soluções é proposto: com a população ordenada, para cada solução $q_{k}(i, t)$, verificar se fitness $\left(q_{k+1}(i, t)\right)-$ fitness $\left(q_{k-1}(i, t)\right)<\epsilon$, ou seja, se as soluções $q_{k-1}(i, t)$ e $q_{k+1}(i, t)$ possuirem valores de função de desempenho suficientemente próximas, ambas são substituídas por novas soluções aleatórias, mantendo apenas a $k$-ésima solução na população.

As soluções finais são os melhores indivíduos das gerações, que evoluiram carregando fortes características e obtiveram os melhores desempenhos, ou seja, soluções factíveis com os melhores valores para a função-objetivo.

Os demais métodos e operadores são descritos nas Seções a seguir.

\footnotetext{
3 Não é uma infactibilidade, mas também foi tratada nesta etapa do algoritmo.

4 indivíduos que continuam infactíveis mesmo após passarem pelos Operadores de Factibilização.
} 


\subsection{Algoritmo genético}

As considerações específicas para o Algoritmo Genético são apresentadas nesta Seção. Diferentes operadores de cruzamento e mutação foram propostos com o intuito de balancear a explotação (busca local) com a exploração, na busca pelas melhores soluções.

\section{Seleção}

Todos os indivíduos que representam soluções factíveis podem ser selecionados. O processo de seleção é realizado através de torneio. Ou seja, duas soluções factíveis são selecionadas aleatoriamente para competirem; aquela que possuir o melhor fitness será escolhida para compor o conjunto dos pais. Pares de pais são formados, aleatoriamente, com os indivíduos da seleção que passaram pelo torneio. Estes pares podem passar pelo cruzamento e pela mutação, dependendo da probabilidade, $P C$ e $P M$ associadas aos operadores.

\section{Cruzamento}

O operador de cruzamento pode ou não ser acionado, dependendo da probabilidade a ele associada, $P C$. Para cada par, sorteia-se um número aleatório entre 0 e 1 ; se este número for menor que $P C$ então o operador atua na formação dos filhos, caso contrário, filhos são cópias dos pais. O operador de cruzamento é aplicado nos pares selecionados (nas variáveis $q_{k}(i, t)$ ), sendo que cada par gera dois filhos. Os indivíduos filhos são avaliados e, se necessário, operadores de factibilização são aplicados. Uma comparação entre os indivíduos (dois pais e dois filhos) envolvidos no cruzamento é realizada; os dois melhores permanecem na população.

Sejam $q_{p_{1}}(i, t)$ e $q_{p_{2}}(i, t)$ dois indivíduos pais selecionados para cruzamento. Dois tipos diferentes de cruzamento foram implementados:

O Cruzamento Aritmético é definido como uma combinação linear conforme descrito a seguir:

$$
\begin{aligned}
& q_{f_{1}}(i, t)=\alpha \cdot q_{p_{1}}(i, t)+(1-\alpha) \cdot q_{p_{2}}(i, t) \\
& q_{f_{2}}(i, t)=(1-\alpha) \cdot q_{p_{1}}(i, t)+\alpha \cdot q_{p_{2}}(i, t)
\end{aligned}
$$

Onde $\alpha$ é um número aleatório pertencente ao intervalo $[0,1]$. Em problemas de otimização com restrições, onde a região factível é convexa, se $q_{p_{1}}(i, t)$ e $q_{p_{2}}(i, t)$ pertencem à região factível, combinações convexas de $q_{p_{1}}(i, t)$ e $q_{p_{2}}(i, t)$ também são factíveis.

No Cruzamento BLX-Alfa, os dois descendentes resultantes são:

$$
\begin{aligned}
& q_{f_{1}}(i, t)=q_{p_{1}}(i, t)+\alpha_{1} \cdot\left(q_{p_{2}}(i, t)-q_{p_{1}}(i, t)\right) \\
& q_{f_{2}}(i, t)=q_{p_{1}}(i, t)+\alpha_{2} \cdot\left(q_{p_{2}}(i, t)-q_{p_{1}}(i, t)\right)
\end{aligned}
$$

Onde $\alpha_{1}$ e $\alpha_{2}$ são números aleatórios pertencentes ao intervalo $[-\beta, 1+\beta]$ e $\beta$ pertence ao intervalo $[0 ; 0,5]$. Os parâmetros $\alpha_{1}, \alpha_{2}$ e $\beta$ são responsáveis pelas características do operador, definindo as regiões nas quais os indivíduos filhos podem se situar: $(i)$ para $\beta$ igual a 0 , este cruzamento se comporta como o Cruzamento Aritmético, ou seja, os filhos são gerados no intervalo entre os pais e (ii) para $\beta>0$, o intervalo onde os filhos podem ser gerados se estende, diversificando as soluções.

\section{Mutação}

O operador de mutação pode ou não ser acionado, dependendo da probabilidade a ele associada, $P M$. A mutação é realizada nos indivíduos finais do cruzamento (os dois melhores entre pais e filhos); é aplicada na variável $q_{k}(i, t)$. Para cada indivíduo, para cada usina $i$, para cada período de tempo $t$, sorteia-se um número aleatório entre 0 e 1 . Se este número for menor que $P M$ então o operador atua no indivíduo, promovendo variação em sua posição $i, t$; caso contrário, permanece como está. Dois tipos de mutação foram implementados.

A Mutação Uniforme considera uma direção de mutação $d$, aleatória e pertencente a $[-1,1]$. O tamanho do passo $\alpha$ é um valor aleatório e pertencente a $\left[0, \frac{q_{k}(i, t)}{10}\right]$, ou seja, a mutação aumenta ou diminui a vazão turbinada em até $10 \%$ de seu valor.

A Mutação Não-Uniforme, especialmente desenvolvida para problemas de otimização com restrição e codificação em ponto flutuante (Michalewicz, 1996), é um operador dinâmico destinado a melhorar o processo de busca. Pode-se defini-lo da seguinte forma: seja $q_{k}(i, t)=\left[q_{k}(1,1) \ldots q_{k}(1, T) ; q_{k}(2,1) \ldots\right.$ $\left.q_{k}(2, T) ; \ldots ; q_{k}(N, 1) \ldots q_{k}(N, T)\right]$ um indivíduo $k$ e suponha que o elemento $q_{k}(2,4)$ (vazão turbinada 
pela usina 2 no período 4) foi selecionado para mutação. O novo elemento resultante da mutação é, com $50 \%$ de probabilidade cada:

$$
q_{k}^{\prime}(2,4)=\left\{\begin{array}{l}
q_{k}(2,4)+\Delta\left(g, a-q_{k}(2,4)\right) \text { ou } \\
q_{k}(2,4)-\Delta\left(g, q_{k}(2,4)-b\right)
\end{array}\right.
$$

onde, neste caso, $[a, b]$ equivale a $\left[u_{\min }(2), q_{\max }(2)\right]$. A função $\Delta(g, y)$ retorna um valor no intervalo $[0, y]$ tal que a probabilidade de $\Delta(g, y)$ ser próximo de zero aumenta à medida que $g$ aumenta $(g=1, \ldots, G)$. Esta propriedade faz com que este operador explore o espaço de busca de forma mais ampla, nas gerações iniciais, e localmente, em gerações avançadas. Michalewicz (1996) propõe a seguinte função: $\Delta(g, y)=y \cdot\left(1-r^{\left(\frac{1-g}{G}\right)^{5}}\right)$, onde $r$ é um número aleatório no intervalo $[0,1]$.

Os indivíduos resultantes da mutação são avaliados e, se necessário, operadores de factibilização são aplicados.

\subsection{Evolução diferencial}

A seguir, são apresentados os métodos e operadores implementados especificamente para a Evolução Diferencial.

\section{Mutação}

Para cada solução $q_{k}(i, t)$ (target) da população, para $k=1, \ldots, T P$, uma nova solução $q_{k}^{\prime}(i, t)$ é gerada, através da mutação:

$$
q_{k}^{\prime}(i, t)=q_{r_{1}}(i, t)+F \cdot\left(q_{r_{2}}(i, t)-q_{r_{3}}(i, t)\right)
$$

onde $r_{1}, r_{2}, r_{3} \in 1, \ldots, T P$ são índices mutuamente distintos e diferentes de $k$; e $F$ é a constante de mutação, real e pertencente ao intervalo $[0,2]$. $F$ pode ser interpretada como o passo a ser dado na direção $q_{r_{2}}(i, t)-q_{r_{3}}(i, t)$. Esta é a proposta clássica da Evolução Diferencial.

Outra forma de mutação também foi implementada. A ideia é semelhante à Otimização por Enxame de Partículas (Particle Swarm) (Kennedy \& Eberhart, 1995):

$$
q_{k}^{\prime}(i, t)=q_{k}(i, t)+F \cdot\left(q_{b e s t}(i, t)-q_{k}(i, t)\right)+F \cdot\left(q_{r_{1}}(i, t)-q_{r_{2}}(i, t)\right)
$$

Desta forma, a mutação carrega informações sobre a solução atual $q_{k}(i, t)$, sobre a melhor solução $q_{b e s t}(i, t)$, além de uma variação aleatória $q_{r_{1}}(i, t)-q_{r_{2}}(i, t)$.

\section{Cruzamento}

Seja $q_{k}(i, t)$ a solução target e $q_{k}^{\prime}(i, t)$ a respectiva solução mutada (donor). A solução trial $q_{k}^{\prime \prime}(i, t)$ é obtida através do cruzamento:

$$
q_{k}^{\prime \prime}(i, t)=\left\{\begin{array}{c}
q_{k}^{\prime}(i, t), \text { se } r_{i t} \leqslant C R \text { ou }(i, t)=\left(l_{i}, l_{t}\right) \\
q_{k}(i, t), \text { se } r_{i t}>C R \text { e }(i, t) \neq\left(l_{i}, l_{t}\right)
\end{array}\right.
$$

onde $i=1, \ldots, N, t=1, \ldots, T, r_{i t}$ é um número aleatório entre [0,1] (distribuição uniforme), $C R \in[0,1]$ é a constante de cruzamento e $\left(l_{i}, l_{t}\right)$ são valores aleatoriamente escolhidos para $(i, t)$ que garantem que $q_{k}^{\prime \prime}(i, t)$ recebe pelo menos uma componente de $q_{k}^{\prime}(i, t)$.

\section{Seleção}

Se o fitness de $q_{k}^{\prime \prime}(i, t)$ é melhor que o fitness de $q_{k}(i, t)$, então $q_{k}(i, t)=q_{k}^{\prime \prime}(i, t)$, caso contrário, $q_{k}(i, t)$ passa para a próxima geração.

\section{Resultados}

Os testes foram realizados com Subsistemas Brasileiros, por possuírem características específicas que os diferenciam dos demais sistemas no mundo (Cicogna \& Soares, 2003). A validação (Berbert et al., 2011b,a) dos métodos propostos foi realizada através de comparações quantitativas e qualitativas com os resultados do modelo HydroMax (Cicogna, 1999, 2003; Cicogna \& Soares, 2005). Atestada a viabilidade de aplicação dos Algoritmos Evolutivos ao problema, buscou-se aperfeiçoar os algoritmos propostos com o intuito de superar as dificuldades encontradas e melhorar seus desempenhos.

Para as análises dos resultados foram escolhidos conjuntos de usinas da região Sudeste do Brasil. O horizonte de planejamento dos estudos iniciais, 12 meses, foi escolhido em virtude da sazonalidade apresentada nas bacias escolhidas para o estudo, típicas da região Sudeste. Além disto, os estudos de otimização de sistemas 
hidrelétricos em ambientes determinísticos com horizontes maiores (até 5 anos) revelaram a repetição do comportamento dos sistemas quanto à trajetória de volume armazenado. Ou seja, mesmo em estudos com horizontes maiores que um ano, o comportamento ótimo dos sistemas hidrelétricos faz uso predominante da regularização intra-anual (Francato, 1997). Para a verificação desta característica um caso de estudo com 48 meses também é apresentado na Seção 5.2.

Foi assumida a hipótese determinística para as vazões naturais afluentes a cada reservatório, considerando a vazão mensal de cada usina igual à média de longo termo (MLT). Os dados foram obtidos a partir do histórico de vazões (de 1931 a 2007) disponibilizado pelo Operador Nacional do Sistema Elétrico (ONS) ${ }^{5}$. A partir do histórico, percebe-se que os reservatórios das usinas atingem seus valores máximos, na maior parte dos anos, sempre no mês de maio. É em maio, com os reservatórios cheios, que se iniciam as execuções do algoritmo. Considerando a função-objetivo penalizada, os reservatórios tendem a voltar ao nível máximo no último período de tempo, ao mesmo tempo que o algoritmo tenta minimizar a complementação térmica.

A taxa de juros adotada foi de $12 \%$ ao ano. Os demais dados de todas as usinas foram retirados do banco de dados HydroData (Cicogna \& Soares, 2003). Os testes contemplam os resultados obtidos pelos dois algoritmos propostos: Algoritmo Genético (hidroGA) e Evolução Diferencial (hidroDE). Os estudos foram divididos em 4 casos. A seguir, a descrição e análise de cada um dos casos de estudo.

\subsection{Primeiro estudo: operação em cascata}

Para este estudo foram escolhidas duas usinas com reservatório interligados, Furnas e Água Vermelha, um horizonte de planejamento de 12 meses e demanda de $2000 \mathrm{MW}$ mensais. Os parâmetros comuns às duas abordagens propostas são: tamanho da população $T P=100$ indivíduos e vetor de penalidade $\mathcal{M}()=$. $[200,120]$.

Os primeiros testes foram realizados com o intuito de testar a sensibilidade da solução em relação às alterações nos valores dos parâmetros: número de gerações $G$, taxas de cruzamento e taxas de mutação, respectivamente, $P M, P C$ (hidroGA) e $F, C R$ (hidroDE). Para cada algoritmo foram realizadas 180 rodadas de testes, ou seja, 10 rodadas para cada uma das 18 combinações de parâmetros consideradas. As Tabelas 1, 2 e 3 apresentam os resultados de geração hidrelétrica obtidos com o melhor indivíduo da população na última geração. Em cada célula, o primeiro valor é referente à geração média mensal; o segundo, apresenta o desvio padrão médio da geração mensal; e o terceiro, refere-se à geração hidrelétrica total. Estes três valores foram cálculados considerando, em cada caso, as 10 rodadas executadas.

Tabela 1. Geração Hidrelétrica $(\overline{M W})$ Média, Desvio e Total Caso $1, G=50$ gerações.

\begin{tabular}{cccc}
\hline$P M$ ou $F$ & $P C$ ou $C R$ & hidroGA & hidroDE \\
\hline \multirow{2}{*}{0,1} & & 1824,29 & 1827,75 \\
& 0,2 & 31,91 & 63,58 \\
& & 21891,48 & 21933,04 \\
\hline \multirow{2}{*}{0,1} & 0,6 & 1824,06 & 1825,21 \\
& & 15,55 & 28,78 \\
& & 21888,76 & 21902,51 \\
\hline \multirow{2}{*}{0,1} & 0,9 & 1824,18 & 1825,75 \\
& & 14,22 & 41,15 \\
0,3 & 0,6 & 21890,12 & 21909,01 \\
\hline \multirow{2}{*}{0} & & 23,39 & 1824,52 \\
& & 21894,20 & 21889,31 \\
\hline \multirow{2}{*}{0,3} & 0,9 & 1824,46 & 1824,06 \\
& & 16,61 & 17,96 \\
0,5 & 0,9 & 21893,49 & 21888,71 \\
\hline \multirow{2}{*}{0} & & $21897,97,76$ & 21886,19 \\
\hline
\end{tabular}

Estes dados correspondem às melhores soluções, ou seja, para cada combinação de parâmetros em cada rodada de testes, a solução que apresentou o menor custo penalizado dentre todas as soluções da população.

Considerando a geração hidrelétrica mais estável ou constante como uma característica desejável para a solução, o desvio médio da geração hidrelétrica será considerado como critério de decisão para a escolha

5 http://www.ons.org.br/operacao/vazoes_naturais.aspx 
Tabela 2. Geração Hidrelétrica $(\overline{M W})$ Média, Desvio e Total Caso $1, G=100$ gerações.

\begin{tabular}{cccc}
\hline$P M$ ou $F$ & $P C$ ou $C R$ & hidroGA & hidroDE \\
\hline \multirow{2}{*}{0,1} & & 1823,98 & 1824,67 \\
& 0,2 & 14,56 & 23,80 \\
& & 21887,76 & 21896,02 \\
\hline \multirow{2}{*}{0,1} & 0,6 & 1823,83 & 1823,94 \\
& & 10,19 & 8,56 \\
& & 21885,95 & 21887,25 \\
\hline \multirow{2}{*}{0,1} & 0,9 & 1823,85 & 1824,43 \\
& & 9,12 & 33,22 \\
0,3 & 0,6 & 1824,08 & 1823,75 \\
& & 11,26 & 3,93 \\
& & 21888,96 & 21885,06 \\
\hline \multirow{2}{*}{0,3} & 0,9 & 1824,00 & 1823,93 \\
& & 10,05 & 11,04 \\
& & 21888,05 & 21887,18 \\
\hline \multirow{2}{*}{0,5} & \multirow{2}{*}{0,9} & 1824,23 & 1823,76 \\
& & 15,44 & 3,27 \\
& & 21890,75 & 21885,10 \\
\hline
\end{tabular}

Tabela 3. Geração Hidrelétrica $(\overline{M W})$ Média, Desvio e Total Caso $1, G=150$ gerações.

\begin{tabular}{|c|c|c|c|}
\hline$P M$ ou $F$ & $P C$ ou $C R$ & hidroGA & hidroDE \\
\hline \multirow{3}{*}{0,1} & \multirow{3}{*}{0,2} & 1823,82 & 1824,06 \\
\hline & & 9,75 & 14,39 \\
\hline & & 21885,79 & 21888,72 \\
\hline \multirow{3}{*}{0,1} & \multirow{3}{*}{0,6} & 1823,81 & 1823,87 \\
\hline & & 7,91 & 6,95 \\
\hline & & 21885,71 & 21886,39 \\
\hline \multirow{3}{*}{0,1} & \multirow{3}{*}{0,9} & 1823,85 & 1824,24 \\
\hline & & 7,27 & 17,41 \\
\hline & & 21886,22 & 21890,87 \\
\hline \multirow{3}{*}{0,3} & \multirow{3}{*}{0,6} & 1823,76 & 1823,76 \\
\hline & & 8,50 & 3,54 \\
\hline & & 21885,10 & 21885,06 \\
\hline \multirow{3}{*}{0,3} & \multirow{3}{*}{0,9} & 1823,95 & 1823,77 \\
\hline & & 8,13 & 6,91 \\
\hline & & 21887,38 & 21885,26 \\
\hline \multirow{3}{*}{0,5} & \multirow{3}{*}{0,9} & 1824,15 & 1823,76 \\
\hline & & 11,25 & 3,03 \\
\hline & & 21889,84 & 21885,07 \\
\hline
\end{tabular}

da melhor combinação de parâmetros. Verificando os menores valores de desvio padrão ${ }^{6}$ nas Tabelas 1,2 e $3^{7}$, conclui-se que, para este caso de estudo e seguindo este critério, a alternativa $G=150, P M=0,1$ e $P C=0,9$ representa a melhor configuração de parâmetros para o hidroGA. Para o hidroDE, a melhor configuração de parâmetros é representada pela alternativa $G=150, F=0,5$ e $C R=0,9$. Além disto, para estas combinações de parâmetros, o hidroDE tem menor desvio padrão médio que o hidroGA, apresentando uma geração hidrelétrica mensal mais estável.

Os tempos médios de execução (em segundos) para cada conjunto de rodadas, considerando $G=150$ gerações, estão apresentados na Tabela 4.

Os gráficos a seguir apresentam o fitness do melhor indíviduo e a média do fitness da população juntamente com seu desvio padrão, durante as $G=150$ gerações, obtidos com o hidroGA e com o hidroDE. Para esta

6 segundo valor de cada célula.

7 as combinações com os menores valores de desvio estão em destaque nas tabelas. 
Tabela 4. Médias dos tempos de execução $(s)$ - Caso $1, G=150$.

\begin{tabular}{cccc}
\hline$P M$ ou $F$ & $P C$ ou $C R$ & hidroGA & hidroDE \\
\hline 0,1 & 0,2 & 0,497 & 0,479 \\
0,1 & 0,6 & 0,500 & 0,485 \\
0,1 & 0,9 & 0,506 & 0,472 \\
0,3 & 0,6 & 0,526 & 0,484 \\
0,3 & 0,9 & 0,531 & 0,471 \\
0,5 & 0,9 & 0,552 & 0,460 \\
\hline
\end{tabular}

análise, foram consideradas as melhores configurações de parâmetros apontadas anteriormente: $P M=0,1$ e $P C=0,9$ para o hidroGA (Figura 4$), F=0,5$ e $C R=0,9$ para o hidroDE (Figura 5). Cada gráfico apresenta os resultados de 10 rodadas de testes.

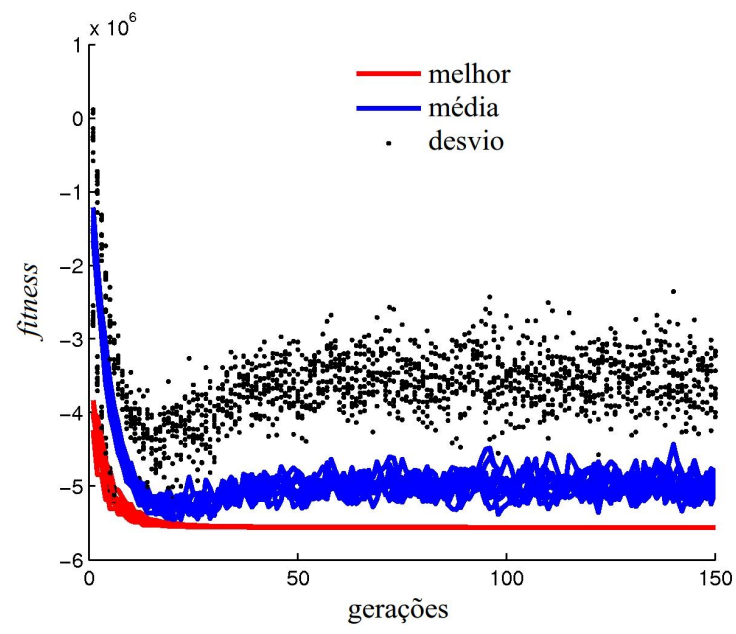

Figura 4. Evolução do fitness do melhor indivíduo do hidroGA - Caso 1.

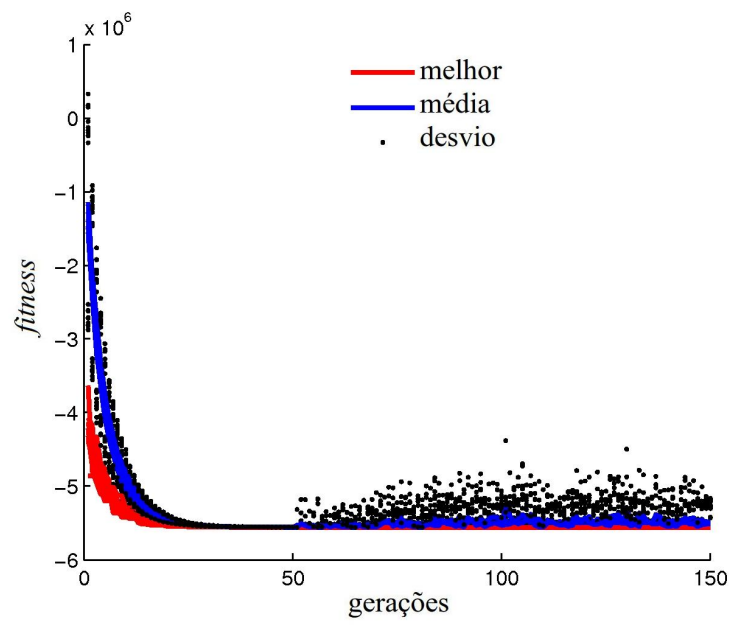

Figura 5. Evolução do fitness do melhor indivíduo do hidroDE - Caso 1.

O hidroGA consegue manter a população mais diversificada durante todo o processo evolutivo, o que é percebido através da média e do desvio padrão do fitness dos indivíduos da população (Figura 4). Com o hidroDE, o fitness da população converge mais rapidamente, tendendo ao fitness do melhor indivíduo. A partir da 50 $\underline{a}$ geração, a diversidade da população aumenta (Figura 5). Isto ocorreu porque, o Operador de Manutenção de Diversidade (Seção 4) inseriu novos indivíduos na população. Em relação à convergência do fitness do melhor indivíduo, hidroGA e hidroDE obtiveram soluções com as mesmas características.

Outras análises com a melhor solução obtida com o hidroGA e com o hidroDE estão apresentadas a seguir ${ }^{8}$. Os gráficos referem-se ao caso com $G=150$. Com menos gerações é possível obter resultados quantitativamente semelhantes, em relação a geração hidrelétrica total, como foi verificado anteriormente (Tabelas 1, 2 e 3 ). Porém, com mais gerações, as soluções melhoram qualitativamente. Empiricamente, observou-se que a geração total $H(t)$ tem maiores variações com menos gerações e um comportamento aproximadamente constante com mais gerações. Geração Hidrelétrica uniforme é o mais desejável para o problema, pois, por consequência, a geração térmica também será uniforme.

Os volumes dos reservatórios obtidos nestes casos de estudo estão apresentados nas Figuras 6 e 7 . O reservatório de Furnas sofreu deplecionamento e o de Água Vermelha manteve-se cheio durante todo o período de tempo, uma característica de soluções que maximizam a produtividade em cascata Cicogna (2003); Cicogna \& Soares (2005): a usina a montante (Furnas) regulariza a vazão afluente da usina a jusante (Água Vermelha). A função-objetivo penalizada conseguiu fazer com que o volume do reservatório de Furnas retornasse ao nível máximo. Os dois métodos de resolução obtiveram soluções com características semelhantes. Na usina de Furnas, os primeiros meses correspondem ao período de seca (maio a novembro) e a vazão turbinada é maior que a vazão afluente (Figura 8). Com isto o reservatório é deplecionado (Figuras 6 e 7). De dezembro a abril (período de cheia), a vazão turbinada fica abaixo da vazão afluente. Isto faz com que o reservatório recupere o armazenamento até atingir o máximo novamente, no último período de tempo.

A usina de Água Vermelha manteve seu reservatório cheio (Figuras 6 e 7 ) durante todo o tempo. No período de cheia a vazão turbinada aumenta (Figura 9), mas não ocorre vertimento ${ }^{9}$ porque a defluência de

\footnotetext{
8 As informações a seguir são referentes a uma das dez rodadas executadas. As demais rodadas, para a mesma configuração de parâmetros obtiveram as mesmas características e para melhor visualização dos resultados, foram suprimidas.

9 No caso 1, em nenhuma das usinas ocorre vertimento.
} 


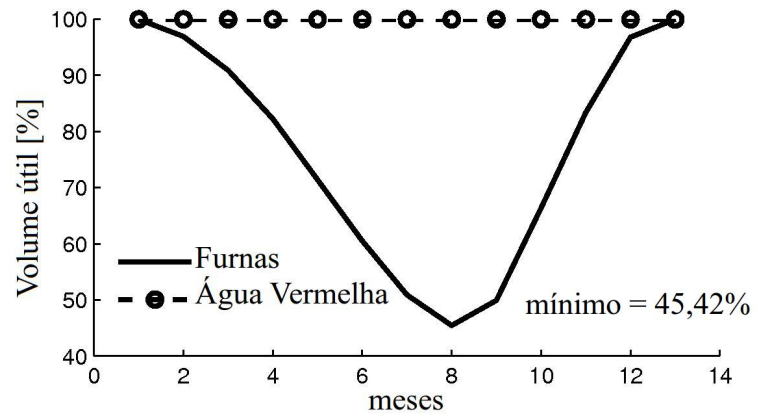

Figura 6. Volumes dos reservatórios, hidroGA Caso 1.

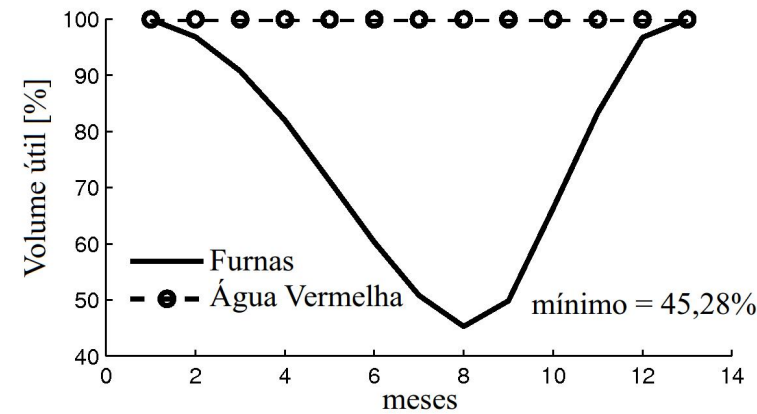

Figura 7. Volumes dos reservatórios, hidroDE Caso 1.

Furnas (a montante) é controlada pela otimização, regularizando a afluência de Água Vermelha. As gerações hidrelétricas obtidas por cada algoritmo estão apresentadas nas Figuras 10 e 11.

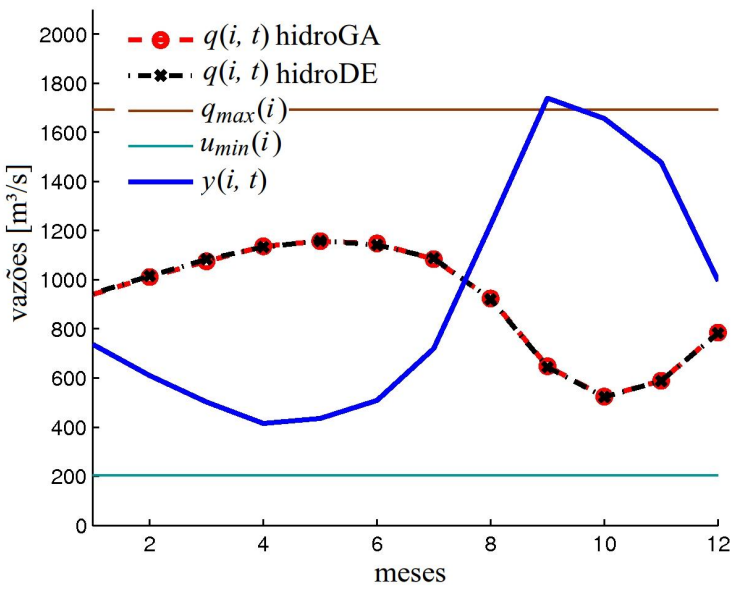

Figura 8. Vazões de Furnas - Caso 1.

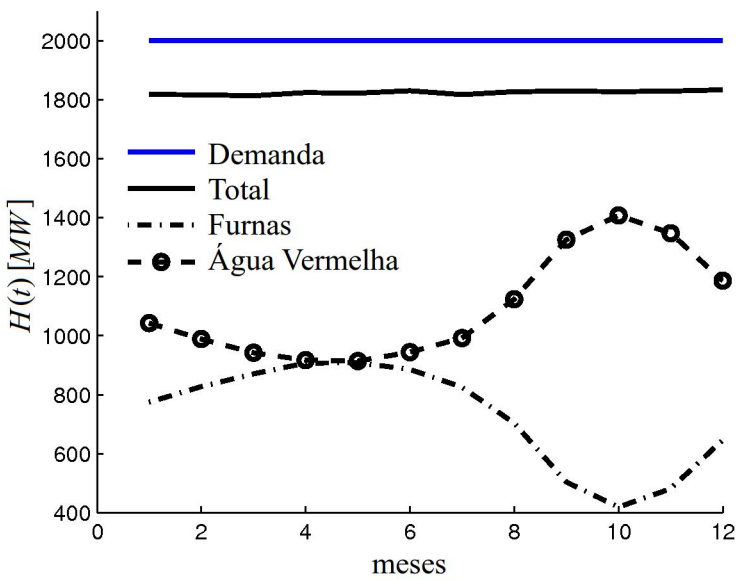

Figura 10. Geração Hidrelétrica mensal, hidroGA Caso 1.

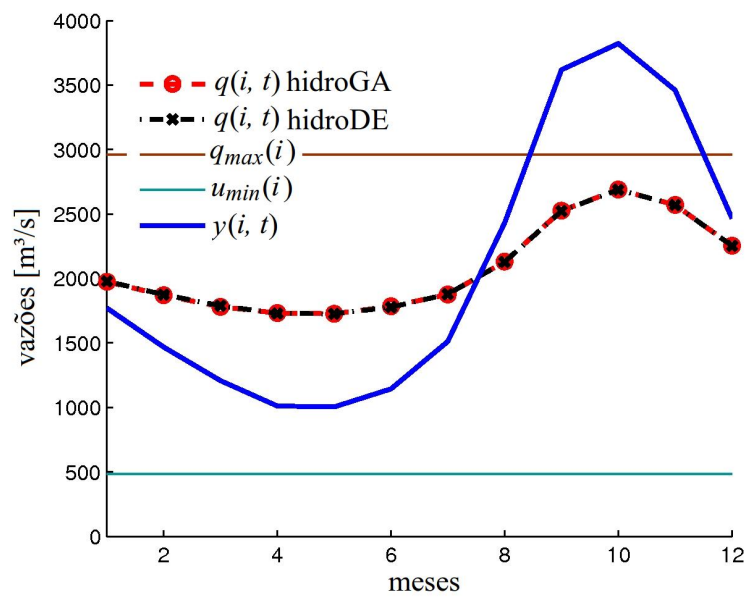

Figura 9. Vazões de Água Vermelha - Caso 1.

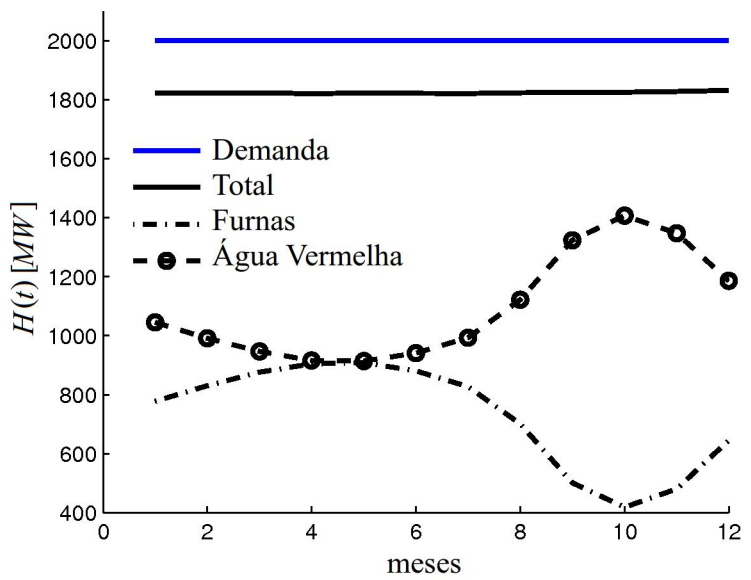

Figura 11. Geração Hidrelétrica mensal, hidroDE Caso 1.

\subsection{Segundo estudo: horizontes de planejamento}

Para este estudo, foram mantidas as usinas de Furnas e Água Vermelha e escolhido um horizonte de planejamento maior: 48 meses. A demanda foi fixada em 2000 MW mensais e os parâmetros comuns aos algoritmos são: tamanho da população $T P=100$ indivíduos e vetor de penalidade $\mathcal{M}()=.[200,120]$.

O número de gerações foi fixado em $G=600$, com o objetivo de se obter uma geração hidrelétrica total mais uniforme. Para verificar a variação da solução em relação às alterações nos valores das taxas de cruzamento e mutação, foram realizadas, para cada algoritmo, 60 rodadas de testes. Ou seja, 10 rodadas para cada uma das 6 combinações de parâmetros consideradas ( $P M, P C$ para hidroGA e $F, C R$ para hidroDE), análogo ao Primeiro Estudo (Seção 5.1). 
Novamente, o desvio padrão médio da geração hidrelétrica é considerado como critério de decisão para a escolha da melhor combinação de parâmetros. Verificando os menores valores de desvio, as alternativas que representam as melhores configurações de parâmetros são: $P M=0,1$ e $P C=0,9$ (hidroGA), $F=0,5$ e $C R=0,9$ (hidroDE). Os resultados obtidos com estas configurações estão apresentados na Tabela 5 . O hidroDE obteve o menor desvio padrão médio, apresentando uma geração hidrelétrica mensal mais estável. Os tempos de execução com estas combinações de parâmetros foram: 9,655 segundos (hidroGA) e 7,429 segundos (hidroDE).

Tabela 5. Geração Hidrelétrica $(\overline{M W})$ Média, Desvio e Total - Caso 2.

\begin{tabular}{ccc}
\hline Geração Hidrelétrica & hidroGA & hidroDE \\
\hline Média & 1823,71 & 1823,73 \\
Desvio & 16,62 & 8,98 \\
Total & 87537,91 & 87539,18 \\
\hline
\end{tabular}

As características das soluções são semelhantes ao primeiro caso de estudo. Neste caso, novamente, não ocorre vertimento. As Figuras 12 e 13 apresentam os volumes do reservatórios de Furnas e Água Vermelha. Os algoritmos conseguiram recuperar o volume do reservatório de Furnas, chegando sempre ao máximo no mês de maio de cada ano.

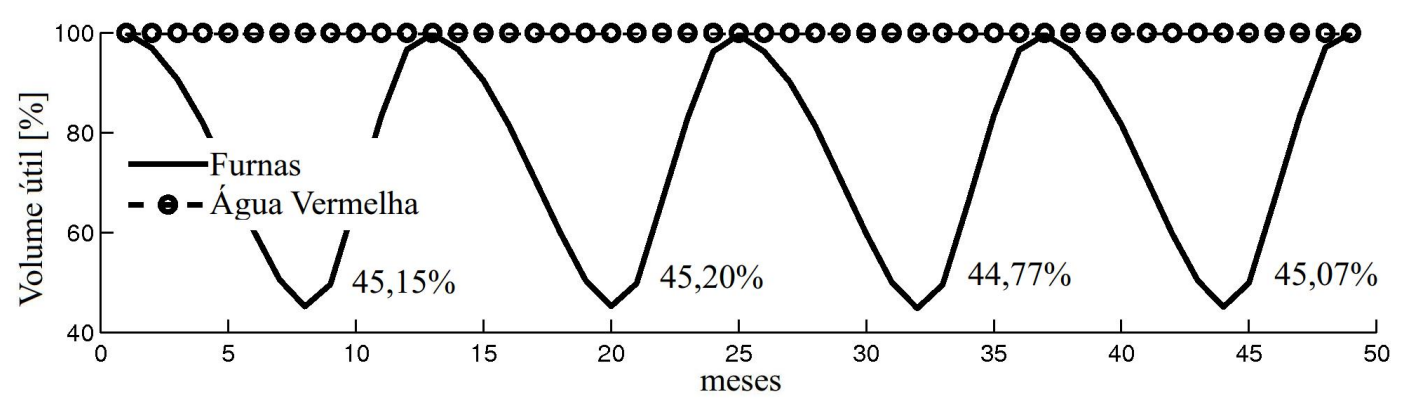

Figura 12. Volumes dos reservatórios, hidroGA - Caso 2.

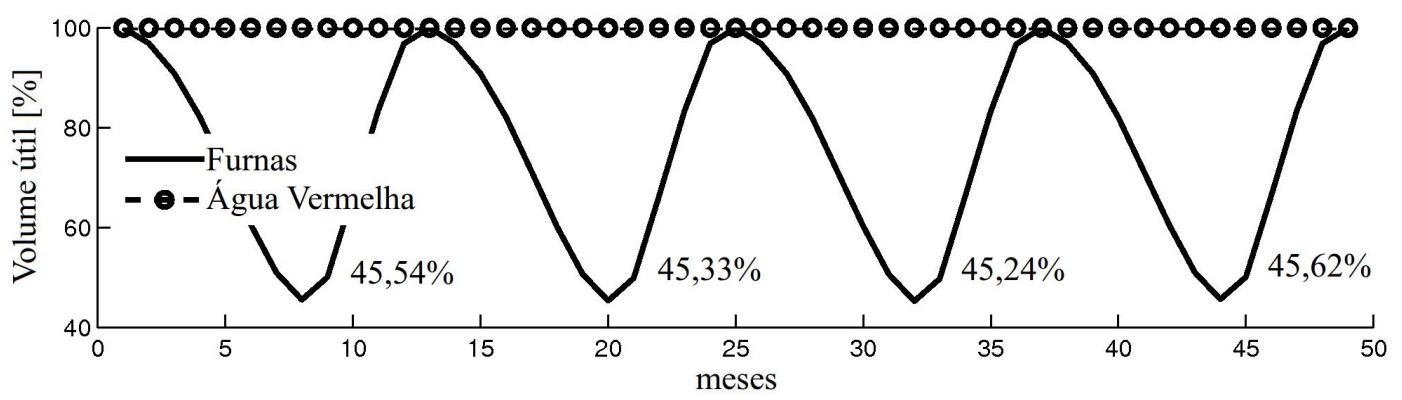

Figura 13. Volumes dos reservatórios, hidroDE - Caso 2.

As Figuras 14 e 15 apresentam os resultados de geração hidrelétrica total e por usina, obtidos com os dois algoritmos.

\subsection{Terceiro estudo: usinas a fio d'água}

Este estudo tem o objetivo de verificar o comportamento do algoritmo proposto com usinas a fio d'água (sem reservatórios de capacidade regularizadora). Foram consideradas as usinas de Furnas, Estreito (fio d'água) e Água Vermelha, em um horizonte de planejamento de 12 meses. A demanda foi fixada em $2700 \mathrm{MW}$ mensais e os parâmetros comuns aos algoritmos são: tamanho da população $T P=100$ indivíduos, gerações $G=100$ e vetor de penalidade $\mathcal{M}()=.[350,0,120]$.

Foram realizadas 10 rodadas de testes, para cada algoritmo e para cada uma das 6 combinações de taxas de mutação e crossover. Verificando os menores valores de desvio padrão médio de geração, as alternativas que representam as melhores configurações de parâmetros são, novamente, $P M=0,1$ e $P C=0,9$ (hidroGA), $F=0,5$ e $C R=0,9$ (hidroDE). Os resultados obtidos com tais configurações estão apresentados na Tabela 6 . 


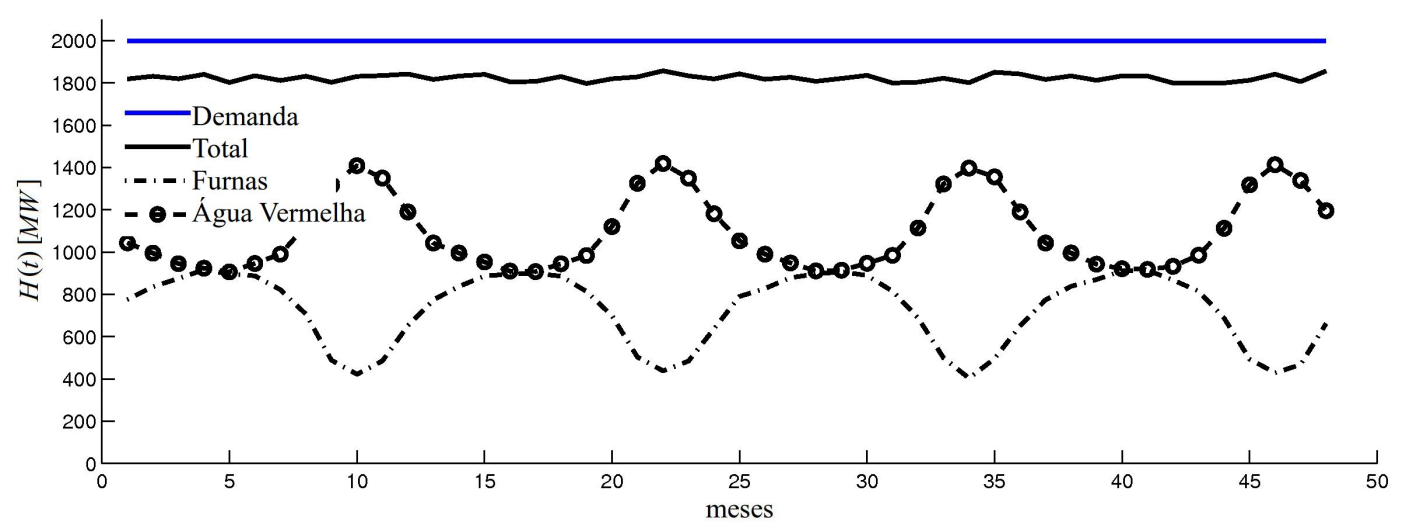

Figura 14. Geração Hidrelétrica mensal, hidroGA - Caso 2.

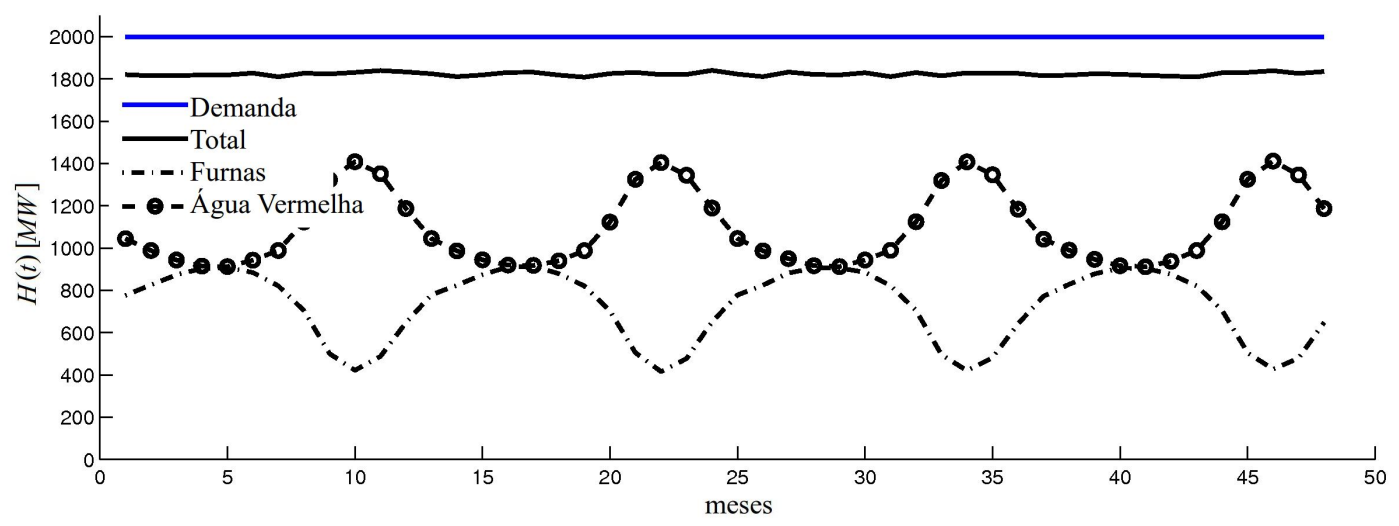

Figura 15. Geração Hidrelétrica mensal, hidroDE - Caso 2.

Tabela 6. Geração Hidrelétrica $(\overline{M W})$, Média, Desvio e Total - Caso 3.

\begin{tabular}{ccc}
\hline Geração Hidrelétrica & hidroGA & hidroDE \\
\hline Média & 2430,56 & 2430,06 \\
Desvio & 3,75 & 2,99 \\
Total & 29166,69 & 29160,69 \\
\hline
\end{tabular}

O hidroDE obteve o menor desvio padrão médio, apresentando uma geração hidrelétrica mensal mais estável. Os tempos de execução com estas combinações de parâmetros foram: 0,524 segundos (hidroGA) e 0,466 segundos (hidroDE).

As trajetórias de volume obtidas para as usinas de Furnas e Água Vermelha, foram semelhantes ao Primeiro Estudo (Seção 5.1). Vale lembrar que Estreito, localizada entre as usinas de Furnas e Água Vermelha, é usina fio d'água, logo, não possui volume útil. A mesma semelhança com o Primeiro Estudo foi observada nos resultados de vazão turbinada. Isto porque usinas a fio d'água não possuem grande influência na solução ótima quando a vazão incremental que atua entre uma usina com reservatório (Furnas) e outra fio d'água (Estreito) é pequena (Cicogna \& Soares, 2005). Neste caso, novamente, não ocorre vertimento. As Figuras 16 e 17 apresentam os resultados de geração hidrelétrica total e por usina, obtidos com cada algoritmo.

\subsection{Quarto estudo: 14 usinas}

O último estudo é realizado com um sistema composto por 14 usinas hidrelétricas, abrangendo grande parte do Sistema Sudeste Brasileiro e considerando usinas com reservatório e a fio d'água. O objetivo é verificar o comportamento dos algoritmos propostos, quanto ao crescimento do número de usinas. Foram consideradas 8 usinas com reservatório (Emborcação, Itumbiara, São Simão, Furnas, Peixoto, Marimbondo, Água Vermelha e Ilha Solteira) e 6 usinas a fio d'água (Cachoeira Dourada, Estreito, Jaguara, Igarapava, Volta Grande e Porto Colômbia), em um horizonte de planejamento de 12 meses. A demanda foi fixada em $11500 \mathrm{MW}$ mensais e os parâmetros comuns ao hidroGA e o hidroDE são: tamanho da população $T P=100$ indivíduos, $G=1000$ gerações e vetor de penalidade $\mathcal{M}()=.[1900,1700,0,1200,2500,2500,0,0,0,0,0,1200,1100,2100]$. 


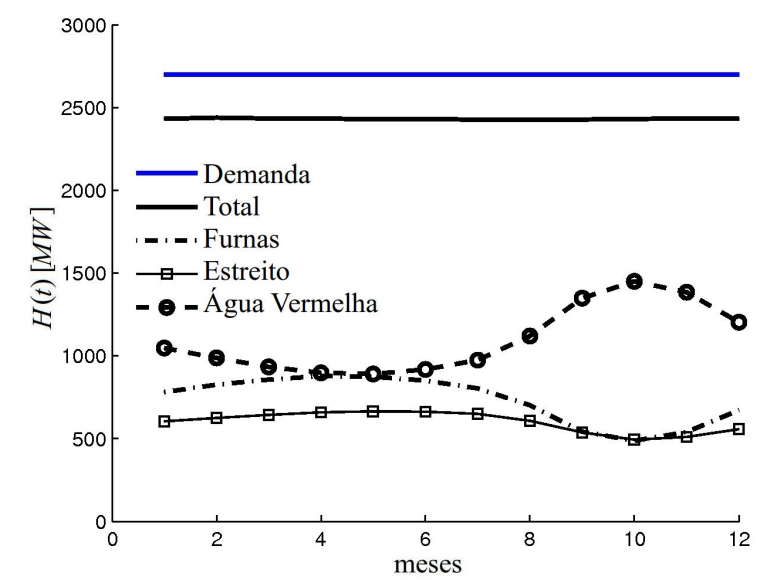

Figura 16. Geração Hidrelétrica mensal, hidroGA Caso 3.

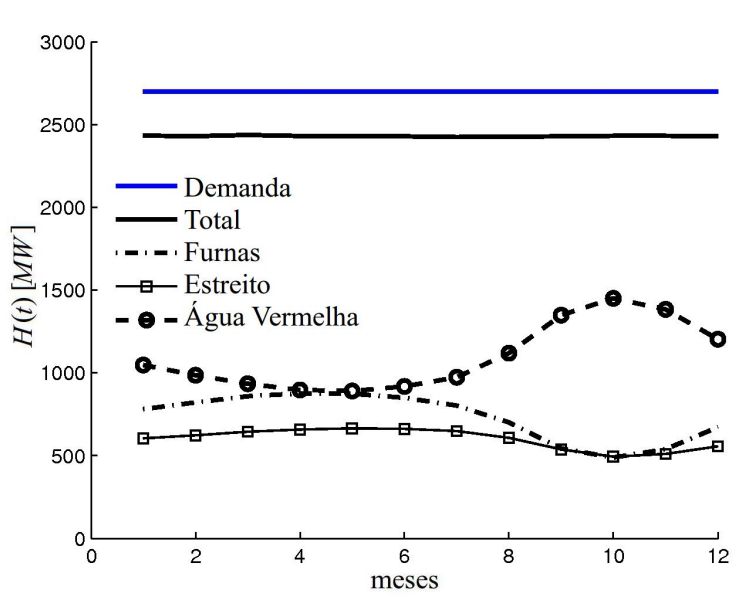

Figura 17. Geração Hidrelétrica mensal, hidroDE Caso 3.

Foram realizadas 10 rodadas de testes, para cada algoritmo e para cada uma das 6 combinações de taxas de mutação e crossover. Verificando os menores valores de desvio padrão médio de geração, as alternativas que representam as melhores configurações de parâmetros são, novamente, $P M=0,1$ e $P C=0,9$ (hidroGA), $F=0,5$ e $C R=0,9$ (hidroDE). Os resultados com estas configurações estão apresentados na Tabela 7.

Tabela 7. Geração Hidrelétrica $(\overline{M W})$, Média, Desvio e Total — Caso 4.

\begin{tabular}{ccc}
\hline Geração Hidrelétrica & hidroGA & hidroDE \\
\hline Média & 10792,20 & 10733,94 \\
Desvio & 140,93 & 103,30 \\
Total & 129506,38 & 128807,28 \\
\hline
\end{tabular}

O hidroDE obteve o menor desvio padrão médio, apresentando uma geração hidrelétrica mensal mais estável. Os tempos de execução com estas combinações de parâmetros foram: 81,015 segundos (hidroGA) e 24,821 segundos (hidroDE).

A usina de Furnas apresentou comportamento semelhante ao primeiro estudo (Seção 5.1). Ilha Solteira, usina a jusante das cascatas, manteve seu reservatório cheio durante todo o horizonte de planejamento com a vazão afluente regularizada pelas usinas a montante.

A Figura 18 apresenta os resultados de geração hidrelétrica total, obtidos com os dois algoritmos.

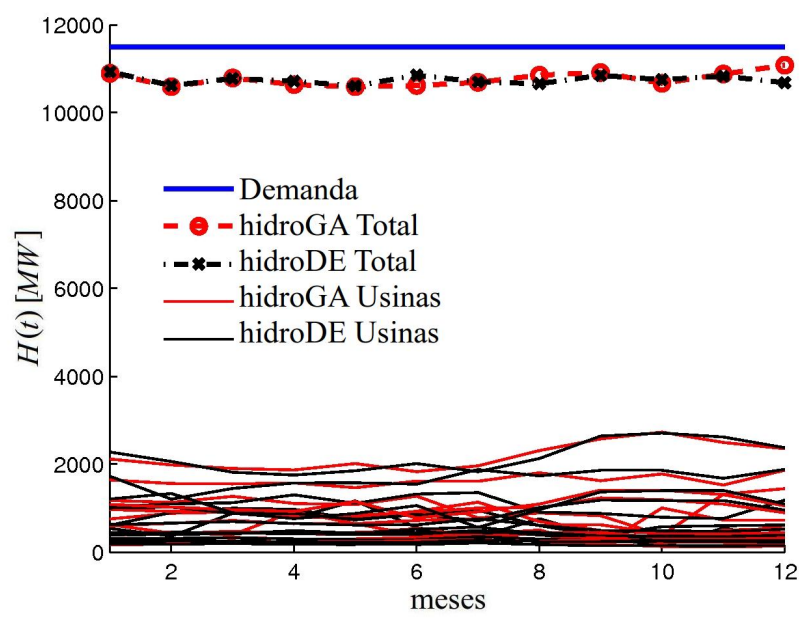

Figura 18. Geração Hidrelétrica mensal - Caso 4.

\section{Conclusões}

As abordagens propostas demonstraram possuir grande potencial na resolução deste problema, trabalhando com um conjunto de soluções, denominado população, e otimizando cada solução em paralelo. Essa 
característica possibilita obter como resultado final, não apenas um ótimo local com qualidade próximo ou igual ao ótimo global, mas também soluções distintas com boa qualidade, que podem ser usadas como alternativas. Por exemplo, maior geração hidrelétrica, porém com maior deplecionamento dos reservatórios. Soluções alternativas também podem ser obtidas variando o parâmetro de penalidade $\mathcal{M}($.$) , alterando assim$ a importância do volume dos reservatórios em relação à minimização do custo da complementação térmica. Isso pode ser interessante para o problema de Planejamento Hidrelétrico uma vez que este é um problema que sofre variações no tempo. Além disto, as várias soluções factíveis e de qualidade são encontradas em uma única rodada do algoritmo. Estas soluções podem ser consideradas como soluções iniciais de outros algoritmos que dependam de uma solução inicial factível.

O hidroGA apresentou os melhores resultados com $P M=0,1$ e $P C=0,9$. O hidroDE obteve os melhores resultados com $F=0,5$ e $C R=0,9$. Em relação ao tempo computacional, o hidroDE obteve os melhores resultados em todos os testes. Isto comprova, também para este problema, que a Evolução Diferencial é uma versão melhorada do Algoritmo Genético, resolvendo de forma mais rápida os problemas de otimização (Price et al., 2005). O hidroDE também obteve o melhor desempenho em relação à geração hidrelétrica total mais uniforme.

Uma característica dos dois algoritmos, percebida durantes os testes, é a capacidade de continuar melhorando a qualidade das soluções mesmo após a convergência (quantitativa). Com mais iterações, a geração hidrelétrica total se torna mais uniforme.

Dentre os trabalhos futuros, novos experimentos estão sendo realizados, visando a melhoria dos algoritmos. A característica multimodal descrita acima que leva a possibilidade de encontrar soluções alternativas será estudada de forma aprofundada. A otimização do tempo de execução do algoritmo também será realizada.

\section{Agradecimentos}

Os autores agradecem à CAPES e à FAPESP pelo apoio financeiro ao projeto.

\section{Referências}

Bäck, T.; Fogel, D. \& Michalewicz, Z., Evolutionary Computation 2: Advanced Algorithms and Operators. 1a edição. Bristol, UK: Institute of Physics Publishing, 2000a.

Bäck, T.; Fogel, D.B. \& Michalewicz, Z., Evolutionary Computation 1: Basic Algorithms and Operators. 1 a edição. Bristol, UK: Institute of Physics Publishing, 2000b.

Berbert, P.C.; Yamakami, A. \& de França, F.O., Abordagem bio-inspirada para o problema de planejamento hidrelétrico. In: Anais do XLIII Simpósio Brasileiro de Pesquisa Operacional. Ubatuba, Brasil, p. 1-6, 2011a.

Berbert, P.C.; Yamakami, A. \& de França, F.O., Planejamento hidrelétrico: Abordagem bio-inspirada. In: Proceedings of $9^{\text {th }}$ Congress Latin American on Electricity Generation and Transmission. Mar del Plata, Argentina, p. 1-6, 2011b.

Carvalho, M. \& Soares, S., An efficient hydrothermal scheduling algorithm. IEEE Transactions on Power Systems, $2(3): 537-542,1987$.

Catalão, J.P.S.; Mariano, S.J.P.S.; Mendes, V.M.F. \& Ferreira, L.A.F.M., Scheduling of head-sensitive cascaded hydro systems: A nonlinear approach. IEEE Transactions on Power Systems, 24(1):337-346, 2009a.

Catalão, J.P.S.; Pousinho, H.M.I. \& Mendes, V.M.F., Mixed-integer nonlinear programming for head-dependent shortterm hydro scheduling. In: Proceedings of the International Conference on Power Engineering, Energy and Electrical Drives (POWERENG'09). Piscataway, USA: IEEE Press, p. 90-94, 2009b.

Cicogna, M.A., Modelo de Planejamento da Operação Energética de Sistemas Hidrotérmicos a Usinas Individualizadas Orientado por Objetos. Dissertação de mestrado, Faculdade de Engenharia Elétrica e de Computação, Universidade Estadual de Campinas, Campinas, SP, 1999.

Cicogna, M.A., Sistema de Suporte à Decisão para o Planejamento e a Programação da Operação de Sistemas de Energia Elétrica. Tese de doutorado, Faculdade de Engenharia Elétrica e de Computação, Universidade Estadual de Campinas, Campinas, SP, 2003.

Cicogna, M.A. \& Soares, S., Um sistema gerenciador de dados cadastrais para as usinas hidrelétricas brasileiras. In: Anais do XV Simpósio Brasileiro de Recursos Hídricos. p. 1-6, 2003.

Cicogna, M.A. \& Soares, S., Hydrolab: Manual de Características da Produção de Energia Elétrica. 2005. http: //www.cose.fee.unicamp.br.

Coello-Coello, C.A., Evolutionary multiobjective optimization: Past, present and future, 2002. Tutorial - CINVESTAVIPN, Depto. de Ingeniería Eléctrica, Sección de Computación.

Dias, B.H.; Marcato, A.L.M.; Souza, R.C.; Soares, M.P.; Silva Junior, I.C.; de Oliveira, E.J.; Brandi, R.B.S. \& Ramos, T.P., Stochastic dynamic programming applied to hydrothermal power systems operation planning based on the convex hull algorithm. Mathematical Problems in Engineering, 2010:1-21, 2010.

El-Hawary, M.E. \& Christensen, G.S., Optimal Economic Operation of Eletric Power System. 1a edição. New York, USA: Academic Press, 1979. 
Ferreira, V.H. \& Silva, G.H.C., Natural optimization applied to medium-term hydrothermal coordination. In: Proceedings of the $16^{\text {th }}$ International Conference on Intelligent Systems Application to Power Systems. Piscataway, USA: IEEE Press, p. 1-6, 2011.

Francato, A.L., Contribuição ao Estudo das Propriedades Ótimas da Operação de Sistemas Hidroelétricos. Dissertação de mestrado, Faculdade de Engenharia Civil, Universidade Estadual de Campinas, Campinas, SP, 1997.

Goldberg, D.E., Genetic Algorithms in Search, Optimization and Machine Learning. 1a edição. Reading, USA: Addison-Wesley, 1989.

Kennedy, J. \& Eberhart, R., Particle swarm optimization. In: Proceedings of IEEE International Conference on Neural Networks. Washington, USA: IEEE Computer Society, p. 1942-1948, 1995.

Leite, P.T.; Carneiro, A.A.F.M. \& Carvalho, A.C.P.L.F., Aplicação de algoritmos genéticos na determinação da operação ótima de sistemas hidrotérmicos de potência. Revista Controle $\mathcal{G}$ Automação, 17(1):81-88, 2006a.

Leite, P.T.; Carneiro, A.A.F.M. \& Carvalho, A.C.P.L.F., Energetic operation planning using genetic algorithms. IEEE Transactions on Power Systems, 17(1):173-179, 2006b.

Leite, P.T. \& Carvalho, A.C.P.L.F., Hybrid genetic algorithm applied to the determination of the optimal operation of hydrothermal systems. In: Proceedings of the Ninth Brazilian Symposium on Neural Networks. Washington, USA: IEEE Computer Society, p. 1-6, 2006.

Man, K.F.; Tang, K.S. \& Kwong, S., Genetic algorithms: Concepts and applications. IEEE Transactions on Industrial Electronics, 43(5):519-534, 1996.

Michalewicz, Z., Genetic Algorithms + Data Structures = Evolution Programs. 3a edição. Berlin, Germany: SpringerVerlag, 1996.

Oliveira, G. \& Soares, S., A second-order network flow algorithm for hydrothermal scheduling. IEEE Transactions on Power Systems, 10(3):1635-1641, 1995.

Price, K.V.; Storn, R.M. \& Lampinen, J.A., Differential evolution: a practical approach to global optimization. 1a edição. Berlin, Germany: Springer-Verlag, 2005.

Rosenthal, R.E., A nonlinear network flow algorithm for maximization of benefits in a hydroelectric power system. Operations Research, 29(4):763-785, 1981.

Scola, L.A.; Neto, O.M.; Takahashi, R.H.C. \& Cerqueira, S.A.A.G., Multi-objective optimal multiple reservoir operation. In: Proceedings of the IEEE Congress in Evolutionary Computation. Piscataway, USA: IEEE Press, p. 1927-1933, 2011.

Soares, S. \& Carneiro, A.A.F.M., Optimal operation of reservoirs for electric generation. IEEE Transactions on Power Delivery, 6(3):1101-1107, 1991.

Storn, R. \& Price, K., Differential evolution - a simple and efficient heuristic for global optimization over continuous spaces. Journal of Global Optimization, 11(1):341-359, 1997.

Toro, F.; Ros, E.; Mota, S. \& Ortega, J., Evolutionary algorithms for multiobjective and multimodal optimization of diagnostic schemes. IEEE Transactions on Biomedical Engineering, 53(2):178-189, 2006.

Zambon, R.C., Planejamento da Operação de Sistemas Hidrotérmicos de Grande Porte. Tese de doutorado, Escola Politécnica, Universidade de São Paulo, São Paulo, SP, 2008.

Zoumas, C.E.; Bakirtzis, A.G.; Theocharis, J.B. \& Petridis, V., A genetic algorithm solution approach to the hydrothermal coordination problem. IEEE Transactions on Industrial Electronics, 19(2):1356-1364, 2004.

\section{Notas Biográficas}

Priscila Cristina Berbert Rampazzo é graduada em Matemática Aplicada e Computacional, mestre e doutora em Engenharia Elétrica (UNICAMP, 2005, 2008 e 2012, respectivamente). Suas principais áreas de pesquisa são: otimização multiobjetivo, computação evolutiva e planejamento hidrelétrico.

Akebo Yamakami é graduado em Engenharia Elétrica (PUC-Rio, 1973) e doutor em Controle de Sistemas Dinâmicos (UNICAMP, 1985). Atualmente é professor Titular da FEEC-UNICAMP, onde atua desde 1974. Foi chefe de departamento, coordenador e coordenador associado de graduação.

Fabrício Olivetti de França é graduado em Engenharia Elétrica (Universidade Católica de Santos, 2002), mestre e doutor em Engenharia Elétrica (UNICAMP, 2005 e 2010, respectivamente). Atualmente é professor adjunto da Universidade Federal do ABC. Suas principais áreas de pesquisa são inteligência computacional, clusterização, biclusterização, otimização dinâmica, combinatória e multiobjetivo, sistemas imunológicos artificiais, sistemas colaborativos e sistemas de recomendação. 


\title{
Simulated Annealing Aplicado ao Problema de Alocação de Salas com Deslocamentos Mínimos
}

\author{
Rosana Maria Luvezute Kripka*e Moacir Kripka
}

\begin{abstract}
Resumo: A otimização combinatorial é comumente utilizada na resolução de aplicações reais complexas, onde geralmente a solução pertence a um conjunto discreto, resultante de todas as combinações entre as possibilidades existentes. Um problema desta natureza é o de alocação de salas de aula em instituições de ensino onde, na distribuição das salas de aula disponíveis, devem ser respeitados tanto o número de alunos de cada disciplina/turma, bem como as capacidades das salas de aula. Neste capítulo apresentase uma formulação matemática desenvolvida para a otimização do problema de alocação de salas na Universidade de Passo Fundo, na qual a função objetivo consiste em minimizar a distância total percorrida pelos alunos, com intuito de realizar a distribuição das salas de aula, dos diversos prédios, de modo a manter os alunos o mais próximo possível das suas respectivas unidades. O processo de otimização foi realizado através do método Simulated Annealing, uma vez que apresenta um bom desempenho na resolução de problemas de otimização combinatórial e utiliza poucos parâmetros de controle, comparado a outras metaheurísticas. Foram realizados testes diversos que comprovaram a validação do modelo. Acredita-se que a formulação matemática apresentada, com pequenas adaptações, poderá resolver problemas específicos de outras Instituições de ensino.
\end{abstract}

Palavras-chave: Modelagem matemática, Alocação de salas de aula, Otimização combinatorial, Simulated annealing.

\begin{abstract}
In general, combinatorial optimization is used in the resolution of real complex applications, where a solution is obtained from a discrete set, resulting from all the combinations among the possibilities. One such problem is the Classroom Assignment Problem because in the distribution of available classrooms, the number of registered students in each course and the capacities of the classrooms must be respected. This chapter presents a mathematical formulation developed for the optimization of the Classroom Assignment Problem at the University of Passo Fundo, in which the objective function is to minimize the total distance traveled by students, aiming assign classrooms at various buildings in order to keep students as close as possible of their respective units. The optimization process was solved by the Simulated Annealing method because it presents a good performance in solving combinatorial optimization problems and uses fewer control parameters, when compared to other metaheuristics. Various tests were performed for model validation with good results. It is believed that the mathematical modeling presented, with a few adjustments, can solve specific problems of other education institutions.
\end{abstract}

Keywords: Mathematical modeling, Classroom assignment problem, Combinatorial optimization, Simulated annealing.

\section{Introdução}

A resolução de problemas reais através de técnicas de otimização tem sido muito empregada atualmente, tendo em vista que, no planejamento econômico, a busca das melhores soluções possíveis, para problemas restritos, possui grande importância. Neste contexto, identifica-se o Problema de Alocação de Salas de aula (PAS), em instituições de ensino superior de médio e grande porte, o qual se refere à atribuição de salas de aula às turmas, relativas às disciplinas que ocorrem nos períodos letivos, de tal modo que sejam respeitadas algumas restrições próprias do problema.

O Problema de Alocação de Salas é referido na literatura como um problema pertencente à classe NP-difícil, para os quais a obtenção da solução ótima do problema, em um período de tempo computacional aceitável, não é uma tarefa simples (Even et al., 1976). Para problemas combinatórios desta natureza, a utilização de

*Autor para contato: rkripka@upf.br 
métodos baseados em programação matemática exata têm se mostrado pouco eficiente, mesmo para problemas de pequena ou média dimensão. Em função disto, métodos heurísticos vêm sendo empregados com êxito não apenas para a alocação de salas, mas para outras classes de problemas de organização acadêmica (Carter \& Laporte, 1995; Alvarez-Valdés et al., 2001; Rossi-Doria et al.; Dammak et al., 2008; Subramanian et al., 2006; Jat \& Yang, 2008; Subramanian et al., 2011).

Diversos estudos e formulações foram e vêm sendo desenvolvidos com o objetivo de efetuar a otimização da alocação de salas, abordando particularidades e interesses específicos das instituições de ensino. Neste capítulo se apresenta uma formulação desenvolvida com o objetivo de contemplar o problema enfrentado na Universidade de Passo Fundo (UPF), localizada em Passo Fundo, no estado do Rio Grande do Sul, na região sul do Brasil.

A universidade possui uma estrutura multi-campi. Assim, além do câmpus central, existem mais seis câmpus da UPF, localizados nas seguintes cidades: Carazinho, Casca, Lagoa Vermelha, Palmeira das Missões, Sarandi e Soledade. Atualmente, na totalidade dos cursos, a UPF possui mais de 17 mil alunos de graduação, sendo que a maioria destes estuda no câmpus central, com uma parcela significativa concentrada no período da noite. Desta forma, a formulação elaborada objetiva não apenas a alocação das salas, mas também a minimização dos deslocamentos dos alunos pelo câmpus, buscando acomodá-los em salas próximas aos prédios onde seus cursos estão sediados. Para a otimização foi empregado o método Simulated Annealing (Kirkpatrick et al., 1983).

\section{Fundamentação Teórica}

O Problema de Alocação de Salas (PAS), também conhecido na literatura por Classroom Assignment Problem, é classificado como um problema de organização acadêmica, pelo fato de envolver variáveis relacionadas a professores/alunos/turmas/disciplinas/horários/salas de aula. Além do PAS, também podem ser citados como exemplos de problemas de organização acadêmica a distribuição de carga horária de professores, a distribuição de datas de exames de disciplinas ou, ainda, problemas de construção de grade horária.

Dentre os problemas de organização acadêmica, destacam-se os problemas de programação (organização) de horários (PPH), também chamados de problemas de timetabling, os quais são classificados por Schaerf (1999) em três categorias: school timetabling, course timetabling e examination timetabling.

Schaerf (1999) entende que os problemas classificados na categoria school timetabling dizem respeito a programação semanal de horários de professores ou turmas em escolas, onde neste caso, o estudante deve cursar um número fixo de disciplinas. Assim, além da programação da grade horária, que deve evitar choques de horários entre todas as disciplinas oferecidas, também existe o problema de distribuição de professores por disciplina, de modo que um professor receba apenas uma turma em um determinado horário, evitando choques de horários.

Os problemas classificados na categoria course timetabling envolvem a programação semanal de horários de disciplinas para todos os períodos dos cursos universitários, bem como a distribuição de professores para as turmas existentes, de modo a minimizar possíveis choques entre professor/turma/horário. Schaerf (1999) afirma que estes se diferenciam do school timetabling, pois os estudantes podem escolher as matérias que desejam se matricular.

Já na categoria examination timetabling se enquadram os problemas de programação de exames para cursos universitários, onde se busca evitar sobreposições de datas de exames de disciplinas que possuem estudantes em comum, onde também se objetiva distanciar as datas dos exames dos estudantes o máximo possível.

Vários autores consideram o PAS como um problema de course timetabling (Schaerf, 1999; Silva \& Silva, 2010). Neste problema específico se considera que os horários em que ocorrerão as disciplinas já estão estabelecidos e busca-se distribuí-las entre as salas de aula disponíveis na Instituição, de modo que seja evitado que duas disciplinas sejam atribuídas, num mesmo horário, a uma mesma sala de aula disponível. Além disto, também deve ser respeitada a capacidade da sala, ou seja, a distribuição deve considerar que existam classes e cadeiras suficientes para comportar os alunos matriculados na disciplina. Assim, as soluções possíveis para o PAS são resultantes de combinações possíveis entre disciplinas/salas que respeitem as restrições do problema.

Em processos de otimização, inicialmente foram elaborados técnicas para se encontrar as soluções ótimas através de estratégias descendentes, quando as funções objetivo eram contínuas e diferenciáveis, sendo chamados na Programação Matemática de métodos exatos. Nestes, a partir de uma solução inicial, uma nova solução é gerada, através de uma direção de descida, e o valor da função objetivo obtido para esta nova solução é comparado ao valor da função objetivo inicial. Caso exista uma redução significativa no valor da função objetivo, a mesma passa a ser adotada como solução corrente e o processo se repete até que nenhuma melhora seja verificada no valor da função, dentro de uma precisão considerada aceitável. $O$ resultado obtido deste processo, dependendo das características das funções envolvidas, pode se constituir na melhor solução nas vizinhanças da solução inicial, mas não necessariamente consiste no ótimo global para 
o problema abordado. Neste caso, uma estratégia alternativa usual, para se melhorar a solução otimizada obtida, consiste na otimização do problema a partir de diversas soluções iniciais.

Posteriormente, para se resolver os problemas cujas funções objetivo não eram diferenciáveis ou não contínuas, foram criados métodos alternativos chamados de "heurísticas" ou "métodos aproximativos", que possibilitam percorrer o espaço de busca de modo aleatório, com intuito de obter uma solução otimizada factível para o problema em questão. Além dos métodos heurísticos também foram desenvolvidas as meta-heurísticas que possuem uma importante vantagem em relação às heurísticas: possuem estratégias que possibilitam escapar de possíveis ótimos locais existentes no espaço das soluções. Assim, na resolução de problemas de otimização combinatorial, onde as soluções são resultantes de combinações entre variáveis e a função objetivo não é contínua, geralmente aplicam-se heurísticas, ou meta-heurísticas ou ainda, heurísticas híbridas, que combinam dois métodos para encontrar a solução otimizada para o problema.

Pela natureza combinatorial das soluções do PAS para problemas reais de grande porte, encontrar uma solução ótima se torna inviável através de métodos exatos. Dentre as diversas técnicas utilizadas na literatura para a resolução do PAS destacam-se o Simulated Annealing (SA), a Busca Tabu (Alvarez-Valdés et al., 2001; Subramanian et al., 2006, 2011), os Algoritmos Genéticos e Meméticos (Oliveira, 2006; Jat \& Yang, 2008), o processo de coloração de Grafos (Silva \& Silva, 2010), o GRASP (Greedy Randomized Adaptive Search Procedure) e o Método de Pesquisa em Vizinhança Variável (Souza et al., 2002).

O método escolhido para resolução otimizada do PAS, no presente trabalho é o método Simulated Annealing $(S A)$. A opção por este método se deve a sua vasta aplicação ao tipo de problema em estudo (Martinez-Alfaro \& Flores-Teran, 1998; Silva et al., 2005), bem como à experiência anterior dos autores em outros problemas de natureza combinatória (Kripka, 2004; Kripka et al., 2005). Além disto, é um método que possui poucos parâmetros de controle, quando comparado a outras meta-heurísticas consagradas.

\section{Modelagem Matemática}

Inicialmente, para resolução do problema de alocação de salas, foi elaborado um modelo matemático diferenciado dos demais propostos, disponíveis na literatura. Usualmente, em problemas de alocação de salas, a função objetivo é composta por um somatório das restrições, às quais são atribuídos pesos conforme sua importância relativa.

Segundo Souza et al. (2002) existem dois tipos de requisitos para avaliação de uma alocação, chamados de requisitos essenciais e não essenciais. Os requisitos essenciais se referem aqueles que, caso não sejam atendidos, geram uma alocação inviável, ou seja, que não pode ser executada na prática, como por exemplo, alocar duas turmas para uma mesma sala, no mesmo horário de aula.

Os requisitos não essenciais são aqueles que podem não ser necessariamente atendidos de modo a se obter uma alocação viável, mas que se fossem atendidos, certamente indicariam melhorias na alocação otimizada, como por exemplo, evitar a atribuição de turmas pequenas à salas de aula com uma capacidade grande.

De modo geral, a modelagem matemática do PAS consiste em minimizar uma função de avaliação $f(s)$ constituída de um somatório de restrições essenciais, representado por $g(s)$, chamado de inviabilidade da alocação s, adicionado a um somatório de restrições não essenciais, representado por $h(s)$. Salienta-se que, na formulação tradicionalmente proposta na literatura, uma solução $s$ será viável se, e somente, se $g(s)=0$. Além disto, como na função de avaliação $f(s)$, os pesos atribuídos às restrições devem refletir a importância de cada uma delas. Assim, naturalmente, os pesos associados às restrições essenciais $\left(\alpha_{k}\right)$ devem ser muito maiores que os pesos associados às restrições não essenciais $\left(\beta_{l}\right)$, com intuito de se evitar as soluções inviáveis.

Considerando $S$ o conjunto de alocações possíveis (espaço de soluções) para uma dada instância do PAS, Silva et al. (2005) apresentam resumidamente a modelagem clássica do PAS como:

Minimizar:

$$
f(s)=g(s)+h(s)
$$

onde:

$$
\begin{aligned}
& g(s)=\sum_{k=1}^{K} \alpha_{k} I_{k} \\
& h(s)=\sum_{l=1}^{L} \beta_{l} Q_{k}
\end{aligned}
$$

Sujeito a: 


$$
\begin{gathered}
s \in S \\
g(s)=0 \\
\alpha_{k} \geqslant \beta_{l}, \forall k, l
\end{gathered}
$$

onde:

$K$ : é o número de medidas de inviabilidade;

$I_{k}$ : é o valor da $k$-ésima medida de inviabilidade;

$\alpha_{k}$ : é o peso associado a esta $k$-ésima medida de inviabilidade;

$L$ : é o número de medidas de qualidade;

$Q_{l}$ : é o valor da $l$-ésima medida de qualidade e

$\beta_{l}$ : é o peso associado a esta $l$-ésima medida de qualidade;

\subsection{Formulação do modelo de otimização}

Na formulação proposta no presente capítulo, o objetivo consiste, além da alocação de salas, na minimização da distância a ser percorrida pelos alunos, com relação ao prédio de origem de seu curso (aqui chamado de sede). Assim, caso uma turma necessite ser acomodada em outro prédio que não sua sede, o custo desta operação será obtido pelo produto da distância até a sede pelo número de alunos matriculados na disciplina correspondente.

As restrições empregadas na formulação do problema, que são comuns aos problemas de alocação de salas, são as seguintes:

- as aulas de duas disciplinas não podem ocorrer simultaneamente em uma mesma sala;

- a aula de uma disciplina não pode ocorrer em mais de uma sala no mesmo instante;.

- a capacidade da sala deve ser maior ou igual ao número de alunos inscritos para a disciplina.

Todas as restrições listadas possuem caráter impeditivo, ou seja, são consideradas como restrições essenciais. Neste sentido, somente serão aceitas como viáveis as soluções que atendam simultaneamente todas as restrições essenciais.

Além destas, também foi considerada uma restrição de caráter não impeditivo, considerada como não essencial, que se refere a existência de uma sobra de lugares na sala, com relação ao número de alunos inscritos na disciplina a ser ministrada nesta sala. Esta restrição foi considerada pois, normalmente, o período de complementação de matrículas na UPF se estende por alguns dias após o início das aulas. Neste caso, o número de alunos matriculados poderá exceder a capacidade da sala para a qual a turma foi designada. Caso isto ocorra, haverá a necessidade de mudança da sala de aula originalmente atribuída. Assim, dependendo do número de novas matrículas, nas turmas das disciplinas, pode ocorrer um número significativo de trocas de sala de aula, justificando-se que se atribua, sempre que possível, uma sala com número de lugares maior que o número exato de alunos originalmente matriculados.

Em função das considerações efetuadas, o problema de alocação de salas de aula foi formulado como:

Minimizar:

$$
\sum_{i=1}^{n d} \sum_{j=1}^{n s} X_{i j} D_{j} N_{i}
$$

Sujeito a:

$$
\begin{gathered}
\sum_{j=1}^{n s} X_{i j}=1, i=1, \ldots, n d \\
\sum_{i=1}^{n d} X_{i j} \leq 1, j=1, \ldots, n s \\
N_{i} \leq \sum_{j=1}^{n s} X_{i j} C_{j}, i=1, \ldots, n d
\end{gathered}
$$




$$
N_{i}+\delta \leq \sum_{j=1}^{n s} X_{i j} C_{j}, i=1, \ldots, n d
$$

onde:

$X_{i j}$ : matriz binária, com:

$x_{i j}=1$, se a disciplina $i$ for atribuída à sala $j$, e $x_{i j}=0$, caso contrário;

$D_{j}$ : distância da sala $j$ à sede, ou seja, da sala, atribuída à disciplina, ao prédio de origem do curso;

$N_{i}$ : número de alunos matriculados na disciplina $i$

$C_{j}$ : capacidade da sala $j$

$\delta$ : um folga ou reserva em cada sala;

$n d$ : número total de disciplinas e

nd : número de salas disponíveis.

As Equações 8 e 9 correspondem, respectivamente, às condições de que cada disciplina deve ser atribuída a uma sala, e cada sala deve comportar no máximo uma disciplina. Na Equação 10 tem-se que o número de alunos da disciplina não deve superar a capacidade da sala à ela atribuída. Por fim, a relação descrita na Equação 11 corresponde à restrição não impeditiva, segundo a qual é aconselhável um folga ou reserva em cada sala.

Segundo a formulação desenvolvida, a atribuição das salas é efetuada para cada dia da semana de forma isolada, sem a preocupação de que uma turma tenha aula em uma mesma sala nos diversos dias da semana, mas apenas que, a cada noite, os alunos que estejam regularmente matriculados nas disciplinas de um determinado nível do curso não precisem se deslocar de um prédio a outro. Assim, a atribuição é feita com base na disciplina com maior número de alunos daquele turno.

A formulação proposta foi implementada em linguagem FORTRAN, sendo a otimização efetuada com o método Simulated Annealing. No processo de otimização, de maneira análoga às formulações propostas na literatura, as restrições não atendidas foram consideradas por meio de penalização da função objetivo, onde foram empregados fatores de penalização distintos para cada grupo de restrições, conforme o caráter impeditivo ou não destas restrições.

\subsection{Método de otimização Simulated Annealing}

O Método do Recozimento Simulado, ou Simulated Annealing, utiliza uma estratégia diferente dos métodos exatos, a qual possibilita evitar a convergência para um mínimo local aceitando também, a partir de um critério probabilístico, soluções que possam piorar o valor da função objetivo. O método foi originalmente proposto por Kirkpatrick et al. (1983), e se baseou na fundamentação teórica proposta por Metropolis et al. (1953) sobre a simulação do processo de recozimento, utilizado em metalurgia, para obtenção de estados de baixa energia de um sólido. O termo recozimento é dado ao processo de aquecimento de um sólido até seu ponto de fusão, seguido de um resfriamento lento. Neste processo, o resfriamento lento é essencial para a manutenção do equilíbrio térmico no qual os átomos possam se reorganizar em uma estrutura de mínima energia. Caso o sólido seja resfriado de forma abrupta, seus átomos poderão formar uma estrutura cristalina frágil. Computacionalmente, o recozimento pode ser considerado como um processo estocástico de organização dos átomos com mínima energia interna. Quando em temperaturas altas os átomos movem-se livremente podendo, com maior probabilidade, atingir estados (ou estruturas cristalinas) que acarretam em aumento na sua energia interna. A redução gradual da temperatura possibilita aos átomos a movimentação no sentido de formarem uma estrutura cristalina estável, e a probabilidade de aumento na energia interna é reduzida.

No Simulated Annealing, a função objetivo corresponde à energia do sólido de forma análoga ao recozimento em termodinâmica. Esta técnica começa o processo de otimização através de uma solução inicial qualquer, considerada como solução atual, e para busca de valores otimizados são geradas soluções aleatórias para o problema. O processo também considera inicialmente um alto valor para o parâmetro da temperatura $T$, para a qual uma nova solução é gerada na vizinhança da solução atual. Se no processo surgirem soluções melhores, estas naturalmente são aceitas como soluções e como novos centros de busca, onde o processo será reiniciado a partir da nova solução encontrada. Porém, caso a solução gerada seja pior que a solução anterior, a aceitação da nova solução como novo centro de busca se dará através de um critério probabilístico, onde se considera:

$$
p=\exp \left(\frac{-\Delta f}{T}\right)
$$

onde:

$p$ : função aceite da nova solução gerada aleatoriamente; 
$T$ : parâmetro do chamado de temperatura, que regula a probabilidade de piora na função objetivo;

$\Delta f$ : variação da função objetivo entre o valor da solução considerada como central e a solução vizinha, gerada aleatoriamente.

A nova solução será aceita se $p$ for maior que um número entre zero e um, gerado aleatoriamente. Caso contrário, a solução atual, que correponde ao centro de busca, é mantida. Para valores altos de $T$, a chance de aceitação de soluções piores será maior, sendo $T$ gradualmente reduzido até que o critério de parada estabelecido seja atendido.

A estratégia usual para redução da temperatura, e considerada no presente estudo, consiste no emprego de um fator de redução $\alpha$ pelo qual a temperatura atual vai sendo multiplicada. Neste caso, cabe ressaltar que, caso seja adotado um valor grande para $\alpha$ (próximo da unidade), o processo pode se tornar demasiadamente lento. Em contrapartida, um valor pequeno para $\alpha$ pode acarretar na convergência prematura para um mínimo local.

A cada iteração do método, um novo vizinho $s^{\prime}$ é gerado de $s$ e se realiza o teste para a variação $\Delta f$ do valor da função objetivo, isto é, calcula-se $\Delta f=f\left(s^{\prime}\right)-f(s)$, onde podem ocorrer as seguintes situações:

- $\Delta f<0$ : Neste caso, há uma redução de energia, o que significa que a nova solução é melhor que a anterior e o método aceita a nova solução como solução otimizada e $s^{\prime}$ passa a ser a nova solução correpondente ao centro de busca;

- $\Delta f=0$ : Neste caso, não há nem aumento nem redução de energia, o que indicaria estabilidade. Porém, os autores afirmam que esta situação seria pouco provável, e a nova solução seria aceita;

- $\Delta f>0$ : Neste caso, há um aumento do estado de energia, o que significa que a aceitação deste tipo de solução estaria condicionada ao critério probabilístca, sendo mais provável a altas temperaturas e bastante improvável a temperaturas reduzidas.

No início do procedimento, quando a temperatura é alta, há uma chance maior de se escapar de mínimos locais, pois são aceitos mais pontos avaliados nas vizinhanças da solução considerada. No entanto, à medida que se aproxima de zero, o algoritmo comporta-se como o método de descida, uma vez que diminui a probabilidade de se aceitarem movimentos que possam piorar a solução encontrada. O procedimento é finalizado ao chegar a temperatura a um valor próximo de zero, quando soluções que pioram o valor da função objetivo não são mais aceitas, o que significa que o sistema está estável e evidencia o encontro de um ótimo local.

Em resolução de problemas reais também é comumente usado o procedimento chamado Reannealing, que consiste novamente na aplicação do método Simulated Annealing, tomando como solução inicial a solução otimizada obtida do processo de busca anterior, quando a temperatura mínima foi atingida. Neste caso, o procedimento representaria o reaquecimento, seguido de um novo processo de resfriamento, o que possibilitaria uma nova busca por soluções melhores, quando a quantidade de movimentos consecutivamente rejeitados é baixa. Também é possível se trabalhar com taxa de resfriamento menor quando as temperaturas são mais altas e aumentá-la à medida que a temperatura vá sendo reduzida.

Um algoritmo básico do Simulated Annealing, encontrado em Souza (2000), pode ser visualizado no Algoritmo 1.

\section{Exemplo de Aplicação da Formulação}

Com o objetivo de ilustrar a aplicação da formulação desenvolvida apresentam-se, na sequência, os dados e correspondentes resultados de um dos diversos testes efetuados. Nestas simulações, os valores empregados para os parâmetros específicos do Simulated Annealing foram temperatura inicial $T=100$ e redutor de temperatura $\alpha=0,95$.

O problema apresentado é composto de 15 disciplinas, as quais devem ser alocadas nas 17 salas disponíveis em quatro prédios do câmpus. Na Tabela 1 estão relacionados, para cada disciplina, o correspondente número de alunos matriculados e a sede (prédio de origem) do curso a que pertence. Já a Tabela 2 relaciona, para cada sala, a respectiva capacidade e o prédio onde se situa.

A matriz de distâncias $D$ é constituída a partir do conhecimento das distâncias entre os prédios, e é empregada para o cálculo da função objetivo. Uma vez que as distâncias supostamente serão percorridas a pé, foi constituída uma matriz simétrica, ou seja, o percurso de ida entre um prédio e outro possui a mesma distância do percurso de retorno. Especificamente, para o exemplo, foram consideradas as distâncias (em metros) conforme apresentado na Tabela 3.

As análises foram efetuadas a partir de diversas soluções iniciais, todas elas infactíveis. O resultado, invariavelmente, convergiu para um mesmo valor da função objetivo. A Tabela 4 apresenta os resultados obtidos sem consideração de folga (diferença entre a capacidade da sala e o tamanho da turma). O custo da 


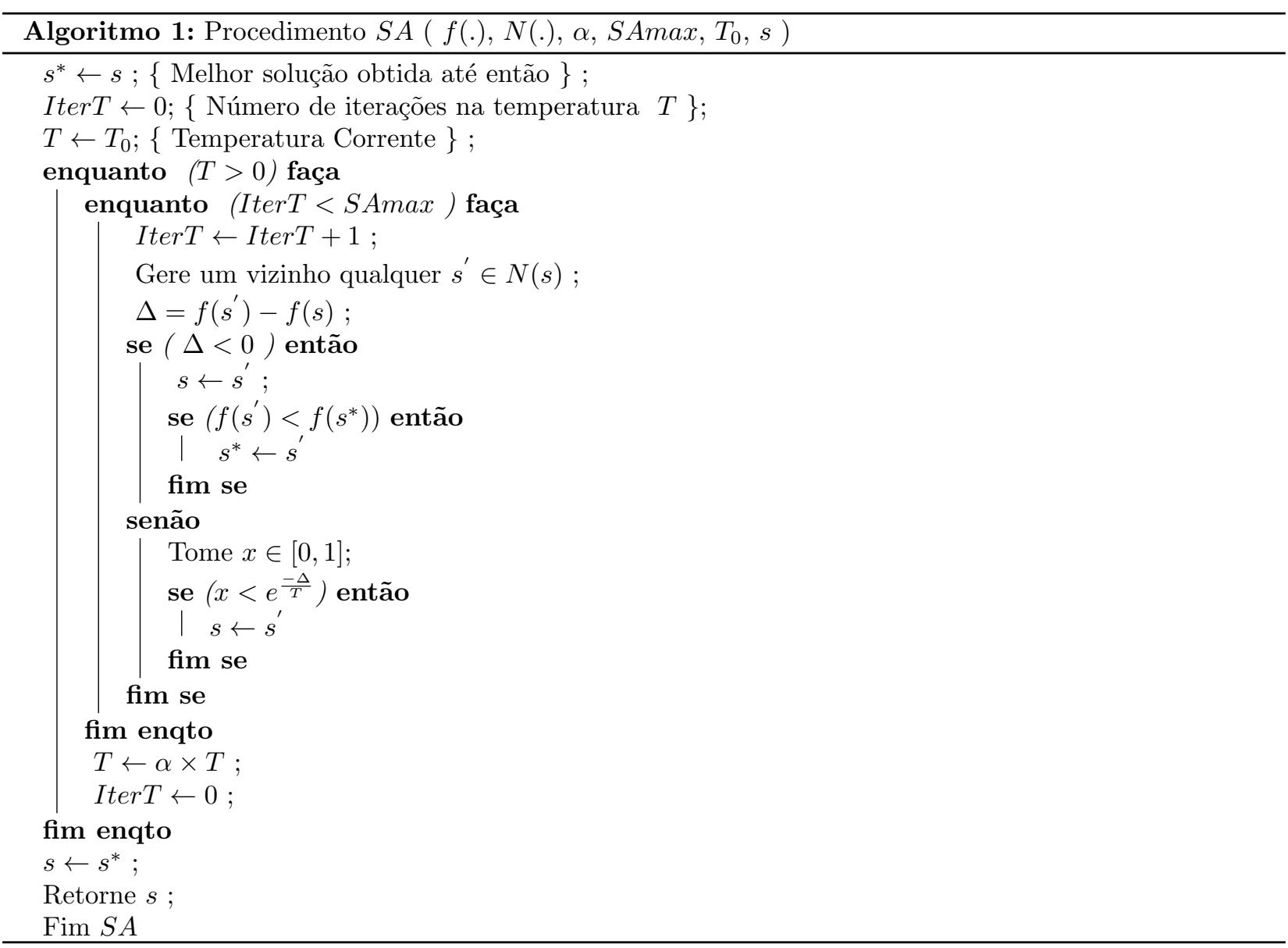

Tabela 1. Dados gerais das disciplinas.

\begin{tabular}{ccc}
\hline Disciplina & N $^{\mathbf{0}}$ Alunos & Origem \\
\hline 1 & 48 & 1 \\
2 & 45 & 1 \\
3 & 38 & 1 \\
4 & 30 & 1 \\
5 & 23 & 1 \\
6 & 20 & 1 \\
7 & 40 & 3 \\
8 & 35 & 3 \\
9 & 27 & 3 \\
10 & 22 & 3 \\
11 & 13 & 3 \\
12 & 41 & 4 \\
13 & 34 & 4 \\
14 & 29 & 4 \\
15 & 18 & 4 \\
\hline
\end{tabular}

solução ótima é composto do somatório dos valores constantes da última coluna, obtidos a partir do produto entre o número de alunos da turma e a distância entre o prédio que comporta a sala e o prédio sede. Assim, as parcelas para as quais o custo é nulo indicam que a disciplina correspondente ocorrerá na própria sede do curso.

Para o exemplo, o custo total resultou em $35 \times 200+18 \times 150=9700$ metros, correspondendo ao somatório das distâncias percorridas por cada um dos alunos.

Ainda para o exemplo analisado cabe destacar que, apesar da solução otimizada indicar a necessidade de duas turmas terem de se deslocar ao longo do câmpus, esta solução é factível, uma vez que todas as turmas 
Tabela 2. Dados das salas disponíveis.

\begin{tabular}{ccc}
\hline Sala & Capacidade & Prédio \\
\hline 1 & 20 & 1 \\
2 & 25 & 1 \\
3 & 35 & 1 \\
4 & 40 & 1 \\
5 & 40 & 1 \\
6 & 45 & 1 \\
7 & 50 & 1 \\
8 & 20 & 2 \\
9 & 40 & 2 \\
10 & 50 & 2 \\
11 & 20 & 3 \\
12 & 25 & 3 \\
13 & 30 & 3 \\
14 & 50 & 3 \\
15 & 35 & 4 \\
16 & 40 & 4 \\
17 & 50 & 4 \\
\hline
\end{tabular}

Tabela 3. Distância entre os prédios (metros).

\begin{tabular}{ccccc}
\hline Prédios & $\mathbf{1}$ & $\mathbf{2}$ & $\mathbf{3}$ & $\mathbf{4}$ \\
\hline 1 & 0 & 100 & 300 & 250 \\
2 & 100 & 0 & 200 & 150 \\
3 & 300 & 200 & 0 & 100 \\
4 & 250 & 150 & 100 & 0 \\
\hline
\end{tabular}

Tabela 4. Resultados obtidos sem reserva de lugares nas salas.

\begin{tabular}{ccccccc}
\hline Disc. & Sala & N $^{\text {o }}$ Al. & Cap. & Sede Disc. & Prédio & Custo \\
\hline 1 & 7 & 48 & 50 & 1 & 1 & 0 \\
2 & 6 & 45 & 45 & 1 & 1 & 0 \\
3 & 5 & 38 & 40 & 1 & 1 & 0 \\
4 & 3 & 30 & 35 & 1 & 1 & 0 \\
5 & 2 & 23 & 25 & 1 & 1 & 0 \\
6 & 1 & 20 & 20 & 1 & 1 & 0 \\
7 & 14 & 40 & 50 & 3 & 3 & 0 \\
8 & 10 & 35 & 50 & 3 & 2 & 7000 \\
9 & 13 & 27 & 30 & 3 & 3 & 0 \\
10 & 12 & 22 & 25 & 3 & 3 & 0 \\
11 & 11 & 13 & 20 & 3 & 3 & 0 \\
12 & 17 & 41 & 50 & 4 & 4 & 0 \\
13 & 15 & 34 & 35 & 4 & 4 & 0 \\
14 & 16 & 29 & 40 & 4 & 4 & 0 \\
15 & 8 & 18 & 20 & 4 & 2 & 2700 \\
\hline
\end{tabular}

foram alocadas a salas com capacidade igual ou superior ao número de alunos matriculados nas disciplinas. No caso específico, a folga variou entre 0 e 15 alunos.

\section{Aplicação ao Problema da Universidade de Passo Fundo}

Apresentam-se na sequência os resultados obtidos a partir de uma pesquisa de campo no Instituto de Ciências Exatas e Geociências, da Universidade de Passo Fundo, realizada com a finalidade de coletar dados reais para validação do modelo de otimização proposto para o problema de alocação de salas. 
As análises foram efetuadas com e sem a consideração da reserva de lugares (diferença entre a capacidade da sala e o número de alunos matriculados). Nas otimizações com reserva de lugares, foram buscadas cinco vagas adicionais por disciplina.

\subsection{Dados gerais}

Para os seis dias letivos (segunda-feira a sábado) foram considerados os dados conforme a Tabela 5, relativos ao número total de disciplinas, de salas disponíveis e de alunos matriculados. A enumeração dos prédios foi realizada conforme a Tabela 6 . As distâncias consideradas entre eles, para construção da matriz de distâncias, empregada para o cálculo da função objetivo, estão apresentadas na Tabela 7. Na Tabela 8 estão relacionados os dados gerais relativos às 38 salas de aula disponíveis (capacidade e prédio onde se situam). Por questão de concisão, apenas os dados relativos a algumas salas são apresentados.

Tabela 5. Dados Gerais dos problemas de alocação de salas.

\begin{tabular}{cccc}
\hline Dia & $\mathbf{N}^{\circ}$ Disciplinas & $\mathbf{N}^{\circ}$ Salas & $\mathbf{N}^{\mathbf{0}}$ Alunos \\
\hline Segunda & 28 & 38 & 685 \\
Terça & 29 & 37 & 691 \\
Quarta & 23 & 36 & 573 \\
Quinta & 28 & 37 & 679 \\
Sexta & 22 & 38 & 523 \\
Sábado & 10 & 36 & 224 \\
\hline
\end{tabular}

Tabela 6. Numeração dos prédios considerados.

\begin{tabular}{cc}
\hline Prédio & Numeração considerada \\
\hline ICEG-B2 & 1 \\
ICEG-B5 & 2 \\
FEFF-A12 & 3 \\
CENTRAL DE SALAS-D5 & 4 \\
FAED & 5 \\
\end{tabular}

Tabela 7. Distância entre os prédios (metros).

\begin{tabular}{ccccccc}
\hline Prédios & $\mathbf{1}$ & $\mathbf{2}$ & $\mathbf{3}$ & $\mathbf{4}$ & $\mathbf{5}$ & $\mathbf{6}$ \\
\hline 1 & 0 & 218 & 292 & 420 & 112 & 850 \\
2 & 218 & 0 & 390 & 212 & 325 & 740 \\
3 & 292 & 390 & 0 & 605 & 380 & 1010 \\
4 & 420 & 212 & 605 & 0 & 521 & 930 \\
5 & 112 & 325 & 380 & 521 & 0 & 980 \\
6 & 850 & 740 & 1010 & 930 & 980 & 0 \\
\hline
\end{tabular}

Tabela 8. Descrição de salas de aula disponíveis.

\begin{tabular}{cccc}
\hline Sala & Número & Capacidade & Prédio \\
\hline 001 & 1 & 20 & 1 \\
202 & 2 & 20 & 1 \\
203 & 3 & 20 & 1 \\
$\ldots$ & $\ldots$ & $\ldots$ & $\ldots$ \\
214 & 38 & 25 & 6 \\
\hline
\end{tabular}

Em seguida, apresenta-se um exemplo específico sobre os dados utilizados na otimização da alocação de salas para segunda-feira, bem como todos os resultados computacionais gerais obtidos. 


\subsection{Resultados computacionais}

Considerando os dados reais apresentados, foram realizadas as otimizações dos seis dias letivos para a demanda de disciplinas do Instituto de Ciências Exatas e Geociências relativas ao segundo semestre de 2010.

Como exemplo, são apresentadas, na Tabela 9, algumas das 28 disciplinas previstas para ocorrerem nas segundas-feiras que poderiam ser alocadas nas 38 salas disponíveis, conforme apresentado na Tabela 8. Estão relacionados na Tabela 9 os nomes das disciplinas apenas como dados informativos sobre o problema real. Já o curso ao qual a disciplina pertence indica a sede (última coluna da tabela). Cada disciplina ocupará uma sala durante todo o turno (quatro períodos letivos).

Tabela 9. Descrição das disciplinas que ocorrem na segunda-feira.

\begin{tabular}{ccccc}
\hline Curso & Disciplina & $\mathbf{N}^{\circ}$ Disc. & $\mathbf{N}^{\circ}$ Alunos & Sede \\
\hline Física & Física Geral e Exp. IV & 1 & 16 & 1 \\
Física & Sem. de Ed. & 2 & 30 & 1 \\
Química L/B & Inic. ao Conh. Ac. & 3 & 21 & 1 \\
$\ldots$ & $\ldots$ & $\ldots$ & $\ldots$ & $\ldots$ \\
Ciência da Computação & Teoria da Computação & 28 & 30 & 2 \\
\hline
\end{tabular}

Nas Tabelas 10 e 11, apresentam-se os resultados obtidos das otimizações realizadas.

Conforme comentado na descrição da formulação do problema, é interesse da instituição que, sempre que possível, haja um excedente prevendo eventuais matrículas posteriores ao início das aulas. Por este motivo também se optou em realizar a otimização prevendo obrigatoriamente a existência de lugares excedentes nas salas, para se verificar a possibilidade de existência de uma solução viável, considerado as folgas.

As análises foram efetuadas com e sem sobras, ou seja, a consideração da reserva de lugares (diferença entre a capacidade da sala e o número de alunos matriculados). Nas otimizações com reserva de lugares, foram buscadas cinco vagas adicionais por disciplina.

Na Tabela 10 apresenta-se o resultado da otimização da alocação de salas para segunda-feira, onde se considerou a restrição de folga como não impeditiva, chamada de Solução Otimizada 1.

Na Tabela 11 apresenta-se o resultado da otimização da alocação de salas para segunda-feira, onde a restrição de folga foi considerada como restrição essencial ou impeditiva, chamada de Solução Otimizada 2. Pode se observar, pelos resultados obtidos, que, em função da capacidade das salas disponíveis, a restrição de folga pode ser integralmente atendida.

Ressalta-se que, no processo de otimização, como solução inicial foram utilizadas tanto soluções iniciais infactíveis, como também foi considerada a solução praticada atualmente pela secretaria da Unidade, chamada de atual. Os resultados, invariavelmente, convergiram para os mesmos valores otimizados das funções objetivos.

Ainda cabe observar que, em alguns casos, a solução inicial, adotada pelo instituto, seria infactível, uma vez que o número de alunos foi superior à capacidade da sala. Esta foi a solução adotada pela secretaria, a partir do deslocamento de mesas entre as salas. Exemplificando, a disciplina 2 (com 30 alunos matriculados) foi alocada originalmente na sala 2 (vinte lugares).

Além da resolução do problema de Alocação de Salas de Aula para segunda-feira, o processo de otimização foi realizado para os demais dias da semana, obtendo-se valores otimizados para a função de avaliação, apresentados na Tabela 12. Resumidamente nesta tabela, apresentam-se os valores da Função Objetivo (FO) com os valores das penalizações e sem os valores das penalizações, que indicam as distâncias percorridas pelos alunos pelo Campus da UPF. Na coluna relativa à Solução Otimizada 1, a restrição de folga foi considerada como não impeditiva e na coluna relativa à Solução Otimizada 2, a restrição de folga foi considerada como impeditiva.

Observa-se que, em todos os casos analisados, o software encontrou uma solução factível ou viável, com resultados significativamente melhores que a solução atual adotada para as otimizações que previam folgas e praticamente em todos os casos em que não se previam folgas. O único caso em que distância total percorrida foi maior, após a otimização ocorreu na quarta-feira, onde a solução inicial praticada violava uma restrição de capacidade, considerada impeditiva, o que não ocorreu na solução otimizada encontrada.

Ainda é possível verificar, ao serem comparados os valores da FO otimizadas, que ao se considerar a folga como restrição impeditiva, apesar de existir um percentual de redução significativo, a redução foi bem maior quando a restrição de folga foi considerada como não impeditiva.

Com a finalidade de se comparar os resultados obtidos podem ser calculadas as distâncias médias percorridas por aluno, conforme apresentados na Tabela 13.

Pode-se observar na Tabela 13 que, com exceção da quarta-feira, os demais resultados otimizados indicaram reduções significativas na distância média percorrida pelos alunos. 
Tabela 10. Resultados da otimização com restrição de folga não impeditiva.

\begin{tabular}{|c|c|c|c|c|c|c|c|c|}
\hline \multirow[b]{2}{*}{ Disc. } & \multirow[b]{2}{*}{ Alunos } & \multirow[b]{2}{*}{ Sede } & \multicolumn{3}{|c|}{ Solução Atual } & \multicolumn{3}{|c|}{ Solução Otimizada 1} \\
\hline & & & Sala & Cap. & Prédio & Sala & Cap. & Prédio \\
\hline 1 & 16 & 1 & 23 & 54 & 3 & 36 & 25 & 5 \\
\hline 2 & 30 & 1 & 2 & 20 & 1 & 5 & 55 & 1 \\
\hline 3 & 21 & 1 & 1 & 20 & 1 & 10 & 30 & 1 \\
\hline 4 & 19 & 1 & 5 & 55 & 1 & 3 & 20 & 1 \\
\hline 5 & 23 & 1 & 34 & 25 & 5 & 4 & 25 & 1 \\
\hline 6 & 18 & 1 & 3 & 20 & 1 & 8 & 20 & 1 \\
\hline 7 & 13 & 1 & 11 & 70 & 1 & 33 & 30 & 5 \\
\hline 8 & 30 & 1 & 33 & 30 & 5 & 6 & 70 & 1 \\
\hline 9 & 14 & 1 & 35 & 25 & 5 & 34 & 25 & 5 \\
\hline 10 & 19 & 1 & 32 & 25 & 5 & 6 & 70 & 1 \\
\hline 11 & 7 & 1 & 38 & 25 & 6 & 26 & 54 & 3 \\
\hline 12 & 12 & 1 & 4 & 25 & 1 & 15 & 25 & 2 \\
\hline 13 & 21 & 1 & 27 & 30 & 4 & 9 & 30 & 1 \\
\hline 14 & 13 & 1 & 28 & 40 & 4 & 32 & 25 & 5 \\
\hline 15 & 27 & 1 & 10 & 30 & 1 & 7 & 50 & 1 \\
\hline 16 & 23 & 1 & 8 & 20 & 1 & 12 & 25 & 1 \\
\hline 17 & 14 & 1 & 9 & 30 & 1 & 35 & 25 & 5 \\
\hline 18 & 20 & 1 & 29 & 40 & 4 & 2 & 20 & 1 \\
\hline 19 & 35 & 1 & 7 & 50 & 1 & 11 & 70 & 1 \\
\hline 20 & 26 & 2 & 17 & 38 & 2 & 17 & 38 & 2 \\
\hline 21 & 31 & 2 & 14 & 40 & 2 & 19 & 40 & 2 \\
\hline 22 & 68 & 2 & 13 & 75 & 2 & 13 & 75 & 2 \\
\hline 23 & 23 & 2 & 18 & 26 & 2 & 14 & 40 & 2 \\
\hline 24 & 48 & 2 & 6 & 70 & 1 & 31 & 50 & 4 \\
\hline 25 & 21 & 2 & 21 & 40 & 2 & 16 & 35 & 2 \\
\hline 26 & 25 & 2 & 20 & 45 & 2 & 20 & 45 & 2 \\
\hline 27 & 18 & 2 & 15 & 25 & 2 & 18 & 26 & 2 \\
\hline 28 & 30 & 2 & 19 & 40 & 2 & 21 & 40 & 2 \\
\hline
\end{tabular}

\section{Conclusões}

Com o objetivo de atender a uma demanda específica da Universidade de Passo Fundo foi desenvolvida uma formulação matemática para a otimização da alocação das salas de aula no câmpus. Nesta formulação, além do atendimento às restrições usuais neste tipo de problema, buscou-se manter os alunos o mais próximo possível da sede de seus respectivos cursos, através da minimização das distâncias a serem percorridas.

A formulação foi implementada e otimizada com o emprego do método Simulated Annealing, o qual já havia sido utilizado com êxito pelos autores em aplicações de natureza semelhante.

Em todas as otimizações realizadas obteve-se soluções factíveis melhores que as praticadas, o que indica que o modelo proposto, além de atender as necessidades do referido Instituto, propõe soluções melhores do que as elaboradas manualmente. Para todos os dias da semana, foram encontradas soluções otimizadas factíveis que apresentaram melhoras significativas em relação a solução real praticada.

As análises foram efetuadas com e sem folgas, ou seja, a consideração da reserva de lugares (diferença entre a capacidade da sala e o número de alunos matriculados). Nas simulações com reserva de lugares, foram buscadas cinco vagas adicionais por disciplina. Além disto, como solução inicial no processo de otimização foram utilizadas tanto soluções iniciais infactíveis, como também foi considerada a solução encontrada, praticada, chamada de atual. Os resultados, invariavelmente, convergiram para os mesmos valores otimizados das funções objetivos.

Em todos os casos o software encontrou uma solução factível e com resultados significativamente melhores que a solução atual adotada para as otimizações que não previam folgas e, em praticamente todos os casos em que não se previam folgas. Os resultados obtidos evidenciam a importância do emprego de técnica de otimização a este tipo de problema, bem como a validade da abordagem efetuada.

Acredita-se que a formulação matemática apresentada, com pequenas adaptações, poderá resolver problemas específicos de outras Instituições de ensino. 
Tabela 11. Resultados da otimização com restrição de folga impeditiva.

\begin{tabular}{|c|c|c|c|c|c|c|c|c|}
\hline \multirow[b]{2}{*}{ Disc. } & \multirow[b]{2}{*}{$\mathrm{N}^{\mathrm{o}}$ Alunos } & \multirow[b]{2}{*}{ Sede } & \multicolumn{3}{|c|}{ Solução Atual } & \multicolumn{3}{|c|}{ Solução Otimizada 2} \\
\hline & & & Sala & Cap. & Prédio & Sala & Cap. & Prédio \\
\hline 1 & 16 & 1 & 23 & 54 & 3 & 36 & 25 & 5 \\
\hline 2 & 30 & 1 & 2 & 20 & 1 & 7 & 50 & 1 \\
\hline 3 & 21 & 1 & 1 & 20 & 1 & 33 & 30 & 5 \\
\hline 4 & 19 & 1 & 5 & 55 & 1 & 34 & 25 & 5 \\
\hline 5 & 23 & 1 & 34 & 25 & 5 & 10 & 30 & 1 \\
\hline 6 & 18 & 1 & 3 & 20 & 1 & 32 & 25 & 5 \\
\hline 7 & 13 & 1 & 11 & 70 & 1 & 1 & 20 & 1 \\
\hline 8 & 30 & 1 & 33 & 30 & 5 & 5 & 55 & 1 \\
\hline 9 & 14 & 1 & 35 & 25 & 5 & 2 & 20 & 1 \\
\hline 10 & 19 & 1 & 32 & 25 & 5 & 4 & 25 & 1 \\
\hline 11 & 7 & 1 & 38 & 25 & 6 & 22 & 54 & 3 \\
\hline 12 & 12 & 1 & 4 & 25 & 1 & 35 & 25 & 5 \\
\hline 13 & 21 & 1 & 27 & 30 & 4 & 25 & 54 & 3 \\
\hline 14 & 13 & 1 & 28 & 40 & 4 & 3 & 20 & 1 \\
\hline 15 & 27 & 1 & 10 & 30 & 1 & 19 & 40 & 2 \\
\hline 16 & 23 & 1 & 8 & 20 & 1 & 9 & 30 & 1 \\
\hline 17 & 14 & 1 & 9 & 30 & 1 & 8 & 20 & 1 \\
\hline 18 & 20 & 1 & 29 & 40 & 4 & 12 & 25 & 1 \\
\hline 19 & 35 & 1 & 7 & 50 & 1 & 6 & 70 & 1 \\
\hline 20 & 26 & 2 & 17 & 38 & 2 & 21 & 40 & 2 \\
\hline 21 & 31 & 2 & 14 & 40 & 2 & 20 & 45 & 2 \\
\hline 22 & 68 & 2 & 13 & 75 & 2 & 13 & 75 & 2 \\
\hline 23 & 23 & 2 & 18 & 26 & 2 & 17 & 38 & 2 \\
\hline 24 & 48 & 2 & 6 & 70 & 1 & 11 & 70 & 1 \\
\hline 25 & 21 & 2 & 21 & 40 & 2 & 18 & 26 & 2 \\
\hline 26 & 25 & 2 & 20 & 45 & 2 & 14 & 40 & 2 \\
\hline 27 & 18 & 2 & 15 & 25 & 2 & 15 & 25 & 2 \\
\hline 28 & 30 & 2 & 19 & 40 & 2 & 16 & 35 & 2 \\
\hline
\end{tabular}

Tabela 12. Distância entre os prédios (metros).

\begin{tabular}{|c|c|c|c|c|c|c|}
\hline Dia & Resultados & Atual & $\begin{array}{c}\text { Solução } \\
\text { Otimizada } 1\end{array}$ & Redução & $\begin{array}{c}\text { Solução } \\
\text { Otimizada } 2\end{array}$ & Redução \\
\hline $\mathrm{S}$ & $\begin{array}{l}\text { FO c/ pen. } \\
\text { Dist. s/ pen. }\end{array}$ & & $\begin{array}{l}22776 \\
22676\end{array}$ & $\begin{array}{l}88,23 \% \\
57.53 \%\end{array}$ & $\begin{array}{l}42318 \\
42058\end{array}$ & $\begin{array}{l}78,13 \% \\
21.24 \%\end{array}$ \\
\hline $\mathrm{T}$ & $\begin{array}{l}\text { FO c/ pen. } \\
\text { Dist. s/ pen. }\end{array}$ & $\begin{array}{c}278308 \\
98258\end{array}$ & $\begin{array}{l}27554 \\
27334\end{array}$ & $\begin{array}{l}90,10 \% \\
72,18 \%\end{array}$ & $\begin{array}{l}55698 \\
55478\end{array}$ & $\begin{array}{l}79,99 \% \\
43,54 \%\end{array}$ \\
\hline $\mathrm{Q}$ & $\begin{array}{l}\text { FO c/ pen. } \\
\text { Dist. s/ pen. }\end{array}$ & $\begin{array}{l}136160 \\
36060^{*}\end{array}$ & $\begin{array}{l}3908 \\
3808\end{array}$ & $\begin{array}{l}97,13 \% \\
89,44 \% \\
\end{array}$ & $\begin{array}{l}40294 \\
40144 \\
\end{array}$ & $\begin{array}{r}70,41 \% \\
-11,33 \% * \\
\end{array}$ \\
\hline $\mathrm{Q}$ & $\begin{array}{l}\text { FO c/ pen. } \\
\text { Dist. s/ pen. }\end{array}$ & $\begin{array}{l}399984 \\
69924\end{array}$ & $\begin{array}{l}12100 \\
12060\end{array}$ & $\begin{array}{l}96,97 \% \\
82,75 \%\end{array}$ & $\begin{array}{l}23700 \\
23480\end{array}$ & $\begin{array}{l}94,07 \% \\
66,42 \%\end{array}$ \\
\hline $\mathrm{S}$ & $\begin{array}{l}\text { FO c/ pen. } \\
\text { Dist. s/ pen. }\end{array}$ & $\begin{array}{l}413595 \\
93545\end{array}$ & $\begin{array}{l}5120 \\
5040\end{array}$ & $\begin{array}{l}98,76 \% \\
94,61 \%\end{array}$ & $\begin{array}{l}13170 \\
13030\end{array}$ & $\begin{array}{l}96,82 \% \\
86,07 \%\end{array}$ \\
\hline$S$ & $\begin{array}{l}\text { FO c/ pen. } \\
\text { Dist.s/ pen. }\end{array}$ & $\begin{array}{l}49624 \\
19594\end{array}$ & $\begin{array}{l}0 \\
0\end{array}$ & $\begin{array}{l}100 \% \\
100 \%\end{array}$ & $\begin{array}{l}0 \\
0\end{array}$ & $\begin{array}{l}100 \% \\
100 \%\end{array}$ \\
\hline
\end{tabular}

* Solução inicial infactível, fornecida pela secretaria.

Tabela 13. Distância média percorrida por aluno (metros).

\begin{tabular}{ccccccc}
\cline { 2 - 7 } & $\mathbf{S}$ & $\mathbf{T}$ & $\mathbf{Q}$ & $\mathbf{Q}$ & $\mathbf{S}$ & $\mathbf{S}$ \\
\hline Solução Atual & 77,95 & 142,20 & 62,93 & 102,98 & 178,86 & 87,47 \\
Solução Otimizada 1 & 33,10 & 39,56 & 6,65 & 17,76 & 9,64 & 0 \\
Solução Otimizada 2 & 61,40 & 80,29 & 70,06 & 34,58 & 24,91 & 0 \\
\hline
\end{tabular}




\section{Agradecimentos}

Os autores agradecem à Fundação Universidade de Passo Fundo pelo apoio financeiro ao projeto de pesquisa que possibilitou gerar os resultados apresentados.

\section{Referências}

Alvarez-Valdés, R.; Crespo, E. \& Tamarit, J.M., Tabu search: an efficient metaheuristic for university organization problems. Revista Investigación Operacional, 22(2):104-113, 2001.

Carter, M.W. \& Laporte, G., Recent developments in practical examination timetabling. In: Practice and Theory of Automated Timetabling. Heidelberg, Germany: Springer-Verlag, v. 1153 de Lecture Notes in Computer Science, p. 3-21, 1995.

Dammak, A.; Elloumi, A.; Kamoun, H. \& Ferland, J.A., Course timetabling at a tunisian university: A case study. Journal of System Science and System Engineering, 17(3):334-352, 2008.

Even, S.; Itai, A. \& Shamir, A., On the complexity of timetabling and multicommodity flow problems. SIAM Journal of Computation, 5(4):691-703, 1976.

Jat, S.N. \& Yang, S., A memetic algorithm for the university course timetabling problem. In: Proceedings of the 20th IEEE International Conference on Tools with Artificial Intelligence. Piscataway, USA: IEEE Press, v. 1, p. 427-433, 2008.

Kirkpatrick, S.; Gelatt, C.D. \& Vecchi, M.P., Optimization by simulated annealing. Science, 220(4598):671-680, 1983.

Kripka, M., Discrete optimization of trusses by simulated annealing. Journal of the Brazilian Society of Mechanical Sciences and Engineering, 26(2):170-173, 2004.

Kripka, R.M.L.; Oro, N.T. \& Kripka, M., Distribuição de cargas horárias em instituições de ensino superior: uma formulação para a maximização do aproveitamento dos recursos humanos. Ciência e Engenharia, 14(1):65-72, 2005.

Martinez-Alfaro, H. \& Flores-Teran, G., Solving the classroom assignment problem with simulated annealing. In: IEEE International Conference on Systems, Man, and Cybernetics. Piscataway, USA: IEEE Press, v. 4, p. 3703-3708, 1998.

Metropolis, N.; Rosenbluth, A.W.; Rosenbluth, M.N.; Teller, A.H. \& Teller, E., Equation of state calculations by fast computing machines. The Journal of Chemical Physics, 21(6):1087-1092, 1953.

Oliveira, A.C., Uso do Algoritmo Genético e Recozimento Simulado para o problema de alocação de salas. Monografia de graduação, Ciêencia da Computação, Universidade Federal de Lavras, Lavras, MG, 2006.

Rossi-Doria, O.; Sampels, M.; Birattari, M.; Chiarandini, M.; Dorigo, M.; Gambardella, L.; Knowles, J.; Manfrin, M.; Mastrolilli, M.; Paechter, B.; Paquete, L. \& Stützle, T., A comparison of the performance of different metaheuristics on the timetabling problem, .

Schaerf, A., A survey of automated timetabling. Artificial Intelligence Review, 13(2):87-127, 1999.

Silva, A.S.N.; Sampaio, R.M. \& Alvarenga, G.B., Uma aplicação de Simulated Annealing para o problema de alocação de salas. INFOCOMP - Journal of Computer Science, 4(3):59-66, 2005.

Silva, D.J. \& Silva, G.C., Heurísticas baseadas no algoritmo de coloração de grafos para o problema de alocação de salas em uma instituição de ensino superior. In: Anais do XLII Simpósio Brasileiro de Pesquisa Operacional. Bento Gonçalves, RS, p. 1-11, 2010.

Souza, M.J.F., Programação de horários em escolas: uma aproximação por meta-heurísticas. Tese de doutorado, Engenharia de Sistemas de Computação, COPPE, Universidade Federal do Rio de Janeiro, Rio de Janeiro, RJ, 2000.

Souza, M.J.F.; Martins, A.X.; Araujo, C.R. \& Costa, F.W.A., Metodos de pesquisa em vizinhança variável aplicados ao problema de alocação de salas. In: Anais do XXII Encontro Nacional de Engenharia de Produção. Curitiba, PR, v. 1, p. 1-8, 2002.

Subramanian, A.; Medeiros, J.M.F.; Cabral, L.A.F. \& Souza, M., Aplicação da metaheurística busca tabu na resolução do problema de alocação de salas do centro de tecnologia da UFPB. In: Anais do XXVI Encontro Nacional de Engenharia de Produção. Fortaleza, CE, v. 1, p. 1-8, 2006.

Subramanian, A.; Medeiros, J.M.F.; Formiga, L.A. \& Souza, M.J.F., Aplicação da metaheurística busca tabu ao problema de alocação de aulas e salas em uma instituição universitária. Revista Produção Online, 11(1):54-75, 2011. 


\section{Notas Biográficas}

Rosana Maria Luvezute Kripka é graduada em Matemática com ênfase em Computação e mestre em Ciência da Computação e Matemática Computacional (USP/São Carlos, 1992 e 1995, respectivamente). Atualmente é professora do curso de Matemática do Instituto de Ciências Exatas e Geociências da Universidade de Passo Fundo.

Moacir Kripka é graduado em Engenharia Civil (PUC-RS, 1986), mestre e doutor em Engenharia Civil (COPPE/UFRJ, 1990 e EESC/USP, 1998, respectivamente). Atualmente é professor do curso de Engenharia Civil e Coordenador do Programa de Pós-Graduação em Engenharia da Universidade de Passo Fundo. 


\title{
Solução de Problemas de Planejamento Florestal com Variáveis Inteiras com o Emprego de Meta-heurísticas
}

\author{
Gilson Fernandes da Silva; Antonio Almeida de Barros Junior, \\ Gustavo Willam Pereira e Adriano Ribeiro de Mendonça
}

\begin{abstract}
Resumo: Neste capítulo é abordado um Problema de Planejamento Florestal (PF) cujo foco principal é o manejo florestal para a produção de madeira. O objetivo do problema é a maximização do Valor Presente Líquido (VPL). Para resolver o problema, foram testadas as meta-heurísticas Algoritmo Genético (AG) e Greedy Randomized Adaptive Search Procedure (GRASP), ambas com a técnica de intensificação Path Relinking (PR). O desempenho das heurísticas é testado em um conjunto de 10 problemas gerados com base em dados reais. Os resultados das meta-heurísticas foram comparados mostrando que o acréscimo do PR trouxe aumento de eficácia na obtenção da solução, especialmente para o GRASP.
\end{abstract}

Palavras-chave: Planejamento floretal, Otimização combinatória, Meta-heurísticas.

\begin{abstract}
In this chapter we considered the Forest Planning problem (PF) whose primary focus is the forest management for timber production. The objective of the problem is to maximize the Net Present Value. To solve the problem, Genetic Algorithm (AG) and Greedy Randomized Adaptive Search Procedure (GRASP) metaheuristics were tested, both with the technique of intensification Path Relinking (PR). The performance of the Algorithms was tested with a set of 10 problems created using real data. The performance of the metaheuristics were compared showing that the addition of $P R$ promoted more efficiency in the search of solutions, especially for the GRASP.
\end{abstract}

Keywords: Forest management, Optimization, Metaheuristics.

\section{Introdução}

O Brasil é um país com grande potencial florestal e só mais recentemente vem se preocupando em utilizar seus recursos florestais de forma mais ordenada. Até então, a produção florestal tinha como sua principal origem as florestas nativas e pouco se fez para que os recursos fossem manejados de forma sustentável. Mesmo assim, o setor florestal apresenta números significativos dentro da economia brasileira. Em 2011, O saldo da balança comercial florestal totalizou US $\$ 5,7$ bilhões, (19,1\% do saldo total do país) e manteve 4,7 milhões de postos de emprego (ABRAF, 2012). De acordo com esta fonte, o Valor Bruto da Produção Florestal (VBPF) estimado em 2011, para o setor de florestas plantadas, foi de $\mathrm{R} \$ 53,9$ bilhões, sendo mais da metade deste valor $(57,1 \%)$ gerado pelo setor de celulose e papel.

Dentro deste contexto, os problemas de planejamento da produção florestal, normalmente, envolvem um grande número de aspectos, tais como, limitações de área, capital e mão-de-obra, além de outros objetivos a serem alcançados, como atendimento da demanda de mercado, regulação da floresta, dentre outros. Paralelamente, a aleatoriedade de alguns fenômenos inerentes ao processo de produção, como fenômenos climáticos e biológicos, pode afetar decisivamente os objetivos a serem alcançados. Ainda, variáveis econômicas de ocorrência aleatória, como os custos de produção, o preço da madeira, a taxa de desconto, incertezas do mercado, bem como a própria produção, são de suma importância quando se pensa na maximização de retornos ou minimização de custos. Todos estes fatores são agravados pelas características do setor florestal, que trabalha com ciclos de longa duração, o que aumenta ainda mais o peso destas variáveis aleatórias. Associado a tudo isto, a empresa florestal ainda tem que atender exigências legais, ambientais e sociais, o que torna o espectro de análise muito complexo. Aliado a esta complexidade da gestão dos recursos florestais, nos últimos anos, o estabelecimento de economias de livre mercado em quase todo o mundo tem gerado um grande desafio em termos de competitividade para as empresas.

*Autor para contato: gfsilva2000@yahoo.com 
É indiscutível, para o país e para as empresas da área florestal, a importância da gestão do processo de produção florestal de modo a maximizar os retornos econômicos, ambientais e sociais, procurando também atender às exigências legais impostas a este tipo de processo de produção. Assim, deve ser possível manejar a floresta para produzir de forma racional de modo a conseguir resultado econômico sem, contudo, provocar problemas ambientais. Estas preocupações já ocorriam no passado, e diversos pesquisadores desenvolveram trabalhos buscando modelar problemas de planejamento florestal para tomar decisões melhores em situações muito complexas. Historicamente, para gerar as alternativas de manejo de um dado problema são usados dois modelos clássicos de otimização no planejamento florestal, denominados por Johnson \& Scheurman (1977) como Modelo I e Modelo II. No Brasil, o Modelo I tem sido empregado com maior frequência, por ser esta técnica mais amplamente difundida. O Modelo I foi originalmente proposto por Kidd et al. (1966, apud Dykstra (1984)). Neste Modelo, cada variável de decisão representa uma prescrição, ou seja, uma sequência única de intervenções programadas para uma unidade de produção (Clutter et al., 1983). Vários exemplos de aplicação do Modelo I no planejamento dos recursos florestais no Brasil são encontrados na literatura como os trabalhos de Rodrigues (2001), Pereira (2004), Rodrigues et al. (2006), Castro (2007), Silva et al. (2009) e Gomide (2009). Por outro lado, poucos são os trabalhos encontrados no Brasil que aplicam o Modelo II no meio florestal, sendo encontrados os de Rodrigues et al. (1998) e Rodrigues et al. (2006).

Em função da complexidade dos problemas de planejamento florestal, a escolha da técnica de solução destes problemas é fundamental no sentido de que, uma vez modelado o problema, o mesmo possa ser implementado em nível prático. Tradicionalmente, as técnicas de Programação Linear (PL) constituem o instrumental analítico mais utilizado no processo de tomada de decisão no planejamento florestal, embora esta realidade tenha se alterado nos últimos anos. Entretanto, apesar da inegável contribuição desta técnica para a solução de problemas nas diversas áreas, deve-se reconhecer que esta metodologia apresenta limitações: fornece soluções com variáveis fracionadas, trabalha com apenas uma função objetivo e assume que as restrições devem ser rigorosamente respeitadas (Silva, 2001).

Para comprovar estas e outras limitações, pode-se citar as seguintes características inerentes aos problemas de planejamento florestal: o grande porte dos problemas, que são de natureza combinatorial, podendo chegar a milhares de variáveis; a necessidade de satisfazer a vários objetivos simultaneamente, como, por exemplo, uma empresa pode estar interessada em manter os lucros estáveis, aumentar sua fatia do mercado, diversificar produtos, aumentar a produtividade, minimizar as perdas de solo e incrementar os benefícios sociais gerados para a comunidade local; são típicos problemas de programação inteira (0-1), pela conveniência operacional de se manter a identidade das unidades de produção, ou seja, mantê-las sempre com a mesma área; a natureza estocástica da maioria das variáveis do problema, o que aumenta ainda mais sua complexidade (Teixeira, 2002).

\section{Justificativa}

Para Rodrigues et al. (2000), apesar do grande avanço da Pesquisa Operacional (PO) na área florestal, com a evolução dos modelos de Programação Linear (PL) para modelos de Programação Inteira (PI) e Programação com Múltiplos Objetivos (PMO), a solução de problemas de grande porte ainda tem sido limitada. A complexidade dos problemas, o volume de dados envolvidos e a carência de tecnologias adequadas são alguns fatores que dificultam a utilização destes modelos em larga escala. Piassi (2011) discute este problema e tece considerações sobre as dificuldades em se implementar estratégias de planejamento a partir de modelos de grande porte utilizando métodos exatos. Entretanto, alguns esforços buscando soluções eficientes para a aplicação destes modelos podem ser encontrados em Rodrigues et al. (1998), Silva (2001), Silva et al. (2003), Silva (2004), Mello et al. (2005), Menon (2005), Rodrigues et al. (2006), Castro (2007), Gomide (2009).

$\mathrm{Na}$ busca por métodos mais eficientes para soluções deste tipo de problemas, vários procedimentos heurísticos têm sido desenvolvidos em diversas áreas da ciência. De acordo com Ignizio \& Cavalier (1994), as heurísticas são as mais promissoras abordagem para solução de problemas de programação inteira. Os problemas comuns em planejamento florestal são problemas de difícil solução e, portanto, as abordagens por heurísticas parecem ser uma alternativa viável.

\section{Objetivos}

Este trabalho teve como objetivo geral testar e validar meta-heurísticas que permitam a otimização de problemas de planejamento florestal uniobjetivo. Considerar os diversos aspectos da produção florestal em um único contexto, de modo a alcançar as metas relacionadas, em problemas de grande porte e que exigem abordagens de formulação via Programação Inteira, é tarefa árdua utilizando-se as técnicas tradicionais de solução. Assim, definiu-se os seguintes objetivos específicos: 
- Testar as meta-heurísticas de Algoritmos Genéticos (AG) e Greedy Randomized Adaptive Search Procedure (GRASP) avaliando estas técnicas em eficácia e eficiência para a solução dos modelos de planejamento florestal para um único objetivo;

- Incluir nas meta-heurísticas citadas, a técnica de intensificação Path Relinking na tentativa de melhorar as soluções encontradas pelas mesmas;

- Testar diferentes parametrizações para os algoritmos citados acima na solução de modelos de planejamento florestal.

\section{Materiais e Métodos}

Para os problemas de planejamento florestal, foram testadas as meta-heurísticas Algoritmo Genético (AG) e Greedy Randomized Adaptive Search Procedure (GRASP). As meta-heurísticas Algoritmos Evolucionários - Evolutionary Algorithms (EA) vêm de uma classe de métodos estocásticos de otimização que simulam o processo da evolução natural. A origem dos EA's pode ser datada do final dos anos cinquenta e, desde os anos setenta, várias metodologias evolucionárias têm sido propostas, principalmente algoritmos genéticos, programação evolucionária e estratégias de evolução (Bäck et al., 1997). Todas estas abordagens operam com um conjunto de soluções candidatas, inicialmente definidas. Usando fortes simplificações, este conjunto é, subsequentemente, modificado pelos dois princípios básicos da evolução: seleção e variação. A seleção representa a competição por recursos entre os seres vivos. Alguns são melhores do que outros e mais prováveis de sobreviverem e reproduzirem suas informações genéticas. Em algoritmos evolucionários, a seleção natural é simulada por um processo estocástico de seleção. A cada solução é dada a chance de reproduzir um certo número de vezes, dependendo de sua qualidade. Deste modo, a qualidade é calculada avaliando os indivíduos e atribuindo a eles um valor escalar denominado fitness. O outro princípio, variação, imita a capacidade natural de criar "novos" seres vivos por meio de recombinação e mutação (Zitzler, 1999).

A meta-heurística GRASP procura usar as melhores características dos algoritmos gulosos e procedimentos aleatórios para construção das soluções iniciais, e estas, posteriormente, são refinadas por meio de uma fase de busca local (Resende \& Ribeiro, 2002). Algoritmos gulosos são aqueles que, a cada decisão, sempre escolhem a alternativa que parece mais promissora naquele instante (decisão localmente ótima). Por exemplo, caminho mais curto, menor número de jogadas etc.

Mais informações sobre os algoritmos AG e GRASP serão abordados no decorrer do capítulo.

\subsection{Modelo de planejamento da produção florestal}

O problema de planejamento florestal foi formulado por um modelo de Programação Inteira. Para tanto, foi empregado o Modelo I proposto por (Johnson \& Scheurman, 1977). Este modelo apresenta a seguinte especificação:

\subsubsection{Função objetivo}

Com o objetivo de maximizar o Valor Presente Líquido (VPL) da floresta, foi estabelecida a seguinte função objetivo:

$$
(M a x) \quad \mathrm{VPL}=\sum_{i=1}^{M} \sum_{j=1}^{N_{i}} D_{i j} Y_{i j}
$$

em que:

$D_{i j}=$ Valor Presente Líquido (VPL) resultante da exploração da unidade de produção $i$, caso a alternativa de manejo $j$ seja adotada;

$Y_{i j}=$ Variável binária, em que 1 significa explorar toda a área da unidade de produção $i$ seguindo a alternativa $j$ e 0 significa que nenhum corte será feito na unidade de produção $i$;

$M=$ Número total de unidades de produção;

$N_{i}=$ Número total de alternativas de manejo disponível para a i-ésima unidade de produção;

\subsubsection{Restrição de área disponível para colheita}

Esta restrição deve ser estabelecida para cada unidade de produção $i$, isto é, o modelo deve conter $M$ restrições de área. Esta restrição garante que a área total da unidade de produção $i$ só pode seguir uma única alternativa de manejo.

Para cada uma das i-ésima restrição de área, a expressão pode ser definida como se segue: 


$$
\sum_{j=1}^{N_{i}} Y_{i j}=1\left(i=1,2, \ldots, N_{i}\right)
$$

Esta restrição de área garante a escolha de apenas uma prescrição de manejo para cada unidade.

\subsubsection{Imposição de cotas ou produções anuais}

As empresas florestais normalmente trabalham com demandas anuais de produção de volume. Assim, esta restrição procura garantir que a cada período do horizonte de planejamento, a demanda periódica de madeira da empresa seja atendida. Deste modo, esta restrição deve ser estabelecida para cada período do horizonte de planejamento $H$. Portanto, para cada um dos $k$-ésimos período de planejamento, a restrição de cotas anuais pode ser definida como se segue:

$$
V_{k}=\sum_{i=1}^{M} \sum_{j=1}^{N_{i}} V_{i j k} Y_{i j}(k=1,2, \ldots, H-1)
$$

em que:

$V_{i j k}=$ volume total $\left(\mathrm{m}^{3}\right)$ produzido pela i-ésima unidade de manejo admitindo que para ela foi selecionada à j-ésima alternativa de manejo, no início do período $k$;

$V_{k}=$ volume total $\left(\mathrm{m}^{3}\right)$ removido no período $k$, representando a demanda a ser atendida naquele período; e

$H=$ horizonte de planejamento, isto é, período de tempo em que a floresta será manejada.

A variável $Y_{i j}$ representa a combinação das unidades de produção e alternativas de manejo. Entretanto, no caso desta restrição, deve-se considerar apenas as combinações de $Y_{i j}$ disponíveis para corte no período $k$.

\subsubsection{Capacidade de reforma}

A reforma é uma atividade que demanda grande esforço operacional dentro da empresa florestal. Neste sentido, as empresas florestais apresentam um certo limite para conseguir realizar esta operação. Assim, esta restrição garante com que a capacidade máxima de realizar reforma não seja ultrapassada. Esta capacidade deve ser definida a cada período $k$, o que exige uma restrição de reforma para cada um dos $k$-ésimos períodos. Sendo definida como se segue:

$$
C R_{k} \geq \sum_{i=1}^{M} \sum_{j=1}^{N_{i}} A_{i j k} Y_{i j}(k=1,2, \ldots, H-1)
$$

em que:

$C R_{k}=$ capacidade de reforma no período $k$.

$A_{i j k}=$ área da $i$-ésima unidade de produção, manejada sob a $j$-ésima alternativa de manejo, no início do período $k$ e que esteja sob o regime de manejo de reforma.

\subsubsection{Gerador de prescrições para o modelo}

Para o desenvolvimento dos algoritmos, foi utilizado o protótipo proposto por Teixeira (2002) que simula o real conjunto de soluções viáveis. O protótipo foi desenvolvido utilizando-se o ambiente de programação Borland Delphi 7.0, que tem como linguagem nativa o Object Pascal. O software foi concebido tomando como referência o modelo do tipo I, apresentado na Seção 4.4.1,possuindo três módulos básicos: Dados, Gerador de Prescrições e Otimizador. Nele, o usuário trabalha com os projetos de forma independente, inserindo-se assim os dados e salvando-os em um arquivo, podendo carregá-lo a qualquer momento. É permitido trabalhar com apenas um projeto por vez.

Por meio do módulo Dados pode-se cadastrar as informações relativas ao projeto, tais como:

- a idade mínima e máxima de corte, horizonte de planejamento, taxa de desconto anual para a atualização para os valores presente das receitas e dos custos;

- cadastro das unidades de produção: para cada unidade de produção deve-se cadastrar a idade, a área, os valores de custos das atividades realizadas na unidade, aqui resumidos em implantação, manutenção anual média, exploração, reforma e condução de brotação, e os valores de produção de madeira esperados em diferentes idades;

- o valor da madeira a ser utilizado para o cálculo do retorno econômico da produção, podendo este ser expresso como valor único ou por idade da madeira; 
- as demandas anuais mínimas (expressa em $m^{3}$ ) a serem atendidas e

- as capacidades máximas de reformas anuais (expressa em ha) da empresa florestal. Informações estas utilizadas para geração das restrições dos problemas.

O módulo Gerador de Prescrições (Figura 1) é responsável por gerar alternativas de manejo para cada uma das unidades de produção (UP) cadastradas. Por meio de uma estrutura matricial em que, para as colunas, tem-se a linha do tempo, que vai do período de plantio da UP, passando pelo estado atual até o último período do horizonte planejado. Além do horizonte de planejamento, o algoritmo leva em consideração as idades máxima e mínima de corte e as formas de condução da floresta, onde foram consideradas apenas as opções de reforma do povoamento florestal, de uma e de duas conduções de brotação. Neste caso, reformar o povoamento significa retirar todas as árvores existentes em um único corte e realizar um novo plantio. Já conduzir a brotação significa cortar todas as árvores e ao invés de realizar novo plantio, conduzir os brotos que irão surgir se transformem em novas árvores.

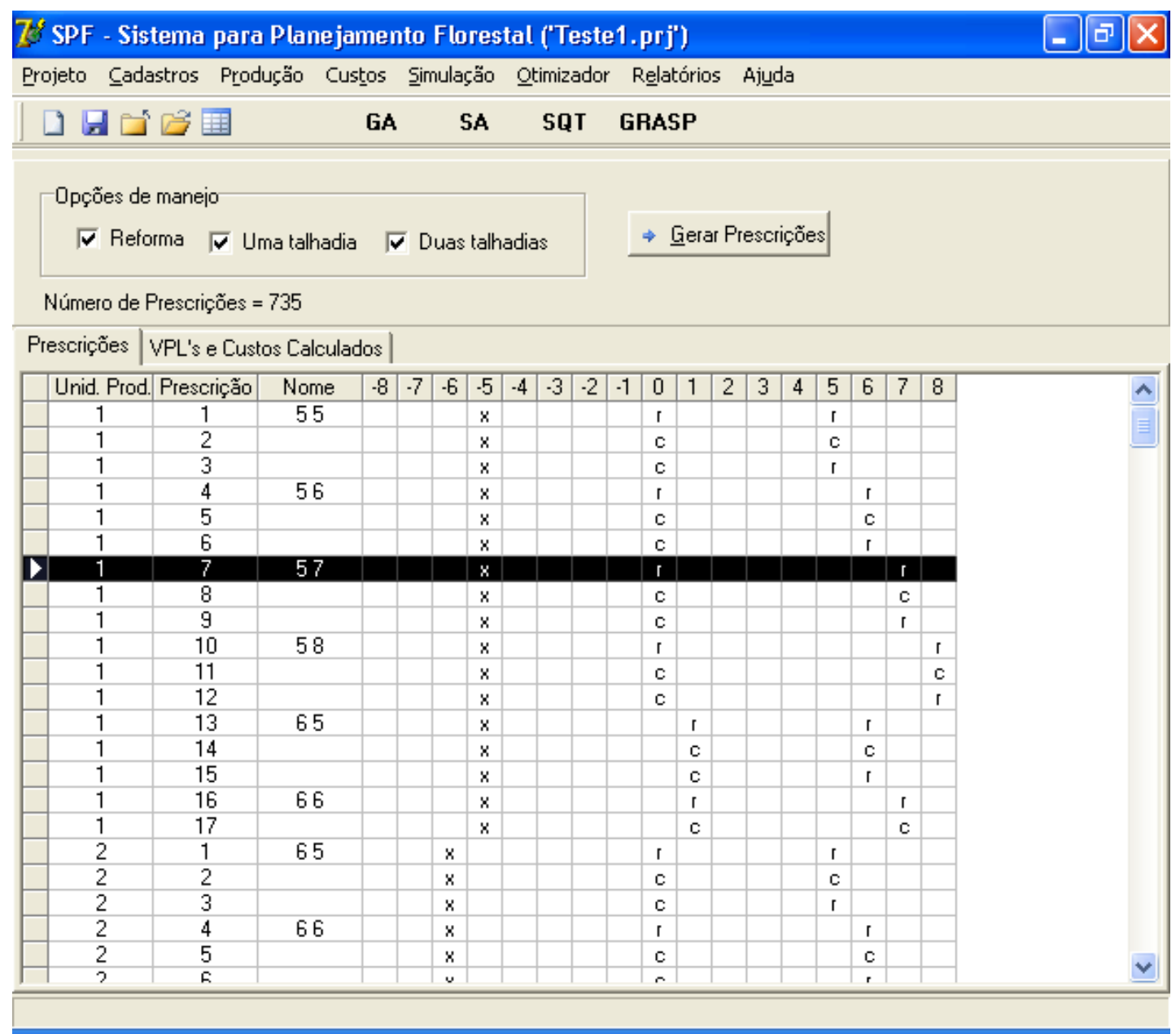

Figura 1. Módulo Gerador de Prescrições do Protótipo.

Cada célula da matriz pode assumir um dos seguintes estados:

- vazio quando houver apenas atividades de manutenção;

- "x" para a atividade de implantação da floresta;

- "r" para a atividade de exploração imediatamente seguida de reforma; e

- "c" para a atividade de exploração imediatamente seguida de condução da brotação.

No exemplo da Figura 1, observa-se que foram geradas 17 alternativas de manejo (também chamadas de prescrições) para a unidade de produção 1. A primeira prescrição representa uma alternativa de manejo onde a UP sofrerá duas reformas representadas pela letra "r", ambas com 5 anos de idade. O ano 0 (zero) representa o ano corrente, o que mostra que a UP 1 foi plantada há 5 anos atrás, representado pela letra "x" no ano -5 . 
A prescrição número 7 (assinalada) representa que o regime adotado é o 57, onde a unidade de produção 1 vai sofrer uma reforma no $5^{\circ}$ período e, posteriormente, uma nova reforma no $7^{\circ}$ período.

Com base no modelo do tipo I (Seção 4.4.1), o objetivo do problema é encontrar a melhor alternativa de manejo para cada unidade de produção considerando as limitações operacionais e condições de produção impostas ao projeto. O módulo Otimizador é o responsável por esta tarefa. Ele contém as heurísticas apresentadas neste trabalho.

\subsection{Representação de uma solução}

Para a representação das variáveis do problema, foram feitas as seguintes considerações: cada solução $S$ contém um determinado número de unidades de produção (UP's), representadas na Figura 2 pelas letras de "A" a "E". E, para cada UP, existe um conjunto de possíveis alternativas de manejo (AM). O objetivo do problema é realizar a busca pela melhor combinação que atenda a função objetivo e satisfaça as restrições do problema.

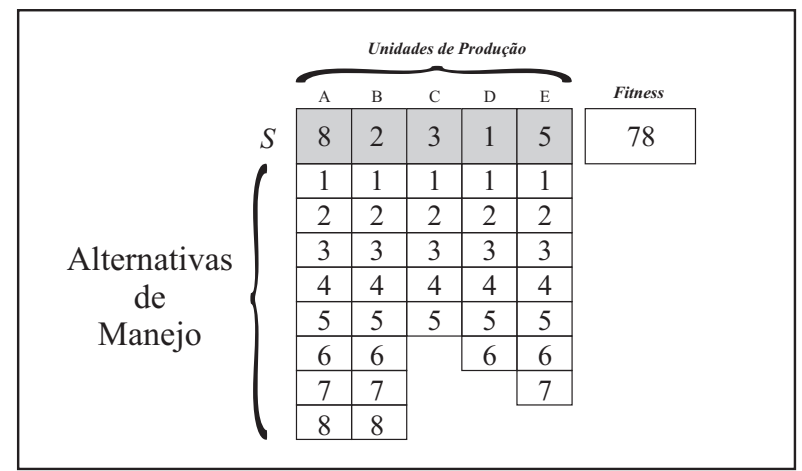

Figura 2. Esquema representativo da solução. Na solução $S$ são utilizadas as alternativas de manejo 8, 2, 3, 1,5 para as unidades de produção A, B, C, D,E, respectivamente.

A Figura 3 ilustra uma situação onde o usuário deseja obter a alternativa de manejo que contenha o maior Valor Presente Líquido (VPL). Neste caso, a AM número 8 seria a escolhida para a unidade de produção "A", uma vez que o maior VPL pertence a esta alternativa. No detalhe, a alternativa de manejo 8 está associada a uma condução no $7^{\circ}$ período do planejamento, isto implica em um VPL de R $\$ 502.005,40$ e um custo de R\$ $331.438,20$.

\begin{tabular}{|c|c|c|c|c|c|c|c|c|c|c|c|c|c|c|c|c|c|c|c|c|c|}
\hline \multicolumn{22}{|c|}{ Horizonte de Planejamento } \\
\hline $\mathbf{U P}$ & $\mathbf{A M}$ & Regime & -8 & -7 & -6 & -5 & -4 & -3 & -2 & -1 & $\mathbf{0}$ & 1 & 2 & 3 & 4 & 5 & 6 & 7 & 8 & VPL & Custo \\
\hline $\mathrm{A}$ & 1 & 55 & & & & $\mathrm{x}$ & & & & & $\mathrm{r}$ & & & & & $\mathrm{r}$ & & & & $296.514,10$ & $400.583,40$ \\
\hline A & 2 & & & & & $\mathrm{x}$ & & & & & $\mathrm{c}$ & & & & & $\mathrm{c}$ & & & & $395.611,80$ & $301.485,60$ \\
\hline A & 3 & & & & & $\mathrm{x}$ & & & & & $\mathrm{c}$ & & & & & $\mathrm{r}$ & & & & $349.846,70$ & $347.250,70$ \\
\hline $\mathrm{A}$ & 4 & 56 & & & & $\mathrm{x}$ & & & & & $\mathrm{r}$ & & & & & & $\mathrm{r}$ & & & $354.817,80$ & $418.761,30$ \\
\hline A & 5 & & & & & $\mathrm{x}$ & & & & & $\mathrm{c}$ & & & & & & c & & & $455.284,50$ & $318.294,60$ \\
\hline $\mathrm{A}$ & 6 & & & & & $\mathrm{x}$ & & & & & $\mathrm{c}$ & & & & & & $\mathrm{r}$ & & & $408.150,40$ & $365.428,60$ \\
\hline $\mathrm{A}$ & 7 & 57 & & & & $\mathrm{x}$ & & & & & $\mathrm{r}$ & & & & & & & $\mathrm{r}$ & & $400.740,40$ & $432.703,20$ \\
\hline $\mathrm{A}$ & 8 & & & & & $\mathrm{x}$ & & & & & $\mathrm{c}$ & & & & & & & c & & $502.005,40$ & $331.438,20$ \\
\hline
\end{tabular}

Figura 3. Esquema representativo da alternativa de manejo para a Unidade de Produção "A".

\subsection{Algoritmo genético com path relinking para o problema de planejamento florestal}

A meta-heurística Algoritmo Genético (AG) é um algoritmo de otimização global, idealizado por Holland (1975) e baseado nos princípios da genética populacional (a variabilidade entre indivíduos em uma população de organismos que se reproduzem sexualmente é produzida pela mutação e pela recombinação genética).

$\mathrm{Na}$ tentativa de melhorar as soluções encontradas pelo AG, foi adicionado ao algoritmo a técnica de intensificação Path Relinking. A Figura 4 apresenta o pseudocódigo do procedimento AG com Path Relinking $(\mathrm{AG}+\mathrm{PR})$ proposto.

A execução de um AG+PR começa testando um número de indivíduos selecionados, aleatoriamente, do espaço de busca (Passo 1 da Figura 4). Este conjunto de indivíduos denomina-se população inicial $(P)$. No passo 2 (Figura 4), a melhor solução encontrada neste conjunto, é escolhida inicialmente como a solução global $\left(S^{*}\right)$. No passo seguinte, é construído de forma gulosa, um conjunto de soluções denominado Conjunto Elite $(C E) \operatorname{com} \pi$ soluções. Este conjunto tem um papel importante na técnica de intensificação Path Relinking. 


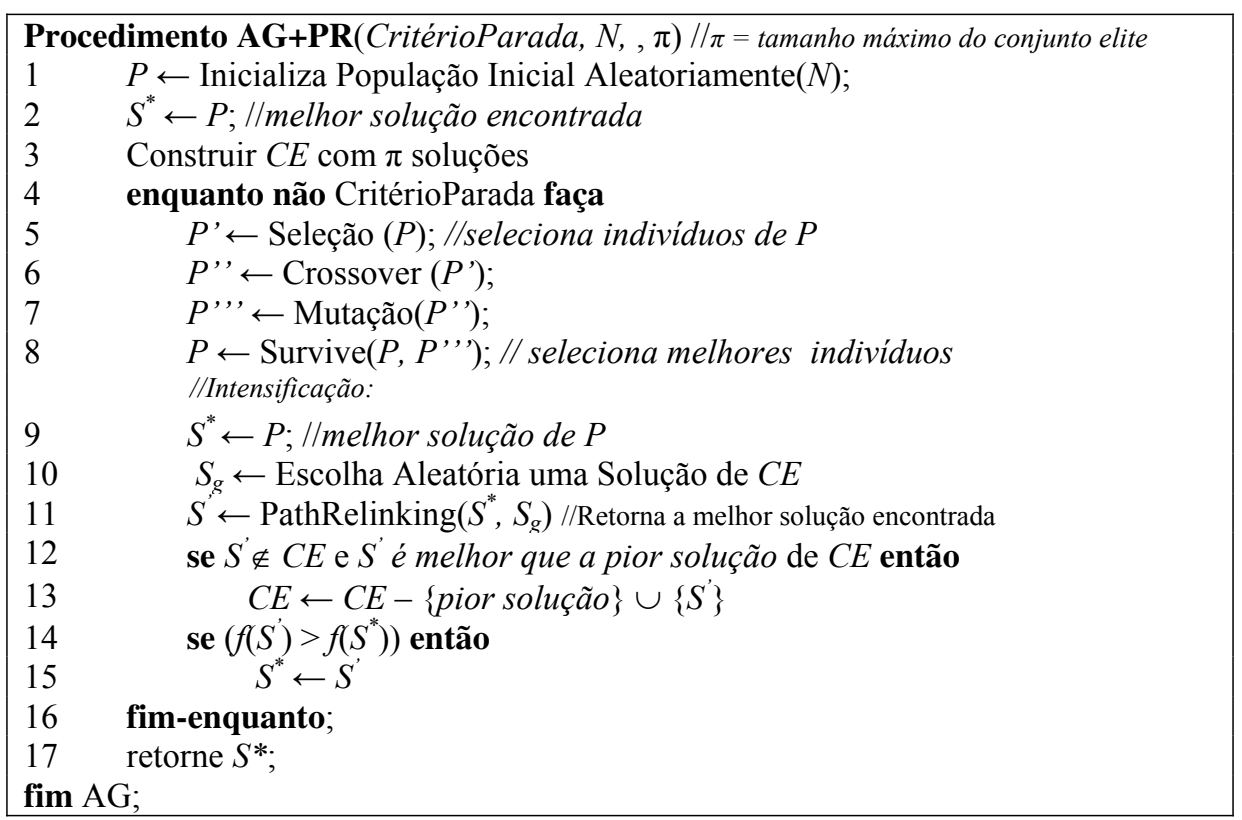

Figura 4. Algoritmo AG com Path Relinking (GA+PR).

Esta primeira fase do algoritmo pode ser melhor entendida pela Figura 5. Observe que foram escolhidas as melhores soluções do conjunto $P$ para a solução global $S^{*}$ e para a construção do conjunto $C E$. Para o problema abordado neste trabalho, o tamanho do conjunto de soluções elite foi definido por $\pi=15$.

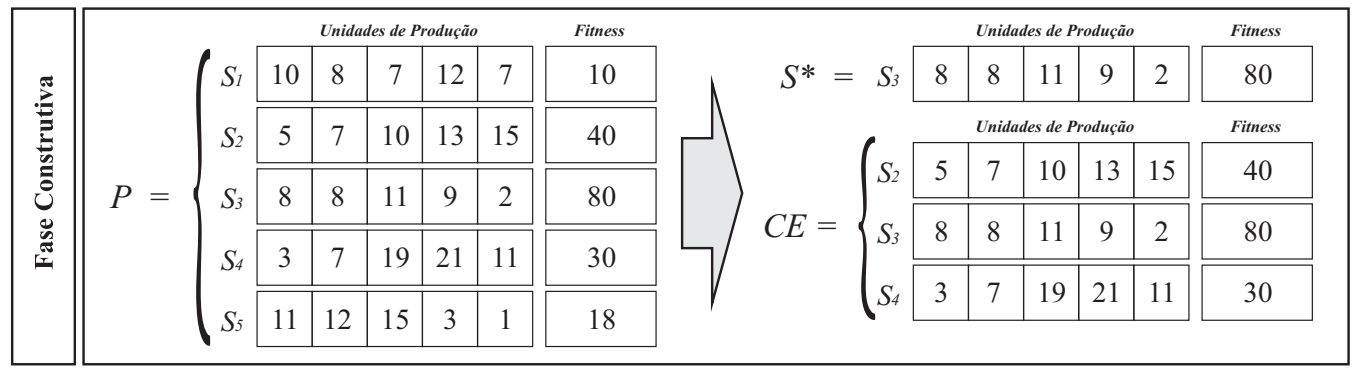

Figura 5. Fase Construtiva do Algoritmo GA+PR.

A quantidade de iterações realizadas pelo algoritmo depende do critério de parada configurado no protótipo, podendo ser o tempo, o número de iterações ou um valor desejável para a função objetivo. Neste trabalho, foi utilizado o critério por tempo.

No passo 5 do algoritmo (Figura 4) é realizada a seleção de forma aleatória dos indivíduos pais. A Figura 6 ilustra uma situação, onde, duas soluções foram escolhidas aleatoriamente no conjunto $P$.

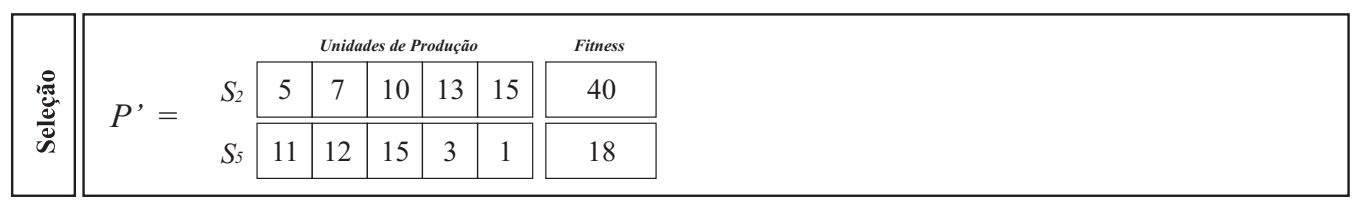

Figura 6. Seleção dos indivíduos pais no Algoritmo GA+PR.

Selecionados os indivíduos, é realizado o cruzamento dos mesmos (crossover). Existem várias formas de cruzar indivíduos: cruzamento de 1-ponto (one-point crossover), cruzamento de n-pontos ( $n$-points crossover), entre outros. Neste trabalho, a forma utilizada foi de 1-ponto, como mostra o exemplo da Figura 7.

A partir do cruzamento, realiza-se uma mutação nos novos indivíduos gerados (Passo 7 da Figura 4), promovendo a fuga dos ótimos locais.

O operador de mutação é usado para diversificar a população e consiste em trocar aleatoriamente dois genes num cromossomo, isto é, trocar a alternativa de manejo de duas unidades de produção. O melhor cromossomo é copiado sem sofrer mutação e cada um dos outros tem uma probabilidade $p_{m}=5 \%$ de sofrer mutação, valor este obtido experimentalmente. A Figura 8 ilustra uma situação onde a solução $S_{7}$ sofre uma mutação, gerando-se uma nova solução $S_{8}$. 


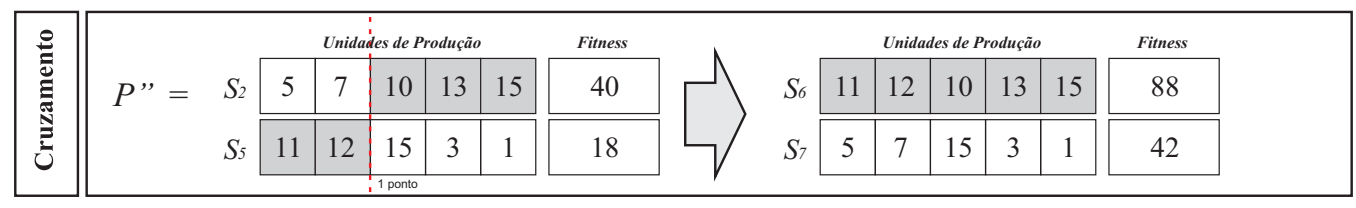

Figura 7. Crossover de 1-ponto.

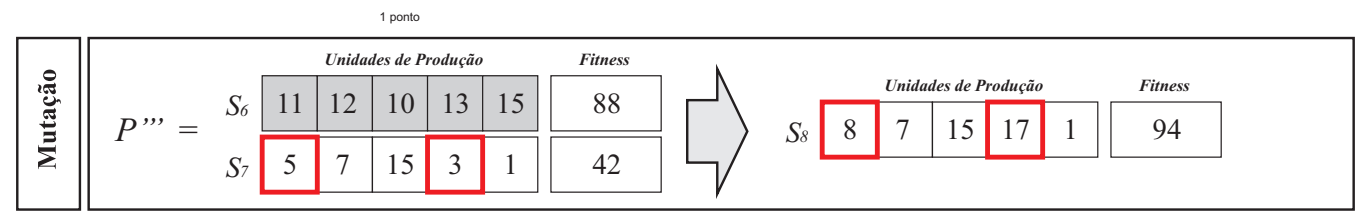

Figura 8. Fase de Mutação do Algoritmo GA+PR.

A nova população $P$ será formada pelos melhores indivíduos entre $P$ e $P$ "', a partir do método Survive (Passo 8 da Figura 4). Este método, é responsável por, selecionar os melhores indivíduos entre a população original $P$ e a população $P$ "', gerada após a realização de crossover e mutação, de acordo com o valor da função objetivo ou fitness de cada indivíduo e do número de indivíduos parametrizados no algoritmo para a população $P$. A Figura 9 ilustra a união dos conjuntos $P$ e $P$ "', a partir desta união, um novo conjunto $P$ é formado com as melhores soluções. A melhor solução do conjunto $P$ é atribuída como solução global $S^{*}$ (Passo 9 da Figura 4).

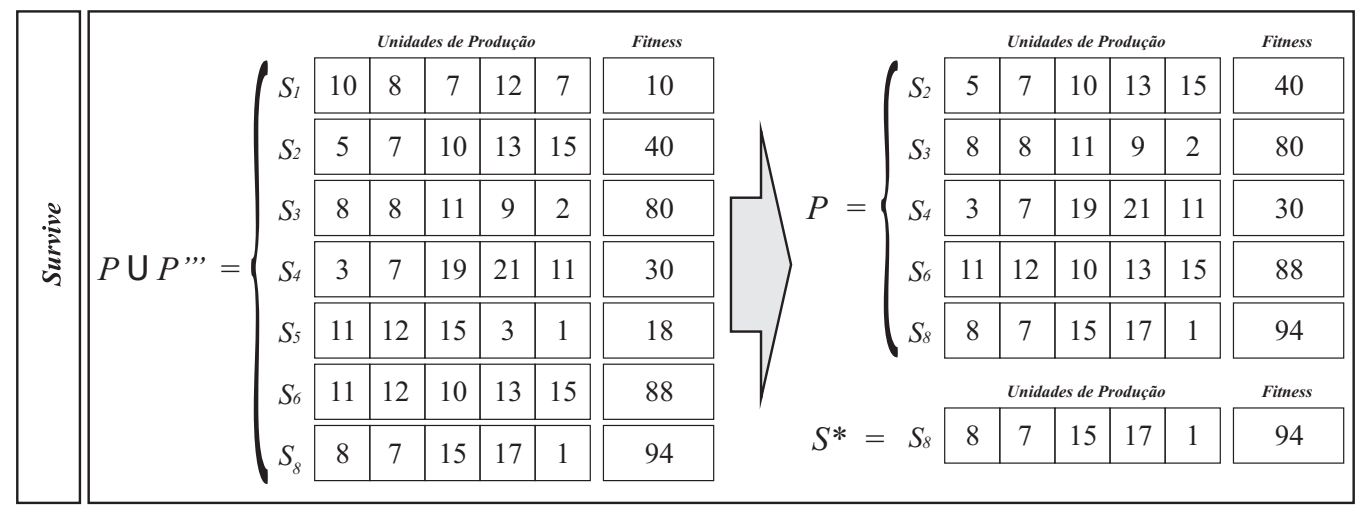

Figura 9. Método Survive do Algoritmo GA+PR.

A intensificação é realizada à partir do passo 10 (Figura 4). Neste passo, é realizada de forma aleatória, no conjunto $C E$, a escolha da solução guia $S_{g}$. No passo seguinte (passo 11), a solução $S^{*}$, obtida no Algoritmo Genético, é "combinada" com a solução $S_{g}$ por meio da técnica Path Relinking. A cada iteração do algoritmo, o conjunto $C E$ é atualizado com a melhor solução encontrada pelo Path Relinking S. Mais informações sobre a técnica Path Relinking serão descritas no tópico à seguir.

Ao final da iteração do algoritmo GA, a solução encontrada pela técnica Path Relinking $S$ ', é comparada com a solução global $S^{*}$ (Passo 14 da Figura 4). Caso a solução $S^{\prime}$ seja melhor que a solução $S^{*}$, a solução global passa a ser $S^{\prime}$ (Passo 15).

\subsubsection{Path relinking}

A técnica de Path relinking (PR) foi proposta por Glover (1999) como uma forma de explorar as possíveis trajetórias existentes entre duas soluções que apresentam certo nível de qualidade, obtidas por meio de heurísticas como a Busca Tabu (Bastos \& Ribeiro, 2002; Rosseti, 2003) e Scatter Search (Glover, 1999; Glover et al., 2000, 2004). No contexto da heurística GRASP, o PR foi introduzido pela primeira vez por Laguna \& Martí (1999). A técnica PR possui como entrada duas soluções $S_{0}$ e $S_{g}$, denominadas de origem e guia, respectivamente. A idéia é construir um caminho de $S_{0}$ para $S_{g}$ com o objetivo de encontrar novas soluções com características das duas soluções. Este caminho é obtido transformando gradativamente $S_{0}$ em $S_{g}$.

$\mathrm{Na}$ implementação do procedimento $\mathrm{PR}$, a solução origem é originada pelo procedimento de busca local no GRASP ou no procedimento de Survive do AG e a solução guia é escolhida de um conjunto elite $C E$. O procedimento retorna a melhor solução encontrada no caminho explorado, incluindo $S_{0}$ e $S_{g}$. Dando sequência ao exemplo utilizado para o algoritmo AG, a Figura 10 ilustra este primeiro passo do procedimento PR.

Durante a trajetória entre a solução origem $\left(S_{0}\right)$ e a solução guia $\left(S_{g}\right)$, o algoritmo gera, a cada iteração, um novo conjunto de soluções $P_{a u x}$. Este conjunto é construído a partir de movimentos realizados na solução 


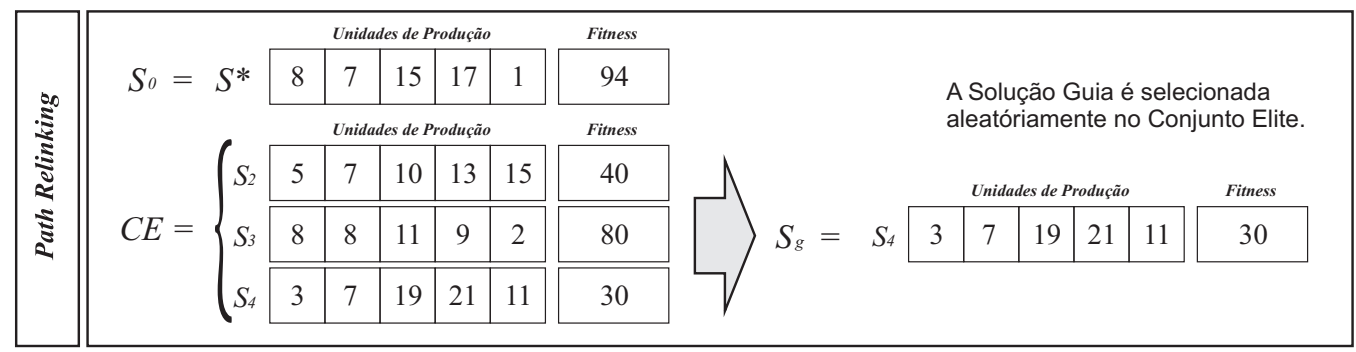

Figura 10. Fase inicial da técnica PR.

origem $\left(S_{0}\right)$, em função da solução guia $\left(S_{g}\right)$. A Figura 11 ilustra as duas primeiras iterações do procedimento PR.

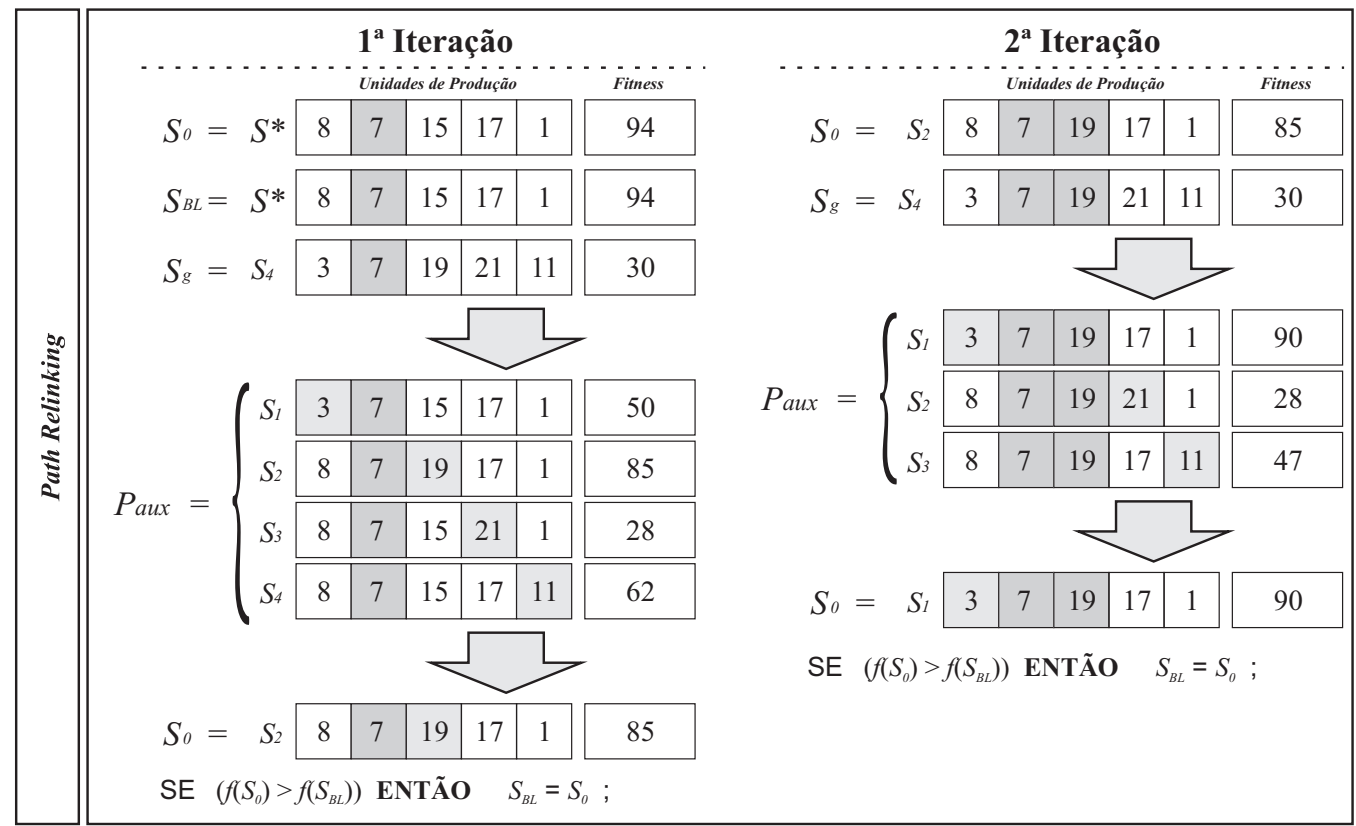

Figura 11. Iterações 1 e 2 do procedimento Path Relinking.

Observa-se que, na primeira iteração, a melhor solução encontrada $S^{*}$ foi atribuída à variável $S_{B L}$, que representa a melhor solução encontrada durante o processamento da técnica PR. As soluções do conjunto $P_{a u x}$ foram geradas a partir da combinação de alternativas entre as soluções $S_{0}$ e $S_{g}$. A melhor solução deste conjunto (no exemplo $S_{2}$ ) é selecionada para ser a solução origem $\left(S_{0}\right)$ da próxima iteração. Este processo é repetido sucessivamente, até que a solução origem seja igual à solução guia.

A Figura 12 ilustra as últimas iterações do procedimento PR. Ao final da quarta iteração, a solução inicial $S_{0}$ é igualada à solução guia $S_{g}$. É importante destacar que, ao final de cada iteração, é atribuída à variável $S_{B L}$ a melhor solução encontrada.

Como descrito anteriormente, ao final do processamento da técnica Path Relinking, o conjunto elite CE é atualizado com a melhor solução encontrada pelo Path Relinking S. É importante destacar que o conjunto $C E$ não permite a inclusão de uma solução repetida. Portanto, uma solução, para fazer parte deste conjunto, deverá atender ao seguinte critério: ser melhor que a pior de todas as soluções contidas em $C E$. Se o critério for atendido, a pior solução de $C E$ é excluída e a solução $S_{B L}$ obtida pelo Path Relinking é inserida em $C E$. A Figura 13 ilustra esta situação.

\subsection{Algoritmo GRASP para o problema de planejamento florestal}

A heurística GRASP (Figura 14) proposta por Feo \& Resende (1995), consiste em um procedimento iterativo de duas fases: A primeira fase, denominada de fase construtiva, consiste na geração de uma solução viável $S$ utilizando um algoritmo guloso e aleatório de acordo com um parâmetro $\alpha$ (passo 3); a segunda fase realiza uma busca local onde a vizinhança da solução $S$ é pesquisada até que se encontre uma solução ótima local $S$ ' (passo 4). A seguir, esta solução $S^{\prime}$ é comparada com a melhor solução encontrada até o momento $\left(S^{*}\right)$. Caso ela seja melhor, $S^{\prime}$ passa a ser a melhor solução (passos 5 a 7). Ao encerrar as iterações, a melhor solução $\left(S^{*}\right)$ é retornada (passo 11). 


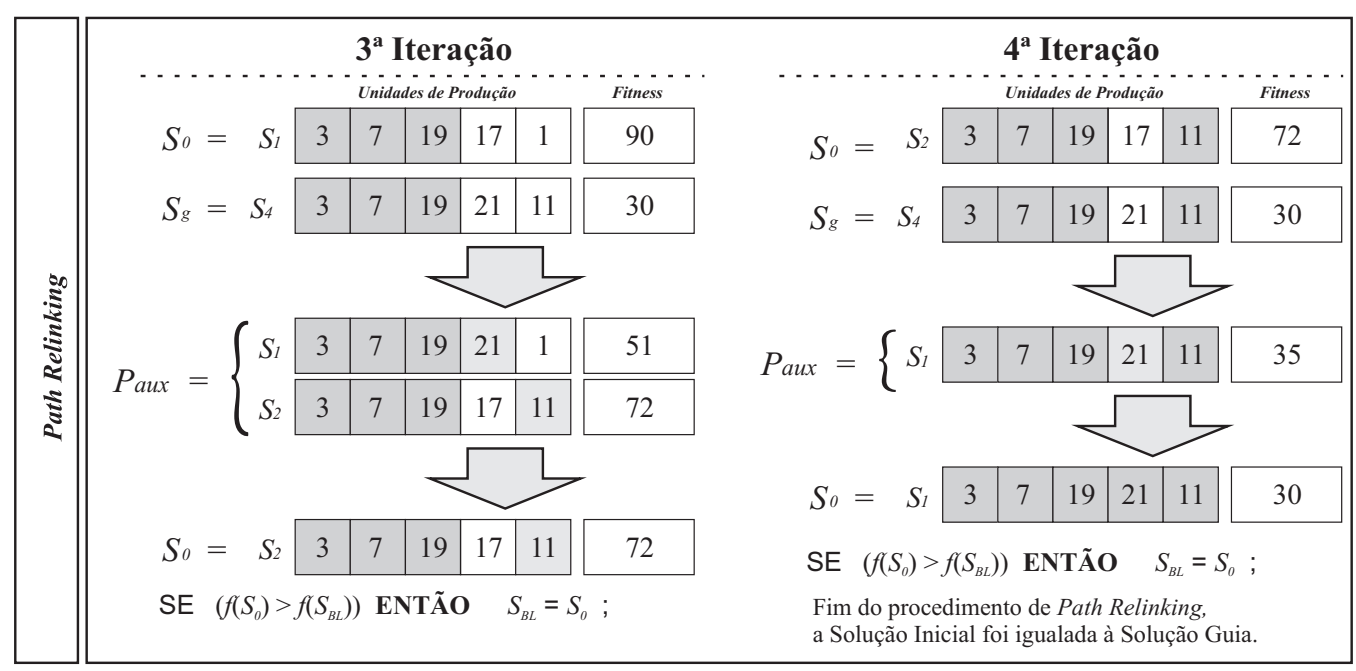

Figura 12. Iterações 3 e 4 do procedimento Path Relinking.

\begin{tabular}{|c|c|c|c|c|c|c|c|c|c|c|c|c|c|c|c|}
\hline \multirow{4}{*}{ 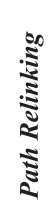 } & \multirow{4}{*}{$C E=$} & \multirow{2}{*}{\multicolumn{7}{|c|}{ Unidades de Produçũo }} & & \multicolumn{5}{|c|}{ Unidades de Produção } & \multirow{2}{*}{$\begin{array}{c}\text { Fithess } \\
94\end{array}$} \\
\hline & & & & & & & & & $S_{B L}$ & 8 & 7 & 15 & 17 & 1 & \\
\hline & & $S_{3}$ & 8 & 8 & 11 & 9 & 2 & 80 & & \multicolumn{5}{|c|}{ Unidades de Produçẫo } & Fitness \\
\hline & & $S_{2}$ & 5 & 7 & 10 & 13 & 15 & 40 & $S_{4}$ & 3 & 7 & 19 & 21 & 11 & 30 \\
\hline
\end{tabular}

Figura 13. Atualização do conjunto elite $C E$.

A Figura 15 mostra o pseudocódigo do procedimento GRASP com Path Relinking (GRASP+PR) utilizado neste trabalho. No algoritmo GRASP+PR, na primeira iteração é construído um conjunto $C E \operatorname{com} \pi$ soluções de elite. A solução $S$ ' obtida após a busca local é "combinada" como uma solução $S_{g}$ selecionada do conjunto $C E$ por meio da técnica Path Relinking. A cada iteração do algoritmo, o conjunto $C E$ é atualizado com a melhor solução encontrada pelo Path Relinking. Como dito anteriormente, o conjunto $C E$ não permite a inclusão de uma solução repetida. Portanto, uma solução para fazer parte deste conjunto, deverá atender ao seguinte critério: ser melhor que a pior de todas as soluções contidas em $C E$. Se o critério for atendido, a pior solução de $C E$ é excluída e a solução obtida pelo Path Relinking é inserida em $C E$.

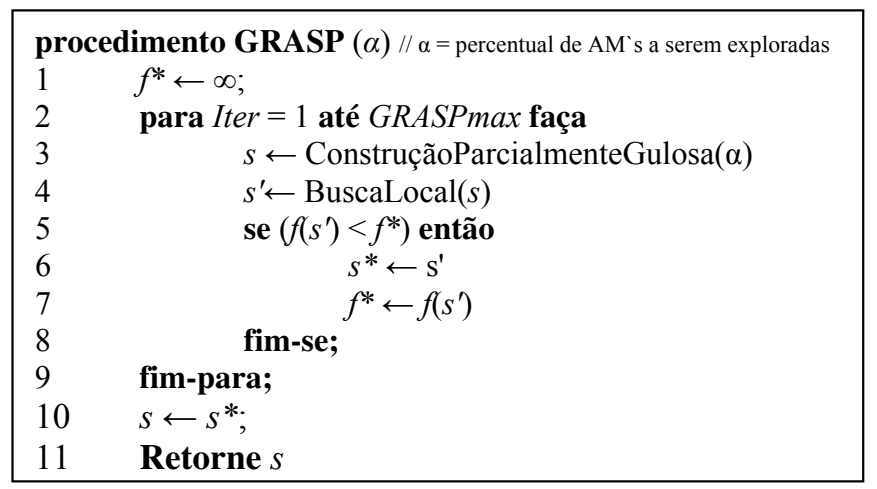

Figura 14. Algoritmo GRASP. (Feo \& Resende, 1995).

Na implementação da heurística GRASP+PR, o tamanho do conjunto de soluções de elite foi definido por $\pi=15$.

A fase construtiva "Construção Parcialmente Gulosa" (Passo 3 da Figura 15) consiste basicamente em gerar uma solução inicial a partir de um conjunto $C S$ de soluções geradas de forma aleatória. Primeiramente, as soluções deste conjunto $C S$ são ordenadas com base na função objetivo. Para cada unidade de produção, existe um conjunto de possíveis valores (alternativas de manejo) que ela pode assumir (Vide Figura 2).

Na Figura 16 é construída uma solução $S^{*}$. Observa-se que ela foi definida a partir de valores (alternativa de manejo) extraídos das soluções do conjunto $C S$ devidamente ordenado. A escolha de uma alternativa de manejo é feita de forma aleatória e obedecendo ao limite estabelecido pelo parâmetro $\alpha$. Esta operação é realizada para cada uma das unidades de produção (de "A" a "E"). 


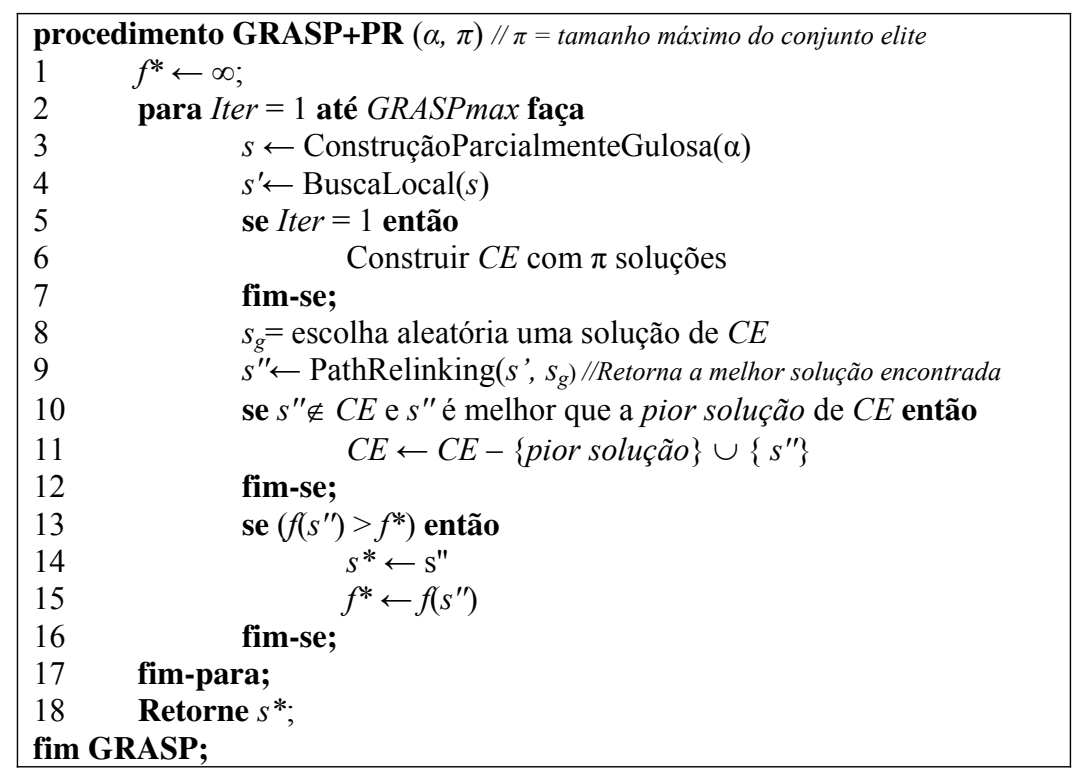

Figura 15. Algoritmo GRASP com Path Relinking.

Suponha que o conjunto $C S$ contenha 10 soluções, como mostra a Figura 16. Estas soluções são ordenadas de acordo à função objetivo. Para construir a solução $S^{*}$, para cada unidade de produção (UP) de $S^{*}$, escolhese uma alternativa de manejo dentre as $\alpha$ primeiras soluções do conjunto $C S$. Observe que, para a UP "A", foi escolhida a alternativa de manejo 8 que corresponde à solução $S_{3}$, para a UP "B" foi escolhida a alternativa de manejo 7 que corresponde à solução $S_{2}$, e assim por diante. Note que, se a solução $S^{*}$ fosse construída de forma gulosa, seriam selecionadas todas as alternativas de manejo da solução $S_{1}$.

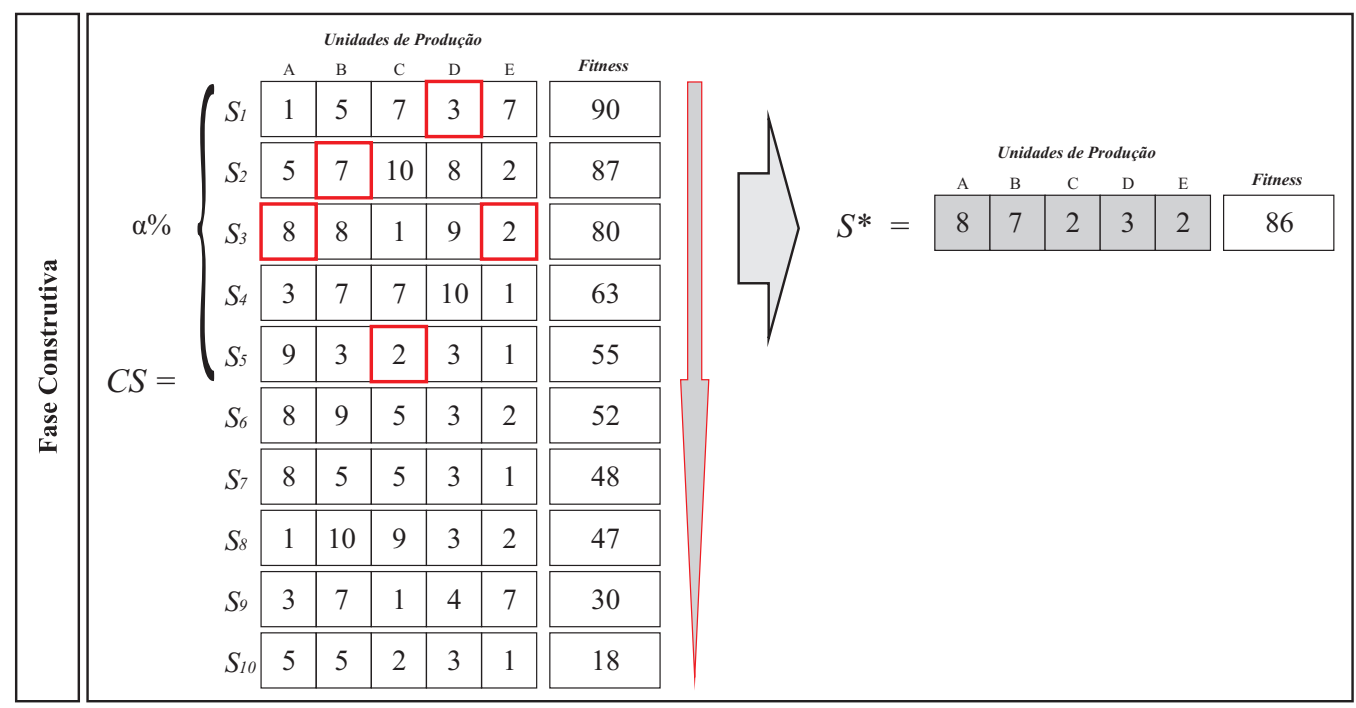

Figura 16. Representação da Fase Construtiva.

Após construir a solução inicial, calcula-se a função objetivo e verifica-se sua viabilidade para o problema, conforme as restrições impostas. Caso a solução definida seja viável, ela é retornada pelo procedimento, e caso ela não seja viável, uma nova solução é gerada.

A próxima fase, denominada de "Busca Local" (Passo 4 da Figura 15), a vizinhança da solução gerada pela fase de construção $(S)$ é analisada, em busca de alguma solução que, de acordo com a função objetivo do problema, seja melhor. Caso esta busca apresente um resultado de qualidade superior ao obtido na fase anterior, ela passa a considerar este indivíduo como a melhor solução encontrada.

O comportamento deste procedimento é representado na Figura 17. Neste exemplo, $S^{*}$ é a solução retornada pela fase construtiva, assim a rotina inicia a troca das alternativas de manejo de cada uma das UP's da solução. A $1^{\text {a }}$ Troca é realizada na primeira UP, representada pela letra "A", observa-se que a alternativa 8 é substituída pela alternativa 1 . Feito isto, a rotina calcula a função objetivo na nova solução gerada $\left(S_{1}\right)$ e, em seguida, compara $S_{1} \operatorname{com} S^{*}$ e caso $S_{1}$ seja melhor que $S^{*}, S_{1}$ passa a ser a nova $S^{*}$ (melhor solução encontrada). Na $2^{\text {a }}$ Troca, uma nova solução é gerada $\left(S_{2}\right)$ por meio da troca das alternativas: 1 com 
2. Novamente $S^{*}$ é colocado a prova sendo comparado com $S_{2}$. Caso $S_{2}$ seja superior, ele passa a ser $S^{*}$. Este procedimento se repete para todas as alternativas de manejo em cada uma das UP's.

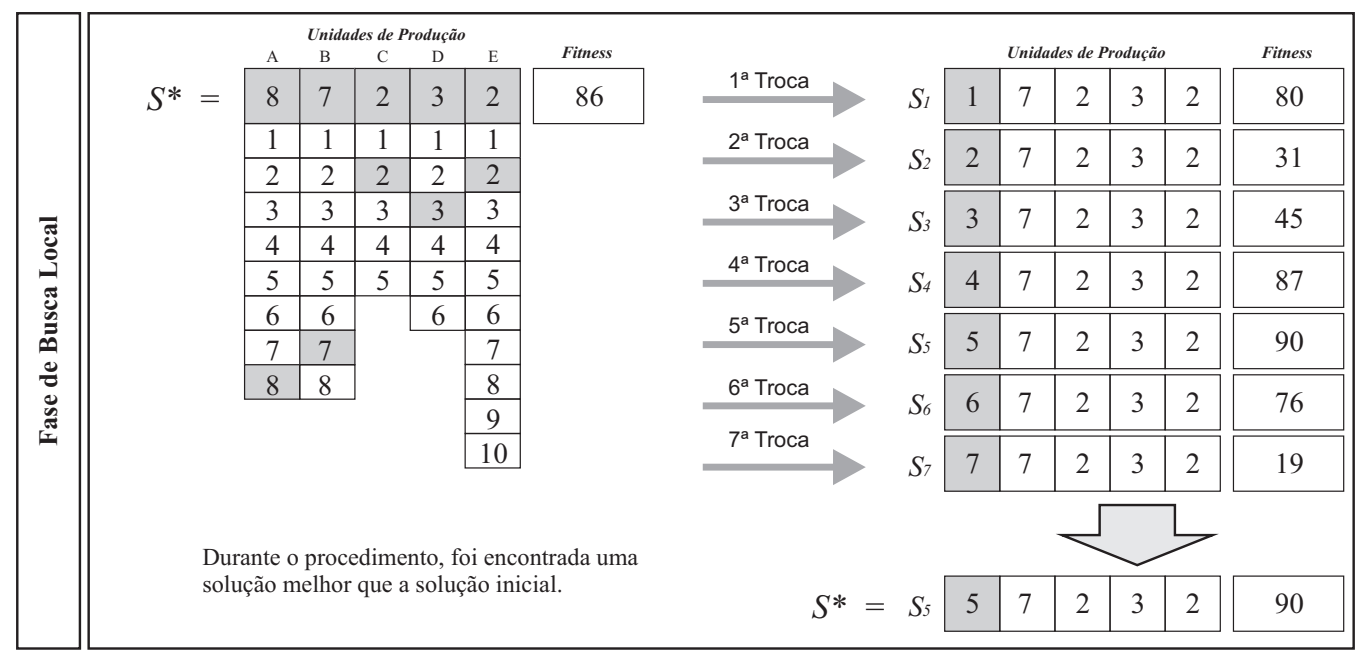

Figura 17. Representação da Fase de Busca Local.

Observa-se que esta fase representa a etapa mais dispendiosa em termos de tempo computacional exigida pelo GRASP, o que a torna uma busca local exaustiva. Nesta fase, são analisadas de forma iterativa todas as soluções (alternativas de manejo) que constituem a vizinhança. Sempre que uma solução encontrada for melhor que a solução corrente (ótimo local) a segunda é substituída. Este processo é repetido sucessivamente, até que não exista nenhuma solução melhor na vizinhança da solução corrente.

\subsubsection{Problemas-teste}

Com objetivo de mostrar a potencialidade de aplicação do Algoritmo Genético e GRASP com Path Relinking na solução de problemas de planejamento florestal, foram realizados alguns estudos de casos. É relevante ressaltar que, em todos os casos apresentados, foi considerada uma mesma empresa florestal hipotética, com algumas características básicas, simulando-se cenários diferentes, de forma a possibilitar a criação de problemas-teste necessários às demonstrações.

As seguintes premissas devem ser consideradas para todos os problemas:

- uma empresa florestal deseja planejar sua produção de madeira por meio de um plano de manejo florestal;

- as possíveis opções de manejo incluem: reforma, uma ou duas conduções da brotação;

- as idades mínima e máxima de corte são de 5 e 8 anos, respectivamente;

- as operações de corte são realizadas uma vez a cada período, sempre no início do período;

- os sítios são homogêneos;

- para simplificar o problema, foi considerada, para todas as unidades de produção, uma mesma classe de produtividade. Para o caso de exploração sob o regime da primeira condução da brotação, foi considerada uma redução de $10 \%$ na produção e de $15 \%$ para o caso de ser a exploração sob o segundo regime de condução da brotação;

- foi considerada uma taxa de desconto de $5 \%$ a.a.;

- o preço da madeira utilizado foi de $\mathrm{R} \$ 42,00 / \mathrm{m}^{3}$; e

- os valores de custo das principais atividades da floresta são apresentados na Tabela 1.

Na Tabela 2 são apresentados os problemas-teste com relação aos principais parâmetros usados na definição de cada um. Em todos os cenários, a empresa objetiva maximizar o Valor Presente Líquido (VPL).

Ainda na Tabela 2, os problemas 1, 2 e 3 representam um cenário onde a empresa pretende planejar sua produção para os próximos 9 anos (horizonte de planejamento). Nestes problemas, as formas de manejo utilizadas foram as opções de reforma e uma condução de brotação. A principal diferença entre os problemas 1, 2 e 3 está relacionada com os valores utilizados para se definir os níveis de demanda anual a serem considerados para cada um dos problemas. Esta diferenciação dos valores utilizados serve como forma de exploração de 
Tabela 1. Custos médios das atividades principais.

\begin{tabular}{cc}
\hline Atividade & Custo (R\$/ha) \\
\hline Implantação & 1040,12 \\
Manutenção básica anual média & 106,31 \\
Reforma & 871,27 \\
Condução da brotação & 40,25 \\
Exploração $\left(\mathrm{R} \$ / m^{3}\right)$ & 10,91 \\
\hline
\end{tabular}

cenários diferentes e influencia diretamente no desempenho das técnicas utilizadas. Para cada um destes problemas, foram geradas 735 prescrições.

Para os Problemas 4, 5 e 6 foi considerado um cenário onde a empresa pretende planejar sua produção para os próximos 14 anos. Nestes problemas foram utilizadas 50 unidades de produção e, como formas de manejo, foram utilizadas as opções de reforma, uma e duas conduções de brotação. Da mesma forma que os problemas anteriores (1, 2 e 3), a diferença entre os problemas 4, 5 e 6 também está relacionada com os valores utilizados para se definir as restrições de demanda anual mínima. Esta diferença entre estes valores, também serve como forma de obtenção de cenários diferentes. Para estes problemas, contudo, foram consideradas demandas anuais mínimas previstas, diferenciadas para cada período de produção. Este cenário pode ocorrer quando a empresa florestal está projetando o seu crescimento ou o aumento da demanda de madeira no mercado ao longo do tempo. Foram geradas para cada um destes problemas um total de 2466 prescrições.

Tabela 2. Problemas-teste utilizados para as demonstrações.

\begin{tabular}{ccccc}
\hline Problema & No UP's $^{\text {Porizonte }}$ & No & Prescrições & Tempo \\
\hline 1 & 50 & 9 anos & 735 & $11 \mathrm{~min}$. \\
2 & 50 & 9 anos & 735 & $11 \mathrm{~min}$. \\
3 & 50 & 9 anos & 735 & $11 \mathrm{~min}$. \\
4 & 50 & 14 anos & 2466 & $20 \mathrm{~min}$. \\
5 & 50 & 14 anos & 2466 & $20 \mathrm{~min}$. \\
6 & 50 & 14 anos & 2466 & $20 \mathrm{~min}$. \\
7 & 100 & 9 anos & 1533 & $30 \mathrm{~min}$. \\
8 & 100 & 9 anos & 1533 & $30 \mathrm{~min}$. \\
9 & 100 & 14 anos & 5094 & $60 \mathrm{~min}$. \\
10 & 100 & 14 anos & 5094 & $60 \mathrm{~min}$. \\
\hline
\end{tabular}

Nos problemas 7, 8, 9 e 10 foram considerados dois cenários para planejar a produção: 9 e 14 anos, respectivamente. Foram utilizadas 100 unidades de produção e, como formas de manejo, foram utilizadas as opções de reforma, uma e duas conduções de brotação. As restrições para estes problemas foram consideradas demandas anuais mínimas previstas para o mercado de madeira e capacidade anual de reforma. Foram gerados um total de 1533 prescrições para os problemas 7 e 8, e 5094 prescrições para os problemas 9 e 10 . Também, para estes problemas, a principal diferença está relacionada aos valores utilizados para se definir os níveis de demanda anual.

A coluna Tempo (Tabela 2) contém os tempos computacionais, em minutos, estabelecidos como critério de parada de cada algoritmo (AG, AG+PR, GRASP e GRASP+PR). Para determinar o tempo de execução dos algoritmos, foi utilizada a seguinte fórmula: $(M \times \sqrt{m}) \div 2$, onde $M$ representa o número total de UP's e $m$ representa o número total de alternativas de manejo disponíveis no problema. O resultado é dado em segundos e, posteriormente, convertido para minutos.

É importante ressaltar que todos os testes foram efetuados em um microcomputador Intel Core 2 Duo 2.20GHz com 3GB de memória RAM. Para cada problema, o algoritmo foi executado 5 vezes, visto que se trata de algoritmos probabilísticos.

Para todos os problemas propostos foi calculado a média e o coeficiente de variação em percentagem no sentido de se fazer uma comparação descritiva da eficácia dos algoritmos avaliados em resolver os problemas propostos.

\section{Resultados}

Como resultados, são apresentados o desempenho das meta-heurísticas Algoritmo Genético (AG), Algoritmo Genético com Path Relinking (AG+PR), GRASP e GRASP com Path Relinking propostos como alternativas de soluções para o problema de planejamento florestal. A Tabela 3 apresenta os resultados dos testes contendo 
a média e o coeficiente de variação $(\mathrm{CV})$ em percentagem da função objetivo obtidas durante as 10 execuções para cada problema.

Tabela 3. Médias dos VPL's e coeficientes de variação em percentagem dos problemas-teste. Os valores dos coeficientes de variação estão apresentados entre parênteses na sequência das médias

\begin{tabular}{ccrrr}
\hline \multirow{2}{*}{ Problema } & \multicolumn{5}{c}{ Média } \\
\cline { 2 - 5 } & AG & AG+PR & GRASP & GRASP+PR \\
\hline 1 & $180.296 .279,02(0,37)$ & $181.448 .340,68(0,31)$ & $170.568 .901,33(2,29)$ & $180.770 .647,90(0,47)$ \\
2 & $177.424 .758,51(1,01)$ & $178.041 .811,50(0,44)$ & $168.005 .501,97(0,58)$ & $177.739 .425,96(0,59)$ \\
3 & $176.828 .224,86(0,50)$ & $176.970 .883,25(0,53)$ & $165.736 .524,15(0,39)$ & $175.802 .715,38(0,71)$ \\
4 & $260.359 .667,22(0,16)$ & $261.105 .578,30(0,18)$ & $238.477 .829,62(0,30)$ & $261.287 .659,37(0,33)$ \\
5 & $254.401 .665,60(0,19)$ & $254.256 .855,22(0,36)$ & $237.317 .743,93(0,30)$ & $256.631 .443,15(0,33)$ \\
6 & $254.258 .678,44(0,73)$ & $254.874 .690,05(0,31)$ & $236.504 .492,97(0,36)$ & $254.934 .774,68(0,42)$ \\
7 & $392.070 .325,26(0,19)$ & $392.234 .885,63(0,16)$ & $362.530 .132,21(0,55)$ & $394.804 .326,16(0,27)$ \\
8 & $393.973 .840,26(0,19)$ & $392.437 .590,19(0,22)$ & $359.728 .766,18(0,38)$ & $392.870 .997,40(0,16)$ \\
9 & $562.786 .455,69(0,18)$ & $563.703 .157,22(0,13)$ & $520.454 .711,87(0,24)$ & $561.551 .600,67(0,44)$ \\
10 & $554.994 .048,44(0,24)$ & $554.151 .147,86(0,64)$ & $511.506 .009,49(0,42)$ & $552.307 .242,49(0,42)$ \\
\hline
\end{tabular}

Quando se compara as médias do AG com o AG+PR e o GRASP com o GRASP+PR, nota-se que a técnica Path Relinking proporcionou um aumento da média, indicando, assim, soluções mais eficazes, especialmente para o GRASP. Isto pode ser explicado pelo fato de o AG, por concepção, proporcionar uma maior diversidade no processo de solução, o que não ocorre com o GRASP. Assim, os resultados indicam que acrescentar o Path Relinking ao GRASP pode ter proporcionado uma maior diversidade, o que produziu soluções mais eficazes.

Dos 10 problemas testados, o AG+PR obteve melhores médias em 5 problemas quando comparado com o GRASP+PR que obteve 5 médias superiores. Este resultado reforça o fato de que, quando a técnica aumenta a sua diversidade, soluções mais eficazes tendem a ser encontradas. Assim, ao aumentar a base genética do GRASP com a introdução do Path Relinking, ele se aproximou em desempenho ao AG, mesmo que este tenha incorporado o Path Relinking. Isto é, o efeito do Path Relinking foi mais significativo no GRASP do que no AG.

Em relação ao tamanho dos 10 problemas testados, tendo em vista os resultados encontrados, não se observa uma influência clara do tamanho do problema na eficácia das meta-heurísticas avaliadas. Isto não significa que o tamanho não seja importante, mas que novas pesquisas com tamanhos ainda maiores sejam realizadas para que, de fato, se verifique a influência deste efeito.

Finalmente, é válido comentar os valores reduzidos do coeficiente de variação encontrados para todas as situações avaliadas (Tabela 3). Neste caso, os valores reduzidos indicam que as meta-heurísticas se comportaram de forma estável na obtenção da solução. Isto é, não houve soluções muito discrepantes, o que seria indesejável. Assim, esta baixa variação torna as técnicas avaliadas confiáveis no sentido de obter soluções mais próximas de um valor ótimo sem oscilar muito.

\section{Conclusões}

Considerando os resultados encontrados, pode-se concluir que:

- As quatro meta-heurísticas avaliadas produziram soluções eficazes no tempo determinado para os problemas de planejamento considerados;

- O acréscimo do Path Relinking no AG e no GRASP tende a promover ganho em eficácia, sendo este ganho mais visível no GRASP;

- Os coeficientes de variação encontrados permitiram concluir que as meta-heurísticas avaliadas produziram soluções estáveis, com pequena variação.

\section{Referências}

ABRAF, , Anuário Estatístico da ABRAF 2012 - Ano Base 2011. 7a edição. Brasília, DF: Associação Brasileira de Produtores de Florestas Plantadas, 2012.

Bäck, T.; Hammel, U. \& P.Schwefel, H., Evolutionary computation: comments on the history and current state. IEEE Transactions on Evolutionary Computation, 1(1):3-17, 1997. 
Bastos, M.P. \& Ribeiro, C.C., Reactive tabu search with path relinking for the steiner problem in graphs. In: Essays and Surveys in Metaheuristics. Norwell, USA: Kluwer Academic Publishers, v. 15 de Operations Research/Computer Science Interfaces, p. 39-58, 2002.

Castro, R.R., Regulação de florestas equiâneas incluindo restrições de adjacência. Dissertação de Mestrado em Ciência Florestal, Universidade Federal de Viçosa, Viçosa, MG, 2007.

Clutter, J.C.; Pienaar, L.V. \& Brister, G.H., Timber management: a quantitative approach. 3a edição. New York, USA: J. Wiley \& Sons, 1983.

Dykstra, D.P., Mathematical programming for natural resource management. 3a edição. New York, USA: McGraw-Hill, 1984.

Feo, T.A. \& Resende, M.G.C., Greedy randomized adaptive search procedures. Journal of Global Optimization, (6):109-133, 1995.

Glover, F., Scatter Search and Path Relinking, New Ideas in Optimization. New York, USA: McGraw-Hill, 1999.

Glover, F.; Laguna, M. \& Martí, R., Fundamentals os scatter search and path relinking. Control and Cybernetics, 19(3):653-684, 2000.

Glover, F.; Laguna, M. \& Martí, R., Scatter search and path relinking: Foundations and advanced designs, new optimization techniques in engineering. In: Onwubulu, G. (Ed.), New Optimization Techniques in Engineering. Heidelberg, Gernany: Springer-Verlag, v. 141 de Studies in Fuzziness and Soft Computing, p. 87-99, 2004.

Gomide, L.R., Planejamento florestal espacial. Tese de Doutorado em Ciência Florestal, Universidade Federal do Paraná, Curitiba, PR, 2009.

Holland, J.H., Adaptation in natural and artificial systems. Ann Arbor, USA: The University of Michigan Press, 1975.

Ignizio, J.P. \& Cavalier, T.M., Linear Programming. Englewood Cliffs, USA: Prentice Hall, 1994.

Johnson, K.N. \& Scheurman, H.L., Techiniques for prescribing optimal timber harvest and investment under different objectives - discussion and synthesis. Forest Science, 18(1):1-31, 1977.

Laguna, M. \& Martí, R., Grasp and path-relinking for 2-layer straight line crossing minimization. INFORMS Journal on Computing, 11(1):44-52, 1999.

Mello, A.A.; Carnieri, C.; Arce, J.E. \& Sanqueta, C.R., Planejamento florestal visando a maximização dos lucros e a manutenção do estoque de carbono. Cerne, 11(3):205-217, 2005.

Menon, M.U., Meta-heurísticas na otimização do sortimento florestal. Tese de Doutorado em Ciência Florestal, Universidade Federal do Paraná, Curitiba, PR, 2005.

Pereira, G.W., Aplicação da técnica de recozimento simulado em problemas de planejamento florestal multiobjetivo. Dissertação de Mestrado em Ciência da Computação, Universidade Federal de Minas Gerais, Belo Horizonte, MG, 2004.

Piassi, L.C., Métodos de regulação florestal no planejamento da produção de madeira. Dissertação de Mestrado em Ciência Florestal, Universidade Federal do Espírito Santo, Gerônimo Monteiro, ES, 2011.

Resende, M.G.C. \& Ribeiro, C.C., Greedy randomized adaptive search procedures. In: Glover, F. \& Kochenberger, G.A. (Eds.), Handbook of Metaheuristics. Norwell, USA: Kluwer Academic Publishers, 2002.

Rodrigues, F.L., Metaheurística e sistema de suporte à decisão no gerenciamento de recursos florestais. Tese de Doutorado em Ciência Florestal, Universidade Federal de Viçosa, Viçosa, MG, 2001.

Rodrigues, F.L.; Leite, H.G. \& Alves, J.M., Sisflor - um sistema de suporte a decisão em planejamento florestal. In: Anais do Simpósio Brasileiro de Pesquisa Operacional. Viçosa, MG: SBPO, p. 974-995, 2000.

Rodrigues, F.L.; Leite, H.G.; Souza, A.L.; Ribeiro, C.A.A.S. \& Silva, M.L., Regulação de florestas equiâneas utilizando programação linear: uma aplicação da teoria do modelo II. Revista Árvore, 22(2):193-213, 1998.

Rodrigues, F.L.; Leite, H.G.; Xavier, A.C. \& Pezzopane, J.E.M., Um modelo de regulação florestal e suas implicações na formulação e solução de problemas com restrições de recobrimento. Revista Árvore, 30(5):769-778, 2006.

Rosseti, I.C.M., Estratégias Sequenciais e Paralelas de GRASP com Reconexão por Caminhos para o problema de sintese de redes a 2-caminhos. Tese de Doutorado em Informática, Pontifícia Universidade Católica do Rio de Janeiro, Rio de Janeiro, RJ, 2003.

Silva, G.F.; Leite, H.G.; Soares, C.P.B. \& Silva, M.L., Influência de estimativas de produção de madeira em processos de regulação florestal utilizando programação linear. Revista Árvore, 13(1):57-72, 2003.

Silva, G.F.; Piassi, L.C.; Môra, R.; Martins, L.T.; Teixeira, A.F. \& Junior, A.A.B., Metaheurística algoritmo genético na solução de modelos de planejamento florestal. Revista Agrária, 4(2):160-166, 2009.

Silva, G.F.S., Problemas no uso de programação matemática e simulação em regulação florestal. Tese de Doutorado em Ciência Florestal, Universidade Federal de Viçosa, Viçosa, MG, 2001.

Silva, R.T., Planeamento florestal, modelos de programação inteira multiobjectivo e aplicações. Dissertação de Mestrado em Gestão da Informação nas Organizações, Faculdade de Economia da Universidade de Coimbra, Coimbra, Portugal, 2004.

Teixeira, A.F., Aplicação de algoritmos evolucionários na solução de problemas de planejamento florestal multiobjetivo. Dissertação de Mestrado em Ciência da Computação, Universidade Federal de Minas Gerais, Belo Horizonte, MG, 2002.

Zitzler, E., Evolutionary algorithms for multiobjective optimization: methods and applications. PhD Thesis, Swiss Federal Institute of Technology, Zurich, Switzerland, 1999. 


\section{Notas Biográficas}

Gilson Fernandes da Silva é graduado em Engenharia Florestal, mestre e doutor em Ciência Florestal (Universidade Federal de Viçosa - UFV, 1995, 2001 e 2002, respectivamente). Tem pós-doutorado na Universidade de Brasília (2002) e é bolsista de produtividade em pesquisa do CNPq. Atualmente é Professor Associado I da UFES. Tem experiência na área de Recursos Florestais e Engenharia Florestal, com ênfase em Ordenamento Florestal, atuando principalmente nos seguintes temas: mensuração florestal, manejo florestal e otimização.

Antonio Almeida de Barros Junior é graduado em Sistemas de Informação (Universidade Iguaçú, 2004) e mestre em Ciência da Computação (UFV, 2010). Atualmente é Professor Assistente na Universidade Federal do Espírito Santo. Tem experiência na área de Ciência da Computação, com ênfase em Sistemas de Informação, atuando principalmente nos seguintes temas: sistemas de apoio à decisão, heurísticas, banco de dados e data warehouse.

Gustavo Willam Pereira é graduado em Ciência da Computação (UFV, 2002) e mestre em Ciência da Computação (UFMG, 2004). Atualmente é professor assistente da Faculdade de Filosofia Ciências e Letras Santa Marcelina. Tem experiência na área de Ciência da Computação, com ênfase em Desenvolvimento de Sistemas, Pesquisa Operacional, atuando principalmente nos seguintes temas: análise e desenvolvimento de sistemas, banco de dados, estrutura de dados, pesquisa operacional, programação linear e otimização sob múltiplos objetivos.

Adriano Ribeiro de Mendonça é graduado em Engenharia Florestal e mestre em Produção Vegetal (UFES, 2004 e 2006, respectivamente) e doutor em Engenharia Florestal (UFLA, 2010). Atualmente é Professor Adjunto I e Coordenador do Colegiado de Curso de Engenharia Florestal da Universidade Federal do Espírito Santo. Tem experiência na área de Recursos Florestais e Engenharia Florestal, com ênfase em dendrometria, inventário florestal e manejo florestal, atuando principalmente nos seguintes temas: crescimento e produção florestal, sortimentos e afilamento. 


\title{
Meta-Heurística Otimização por Enxame de Partículas Aplicada ao Planejamento Florestal
}

\author{
Flávio Augusto Ferreira do Nascimento, Julio Eduardo Arce, Andrea Nogueira Dias, \\ Afonso Figueiredo Filho, Gabriel de Magalhães Miranda e Celso Carnieri
}

\begin{abstract}
Resumo: Neste capítulo investigou-se a aplicação da meta-heurística Otimização por Enxame de Partículas (PSO) na resolução do problema de planejamento florestal. Foram avaliadas as abordagens do algoritmo com momento de inércia e com fator de contrição, combinadas a duas topologias de vizinhança denominadas de gbest e lbest. Estas combinações foram comparadas à meta-heurística simulated annealing (SA) e ao algoritmo exato branch-and-bound. Os resultados alcançados indicam que o algoritmo PSO é uma ferramenta viável para solução do problema e que apresenta resultados superiores ao algoritmo SA.
\end{abstract}

Palavras-chave: Planejamento florestal, Modelo tipo I, Otimização por enxame de partículas.

\begin{abstract}
In this chapter we investigate the application of metaheuristic Particle Swarm Optimization (PSO) to solve the problem of forest planning. We evaluated the algorithm approaches moment of inertia and constriction factor, combined with two neighborhood topologies called lbest and gbest. These combinations were compared to the metaheuristic simulated annealing (SA) and the exact algorithm branchand-bound. The results indicate that PSO algorithm is a viable tool for solving the problem, and it has better results than the $S A$ algorithm.
\end{abstract}

Keywords: Forest planning, Model type I, Particle swarm optimization.

\section{Introdução}

O planejamento da sequência futura de colheitas em uma floresta é umas das inúmeras atividades do gestor florestal, sendo uma etapa fundamental para o manejo adequado de cultivos florestais. Com tal planejamento, é possível definir, por exemplo, se o negócio florestal pode ou não ser considerado viável. Este tipo de problema consiste em determinar quais talhões ou unidades de manejo florestal devem ser colhidos em cada período do tempo, de forma a alcançar a maximização do retorno financeiro, a minimização de custos, dentre outros inúmeros objetivos, ao mesmo tempo em que se respeitam as restrições do problema, como por exemplo, a manutenção da produção de madeira durante todos os anos do horizonte de planejamento.

O problema de planejamento florestal pode se tornar complexo por diversas questões. Segundo Silva et al. (2009), entre os fatores que dificultam a tomada de decisão no ambiente das empresas florestais, citam-se o elevado número de variáveis ou alternativas de manejo (diferentes idades de corte, espaçamentos, épocas e intensidades de desbastes, entre outros), os múltiplos objetivos a serem atingidos (minimizar custos, maximizar receitas, atender a legislação, entre outros), a necessidade de aumento da eficiência do processo e a escassez de técnicas de auxílio à tomada de decisão.

O sequenciamento da colheita florestal é um problema de otimização combinatória que é $N P$-hard, ou seja, não existe um algoritmo exato capaz de obter a solução ótima em tempo computacional razoável. Nos anos recentes, pesquisas com técnicas meta-heurísticas se mostraram adequadas para a resolução de problemas florestais, cabendo citar as abordagens via simulated annealing (Rodrigues et al., 2004a; Pereira, 2004), algoritmo genético (Rodrigues et al., 2004b; Ducheyne et al., 2004; Gomide et al., 2009; Silva et al., 2009) e busca tabu (Rodrigues et al., 2003; Bettinger et al., 2007), cujo conjunto genericamente é denominado de SA-GA-TS. O foco deste capítulo é apresentar avanços similares considerando a abordagem denominada otimização por enxame de partículas (PSO, Particle Swarm Optimization).

Em 1995 os pesquisadores James Kennedy (um psicólogo social) e Russel Eberhart (um engenheiro eletricista), inspirados pelas teorias da inteligência coletiva, criaram um novo método de otimização

*Autor para contato: fafnascimento@gmail.com 
denominado otimização por enxame de partículas. O método é baseado em uma população de agentes, denominados de partículas, que mudam sua posição no espaço de busca do problema, de acordo com a própria experiência e a experiência das partículas vizinhas que constituem o enxame (Muller, 2007).

Segundo Mendes (2004), a PSO apresenta algumas vantagens em relação a outras meta-heurísticas: (1) simplicidade de implementação; (2) existência de poucos parâmetros a serem ajustados; (3) utilização de uma população relativamente pequena; e (4) necessidade de um número relativamente pequeno de avaliações da função objetivo para a convergência.

O objetivo deste capítulo é avaliar o algoritmo PSO na resolução de um problema de planejamento florestal, comparando-o à meta-heurística Simulated Annealing (SA) e ao algoritmo exato Branch-and-Bound (B\&B).

\section{Metodologia}

\subsection{Fonte de dados}

O estudo foi desenvolvido em uma empresa florestal localizada na região norte do Estado de Santa Catarina. A empresa possui plantios com as espécies Pinus Taeda e Pinus elliottii. Para a formulação do problema considerou-se apenas parte da área total de plantios. Cerca de 498.000 ha de plantios da espécie $P$. Taeda foram utilizados. Adotou-se este critério para simplificar a resolução do problema, principalmente para a comparação das meta-heurísticas com o algoritmo B\&B.

\subsection{Descrição do problema de planejamento florestal}

O problema de planejamento florestal empregado se baseia no manejo de áreas homogêneas denominadas talhões (Figura 1). Um talhão consiste de uma área contínua com características semelhantes, tais como, material genético e idade das árvores, classe de produtividade, declive, altitude, dentre outros e, ainda, submetida ao mesmo regime de manejo. Este regime de manejo pode ser composto, por exemplo, por um desbaste, onde é retirado um determinado percentual das árvores do talhão, aos nove anos de idade, seguido do corte raso, onde todas as árvores remanescentes do talhão são removidas, aos 17 anos de idade. Ao longo do tempo os talhões são submetidos sucessivamente às atividades de plantio, desbaste e cortes raso. O conjunto destas opções de manejo é denominado prescrição ou regime de manejo.

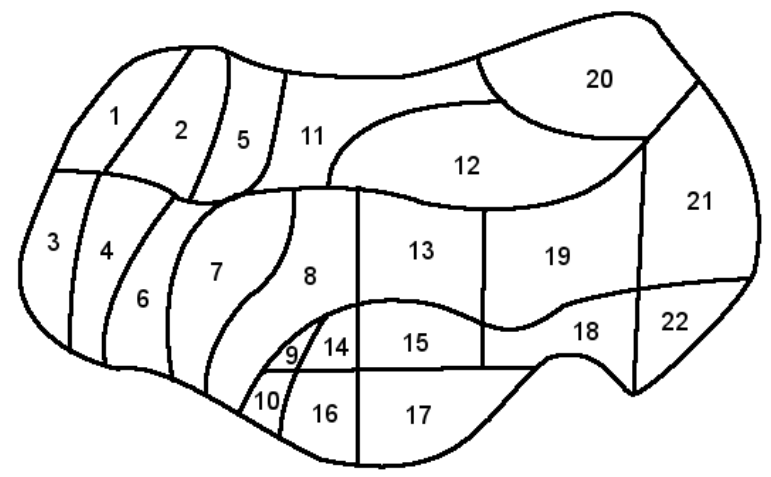

Figura 1. Exemplo de área florestal dividida em 22 talhões.

Os desbastes e cortes rasos realizados em uma área florestal produzem matéria-prima para abastecer a indústria de processamento desta madeira. Consequentemente, estas etapas geram receitas com a venda da madeira e custos referentes ao plantio das mudas pós-corte raso. Com base nestas receitas, nos custos e na taxa de juros é possível determinar o momento econômico ideal para se realizar cada desbaste e corte raso. No entanto, é imprescindível que a produção de madeira mantenha-se equilibrada durante o tempo. Neste sentido, o desafio do gerente florestal é decidir qual é o momento ideal de realizar cada intervenção em seus talhões de modo a manter produção constante ao mesmo tempo em que se obtém o máximo retorno financeiro do empreendimento como um todo.

Johnson \& Scheurman (1977), após levantamento do estado da arte, denominaram estes problemas em dois tipos: modelo tipo I e modelo tipo II. Enquanto no modelo tipo I a variável de decisão é a área do talhão a ser manejada sob determinada prescrição, no modelo tipo II a decisão é em relação à idade dos talhões. Na presente pesquisa foi utilizado o modelo tipo I. Originalmente o problema, por utilizar variáveis contínuas, se configura como de Programação Linear, facilmente solucionado por meio do algoritmo Simplex. No entanto, esta formulação pode apresentar soluções que dividem os talhões em duas ou mais prescrições de manejo, quando pode ser desejável manter a integridade destes talhões ao longo do horizonte de planejamento. Neste sentido, a variável de decisão pode ser alterada de modo a representar prescrição de manejo para determinado talhão, neste caso, toda a área deste talhão. 
Seguindo a formulação do modelo tipo I, optou-se como função objetivo do problema a utilização da maximização do valor periódico equivalente global da floresta (Silva et al., 2005), um critério de avaliação econômica frequentemente utilizado na área florestal, conforme apresentado na Equação 1.

$$
\max V P E_{G}=\sum_{i=1}^{M} \sum_{j=1}^{N} C_{i j} \cdot X_{i j}
$$

onde: $V P E_{G}=$ valor periódico equivalente global da floresta; $C_{i j}=$ valor periódico equivalente de cada talhão $i$, manejado sob a prescrição $j ; X_{i j}=$ talhão $i$ assinalado à prescrição $j ; M=$ número de talhões; $N=$ número total de prescrições de manejo $j$ no talhão $i$.

Uma das restrições do problema permite que apenas uma alternativa de manejo seja alocada para cada unidade de manejo. Esta restrição é apresentada na Equação 2.

$$
\sum_{j=1}^{N} X_{i j}=1 \quad \forall_{i=1,2, \ldots M}
$$

onde:

$$
X_{i j}=\left\{\begin{array}{l}
1, \text { se a prescrição } j \text { for adotada no talhão } i, \\
0, \text { caso constrário. }
\end{array}\right.
$$

Há também um conjunto de restrições que impõem cotas de produção anual, estabelecendo níveis desejáveis de produção em cada ano do horizonte de planejamento. A forma escolhida para definir esta restrição foi incluir um par de limites inferior e superior na produção, como apresentado nas Equações 4 e 5.

$$
\begin{aligned}
& \sum_{i=1}^{M} \sum_{j=1}^{N} V T_{i j k} \cdot X_{i j}>=\operatorname{Pmin}_{k}(k=1,2,3, \ldots, n) \\
& \sum_{i=1}^{M} \sum_{j=1}^{N} V T_{i j k} \cdot X_{i j}<=\operatorname{Pmax}_{k}(k=1,2,3, \ldots, n)
\end{aligned}
$$

onde: $V T_{i j k}=$ volume total $\left(\mathrm{m}^{3}\right)$ produzido pelo $i$-ésimo talhão assinalado na $j$-ésima prescrição de manejo, no início do ano $k ; \operatorname{Pmin}_{k}=$ produção mínima estabelecida para o ano $k$, em $\mathrm{m}^{3} ; P \max x_{k}=$ produção máxima estabelecida para o ano $k$, em $m^{3} ; n=$ horizonte de planejamento, em anos.

\subsection{Codificação do problema}

O problema de planejamento florestal consiste basicamente em decidir qual prescrição de manejo deve ser adotada em cada talhão. A quantidade de prescrições para cada talhão depende da idade dos mesmos, da definição das opções de manejo e do horizonte de planejamento do problema. Neste trabalho optou-se por utilizar como opções de manejo as idades do desbaste entre 9 e 11 anos, bem como as idades de corte final entre 16 e 22 anos. Estas opções estão de acordo com o manejo atualmente utilizado pela empresa que forneceu os dados.

Para a formulação do problema a variável de decisão $X_{i j}$ assume valor igual a um se a prescrição de manejo $j$ for adotada para o talhão $i$, e zero caso contrário. Somente uma prescrição de manejo pode ser escolhida para cada talhão. Assim, esta alternativa escolhida pode ser entendida como a posição que é alterada durante a movimentação das partículas, no caso do algoritmo PSO, e na geração das soluções candidatas vizinhas, no caso do algoritmo SA. Na Figura 2 é apresentada uma solução possível considerando esta codificação adotada para o problema.

\subsection{O algoritmo otimização por enxame de partículas}

A PSO é uma técnica que se baseia no movimento coletivo de um grupo de partículas: o enxame de partículas. Cada membro deste enxame é movimentado através do espaço de busca do problema por duas forças. Uma os atrai com magnitude aleatória para a melhor localização já encontrada por ele próprio (pbest) e outra para a melhor localização encontrada na sua vizinhança (gbest). A posição e a velocidade de cada partícula são atualizadas a cada iteração até todo o enxame convergir (Castro \& Tsuzuki, 2007). Cada partícula possui dois componentes básicos: a posição em que se encontra $\left(x_{p}\right)$ e a velocidade $\left(v_{p}\right)$. No algoritmo original (Kennedy \& Eberhart, 1995), a cada iteração estes dois componentes são atualizados pelas Equações 6 e 7.

$$
v_{p}^{(i t+1)}=v_{p}^{(i t)}+c_{1} \cdot \operatorname{rand}_{1}^{(i t)} \cdot\left[\text { pbest }_{p}-x_{p}^{(i t)}\right]+c_{2} \cdot \operatorname{rand}_{2}^{(i t)} \cdot\left[\text { gbest }_{p}-x_{p}^{(i t)}\right]
$$




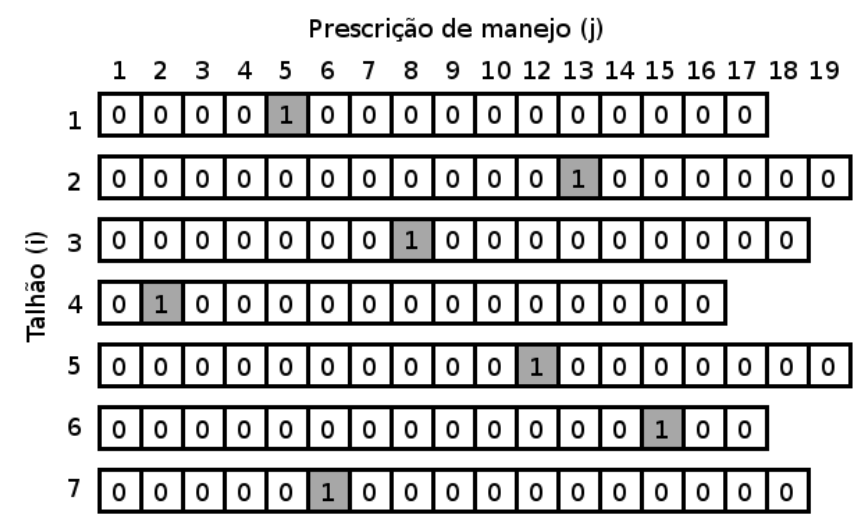

Figura 2. Exemplo de codificação de uma solução para o problema de planejamento florestal.

$$
x_{p}^{(i t+1)}=x_{p}^{(i t)}+v_{p}^{(i t+1)}
$$

onde: $v_{p}=$ velocidade da partícula $p ; x_{p}=$ posição da partícula $p ; c_{1}$ e $c_{2}=$ coeficientes cognitivos e social;

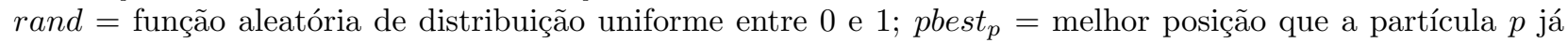
obteve durante a busca; gbest $_{p}=$ melhor posição encontrada na vizinhança da partícula $p$; e $i t=$ iteração atual.

De acordo com Sierakowski (2006), as constantes positivas denominadas de coeficientes cognitivo e social, respectivamente $c_{1}$ e $c_{2}$, são as constantes de aceleração que variam a velocidade de uma partícula em direção ao pbest e gbest, de acordo com a experiência passada. Ainda segundo este autor, não são fatores críticos para determinar a convergência do algoritmo. Porém, um ajuste correto destes valores pode levar a uma convergência mais rápida do algoritmo

A posição $x_{p}$ de cada partícula é composta por um conjunto de coordenadas que representa uma solução pontual dentro do espaço de busca. A cada iteração esta posição é avaliada de acordo com uma função de aptidão (fitness). Caso esta posição seja melhor que a já encontrada, ela é armazenada em pbest . $_{\text {. }}$.

O algoritmo inicia cada partícula com valores aleatórios de posição e velocidade. A posição é limitada pelo tamanho do espaço de busca do problema, enquanto a velocidade é limitada pelo valor do coeficiente velocidade máxima $\left(V_{\max }\right)$. Depois de inicializado, o algoritmo entra em um loop até alcançar o critério de parada estabelecido. Dentro do loop cada partícula avaliará sua posição atual (ou solução atual) em relação à melhor posição já encontrada por ela mesma, isso permite que o valor de pbest seja atualizado. Cada partícula também avaliará a qualidade da melhor solução encontrada na sua vizinhança, permitindo a atualização do valor de gbest. A avaliação da qualidade de uma posição (ou solução) é realizada por meio da função de fitness ou aptidão. Após atualizar o valor de velocidade com os novos valores de pbest e gbest, cada partícula irá se deslocar para uma nova posição. O fluxograma básico de funcionamento do algoritmo PSO é apresentado na Figura 3.

Como a codificação do problema exige que a posição tenha valores inteiros e, ainda, as Equações de velocidade 6 e 7 podem apresentar valores contínuos, a posição das partículas $\left(x_{p}\right)$ é sempre arredondada para o valor inteiro mais próximo.

\subsubsection{Abordagens testadas do algoritmo PSO}

Diversas pesquisas têm sido conduzidas com o intuito de realizar variações no algoritmo original da PSO. Estas modificações buscam superar alguns pontos fracos do algoritmo, melhorando o seu desempenho e diminuindo a quantidade de parâmetros a serem ajustados. Neste trabalho foram testadas duas variações do algoritmo PSO: a abordagem com o momento de inércia (Shi \& Eberhart, 1998) e com o fator de constrição (Clerc \& Kennedy, 2002), denominados neste trabalho de PSOw e PSOx, respectivamente.

O desenvolvimento da PSOw foi motivado pela obtenção de melhor controle sobre o processo de busca do algoritmo e, ainda, a redução ou até mesmo a eliminação da importância de $V_{\max }$. Shi e Eberhart (1998) propuseram esta modificação que inclui um parâmetro denominado momento de inércia $(w)$. Apenas a Equação de velocidade é modificada e passa a assumir a Equação 8.

$$
v_{p}^{(i t+1)}=w \cdot v_{p}^{(i t)}+c_{1} \cdot \operatorname{rand}_{1}^{(i t)} \cdot\left[\text { pbest }_{p}-x_{p}^{(i t)}\right]+c_{2} \cdot \operatorname{rand}_{2}^{(i t)} \cdot\left[\text { gbest }_{p}-x_{p}^{(i t)}\right]
$$

onde: $w=$ momento de inércia. 


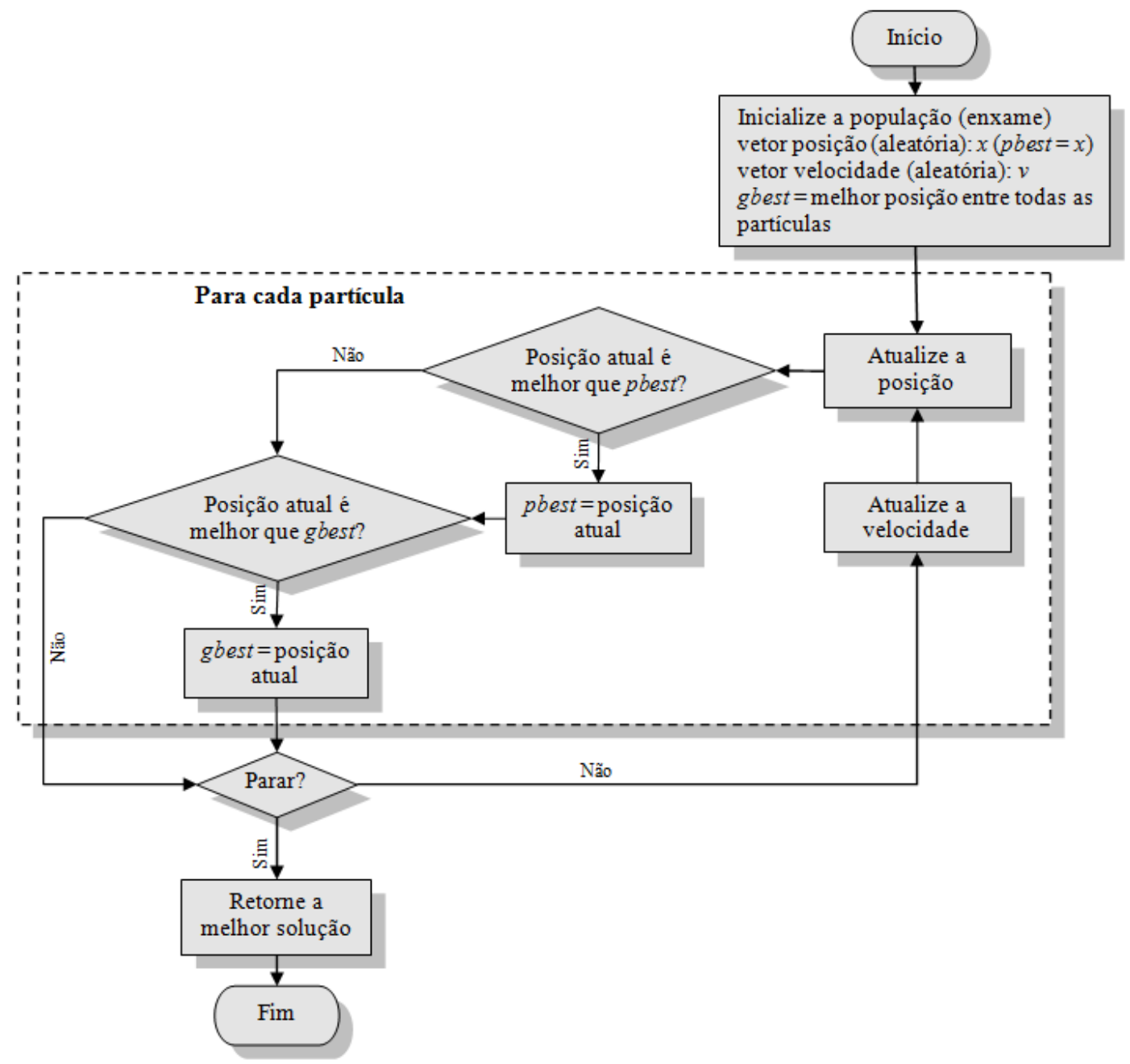

Figura 3. Fluxograma básico do algoritmo PSO.

Segundo Eberhart \& Shi (2000), o parâmetro $w$ atua sobre a velocidade fazendo com que, dependendo do seu valor, as partículas explorem maiores ou menores áreas do espaço de busca. De acordo com estes autores, melhores desempenhos têm sido encontrados configurando inicialmente $w$ com um valor relativo alto (p.ex.: 0,9 ), o que corresponde a maiores áreas de busca, e gradualmente diminuindo $w$ para valores menores (p.ex.: $0,4)$, onde a busca passa a ser direcionada a encontrar um ótimo local.

O algoritmo PSO com fator de constrição (PSOx) foi desenvolvido como uma forma de evitar o uso do parâmetro $V_{\max }$. Segundo Poli et al. (2007), a razão do uso do parâmetro $V_{\max }$, como forma de limitar a dinâmica das partículas não foi totalmente compreendida. Se o algoritmo for executado sem uma restrição para a velocidade, de algum modo, a velocidade aumenta rapidamente a níveis inaceitáveis em poucas iterações. Como forma de limitar a movimentação das partículas, Clerc \& Kennedy (2002) criaram um coeficiente denominado de fator de constrição. A Equação de velocidade muda para a Equação 9.

$$
v_{p}^{(i t+1)}=\chi \cdot\left\{v_{p}^{(i t)}+c_{1} \cdot \operatorname{rand}_{1}^{(i t)} \cdot\left[\text { pbest }_{p}-x_{p}^{(i t)}\right]+c_{2} \cdot \operatorname{rand}_{2}^{(i t)} \cdot\left[\text { gbest }_{p}-x_{p}^{(i t)}\right]\right\}
$$

onde: $\chi=$ coeficiente de constrição que é calculado pela Equação 10:

$$
\chi=\frac{2 \cdot k}{\left|2-\varphi-\sqrt{\varphi^{2}-4 \cdot \varphi}\right|}
$$

onde: $k \in[0,1], \varphi=c_{1}+c_{2}, \varphi>4$

Segundo Mendes (2004), a maioria das pesquisas que usam o método de constrição costumam configurar $\varphi$ igual a 4,1 (tendo assim $\left.c_{1}=c_{2}=2,05\right)$ e $k=1$ o que determina um $\chi \approx 0,729$. Isto é algebricamente equivalente a usar o momento de inércia com $w=0,729$ e $c_{1}=c_{2} \approx 1,49445$.

Estas duas abordagens também foram avaliadas com duas topologias de vizinhança (Figura 4): estrela (ou gbest) e círculo (ou lbest). Segundo Guo et al. (2006), a topologia gbest (Figura 4a), é a relação totalmente conectada de vizinhança. Cada partícula tem todas as outras partículas como vizinhas. Isto implica que 
a melhor posição global das partículas é igual para todas as partículas. Também segundo estes autores, a topologia lbest (Figura 4b) conecta cada partícula com seus vizinhos imediatos. Para dois vizinhos a topologia em círculo corresponde a um anel. O fluxo da informação é extremamente reduzido comparado com a topologia em estrela. Isto faz com que o tempo para uma nova melhor posição global se propague para o outro lado do anel seja igual à metade do tamanho do enxame.

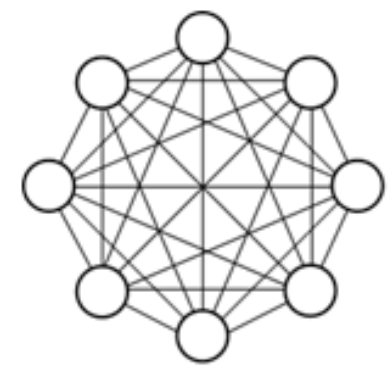

(a) Estrela (gbest)

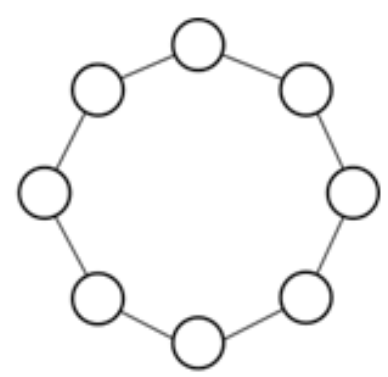

(b) Círculo (lbest)

Figura 4. Topologias de vizinhança.

\subsection{0 algoritmo simulated annealing}

Como forma de comparar o desempenho do algoritmo PSO o problema de planejamento florestal foi também resolvido com a meta-heurística simulated annealing (SA). A SA foi escolhida por ter demonstrado bons resultados em inúmeras pesquisas com este tipo de problema (Rodrigues et al., 2004a; Pereira, 2004; Pukkala \& Kurttila, 2005; Falcão \& Borges, 2003; Liu et al., 2006; Heinonen \& Pukkala, 2004). As ideias que formam a base para o algoritmo SA foram publicadas primeiramente por Metropolis et al. (1953). De acordo com Bettinger et al. (2002) o algoritmo emprega uma abordagem de Monte Carlo, fazendo uma busca local na qual um subconjunto de soluções é explorado pela movimentação de uma solução para uma solução vizinha. Para evitar permanecer "preso" em ótimos locais o algoritmo pode aceitar, ocasionalmente, soluções inferiores, permitindo, assim, o distanciamento de um máximo (ou mínimo) local. Na Figura 5 é apresentado o fluxograma de funcionamento do algoritmo SA

\subsubsection{Movimentos}

Os movimentos são os procedimentos de geração de soluções candidatas. O algoritmo SA gera e avalia apenas uma solução vizinha candidata a cada iteração. Neste trabalho a geração da solução vizinha foi implementada da seguinte forma: aleatoriamente escolhe-se um talhão e nele é modificada a alternativa de manejo anteriormente escolhida. Aquela alternativa de manejo do talhão escolhido que possuía valor igual a 1 passa a assumir valor zero e uma nova alternativa é escolhida para receber valor 1. Este procedimento garante que somente uma alternativa de manejo seja escolhida para cada talhão.

Quando a solução candidata é melhor que a solução atual ela é aceita. Caso contrário, ela é aceita somente se o valor da constante $Z$ for maior que um número aleatório $(r)$ distribuído uniformemente no intervalo entre 0 e 1, sendo $Z$ calculado com a Equação 11 .

$$
Z=e^{\left\{f\left(x^{\prime}\right)-f^{*}(x)\right\} / T}
$$

onde: $f\left(x^{\prime}\right)=$ valor da função objetivo da solução candidata; $f^{*}(x)=$ valor da função objetivo da melhor solução encontrada até a presente iteração e $T=$ temperatura.

\subsubsection{Temperatura}

De acordo com Rodrigues et al. (2004a), a temperatura (T) é um dos principais parâmetros da SA. Esta temperatura começa com um valor alto, permitindo que movimentos de pior qualidade (ou que piorem a função objetivo) tenham maiores chances de serem escolhidos, sendo a mesma gradativamente reduzida até a convergência do algoritmo, o que equivale a diminuir as chances de escolha de um movimento de baixa qualidade à medida que o algoritmo progride.

Dois parâmetros são utilizados para definir a temperatura $(T)$ em um dado instante: a temperatura inicial $\left(T_{0}\right)$ e a taxa de redução da temperatura $\left(T_{R}\right)$. A cada iteração a temperatura é calculada por meio da Equação 12. 


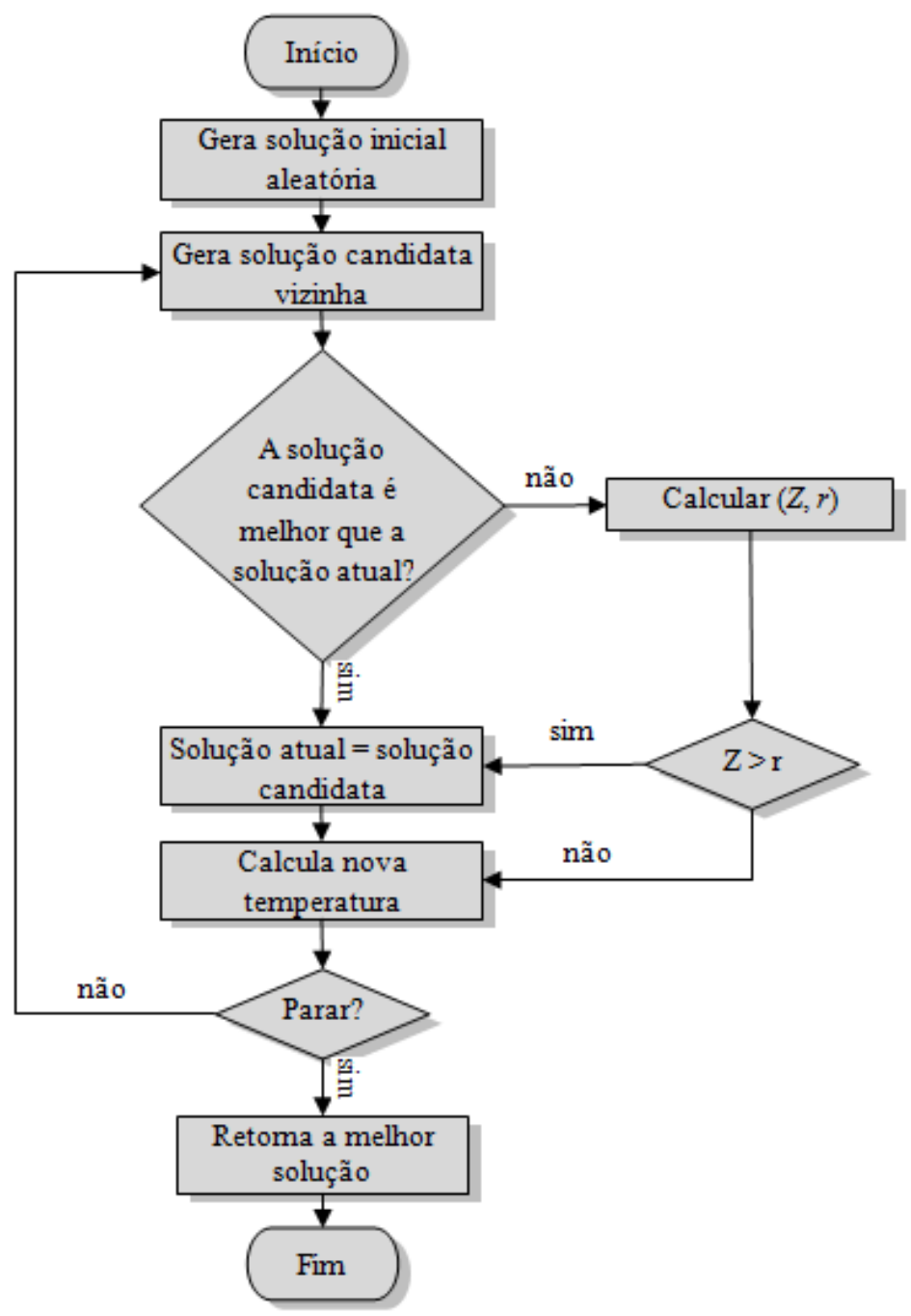

Figura 5. Fluxograma do algoritmo SA.

$$
T_{k}=T_{0} \cdot\left(1-\frac{T_{R}}{100}\right)^{k}
$$

onde: $T_{k}=$ temperatura na iteração $k ; T_{0}=$ temperatura inicial; $T_{R}=$ taxa de redução da temperatura, expressa em porcentagem; e $k=$ iteração atual.

\subsection{Parâmetros utilizados nas meta-heurísticas}

Os parâmetros utilizados nos algoritmos são apresentados na Tabela 1. Foram testadas duas abordagens combinadas a duas topologias de vizinhança para a PSO. No caso da topologia lbest cada partícula foi conectada a outras duas partículas.

Para o algoritmo SA foram testados diferentes valores dos parâmetros $T_{0}$ e $T_{R}$, sendo apresentadas nesta pesquisa as duas melhores configurações.

A cada iteração a PSO avalia a função objetivo tantas vezes quanto for o tamanho da população. Como forma de aplicar uma comparação mais justa entre as meta-heurísticas, configurou-se a quantidade de iterações da SA de forma a igualar as avaliações da função objetivo das duas meta-heurísticas, no caso, 150.000 iterações.

\subsection{Função de avaliação}

Com as meta-heurísticas testadas não é possível trabalhar diretamente com restrições. Uma estratégia para que estes algoritmos gerenciem restrições é utilizando funções de penalidade. Assim, a função-objetivo penalizada $f_{p}(x)$ é obtida com a modificação da função objetivo $f(x)$, na forma da Equação 13.

$$
f_{p}(x)=f(x)-v p \cdot V T
$$


Tabela 1. Parâmetros utilizados nas meta-heurísticas.

\begin{tabular}{lcccc}
\hline \multirow{2}{*}{ Parâmetro } & \multicolumn{4}{c}{ Meta-heurística } \\
\cline { 2 - 5 } & PSOw & PSOx & SA(1) & SA(2) \\
\hline População & 50 & 50 & & \\
Coeficiente cognitivo $\left(c_{1}\right)$ & 2 & 2,05 & & \\
Coeficiente social $\left(c_{2}\right)$ & 2 & 2,05 & & \\
Inércia inicial $\left(w_{\text {ini }}\right)$ & 0,9 & & & \\
Inércia final $\left(w_{\text {fin }}\right)$ & 0,4 & & & \\
$V_{\text {max }}$ & $10 \%$ & $100 \%$ & & \\
Iterações & 3.000 & 3.000 & 150.000 & 150.000 \\
Avaliações da FO & 150.000 & 150.000 & 150.000 & 150.000 \\
temperatura inicial $\left(T_{0}\right)$ & & & $1 \times 10^{7}$ & $1 \times 10^{7}$ \\
Taxa de redução de Temperatura $\left(T_{R}\right)$ & & & 0,125 & 0,25 \\
\hline
\end{tabular}

onde: $f_{p}(x)=$ valor da função-objetivo penalizada para a solução $x ; f(x)=$ valor da função-objetivo do problema; $v p=$ penalização $\left(R \$ / \mathrm{m}^{3}\right)$ para cada unidade de produção violada; $V T$ = violação total $\left(m^{3}\right)$ das restrições de produção (mínima e máxima).

\subsection{Avaliação do algoritmos}

Foram efetuadas 30 execuções independentes para cada meta-heurística testada. A partir desta amostra, o desempenho dos algoritmos foi comparado com base na média, desvio padrão, coeficiente de variação (CV(\%)), valor máximo e mínimo do VPE das soluções obtidas. Aplicou-se o teste não paramétrico de Kruskall-Wallis, seguido do teste de Dunn, um procedimento não paramétrico de comparações múltiplas semelhante ao teste de Tukey. Para os dois testes foi adotado o nível de significância de 5\%. Para o teste de Kruskal-Wallis foi utilizado o software R, enquanto o teste de Dunn foi executado conforme descrito em Callegari-Jacques (2003).

As meta-heurísticas também foram avaliadas em relação ao algoritmo exato branch-and-bound, implementado no software Extended LINGO versão 9.0. Foram utilizadas duas medidas: a Eficácia, que avalia a qualidade da solução da meta-heurística em relação ao ótimo global, e a Eficiência, que compara os tempos de processamento meta-heurísticas e do branch-and- bound, utilizando para ambos os mesmos recursos computacionais.

\section{Resultados}

A estrutura do problema teste gerou 68 restrições e 9.123 variáveis de decisão. O solver do LINGO foi interrompido após 619 horas e 48 minutos (aproximadamente 26 dias) de processamento. Com este tempo foi alcançada uma solução com VPE no valor de $\mathrm{R} \$ 511.387,60$, sendo realizadas mais de 725 milhões de iterações. Não há como saber o quão próxima do ótimo global esteja esta solução. No entanto, é de se esperar que após este tempo de processamento tenha sido alcançada uma boa solução e que esta se aproxime do ótimo global. A eficácia dos algoritmos (Tabela 2) foi comparada com esta solução.

Tabela 2. Eficácia das abordagens testadas.

\begin{tabular}{lcccc}
\hline \multirow{2}{*}{ Abordagem } & \multicolumn{3}{c}{ Eficácia(\%) } & Tempo médio de solução \\
\cline { 2 - 4 } & Máxima & Média & Mínima & (segundos) \\
\hline PSOw gbest & 96,20 & 94,09 & 91,69 & 223 \\
PSOw lbest & 95,85 & 94,56 & 92,97 & 225 \\
PSOx gbest & 96,24 & 94,53 & 92,28 & 224 \\
PSOx lbest & 95,29 & 93,94 & 92,68 & 228 \\
SA(1) & 93,57 & 92,39 & 90,54 & 183 \\
SA(2) & 93,42 & 92,42 & 90,72 & 183 \\
\hline
\end{tabular}

A abordagem PSOw lbest apresentou a melhor média e a maior eficácia mínima. Isto se deve às características da topologia lbest. Nessa topologia, cada partícula está conectada a apenas outras duas vizinhas o que faz com que a informação demore mais tempo para ser propagada por todo o enxame. Maior diversidade de soluções é mantida durante a execução do algoritmo, impedindo o agrupamento de partículas em uma mesma região e evitando os ótimos locais. 
O algoritmo SA apresentou resultados inferiores em relação às abordagens do algoritmo PSO testadas. No entanto, a implementação da SA nesta pesquisa pode ser considerada uma das mais simples e, neste sentido, pode ser melhorada para se obter melhores resultados. O algoritmo SA tem como maiores vantagens a facilidade de implementação e o fato de basear-se em procedimentos simples que podem resultar em menores tempos de processamento do algoritmo.

Um problema da abordagem SA empregada foi de ter apresentado, para as duas configurações de seus parâmetros, apenas oito soluções viáveis das 30 execuções dos algoritmos. Isto é um indicativo que esta metaheurística pode facilmente ficar presa em ótimos locais. No entanto, uma possível melhoria seria reiniciar aleatoriamente a solução atual após determinado número de iterações em que o algoritmo não consegue melhorar a função objetivo.

As estatísticas de comparação são apresentadas na Tabela 3. A abordagem que apresentou a melhor solução foi a PSOx gbest, muito embora tenha apresentado o maior CV(\%), indicando maior variação nas soluções encontradas. Isto significa que, apesar de encontrar boas soluções, esta abordagem também pode apresentar soluções ruins. Isto pode ser explicado pela fragilidade da topologia gbest em ficar presa em ótimos locais, ocasionando em muitas execuções soluções de baixa qualidade. No entanto, as melhores soluções foram encontradas com esta topologia. Por concentrar rapidamente uma maior quantidade de partículas em uma mesma região do espaço de busca, esta topologia permite um melhor refinamento na busca de melhores soluções em relação à lbest.

Tabela 3. Média, desvio padrão, coeficiente de variação, e valores máximos e mínimos do VPE das abordagens/topologias avaliadas.

\begin{tabular}{lccccc}
\hline Abordagem & Média $\mathbf{( R \$ )}$ & Desv. pad. $\mathbf{( R \$ )}$ & $\mathbf{C V}(\boldsymbol{\%})$ & Máximo $\mathbf{( R \$ )}$ & Mínimo $(\mathbf{R} \$)$ \\
\hline PSOw gbest & $481.142,91$ & $6.008,29$ & 1,2488 & $491.944,94$ & $468.899,38$ \\
PSOw lbest & $483.578,43$ & $3.539,56$ & 0,7320 & $490.157,38$ & $475.420,19$ \\
PSOx gbest & $483.406,29$ & $6.113,17$ & 1,2646 & $492.148,84$ & $471.917,97$ \\
PSOx lbest & $480.380,68$ & $2.992,55$ & 0,6230 & $487.285,22$ & $473.931,53$ \\
SA(1) & $472.482,96$ & $4.939,06$ & 1,0453 & $478.507,25$ & $463.002,94$ \\
SA(2) & $472.602,29$ & $4.738,31$ & 1,0026 & $477.741,13$ & $463.906,84$ \\
\hline
\end{tabular}

De acordo com a prova não paramétrica de Kruskal-Wallis, ao nível de $5 \%$ de significância (p-valor < 0,05), ao menos uma das abordagens é diferente das demais. Como forma de diferenciar as meta-heurísticas testadas, aplicou-se o teste de Dunn, cujos resultados são apresentados na Tabela 4.

Tabela 4. Resultados do teste de Dunn.

\begin{tabular}{lcclc}
\hline Algoritmos & Soma de postos & Postos Médios & Comparação dos grupos \\
\hline PSOw lbest & 2136 & 71,2000 & $\mathrm{a}^{*}$ & \\
PSOx gbest & 2099 & 69,9667 & $\mathrm{a}$ & \\
PSOw gbest & 1634 & 54,4667 & $\mathrm{a}$ & $\mathrm{b}$ \\
PSOx lbest & 1391 & 46,3667 & $\mathrm{a}$ & $\mathrm{b}$ \\
SA(1) & 138 & 17,2500 & & $\mathrm{~b}$ \\
SA(2) & 136 & 17,0000 & & \\
\hline
\end{tabular}

* Abordagens seguidas de mesma letra não diferem estatisticamente pelo teste de Dunn ao nível de significância de 5\%

De acordo com os resultados apresentados na Tabela 4 todas as abordagens do algoritmo PSO avaliadas não diferem estatisticamente entre si, considerando os níveis de probabilidade empregados. A PSOx lbest apresentou as piores soluções dos algoritmos PSO. Desta forma, seu desempenho foi também considerado estatisticamente igual ao algoritmo SA.

Percebe-se do ponto de vista de usuário dos algoritmos que, apesar de estatisticamente iguais, estes apresentam diferenças que resultam em melhores ou piores resultados. Neste sentido, são apresentadas nas Figuras 6 e 7 as distribuições das soluções encontradas com cada uma das meta-heurísticas utilizando gráficos de pontos e Box Plot. Neste último, pode-se observar, além da mediana, a posição das soluções em relação aos percentis 25 e $75 \%$ e a amplitude das soluções com os valores máximos e mínimos de VPE.

Quanto mais concentradas são as soluções, ou seja, quanto menor a amplitude de soluções da metaheurística, mais ela pode ser considerada confiável. Isto quer dizer que menos execuções são necessárias para conseguir boas soluções. É óbvio que, aumentando o número de execuções, a probabilidade de encontrar melhores soluções também aumenta, até certo limite. No entanto, há sempre o problema de tempo de processamento. Problemas reais de planejamento florestal usualmente contêm centenas ou milhares de 


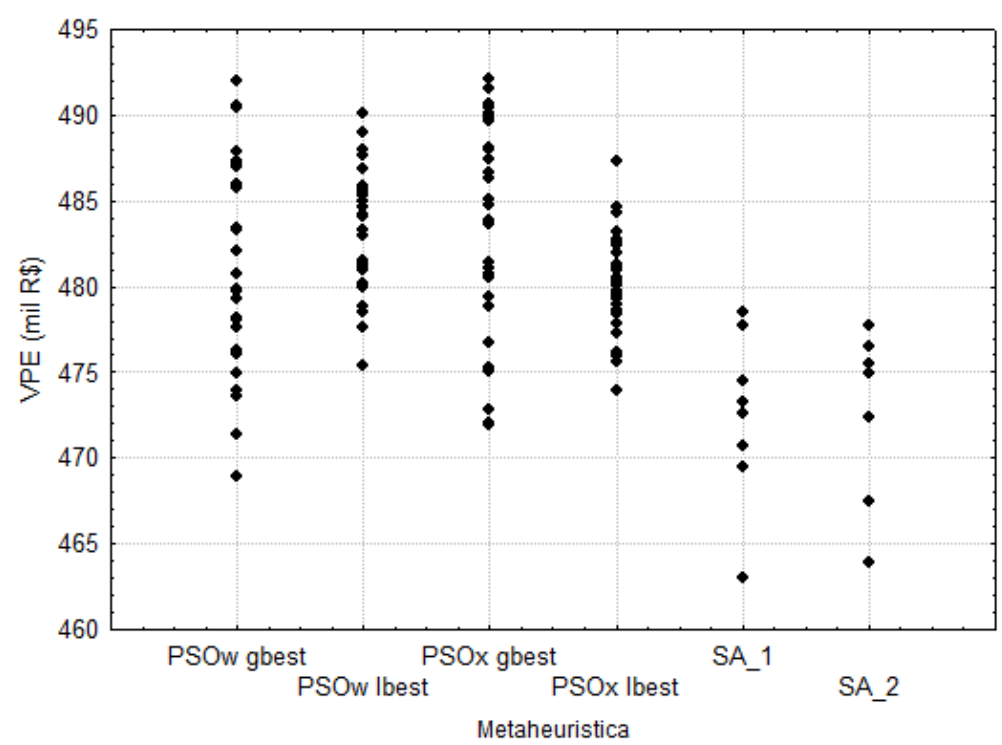

Figura 6. Gráfico de pontos das soluções obtidas com as meta-heurísticas testadas.

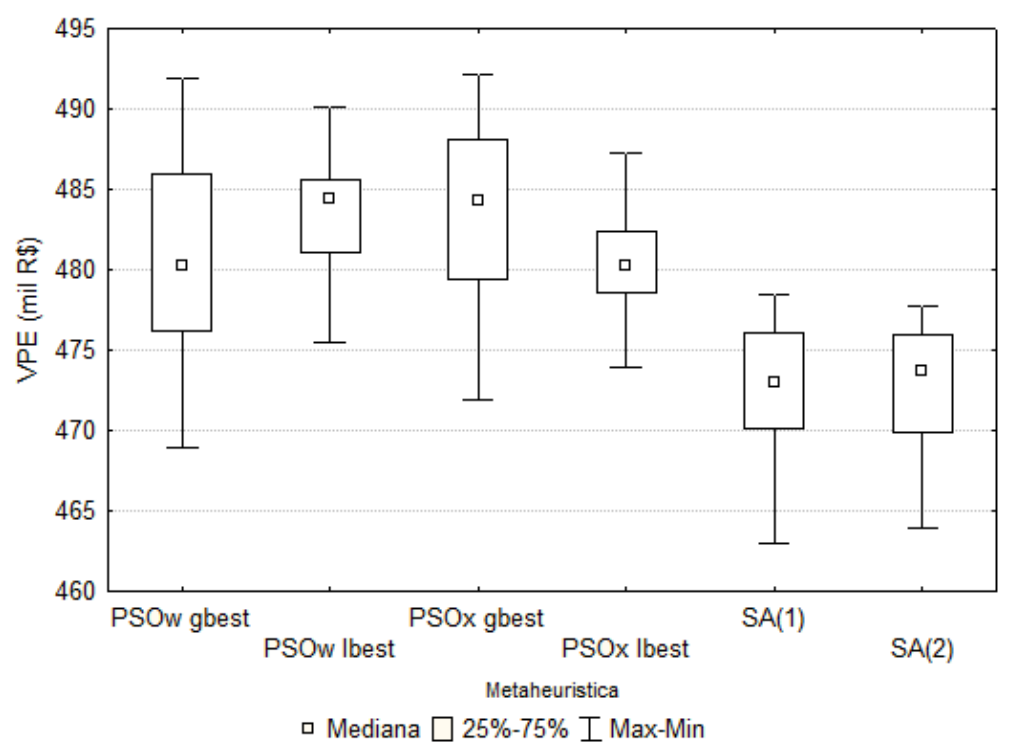

Figura 7. Box Plot das soluções obtidas com as meta-heurísticas testadas.

variáveis que podem requerer longo tempo de processamento. Neste sentido, o usuário ao escolher a metaheurística e aplicar ao seu problema, deve levar em consideração estas ponderações.

Pode-se observar nas Figuras 6 e 7 que para a meta-heurística PSO a topologia lbest pode ser considerada mais confiável em relação à gbest, apesar desta última ter apresentado os melhores resultados. A metaheurística SA, apesar dos resultados inferiores, pode ser considerada viável para a solução de problemas de planejamento florestal pelos resultados apresentados de eficácia e eficiência.

\section{Conclusões}

- A meta-heurística PSO pode ser empregada na solução de problemas de planejamento florestal com variáveis inteiras;

- A meta-heurística SA apresentou resultados inferiores à PSO, no entanto a mesma pode também ser aplicada a problemas de planejamento florestal. Sugere-se que modificações sejam feitas ao algoritmo implementado nesta pesquisa para melhores resultados;

- A PSOx gbest é uma abordagem indicada para o problema de planejamento florestal com variáveis inteiras, por ter apresentado o melhor valor para a função objetivo, assim como a abordagem PSOw lbest, por ter apresentado o melhor valor de média e valor mínimo;

- A topologia de vizinhança gbest possui maior capacidade de obter melhores soluções, enquanto a topologia lbest consegue evitar os ótimos locais e com isso, apresenta maior homogeneidade nas soluções. 


\section{Referências}

Bettinger, P.; Boston, K.; Kim, Y. \& Zhu, J., Landscape-level optimization using tabu search and stand density-related forest management prescriptions. European Journal of Operations Research, 176(2):1265-1282, 2007.

Bettinger, P.; Graetz, D.; Boston, K.; Sessions, J. \& Chung, W., Eight heuristic planning techniques applied to three increasingly difficult wildlife planning problems. Silva Fennica, 36(2):561-584, 2002.

Callegari-Jacques, S.M., Bioestatística: princípios e aplicações. Porto Alegre, RS: Artmed, 2003.

Castro, E.G. \& Tsuzuki, M.S.G., Simulation optimization using swarm intelligence as tool for cooperation strategy design in 3d predator prey game. In: Chan, F.T.S. \& Tiwari, M.K. (Eds.), Swarm intelligence, focus on ant and particle swarm optimization. Viena, Austria: I-Tech Education and Publishing, p. 165-187, 2007.

Clerc, M. \& Kennedy, J., The particle swarm: Explosion, stability, and convergence in a multi-dimensional complex space. IEEE Transactions on Evolutionary Computation, 6(1):58-73, 2002.

Ducheyne, E.I.; Wulf, R.R. \& DeBaets, B., Single versus multiple objective genetic algorithms for solving the even-flow forest management problem. Forest Ecology and Management, 201(2-3):259-273, 2004.

Eberhart, R.C. \& Shi, Y., Comparing inertia weights and constriction factors in particle swarm optimization. In: Proceedings of the 2000 Congress on Evolutionary Computation. Piscataway, USA: IEEE Press, p. 84-88, 2000.

Falcão, A.O. \& Borges, J.G., Heuristics for integrating strategic and operational levels in large scale forest management problems. Scientia Forestalis, 63:94-102, 2003.

Gomide, L.R.; Arce, J.L. \& Silva, A.C.L., Uso do algoritmo genético no planejamento florestal considerando seus operadores de seleção. Cerne, 15(4):460-467, 2009.

Guo, H.; Yu, H. \& Xu, A., A hybrid PSO-GD based intelligent method for machine diagnosis. Digital Signal Processing, 16(4):402-418, 2006.

Heinonen, T. \& Pukkala, T., A comparison of one- and two-compartment neighbourhoods in heuristic search with spatial forest management goals. Silva Fennica, 38(3):319-332, 2004.

Johnson, K.N. \& Scheurman, H.L., Techniques for prescribing optimal timber harvest and investment under different objectives discussion and synthesis. Forest Science, 18(1):1-31, 1977.

Kennedy, J. \& Eberhart, R.C., Particle swarm optimization. In: IEEE International Conference on Neural Networks. Piscataway, USA: IEEE Press, p. 1942-1948, 1995.

Liu, G.; Han, S.; Zhao, X.; Nelson, J.D.; W., H. \& Wang, W., Optimisation algorithms for spatially constrained forest planning. Ecological Modelling, 194(4):421-428, 2006.

Mendes, R., Population topologies and their influence in particle swarm performance. Tese de Doutorado, Departamento de Informática, Universidade do Minho, Braga, Portugal, 2004.

Metropolis, N.; Rosenbluth, A.; Rosenbluth, M.; Teller, A. \& Teller, E., Equation of state calculations by fast computing machines. Journal of Chemical Physics, 21(6):1087-1101, 1953.

Muller, V., Otimização de layouts industriais através do método enxame de partículas. Dissertação de Mestrado em Sistemas e Processos Industriais, Universidade de Santa Cruz do Sul, Santa Cruz do Sul, RS, 2007.

Pereira, G.W., Aplicação da técnica de recozimento simulado em problemas de planejamento florestal multiobjetivo. Dissertação de Mestrado, Departamento de Ciência da Computação, Universidade Federal de Minas Gerais, Belo Horizonte, MG, 2004.

Poli, R.; Kennedy, J. \& Blackwell, T., Particle swarm optimization. Swarm Intelligence, 1(1):33-57, 2007.

Pukkala, T. \& Kurttila, M., Examining the performance of six heuristic optimisation techniques in different forest planning problems. Silva Fennica, 39(1):67-80, 2005.

Rodrigues, F.L.; Leite, H.G.; Santos, H.N. \& Souza, A.L., Soluções de problemas de planejamento florestal com restrições de inteireza utilizando busca tabu. Revista Árvore, 27(5):701-713, 2003.

Rodrigues, F.L.; Leite, H.G.; Santos, H.N.; Souza, A.L. \& Ribeiro, A.A.S.R., Metaheurística simulated annealing para soluções de problemas de planejamento florestal com restrições de integridade. Revista Árvore, 28(2):247-256, $2004 \mathrm{a}$.

Rodrigues, F.L.; Leite, H.G.; Santos, H.N.; Souza, A.L. \& Silva, G.F., Metaheurística algoritmo genético para soluções de problemas de planejamento florestal com restrições de integridade. Revista Árvore, 28(2):233-245, 2004b.

Shi, Y. \& Eberhart, C., A modified particle swarm optimizer. In: Proceedings of the IEEE International Conference on Evolutionary Computation. Piscataway, USA: IEEE Press, p. 69-73, 1998.

Sierakowski, C.A., Inteligência coletiva aplicada a problemas de robótica móvel. Dissertação de Mestrado em Engenharia de Produção e Sistemas, Pontifícia Universidade Católica do Paraná, Curitiba, PR, 2006.

Silva, G.F.; Piassi, L.C.; Mora, R.; Martins, L.T.; Teixeira, A.F. \& Junior, A.A.B., Metaheurística algoritmo genético na solução de modelos de planejamento florestal. Revista Brasileira de Ciências Agrárias, 4(2):160-166, 2009.

Silva, M.L.; Jacovine, L.A.G. \& Valverde, S.R., Economia florestal. $2^{a}$ edição. Viçosa, MG: UFV, 2005. 


\section{Notas Biográficas}

Flávio Augusto Ferreira do Nascimento é graduado em Engenharia Florestal e mestre em Ciências Florestais (Universidade Estadual do Centro-Oeste - UNICENTRO, 2005 e 2010, respectivamente). Atualmente é doutorando em Engenharia Florestal (Universidade Federal do Paraná - UFPR). Ele tem interesse na área de meta-heurística e otimização combinatória, principalmente com aplicações em problema de gestão e planejamento florestal.

Julio Eduardo Arce é graduado em Ingeniería Florestal (Universidad Nacional de La Plata, 1993), mestre e doutor em Engenharia Florestal (UFPR, 1997 e 2000, respectivamente). Atualmente é Professor Associado da Universidade Federal do Paraná no curso de Engenharia Florestal nas áreas de manejo florestal, planejamento florestal e pesquisa operacional.

Andrea Nogueira Dias é graduada em Engenharia Florestal (Universidade Federal de Viçosa - UFV, 1997), mestre e doutor em Ciências Florestais (UFV, 2000 e 2005, respectivamente). Atualmente é Professor Adjunto da Universidade Estadual do Centro-Oeste (UNICENTRO).

Afonso Figueiredo Filho é graduado, mestre e doutor em Engenharia Florestal (Universidade Federal do Paraná, 1976, 1983 e 1991, respectivamente). Atualmente é Professor Associado da UNICENTRO e Professor Senior na UFPR. Trabalha na área de manejo florestal.

Gabriel de Magalhães Miranda é graduado em Engenharia Florestal (Universidade Federal de Viçosa - UFV, 1997), mestre e doutor em CiênciasFlorestais (UFV, 2000 e 2003, respectivamente). Atualmente é Professor Adjunto da UNICENTRO.

Celso Carnieri é graduado em Matemática e em Engenharia Agronômica (Universidade Federal do Paraná, 1970 e 1971, respectivamente), mestre em Matemática (Instituto Nacional de Matemática Pura e Aplicada, 1973) e doutor em Engenharia Elétrica, na área de Otimização (Universidade Estadual de Campinas, 1989). Atualmente é professor Senior do Programa de Pós-Graduação em Métodos Numéricos em Engenharia da UFPR. Atua nas áreas de planejamento florestal otimizado, programação linear, modelos de transporte, programação dinâmica e programação inteira. 


\title{
Busca Tabu: Implementação de Estratégias de Memórias de Curto e Longo Prazo
}

\author{
Vinícius Amaral Armentano, Débora Pretti Ronconi, \\ Cintia Rigão Scrich e André Luís Shiguemoto
}

\begin{abstract}
Resumo: Este capítulo apresenta estratégias de memórias de curto e longo prazo em busca tabu, que compreendem técnicas de lista de candidatos, enfoques de intensificação, diversificação e trajetórias de soluções factíveis e infactíveis. As estratégias são ilustradas por implementações computacionais em trabalhos associados com três teses de doutorado nos temas de programação de tarefas nos ambientes flowshop e jobshop, e de planejamento integrado de produção e distribuição. O objetivo é mostrar o ganho advindo do uso dessas estratégias, mesmo que implementadas de forma simples.

Palavras-chave: Estratégias em busca tabu, Memória de curto prazo, Memória de longo prazo.

Abstract: This chapter presents strategies associated with short and long term memories in tabu search, which include candidate list techniques, and approaches of intensification, diversification and trajectories of feasible and infeasible solutions. The strategies are illustrated by computational implementations associated with three doctoral theses on problems of job scheduling in the flowshop and jobshop environments, and an integrated production and distribution problem. The objective is to show the gain provided by such strategies even with a simple implementation.
\end{abstract}

Keywords: Strategies in tabu search, Short term memory, Long term memory.

\section{Introdução}

Busca tabu é uma meta-heurística proposta por Glover (1986) e descrita em detalhes em Glover \& Laguna (1997). Este método guia uma heurística de busca local pela utilização de características da solução corrente e da história da busca para explorar o espaço de soluções além da otimalidade local. A busca local é uma heurística de busca que usa uma operação chamada movimento para definir uma vizinhança.

O uso sistemático de memória adaptativa constitui a propriedade que distingue busca tabu de outras metaheurísticas. A palavra "adaptativa" significa que a memória atualiza o armazenamento de elementos de soluções ou de soluções completas encontradas durante a exploração do espaço de soluções. A metodologia de busca tabu contém diversas estratégias associadas com memória adaptativa, o que permite muitas implementações distintas.

Estruturas de memória de curto prazo e de longo prazo são usadas para armazenar uma história seletiva da busca. Na memória de curto prazo, atributos de soluções visitadas recentemente são armazenados em uma lista tabu e uma regra de ativação tabu é definida para bloquear a busca em uma parte do espaço de soluções. Isto impede a ciclagem de soluções e força a exploração de soluções em outras regiões. Critérios de aspiração são utilizados em busca tabu para remover a regra de ativação tabu, e o critério largamente usado na literatura é permitir que um movimento proibido seja executado se este leva à atualização da melhor solução encontrada até o momento (solução incumbente).

Um aspecto importante na busca tabu de curto prazo, infelizmente pouco explorado na literatura, é a consideração de estratégias de lista de candidatos que podem ser genéricas ou específicas para cada problema. Essas estratégias restringem a avaliação de elementos da vizinhança àqueles mais promissores. Este caráter promitente pode levar à obtenção de uma solução de melhor qualidade para um dado tempo de execução computacional ou um dado número de soluções avaliadas, estabelecido como função da dimensão da instância

*Autor para contato: vinicius@densis.fee.unicamp.br 
do problema. Um exemplo muito simples de estratégia é selecionar o primeiro elemento da vizinhança que produz uma solução com valor melhor que a solução corrente.

A memória de longo prazo contém uma história seletiva de soluções completas e de atributos de soluções encontradas durante o processo de busca. Os elementos desta memória são usados para implementar estratégias de diversificação e intensificação da busca.

Estratégias de diversificação e intensificação são componentes importantes de busca tabu. Estratégias de intensificação envolvem combinação de características de soluções de alta qualidade (soluções elite) encontradas durante a busca, bem como retorno a estas soluções para um exame mais detalhado na vizinhança destas. Estratégias de diversificação incentivam o processo de busca a visitar regiões ainda não visitadas. Uma forma de diversificação/intensificação envolve armazenar a frequência de atributos de soluções. Atributos com alta frequência que pertencem a soluções elite podem ser incentivados durante a busca, enquanto atributos presentes com alta frequência em todas as soluções visitadas podem ser penalizados para promover diversificação. Outra estratégia importante envolve a consideração de trajetórias de soluções factíveis e infactíveis, que permite atingir soluções de acesso muito difícil ao se restringir a busca em soluções factíveis.

Um dos objetivos deste trabalho é expor, de forma integrada, a implementação de estratégias de memória de curto e longo prazo em busca tabu por meio de três trabalhos associados com três teses de doutorado. Outro objetivo é ressaltar o ganho em qualidade das soluções obtido pelo uso dessas estratégias.

Glover (1997) aponta que diversas estratégias mais avançadas têm sido negligenciadas em aplicações de busca tabu e destaca que é melhor ter a inclusão destas, mesmo de forma simples, do que não incluí-las. Infelizmente, esta constatação ainda persiste na literatura.

Dois trabalhos estão associados com problemas de programação de tarefas (job scheduling) nos ambientes de flowshop (Ronconi, 1997; Armentano \& Ronconi, 1999) e jobshop (Scrich, 1997; Armentano \& Scrich, 2000). O terceiro trabalho aborda um problema de uma cadeia de suprimento que integra decisões de produção e distribuição (Shiguemoto, 2008; Armentano et al., 2011).

\section{Minimização da Soma de Atrasos em um Flowshop}

Este problema consiste de $n$ tarefas a serem processadas em $m$ máquinas ordenadas, isto é, a $j$-ésima operação de todas as tarefas deve ser executada na $j$-ésima máquina. A sequência de processamento das tarefas é a mesma em todas as máquinas, e os programas correspondentes são denominados programas de permutação. O objetivo é encontrar um programa das tarefas que minimiza a soma total dos atrasos. Cada tarefa $i$ tem um tempo de processamento $p_{i j}$ na máquina $j$, e uma data de entrega $d_{i}$.

\subsection{Memória de curto prazo}

Solução Inicial: é obtida pela regra de prioridade ou despacho chamada modified due date (MDD) proposta por Baker \& Kanet (1983). Para cada tarefa $i$, a regra avalia a medida $\max \left(d_{i}, C_{i}(\sigma)\right)$, em que $\sigma$ é a sequência de tarefas já definida no instante $t=\sum_{i \in \sigma} p_{i 1}, C_{i}(\sigma)$ é o instante de término do processamento da tarefa $i, i \notin \sigma$, se esta tarefa é processada logo após a sequência $\sigma$. A tarefa com menor medida é selecionada para processamento no instante $t$.

Atributo da solução: nenhum atributo específico da solução é usado. No entanto, um atributo absoluto é aquele que a tarefa $i$ ocupa a posição $\pi(i)$ na sequência ou um atributo relativo em que a tarefa $i$ é imediatamente precedida pela tarefa $p$ e/ou imediatamente sucedida pela tarefa $q$.

Movimento: a tarefa $i$ é inserida em todas as posições da sequência.

Regra de ativação tabu: a tarefa $i$ não pode ser escolhida para inserção até que sua duração tabu termine.

Duração tabu : a cada 20 iterações, uma duração tabu é escolhida com distribuição uniforme no intervalo $[n / 2, n-1]$ e é ajustada da seguinte forma. Se o valor da nova solução é maior que o valor da solução corrente, a duração escolhida é aumentada de uma unidade, caso contrário, é reduzida de uma unidade. O limite inferior do intervalo acima foi determinado experimentalmente, enquanto o limite superior é explicado pelo fato que quando uma tarefa é escolhida para inserção, então existem tarefas a serem analisadas para o próximo movimento de inserção.

Lista de candidatos: para várias instâncias do problema, observou-se que as primeiras inserções executadas eram distantes da posição corrente da tarefa. Por exemplo, uma inserção distante da posição corrente da tarefa para um problema de 10 tarefas seria mover a primeira tarefa da sequência (posição corrente=1) para a posição entre a última e a penúltima tarefa da sequência (posição 9), resultando numa distância de 8 posições $(\mid$ nova posição - posição corrente $|=| 9-1 \mid=8$ ). Por outro lado, também foi observado que as inserções executadas próximas de ótimos locais eram de baixas distâncias, ou seja, próximas da 
posição corrente da tarefa a ser movida. Por este motivo, foi introduzida uma lista de candidatos cíclica de modo a permitir inserções com maior distância no início do ciclo e reduzir esta distância ao longo do ciclo. Ao se atingir $n$ iterações a distância é zero e o ciclo é reiniciado. Em cada iteração, a distância máxima de inserção em um ciclo é dada pela expressão: distância máxima $=$ - número de iterações $+n$. Esta estratégia é baseada em informação coletada durante a busca tabu para um conjunto de instâncias representativo.

\subsection{Memória de longo prazo}

A estratégia de diversificação envolve a penalização de atributos que ocorrem em soluções obtidas durante a busca, e é baseada em penalidade $i l$ que expressa a frequência de residência de cada tarefa $i$, isto é, o número de vezes que esta ocupa uma posição $l$ na sequência, dividida pelo número máximo sobre todas as tarefas. Desta forma o valor de um movimento candidato é expresso por

$$
\text { valor do movimento' = valor do movimento }+ \text { d.penalidade } e_{i l}
$$

em que $d$ é um parâmetro de diversificação, que foi determinado experimentalmente como $5 \%$ do valor da solução inicial de cada instância.

A diversificação é ativada quando após $k$ iterações sem atualização no valor da solução incumbente, a busca está em um ótimo local semelhante ao último ótimo local. Esta semelhança é baseada em uma similaridade (SM) entre duas soluções, definida da seguinte forma. Se uma tarefa ocupa a mesma posição nas duas soluções, SM é aumentada de dois; se a tarefa de uma solução ocupa a posição imediatamente predecessora ou sucessora, SM é aumentada de um. Soluções com SM maior que 1,5n são consideradas semelhantes. Para instâncias com datas de entrega folgadas, o parâmetro $k=n$ e para datas de entrega apertadas $k=n / 2$.

A estratégia de intensificação envolve o armazenamento das cinco melhores soluções elite encontradas durante a busca e da memória tabu associada com estas soluções e o melhor movimento executado a partir destas soluções. No final da busca tabu, a intensificação é ativada por meio do reinício a partir de cada solução elite, escolhendo o segundo melhor movimento a partir destas. Se a melhor solução é atualizada por esta estratégia, então a busca é reiniciada a partir desta solução.

\subsection{Resultados}

Foram geradas 40 instâncias de cada dimensão mostrada na Tabela 1, totalizando 240 instâncias. Esta tabela também mostra o tempo de parada de execução para cada dimensão. O total de 240 instâncias é dividido em 4 cenários de acordo com o fator baixo ou alto e faixa alta ou baixa das datas de entrega geradas, veja Armentano \& Ronconi (1999). Os códigos das heurísticas foram escritos na linguagem C e os testes foram executados em um estação SUN SPARC com processador de 50 MHz e 48 MB RAM. A Tabela 1 mostra o tempo computacional usado para cada tamanho de instância.

Tabela 1. Tempo usado para cada tamanho.

\begin{tabular}{cc}
\hline $\begin{array}{c}\text { Tamanho } \\
(n \times m)\end{array}$ & $\begin{array}{c}\text { Tempo } \\
(\mathbf{s})\end{array}$ \\
\hline $20 \times 5$ & 25 \\
$20 \times 10$ & 50 \\
$20 \times 20$ & 90 \\
$50 \times 5$ & 200 \\
$50 \times 10$ & 500 \\
$50 \times 20$ & 1000 \\
\hline
\end{tabular}

\subsubsection{Busca tabu básica}

A busca tabu básica (BTB) consiste da busca somente com memória de curto prazo, sem estratégias de lista de candidatos, intensificação e diversificação. O desempenho de BTB é comparado com o resultado de uma heurística de enumeração parcial (NEH) proposta por Nawaz et al. (1983) para flowshop com critério de makespan. Esta heurística requer um ordenamento de tarefas que é dependente do critério a ser minimizado. Para o critério de minimização da soma dos atrasos, foi sugerida uma regra baseada no limitante inferior (LI) do atraso de cada tarefa dado por $d_{i}-\sum_{j} p_{i j}$ e as tarefas foram arranjadas em ordem não decrescente de LI.

A qualidade das soluções encontradas por BTB é avaliada pela melhoria percentual entre o atraso total da solução encontrada $T_{\mathrm{BTB}}$ e o atraso total da solução obtida pela heurística de enumeração parcial $T_{\mathrm{NEH}}$. Esta melhoria é calculada da seguinte forma: 


$$
\text { Melhoria }=\frac{T_{\mathrm{NEH}}-T_{\mathrm{BTB}}}{T_{\mathrm{NEH}}} \times 100 .
$$

A Tabela 2 mostra que nos cenários 1 e 2 com baixo fator de atraso, BTB obtém um grau maior de melhoria, quando comparado com a heurística NEH, 59,1\% e 29,3\%, respectivamente, e um grau menor de melhoria nos cenários 3 e 4 com alto fator de atraso, $17,2 \%$ e 14,3\%, respectivamente.

Tabela 2. Melhoria da busca tabu básica.

\begin{tabular}{ccccc}
\hline Tamanho & \multicolumn{4}{c}{ Cenário } \\
\hline$n \times m$ & $\mathbf{1}$ & $\mathbf{2}$ & $\mathbf{3}$ & $\mathbf{4}$ \\
\hline $20 \times 5$ & 78,68 & 10,65 & 21,75 & 17,44 \\
$20 \times 10$ & 34,22 & 12,54 & 10,12 & 9,65 \\
$20 \times 20$ & 10,90 & 8,32 & 5,50 & 5,44 \\
$50 \times 5$ & 98,19 & 89,52 & 30,45 & 22,44 \\
$50 \times 10$ & 87,02 & 37,09 & 25,32 & 18,29 \\
$50 \times 20$ & 45,59 & 17,52 & 10,30 & 12,76 \\
\hline Média & 59,10 & 29,27 & 17,24 & 14,34 \\
\hline
\end{tabular}

\subsubsection{Busca tabu com estratégias}

A Tabela 3 mostra a melhoria média e máxima de estratégias de lista de candidatos, diversificação, diversificação com intensificação, em relação à busca tabu básica, bem como a melhoria média e máxima da busca tabu básica em relação às versões com estratégias. O número de sucessos representa o número de vezes que uma versão de busca tabu obteve o melhor resultado. A última coluna mostra o número de instâncias em que as versões de busca tabu obtiveram o mesmo valor de solução. A estratégia de intensificação só é aplicada em dois cenários, quando resta 10\% e $25 \%$ do tempo, respectivamente, e não melhora o desempenho da busca tabu (com ou sem diversificação) nos dois cenários restantes.

A lista de candidatos tem uma pequena vantagem em termos de sucessos com semelhante melhoria média em relação à busca tabu básica, mas o que chama a atenção é a grande diferença de qualidade de algumas instâncias observada nas colunas Max\%. O grande número de empates parece indicar que a inclusão de estratégias de diversificação e intensificação é pouco relevante. Embora a melhoria média em relação à busca tabu básica seja relativamente pequena, a melhoria máxima atinge 30,41\%. A combinação de diversificação e intensificação resulta em um número maior de sucessos e uma melhoria média inferior, quando comparada com a estratégia de diversificação.

Tabela 3. Comparação da busca tabu básica e estratégias.

\begin{tabular}{cccccccc}
\hline Estratégia & $\begin{array}{c}\text { Núm. } \\
\text { suces. }\end{array}$ & $\begin{array}{c}\text { Melhoria \% } \\
\text { estratégia }\end{array}$ & Max \% & $\begin{array}{c}\text { Núm. } \\
\text { suces. }\end{array}$ & $\begin{array}{c}\text { Melhoria \% } \\
\text { busca tabu }\end{array}$ & Max \% & Iguais \\
\hline Lista Candid. & 80 & 4,21 & 89,29 & 70 & 4,36 & 64,29 & 90 \\
Diver. & 48 & 3,16 & 30,41 & 27 & 1,94 & 11,16 & 165 \\
Diver. + inten. & 63 & 2,76 & 30,41 & 26 & 1,64 & 11,16 & 151 \\
\hline
\end{tabular}

A Tabela 4 apresenta o tempo computacional requerido pelo algoritmo branch-and-bound proposto por Kim (1995) e implementado no trabalho. Este algoritmo, com tolerância de 0,5\% entre o valor da solução ótima e o valor do limitante inferior, foi aplicado a um grupo de instâncias pequenas, tal que para cada matriz de tempo de processamento, 4 cenários são gerados, totalizando 216 instâncias. O número de tarefas tem maior influência no tempo computacional, pois aumenta diretamente o número de nós na árvore branch-and-bound.

Os valores de tempo médio por cenário indicam que instâncias dos cenários 1 e 2 . com baixo fator de atraso, são mais fáceis para o branch-and-bound. A versão básica do tabu encontrou valores ótimos em 210 instâncias, a variante com somente lista de candidatos encontrou 208 valores ótimos em tempo $40 \%$ menor que aquele da Tabela 1 enquanto a versão somente com diversificação e intensifição encontrou 212 valores ótimos. A adaptação da heurística NEH encontrou 19 soluções ótimos. No pior caso, as soluções encontradas pela busca tabu básica, com lista de candidatos, e com intensificação e diversificação apresentam desvios relativos de $3,9 \%, 13,5 \%$ e 3,9\% do valor ótimo, e a solução produzida pela heurística NEH tem 440,9\% acima do valor ótimo. 
Tabela 4. Tempo para algoritmo branch-and-bound.

\begin{tabular}{|c|c|c|c|c|c|c|}
\hline $\begin{array}{c}\text { Tamanho } \\
(n \times m)\end{array}$ & $\begin{array}{c}\text { Número de } \\
\text { matrizes }\end{array}$ & Cenário 1 & Cenário 2 & Cenário 3 & Cenário 4 & $\begin{array}{c}\text { Média } \\
\text { por tamanho }\end{array}$ \\
\hline $10 \times 5$ & 10 & 0,66 & 3,92 & 6,82 & 6,06 & 4,37 \\
\hline $10 \times 7$ & 10 & 7,19 & 11,95 & 30,53 & 32,54 & 20,55 \\
\hline $10 \times 10$ & 10 & 24,93 & 38,39 & 87,26 & 92,87 & 60,86 \\
\hline $12 \times 5$ & 5 & 10,21 & 28,19 & 89,27 & 314,90 & 110,64 \\
\hline $12 \times 7$ & 5 & 44,37 & 275,33 & 321,04 & 596,73 & 309,36 \\
\hline $12 \times 10$ & 5 & 182,51 & 941,75 & 1425,00 & 6722,10 & 2317,84 \\
\hline $14 \times 5$ & 3 & 5,31 & 1710,66 & 592,01 & 8170,54 & 2619,63 \\
\hline $14 \times 7$ & 3 & 326,02 & 5945,04 & 2178,58 & 32291,70 & 10185,33 \\
\hline $14 \times 10$ & 3 & 5235,52 & 77632,27 & 176212,58 & 412183,22 & 167815,89 \\
\hline \multicolumn{2}{|c|}{ Média por cenário } & 648,53 & 9620,83 & 20104,79 & 51156,74 & \\
\hline
\end{tabular}

\subsection{Considerações}

As colunas de Max \% da Tabela 3 mostram que a estratégia de lista de candidatos tem um desempenho radical. Ao focar nos movimentos promissores, a busca pode levar a soluções muito melhores que a busca tabu sem lista de candidatos, como também a soluções bem piores. A explicação é que, ao não visitar soluções não promissoras, pode-se perder a oportunidade de atingir boas soluções a partir das não promissoras (é necessário subir colinas para descobrir bons vales). Por este motivo, a memória de curto prazo da busca tabu com lista de candidatos tem um mau desempenho quando integrada com estratégias de diversificação e intensificação são adicionadas, um aspecto que poderia ter sido relatado na tese de Ronconi (1997) quantitativamente para que se aprenda com erros e acertos.

Outro aspecto restritivo é limitar a intensificação somente para o final da busca tabu, um tipo de pósotimização. Sun (2012) propõe uma busca tabu para o problema de localização de instalações (facilities) ${ }^{1}$ com restrições de capacidade. A busca tabu é composta de ciclos de busca que, exceto pelo primeiro ciclo, é composto de fases de diversificação, memória de curto prazo e intensificação, nesta ordem. O autor mostra em experimentos que a intensificação é fundamental para atingir os melhores resultados da busca tabu. De nosso conhecimento, existem poucas implementações de busca tabu que usam este enfoque de ciclos, aparentemente natural, e que deveria ser explorado em outros problemas.

\section{Minimização da Soma de Atrasos em um Jobshop}

Este problema envolve $J$ tarefas e $M$ máquinas, e cada tarefa consiste de uma sequência ordenada de $M$ operações. O tempo de processamento da operação $i$ da tarefa $j$ é denotado por $p_{i j}$, e a data de entrega da tarefa $j$ é $d_{j}$. Cada operação é processada em uma única máquina e cada máquina pode processar somente uma operação por vez, com operações distintas processadas em máquinas distintas.

Este problema pode ser representado por um grafo disjuntivo em que cada operação de cada tarefa corresponde a um nó com peso igual ao tempo de processamento. Para cada tarefa existe um conjunto de arcos para representar a sequência ordenada de operações da tarefa. Dois nós artificiais com peso zero são incluídos para representar a operação inicial e a operação final, respectivamente. Estes nós são ligados aos nós da primeira e última operação de cada tarefa. Os nós correspondentes às operações a serem executadas na mesma máquina são conectados por arcos disjuntivos. A orientação destes arcos indica a precedência de operações nas máquinas. A Figura 1 mostra um grafo disjuntivo para um problema com três tarefas e quatro máquinas. Quando a orientação dos arcos disjuntivos é selecionada, obtém-se um grafo orientado.

O caminho crítico para cada tarefa corresponde ao caminho mais longo do nó 0 ao seu nó final, por exemplo, o nó final da tarefa 2 é o nó 8 . Este caminho determina o instante de término da tarefa, e, consequentemente, qualquer atraso envolvido. O objetivo é encontrar um programa, isto é, uma designação de operações a intervalos de tempo, de modo a minimizar a soma dos atrasos.

1 É um falso cognato. Não há uma tradução de facilities que seja adequada a todas as situações, tais como, infraestrutura, instalações, conforto, comodidade, recursos e serviços. 


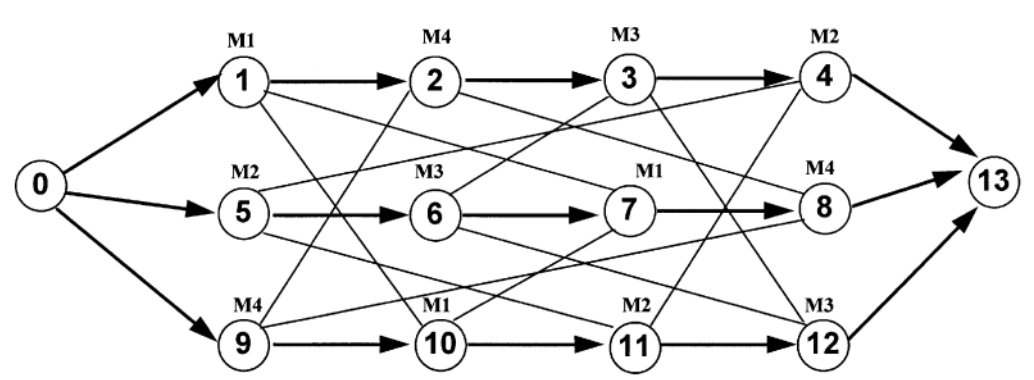

Figura 1. Grafo disjuntivo.

\subsection{Memória de curto prazo}

Solução Inicial: é obtida pela regra de prioridade ou despacho modified due date (MDD). Para cada instante de tempo $t$ de decisão de programação, para cada tarefa $j$, a regra avalia a medida

$$
\max \left\{d_{j}, t+\sum_{i=k}^{g_{j}} p_{i j}\right\}
$$

tal que $g_{j}$ corresponde ao número total de operações da tarefa $j$. A tarefa com menor medida é selecionada para processamento no instante $t$.

Atributo da solução: arco disjuntivo no caminho crítico de cada tarefa.

Movimento: inversão de cada arco disjuntivo de uma dada tarefa.

Regra de ativação tabu: se o arco $(k, l)$ é invertido para $(l, k)$, então o arco $(k, l)$ é proibido.

Duração tabu: o número de iterações em que um movimento fica proibido é selecionado de uma distribuição uniforme $U[\min , \max ]$. Testes computacionais indicam que min é gerado de $U[a, b]$, tal que $a=2$ e $b=\lfloor(J+M) / 3\rfloor$, e max é gerado de $U[A, B]$, tal que $A=\min +6$ e $B=A+\lfloor(J+M) / 3\rfloor$.

Lista de candidatos: A vizinhança completa consiste da inversão de todos os arcos disjuntivos nos caminhos críticos de todas as tarefas. No entanto, a exploração de uma vizinhança de cada tarefa $j=1, \ldots, J$ e execução do melhor movimento leva a resultados melhores.

\subsection{Memória de longo prazo}

Intensificação: consiste do armazenamento de soluções elite e reinício da busca a partir dessas soluções. Várias alternativas foram testadas e a melhor consiste do armazenamento de cinco soluções elite e reinício da busca a cada 10 iterações, com lista tabu zerada.

Diversificação: é baseada em frequência de atributos, utilizada para estimular ou desencorajar movimentos. Para tal, utiliza-se uma matriz que armazena a razão do número de vezes que uma operação na máquina em que é processada e a iteração corrente. Movimentos que levam a uma solução com alta frequência são penalizados para direcionar a busca para examinar regiões não visitadas. Por exemplo, suponha que um movimento de inversão do arco $(2,5)$ está sendo avaliado, tal que a operação 2 ocupa a terceira posição na máquina e a operação 5 ocupa a quarta posição. O valor do movimento é penalizado de acordo com a frequência das operações 5 e 2 nas posições 3 e 4 , respectivamente. O valor do movimento é alterado para:

valor do movimento' $=$ valor do movimento + P.freq $[o p(5), \operatorname{pos}(3)]+$ P.freq $[o p(2), \operatorname{pos}(4)]$

em que $P$ é um fator de penalidade.

A diversificação baseada em frequência foi usada de duas formas:

- A cada 50 iterações, os movimentos são penalizados ou não, isto é, sem penalização da iteração 1 a 50, com penalização da iteração 51 a 100, sem penalização da iteração 101 a 150, etc.

- A penalização da frequência de uma dada operação em uma certa posição é usada para modificar a regra de prioridade MDD. A cada 20 iterações a regra de despacho MDD é reaplicada da seguinte forma. Considere, por exemplo, uma operação alocada a uma máquina na posição 2. Para cada operação $k$ que está na fila desta máquina, o valor da nova regra de prioridade é representado por

$$
\text { valor da prioridade' }=\text { valor da prioridade }+ \text { P. freq }[o p(k), \operatorname{pos}(2)] \text {. }
$$


A memória de longo prazo resulta da aplicação das duas formas de diversificação com $P=10$ até a iteração 200 e do esquema de intensificação aplicado até a iteração 250, que é o critério de parada da busca tabu.

\subsection{Resultados}

Os códigos das heurísticas foram escritos na linguagem $\mathrm{C}$ e os testes foram executados em um estação SUN SPARCclassic. Testes computacionais foram realizados em instâncias com parâmetros obtidos da literatura. Cada instância pode ser caracterizada pelos seguintes dados: número de tarefas, número de máquinas, tempo de processamento das operações das tarefas e datas de entrega das tarefas.

O número de tarefas $(J)$ e máquinas $(M)$ é pré-determinado. Para cada grupo $(J \times M)$, cinco instâncias foram geradas da seguinte maneira:

- Tempo - $U[1,99]$, que representa uma distribuição uniforme no intervalo correspondente.

- Máquina em que a operação de uma tarefa é processada - $U[1, M]$.

- Data de entrega: $d_{j}=\alpha \cdot P_{j}$, tal que $P_{j}$ é a soma dos tempos de processamento da operações da tarefa $j$ e $\alpha$ assume dois valores, $\alpha_{1}=(J \times M) / 1000+0,5$ e $\alpha_{2}=\alpha_{1}+1$ para gerar datas de entrega mais folgadas.

Seja $T_{\mathrm{BT}}$ o atraso total da melhor solução obtida pela busca tabu com memórias de curto e longo prazo, e $T_{\text {MDD }}$ o atraso total resultante da aplicação da regra MDD. A porcentagem de melhoria da solução obtida por busca é definida como:

$$
\text { Melhoria }=\frac{T_{\mathrm{MDD}}-T_{\mathrm{BT}}}{T_{\mathrm{MDD}}} .
$$

As instâncias em que BT fornece soluções com valor zero, independente de $T_{\mathrm{MDD}}$, não estão incluídas no cálculo da melhoria média. Estas instâncias pertencem a grupos com um asterisco na Tabela 5.

Tabela 5. Melhoria média da busca tabu.

\begin{tabular}{ccccc}
\hline G & $(J \times M)$ & MDD & Melhoria $\%$ & Tempo $(\mathbf{s})$ \\
\hline 1 & $5 \times 5$ & $1.056,6$ & 12,08 & 1,4 \\
2 & $10 \times 5$ & $3.641,0$ & 6,64 & 5,0 \\
3 & $50 \times 5$ & $61.618,4$ & 3,40 & 107,9 \\
4 & $10 \times 10$ & $4.857,6$ & 15,68 & 11,6 \\
5 & $15 \times 10$ & $9.215,4$ & 10,58 & 25,9 \\
6 & $50 \times 10$ & $66.954,6$ & 4,57 & 240,4 \\
7 & $100 \times 10$ & $229.558,8$ & 2,28 & 938,1 \\
8 & $15 \times 15$ & $9.339,6$ & 8,88 & 44,1 \\
9 & $30 \times 15$ & $27.112,4$ & 4,42 & 155,9 \\
10 & $50 \times 15$ & $60.902,4$ & 4,02 & 426,0 \\
11 & $5 \times 5$ & 99,0 & $86,41 *$ & 0,4 \\
12 & $10 \times 5$ & $1.100,8$ & 19,75 & 5,6 \\
13 & $50 \times 5$ & $48.626,6$ & 1,99 & 109,3 \\
14 & $10 \times 10$ & 407,4 & $92,41 *$ & 11,0 \\
15 & $15 \times 10$ & $2.180,6$ & 32,77 & 32,2 \\
16 & $50 \times 10$ & $42.560,4$ & 5,58 & 258,4 \\
17 & $100 \times 10$ & $179.572,0$ & 2,03 & 995,6 \\
18 & $15 \times 15$ & 454,0 & $89,01 *$ & 39,2 \\
19 & $30 \times 15$ & $7.218,4$ & 22,09 & 189,7 \\
20 & $50 \times 15$ & $26.638,6$ & 8,40 & 527,6 \\
\hline & & & &
\end{tabular}

A primeira coluna e a segunda coluna da Tabela 5 mostram os grupos e suas dimensões, respectivamente. A terceira coluna mostra o atraso total médio para a solução inicial obtida pela regra MDD. A quarta coluna e a quinta coluna indicam a melhoria média e o tempo computacional, respectivamente. A melhoria média varia entre $2 \%$ e $92 \%$, com melhoria maior para instâncias com menor valor de atraso total.

A incorporação de estratégias de diversificação e intensificação à busca tabu com memória de curto prazo aumenta a melhoria média em $80 \%$ dos grupos com tempo computacional equivalente. Para algumas instâncias com atraso total inferior a 10.000, a inclusão das estratégias leva a resultados ligeiramente inferiores. 
O desempenho da busca tabu foi também testado em instâncias pequenas resolvidas por um modelo matemático pelo software CPLEX 3.0. Este modelo é uma adaptação imediata do modelo apresentado por Baker (1974) para minimização do makespan. Foram geradas 10 instâncias para 20 diferentes dimensões $(J \times M)$, totalizando 200 instâncias. Para um número de variáveis binárias maior que 80 , o software não foi capaz de gerar uma solução ótima em tempo razoável. Por exemplo, uma instância $8 \times 3$ consumiu mais de 18 horas.

A Tabela 6 apresenta os resultados computacionais. As colunas 2 e 3 indicam, respectivamente, o tempo computacional médio para obter soluções ótimas geradas por busca tabu. A coluna 4 mostra o número de soluções ótimas encontradas pela busca tabu. A coluna 5 indica o número de instâncias em que o desvio relativo do valor obtido pela busca tabu em relação ao valor ótimo é menor que 10\%. A coluna 6 apresenta o maior desvio para 10 instâncias. A coluna 7 mostra o valor médio gerado pela regra MDD. Finalmente, a coluna 8 mostra a melhoria média da busca tabu em relação à regra MDD. Os resultados da Tabela 6 revelam que para datas de entrega mais apertadas, a busca tabu provê soluções ótimas para $61 \%$ das instâncias e esta porcentagem sobe para $81 \%$ no caso de datas de entrega mais folgadas. Nota-se também que o número de soluções ótima geradas pela busca tabu diminui para um número fixo de máquinas. Além disto, maiores melhorias são obtidas para instâncias com datas folgadas.

Tabela 6. Desempenho da busca tabu em relação a soluções ótimas e regra MDD.

\begin{tabular}{cccccccc}
\hline $\begin{array}{c}\text { Dimensões } \\
J \times M\end{array}$ & $\begin{array}{c}\text { Tempo(s) } \\
\text { Cplex }\end{array}$ & $\begin{array}{c}\text { Tempo(s) } \\
\text { TSB }\end{array}$ & $\begin{array}{c}\text { Soluções } \\
\text { ótimas }\end{array}$ & $<10 \%$ & $\begin{array}{c}\text { Maior } \\
\text { desvio }\end{array}$ & MDD & $\begin{array}{c}\text { Melhoria } \\
(\%)\end{array}$ \\
\hline $3 \times 3$ & 0,13 & 0,9 & 10 & 0 & - & 363.0 & 4,86 \\
$4 \times 3$ & 0,86 & 0,66 & 10 & 0 & - & 619,7 & 7,65 \\
$5 \times 3$ & 4,84 & 0,86 & 6 & 4 & 4,63 & 879,5 & 9,25 \\
$6 \times 3$ & 54,35 & 1,19 & 4 & 6 & 5,27 & $1.192,9$ & 8,48 \\
$7 \times 3$ & $1.295,25$ & 1,55 & 5 & 5 & 7,62 & $1.564,2$ & 6,59 \\
$4 \times 4$ & 1,13 & 0,84 & 9 & 1 & 1,54 & 716,9 & 7,62 \\
$5 \times 4$ & 9,10 & 1,20 & 4 & 6 & 3,23 & $1.032,9$ & 8,11 \\
$6 \times 4$ & 140,82 & 1,64 & 4 & 5 & 12,46 & $1.396,5$ & 8,28 \\
$5 \times 5$ & 10,53 & 1,53 & 5 & 3 & 10,23 & $1.087,3$ & 11,69 \\
$6 \times 5$ & 115,87 & 2,04 & 4 & 5 & 11,40 & $1.457,9$ & 11,66 \\
$3 \times 3$ & 0,11 & 0,16 & 10 & 0 & - & 23,3 & 30,01 \\
$4 \times 3$ & 0,56 & 0,64 & 10 & 0 & - & 68,1 & 26,37 \\
$5 \times 3$ & 3,69 & 0,94 & 10 & 0 & - & 172,6 & 26,14 \\
$6 \times 3$ & 37,38 & 1,27 & 7 & 2 & 17,14 & 333,6 & 24,51 \\
$7 \times 3$ & 626,87 & 1,60 & 3 & 6 & 11,68 & 520,9 & 15,63 \\
$4 \times 4$ & 0,77 & 0,66 & 9 & 0 & 63,60 & 51,1 & 53,38 \\
$5 \times 4$ & 5,22 & 1,32 & 9 & 1 & 9,02 & 124,0 & 38,69 \\
$6 \times 4$ & 59,21 & 1,80 & 7 & 2 & 17,02 & 248,1 & 31,04 \\
$5 \times 5$ & 4,47 & 0,44 & 10 & 0 & - & 90,7 & 73,41 \\
$6 \times 5$ & 51,37 & 1,82 & 9 & 0 & 29,37 & 174,9 & 62,61 \\
\hline
\end{tabular}

\subsection{Considerações}

A estratégia de lista de candidatos apresenta um bom desempenho não somente de forma isolada (em relação a uma vizinhança maior) mas também quando integrada a estratégias de intensificação e diversificação. Os resultados com a vizinhança completa são muito ruins em termos de qualidade e tempo computacional, e por este motivo, não foram relatados em Scrich (1997).

Novamente o aspecto restritivo é limitar a intensificação somente para o final da busca tabu, um tipo de pós-otimização. Watson et al. (2006) sugerem uma descontrução do algoritmo de busca tabu $i$-TSAB proposto por Nowicki \& Smutnicki (2005), que representa o estado da arte para o critério de minimização do makespan em um jobshop. Através de experimentos controlados, Watson et al. (2006) identificam os componentes de $i$-TSAB que fazem com que este algoritmo atinja o nível de estado da arte. Uma estrutura (framework) é proposta para analisar a intensificação e a diversificação. Além disso, experimentos estatísticos mostram que intensificação e diversificação são fundamentais para obter soluções de alta qualidade, e que estas estratégias devem ser aplicadas ao longo da busca. Uma pesquisa destes aspectos para o critério de soma dos atrasos das tarefas seria muito importante. 


\section{Problema Integrado de Produção e Distribuição}

O problema integrado de produção e distribuição (PIPD) ocorre em diversas empresas, incluindo aquelas que usam o enfoque de cadeia de suprimento. Este problema envolve decisões em cada período de um horizonte finito. Uma planta com restrições de capacidade produz vários itens, e uma frota homogênea de veículos com um número irrestrito ou restrito de veículos está disponível para a distribuição de itens de modo a atender demandas de clientes. Em cada período, o problema de produção envolve a determinação da quantidade a produzir de cada item, enquanto o problema de distribuição consiste da definição da quantidade de cada item a ser entregue a cada cliente e as rotas dos veículos. Um custo fixo de produção e um custo fixo de transporte são incorridos em cada período que um item é produzido, e cada período que um veículo é usado, respectivamente. Se o cliente é visitado em um período, assume-se que é servido por um único veículo. O objetivo é minimizar custos fixos e variáveis de produção, custos de estoque na planta e nos clientes e custos de transporte. Sarmiento \& Nagi (1999) apresentam uma revisão de sistemas integrados de produção e distribuição e enfatizam a importância de otimizar simultaneamente as decisões de funções ou estágios distintos de uma cadeia de suprimento, em lugar do enfoque da tradicional otimização desacoplada, na qual a saída otimizada de um estágio torna-se a entrada para outro estágio, como por exemplo, estabelecer primeiro um plano de distribuição e, então, planejar a distribuição.

O PIPD é definido em um grafo completo $G=(W, E)$, tal que $W=\{0,1, \ldots, N\}$ é o conjunto de nós e $E=\{(k, l): k, l \in W, k \neq l\}$ é o conjunto de arestas. O nó $k=0$ representa a planta que produz um conjunto de itens $j \in\{1, \ldots, J\}$ enviados para um conjunto de clientes correspondentes aos nós $k \in\{1, \ldots, n\}$ por um conjunto homogêneo de veículos $v \in\{1, \ldots, V\}$ com capacidade $C$ em períodos de tempo $t \in\{1, \ldots, T\}$. O número de veículos pode ser restrito ou irrestrito. Em cada período, cada veículo pode realizar no máximo uma rota de comprimento limitado a $L$, e cada cliente pode ser visitado por um único veículo.

A capacidade da planta em unidades de tempo é $B$ e o tempo para produzir uma unidade do item $j$ é $b_{j}$. O custo unitário de estoque na planta é $h_{j 0}$, o custo unitário de produção em cada período é $c_{j}^{p}$, e se o item $j$ é produzido em um período, um custo de preparação (setup) $f_{j}^{p}$ é incorrido. A demanda do item $j$ do cliente $k$ no período $t$ é $d_{j k t}$ e o custo unitário de estoque no cliente é $h_{j k}$. Para cada item $j$ e cada cliente $k$ estão associados um limite mínimo de estoque $L_{j k}$ e um estoque máximo $U_{j k}$. Custos de transporte incluem um custo fixo $f^{v}$, se um veículo $v$ é usado no período $t$ e uma distância $c_{k l}^{v}$ para percorrer a aresta $(k, l)$.

Considere as seguintes variáveis:

$p_{j t}=$ quantidade do item $j$ produzido no período $t$;

$I_{j k t}=$ estoque do item $j$ no cliente $k$ no fim do período $t$;

$y_{j t}=1$, se o item $j$ é produzido no período $t$; 0 , caso contrário;

$q_{j k t}^{v}=$ quantidade do item $j$ entregue ao cliente $k$ pelo veículo $l$ no período $t$

$x_{j k l t}^{v}=$ quantidade do item $j$ transportado na aresta $(k, l)$ pelo veículo $l$ no período $t$;

$z_{k l t}^{v}=1$, se o veículo $v$ percorre a aresta $(k, l)$ no período $t ; 0$, caso contrário.

A formulação a seguir é baseada no modelo matemático proposto por Fumero \& Vercellis (1999):

$$
\min \sum_{t=1}^{T}\left\{\sum_{j=1}^{J}\left(\sum_{k=0}^{N} h_{j k} I_{j k t}+c_{j}^{p} p_{j t}+f_{j}^{p} y_{j t}\right)+\sum_{v=1}^{V}\left(\sum_{l=1}^{N} f^{v} z_{0 l t}^{v}+\sum_{l=0, l \neq k}^{N} c_{k l}^{v} z_{k l t}^{v}\right)\right\}
$$

sujeito a

$$
\begin{gathered}
p_{j t}+I_{j 0, t-1}-I_{j 0 t}=\sum_{k=1}^{N} \sum_{v=1}^{V} q_{j k t}^{v}, \quad \forall t, j \\
q_{j k t}^{v}+I_{j k, t-1}-I_{j k t}=d_{j k t}, \quad \forall t, v, j, k \\
\sum_{j=1}^{J} b_{j} p_{j t} \leq B, \quad \forall t \\
p_{j t} \leq M y_{j t}, \quad \forall t, j \\
\sum_{i=0, i \neq k}^{N} x_{j i k t}^{v}-\sum_{m=0, m \neq k}^{N} x_{j k m t}^{v}=q_{j k t}^{v}, \quad \forall t, v, j, k \neq 0
\end{gathered}
$$




$$
\begin{gathered}
\sum_{i=1}^{N} \sum_{v=1}^{V} x_{j i 0 t}^{v}-\sum_{m=1}^{N} \sum_{v=1}^{V} x_{j 0 m t}^{v}=-\sum_{k=1}^{N} \sum_{v=1}^{V} q_{j k t}^{v}, \quad \forall t, j \\
\sum_{j=1}^{J} x_{j k l t}^{v} \leq C z_{k l t}^{v}, \quad \forall t, v, k, l ; k \neq l \\
\sum_{k=0}^{N} \sum_{l=0}^{N} c_{k l}^{v} z_{k l t}^{v} \leq L, \quad \forall t, v ; k \neq l \\
\sum_{i=0, i \neq k}^{N} z_{i k t}^{v}-\sum_{m=0, m \neq k}^{N} z_{0 k t}^{v} \leq 1, \quad \forall t, v \\
\sum_{k=0}^{N} \sum_{v=1}^{V} z_{k l t}^{v} \leq 1, \quad \forall t, l \\
L_{j k} \leq I_{j k t} \leq U_{j k t}, p_{j t} \geq 0, q_{j k t}^{v} \geq 0, x_{j k l t}^{v} \geq 0, y_{j t} \in\{0,1\}, z_{k l t}^{v} \in\{0,1\}, \forall j, k, l, t
\end{gathered}
$$

A função objetivo minimiza os custos de produção, estoque e distribuição. As restrições (7) expressam o balanço entre produção, estoque e entregas na planta. As restrições (8) correspondem ao balanço entre entregas, estoque e demanda nos clientes. As restrições (9) representam a capacidade da planta, e as restrições (10) garantem que um custo de preparação é incorrido somente se existe produção. As restrições (11) e (12) expressam a conservação de fluxo dos itens nos clientes e na planta. As restrições (13) e (14) impõem limites de capacidade do veículo e comprimento da rota, respectivamente. As restrições (15) garantem que, em cada período, cada veículo é alocado somente a uma rota, enquanto que as restrições (16) garantem que cada veículo retorna à planta no fim da rota. As restrições (17) forçam que, no máximo, um veículo visita um cliente em um período, e as restrições (18) definem o domínio das variáveis. O parâmetro $M$ representa um número grande, por exemplo, $M=\sum_{j=1}^{J} \sum_{t=1}^{T} \sum_{k=1}^{N} d_{j k t}$.

A integração das decisões de produção e distribuição é feita pelas restrições (7). Como mencionado anteriormente, um enfoque comum no problema de produção e distribuição é primeiro resolver o problema de produção e, em seguida, resolver o problema de distribuição, chamado de problema desacoplado de produção e distribuição (PDPD). Neste caso, o lado direito das restrições (7) torna-se $\sum_{k=1}^{N} d_{j k t}$ e o problema de produção consiste em minimizar os custos de produção sujeito às restrições (7), (9), (14) e (15). Este problema é conhecido na literatura como problema de dimensionamento de lotes, veja Karimi et al. (2003). As variáveis de decisão do problema de distribuição, $I_{j k t}, q_{j k t}^{v}, x_{j k l t}^{v}$ e $z_{k l t}^{v}$ são determinadas de forma a minimizar os custos de distribuição sujeito às restrições (8), (11)-(17) e $\sum_{k=1} \sum_{v=1}^{V} q_{j k t}^{v} \leq I_{j 0 t}, j=1, \ldots, J ; t=1, \ldots, T$.

A primeira variante do procedimento de busca tabu tem uma fase de construção de uma solução inicial, e uma fase de memória de curto prazo, enquanto a segunda incorpora uma memória de longo prazo para utilização em um procedimento de religação de caminho (path relinking).

Uma característica importante do enfoque proposto é o uso de soluções infactíveis nos dois procedimentos. Isto aumenta o poder de atingir soluções factíveis de boa qualidade com vizinhanças simples. A infactibilidade está relacionada com a relaxação das restrições de capacidade de produção, restrições de capacidade dos veículos e restrições de comprimento da rota.

Seja $S$ o conjunto de soluções que podem ser infactíveis com relação às restrições de capacidade (9), (13) e (14). Para uma solução $s \in S$, seja $c(s)$ a função de custo total de produção e transporte (6), e

$$
\begin{gathered}
g(s)=\sum_{t=1}^{T} \max \left\{\sum_{j=1}^{J} b_{j} p_{j t}-B, 0\right\} \\
h(s)=\sum_{t=1}^{T} \sum_{v=1}^{V} \sum_{l=0}^{N} \sum_{k=0, k \neq l}^{N} \max \left\{\sum_{j=1}^{J} x_{j k l t}^{v}-C z_{k l t}^{v}, 0\right\} \\
l(s)=\sum_{t=1}^{T} \sum_{v=1}^{V} \max \left\{\sum_{k=0, k \neq l}^{N} \sum_{l=0}^{N} c_{j k}^{l} z_{k l t}^{v}-L, 0\right\}
\end{gathered}
$$


a violação total da capacidade de produção, capacidade do veículo e comprimento da rota, respectivamente. As soluções são avaliadas pela função de custo penalizada

$$
f(s)=c(s)+\alpha g(s)+\beta h(s)+\gamma l(s) t .
$$

\subsection{Construção da solução inicial}

O procedimento de construção de uma solução inicial consiste de três estágios descritos a seguir.

Passo 1: Para facilitar a explicação, assuma que o estoque inicial é zero, caso contrário, use este estoque para atender demandas futuras. Faça $q_{j k t}=d_{j k t}, t=1, \ldots, T ; j=1, \ldots, J ; k=1, \ldots, N$.

Passo 2: Use a versão paralela do algoritmo proposto por Clarke \& Wright (1964) para determinar as rotas de cada período $t=1, \ldots, T$. Se existe um número máximo de veículos, então, a última rota construída pode ser infactível.

Passo 3: Determine um plano de produção para cada item $j=1, \ldots, J$ pela implementação eficiente de Evans (1985) do algoritmo sugerido por Wagner \& Whitin (1958). Este plano pode ser infactível.

\subsection{Memória de curto prazo}

O procedimento de busca tabu começa a partir da solução inicial. A vizinhança $N(s)$ de uma solução $s$ é definida por um movimento composto com três componentes:

Componente 1 do movimento: Transferência de uma quantidade máxima $r_{j k t t^{\prime}} \leq q_{j k t}$ do período $t$ para um período $t^{\prime} \neq t$ sem violar os limites de $I_{j k t}$ e $I_{j k t^{\prime}}$.

Componente 2 do movimento: Inserção da quantidade $r_{j k t t^{\prime}}$ em uma rota do período $t^{\prime}$.

Componente 3 do movimento: Determinação de um novo plano de produção.

Detalhes de cada um dos componentes são descritos a seguir.

Componente 1 do movimento. Das restrições (7) e (8) segue-se que a mudança da quantidade $r_{j k t t^{\prime}}$ de um período $t$ para um período $t^{\prime}<t$ faz com que os níveis de estoque $I_{j 0 \tau}$ e $I_{j k \tau}, \tau=t^{\prime}, \ldots, t-1$ decresçam e aumentem, respectivamente, de $r_{j k t t^{\prime}}$. Analogamente, a transferência da quantidade $r_{j k t t^{\prime}}$ de um período $t$ para um período $t^{\prime}>t$ causa o acréscimo e decréscimo dos níveis de estoque $I_{j 0 \tau}$ e $I_{j k \tau}, \tau=t^{\prime}, \ldots, t-1$, respectivamente, de $r_{j k t t^{\prime}}$. Portanto, se $t^{\prime}<t$,

$$
r_{j k t t^{\prime}}=\min \left\{q_{j k t}, \min _{\tau}\left\{U_{j k}-I_{j k \tau}, I_{j 0 \tau}\right\}, \quad{ }_{\tau}=t^{\prime}, \ldots, t-1\right.
$$

e se $t^{\prime}>t$

$$
r_{j k t t^{\prime}}=\min \left\{q_{j k t}, \min _{\tau}\left\{I_{j k \tau}-L_{j k}, I_{j 0 \tau}\right\}, \quad{ }_{\tau}=t, \ldots, t^{\prime}-1 .\right.
$$

Componente 2 do movimento. Um cliente pode ser visitado por um único veículo em cada período. Se o cliente $k$ é visitado no período $t^{\prime}$, então uma quantidade $r_{j k t t^{\prime}}$ é adicionada à quantidade a ser entregue para o cliente $k$ e a rota é mantida, mesmo que infactível. Se o cliente $k$ não é visitado no período $t^{\prime}$, duas alternativas são avaliadas e a mais econômica é selecionada: (i) insira o cliente $k$ em todas as posições das rotas do período $t^{\prime}$ e escolha a inserção mais barata de acordo com a função $f(s)$; (ii) abra uma nova rota para o cliente $k$, se o número máximo de veículos não é excedido. Se não existem rotas no período $t^{\prime}$, uma nova rota é aberta para o cliente $k$.

Componente 3 do movimento. Depois de mover $r_{j k t t^{\prime}}$, e designar esta quantidade para um veículo $v$, tem-se uma nova quantidade a ser entregue $q_{j k t^{\prime}}^{v} \longleftarrow q_{j k t^{\prime}}^{v}+r_{j k t t^{\prime}}$, e um novo plano de produção é determinado devido à mudança do lado direito das restrições (7). Este plano é determinado pelo algoritmo de Evans (1985) para resolver o seguinte subproblema de produção:

$$
\min \sum_{t=1}^{T}\left(\alpha b_{j}+c_{j}^{p}\right) p_{j t}+h_{j k} I_{j k t}+f_{j}^{p} y_{j t}
$$

sujeito a

$$
p_{j t}+I_{j 0, t-1}-I_{j 0 t}=\sum_{k=1}^{N} \sum_{v=1}^{V} q_{j k t}^{v}
$$




$$
p_{j t} \geq 0, I_{j 0 t} \geq 0, t=1, \ldots, T .
$$

O movimento composto é avaliado para cada item $j$, cada cliente $k$, cada par de períodos $t$ e $t^{\prime}, t \neq t^{\prime}$, e aquele que resulta em custo total mínimo é selecionado. O par $\left(j, t^{\prime}\right)$ associado com este movimento é armazenado em uma matriz para indicar que a transferência de qualquer quantidade do item $j$ a partir do período $t^{\prime}$ é tabu por $\varphi$ iterações, tal que o valor discreto de $\varphi$ é selecionado de um intervalo $[a, b]$ com distribuição uniforme.

A busca termina quando atinge $\delta \times N \times J \times T \times V$ iterações ou quando durante $\eta \times N \times J \times T \times V$ iterações não há atualização da solução incumbente, em que $\delta$ e $\eta$ são parâmetros.

\subsection{Religação de caminho}

Religação de caminho (path relinking) foi proposto por Glover (1997) como um enfoque que integra estratégias de intensificação e diversificação no contexto de busca tabu e scatter search Glover (1998b). Este enfoque gera novas soluções pela exploração de trajetórias que conectam soluções de alta qualidade (intensificação), ou soluções de regiões distintas ou que têm características contrastantes (diversificação). Ao partir de uma destas soluções, chamada solução iniciante, gera-se um caminho composto de soluções factíveis e infactíveis em um espaço restrito de busca que leva em direção a outra solução, chamada solução guia. Isto é realizado pela seleção de movimentos que introduzem atributos contidos na solução guia. O melhor movimento nesta vizinhança restrita, que aumenta o número de atributos presente na solução guia, é executado. A busca em vizinhança descrita anteriormente é aplicada a cada mínimo local do caminho, que é uma solução que é imediatamente precedida e sucedida no caminho por soluções piores, de acordo com a função $f(s)$.

Nesta implementação, uma das soluções, $s_{1}$, é um mínimo local da busca tabu, a outra solução $s_{2}$, é selecionada de um conjunto de soluções elite $E$ que contém as $e$ melhores soluções encontradas durante a busca sujeito à restrição de distância de Hamming ${ }^{2}$ mínima entre soluções para manter um grau de diversidade. Sejam $s_{\text {melhor }}$ e $s_{\text {pior }}$ as soluções de custo mínimo e custo máximo em $E$. Uma nova solução entra em $E$ se tem custo menor que $s_{\text {melhor }}$ ou se tem custo menor que $s_{\text {pior }}$ e aumenta a distância entre soluções de $E$. Em ambos os casos, a pior solução é retirada do conjunto $E$. A distância entre uma solução $s_{1}$ e uma solução $s_{2}$ é definida como o número de períodos em que as quantidades dos itens entregues aos clientes são diferentes. A distância máxima é $T \times N \times J$ e a distância mínima é $\lfloor\rho \times T \times N \times J\rfloor$, em que $\rho$ é um parâmetro.

É utilizada uma estratégia mista de religação de caminho que é aplicada para conectar cada mínimo local $s_{1}$ à solução $s_{2}$ de $E$, que é selecionada como a mais distante de $s_{1}$. A estratégia mista constrói dois caminhos, um que é iniciado em $s_{1}$ e outro iniciado em $s_{2}$, e trocando a função de solução iniciante e solução guia em cada passo do procedimento de religação de caminho. Os caminhos evoluem e se encontram em uma solução $s_{\mathrm{m}}$ situada entre $s_{1}$ e $s_{2}$, como mostrado na Figura 2. Resende et al. (2010) ressaltam que, em geral, existem mais soluções de alta qualidade próximas das soluções de $E$, porque o tamanho da vizinhança restrita diminui ao se mover para a solução guia. O caminho misto compartilha do benefício de iniciar a partir de $s_{1}$ e $s_{2}$, e, em geral, leva menos tempo do que explorar dois caminhos, um iniciado em $s_{1}$ e outro em $s_{2}$.

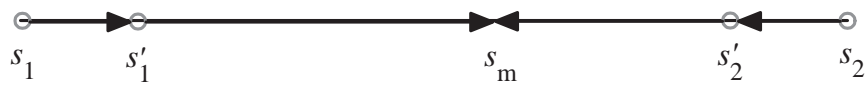

Figura 2. Religação de caminho mista.

O procedimento de religação entre as soluções $s_{1}$ e $s_{2}$ é mostrado no Algoritmo 1. Sejam $q_{j k t}^{1}$ e $q_{j k t}^{2}$ as quantidades do item $j$ que são entregues ao cliente $k$ no período $t$ na solução iniciante $s_{1}$ e na solução guia $s_{2}$, respectivamente. Enquanto $s_{1} \neq s_{2}$, as linhas 1 a 18 são executadas. Para todos os itens, clientes e períodos, a diferença $u_{j k t}=q_{j k t}^{1}-q_{j k t}^{2}$ é calculada na linha 4 . Para cada período $t^{\prime} \neq t$, considera-se nas linhas 7 e 9 a quantidade tranferida $w_{j k t t^{\prime}}$ do período $t$ para todo período $t^{\prime}$ na solução $s_{1}$, tal que os limites de estoque não são violados e a distância entre soluções não é aumentada. Na linha 15 a transferência de menor custo é executada e uma solução intermediária $s_{\text {int }}$ é obtida. Nas linhas 16 e 17, $s_{2}$ torna-se a solução iniciante e $s_{\text {int }}$ é a nova solução guia.

\subsection{Resultados}

Os algoritmos das heurísticas foram codificados na linguagem $\mathrm{C}++$ e os teste computacionais foram realizados em computador Intel Pentium IV 2.8 Ghz As heurísticas foram testadas em instâncias com múltiplos itens geradas pelos autores (conjuntos $C_{1}$ e $C_{2}$ ) e em instâncias com um único item geradas por Boudia et al. (2007) (conjunto $C_{3}$ ).

2 A distância de Hamming entre dois vetores de mesma dimensão é o número de posições nas quais os símbolos correspondentes são diferentes. 


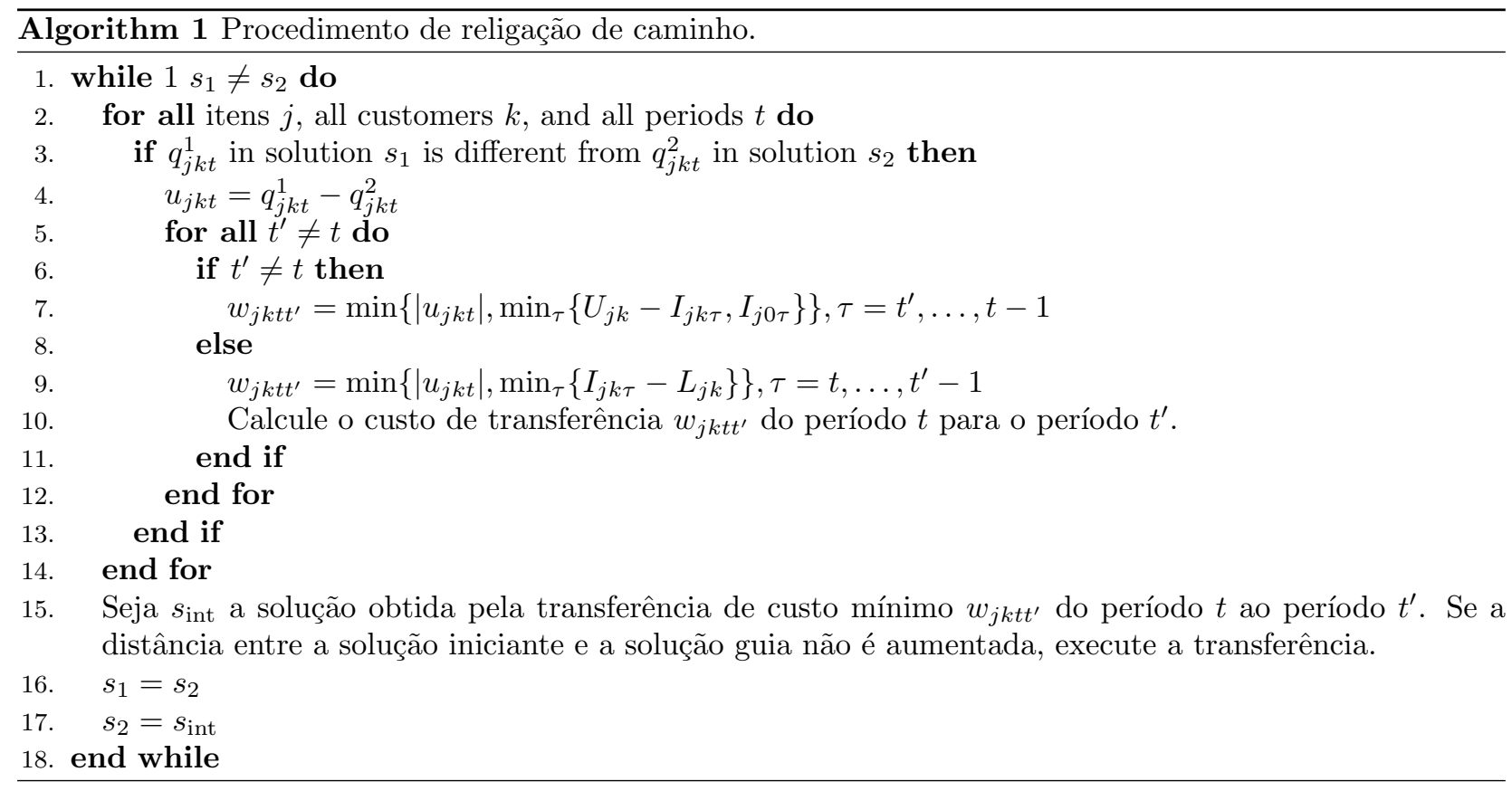

\subsubsection{Geração de instâncias}

Um conjunto $C_{1}$ com instâncias pequenas e um conjunto $C_{2}$ com instâncias maiores foram geradas. O número de clientes, períodos e itens no conjunto $C_{1}$ pertence a $\{5,10,15\},\{7,14\}$ e $\{3,5\}$, respectivamente. Para cada combinação de clientes, períodos e itens, seis instâncias foram geradas, totalizando 72 instâncias. Para o conjunto $C_{2}$, o número de clientes, períodos e itens é $\{30,50,100\},\{12,24\}$ e $\{5,19\}$, respectivamente. Para cada combinação de clientes, períodos e itens, nove instâncias foram geradas, totalizando 108 instâncias com número irrestrito de veículos $V$. A descrição da geração das instâncias encontra-se em Armentano et al. (2011).

\subsubsection{Valor dos parâmetros}

A Tabela 7 apresenta os valores selecionados e a faixa de valores testados para os parâmetros $\eta$ e $\delta$ associados com o critério de parada, o parâmetro $\rho$ que determina a distância mínima entre soluções elite no procedimento de religação de caminho, e os valores iniciais $\alpha, \beta$ e $\gamma$ que penalizam a violação da capacidade de produção, capacidade de veículo e comprimento da rota. Os últimos três parâmetros são atualizados dinamicamente da seguinte maneira. Cada parâmetro é multiplicado por 2 toda vez que a próxima solução viola a restrição associada e dividido por 2 toda vez que a próxima solução é factível em relacão à restrição correspondente.

Tabela 7. Parâmetros dos procedimentos heurísticos.

\begin{tabular}{ccc}
\hline Parâmetro & Valor selecionado & Faixa de valores testados \\
\hline$\eta$ & 0,005 & {$[0,0001,0,5]$} \\
$\delta$ & 50 & {$[15,75]$} \\
$\rho$ & 0,3 & {$[0,1,0,5]$} \\
$\alpha$ & 1 & {$[1,5]$} \\
$\beta$ & 0,001 & {$[0,00001,0,5]$} \\
$\gamma$ & 1 & {$[1,5]$} \\
\hline
\end{tabular}

A duração da busca tabu $\varphi$ é selecionada de um intervalo com distribuição uniforme que depende do tamanho da instância, dada por $[[\sqrt{T \times J \times V / 3}],[\sqrt{T \times J \times V / 3}\rceil]$. Este intervalo é obtido pela atribuição de uma duração tabu adequado a um conjunto representativo de instâncias. Como o número de veículos $V$ é irrestrito, seu valor inicial no intervalo da busca tabu é igual ao número de clientes. Em cada iteração, o valor de $V$ é ajustado dinamicamente de acordo com o número máximo de veículos ao longo dos períodos do horizonte de planejamento da solução corrente. A cardinalidade do conjunto de soluções elite $e$ tem o valor de 20 para o procedimento de religação de caminho. 


\subsubsection{Resultados para o conjunto de teste $C_{1}$}

A primeira e segunda colunas da Tabela 8 indicam o número de itens $J$ e o número de períodos $T$ para o conjunto $C_{1}$ de 72 instâncias. As colunas restantes mostram o desvio percentual médio sobre seis instâncias do custo das soluções obtidos pelos procedimentos de busca tabu (BT) e busca tabu com religação de caminho (BTR) com relação ao valor da solução ótima (OT) obtida pela resolução do modelo matemático apresentado no início da Seção 4, através do software CPLEX 10. A seguinte terminologia é usada na análise dos resultados. Para cada instância, o número de veículos requerido é o valor máximo do número de veículos usados sobre todos os períodos do horizonte de planejamento. O número total de veículos, que é a soma do número de veículos sobre seis instâncias, é mostrado na Tabela 9. Os dois procedimentos geram soluções de alta qualidade, mas BTR, tem um desempenho ligeiramente superior em instâncias maiores.

Tabela 8. Desvio percentual de BT e BTR com relação a soluções ótimas para o conjunto $C_{1}$.

\begin{tabular}{cccccccc}
\hline \multirow{2}{*}{$J$} & \multirow{2}{*}{ T } & \multicolumn{2}{c}{ 5 Clientes } & \multicolumn{2}{c}{ 10 Clientes } & \multicolumn{2}{c}{ 15 Clientes } \\
\cline { 3 - 8 } & & BT & BTR & BT & BTR & BT & BTR \\
\hline \multirow{2}{*}{5} & 12 & 28,39 & 29,96 & 35,82 & 37,86 & 50,12 & 52,31 \\
& 24 & 25,23 & 27,07 & 35,78 & 36,93 & 49,26 & 50,88 \\
\multirow{2}{*}{10} & 12 & 27,60 & 29,06 & 33,59 & 35,05 & 50,42 & 52,85 \\
& 24 & 27,02 & 27,97 & 35,01 & 36,06 & 50,64 & 51,18 \\
\hline \multicolumn{2}{c}{ Média global } & 27,06 & 28,51 & 35,05 & 36,47 & 50,11 & 51,81 \\
\hline
\end{tabular}

Tabela 9. Número total de veículos para $C_{1}$.

\begin{tabular}{ccccccccccc}
\hline \multirow{2}{*}{$J$} & \multirow{3}{*}{$T$} & \multicolumn{3}{c}{ 5 Clientes } & \multicolumn{3}{c}{ 10 Clientes } & \multicolumn{3}{c}{ 15 Clientes } \\
\cline { 2 - 10 } & & BT & BTR & OT & BT & BTR & OT & BT & BTR & OT \\
\hline \multirow{2}{*}{3} & 13 & 13 & 13 & 23 & 22 & 22 & 33 & 32 & 32 \\
& 14 & 15 & 15 & 15 & 25 & 25 & 25 & 36 & 36 & 35 \\
5 & 7 & 15 & 15 & 15 & 25 & 25 & 25 & 33 & 33 & 32 \\
& 14 & 17 & 17 & 17 & 27 & 26 & 26 & 36 & 35 & 35 \\
\hline \multicolumn{2}{c}{ Total global } & 60 & 60 & 60 & 100 & 98 & 98 & 138 & 136 & 134 \\
\hline
\end{tabular}

A Tabela 10 mostra o tempo computacional, em segundos, necessário por BT, BTR e CPLEX (OT). O tempo computacional para encontrar uma solução ótima pelo CPLEX aumenta drasticamente, atingindo mais de 4 horas para resolver instâncias com 5 itens, 14 períodos e 15 clientes, enquanto BT requer 22 segundos para atingir boas soluções com desvio médio de 1,91\%, e em torno de 2 minuutos para BTR obter soluções melhores com desvio médio de $1,48 \%$.

Tabela 10. Tempo computacional para $C_{1}$.

\begin{tabular}{ccccccccccc}
\hline \multirow{2}{*}{$J$} & \multirow{4}{*}{$T$} & \multicolumn{3}{c}{ 5 Clientes } & \multicolumn{3}{c}{ 10 Clientes } & \multicolumn{3}{c}{ 15 Clientes } \\
\cline { 2 - 10 } & & BT & BTR & OT & BT & BTR & OT & BT & BTR & OT \\
\hline 3 & 7 & 1,6 & 12,9 & 1588,4 & 5,1 & 38,4 & 2588,7 & 12,9 & 118,4 & 6084,9 \\
& 14 & 3,4 & 27,0 & 2887,6 & 8,2 & 71,7 & 4660,1 & 25,4 & 152,4 & 13293,1 \\
5 & 7 & 2,3 & 16,1 & 1667,6 & 5,7 & 39,6 & 3017,5 & 14,6 & 122,7 & 6433,5 \\
& 14 & 3,7 & 28,8 & 3075,6 & 10,2 & 75,3 & 5424,6 & 25,9 & 167,5 & 14580,6 \\
\hline \multicolumn{2}{l}{ Média global } & 2,8 & 21,2 & 2304,8 & 7,3 & 56,3 & 3922,7 & 19,7 & 140,3 & 10098,0 \\
\hline
\end{tabular}

\subsubsection{Resultados para o conjunto de teste $C_{2}$}

As 108 instâncias do conjunto $C_{2}$ foram resolvidas por BT e BTR para estabelecer um compromisso tradeoff $^{3}$ entre redução de custo computacional e acréscimo de custo de BT em relação a BTR, que fornece a solução de custo mínimo para todas as instâncias.

A solução do problema desacoplado de produção e distribuição PDPD é obtida ao se resolver, inicialmente, o problema de dimensionamento de lotes com restrições de capacidade por uma heurística Lagrangeana, veja

3 Não há uma tradução para a língua portuguesa. O significado de trade-off é uma perda de um benefício ou vantagem de modo a ganhar outro benefício (vide fronteira de Pareto em otimização multiobjetivo). Este é o significado no dicionário Collins e a palavra compromisso sugerida em várias fontes não representa este conceito. 
Toledo \& Armentano (2006). O problema de distribuição é, então, resolvido pela aplicação dos passos 1 e 2 da fase de construção e os componentes 1 e 2 da busca tabu com religação de caminho.

A Tabela 11 mostra a redução de custo percentual médio obtida por BT e BTR para o PIPD em relação à solução do PDPD sobre 9 instâncias. A redução média total indica que as soluções de PDPD têm baixa qualidade e tornam-se piores à medida que o número de clientes aumenta, mostrando que PDPD requer mais veículos. A Tabela 13 mostra que o tempo computacional é mais afetado pelo número de períodos do que pelo número de itens. Como esperado, PDPD requer tempo computacional menor em relação à resolução de PIPD por BT ou BTR.

Tabela 11. Redução percentual do custo de PIPD em relação a PDPD.

\begin{tabular}{cccccccc}
\hline \multirow{2}{*}{$J$} & \multirow{2}{*}{$T$} & \multicolumn{2}{c}{ 30 Clientes } & \multicolumn{2}{c}{ 50 Clientes } & \multicolumn{2}{c}{ 100 Clientes } \\
\cline { 3 - 8 } & & BT & BTR & BT & BTR & BT & BTR \\
\hline \multirow{2}{*}{5} & 12 & 28,39 & 29,96 & 35,82 & 37,86 & 50,12 & 52,31 \\
& 24 & 25,23 & 27,07 & 35,78 & 36,93 & 49,26 & 50,88 \\
& 12 & 27,60 & 29,06 & 33,59 & 35,05 & 50,42 & 52,85 \\
& 24 & 27,02 & 27,97 & 35,01 & 36,06 & 50,64 & 51,18 \\
\hline \multicolumn{2}{c}{ Média global } & 27,06 & 28,51 & 35,05 & 36,47 & 50,11 & 51,81 \\
\hline
\end{tabular}

Tabela 12. Número de veículos para PIPD e PDPD.

\begin{tabular}{|c|c|c|c|c|c|c|c|c|c|c|}
\hline \multirow{3}{*}{$J$} & \multirow{3}{*}{$T$} & \multicolumn{3}{|c|}{30 Clientes } & \multicolumn{3}{|c|}{50 Clientes } & \multicolumn{3}{|c|}{100 Clientes } \\
\hline & & \multirow{2}{*}{$\begin{array}{c}\text { PDPD } \\
\text { BTR }\end{array}$} & \multicolumn{2}{|c|}{ PIPD } & \multirow{2}{*}{$\begin{array}{c}\text { PDPD } \\
\text { BTR }\end{array}$} & \multicolumn{2}{|c|}{ PIPD } & \multirow{2}{*}{$\begin{array}{c}\text { PDPD } \\
\text { BTR }\end{array}$} & \multicolumn{2}{|c|}{ PIPD } \\
\hline & & & $\mathrm{BT}$ & BTR & & BT & BTR & & BT & BTR \\
\hline \multirow[t]{2}{*}{5} & 12 & 106 & 100 & 99 & 159 & 155 & 154 & 285 & 280 & 278 \\
\hline & 24 & 109 & 106 & 104 & 162 & 157 & 155 & 289 & 286 & 283 \\
\hline \multirow[t]{2}{*}{10} & 12 & 108 & 104 & 103 & 161 & 157 & 155 & 289 & 285 & 282 \\
\hline & 24 & 110 & 105 & 105 & 165 & 160 & 158 & 292 & 288 & 285 \\
\hline \multicolumn{2}{|c|}{ Total global } & 433 & 415 & 411 & 647 & 629 & 622 & 1155 & 1139 & 1128 \\
\hline
\end{tabular}

Tabela 13. Tempo computacional para PIPD e PDPD.

\begin{tabular}{|c|c|c|c|c|c|c|c|c|c|c|}
\hline \multirow{3}{*}{$J$} & \multirow{3}{*}{$T$} & \multicolumn{3}{|c|}{30 Clientes } & \multicolumn{3}{|c|}{50 Clientes } & \multicolumn{3}{|c|}{100 Clientes } \\
\hline & & \multirow{2}{*}{$\begin{array}{c}\text { PDPD } \\
\text { BTR }\end{array}$} & \multicolumn{2}{|c|}{ PIPD } & \multirow{2}{*}{$\begin{array}{c}\text { PDPD } \\
\text { BTR }\end{array}$} & \multicolumn{2}{|c|}{ PIPD } & \multirow{2}{*}{$\begin{array}{c}\text { PDPD } \\
\text { BTR }\end{array}$} & \multicolumn{2}{|c|}{ PIPD } \\
\hline & & & BT & BTR & & BT & BTR & & BT & BTR \\
\hline \multirow[t]{2}{*}{5} & 12 & 49,7 & 127,2 & 858,4 & 76,6 & 197,2 & 1320,1 & 1320,1 & 123,0 & 822,7 \\
\hline & 24 & 103,9 & 344,7 & 1243,1 & 129,0 & 562,8 & 1857,8 & 1857,8 & 245,5 & 1714,9 \\
\hline \multirow[t]{2}{*}{10} & 12 & 85,4 & 195,9 & 1442,1 & 174,0 & 327,2 & 2205,8 & 2205,8 & 280,0 & 990,0 \\
\hline & 24 & 119,7 & 565,7 & 5288,9 & 241,9 & 861,2 & 6728,0 & 6728,0 & 435,7 & 2300,3 \\
\hline & global & 89,7 & 308,4 & 2208,1 & 155,4 & 487,1 & 3027,9 & 3027,9 & 271,1 & 1457,0 \\
\hline
\end{tabular}

\subsubsection{Resultados para o conjunto de teste $C_{3}$}

O desempenho de busca tabu e busca tabu com religação de caminho é testado em um conjunto de instâncias $C_{3}$ com um único item gerado por Boudia et al. (2007). Os resultados são comparados com o algorimo genético com gerenciamento de população (MA|PM) desenvolvido por Boudia \& Prins (2009) e os melhores resultados entre uma busca tabu reativa (RTS) e religação de caminho propostos por Bard \& Nananukul (2009). O conjunto $C_{3}$ contém subconjuntos de 30 instâncias, cada um com 50, 100 e 200 clientes, com uma frota limitada de 5, 9 e 13 veículos e um horizonte de 20 períodos. Isto leva a um limite total de 150, 270 e 390 veículos para cada subconjunto de 30 instâncias.

A Tabela 14 apresenta um resumo dos resultados. A primeira e segunda colunas mostram o número de clientes e os nomes dos métodos, respectivamente. A terceira, quarta e quinta colunas mostram a média, valor percentual mínimo e máximo sobre 30 instâncias do custo obtido por cada método em relação à melhor solução, que é sempre obtida por BTR. A sexta coluna indica o número total de veículos utilizados nas 30 instâncias para BT e BTR. Este número não é fornecido pelos outros métodos, e, portanto, assumimos que o número total de veículos foi usado. Para quase metade das 90 instâncias BT requer um número menor de 
veículos que BTR. Os procedimentos BT e BTR superam MA|PM e RTS em todas as instâncias, e a qualidade da solução tende a melhorar com o número de clientes, como indicado pelos desvios médios. O menor desvio desvio em relação a BTR é 1,06\% para BT para 50 clientes e 8,57 \% para RTS para 200 clientes.

A última coluna mostra que BT requer um tempo computacional médio menor para qualquer número de clientes, enquanto BTR requer em torno do dobro deste tempo.

Tabela 14. Resumo dos resultados para um único item.

\begin{tabular}{ccccccc}
\hline Clientes & Método & $\begin{array}{c}\text { Desvio } \\
\text { médio }\end{array}$ & $\begin{array}{c}\text { Desvio } \\
\text { mínimo }\end{array}$ & $\begin{array}{c}\text { Desvio } \\
\text { máximo }\end{array}$ & $\begin{array}{c}\text { Total } \\
\text { veículos }\end{array}$ & Tempo \\
\hline \multirow{3}{*}{50} & MA | PM & 8,53 & 0,99 & 18,72 & 150 & 172,7 \\
& RTS & 1,98 & 0,62 & 6,44 & 150 & 330,6 \\
& BT & 1,06 & 0,18 & 1,99 & 150 & 144,9 \\
& BTR & 0 & 0 & 0 & 150 & 293,8 \\
\hline \multirow{2}{*}{100} & MA P PM & 4,20 & 1,14 & 12,93 & 270 & 1108,1 \\
& RTS & 3,85 & 0,86 & 8,23 & 270 & 975,6 \\
& BT & 1,46 & 0,37 & 1,98 & 263 & 507,9 \\
& BTR & 0 & 0 & 0 & 268 & 1059,7 \\
\hline & MA PM & 5,05 & 1,03 & 11,80 & 390 & 4098,5 \\
& RTS & 8,57 & 4,34 & 12,29 & 390 & 2492,3 \\
& BT & 2,10 & 0,63 & 4,97 & 383 & 1783,7 \\
& BTR & 0 & 0 & 0 & 387 & 3659,2 \\
\hline
\end{tabular}

\subsection{Considerações}

Vários aspectos merecem mais pesquisa neste problema. A utilização de trajetórias de soluções factíveis e infactíveis requer um controle de penalização mais elaborado para oscilar entre a região factível e a região infactível e, também, uso de uma duração tabu dependente da região. Além disto, a diversificação por meio de frequência de atributos de solução é importante. Estes aspectos foram discutidos em outro capítulo deste livro.

Outro ponto importante é investigar com mais detalhes a religação de caminho em termos de intensificação e diversificação, e se deve ser aplicada durante a busca em todo mínimo local da busca tabu.

\section{Considerações Finais}

A busca tabu oferece uma estrutura muito flexível com uma grande variedade de elementos pouco pesquisados, tais como, lista de candidatos, busca tabu probabilística, enfoques de intensificação e diversificação, oscilação estragégica, religação de caminho e métodos de tabu cíclico e probabilidade condicional. Glover (1998a) destaca que a pesquisa atual (ainda válida em 2012) sugere instâncias desta estrutura que geram resultados efetivos e que estabelecem a base de quais componentes da busca tabu vão oferecer mais vantagem em diversas condições. O uso de elementos mais avançados não implica em complexidade e pode ser posto em prática com implementações simples e análise dos resultados obtidos. Infelizmente, a literatura ainda é relativamente pobre neste aspecto.

Outro aspecto importante em meta-heurísticas é entender o comportamento de algoritmos existentes através de experimentos projetados para identificar a relevância de cada componente de um algoritmo e a interação entre componentes. Existe muito pouca pesquisa com este objetivo e o trabalho de Watson et al. (2006) para um algoritmo de programação em jobshop, além de pioneiro, pode ser estendido para outros algoritmos de quaisquer meta-heurísticas para outros problemas.

\section{Agradecimentos}

O primeiro autor agradece ao Conselho Nacional de Desenvolvimento Científico e Tecnológico, CNPq, pelo apoio financeiro por meio de bolsa de produtividade em pesquisa.

\section{Referências}

Armentano, V.A. \& Ronconi, D.P., Tabu search for total tardiness minimization in flowshop scheduling problems. Computers \&3 Operations Research, 26(3):219-235, 1999.

Armentano, V.A. \& Scrich, C.R., Tabu search for minimizing total tardiness in a job shop. International Journal of Production Economics, 63(2):131-140, 2000. 
Armentano, V.A.; Shiguemoto, A.L. \& Løkketangen, A., Tabu search with path relinking for an integrated productiondistribution problem. Computers $\&$ Operations Research, 38(8):1119-1209, 2011.

Baker, K.R., Introducing to Sequencing and Scheduling. New York, USA: J. Wiley \& Sons, 1974.

Baker, K.R. \& Kanet, J.J., Job shop scheduling with modifed due dates. Journal of Operations Management, 4(1):11$22,1983$.

Bard, J.F. \& Nananukul, N., The integrated production-inventory-distribution-routing problem. Journal of Scheduling, 12(3):257-280, 2009.

Boudia, M.; Louly, M.A.O. \& Prins, C., A reactive GRASP and path relinkng for a combined production-distribution problem. Computers \&5 Operations Research, 34(11):3402-3419, 2007.

Boudia, M. \& Prins, C.A., Memetic algorithm with dynamic population management for an integrated productiondistribution problem. European Journal of Operational Research, 195(3):703-715, 2009.

Clarke, G. \& Wright, J.W., Scheduling of vehicles from a central depot to a number of delivery points. Operations Research, 12(4):568-581, 1964.

Evans, J.R., An efficient implementation of the Wagner-Whitin algorithm for dynamic lot-sizing. Journal of Operations Management, 5(2):229-235, 1985.

Fumero, F. \& Vercellis, C., Synchronized development of production, inventory, and distribution schedules. Transportation Science, 33(3):330-340, 1999.

Glover, F., Future paths for integer programming and links to artificial intelligence. Computers $E$ Operations Research, 13(5):533-549, 1986.

Glover, F., Adaptive memory programming-advances, applications and challenges. In: Barr, R.S.; Helgason, R.V. \& Kennington, J.L. (Eds.), Interfaces in Computer Science and Operations Research. Norwell, USA: Kluwer Academic, p. 1-75, 1997.

Glover, F., Tabu search - wellsprings and challenges. European Journal of Operational Research, 106(2-3):221-225, 1998a.

Glover, F., A template for scatter search and path relinking. In: Hao, J.K.; Luton, E.; Ronald, E.; Schoenauer, M. \& Snyer, S.D. (Eds.), Artificial Evolution. London, UK: Springer-Verlag, v. 1363 de Lecture Notes in Computer Science, p. 13-54, 1998b.

Glover, F. \& Laguna, M., Tabu Search. Norwell, USA: Kluwer Academic, 1997.

Karimi, B.; Fatemi, S.M.T. \& Wilson, J.M., The capacitated lotsizing problem: a review of models and algorithms. Omega, 31(5):365-378, 2003.

Kim, Y.D., Minimizing mean tardiness on flowshops. European Journal of Operational Research, 85(3):541-555, 1995.

Nawaz, M.; Enscore, E.E. \& Ham, I., A heuristic algorithm for the $m$-machine, $n$-jobflow-shop sequencing problem. OMEGA, 11(1):91-95, 1983.

Nowicki, E. \& Smutnicki, C., An advanced tabu search algorithm for the job shop problem. Journal of Scheduling, 8(2):145-159, 2005.

Resende, M.G.C.; Ribeiro, C.C.; Glover, F. \& Marti, R., Scatter search and path-relinking: fundamentals, advances and applications. In: Gendreau, M. \& Potvin, J.Y. (Eds.), Handbook of Metaheuristics. Springer, 2a edição, 2010.

Ronconi, D.P., Uma contribuição para o estudo do problema de flowshop com buffer ilimitado e zero para minimizar a soma dos atrasos. Tese de Doutorado, Faculdade de Engenharia Elétrica e de Computação, Universidade Estadual de Campinas, Campinas, SP, 1997.

Sarmiento, A.M. \& Nagi, R.A., A review of integrated analysis of production-distribution. IIE Transactions, 31(11):1061-1074, 1999.

Scrich, C.R., Busca tabu para a programação de tarefas em job shop com datas de entrega. Tese de Doutorado, Faculdade de Engenharia Elétrica e de Computação, Universidade Estadual de Campinas, Campinas, SP, 1997.

Shiguemoto, A.L., Métodos heurísticos para resolução de problemas integrados de produção, estoque e distribuição. Tese de Doutorado, Faculdade de Engenharia Elétrica e de Computação, Universidade Estadual de Campinas, Campinas, SP, 2008.

Sun, M., A tabu search heuristic procedure for the capacitated facility location. Journal of Heuristics, 18(1):91-118, 2012.

Toledo, F.M.B. \& Armentano, V.A., A Lagrangian-based heuristic for the capacitated lot-sizing problem in parallel machines. European Journal of Operational Research, 175(2):1070-1083, 2006.

Wagner, H.M. \& Whitin, T.M., Dynamic version of the economic lot size model. Management Science, 5(1):89-96, 1958.

Watson, J.P.; Howe, A.E. \& Whitley, L.D., Deconstructing Nowicki and Smutnicki's i-TSAB tabu search algorithm for the job-shop scheduling problem. Computers \& Operations Research, 33(9):2623-2644, 2006. 


\section{Notas Biográficas}

Vinícius Amaral Armentano é graduado, mestre e doutor em Engenharia Elétrica (Universidade Mackenzie, 1974; Universidade Estadual de Campinas - UNICAMP, 1979; Imperial College London, 1983). Desde 1983 é docente da Faculdade de Engenharia Elétrica e de Computação (FEEC) da UNICAMP, e professor titular desde 1997. Foi professor visitante da Leeds School of Business da University of Colorado, Estados Unidos, em 2000. Tem experiência e interesse na área de otimização combinatória, com a modelagem e resolução de problemas práticos em logística, e desenvolvimento de métodos exatos e heurísticos em programação inteira. É titular de uma bolsa de produtividade em pesquisa do CNPq, nível 1A, desde 2001.

Débora Pretti Ronconi é graduada em Engenharia Elétrica (Universidade Federal do Espírito Santo, 1990), mestre e doutor em Engenharia Elétrica (Universidade Estadual de Campinas, 1993 e 1997, respectivamente). Atualmente é professora livre docente na Engenharia de Produção da Universidade de São Paulo. Tem interesse na área de otimização combinatória com ênfase no desenvolvimento de métodos heurísticos e exatos para programação de tarefas (scheduling). É titular de uma bolsa de produtividade em pesquisa do CNPq, nível 1B.

Cintia Rigão Scrich é graduada em Matemática Aplicada e Computacional (Universidade Estadual de Campinas, 1989), mestre e doutor em Engenharia Elétrica (Universidade Estadual de Campinas, 1992 e 1997, respectivamente). Atualmente é professor titular do Instituto de Ensino Superior de Americana, professor Temporário da Pontifícia Universidade Católica de Campinas e professor Titular da Faculdade de Tecnologia Padre Anchieta. Atua principalmente nos seguintes temas: programação de tarefas, heurísticas, busca tabu, job shop, datas de entrega.

André Luís Shiguemoto é graduado em Ciência da Computação (Escola de Engenharia de Piracicaba, 2001), mestre e doutor em Engenharia Elétrica (Universidade Estadual de Campinas, 2004 e 2008) com período sandwich em Molde University College, Noruega (2006). Atualmente é professor do departamento de Estatística e Matemática Aplicada da Universidade Federal do Ceará. Atua principalmente nos seguintes temas: meta-heurísticas, dimensionamento de lotes, controle de estoque, roteirização, logística e programação dinâmica. 


\title{
Um Estudo Comparativo de Algoritmos Genéticos e Beam Search para o Problema de Alocação de Células de Telefonia Celular
}

\author{
Anibal Tavares de Azevedo*e Cassilda Maria Ribeiro
}

\begin{abstract}
Resumo: Este capítulo apresenta o problema de atribuição de células às centrais de telefonia móvel. Este problema é conhecido como um problema de otimização NP-completo. Isto significa que ainda não se encontrou um método de otimização exato que seja capaz de encontrar a solução ótima do problema num tempo computacional razoável. Uma alternativa para a solução deste tipo de problema é a utilização de métodos heurísticos, pois eles permitem que se encontre uma solução de boa qualidade num tempo computacional bastante satisfatório. Três heurísticas são apresentadas para resolver este problema, sendo duas baseadas em Algoritmos Genéticos e uma relacionada ao Beam Search. Os resultados mostram a qualidade das soluções produzidas por cada método tanto em termos numéricos como através de uma análise gráfica da alocação de células para cada central. É observado o melhor desempenho do Beam Search devido a capacidade deste método em lidar com problemas cujas soluções devem atender muitas restrições.
\end{abstract}

Palavras-chave: Rede de telefonia celular, Otimização combinatória, Beam search, Algoritmo genético.

\begin{abstract}
This chapter presents the optimization problem of cell assignment to switches in a cellular mobile network. This optimization problem is known to be NP-Complete. It means, until now, it can not be solved by exact optimization algorithms, so the alternative is the heuristic methods, which can practically lead to good feasible solutions to problems of a certain size in a satisfactory computational time. Three heuristics are presented to solve these problems such that two of them are based on Genetic Algorithms and one is the Beam Search. It is also presented the solutions for each approach in terms of numerical and visualization of the cellular allocation for each central. We observed that the Beam Search Method always produces the best solutions. A possible explanation is the fact that the Beam Search Method is especially designed to deal with severely constrained problems.
\end{abstract}

Keywords: Cellular mobile network, Combinatorial optimization, Beam search, Genetic algorithm.

\section{Introdução}

Uma rede sem fio capaz de oferecer diferentes serviços tais como: voz, vídeo, correio eletrônico, etc; e acessível a partir de um terminal único é chamada Rede de Comunicação Pessoal (RCP). Os diferentes serviços da RCP são oferecidos por regiões. Essas regiões, também chamadas de zona de cobertura, são divididas em pequenas áreas geográficas denominadas de células. As células são, então, as unidades básicas do sistema de telefonia celular típica. Cada célula é responsável pelos serviços oferecidos (cobrir) a um certo número de assinantes. Para tanto, em cada célula existe uma estação básica (antena) que faz a comunicação entre os assinantes pertencentes à mesma célula. Além disto, cada célula está conectada a uma central de telefonia móvel (central de comutação) que é a responsável por fazer as ligações entre os assinantes de duas células diferentes. Cada central de telefonia móvel tem capacidade de comutar um determinado número de assinantes. Assim, várias células podem ser conectadas a uma mesma central, bastando que se respeite a capacidade máxima da mesma. Contudo, uma célula não pode estar conectada a duas ou mais centrais ao mesmo tempo.

As células possuem, por razões de cálculos, o formato hexagonal, formando algo parecido com uma colméia de abelhas. O raio deste hexágono varia de acordo com o número de assinantes por unidade de superfície (1, 2, 4, 8, 16 e 32 quilômetros). No exemplo da Figura 1 as células $\mathrm{A}$ e B estão conectadas à central telefônica 1 e as células $\mathrm{C}$ e D estão conectados à central telefônica 2 .

*Autor para contato: anibal.azevedo@fca.unicamp.br 


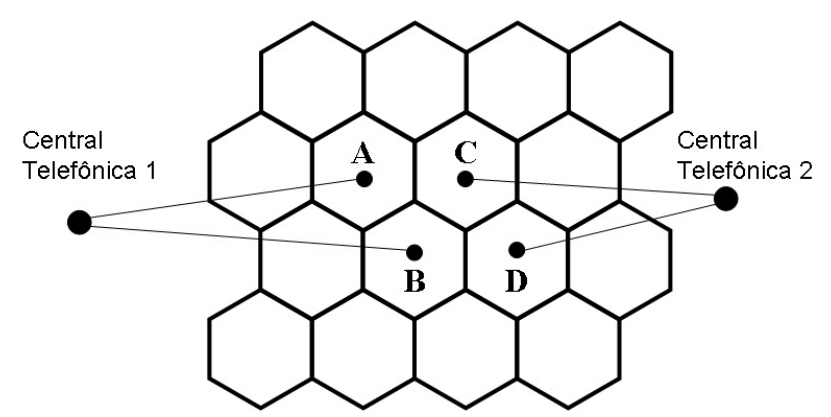

Figura 1. Divisão do sistema de telefonia celular em células.

As antenas situadas nas células utilizam canais de rádio para fazer a comunicação entre os assinantes da rede de telefonia móvel e, para evitar interferências, os grupos de canais de rádios utilizados por duas células adjacentes são diferentes.

Quando um usuário em comunicação se move de uma célula para outra, a estação básica (antena) da nova célula tem a responsabilidade de manter a comunicação deste usuário, devendo para isto alocar para ele um novo canal de rádio. A transferência de comunicação de uma estação básica para outra é chamada (em inglês) de handoff. O mecanismo que envolve a transferência de um usuário entre duas estações básicas (células) ocorre quando o nível do sinal recebido do usuário fica muito fraco. Existem dois tipos de handoff. No exemplo da Figura 1, quando o usuário se move da célula A para a B, o handoff é chamado de simples porque as duas células estão conectadas à mesma central telefônica de comutação, e o custo induzido para se fazer a transferência de A para B não é elevado. Por outro lado, quando o usuário se move da célula A para a célula $\mathrm{C}$, o handoff é dito complexo e custo induzido para se fazer esta transferência é alto, pois as duas centrais de comutação (1 e 2) devem estar ativas durante o processo de handoff e a base de dados contendo informações sobre os assinantes deve ser atualizada.

O Problema de Atribuição de Células a Centrais (PACA) consiste em atribuir $n$ células a $m$ centrais telefônicas de comutação de modo ótimo, isto é, encontrar uma atribuição de células a centrais que respeite certas restrições e minimize o custo total de operação. Na minimização do custo total de operação, dois fatores devem ser considerados. O primeiro deles é o custo da ligação entre os assinantes das células e a central de comutação na qual elas estão conectadas. Este custo é chamado de custo de cabeamento. O segundo fator é o custo gerado pelo handoff entre células.

O PACA tal como formulado por Merchant \& Sengupta (1995) é um problema NP-Completo e, portanto, de difícil solução. Aqui serão apresentadas duas versões de um algoritmo genético e uma versão do algoritmo Beam Search para resolução do PACA. A primeira versão do Algoritmo Genético usa uma estratégia de factibilização das soluções e a segunda usa uma estratégia de penalização. Serão apresentadas comparações entre as duas versões do Algoritmo Genético e o Beam Search.

\section{O Problema de Atribuição de Células a Centrais}

Uma das tarefas mais importantes no planejamento de redes de telefonia celular móvel é encontrar uma atribuição de células às centrais telefônicas de comutação que seja ao mesmo tempo barata e eficaz. O que se pretende então é encontrar uma atribuição de células às centrais que respeite algumas restrições e minimize o custo total de operação considerando dois fatores. O primeiro fator a ser considerado é o custo da ligação entre os assinantes das células e a central telefônica à qual elas estão conectadas (custo de cabeamento). Este custo depende da distância entre a célula e sua central. O segundo fator é o custo gerado pelo handoff entre células. Assim, uma atribuição lógica é fazer com que duas células sejam conectadas a uma mesma central telefônica se a frequência do handoff entre elas é alta.

O problema de se atribuir $n$ células a $m$ centrais numa rede de telefonia celular é um problema NP-completo (AbuAmara et al., 2006) e, por isto, de modo geral os métodos de busca exaustiva não são adequados para resolvê-los. Para se encontrar a solução ótima deste problema através de uma busca exaustiva, seria necessário examinar todo o espaço de soluções possíveis. Por exemplo, para uma rede com 150 células e 4 centrais telefônicas; rede esta considerada de tamanho médio; seria necessário examinar $\left(4^{150}\right)$ soluções possíveis. Utilizando-se um computador capaz de examinar uma solução a cada 1ns, seriam necessários $6,46 \times 10^{73}$ anos para examinar todas as soluções possíveis. Este problema vem sendo bastante estudado e devido à dificuldade de se resolvê-lo os métodos utilizados na sua resolução são invariavelmente as heurísticas.

Um dos primeiros a propor um modelo e uma heurística para a resolução do problema de atribuição de células a centrais foi Merchant \& Sengupta (1995), depois Saha et al. (2000) apresentaram algumas heurísticas e fizeram algumas comparações com as heurísticas já existentes, comparando inclusive com a heurística de Merchant \& Sengupta (1995). Hedible \& Pierre (2000) estudaram este problema de maneira sistemática e usaram a Busca Tabu (Houeto \& Pierre, 2002), algoritmos genéticos (Hedible \& Pierre, 2000) 
e Simulated Annealing (Quintero \& Pierre, 2003). Algoritmos combinando duas ou mais técnicas de solução também já foram propostas. Na abordagem proposta por Menon \& Gupta (2002) a técnica de Geração de Colunas é combinada com a meta-heurística Simulated Annealing. Houeto \& Pierre (2002) propuseram um Algoritmo Memético e na comparação com o Busca Tabu obtiveram melhores resultados para problemas de tamanho médio e grande. Salomão (2005) propôs um método de geração de colunas e AbuAmara et al. (2006) propuseram uma heurística usando técnicas de computação evolutiva.

\subsection{Formulação matemática do problema}

O problema de atribuição de células a centrais de comutação foi formulado por Merchant \& Sengupta (1995) como um problema de programação inteira com variáveis zero-um como mostrado a seguir.

Sejam $n$ células que devem ser atribuídas a $m$ centrais de comutação. É assumido que a localização das células e das centrais é fixa e conhecida.

Sejam $H_{i j}$ e $H_{i j}^{\prime}$ respectivamente os custos por unidade de tempo dos handoffs simples e complexo que ocorrem entre as células $i$ e $j(i, j=1, \cdots, n)$. As taxas de handoffs entre células podem ser estimadas usandose ou as estatísticas de medição do tráfego de chamadas existentes nos sistemas, ou modelos analíticos e de simulação (Alonso et al., 1992; Nanda, 1993). Portanto, é assumido que os custos de handoffs são conhecidos e proporcionais à freqüência de handoffs que ocorrem entre as células $i$ e $j$.

Seja $c_{i k}$ o custo de cabeamento por unidade de tempo entre a célula $i$ e a central de comutação $k$. Seja $\lambda_{i}$ o número de chamadas que a célula $i$ faz por unidade de tempo e seja $M_{k}$ a capacidade da central $k$ de efetuar chamadas. O objetivo deste problema consiste em atribuir cada célula a uma central de modo a minimizar o custo total por unidade de tempo. Esse custo tem dois componentes: o custo do handoff por unidade de tempo e o custo de cabeamento entre as células e as centrais. A otimização deste problema deve ser feita de modo que a capacidade máxima de cada central não seja violada e que cada célula seja atribuída a uma única central.

Seja $x_{i k}$ a variável que representa a atribuição de uma célula $i$ à uma central $k$. Assim pode-se escrever que $x_{i k}=1$ se a célula $i$ for atribuída à central $k$ e zero caso contrário. Como cada célula só pode ser atribuída à uma única central, tem-se a restrição dada pela Equação (1).

$$
\sum_{k=1}^{m} x_{i k}=1, \forall i=1, \cdots, n .
$$

A restrição de capacidade das centrais de efetuar as chamadas é dada pela Equação (2).

$$
\sum_{k=1}^{m} \lambda_{i} x_{i k} \leq M_{k}, \forall k=1, \cdots, m .
$$

O custo total de cabeamento é dado pela Equação (3).

$$
\sum_{i=1}^{n} \sum_{k=1}^{m} c_{i k} x_{i k}
$$

Para se definir os custos de handoff foram criadas as variáveis dadas pela Equação (4).

$$
z_{i j k}=x_{i k} x_{j k}, \forall i, j=1, \cdots, n, \forall k=1, \cdots, m
$$

Observe que a Equação (4) é tal que $z_{i j k}=1$ se as células $i$ e $j$ são conectadas na mesma central de comutação $k$ e $z_{i j k}=0$ caso contrário. Deste modo, pode-se definir a Equação (5).

$$
y_{i j}=\sum_{k=1}^{m} z_{i j k}=1, \forall i, j=1, \cdots, n
$$

A partir da Equação (5) é possível verificar que se $y_{i j}=1$, então, as células $i$ e $j$ estão conectadas à mesma central de comutação e se $y_{i j}=0$, então, as células $i$ e $j$ estão conectadas a centrais distintas. Assim, o custo total da rede pode ser dado pela Equação (6). 


$$
\sum_{i=1}^{n} \sum_{k=1}^{m} c_{i k} x_{i k}+\sum_{i=1}^{n} \sum_{j=1}^{n} H_{i j} y_{i j}+\sum_{i=1}^{n} \sum_{j=1}^{n} H_{i j}^{\prime}\left(1-y_{i j}\right)
$$

Segundo Hedible \& Pierre (2000), o custo do handoff simples $H_{i j}$ pode ser considerado irrelevante quando comparado ao custo do handoff complexo $H_{i j}^{\prime}$. Fazendo-se, então, $h_{i j}=H_{i j}^{\prime}-H_{i j}$, substituindo-o em (6) e desconsiderando a parte constante, a função objetivo a ser minimizada é dada pela Equação(7).

$$
\sum_{i=1}^{n} \sum_{k=1}^{m} c_{i k} x_{i k}+\sum_{i=1}^{n} \sum_{j=1}^{n} h_{i j}\left(1-y_{i j}\right)
$$

As restrições (4) e (5) são condições de igualdade que foram usadas para definir as variáveis $z_{i j k}$ e $y_{i j}$. Assim, $z_{i j k}$ pode ser substituída em (5) de modo a se obter a equação $y_{i j}=\sum_{k=1}^{m} x_{i k} x_{j k}$, que por sua vez pode ser substituída na função objetivo. Com estas modificações o problema pode ser formulado como dado por (8).

$$
\min \sum_{i=1}^{n} \sum_{k=1}^{m} c_{i k} x_{i k}+\sum_{i=1}^{n} \sum_{j=1}^{n} h_{i j}-\sum_{i=1}^{n} \sum_{j=1}^{n} \sum_{k=1}^{m} h_{i j} x_{i k} x_{j k}
$$

sujeito à:

$$
\begin{array}{r}
\sum_{k=1}^{m} x_{i k}=1, \forall i=1, \cdots, n \\
\sum_{i=1}^{n} \lambda_{i} x_{i k} \leq M_{k}, \forall k=1, \cdots, m \\
x_{i k}=0 \text { ou } 1, \forall i=1, \cdots, n, \forall k=1, \cdots, m
\end{array}
$$

Na formulação (8), note que as restrições (4) e (5) foram integradas na função objetivo e por isto puderam ser eliminadas do problema tal que o problema é não-linear. Este problema tem sido resolvido como um problema de Programação Linear Inteira (Menon \& Gupta, 2002; Merchant \& Sengupta, 1995; Salomão, 2005). Para isto basta que não se incorpore as restrições (4) e (5) à função objetivo, mas ao se proceder deste modo, o problema, que já é grande, torna-se ainda maior, pois para cada variável $z_{i j k}$ são acrescentadas mais quatro restrições.

Neste capítulo são propostos três algoritmos para resolver o PACA. Os algoritmos utilizam formulação matemática mostrada anteriormente, sem transformá-lo em um problema linear. Dois dos algoritmos que serão apresentados são do tipo Algoritmo Genético e o outro é um Beam Search.

\section{Algoritmos Genéticos}

Os algoritmos genéticos (AGs) foram introduzidos por Holland (1975). Tratam-se de algoritmos de busca geral cujo funcionamento baseia-se nos mecanismos existentes na genética e na teoria da evolução natural. A idéia apresentada por Holland despertou o interesse de outros autores tais como Goldberg (1989) e Michalewicz (1996) que aprofundaram os conceitos e técnicas envolvendo os AGs. Foi Goldberg (1989) quem descreveu a forma usual dos algoritmos genéticos como sendo técnicas de busca estocástica baseadas no mecanismo de seleção natural e genética natural.

Os AGs se diferenciam das técnicas convencionais de pesquisa na medida que eles utilizam um conjunto aleatório de soluções iniciais chamado população. A população é então um conjunto de indivíduos ou cromossomos sendo que cada cromossomo representa uma solução para o problema. Cada cromossomo é então, uma sequência de símbolos chamada de genes. O gene é a menor unidade de informação em um cromossomo e cada gene representa uma variável da solução do problema. Os cromossomos ou indivíduos (soluções) evoluem através de sucessivas iterações, chamada geração. Durante cada geração (iteração), os cromossomos são avaliados através de uma função de avaliação também chamada de fitness. A próxima geração (iteração) é obtida com a criação de um novo cromossomo que pode ser formado de dois modos:

- Utilizando um operador de crossover (ou cruzamento) que mescla dois cromossomos da geração atual;

- Modificando o cromossomo através de um operador de mutação. 
Uma nova geração $(t+1)$ é então formada selecionando, de acordo com a avaliação dos cromossomos (soluções), alguns dos pais e descendentes gerados e rejeitando outros cromossomos, de modo a manter as populações com tamanhos constantes. Depois de várias gerações, o algoritmo converge para o melhor cromossomo, o qual se espera que represente uma solução ótima ou próxima ao valor ótimo para o problema. Por ser uma ferramenta de propósito geral, o Algoritmo Genético pode ser aplicado a problemas cuja estrutura inviabiliza a aplicação de métodos exatos, tal como o problema de alocação de células de telefonia celular cuja formulação apresenta um problema combinatório. A Figura 2, a seguir, mostra a estrutura geral do Algoritmo Genético utilizada para resolver o PACA tal que $S(t)=\left\{S^{1}, S^{2}, \cdots, S^{b}\right\}$ é uma população de $b$ indivíduos de uma (iteração) geração $t$.

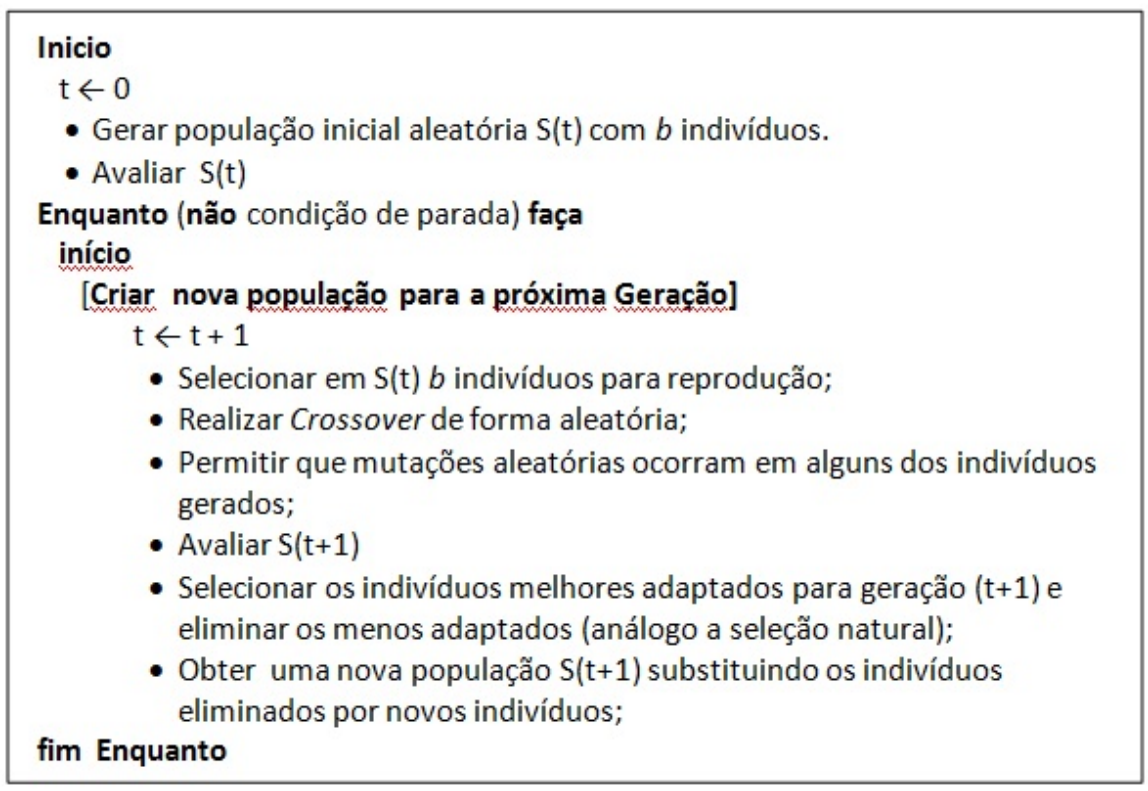

Figura 2. Estrutura geral de um algoritmo genético.

\subsection{Representação dos cromossomos para o PACA}

Os AGs têm como princípio a evolução através de gerações de uma população de indivíduos (ou cromossomos). Indivíduos nada mais são do que uma possível solução do problema, ou seja, são pontos dispostos dentro do universo de busca da solução ótima. Deste modo, a primeira coisa a ser definida na implementação de um algoritmo genético é como codificar um indivíduo, isto é, como cada indivíduo da população representa uma solução para o PACA. Aqui, a representação de cada indivíduo da população $S(t)$ foi feita através de um vetor $s$ cujo elemento $s_{j}^{t}=k$ indica que a antena $j$ foi alocada para central $k$ tal como dado na Figura 3.

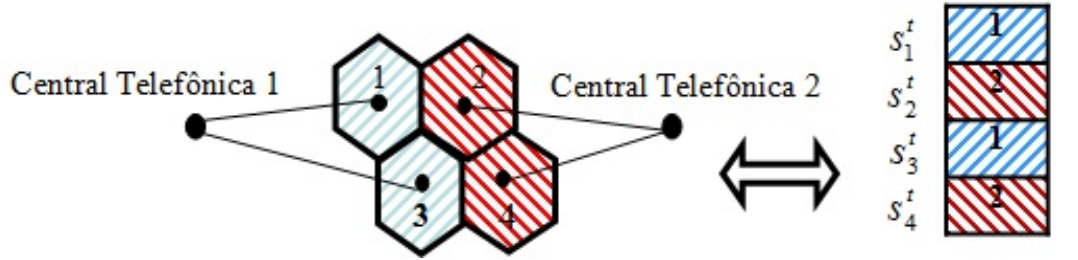

Figura 3. Codificação que relaciona uma solução do PACA com um cromossomo do AG.

Então, a cada geração (iteração $t$ ) uma população com $b$ indivíduos (soluções), pode ser armazenada em uma matriz $S(t)$ de dimensão $(n \times b)$, onde $n$ é o número de antenas e $b$ os indivíduos da geração $t$. De modo geral pode-se adotar $b$ como sendo igual ao número de antenas $n$. Assim, cada coluna com $q=1, \cdots, n$ da matriz representa uma solução (indivíduo) para o problema de alocação de antenas na geração $t$. Então, cada elemento $s_{j, q}^{t}$ da matriz $\mathrm{S}(\mathrm{t})$, representa a decisão tomada na geração $t$ de se atribuir a antena $j$ a uma central $k$, isto é, $S_{j, q}^{t}=k$. A Figura 4 mostra a matriz $S(t)$, para um exemplo com duas centrais e 4 antenas. Nesta figura supondo $t=1$, os genes do individuo 1 são os elementos da primeira coluna da matriz $S(t)$. Assim, nesta coluna $s_{1,1}^{1}=2$ significa que a antena $A 1$ foi atribuída a central 2 na geração $1, s_{2,1}^{1}=1$ significa que a antena $A 2$ foi atribuída a central 1 na geração $1, s_{3,1}^{1}=1$ indica que a antena $A 3$ foi atribuída a central 1 na geração 1 e assim por diante. Neste exemplo considerou-se o número de indivíduos iguais ao número de antenas, isto é, $b=4$. 


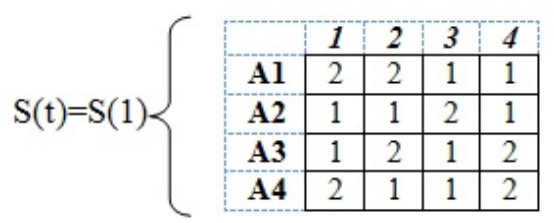

Figura 4. Representação das $b$ melhores soluções através da matriz $S(t)$.

O número de indivíduos de uma população deve ser escolhido em função do problema a ser resolvido. Com um número muito baixo de indivíduos, o universo de busca pode ser representado de maneira muito pobre. Já com um número muito grande de indivíduos, o tempo computacional pode se tornar inviável. (Haupt, 2000) fez um estudo sobre como identificar o número ideal de indivíduos. No PACA, uma boa escolha é ter, no mínimo, o número de centrais. Testes computacionais para instâncias de pequeno porte indicam que um tamanho adequado para a população é de 50 indivíduos desde que combinado com operadores de mutação apropriados.

Definindo que uma solução para o PACA está associada a uma coluna $S^{q}$ da matriz $S(t)$ de população, isto é, $S^{q}=\left\{s_{1, q}^{t}, s_{2, q}^{t}, \cdots, s_{n, q}^{t}\right\}$ com $s_{i, q}^{t}$, onde $i$ refere-se a antena; $k$ refere-se à central onde a antena $i$ foi atribuída e $q$ refere-se à coluna da matriz $S(t)$.

Uma das formas mais frequentes de codificação de solução utilizada na literatura é a binária, mas neste trabalho foi utilizada uma codificação de solução do tipo inteira. Este tipo de codificação foi escolhido pois a codificação binária demanda um vetor de soluções de maior tamanho. Observe também que uma vez obtida uma solução $S^{q}$, fica fácil de se obter dos valores das variáveis $x_{i k}$ do problema dado pela Equação (8), pois $x_{i k}=1$ para todo gene $s_{i, q}^{t}=k$ representado no individuo $S^{q}$ e $x_{i k}=0$, caso contrário. A obtenção dos valores das variáveis $x_{i k}$ se faz necessário para se calcular o valor da função objetivo durante ao execução do algoritmo.

\subsection{Tratamento das restrições}

Uma vez definida a codificação das soluções é preciso pensar em como respeitar as restrições do PACA, ou seja, a atribuição de antenas às centrais deve ser feita de modo que o total de assinantes atribuídos a uma central não ultrapasse sua capacidade. Para tanto, foram estabelecidas duas estratégias de atribuições e cada qual está associada a um algoritmo genético.

1. Estratégia de Factibilização: Toda vez que uma solução infactível é gerada aplica-se um operador heurístico de reparação (Din \& Tseng, 2002) que consiste nos seguintes passos.

- Passo 1: Para uma dada solução infactível $S^{q}$, ordenar as centrais em ordem crescente de acordo com a utilização de suas capacidades.

- Passo 2: Após a ordenação, criar duas listas de centrais: uma lista $L_{1}$ com $k_{1}$ centrais em ordem decrescente de violação da capacidade e outra lista $L_{2}$ com $k_{2}$ centrais em ordem decrescente de capacidade ociosa.

- Passo 3: Para $i=1, \cdots, k_{1}$ verificar se a $i$-ésima central de $L_{1}$ pode ter sua capacidade respeitada transferindo-se sua primeira atribuição de antena para a $j$-ésima central de $L_{2}\left(j=1, \cdots, k_{2}\right)$ desde que a $j$-ésima central não ultrapasse sua capacidade máxima. Repetir este procedimento para a segunda antena alocada à $i$-ésima central e assim por diante até que a central que estava infactível seja factibilizada. Ao se fazer isto, se a capacidade da $j$-ésima central se esgotar, passa-se para a próxima central na lista $L_{2}$ com capacidade disponível.

2. Estratégia de Penalização: Seja $S^{q}$ uma solução que produz uma infactibilidade $g\left(S^{q}\right)$ relativa às restrições de capacidade. Adiciona-se então uma penalidade $p\left(S^{q}\right)$ ao valor da função objetivo $f\left(S^{q}\right)$ para reduzir a probabilidade deste indivíduo, que representa esta solução, de participar da população da próxima geração. Esta estratégia foi inicialmente proposta por Goldberg (1989) e torna o problema irrestrito e a função objetivo passa a ser dada pela Equação (9):

$$
\min f\left(S^{q}\right)+p\left(S^{q}\right) \cdot g\left(S^{q}\right)
$$

onde: 


$$
\begin{array}{r}
f\left(S^{q}\right)=\sum_{i=1}^{n} \sum_{k=1}^{m} c_{i k} x_{i k}+\sum_{i=1}^{n} \sum_{j=1}^{n} h_{i j}-\sum_{i=1}^{n} \sum_{j=1}^{n} \sum_{k=1}^{m} h_{i j} x_{i k} x_{j k}, \\
p\left(S^{q}\right)=100\left(\max _{i}\left\{c_{i k}\right\}+\max _{i}\left\{\sum_{j=1}^{m} h_{i j}\right\}\right), \\
g\left(S^{q}\right)=\max \left\{0, \sum_{i=1}^{n} \lambda_{i} x_{i k}-M_{k}\right\}
\end{array}
$$

A função de penalização $p\left(S^{q}\right)$ é geral e não depende de ajustes para cada instância em questão, pois foi construída de modo que a penalidade é calculada considerando os custos de cabeamento $\left(c_{i k}\right)$ e handoff $\left(h_{i j}\right)$, bem como das capacidades das centrais $\left(M_{k}\right)$ de cada instância.

\subsection{Função de avaliação (fitness)}

O terceiro passo a ser realizado é definir a função de avaliação da solução, ou seja, a função de fitness. Ela é responsável por estabelecer uma relação de ordem entre os indivíduos de uma população para uma dada geração $t$. A função de fitness deve ser tal que os indivíduos mais aptos tenham uma melhor avaliação de modo que estes indivíduos quando presentes na solução façam com que a função objetivo do problema seja menor. Isto se aplica tanto para a estratégia de factibilização (função objetivo do problema (1)), como para a estratégia de penalização (função objetivo do problema (9)).

A função de fitness utilizada é a da Equação (10), onde $S^{q}$ é o $q$-ésimo indivíduo de uma população $t$, que representa uma solução.

$$
\operatorname{Fit}\left(S^{q}\right)=\frac{1}{1+f\left(S^{q}\right)+p\left(S^{q}\right)}
$$

\subsection{Seleção}

O quarto passo a ser realizado é a seleção de indivíduos para a próxima geração. Não foram realizados testes com todas as possibilidades de processo de seleção, devido à ênfase da literatura na elaboração de operadores de mutação e crossover como forma de superar a dificuldade em se obter soluções factíveis e ao mesmo tempo com baixo valor de função objetivo (Hedible \& Pierre, 2000; Din \& Tseng, 2002; Dianati et al., 2003). O processo de seleção empregado é do Roulette Wheel, ou seja, é realizado um sorteio aleatório onde a probabilidade de sorteio do $q$-ésimo indivíduo, de uma população com $k$ indivíduos, para participar da próxima geração é diretamente relacionado ao seu fitness tal como dado pela Equação (11):

$$
Q\left(S^{q}\right)=\frac{F i t\left(S^{q}\right)}{\sum_{t=1}^{k} F i t\left(S^{q}\right)}
$$

Além disto, o melhor indivíduo de todas as gerações sempre é selecionado para a próxima geração (elitismo).

\subsection{Operadores de crossover e mutação}

A seguir é necessário estabelecer os chamados operadores de crossover. Esses operadores tem a função de gerar novos indivíduos para a população combinando as informações de gerações anteriores contidas em seus indivíduos. Foram estabelecidos dois operadores e a definição de qual dos dois operadores será utilizado é feita através de um sorteio aleatório em que cada um dos operadores tem $50 \%$ de chance de ser escolhido. Os operadores utilizados são:

- Crossover OX: Primeiro seleciona-se aleatoriamente dois indivíduos $I_{1}$ e $I_{2}$ de uma geração $t$. O vetor de soluções $S^{q}$ possui $n$ (número de antenas) elementos e um valor aleatório inteiro $r$ é sorteado dentro do intervalo [1 $n-1]$. Após isto, os genes de $I_{1}$ que estão nas posições $r+i$, até $n$ são trocados com os genes de $I_{2}$ que também estão nas posições $r+i$ até $n$, de modo que esta troca gere dois novos indivíduos $N_{1}$ e $N_{2}$ que poderão participar da geração $t+1$. A descrição deste processo está ilustrada na Figura 5 . 


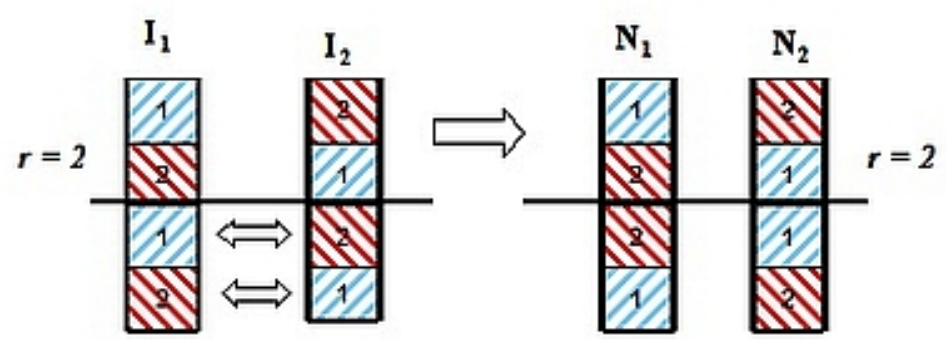

Figura 5. Exemplo de aplicação do operador de crossover OX.

- Crossover CE: Este operador é uma modificação do que é apresentado no trabalho de Din \& Tseng (2002). Ele consiste em primeiro empregar o crossover OX para obter dois novos indivíduos $N_{1}$ e $N_{2}$. O segundo passo é, para cada um dos novos indivíduos, escolher dois elementos $v_{i}$ e $v_{j}$. Então, todo elemento do vetor de solução $S^{q}$, cujo valor é igual ao valor contido em $i$ será trocado pelo valor contido em $j$ e vice-versa. A Figura 6 ilustra o funcionamento deste operador para o indivíduo $N_{1}, i=2$ e $j=4$.

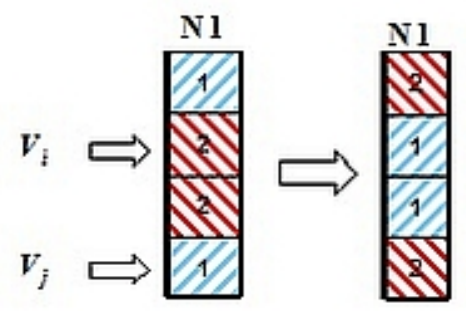

Figura 6. Exemplo de aplicação do operador de crossover CE.

O próximo passo consiste em definir os Operadores de Mutação. Foram definidos quatro Operadores de Mutação que serão apresentados a seguir. Eles são utilizados para alterar informações existentes dentro de um único indivíduo. O Algoritmo Genético emprega um processo de sorteio que considera diferentes probabilidades de utilização de cada operador de mutação. Estas probabilidades levam em conta o custo de utilização do operador. Todas as mutações empregadas foram extraídas do trabalho de Din \& Tseng (2002).

- Mutação Simples (S): Este operador de mutação simplesmente realiza a mutação de um gene $s_{i, q}^{t}$ do indivíduo $S^{q}$ na iteração $t$, de acordo com uma probabilidade dada por pela Equação (12).

$$
p m_{i t}=0,5 \times\left(\frac{\max (F i t(S(t)))-F i t\left(S^{q}\right)}{\max (F i t(S(t)))-\operatorname{avg}(F i t(S))}\right)
$$

onde: Fit $\left(S^{q}\right)$ é o fitness do indivíduo $S^{q}$ na geração $t, \max (F i t(S(t)))$ é o maior valor de fitness na geração $t$ e $\operatorname{avg}(F i t(S))=\left(\sum_{q=1}^{b} F i t\left(S^{q}\right)\right) / b$ é a média do fitness da população com $b$ indivíduos na geração $t$.

- Mutação Menor Custo de Cabeamento Primeira Preferência (MMCPP): Este operador de mutação orienta a redução de custo de cabeamento, privilegiando a atribuição de uma antena à central mais próxima. Dada uma antena $A_{i}$ e uma central $C_{k}$ com custo de cabeamento $c_{i k}$, que é o menor de todos os custos de cabeamento, então, isto resultará em uma maior probabilidade da antena $A_{i}$ ser atribuída à central $C_{k}$. A probabilidade de que uma antena $A i$ seja selecionada aleatoriamente, e que estava atribuída à central $j$, passe a ser atribuída para a central $k$, é dada por (13):

$$
p m_{i k}=\frac{L_{\max }-c_{i k}}{\sum_{i=1}^{m}\left(L_{\max }-c_{i k}\right)}
$$

onde: $L_{\max }=\max _{k=1}^{m}\left\{c_{i k}\right\}$ 
- Mutação Maior Peso Primeira Preferência (MPPP): Este operador de mutação considera que o custo de handoff é importante e que duas antenas $A_{i}$ e $A_{j}$ com grande valor $h_{i j}$ devem ter uma probabilidade maior de pertencerem à mesma central. Assim, a probabilidade de que o valor $s_{i, q}^{t}$ (alocação para a antena $A_{i}$ ) seja transformado no valor $s_{j, q}^{t}$ (alocação para a antena $A_{j}$ ) é dado pela Equação (14).

$$
p m_{i k}=\frac{h_{i j}}{\sum_{i=1}^{n} \sum_{j=1}^{n} h_{i j}}
$$

- Mutação Mínimo Incremento Radial Primeira Preferência (MIRPP): Este operador de mutação tem por objetivo a verificação da redução do custo de handoff quando antenas $A_{i}$ e $A_{j}$, inicialmente atribuídas a centrais distintas, passam a serem alocadas a uma mesma central. Para tanto, é introduzida uma medida de variação do custo de handoff, $\Delta h_{i j}$, quando a antena $A_{i}$ é atribuída à mesma central da antena $A_{j}$. A partir desta medida é calculada a probabilidade que o valor $v_{i}$ (alocação à antena $A_{i}$ ) seja transformado no valor $v_{j}$ (alocação à antena $A_{j}$ ) através da Equação (15).

$$
p m_{i k}=\frac{\Delta h_{i j}}{\sum_{i=1}^{n} \sum_{k \in \Omega_{i}}\left(D-\left(\Delta h_{i k}+R\right)\right)}
$$

onde: $\Delta h_{i j}=\sum_{k \in \Omega_{i}} h_{j k}-h_{i j}-h_{j i}, R=\left|\min _{i \in N} \min _{j \in N}\left\{\Delta h_{i j}\right\}\right|, D=\max _{i \in N} \max _{k \in \Omega_{i}}\left|\Delta h_{i k}+R\right|, N=\{1,2,3, \ldots, n\}$ o conjunto dos índices das antenas e $\Omega_{j}$ o conjunto de antenas que não pertencem à mesma central que foi atribuída à antena $A_{j}$.

A principal diferença entre a Equação (15) e a Equação (14), é que a Equação (15) capta detalhada e corretamente a variação no custo de handoff quando ocorre a modificação da atribuição de uma antena de uma central para outra, mas a um custo computacional elevado, ao passo que a Equação (14) fornece apenas uma estimativa desta variação, mas sua utilização é de baixo custo computacional.

Devido ao alto custo computacional no cálculo da Equação (15), foi desenvolvido um mecanismo, em adição às mutações especificadas anteriormente, que visa aumentar a utilização da mutação MIRPP de acordo com o número de gerações sem melhoria no valor da função objetivo. Inicialmente o algoritmo considera as seguintes probabilidades de utilização das mutações: 30\% para MPPP, 1\% para MIRPP e $69 \%$ para MMCPP. Se após 10 gerações não ocorrer melhoria no valor da função objetivo do melhor indivíduo da população (que é sempre passado para a próxima geração), então, a probabilidade de uso de MIRPP, $p_{u} s o$, será incrementada segundo a Equação (16).

$$
p_{\text {uso }}=\min \left(\gamma, \max \left(\theta, \gamma\left(1-e^{\frac{-t}{N / \alpha}}\right)\right)\right)
$$

onde: $\gamma$ é o maior valor que a probabilidade de escolha da mutação MIRPP pode assumir, $\gamma=5 \% ; \theta$ é o menor valor que a probabilidade de escolha da mutação MIRPP pode assumir, $\theta=1 \%$; é um índice que indica qual a geração atual; $N$ é o número máximo de gerações, atribuído como 1000; $\alpha$ é o parâmetro que indica o número de gerações sucessivas que poderá ocorrer incremento no valor de $p_{\text {uso }}$, assumido como $\alpha=7$.

Se para um dado valor de $\gamma$ ocorrer em uma dada geração uma melhoria no valor da função objetivo do melhor indivíduo, então, faz-se uma redução na probabilidade de utilização da mutação MIRPP de acordo com a Equação (17).

$$
p_{\text {uso }}=\gamma\left(1-e^{\frac{-t}{N / \beta}}\right)
$$

onde: $\beta$ é o parâmetro que indica o número de gerações sucessivas que poderá ocorrer decréscimo no valor de $p_{\text {uso }}$, assumido como $\beta=8$.

A Figura 7 fornece um indicativo da evolução do valor de $p_{\text {uso }}$ ao longo das gerações de acordo com a Equação (16) e com a Equação (17).

A Figura 7(a) ilustra o comportamento do Algoritmo Genético com relação à probabilidade de mutação $\left(p_{\text {uso }}\right)$. Observe que o algoritmo procura adotar valores mais altos de utilização da mutação MIRPP à medida 


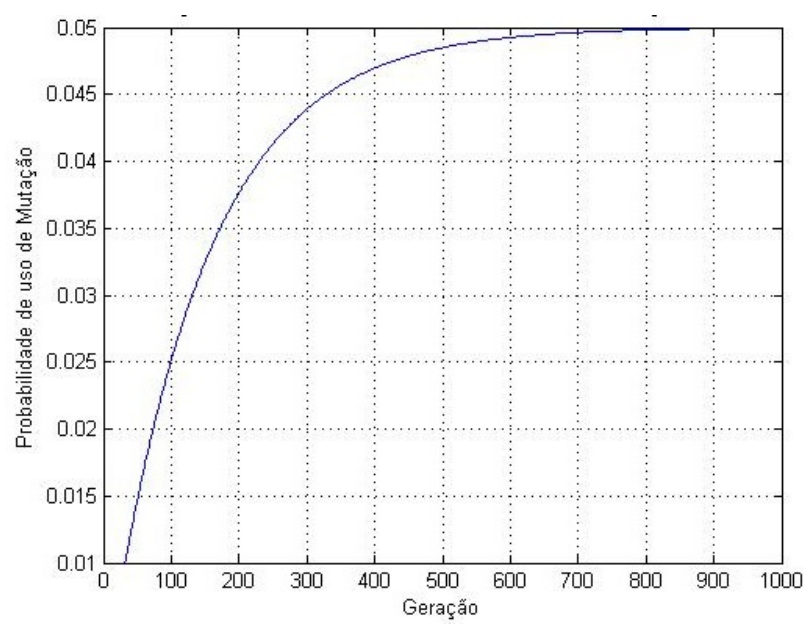

(a) Incremento de $p_{\text {uso }}$

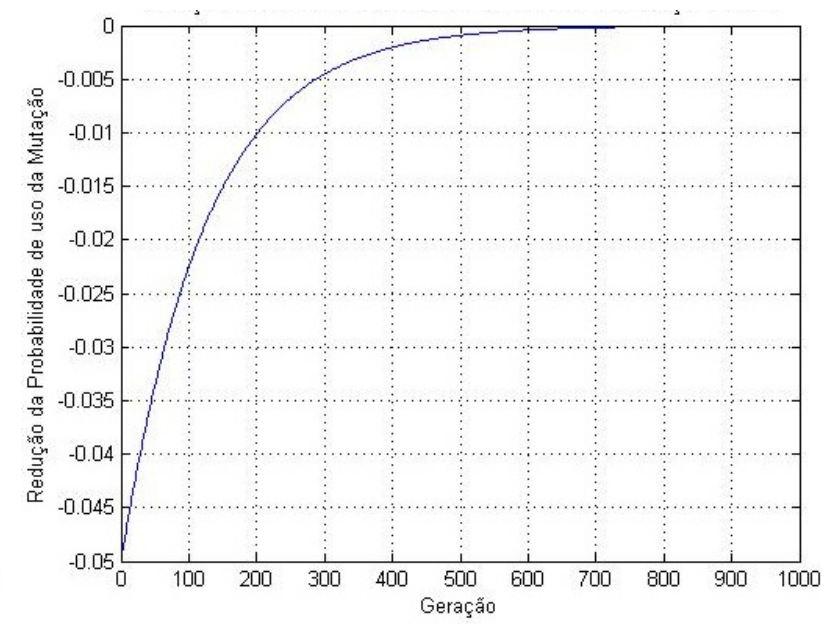

(b) Decremento de $p_{\text {uso }}$

Figura 7. Exemplo da evolução dos incrementos de $p_{\text {uso }}$ ao longo das gerações com a Equação (16) e evolução dos decrementos de $p_{\text {uso }}$ ao longo das gerações com a Equação (17).

que o número de gerações sem melhoria da função objetivo se aproxima do número máximo adotado, que neste caso é 1000. A Figura 7(b) mostra a evolução dos decréscimos da probabilidade de mutação $p_{\text {uso }}$ cada vez que 10 gerações não apresentam melhoria no fitness do melhor indivíduo de uma população. Com esta figura é possível verificar que no início a adoção de valores altos de mutação MIRPP não perdura muito tempo, pois a cada geração com melhoria, os valores de decréscimos a serem aplicados são altos. Após 500 gerações os valores de redução são muito próximos de zero.

Foram implementadas duas versões do algoritmo genético: uma que emprega a estratégia de penalização (AGP) e outra que usa a estratégia de factibilização (AGF). As duas versões utilizam a estrutura de dados descrita na Seção 3.1, a função de avaliação (Equação (10)) e o processo de seleção de indivíduo para a próxima geração (Equação (11)). A Tabela 1 resume as características que diferenciam as duas versões dos Algoritmos Genéticos.

Tabela 1. Algoritmos Genéticos implementados.

\begin{tabular}{lccc}
\hline & Restrições & Crossover & Mutação \\
\hline AGP & Penalização & OX & S \\
AGF & Factibilização & OX, CE & MCCP, MPPP, MIRPP \\
\hline
\end{tabular}

\section{Método Beam Search}

O Beam Search (BS) é um método heurístico para resolver problemas de Otimização combinatória. Pode-se dizer que ele é uma adaptação do método de Branch and Bound onde somente os nós mais promissores de cada nível da árvore de busca são guardados na memória para serem visitados, enquanto que os demais nós são descartados permanentemente. Como uma grande parte dos nós da árvore de busca é descartada, isto é, somente alguns poucos nós são selecionados para serem analisados, o tempo de execução do método é polinomial com o tamanho do problema. Em resumo pode-se dizer que o Beam Search é uma técnica de busca em árvore que utiliza um número de soluções em paralelo. O número de soluções em paralelo é chamado de largura de busca e é denotado por $\beta$.

O Beam Search foi usado pela primeira vez pela comunidade de Inteligência Artificial para tratar problemas de reconhecimento de fala (Lowerre, 1976). Desde então, tem aparecido na literatura várias aplicações deste método em problemas de sequenciamento da produção (Fox, 1983; Ow \& Morton, 1988a,b) criaram uma variação do método, para o qual deram o nome de Beam Search filtrado. Outra variante do método foi proposta por Della Croce \& T'Kindt (2002). A esta variante foi dado o nome de Beam Search Recuperado (Recovering Beam Search). Valente et al. (2005) desenvolveram um Beam Search que mistura as versões propostas por Ow \& Morton (1988a) e Della Croce \& T'Kindt (2002). 


\section{1 Árvore completa}

Como já foi dito anteriormente, o BS consiste numa técnica de busca em árvore, logo é preciso que se gere uma árvore com as soluções possíveis do problema. Mas vale lembrar que esta técnica não gera todas as soluções, pois não se trata de um algoritmo de busca exaustiva. Assim serão geradas somente as soluções dentro de uma certa largura de busca $\beta$, pré-determinada.

Será utilizado um exemplo para mostrar como seria a árvore de soluções se fossem consideradas todas as soluções possíveis. Sejam $n=4$, o número de células (antenas) que devem ser atribuídas a $m=2$ centrais de comutação. Cada célula (antena) $A_{i}$ tem capacidade de realizar um número fixo de chamadas $\lambda_{i}$ por unidade de tempo. Assim, o número de chamadas cobertas pela antena $A_{1}$ é $\lambda_{1}$, e $\lambda_{2}$ é o número de chamadas cobertas pela antena $A_{2}$ e assim por diante. Essas chamadas serão realizadas pela central de comutação $C_{j}$, se a célula $A_{i}$ estiver conectada à central $C_{j}$. Cada uma destas centrais tem uma capacidade $M_{j}$ de efetuar chamadas. Ou seja, $M_{1}$ é a capacidade da central $C_{1}, M_{2}$ é a capacidade da central $C_{2}$ e assim sucessivamente. Cada célula só pode estar conectada a uma única central. A variável é $x_{i j}$, onde $x_{i j}=1$ significa que a célula $i$ está conectada a central $j$ e $x_{i j}=0$, caso contrário.

As Tabelas 2 e 3 mostradas a seguir apresentam as informações sobre custo de cabeamento, custo de handoff, número de chamadas de cada antena e capacidade das centrais, para o problema da Figura 8.

Tabela 2. Custo de Cabeamento $C_{i k}$ entre as antenas e as centrais, número de chamadas $\lambda_{i}$ de cada antena e capacidade $M_{i}$ de cada central.

\begin{tabular}{|c|c|c|c|}
\hline \multirow{2}{*}{ Antena } & \multicolumn{2}{|c|}{$C_{i k}$} & \multirow{2}{*}{$\lambda_{i}$} \\
\hline & Central 1 & Central 2 & \\
\hline 1 & 0 & 0 & 4 \\
\hline 2 & 4 & 4 & 4 \\
\hline 3 & 4 & 4 & 4 \\
\hline 4 & 8 & 8 & 4 \\
\hline$M_{i}$ & 10 & 10 & \\
\hline
\end{tabular}

Tabela 3. Custo de handoff $H_{i j}$ entre as antenas.

\begin{tabular}{ccccc}
\hline Antena & $\mathbf{1}$ & $\mathbf{2}$ & $\mathbf{3}$ & $\mathbf{4}$ \\
\hline $\mathbf{1}$ & 0 & 3 & 2 & 2 \\
$\mathbf{2}$ & 3 & 0 & 1 & 51 \\
$\mathbf{3}$ & 2 & 1 & 0 & 4 \\
$\mathbf{4}$ & 2 & 51 & 4 & 0 \\
\hline
\end{tabular}

Antes de construir a árvore de decisões com todas as soluções possíveis para este problema é necessário estabelecer as seguintes definições:

- (D.1) A árvore é construída por níveis e, a cada nível $i$, é estabelecida a atribuição da $i$-ésima antena a $k$-ésima central.

- (D.2) Os nós da árvore associados ao nível 1 são chamados de nó semente.

- (D.3) De (D.1) vem que a árvore possui $n$ níveis e que uma solução completa, com a atribuição de todas as antenas a todas as centrais só será obtida ao se definir as atribuições até o nível $n$.

- (D.4) A cada nível $i$, ao se realizar a atribuição da $i$-ésima antena à $k$-ésima central, são contabilizados dois custos: custo fixo de cabeamento $C_{k}$ e custo de handoff $H_{i j}$ considerando todas as $k-1$ atribuições anteriores.

A Figura 8 mostra como é a árvore de decisões para este problema, considerando-se todas as soluções possíveis.

Os nós de cada nível da árvore representam uma atribuição. Começa-se a construir a árvore fixando uma central, por exemplo, a central $C_{1}$ e atribuindo a ela uma célula, por exemplo, $A_{1}$. Assim, o nó 1 do nível 


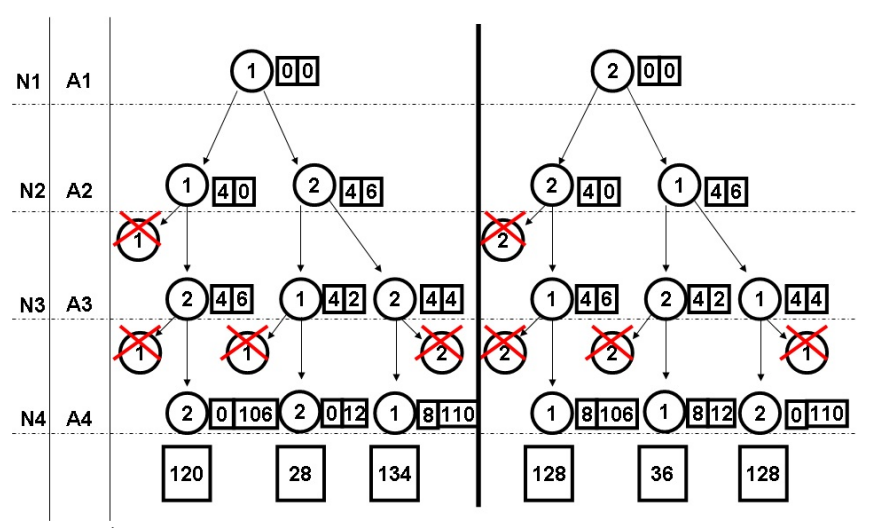

Figura 8. Árvore de soluções factíveis considerando o nó semente $C_{1}$ no nível 1 (árvore da esquerda) e $C_{2}$ no nível 1 (árvore da direita).

$N_{1}$ significa que a célula $A_{1}$ foi atribuída a central $C_{1}$, isto é, $x_{11}=1$. Para esta atribuição inicial foi dado o nome de nó semente. Uma vez feita a atribuição do nó semente segue-se fazendo as demais atribuições, sempre levando em conta as atribuições que já foram feitas nos nós anteriores. Note que o número de nós sementes é igual ao número de centrais $m$, logo são criadas $m$ árvores, uma para cada central.

Em cada nó da Figura 8 também estão representados os custos fixos de cabeamento e custos de handoff relativos à atribuição efetuada no nó. Os nós marcados com uma cruz fornecem uma atribuição infactível e, por esta razão, eles são automaticamente eliminados do processo. É importante frisar que o número total de soluções é de $m^{n}=2^{4}=16$ soluções possíveis, mas que dentre estas apenas 6 eram factíveis, justificando a aplicação de um procedimento de busca em árvore, como o é o BS.

\section{2 Árvore de soluções do beam search}

Um melhor detalhamento e descrição da adaptação do Beam Search para o PACA pode ser obtido em Ribeiro et al. (2009) e Ribeiro et al. (2011). Para fins didáticos aqui será ilustrado a aplicação do BS no exemplo fornecido na Seção 4.1.

As Figuras (9(a))-(11(b)), apresentam a resolução detalhada do exemplo da Seção 4.1 pelo BS. No exemplo é considerada largura igual a $\beta=2$. Os passos a serem seguidos para se resolver o exemplo são:

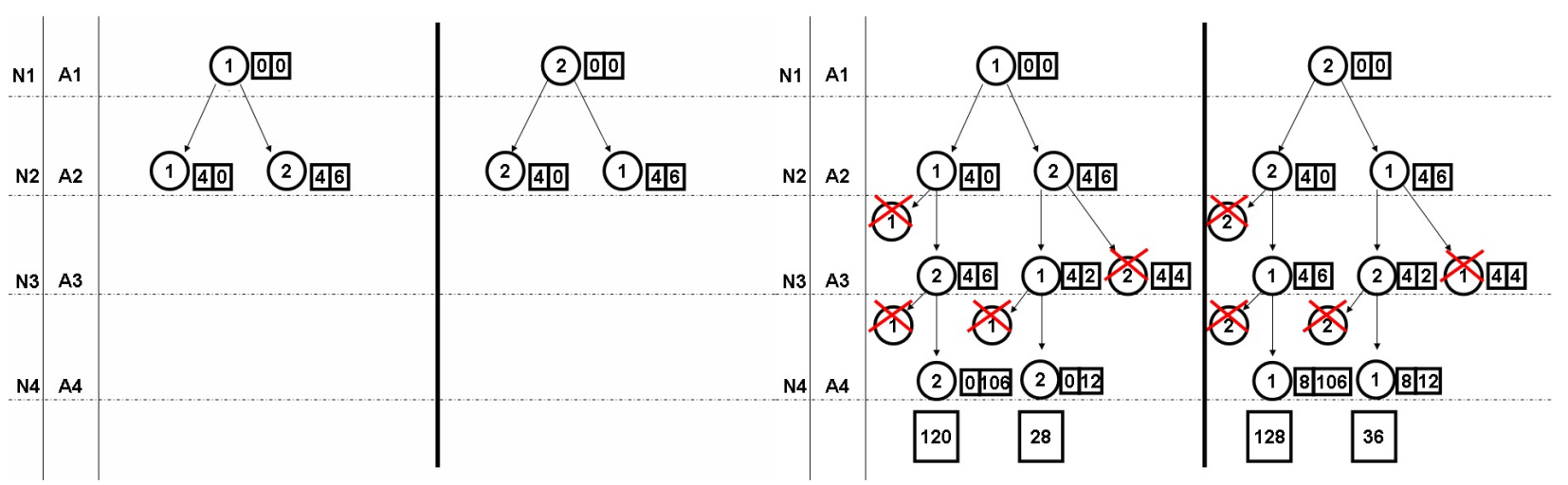

(a)

(b)

Figura 9. Passos da execução do BS para o exemplo da Seção 4.1 (Parte 1).

1. Construir os nós do nível 1 (um nó para cada central). Os custos de cabeamento e handoff, neste nível são iguais à zero (veja Tabelas 2 e 3).

2. No nível 2 inicialmente são criados 4 nós, pois a partir da atribuição feita no nível 1, existem 4 atribuições possíveis para a antena 2 a saber: $A_{2} C_{1}$ e $A_{2} C_{2}$ na árvore da esquerda e $A_{2} C_{2}$ e $A_{2} C_{1}$ na árvore da direita. Esta situação esta descrita na Figura 9 (a) e corresponde ao primeiro passo do Beam Search. Como a largura da busca é dois, somente dois destes nós permanecem na árvore.

3. Para escolher quais nós do nível 2 devem permanecer é realizada uma busca em profundidade, até o ultimo nível, para cada uma das 4 alocações parciais do nível 2. Esta busca escolhe os nós com atribuições factíveis e com menor custo de cabeamento mais handoff. Tal situação está descrita na Figura 9(b) e corresponde ao segundo passo do Beam Search. A Figura 10(a) mostra quais foram os nós escolhidos 


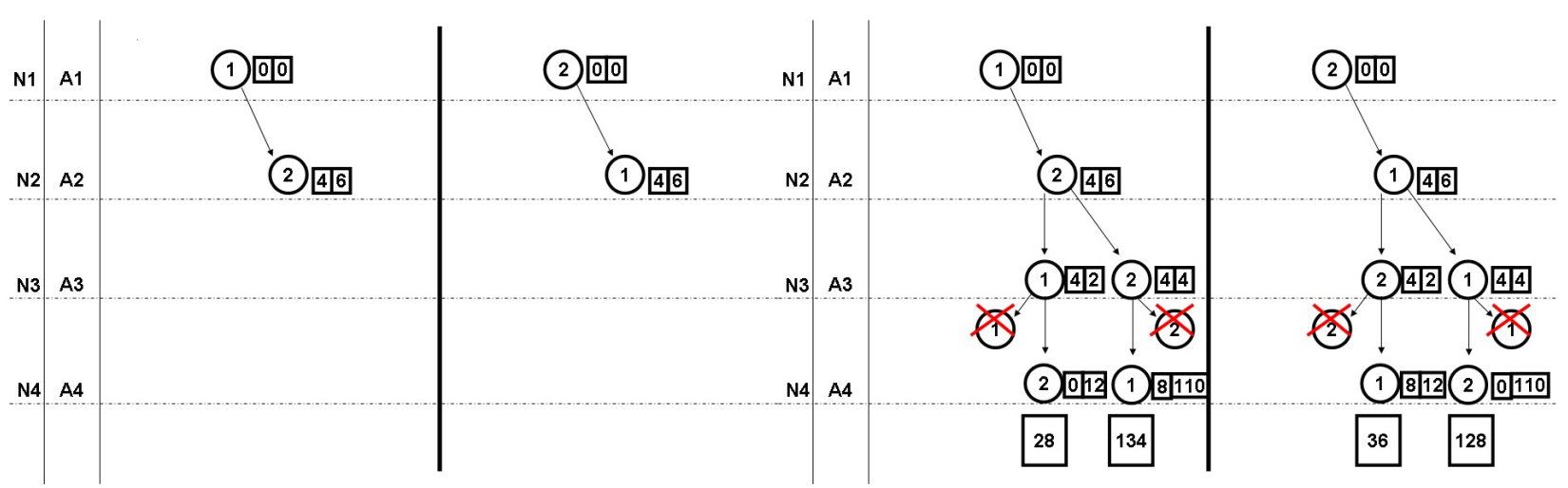

(a)

(b)

Figura 10. Passos da execução do BS para o exemplo da Seção 4.1 (Parte 2).

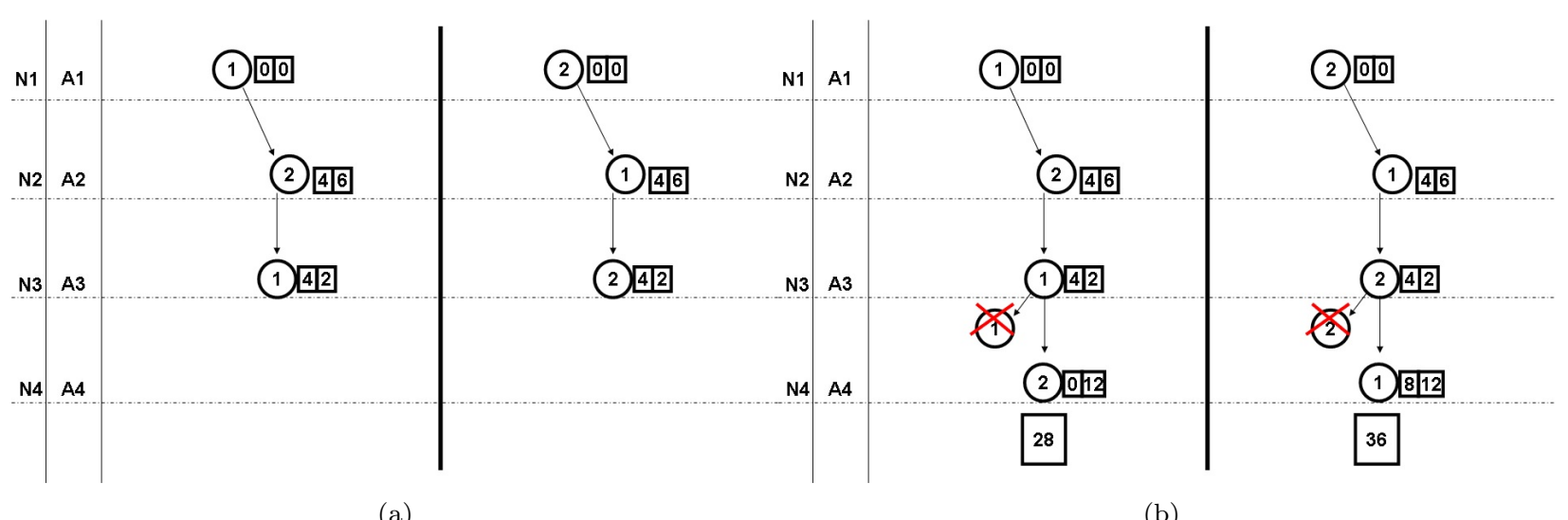

Figura 11. Passos da execução do BS para o exemplo da Seção 4.1 (Parte 3).

para ficar na árvore. A seguir é feita uma arborescência dos nós do nível 3 (passo 1) e depois uma busca em profundidade a partir destes nós $(10(\mathrm{~b})$ ) de modo a se escolher quais nós do nível 3 vão permanecer na árvore. A Figura 11(a) mostra os nós escolhidos do nível 3. A Figura 11(b) mostra arborescência (passo 1) dos nós da Figura 11(b) e a nova solução gulosa (passo 2). Obtêm-se assim duas soluções finais: $A_{1} C_{1}, A_{2} C_{2}, A_{3} C_{1}, A_{4} C_{2}$ com custo de 28 e $A_{1} C_{2}, A_{2} C_{1}, A_{3} C_{2}, A_{4} C_{1}$ com custo de 36 . Adota-se então a solução de menor custo entre as duas.

\section{Resultados Computacionais}

Com o intuito de se fazer um estudo comparativo entre as duas versões do algoritmo genético (AGP e AGF), do Beam Search (BS) e do método apresentado por Merchant \& Sengupta (1995) (MS) foram feitos testes computacionais com 28 instâncias com dimensões variadas. Foram testadas as mesmas instâncias utilizadas por Merchant \& Sengupta (1995). Os resultados obtidos são apresentados na Tabela 4 a seguir. Começouse com problemas de tamanho considerado pequeno (15 antenas e 2 centrais), até problemas de tamanho considerado médio (125 antenas e 4 centrais).

Os resultados na Tabela 4 indicam que o algoritmo genético com estratégia de factibilização das soluções (AGF) apresenta melhores resultados do que a estratégia de penalização (AGP). Além disto, o mecanismo de controle do uso de mutações permitiu a redução do esforço computacional demandado pelos operadores genéticos do AGF, sem que isto ocasionasse a perda de qualidade das soluções obtidas.

Disto pode-se concluir que estratégias cujo foco é verificar a factibilidade das soluções vão, na maioria das vezes, apresentar melhores resultados que as estratégias de penalização. A prova disto é o pior desempenho desta estratégia em comparação com o AGF e o BS. A qualidade da soluções encontradas para o AGP, na maioria das instâncias, só não é pior que a heurística de Merchant \& Sengupta (1995). Isto pode ser melhor visualizado através das Figuras 12(a), 12(b), 12(c) e 12(d) que fornecem a qualidade das melhores soluções obtidas para cada metodologia para a instância com 60 antenas e 5 centrais.

A qualidade das soluções obtidas pelos algoritmos AGP, BS, AGF e MS para a instância com 60 antenas e 5 centrais pode ser verificada visualmente através Figuras 12(a), 12(b), 12(c) e 12(d). Nestas figuras é possível 
Tabela 4. Resultados obtidos com $A G P, A G F, M S$ e $B S$.

\begin{tabular}{|c|c|c|c|c|c|}
\hline \multirow{3}{*}{$\# A$} & \multirow{3}{*}{$\# C$} & \multicolumn{4}{|c|}{$F_{o b j}$} \\
\hline & & \multicolumn{2}{|c|}{ Genéticos } & \multirow{2}{*}{$\begin{array}{c}\text { Heurística } \\
\text { MS }\end{array}$} & \multirow{2}{*}{$\begin{array}{c}\text { Beam Search } \\
\text { BS }\end{array}$} \\
\hline & & AGF & AGP & & \\
\hline \multirow{4}{*}{15} & 2 & 130,9110 & 130,9110 & 140,5057 & 134,6165 \\
\hline & 3 & 124,6243 & 126,5147 & 136,8644 & 131,9053 \\
\hline & 4 & 100,8334 & 102,5019 & 106,0827 & 100,8334 \\
\hline & 5 & 105,7730 & 112,6118 & 110,5230 & 106,4477 \\
\hline \multirow{4}{*}{30} & 2 & 328,2806 & 328,2806 & 331,2613 & 328,2806 \\
\hline & 3 & 346,2276 & 347,1058 & 348,8777 & 345,5388 \\
\hline & 4 & 289,8188 & 307,1258 & 305,1077 & 285,9955 \\
\hline & 5 & 252,7450 & 298,2984 & 250,2420 & 246,7576 \\
\hline \multirow{4}{*}{45} & 2 & 940,6231 & 945,8115 & 1136,7193 & 960,3399 \\
\hline & 3 & 546,0876 & 605,9818 & 592,2188 & 555,8071 \\
\hline & 4 & 532,5536 & 614,1382 & 642,3129 & 529,0161 \\
\hline & 5 & 477,7655 & 591,5730 & 498,2100 & 427,9526 \\
\hline \multirow{4}{*}{60} & 2 & 921,9139 & 980,5671 & 924,6604 & 921,9139 \\
\hline & 3 & 716,2282 & 903,9688 & 875,8786 & 767,2522 \\
\hline & 4 & 773,8595 & 913,4981 & 755,2581 & 739,8948 \\
\hline & 5 & 728,4790 & 917,4070 & 825,8006 & 696,0658 \\
\hline \multirow{4}{*}{75} & 2 & 1537,6759 & 1636,7313 & 1538,8437 & 1537,6759 \\
\hline & 3 & 998,1641 & 1287,5002 & 996,1693 & 995,4171 \\
\hline & 4 & 1435,9658 & 1621,9197 & 1450,8298 & 1444,1450 \\
\hline & 5 & 1043,2567 & 1420,2235 & 1066,2254 & 973,0930 \\
\hline \multirow{4}{*}{100} & 2 & 1736,0389 & 2046,8755 & 1738,4696 & 1736,0389 \\
\hline & 3 & 1389,0926 & 1888,8002 & 1405,1077 & 1401,5673 \\
\hline & 4 & 1518,0191 & 2316,4231 & 1471,2770 & 1448,9114 \\
\hline & 5 & 1631,1551 & 2400,4563 & 1867,2980 & 1466,6661 \\
\hline \multirow{4}{*}{125} & 2 & 2914,4800 & 3376,5644 & 2917,0490 & 2914,4800 \\
\hline & 3 & 2221,1392 & 2974,0999 & 2454,2371 & 2213,7804 \\
\hline & 4 & 3023,9196 & 3784,9294 & 3184,9914 & 2959,1424 \\
\hline & 5 & 2150,9579 & 3133,3012 & 2284,7271 & 2041,4051 \\
\hline
\end{tabular}

constatar que quanto menor o valor da solução, em termos de valor da função objetivo, mais compacto é o agrupamento de células pertencentes a mesma central. Por exemplo, a melhor solução obtida pelo AGP para as células pertencentes a central 2 estão bem distantes entre si o que implica em um grande custo de handoff. A solução apresentada pela heurística MS também apresenta o mesmo tipo de características para as células pertencentes à central 3. Já para as soluções do AGF e BS é possível perceber que as soluções propostas são tais que as células percentes a uma mesma central formam grupos mais nitidos e compactos.

Na comparação entre o algoritmo BS com a MS, o BS teve melhores resultados em $100 \%$ dos casos e comparando do BS com os AGs, o BS teve melhores resultados em 71,4\% dos casos. Os resultados do AGF só foram melhores que o BS nos problemas de menor porte. Outra vantagem do BS advém do fato dele não necessitar de uma solução inicial e toda solução que ele fornece é sempre factível.

As comparações de tempo computacional entre os métodos não foi estudada tendo em vista que que o problema em questão é de planejamento e a qualidade das soluções obtidas é mais importante. Todos os métodos foram implementados em Matlab 7.0.1, Windows XP e foram executados num Pentium 4 com processador de $2 \mathrm{GHz}$ e memória RAM de $1 \mathrm{~Gb}$.

Tanto o Beam Search como os Algoritmos Genéticos podem ser facilmente implementados em paralelo. No caso do Beam Search a implementação em paralelo é mais simples porque os processos não requerem nenhuma comunicação entre eles. Como cada central, no nível 1, resulta numa árvore independente (nó semente), basta colocar um processador para trabalhar em cada uma destas árvores. Deste modo, cada uma destas árvores pode ser resolvida de modo totalmente independente, não sendo necessário nenhuma comunicação entre processadores durante o processo de resolução das árvores. 


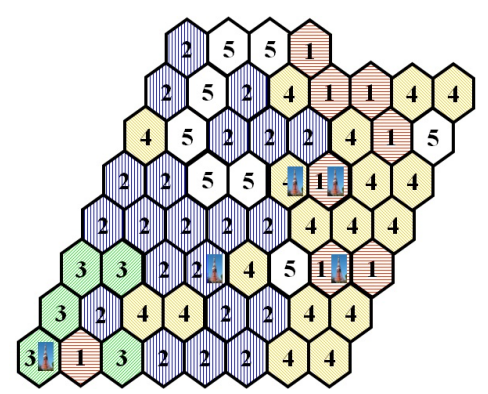

(a) AGP

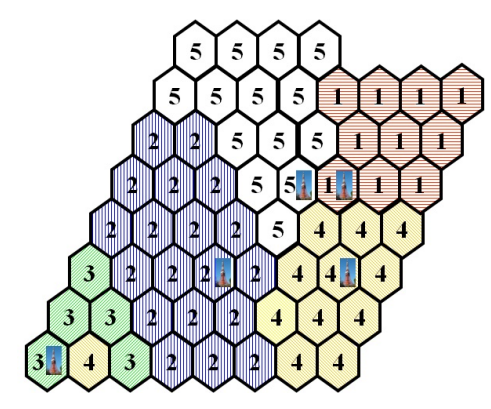

(b) BS

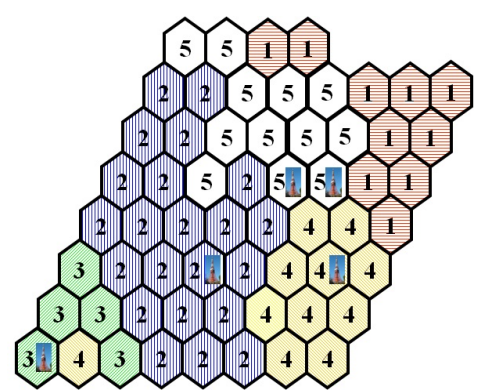

(c) AGF

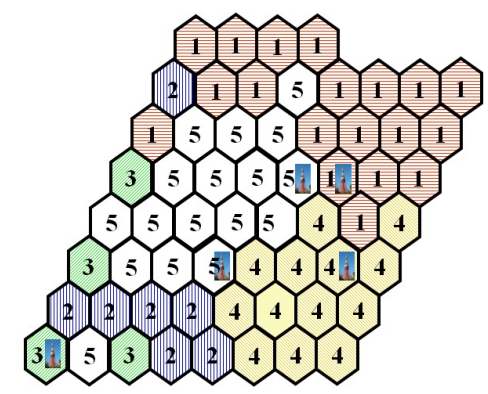

(d) MS

Figura 12. Melhores soluções obtidas para o AGP, BS, AGF e MS para a instância com 60 antenas e 5 centrais.

\section{Agradecimentos}

Os autores agradecem ao CNPq pelo apoio financeiro através do processo do Edital Universal do CNPq, número $472385 / 2007-0$.

\section{Referências}

AbuAmara, M.H.; Sait, S.M. \& Subhan, A., A heuristics based approach for cellular mobile network planning. In: Onoe, S.; Guizani, M.; Chen, H.H. \& Sawahashi, N. (Eds.), The International Conference on Wireless Communications and Mobile Computing. New York, USA: ACM, p. 79-84, 2006.

Alonso, E.; Meier-Hellstern, S. \& Pollini, G.P., Influence of cell geometry on handover and registration rates in cellular and universal personal telecommunications networks. In: Proceedings of the $8^{\text {th }}$ ITC Specialist Seminar on Universal Telecommunications. Genova, Italy, p. 261-270, 1992.

Della Croce, F. \& T'Kindt, V., A recovering beam search algorithm for the one-machine dynamic total completion time scheduling problem. Journal of the Operational Research Society, 53(11):1275-1280, 2002.

Dianati, M.; Naik, S.; Shen, X. \& Karray, F., A genetic algorithm approach for cell to switch assignment in cellular mobile networks. In: Rothlauf, F. \& Konstantinos, G. (Eds.), Proceedings of 2003 Canadian Workshop on Information Theory. Waterloo, Canada, p. 159-162, 2003.

Din, D.R. \& Tseng, S.S., Genetic algorithms for optimal design of the two-level wireless atm network. Proceedings of the National Science Council (Republic of China), 25(3):151-162, 2002.

Fox, M.S., Constraint-Directed Search: A case Study of Job-Shop Scheduling. PhD thesis, Carnegie Mellon University, Pittsburgh, USA, 1983.

Goldberg, D.E., Genetic Algorithms in Search, Optimization, and Machine Learning. Reading, USA: Addison-Wesley, 1989.

Haupt, R.L., Optimum population size and mutation rate for a simple real genetic algorithm that optimizes array factors. In: Proceedings of IEEE Antennas and Propagation Society International Symposium. Piscataway, USA: IEEE Press, v. 2, p. 1034-1037, 2000.

Hedible, C. \& Pierre, S., Genetic algorithm for the assignment of cells to switches in personal communication networks. In: Proceedings of Canadian Conference on Electrical and Computer Engineering. Piscataway, USA: IEEE Press, v. 2, p. 1077-1081, 2000.

Holland, J.H., Adaptation in natural and artificial systems. $1^{\text {st }}$ edição. Ann Arbor, USA: The University of Michigan Press, 1975.

Houeto, F. \& Pierre, S., Assigning cells to switches in cellular mobile networks using taboo search. IEEE Transactions on Systems, Man and Cybernetics, 32(3):351-356, 2002.

Lowerre, B.T., The HARPY Speech Recognition System. PhD thesis, Carnegie Mellon University, Pittsburgh, USA, 1976. 
Menon, S. \& Gupta, R., Assigning cells to switches in cellular networks by incorporating a pricing mechanism into simulated annealing. IEEE Transactions on Systems, Man and Cybernetics, Part B, 34(1):558-565, 2002.

Merchant, A. \& Sengupta, B., Assignment of cells to switches in PCS networks. IEEE/ACM Transactions on Networking, 3(5):521-526, 1995.

Michalewicz, Z., Genetic Algorithms + Data Structures = Evolution Programs. $3^{\text {rd }}$ edição. Berlin/Heidelberg, Germany: Springer-Verlag, 1996.

Nanda, S., Teletraffic models for urban and suburban microcells: cell sizes and handoff rates. IEEE Transactions on Vehicular Technology, 42(4):673-682, 1993.

Ow, P.S. \& Morton, T.E., Filtered beam search in scheduling. International Journal of Production Research, 26(1):3562, 1988a.

Ow, P.S. \& Morton, T.E., The single machine early/tardy problem. Management Science, 35(2):177-191, 1988b.

Quintero, A. \& Pierre, S., Assigning cells to switches in cellular mobile networks: a comparative study. Computer Communications, 26(9):950-960, 2003.

Ribeiro, C.M.; Azevedo, A.T. \& Rodolfo, R.F., Um algoritmo do tipo Beam Search para alocação de células a centrais de telefonia celular. In: Anais do XLI Simpósio Brasileiro de Pesquisa Operacional. Porto Seguro, BA, p. 1-12, 2009.

Ribeiro, C.M.; Azevedo, A.T. \& Teixeira, R.F., Problem of assignment cells to switches in a cellular mobile network via beam search method. WSEAS Transactions on Communications, 9(1):11-21, 2011.

Saha, D.; Mukherjee, A. \& Battacharya, P.S., A simple heuristic for assignment of cells to switches in a pcs network. Wireless Personal Communications, 12(3):209-224, 2000.

Salomão, N.A., Métodos de Geração de Colunas para Problemas de Atribuição. Tese de Doutorado em Computação Aplicada, Instituto Nacional de Pesquisas Espaciais, São José dos Campos, SP, 2005.

Valente, J.M.; Alves, R.A.F.S. \& Rui, A.F.S., Filtered and recovering beam search algorithm for the early/tardy scheduling problem with no idle time. Computers \& Industrial Engineering, 48(2):363-375, 2005.

\section{Notas Biográficas}

Anibal Tavares de Azevedo é graduado em Matemática Aplicada e Computacional, tem mestrado, doutorado e pósdoutorado em Engenharia Elétrica (UNICAMP, 1999, 2002, 2006 e 2007, respectivamente). Foi Professor Assistente da UNESP-Guaratinguetá (2007-2011) e atualmente é Professor Assistente da Faculdade de Ciências Aplicadas da UNICAMP. Tem interesse na área de meta-heurísticas e otimização combinatória, como aplicações em problemas de sistemas de potência, planejamento e controle da produção, telecomunicações e logística portuária.

Cassilda Maria Ribeiro é graduada em Engenharia Mecânica (UNESP, 1982), mestre em Engenharia Elétrica (UNICAMP, 1985) e doutor em Automação Industrial e Informática (LAAS-Toulouse-França, 1991). Atualmente é Professora Assistente do Departamento de Matemática da Faculdade Engenharia de Guaratinguetá da UNESP. Tem interesse na área de meta-heurísticas e otimização combinatória, como aplicações em problemas de telecomunicações e logística. 


\title{
Sistema de Apoio à Decisão MILP-Fuzzy para o Planejamento de Redes de Acesso em Telecomunicações
}

\author{
Marcos Antônio de Sousa, Flávio Henrique Teles Vieira, Carlos Magnus Carlson Filho, \\ Bruno Henrique Pereira Gonçalves e Victor Hugo Teles Costa
}

\begin{abstract}
Resumo: As telecomunicações experimentam acelerada evolução. O ambiente é muito competitivo e o volume de recursos financeiros envolvidos é significativo. A rede de acesso do usuário constitui um foco importante destas transformações. A busca de uma plataforma capaz de disponibilizar serviços diversificados de qualidade e lucrativos é uma tendência a ser seguida pelas empresas operadoras do setor. Este capítulo apresenta uma solução heurística para a análise paramétrica de um modelo de programação linear inteira mista, que é utilizado no planejamento estratégico de sistemas de acesso. O dimensionamento da rede é feito admitindo-se previsões imprecisas de demanda para os serviços. A avaliação técnicoeconômica é orientada à maximização de receita e está baseada no conceito de números fuzzy.
\end{abstract}

Palavras-chave: Sistemas de telecomunicações, Otimização, Números fuzzy, Métodos heurísticos.

\begin{abstract}
Telecommunications are significantly changing. The field is very competitive, and the amount of involved financial resources is important. The customer access network is a major focus of transformations. The goal of the operating companies is to get a network structure which is able to offer several good-quality, lucrative services. This chapter shows a heuristic solution for the parametric analysis on a mixed-integer linear programming model, that is used in the strategic planning of the access systems. The network sizing is made admitting inexact forecast on service's demand values. The tech-economical evaluation is driven by max-revenue criterion and is based on the concept of fuzzy number.
\end{abstract}

Keywords: Telecommunications systems, Optimization, Fuzzy numbers, Heuristic methods.

\section{Introdução}

Os sistemas de telecomunicações estão atualmente em fase de grande transformação e expansão, com o desenvolvimento de novos tipos de serviços, principalmente os de multimídia e de faixa-larga.

O ambiente competitivo obriga as empresas operadoras a investirem continuamente, tanto na evolução tecnológica quanto nos serviços oferecidos. A expansão do sistema fica condicionada à análise das estratégias de mercado, as quais exigem o levantamento das demandas dos serviços e o estudo sobre as diferentes possibilidades tecnológicas a se adotar. Grandes velocidades de comutação, altas taxas de transmissão de dados, baixas taxas de erro e atrasos aceitáveis são alguns dos atrativos imprescindíveis para se conquistar e estimular a fidelidade de um cliente em potencial.

Os sistemas de acesso do usuário são exemplos de sistemas que passaram por mudanças importantes. Estes sistemas foram desenvolvidos, a princípio, para o provimento do serviço de voz. Atualmente, eles se encontram em contínua transformação, objetivando uma plataforma cada vez mais faixa-larga e multimídia.

O planejamento do sistema fica condicionado a estas transformações. Por um lado, é possível haver seletividade no atendimento da demanda, o que significa dizer que as demandas potencialmente mais lucrativas serão prioritárias. Por outro lado, existe a variedade de serviços a se oferecer, cada qual gerando receita diferenciada e eventualmente exigindo equipamentos, topologias e meios de transmissão específicos.

A limitação orçamentária, naturalmente, é outro fator a ser previsto, pois nem sempre é possível implantar todos os sistemas necessários ao atendimento pleno da demanda. O dimensionamento dos sistemas precisa, portanto, contemplar fatores técnicos e econômicos que vão além da tarefa de planejar a rede objetivando o custo mínimo, seja de implantação, aluguel, manutenção e/ou operação. Implantar soluções que signifiquem garantia de participação no mercado e receitas compensadoras é uma questão de sobrevivência.

\footnotetext{
*Autor para contato: marcos@emc.ufg.br
} 
Assim, a expansão dos sistemas de acesso requer intensa atividade de planejamento. Onde, quando, quanto e como investir são questões para as quais o planejamento deve encontrar respostas. A enorme quantidade de opções técnico-mercadológicas a se analisar requer, de antemão, escolhas essencialmente difíceis. Além disto, a complexidade dos problemas e a velocidade das transformações exigem metodologias de planejamento consistentes, flexíveis (capazes de suportar diferentes cenários) e apoiadas em ferramentas computacionais. Os valores significativos, geralmente envolvidos neste tipo de situação, tornam desejável o uso de sistemas de apoio à decisão baseados em modelos matemáticos.

\subsection{Problema de otimização no planejamento de sistemas de telecomunicações}

Os modelos matemáticos que podem ser desenvolvidos para o planejamento de sistemas de telecomunicações são fortemente dependentes de dados de demanda (Rouskas et al., 2008; Kasap et al., 2007; Bienstock et al., 2006; Cruz et al., 2003). Entretanto, muitos destes dados não são precisamente conhecidos no momento da elaboração do plano. Isto acontece não somente com a demanda, mas também com outros dados necessários aos modelos.

Dada esta imprecisão, os termos independentes (das restrições) dos modelos baseados nestes dados não são mais fixos. A maneira de se resolver o problema matemático, agora não mais "exato", pode mudar consideravelmente. Na tentativa de solucionar o problema, a ideia é incorporar ao modelo aspectos da imprecisão, no sentido de flexibilizá-lo e torná-lo mais fiel ao ambiente que se pretende retratar. As técnicas mais usadas são a programação estocástica (Albuquerque et al., 2008) e a aplicação de conceitos de conjuntos nebulosos (Pedrycz \& Gomide, 1998).

Uma abordagem por programação estocástica pressupõe aleatoriedade dos valores dos dados de demanda que se pretende usar. No entanto, isto não se amolda aos problemas de planejamento ora tratados. A evolução tecnológica é previsível no horizonte de tempo compreendido pelo planejamento. O efeito sobre a demanda também é previsível: em geral, os serviços faixa-estreita tendem à estabilidade (como, por exemplo, o serviço de telefonia), enquanto os serviços faixa-larga, com tarifas inicialmente elevadas, experimentam redução de custo ao mesmo tempo em que procuram "conquistar" usuários dos serviços faixa-estreita.

Outro aspecto importante para o planejamento é a interdependência entre os serviços, cuja representação por conceitos estocásticos pode não ser simples. Além disto, obter funções de distribuição de probabilidade geralmente é um processo caro do ponto de vista computacional. Abordagens construídas em bases estocásticas e diretamente relacionadas ao planejamento de sistemas de telecomunicações podem ser vistas em Bolia \& Kulkarni (2009) e Gaivoronski \& Zoric (2008).

Já conceitos de conjuntos nebulosos (conjuntos fuzzy) e números nebulosos (números fuzzy) têm sido bastante utilizados em situações de incerteza. Sahinidis (2004) organizou um survey com vários trabalhos sobre este assunto. Cantão (2003) também é uma boa referência para problemas não-lineares com parâmetros fuzzy. De fato, os conjuntos nebulosos oferecem a simplicidade dos intervalos e, ao mesmo tempo, incorporam aspectos possibilísticos. Em outras palavras, permitem expressar preferências (maior expectativa de efetivação) sobre alguns dos valores em relação a outros.

\subsection{Motivação}

Dados sobre comportamento de mercado e inovações tecnológicas, por exemplo, a penetração (aceitação) de um determinado serviço em uma determinada região de atendimento, são informações fundamentais que precisam ser oferecidas ao planejador do sistema. Porém, informações "precisas" nem sempre estão disponíveis durante a etapa de planejamento, o que é natural num contexto de rápido desenvolvimento tecnológico e surgimento de novos serviços. O resultado do planejamento, portanto, pode ser sensível à variação destes dados de entrada. A ferramenta computacional desenvolvida para este fim exige preparo para absorver estas "imprecisões" existentes nos dados do planejamento.

Em DeSousa et al. (2011), DeSousa et al. (2010b), DeSousa \& Carlson (2010), DeSousa et al. (2010a) e DeSousa et al. (2006) foram propostos modelos de programação linear inteira mista (MILP-Mixed-Integer Linear Programming) para o planejamento estratégico de sistemas de acesso do usuário. Os modelos procuram refletir o ambiente de competição entre as soluções tecnológicas e os serviços. Com o objetivo de se obter o menor custo ou a maior receita dos serviços a serem oferecidos, os dimensionamentos são feitos respeitando topologias de rede, demandas, capacidades, custo das tecnologias candidatas e condições de investimento.

Uma característica marcante destes modelos é o fato de que permitem a adoção de valores imprecisos para a demanda dos serviços previstos para serem oferecidos. Esta capacidade de avaliar o risco técnico-econômico e antecipar soluções em diferentes cenários de demanda baseia-se no conceito de números fuzzy. 


\subsection{Objetivos}

A estratégia escolhida para resolver o modelo MILP-Fuzzy com dados imprecisos em DeSousa et al. (2011), DeSousa et al. (2010b), DeSousa \& Carlson (2010), DeSousa et al. (2010a) e DeSousa et al. (2006) foi substituir a demanda fuzzy por equivalentes paramétricos, em particular nos valores right-hand-side (rhs) das restrições. Com este procedimento é possível avaliar, computacionalmente, o comportamento da topologia da rede de acesso sem comprometer a robustez e a flexibilidade da modelagem.

Porém, a dificuldade de se realizar a análise paramétrica em problemas MILP-Fuzzy deixa ainda mais complicado o procedimento de análise técnico-econômica. As aplicações naqueles trabalhos ficaram restritas a alguns valores particulares escolhidos para o parâmetro que controla os níveis de demanda de usuários a serem atendidos pelo sistema.

O propósito deste capítulo é apresentar regras heurísticas e procedimentos computacionais para desempenhar a análise paramétrica sobre os valores rhs do MILP-Fuzzy, desenvolvido como suporte para o sistema de apoio à decisão para o planejamento estratégico de redes de acesso em telecomunicações. A metodologia empregada busca resolver o modelo MILP-Fuzzy em valores fixados para o parâmetro de controle de demanda e, posteriormente, agregar estas soluções através de programação linear paramétrica (PLP) quando permitida a variação contínua deste parâmetro de controle de demanda.

\section{Infra-estrutura da Rede de Acesso}

O sistema de acesso representa a "porta de entrada" de cada usuário (denominado assinante) do sistema de telecomunicações (Figura 1).

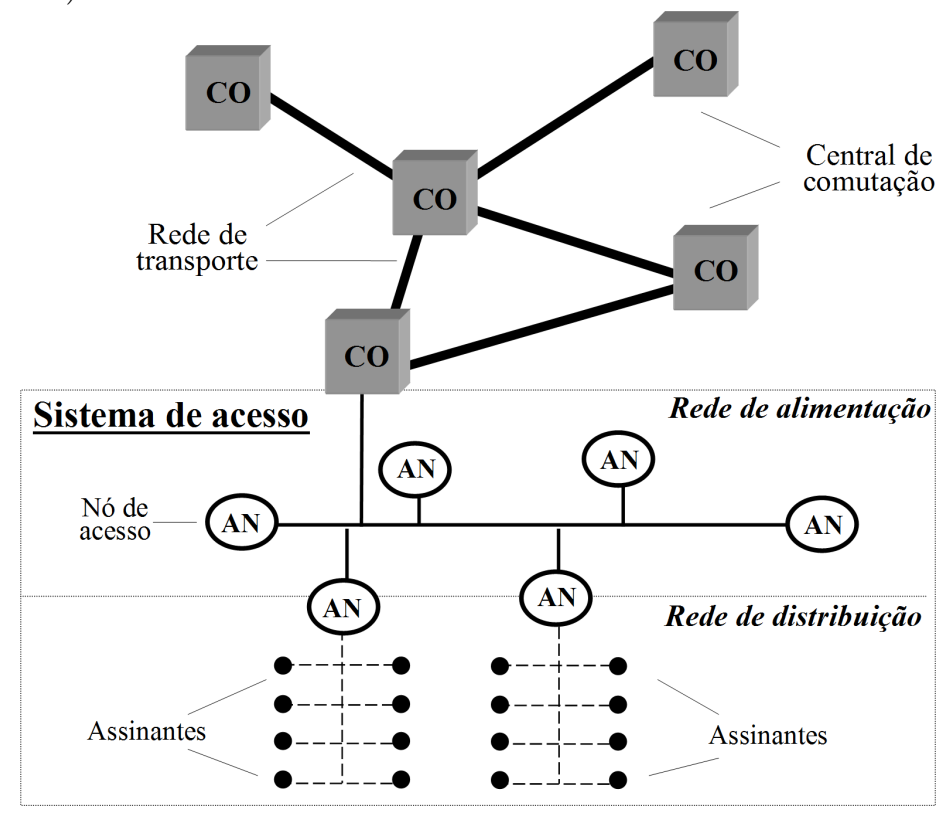

Figura 1. Componentes do sistema de acesso.

Tradicionalmente, no sistema de acesso fixo cabeado, a conexão é feita através de cabos de cobre que conectam o assinante a um ponto de concentração, o nó de acesso (AN-Access Node). Este segmento da rede recebe o nome de rede de distribuição. A partir do nó de acesso, os assinantes são ligados à central de comutação do sistema (CO-Central Office) por meio de enlaces de maior capacidade e/ou são concentrados de maneira a compartilhar o mesmo meio de transmissão. Este segmento recebe o nome de rede de alimentação. A rede de distribuição e a rede de alimentação constituem o sistema de acesso fixo cabeado.

O Sistema de Acesso Móvel Celular é outra alternativa de acesso para o usuário. Este sistema constituise de uma componente móvel e de uma componente fixa. A componente móvel consiste no usuário (MSMobile Station), que é conectado ao sistema através da interface aérea localizada no nó de acesso (BTS-Base Transceiver Station). Atualmente, as tecnologias mais adotadas neste segmento da rede são baseadas no Global System for Mobile Communications (GSM) (Garg, 2007). A parte fixa, infra-estrutura da rede, representa os sistemas responsáveis pela interconexão entre BTSs e a CO (BSC/MSC-set Base Station Controller / Mobile Switching Center).

Em ambos os sistemas de acesso (cabeado fixo ou celular móvel), se dois assinantes não pertencem à área coberta por uma mesma central de comutação, a ligação entre eles envolverá duas ou mais CO, interligadas por uma rede de transporte. 


\section{Modelo de Planejamento}

A modelagem técnico-econômica proposta pode ser aplicada tanto para o sistema de acesso fixo cabeado quanto para a infra-estrutura do sistema de acesso móvel celular. Admite-se que cada CO tenha sua própria rede de acesso independente. O objetivo principal é alocar e dimensionar os equipamentos na rede de forma a maximizar a receita, permitindo a competição entre os serviços e tecnologias candidatas.

A rede é modelada através de um grafo orientado (Ahuja et al., 1993) e o dimensionamento dos equipamentos é efetuado em função da capacidade exigida dos arcos utilizados para escoar a demanda desde o nó de acesso do usuário até a CO do sistema.

O modelo matemático é um problema de programação linear inteira mista com variáveis 0-1 que utiliza a abordagem nó-arco (Bazaraa et al., 1990). As variáveis de decisão se referem ao valor do fluxo nos arcos e à alocação (ou não) e dimensionamento de facilidades (equipamentos de transmissão, cabos ópticos e metálicos, infra-estrutura), instaláveis em cada arco (ou nó) para o atendimento dos serviços. A formulação geral do modelo, de acordo com DeSousa et al. (2006), é apresentada nas seções seguintes.

\subsection{Função objetivo}

Considera-se que exista um valor de receita unitária mensal (ou anual) para cada um dos serviços. A receita precisa ser maximizada, mas a pressão orçamentária pode não permitir que sejam implantados equipamentos e rede suficientes para todos. Trata-se de atender seletivamente à demanda. A receita total é calculada somando-se a receita dos serviços escolhidos.

$$
\operatorname{Max} R(y)=\sum_{(s, i) \in A_{E}} r_{s i} Y_{s i}
$$

onde:

$R(y)$ : receita total dos serviços oferecidos;

$A_{E}$ : conjunto dos arcos de escoamento que conectam os nós artificiais de serviço aos nós de acesso;

$Y_{s i}$ : variável real não-negativa associada ao fluxo de demanda escoado pelo arco de escoamento que liga o nó artificial de serviço $s$ ao nó de acesso $i$

$r_{s i}$ : receita unitária do serviço $s$ oferecido ao nó de acesso $i$.

\subsection{Restrição de limite de orçamento}

É a garantia de que o custo total de alocação e dimensionamento dos equipamentos e infra-estrutura não ultrapassará o orçamento previsto. A primeira parcela da inequação (2) refere-se ao custo da solução tecnológica $X$, a segunda ao custo com expansão em rede metálica e a última ao custo da rede de distribuição para a oferta dos serviços. Na aplicação do modelo, seja para o sistema de acesso fixo cabeado ou para a infra-estrutura do sistema de acesso móvel celular, as parcelas são constituídas pelos custos de equipamentos e infra-estrutura candidatados pelo planejador.

$$
\begin{aligned}
& \sum_{(i, j) \in A_{S T}} \sum_{n \in N_{S T i j}}\left(\varphi_{i j}^{X_{e q}, n}+\varphi_{i j}^{X_{r}, n} \cdot l_{i j}\right) \cdot X_{i j n} \\
& +\sum_{(i, j) \in A_{M}} \sum_{p \in C_{M}}\left(\varphi_{i j}^{M_{e q}, p}+\varphi_{i j}^{M_{r}, p} \cdot l_{i j}\right) \cdot M_{i j p}+\sum_{(s, i) \in A_{E}} \varphi_{s i} \cdot Y_{s i} \leq L
\end{aligned}
$$

onde:

$A_{S T}:$ conjunto de arcos que podem receber como candidata a solução tecnológica $X$;

$N_{S T i j}$ : conjunto de soluções tecnológicas candidatas no arco $(i, j) \in A_{S T}$;

$X_{i j n}$ : variável binária associada à escolha da solução tecnológica $X$, do tipo $n$, candidata no $\operatorname{arco}(i, j) \in A_{S T}$;

$\varphi_{i j}^{X_{e q}, n}$ : custo associado à escolha dos equipamentos da solução tecnológica $X$, do tipo $n$, candidata no arco $(i, j) \in A_{S T}$

$\varphi_{i j}^{X_{r}, n}$ : custo (por unidade de comprimento) associado à escolha da infra-estrutura (cabos e dutos) da solução tecnológica $X$, do tipo $n$, candidata no $\operatorname{arco}(i, j) \in A_{S T}$

$l_{i j}:$ comprimento do arco $(i, j) \in A_{S T}$;

$A_{M}$ : conjunto de arcos que podem receber cabos metálicos;

$C_{M}$ : conjunto de modularidades de cabos metálicos (novos);

$M_{i j p}$ : variável binária associada à escolha do cabo metálico $M$, de modularidade $p$, candidato no arco $(i, j) \in$ $A_{M}$; 
$\varphi_{i j}^{M_{e q}, p}$ : custo associado à escolha dos equipamentos relacionados com o cabo metálico $M$, de modularidade $p, \operatorname{no} \operatorname{arco}(i, j) \in A_{M}$

$\varphi_{i j}^{M_{r}, p}$ : custo (por unidade de comprimento) associado à escolha da infra-estrutura do cabo metálico $M$, de modularidade $p$, no arco $(i, j) \in A_{M}$;

$\varphi_{s i}$ : custo da rede de distribuição para a disponibilização do serviço do tipo $s$ para o nó de acesso $i$, usando o $\operatorname{arco}(s, i) \in A_{E}$;

$L$ : orçamento.

\subsection{Restrições de satisfação de demanda}

São necessárias para garantir o balanço de fluxo nos nós do grafo. A restrição sobre o orçamento significa que parte da demanda pode não ser atendida. Por isto, são utilizados arcos de escape nos nós artificiais de serviço. Devido à diversidade encontrada nas taxas de transmissão dos serviços, poderá ser necessário utilizar alguns coeficientes de conversão $\left(f c_{s}\right)$ na matriz de incidência nas equações referentes aos nós de acesso.

$$
\begin{gathered}
\sum_{i \in I-I_{S}} Y_{s i}+\operatorname{Yesc}_{s}=d_{s}, \forall s \in I_{S} \\
\sum_{j \in J_{1}} Y_{i j}-\sum_{j \in J_{2}-I_{S}} Y_{j i}-\sum_{s \in I_{s}} f c_{s} . Y_{s i}=0, \forall i \in I-I_{S}
\end{gathered}
$$

onde:

$I \quad$ : conjunto de todos os nós do grafo, exceto o nó da CO;

$I_{S}$ : conjunto dos nós artificiais de serviço;

$Y e s c_{s}$ : variável real não-negativa associada à demanda não atendida do serviço $s$ (fluxo de demanda através de um arco de escape);

$d_{s}$ : demanda total do serviço $s$, entrando na rede pelo nó $s \in I_{S}$;

$J_{1}$ : conjunto de nós $j$ diretamente conectados ao nó $i$, por arcos orientados de $i$ para $j$ (fluxo saindo do nó $i)$;

$J_{2}$ : conjunto de nós $j$ diretamente conectados ao nó $i$, por arcos orientados de $j$ para $i$ (fluxo entrando no nó $i$ );

$Y_{i j}$ : variável real não-negativa associada ao fluxo de demanda escoado pelo arco $(i, j)$;

$f c_{s}$ : fator de conversão de taxa de transmissão do serviço $s$.

\subsection{Restrições técnicas de capacidade}

Ocorrem em cada arco do grafo responsável pelo atendimento da demanda prevista nos nós de acesso, assegurando que a soma das capacidades dos equipamentos alocados seja superior ao fluxo escoado pelo arco. As especificações dos equipamentos candidatos dependem do tipo de sistema de acesso em que se efetua a aplicação do modelo.

$$
\begin{gathered}
\sum_{n \in N_{S T i j}} \operatorname{cap}_{i j}^{X, n} \cdot X_{i j n}-Y_{i j} \geq 0, \forall(i, j) \in A_{S T} \\
\sum_{p \in C_{M}} \operatorname{cap}_{i j}^{M, p} \cdot M_{i j p}-Y_{i j} \geq 0, \forall(i, j) \in A_{M}
\end{gathered}
$$

onde:

$\operatorname{cap}_{i j}^{X, n}$ : capacidade da solução tecnológica $X$, do tipo $n$, candidata no $\operatorname{arco}(i, j) \in A_{S T}$;

$\operatorname{cap}_{i j}^{M, p}$ : capacidade do cabo metálico $M$, de modularidade $p$, candidato (ou instalado) no arco $(i, j) \in A_{M}$.

\subsection{Restrições de atendimento}

Gerenciam as preferências no atendimento dos serviços. São exemplos de controle de demanda dos serviços:

- Controle de demanda por nó de acesso:

$$
\begin{aligned}
& Y_{s i} \geq \operatorname{dmin}_{s i}, \forall s \in I_{S}, \forall i \in I-I_{S} \\
& Y_{s i} \leq \operatorname{dmax}_{s i}, \forall s \in I_{S}, \forall i \in I-I_{S}
\end{aligned}
$$


- Controle de demanda por serviço:

$$
\begin{gathered}
Y_{s i} \leq \operatorname{dmax}_{s i}, \forall s \in I_{S}, \forall i \in I-I_{S} \\
Y \operatorname{Ysc}_{s} \leq\left(d_{s}-\operatorname{dmin}_{s}\right), \forall s \in I_{S}
\end{gathered}
$$

onde:

$d_{m i n}{ }_{s i}$ : demanda mínima prevista para o serviço $s$ no nó de acesso $i \in I-I_{S}$;

$d_{\max }$ : demanda máxima prevista para o serviço $s$ no nó de acesso $i \in I-I_{S}$;

$d \min _{s}$ : demanda mínima do serviço $s$ a ser atendida pela rede, entrando pelo nó $s \in I_{S}$.

\section{Abordagem Fuzzy para a Demanda Imprecisa}

A demanda é quantificada em termos do número de assinantes de um ou mais serviços e representa um dado de entrada para o modelo. Numa situação típica, o planejador possui uma boa ideia a respeito do grau de penetração do serviço, ou seja, ele é capaz de definir, para o número total de usuários de uma área de atendimento, uma faixa de possíveis valores para a demanda de cada serviço, inclusive com discriminação de valores com maior ou menor possibilidade de ocorrência. Esta particularidade quanto aos dados de demanda sugere a adoção do conceito de número fuzzy para representá-los.

Um conjunto fuzzy $\tilde{d}_{s i}=\left(\underline{d}_{s i}, D_{s i}, \bar{d}_{s i}\right)$ pode ser definido como "o conjunto dos valores possíveis para a demanda do serviço $s \in I_{S}$ a ser atendida no nó de acesso $i \in I-I_{S}$ ". Para este conjunto, uma função de pertinência triangular pode ser descrita conforme a Figura 2. Definido desta forma, $\tilde{\tilde{d}}_{s i}$ é um número fuzzy triangular cujo valor de maior grau de pertinência é $D_{s i}$ (não é obrigatório que o triângulo seja isósceles). Neste trabalho são adotados apenas números fuzzy triangulares, mas a definição poderia ser alterada, por exemplo, para traduzir um número fuzzy trapezoidal.

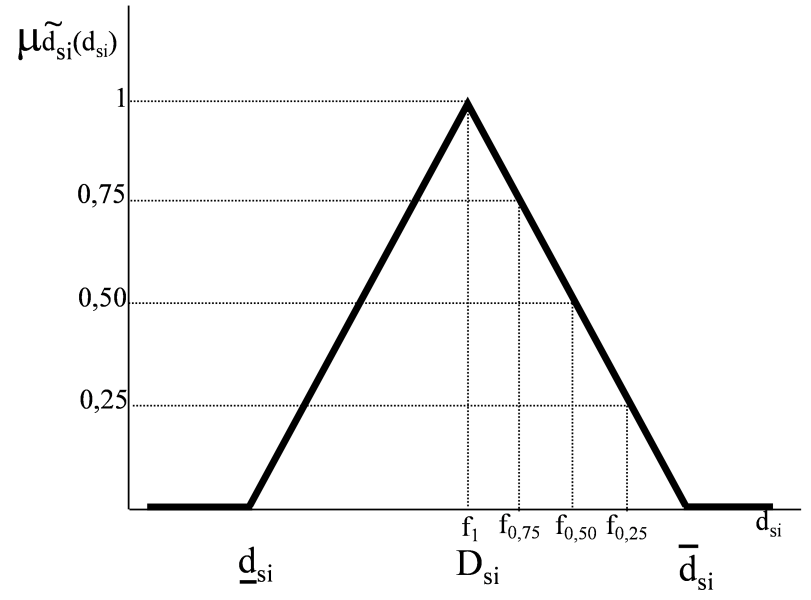

Figura 2. Demanda imprecisa e seu Equivalente de Adamo.

A presença de números fuzzy nas restrições do MILP pode alterar substancialmente o seu procedimento de resolução. Há necessidade de se transformar os números fuzzy de maneira a permitir o seu tratamento. Este processo é denominado "defuzzificação" e consiste em encontrar um "valor de trabalho" para o número fuzzy tratado.

A opção escolhida foi a substituição do número fuzzy por um parâmetro que permita um processo de resolução mais simples sem perder as características de imprecisão expressas pelo número fuzzy. A variação do parâmetro permite a análise de diferentes possibilidades para o valor assumido como demanda dos serviços. A solução do problema passa a ser dependente do valor deste parâmetro.

A função paramétrica adotada para a determinação do equivalente do número fuzzy é a de Adamo (Campos \& Verdegay, 1989):

$$
f \alpha\left(\tilde{d}_{s i}\right)=\max \left\{d_{s i} \mid \mu \tilde{d}_{s i}\left(d_{s i}\right) \geq \alpha\right\}
$$

$\operatorname{com} \alpha \in[0,1]$.

Para o caso triangular tem-se:

$$
f \alpha\left(\tilde{d}_{s i}\right)=D_{s i}+\left(\bar{d}_{s i}-D_{s i}\right) \cdot(1-\alpha)
$$


O número fuzzy é reduzido a um intervalo do qual se toma o limitante superior como valor de trabalho. O parâmetro $\alpha$ indica o grau de confiança nos valores a adotar. A Figura 2 mostra o funcionamento do equivalente de Adamo para um número fuzzy triangular.

Obedecida a linearidade da função de Adamo para números fuzzy triangulares, as restrições (3), (7), (8), (9) e (10) tornam-se, respectivamente:

$$
\begin{gathered}
\sum_{i \in I-I_{S}} Y_{s i}+\operatorname{Yesc}_{s}=D_{s}+\left(\bar{d}_{s}-D_{s}\right) \cdot(1-\alpha), \forall s \in I_{S} \\
Y_{s i} \geq \operatorname{Dmin}_{s i}+\left(\bar{d} \min _{s i}-\operatorname{Dmin}_{s i}\right) \cdot(1-\alpha), \forall s \in I_{S}, \forall i \in I-I_{S} \\
Y_{s i} \leq \operatorname{Dmax}_{s i}+\left(\bar{d} \max _{s i}-\operatorname{Dmax}_{s i}\right) \cdot(1-\alpha), \forall s \in I_{S}, \forall i \in I-I_{S} \\
Y \operatorname{Psc}_{s} \leq\left\{\left[D_{s}+\left(\bar{d}_{s}-D_{s}\right) \cdot(1-\alpha)\right]-\right. \\
\left.\left[\operatorname{Dmin}_{s}+\left(\bar{d} \min _{s}-\operatorname{Dmin}_{s}\right) \cdot(1-\alpha)\right]\right\}, \forall s \in I_{S}
\end{gathered}
$$

Observa-se que as restrições (8) e (9) são equivalentes.

\section{Abordagem Heurística para a Análise Paramétrica do MILP-Fuzzy}

A teoria e as técnicas computacionais para análise paramétrica de problemas MILP ainda não estão totalmente fundamentadas, e muito menos disponíveis comercialmente. Assim, encontrar soluções para os problemas apresentados não é uma tarefa simples. A complexidade computacional aumenta se as instâncias possuem um grande número de variáveis binárias. Isto porque a solução completa exige a obtenção do objetivo ótimo para todos os valores de $\alpha$.

A proposta aqui é desenvolver um algoritmo que permita fazer uma escolha mais criteriosa dos valores pontuais para o parâmetro de controle da demanda $(\alpha)$. O método propõe resolver o MILP a partir de valores fixados para o parâmetro de controle e, posteriormente, agregar estas soluções por meio de programação linear paramétrica (PLP), quando se permite a variação contínua do parâmetro.

O método heurístico apresentado a seguir baseia-se nos trabalhos de Crema (1998) e Jenkins (1982) que, em outro contexto, dispensaram tratamento similar ao que será apresentado aqui. Vários trabalhos sobre o assunto podem ser encontrados no survey organizado por Sahinidis (2004).

Uma vez que o principal custo computacional se deve à resolução dos MILPs em diferentes valores do parâmetro de controle, o algoritmo é projetado para completar cada análise paramétrica com a solução do menor número possível de MILPs. A meta é automatizar o processo de resolução, otimizando a quantidade de problemas MILP a serem avaliados. Acrescente-se a isto a possibilidade de utilizar o histórico de soluções no processo de decisão.

O algoritmo proposto independe do solver utilizado, desde que ele seja capaz de resolver problemas MILP e de desempenhar análise paramétrica em problemas de programação linear. Neste trabalho o CPLEX ${ }^{\mathbb{R}}$ é o solver adotado (CPLEX, 1994).

\subsection{Definições}

O algoritmo opera com dois conjuntos de valores de $\alpha$. Um, $\left\{\alpha_{n A}\right\}$ - conjunto dos $\alpha$ não-avaliados, contém os valores para os quais um MILP será resolvido. O outro, $\left\{\alpha_{A}\right\}$ - conjunto dos $\alpha$ já-avaliados, contém aqueles valores para os quais um MILP já foi resolvido. A cada iteração, um $\alpha_{c}$ é removido do primeiro conjunto, um MILP é resolvido para este valor, as variáveis binárias são fixadas e é feita uma análise paramétrica sobre o problema de programação linear (PL) resultante. Algumas definições:

$P_{\alpha}:$ MILP a ser resolvido (seções 3 e 4) com $\alpha$ já definido;

$X$ : subconjunto formado por todas as variáveis reais do MILP - todas as variáveis de fluxo de demanda (YeYesc);

$\underline{X}$ : subconjunto formado por todas as variáveis binárias do MILP - todas as variáveis de rede ou de equipamento;

$Z(\alpha)$ : valor da solução ótima quando $P_{\alpha}$ é resolvido em $\alpha$. Mudanças em $\alpha$ modificam o espaço de soluções de $P_{\alpha}$. Se um valor de $\alpha$ não permite nenhuma solução factível, então $Z(\alpha)$ é tomada como tendo valor $-\infty$ (lembre-se que o problema é de maximização);

$\underline{X}\left(\alpha_{1}\right)$ : assumindo que $P_{\alpha}$ possua uma solução factível em $\alpha_{1}$, então $\underline{X}\left(\alpha_{1}\right)$ representa o valor ótimo de $\underline{X}$ quando $P_{\alpha}$ é resolvido em $\alpha_{1} \cdot \underline{X}\left(\alpha_{1}\right)$ é a configuração de rede ótima para $\alpha_{1}$;

$Z\left(\alpha, \underline{X}\left(\alpha_{1}\right)\right)$ : solução ótima para um PL, com o parâmetro $\alpha$ variando continuamente dentro do intervalo $[0,1]$. Esta função é côncava e linear por partes sobre os valores de $\alpha$ que permitem solução factível (Crema, 1998; Jenkins, 1982). Se $\underline{X}\left(\alpha_{1}\right)$ não permite uma solução factível em $\alpha_{2}$, então $Z\left(\alpha_{2}, \underline{X}\left(\alpha_{1}\right)\right)=$ 
$-\infty$. Na computação de $Z\left(\alpha, \underline{X}\left(\alpha_{1}\right)\right)$, as variáveis reais $X$ podem variar para maximizar a receita, enquanto as variáveis binárias $\underline{X}$ são fixadas em $\underline{X}\left(\alpha_{1}\right)$;

$g_{\underline{x}^{1}, \ldots, \underline{x}^{p}}(\alpha): \max \left\{Z\left(\alpha, \underline{X}\left(\alpha_{j}\right)\right): 1 \leq j \leq p\right\} \forall \alpha \in[0,1] . g_{\underline{x}^{1}, \ldots, \underline{x}^{p}}(\alpha)$ é uma função côncava, linear por partes, e é também uma função limite inferior de $Z(\alpha)$;

$\alpha_{c}: \min \left\{\alpha_{n A}\right\}$. $\alpha$ corrente $=$ menor valor em $\left\{\alpha_{n A}\right\}$;

$\alpha_{c e}: \max \left\{\alpha_{A} \mid \alpha_{A}<\alpha_{c}\right\}$. $\alpha$ já-avaliado mais próximo de $\alpha_{c}$ à esquerda;

$\alpha_{c d}: \min \left\{\alpha_{A} \mid \alpha_{A}>\alpha_{c}\right\} . \alpha$ já-avaliado mais próximo de $\alpha_{c}$ à direita;

\{\}$\rightarrow \mathbf{\square}$ : retirar elemento $\mathbf{\square}$ do conjunto \{\} ;

$\rightarrow\{\}$ : colocar elemento $\boldsymbol{\square}$ no conjunto \{\} .

\subsection{0 método heurístico}

A análise paramétrica sobre o MILP é realizada conforme o algoritmo descrito a seguir.

Passo 1: iniciar $\left\{\alpha_{n A}\right\}=\{1,0\}$. (Nota: os próximos elementos de $\left\{\alpha_{n A}\right\}$ são obtidos conforme Passo 8);

Passo 2: $\left\{\alpha_{n A}\right\} \rightarrow \alpha_{c}=0$, resolver $P_{0}$

Passo 3: fixar $\underline{X}(0)$, obter $Z(\alpha, \underline{X}(0))$ por Programação Linear Paramétrica (PLP), com $\alpha \in[0,1]$;

Passo 4: $\quad \alpha_{c}=0 \rightarrow\left\{\alpha_{A}\right\}$

Passo 5: $\left\{\alpha_{n A}\right\} \rightarrow \alpha_{c}=1$, resolver $P_{1}$;

Passo 6: $\quad$ se $\underline{X}(0)=\underline{X}(1)$ FIM (redes iguais), senão continue;

Passo 7: fixar $\underline{X}(1)$, obter $Z(\alpha, \underline{X}(1))$ por PLP, com $\alpha \in[0,1]$;

Passo 8: obter $\alpha^{\prime}$ tal que $Z\left(\alpha^{\prime}, \underline{X}(0)\right)=Z\left(\alpha^{\prime}, \underline{X}(1)\right)$, conforme a Figura 3;

Passo 9: $\alpha^{\prime} \rightarrow\left\{\alpha_{n A}\right\}$

Passo 10: ir para INÍCIO do fluxograma da Figura 4, com $\left\{\alpha_{n A}\right\}=\left\{\alpha^{\prime}\right\}$.

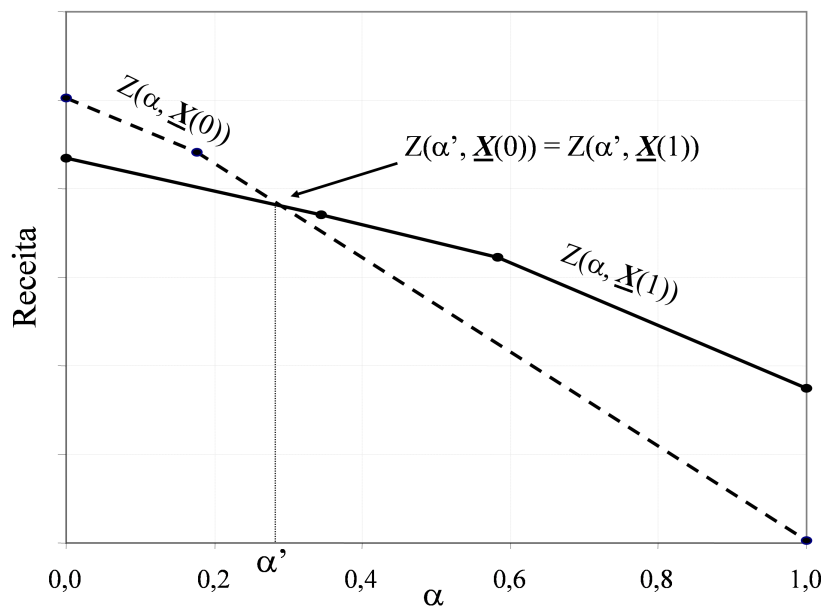

Figura 3. Definição dos elementos de $\left\{\alpha_{n A}\right\}$ a partir da PLP.

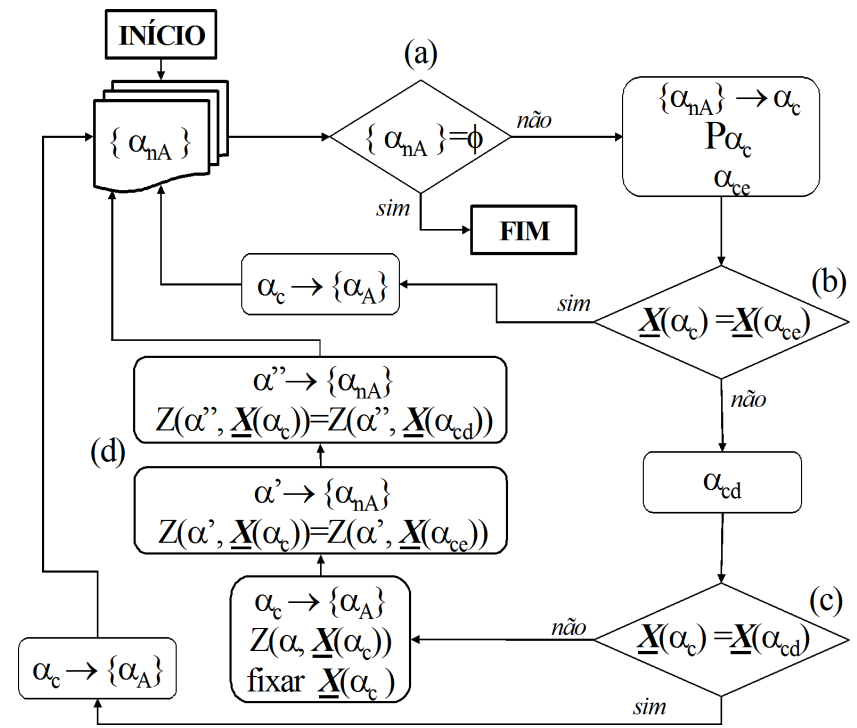

Figura 4. Fluxograma do método heurístico utilizado para fazer a análise paramétrica do MILP-Fuzzy. 


\subsection{Funcionamento da heurística}

Algumas anotações quanto ao funcionamento do algoritmo, indicadas na Figura 4, são necessárias:

(a) os MILPs são resolvidos para $\alpha_{c}$ enquanto $\left\{\alpha_{n A}\right\}$ não se tornar um conjunto vazio. Da forma como é feita a escolha de $\alpha_{c}$, o intervalo [0,1] é analisado "da esquerda para a direita". A cada iteração ele é reduzido até que se obtenha a mesma configuração de rede para os seus valores de $\alpha$ extremos, $\alpha_{c e}-\alpha_{c}$ ou $\alpha_{c}-\alpha_{c d}$. Quando uma das situações $\underline{X}\left(\alpha_{c e}\right)=\underline{X}\left(\alpha_{c}\right)$ ou $\underline{X}\left(\alpha_{c}\right)=\underline{X}\left(\alpha_{c d}\right)$ é alcançada, o algoritmo passa a avaliar o subintervalo adjacente à direita, e assim por diante, até que se tenha concluído todo o intervalo de $\alpha$. Esta escolha da direção em que o algoritmo caminha dentro do intervalo $[0,1]$ é arbitrária. Poderia ser de outra forma, por exemplo, "da direita para a esquerda", escolhendo-se $\alpha_{c}=\max \left\{\alpha_{n A}\right\}$.

Para melhorar o desempenho computacional do algoritmo, $Z\left(\alpha_{c d}\right)$ pode ser usado como "limite inferior" durante o processo de busca da solução ótima de $P \alpha_{c}$.

(b) verifica-se se a rede corrente é idêntica à rede obtida para o $\alpha$ mais próximo à esquerda. Caso seja, considerar $\underline{X}\left(\alpha_{c e}\right)$ como sendo a configuração da rede solução para $\alpha \in\left[\alpha_{c e}, \alpha_{c}\right]$.

(c) verifica-se se a rede corrente é idêntica à rede obtida para o $\alpha$ mais próximo à direita. Caso seja, considerar $\underline{X}\left(\alpha_{c}\right)$ como sendo a configuração da rede solução para $\alpha \in\left[\alpha_{c}, \alpha_{c d}\right]$.

(d) as intersecções de $Z\left(\alpha, \underline{X}\left(\alpha_{c}\right)\right)$ com $Z\left(\alpha, \underline{X}\left(\alpha_{c e}\right)\right)$ e de $Z\left(\alpha, \underline{X}\left(\alpha_{c}\right)\right)$ com $Z\left(\alpha, \underline{X}\left(\alpha_{c d}\right)\right)$ definem os novos elementos de $\left\{\alpha_{n A}\right\}$ a serem avaliados, que são $\alpha^{\prime}$ e $\alpha^{\prime \prime}$, respectivamente. Estas tarefas são executadas para as situações em que não se confirma a igualdade de redes para o subintervalo de $\alpha$ que se encontra em análise.

Conforme dito anteriormente, mudanças em $\alpha$ alteram os valores rhs do MILP e, conseqüentemente, modificam o espaço de soluções factíveis de $P_{\alpha}$. Em particular, a rede $\underline{X}\left(\alpha_{1}\right)$ pode se tornar infactível para alguns valores de $\alpha$, o que impossibilita uma análise $Z\left(\alpha, \underline{X}\left(\alpha_{1}\right)\right)$ completa. Nos casos em que esta infactibilidade proíbe determinar $\alpha^{\prime}$ e/ou $\alpha^{\prime \prime}$, os novos elementos de $\left\{\alpha_{n A}\right\}$ são tomados como sendo o valor médio do subintervalo de avaliação. Nestas situações, a solução $g_{\underline{x}^{1}, \ldots, \underline{x}^{p}}(\alpha)$ pode ter uma "descontinuidade" em $\alpha^{\prime}$ e/ou $\alpha^{\prime \prime}$.

Outro fato relevante durante o procedimento para definir $\alpha^{\prime}$ e $\alpha^{\prime \prime}$ é a modularidade dos equipamentos candidatos. Não se descarta a possibilidade de que soluções de rede com custos diferenciados sejam encontradas dentro do limite de orçamento estipulado, porém tais soluções devem apresentar o mesmo comportamento de receita para todo o intervalo de demanda previsto. Isto significa dizer que podem existir situações em que uma pequena variação no valor de $\alpha$ provoque uma mudança de hierarquia de algum equipamento ou até mesmo uma troca de nó de acesso a ser atendido (soluções de $P_{\alpha}$ ); mas quando se verifica o número total de usuários atendidos (receita gerada), estas situações mantêm o mesmo comportamento: $Z\left(\alpha, \underline{X}\left(\alpha_{1}\right)\right)=Z\left(\alpha, \underline{X}\left(\alpha_{2}\right)\right)$.

Portanto, durante a aplicação do algoritmo, o planejador deve ter liberdade de definir outros critérios de decisão (por exemplo: a rede mais barata, a que atende ao maior número de nós de acesso, a que possui maior capacidade total de atendimento, entre outros) que possam auxiliá-lo na escolha da solução de melhor qualidade dentre aquelas que apresentam o mesmo comportamento de receita gerada. Uma opção mais simples do ponto de vista de planejamento, porém mais eficiente do ponto de vista computacional, é adotar a primeira solução encontrada e descartar as demais.

\section{Exemplo de Aplicação: Sistema de Acesso Móvel Celular}

A avaliação do risco técnico-econômico é realizada com o objetivo de medir o impacto sofrido pelo sistema de acesso móvel celular em situações de imprecisão nos dados de demanda dos serviços. É utilizado o controle de demanda por serviço (inequações (9), (10), (15) e (16)).

As principais variáveis a serem analisadas são: hierarquia dos equipamentos a serem alocados, topologia da rede, demanda por serviço em cada nó de acesso e comportamento da receita gerada pelo sistema.

\subsection{Dados de entrada}

Os parâmetros do modelo foram escolhidos de forma a refletir, o máximo possível, dados reais. A rede exemplo, apresentada pela Figura 5, contém 1 BSC/MSC e 15 BTSs. Ela indica os 28 arcos candidatos e seus respectivos comprimentos. A demanda em cada nó pode ser atendida através de um arco direto (BTSBSC/MSC, numerados de 1 a 15) e/ou utilizar uma (ou mais) rota alternativa (BTS-BTS, numerados de 16 a 28$)$.

No estudo, o atendimento da demanda prevista pode ser realizado por equipamentos das seguintes tecnologias: 


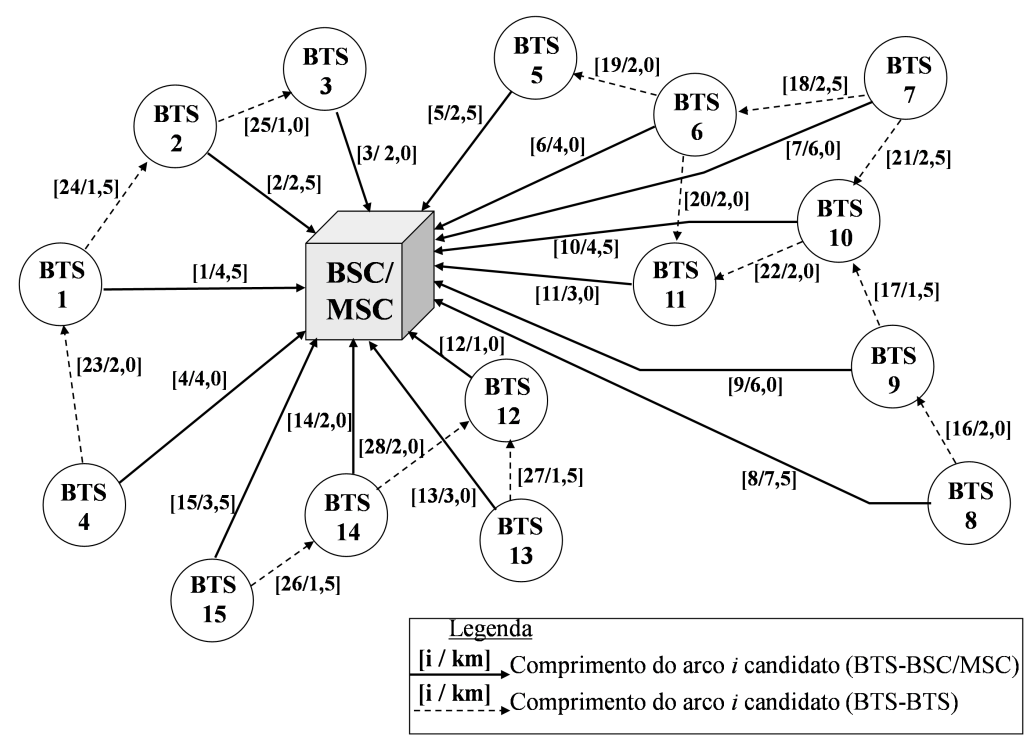

Figura 5. Rede candidata.

a) modem HDSL - High-data-rate Digital Subscriber Line: sistema que utiliza o cabo de cobre como meio de transmissão. Por apresentar hierarquia única (taxa de transmissão de 2,048 Mbps = 1 canal E1), a interconexão é ponto-a-ponto, com topologia de rede do tipo estrela simples. A distância máxima permitida para um enlace com HDSL é de $4 \mathrm{Km}$.

b) modem óptico: sistema ponto-a-ponto que permite a transmissão de dados sobre fibras ópticas. Permite maior alcance e imunidade à interferência no sinal que o modem convencional. Devido a sua constituição modular e ao sistema de gerenciamento, pode ser adquirido em várias versões de capacidade.

c) enlace via rádio micro-ondas: a rápida instalação e alta flexibilidade de configuração são os principais fatores que fazem com que os equipamentos de rádio digital sejam bastante utilizados como forma de acesso. Estes sistemas operam na faixa de frequências que vai de 7 a $38 \mathrm{GHz}$ e oferecem opções de topologia e de taxa de transmissão compatíveis com as do modem óptico.

As três soluções tecnológicas apresentam taxa de transmissão simétrica. A Tabela 1 lista as capacidades (em canais E1) e os custos de equipamentos/infra-estrutura para cada uma delas. O custo do sistema HDSL é adotado como referência.

Tabela 1. Informações sobre as tecnologias.

\begin{tabular}{ccccccc}
\hline Sistema & \multicolumn{6}{c}{ Custos } \\
\cline { 2 - 7 } candidato & \multicolumn{5}{c}{ Equipamento } & \multicolumn{1}{c}{ Infra-estrutura (Km) } \\
\hline & $1 \times E 1$ & $2 \times E 1$ & $4 \times E 1$ & $8 \times E 1$ & Dutos & Cabos \\
HDSL & 1,00 & - & - & - & 4,17 & 4,30 \\
Óptico & 1,00 & 1,50 & 1,75 & 2,00 & 5,00 & 3,80 \\
Rádio & - & 8,50 & 13,50 & 20,00 & 0 & 0 \\
\hline
\end{tabular}

Várias configurações de rede existentes podem ser contempladas, porém, durante todo o processo de avaliação que se segue, é admitida uma única configuração de rede: para todos os arcos candidatados pelo planejador (Figura 5), apenas os dutos necessários para os sistemas HDSL e para os modems ópticos estão disponíveis, sem custo de implantação.

\subsection{Impacto da demanda imprecisa}

Ao utilizar as três tecnologias candidatas, a rede é capaz de oferecer dois perfis de serviço: um que exige canais de transmissão a $64 \mathrm{Kbps}$ e outro a $144 \mathrm{Kbps}$. Ambos necessitam de transmissão simétrica e comutação por circuito.

A análise técnico-econômica tem por objetivo avaliar, estrategicamente, o comportamento de um sistema de acesso que exige, a priori, a presença de 10 BTSs com suas demandas perfeitamente definidas. Juntamente com estas BTSs, pretende-se estudar a possibilidade de implantação de mais 5 novas BTSs em posições estratégicas dentro do sistema. 
A Tabela 2 indica as dez BTSs que, necessariamente, integram o sistema de acesso final e cuja demanda a ser atendida é conhecida pelo planejador (total de 255 canais de 64 Kbps para o serviço 1 e 165 canais de $144 \mathrm{Kbps}$ para o serviço 2). As outras cinco BTSs, que ainda podem ser interconectadas, têm suas demandas representadas através de números fuzzy triangulares. Os triângulos são todos simétricos. Na Tabela 3, os dados retratam a demanda destas BTSs. Todos os valores são expressos em número de canais de cada serviço.

Tabela 2. BTSs com demandas precisas.

\begin{tabular}{ccc}
\hline \multirow{2}{*}{ BTS } & \multicolumn{2}{c}{ Demanda (em número de canais) } \\
\cline { 2 - 3 } & Serviço 1 & Serviço 2 \\
\hline 2 & 32 & 16 \\
3 & 20 & 13 \\
4 & 24 & 17 \\
5 & 24 & 20 \\
6 & 30 & 20 \\
9 & 27 & 15 \\
10 & 30 & 15 \\
12 & 23 & 17 \\
13 & 25 & 15 \\
15 & 20 & 17 \\
\hline Total & 255 & 165 \\
\hline Receita & 0,1 & 0,2 \\
\hline
\end{tabular}

Tabela 3. BTSs com demandas imprecisas.

\begin{tabular}{ccccccc}
\hline \multirow{2}{*}{ BTS } & \multicolumn{3}{c}{ Demanda (em número de canais) } \\
\cline { 2 - 7 } & \multicolumn{3}{c}{ Serviço } & \multicolumn{4}{c}{ Serviço } \\
\cline { 2 - 7 } & $\underline{d}_{s i}$ & $D_{s i}$ & $\bar{d}_{s i}$ & $\underline{d}_{s i}$ & $D_{s i}$ & $\bar{d}_{s i}$ \\
\hline 1 & 11 & 18 & 25 & 7 & 13 & 19 \\
7 & 18 & 26 & 34 & 6 & 10 & 14 \\
8 & 9 & 14 & 19 & 5 & 9 & 13 \\
11 & 11 & 20 & 29 & 6 & 10 & 14 \\
14 & 7 & 16 & 25 & 4 & 8 & 12 \\
\hline Total & 56 & 94 & 132 & 28 & 50 & 72 \\
\hline
\end{tabular}

A receita unitária (em valor relativo) de cada serviço é perfeitamente conhecida e encontra-se no final da Tabela 2. Como se trata de um planejamento estratégico que avalia uma possibilidade de expansão, a exigência de atendimento encontra-se apenas para aquelas BTSs que possuem a obrigatoriedade de fazer parte do sistema final. A escolha (ou não) das outras depende da disponibilidade orçamentária. O parâmetro de confiabilidade $\alpha$, de cada serviço, é o mesmo para todos os nós de acesso.

\subsection{Modelagem das especificidades das soluções tecnológicas}

O cenário mercadológico a ser avaliado orienta a modelagem do MILP-Fuzzy. Isto acontece devido às especificidades da rede a ser planejada, assim como das soluções tecnológicas candidatas. A aplicação da heurística independe destas especificidades, desde que o MILP-Fuzzy elaborado para cada cenário possua a estrutura descrita anteriormente.

Para as tecnologias consideradas no planejamento da infra-estrutrura do sistema de acesso móvel celular, são necessárias as seguintes adaptações (DeSousa \& Carlson, 2010):

- Contabilização do custo: substituir a restrição (2), que limita o orçamento, pela restrição (17).

$$
\begin{aligned}
& \sum_{(i, j) \in A} \sum_{n \in H_{i j}}\left[\left(\varphi_{i j}^{X_{e q}, n}+\varphi_{i j}^{X_{r}, n} \cdot l_{i j}\right) \cdot \sum_{k \in \psi} 2^{k} \cdot X_{i j n k}\right]+ \\
& \sum_{(i, j) \in A} \sum_{(s, i) \in A}\left(\varphi_{i j}^{Z_{e q}, n}+\varphi_{i j}^{Z_{r}, n} \cdot l_{i j}\right) \cdot Z_{i j n}+ \\
& \sum_{n \in O_{i j}}\left(\varphi_{i j}^{W_{e q}, n}+\varphi_{i j}^{W_{r}, n} \cdot l_{i j}\right) \cdot W_{i j n} \leq L
\end{aligned}
$$


onde:

$A$ : conjunto de arcos conectanto nós BTS-BTS ou nós BTS-BSC/MSC;

$H_{i j}$ : conjunto de sistemas de modems HDSL candidatos no arco $(i, j) \in A$;

$\psi$ : conjunto dos números naturais não-negativos $\{0,1,2,3 \ldots\}$;

$X_{i j n k}$ : variável binária, de ordem $k$, associada à escolha do sistema de modems HDSL, tipo $n$, candidato no $\operatorname{arco}(i, j) \in A$;

$\varphi_{i j}^{X e q, n}:$ custo associado à escolha do sistema de modems HDSL (equipamentos), tipo $n$, candidato no $\operatorname{arco}(i, j) \in A$

$\varphi_{i j}^{X r, n}$ : custo associado à escolha do sistema de modems HDSL (cabos e dutos), tipo $n$, candidato no $\operatorname{arco}(i, j) \in A$

$O_{i j}$ : conjunto dos sistemas de modems ópticos candidatos no arco $(i, j) \in A$;

$Z_{i j n}$ : variável binária associada à escolha do sistema de modems ópticos, tipo $n$, candidato no arco $(i, j) \in A$

$\varphi_{i j}^{Z e q, n}$ : custo associado à escolha do sistema de modems ópticos (equipamentos), tipo $n$, candidato no $\operatorname{arco}(i, j) \in A$

$\varphi_{i j}^{Z r, n}$ : custo associado à escolha do sistema de modems ópticos (cabos e dutos), tipo $n$, candidato no $\operatorname{arco}(i, j) \in A$

$R_{i j}$ : conjunto dos sistemas rádio micro-ondas candidatos no arco $(i, j) \in A$;

$W_{i j n}$ : variável binária associada à escolha do sistema rádio micro-ondas, tipo $n$, candidato no arco $(i, j) \in A$;

$\varphi_{i j}^{W e q, n}$ : custo associado à escolha do sistema rádio micro-ondas (equipamentos), tipo $n$, candidato no $\operatorname{arco}(i, j) \in A$;

$\varphi_{i j}^{W r, n}$ : custo associado à escolha do sistema rádio micro-ondas (repetidores e amplificadores), tipo $n$, candidato no arco $(i, j) \in A$;

$l_{i j}$ : comprimento do arco $(i, j) \in A$.

- Garantia de capacidade dos arcos: substituir o conjunto de restrições (5), que controla a capacidade das tecnologias escolhidas, pelo conjunto de restrições (18):

$$
\begin{aligned}
& \sum_{n \in H_{i j}}\left[\operatorname{cap}_{i j}^{X, n} \cdot \sum_{k \in \psi} 2^{k} \cdot X_{i j n k}\right]+\sum_{n \in O_{i j}} \operatorname{cap}_{i j}^{Z, n} \cdot Z_{i j n}+ \\
& \sum_{n \in R_{i j}} c a p_{i j}^{W, n} \cdot W_{i j n}-Y_{i j} \geq 0, \forall(i, j) \in A
\end{aligned}
$$

onde:

$\operatorname{cap}_{i j}^{X, n}$ : capacidade do sistema de modems HDSL, tipo $n$, candidato no arco $(i, j) \in A$;

$\operatorname{cap}_{i j}^{Z, n}$ : capacidade do sistema de modems ópticos, tipo $n$, candidato no arco $(i, j) \in A$;

$\operatorname{cap}_{i j}^{W, n}$ : capacidade do sistema rádio micro-ondas, tipo $n$, candidato no $\operatorname{arco}(i, j) \in A$.

- Restrições de distância para o sistema HDSL: acrescentar o conjunto de restrições (19) para garantir que a escolha da tecnologia HDSL só aconteça para aqueles enlaces com comprimento no máximo igual ao permitido.

$$
X_{i j n k}=0, \forall l_{i j}>l_{\max }
$$

onde:

$l_{\max }:$ comprimento máximo permitido para um enlace HDSL.

- Restrições de topologia para o sistema HDSL: acrescentar o conjunto de restrições (20) para proibir a formação de rotas alternativas onde se tenha o compartilhamento de demandas, oriundas de BTSs distintas, em um enlace utilizando apenas sistemas HDSL.

$$
\sum_{j \in J_{1}} \sum_{n \in H_{i j}}\left[\operatorname{cap}_{i j}^{X, n} \cdot \sum_{k \in \psi} 2^{k} \cdot X_{i j n k}\right]-\sum_{s \in I_{s}} f c_{s} \cdot Y_{s i} \leq 0, \forall i \in I-I_{s}
$$

Outras propostas de modelagem MILP-Fuzzy, contemplando cenários mercadológicos diferenciados, podem ser conferidas em DeSousa et al. (2011), DeSousa et al. (2010b) e DeSousa et al. (2010a). 


\subsection{Análise dos resultados}

Todos os experimentos computacionais foram realizados em uma máquina Sun Workstation Ultra-1 com sistema operacional SunOS 5.7. O método heurístico e as instâncias foram implementados em linguagem C. As soluções dos MILPs e PLs, sempre que necessárias, foram obtidas através de "chamadas" ao solver CPLEX $^{\circledR}$ (CPLEX, 1994).

Embora o método heurístico discutido na Seção 5 possa ser utilizado para avaliar todo o intervalo de variação de demanda indicado na Tabela 3, nas análises que se seguem sua aplicação fica restrita ao intervalo $\left[\mathbf{D}_{\mathbf{s i}}, \overline{\mathbf{d}}_{\mathbf{s i}}\right]$, resultante da modelagem da demanda fuzzy presente no MILP (Seção 4).

A configuração de atendimento mais econômica, capaz de interconectar as 10 BTSs que exigem atendimento pleno da demanda (Tabela 2), é indicada na Figura 6. Esta rede gera 58,50 unidades de receita e exige um orçamento de 110,90 unidades de custo. Se o planejador não disponibiliza esta quantia mínima, certamente haverá repressão de demanda, independente de seu valor efetivo.

A tecnologia óptica é predominante. Ela atende 8 das 10 BTSs previstas. A rede possui topologia mista. Destacando que:

1. 4 BTSs são atendidas em estrela simples: 4, 5, 6 e a 15 ; e

2. 6 BTSs formam três configurações tipo rota: 2-3, 9-10 e 13-12.

Partindo do plano da Figura 6, considere que seja possível atingir um orçamento de 140,00 unidades de custo. Qual seria a melhor forma de investir esta folga $(140,00-110,90=29,10)$ no orçamento? Quais seriam as mudanças a serem feitas no plano original de forma a agregar mais usuários ao sistema? Este estudo é feito verificando-se a implantação conjunta de mais 5 novas BTSs, indicadas na Figura 6, caso o orçamento de 140,00 unidades seja suficiente. Esta estimativa de orçamento é mantida fixa durante toda a análise.

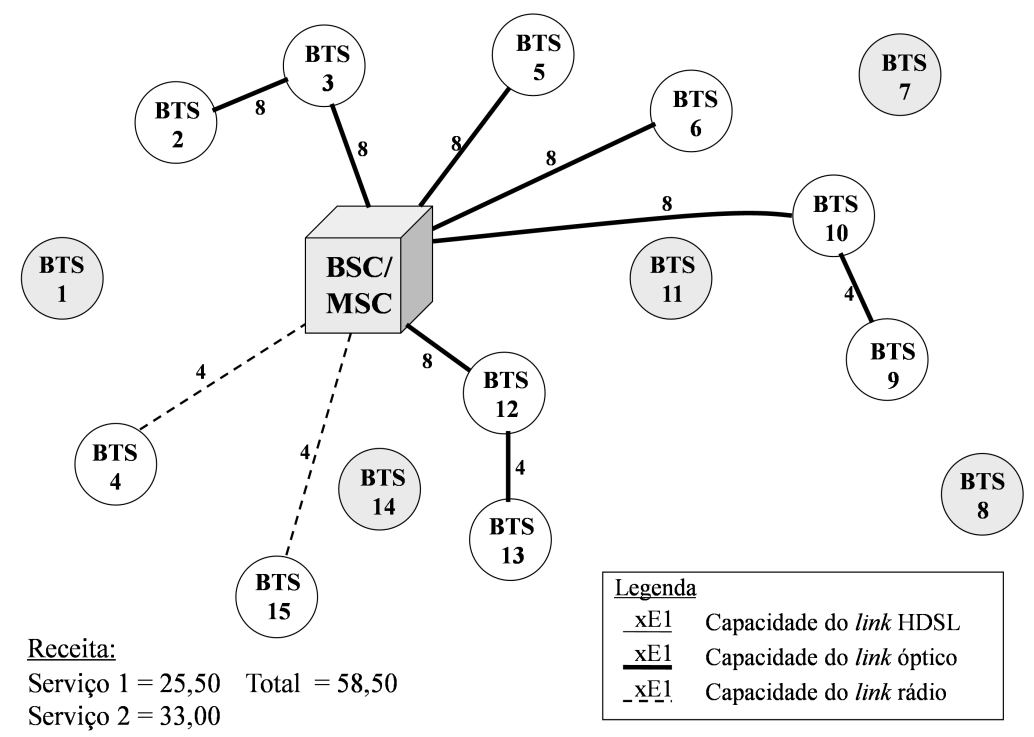

Figura 6. Rede mínima para atender 10 BTSs, com indicação de localização de outras 5 .

A solução completa (estudo de todo o intervalo $\left.\left[\mathbf{D}_{\mathbf{s i}}, \overline{\mathbf{d}}_{\mathbf{s i}}\right]\right)$ exigiu a execução de 12 MILPs e consumiu 18 minutos e 37 segundos de processamento. As configurações de rede, em função da confiabilidade $\alpha$ (da maior para a menor), são listadas na Tabela 4. Ela mostra o "ranking" das soluções e indica, para cada configuração, a sua capacidade total. Cada arco escolhido (variável na solução=1) é formado pela tríade: TECNOLOGIAarco_capacidade (Z010_8, por exemplo, significa que foi alocado um sistema de modems ópticos para o arco de número 10, com capacidade de 8 canais E1), onde a numeração dos arcos obedece a Figura 5.

As soluções indicam a variedade de respostas que o método heurístico é capaz de gerar. Um "ranking de redes" é disponibilizado ao planejador, que tem a oportunidade de escolher a mais apropriada, de acordo com a sua confiança nos dados de demanda imprecisa.

À medida que o valor de $\alpha$ vai de 1 para 0 (diminui o grau de confiança nos dados de demanda ou; equivalentemente, aumenta a demanda prevista nas BTSs imprecisas) podem ser encontradas até sete mudanças na topologia do sistema. Isto vai depender das escolhas do planejador, uma vez que o método heurístico indica dois subintervalos para $\alpha([0,306,0,228]$ e $[0,227,0,000])$ onde se tem soluções múltiplas aquelas com redes diferentes, mas que apresentam o mesmo comportamento de receita. Em todas as soluções 
Tabela 4. Soluções de rede

\begin{tabular}{|c|c|c|}
\hline $\begin{array}{c}\text { Intervalo } \\
\qquad \alpha\end{array}$ & Configuração da rede & $\begin{array}{l}\text { Capacidade } \\
\text { total }\end{array}$ \\
\hline$[1,000,0,653]$ & $\begin{array}{l}\text { Z026_4 Z027_4 Z003_8 Z005_8 Z010_8 Z011_8 Z012_8 } \\
\text { Z014_8 Z017_8 Z020_8 Z025_8 W001_2 W007_2 W004_4 }\end{array}$ & $88 \mathrm{xE} 1$ \\
\hline$[0,653,0,306]$ & $\begin{array}{l}\text { Z019_4 Z023_4 Z026_4 Z027_4 Z001_8 Z003_8 Z005_8 } \\
\text { Z011_8 Z012_8 Z014_8 Z022_8 Z025_8 W006_2 W009_4 }\end{array}$ & $86 \times \mathrm{xE} 1$ \\
\hline$[0,306,0,228]$ & $\begin{array}{l}\text { Z019_4 Z023_4 Z026_4 Z027_4 Z001_8 Z003_8 Z005_8 } \\
\text { Z011_8 Z012_8 Z014_8 Z022_8 Z025_8 W006_2 W009_4 } \\
\text { ou } \\
\text { Z023_4 Z026_4 Z027_4 Z001_8 Z003_8 Z005_8 Z006_8 } \\
\text { Z011_8 Z012_8 Z014_8 Z022_8 Z025_8 W009_4 }\end{array}$ & $88 \times \mathrm{xE} 1$ \\
\hline$[0,228,0,227]$ & $\begin{array}{l}\text { Z023_4 Z026_4 Z027_4 Z001_8 Z003_8 Z005_8 Z006_8 } \\
\text { Z011_8 Z012_8 Z014_8 Z022_8 Z025_8 W009_4 }\end{array}$ & $88 x E 1$ \\
\hline \multirow[t]{3}{*}[0,227,0,000]{} & $\begin{array}{l}\text { Z026_4 Z027_4 Z003_8 Z005_8 Z011_8 Z012_8 Z014_8 } \\
\text { Z019_8 Z022_8 Z025_8 W005_2 W004_4 W007_4 W009_4 } \\
\text { ou } \\
\text { Z026_4 Z027_4 Z003_8 Z005_8 Z006_8 Z011_8 Z012_8 } \\
\text { Z014_8 Z022_8 Z025_8 W004_4 W007_4 W009_4 } \\
\text { ou }\end{array}$ & $86 \times \mathrm{xE} 1$ \\
\hline & $\begin{array}{l}\text { Z019_4 Z026_4 Z027_4 Z003_8 Z005_8 Z011_8 Z012_8 } \\
\text { Z014_8 Z022_8 Z025_8 W006_2 W004_4 W007_4 W009_4 } \\
\text { ou }\end{array}$ & $82 \times E 1$ \\
\hline & $\begin{array}{l}\text { Z026_4 Z027_4 Z003_8 Z005_8 Z011_8 Z012_8 Z014_8 } \\
\text { Z019_8 Z022_8 Z025_8 W006_2 W004_4 W007_4 W009_4 }\end{array}$ & $86 \times \mathrm{xE} 1$ \\
\hline & nlace HDSL $\mathbf{Z}=$ Enlace Óptico $\mathbf{W}=$ Enlace Rádio Micro-o & \\
\hline
\end{tabular}

encontradas, pode-se observar que a tecnologia óptica atende à maioria dos nós, entre $71 \%$ (10/14) e 92\% $(12 / 13)$.

Ao comparar a capacidade das redes na Tabela 4, deve-se fazer a seguinte ponderação: a capacidade total do sistema dimensionado para $\alpha \in[1,000,0,653]$, por exemplo, é maior que a do sistema obtido com $\alpha \in[0,227,0,000]$, porém a primeira rede não é capaz de atender à configuração de demanda prevista para a segunda. O fato é que o sistema pode ter uma capacidade total maior, mas apresentar enlaces de baixa taxa de transmissão que não sejam capazes de suportar um pequeno acréscimo de demanda. Este fato pode ser observado nos enlaces que utilizam rádio micro-ondas W001_2 e W007_2 (Figura 7).

A rede escolhida para a configuração de demanda com maior possibilidade de ocorrência (Figura 7) adiciona as BTSs 11 e 14 como pontos de concentração de demanda de outras BTSs (6 e 15, respectivamente) formando, assim, duas novas oportunidades de rota em relação ao sistema originalmente dimensionado para as 10 BTSs (Figura 6). As BTSs 1 e 7 foram interconectadas ao sistema através de enlaces de micro-ondas em baixa capacidade $(2 \mathrm{xE} 1)$.

Inspecionando, simultaneamente, todas as configurações de atendimento da Tabela 4, verifica-se que a topologia permanece constante em algumas regiões da rede. É o caso das rotas formadas pelas BTSs 2-3, 13-12 e 15-14. Com $\alpha$ a partir de 0,653, esta característica também é observada para as BTSs 9 e 10-11.

As principais modificações são causadas pelas BTSs 1 e 7 . Na busca da máxima receita, acomodar (ou não) os clientes previstos para estas BTSs exige modificações na forma de atendimento das BTSs vizinhas. A BTS 8 mostrou-se pouco atrativa. Sua demanda foi totalmente penalizada durante toda a análise.

A Figura 8 mostra a evolução da receita de acordo com a variação de $\alpha$. Como esperado, a receita gerada é uma função linear por partes e cresce à medida que $\alpha$ se aproxima de 0 . Isto se deve à adição incremental de demanda nas BTSs imprecisas. A solução apresenta uma "descontinuidade de receita" em $\alpha=0,653$, em aproximadamente 1,000 unidade de receita. Esta descontinuidade ocorre porque $\alpha=0,653$ foi escolhido para ser resolvido $\left(P_{\alpha=0,653}\right)$ a partir de um subintervalo de $[0,1]$, que apresentou infactibilidade durante a sua análise paramétrica linear.

Para as situações que possuem soluções múltiplas (intervalos $0 \leq \alpha \leq 0,227$ e $0,228 \leq \alpha \leq 0,306$ ), em que as redes são capazes de gerar o mesmo patamar de receita, a distribuição desta receita entre os serviços pode ser diferenciada, mesmo porque estas redes podem apresentar (e apresentam) topologias de atendimento distintas (Tabela 4). 


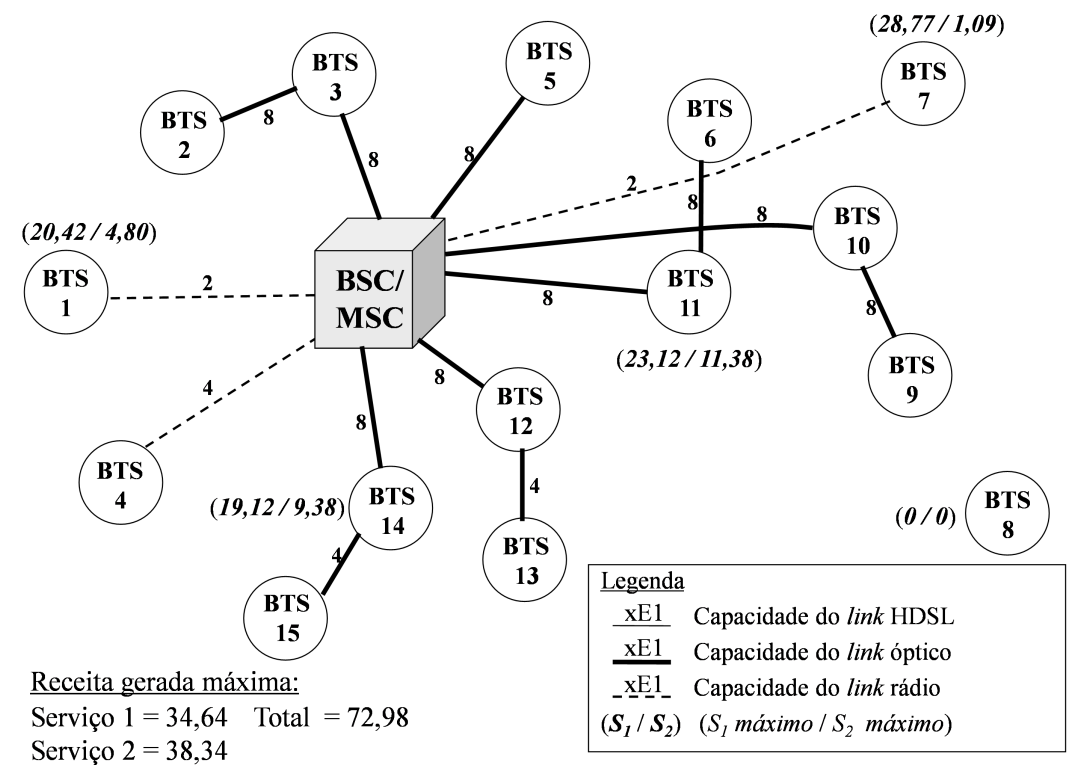

Figura 7. Configuração da rede para $\alpha \in[1,000,0,653]$ - maior possibilidade de ocorrência.

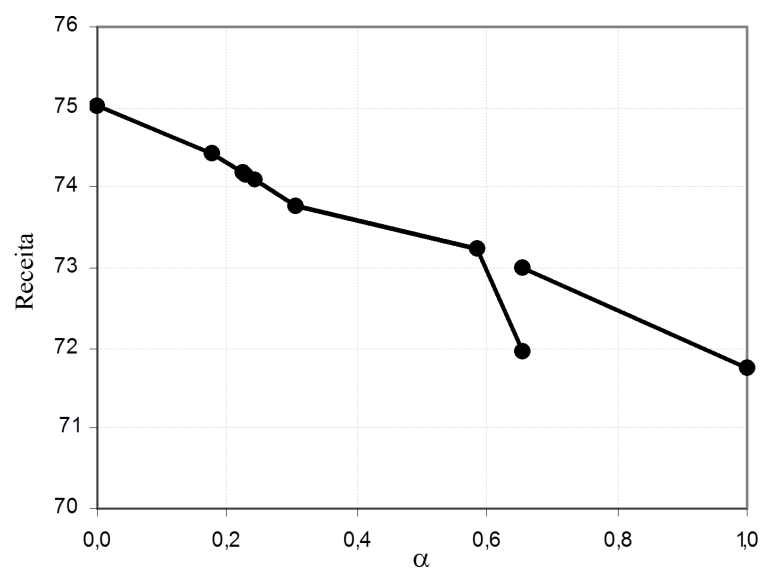

Figura 8. Comportamento da receita x nível de confiança.

\section{Conclusões}

A possibilidade de oferecer novos serviços aos usuários e o surgimento de novas tecnologias são características atuais das telecomunicações. Grandes operadores de rede, múltiplos provedores de serviço e uma enorme variedade de fornecedores de equipamentos disputam este mercado.

O sistema de acesso, por representar o segmento responsável pelo atendimento individual de cada usuário, é o foco imediato destas transformações. Planejar a sua evolução não é uma tarefa simples, principalmente porque envolve recursos financeiros volumosos. Dúvidas sobre quais serviços oferecer, bem como sobre as suas rentabilidades, são inevitáveis.

Neste capítulo é apresentado um sistema de apoio à decisão fundamentado em um modelo matemático bastante flexível, que pode ser aplicado no planejamento de sistemas de acesso multi-serviço, fixo e/ou móvel, em situações nas quais existe imprecisão sobre os valores adotados de demanda dos serviços. O dimensionamento dos componentes da rede é a atividade mais explorada. A rede é vista como um grafo e a modelagem de maximização de receita é traduzida como um problema de programação linear inteira mista, o qual obedece restrições técnicas de capacidade e orçamento. A imprecisão é abordada de acordo com o conceito de números fuzzy. Um método de solução heurístico, baseado em programação paramétrica, é elaborado para tratar o problema matemático correspondente.

São relatados e discutidos os resultados da aplicação da metodologia no planejamento da infra-estrutura de um sistema de acesso móvel celular de médio porte, capaz de oferecer dois perfis de serviço. Foram avaliadas três tecnologias de transmissão: modem HDSL, modem óptico e enlace via rádio micro-ondas.

Em relação aos cenários analisados, é interessante ressaltar, do ponto de vista técnico-econômico, as seguintes constatações sobre os resultados obtidos: os resultados combinam as tecnologias ópticas e rádio; com a estrutura de custos adotada, a tecnologia HDSL tornou-se proibitiva; à medida que a hierarquia 
dos equipamentos alocados aumenta, consequência direta de cenários mais otimistas para a demanda, o compartilhamento de recursos torna-se mais acentuado, o que melhora o retorno (receita/investimento) financeiro do sistema.

Considerando o ponto de vista da modelagem, cuja finalidade é auxiliar o planejador ao longo do processo de decisão, verifica-se que a metodologia proposta é capaz de refletir todas as principais situações encontráveis no ambiente das telecomunicações. A flexibilidade quanto a variações nos cenários possíveis de serem contemplados é uma das suas principais virtudes. Pode-se destacar: possibilidade de realizar um planejamento multi-serviço; possibilidade de atribuir prioridades no atendimento dos serviços; possibilidade de classificação de redes, da qual o planejador é capaz de selecionar aquela(as) que atende(m) as suas exigências de fornecimento de serviços e, ao mesmo tempo, permite vislumbrar outros planos que possibilitam acompanhar a evolução da demanda prevista.

Como o mercado de telecomunicações é altamente dinâmico, e, às vezes, até imprevisível, seu estudo não se limita aos aspectos ora abordados. Extensões da modelagem que admitem os efeitos de uma receita unitária variável na função objetivo do MILP-Fuzzy, além de propostas de resolução baseadas em algoritmos meméticos, já estão sendo avaliadas.

\section{Referências}

Ahuja, R.K.; Magnanti, T.L. \& Orlin, J.B., Network Flows: Theory, Algorithms and Applications. $1^{\text {st }}$ edição. Englewood Cliffs, USA: Prentice Hall, 1993.

Albuquerque, J.P.A.; Fortes, J.M.P. \& Finamore, W.A., Probabilidade, Variáveis Aleatórias e Processos Estocásticos. $1^{\text {st }}$ edição. Rio de Janeiro, RJ: Interciência, 2008.

Bazaraa, M.S.; Jarvis, J.J. \& Sherali, H.D., Linear Programming and Network Flows. $2^{\text {nd }}$ edição. New York, USA: John Wiley \& Sons, 1990.

Bienstock, D.; Raskina, O.; Saniee, I. \& Wang, Q., Combined network design and multiperiod pricing: Modeling, solution techniques, and computation. Operations Research, 54(2):261-276, 2006.

Bolia, N. \& Kulkarni, V.G., Index policies for resource allocation in wireless networks. IEEE Transactions on Vehicular Technology, 58(4):1823-1835, 2009.

Campos, L. \& Verdegay, J.L., Linear programming problems and ranking of fuzzy numbers. Fuzzy Sets and Systems, $32(1): 1-11,1989$.

Cantão, L.A.P., Programação Não-Linear com Parâmetros Fuzzy: Teoria e Algoritmos. Tese de Doutorado, FEEC / Universidade Estadual de Campinas, Campinas, SP, 2003.

CPLEX, , Using the CPLEX Callable Library. Incline Village, USA: CPLEX Optimization Inc., 1994.

Crema, A., A procedure to verify the completeness of the right-hand-side parametric analysis for a mixed integer linear programming problem. European Journal of Operational Research, 108(3):684-695, 1998.

Cruz, F.R.B.; Mateus, G.R. \& Smith, J.M., A branch-and-bound algorithm to solve a multi-level network optimization problem. Journal of Mathematical Modelling and Algorithms, 2(1):37-56, 2003.

DeSousa, M.A. \& Carlson, C.M.F., Alocação otimizada de sistemas de transmissão para o problema de interconexão de ERBs em um SMC - um estudo de caso. In: Anais do XLII Simpósio Brasileiro de Pesquisa Operacional. Bento Gonçalves, RS, BR, 2010.

DeSousa, M.A.; Carlson, C.M.F.; Machado, J.T. \& Ribeiro, R.V., Uma abordagem fuzzy para a avaliação técnicoeconômica de redes de acesso. SBA Controle $\mathcal{E}$ Automação, 17(2):226-244, 2006.

DeSousa, M.A.; Oliveira, B.Q. \& Santos, M.T.L., Contratação de serviços de telecomunicações: Competição entre provedores, configurações de rede e custos - modelagem com dados imprecisos de demanda e tarifa. In: Anais do XLII Simpósio Brasileiro de Pesquisa Operacional. Bento Gonçalves, RS, 2010a.

DeSousa, M.A.; Santos, M.T.L.; Oliveira, B.Q. \& Costa, C.S., Um modelo de suporte à decisão para a avaliação técnico-econômica de contratos de serviços comporativos de telecomunicações mediantes dados incertos. In: Anais do XVIII Congresso Brasileiro de Automática. Bonito, MS, 2010b.

DeSousa, M.A.; Santos, M.T.L.; Oliveira, B.Q.; Dantas, M.J. \& Santana, A.C., Seleção de contratos de prestação de serviços de telecomunicações: Um estudo de caso com demanda fuzzy e tarifa ajustável. In: Anais do XLIII Simpósio Brasileiro de Pesquisa Operacional. Ubatuba, SP, 2011.

Gaivoronski, A.A. \& Zoric, J., Evaluation and design of business models for collaborative provision of advanced mobile data services: a portfolio theory approach. In: Raghavan, S.; Golden, B. \& Wasil, E. (Eds.), Telecommunications Modeling, Policy, and Technology. Heidelberg, Germany, p. 353-386, 2008.

Garg, V.K., Wireless Communications and Networking. San Francisco, USA: Morgan Kaufmann, 2007.

Jenkins, L., Parametric mixed integer programming: an appication to solid waste management. Management Science, 28(11):1270-1284, 1982.

Kasap, N.; Aytug, H. \& Erenguc, S.S., Provider selection and task allocation issues in networks with different QoS levels and all you can send pricing. Decision Support Systems, 43(2):375-389, 2007.

Pedrycz, W. \& Gomide, F., An Introduction to Fuzzy Sets: Analysis and Design. Cambridge, USA: MIT Press, 1998. 
Rouskas, A.N.; Kikilis, A.A. \& Ratsiatos, S.S., A game theoretical formulation of integrated admission control and pricing in wireless networks. European Journal of Operational Research, 191(3):1175-1188, 2008.

Sahinidis, N.V., Optimization under uncertainty: state-of-the-art and opportunities. Computers $\&$ Chemical Engineering, 28(6-7):971-983, 2004.

\section{Notas Biográficas}

Marcos Antônio de Sousa é graduado em Engenharia Elétrica (UFG, 1996), mestre e doutor em Engenharia Elétrica (UNICAMP, 1999 e 2004, respectivamente). Atualmente é Professor Adjunto da Escola de Engenharia Elétrica, Mecânica e de Computação da Universidade Federal de Goiás e do Departamento de Engenharia da PUC-Goiás. Possui experiência na área de Engenharia Elétrica e Pesquisa Operacional, tendo desenvolvido trabalhos nos seguintes temas: modelagem matemática, engenharia econômica, otimização, sistemas de apoio à decisão e inteligência computacional aplicada ao planejamento de sistemas de telecomunicações.

Flávio Henrique Teles Vieira é graduado e mestre em Engenharia Elétrica (UFG, 2000 e 2002, respectivamente) e doutor em Engenharia Elétrica (FEEC-UNICAMP, 2006). Atualmente é Professor Adjunto da Escola de Engenharia Elétrica, Mecânica e de Computação da UFG. Possui experiência na área de Engenharia Elétrica e Pesquisa Operacional, atuando nas seguintes áreas de pesquisa: modelagem matemática, tráfego de redes, sistemas de apoio à decisão, inteligência computacional aplicada a telecomunicações e sistemas de telecomunicações.

Carlos Magnus Carlson Filho é graduado em Engenharia Elétrica (UNESP, 1981), mestre e doutor em Engenharia Elétrica (UNICAMP, 1984 e 1998, respectivamente) e atualmente é Professor Pleno da Faculdade de Tecnologia de São José do Rio Preto. Possui experiência na área de Engenharia Elétrica e Pesquisa Operacional, tendo desenvolvido trabalhos nos seguintes temas: planejamento, redes celulares, sistemas de telecomunicações, otimização nebulosa e apoio à decisão.

Bruno Henrique Pereira Gonçalves é graduado em Engenharia de Computação (UFG, 2010) e atualmente é mestrando em Engenharia Elétrica e de Computação (UFG). Ele tem interesse nas áreas de Telecomunicações e Sistemas de Computação.

Victor Hugo Teles Costa é graduado em Engenharia de Computação (UFG, 2011) e atualmente é mestrando em Engenharia Elétrica e de Computação pela (UFG). Atua nas áreas de Telecomunicações e Computação Aplicada, envolvendo modelagem matemática, análise de desempenho de sistemas de comunicação e sistemas inteligentes de auxílio à tomada de decisão. 


\title{
Algoritmo Transgenético para o Passeio do Pistoneio Periódico com Realimentação Contínua nos Poços
}

\author{
Marco César Goldbarg, Elizabeth Ferreira Gouvêa Goldbarg e Herbert de Mélo Duarte
}

\begin{abstract}
Resumo: Este trabalho descreve um complexo problema na área de explotação de campos terrestres de petróleo, o Problema do Passeio do Pistoneio Periódico com realimentação contínua dos poços, e relata a aplicação de um algoritmo evolucionário transgenético ao problema. Os algoritmos transgenéticos se baseiam na mimetização da endossimbiose intracelular mutualista para desenvolver sua evolução artificial. São apresentados resultados de um experimento computacional com vinte e seis casos teste a fim de validar a eficiência da abordagem proposta.
\end{abstract}

Palavras-chave: Problema do passeio do pistoneio periódico, Algoritmos evolucionários, Algoritmos transgenéticos.

\begin{abstract}
This paper describes a complex problem in the area of exploitation of oil fields, the Periodic Piston Pump Truck Tour Problem with continuous replenishment of wells, and presents the application of a transgenetic algorithm to this problem. The transgenetic algorithms are based on mimicking the intracellular mutualistic endosymbiosis to develop their artificial evolution. The results of a computational experiment on twenty-six instances are reported in order to validate the efficiency of the proposed approach.
\end{abstract}

Keywords: Periodic piston pump truck tour, Evolutionary algorithms, Transgenetic algorithms.

\section{Introdução}

A exploração de petróleo em campos terrestres é basicamente efetuada em dois tipos de poços: poços surgentes, nos quais a pressão dos gases no interior da jazida é suficiente para fazer o óleo aflorar à superfície e poços nãosurgentes, em que é necessário um processo de retirada forçada do petróleo (elevação por meios artificiais). Ao longo de sua vida útil um poço migra da condição de surgente para a de não surgente na medida em que seu reservatório vai se esgotando. Em um dado momento o decaimento da vazão do poço pode ser de tal magnitude que não mais se justifique a alocação de equipamentos fixos de elevação, indicando-se então o uso de equipamentos móveis que possam atender simultaneamente vários poços ou de outras técnicas de revitalização. No caso da opção via equipamentos móveis, uma única unidade poderá coletar o petróleo de vários poços de pequena vazão permitindo que, no intervalo entre as coletas, o reservatório tenha tempo de realimentar o poço até que alcance seu nível de equilíbrio hidrostático.

O Problema do Passeio do Pistoneio (PPP) consiste em programar o uso de um equipamento móvel de elevação de petróleo - denominado unidade móvel do pistoneio. Essa programação é traduzida em designar a sequência de poços a serem visitados, bem como a rota que será utilizada pela unidade móvel nessa visita. O objetivo é maximizar o volume de óleo a ser extraído dentro de um horizonte de planejamento. Quando o horizonte de planejamento é suficientemente grande, os poços podem ter tempo suficiente para recompor sua oferta de petróleo após uma dada coleta sendo, portanto, passíveis de revisita. Assim, a partir de um dado horizonte de planejamento, o problema do passeio do pistoneio se transforma em um problema periódico.

O presente trabalho descreve um novo tipo de algoritmo evolucionário para a solução do Problema do Passeio do Pistoneio Periódico com Realimentação Contínua nos Poços (PPPP_R), relatando um experimento computacional associado. Na Seção 2 o Problema do Passeio do Pistoneio é descrito e é apresentada uma revisão bibliográfica dos algoritmos meta-heurísticos propostos para a solução de problemas correlatos ao presentemente abordado. Na Seção 3 é apresentado um algoritmo transgenético para a solução do problema. Na Seção 4 um experimento computacional é realizado e, finalmente, na Seção 5 conclusões são apresentadas.

*Autor para contato: marcocgold@gmail.com 


\section{O Problema do Passeio do Pistoneio Periódico com Realimentação Contínua}

Em campos terrestres de petróleo maduros o número de poços surgentes pode ser muito pequeno. Por exemplo, no caso da Bacia Potiguar, no estado do Rio Grande do Norte, Brasil, presentemente esse número é menor que 2\%. Como essa bacia possui cerca de 4.000 poços distribuídos em oito campos produtores, aproximadamente 3.800 poços serão candidatos à explotação através de métodos de elevação artificial como o Mechanical Rod Pump, Progressing Cavity Pump, bombeio centrífugo submerso, Piston Pump, e outros (Thomas, 2001). Contudo, em virtude de sua baixa produção, parte significativa desses poços não justifica mais o uso de equipamentos fixos de elevação sendo, portanto, candidatos ao uso de métodos de coleta móvel ou de outros métodos de recuperação avançada como Gas Lift e Pig Lift. Observa-se que o uso de técnicas de recuperação avançada são soluções clássicas no processo de incrementar o potencial de produção de campos maduros de forma economicamente viável (Lake, 2001).

Uma unidade móvel de pistoneio (UMP) consiste de um caminhão, equipado com um tanque, guincho hidráulico, cabo de aço, lança móvel e o copo de pistoneio. A UMP normalmente visita vários poços do campo a cada dia. O número dos poços visitados varia de acordo com a duração da jornada de trabalho, com o tempo gasto no percurso entre os poços, como o tempo de preparo do equipamento junto ao poço e no processo de pistoneio, em si. Ao final da jornada a UMP retorna a sua garagem.

O volume de petróleo disponível no poço por ocasião de uma visita depende, além das características do próprio poço, do tempo entre as visitas da UMP, uma vez que os poços são realimentados de óleo pelo reservatório de forma lenta e contínua assim que são esgotados pelo método de elevação artificial. O reenchimento cessa assim que a coluna de óleo do poço encontra seu equilíbrio hidrostático com o reservatório, de forma que longos períodos de repouso não aumentam a disponibilidade de óleo no poço. A realimentação dos poços obedece à função descrita na equação 1

$$
\Delta V=V_{\max }\left(1-e^{-\frac{\tau}{t}}\right)
$$

onde $\Delta V$ representa a variação no volume disponível em um poço cujo volume de óleo máximo (coluna estática) é $V_{\max }$ e que foi explotado pela última vez a $t$ unidades de tempo, com a velocidade de re-enchimento definida pelo parâmetro $\tau$, uma característica do poço. A variação no volume disponível no poço considera que o conteúdo do mesmo é esgotado a cada visita da UMP.

Considera-se o grafo $G=(V, A)$, onde o conjunto $V=\{0, \ldots, n\}$ representa os $n$ poços que deverão ser visitados no campo e mais a garagem da unidade móvel, representada pelo vértice 0 , e $A=\{1, \ldots, m\}$ o conjunto das ligações existentes no campo. O problema do Passeio do Pistoneio Periódico com Realimentação Contínua (PPPP_R) consiste em determinar um conjunto de $k$ rotas em no grafo $G$, cada uma iniciando e terminando em $v_{0}$ e respeitando o limite do turno de trabalho da UMP, de forma que o óleo coletado no conjunto de $k$ dias seja máximo. Nesse problema os poços de petróleo podem ser explotados em qualquer ocasião que se deseje, sendo que, tanto o volume disponível como o tempo de explotação necessário dependem do estágio de recuperação do poço. Presentemente considera-se que a UMP dispõe, quando necessário, de um caminhão-tanque auxiliar para o escoamento do petróleo retirado, o que representa as condições reais de trabalho da bacia Potiguar. Assim, a capacidade de retirada de óleo da UMP é considerada ilimitada.

A possibilidade de re-visita aos poços dentro de um dado horizonte de planejamento e a independência das rotas diárias estabelece o caráter periódico deste problema. Inclusive, de uma forma geral, um poço pode ser explorado antes de atingir o seu nível estático desde que o volume do poço seja atrativo em certa rota da UMP. O fato de haver realimentação dos poços após cada visita condiciona a futura oferta de petróleo ao próprio desenvolvimento da solução, o que confere ao problema um aspecto de dinamicidade determinística.

\subsection{Revisão da literatura}

O presente item visa resumir as pesquisas já desenvolvidas para o presente problema.

\section{Problemas da literatura com pontos em comum com o PPPP_R}

O problema do passeio do pistoneio periódico pertence à classe dos problemas de roteamento seletivo (PRVS) por não exigir que todos os vértices de demanda sejam atendidos pelo veículo de coleta e buscar a maximização do óleo retirado nos vértices. Todavia o problema possui características próprias de modo a constituir uma variante que se distingue dos problemas classicamente definidos na literatura.

A classe geral dos problemas de coleta que se assemelham ao PPPP é conhecida na literatura sob o nome de team orienteering problem - OP (Chao et al., 1996). O OP é geralmente definido em termos da determinação de um caminho entre específicos pontos de um dado circuito. Dessa forma diferencia-se ligeiramente do PPPP, todavia em muitas aplicações os dois pontos do caminho coincidem formando ciclo. Outros modelos que também poderiam representar o problema seriam: 
- The selective travelling salesperson problem (Laporte \& Martello, 1990). No caso do PPPP o comprimento do tour do selective travelling salesperson é limitado pelo tempo necessário ao deslocamento na rota e atividades nos vértices e objetivando-se maximizar o retorno nos vértices.

- The maximum collection problem (Kataoka \& Morito, 1988; Butt \& Cavalier, 1994), seria adaptável ao PPPP permitindo-se a revisita dos vértices.

- The bank robber problem (Balas, 1989; Arkin et al., 1998) ou outras variantes como o Tourist Trip Design Problem (Vansteenwegen \& Oudheusden, 2007).

O problema de roteamento de veículos (PRV), de forma geral, é NP-Difícil (Backer \& Furton, 1997). O problema de roteamento periódico (PRVP) é uma generalização do (PRV), e o problema de roteamento seletivo também é NP-Difícil (Golden et al., 1987).

Recentemente um procedimento baseado na meta-heurística Scatter Search foi desenvolvido por (Alegre et al., 2007) para a solução do problema periódico de recolhimento de sobra de materiais em uma manufatura de peças para carros. Os autores utilizam uma abordagem em duas fases. A primeira designando os pedidos aos dias e uma segunda fase construindo as rotas diárias. Hemmelmayr et al. (2009) reportam um procedimento VNS (Variable Neighborhood Search) para o problema.

Para o problema do roteamento seletivo de veículos (PRVS), Hayari et al. (2003) são os primeiros a proporem um algoritmo evolucionário para a versão com janelas de tempo. Tang \& Miller-Hooks (2005) reportam um algoritmo de Busca Tabu. Khemakhem et al. (2005) apresentaram uma meta-heurística híbrida para a solução do PRVS, na qual uma Busca Tabu foi combinada com uma busca em vizinhança variável descendente (VND). Archetti et al. (2007) propuseram duas variantes de um algoritmo baseado em Busca Tabu e VNS. Os resultados são comparados com os resultados obtidos pelas heurísticas de Chao et al. (1996) e de Tang \& Miller-Hooks (2005). Recentemente, Ke et al. (1988) reportam um algoritmo em Colônia de Formigas e Bouly et al. (2008) relatam um Algoritmo Memético.

\section{Trabalhos desenvolvidos anteriormente em variantes do tema}

Em relação ao problema de aplicação presentemente abordado, os primeiros trabalhos relatados na literatura abordaram a solução do PPP com várias simplificações. O primeiro trabalho relatado é o de Ferreira (2001) que desenvolve um Algoritmo Genético e um Algoritmo Transgenético para a solução de uma versão do Problema do Passeio do Pistoneio em que o horizonte de planejamento é fixado em no máximo de setes dias. Tal horizonte é suficiente curto para, de forma realística, desconsiderar a revisita aos poços. Dantas (2001) relata um algoritmo Busca Tabu para o PPP. Os dois trabalhos anteriormente citados apresentam resultados para a solução de casos reais associados ao campo terrestre de Canto do Amaro, localizado em Mossoró RN. Medeiros (2001) relata um experimento computacional envolvendo o desenvolvimento de um algoritmo Genético e um Transgenético baseado exclusivamente em troca de plasmídeos tratando casos do PPP com horizonte de planejamento de 15 dias, todavia ainda preserva a simplificação de não considerar o retorno aos poços. Nesse trabalho o desempenho dos algoritmos é verificado tanto sobre situações reais no campo de Canto do Amaro como em um conjunto de instâncias testes geradas aleatoriamente em conformidade com a metodologia que é emprega e descrita no presente trabalho. O trabalho de Medeiros (2001) envolveu testes com campos com 100, 200, 300, 400, 500 e 800 poços. Dalboni (2003) relata algoritmos evolucionários sequenciais e paralelos para o problema. Dentre eles destaca-se um algoritmo genético com busca local e mineração de dados. Neste trabalho são desconsiderados os tempos de montagem e desmontagem do equipamento para retirada do petróleo, assim como o tempo de trabalho da UMP em cada poço visitado. O tempo de percurso entre os poços é considerado igual. A possibilidade de realimentação dos poços é desconsiderada. Finalmente, o PPPP é abordado por Gonçalves (2005) que desenvolve quatro algoritmos GRASP para sua solução. Os algoritmos são testados em casos gerados aleatoriamente com horizontes de planejamento variando de 1 a 15 dias. O número de poços dos campos nos casos teste varia entre 50 a 1000 . Esse último trabalho considera a possibilidade do retorno a poços já visitados, todavia somente no caso de sua recuperação plena.

\section{Algoritmos Transgenéticos}

Os Algoritmos Transgenéticos (ATs) pertencem à classe dos algoritmos evolucionários que apóiam sua metáfora na endossimbiose intracelular mutualista como esclarece o capítulo Transgenética Computacional do presente livro. O processo de evolução dos algoritmos transgenéticos é desenvolvido no contexto de uma célula hospedeira. A evolução transgenética consiste em um processo co-evolucionário de adaptação entre os endossimbiontes e seu hospedeiro (Goldbarg \& Goldbarg, 2009). Os endossimbiontes são representados, no processo evolucionário artificial, por seus cromossomos e codificam as soluções do problema em solução. A célula hospedeira possui seu próprio material genético - DNA. 


\subsection{Componentes do algoritmo transgenético na solução do PPPP_R}

\section{Cromossomos dos endossimbiontes}

As soluções para o PPPP_R são representadas pelos cromossomos dos endossimbiontes. Esses cromossomos são $k$-dimensionais tendo uma dimensão associada a cada dia do horizonte de planejamento. As rotas diárias, por sua vez, indicam a seqüência de vértices visitados a partir do vértice 0 . $\mathrm{O}$ cromossomo $k$-dimensional possui a estrutura exemplificada na Figura 1, em que os números nos quadrados representam os índices dos poços visitados em cada rota diária, e o vetor vertical exibe os dias associados às rotas.

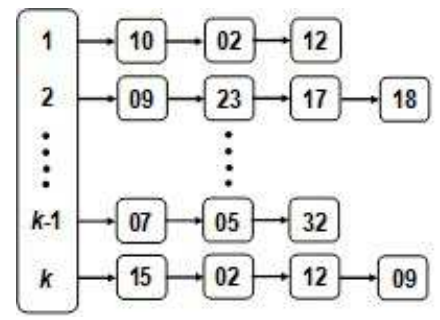

Figura 1. Representação de uma solução do PPPP.

\section{Formação da população dos cromossomos endossimbiontes}

Dois métodos de construção da solução inicial foram testados. O primeiro compreende o sorteio aleatório dos vértices de cada rota, iniciando-se e terminando-se a rota no vértice 0 . O sorteio inclui novos vértices na rota até que o tempo da jornada de trabalho seja esgotado. O segundo método desenvolve um procedimento guloso aleatório semelhante à primeira fase de um algoritmo GRASP (Feo \& Resende, 1995) denominado Gula. O método guloso parte da estação de tratamento de óleo inserindo sequencialmente os poços em cada rota baseado no critério de atratividade (relacionado ao volume e à distância a partir do nó atual) do poço para cada dia. Para definir a etapa de aleatorização da escolha o próximo poço a ser incluído na rota é escolhido com equiprobabilidade entre os dois poços ainda não visitados de maior atratividade, contada a rota a partir do último poço incluído na rota em formação e verificada se a inserção garante viabilidade de retorno ao vértice 0 . A atratividade do poço é calculada pela expressão 2:

$$
A_{i}^{j s}=\frac{v_{i s}^{2}}{d_{i j}}
$$

onde $A_{i}^{j s}$ é a atratividade do nó $i$ quando a UMP está no nó $j$ e o poço $i$ foi visitado pela última vez há $s$ dias, $v_{i s}$ é o volume atual do poço $i$ dado que ele foi visitado pela última vez há $s$ dias e $d_{i j}$ é o tempo de viagem entre os vértices $i$ e $j$.

\section{Natureza das informações contidas no hospedeiro}

As informações genéticas do hospedeiro são constituídas de $s$ subcadeias de DNA de codificação semelhante à codificação utilizada nos cromossomos dos endossimbiontes, possuindo entre duas e cinco cidades. As subcadeias de DNA possuem sua atratividade avaliada pela razão entre o volume total de óleo coletado nos poços do trecho e o tempo total utilizado na coleta. O tempo total de coleta associado a uma subcadeia de coleta é igual a soma do tempo gasto no percurso e na explotação dos vértices da subcadeia. Apenas para efeito de avaliação das cadeias considera-se a capacidade máxima em óleo dos poços coletados.

\section{Processo de obtenção e realimentação das informações do hospedeiro}

As cadeias do hospedeiro são obtidas dentre os melhores cromossomos da população de endossimbiontes. O comprimento máximo das cadeias foi determinado de forma a torná-las menores que a menor rota diária prevista nas instâncias de teste. Sempre que um cromossomo campeão é formado na população sorteia-se um dia e um vértice na rota do dia selecionado, copiando-se o trecho da rota a partir do vértice sorteado até que o comprimento definido para a cadeia seja alcançado. Formam-se $r$ cadeias. As cadeias formadas são comparadas com as $s$ cadeias existentes no hospedeiro preservando-se do grupo de $r+s$ cadeias as $s$ melhores. No início do processo as informações genéticas do hospedeiro são constituídas por $s / 5$ cadeias de cada um dos melhores cinco cromossomos da população de endossimbiontes.

\section{Os vetores transgenéticos utilizados na solução do PPPP_R}

O algoritmo utiliza dois tipos de vetores plasmídeos denominados de $\lambda_{1}$ e $\lambda_{2}$. $\lambda_{1}$ é um plasmídeo em que a cadeia de informações é obtida diretamente do material genético do hospedeiro. A cadeia do plasmídeo $\lambda_{1}$ 
é sorteada equiprovavelmente dentre as $s$ cadeias disponíveis no hospedeiro. $\lambda_{2}$ é um plasmídeo híbrido cuja cadeia de informações é obtida com a aplicação de um dentre os seguintes procedimentos heurísticos:

1. Algoritmo guloso empregado na formação da população inicial com limitação de comprimento variando entre dois e cinco poços.

2. Algoritmo guloso construtivo empregando estritamente o critério do poço mais atrativo segundo a taxa de re-enchimento. A taxa de re-enchimento pode ser obtida dividindo-se o volume total de óleo do poço cheio pelo volume que o mesmo apresenta um dia após ter sido explotado. Nesse procedimento um vértice qualquer é sorteado e ligado ao vértice 0 . A partir do vértice aleatoriamente inserido a cadeia é formada de modo guloso.

3. Algoritmo que reúne poços próximos, de forma a minimizar o tempo gasto no percurso entre os poços e maximizar o aproveitamento do tempo gasto no pistoneio em si. Os poços próximos são obtidos por um processo semelhante ao da construção de uma árvore geradora mínima, mas apenas 2 a 5 poços são considerados no trecho.

\section{O processo de ataque e transcrição dos vetores transgenéticos}

Os vetores $\lambda_{1}$ e $\lambda_{2}$ empregam o mesmo operador de transcrição. A cada iteração um plasmídeo é gerado e ataca todos os cromossomos da população. A cadeia de informação dos plasmídeos é obtida do DNA do hospedeiro ou através de um dos três procedimentos construtivos. As duas fontes são sorteadas com eqüiprobabilidade em cada iteração do algoritmo. As fontes de informação heurísticas são submetidas à pressão de seleção natural através da contabilização do sucesso das manipulações dos plasmídeos associados. Inicialmente as fontes heurísticas recebem a mesma prioridade para a escolha, mas na medida do desenvolvimento das iterações a chance da escolha de uma heurística vai se tornar proporcional ao sucesso obtido pelos plasmídeos que dela foram derivados. O sucesso é mensurado pelo número de transcrições concretizadas. Observe-se que uma transcrição só é concretizada se melhorar a adequação do cromossomo atacado.

Durante o ataque, o plasmídeo avalia cada rota existente no cromossomo testando a possibilidade de infiltrar sua informação transportada. Uma rota será considerada sensível se não contiver algum dos poços presentes na informação do vetor. Repetidamente, cada uma das rotas sensíveis é selecionada de forma aleatória para ser manipulada pelo vetor, até onde for possível introduzir as informações da cadeia sem violar as restrições do turno de trabalho da UMP, ou até que a lista de rotas sensíveis se esgote. O plasmídeo ataca uma rota sensível tentando inserir os poços de sua cadeia de informação na seqüência em que eles se apresentam na cadeia. Os poços são examinados um a um. Um poço é simplesmente inserido se pode ser incluído entre algum par de poços existentes na rota do cromossomo preservando-se a viabilidade da rota sua conclusão dentro do tempo máximo previsto.

Todos os poços da cadeia do plasmídeo devem ter sua inserção testada em cada uma das rotas existentes no cromossomo. Se um poço não pode ser simplesmente inserido porque sua inclusão inviabiliza a rota em todas as posições possíveis de inserção, então terá sua inserção testada considerando-se a exclusão de poços existentes na rota de forma a viabilizar o tempo de rota. Antes de qualquer inserção com exclusão em uma rota, são testadas todas as inclusões simples possíveis. Para realizar uma inserção com exclusão são removidos aleatoriamente tantos vértices quantos forem necessários para viabilizar a rota que recebeu um poço de inserção. Não existe restrição para a exclusão de vértices recentemente incluídos pela manipulação. Finalmente, a melhor solução resultante de todas as etapas do processo de ataque é mantida se for viável e melhor que a solução original.

\section{Critérios de parada}

O critério de parada adotado visa garantir a exploração do processo evolucionário do algoritmo, evitandose a ocorrência de estagnação. A estagnação - valor $\eta$ - foi fixada em 1000 iterações sem melhoria da melhor solução da população. Evitando um consumo computacional excessivo em casos particularmente difíceis, fixou-se também um número máximo total de 10.000 iterações.

\section{Arquitetura geral do algoritmo transgenético de solução - AT_P4R}

O Algoritmo 1 descreve a estratégia geral de evolução do algoritmo AT_P4R e visa auxiliar no entendimento do quadro 2 que detalha o algoritmo. Observe-se que a escolha entre a utilização do plasmídeo híbrido ou plasmídeo recombinado se dá de forma aleatória e equiprovável, como mostram os passos 4 e 5 . O quadro 2 ressalta nos passos 11 e 12 que uma manipulação somente é aceita quando resulta em melhoria do cromossomo atacado e nos passos 13 e 14 esclarece que a atualização do material genético do hospedeiro se dá por ocasião da emergência de um cromossomo endossimbionte campeão. 


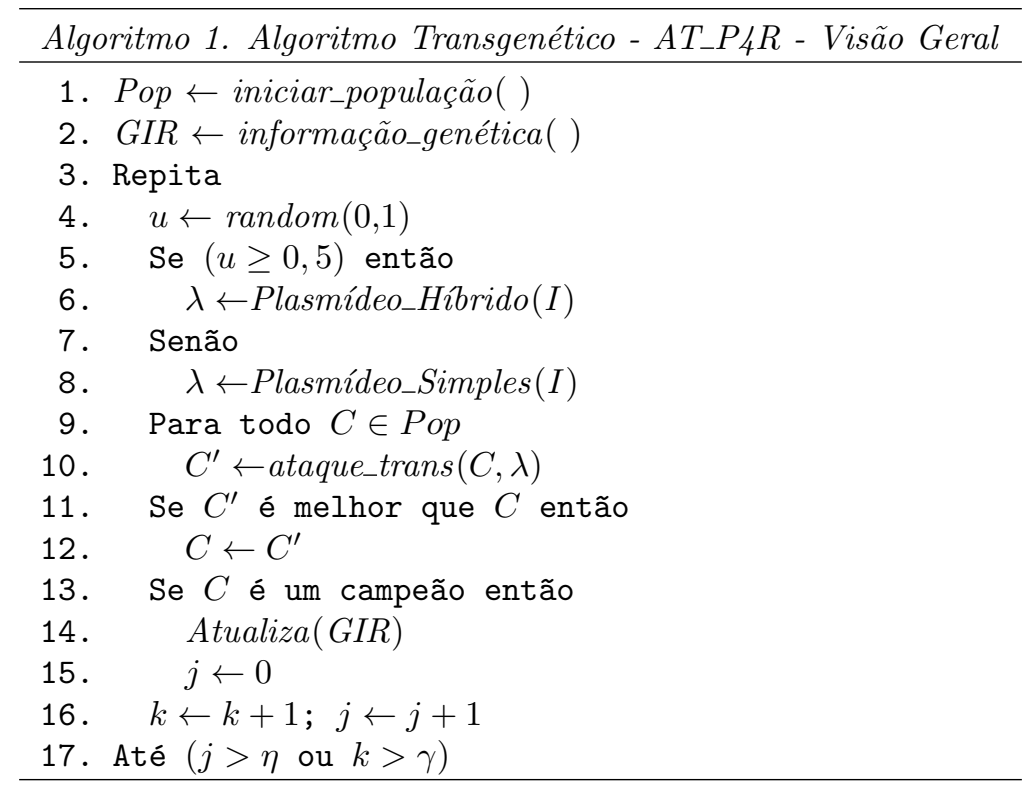

\section{Arquitetura detalhada do algoritmo transgenético - AT_P4R}

O Algoritmo 2 detalha o algoritmo AT_P4R. A variável DNA representa a informação transportada pelos plasmídeos a qual pode ser obtida diretamente das informações do hospedeiro (passo 7) ou através de três procedimentos construtivos heurísticos (passo 13). A variável heurística $[i]$ contabiliza o número de transcrições concretizadas e associadas à aplicação da heurística correspondente. Os passos de 9 a 12 distribuem a probabilidade da escolha das heurísticas de formação da cadeia do plasmídeo recombinado que será utilizado para a tentativa de manipulação proporcionalmente ao número de sucessos anteriormente obtidos por essa heurística. As escolhas são inicialmente equiprováveis como mostra o passo 4. A variável rotas reúne as rotas do cromossomo $C$ que possuem pelo menos um poço diferente dos poços que constam das rotas transportadas pelo plasmídeo. A variável $R$ guarda a posição do elemento aleatório na rota de $C$ que será examinada para receber a inserção de poços da cadeia do plasmídeo.

\section{O banco de casos teste}

Para validar o algoritmo foram construídas 26 instâncias para o problema a partir das instâncias do problema do caixeiro viajante do TSPLIB (Reinelt, 1991). Os casos teste foram constituídos com base em uma topologia variada e consagrada na literatura sem deixar, contudo, de serem aparelhados com dados de operação que simulassem aproximadamente os existentes em um campo real. As seguintes diretrizes foram adotadas:

- As distâncias entre os poços da instância foram transformadas em tempo de viagem entre cada par de poços. Os tempos de viagem respeitam a condição da desigualdade triangula uma vez que, em um campo real, o tempo de percurso associado à distância entre os poços - grandeza euclidiana.

- Optou-se por considerar um turno de trabalho da UMP de 16 horas (960 minutos) e um horizonte de planejamento de 30 dias.

- Os valores da produção dos poços foram gerados de forma aleatória e equiprovável dentre intervalos usualmente encontrados nos campos reais. Os valores do parâmetro da velocidade de re-enchimento - $\tau$ - foram calculados para um tempo re-enchimento de 99,9\% do volume máximo dos poços através das equações de (07) a (11). Esse tempo varia aleatoriamente entre 7 e 30 dias e o volume máximo (volume da coluna estática) varia entre 4 e 12 barris.

- Os tempos de instalação e desinstalação do equipamento durante a visita a cada poço são fixados em 3 minutos cada. Adicionalmente, estabeleceu-se o tempo médio de pistoneio de um barril de óleo em 22,5 minutos. Assim o tempo de operação em um poço somente pode ser calculado conhecendo-se exatamente o dia de sua explotação e o histórico de suas explotações anteriores dentro do horizonte de planejamento.

- Da forma como foram geradas, as instâncias devem produzir, no horizonte de planejamento citado, um volume máximo de 1.280 barris de petróleo. 


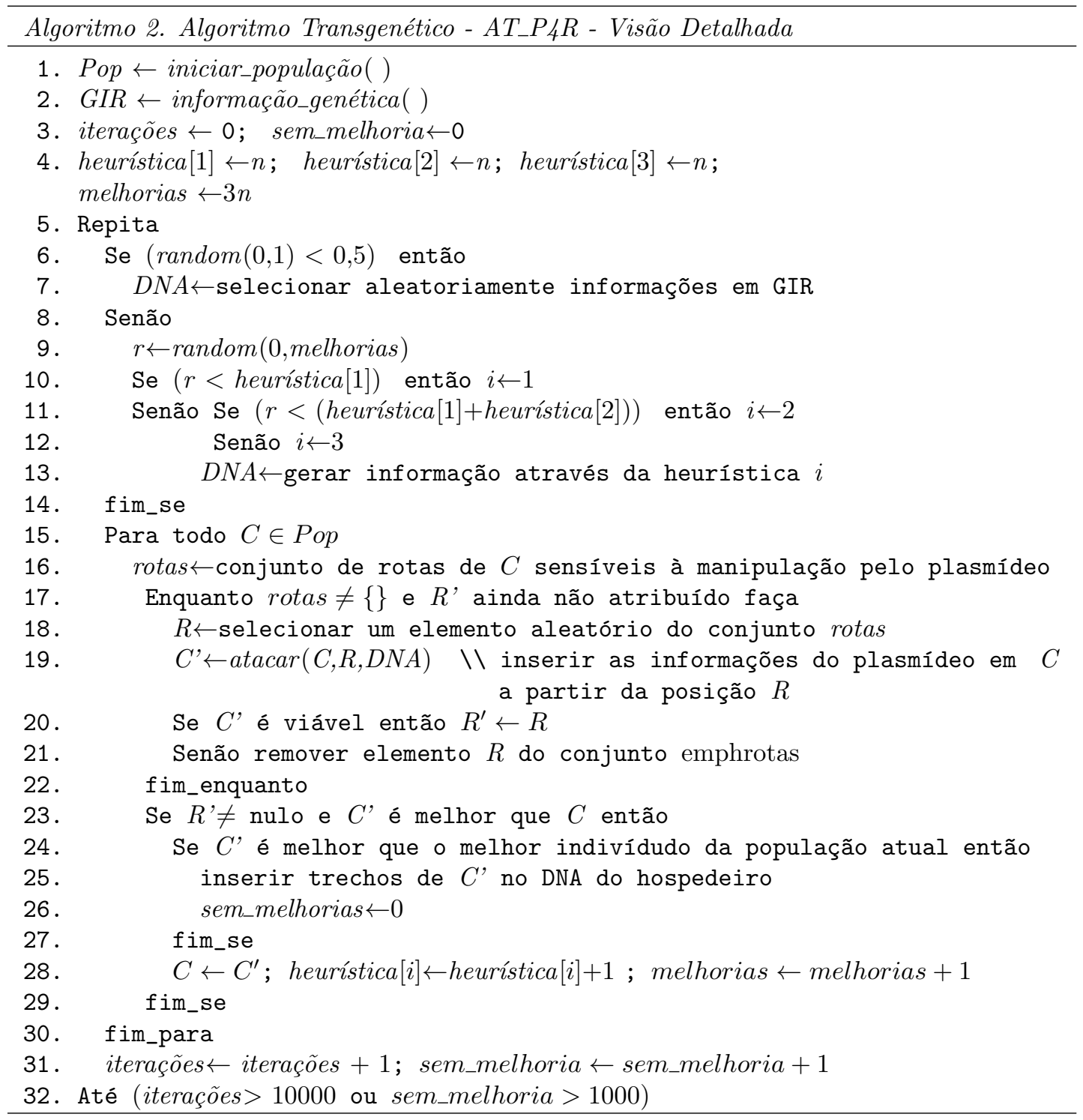

Para obter o parâmetro $\tau$ (indicativo da velocidade do re-enchimento para cada poço) da equação 3.1, como citado, foi gerado aleatoriamente o tempo necessário para que o poço recuperasse 99,9\% do volume máximo (entre 7 e 30 dias). Logo, $\tau$ é obtido como segue:

$$
\begin{gathered}
\Delta V=V_{\max }\left(1-e^{-\frac{\tau}{t}}\right)=0,999 V_{\max } \\
\left(1-e^{-\frac{\tau}{t}}\right)=0,999 \\
1-0,999=e^{-\frac{\tau}{t}}=0,001 \\
\frac{-t}{\tau}=\ln (0,001) \\
\tau=\frac{t}{\ln (0,001)} \cong \frac{t}{6,907755}
\end{gathered}
$$

onde $t$ é o número de dias necessários para que o poço recupere 99,9\% do volume máximo. As instâncias geradas preservam o nome do TSPLIB para caracterizar a herança da topologia de distribuição espacial dos poços. 


\section{Experimento Computacional}

Foram realizados estudos de ajuste dos parâmetros envolvidos, a saber: a geração da população inicial, o tamanho da população de indivíduos e o tamanho do banco de informações. Em todos os testes de parâmetros, os experimentos foram realizados em um micro-computador Pentium IV $2.8 \mathrm{GHz}$ com $512 \mathrm{MB}$ de RAM. Para estes testes, foram escolhidas 8 instâncias - aproximadamente um terço do banco de testes, representativas das famílias de instâncias, e para cada valor dos parâmetros o algoritmo foi executado 10 vezes para cada uma das instâncias, tendo como critério de parada um tempo de execução de 300 segundos. Os experimentos computacionais finais do algoritmo transgenético aplicado ao PPPP_R foram realizados em um microcomputador Pentium IV $3.2 \mathrm{GHz}$ com $1 \mathrm{~GB}$ de RAM. Nestes experimentos, o algoritmo foi executado 30 vezes para cada uma das 26 instâncias testadas. As instâncias possuem de 33 a 443 poços. Em todos os casos, o critério de parada adotado foi um número máximo de 10.000 iterações ou 1.000 iterações sem melhoria do melhor indivíduo da população. Os resultados obtidos estão resumidos na Tabela 1. Nela se efetua uma comparação dos resultados do algoritmo versus os obtidos com um limite superior descrito no trabalho de Duarte (2006). São apresentados o valor do limite superior, o volume máximo em número de barris, o gap percentual (afastamento da solução em relação ao limite superior) do volume máximo, o volume mínimo, o volume médio, o desvio-padrão (DP) do volume e o tempo médio de execução do algoritmo em segundos.

A análise dos resultados mostra uma grande estabilidade no volume do óleo coletado. Por exemplo, na solução da instância ft53, o caso que apresenta o maior gap, a diferença de volume entre o pior e o melhor resultado do algoritmo é de 14 barris, ou seja, uma diferença de aproximadamente 1,2\%. Observese que, em outros casos, essa diferença é menor que 0,5\% como nas instâncias ftv64 e ftv170 quando a diferença cai para $0,3 \%$ e $0,4 \%$, respectivamente. Os resultados médios obtidos mostram que o algoritmo apresenta desvios-padrão reduzidos, nunca ultrapassando uma flutuação de mais de 5 barris ou $0,5 \%$ do total do volume. A qualidade de algumas soluções é claramente garantida, como no caso das instâncias rbg403 e 443. Coincidentemente são essas instâncias que possuem estruturas de clusters nos quais um grande número de poços acaba localizado em regiões restritas (afastados cerca de 1 minuto uns dos outros). Em tais instâncias é de se esperar que a rota utilize, via de regra, as menores arestas de ligação entre os poços de um cluster, o que significará uma razoável freqüência de arestas coincidindo com as arestas consideradas no cálculo do limite inferior. Tal possibilidade minimiza o aspecto conservador do limite superior adotado, o que não acontece nos demais casos. Por outro lado, o tempo de execução mostrou-se reduzido e perfeitamente compatível com a possibilidade de futuras alterações no algoritmo, tempo normalmente em torno de 30s, ou para permitir a utilização do algoritmo em situações práticas. O tamanho das instâncias estudadas também alcança o porte dos casos reais, já que o número de poços considerados nas maiores instâncias é certamente superior ao que pode ser efetivamente designado para a operação de uma única UMP.

\section{Conclusões}

O problema do passeio do pistoneio periódico com realimentação contínua dos poços é um problema de otimização combinatória que apresenta elevado grau de complexidade. Pertencendo a classe dos problemas de roteamento com coleta sendo, adicionalmente, periódico e obrigado a uma estratégia de planejamento das rotas diárias que estabelece uma interdependência entre a futura oferta de óleo e o planejamento passado das rotas.

Para a solução desse problema o presente texto relata um algoritmo evolucionário da classe transgenética. Visando estabelecer uma base para a avaliação qualitativa do algoritmo o trabalho propõe um limite superior para o problema, ainda que conservativo.

O algoritmo transgenético é testado sobre um conjunto de instâncias que, mesmo preservando topologias classicamente aceita na literatura para constituir bancos de testes, busca refletir as condições da operação real em poços terrestres.

Os testes computacionais comprovam que, para efeitos práticos, o algoritmo é capaz de sugerir planejamentos de boa qualidade para campos da ordem de 400 poços designados a serem explotados exclusivamente através do pistoneio móvel e, segundo um horizonte suficientemente longo para abrigar a inclusão, em futuros trabalhos, de restrições adicionais de manutenção das unidades móveis bem como da possibilidade do uso simultâneo de mais de uma unidade móvel.

\section{Agradecimentos}

Esta pesquisa foi parcialmente suportada pelo Programa PRH-ANP 22 e pelo CNPq nos projetos 300778/20104 e 302819/2011-8. 
Tabela 1. Resultados obtidos pelo algoritmo transgenético AT_P4R.

\begin{tabular}{|c|c|c|c|c|c|c|c|}
\hline \multirow[b]{2}{*}{ Caso Teste } & \multirow[b]{2}{*}{ Limite } & \multicolumn{6}{|c|}{ AT_P4R } \\
\hline & & $\begin{array}{l}\text { Vol } \\
\text { Max }\end{array}$ & $\begin{array}{c}\text { Gap } \\
\%\end{array}$ & $\begin{array}{l}\text { Vol } \\
\text { Min }\end{array}$ & $\begin{array}{c}\text { Vol } \\
\text { Médio }\end{array}$ & DP & $\mathrm{T}(\mathrm{s})$ \\
\hline $\mathrm{ft} 53$ & 1229,80 & 1127,40 & 8,33 & 1113,50 & 1118,70 & 3,20 & 105,3 \\
\hline $\mathrm{ft} 70$ & 1177,38 & 1099,70 & 6,59 & 1082,70 & 1091,40 & 3,50 & 93,30 \\
\hline $\mathrm{ftv} 100$ & 1240,30 & 1168,90 & 5,75 & 1162,60 & 1165,70 & 1,40 & 35,90 \\
\hline ftv110 & 1240,30 & 1168,50 & 5,79 & 1164,50 & 1165,90 & 0,90 & 34,30 \\
\hline ftv120 & 1243,50 & 1176,90 & 5,36 & 1173,10 & 1175,00 & 1,00 & 37,20 \\
\hline $\mathrm{ftv} 130$ & 1243,50 & 1174,90 & 5,52 & 1171,10 & 1172,50 & 1.00 & 35,20 \\
\hline ftv140 & 1243,59 & 1179,06 & 5,19 & 1172,02 & 1175,01 & 1,44 & 32,20 \\
\hline ftv150 & 1243,60 & 1181,20 & 5,01 & 1177,20 & 1179,40 & 0,90 & 31,40 \\
\hline ftv160 & 1243,60 & 1178,10 & 5,27 & 1174,30 & 1176,50 & 1,00 & 38,00 \\
\hline ftv170 & 1243,70 & 1183,10 & 4,87 & 1178,30 & 1180,60 & 1,00 & 35,70 \\
\hline ftv33 & 1224,30 & 1129,00 & 7,79 & 1122,80 & 1125,60 & 1,40 & 26,20 \\
\hline ftv35 & 1228,00 & 1129,90 & 7,99 & 1125,00 & 1127,50 & 1,30 & 28,20 \\
\hline $\mathrm{ftv} 38$ & 1228,80 & 1140,80 & 7,16 & 1134,80 & 1137,00 & 1,40 & 27,90 \\
\hline $\mathrm{ftv} 44$ & 1231,40 & 1141,00 & 7,34 & 1133,60 & 1136,10 & 1,50 & 27,20 \\
\hline $\mathrm{ftv} 47$ & 1222,80 & 1128,71 & 7,69 & 1122,99 & 1125,46 & 1,47 & 29,10 \\
\hline $\mathrm{ftv} 55$ & 1235,60 & 1141,98 & 7,58 & 1137,18 & 1139,30 & 1,16 & 31,30 \\
\hline ftv64 & 1240,80 & 1167,26 & 5,93 & 1164,11 & 1165,54 & 0,98 & 29,30 \\
\hline ftv70 & 1240,92 & 1172,97 & 5,48 & 1165,91 & 1168,86 & 1,41 & 27,10 \\
\hline ftv90 & 1240,27 & 1166,04 & 5,98 & 1159,85 & 1162,62 & 1,71 & 33,50 \\
\hline kro124 & 1230,87 & 1164,64 & 5,38 & 1160,87 & 1162,41 & 0,86 & 76,90 \\
\hline p43 & 1242,64 & 1214,27 & 2,28 & 1209,62 & 1212,56 & 1,05 & 28,70 \\
\hline rbg323 & 1178,90 & 1105,74 & 6,21 & 1095,46 & 1099,88 & 2,54 & 40,70 \\
\hline rbg358 & 1156,46 & 1099,23 & 4,95 & 1091,48 & 1094,44 & 1,75 & 40,20 \\
\hline rbg 403 & 1140,30 & 1133,16 & 0,63 & 1126,19 & 1129,45 & 1,65 & 40,60 \\
\hline rbg443 & 1244,27 & 1236,88 & 0,59 & 1229,14 & 1232,37 & 2,04 & 46,70 \\
\hline ry $48 \mathrm{p}$ & 1223,47 & 1137,67 & 7,01 & 1130,12 & 1133,71 & 1,43 & 29,30 \\
\hline
\end{tabular}

\section{Referências}

Alegre, J.; Laguna, M. \& Pacheco, J., Optimizing the periodic pick-up of raw materials for a manufacturer of auto parts. European Journal of Operational Research, 179(3):736-746, 2007.

Archetti, C.; Hertz, A. \& Speranza, M., Metaheuristics for the team orienteering problem. Journal of Heuristics, 13(1):49-76, 2007.

Arkin, E.; Mitchell, J. \& Narasimhan, G., Resource-constrained geometric network optimization. In: Proceedings of the 14th ACM Symposium on Computational Geometry. p. 307-316, 1998.

Backer, B. \& Furton, V., Metaheuristics in constraint programming experiments with tabu search on the vehicle routing problem. In: Proceedings of MIC'97 2nd International Conference on Metaheuristics. Sophia Antipolis, France, p. $1-14,1997$.

Balas, E., The prize collecting traveling salesperson problem. Networks, 19(6):621-636, 1989.

Bouly, H.; Dang, D.C. \& Moukrim, A., A memetic algorithm for the team orienteering problem. In: Applications of Evolutionary Computing. Heidelberg: Springer, Lecture Notes in Computer Science, p. 649-658, 2008.

Butt, S. \& Cavalier, T., A heuristic for the multiple tour maximum collection problem. Computers ES Operations Research, 21(1):101-111, 1994.

Chao, I.M.; Golden, B. \& Wasil, E.A., The team orienteering problem. European Journal of Operational Research, 88(3):464-474, 1996.

Dalboni, F.L., Algoritmos Evolutivos Eficientes para um Problema de Roteamento de Veículos. Dissertação de mestrado, Programa de Pós-Graduação em Computação, Universidade Federal Fluminense, Niterói, RJ, 2003.

Dantas, N.M., Metaheurística busca tabu aplicada a solução do problema da unidade móvel do pistoneio. Dissertação de mestrado, Programa de Pós-Graduação em Sistemas e Computação, Universidade Federal do Rio Grande do Norte, Natal, RN, 2001.

Duarte, H.M., Um estudo algorítmico de problemas logísticos na inústria de petróleo e gás natural. Dissertação de mestrado, Programa de Pós-Graduação em Sistemas e Computação, Universidade Federal do Rio Grande do Norte, Natal, RN, 2006. 
Feo, T. \& Resende, M., Greedy randomized adaptive search procedures. Journal of Global Optimization, 6(2):109 -133, 1995.

Ferreira, I., Contaminações virais na aceleração da solução do problema do passeio do pistoneio. Dissertação de mestrado, Programa de Pós-Graduação em Sistemas e Computação, Universidade Federal do Rio Grande do Norte, Natal, RN, 2001.

Goldbarg, E.F.G. \& Goldbarg, M.C., Transgenetic algorithm: A new endosymbiotic approach for evolutionary algorithms. In: Abraham, A.; Hassanien, A.E.; Siarry, P. \& Engelbrecht, A. (Eds.), Foundations of Computational Intelligence. Heidelberg: Springer, v. 3 de Studies in Computational Intelligence, p. 425-460, 2009.

Golden, B.; Levy, L. \& Vohra, R., The orienteering problem. Naval Research Logistics, 34(3):307-318, 1987.

Gonçalves, L.B., Heurísticas GRASP para um Problema de Roteamento Periódico de Veículos. Dissertação de mestrado, Programa de Pós-Graduação em Computação, Universidade Federal Fluminense, Niterói, RJl, 2005.

Hayari, N.; Manier, M.A.; Bloch, C. \& Moudni, A.E., Un algorithme evolutionniste pour le problème de tournées sélectives avec contraintes de fenêtres de temps. In: Proceedings of 4 e Conférence Francophone de Modélisation et Simulation. Toulouse, France, 2003.

Hemmelmayr, V.C.; Doerner, K.F. \& Hartl, R.F., A variable neighborhood search heuristic for periodic routing problems. European Journal of Operational Research, 195(3):791-802, 2009.

Kataoka, S. \& Morito, S., An algorithm for single constraint maximum collection problem. Journal of the Operational Research Society of Japan, 31(4):515-530, 1988.

Ke, L.; Archetti, C. \& Feng, Z., Ants can solve the team orienteering problem. Computers \& Industrial Engineering, 54(3):648-665, 1988.

Khemakhem, M.; Semet, F. \& Chabchoub, H., A hybrid heuristic for the selective vehicle routing problem. In: Proceedings of MIC'05 6th International Conference on Metaheuristics. Viena, Austria, p. 577-582, 2005.

Lake, L.W., Enhanced Oil Recovery. Prentice Hall, Estados Unidos, 2001.

Laporte, G. \& Martello, S., The selective travelling salesman problem. Discrete Applied Mathematics, 26(2-3):193-207, 1990.

Medeiros, A.C.C., Algoritmo transgenético para o problema do passeio do pistoneio. Dissertação de mestrado, Programa de Pós-Graduação em Sistemas e Computação, Universidade Federal do Rio Grande do Norte, Natal, RN, 2001.

Reinelt, G., A traveling salesman problem library. ORSA Journal on Computing, 3(4):376-384, 1991.

Tang, H. \& Miller-Hooks, E., A tabu search heuristic for the team orienteering problem. Computers ES Operations Research, 32(6):1379-1407, 2005.

Thomas, J.E., Fundamentos de Engenharia de Petróleo. Rio de Janeiro: PETROBRAS, 2001.

Vansteenwegen, P. \& Oudheusden, D.V., The mobile tourist guide: An OR opportunity. OR Insight, 20(3):21-27, 2007.

\section{Notas Biográficas}

Marco César Goldbarg é Engenheiro de Fortificação e Construção (Instituto Militar de Engenharia, 1982), mestre em Sistemas e Computação (Instituto Militar de Engenharia, 1987), doutor em Sistemas e Computação pela (COPPE/UFRJ, 1990) e tem pós-doutorado em Ciência da Computação (UFMG, 1999). Atualmente é professor associado na Universidade Federal do Rio Grande do Norte.

Elizabeth Ferreira Gouvêa Goldbarg é graduada em Engenharia Industrial (Centro Federal de Educação Tecnológica - Celso Suckow da Fonseca, 1985), mestre em Sistemas e Computação (Instituto Militar de Engenharia, 1993), doutora em Engenharia de Produção (COPPE/UFRJ, 2001) e tem pós-doutorado em Sistemas e Computação (COPPE/UFRJ, 2006). Atualmente é professor associado na Universidade Federal do Rio Grande do Norte.

Herbert de Mélo Duarte é graduado em Engenharia de Computação (Universidade Federal do Rio Grande do Norte, 2004) e mestre em Sistemas e Computação (Universidade Federal do Rio Grande do Norte, 2006). Atualmente trabalha como engenheiro de software no Facebook, Inc. 


\title{
Problema de Formação de Células de Manufatura com Roteiros Alternativos e Considerações de Capacidade
}

\author{
Luiz Carlos Abreu Rodrigues, Adriano Pereira Balau e Tiago Rodrigues Weller
}

\begin{abstract}
Resumo: O problema de formação de células de manufatura, considerando a disponibilidade de rotas alternativas e da capacidade de processamento das máquinas disponíveis, é um problema de otimização desafiador, uma vez que impõe a solução de um problema em duas fases: $i$ ) atribuir máquinas às células; e $i$ ) atribuir peças (e seu roteiro de fabricação) às células. O objetivo é o de minimizar o processamento extra-celular de tarefas quando os roteiros de fabricação das peças são selecionados. Duas abordagens híbridas, usando busca tabu (BT) e simulated annealing (SA), são testadas para atribuir as máquinas às células de manufatura, enquanto o método de branch-and-bound é usado para atribuir as peças (e seu roteiro de fabricação) às células.
\end{abstract}

Palavras-chave: Tecnologia de grupo, Busca tabu, Simulated annealing, Branch-and-bound.

\begin{abstract}
Cell formation considering the availability of alternative routings and the processing capacity of available machines is a challenging optimization problem, since it imposes the solution of a two-step problem: i) assign machines to cells; and ii) assign manufacturing parts (routings) to cells. The objective is to minimize extra-cellular processing of tasks when routings of parts are selected. The proposed approaches apply tabu search or simulated annealing to assign machines to cells and branch-and-bound to select routings.
\end{abstract}

Keywords: Group technology, Tabu search, Simulated annealing, Branch-and-bound.

\section{Introdução}

Aumentos de produção, redução de custos de produtos e melhorias no gerenciamento de estoque de trabalho em processo (WIP) têm sido cada vez mais buscados pelas indústrias. Apesar de os conceitos associadas ao Just-in-Time proporem o uso de células de manufatura, sua definição pode ser uma tarefa desafiadora. O método mais utilizado na indústria é tentar associar peças fabricadas que são visualmente semelhantes. A desvantagem principal deste procedimento é a de que, com eles, as células podem ser subutilizadas ou superar sua capacidade de produção. Ou seja, pode não ser uma tarefa fácil compor células de manufatura balanceadas e coerentes baseando-se apenas na semelhança visual entre as peças produzidas. A Tecnologia de Grupo (TG) foi proposta para permitir a formação de células de manufatura, sem ter em conta a semelhança visual de peças fabricadas. A TG visa identificar grupos de peças que compartilham um grupo comum de máquinas (Burbidge, 1975). A TG geralmente se baseia em uma matriz de incidência máquina-componente para identificar grupos de máquinas e componentes (ou peças) que podem ser agrupados em células. Este conceito evoluiu desde a sua primeira proposição e uma extensa literatura sobre a formação de células foi produzida, numa indicação de que diversos procedimentos heurísticos têm sido propostos para solucionar este problema (Irani, 1999; Nsakanda et al., 2006; Caux et al., 2000). De acordo com Irani (1999), alguns dos critérios para a medição da qualidade de formação de células são: $i$ ) Minimização de operações extra-celulares; ii) minimização do carregamento de máquina imposto por operações extra-celulares; e iii) minimização do fluxo de produção entre células de manufatura.

Este trabalho destina-se a resolver o problema de formação de células de manufatura com roteiros de produção alternativos e restrições de capacidade de produção. O objetivo consiste em minimizar o número de operações extra-celulares. Mas, não importando o critério de minimização utilizado, a principal dificuldade de qualquer procedimento utilizado para este problema é que a qualidade de uma solução é medida apenas depois que as máquinas são agrupadas. Isto é, este é um problema desafiador já que, normalmente, ele é resolvido em

*Autor para contato: lcar@utfpr.edu.br 
dois passos. Primeiro, as máquinas são agrupadas em células de manufatura e, em seguida, no segundo passo, um roteiro de fabricação é selecionado para cada peça. Quando um roteiro é selecionado para uma peça, esta peça é associada a uma célula, tal que ocorra a minimização na quantidade de tarefas extra-celulares. Esta associação permite calcular a função de avaliação (função objetivo).

No presente trabalho apenas uma breve revisão relacionada ao problema de formação de células de manufatura será apresentado. O leitor pode encontrar revisões na literatura para o problema de formação de células e as suas variações em Irani (1999), Nsakanda et al. (2006) e Caux et al. (2000).

Esta revisão destina-se a identificar as principais meta-heurísticas que já foram propostas para resolver o problema de formação de células de manufatura com roteiros alternativos e restrições de capacidade de produção. Uma heurística utilizando programação linear foi proposta por Nagi et al. (1990) para resolver este problema. Eles iterativamente resolvem os dois passos do problema de formação de células como um procedimento de hill-climbing de dois passos. Este mesmo problema também foi resolvido usando um algoritmo genético híbrido (Nsakanda et al., 2006) e de simulated annealing (Caux et al., 2000; Xambre \& Vilarinho, 2003). Mas, em Caux et al. (2000), o simulated annealing foi usado apenas para resolver o primeiro passo do algoritmo, agrupando máquinas em células, e branch-and-bound foi utilizado para resolver o segundo passo, associando peças às células de manufatura de acordo com a função de avaliação. O algoritmo genético proposto por Nsakanda et al. (2006) utiliza um algoritmo genético para o agrupamento das máquinas em células. Em seguida, a associação das peças às células é realizada utilizando um método de decomposição baseado em Dantzig-Wolfe. Um sistema de colônia de formigas foi utilizado por Prabhaharan et al. (2005) para resolver um problema bastante semelhante em que o objetivo é o de minimizar a variação total na carga das células e o total de movimentos intercelulares.

A busca tabu (BT) foi utilizada por Lei \& Wu (2005) e Lei \& Wu (2006) para resolver problemas de formação de células multi-objetivo. Ambas as abordagens não consideraram roteiros alternativos e restrições de capacidade de produção. Por conseguinte, o problema pode ser resolvido em uma etapa porque o agrupamento de máquinas em células é suficiente para permitir o cálculo da função de avaliação. Embora o problema resolvido por Lei \& Wu (2005) e Lei \& Wu (2006) seja mais simples do que com roteiros alternativos e restrições de capacidade de produção, apenas um número limitado de soluções vizinhas foram geradas aleatoriamente em cada iteração.

A programação linear inteira mista, algoritmos gulosos e BT foram usados por Foulds et al. (2006) para tratar o problema de formação de células de manufatura sustentável, com roteiros de fabricação alternativos. O desafio deste problema está em definir quais máquinas comprar, ou não, quando uma nova célula é criada ou quando novas peças serão produzidas. Foulds et al. (2006) apenas trataram problemas de pequenas dimensões.

Para resolver o problema proposto, uma aplicação de BT e de simulated annealing (SA) híbridos são apresentados e os resultados são comparados com os obtidos por Caux et al. (2000), que propôs uma abordagem SA híbrida. A aplicação de BT híbrida que é apresentada neste capítulo foi originalmente apresentada em Rodrigues \& Weller (2008). Nesta abordagem, a BT é utilizada para resolver o primeiro passo do problema e branch-and-bound é usado para resolver a segunda etapa. Este capítulo está organizado da seguinte forma. Na Seção 2 deste capítulo, são apresentadas a descrição e formulação do problema de formação de células com roteiros alternativos de fabricação e restrições de capacidade de produção. A abordagem proposta de BT híbrido, com seu procedimento branch-and-bound, é apresentada na Seção 3. Na Seção 4 será apresentada a abordagem de simulated annealing híbrida proposta por Caux et al. (2000), que será comparada com a abordagem de BT híbrida proposta neste trabalho. Resultados computacionais e conclusões são apresentados nas Seções 5 e 6, respectivamente.

\section{Problema de Formação de Células de Manufatura}

O modelo proposto para o problema de formação de células de fabricação com roteiros alternativos e restrições de capacidade de produção é baseado no seguinte conjunto de premissas básicas:

- A produção é estável ao longo do tempo e identificada como quantidades pré-determinadas de peças produzidas dentro de um horizonte de planejamento determinado;

- Cada peça i é obtida após uma sequência $O_{i}$ de operações;

- Um conjunto de máquinas $(m=1, \ldots, T M)$ está disponível para a produção de todas as peças, sendo que algumas das máquinas são semelhantes;

- O número máximo de máquinas permitidas por célula $(c=1, \ldots, C)$ é $N M$.

O modelo matemático deste problema de formação de células, que é apresentado a seguir, foi proposto por Rodrigues \& Weller (2008). As variáveis deste problema são: 


$$
\begin{aligned}
& x_{m c}= \begin{cases}1, & \text { se a máquina } m \text { é alocada à célula } c, \\
0, & \text { caso contrário; }\end{cases} \\
& y_{r p}= \begin{cases}1, & \text { se a peça } p \text { é produzida pelo roteiro } r, \\
0, & \text { caso contrário. }\end{cases}
\end{aligned}
$$

A equação 1 é utilizada quando o objetivo do problema é a minimização de operações extra-celulares. Assume-se que a máquina $m_{1}$ precede a máquina $m_{2}$ no processamento do roteiro de fabricação $r$. Esta equação indica que quando o roteiro de fabricação $r$ é escolhido para o processamento da peça $p$ (indicado por $y_{r p}=1$ ), então a presença das máquinas $m_{1}$ (indicado por $x_{m_{1} c}=1$ ) e $x_{m_{2}}$ (indicado por $x_{m_{2} c}=1$ ) na mesma célula de manufatura $c$ é verificado. Note que uma operação é extra-celular apenas se $x_{m_{1} c}=1 \mathrm{e}$ $x_{m_{2} c}=0$. A Tabela 1 apresenta os parâmetros usados para a modelagem do problema proposto de formação de células de manufatura.

Tabela 1. Parâmetros do problema.

\begin{tabular}{ll}
\hline$C a p_{m}$ & capacidade de processamento disponível da máquina $m$ \\
$d_{p}$ & demanda durante o horizonte de planejamento da peça $p$ \\
$F M_{m r}$ & máquina usada pelo roteiro $r$ após o processamento em $m$ \\
$M R_{r}$ & conjunto de máquinas usadas pelo roteiro $r$ \\
$R M_{m}$ & conjunto de roteiros que usam a máquina $m$ \\
$R P_{p}$ & conjunto de roteiros associados à peça $p$ \\
$t p_{m r}$ & tempo de processamento do roteiro $r$ na máquina $m$ \\
$N M$ & limite máximo de máquinas que podem ser alocadas numa célula \\
\hline
\end{tabular}

O problema estudado está sujeito às seguintes restrições. A restrição 2 impõe que qualquer peça $p$ deve necessariamente ser associada a somente um roteiro de fabricação $r$. A restrição 3 impõe que qualquer máquina $m$ deve ser associada a uma célula de manufatura $c$. A restrição 4 limita a alocação de roteiros de fabricação de peças de tal forma que não sejam ultrapassadas as capacidades de processamento das máquinas. A restrição 5 define um limite máximo de máquinas associadas a cada célula de manufatura.

$$
\text { (Min) } \mathrm{Z}=\sum_{p} \sum_{r \in R P_{p}} y_{r p} \sum_{m_{1} \in M R_{r}} \sum_{c} x_{m_{1} c}\left(1-\sum_{m_{2} \in F M_{m_{1} r}} x_{m_{2} c}\right)
$$

sujeito a:

$$
\begin{aligned}
& \sum_{r \in R P_{p}} y_{r p}=1 \quad, \forall p \\
& \sum_{p} d_{p} x_{m c}=1 \quad, \forall m \\
& \sum_{c} x_{m c} \sum_{r \in R P_{p}, r \in R P_{p}} t p_{r m} y_{r p} \leq C a p_{m} \quad, \forall m \\
& \sum_{m} x_{m c} \leq N M \quad, \forall c .
\end{aligned}
$$

Devido à complexidade computacional deste modelo, proposto por Rodrigues \& Weller (2008), e outros modelos propostos na literatura por Nsakanda et al. (2006), Caux et al. (2000) e Xambre \& Vilarinho (2003), serão comparadas duas abordagens meta-heurísticas, usando BT e SA para resolver o problema proposto.

\section{Busca Tabu Híbrida}

Nesta seção é apresentada uma abordagem de BT híbrida para resolver o problema de formação de células de manufatura, considerando-se roteiros de fabricação alternativos e restrições de capacidade de processamento. A abordagem proposta é dividida em duas etapas que são resolvidas iterativamente, sendo que ambas as etapas apresentam procedimentos originais de poda, ou redução do espaço de busca. Na primeira etapa, a busca tabu (BT) é usada para realizar a atribuição das máquinas às células, respeitando o limite máximo $N M$ de máquinas em qualquer célula. Na segunda etapa, um procedimento branch-and-bound (BB) é proposto para identificar os roteiros de fabricação que minimizam o número de operações extra-celulares de peças, respeitando a capacidade de processamento das máquinas, $\mathrm{Cap}_{m}$. 
Um aspecto interessante no uso de uma abordagem de BT híbrida para resolver o problema de formação de células de manufatura proposto é que há pouca literatura utilizando BT para resolver estes problemas. $\mathrm{Na}$ verdade, a literatura disponível usando BT para resolver os problemas relacionados, como em Lei \& Wu (2005) e Lei \& Wu (2006), propuseram processos que não exploraram todo o conjunto de soluções vizinhas. De fato, eles geraram aleatoriamente apenas algumas das possíveis soluções vizinhas. Portanto, tornou-se claro, visando tornar eficiente a BT, que é necessário podar o espaço de busca, eliminando soluções vizinhas infactíveis ou não promissoras. Além disto, seria necessário implementar um procedimento eficiente de seleção do roteiro de fabricação das peças, o qual é resolvido usando BB neste trabalho. Caso contrário, a pesquisa pode adquirir um tempo computacional proibitivo.

\subsection{Procedimento de busca tabu}

O processo híbrido proposto é resolvido usando busca tabu (BT). O leitor interessado encontrará maiores informações sobre esta abordagem em Glover \& Laguna (1997) e no capítulo 3 deste livro. Esta metaheurística explora possíveis soluções sobre a vizinhança de uma solução vigente. Isto se destina a identificar a melhor solução vizinha da solução vigente usando estratégias de movimento predefinidas. Então, a melhor solução vizinha torna-se a nova solução vigente e a busca na vizinhança é reiniciada mais uma vez. Várias estruturas de memória podem ser adotadas de forma a aprimorar a busca e, idealmente, evitar que ela fique presa em pontos ótimos locais. O leitor pode encontrar muitas possíveis estruturas de memória em implementações de BT em Glover \& Laguna (1997). Mas, há uma estrutura de memória, chamada de Lista Tabu, que sempre é encontrada na BT. Quando um movimento é realizado e fornece a melhor solução vizinha da solução vigente, este movimento torna-se proibido (ou tabu) por certo número de iterações. Ou seja, este movimento é introduzido na lista tabu, numa tentativa de evitar ciclos na exploração do espaço de busca. Um movimento colocado na lista tabu só será aceito se ele proporcionar a melhor solução encontrada até aquele ponto da pesquisa. Este procedimento é chamado Critério de Aspiração.

A BT é caracterizada por duas situações de busca. A primeira situação é chamada de Intensificação, quando a busca se aproxima de uma região promissora e esta região tende a ser intensivamente explorada. Se for identificado que a busca tornou-se presa em uma região de ótimos locais, a Diversificação, a segunda situação de busca da BT, é executada. Diversificação é obtida gerando-se uma nova solução inicial ou executando-se vários movimentos consecutivos, normalmente aleatórios, que visam mover a busca para longe da região de busca anterior. A busca é reiniciada após a diversificação. O algoritmo de BT implementado é apresentado no Algoritmo 1.

A melhor solução encontrada até então é identificada como $s^{\text {best }}$. No Algoritmo 1, inicialmente, $s^{\text {best }}$ é definida na linha 1. A linha 2 do algoritmo impõe que a busca prossiga até que o critério de parada seja atingido. Na linha 3, a solução inicial é gerada aleatoriamente. A solução inicial $s$ será a nova melhor solução $s^{\text {best }}$ se o seu valor $\mathrm{Z}(s)$ for menor que o valor do melhor atual $\mathrm{Z}\left(s^{\text {best }}\right)$, conforme indicado nas linhas 4 a 6. Na linha 7, prossegue-se a busca enquanto o critério de diversificação não for atingido. Neste algoritmo, o critério de diversificação corresponde a um número de iterações sem encontrar um novo $s^{\text {best }}$. A solução vigente é identificada como $s$, a melhor solução vizinha é identificada como $s$. A rotina de busca na vizinhança (Algoritmo 2) é ativada na linha 8. As Seções 3.2 e 3.3 apresentam as duas etapas da rotina de busca na vizinhança. A cada iteração, nas linhas 9 a 11, é testado se a melhor solução gerada $s^{\prime}$ é melhor que $s^{\text {best }}$. $\mathrm{Na}$ sequência, na linha 12, a melhor solução $s^{\prime}$ se torna a nova solução vigente $s$. Na linha 15 , retorna-se a melhor solução $s^{\text {best }}$ encontrada.

\subsection{Geração de soluções vizinhas}

Neste trabalho, serão adotados os mesmos movimentos que em trabalhos anteriores sobre o problema proposto, como em Caux et al. (2000) e em Rodrigues \& Weller (2008). Serão usados dois movimentos: i) inserção é o movimento quando uma máquina é movida de uma célula de manufatura para outra; ii) o movimento de troca ou swap ocorre quando duas máquinas trocam entre si suas respectivas células de manufatura. Como mencionado anteriormente, a fim de utilizar de forma eficiente a BT, é necessário podar o espaço de busca, eliminando soluções vizinhas infactíveis ou não promissoras. Ao gerar soluções vizinhas, três restrições foram consideradas:

- Como uma restrição de factibilidade, movimentos de inserção podem ser feitos apenas para células com menos do que o limite máximo de máquinas $N M$;

- Qualquer célula deve permanecer com uma quantidade mínima de máquinas. Esta restrição foi imposta como uma tentativa de evitar soluções vizinhas não promissoras e impor a quantidade mínima de duas máquinas por célula de manufatura; 


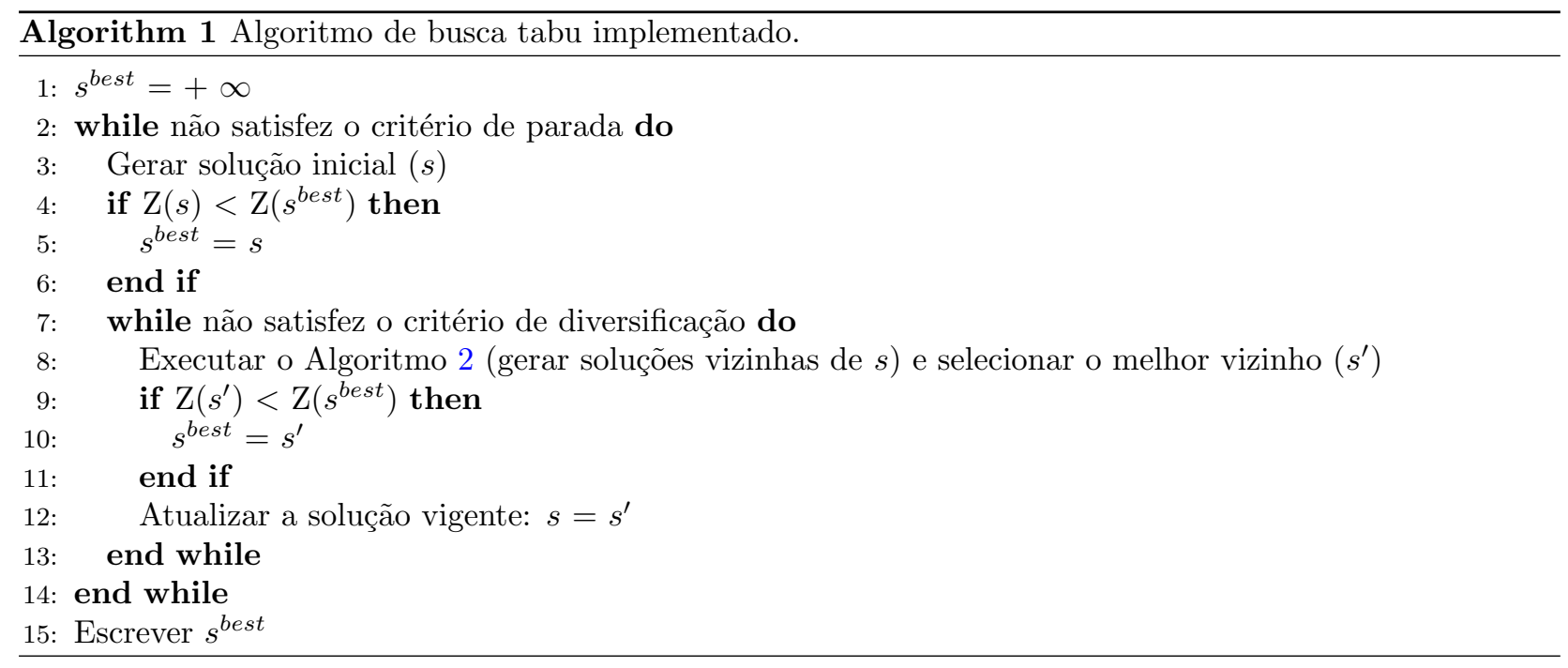

- Um movimento de inserção ou troca de uma máquina $m$ só pode ser feito para outra célula $c$ se houver pelo menos uma outra máquina relacionada com a máquina $m$ na célula $c$. Duas máquinas são consideradas relacionadas se existir pelo menos um roteiro de fabricação onde ambas as máquinas estão presentes. Este procedimento de poda é baseado no fato de que uma inserção para uma célula sem outras máquinas relacionadas não pode gerar uma solução melhor que a solução vigente. Assim, evitando-se uma solução não promissora, economiza-se tempo de busca.

O Algoritmo 2 realiza a busca na vizinhança da BT. Na linha 1, o valor da melhor solução é definido como $+\infty$. Na linha 4 , é avaliado se o movimento de inserção da máquina $m$ para a célula $c$ satisfaz as três restrições apresentadas no início desta seção. Caso o movimento de inserção seja viável, na linha 5, executa-se o Algoritmo 3, que avalia esta solução. Na linha 9, verifica-se se o movimento de troca da máquina $m$ com a máquina $m^{\prime}$ satisfaz as três restrições apresentadas no início desta seção. Caso o movimento de troca seja viável, na linha 10, executa-se o Algoritmo 3, que avalia esta solução.

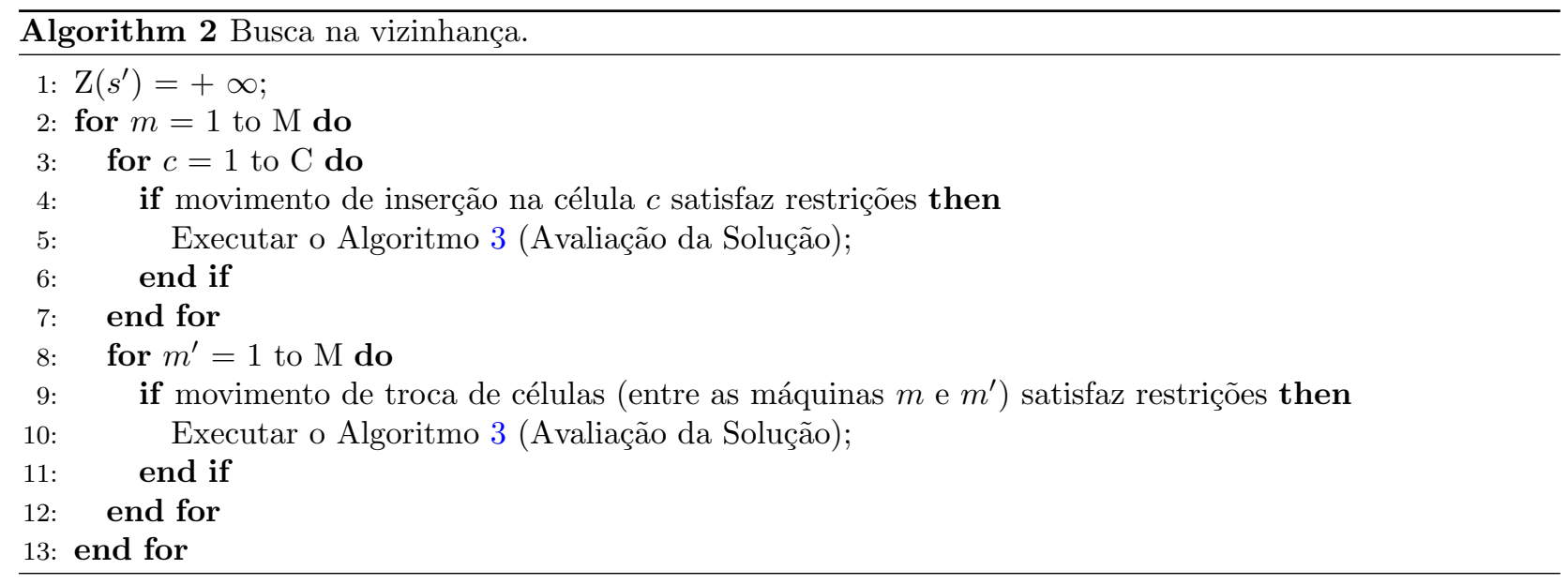

Os Algoritmos 1 e 2 apresentam diferentes partes do algoritmo de BT, onde as máquinas são alocadas às células, realizando os movimentos de inserção e de troca. Por sua vez, o Algoritmo 3 realiza a avaliação de cada solução vizinha gerada, aplicando o BB para definir a associação ótima de cada peça a um roteiro de fabricação. Ao executar o BB, identifica-se o número de operações extra-celulares da solução vizinha analisada.

Na linha 1 do Algoritmo 3 (avaliação da solução) é executado o Algorimo 4, que executa o BB. Na linha 2 do Algoritmo 3 verifica-se se é tabu o movimento da máquina $m$, que faz parte da solução vizinha. Se a máquina $m$ (ou $m^{\prime}$, se for um movimento de troca) é tabu, aplica-se o Critério de Aspiração a partir da linha 3. O movimento da máquina $m$ (e $m^{\prime}$, se for o caso) só será aceito como melhor vizinha $s^{\prime}$ se este movimento for melhor que a melhor solução encontrada $s^{\text {best }}$. Neste caso, entre as linhas 4 e 7 , define-se que esta solução vizinha é a nova melhor solução $s^{\text {best }}$ e nova melhor solução vizinha $s^{\prime}$, atualizando-se os valores da melhor solução Z $\left(s^{\text {best }}\right)$ e da solução vizinha $\mathrm{Z}\left(s^{\prime}\right)$. Na sequência, na linha 8 , redefine-se a máquina $m$ (e $m^{\prime}$, se for um 
movimento de troca) como movimento tabu, atualizando-se até quando esta(s) máquina(s) permanecerá(ão) tabu. Se o movimento da máquina $m$ (ou $m^{\prime}$, se for um movimento de troca) não for tabu, na linha 10 , é analisado se a solução vizinha gerada é melhor que a melhor solução vizinha $s^{\prime}$ encontrada até este momento. Se a solução vizinha gerada for melhor que a solução $s^{\prime}$, então esta solução vizinha é definida como a nova solução $s^{\prime}$ na linha 11 e o valor da solução $s^{\prime}, \mathrm{Z}\left(s^{\prime}\right)$, é atualizado na linha 12 . Na linha 13 é definido que a máquina $m$ (e $m^{\prime}$, se for um movimento de troca) é um movimento tabu, indicando-se até quando esta(s) máquina(s) permanecerá(ão) tabu.

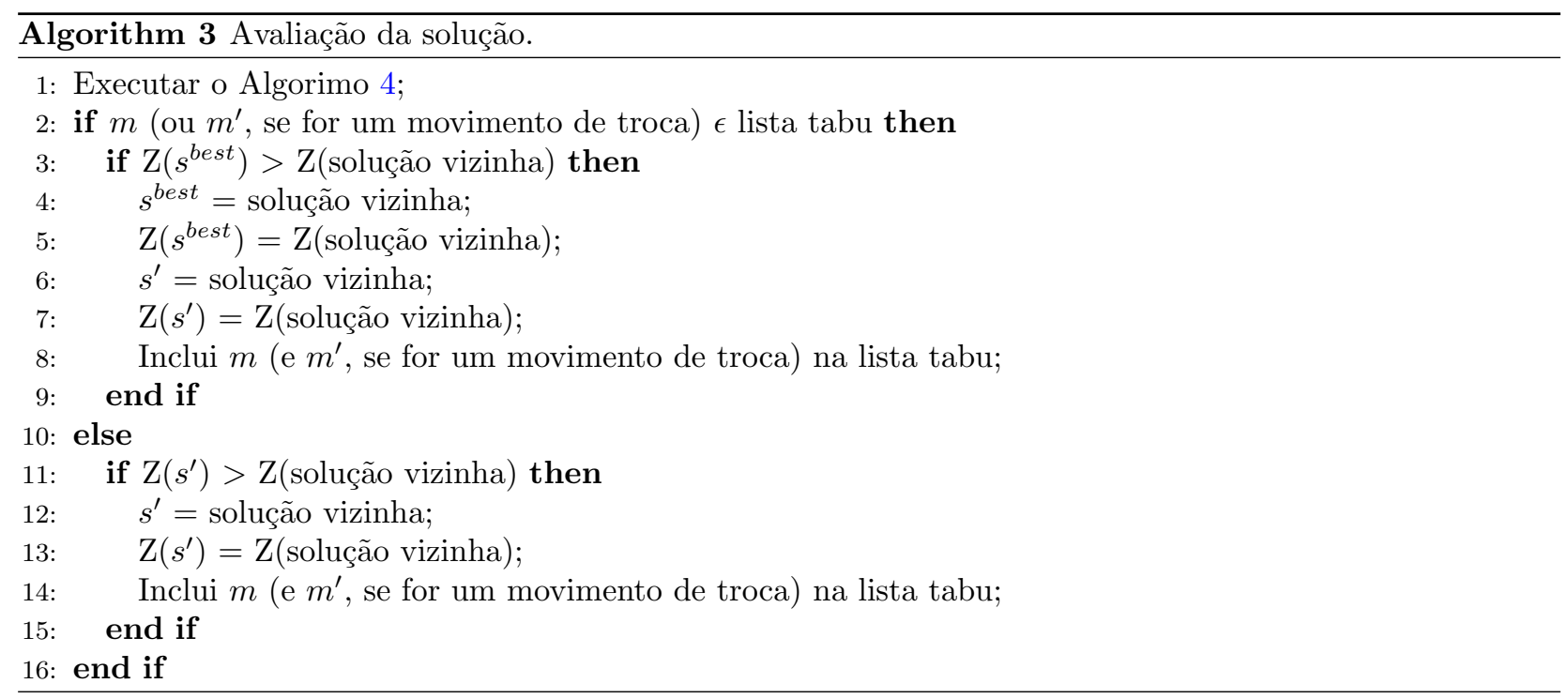

\subsection{Associação de peças a roteiros usando BB}

Na abordagem de BT híbrida proposta, um procedimento de branch - and - bound (BB) é aplicado sempre que uma solução factível (devido à alocação viável de máquinas às células) vizinha da solução $s$ é produzida. O objetivo desta etapa da BT híbrida é definir a alocação de um roteiro de fabricação para cada peça, visando minimizar o número de operações extra-celulares, mas levando em conta a capacidade de processamento de todas as máquinas. O desafio do BB é que, se não for devidamente implementado, ele pode apresentar um alto custo computacional. A fim de executar atribuições de roteiros às peças, são propostos dois algoritmos que trabalharão conjuntamente. O Algoritmo 4 é responsável pela preparação das informações necessárias ao $\mathrm{BB}$, enquanto o Algoritmo 5 realizará o BB propriamente dito.

Uma vez que as máquinas foram alocadas nas células na primeira etapa da BT, apresentada na Seção 3.2, na linha 3 do Algoritmo 4 identifica-se o número de operações extra-celulares para cada roteiro $r$ da peça $p$, já que a sua alocação é testada em cada célula $c$. Assim, identifica-se a célula onde ocorre o menor número de operações extra-celulares para o roteiro $r$ e registra-se o número de operações extra-celulares em $E C$ min $_{r}$.

Peças com apenas um roteiro possível não são incluídas na lista $E X P A N D_{n}$, já que a atribuição ótima do roteiro à peça já é conhecido. O objetivo da lista $E X P A N D_{n}$ é favorecer a busca em profundidade no BB. Na linha 6, para qualquer peça $p$ com apenas um roteiro $r$ disponível, atualizar a capacidade disponível de qualquer máquina $m$ associada ao roteiro $r$ (onde $m \in M R_{r}$ ). Isto é realizado, na máquina $m$, subtraindose da capacidade disponível $C_{a} p_{m}$ o tempo de processamento total do roteiro, levando em consideração a demanda da peça $p$.

Depois que todos os roteiros associados à peça $p$ foram analisados, na linha 11, para cada peça p, identifique a diferença entre os dois menores $E C$ min $_{r}$, indicando-a como dif $f_{p}$. Na linha 8, as peças são ordenadas numa lista chamada $E X P A N D_{n}$, onde $n$ é o nó raiz do BB, em ordem decrescente de dif $f_{p}$. Na linha 12 , some o menor $E_{C \text { min }_{r}}$ (para cada peça $p$ ). Esta soma é usada como a solução relaxada ou limite inferior do nó raiz do BB. Na linha 14, aplicar o procedimento de busca do BB (Algoritmo 5).

No nó raiz, a lista $E X P A N D_{0}$ contém todas as peças exceto aquelas com apenas um roteiro disponível. A lista $E X P A N D_{n}$ é atualizada a medida que novos nós são gerados na árvore de busca, através da alocação de um roteiro de fabricação a uma peça. Cada nó $n$ terá sua própria lista $E X P A N D_{n}$. Na medida em que a busca evolui, através da geração de novos nós, o procedimento de $\mathrm{BB}$ mantém uma lista dos nós abertos, chamada $O P E N$. Nós abertos correspondem a soluções parciais, quando a lista $E X P A N D_{n}$ ainda não está vazia. Inicialmente, quando a lista $O P E N$ é composta apenas do nó raiz, o limite inferior do procedimento de BB é calculado através do Algoritmo 4 e o limite superior da busca (valor da melhor solução completa 


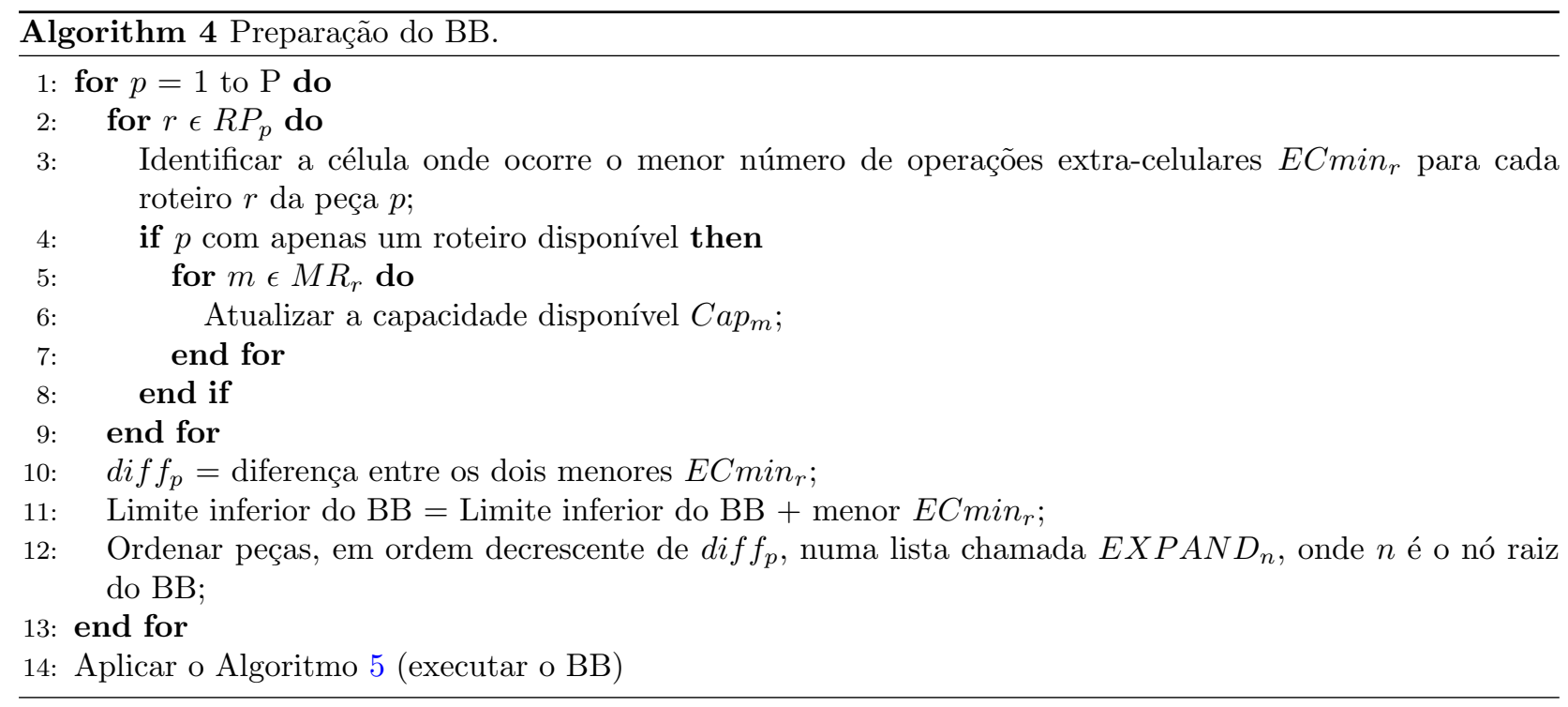

factível encontrada) é definido como $+\infty$. Em problemas de minimização, os nós abertos na lista $O P E N$ são ordenados em ordem crescente do valor da função objetivo (ou função de avaliação), tal que o primeiro nó nesta lista corresponde à solução parcial avaliada como a mais promissora. O leitor encontrará uma explicação detalhada da lista OPEN e do BB em Pearl (1984). O procedimento de busca do BB (Pearl, 1984) é resumido no Algoritmo 5, apresentado a seguir.

Na linha 1 do Algoritmo 5, define-se que o limite superior da função objetivo, chamado limsup, será igual a $+\infty$. No Algoritmo 5, serão eliminados da lista $O P E N$ todos os nós cujo valor da solução é maior ou igual a limsup. A linha 2 do algoritmo 5 verifica se a lista $O P E N$ está vazia. A busca do BB é encerrada quando a lista $O P E N$ estiver vazia. Se a lista $O P E N$ não está vazia, ramificar o (fazer o branching do) primeiro nó da lista $O P E N$. Na linha 3, o primeiro nó da lista $O P E N$ é identificado como $N o_{p a i}$. Isto significa que a primeira peça $p$ na lista $E X P A N D_{N o_{p a i}}$, que é identificada como $p 1$ na linha 4 , será ramificada. Ou seja, na linha 6 , será gerado um novo nó, identificado como $N o_{\text {filho }}$, para cada roteiro $r$ associado à peça $p 1$ (onde $r$ $\left.\epsilon R P_{p 1}\right)$.

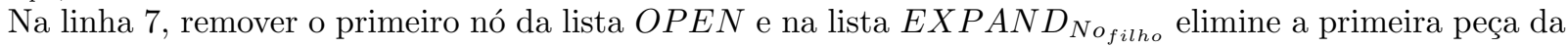
lista $E X P A N D_{N o_{p a i}}$, mantendo as demais peças. A cada novo nó gerado, na linha 9, atualizar a capacidade

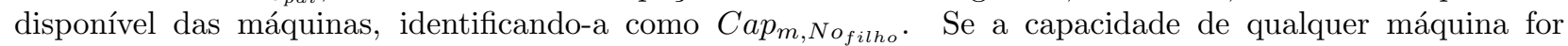
excedida, este novo nó será considerado infactível e não será incluído na lista $O P E N$. Caso contrário, calcule o valor da função objetivo para cada novo nó factível associado ao roteiro $r$ da peça $p$. Na linha 12 , o valor estimado da função objetivo do $N o_{\text {filho }}$ é dada pela soma do valor da solução estimado para $N o_{\text {pai }}$ mais $\Delta$, onde $\Delta$ é a diferença entre o $E C$ min $_{r}$ para o roteiro $r$ e a menor $E C \min _{r}$ para a peça $p$, como indicado na linha 11. Note que sempre $\Delta \geq 0$.

Na linha 13 é testado se a lista $E X P A N D_{n}$ não está vazia. Se foi criado um nó aberto (solução parcial) factível, na linha 14, ele é inserido e ordenado na lista $O P E N$. Se a lista $E X P A N D_{n}$ está vazia, novas soluções completas (nós fechados) factíveis foram identificadas. No teste da linha 16, se a nova solução completa é factível e o seu valor da função objetivo $\left(\mathrm{Z}\left(N_{o_{f i l h o}}\right)\right)$ é menor do que o limite superior da função objetivo, chamado limsup, então, na linha 17, limsup é atualizado para o valor da função objetivo desta solução $\left(\mathrm{Z}\left(N o_{\text {filho }}\right)\right)$. Esta solução é salva como a melhor solução até então $\left(s^{\prime}\right)$. Na linha 18 , é realizado o procedimento de fathoming. Ou seja, eliminar qualquer nó aberto (da lista $O P E N$ ) cujo valor estimado da função objetivo seja maior ou igual ao limite superior.

A maior contribuição do BB apresentado está em propor a utilização da lista $E X P A N D_{n}$. Pretende-se fomentar, tanto quanto possível, uma busca em profundidade. Portanto, parece haver uma poda significativa do espaço de busca do BB, como indicado nos tempos de processamento da abordagem, apresentados nos resultados.

\subsection{Exemplo didático}

A seguir, apresenta-se um exemplo didático da abordagem de BT híbrida proposta. A Tabela 2 apresenta os dados usados neste exemplo. Há 10 peças diferentes, cada uma com uma demanda definida e um ou mais roteiros de fabricação disponíveis. A cada operação foi associado um tempo de processamento, identificado em unidades de tempo correspondentes a um percentual da capacidade de produção disponível, que é igual a 


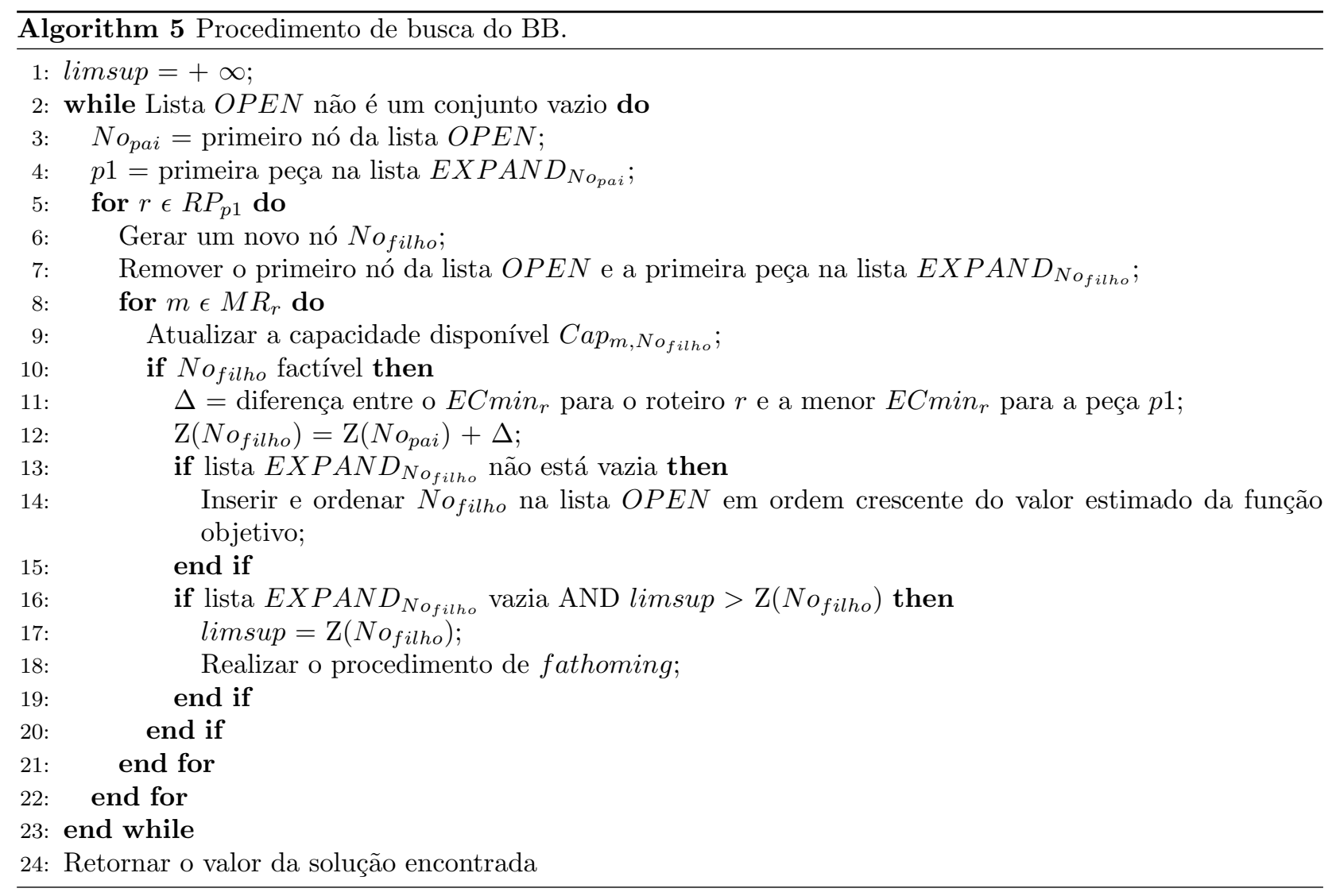

um (1) para todas as máquinas. No total, há 9 máquinas e 27 roteiros disponíveis. Na seção 3.1 foi descrita a primeira etapa da BT híbrida, que foi apresentado no Algoritmo 1.

\section{i) Iteração 0 (solução inicial da BT):}

Inicialmente, gerou-se a solução inicial (linha 3 do Algoritmo 1), alocando-se aleatoriamente as 9 máquinas em quatro (4) células de manufatura, como indicado na Tabela 3. Para calcular o custo da solução inicial, foi executado o Algoritmo 4, que corresponde à execução de um BB para alocar as peças às células, tal que o número de operações extra-celulares existentes $\left(E C \min _{r}\right)$ seja minimizado. A Tabela 4 apresenta, na linha 2 e 3, um resumo do resultado da execução das linhas 3 do Algoritmo 4. Nestas duas linhas, apresenta-se os dois menores $\mathrm{ECmin}_{r}$ encontrados e, entre parênteses, o roteiro responsável por este $E C \mathrm{~min}_{r}$. A Tabela 5 é o resultado da execução das linhas 4 a 9 do Algoritmo 4. Nesta tabela é apresentada a capacidade de todas as máquinas $C a p_{m}$ após a dedução dos consumos das peças 4 e 10, que só possuem um roteiro de fabricação e, por isto, são as unicas peças alocadas na solução parcial do nó raiz.

No início do $\mathrm{BB}$, a lista $O P E N$ será composta apenas pelo nó raiz: $O P E N=(0)$. A última linha da Tabela 4 apresenta dif $f_{p}$ que é a diferença entre os dois menores $E C \min _{r}$ para cada peça, que corresponde à execução da linha 10 do Algoritmo 4. Neste algoritmo, na linha 11, calculou-se o limite inferior do BB, que corresponde ao valor da função objetivo estimada para o primeiro nó na lista $O P E N$. Na solução inicial, o limite inferior do BB corresponde ao valor da função objetivo estimada para o nó raiz. Inicialmente, o limite inferior do $\mathrm{BB}$ foi obtido somando-se todos os valores do menor $E C$ min $_{r}$ para todas as peças, indicado na linha 2 da Tabela 4. Assim, neste exemplo, o limite inferior do BB é igual a seis (6) operações extra-celulares. A linha 12 do algoritmo prevê a definição da lista $E X P A N D_{0}$, relacionada ao nó raiz. Esta lista é gerada ordenando as peças pela ordem decrescente do valor de diff $f_{p}$, apresentado na última linha da Tabela 4. Observe que as peças 1, 3 e 9 apresentam todas dif $f_{p}$ igual a 1. Logo, o ordenamento entre estas três peças pode ser aleatório. Neste exemplo, peças com mesmo valor de dif $f_{p}$ foram ordenadas em ordem crescente $(1$, 3 e 9). O mesmo critério foi aplicado para as demais peças que apresentaram dif $f_{p}$ igual a zero. Portanto, a lista $E X P A N D_{0}$ será:

$E X P A N D_{0}=(1,3,9,2,5,6,7,8)$. 
Tabela 2. Dados do exemplo didático.

\begin{tabular}{|c|c|c|c|c|}
\hline Peça & Roteiro & Máquina & Tempo de processamento & Demanda \\
\hline \multirow{4}{*}{1} & \multirow{2}{*}{$\mathrm{R} 1$} & M3 & 0,1 & \multirow{4}{*}{2} \\
\hline & & M5 & 0,2 & \\
\hline & \multirow{2}{*}{$\mathrm{R} 2$} & M4 & 0,1 & \\
\hline & & M5 & 0,2 & \\
\hline \multirow{4}{*}{2} & \multirow{2}{*}{ R3 } & M1 & 0,3 & \multirow{4}{*}{2} \\
\hline & & M3 & 0,2 & \\
\hline & \multirow{2}{*}{$\mathrm{R} 4$} & M1 & 0,3 & \\
\hline & & M4 & 0,2 & \\
\hline \multirow{6}{*}{3} & & M1 & 0,1 & \multirow{6}{*}{2} \\
\hline & & M3 & 0,1 & \\
\hline & $\mathrm{R} 5$ & M5 & 0,2 & \\
\hline & & M1 & 0,1 & \\
\hline & & M3 & 0,1 & \\
\hline & R6 & M5 & 0,2 & \\
\hline \multirow[t]{2}{*}{4} & \multirow{2}{*}{$\mathrm{R} 7$} & M1 & 0,2 & \multirow[t]{2}{*}{2} \\
\hline & & M5 & 0,1 & \\
\hline \multirow{4}{*}{5} & \multirow{2}{*}{$\mathrm{R} 8$} & M2 & 0,2 & \multirow{4}{*}{2} \\
\hline & & M3 & 0,2 & \\
\hline & BO & M2 & 0,2 & \\
\hline & КУ & M4 & 0,2 & \\
\hline & & M4 & 0,1 & \\
\hline & R10 & M8 & 0,2 & \\
\hline & & M4 & 0,1 & \\
\hline & $\mathrm{R} \perp \mathrm{I}$ & M7 & 0,2 & \\
\hline & & M4 & 0,1 & \\
\hline 6 & R12 & M9 & 0,2 & 2 \\
\hline & & M3 & 0,1 & \\
\hline & К13 & M8 & 0,1 & \\
\hline & & M3 & 0,1 & \\
\hline & R14 & M7 & 0,2 & \\
\hline & & M3 & 0,1 & \\
\hline & R15 & M9 & 0,2 & \\
\hline & & M2 & 0,2 & \\
\hline & & M4 & 0,1 & \\
\hline & $\mathrm{R} 16$ & M8 & 0,4 & \\
\hline & & M2 & 0,2 & \\
\hline & & M3 & 0,1 & \\
\hline & $\mathrm{R} 17$ & M8 & 0,4 & \\
\hline & & M2 & 0,2 & \\
\hline & & M4 & 0,1 & \\
\hline 7 & $\mathrm{R} 18$ & M7 & 0,4 & 1 \\
\hline & & M2 & 0,2 & \\
\hline & & M3 & 0,1 & \\
\hline & R19 & M8 & 0,4 & \\
\hline & & M2 & 0,2 & \\
\hline & & M4 & 0,1 & \\
\hline & $\mathrm{R} 20$ & M9 & 0,4 & \\
\hline & & M2 & 0,2 & \\
\hline & & M3 & 0,1 & \\
\hline & $\mathrm{R} 21$ & M9 & 0,4 & \\
\hline & & M2 & 0,1 & \\
\hline 8 & $\mathrm{R} 22$ & M3 & 0,1 & 3 \\
\hline & & M2 & 0,1 & \\
\hline & R23 & M4 & 0,1 & \\
\hline & & M6 & 0,3 & \\
\hline & $\mathrm{R} 24$ & M7 & 0,4 & \\
\hline 9 & & M6 & 0,3 & 2 \\
\hline & $\mathrm{R} 25$ & M8 & 0,4 & \\
\hline & & M6 & 0,3 & \\
\hline & $\mathrm{R} 26$ & M9 & 0,4 & \\
\hline 10 & $\mathrm{R} 27$ & M6 & 0,1 & 2 \\
\hline
\end{tabular}




\section{$1^{a}$ iteração do BB:}

A última ação do Algoritmo 4, na linha 14, é iniciar a execução do Algoritmo 5, ou seja, iniciar o BB propriamente dito. Portanto, na linha 1 do Algoritmo 5, define-se o valor inicial de limsup. No BB, todas as soluções parciais ou nós da lista $O P E N$ serão podadas desta lista se seu valor for maior que limsup. Isto ocorre porque a lista $O P E N$ apenas deve conter soluções parciais promissoras, cujo valor, consequentemente, deve ser sempre inferior (num problema de minimização) à melhor solução completa encontrada, cujo valor será atribuído a limsup. Como nenhuma solução completa é conhecida no nó raiz (nó 0), limsup $=+\infty$.

Tabela 3. Geração da solução inicial: alocação de máquinas.

\begin{tabular}{ccccc}
\hline \multirow{2}{*}{ Alocações } & Célula 1 & Célula 2 & Célula 3 & Célula 4 \\
\cline { 2 - 5 } & M4, M5 e M8 & M1 e M2 & M3 e M7 & M6 e M9 \\
\hline
\end{tabular}

Tabela 4. Menor número de operações extra-celulares de $\mathrm{ECmin}_{r}$.

\begin{tabular}{ccccccccccc}
\hline & \multicolumn{10}{c}{ Peça } \\
\cline { 2 - 12 } & $\mathbf{1}$ & $\mathbf{2}$ & $\mathbf{3}$ & $\mathbf{4}$ & $\mathbf{5}$ & $\mathbf{6}$ & $\mathbf{7}$ & $\mathbf{8}$ & $\mathbf{9}$ & $\mathbf{1 0}$ \\
\hline Menor & 0 & 1 & 1 & 1 & 1 & 0 & 1 & 1 & 0 & 0 \\
Custo & $(\mathrm{R} 2)$ & $(\mathrm{R} 3)$ & $(\mathrm{R} 6)$ & $(\mathrm{R} 7)$ & $(\mathrm{R} 8)$ & $(\mathrm{R} 10)$ & $(\mathrm{R} 16)$ & $(\mathrm{R} 22)$ & $(\mathrm{R} 26)$ & $(\mathrm{R} 27)$ \\
\hline $2^{\circ}$ menor & 1 & 1 & 2 & & 1 & 0 & 1 & 1 & 1 & \\
Custo & $(\mathrm{R} 1)$ & $(\mathrm{R} 4)$ & $(\mathrm{R} 5)$ & & $(\mathrm{R} 9)$ & $(\mathrm{R} 14)$ & $(\mathrm{R} 19)$ & $(\mathrm{R} 23)$ & $(\mathrm{R} 24)$ & \\
\hline $\operatorname{diff}_{p}$ & 1 & 0 & 1 & & 0 & 0 & 0 & 0 & 1 & \\
\hline
\end{tabular}

Tabela 5. Capacidade $C a p_{m}$ após a alocação das peças 4 e 10 .

\begin{tabular}{ccccccccc}
\hline \multicolumn{1}{c}{ Máquina } \\
\hline M1 & M2 & M3 & M4 & M5 & M6 & M7 & M8 & M9 \\
\hline 0,6 & 1 & 1 & 1 & 0,8 & 0,8 & 1 & 1 & 1 \\
\hline
\end{tabular}

Na sequência do Algoritmo 5, como a lista $O P E N$ não está vazia, na linha 3 é definido que $N o_{p a i}$ será o primeiro nó da lista $O P E N$. Ou seja, $N o_{p a i}=0$. Na linha 4, a primeira peça na lista $E X P A N D_{0}$ é a peça 1. Nas linhas 5 e 6 , como a peça 1 tem dois roteiros (R1 e R2), ela gerará dois nós filhos, identificados como 1 e 2. Na linha 7, removeu-se o primeiro nó da lista $O P E N$ e a primeira peça da lista $E X P A N D_{0}$. Haverá uma lista $E X P A N D_{1}$ e outra $E X P A N D_{2}$ para os nós filhos 1 e 2, respectivamente. Assim, obtém-se:

OPEN $=()$

$E X P A N D_{n}=(3,9,2,5,6,7$ e 8$)$, para $n=1$ e 2.

A linha 9 prevê a atualização da capacidade disponível $C a p_{m, N o_{\text {filho }}}$ para os dois $N o_{\text {filho }}(1$ e 2), sendo que estas informações são apresentadas nas colunas 4 até 13 da Tabela 6 para os dois nós gerados. A fim de facilitar a visualização dos novos nós 1 (associado ao roteiro $R 1$ ) e 2 (associado ao roteiro R2) que foram gerados, a primeira linha desta tabela apresenta a informações do nó pai (nó 0). A terceira coluna da Tabela 6 apresenta o valor da função objetivo $\left(\mathrm{Z}\left(N o_{\text {filho }}\right)\right)$ para cada novo nó (roteiro) factível associado à peça 1. Note que, na linha 12 , o valor de $\mathrm{Z}\left(N o_{\text {filho }}\right)$ é dada pela soma do $\mathrm{Z}\left(N o_{\text {pai }}\right)$ (que é o custo do nó 0 nesta Tabela) mais $\Delta$, onde $\Delta$ (calculado na linha 11) é a diferença entre o ECmin $r$ para o roteiro $r$ e a menor $E C \min _{r}$ para a peça 1 . Na Tabela 4 observa-se que $E C \min _{r}$ têm valores 1 e 0 , respectivamente, para os roteiros R1 e R2. Logo, $\Delta=1$ para R1 e $\Delta=0$ para R2. Como as listas $E X P A N D_{1}$ e $E X P A N D_{2}$ (verificadas na linha 13 do algoritmo) não estão vazias, os dois nós (1 e 2) são inseridos na lista $O P E N$ na linha 14 do algoritmo. Esta lista é ordenada pela ordem crescente de seus valores da função objetivo (que são indicados entre parênteses nesta lista):

$O P E N=(2(6), 1(7))$.

$O P E N=(4(6), 3(7), 1(7))$. 
Tabela 6. Capacidade $\operatorname{Cap}_{m, N o_{f i l h o}}$ após a alocação da peça 1 .

\begin{tabular}{cccccccccccc}
\hline \multirow{2}{*}{$\mathbf{N}^{o}$} & \multirow{2}{*}{ Roteiro } & \multirow{2}{*}{$\mathbf{Z}$} & \multicolumn{10}{c}{ Máquina } \\
\cline { 3 - 13 } & & M1 & M2 & M3 & M4 & M5 & M6 & M7 & M8 & M9 \\
\hline 0 & & 6 & 0,6 & 1 & 1 & 1 & 0,8 & 0,8 & 1 & 1 & 1 \\
1 & R1 & 7 & 0,6 & 1 & 0,8 & 1 & 0,4 & 0,8 & 1 & 1 & 1 \\
2 & R2 & 6 & 0,6 & 1 & 1 & 0,8 & 0,4 & 0,8 & 1 & 1 & 1 \\
\hline
\end{tabular}

\section{$2^{a}$ à $8^{a}$ iterações do $\mathrm{BB}$ :}

A partir da $2^{a}$ iteração, as Tabelas 7 e 8 apresentam um resumo das ações tomadas ao seguir os passos do Algoritmo 5. Até a $7^{a}$ iteração deste algoritmo, os passos seguidos são idênticos ao seguido na $1^{a}$ iteração. Na Tabela 7, a primeira e segunda colunas indicam, respectivamente, o número da iteração do BB e o nó pai dos nós gerados nesta iteração. A terceira coluna apresenta a lista $O P E N$ obtida ao final desta iteração. Observe que o primeiro nó na lista $O P E N$ na iteração $i$ será sempre o nó pai na iteração $i+1$, como indicado nesta tabela e na Tabela 8. Além disto, observe também que, quando dois ou mais nós na lista $O P E N$ têm o mesmo valor estimado para a função objetivo, estes nós podem ser ordenados aleatoriamente. Porém, optou-se por dar preferência nesta lista ao(s) nó(s) com mais peças alocadas. A quarta coluna apresenta a lista $E X P A N D_{n}$ e os nós $n$ gerados nesta iteração (e que são detalhados na Tabela 8). Observe que a primeira peça na lista $\operatorname{EXPAND} D_{n}$ na iteração $i$ será sempre a peça a ser inserida na solução na iteração $i+1$, como indicado na Tabela 8.

Tabela 7. Lista $O P E N$ e $E X P A N D_{n}$ da $2^{a}$ à $8^{a}$ iterações.

\begin{tabular}{|c|c|c|c|}
\hline Iter. & $N o_{p a i}$ & OPEN & $E X P A N D_{n}$ \\
\hline 2 & 2 & $(4(6), 3(7), 1(7))$ & $(9,2,5,6,7,8)$, para $\mathrm{n}=3$ e 4 \\
\hline 3 & 4 & $(7(6), 5(7), 6(7), 3(7), 1(7))$ & $(2,5,6,7,8), \quad$ para $\mathrm{n}=5,6$ e 7 \\
\hline 4 & 7 & $(8(6), 9(6), 5(7), 6(7), 3(7), 1(7))$ & para $\mathrm{n}=8$ e 9 \\
\hline 5 & 8 & $\begin{array}{l}(10(6), 11(6), 9(6), 5(7), 6(7), 3(7), \\
1(7))\end{array}$ & para $n=10$ e 11 \\
\hline 6 & 10 & $\begin{array}{l}(12(6), 16(6), 11(6), 9(6), 13(7), 15 \\
(7), 5(7), 6(7), 3(7), 1(7))\end{array}$ & para $\mathrm{n}=12,13,14,15,16$ e 17 \\
\hline 7 & 12 & $\begin{array}{l}(18(6), 21(6), 16(6), 11(6), 9(6), 19 \\
(7), 20(7), 13(7), 15(7), 5(7), 6(7), \\
3(7), 1(7))\end{array}$ & para $\mathrm{n}=18,19,20,21,22$ e 23 \\
\hline 8 & 18 & $($ ) & para $n=24$ e 25 \\
\hline
\end{tabular}

Na Tabela 8, a primeira, segunda e terceira colunas indicam, respectivamente, o número da iteração do BB, o nó pai dos nós gerados e a peça $p$ que será inserida na solução nesta iteração. A quarta, quinta e sexta colunas apresentam, respectivamente, o nó filho gerado $\left(N o_{\text {filho }}\right)$, o roteiro associado a $N o_{\text {filho }}$ da peça $p$ que será alocado e o valor da função objetivo $(Z)$ estimado para esta solução. Na sexta coluna, soluções infactíveis são identificadas por "inf.". As colunas 7 a 15 da Tabela 7 apresentam, respectivamente, os valores de $C a p_{m, N o} o_{\text {filho }}$. A função objetivo $(Z)$ será infactível sempre que houver alguma máquina $m$ cujo valor de $\mathrm{Cap}_{m, \mathrm{No}_{\text {filho }}}$ for negativo.

$\mathrm{Na} 8^{a}$ iteração, o nó 25 é a primeira solução completa encontrada, já que a lista $E X P A N D_{n}$, na Tabela 7 , será vazia $\left(E X P A N D_{25}=()\right)$ pela primeira vez. Assim, como o nó 25 foi a única solução factível desta iteração, o Algoritmo 5 atingiu a linha 17 pela primeira vez, neste exemplo. Assim, o limite superior limsup assumirá o valor $\mathrm{Z}\left(N_{o_{25}}\right)=6$. E, na linha 18 deste algoritmo, será realizado o procedimento de fathoming. Este procedimento implicou na eliminação de todos os nós da lista $O P E N$, já que, do segundo ao último nó da iteração 7 , todos os nós têm valor maior ou igual a limsup. Logo, o nó 25 representa a solução ótima encontrada, já que a busca do BB (Algoritmo 5) será encerrada quando a lista OPEN estiver vazia. Assim, a solução inicial da busca tabu terá custo de 6 operações extra-celulares, retornando às linhas 4 e 5 do Algoritmo 1 , que definirá a solução inicial como a melhor solução encontrada $\left(s^{\text {best }}\right)$ até então. 
Tabela 8. Análise das soluções geradas nas iterações 2 a 8 .

\begin{tabular}{|c|c|c|c|c|c|c|c|c|c|c|c|c|c|c|}
\hline \multirow{2}{*}{ Iter. } & \multirow{2}{*}{$N o_{p a i}$} & \multirow{2}{*}{ peça } & \multirow{2}{*}{ No filho } & \multirow{2}{*}{ Roteiro } & \multirow{2}{*}{$\mathbf{Z}$} & \multicolumn{9}{|c|}{ Máquina } \\
\hline & & & & & & M1 & M2 & M3 & M4 & M5 & M6 & M7 & M8 & M9 \\
\hline \multirow{2}{*}{2} & \multirow{2}{*}{2} & \multirow{2}{*}{3} & 3 & R5 & 7 & 0,4 & 1 & 0,8 & 0,8 & 0 & 0,8 & 1 & 1 & 1 \\
\hline & & & 4 & $\mathrm{R} 6$ & 6 & 0,4 & 1 & 0,8 & 0,6 & 0 & 0,8 & 1 & 1 & 1 \\
\hline \multirow{3}{*}{3} & \multirow{3}{*}{4} & \multirow{3}{*}{9} & 5 & $\mathrm{R} 24$ & 7 & 0,4 & 1 & 1 & 0,6 & 0 & 0,2 & 1 & 1 & 1 \\
\hline & & & 6 & $\mathrm{R} 25$ & 7 & 0,4 & 1 & 1 & 0,6 & 0 & 0,2 & 1 & 1 & 1 \\
\hline & & & 7 & $\mathrm{R} 26$ & 6 & 0,4 & 1 & 1 & 0,6 & 0 & 0,2 & 1 & 1 & 0,2 \\
\hline \multirow{2}{*}{4} & \multirow{2}{*}{7} & \multirow{2}{*}{2} & 8 & $\mathrm{R} 3$ & 6 & 0,1 & 1 & 0,6 & 0,6 & 0 & 0,2 & 1 & 1 & 0,2 \\
\hline & & & 9 & $\mathrm{R} 4$ & 6 & 0,1 & 1 & 1 & 0,2 & 0 & 0,2 & 1 & 1 & 0,2 \\
\hline \multirow{2}{*}{5} & \multirow{2}{*}{8} & \multirow{2}{*}{5} & 10 & $\mathrm{R} 8$ & 6 & 0,1 & 0,6 & 0,2 & 0,6 & 0 & 0,2 & 1 & 1 & 0,2 \\
\hline & & & 11 & $\mathrm{R} 9$ & 6 & 0,1 & 0,6 & 0,6 & 0,2 & 0 & 0,2 & 1 & 1 & 0,2 \\
\hline \multirow{6}{*}{6} & \multirow{6}{*}{10} & \multirow{6}{*}{6} & 12 & $\mathrm{R} 10$ & 6 & 0,1 & 0,6 & 0,2 & 0,4 & 0 & 0,2 & 1 & 0,6 & 0,2 \\
\hline & & & 13 & R11 & 6 & 0,1 & 0,6 & 0,2 & 0,4 & 0 & 0,2 & 0,6 & 1 & 0,2 \\
\hline & & & 14 & $\mathrm{R} 12$ & inf. & 0,1 & 0,6 & 0,2 & 0,4 & 0 & 0,2 & 1 & 1 & $-0,2$ \\
\hline & & & 15 & $\mathrm{R} 13$ & 7 & 0,1 & 0,6 & 0 & 0,6 & 0 & 0,2 & 1 & 0,8 & 0,2 \\
\hline & & & 16 & $\mathrm{R} 14$ & 6 & 0,1 & 0,6 & 0 & 0,6 & 0 & 0,2 & 0,6 & 1 & 0,2 \\
\hline & & & 17 & $\mathrm{R} 15$ & inf. & 0,1 & 0,6 & 0 & 0,6 & 0 & 0,2 & 1 & 1 & $-0,2$ \\
\hline \multirow{6}{*}{7} & \multirow{6}{*}{12} & \multirow{6}{*}{7} & 18 & R16 & 6 & 0,1 & 0,4 & 0,2 & 0,3 & 0 & 0,2 & 1 & 0,2 & 0,2 \\
\hline & & & 19 & $\mathrm{R} 17$ & 7 & 0,1 & 0,4 & 0,1 & 0,4 & 0 & 0,2 & 1 & 0,2 & 0,2 \\
\hline & & & 20 & $\mathrm{R} 18$ & 7 & 0,1 & 0,4 & 0,2 & 0,3 & 0 & 0,2 & 0,6 & 0,6 & 0,2 \\
\hline & & & 21 & R19 & 6 & 0,1 & 0,4 & 0,1 & 0,4 & 0 & 0,2 & 0,6 & 0,6 & 0,2 \\
\hline & & & 22 & $\mathrm{R} 20$ & inf. & 0,1 & 0,4 & 0,2 & 0,3 & 0 & 0,2 & 1 & 0,6 & $-0,2$ \\
\hline & & & 23 & $\mathrm{R} 21$ & inf. & 0,1 & 0,4 & 0,1 & 0,4 & 0 & 0,2 & 1 & 0,6 & $-0,2$ \\
\hline \multirow{2}{*}{8} & \multirow{2}{*}{18} & & 24 & $\mathrm{R} 22$ & inf. & 0,1 & 0,1 & $-0,1$ & 0,3 & 0 & 0,2 & 1 & 0,2 & 0,2 \\
\hline & & & 25 & $\mathrm{R} 23$ & 6 & 0,1 & 0,1 & 0,2 & 0 & 0 & 0,2 & 1 & 0,2 & 0,2 \\
\hline
\end{tabular}

\section{ii) Iteração 1 da BT:}

Prosseguindo com a BT, após a geração da solução inicial e, como o critério de diversificação não foi atingido neste caso, na linha 8 do Algoritmo 1 é iniciada a busca na vizinhança (Algoritmo 2). Os movimentos de inserção e de troca para este problema possuem três restrições que foram propostas, no início da Seção 3.2, e que visam podar o espaço de busca das soluções vizinhas. Na Tabela 3, todas as máquinas presentes nas células 2, 3 e 4 não podem sofrer um movimento de inserção, porque sua células ficariam com apenas uma máquina, quando o número mínimo de máquinas por célula é igual a dois. Assim, por exemplo, as máquinas nas células 2, 3 e 4 só podem sofrer movimento de troca nesta iteração da BT.

Para a máquina $M 1$, observa-se na Tabela 2 que ela está presente na fabricação das peças 2,3 e 4 . Consequentemente, apenas as máquinas $M 3, M 4$ e $M 5$ estão associadas à máquina $M 1$. Analisando-se a Tabela 2, identifica-se na Tabela 9 quais máquinas estão relacionadas entre si, ao haver ao menos um roteiro onde elas estão juntas. A partir das informações da Tabela 9, levando-se em consideração às restrições propostas na Seção 3.2, a Tabela 10 apresenta todas as soluções vizinhas geradas nesta iteração da BT.

A primeira coluna da Tabela 10 identifica cada uma das soluções geradas, onde a solução inicial $(s)$ e a melhor solução vizinha encontrada $\left(s^{\prime}\right)$ são apresentadas, respectivamente, na segunda e na quinta linhas. A segunda coluna apresenta o valor associado a cada solução $(Z)$ e nas colunas seguintes apresenta-se a alocação das máquinas às células. Devido ao espaço consumido, a execução do BB só foi apresentada para a solução inicial.

\section{Simulated Annealing (Caux et al., 2000)}

O simulated annealing (SA) híbrido proposto por Caux et al. (2000) será resumido nesta seção. O SA simula o processo de mudança de estado dos materiais durante sua têmpera ou recozimento. A fim de garantir o carater didático deste capítulo, o algoritmo apresentado nesta seção é mais detalhado que o descrito por Caux et al. (2000), ainda que ambos se comportem igual.

$\mathrm{Na}$ primeira linha, são definidos os parâmetros iniciais: temperatura inicial $(C)$ e a probabilidade do movimento de troca $(p p)$. A cada iteração, será definida uma nova temperatura $T$ na linha 17 do algoritmo. Assim, $T$ corresponde à temperatura a cada iteração, enquanto $C$ indica o seu valor inicial. A processo de geração da solução inicial no SA híbrido, na linha 2, é similar ao da BT híbrida apresentada na Seção 3 . Na 
Tabela 9. Máquinas associadas entre si.

\begin{tabular}{cc}
\hline$m$ & Máquinas associadas à máquina $m$ \\
\hline M1 & M3, M4 e M5 \\
M2 & M3, M4, M7, M8 e M9 \\
M3 & M1, M2, M5, M7, M8 e M9 \\
M4 & M1, M2, M5, M7, M8 e M9 \\
M5 & M1, M3 e M4 \\
M6 & M7, M8 e M9 \\
M7 & M1, M2, M3, M4, M5 e M6 \\
M8 & M1, M2, M3, M4, M5 e M6 \\
M9 & M1, M2, M3, M4, M5 e M6 \\
\hline
\end{tabular}

Tabela 10. Busca na vizinhança na $1^{a}$ iteração da BT.

\begin{tabular}{cccccc}
\hline & & \multicolumn{4}{c}{ Alocações das máquinas na solução $i$} \\
\cline { 2 - 6 }$i$ & $\mathbf{Z}(i)$ & Célula 1 & Célula 2 & Célula 3 & Célula 4 \\
\hline$s$ & 6 & M4, M5 e M8 & M1 e M2 & M3 e M7 & M6 e M9 \\
1 & 5 & M1, M5 e M8 & M4 e M2 & M3 e M7 & M6 e M9 \\
2 & 6 & M4, M1 e M8 & M5 e M2 & M3 e M7 & M6 e M9 \\
$s^{\prime}$ & $\mathbf{3}$ & M4, M5 e M1 & M8 e M2 & M3 e M7 & M6 e M9 \\
3 & 4 & M4, M5 e M8 & M3 e M2 & M1 e M7 & M6 e M9 \\
4 & 5 & M4, M5 e M8 & M7 e M2 & M3 e M1 & M6 e M9 \\
5 & 6 & M2, M5 e M8 & M1 e M4 & M3 e M7 & M6 e M9 \\
6 & 4 & M4, M2 e M8 & M1 e M5 & M3 e M7 & M6 e M9 \\
7 & 5 & M4, M5 e M2 & M1 e M8 & M3 e M7 & M6 e M9 \\
8 & 5 & M4, M5 e M8 & M1 e M3 & M2 e M7 & M6 e M9 \\
9 & 4 & M4, M5 e M8 & M1 e M7 & M3 e M2 & M6 e M9 \\
10 & 7 & M4, M5 e M8 & M1 e M6 & M3 e M7 & M2 e M9 \\
11 & 6 & M4, M5 e M8 & M1 e M2 & M3 e M7 & M6 e M9 \\
12 & 6 & M3, M5 e M8 & M1 e M2 & M4 e M7 & M6 e M9 \\
13 & 8 & M4, M3 e M8 & M1 e M2 & M5 e M7 & M6 e M9 \\
14 & 8 & M4, M5 e M3 & M1 e M2 & M8 e M7 & M6 e M9 \\
15 & 6 & M4, M5 e M8 & M1 e M2 & M6 e M7 & M3 e M9 \\
16 & 8 & M6, M5 e M8 & M1 e M2 & M3 e M7 & M4 e M9 \\
17 & 6 & M5 e M8 & M4, M1 e M2 & M3 e M7 & M6 e M9 \\
18 & 8 & M5 e M8 & M1 e M2 & M4, M3 e M7 & M6 e M9 \\
19 & 8 & M5 e M8 & M1 e M2 & M3 e M7 & M4, M6 e M9 \\
20 & 6 & M4 e M8 & M5, M1 e M2 & M3 e M7 & M6 e M9 \\
21 & 6 & M4 e M8 & M1 e M2 & M5, M3 e M7 & M6 e M9 \\
22 & 6 & M4, M5 e M7 & M1 e M2 & M3 e M8 & M6 e M9 \\
23 & 6 & M4, M5 e M8 & M1 e M2 & M3 e M9 & M6 e M7 \\
\hline & & & & &
\end{tabular}

linha 3, a busca prosseguirá até que o critério de parada seja atingido. O critério de parada pode ser um número máximo de iterações ou um valor da temperatura $T$.

$\mathrm{Na}$ linha 4 gera-se a solução vizinha $s^{\prime}$. Enquanto a BT híbrida preve o teste de todas as soluções vizinhas promissoras (que satisfazem as restrições nos movimentos de inserção e de troca), será gerada apenas uma solução vizinha por iteração no SA híbrido. A cada iteração gera-se um número aleatório entre 0 e 1 . Se este número aleatório for menor que a probabilidade de movimento de troca $(p p)$, nesta iteração ocorrerá um movimento de troca. Senão, será realizado um movimento de inserção. Igual à BT híbrida proposta, Caux et al. (2000) propuseram que o SA realize a alocação das máquinas às células e que um algoritmo de BB identifique qual roteiro fabricará cada peça, definindo a solução de menor custo.

$\mathrm{Na}$ linha 5 calcula-se o valor de $\Delta$, que é a diferença entre os valores das soluções vizinha $\left(s^{\prime}\right)$ e vigente $(s)$. Na linha 6 , se $\Delta$ for menor ou igual a zero, num problema de minimização, a solução vizinha $\left(s^{\prime}\right)$ será melhor ou igual que a solução vigente $(s)$. Assim, $s^{\prime}$ se tornará a nova solução vigente $(s)$ na linha 7 . Posteriormente, nas linhas 8 a 10, verifica-se se esta é a melhor solução encontrada até esta iteração $\left(s^{\text {best }}\right)$. Se $\Delta$ for maior que zero, $s^{\prime}$ é uma solução pior que $s$. O SA prevê que haja uma chance igual a $\exp (-\Delta / T)$ de aceitação 


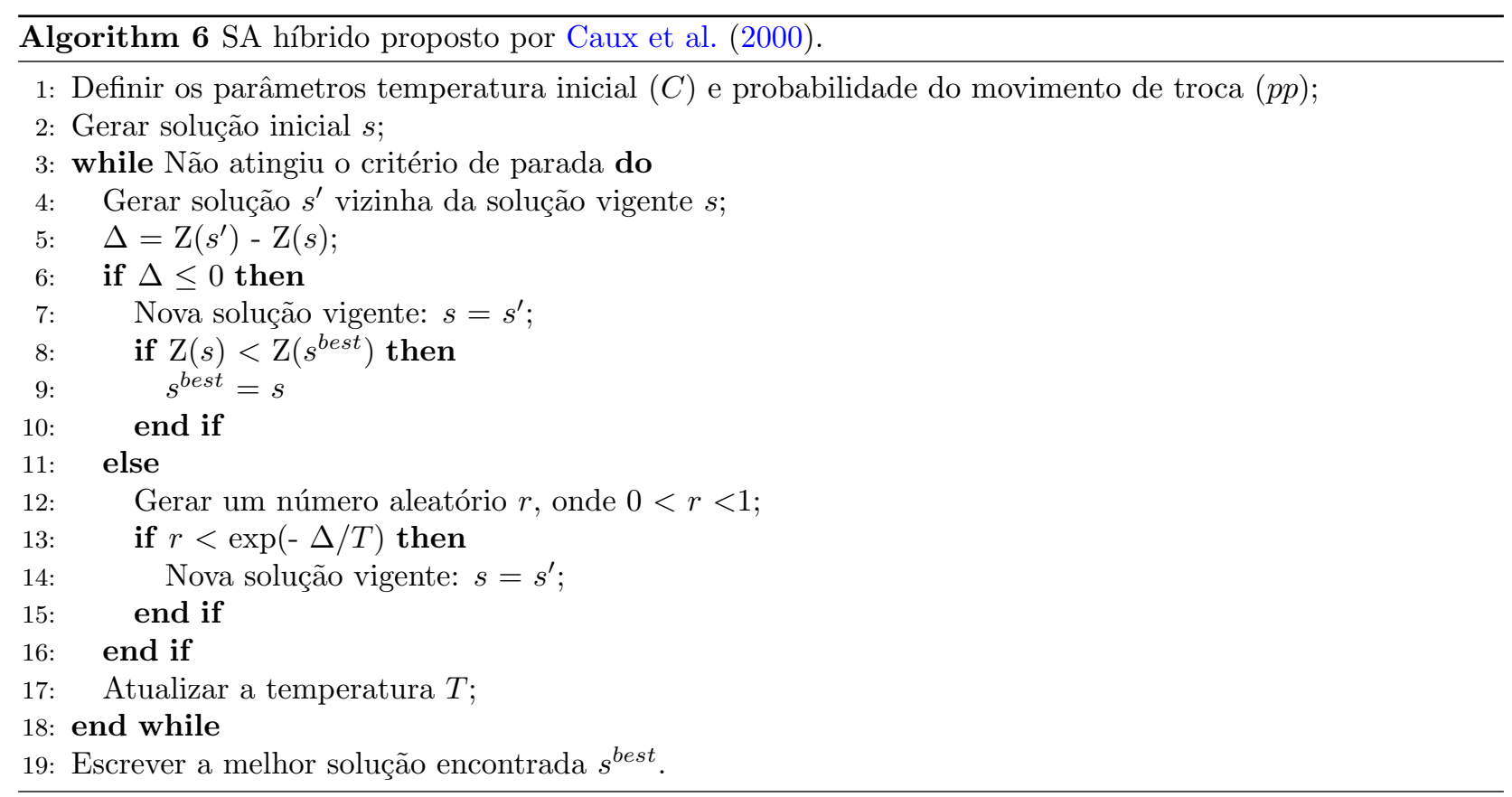

desta solução pior $s^{\prime}$ como nova solução vigente $s$. O propósito desta chance de aceitação de uma solução pior que $s$ é o de permitir que a busca não fique presa num ponto ótimo local. Se esta chance não existisse, este algoritmo equivaleria a um hill - climbing. A chance de aceitação de uma solução pior que $s$ é executada entre as linhas 12 e 15. Ao fim da busca, quando o critério de parada for atingido, na linha 18, escreve-se a melhor solução encontrada $s^{\text {best }}$.

\section{Resultados}

A abordagem proposta foi executada em um Pentium IV PC com CPU de $3.00 \mathrm{GHz}$ e memória RAM de 2.00 GB. Esta abordagem foi implementada usando Visual Studio 2005. A instância usada foi publicada por Nagi et al. (1990), que a usou para testar sua abordagem proposta, já que ela foi usada também por Caux et al. (2000) para testar sua abordagem de SA híbrido. Os resultados da BT híbrida proposta é comparada aos resultados obtidos por Caux et al. (2000). Nesta instância, 20 peças, com 51 roteiros e 20 máquinas foram agrupadas em 5 células. A solução inicial foi obtida aleatoriamente.

A Tabela 11 indica os resultados apresentados por Caux et al. (2000), em número de iterações. Para testar o SA, dois parâmetros foram variados por teste: temperatura inicial $(C)$ e probabilidade de troca ou swap $(p p)$. Ou seja, um vizinho é criado usando probabilidade de troca igual a pp e usando probabilidade de inserção igual a $(1-p p)$. Para cada conjunto de parâmetros $C$ e $p p, 25$ execuções foram realizadas. No melhor caso, a solução ótima obtida por Caux et al. (2000) ocorreu, em media, após 218 iterações (para $C=$ 10 e probabilidade de troca $p p=0,5$ ). Os testes com o algoritmo apresentado por Caux et al. (2000) foram consistentes com aqueles apresentados na Tabela 11, já que o desvio padrão da média (quando a média era inferior a 600 iterações) variou entre 199,94 e 333,76 iterações. A Tabela 12 apresenta uma comparação entre os resultados após 100 execuções das duas abordagens (BT e SA). O único parâmetro que foi definido para a BT híbrida foi o tamanho da lista tabu, que foi fixado em cinco (5) iterações devido à dimensão da instância proposta. Para o problema proposto por Nagi et al. (1990), pode ser observado que a abordagem proposta de BT híbrida supera os melhores resultados apresentados no SA híbrido, proposto por Caux et al. (2000). O pior caso nos tempos de CPU foi utilizado para comparar os tempos de processamento de ambas as abordagens por causa do desvio padrão significativo apresentado pelo SA. De fato, uma desvantagem importante do SA foi o seu desvio padrão.

Os autores deste trabalho acreditam que a principal razão para o uso do SA, como visto na revisão da literatura, para o problema proposto está na simplicidade desta abordagem, já que o problema foi resolvido em dois passos. Além disto, devido à sua complexidade computacional, o uso do BB no segundo passo da solução do problema proposto parece exercer uma influência negativa à adoção de BT e algoritmos genéticos, que exploraram várias soluções vizinhas a cada iteração. Ou seja, se o procedimento de BB não for eficaz, torna-se difícil combinar o BB com abordagens como a BT ou algoritmos genéticos.

No algoritmo de BT híbrido implementado, note que três regras foram usadas para pesquisar soluções vizinhas no primeiro passo da abordagem, mas somente a primeira foi uma restrição do problema. As duas 
Tabela 11. Número total médio de iterações necessárias para atingir a solução ótima (Caux et al., 2000).

\begin{tabular}{cccccc}
\hline \multirow{2}{*}{$p p$} & \multicolumn{5}{c}{$C$} \\
\cline { 2 - 6 } & $\mathbf{1}$ & $\mathbf{5}$ & $\mathbf{1 0}$ & $\mathbf{1 5}$ & $\mathbf{2 0}$ \\
\hline $\mathbf{0}$ & 2000 & 556 & 321 & 308 & 1538 \\
$\mathbf{0 , 2 5}$ & 1031 & 397 & 450 & 743 & 1622 \\
$\mathbf{0 , 5}$ & 775 & 319 & 218 & 949 & 1100 \\
$\mathbf{0 , 7 5}$ & 764 & 280 & 671 & 1861 & 2000 \\
$\mathbf{1}$ & 2000 & 2000 & 2000 & 2000 & 2000 \\
\hline
\end{tabular}

Tabela 12. Resultados obtidos para encontrar a solução ótima usando BT e SA (no seu melhor desempenho).

\begin{tabular}{ccc}
\hline Abordagem & Número de iterações & Pior tempo de CPU \\
\hline BT híbrida & $12.7 \pm 3.45$ & 2 segundos \\
SA híbrido & $218 \pm 199.94$ & 5 segundos \\
(Caux et al., 2000) & & \\
\hline
\end{tabular}

regras de poda que foram adicionados ao primeiro passo contribuíram para reduzir o espaço de soluções vizinhas. A segunda contribuição importante deste trabalho foi a incorporação da lista $E X P A N D_{n}$ ao $\mathrm{BB}$, o que tornou o tempo de processamento do algoritmo razoável. Um comentário sobre o exemplo utilizado, proposto por Nagi et al. (1990), é necessário. Foi o único exemplo encontrado para o problema proposto e que tinha sido utilizado em comparações anteriores entre diferentes abordagens. A literatura sobre o problema de formação de células indica o uso de problemas de tamanho similar. Apesar disto, o exemplo usado foi considerado pequeno. Devido a isto, a BT híbrida convergiu bastante rápido para a solução ótima, tornando desnecessária a diversificação para este exemplo. Uma vez que os resultados foram promissores, exemplos maiores serão utilizados no futuro.

\section{Conclusões}

Este capítulo é focado na solução do problema de formação de células, com roteiros alternativos e considerações de capacidade. Um modelo matemático foi apresentado para este problema. Este é um problema desafiador que requer dois passos para resolver uma iteração usando meta-heurísticas: i) atribuição das máquinas às células de manufatura; e ii) cálculo da função objetivo. Devido a isto, apenas uma gama limitada de metaheurísticas tem sido proposta para resolver o problema. Uma abordagem de BT híbrida foi apresentada com duas contribuições importantes: i) duas regras de podar para o primeiro passo do problema; e ii) um procedimento rápido BB para resolver a segunda etapa do problema. Resultados da BT híbrida superaram os do SA híbrido, proposto por Caux et al. (2000). Estes são os primeiros resultados da abordagem de BT híbrida proposta. Exemplos de maior tamanho serão propostos no futuro, tornando possível explorar melhor outros recursos da BT, como outros mecanismos de memória (Glover \& Laguna, 1997). Além disto, outras abordagens, como algoritmos genéticos, podem ser testadas no futuro, utilizando o procedimento BB proposto neste trabalho.

\section{Referências}

Burbidge, J.L., An Introduction to Group Technology. New York, USA: John Wiley \& Sons, 1975.

Caux, C.; Bruniaux, R. \& Pierreval, H., Cell formation with alternative process plans and machine capacity constraints: A new combined approach. International Journal of Production Economics, 64(1-3):279-284, 2000.

Foulds, L.R.; French, A.P. \& Wilson, J.M., The sustainable cell formation problem: Manufacturing cell creation with machine modification costs. Computers $\&$ Operations Research, 33(4):1010-1032, 2006.

Glover, F. \& Laguna, M., Tabu Search. Norwell, USA: Kluwer Academic, 1997.

Irani, S.A., Handbook of Cellular Manufacturing Systems. New York, USA: John Wiley \& Sons, 1999.

Lei, D. \& Wu, Z., Tabu search-based approach to multi-objective machine-part cell formation. International Journal of Production Research, 43(24):5241-5252, 2005.

Lei, D. \& Wu, Z., Tabu search for multi-criteria manufacturing cell design. International Journal of Advanced Manufacturing Technology, 28(9-10):950-956, 2006.

Nagi, R.; Harhalakis, G. \& Proth, J.M., Multiple routeings and capacity considerations in group technology applications. International Journal of Production Research, 28(12):2243-2257, 1990. 
Nsakanda, A.L.; Diaby, M. \& Price, W.L., Hybrid genetic approach for solving large-scale capacitated cell formation problems with multiple routings. European Journal of Operational Research, 171(3):1051-1070, 2006.

Pearl, J., Heuristics: intelligent search strategies for computer problem solving. Reading, USA: Addison-Wesley, 1984.

Prabhaharan, G.; Muruganandam, A.; Asokan, P. \& Girish, B.S., Machine cell formation for cellular manufacturing systems using an ant colony system approach. International Journal of Advanced Manufacturing Technology, 25(9-10):1013-1019, 2005.

Rodrigues, L.C.A. \& Weller, T.R., Cell formation with alternative routings and capacity considerations: A hybrid tabu search approach. In: Gelbukh, A. \& Morales, E.F. (Eds.), MICAI 2008: Advances in Artificial Intelligence. Heidelberg, Germany: Springer-Verlag, v. 5317 de Lecture Notes in Computer Science, p. 482-491, 2008.

Xambre, A.R. \& Vilarinho, P.M., A simulated annealing approach for manufacturing cell formation with multiple identical machines. European Journal of Operational Research, 151(2):434-446, 2003.

\section{Notas Biográficas}

Luiz Carlos Abreu Rodrigues é graduado em Engenharia Mecânica (UNICAMP, 1989), mestre e doutor em Engenharia Elétrica (UNICAMP, 1996 e 2000, respectivamente). Atualmente é Professor Associado do Departamento Acadêmico de Mecânica da Universidade Tecnológica Federal do Paraná (UTFPR). Ele tem interesse na área de otimização combinatória, com aplicações em problemas de planejamento, projeto e controle da produção.

Adriano Pereira Balau é graduado em Engenharia de Produção Mecânica (USP/São Carlos, 1999). Atualmente é discente de mestrado no Programa de Pós-Graduação em Engenharia de Mecânica e de Materiais da Universidade Tecnológica Federal do Paraná (UTFPR).

Tiago Rodrigues Weller é graduado em Tecnologia Mecânica (UTFPR, 2004) e mestre em Engenharia Mecânica (UTFPR, 2008). Atualmente é Professor Adjunto do Departamento Acadêmico de Mecânica da Universidade Tecnológica Federal do Paraná (UTFPR). Ele tem interesse em problemas de planejamento, projeto e controle da produção. 


\title{
Uma Solução para o Problema de Alocação de Registradores baseada em Meta-heurísticas
}

\author{
Carla Négri Lintzmayer, Mauro Henrique Mulati e Anderson Faustino da Silva*
}

\begin{abstract}
Resumo: Um alocador de registradores tem por objetivo alocar um número ilimitado de valores do programa para um número finito de registradores da máquina. Neste contexto, algoritmos baseados em coloração de grafo tem sido tradicionalmente utilizados. Contudo, a alocação gerada pode ocasionar sérios problemas, como constante acesso á hierarquia de memória, devido ao uso de heurísticas simples. Por outro lado, algoritmos baseados meta-heurísticas tendem a fornecer melhores soluções do que aqueles algoritmos que não são baseados em meta-heurísticas. Assim, este capítulo apresenta a aplicação de meta-heurísticas na resolução do problema de alocação de registradores. Os experimentos realizados demonstram que um alocador com uma fase meta-heurística é capaz de melhorar a qualidade do código gerado.
\end{abstract}

Palavras-chave: Alocação de Registradores, Coloração de Grafo, Meta-heurísticas.

\begin{abstract}
A register allocator aims to allocate an unlimited number of program values for a finite number of machine registers. In this context, algorithms based on graph coloring has been traditionally used. However, the allocation may result serious problems such as constant access to memory hierarchy due to the use of simple heuristics. Moreover, algorithms based on metaheuristics tend to provide better solutions than those algorithms which are not based on metaheuristics. This chapter presents the application of metaheuristics in register allocation problem. The experiments show that an allocator with a metaheuristic phase is able to improve the quality of generated code.
\end{abstract}

Keywords: Register allocation, Graph coloring, Metaheuristics.

\section{Introdução}

Alocação de registradores, uma das mais importantes otimizações aplicadas por um compilador, determina quais valores do programa (variáveis e temporários) devem ser mantidos em registradores (ou memória) durante sua execução (Muchnick, 1997).

Em uma máquina real, registradores são geralmente poucos porém rápidos para acessar (Patterson \& Hennessy, 2008; Stallings, 2010), então o problema abordado aqui é como minimizar o tráfego entre registradores e a hierarquia de memória. Portanto, o desafio é representar a menor quantidade possível de valores do programa em memória.

A alocação de registradores pode ser mapeada como um problema de coloração gráfico (PCG) (Chaitin et al., 1981; Glover \& Laguna, 1997). O PCG tradicional consiste em encontrar o mínimo valor de $k$ para que um gráfico seja $k$-colorível. Já o $k$-PCG consiste em tentar colorir um grafo com $k$ cores fixas, minimizando a quantidade de conflitos (vértices adjacentes atribuído a mesma cor). Na alocação de registradores o $k$-PCG tem uma ligeira variação: ele é forçado a eliminar os conflitos existentes além de colorir o gráfico com apenas $k$ cores, devido ao fato de existirem somente $k$ registradores.

Coloração de grafos (Muchnick, 1997) é uma abordagem altamente eficaz para alocação de registradores intraprocedural, e pode ser brevemente descrita como segue. Durante a geração de código, o compilador (Fischer et al., 2010) utiliza infinitos registradores simbólicos para manter os valores do programa e determina os valores que são bons candidatos para alocação em registradores. Inicialmente, o alocador de registradores gera um grafo de interferência, cujos vértices representam os valores do programa e os registradores reais da máquina e cujas arestas representam as interferências. Neste grafo, uma aresta (interferência) é adicionada, se dois valores estão simultaneamente vivos ou um valor não pode ser atribuído a um determinado registrador. Após, o alocador irá colorir os vértices do grafo de interferência com $k$ cores, de modo que quaisquer dois

*Autor para contato: anderson@din.uem.br 
vértices adjacentes tenham cores diferentes. E, finalmente, o alocador irá alocar cada valor ao registrador que tem a mesma cor a ele atribuído.

Em aplicações onde o tempo de compilação é uma preocupação, como sistemas de compilação dinâmica (Arnold et al., 2011; Ishizaki et al., 2003; Suganuma et al., 2004), pesquisadores tentam equilibrar o tempo necessário para a alocação de registradores e a qualidade do código resultante. Para alcançar este equilíbrio, geralmente não escolhem um algoritmo de alocação de registradores baseado em coloração de grafo, pelo fato deste ser um algoritmo complexo e possuir um alto tempo de execução. No entanto, alocadores (Poletto \& Sarkar, 1999; Johansson \& Sagonas, 2002; Mössenböck \& Pfeiffer, 2002; Wimmer \& Mössenböck, 2005) que são considerados mais rápidos do que aqueles baseados em coloração de grafo resultam em um código de qualidade inferior (Muchnick, 1997; Smith et al., 2004; Cooper \& Dasgupta, 2006; Appel, 1998).

Um problema com algumas abordagens de alocação de registradores baseadas em coloração de grafo é o fato de aplicarem métodos heurísticos simples, resultando em uma má alocação de registradores. Neste caso, haverá um constante tráfego de dados entre o processador e a hierarquia de memória ocasionando uma perda de desempenho. Contudo, encontrar uma solução para o $k$-PCG é um problema $\mathcal{N} \mathcal{P}$-completo $($ Karp, 1972). Nenhum algoritmo exato em tempo polinomial é conhecido, estimulando o uso de meta-heurísticas para encontrar boas soluções.

Este capítulo apresenta duas meta-heurísticas aplicadas ao problema de alocação de registradores intraprocedural. Desta forma, este capítulo descreve uma extensão do alocador de registradores proposto por George e Appel (George \& Appel, 1996; Appel, 1998) para utilizar um algoritmo heurístico baseado em colônia de formigas ou um algoritmo heurístico híbrido evolucionário. Portanto, foram projetados dois novos alocadores de registradores interprecedurais baseados em coloração de grafo. A avaliação destes novos alocadores irá demonstrar que um alocador que utilize uma heurística mais agressiva gera um código de melhor qualidade.

O restante deste capítulo está organizado da seguinte forma. A Seção 2 descreve o alocador proposto por George e Appel. A Seção 3 apresenta os detalhes das meta-heurísticas aplicadas ao problema de alocação de registradores. A Seção 4 apresenta os resultados alcançados com as meta-heurísticas. E, finalmente, a Seção 5 apresenta as conclusões.

\section{O Alocador de Registradores Proposto por George e Appel}

Com base na observação de que um bom alocador de registradores baseado em coloração de grafo deve não apenas atribuir cores diferentes aos valores do programa, mas também tentar atribuir a mesma cor para temporários relacionados por cópias ${ }^{1}$, George e Appel desenvolveram um algoritmo iterativo de alocação de registradores, daqui para frente chamado de George-Appel (George \& Appel, 1996; Appel, 1998).

George-Appel itera até que não existam mais derramamentos ${ }^{2}$. Os resultados demonstraram como intercalar as reduções na coloração com heurísticas de fundir ${ }^{3}$, levando a um algoritmo que é seguro e agressivo.

O pressuposto desta abordagem é que o compilador é livre para gerar novos temporários e cópias, porque quase todas as cópias serão fundidas.

As fases de George-Appel são como segue:

Construir: Nesta fase, o gráfico de interferência é construído por meio de análise de fluxo de dados (Muchnick, 1997) e seus vértices são categorizados como relacionados ou não a instruções de movimentação (cópia), significando que o vértice é a origem ou destino de uma movimentação.

Simplificar: George-Appel utiliza uma heurística simples para simplificar o grafo. Se o grafo $G$ contém um vértice $n$ com menos de $k$ vizinhos, então $G^{\prime}$ é construído fazendo $G^{\prime}=G-\{n\}$. Em seguida, se $G^{\prime}$ pode ser colorido com $k$ cores, então $G$ também pode. Esta fase repetidamente remove do grafo os vértices não relacionados a movimentação se eles possuirem grau baixo $(<k)$ armazenando-os em uma pilha.

Fundir :Esta fase tenta encontrar movimentações no grafo reduzido obtido na fase Simplificar para aglutinar. Se dois temporários $T 1$ e T2 não interferem é desejável que sejam alocados em um mesmo registrador. Esta fase elimina todas possíveis instruções de movimentação, unindo a origem e destino em um novo vértice. Se possível, esta fase também remove as instruções redundantes do programa. As fases Simplificar e Fundir são repetidas enquanto o grafo conter vértices não relacionados a movimentação ou vértices de grau baixo.

Congelar: Às vezes, nem Simplificar nem Fundir podem ser aplicadas. Neste caso, George-Appel congela um vértice de grau baixo relacionado a movimentação considerando-o um vértice não relacionado a

\footnotetext{
1 Instruções de movimentação cuja origem e o destino são temporários, ou seja, uma instrução do tipo: $T 1 \leftarrow T 4$.

2 Do original em inglês spill: valor do programa que será efetivamente representado em memória.

3 Do original em inglês coalescing: ação de fundir dois vértices do grafo.
} 
movimentação, o que potencialmente permitirá uma maior simplificação. Após isso, Simplificar e Fundir são retomadas.

Derramamento Potencial :Se o grafo, em algum momento, tiver apenas vértices de grau $\geq k$, esses são marcados para derramamento, pois provavelmente serão representados em memória. Mas, neste ponto, eles são apenas removidos do grafo e armazenados na pilha.

Selecionar: Esta fase remove os vértices da pilha e tenta colorí-los a medida que reconstrói o grafo original. Este processo não garante que o grafo será $k$-colorível. Se os vértices adjacentes já estiverem coloridos com $k$ cores, o vértice atual, não poderá ser colorido e será um derramamento real. Este processo continuará até que não hajam mais vértices na pilha.

Derramamento Real: Em caso da fase Selecionar identificar um derramamento real, o programa é reescrito para buscar o vértice derramado na memória antes de cada utilização e armazená-lo após cada definição. Agora, o algoritmo executará uma nova iteração. Portanto, a execução do algoritmo somente termina quanto em uma iteração não existirem derramamentos.

Desta forma as fases de George-Appel estão organizadas como apresentadas na Figura 1.

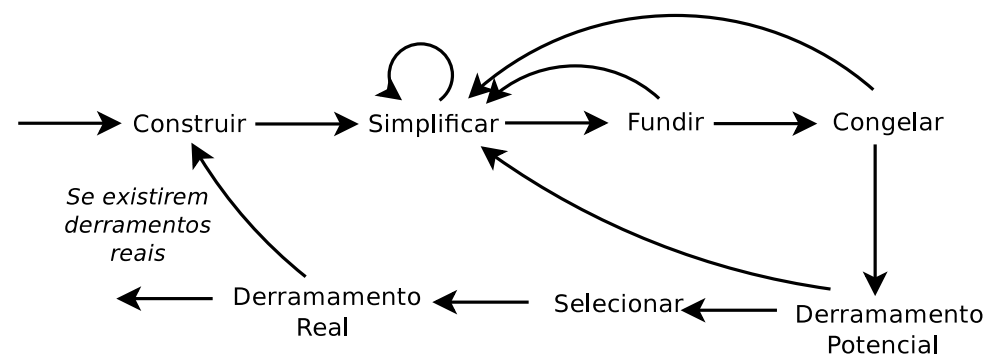

Figura 1. Fases de George-Appel (George \& Appel, 1996; Appel, 1998).

\section{Solução do Problema Utilizando Meta-heurísticas}

Para solucionar o problema da alocação de registradores foram utilizadas duas meta-heurísticas: uma baseada em colônia de formigas e outra baseada em algoritmo heurístico híbrido evolucionário.

Cada meta-heurística deu origem a um algoritmo heurístico, o qual foi utilizado para substituir a fase Selecionar de George-Appel. Portanto, são propostas duas soluções para o problema da alocação de registradores baseada em coloração de grafo. Ambas soluções realizam duas modificações em George-Appel:

1. A fase Selecionar foi substituída pelo algoritmo ColorAnt 3 -RT (Lintzmayer et al., 2011d) ou pelo algoritmo HCA (Galinier \& Hao, 1999), desta forma as duas novas versões de George-Appel possuem uma fase de coloração mais agressiva do que aquela implementada pelo alocador original; e

2. A estratégia utilizada para selecionar valores para representar em memória não é baseada no grau do vértice, mas na quantidade de conflitos.

Inicialmente, as fases clássicas de George-Appel constroem o grafo de interferência e o reduz. Após, uma das meta-heurísticas reconstrói o grafo colorindo-o. E, finalmente, a nova fase Derramamento seleciona um vértice apropriado para ser representado em memória. Portanto, a arquitetura da nova versão do alocador é como apresentada na Figura 2.

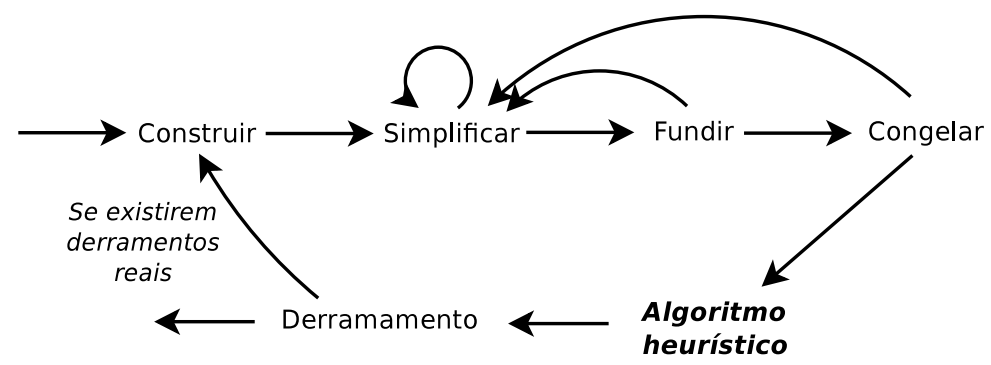

Figura 2. Fases do novo alocador de registradores.

As próximas seções descrevem os algoritmos implementados, os quais deram origem aos alocadores: CARTRA (Lintzmayer et al., 2011b), que utiliza o algoritmo ColorAnt 3 -RT; e HCRA, que utiliza o $H C A$. 


\subsection{O algoritmo colorAnt $_{3}-R T$}

A primeira abordagem utilizada para implementar a fase Selecionar usa um algoritmo heurístico baseado em colônia de formigas artificiais (Dorigo \& Stützle, 2004) com busca local.

Para alcançar tal objetivo foram desenvolvidas três versões de ColorAnt-RT. A primeira versão se mostrou capaz de obter soluções satisfatórias, isto relativo à redução da quantidade de conflitos (Lintzmayer et al., 2011c). Porém, novas investigações demonstraram que mudanças na maneira de depositar feromônio ocasionam uma menor quantidade de conflitos, impulsionando o desenvolvimento de duas novas versões de ColorAnt-RT (Lintzmayer et al., 2011a,d). CARTRA utiliza a melhor versão de ColorAnt-RT: ColorAnt 3 -RT (Lintzmayer et al., 2011d).

ColorAnt 3 -RT utiliza como método construtivo para cada formiga, o procedimento chamado de Ant_Fixed_K, que é apresentado no Algoritmo 1 e foi sugerido como um método construtivo para uma versão do ANTCOL para a $k$-PCG (Costa \& Hertz, 1997).

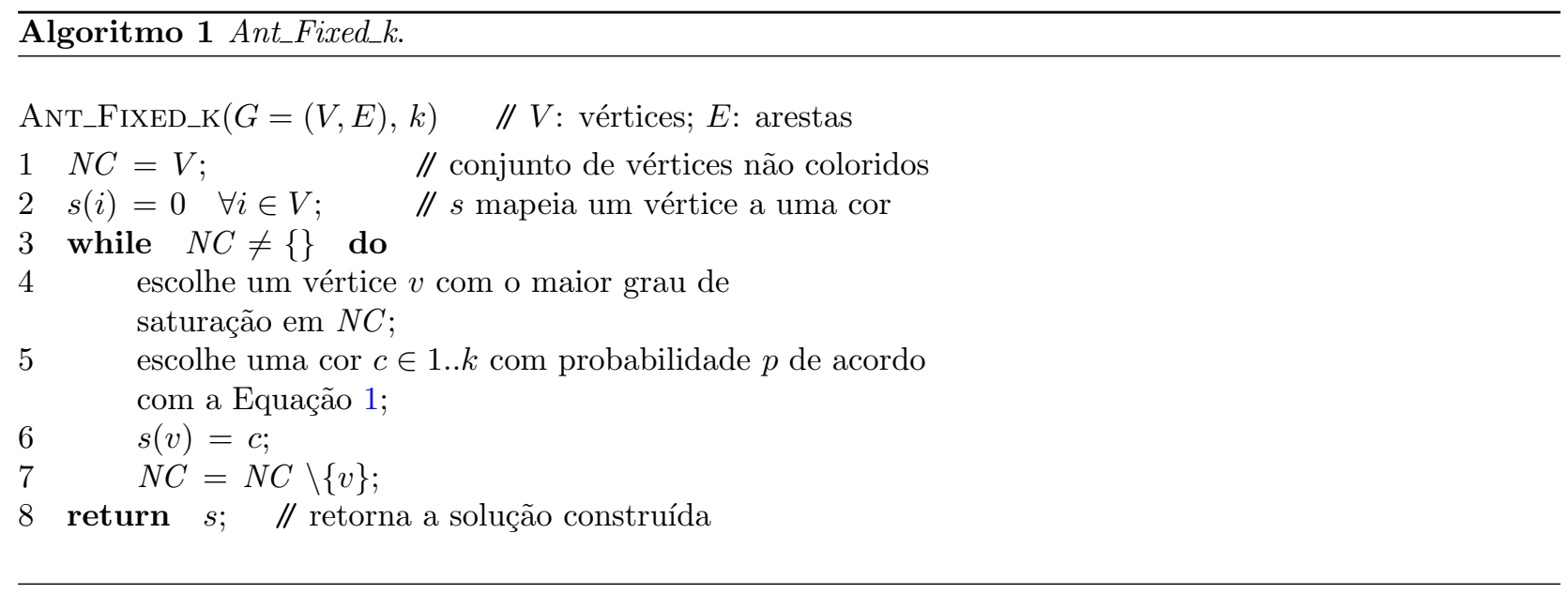

Em cada etapa da construção da solução, Ant_Fixed_K escolhe um vértice $v$ não colorido que tenha o maior grau de saturação ${ }^{4}$ e uma cor $c$ para atribuir a $v$. A cor $c$ é escolhida com probabilidade $p$, apresentada na Equação 1, que é calculada com base na trilha de feromônio $\tau$, apresentada na Equação 2, e com base na informação heurística $\eta$, apresentada na Equação 3.

$$
p(s, v, c)=\frac{\tau(s, v, c)^{\alpha} \cdot \eta(s, v, c)^{\beta}}{\sum_{i \in\{1, \ldots, k\}} \tau(s, v, i)^{\alpha} \cdot \eta(s, v, i)^{\beta}}
$$

onde $\alpha$ e $\beta$ são parâmetros do algoritmo e controlam a influência dos valores a eles associados na equação, e

$$
\begin{gathered}
\tau(s, v, c)= \begin{cases}\sum_{u \in C_{c}(s)} P_{u v} & \text { se } C_{c}(s)=\{\} \\
\left|C_{c}(s)\right| & \text { caso contrário }\end{cases} \\
\eta(s, v, c)=\frac{1}{\left|N_{C_{c}(s)}(v)\right|}
\end{gathered}
$$

onde $P_{u v}$ é a trilha de feromônio entre os vértices $u$ e $v \cdot C_{c}(s)$ é a classe de cor $c$ da solução $s$, isto é, o conjunto de vértices já coloridos, com $c$ nesta solução e $N_{C_{c}(s)}(v)$ são os vértices $x \in C_{c}(s)$ adjacentes a $v$ na solução $s$.

A trilha de feromônio, armazenada na matriz $P_{|V| \times|V|}$, é inicializada com "1" para cada aresta entre vértices não adjacentes e com "0" para cada aresta entre vértices adjacentes. A sua atualização implica na persistência da trilha atual por um fator $\rho$, o que significa que $1-\rho$ é a taxa de evaporação utilizando a experiência obtida pelas formigas. Arestas entre pares de vértices não adjacentes são reforçados quando recebem a mesma cor. A evaporação é apresentada na Equação 4 e a forma geral de depósito de feromônio é apresentada na Equação 5.

$$
P_{u v}=\rho P_{u v} \quad \forall u, v \in V
$$

\footnotetext{
4 Grau de saturação é o número de cores diferentes que já foram atribuídas aos vértices adjacentes de um vértice.
} 


$$
P_{u v}=P_{u v}+\frac{1}{f(s)} \quad \forall u, v \in C_{c}(s) \mid(u, v) \notin E, c=1 . . k
$$

onde $C_{c}(s)$ é o conjunto de vértices coloridos com $c$ na solução $s$ e $f$ é a função objetivo, que retorna o número de arestas conflitantes da solução.

O reforço da trilha de feromônio é como segue. A melhor formiga do ciclo $\left(s^{\prime}\right)$ e a melhor formiga da solução $\left(s^{*}\right)$ intercambiavelmente reforçam a trilha de feromônio. Inicialmente, $s^{\prime}$ reforça mais frequentemente que $s^{*}$. A troca gradual nesta frequência é feita com base no número máximo de ciclos do algoritmo: a cada intervalo de um número fixo de ciclos, a quantidade de ciclos em que $s^{*}$ reforça a trilha (em vez de $s^{\prime}$ ) é aumentado em uma unidade. Nas versões anteriores esse processo possui diferenças: em ColorAnt 1 -RT, além das soluções de todas as formiga do ciclo serem utilizadas para atualizar a trilha de feromônio, $s^{\prime}$ e $s^{*}$ também depositam feromônio; e em Color $A n t_{2}-R T$, apenas $s^{\prime}$ e $s^{*}$ são utilizadas para atualizar a trilha de feromônio, porém não intercambiavelmente. Color $A n t_{3}-R T$ é apresentado no Algoritmo 2.

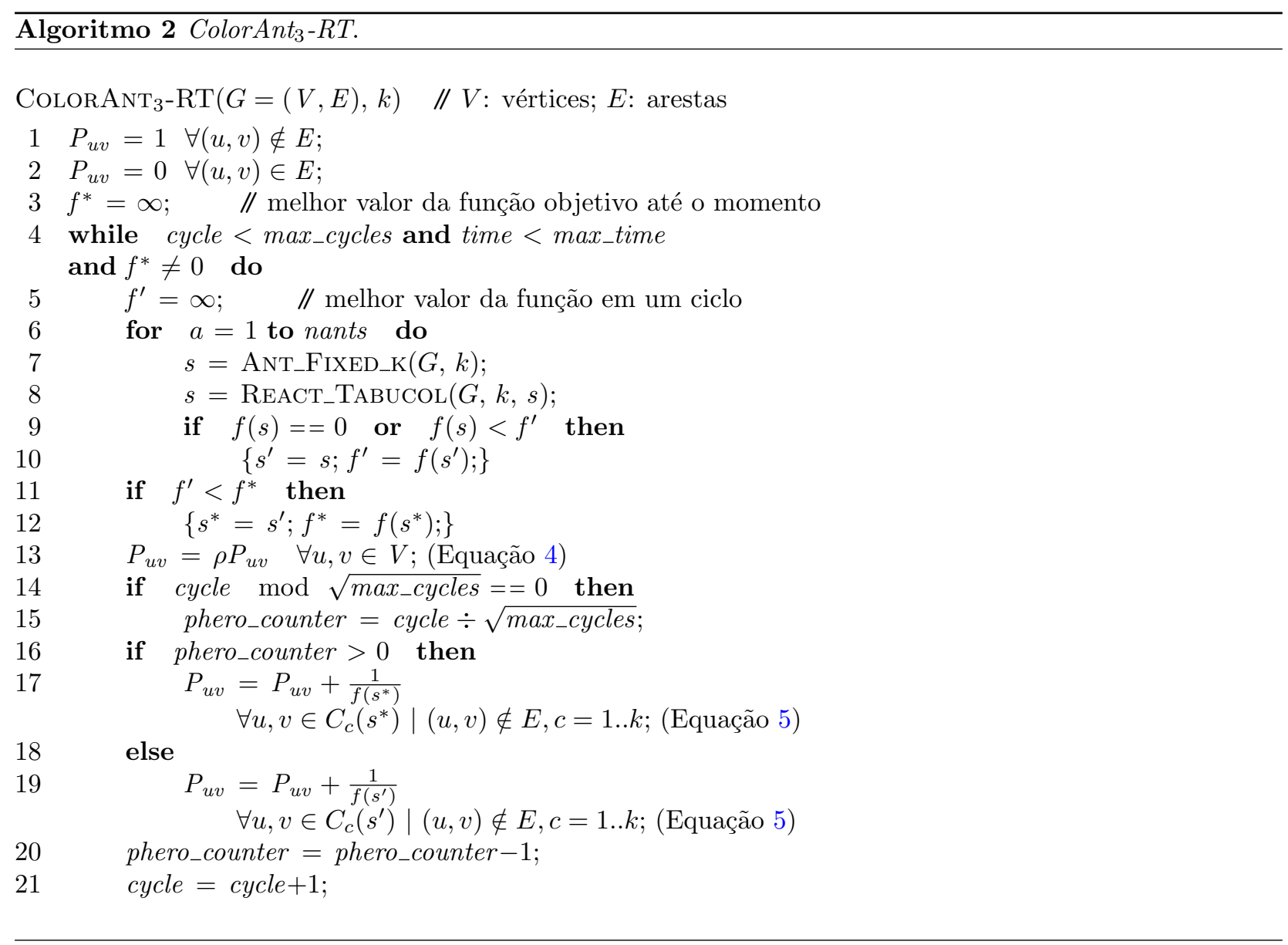

Color $A_{n} t_{3}-R T$ utiliza um método de busca local para melhorar a qualidade dos resultados de sua solução: a busca tabu reativa React-Tabucol (RT) (Blöchliger \& Zufferey, 2008) que é aplicada a todas as formigas em cada ciclo. Em Color $A n t_{1}-R T$ e Color $A n t_{2}-R T$ a busca local é aplicada apenas na melhor formiga do ciclo. A busca tabu reativa será detalhada em uma seção posterior

\subsection{O algoritmo $H C A$}

A segunda abordagem utilizada para implementar a fase Selecionar usa um algoritmo heurístico híbrido evolucionário (Hybrid Coloring Algorithm - HCA) baseado em busca local e um operador de crossover altamente especializado (Galinier \& Hao, 1999).

Normalmente, um algoritmo híbrido evolucionário começa com uma população e repete um processo iterativo por um certo número de gerações: em duas configurações dessa população (pais) o operador de crossover é aplicado para gerar uma nova configuração (filho), na qual a busca local será aplicada de forma a melhorá-la antes que ela seja devolvida à população (ao invés de haver uma mutação).

O HCA é como apresentado no Algoritmo 3. Este trabalha com uma população fixa de tamanho $p$ e funciona conforme descrito a seguir. Uma população inicial é construída de acordo com o Algoritmo 4 . A cada geração, duas configurações pais são escolhidas aleatoriamente pelo método Escolher_Pais e a elas são 
aplicado o operador de crossover. A configuração filha gerada é melhorada pela aplicação de uma busca local, a Tabucol ${ }_{H C A}$, por um número fixo de $L$ iterações antes que ela seja incluída novamente na população, substituindo o pior dos pais que a geraram.

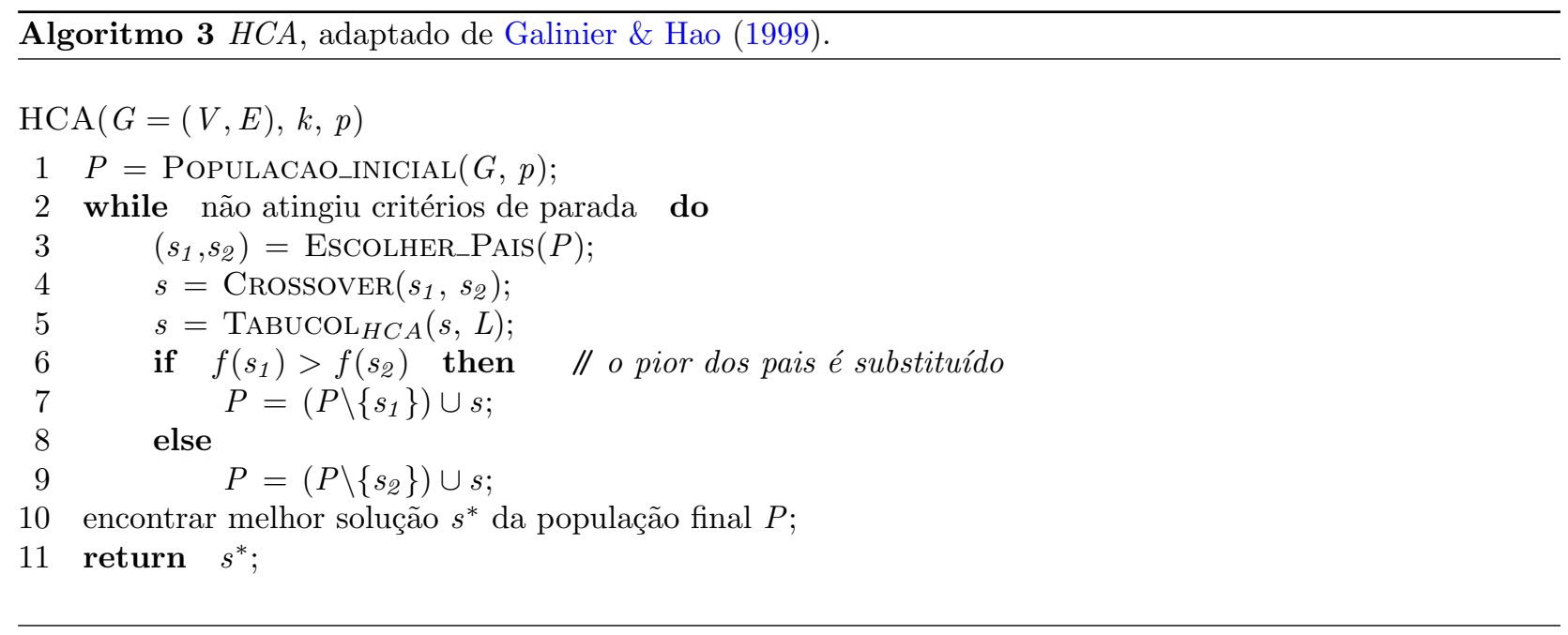

Galinier \& Hao (1999) desenvolveram uma nova classe de operadores de crossover, e utilizaram o Greedy Partition Crossover (GPX) no HCA. Este operador funciona construindo sucessivamente as $k$ classes de cores do filho. A cada cor $c$, um dos pais é escolhido (alternadamente) e neste é escolhida a classe de maior número de vértices para se tornar a classe $C_{c}$ do filho. Os vértices dessa classe são removidos de ambos os pais e, ao final, os vértices ainda não coloridos recebem cores aleatoriamente. O operador de crossover GPX é apresentado no Algoritmo 5, no qual $C_{i}^{A}$ representa a classe de cores $C_{i}$ do pai $A$.

A diversidade da população é calculada como sendo a média das distâncias entre todos os indivíduos. A distância entre duas soluções é o número de modificações que devem ser feitas em uma para que ela fique igual à outra. Por exemplo, dado um grafo com 3 vértices, seja uma solução $s_{1}=\{(0,1),(1,2),(2,1)\}$ (ou seja, o vértice 0 está colorido com a cor 1 , o vértice 1 está colorido com a cor 2 e o 2 está colorido com a cor 1 ) e outra solução $s_{2}=\{(0,1),(1,2),(2,2)\}$, a distância entre $s_{1}$ e $s_{2}$ é 1 , pois basta trocar a cor do vértice 2 .

\subsection{A busca local}

A busca local utilizada por Color Ant $t_{3}-R T$ e $H C A$ é um algoritmo do tipo busca tabu (Tabucol) que foi criado inicialmente por Hertz \& Werra (1987) e vem sendo utilizado em vários trabalhos por ser o algoritmo mais simples, rápido e eficiente entre os melhores procedimentos de busca local (Blöchliger \& Zufferey, 2008). Galinier \& Hao (1999) apresentaram uma versão melhorada deste algoritmo, e é esta versão, Tabucol $_{H C A}$, que é utilizada por $H C A$.

A busca local Tabucol é como descrita a seguir. Dados a função objetivo $f$ que retorna o número de arestas conflitantes, um espaço de soluções $S$ onde cada solução é formada por $k$ classes de cores e todos os vértices estão coloridos (provavelmente com arestas conflitantes) e uma solução inicial $s_{0} \in S, f$ deve ser minimizada sobre $S$. A cada iteração, a melhor solução vizinha é escolhida para substituir a solução atual. Uma solução vizinha é obtida movendo um vértice $v$ de sua classe de cor atual $\left(C_{s(v)}\right)$ para uma classe nova $C_{c}$, esse movimento é representado por $(v, c)$. O vértice $v$ deve ser conflitante com pelo menos um vértice que pertença à sua classe. Quando o movimento $(v, c)$ ocorre, o par $(v, s(v))$ é classificado como tabu pelas próximas $t l$ iterações, garantindo que $v$ não volte a pertencer à classe de cores $C_{s(v)}$ neste período.

A busca gera então uma sequência $s_{1}, s_{2}, \ldots$ de soluções em $S$, na qual $s_{i+1}$ é vizinha de $s_{i}$ e deve ser gerada por um movimento não-tabu e possuir o menor número de conflitos entre as possíveis soluções vizinhas de $s_{i}$, a não ser que ela leve a um valor de função objetivo melhor do que o melhor encontrado até o momento durante a busca (critério de aspiração).

O parâmetro $t l$ é chamado de tabu tenure, ou, algumas vezes, de comprimento da lista tabu. Normalmente é utilizado um esquema dinâmico de tabu tenure, cujo valor depende da solução atual e do movimento que foi executado. O tabu tenure dinâmico é dado por $t l=\alpha f(s)+\operatorname{RANDOM}(A)$, onde $A$ e $\alpha$ são parâmetros passados ao algoritmo. O ajuste do tabu tenure depende de como a função objetivo evolui durante a busca. Três parâmetros auxiliam nessa atualização: $\varphi$ (frequência), $\eta$ (incremento) e $\delta$ (limiar). A cada $\varphi$ iterações 

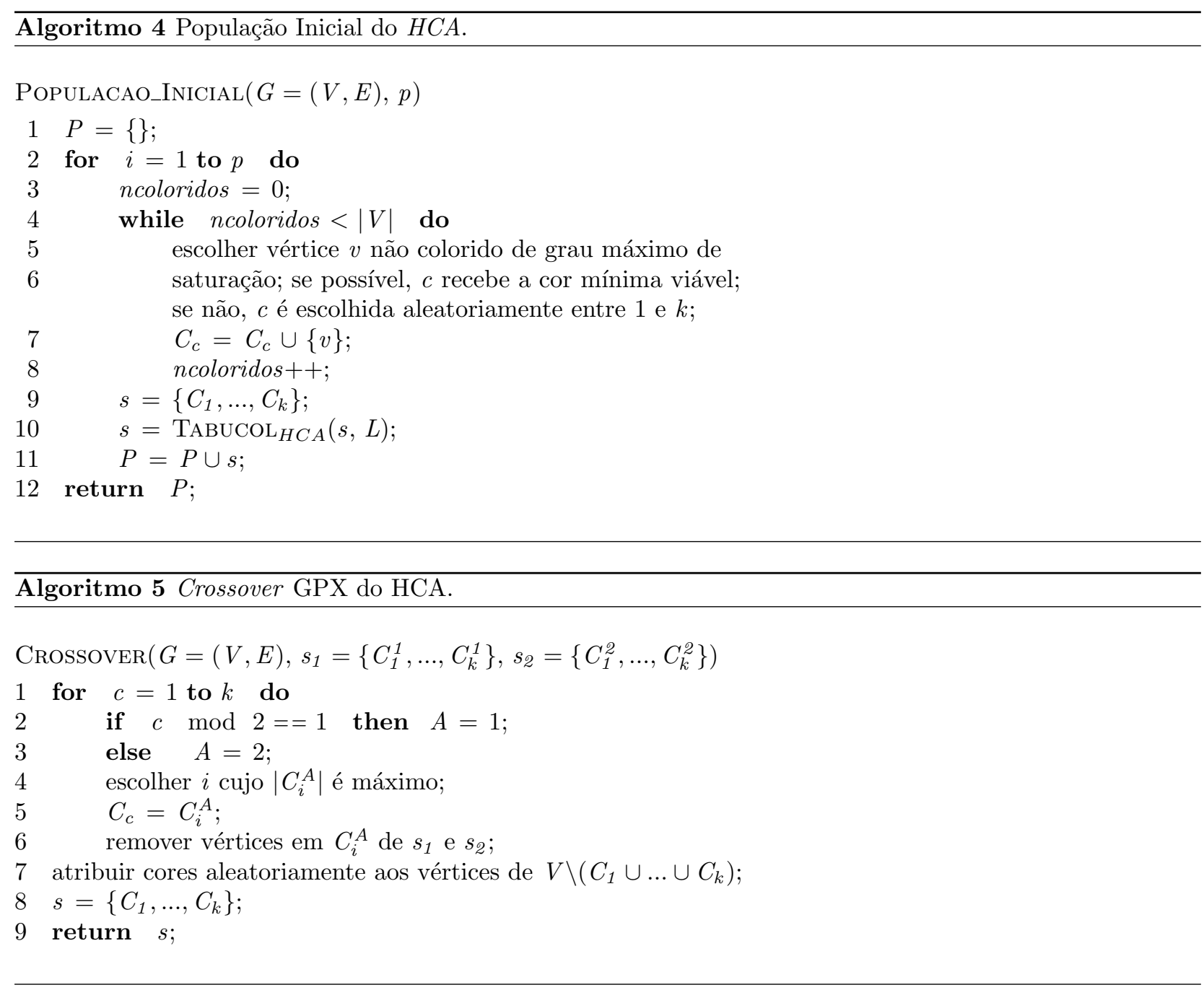

determina-se $\Delta$, que é a diferença entre os valores máximo e mínimo que a função objetivo atingiu nas últimas $\varphi$ iterações. O novo valor de $t l$ será:

$$
t l= \begin{cases}t l+\eta & \text { se } \Delta \leq \delta \\ t l-1 & \text { caso contrário }\end{cases}
$$

Tabucol $_{H C A}$ agora nomeia o algoritmo com uso do tabu tenure dinâmico, enquanto React-Tabucol nomeia o algoritmo com uso do tabu tenure reativo, cujo valor é determinado com base no histórico de busca. Portanto, a diferença entre os dois está no mecanismo de atualização de $t l$. Enquanto em React-Tabucol tl é atualizado de acordo com o esquema tabu reativo, em Tabucol $_{H C A} t l$ é atualizado de acordo com um esquema dinâmico. Tabucol é apresentado no Algoritmo 6.

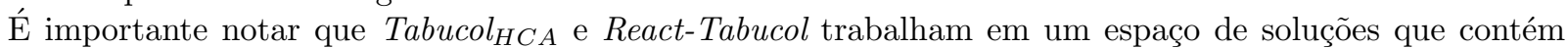
$k$-colorações (próprias ou impróprias). Assim, qualquer que seja a solução inicial $s_{0}$ fornecida ao algoritmo, ela deve obedecer a esta "restrição".

\subsection{A fase derramamento}

George e Appel demonstraram que o critério conservativo proposto por Briggs et al. (1994) poderia ser flexibilizado para permitir uma fase de fusão mais agressiva sem a introdução de representações em memória adicionais. Além disso, eles descrevem um algoritmo que preserva os vértices fundidos encontrados antes de derramamentos potenciais serem descobertos. CARTRA e HCRA utilizam a mesma estratégia para fundir vértices, mas utilizam uma abordagem diferente para escolher os vértices do grafo que serão representados em memória.

Em George-Appel, se não há oportunidade para Simplificar ou Congelar, o vértice será derramado. Neste caso, a fase Derramamento Potencial irá calcular as prioridades de derramamento para cada vértice utilizando a Equação 6. 


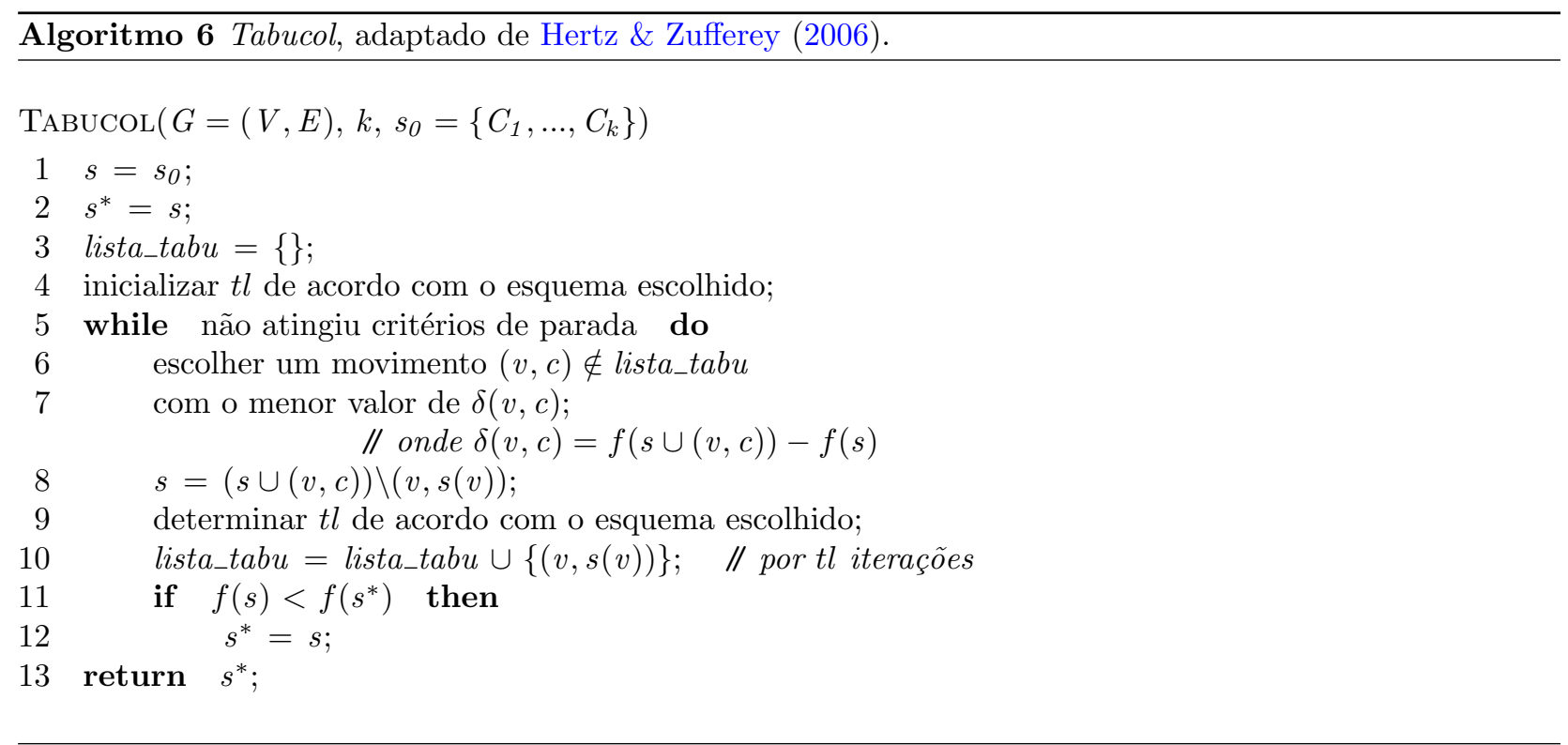

$$
P_{n}=\frac{\left(u_{\operatorname{sos}}+\operatorname{def} s_{f}\right)+10 \times\left(\text { usos }_{d}+\operatorname{def} s_{d}\right)}{g r a u}
$$

onde $u s o s_{f}$ é o conjunto de temporários que o vértice utiliza fora de um laço; def $s_{f}$ é o conjunto de temporários que ele define fora de um laço; ssos $_{d}$ é o conjunto de temporários que ele usa dentro de um laço; def $s_{d}$ é o conjunto de temporários que ele define dentro de um laço, e grau é o número de arestas incidentes no vértice.

$\mathrm{O}$ vértice que tem a prioridade mais baixa será selecionado para ser derramado em primeiro lugar. A abordagem de George e Appel é uma aproximação otimista: o vértice removido do grafo não interfere com qualquer um dos outros vértices do grafo.

CARTRA e HCRA utilizam uma abordagem diferente para selecionar um vértice para derramamento. Uma vez que o grafo resultante dado pelo algoritmo heurístico pode ter arestas conflitantes, a fase Derramamento seleciona o vértice com mais frequência no conjunto de vértices conflitantes, em outras palavras, o vértice de cor $c$ que tem o maior número de arestas incidentes conflitantes é removido do grafo e considerado como um derramamento real. Se houver derramamento real, o programa será reescrito como em George-Appel, e então uma nova iteração será realizada.

\section{Resultados Experimentais}

Para avaliar a qualidade dos resultados obtidos pelas meta-heurísticas utilizadas foram implementados e comparados os alocadores de registradores: George-Appel, CARTRA e HCRA. Tal implementação foi realizada em um compilador que gera código para a arquitetura Intel IA32. Além disto, os compiladores implementados foram executados em um computador Intel Xeon E5620 de 2,40 GHz, 8 GB de memória RAM executando o sistema operacional Rocks Cluster Linux.

O conjunto de programas utilizado na avaliação é composto de onze programas de SNU-RT ${ }^{5}$ e do programa Queens. Para cada programa, cada alocador foi executado 10 vezes para medir o desempenho, sendo que os dados apresentados são as médias entre as 10 execuções. Os parâmetros de CARTRA foram escolhidas de uma forma relativamente arbitrária, são eles: nants $=80, \alpha=3, \beta=16, \rho=0.7$ e max_cycles $=625$. Em geral, para instâncias pequenas os melhores resultados são obtida para $\alpha$ menor que $\beta$. A busca tabu foi limitada por um máximo de 300 ciclos. CARTRA pára se não há melhoria na redução do número de arestas conflitantes para mais de max_cycles/4. HCRA utiliza os parâmetros $p$ fixado em 10 e $L$ fixado em 2000 ciclos.

\subsection{Derramamentos e buscas}

O objetivo principal de cada alocador de registradores é minimizar a quantidade de dados representados em memória (derramamentos) e consequentemente a quantidade de dados que precisam ser buscados da memória (buscas). Como pode ser observado pelos resultados na Tabela 1, CARTRA e HCRA superam George-Appel.

\footnotetext{
5 http://www.cprover.org/goto-cc/examples/snu.html
} 
Tabela 1. Desempenho de CARTRA, HCRA e George-Appel. Para cada alocador duas colunas são apresentadas: a quantidade de dados representados em memória (Derr.) e a quantidade de dados que o programa necessita buscar da memória (Buscas).

\begin{tabular}{lcccccc}
\hline \multirow{2}{*}{ Programa } & \multicolumn{2}{c}{ CARTRA } & \multicolumn{2}{c}{ HCRA } & \multicolumn{2}{c}{ George-Appel } \\
\cline { 2 - 7 } & Derr. & Buscas & Derr. & Buscas & Derr. & Buscas \\
\hline Binary Search & $\mathbf{1 8 , 5}$ & $\mathbf{1 9 , 0}$ & $\mathbf{1 8 , 3}$ & $\mathbf{1 9 , 5}$ & 126 & 142 \\
FFT & $\mathbf{5 5 , 1}$ & $\mathbf{9 1 , 5}$ & $\mathbf{5 6 , 1}$ & $\mathbf{8 4 , 6}$ & 68 & 103 \\
Fibonacci & $\mathbf{4 , 5}$ & $\mathbf{3 , 6}$ & 5,5 & $\mathbf{4 , 3}$ & 5 & 5 \\
FIR & $\mathbf{5 2 , 9}$ & $\mathbf{1 3 9 , 4}$ & $\mathbf{5 4 , 3}$ & $\mathbf{1 4 4 , 4}$ & 68 & 128 \\
Insert Sort & $\mathbf{1 3 , 2}$ & $\mathbf{3 2 , 9}$ & $\mathbf{1 5 , 6}$ & $\mathbf{3 5 , 0}$ & 21 & 39 \\
Jfdctint & 94,4 & 186,6 & 98,5 & 193,1 & $\mathbf{8 7}$ & $\mathbf{1 6 5}$ \\
LMS & $\mathbf{8 6 , 7}$ & $\mathbf{1 3 7 , 2}$ & $\mathbf{1 0 8 , 2}$ & $\mathbf{1 5 6 , 4}$ & 136 & 186 \\
Quick sort & $\mathbf{4 1 , 5}$ & $\mathbf{1 0 3 , 2}$ & $\mathbf{4 3 , 7}$ & $\mathbf{1 0 5 , 4}$ & 171 & 277 \\
Queens & $\mathbf{1 7 , 5}$ & $\mathbf{4 4 , 0}$ & 18,0 & $\mathbf{2 4 , 0}$ & 18 & 44 \\
Qurt & $\mathbf{2 9 , 4}$ & $\mathbf{4 0 , 7}$ & $\mathbf{3 1 , 3}$ & $\mathbf{4 4 , 0}$ & 95 & 126 \\
Select & $\mathbf{4 5 , 4}$ & $\mathbf{8 8 , 1}$ & $\mathbf{4 8 , 1}$ & $\mathbf{9 0 , 6}$ & 191 & 265 \\
Sqrt & $\mathbf{9 , 1}$ & $\mathbf{1 2 , 6}$ & $\mathbf{9 , 7}$ & $\mathbf{1 4 , 0}$ & 12 & 19 \\
\hline
\end{tabular}

CARTRA e HCRA tendem a representar em memória menos temporários, pelo fato de encontrarem uma melhor coloração para o grafo de interferência, de maneira que o número de arestas com conflito seja mínimo. Neste caso, CARTRA e HCRA são capazes de utilizar uma quantidade menor de registradores por função, o que minimiza o seu custo pelo fato de reduzir a quantidade de instruções de acesso a memória, instruções que tipicamente têm um maior custo quando comparadas com outras classes de instruções. Além disso, como CARTRA e HCRA tendem a derramar uma quantidade menor de temporários e utilizar uma quantidade menor de registradores, eles são capazes de encontrar mais oportunidades para fundir vértices do grafo, e assim representar dois temporários em um único registrador.

CARTRA consegue reduções de $2,78 \%$ a $85,32 \%$ na quantidade de derramamentos. Apenas para um único programa George-Appel obteve melhores resultados, a saber: Jfdctint. Além disso, CARTRA atinge reduções de $11,17 \%$ a $86,62 \%$ na quantidade de buscas. No entanto, para buscas, o algoritmo de GeorgeAppel, obteve melhores resultados para FIR e Jfdctint. Em resumo, apenas para um programa CARTRA não conseguiu um desempenho superior a George-Appel.

HCRA consegue reduções de 17,50\% a 85,48\% na quantidade de derramamentos, sendo que para Queens a quantidade ficou estável e George-Appel obteve melhores resultados para Fibonacci e Jfdctint. Para dois programas HCRA não conseguiu desempenho superior a George-Appel.

Na média, a quantidade de derramamentos é 39,02, 43,11 e 83,17 para CARTRA, HCRA e GeorgeAppel, respectivamente. Para buscas esses números são 74,90, 76,28 e 124,92. Isto demonstra que a estratégia utilizada tanto por CARTRA quanto por HCRA é a melhor abordagem para minimizar o número de derramamentos e de buscas.

Estes resultados demonstram que embora todos os programas derramem alguns temporários, o número de instruções de armazenamento é similar a quantidade de buscas, o que sugere que os vértices que foram derramados possuem poucas definições e usos. Além disto, os resultados também demonstram que utilizar um algoritmo heurístico é uma boa opção para minimizar a quantidade de dados representados em memória.

\subsection{Convergência}

É importante observar que os três alocadores utilizam um algoritmo iterativo, isto é, o alocador de registradores somente termina quando não existem derramamentos (ver Figura 1 - Se existirem derramamentos reais). Portanto, a finalização do algoritmo somente ocorre se existir a possibilidade de todos os valores representados no grafo de interferência serem armazenados em registradores, em outras palavras, se o grafo de interferência for $k$-colorível.

A Tabela 2 apresenta o padrão médio de convergência de cada alocador de registradores. Para cada grafo de interferência é apresentada uma lista contendo a quantidade de derramamentos em cada iteração do algoritmo e o tamanho da lista (indicando a quantidade de iterações necessárias para que o grafo de interferência seja $k$-colorível).

Os resultados demonstram que CARTRA e HCRA encontram uma coloração que elimina a quantidade de derramamentos em menos iterações (reconstruções) do que George-Appel. Em geral, o número de iterações necessárias por George-Apple é de até 5 vezes a quantidade necessária por CARTRA ou HCRA. 
Tabela 2. Convergência.

\begin{tabular}{|c|c|c|c|c|}
\hline \multicolumn{2}{|c|}{ Programa } & \multicolumn{3}{|c|}{ Alocador } \\
\hline Nome & Função & CARTRA & HCRA & George-Appel \\
\hline $\begin{array}{l}\text { Binary } \\
\text { Search }\end{array}$ & $\begin{array}{l}\text { bs } \\
\text { main }\end{array}$ & & & $\begin{array}{c}{[9,3,1,1,1,2,1,1,1,0](10)} \\
{[18,16,16,16,16,0](6)}\end{array}$ \\
\hline FFT & $\begin{array}{l}\text { sin } \\
\text { init_w } \\
\text { fft } \\
\text { main }\end{array}$ & $\begin{array}{l}{[5,1,0](3)} \\
{[5,0](2)} \\
{[22,0](2)} \\
{[4,2,0](3)}\end{array}$ & $\begin{array}{c}{[5,2,0](3)} \\
{[\mathbf{6}, \mathbf{1}, \mathbf{3}](\mathbf{3})} \\
{[21,2,0](3)} \\
{[\mathbf{4}, \mathbf{2}, \mathbf{0}](\mathbf{3})}\end{array}$ & $\begin{array}{c}{[\mathbf{5 , 0} \mathbf{0}(\mathbf{2})} \\
{[6,3,3,1,1,1,1,0](8)} \\
{[18,3,0](3)} \\
{[4,2,2,2,0](5)} \\
\end{array}$ \\
\hline Fibonacci & & $\begin{array}{c}{[2,1,0](3)} \\
{[0](1)}\end{array}$ & $\begin{array}{c}{[2,1,0](3)} \\
{[0](1)}\end{array}$ & \\
\hline FIR & $\begin{array}{l}\text { sin } \\
\text { sqrt } \\
\text { fir_filter } \\
\text { gaussian } \\
\text { main }\end{array}$ & $\begin{array}{c}6,0](2) \\
{[\mathbf{8}, \mathbf{1}, \mathbf{0}](\mathbf{3})} \\
{[\mathbf{8 , 1}, \mathbf{0}](\mathbf{3})} \\
{[\mathbf{5 , 0 ] ( 2 )}} \\
{[8,0](2)} \\
\end{array}$ & $\begin{array}{c}5,0](2) \\
{[7,0](2)} \\
{[8,2,0](3)} \\
{[5,0](2)} \\
{[7,0](2)} \\
\end{array}$ & $\begin{array}{c}{[6,0](2)} \\
{[8,1,1,0](4)} \\
{[9,1,0](3)} \\
{[5,1,1,2,1,1,0](7)} \\
{[\mathbf{7 , 0}](\mathbf{2})} \\
\end{array}$ \\
\hline Insert Sort & main & {$[8,0](2)$} & {$[9,0](2)$} & {$[7,7,8,1,0](5)$} \\
\hline Jfdctint & & $\begin{array}{c}{[33,0](2)} \\
{[5,1,1,0](4)}\end{array}$ & $\begin{array}{c}{[39,0](2)} \\
{[5,2,1,1,1,1,0](7)}\end{array}$ & $\begin{array}{c}{[24,0](2)} \\
{[6,0](2)}\end{array}$ \\
\hline LMS & $\begin{array}{l}\text { sqrt } \\
\text { sin } \\
\text { gaussian } \\
\text { lms } \\
\text { main }\end{array}$ & $\begin{array}{c}{[8,0](2)} \\
{[6,0](2)} \\
{[5,0](2)} \\
{[22,3,1,0](4)} \\
{[17,0](2)} \\
\end{array}$ & $\begin{array}{c}{[7,0](2)} \\
{[5,0](2)} \\
{[5,0](2)} \\
{[23,4,1,0](4)} \\
{[16,0](2)}\end{array}$ & $\begin{array}{c}{[8,1,1,0](4)} \\
{[\mathbf{6 , 0}] \mathbf{( 2 )}} \\
{[5,1,1,2,1,1,0](7)} \\
{[18,10,9,10,5,3,1,0](8)} \\
{[15,2,1,1,0](5)}\end{array}$ \\
\hline $\begin{array}{l}\text { Quick } \\
\text { Sort }\end{array}$ & & $\begin{array}{c}{[15,0](2)} \\
{[2,0](2)}\end{array}$ & $\begin{array}{c}{[16,2,1,0](4)} \\
{[2,0](2)}\end{array}$ & $\begin{array}{c}{[16,2,2,2,2,2,0](7)} \\
{[3,0](2)}\end{array}$ \\
\hline Queens & $\begin{array}{l}\text { print } \\
\text { tree } \\
\text { main }\end{array}$ & $\begin{array}{c}{[6,0](2)} \\
{[7,0](2)} \\
{[1,0](2)}\end{array}$ & $\begin{array}{c}{[6,1,0](3)} \\
7,0](2) \\
{[\mathbf{1}, \mathbf{0}](\mathbf{2})}\end{array}$ & $\begin{array}{r}{[8,0](2)} \\
{[\mathbf{6 , 0}](\mathbf{2})} \\
{[\mathbf{1 , 0}](\mathbf{2})} \\
\end{array}$ \\
\hline Qurt & $\begin{array}{l}\text { sqrt } \\
\text { qurt } \\
\text { main } \\
\end{array}$ & $\begin{array}{c}{[7,0](2)} \\
{[11,2,0](3)} \\
{[2,0](2)} \\
\end{array}$ & $\begin{array}{c}{[7,0](2)} \\
{[11,4,1,0](4)} \\
{[2,0](2)}\end{array}$ & $\begin{array}{c}{[\mathbf{7 , 0}](\mathbf{2})} \\
{[11,2,3,2,3,1,1,1,0](9)} \\
{[10,9,9,9,9,0](5)} \\
\end{array}$ \\
\hline Select & $\begin{array}{l}\text { select } \\
\text { main }\end{array}$ & $\begin{array}{c}{[16,0](2)} \\
{[2,0](2)}\end{array}$ & $\begin{array}{c}{[16,1,1,0](4)} \\
{[2,0](2)}\end{array}$ & $\begin{array}{l}{[19,1,6,4,5,4,3,2,0](9)} \\
{[21,20,20,20,20,0](6)}\end{array}$ \\
\hline Sqrt & $\begin{array}{l}\text { sqrt } \\
\text { main }\end{array}$ & $\begin{array}{c}{[7,0](2)} \\
{[0](1)}\end{array}$ & $\begin{array}{c}{[7,0](2)} \\
{[0](1)}\end{array}$ & $\begin{array}{c}{[7,0](2)} \\
{[0](1)}\end{array}$ \\
\hline
\end{tabular}

A abordagem de George-Appel para selecionar valores para serem representados em memória ocasiona uma diminuição gradual na quantidade de derramamentos até que esta alcance o valor zero. Por outro lado, qualquer versão que utilize uma fase meta-heurística conduz a uma convergência mais rápida.

Em geral CARTRA e HCRA não necessitam de mais de quatro iterações, enquanto George-Appel necessita em muitos casos, de pelo menos cinco iterações. Além disso, em George-Appel alguns ciclos não reduzem a quantidade de derramamentos resultando em mais iterações.

\subsection{Tamanho do código}

A Tabela 3 apresenta a quantidade média de instruções Assembly e o tamanho médio do código em bytes para cada programa.

A redução da quantidade de instruções Assembly varia entre 1,53\% e 35,35\% para CARTRA e 2,79\% e $35,35 \%$ para HCRA. Isto ocasiona uma redução no tamanho do código entre 1,38\% e 20,56\% para CARTRA e HCRA. Comparando CARTRA com George-Appel é possível perceber que CARTRA não ultrapassa o desempenho de George-Appel apenas para o programa Jfdctint. Porém, HCRA não ultrapassa GeorgeAppel para três programas, a saber: Fir, Jfdctint e Queens.

A redução do tamanho do código é importante para sistemas que utilizam microprocessadores embarcados, devido ao fato de seus componentes consistirem geralmente de recursos limitados, seja em poder computacional 
Tabela 3. Tamanho do Código (IA: Instruções Assembly, TC: Tamanho de código em bytes).

\begin{tabular}{lcccccc}
\hline \multirow{2}{*}{ Programa } & \multicolumn{2}{c}{ CARTRA } & \multicolumn{2}{c}{ HCRA } & \multicolumn{2}{c}{ George-Appel } \\
\cline { 2 - 7 } & IA & TC & IA & TC & IA & TC \\
\hline Binary Search & $\mathbf{5 2 3}$ & $\mathbf{4 8 8 4}$ & $\mathbf{5 2 3}$ & $\mathbf{4 8 8 4}$ & 809 & 6148 \\
FFT & $\mathbf{7 9 7}$ & $\mathbf{6 2 7 6}$ & 809 & 6320 & 840 & 6412 \\
Fibonacci & $\mathbf{4 3}$ & $\mathbf{8 6 0}$ & $\mathbf{4 3}$ & $\mathbf{8 6 0}$ & 47 & 872 \\
FIR & $\mathbf{1 7 3 2}$ & $\mathbf{1 5 1 0 4}$ & 1801 & 15208 & 1759 & 15192 \\
Insert Sort & $\mathbf{3 3 7}$ & $\mathbf{3 4 9 6}$ & 348 & 3508 & 358 & 3564 \\
Jfdctint & 1525 & 10276 & 1516 & 10704 & $\mathbf{1 5 0 1}$ & $\mathbf{1 0 2 0 4}$ \\
LMS & $\mathbf{8 6 7}$ & 6352 & 898 & $\mathbf{6 3 3 6}$ & 1000 & 6996 \\
Quick sort & $\mathbf{1 3 1 4}$ & $\mathbf{1 2 1 3 2}$ & 1355 & 12212 & 1676 & 13840 \\
Queens & $\mathbf{3 9 8}$ & $\mathbf{3 7 4 0}$ & 401 & 3748 & $\mathbf{3 9 8}$ & $\mathbf{3 7 4 0}$ \\
Qurt & $\mathbf{8 0 2}$ & $\mathbf{7 4 9 6}$ & 836 & 7536 & 981 & 8180 \\
Select & $\mathbf{1 2 1 6}$ & $\mathbf{1 1 3 9 2}$ & 1254 & 11468 & 1618 & 13324 \\
Sqrt & $\mathbf{1 0 8}$ & $\mathbf{1 4 3 6}$ & 113 & 1452 & 119 & 1472 \\
\hline
\end{tabular}

ou em memória. CARTRA e HCRA foram capazes de alcançar este objetivo em um proporção maior que George-Appel, para a maioria dos casos aqui apresentados.

Vale ressaltar que o objetivo tradicional de um compilador é tanto gerar um código que melhore o desempenho do processador, como minimizar o tempo de compilação para um nível aceitável de desempenho do processador. Redes de Sensores Sem Fio (Akyildiz \& Vuran, 2010; Ilyas \& Mahgoub, 2004; Hać, 2003), por outro lado, muitas vezes exigem cuidadosa atenção para o armazenamento do programa, restrições de memória e consumo de energia. Tanto CARTRA, quanto HCRA são boas opções para alcançar estes objetivos.

\subsection{Tempo de compilação}

A Tabela 4 apresenta o tempo médio de compilação dos alocadores. Estes resultados demonstram que GeorgeAppel é mais rápido do que CARTRA entre 5,43 a 606,52 vezes, mas apenas entre 1,08 e 3,91 vezes do que HCRA. Além disto, como pode ser observado neste resultados HCRA é mais rápido que CARTRA entre 39,66 e 372,36 vezes.

Tabela 4. Tempo de Compilação (segundos).

\begin{tabular}{lcccccc}
\hline \multirow{2}{*}{ Programa } & \multicolumn{2}{c}{ CARTRA } & \multicolumn{2}{c}{ HCRA } & \multicolumn{2}{c}{ George-Appel } \\
\cline { 2 - 7 } & Média & Desvio & Média & Desvio & Média & Desvio \\
\hline Binary Search & 26,059 & 0,322 & 0,657 & 0,037 & $\mathbf{0 , 1 6 8}$ & $\mathbf{0 , 0 0 1}$ \\
FFT & 43,351 & 4,461 & 0,657 & 0,037 & $\mathbf{0 , 2 1 3}$ & $\mathbf{0 , 0 0 8}$ \\
Fibonacci & 2,431 & 0,483 & $\mathbf{0 , 0 8 7}$ & $\mathbf{0 , 0 2 0}$ & 0,448 & 0,004 \\
FIR & 235,817 & 18,697 & 1,421 & 0,034 & $\mathbf{1 , 3 1 7}$ & $\mathbf{0 , 0 5 3}$ \\
Insert Sort & 22,495 & 7,287 & 0,285 & 0,106 & $\mathbf{0 , 1 1 0}$ & $\mathbf{0 , 0 0 0}$ \\
Jfdctint & 634,870 & 386,634 & 1,705 & 0,360 & $\mathbf{1 , 4 0 2}$ & $\mathbf{0 , 0 4 5}$ \\
LMS & 84,079 & 11,072 & 0,810 & 0,089 & $\mathbf{0 , 3 5 8}$ & $\mathbf{0 , 0 0 2}$ \\
Quick sort & 327,153 & 242,891 & 1,326 & 0,247 & $\mathbf{1 , 1 8 0}$ & $\mathbf{0 , 0 0 0}$ \\
Queens & 21,322 & 3,621 & 0,339 & 0,206 & $\mathbf{0 , 1 1 2}$ & $\mathbf{0 , 0 0 2}$ \\
Qurt & 144,351 & 45,332 & 0,674 & 0,059 & $\mathbf{0 , 2 3 8}$ & $\mathbf{0 , 0 0 6}$ \\
Select & 363,318 & 180,627 & $\mathbf{1 , 3 2 7}$ & $\mathbf{0 , 0 7 9}$ & 1,510 & 0,065 \\
Sqrt & 3,413 & 0,019 & 0,079 & 0,000 & $\mathbf{0 , 0 4 7}$ & $\mathbf{0 , 0 0 8}$ \\
\hline
\end{tabular}

Tais resultados demonstram uma restrição a utilização de CARTRA. Este não é desejável para ser utilizado em um contexto onde o tempo de compilação deve ser reduzido ao máximo, por exemplo, em sistemas dinâmicos. Até mesmo HCRA não é desejável neste contexto. Por outro lado, em um sistema de compilação estática, o tempo consumido durante o processo de compilação não é necessariamente um problema. Desta forma, em compilação estática CARTRA e HCRA são ótimos candidados para gerar código de boa qualidade.

Estes resultados também demonstram a instabilidade do alocador de registradores baseado em colônia de formigas. Este, CARTRA, obteve o desvio padrão muito elevado entre os alocadores. Embora, o tempo de execução do compilador tenha uma variação para HCRA, esta variação é bem menor que CARTRA, mas ainda é superior aquela obtida por George-Appel. Isto ocorre pela natureza de CARTRA e HCRA em utilizarem um algoritmo heurístico, e não um algoritmo exato como George-Appel. 
Um tempo de execução relativamente alto é geralmente um problema em algoritmos baseados em colônia de formigas. Embora estes algoritmos sejam capazes de encontrar soluções satisfatórias para muitos problema, o tempo de execução é um custo que deve ser pago. Assim, muitos pesquisadores utilizam abordagens alternativas evitando algoritmos baseados em colônia de formigas. Algoritmos evolucionários são uma boa alternativa quando o tempo de compilação é um objetivo a ser alcançado, juntamente com um código de boa qualidade.

Por fim, é importante ressaltar a capacidade de CARTRA em reduzir a quantidade de derramamentos, o que elimina a quantidade de ciclos de clock e o tamanho do código, questões que são extremamente importantes em sistemas embarcados. Embora CARTRA tenha um elevado tempo de execução, ele é capaz de alcançar vários objetivos, tais como: reduzir o tamanho do código, reduzir a quantidade de acessos à memória, e consequentemente, reduzir a quantidade de energia consumida. Contudo, quando além destes objetivos desejase um tempo de compilação reduzido a melhor alternativa é utilizar HCRA.

\section{Conclusões}

O problema de alocação de registradores visto como um problema de coloração de grafos foi inicialmente proposto por Chaitin et al. (1981), o qual foi utilizado em um compilador experimental para a máquina IBM 370. Atualmente, versões deste alocador ou alguma derivada deste são utilizadas em compiladores comerciais. Diversos trabalhos melhoraram o trabalho de Chaitin et al. (Bergner et al., 1997; Bernstein et al., 1989). O projeto mais bem sucedido foi desenvolvido por Briggs et al. (1994), que reprojetou o alocador de Chaitin et al. para adiar ao máximo as decisões de derramento.

George e Appel (George \& Appel, 1996; Appel, 1998) projetaram um alocador de registradores que utiliza os passos de simplificação do projeto de Chaitin et al. com a estratégia de fundir vértices do grafo empregada por Briggs et al.. George e Appel asseguram que esta abordagem elimina mais instruções de movimentação do que a abordagem de Briggs et al., além de garantir não introduzir mais derramamentos.

Um ponto negativo destes alocadores de registradores é o fato destes aplicarem um método heurístico simples para colorir o grafo, o que não garante que será encontrada uma boa coloração. Alocadores que utilizam métodos mais agressivos envolvendo probabilidade são capazes de encontrar uma coloração melhor, consequentemente gerando um código de melhor qualidade.

CARTRA e HCRA são dois alocadores de registradores que modificam o projeto de George e Appel com o objetivo de utilizar um método heurístico mais agressivo. No primeiro a coloração do grafo é baseada na meta-heurística colônia de formigas, enquanto no segundo em uma meta-heurística híbrida evolucionária.

Tanto CARTRA quanto HCRA fornecem soluções significativamente melhores que George-Appel, o qual possui um ótimo tempo de execução. Embora CARTRA possua um elevado tempo de execução, ele é capaz de encontrar soluções ligeiramente melhores que HCRA. Este último, por sua vez tem tempo de execução pouco pior embora seja competitivo com George-Appel. Por conseguinte, a utilização de CARTRA exige uma troca: qualidade da solução versus tempo de compilação. Enquanto que a utilização de HCRA é bastante adequada: boa qualidade de solução com um bom tempo de execução.

\section{Referências}

Akyildiz, I.F. \& Vuran, M.C., Wireless Sensor Networks. New York, USA: J. Wiley \& Sons, 2010.

Appel, A.W., Modern Compiler Implementation in C. Cambridge, UK: Cambridge University Press, 1998.

Arnold, M.; Fink, S.; Grove, D.; Hind, M. \& Sweeney, P.F., Adaptive optimization in the Jalapeño JVM. SIGPLAN Notices, 46(4):65-83, 2011.

Bergner, P.; Dahl, P.; Engebretsen, D. \& O’Keefe, M., Spill code minimization via interference region spilling. SIGPLAN Notices, 32(5):287-295, 1997.

Bernstein, D.; Golumbic, M.; Mansour, Y.; Pinter, R.; Goldin, D.; Krawczyk, H. \& Nahshon, I., Spill code minimization techniques for optimizing compilers. SIGPLAN Notices, 24(7):258-263, 1989.

Blöchliger, I. \& Zufferey, N., A graph coloring heuristic using partial solutions and a reactive tabu scheme. Computers 83 Operations Research, 35(3):960-975, 2008.

Briggs, P.; Cooper, K.D. \& Torczon, L., Improvements to graph coloring register allocation. ACM Transactions on Programming Languages and Systems, 16(3):428-455, 1994.

Chaitin, G.J.; Auslander, M.A.; Chandra, A.K.; Cocke, J.; Hopkins, M.E. \& Markstein, P.W., Register allocation via coloring. Computer Languages, 6(1):47-57, 1981.

Cooper, K.D. \& Dasgupta, A., Tailoring graph-coloring register allocation for runtime compilation. In: Proceedings of the International Symposium on Code Generation and Optimization. Washington, USA: IEEE Computer Society, p. 39-49, 2006.

Costa, D. \& Hertz, A., Ants Can Colour Graphs. The Journal of the Operational Research Society, 48(3):295-305, 1997. 
Dorigo, M. \& Stützle, T., Ant Colony Optimization. Cambridge, USA: MIT Press, 2004.

Fischer, C.N.; Cytron, R.K. \& LeBlanc, R.J., Crafting a Compiler. Reading, USA: Addison-Wesley, 2010.

Galinier, P. \& Hao, J.K., Hybrid evolutionary algorithms for graph coloring. Journal of Combinatorial Optimization, 3(4):379-397, 1999.

George, L. \& Appel, A.W., Iterated register coalescing. ACM Transactions on Programming Languages and Systems, 18(3):300-324, 1996.

Glover, F. \& Laguna, M., Tabu Search. Norwell, USA: Kluwer Academic Publishers, 1997.

Hać, A., Wireless Sensor Network Designs. New York, USA: J. Wiley \& Sons, 2003.

Hertz, A. \& Werra, D., Using tabu search techniques for graph coloring. Computing, 39(4):345-351, 1987.

Hertz, A. \& Zufferey, N., A new ant algorithm for graph coloring. In: Pelta, D.A. \& Krasnogor, N. (Eds.), Proceedings of the Workshop on Nature Inspired Cooperative Strategies for Optimization. Granada, Espanha, p. 51-60, 2006.

Ilyas, M. \& Mahgoub, I. (Eds.), Handbook of Sensor Networks: Compact Wireless and Wired Sensing Systems. Boca Raton, USA: CRC Press, 2004.

Ishizaki, K.; Takeuchi, M.; Kawachiya, K.; Suganuma, T.; Gohda, O.; Inagaki, T.; Koseki, A.; Ogata, K.; Kawahito, M.; Yasue, T.; Ogasawara, T.; Onodera, T.; Komatsu, H. \& Nakatani, T., Effectiveness of cross-platform optimizations for a Java just-in-time compiler. SIGPLAN Notices, 38(11):187-204, 2003.

Johansson, E. \& Sagonas, K.F., Linear scan register allocation in a high-performance erlang compiler. In: Proceedings of the 4th International Symposium on Practical Aspects of Declarative Languages. London, UK: Springer-Verlag, p. 101-119, 2002.

Karp, R.M., Reducibility among combinatorial problems. In: Miller, R.E. \& Thatcher, J.M. (Eds.), Complexity of Computer Computations. New York, USA: Plenum Press, The IBM Research Symposia Series, p. 85-103, 1972.

Lintzmayer, C.N.; Mulati, M.H. \& da Silva, A.F., Algoritmo heurístico baseado em colônia de formigas artificiais colorant2 com busca local aplicado ao problema de coloração de grafo. In: Anais do X Congresso Brasileiro de Inteligência Computacional. Fortaleza, SP, 2011a.

Lintzmayer, C.N.; Mulati, M.H. \& da Silva, A.F., Register Allocation with Graph Coloring by Ant Colony Optimization. In: Proceedings of the XXX International Conference of the Chilean Computer Science Society. Curicó, Chile, 2011b.

Lintzmayer, C.N.; Mulati, M.H. \& da Silva, A.F., RT-ColorAnt: um algoritmo heurístico baseado em colônia de formigas artificiais com busca local para colorir grafos. In: Anais do XLIII Simpósio Brasileiro de Pesquisa Operacional. Ubatuba, SP, 2011c.

Lintzmayer, C.N.; Mulati, M.H. \& da Silva, A.F., Toward better performance of ColorAnt ACO algorithm. In: Proceedings of the XXX International Conference of the Chilean Computer Science Society. Curicó, Chile, 2011d.

Mössenböck, H. \& Pfeiffer, M., Linear scan register allocation in the context of SSA form and register constraints. In: Proceedings of the International Conference on Compiler Construction. London, UK: Springer, p. 229-246, 2002.

Muchnick, S.S., Advanced Compiler Design and Implementation. San Francisco, USA: Morgan Kaufmann, 1997.

Patterson, D.A. \& Hennessy, J.L., Computer Organization And Design: The Hardware/software Interface. San Francisco, USA: Morgan Kaufmann, 2008.

Poletto, M. \& Sarkar, V., Linear scan register allocation. ACM Transactions on Programming Languages and Systems, 21(5):895-913, 1999.

Smith, M.D.; Ramsey, N. \& Holloway, G., A generalized algorithm for graph-coloring register allocation. SIGPLAN Notices, 39(6):277-288, 2004.

Stallings, W., Computer Organization and Architecture. Prentice Hall, 2010.

Suganuma, T.; Ogasawara, T.; Kawachiya, K.; Takeuchi, M.; Ishizaki, K.; Koseki, A.; Inagaki, T.; Yasue, T.; Kawahito, M.; Onodera, T.; Komatsu, H. \& Nakatani, T., Evolution of a Java just-in-time compiler for IA-32 platforms. IBM Journal of Research and Development, 48(5/6):767-795, 2004.

Wimmer, C. \& Mössenböck, H., Optimized iinterval splitting in a linear scan register allocator. In: Proceedings of the ACM/USENIX International Conference on Virtual Execution Environments. New York, USA: ACM, p. 132-141, 2005. 


\section{Notas Biográficas}

Carla Négri Lintzmayer é graduada em Ciência da Computação (UEM, 2011) e atualmente é discente de mestrado no programa de pós-gradução em Ciência da Computação na Universidade Estadual de Campinas.

Mauro Henrique Mulati é graduado em Informática (Universidade Estadual de Maringá - UEM, 2005) e mestre em Ciência da Computação (UEM, 2009). Atualmente é Professor Assistente do Departamento de Ciência da Computação da Universidade Estadual do Centro-Oeste - UNICENTRO.

Anderson Faustino da Silva é graduado em Ciência da Computação (Universidade Estadual do Oeste do Paraná - UNIOESTE, 1999), mestre e doutor em Engenharia de Sistemas e Computação (COPPE/UFRJ, 2003 e 2006 , respectivamente). Atualmente é Professor Adjunto do Departamento de Informática da Universidade Estadual de Maringá. 


\title{
Meta-heurísticas Aplicadas ao Desenvolvimento de Novos Fundos de Investimentos
}

\author{
Eder Oliveira Abensur*
}

\begin{abstract}
Resumo: Este capítulo descreve e interpreta os métodos empregados atualmente para a formação de novos fundos de investimento no mercado financeiro brasileiro e propõe um novo procedimento para testar o seu desenvolvimento baseado na integração das técnicas de Dinâmica de Sistemas, Algoritmos Genéticos e Simulated Annealing. O método proposto foi demonstrado com dados reais levantados durante quatro anos no mercado financeiro para o desenvolvimento de um fundo aberto referenciado DI. Os resultados sugerem que a metodologia proposta é inovadora e, particularmente, indicada para o desenvolvimento de complexos produtos financeiros.
\end{abstract}

Palavras-chave: Fundos de investimento, Algoritmos genéticos, Simulated annealing, Dinâmica de sistemas.

\begin{abstract}
This chapter describes and interprets the methods currently used in the development of new investment funds in the Brazilian financial market and proposes a new procedure based on the integration of System Dynamics, Genetic Algorithms and Simulated Annealing. The proposed method was demonstrated with real data collected during four years in the financial market for the development of a fictitious DI fund. The results suggest that the proposed method is particularly suitable for the development of complex financial products.
\end{abstract}

Keywords: Investment funds, Genetic algorithms, Simulated annealing, System dynamics.

\section{Introdução}

A despeito da importância do setor de serviços, que desde meados do século XX tornou-se o setor econômico dominante da economia brasileira conforme mostrado na Figura 1 a seguir, ainda há uma escassez de trabalhos científicos sobre o Desenvolvimento de Novos Serviços (DNS) (Easingwood, 1986; DeBrentani, 1989, 1991; Mendes, 1999). Essa deficiência amplifica-se quando analisamos o tema de Desenvolvimento de Novos Produtos e Serviços embutido na gerência de operações brasileiras (Arkader, 2003).

Tecnicamente, os fundos de investimento são produtos financeiros compostos por títulos públicos e privados, de renda fixa (pré ou pós-fixada) ou variável, provenientes de várias instituições do mercado, permitindo uma diversificação por investirem numa cesta de papéis. Sua forma de administração assemelha-se à de um condomínio predial, em que há a figura do administrador de recursos (síndico), que é responsável pela estratégia de investimentos do fundo, e do cotista (condômino), que é dono de uma fração ideal (sua participação em número de quotas); sua remuneração é consequência da estratégia adotada pelo gestor de recursos e das condições de mercado e reflete-se sobre a valorização da quota do respectivo fundo.

O intuito deste trabalho é contribuir com o processo de Desenvolvimento de Novos Produtos Financeiros. Não só o tema, mas, principalmente, a prática empresarial dos bancos, têm mostrado que esta é uma questão de grande interesse e preocupação tanto por parte dos gestores financeiros como por parte dos investidores. Em particular, será dada ênfase à etapa de experimentação e testes praticados para o desenvolvimento de fundos abertos referenciados DI (os cotistas podem solicitar, a qualquer tempo, resgates de suas quotas de fundos cuja rentabilidade está atrelada à variação do CDI).

Foram realizadas três entrevistas com uma amostra dos principais Administradores de Recursos de Terceiros dos bancos atuantes no Brasil (nacionais e estrangeiros), selecionados devido à proximidade profissional do pesquisador com os gestores de fundos com quem atuou durante muitos anos. Com as informações obtidas nessa etapa foi possível fazer uma descrição genérica do processo de desenvolvimento

*Contato: eder.abensur@ufabc.edu.br 


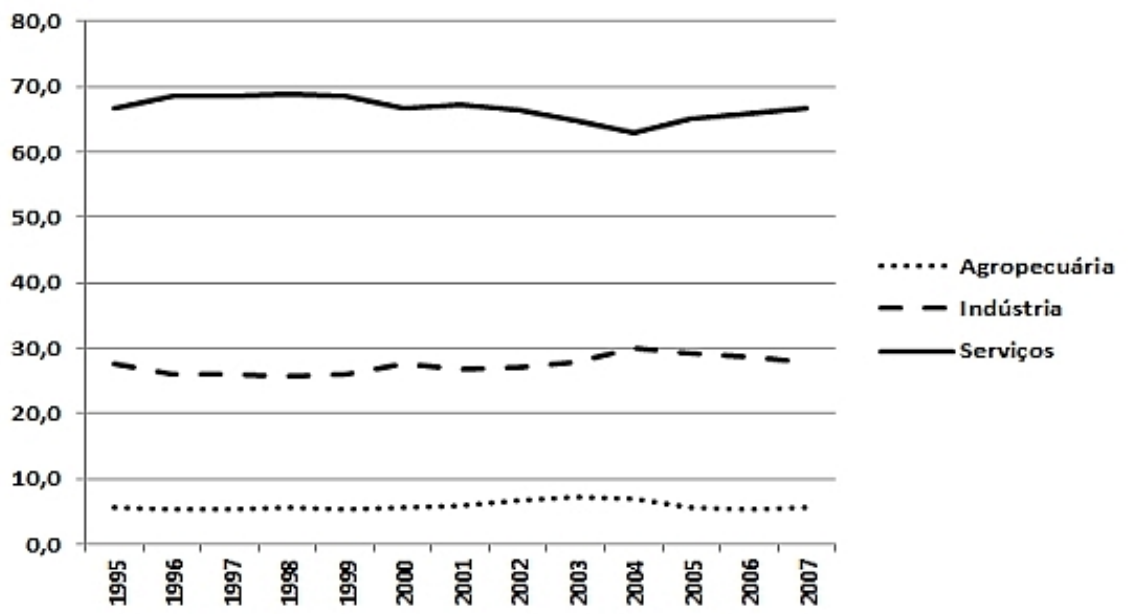

Figura 1. Evolução percentual setorial do PIB Brasileiro. Fonte:

http://www . sei . ba.gov.br/index .php?option=com_content\&view=article\&id=135\&Itemid=218.

de fundos de investimento, da estrutura organizacional, dos métodos de experimentação empregados e das principais variáveis consideradas no processo.

De acordo com a técnica de Dinâmica de Sistemas, desenvolveu-se um simulador estruturado numa relação causa-efeito entre as variáveis identificadas no desenvolvimento de fundos de investimento com regras passíveis de uma modelagem matemática. A metodologia de experimentação e testes foi demonstrada por meio de simulação com o uso de algoritmos genéticos para busca da melhor combinação das variáveis envolvidas para o lançamento de um fundo de investimento fictício da categoria DI, para isso, utilizou-se o software profissional Evolver ßda Palisade. A simulação com uso da técnica baseada no Simulated Annealing foi realizada com um programa desenvolvido em plataforma Visual Basic hospedado no Microsoft Excel. A escolha do fundo cujos dados serviram para a demonstração das propostas de testes foi feita arbitrariamente e por amostragem não probabilística compreendendo o período entre 1999 e 2004.

O capítulo está estruturado como se segue. A Seção 2 descreve o mercado brasileiro de fundos de investimento. A Seção 3 apresenta o processo de desenvolvimento de fundos de investimento. A Seção 4 mostra a aplicação da técnica de Dinâmica de Sistemas. A Seção 5 introduz as meta-heurísticas com ênfase nos Algoritmos Genéticos e no Simulated Annealing. A Seção 6 mostra a formulação do modelo matemático proposto. Na Seção 7 os testes aplicados são caracterizados e os resultados apresentados. A Seção 8 mostra as conclusões do estudo.

\section{O Mercado Brasileiro de Fundos de Investimentos}

Cada investidor tem um objetivo específico ao realizar um investimento. No entanto, as decisões sobre a utilização de seus excedentes financeiros podem ser genericamente classificadas em quatro grupos de interesse: consumo, investimentos, seguros e aposentadoria.

As áreas de administração de recursos de terceiros dos bancos brasileiros especializaram-se na ajuda aos investidores refletida na recomendação, no aconselhamento e na orientação técnica por meio de uma linha de raciocínio lógico que conduza à confiança nos produtos e serviços indicados.

Aos bancos cabe a tarefa de montar e administrar as carteiras de investimento que atendam às necessidades de rentabilidade e aos riscos de cada investidor e que maximizem seus lucros.

O primeiro registro de um fundo de investimentos foi feito na Bélgica, em 1822. Após seu progresso na Europa, principalmente na Inglaterra, chegou aos Estados Unidos. No Brasil, o primeiro fundo de investimentos foi formado em 1957, com a criação do Fundo Crescinco, que, até o início dos anos 70, era o maior fundo brasileiro. Em 1970, foi criada uma regulamentação específica por meio da Resolução 145 (Moraes, 2000).

Os investimentos em Títulos podem ser praticados por pessoas físicas ou jurídicas por meio dos agentes do mercado (instituições financeiras). Entende-se que Títulos são ativos (bens mobiliários) que possuem características distintas no que se refere à renda (variável ou fixa), prazo (determinado ou indeterminado) e emitente (público ou privado).

Os principais títulos negociados no Sistema Financeiro Nacional e utilizados na composição dos fundos de investimento são listados a seguir. 
- Certificado de Depósito Interbancário (CDI): Título de renda fixa que oferece liquidez no mercado interbancário e permite a troca de recursos entre as instituições. As negociações são feitas entre as tesourarias das instituições sem a incidência de impostos, são fechadas por meios eletrônicos e registradas na CETIP (Central de Custódia e Liquidação de Títulos). Sua taxa é divulgada diariamente para operações de um dia ou prazos superiores (30/60 ou mais dias). Geralmente, as taxas são anuais.

- Certificado de Depósito Bancário (CDB): Títulos emitidos por bancos comerciais que têm como lastro os depósitos à vista da instituição emissora. As taxas modificam-se diariamente e são expressas em termos anuais para um prazo de trinta dias.

- Debêntures: Títulos emitidos por uma sociedade anônima para captação de recursos. Podem ser convertidos em ações de acordo com as condições estipuladas pelo emissor.

- Títulos Públicos: Títulos emitidos pelo Banco Central do Brasil (BACEN), Estados, Municípios e Distrito Federal com características próprias de prazo e remuneração. Como exemplo tem-se as Notas do Tesouro Nacional (NTN) e os Títulos Estaduais e Municipais. Ao longo dos anos, os fundos de investimento evoluíram de uma simples divisão entre fundos de renda fixa e renda variável até classificações mais sofisticadas que incorporam a natureza dos diferentes ativos utilizados, dos seus respectivos riscos, tempo de maturação dos ativos e o referencial de avaliação do desempenho esperado. A legislação vigente classifica o mercado de fundos nas categorias descritas a seguir.

- Fundos de Curto Prazo: Compostos por uma carteira de títulos indexados à taxa do sistema de custódia e liquidação de títulos públicos (Selic) ou títulos indexados a índices de preços com prazo máximo de 375 dias.

- Fundos Referenciados: Compostos por uma carteira de títulos cujo desempenho esteja o mais próximo possível de um índice de referência (CDI, dólar, euro, inflação). Um fundo é considerado referenciado se possuir, no mínimo, $80 \%$ de seu patrimônio líquido representado por títulos de emissão do Tesouro Nacional (T.N.) ou do BACEN e se, no mínimo, 95\% de sua carteira estiver composta por ativos financeiros que acompanhem direta ou indiretamente um indicador de desempenho.

- Fundos de Renda Fixa: Representados por uma carteira de ativos com, no mínimo, $80 \%$ em ativos de renda fixa.

- Fundos Cambiais: Fundos com uma carteira composta por ativos com, no mínimo, 80\% relacionados diretamente à variação cambial.

- Fundos Multimercados: Segmento de fundos que possuem políticas de investimentos que envolvam vários fatores de risco (taxa de juros, índice de ações, índice de preços) sem o compromisso de concentração em nenhum fator em especial.

- Fundos Dívida Externa: São fundos com, no mínimo, 80\% do seu patrimônio líquido investido em títulos dívida da externa de responsabilidade da União.

- Fundos de ações: Fundos compostos por uma carteira com, no mínimo, 67\% em ações admitidas à negociação no mercado à vista de bolsa de valores ou entidade de balcão organizado.

\section{O Processo de Desenvolvimento de Fundos de Investimento}

O processo genérico de desenvolvimento de fundos no mercado financeiro brasileiro, a partir do levantamento realizado em três grandes instituições pública, privada nacional e privada multinacional pode ser resumido na Figura 2. Na etapa de concepção ou idéia a área de produtos, aproveitando-se das oportunidades existentes e de ter uma visibilidade privilegiada de todo o processo produtivo, é a grande fomentadora das iniciativas de desenvolvimento de novos produtos. A fase de avaliação conceitual também é predominantemente exercida pela área de produtos como uma avaliação conceitual preliminar do potencial do fundo idealizado. Faz-se um desenho do fundo com suas especificações iniciais, tais como: taxa de administração diferenciada de acordo com o perfil do cliente, aplicação mínima inicial, prazos de aplicação e resgate, política de investimento, horário de movimentação adequado ao canal de atendimento e baixa automática (conta remunerada com resgate automático do fundo de investimento). Realiza-se uma análise do histórico de desempenho de produtos similares para projeções da adequação de fundo idealizado de acordo com as estratégias de risco e retorno estabelecidas pela instituição. A aderência à legislação vigente é reavaliada. A etapa de avaliação interna analisa e discute as características do fundo proposto com outras áreas do banco para uma validação interna em que são consideradas opiniões de profissionais externos à área de produtos. Desta maneira, as 


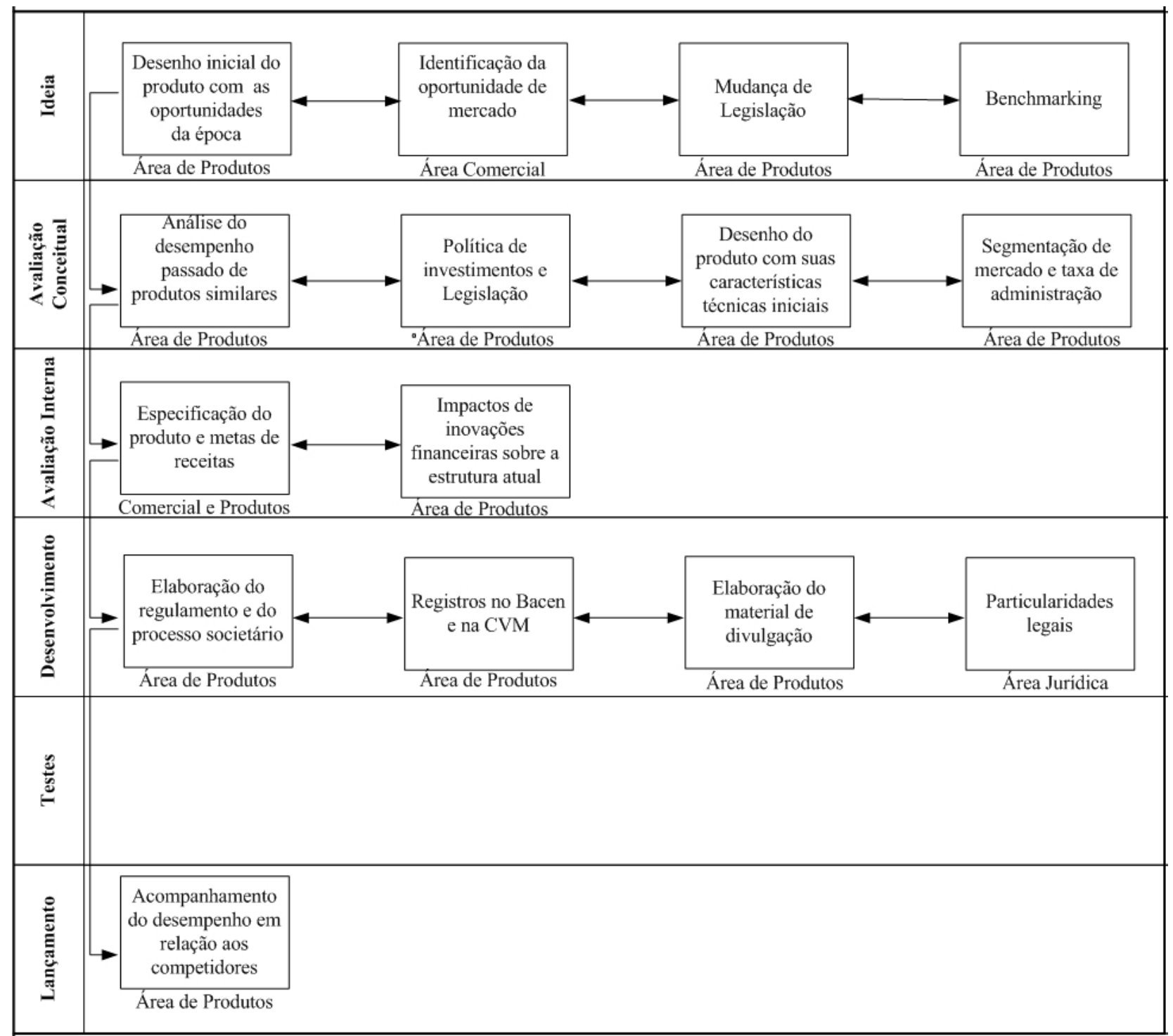

Figura 2. Fluxograma genérico do desenvolvimento de novos fundos de investimento.

especificações dos produtos são definidas de forma mais precisa, bem como as restrições internas e os possíveis impactos operacionais sobre toda a cadeia. A viabilidade econômica dos produtos é estimada de acordo com a experiência dos profissionais do canal de distribuição. A fase de operacionalização ou desenvolvimento encarrega-se dos preparativos legais para a constituição e divulgação do fundo aprovado. Não são realizados testes que possam avaliar com antecedência as possibilidades posteriores de sucesso do fundo. As práticas de testes existentes são focadas no treinamento da rede de distribuição, principalmente os gerentes de agência, para esclarecimento e orientação sobre as características do novo produto a ser comercializado. Após o lançamento, realiza-se o acompanhamento do desempenho do fundo (captação, rentabilidade, risco) em comparação à indústria.

O tempo médio total do ciclo de desenvolvimento normal de um fundo oscila entre 15 e 30 dias, divididos da seguinte forma:

a) Concepção / Avaliação Conceitual / Avaliação Interna - 15 dias.

b) Operacionalização / Lançamento - 15 dias.

Os gestores avaliam o sucesso do fundo de acordo com os seguintes critérios:

a) Rentabilidade do fundo comparada com concorrentes escolhidos como referenciais.

b) Aumento da base de clientes.

c) Atração de novos clientes.

d) Velocidade de evolução do patrimônio líquido. 


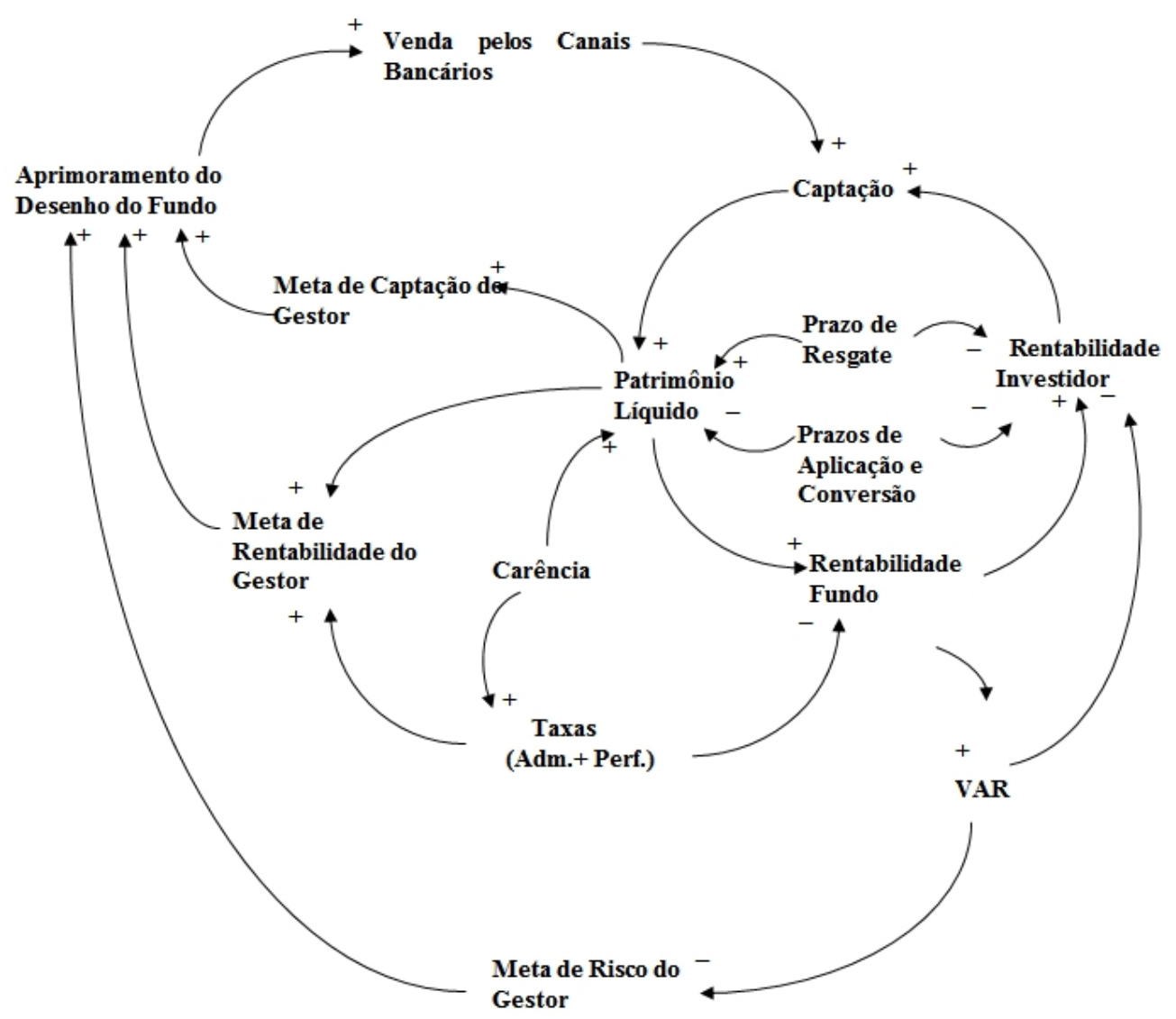

Figura 3. Diagrama Causal para o sistema analisado.

\section{Dinâmica de Sistemas}

O diagrama causal expressa a relação de causa e efeito entre as variáveis envolvidas no modelo. Essa leitura prévia é importante para início dos trabalhos e para uma posterior avaliação qualitativa do comportamento das variáveis e da coerência dos resultados do modelo. Este tipo de procedimento é usado na Dinâmica de Sistemas e em especial será usada a terminologia de Roberts et al. (1983) que fundamentam sua técnica num feedback (retro-alimentação) constante do sistema que interage com o meio ambiente por variáveis internas a ele mesmo.

As variáveis consideradas importantes para a análise conforme descrito na Seção 3 são: patrimônio líquido, taxa de administração, taxa de performance, prazo de conversão das cotas, prazo de resgate e carência. Uma vez identificadas as variáveis consideradas importantes ao modelo, o diagrama causal é desenhado para uma visualização dessas relações. A Figura 3 representa o diagrama causal simplificado para o sistema analisado.

A interpretação da Figura 3 mostra que um maior aprimoramento do desenho do fundo aumenta as possibilidades de vendas pelos canais bancários (agências, Internet). Por sua vez, um aumento nas vendas aumenta a captação do fundo que aumenta seu patrimônio líquido e, por sua vez, aumenta a sua rentabilidade e a do investidor, caracterizando uma malha convergente. O aumento do patrimônio líquido do fundo faz aumentar as chances de se atingir as metas de captação e rentabilidade do gestor. Entretanto, um aumento da volatilidade do fundo (refletido no aumento da sua rentabilidade diária) aumenta seu risco medido pelo VAR, distanciando-o, assim, da meta de gestão de risco estabelecida e caracterizando uma malha divergente.

A complexidade do problema analisado aumenta significativamente com o acréscimo de variáveis e faixas de tolerância podendo alcançar bilhões de possibilidades. Conforme Abensur (2006), este tipo de problema apresenta pontos de máximo e mínimo local, o que reforça a utilização de procedimentos meta-heurísticos.

\section{Meta-heurísticas}

A palavra heurística tem sua origem no termo grego "heuriskein" que significa descobrir. Heurística é um procedimento (algoritmo) para resolver problemas por meio de uma abordagem intuitiva, em geral racional, no qual a estrutura do problema possa ser interpretada e explorada de forma a obter uma solução razoável. Como características principais dos procedimentos heurísticos destacam-se: o bom desempenho, rapidez e simplicidade que, entretanto, não têm prova de convergência e não garantem achar a solução ótima. 
A partir da década de 80, há o surgimento da meta-heurística que fortalece e revigora as técnicas heurísticas por mecanismos de busca inspirados em modelos do cotidiano humano ou da natureza. Fazem parte desta relação:

a) Busca Tabu: faz analogia com a descoberta de uma trilha durante a escalada de uma montanha.

b) Simulated Annealing (SA): analogia ao resfriamento de materiais.

c) Algoritmo Genético (AG): faz analogia à reprodução humana com diversificação e mutação de cromossomos.

d) Ant System: analogia com um sistema de busca de comida por uma colônia de formigas.

e) Híbridos: combinação de duas ou mais técnicas.

Tanto as heurísticas como as meta-heurísticas são consideradas poderosas ferramentas de busca capazes de obter boas soluções em curto espaço de tempo computacional sobre problemas que não possuem solução matemática exata (solução ótima). Elas partem de uma solução inicial viável para o problema e fazem melhorias sucessivas até alcançar um critério de parada pré-definido. Após o término do processo, seleciona-se a solução com melhor desempenho. Em termos práticos, ambas podem ser definidas como tipos de simulação. Entretanto, o progresso dos recursos computacionais proporcionou uma evolução conceitual sobre o seu entendimento e as suas possibilidades de aplicação. As meta-heurísticas são simulações mais complexas que possuem a capacidade de incorporar, durante o processo de simulação, padrões de comportamento humano, como a adaptação e o aprendizado, permitindo assim a seleção de soluções superiores. Por essa razão, algumas meta-heurísticas são consideradas e aplicadas como procedimentos de inteligência artificial (ex. algoritmos genéticos).

Os métodos heurísticos ou meta-heurísticos são recomendados quando:

a) os métodos de solução exata (ex. programação linear) são proibitivos devido ao alto tempo de execução, consumo de memória computacional, alto tempo de desenvolvimento, alto custo de preparação e quando não há garantia científica de explicação do fenômeno;

b) os dados têm baixa confiabilidade, fazendo soluções exatas perderem o sentido;

c) o modelo mais realista com solução aproximada fizer mais sentido que o modelo menos realista com solução ótima;

d) servem para encontrar pontos de partida para métodos exatos reduzindo o número de alternativas viáveis (ex. regras de inicialização, como do canto noroeste para o problema do transporte).

Outra forma de escolha dos métodos citados está associada à complexidade do problema analisado. De acordo com a teoria da complexidade (para maiores detalhes ver Goldbarg \& Luna (2005)), o grau de dificuldade de um problema está relacionado com o número de operações necessárias para resolvê-lo. Os problemas podem ser classificados em duas categorias:

a) Classe P: Problemas que admitem algoritmos de complexidade polinomial;

b) Classe NP: Problemas em que, dada uma solução, pode-se comprovar em tempo polinomial que seu custo é melhor que um determinado valor.

Dentro dessas categorias ainda existem duas subdivisões: (i) NP completo, que abrange problemas NP passíveis de resolução por algoritmo de complexidade polinomial; (ii) NP Hard altamente recomendados para aplicação dos métodos meta-heurísticos. No caso analisado, Kohli \& Krishnamurti (1987) demonstraram que os problemas de maximização do market share pela introdução de novos produtos com múltiplos atributos e níveis são do tipo NP-Hard.

As meta-heurísticas alargaram o campo de atuação e aumentaram as possibilidades de obtenção de melhores resultados em comparação às técnicas heurísticas anteriores. Em comum, elas surgiram para a solução de problemas específicos, entre eles o tema abordado neste trabalho: o desenho de produtos com múltiplos atributos. 


\subsection{Algoritmos genéticos}

O conceito dos algoritmos genéticos (AG) foi inicialmente proposto por Holland (1975). Os fundamentos para o algoritmo basearam-se na observação que a combinação da reprodução sexual e a seleção natural permitem à natureza o desenvolvimento de espécies vivas com alto grau de adaptação ao ambiente.

No contexto dos algoritmos genéticos, existe uma analogia com a terminologia usada pela biologia, embora as entidades a que se refiram sejam um tanto mais simples que as correspondentes biológicas reais.

Todos os organismos vivos consistem de células, e cada célula contém o mesmo conjunto de um ou mais cromossomos - filamentos de DNA - que servem como a impressão digital, por assim dizer, de um organismo. Um cromossomo pode ser conceitualmente dividido em genes - blocos funcionais de DNA, cada um dos quais codifica uma particular proteína. Grosseiramente, pode-se imaginar um gene como o código de uma particular característica, digamos, a cor dos olhos. As diferentes possibilidades para uma característica (olhos verdes, azuis, castanhos) são chamadas de alelos. Cada gene está localizado em um particular locus (posição) no cromossomo.

Muitos organismos têm múltiplos cromossomos em cada célula. O conjunto completo do material genético (todos os cromossomos juntos) é chamado de genoma de um organismo. O termo genótipo refere-se ao grupo particular de genes contido em um genoma.

Nos AG, o termo cromossomo refere-se tipicamente a uma solução candidata para um problema, normalmente codificada como uma sequência de bits. Os genes são bits únicos ou pequenos blocos de bits adjacentes que codificam um particular elemento da solução candidata. Um alelo numa sequência de bits é ou 0 ou 1. Funcionalmente, o algoritmo genético utiliza-se dos seguintes operadores:

a) Reprodução: A solução inicial é formada por uma sequência de bits que representam as características do produto. O operador de seleção escolhe um subconjunto $m$ de cromossomos de tamanho $M$ da população que poderão se reproduzir; na média, os cromossomos mais adaptados produzem mais descendentes do que os menos adaptados. Geralmente, o tamanho do cromossomo é mantido nas sucessivas gerações.

b) Crossover: O operador de crossover troca partes dos cromossomos de posições especificamente escolhidas para a formação de novos descendentes.

c) Mutação: O operador de mutação troca os valores de alguns alelos, de forma aleatória.

Os cromossomos de uma população em um AG normalmente tomam a forma de sequências de bits. Cada locus no cromossomo têm duas possíveis formas, ou alelos: 0 ou 1. Cada cromossomo pode ser visto como um ponto no espaço de busca de soluções candidatas. O algoritmo genético processa sequencialmente as populações de cromossomos, substituindo progressivamente uma população pela outra. Normalmente, se faz uso de uma função de utilidade que dá a cada cromossomo um valor (a utilidade dele). A utilidade de um cromossomo depende basicamente de quão bem ele consegue resolver o problema em questão. Idealmente, a solução ótima dentro de um determinado espaço de busca corresponde àquela com a maior utilidade.

O objetivo básico dos algoritmos genéticos é propor soluções para o problema a ser resolvido e evoluí-las com o tempo. Esse objetivo é alcançado, permitindo-se que as soluções mais adaptadas ao problema tenham maiores chances de sobreviver e, com isto, maiores oportunidades de gerar soluções descendentes, parecidas a elas mesmas e com grandes possibilidades de estarem mais adaptadas. Essas soluções podem também ser chamadas de indivíduos ou soluções candidatas e, quando agrupadas num mesmo período de tempo, formam uma população. Os indivíduos agrupados em uma população e em determinado período de tempo formam uma geração, que é sempre substituída no período seguinte por seus descendentes.

Os algoritmos genéticos apresentam uma série de vantagens no desempenho do seu processo de busca. A principal delas é que a busca é conduzida numa população de pontos ao invés de um único ponto, aumentando-se assim a capacidade exploratória do método. Os AG usam as funções objetivos para comparação de resultados, uma característica facilitadora em contraste com outras técnicas que necessitam de recursos adicionais, como a diferenciação de funções. Os AG avaliam por completo as soluções candidatas especificadas, ao contrário de heurísticas de programação dinâmica que constroem, sequencialmente, as soluções e adicionam um atributo por vez. Os AG são adaptáveis à implementação de processamento em paralelo, propiciando menores tempos computacionais. O funcionamento de um algoritmo genético básico pode ser visualizado na Figura 4, a seguir: 


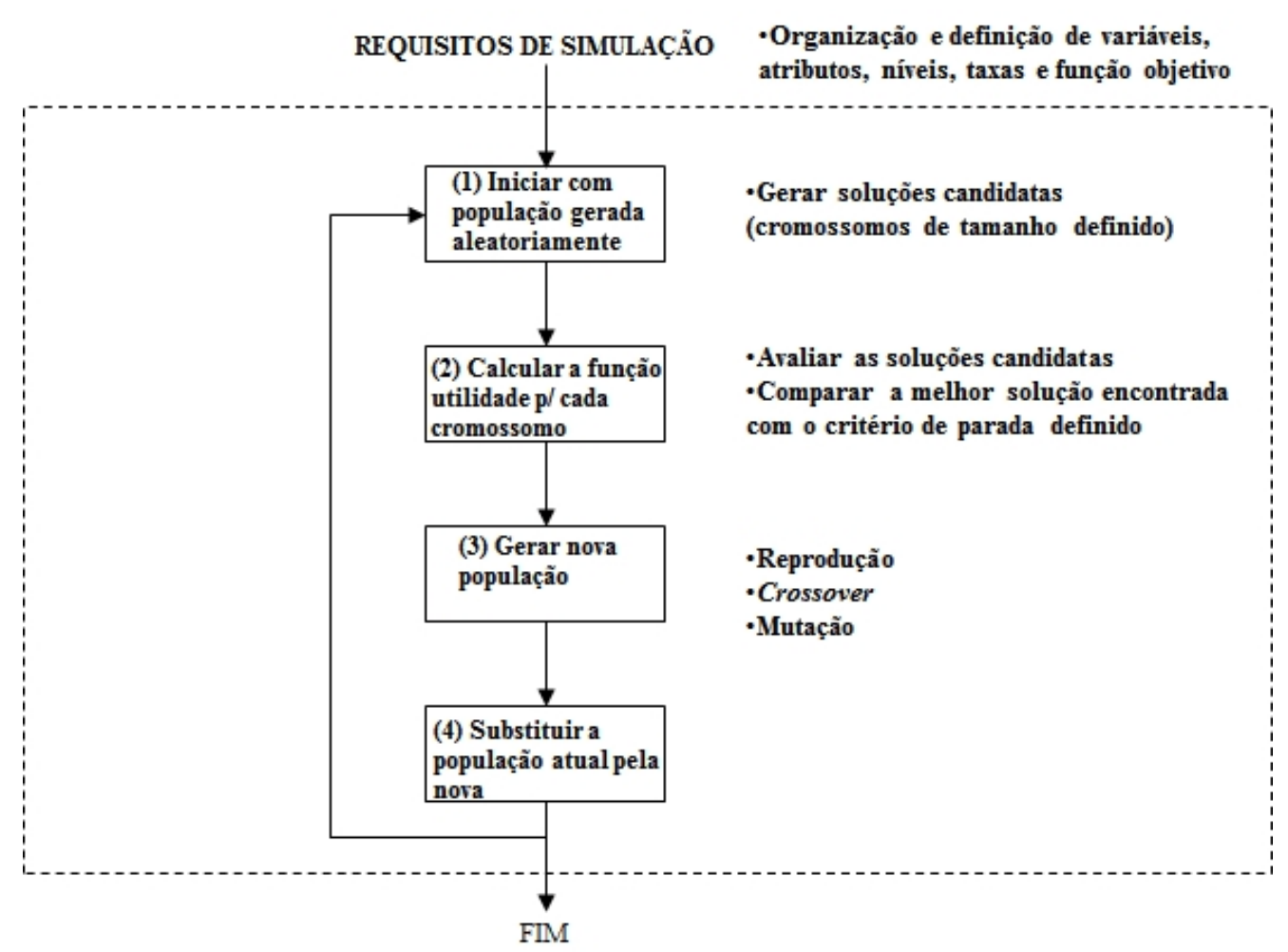

Figura 4. Modelo básico de um algoritmo genético.

\subsection{Simulated annealing}

Entre as muitas meta-heurísticas citadas escolheu-se o Simulated Annealing (SA) pela sua facilidade de implementação. Esta técnica criada por Kirkpatrick et al. (1983), faz uma analogia ao processo térmico de resfriamento de um material a alta temperatura. Há uma avaliação do nível de energia a cada diminuição de temperatura e o processo é encerrado quando o ponto de solidificação ou de energia mínima é atingido. Os parâmetros deste método são:

1. Temperatura inicial $\left(T_{0}\right)$;

2. Temperatura final $\left(T_{f}\right)$;

3. Número de iterações para atingir o equilíbrio a uma dada temperatura $(K)$;

4. Variação do nível de energia ou função objetivo $(\Delta)$;

5. Proporção de redução da temperatura $(\beta)$;

6. Probabilidade de certas configurações terem sua energia aumentada de $\Delta E$ é: $p(\Delta E)=e^{-\Delta E / T}$.

Sendo uma função decrescente esse processo assemelha-se aos métodos de descida (Descent Methods) que procuram construir uma sequência melhorada a partir de uma sequência inicial estudando-se uma vizinhança que representa o conjunto de sequências que podem ser geradas a partir da sequência vigente.

Como as outras meta-heurísticas ela pretende alargar o horizonte de alternativas analisadas. A questão do horizonte de alternativas pode ser entendido através de um exemplo cotidiano. Imagine que uma pessoa queira comprar uma pizza e resolva fazer uma pesquisa a pé pelo seu bairro. Apesar do interesse, essa pessoa não estaria inclinada a fazer uma caminhada muito distante de sua casa e provavelmente limitaria a sua busca a poucos quarteirões de distância da sua residência. Além disso, alguns trajetos mais íngremes como subidas e áreas inseguras seriam evitados. Após algum tempo essa pessoa faria a melhor escolha sobre o número de alternativas encontradas. No entanto, poderia existir alguma pizzaria com uma melhor oferta do produto um pouco além do limite estabelecido ou talvez num dos trajetos evitados pelo consumidor (Abensur, 2011).

O Simulated Annealing tenta evitar esta desvantagem inerente aos métodos de descida aceitando, de forma criteriosa, algumas sequências que produzam um resultado inferior à sequência vigente. Especificamente, quando $\Delta \leq 0$ a sequência é aceita. No entanto, sequências com $\Delta>0$ poderão ser admitidas desde que um valor aleatório $R \operatorname{com} R \leq e^{-\Delta E / T}$. 


\section{O Modelo Proposto}

O modelo proposto é dividido em duas partes principais: (i) um simulador de produto, que envolve as principais variáveis e os objetivos identificados durante a investigação do processo de desenvolvimento de produtos e (ii) um simulador de mercado, que inclui cenários históricos, em situações extremas e divergentes , incluindo o produto do ciclo de vida dividido entre o lançamento e prazos de vencimento e com a turbulência econômica (crises financeiras) ou sem ele.

O aumento do patrimônio líquido $C$ durante um determinado período de tempo $n$ deve-se exclusivamente ao resultado de investimentos diários e $\Delta m$ retiradas de um patrimônio líquido inicial $P_{0}$ na data $t_{0}$ pode ser formulado como:

$$
C_{n}=P_{0}\left(1+\Delta m_{n}\right)
$$

Devido à influência de um período mínimo de investimento, a Equação 1 pode ser formulada como:

$$
C_{n}=\left\{P_{0}\left[\prod_{i=1}^{n}\left(1+m_{i} \cdot F_{i}\right)\right]-M_{c}\right\}
$$

O fator $F_{i}$ assume valores 0 ou 1 que refletem a influência de um período mínimo de investimento cujo impacto positivo em fluxo de caixa líquido do fundo $m$ (o resultado dos investimentos e saídas diárias) evita retiradas diárias durante o período de bônus (os investidores não querem perder seu bônus) aumentando (ou não diminuindo) o patrimônio líquido. A eficiência do processo de acumulação pode ser medido através da meta de acúmulo pré-estabelecida $M_{C}$.

Normalmente, quando os investidores pedem uma retirada sua rentabilidade é influenciada pela taxa anual de gestão $t_{a}$ e pelo prazo de resgate $d_{r}$. Assumindo $R p_{i}$ como a rentabilidade de fundos na data $i$ (esta informação pode ser obtida por dados passados de lançamentos semelhantes de fundos), $d_{u}$ como o número de dias úteis por ano e $i_{b}$ como a taxa de referência (ou o custo de oportunidade durante o período de retirada), a rentabilidade do investidor $R_{i n v}$ é dada pela seguinte equação:

$$
R_{\text {inv }}=\left[R p_{i}-\left(1-t_{a}\right)^{\left(1 / d_{u}\right)}\right]-\left(1+i_{b}\right)^{\left(d_{r} / d_{u}\right)}
$$

De acordo com a categoria do fundo, há uma taxa de performance representando o desempenho superior, quando comparado com uma taxa de referência (por exemplo: taxa de juros), alcançado pela estratégia do gestor do fundo. Considerando que a taxa de performance $t_{p}$ só ocorre se a rentabilidade do fundo superar a taxa de referência $i_{b}$, então a rentabilidade do investidor é dada pela Equação 4 a seguir.

$$
R_{i n v}=\left[\sum_{i=1}^{n} R p_{i}-\left(1-t_{a}\right)^{\left(1 / d_{u}\right)}-\sum_{i=1}^{n} t_{p} \max \left(R p_{i}-i_{b}, 0\right)\right]-\left(1+i_{b}\right)^{\left(d_{r} / d_{u}\right)}
$$

A rentabilidade do gestor do fundo $L$ a é resultado da soma das contribuições da taxa de administração $t_{a}$, e da taxa de performance $t_{p}$ menos o bônus $C_{a}$ pago aos investidores que não tenham retirado durante o período mínimo de investimento $d_{c a}$, menos o custo total $C T$ (fixo + variável) e menos impostos $I R$ dado pela Equação 5 .

$$
L=\left(\left(\sum_{i=1}^{n}\left(1+t_{a}\right)^{\frac{1}{d_{u}}}+\left(\sum_{i=1}^{n} t_{p} \max \left(R p_{i}-i_{b}, 0\right)\right)\right) P_{i}\right)-\left(C_{a}\left(\sum_{i=d_{c a}}^{n+d_{c a}} P_{i-d_{c a}+1}-P_{i-d_{c a}}\right)-C T-I R\right)
$$

Conforme o Acordo de Basileia II e os procedimentos de gestão de riscos adotadas pelos bancos estudados, o valor do risco $(V A R)$ dos rendimentos diários do fundo com desvio-padrão $\sigma$, um investimento inicial $W_{0}$ durante um período de tempo $\Delta t$ é dado, conforme Jorion (2003), é dado pela Equação 6 a seguir.

$$
V A R=1,65 W_{0} \sigma \sqrt{\Delta t}
$$

O objetivo do modelo proposto é conseguir uma boa solução, através do equilíbrio dos múltiplos objetivos definidos. A fim de alcançar resultados imparciais e alinhar os interesses do investidor e gestor, todas as metas foram consideradas igualmente importantes. Os objetivos foram definidos de acordo com os fundos semelhantes que têm sido lançadas e dos comentários dos gestores. Como um exemplo, a faixa e o nível de atributos pode ser obtido a partir de valores de mercado como mostrado na Tabela 1 a seguir. Considerando $M_{V}, M_{L}, M_{R}$ como objetivo do investidor, o objetivo de retorno do gestor e objetivo de risco do fundo, respectivamente, então, a expressão final da função objetivo, de acordo com as Equações 3, 4, 5 e 6, é apresentada a seguir.

$$
\min Z=\left|\frac{1}{M_{C}}\left[P_{0}\left[\prod_{i=1}^{n}\left(1+m_{i} F_{i}\right)\right]-M_{C}\right]\right|+
$$




$$
\begin{gathered}
\left|\frac{1}{M_{V}}\left[\left[\left(\sum_{i=1}^{n} R p_{i}-\left(1-t_{a}\right)^{1 / d_{u}}\right)-\left(\sum_{i=1}^{n} t_{p} \max \left(R p_{i}-i_{b}, 0\right)\right)\right]-\left(i+i_{b}\right)^{d_{r} / d_{u}}-M_{V}\right]\right|+ \\
\left|\frac{1}{M_{L}}\left[\left[\left(\sum_{i=1}^{n} P_{i}\left(1+t_{a i}\right)^{1 / d_{u}}\right)-\left(\sum_{i=1}^{n} P_{i}\left(t_{p} \max \left(R p_{i}-i_{b}, 0\right)\right)\right)-\left(C_{a}\left(\sum_{i=d_{c a}}^{n+d_{c a}} P_{i-d_{c a}+1}-P_{i-d_{c a}}\right)-C T-I R\right)\right]-M_{L}\right]\right| \\
+\left|\frac{1}{M_{R}}\left[1,65 W_{0} \sigma \sqrt{\Delta t}-M_{R}\right]\right|
\end{gathered}
$$

sujeito a:

$P_{0} \leq P_{0 \text { max }}$ : patrimônio líquido mínimo factível em relação a lançamentos anteriores

$d_{r} \leq 5$ : prazo de resgate de 5 dias de acordo com a legislação

$d_{c} \leq d_{r}$ : prazo de conversão inferior ao prazo de resgate

$d_{c a} \leq 4$ : carência para o primeiro resgate inferior a 4 meses

$t_{a} \leq t_{a \max }$ : taxa máxima de administração

$t_{p} \leq t_{p \max }$ : taxa máxima de performance

$\min \left(P i_{i=90}^{n}\right) \geq P_{\min }$ : patrimônio líquido mínimo requerido de acordo com a legislação, onde as variáveis de decisão são positivas $\left(P_{0}, d_{r}, d_{c}, t_{p}, d_{c a}\right)$ e os parâmetros do modelo são os seguintes:

$M_{C}:$ meta de captação líquida;

$n$ : número de dias de captação do período;

$b$ : taxa diária do indicador de referência ou benchmark;

$M_{V}$ : meta de rentabilidade do investidor;

$d_{u}$ : dias úteis em um ano;

$C_{a}$ : bônus concedido durante a carência, suposto constante ao longo do tempo;

$C T$ : custo total da gestão do fundo;

$I R$ : imposto de renda;

$M_{L}$ : meta de lucro do gestor;

$M_{R}$ : meta de risco do fundo;

$P_{0 \text { max }}$ : captação inicial máxima;

$T_{a \text { max }}$ : taxa de administração máxima praticada pelo mercado;

$p$ max: taxa fixa de performance máxima praticada pelo mercado;

$P_{\min }$ : patrimônio líquido mínimo exigido para evitar a liquidação do fundo.

Tabela 1. Faixas das variáveis de simulação.

\begin{tabular}{lcccccccc}
\hline \multirow{2}{*}{ Banco } & $\begin{array}{c}\text { Taxa de } \\
\text { administração } \\
(\% \text { aa })\end{array}$ & $\begin{array}{c}\text { Patrimônio } \\
\text { Líquido } \\
(\mathrm{R} \$ \text { bilhões })\end{array}$ & $\begin{array}{c}\text { Prazo de } \\
\text { resgate } \\
(\text { dia })\end{array}$ & $\begin{array}{c}\text { Prazo de } \\
\text { conversão } \\
(\text { dia })\end{array}$ \\
\cline { 2 - 9 } & mín. & max. & mín. & max. & mín. & max. & mín. & max. \\
\hline Banco do Brasil & 0,50 & 4,50 & 0,02 & 1,50 & $\mathrm{D}+0$ & $\mathrm{D}+0$ & $\mathrm{D}+0$ & $\mathrm{D}+0$ \\
Bradesco & 0,30 & 4,50 & 0,12 & 0,65 & $\mathrm{D}+0$ & $\mathrm{D}+0$ & $\mathrm{D}+0$ & $\mathrm{D}+0$ \\
HSBC & 0,50 & 3,50 & 0,01 & 1,15 & $\mathrm{D}+0$ & $\mathrm{D}+0$ & $\mathrm{D}+0$ & $\mathrm{D}+0$ \\
Itaú Unibanco & 2,50 & 4,00 & 0,06 & 2,15 & $\mathrm{D}+0$ & $\mathrm{D}+0$ & $\mathrm{D}+0$ & $\mathrm{D}+0$ \\
Santander & 0,50 & 4,00 & 0,05 & 0,27 & $\mathrm{D}+0$ & $\mathrm{D}+0$ & $\mathrm{D}+0$ & $\mathrm{D}+0$ \\
\hline Geral & 0,30 & 4,50 & 0,01 & 2,15 & $\mathrm{D}+0$ & $\mathrm{D}+0$ & $\mathrm{D}+0$ & $\mathrm{D}+0$ \\
\hline
\end{tabular}

\section{Resultados}

Foram segmentados dois cenários em função do ciclo de vida do produto e da volatilidade de mercado a saber: (a) fase de nascimento sob condições favoráveis, com período de maturidade sem turbulência e (b) fase de nascimento sob condições desfavoráveis, com período de maturidade com turbulência. As condições desfavoráveis de volatilidade foram captadas de acordo com o histórico de movimentações de fundos similares em situações de crises, em particular, considerou-se a crise asiática de 1997 (Tabela 3) como referencial para as gerações de risco. Analogamente, adotou-se o período entre outubro de 2002 e fevereiro de 2004 como referência para as condições favoráveis de mercado (Tabela 2). Adotou-se o período de três meses como limite entre as fases de nascimento e maturidade. Os resultados da aplicação desta configuração sobre o problema 
com uso dos AG e do SA são mostrados na Tabela 4 a seguir. Como esperado, o cenário mais desfavorável (B) implica em maior taxa de administração e maiores desvios de risco, captação e rentabilidade para o gestor e investidor, enquanto o cenário favorável (A) apresenta menores desvios de metas.

Tabela 2. Movimentação diária (D.U.= dia útil; Mov.= movimentação).

\begin{tabular}{|c|c|c|c|c|c|c|c|c|c|c|c|c|c|c|c|}
\hline D.U & Mov. I & & Mov & & &. $\mathrm{U}$ & Mo & D.U & Mo & $\mathbf{U}$ & Mo & D.U & Mo & D.U & Mov. \\
\hline 1 & - & 33 & $2,01 \%$ & 65 & $2,52 \%$ & 97 & $1,94 \%$ & 129 & $0,11 \%$ & 161 & $0,71 \%$ & 193 & $-0,20 \%$ & 225 & $0,72 \%$ \\
\hline & $213,51 \%$ & 34 & $3,75 \%$ & 66 & $2,29 \%$ & 98 & $1,85 \%$ & 130 & $0,92 \%$ & 162 & $0,97 \%$ & 194 & $0,26 \%$ & 226 & $0,04 \%$ \\
\hline & $112,34 \%$ & 35 & $10,37 \%$ & 67 & $1,47 \%$ & 99 & $1,67 \%$ & 131 & & 163 & $-0,10 \%$ & 195 & & 227 & $16 \%$ \\
\hline & $142,39 \%$ & 36 & $1,35 \%$ & & $5,12 \%$ & 100 & $2,03 \%$ & 132 & $1,05 \%$ & 164 & & 196 & & 228 & $0,32 \%$ \\
\hline 5 & $24,23 \%$ & 37 & $2,26 \%$ & 69 & $3,29 \%$ & 101 & $1,32 \%$ & 133 & $1,11 \%$ & 165 & $0,70 \%$ & 197 & $0,04 \%$ & 229 & $-0,20 \%$ \\
\hline 6 & $17,51 \%$ & 38 & $1,43 \%$ & 70 & $2,56 \%$ & 102 & $1,62 \%$ & 134 & $1,04 \%$ & 166 & $0,83 \%$ & 198 & $0,36 \%$ & 230 & $-0,01 \%$ \\
\hline 7 & $8,48 \%$ & 39 & $1,81 \%$ & 71 & $1,17 \%$ & 103 & $1,10 \%$ & 135 & $0,52 \%$ & 167 & $1,18 \%$ & 199 & $0,85 \%$ & 231 & $0,09 \%$ \\
\hline 8 & $6,52 \%$ & 40 & $4,62 \%$ & 72 & $2,21 \%$ & 104 & $2,25 \%$ & 136 & $0,58 \%$ & 168 & $0,31 \%$ & 200 & $0,35 \%$ & 232 & $0,51 \%$ \\
\hline 9 & $10,74 \%$ & 41 & 2,22 & 73 & $1,63 \%$ & 105 & $1,18 \%$ & 137 & $0,63 \%$ & 169 & $0,44 \%$ & 201 & $0,68 \%$ & 233 & $0,44 \%$ \\
\hline 10 & $12,72 \%$ & 42 & $4,29 \%$ & 74 & $2,12 \%$ & 106 & $2,03 \%$ & 138 & $-0,18 \%$ & 170 & $0,67 \%$ & 202 & $0,62 \%$ & 234 & $0,38 \%$ \\
\hline 11 & $11,71 \%$ & 43 & $3,76 \%$ & 75 & $0,91 \%$ & 107 & $1,44 \%$ & 139 & $1,83 \%$ & 171 & $1,16 \%$ & 203 & $0,66 \%$ & 235 & $-0,17 \%$ \\
\hline 12 & $16,49 \%$ & 44 & $2,90 \%$ & & $0,76 \%$ & 108 & $3,09 \%$ & 140 & $0,70 \%$ & 172 & $0,50 \%$ & 204 & $0,78 \%$ & 236 & $0,30 \%$ \\
\hline 13 & $12,84 \%$ & 45 & $4,52 \%$ & 77 & $1,65 \%$ & 109 & $2,23 \%$ & 141 & $0,73 \%$ & 173 & $0,26 \%$ & 205 & $-0,17 \%$ & 237 & $0,16 \%$ \\
\hline 14 & $7,64 \%$ & 46 & 3,02 & 78 & & 110 & $0,76 \%$ & 142 & $0,35 \%$ & 174 & & 206 & & 238 & $0,15 \%$ \\
\hline 15 & $5,92 \%$ & 47 & 2,7 & 79 & $1,78 \%$ & 111 & $2,51 \%$ & 143 & $1,31 \%$ & 175 & $1,42 \%$ & 207 & $0,54 \%$ & 239 & $-0,67 \%$ \\
\hline 16 & $9,93 \%$ & 48 & $1,20 \%$ & 80 & $2,50 \%$ & 112 & $3,46 \%$ & 144 & $0,95 \%$ & 176 & $0,59 \%$ & 208 & $0,23 \%$ & 240 & $0,29 \%$ \\
\hline 17 & $9,26 \%$ & 49 & $-0,02 \%$ & 81 & $1,69 \%$ & 113 & $0,64 \%$ & 145 & $0,11 \%$ & 177 & $0,74 \%$ & 209 & $0,52 \%$ & 241 & $0,79 \%$ \\
\hline 18 & $5,85 \%$ & 50 & $1,26 \%$ & & $2,21 \%$ & 114 & $1,80 \%$ & 146 & $0,64 \%$ & 178 & $0,15 \%$ & 210 & $0,42 \%$ & 242 & $0,41 \%$ \\
\hline 19 & $1,71 \%$ & 51 & $1,64 \%$ & 83 & $1,41 \%$ & 115 & $1,74 \%$ & 147 & $0,44 \%$ & 179 & $1,02 \%$ & 211 & $0,11 \%$ & 243 & $0,13 \%$ \\
\hline 20 & $6,93 \%$ & 52 & & 84 & $1,66 \%$ & 116 & $2,78 \%$ & 148 & $0,79 \%$ & 180 & $0,54 \%$ & 212 & $-0,18 \%$ & 244 & $0,35 \%$ \\
\hline 21 & & 53 & & 85 & & 117 & $-0,15 \%$ & 149 & $0,73 \%$ & 181 & & 213 & & 245 & $1,20 \%$ \\
\hline 22 & $3,72 \%$ & 54 & $3,80 \%$ & & $0,92 \%$ & 118 & $1,63 \%$ & 150 & $0,22 \%$ & 182 & $0,93 \%$ & 214 & $0,08 \%$ & 246 & $-0,06 \%$ \\
\hline 23 & $4,45 \%$ & 55 & $8,33 \%$ & & $1,22 \%$ & 119 & $2,60 \%$ & 151 & $0,19 \%$ & 183 & $0,68 \%$ & 215 & $0,30 \%$ & 247 & $0,39 \%$ \\
\hline 24 & $5,56 \%$ & 56 & $5,13 \%$ & & $3,00 \%$ & 120 & $1,67 \%$ & 152 & $1,01 \%$ & 184 & $-0,06 \%$ & 216 & $0,29 \%$ & 248 & $0,01 \%$ \\
\hline 25 & $3,49 \%$ & 57 & $3,69 \%$ & & $2,31 \%$ & 121 & $1,43 \%$ & 153 & $1,07 \%$ & 185 & $0,09 \%$ & 217 & $0,96 \%$ & 249 & $0,13 \%$ \\
\hline 26 & $2,72 \%$ & 58 & $3,19 \%$ & 90 & $0,95 \%$ & 122 & $1,94 \%$ & 154 & $0,99 \%$ & 186 & $0,67 \%$ & 218 & $0,58 \%$ & 250 & $0,10 \%$ \\
\hline 27 & $10,30 \%$ & 59 & $3,56 \%$ & 91 & $2,77 \%$ & 123 & $1,85 \%$ & 155 & $0,76 \%$ & 187 & $1,31 \%$ & 219 & $-0,28 \%$ & 251 & $0,08 \%$ \\
\hline 28 & $3,45 \%$ & 60 & $1,82 \%$ & 92 & & 124 & $1,31 \%$ & 156 & $0,44 \%$ & 188 & $-0,03 \%$ & 220 & $-0,02 \%$ & & \\
\hline 29 & $-1,90 \%$ & 61 & $3,79 \%$ & 93 & $1,00 \%$ & 125 & $0,87 \%$ & 157 & $0,88 \%$ & 189 & & 221 & $0,77 \%$ & & \\
\hline 30 & $7,78 \%$ & 62 & $3,27 \%$ & & $1,38 \%$ & 126 & $0,99 \%$ & & $0,87 \%$ & 190 & $0,37 \%$ & 222 & $0,59 \%$ & & \\
\hline 31 & $1,44 \%$ & 63 & $2,49 \%$ & 95 & $1,88 \%$ & 127 & $1,27 \%$ & 159 & $0,17 \%$ & 191 & $0,37 \%$ & 223 & $0,14 \%$ & & \\
\hline 32 & $5,35 \%$ & 64 & $4,39 \%$ & 96 & $4,83 \%$ & 128 & $1,00 \%$ & 160 & $0,43 \%$ & 192 & $0,22 \%$ & 224 & $0,44 \%$ & & \\
\hline
\end{tabular}

Tabela 3. Movimentação diária crise asiática de 1997.

\begin{tabular}{rrrrr}
\hline D.U & Mov. D.U & Mov. D.U & Mov. \\
\hline $1-1,38 \%$ & $9-0,98 \%$ & 17 & $-1,21 \%$ \\
$2-0,65 \%$ & $10-1,60 \%$ & 18 & $-1,07 \%$ \\
$3-1,40 \%$ & $11-1,16 \%$ & $19-0,75 \%$ \\
$4-1,31 \%$ & $12-1,99 \%$ & $20-0,63 \%$ \\
$5-0,91 \%$ & $13-1,78 \%$ & $21-1,38 \%$ \\
$6-0,91 \%$ & $14-1,09 \%$ & \\
$7-1,56 \%$ & $15-8,15 \%$ & \\
$8-1,00 \%$ & $16-0,73 \%$ & \\
\hline
\end{tabular}

Os dados primários da movimentação diária dos fundos de investimento para obtenção dos resultados foram extraídos do sistema da $\mathrm{ANBID}^{1}$ e apresentados na Tabela 2. Esta movimentação representa a variação percentual diária do patrimônio líquido do fundo. A Tabela 3 mostra a movimentação diária percentual entre 03/11 a 28/11/1997, extraída de fundos similares durante a crise asiática, usada para simulação do cenário B. Conforme visualização de outros fundos de investimento durante períodos de crise e de sugestões dos gestores entrevistados, o período de crise asiática selecionado foi incorporado a partir do $23^{\circ}$ dia útil para simulação do cenário B. A Tabela 5 resume as premissas adotadas para as simulações.

\footnotetext{
$\overline{1 \text { http://www.anbid.com.br/top_legislaç ao.asp }}$
} 
Tabela 4. Melhores resultados encontrados.

\begin{tabular}{lcccc}
\hline & \multicolumn{2}{c}{ Cenário A } & \multicolumn{2}{c}{ Cenário B } \\
\cline { 2 - 5 } & AG & SA & AG & SA \\
\hline Des. Captação (\%) & $-0,45$ & 2,79 & $-57,89$ & $-57,89$ \\
Desvio Lucro (\%) & $-0,02$ & 0,04 & $-5,40$ & $-5,22$ \\
Desvio VAR (\%) & $-0,01$ & 2,90 & 0,95 & 0,00 \\
Des. Rent. (\%) & $-0,58$ & $-0,50$ & $-3,24$ & $-3,26$ \\
F. Objetivo (\%) & 1,07 & 9,07 & 67,49 & 129,47 \\
P. Líq. Inicial (R\$) & $15.693,59$ & $16.300,00$ & $14.000,00$ & $14.000,00$ \\
Taxa Adm. (\% aa) & 2,11 & 2,10 & 4,50 & 4,50 \\
Taxa Perf.(\%) & 0,04 & 0 & 1,03 & 0,65 \\
Resgate (dias) & 1 & 0 & 1 & 1 \\
Conversão (dias) & 0 & 0 & 0 & 0 \\
Carência (meses) & 0 & 0 & 0 & 1 \\
\hline
\end{tabular}

Tabela 5. Resumo das premissas e valores dos parâmetros.

\begin{tabular}{|c|c|c|}
\hline Parâmetros & Fonte/Hipóteses Assumidas & Valor \\
\hline$d_{u}:$ dias úteis & Calendário & 251 \\
\hline$P_{0}:$ patrimônio líquido inicial & $\begin{array}{l}\text { Valor adotado de acordo com histórico de } \\
\text { lançamentos de fundos similares }\end{array}$ & $\begin{array}{lr}\mathrm{R} \$ & 14.000 \\
\text { (desfavorável) }\end{array}$ \\
\hline & & $\begin{array}{l}\text { e } \mathrm{R} \$ 21.000 \\
\text { (favorável) }\end{array}$ \\
\hline
\end{tabular}

renda

$C_{a}$ : bônus da carência

$b$ : taxa do indicador de referência

$T_{a \text { max }}:$ taxa de administração máxima

$t_{p \max }$ : taxa fixa de performance máxima praticada

$M V$ : Meta de Rentabilidade do Investidor

$d_{c a}$ : prazo máximo de carência

$M C$ : Meta de captação

$M_{L}:$ Meta de lucro

$M_{R}$ : Meta de risco para o gestor
Análise da concorrência

Valor adotado de acordo com análise de série histórica do CDI

Análise da concorrência

Análise da concorrência combinada com critérios estabelecidos pela Instrução CVM n 409 art. 62

Valor percentual adotado de acordo com o índice de referência escolhido (CDI)

Análise da concorrência

Valor adotado conforme fundo similar de referência ou por consenso entre as áreas interessadas

Valor adotado de acordo com a gestão de custos da instituição

Valor adotado de acordo com a aplicação do método boostrap ponderado sobre as séries históricas de fundos similares
$0,38 \%$

$17 \%$ aa

$4,5 \%$ aa

$20 \%$

$17 \%$ aa

até 4 meses

$\mathrm{R} \$ 32$ milhões

$11 \%$

$\mathrm{R} \$ 1.102,69$

Para os propósitos desta pesquisa e após sucessivas tentativas, visualizou-se uma convergência dos resultados com a seguinte configuração de parâmetros do algoritmo genético: (i) $M=1.000$; (ii) taxa uniforme de crossover igual a 50\%; (iii) taxa de mutação de 10\%; (iv) critério de parada após 50.000 iterações e (v) método recipe interno ao Evolver. A Figura 5 a seguir mostra a codificação usada para busca das soluções pelos Algoritmos Genéticos e Simulated Annealing. Cada uma das variáveis é sensibilizada, de acordo com as regras de simulação de cada meta-heurística, por valores compreendidos nas faixas apresentadas na coluna de tolerância. Após atingir a condição de parada de cada meta-heurística, seleciona-se a combinação de valores que apresentou o melhor resultado.

Os melhores resultados no Simulated Annealing foram obtidos com a seguinte configuração: $T_{0}=100, T_{f}$ $=1, \beta=1, K=10$. Para os cenários A e B partiu-se, respectivamente, das seguintes soluções iniciais:

a) $\left(P_{0}=16000, d_{r}=0, d_{c}=0, t_{a}=2 \%, t_{p}=0, d_{c a}=0\right)$

b) $\left(P_{0}=0, d_{r}=0, d_{c}=0, t_{a}=0, t_{p}=0, d_{c a}=0\right)$. 


\begin{tabular}{|lr|}
\hline Variáveis & Tolerância \\
\hline$T_{a}$ - taxa de administração & $\{0$ a $4,5 \%\}$ \\
$T p$ - taxa de performance & $\{0$ a $20 \%\}$ \\
$d_{r}$ - prazo de resgate & $\{0$ a 5 dias $\}$ \\
$d_{c}$ - prazo de conversão & $\{0$ a 5 dias $\}$ \\
$d_{c a}$ - prazo de carência & $\{0$ a 4 meses $\}$ \\
$P_{0}$ - patrimônio líquido mínimo & $\{0$ a 16500$\}$ \\
\hline
\end{tabular}

\begin{tabular}{|l|l|l|l|l|l|}
\hline$T_{a}$ & $T_{p}$ & $d_{r}$ & $d_{c}$ & $d_{c a}$ & $P_{0}$ \\
\hline
\end{tabular}

Figura 5. Ilustração da codificação para o problema analisado.

\section{Conclusões}

Ainda há uma grande lacuna técnica e conceitual a ser preenchida para a evolução da experimentação e testes na área financeira (serviços). Em parte, o fato de as instituições financeiras pesquisadas serem de grande porte e de alta participação de mercado reduz os riscos de insucesso no lançamento de seus produtos que serão, em menor ou maior escala, absorvidos pelos seus canais de distribuição (principalmente a rede de agências), diminuindo a importância de uma fase estruturada de experimentação e testes. Essa característica, no entanto, não elimina os riscos e nem justifica a ausência dessa etapa no processo de desenvolvimento do produto.

A aplicação da Dinâmica de Sistemas auxiliou na definição de um modelo dinâmico híbrido composto de uma parte quantitativa, que reflete os limites possíveis pertinentes às variáveis para equilíbrio das malhas das forças atuantes, e de uma parte qualitativa, que determina padrões de comportamento, oferecendo uma mudança de percepção da realidade devido aos processos de feedback e delays (carências) introduzidos no modelo. Este modelo matemático com as relações de interdependência entre as variáveis identificadas foi, posteriormente, integrado às ferramentas de busca como os Algoritmos Genéticos e o Simulated Annealing para obtenção da combinação mais favorável destas variáveis em função das metas estabelecidas.

O propósito deste estudo não foi estabelecer uma competição entre os Algoritmos Genéticos e o Simulated Annealing, mas desenvolver uma ferramenta de apoio à decisão do desenvolvimento de novos fundos de investimento baseado em meta-heurísticas. Uma ferramenta de simulação rápida e eficiente cria o dinamismo e a velocidade ideais para um ambiente competitivo e turbulento. O simulador utilizado, a partir das metaheurísticas citadas, consegue obter bons resultados em até 5 minutos, criando uma grande flexibilidade para desenvolvimento do produto. Além disso, a forma como o modelo matemático foi estruturado permitiu a introdução de medidas de erro, pois todos os resultados são comparados com metas passadas factíveis.

A importância de trabalhos desta natureza aumenta na medida em que há uma diminuição das taxas referenciais de juros (taxa SELIC) e, consequentemente, uma redução das margens de lucro do setor financeiro brasileiro tornando o mercado mais competitivo e sensível às definições das taxas incidentes sobre os fundos de investimento.

\section{Referências}

Abensur, E.O., Experimentação e Testes para o Desenvolvimento de Novos Produtos Financeiros. Tese de Doutorado, Escola Politécnica da Universidade de São Paulo, São Paulo, SP, 2006.

Abensur, E.O., Um método heurístico integrado ao Simulated Annealing para a programação de tarefas em uma máquina. In: Anais do XLIII Simpósio Brasileiro de Pesquisa Operacional. Ubatuba, SP: SBPO, 2011.

Arkader, R.A., Pesquisa científica em gerência de operações no brasil. Revista de Administração de Empresas, 43(1):70$80,2003$.

DeBrentani, U., Success and failure of new industrial services. Journal of Product Innovation Management, 6(3):239258, 1989.

DeBrentani, U., Success factors in developing new business services. European Journal of Marketing, 25(2):33-59, 1991.

Easingwood, C.J., New product development for services companies. International Journal of Banking Marketing, $4(3): 264-275,1986$.

Goldbarg, M.C. \& Luna, H.P.L., Otimização Combinatória e Programação Linear. Rio de Janeiro, RJ: Campus, 2005. Holland, J.H., Adaptation in Natural and Artificial Systems. Ann Arbor, USA: The University of Michigan Press, 1975.

Jorion, P., Value at Risk: A Nova Fonte de Referência para a Gestão do Risco Financeiro. 2a edição. São Paulo, SP: Bolsa de Mercadorias \& Futuros, 2003.

Kirkpatrick, S.; Gelatt, C. \& Vecchi, P., Optimization by simulated annealing. Science, 220:671-679, 1983.

Kohli, R. \& Krishnamurti, R., A heuristic approach to product design. Management Science, 33(12):1523-1533, 1987. 
Mendes, G.H.S., O Processo de Desenvolvimento de Novos Serviços: O Caso do Setor Bancário Brasileiro. Dissertação de Mestrado, Departamento de Engenharia de Produção da Universidade de São Carlos, São Carlos, SP, 1999.

Moraes, M.A.S., Desenvolvimento de um Método para Avaliação Qualitativa e Quantitativa de Fundos de Investimento. Dissertação de Mestrado, Faculdade de Economia, Administração e Contabilidade da Universidade de São Paulo, São Paulo, SP, 2000.

Roberts, N.; Andersen, D.F.; Deal, R.M.; Garet, M. \& Shaffer, W.A., Introduction to Computer Simulation: The System Dynamics Approach. Reading, USA: Addison-Wesley, 1983.

\section{Notas Biográficas}

Eder Oliveira Abensur é graduado, mestre e doutor em Engenharia de Produção (Universidade de São Paulo, 1984, 1998 e 2006, respectivamente). Atualmente é professor adjunto do curso de Engenharia de Gestão da Universidade Federal do ABC na área de Pesquisa Operacional. Tem experiência acadêmica em Finan ças da Produção e na área de Engenharia de Produção com ênfase em Gestão Financeira, Análise de Custos, Pesquisa Operacional e Planejamento da Produção, atuando principalmente nos seguintes temas: finanças, custos, análise de investimentos, desenvolvimento de produtos financeiros, otimização matem ática, modelos de simulação, automação bancária e métodos quantitativos aplicados a finanças. Integrante do quadro de Professores Avaliadores do BASIS, selecionado pelo INEP/MEC para proceder avaliações de cursos. 
A Pesquisa Operacional é uma área do conhecimento fortemente interdisciplinar voltada ao desenvolvimento de modelos matemáticos e algorítmicos para a resolução de problemas reais complexos. Métodos de Pesquisa Operacional têm sido utilizados com sucesso para a obtenção de soluções otimizadas nos mais variados contextos de problemas reais. Os problemas tratados pela Pesquisa Operacional requerem, em geral, grande esforço computacional, sendo, muitas vezes, de complexidade não-polinomial. Como alternativa às modelagens puramente matemáticas, têm surgido, ao longo das últimas décadas, soluções através de procedimentos heurísticos e meta-heurísticos. Considerando-se o grande desenvolvimento de métodos computacionais na área, surge a necessidade de disseminação do conhecimento científico sobre $o$ assunto. Desta forma, o objetivo deste livro foi agrupar trabalhos de pesquisa, com foco multidisciplinar, em dois grupos: os que destacam métodos utilizados em problemas de otimização/aplicação e os que destacam aplicações que podem ser abordadas através de métodos de otimização. A coletânea de capítulos possui caráter didático mostrando, também, um panorama atual da pesquisa no Brasil, suprindo a falta de material de referência em língua portuguesa sobre o assunto. O livro é composto por 29 capítulos, dos quais 11 foram enquadrados como métodos e 18 como aplicações.

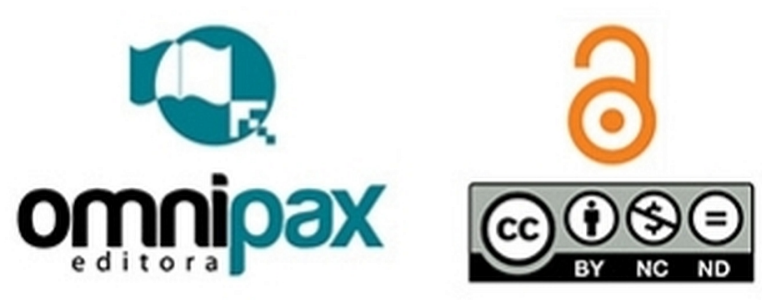

ISBN 978-85-64619-10-4

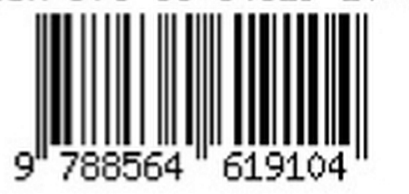

